Adrian Robu

\title{
Mégare et \\ les établissements \\ mégariens de Sicile, \\ de la Propontide \\ et du Pont-Euxin \\ Histoire et institutions
}
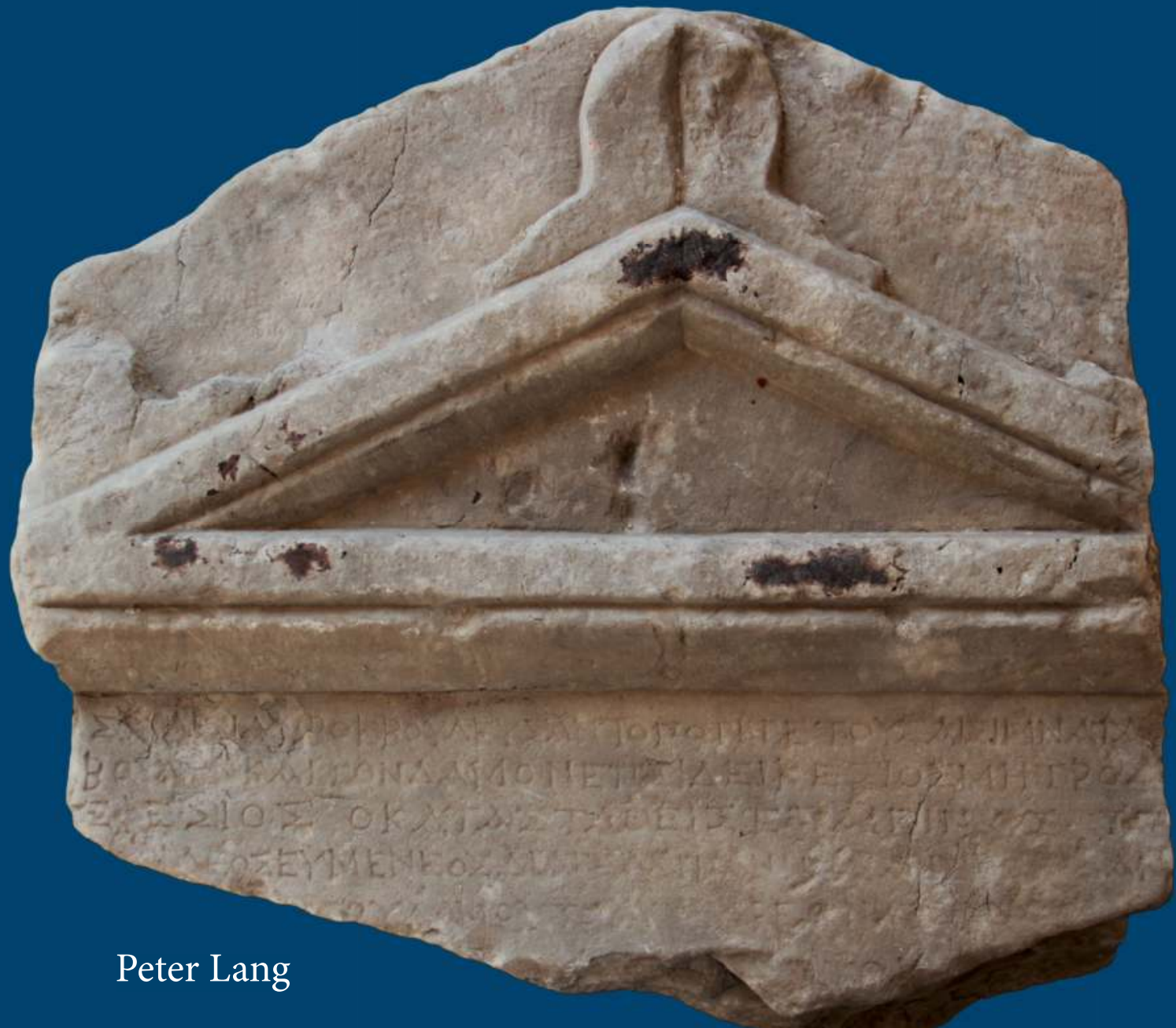
Mégare est la seule cité de Grèce antique à avoir essaimé des colonies aussi bien en Sicile que sur les rives de la Propontide et dans le Pont-Euxin. À partir des récits antiques, des inscriptions et des documents archéologiques, lauteur se propose d'offrir une nouvelle interprétation d'un mouvement colonial unique en son genre. Étudiant les causes du départ des Mégariens, il révèle le rôle déterminant joué par les conflits qui opposaient les familles aristocratiques. Il montre aussi que les fondations mégariennes furent le résultat d'une sorte de synœcisme primitif, d'un rassemblement de plusieurs groupes de colons le plus souvent hétérogènes du point de vue ethnique. Les institutions restaient en revanche calquées sur celles de la métropole: les subdivisions civiques et plusieurs magistratures mégariennes furent ainsi reproduites à l'identique. En outre, létude des institutions permet de mettre en évidence le rapport étroit qui existe entre lémergence de la cité et le début de la colonisation grecque, deux phénomènes simultanés du haut archaïsme, qui ont profondément et durablement marqué l'histoire des communautés helléniques.

Docteur des Universités de Neuchâtel et du Maine, Adrian Robu a poursuivi ses recherches au Collège de France et à l'Institut d'archéologie " Vasile Pârvan » de l'Académie roumaine. Il est actuellement rattaché en tant que chercheur post-doctorant au Centre ANHIMA de Paris (UMR 8210). 
Mégare et les établissements mégariens de Sicile, de la Propontide et du Pont-Euxin 

Adrian Robu

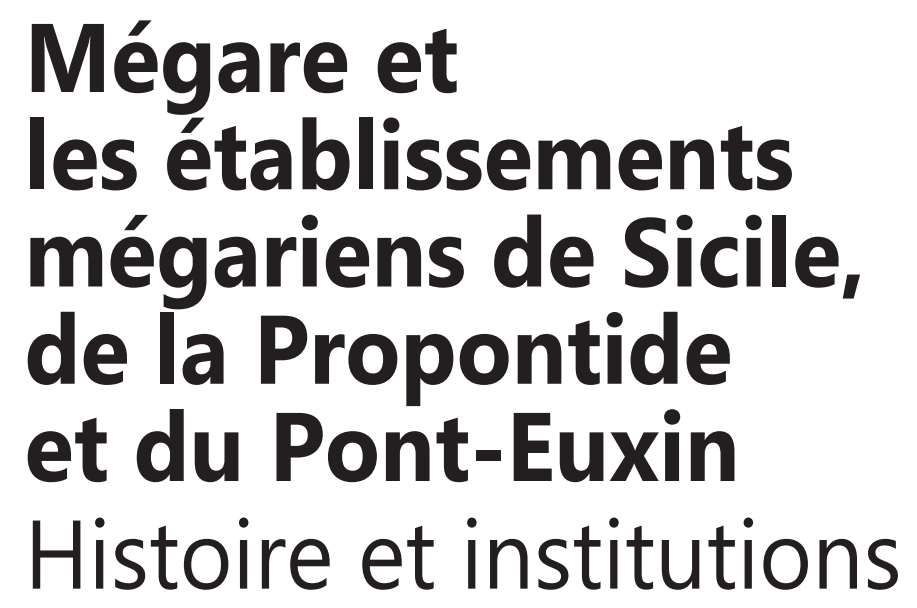

(5)

PETER LANG

Bern • Berlin • Bruxelles • Frankfurt am Main • New York $•$ Oxford $•$ Wien 


\section{Information bibliographique publiée par «Die Deutsche Nationalbibliothek»}

«Die Deutsche Nationalbibliothek» répertorie cette publication dans la «Deutsche Nationalbibliografie»; les données bibliographiques détaillées sont disponibles sur Internet sous «http://dnb.d-nb.de〉.

Publié avec le soutien du Fonds national suisse de la recherche scientifique dans le cadre du projet pilote OAPEN-CH

Ouvrage publié avec l'appui du Fonds national suisse de la recherche scientifique, de la Commission des publications du Collège de France, du Fonds für Altertumswissenschaft, Klassisch-Philologisches Seminar der Universität Zürich.

Couverture: Décret de Mégare pour Hikésios d'Éphèse, IG VII 15

(Musée épigraphique d'Athènes. Inv. EM 11531).

ISBN 978-3-03430461-0 hb.

DOI $10.3726 / b 10572$
ISBN 978-3-0352-0261-8 PDF

ISBN 978-3-0351-9983-3 EPUB

ISBN 978-3-0351-9982-6 MOBI

This book is an open access book and available on www.oapen.org and www.peterlang.com.

This work is licensed under the Creative Commons Attribution-NonCommercialNoDerivs 4.0 which means that the text may be used for non-commercial purposes, provided credit is given to the autor. For details go to http://creativecommons.org/ licenses/by-nc-nd/4.0/

\section{(cc) BY-NC-ND}

(c) Peter Lang SA, Editions scientifiques internationales, Berne 2014

Wabernstrasse 40, CH-3007 Berne, Suisse info@peterlang.com, www.peterlang.com 
À Cristina 

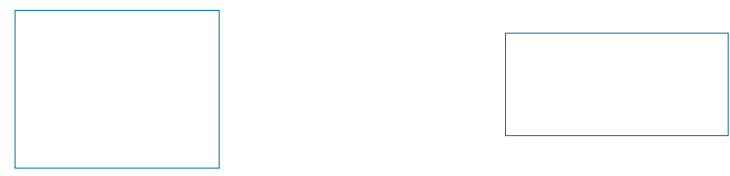


\section{Remerciements}

Ce livre est une version remaniée de la thèse de doctorat que j'ai soutenue le 19 février 2008 aux Universités de Neuchâtel et du Maine. Assurément, mon travail n'aurait pas abouti sans le soutien indéniable de plusieurs personnes, que je tiens à remercier. J'exprime tout d'abord ma gratitude envers mes deux directeurs de thèse. D'une part, le professeur Alexandru Avram, qui n'a jamais cessé de me faire des remarques fort utiles et de m'encourager. C'est à lui d'ailleurs qu'appartient le mérite de m'avoir suggéré le sujet de cette étude. D'autre part, je suis reconnaissant envers le professeur Denis Knoepfler pour son accueil amical à Neuchâtel et pour tous ses conseils et suggestions. La bibliothèque d'épigraphie et de numismatique de la salle Henri Seyrig, où j'ai pu travailler pendant plusieurs années, constitue un endroit extrêmement propice à la recherche. J'exprime également ma reconnaissance envers les deux autres membres de mon jury de thèse, Henri Tréziny (directeur de recherche émérite au CNRS, Centre Camille Julien/Université d'Aix Marseille) et Marcel Piérart (professeur à l'Université de Fribourg), pour leurs remarques et commentaires. Leurs interventions ont été d'un grand secours dans l'élaboration de la présente version de ce livre.

Je remercie ensuite Delphine Ackermann, Petre Alexandrescu $(\dagger)$, Panagiota Avgerinou, Nathan Badoud, Claude Calame, Constantina Chivoci, Stella Dreni, Maria Cecilia d'Ercole, Michel Gras, Zoe Petre, François de Polignac, Jean-Pierre Schneider, Martin Steinrück, Alexandra Trachsel, qui ont lu telle ou telle partie de mon manuscrit, ou m'ont aidé de diverses manières. Mes remerciements vont en égale mesure à mes collègues Silviu Anghel, Iulian Bîrzescu, Arnaud Costa, Mădălina Dana, Dan Dana, Maria Elena De Luna, Adrian Dumitru, William Fata, Yannis Kalliontzis, Mihaela Marcu, Florian Matei Popescu, Florina Panait-Bîrzescu, Petros Tryphonopoulos. Je suis encore redevable envers Thibaut Castelli, qui a pris le soin de relire avec minutie la dernière version de mon ouvrage. Il va de soi que je suis le seul responsable des erreurs qui subsisteraient. 
Il y a lieu d'évoquer également plusieurs institutions qui, par leur aide financière, ont rendu possible mon séjour à Neuchâtel: l'Agence universitaire de la Francophonie (avec son École Doctorale en Sciences Sociales de Bucarest), l'Université de Neuchâtel et l'Institut culturel roumain. En outre, un subside accordé par la Conférence des Recteurs des Universités Suisses a facilité mes déplacements entre la Suisse et la France. Grâce aux bourses offertes par la Kommission für Alte Geschichte und Epigraphik des Deutschen Archäologischen Instituts, par l'École française d'Athènes et l'École française de Rome, j'ai eu l'occasion de travailler pendant quelques mois dans les riches bibliothèques de $\mathrm{Mu}-$ nich, d'Athènes et de Rome. Les recherches postdoctorales que j'ai menées à la chaire d'Épigraphie et d'histoire des cités grecques du Collège de France m'ont permis de revoir les différents chapitres de ma thèse. Mon travail a été facilité par l'aide de Thomas Estrier (Bibliothèque Générale du Collège de France), qui n'a jamais manqué de répondre à mes nombreuses demandes de prêts entre bibliothèques. Qu'il soit lui aussi remercié.

La publication a été possible grâce au soutien de diverses institutions (Fonds national suisse de la recherche scientifique, Université de Zurich, Collège de France), envers lesquelles je tiens naturellement à exprimer ma reconnaissance pour leur générosité et confiance. Le travail d'édition a été mené avec soin et dans les meilleurs délais par Thierry Waser, responsable d'édition chez Peter Lang.

Enfin, je dois avouer que la présente étude n'aurait pas vu le jour sans le soutien constant de mes parents, Maria et Florin Robu. La venue au monde de mon fils, Ştefan, sa joie de vivre et ses progrès m'ont donné le courage de continuer. Avec patience, mon épouse, Cristina, a consacré beaucoup de temps à la lecture des différentes versions de cet ouvrage et c'est à elle que je dédie cette recherche. 


\section{Table des matières}

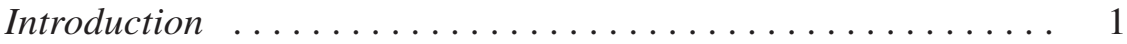

i. Pourquoi la colonisation mégarienne? ............ 1

ii. Structure de l'ouvrage .................. 5

iii. Historique de la recherche $\ldots \ldots \ldots \ldots \ldots \ldots \ldots$

iv. Analyse des sources: les sources littéraires

et documentaires ..................... 11

Partie I

La cité de Mégare à l'époque archaïque .............. 15

I.1 Le synœcisme mégarien $\ldots \ldots \ldots \ldots \ldots \ldots \ldots \ldots \ldots \ldots$

I.1.1 La liste des cinq mérè («districts») mégariens de Plutarque ................... 16

I.1.2 Le catalogue des vaisseaux mégariens chez Strabon . . 34

I.1.3 Les rapports entre Mégare et Corinthe à l'époque archaïque $\ldots \ldots \ldots \ldots \ldots \ldots \ldots \ldots \ldots$

I.1.4 La colonisation et le synœcisme mégariens: deux phénomènes contemporains du haut archaïsme . . 50

I.2 Les conflits de Mégare avec Athènes pour la possession de l'île de Salamine: une affaire de néoi ? . . . . . ... 55

I.2.1 Les traditions relatives aux combats menés par les Mégariens et les Athéniens à l'époque archaïque . . . . 56

I.2.2 Conflits et rivalités entre Mégare et Athènes: récits mythologiques et cultes ............ 63

I.2.3 Les enjeux de la possession de Salamine . . . . . 76

I.3 Les luttes internes à Mégare au $\mathrm{VI}^{\mathrm{e}}$ siècle $\ldots \ldots \ldots \ldots \ldots 82$

I.3.1 Mégare à l'époque archaïque: renversements politiques

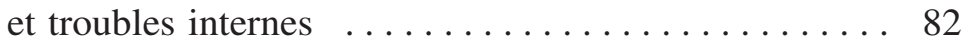

I.3.2 Kakoi et agathoi chez Théognis . .......... 89

I.4 Conclusions: les causes de la colonisation mégarienne . . . 100 
Partie II

Les établissements mégariens de Sicile, de la Propontide et du Pont-Euxin . . . . . . . . . . . . . . . . . . . . . . . . 117

II.1 Les établissements mégariens de Sicile . . . . . . . . . . . . 119

II.1.1 Mégara . . . . . . . . . . . . . . . . . . . . 119

II.1.1.1 Les récits et les découvertes archéologiques concernant la fondation de Mégara . . . . . . 119

II.1.1.2 Les rapports entre les Mégariens et les Sicules ................. 138

II.1.1.3 Les causes de la fondation de Mégara et les rapports avec la métropole . . . . . . 145

II.1.1.4 Les caractéristiques de la première implantation urbaine de Mégara . . . . . . . 148

II.1.2 Sélinonte . . . . . . . . . . . . . . . . . . . . 159

II.1.2.1 Les récits et les découvertes archéologiques concernant la fondation de Sélinonte . . . . . 159

II.1.2.2 Les premiers rapports entre les Sélinontins et les indigènes . ............... 168

II.1.2.3 L'expansion de Sélinonte dans la Sicile occidentale à l'époque archaïque ........ 171

II.1.2.4 Les causes de la fondation de Sélinonte . . . 177

II.1.2.5 Les rapports de Sélinonte avec Mégara de Sicile et Mégare de Grèce . . . . . 188

II.1.2.6 Les caractéristiques de la première implantation urbaine de Sélinonte ........ 195

II.2 Les établissements mégariens de la Propontide . . . . . . . . 201

II.2.1 Astacos . . . . . . . . . . . . . . . . . . . 201

II.2.1.1 Les récits concernant la fondation d'Astacos . . . . . . . . . . . . . . 202

II.2.1.2 Le «réseau mégarien» et la fondation d'Astacos .................. 206

II.2.1.3 L'occupation athénienne et bithynienne d'Astacos . . . . . . . . . . . . . . . 213

II.2.1.4 Les rapports entre Astacos, Olbia et Nicomédie . . . . . . . . . . . . . . . 217

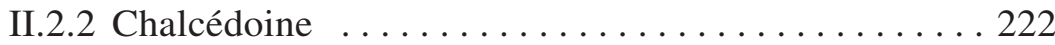


II.2.2.1 Les récits concernant la fondation de Chalcédoine ................. 222

II.2.2.2 Chalcédoine ou la «Cité des Aveugles»: les raisons de l'installation des Mégariens sur la rive asiatique du Bosphore ......... 231

II.2.2.3 La date de fondation de Chalcédoine et la chronologie des installations mégariennes en Propontide ..................240

II.2.3 Sélymbria . . . . . . . . . . . . . . . . . 243

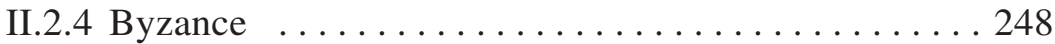

II.2.4.1 Les récits concernant la fondation

de Byzance .................... 248

II.2.4.1.1 La fondation d'Hestiai . . . . . . . 250

II.2.4.1.2 Les Spartiates et les Athéniens: les fondateurs de Byzance? . . . . 256

II.2.4.1.3 Y a-t-il eu une participation des Milésiens à la fondation de Byzance? À propos du soi-disant accord entre les Mégariens et les Milésiens dans la colonisation . . 258

II.2.4.1.4 La participation des Béotiens à la fondation de Byzance . . . . . . 264

II.2.4.1.5 La participation des Corinthiens à la fondation de Byzance . . . . . . 270

II.2.4.1.6 La participation des Argiens à la fondation de Byzance . . . . . . 273

II.2.4.1.7 Les époikoi de Chalcédoine . . . . 278 II.2.4.1.8 Conclusions sur l'origine des fondateurs de Byzance .... . 282

II.2.4.2 Byzas, l'œciste de Byzance, et les rapports entre les Byzantins et les Thraces ........ 285

II.3 Les établissements mégariens du Pont-Euxin . . . . . . . . 293

II.3.1 Héraclée du Pont . . . . . . . . . . . . . . . . . 293

II.3.1.1 Les récits concernant la fondation d'Héraclée du Pont .................. 293

II.3.1.2 Les rapports entre les Héracléotes et les Mariandyniens ............... 306 
II.3.2 Mésambria . . . . . . . . . . . . . . . . 311

II.3.2.1 Les récits concernant la fondation de Mésambria .................. 311

II.3.2.2 Les rapports entre les Mésambriens et les Thraces

Partie III

Les institutions politiques mégariennes . . . . . . . . . 325

III.1 Les subdivisions du corps civique à Mégare

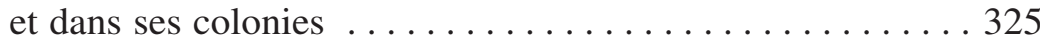

III.1.1 La division par phylai $(«$ tribus $») \ldots \ldots \ldots \ldots 326$

III.1.1.1 Mégare . . .............. 326

III.1.1.2 Byzance, Chalcédoine et Mésambria . . . . 333

III.1.1.3 Héraclée du Pont et ses colonies . . . . . . . 335

III.1.2 La division par hékatostyes («centaines») . . . . . . 339

III.1.2.1 Mégare . . . . . . . . . . . . . . . . 339

III.1.2.2 Byzance et Chalcédoine . . . . . . . . . 342

III.1.2.3 Héraclée du Pont et ses colonies . . . . . . . 347

III.1.2.4 Un cas douteux: Sélinonte . . . . . . . . 353

III.1.2.5 La valeur numérique du mot hékatostys . . 355

III.1.2.6. Les fonctions des hékatostyes . . . . . . 356

III.1.3 Les ikadeis de Mésambria . . . . . . . . . . . . . . . 360

III.1.4 Plutarque, Questions grecques, XVII,

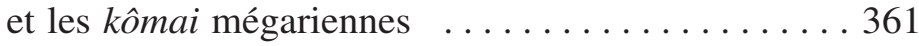

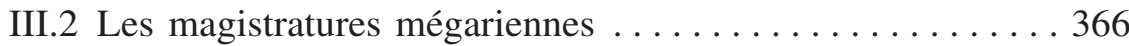

III.2.1 Le magistrat éponyme . . . . . . . . . . . . . . . . 367

III.2.1.1 Le basileus . . . . . . . . . . . . . . 367

III.2.1.2 Le hiéromnamôn . . . . . . . . . . . . . . . 375

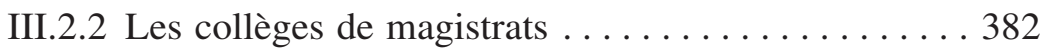

III.2.2.1 Les aisimnatai . . . . . . . . . . . . . . . . 382

III.2.2.2 Les probouloi . . . . . . . . . . . . . . 387

III.2.2.3 Les pentékaidéka . . . . . . . . . . . . . . . . 389

III.2.2.4 Les stratèges . . . . . . . . . . . . . . 391

III.2.2.5 Les damiorgoi . . . . . . . . . . . . . . . . 401

III.2.2.6 Les nomophylakes . . . . . . . . . . . . . . 404 
Annexe

Une coutume épigraphique de Mégare

attestée à Chersonèse Taurique et à Callatis

Conclusions générales ........................ 409

Bibliographie générale ..................... 415

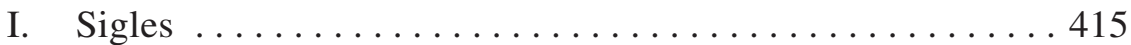

I.1 Sigles des revues .................. 415

I.2 Sigles des ouvrages et des collections . . . . . . . 416

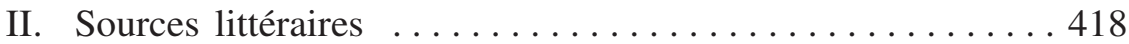

III. Liste bibliographique et abréviations $\ldots \ldots \ldots \ldots \ldots \ldots 420$

Cartes et planches ...................... 487

Crédits des illustrations $\ldots \ldots \ldots \ldots \ldots \ldots \ldots \ldots \ldots \ldots$

Index ................................ 499

I. Index locorum . . . . . . . . . . . . . . . . . . . . 499

I.1 Documents épigraphiques . . . . . . . . . . . . . . . . 499

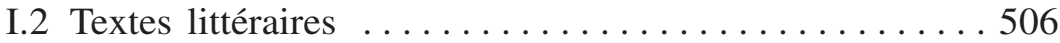

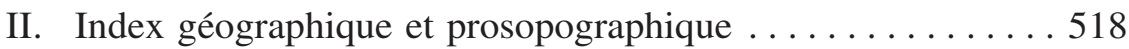

III. Index thématique . . . . . . . . . . . . . . . . . 533 


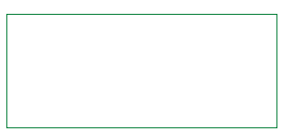




\section{Conventions}

Toutes les dates sont «avant Jésus-Christ», sauf mention contraire. Le terme de Mégare désigne la cité de Grèce, tandis que celui de Mégara est employé pour la cité homonyme de Sicile. 


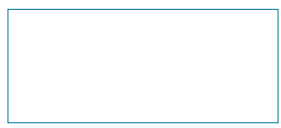




\section{Introduction}

Les écrivains anciens, comme tous les historiens depuis lors, ont horreur du vide. Ils le remplissent comme ils peuvent, et en dernier recours ils inventent ${ }^{1}$.

\section{i. Pourquoi la colonisation mégarienne?}

Mégare a été l'une des cités les plus actives de la Grèce en matière de colonisation, ayant participé à la fondation d'un nombre important d'établissements autant en Sicile (Mégara et Sélinonte) qu'en Propontide (Astacos, Chalcédoine, Sélymbria et Byzance) et dans le Pont-Euxin (Héraclée du Pont et Mésambria). Nonobstant son importance moyenne dans la hiérarchie des cités, la réputation de Mégare en tant que métropole ne fut dépassée que par les cités de Corinthe et de Milet ${ }^{2}$.

Depuis le livre de référence de Hanell, Megarische Studien, publié à Lund en 1934, et malgré l'enrichissement de la documentation épigraphique, archéologique et numismatique, accumulée suite au progrès des fouilles et aux nouvelles trouvailles, les relations de Mégare avec ses apoikiai restent peu étudiées. Il y a bien des raisons à cela: la nature de la documentation disponible, différente pour chaque cité mégarienne; la complexité de la problématique concernant, d'une part, les rapports entre la métropole et les colonies, et d'autre part, les relations entre les Grecs et les indigènes. Il faut ajouter la difficulté d'avoir accès à une bibliographie dont une partie a longtemps été écrite en grec, en russe, en bulgare ou en roumain.

Toutefois, et bien que le projet puisse paraître ambitieux, je crois que l'examen en synergie des fondations mégariennes s'avère très utile pour le monde scientifique. En effet, étant donné que l'idéal serait d'étudier

1 Finley, Sur l'hist. ancienne, p. 44.

2 Hind, Megarian Colonization, p. 131. 
le mouvement de colonisation en prenant en compte toutes les aires géographiques de l'expansion grecque, l'installation des Mégariens à l'époque archaïque à la fois en Sicile, en Propontide (mer de Marmara) et dans le Pont-Euxin (mer Noire) apparaît comme une bonne étude de cas. Il ne s'agira pas seulement de multiplier les parallèles que l'on peut relever entre diverses cités, mais, par la comparaison de plusieurs zones de colonisation, de mieux comprendre le processus de colonisation et d'identifier les «réseaux» établis par les Mégariens en Sicile, en Propontide et dans le Pont-Euxin ${ }^{3}$.

Par ailleurs, un acquis important des recherches récentes consiste dans la mise en évidence de l'importance des relations entre Grecs et indigènes, qui restent fondamentales pour l'implantation et le développement des colonies. Il serait erroné de présenter la fondation des colonies, sans une nouvelle analyse des données en rapport avec les populations locales. L'examen de ces données, que Hanell n'avait pas étudiées, fait également partie de mon étude.

De même, les savants ont récemment insisté sur le caractère mixte de plusieurs expéditions coloniales, et il s'avère aujourd'hui fort important d'étudier le rôle des synoikoi, des cofondateurs, et des vagues ultérieures de colons (des époikoi) dans la colonisation mégarienne ${ }^{4}$. Il convient de préciser que par époikoi on entend, avec Casevitz, «les nouveaux colons sans distinguer ceux qu'une métropole a envoyés sur demande de la cité qui les accueille, de ceux que l'exil a fait s'établir dans une cité »5

3 Pour la question des «réseaux» entre les cités à l'époque archaïque, voir l'article programmatique de J.-P. Morel, «Problématiques de la colonisation grecque en Méditerranée occidentale: l'exemple des réseaux», in Antonetti (éd.), Il dinam. della colon. gr., p. 59-70; et dernièrement Malkin, A Small Greek World, passim.

4 Sur les fondations composites, voir M. Gras, H. Tréziny, in Mégara 5, p. 552, qui rappellent: «En fait, il est difficile - quelles que soient les traditions étudiées - de privilégier la vision de contingents bien étanches les uns des autres, venant de différentes cités grecques et aboutissant chacun à une fondation particulière». $C f$. aussi Lepore, Grande Grèce, p. 54-55. Comme le note Casevitz, Vocabulaire, p. 201, le mot oúvoıxos peut être employé «pour désigner les (colons) associés à la fondation d'une colonie, sans en avoir la direction »; ce terme implique «souvent une association minoritaire».

5 Pour le rapport entre apoikoi et époikoi dans le vocabulaire de la colonisation grecque, on verra De Wever-Van Compernolle, Colonisation, p 498-504; Casevitz, Vocabulaire, p. 118-119, 156-158 (le passage cité se trouve à la p. 157). Voir aussi Graham, Colony, p. 64-66, sur la présence des époikoi dans les colonies grecques. 
Les témoignages confirment l'arrivée des colons additionnels dans les apoikiai mégariennes, surtout à Byzance et Mésambria. La collaboration des Mégariens avec des Grecs provenant d'autres régions (des Mégariens des colonies, des Béotiens, des Argiens, des Carystiens de l'Eubée, voire même des Corinthiens) et l'arrivée des nouveaux colons - à titre individuel ou en communauté - dans les cités déjà fondées, expliquent sans doute le succès de l'établissement de plusieurs colonies.

Ces constatations entraînent une autre question: comment a-t-on assuré dans les colonies la cohésion sociale entre Grecs de provenances variées, indispensable pour constituer un seul corps social? À mon sens, c'est par l'analyse des traditions de fondation, des subdivisions du corps civique, des magistratures et des cultes des colonies qu'on peut répondre à cette question. Les institutions politiques et religieuses (les nomima) sont en effet des domaines susceptibles de révéler l'hétérogénéité des groupes de colons fondateurs et supplémentaires: c'est au sein de ces structures institutionnelles que se réalisait la médiation politique et cultuelle entre les différents groupes de colons (apoikoi ou époikoi). Les nomima occupent par ailleurs un rôle important dans la définition de l'identité d'une communauté politique grecque et leur analyse met en évidence les liens de parenté entre les différentes cités, l'unité culturelle entre la métropole et ses colonies ${ }^{6}$.

Bien que les spécialistes aient repoussé l'interprétation «modernisante» de la relation entre colonie et métropole ${ }^{7}$, remplaçant même le

6 Malkin, Networks, p. 67; idem, A Small Greek World, p. 189-197. Sur le rôle des nomima dans la définition de l'identité d'une cité grecque, on lira aussi M. Nafissi, «From Sparta to Taras: Nomima, Ktiseis, and Relationships between Colony and Mother City», in Sparta: New Perspectives, S. Hodkinson et A. Powell (éds.), London 1999, p. 245-272; A. Brugnone, «Nomima chalkidika. Una laminetta iscritta da Himera», in Quarte giornate internazionali di studi sull'area elima (Erice, 1-4 dicembre 2000). Atti, vol. I, Pisa 2003, p. 77-89; D’Ercole, Colonisation grecque, p. 81-93.

$7 \quad$ F. de Angelis, « Ancient Past, Imperial Present : the British Empire in T. J. Dunbabin's The Western Greeks », Antiquity 72, 1998, p. 539-549; J.-P. Wilson, « < Ideologies > of Greek Colonization», in Greek and Roman Colonization: Origins, Ideologies and Interactions, G. Bradley et J.-P. Wilson (éds.), Swansea 2006, p. 25-57 ; G. R. Tsetskhladze, J. F. Hargrave, «Colonization from Antiquity to Modern Times : Comparisons and Contrasts », Ancient West \& East 10, 2011, p. 161-182. 
terme de colonie par le mot grec apoikia ${ }^{8}$, il reste à déterminer jusqu'à quel niveau une colonie se rattachait à sa métropole du point de vue politique et institutionnel. L'étude des nomima et des rapports entre Mégare et ses colonies peut nous donner une réponse, fût-elle partielle, à cette question.

Quant au vocabulaire employé pour désigner les établissements fondés par les Mégariens, il est certain que le terme grec d'apoikia («installation hors de la maison»), pourvu d'un sens complexe, ne correspond pas en entier au terme latin de colonia. Toutefois, bien que les notions de «colonie» et de «colonisation» soient inadéquates, ils sont entrés dans le vocabulaire scientifique et il est difficile maintenant de les écarter. Il convient néanmoins de rappeler que ces termes se réfèrent aux réalités d'époque romaine ou moderne plutôt qu'à celles de l'époque archaïque grecque ${ }^{9}$. Pour la période archaïque, on ne peut pas parler dans le cas de Mégare d'une politique de colonisation ou d'un empire colonial, parce qu'il n'existe aucune source attestant la dépendance politique ou économique d'une apoikia mégarienne envers sa

8 Petropoulos, Emporion, p. vii. L'existence de la colonisation grecque en tant que phénomène à l'époque archaïque a été niée dans un célèbre article par R. Osborne, «Early Greek Colonization? The Nature of Greek Settlement in the West», in Archaic Greece: New Approaches and New Evidence, N. Fisher et H. van Wees (éds.), London 1998, p. 251-269. Ce courant historiographique a suscité des critiques légitimes: J. Zurbach, «Question foncière et départs coloniaux. À propos des apoikiai archaïques », ASAA 86, serie III, 8, 2008 (2010), p. 87-103; A. J. Domínguez, «The Origins of the Greek Colonisation and the Greek Polis : Some Observations », Ancient West \& East 10, 2011, p. 195-207; E. Greco, «On the Origin of the Western Greek Poleis », Ancient West \& East 10, 2011, p. 233-242.

9 Pour les problèmes de l'équivalence du terme latin de colonia avec le grec apoikia, voir Graham, Colony, p. xxxv-xxxvi; S. Mazzarino, «Metropoli e colonie», in Metropoli e colonie di Magna Grecia. Atti del terzo convegno di studi sulla Magna Grecia (Taranto 1963), Napoli 1964, p. 67-69; De Wever-Van Compernolle, Colonisation, p. 461-467; E. Lepore, «La fioritura delle aristocrazie e la nascita della polis», in Storia e civiltà dei Greci. I. Origini e sviluppo della città, Milano 1978, p. 230-232; idem, «I Greci in Italia», in Storia della società italiana I. Dalla preistoria all'espansione di Roma, Milano 1981, p. 213-216; Ehrhardt, Milet und seine Kolonien $^{2}$, p. 266-267, n. 4. Casevitz, Vocabulaire, p. 128-130, donne une double définition du mot apoikia: (1) «une expédition colonisatrice avec ses membres»; (2) «l'agglomération qui en résulte». Selon De Wever-Van Compernolle, Colonisation, p. 466-467, l'apoikia est chez Thucydide «le collectif désignant un groupe d'émigrés - volontaires ou non - ou la cité où ce groupe s'est installé». 
métropole. Par conséquent, les modernes ont suggéré que seul le domaine religieux pouvait constituer le secteur où la cité-mère ait exercé des influences ${ }^{10}$. Même si les apoikiai étaient des poleis autonomes, sans obligations économiques et politiques envers leur métropole, ce serait une erreur d'exclure tout rapport politique entre Mégare et ses colonies. La collaboration des Mégariens avec ceux des colonies mégariennes de Sicile et de la Propontide en vue de la fondation de Sélinonte, respectivement de Mésambria, révèlent le maintien des contacts entre la métropole de Grèce et ses colonies.

Au demeurant, je précise que j'ai employé le terme d' «établissements mégariens », même si souvent des colons d'autres régions de la Grèce avaient participé à l'installation et au développement des apoikiai. Le fait que les institutions politiques, les cultes et les calendriers de ces cités aient gardé l'héritage «mégarien» dans ces domaines justifie, à mes yeux, ce choix ${ }^{11}$.

\section{ii. Structure de l'ouvrage}

J'ai divisé ma recherche en trois grandes parties. La première se propose d'examiner quelques événements de l'histoire archaïque de Mégare, à savoir la formation de l'État mégarien et les rapports de la cité avec Corinthe et Athènes, en traitant simultanément du développement

10 Les rapports entre les colonies et leurs métropoles à l'époque archaïque ont été examinés, entre autres, par G. Vallet, «Métropoles et colonies. Leurs rapports jusque vers la fin du $\mathrm{VI}^{\mathrm{e}}$ siècle », in Metropoli e colonie di Magna Grecia. Atti del terzo convegno di studi sulla Magna Grecia (Taranto, 13-17 ottobre 1963), Napoli 1964, p. 209-229 (= Vallet, Le monde gr. colonial, p. 19-32); Ehrhardt, Die politischen Beziehungen, p. 78-117; G. Shepherd, «Greeks bearing Gifts: Religious Relationships between Sicily and Greece in the Archaic Period», in Sicily from Aeneas to Augustus. New Approaches in Archaeology and History, C. Smith et J. Serreti (éds.), Edinburg 2000, p. 55-70; I. Malkin, «Categories of Early Greek Colonization : the Case of the Dorian Aegean », in Antonetti (éd.), Il dinam. della colon. gr., p. 26-28.

11 Certes, avec quelques exceptions notables, comme le culte d'Héraclès à Héraclée du Pont (voir infra, chapitre II.3.1.1), le hiéromnamôn éponyme de Byzance (voir infra, chapitre III.2.1.2). 
et des conflits internes à la société mégarienne. Il ne s'agit pas d'écrire une nouvelle histoire politique de la cité, mais de mettre en avant les événements susceptibles d'avoir provoqué le mouvement de colonisation, ou d'avoir influencé l'évolution des relations entre Mégare et ses colonies.

En second lieu, j'aimerais me pencher sur les fondations mégariennes de Sicile, de la Propontide et du Pont-Euxin, en mettant l'accent sur l'occupation globale du territoire (une situation particulièrement visible dans le cas des cités siciliotes), sur les relations entre les différents groupes de colons et sur les contacts avec les indigènes. Il me paraît essentiel de montrer dans ce cadre l'importance des vagues ultérieures de colons, ce qui m'amène à soutenir l'hypothèse de l'existence d'un type de colonisation caractérisé par la succession de groupes hétérogènes de colons.

La troisième partie porte sur les institutions politiques d'origine mégarienne attestées dans les colonies. J'étudie ainsi les subdivisions du corps civique: les trois phylai («tribus») doriennes et les hékatostyes («centaines»), en mettant en doute l'existence d'une troisième division en cinq kômai ( «bourgs») dans le monde mégarien. Ensuite, je me propose d'analyser les principales magistratures des cités mégariennes, dont l'origine peut remonter à l'époque archaïque, soit le magistrat éponyme (le basileus, le hiéromnamôn) et les principaux collèges de magistrats (les aisimnatai, les probouloi, les pentékaidéka, les stratèges, les damiorgoi, les nomophylakes). Il existe, certes, des divergences et des similitudes institutionnelles entre la cité de Mégare et ses apoikiai, que l'on mettra en valeur à travers cet examen systématique des données à disposition.

Quant à l'étude des épiclèses et du calendrier de souche mégarienne - un autre volet important des nomima -, j'ai préféré ne les intégrer que partiellement dans mon étude, et cela pour deux raisons. Premièrement, car les correspondances cultuelles qui existent entre Mégare et ses colonies sont les mieux connues actuellement. De fait, force est de reconnaître qu'après l'examen approfondi des cultes et des calendriers des établissements mégariens de Hanell (digne élève de l'éminent spécialiste de la religion grecque, Martin P. Nilsson), les recherches menées par Avram et Chiekova sur les cultes et le calendrier des colonies mégariennes et héracléotes, d'Antonetti et Lévêque sur les cultes de Mégare, de Kerény, Tusa, Manni, Bejor, Dewailly, Antonetti, Marconi 
et Grotta sur les cultes de Sélinonte ont considérablement enrichi notre connaissance du panthéon mégarien ${ }^{12}$. Deuxièmement, je me propose de revenir sur l'organisation et l'évolution du paysage religieux en Mégaride dans le cadre d'une étude particulière ${ }^{13}$.

12 On constate que par rapport à l'époque de K. Hanell, ce sont surtout de nouvelles inscriptions de Callatis qui ont fourni d'autres divinités et épiclèses mégariennes. À ce propos, voir A. Avram, in ISM III (1999), p. 91-95; Chiekova, Cultes (2008), surtout p. 60-66, 87-88, 119-122, 162-164, 224. Les cultes de Mégare ont été analysés par Antonetti-Lévêque, Devins (1990); Antonetti, Confini della Megaride (1994); eadem, Megara e le sue colonie (1997); eadem, Panthéon de Mégare (1998); eadem, Apollon (1999). Pour le calendrier mégarien, outre les études de K. Hanell, Das Menologium des Liber glossarum, K. Humanistika Vetenskapssamfundets i Lund Årsberättelse (Bulletin de la société royale des lettres de Lund) 1931-1932, II, Lund 1932 ; idem, Megarische Studien (1934), p. 190-204, on verra aussi Samuel, Chronology (1972), p. 87-89; D. M. Pippidi, Scythica Minora. Recherches sur les colonies grecques du littoral roumain de la mer Noire, Bucarest-Amsterdam 1975, p. 126; Loukopoulou, Thrace propontique (1989), p. 120-122; A. Avram, «Les calendriers de Mégare et de ses colonies pontiques», in Religions du Pont-Euxin. Actes du VIII ${ }^{e}$ Symposium de Vani (Colchide)-1997, O. Lordkipanidzé et P. Lévêque (éds.), Besançon-Paris 1999, p. 25-31 ; idem, in ISM III (1999), p. 110-115; Trümpy, Monatsnamen, p. 147-155. Concernant les divinités célébrées à Sélinonte et les temples qui leur étaient consacrés, il convient d'évoquer les études de K. Kerény, «Le divinità ed i templi a Selinunte», Kokalos 19, 1966, p. 3-7; V. Tusa, «Le divinità ed i templi di Selinunte», Kokalos 13, 1967, p. 186-193; E. Manni, «Da Megara a Selinunte: le divinità», Kokalos 21, 1975, p. 174-195; G. Bejor, «Problemi di localizzazione di culti a Selinunte», ASNP serie iii, 7, 2, 1977, p. 439-457; Dewailly, Sanct. de la Malophoros (1987); eadem, Statuettes (1992); C. Antonetti, in C. Antonetti, S. de Vido, «Conflitti locali e integrazione culturale a Selinunte: il nouvo profilo della polis nell'iscrizione della vittoria », in Guerra e pace in Sicilia e nel Mediterraneo antico (VIII-III sec. a. C.). Arte, prassi e teoria della pace e della guerra (Erice, 12-15 ottobre 2003), vol. I, Pisa 2006, p. 148-161 ; C. Marconi, Temple Decoration and Cultural Identity in the Archaic Greece. The Metopes of Selinus, Cambridge 2007; C. Grotta, Zeus Meilichios a Selinunte, Roma 2010. De même, pour les cultes attestés par la loi sacrée de Sélinonte, voir Jameson, Jordan, Kotansky, Lex sacra, p. 77-120.

13 J'ai également examiné quelques divinités du panthéon mégarien (Apollon Pythien, Zeus Meilichios, Poséidon), en relevant les parallèles entre Mégare et ses colonies, dans les articles: Robu, Chalcédoine (2007); idem, Zeus Meilichios (2009); idem, «Le culte de Poséidon à Mégare et dans ses colonies », Dacia N. S. 57, 2013, p. 6580 . 


\section{iii. Historique de la recherche}

En publiant ses Megarische Studien, Hanell a sans doute consacré un modèle de recherche ${ }^{14}$. En effet, bien que cet ouvrage de synthèse soit dépassé sur un certain nombre de points, il reste un exemple de la recherche historique de la première moitié du $\mathrm{XX}^{\mathrm{e}}$ siècle, qui a beaucoup influencé les travaux scientifiques postérieurs consacrés au domaine de la colonisation ${ }^{15}$.

Néanmoins, les progrès des recherches historiques, archéologiques et épigraphiques, et les changements dans l'interprétation historique de la colonisation grecque rendent nécessaire une nouvelle étude approfondie de la colonisation mégarienne et des nomima mégarika. L'explication du mouvement de colonisation doit aujourd'hui prendre en compte, on l'a vu, l'hétérogénéité culturelle des apoikiai, l'importance des colons additionnels (époikoi) et les rapports entre les apoikoi et les indigènes. Il est de même indispensable de tenir compte des réalités régionales et de ne pas proposer une systématisation rigide du mouvement colonial.

14 Quelques années avant la parution des Megarische Studien, F. Bilabel, Die ionische Kolonisation. Untersuchungen über die Gründungen der Ionier, deren staatliche und kultische Organisation und Beziehungen zu den Mutterstädten, Philologus, Suppl. 14, 1, Leipzig 1920, avait étudié la colonisation et les institutions ioniennes. Ultérieurement, N. Ehrhardt allait reprendre l'étude des nomima milésiens, en publiant en 1983 ( $2^{\mathrm{e}}$ édition en 1988) son ouvrage Milet und seine Kolonien.

15 Plusieurs savants ont mis en évidence l'importance du travail de Hanell : M. N. Tod, $C R$ 49, 1935, p. 76-77; G. W. Elderkin, AJA 39, 1935, p. 629; F. Hiller von Gaertringen, DLZ 7, 1935, col. 282-285 ; M. Carry, JHS 55, 1935, p. 96; E. L. Highbarger, AJPh 58, 1937, p. 118-121 ; J. et L. Robert, Bull. ép., 1958, 320. On remarque que l'histoire archaïque de Mégare, les mythes mégariens et la colonisation mégarienne ont constitué dernièrement l'objet d'étude de Paltseva, Mégare (1999). Malgré une bonne connaissance des témoignages antiques, la savante russe ne fait pas appel aux dernières découvertes archéologiques et épigraphiques, ni aux acquis méthodologiques des dernières décennies. Par conséquent, il n'est pas surprenant que ses conclusions soient souvent dépassées (la sténochôria constituerait la cause principale de la colonisation mégarienne, voir infra, chapitre I.4) ou anachroniques (la présentation de Mégare comme une grande puissance coloniale et commerçante, voir infra, chapitre I.3.2). D'ailleurs, cet ouvrage est passé presque inaperçu dans la littérature. $C f$. toutefois G. R. Tsetskhladze, in Northen Pontic Antiquities in the State Hermitage Museum, Colloquia Pontica 7, J. Boardman et al. (éds.), Leiden-Boston-Köln 2001, p. 324 ; I.E. Surikov, VDI, 2002, 3, p. 212-217. 
Par ailleurs, la nouvelle analyse de la colonisation mégarienne est facilitée par le fait que, à la différence de l'époque où écrivait le savant suédois, les chercheurs disposent maintenant de recueils regroupant les inscriptions des cités mégariennes, à savoir celles de Mésambria, de Chalcédoine, d'Héraclée du Pont, de Callatis, de Byzance et de Sélymbria, de Mégara, de Sélinonte ${ }^{16}$. Ces corpus rassemblent enfin les textes jusqu'alors dispersés et rendent commode l'étude des institutions. Il faut également mentionner les recueils numismatiques (surtout les nouveaux recueils regroupant les monnaies de Mégare, de Byzance, de Sélymbria, de Mésambria, de Chersonèse, de Callatis ${ }^{17}$ ) et les volumes du Lexicon of Greek Personal Names, qui rassemblent presque toutes les émissions monétaires et le matériel onomastique émanant des cités mégariennes ${ }^{18}$.

Quant aux principaux travaux que j'ai utilisés, il convient de préciser qu'après les études fondamentales de Highbarger, de Meyer et de

16 G. Mihailov (éd.), IGBulg I² (1970) et V (1997, pour Mésambria); R. Merkelbach, F. K. Dörner, S. Şahin (éds.), I. Kalchedon (1980); L. Jones (éd.), I. Heraclea (1994); A. Avram (éd.), ISM III (1999, pour Callatis); A. Lajtar (éd.), I. Byzantion (2000, pour Byzance et Sélymbria). Les inscriptions de Mégara et de Sélinonte ont été rassemblées par M. T. Manni Piraino (éd.), IGLMP (1973); L. Dubois (éd.), IGDS (1989; vol. II, 2008); R. Arena (éd.), IGASM I² (1996).

17 Schönert-Geiss, Byzantion (1970-1972); eadem, Die Münzprägung von Bisanthe, Dikaia, Selymbria, Berlin 1977; Karayotov, Coinage of Mesambria (vol. I, 1994; vol. II, 2009); V.A. Anokhin, The Coinage of Chersonesus IV Century B.C. - XII Century A. D., BAR International Series 69, Oxford 1980; S. Kovalenko, Die spätklassische Münzprägung von Chersonesos Taurica, Berlin 2008; G. Talmaţchi, The Coinage of the West-Pontic Cities of Histria, Callatis and Tomis during the Autonomous Era. Iconography, Legend, Metrology, Chronology and Countermarking, Cluj-Napoca 2011 (en roumain). Voir aussi les volumes récents de $S N G 9$ (1993) et 11 (2000) pour les monnaies des colonies mégariennes et héracléotes, et respectivement SNG 14 (2002) et BCD Pelop. (2006), pour les monnaies des cités de la Mégaride. On ajoutera à ceux-là les anciens recueils rassemblant les monnaies frappées par Sélinonte (W. Schwabacher, «Die Tetradrachmenprägung von Selinunt», MBNG 43, 1925, p. 1-90, Tafel I-II; G. E. Rizzo, Monete greche della Sicilia, Roma 1946), par Chalcédoine, Astacos, Héraclée du Pont et Prusias de l'Hypios / Kiéros (Waddington-Babelon-Reinach, Recueil, 1908-1925), ainsi que par Callatis (Pick, Münzen von Dacien und Moesien, 1898, p. 83-124).

$18 L G P N$, vol. III A : Sicile; vol. III B : Mégare; vol. IV : la Thrace et les côtes nord et ouest de la mer Noire; vol. V A: les régions côtières de l'Asie Mineure. 
Hanell ${ }^{19}$, l'histoire archaïque de Mégare, les légendes et les mythes mégariens furent analysés surtout par Legon, Muller, Figueira, De Polignac, Bérard, Antonetti, Lévêque, Van Wees, Forsdyke ${ }^{20}$. La Mégaride a aussi fait l'objet de plusieurs recherches topographiques, notamment celles de Lebègue, Hammond, Sakellariou et Pharaklas, Muller, Van de Maele, Bernier, Smith ${ }^{21}$.

D'autre part, pour l'étude des fondations mégariennes et leurs institutions, j'ai pu tirer profit des recherches de Vallet, Villard, Auberson, Van Compernolle, De Angelis, Danner, Gras, Tréziny, Mertens (pour

19 Highbarger, Megara (1927); Meyer, Megara (1931); Hanell, Megarische Studien (1934). Il convient de préciser que bien avant ces études, les témoignages concernant les mythes, l'histoire politique et les institutions de Mégare ont été examinées au XIX ${ }^{\mathrm{e}}$ siècle par $\mathrm{H}$. Reinganum, Das alte Megaris, Berlin 1825 ( $c f$. sur cet ouvrage le compte rendu de M. Hase, JS, janv. 1827, p. 3-13); J. Girard, De Megarensium ingenio, thesim proponebat Facultati litterarum Parisiensi, Paris 1854; G. Vogt, De rebus Megarensium usque ad bella Persica, Cassel 1857; M. Thamm, De re publica ac magistratibus Megarensium, Dissertation Halle 1885; F. Cauer, Parteien und Politiker in Megara und Athen. Studien zur Geschichte Griechenlands im Zeitalter der Tyrannis, Stuttgart 1890. De même, pour les légendes mégariennes, on verra J. Holle, Megara im mythischen Zeitalter, in Programm des Gymnasiums zu Recklinghausen LI. Schuljahr 1880-1881, Recklinghausen 1881; M. Mayer, «Mythistorica. I. Megarische Sagen», Hermes 27, 1892, p. 481-487; K. Seeliger, «Alkathöos und die megarische Königliste. Eine Pausaniasstudie», in Festschrift für Johannes Overbeck, Leipzig 1893, p. 27-44; Pfister, Mythische Königsliste (1907).

20 Legon, Megara Pol. Hist. (1981); idem, Megara (2004); Figueira, Chronological Table (1985); Bohringer (F. de Polignac), Mégare (1980); C. Bérard, «Urbanisation à Mégara Nisaea et l'urbanisme à Mégara Hyblaea», MEFRA 95, 2, 1983, p. 634640; Muller, De Nisée à Mégare (1983); Van Wees, Megara's Mafiosi (2000); Forsdyke, Megara (2005). Voir aussi les Megarika publiés par A. Muller dans BCH (1980-1984) et les études de C. Antonetti et P. Lévêque citées ci-dessus.

21 J.A. Lebègue, De oppidis et portibus Megaridis ac Boeotiae in Corinthiaci sinus littore sitis, Paris 1875; Hammond, Main Road (1954); idem, Heraeum (1954);

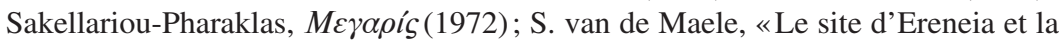
frontière attico-mégariennne», Phoenix 34, 1980, p. 153-159; idem, «La route antique du port mégarien de Pagai à la forteresse d'Aigosthènes », EMC 33, 1989, p. 183-188; idem, «Le réseau mégarien de défense territoriale contre l'Attique à l'époque classique ( $\mathrm{V}^{\mathrm{e}}$ et $\mathrm{IV}^{\mathrm{e}}$ s. av. J.-C.)», in Fortificationes Antiquae, S. van de Maele et J. M. Fossey (éds.), Amsterdam 1992, p. 93-107; idem, «Pausanias et la route de Mégare vers Pagai et Éréneia», $C E A 38,2001$, p. 113-118; A. Muller, $B C H$ 108, 1984, p. 249-266; Bernier, Ports de la Mégaride (1990); Smith, Megaris (2008). 
les colonies mégariennes de Sicile) ${ }^{22}$, et de Latyshev, Robert, Velkov, Asheri, Burstein, Avram, Loukopoulou, Saprykin, Vinogradov, Zolotarev, Dana (pour les colonies mégariennes de la Propontide et du PontEuxin $)^{23}$. Il ne saurait être question de présenter ici toutes ces études, car l'apport de chacune d'entre elles est mis en lumière dans les pages qui suivent.

\section{iv. Analyse des sources: les sources littéraires et documentaires}

On notera d'emblée que la plupart des sources littéraires sont postérieures à l'époque archaïque, la période principalement concernée par cette recherche. Il convient dès lors de les examiner avec attention et surtout d'éviter de superposer à la Mégare archaïque une Mégare classique ou hellénistique. Mieux, les réponses à des questions concernant l'histoire et les institutions des Mégariens sont rendues difficiles par la pauvreté du matériel, car la littérature émanant de Mégare a disparu en

22 Vallet-Villard, Dates de fondation (1952); iidem, «À propos des dates de fondation de Mégara Hyblaea, de Syracuse et de Sélinonte», BIBR 24, 1955, p. 199-214; iidem, La fond. de Sélinonte (1958); G. Vallet, F. Villard, P. Auberson, in Mégara 1, p. 403428; Van Compernolle, La fond. de Sélinonte (1952); idem, La fond. de Sélinonte et de Syracuse (1953); F. de Angelis, Found. of Selinous (1994); idem, Megara Hyblaia and Selinous (2003); Danner, Selinunt (1995); idem, Megara (1996); Gras-Tréziny, in Mégara 5 (2005), p. 547-584; Mertens, Selinus 1 (2003); idem, Städte une Bauten (2006).

23 Latyshev, Const. de Chersonèse (1885); Robert, Inscr. de Bulgarie (1959); idem, in Firatlı, Stèles de Byzance (1964), p. 131-189; Velkov, Mesambria (1969); Asheri, Herakleia (1972); Burstein, Heraclea (1976); Loukopoulou, Thrace propontique (1989); Avram, Zur Verfassung von Kallatis (1994); idem, Kalchedon (2004); idem, Héraclée et ses colonies (2006); Saprykin, Heracleia and Chersonesos (1996); J.G. Vinogradov, «La Chersonèse de la fin de l'archaïsme», in J. G. Vinogradov, Pontische Studien. Kleine Schriften zur Geschichte und Epigraphik des Schwarzmeerraumes, Mainz 2000, p. 397-419 [= in Le Pont-Euxin vu par les Grecs. Sources écrites et archéologie. Symposium de Vani (Colchide, septembre-octobre 1987), T. Khartchilava et E. Geny (éds.), Paris 1990, p. 85-119]; idem, Les tribus doriennes (1993); Vinogradov-Zolotarev, Ostracismo (1999); Dana, Culture (2011). 
bonne partie. On a conservé les poèmes de Théognis qui témoignent des conflits auxquels était confrontée la société mégarienne au $\mathrm{VI}^{\mathrm{e}}$ siècle. Mais le recours à ce poète est malaisé du fait de sa volonté d'universalité. Par conséquent, il n'est pas toujours facile d'établir avec certitude si les questions mises en avant par Théognis ont une spécificité mégarienne ou plutôt une valeur générale, panhellénique.

En plus, il nous reste quelques fragments des historiens hellénistiques de Mégare (notamment de Dieuchidas et d'Héréas), rassemblés d'abord par Jacoby (FGrHist 484-487), et ultérieurement par Piccirilli dans ses Megarika. Par ailleurs, particulièrement importants sont les récits des auteurs de l'époque impériale. Tout d'abord, Strabon, par son approche autant géographique que historique, nous fournit des informations sur la géographie et l'histoire de Mégare et les rapports de celle-ci avec Athènes. Ensuite, Pausanias consacre une importante section de sa Périégèse à la Mégaride, une région qu'il a parcourue en suivant la route d'Athènes à Corinthe. Il énumère dans son ouvrage les lieux de culte, en rassemblant également les principaux récits légendaires. Au surplus, Plutarque (notamment dans Questions grecques, Thésée, Solon) rapporte plusieurs événements concernant l'histoire archaïque de Mégare.

On constate au demeurant que les textes qui transmettent les légendes mégariennes ont souvent un caractère polémique, étant des réponses à des traditions élaborées à Athènes ou à Corinthe. En effet, les récits émanant de ces deux dernières cités tentent parfois de justifier la dépendance de Mégare à l'époque archaïque de l'un ou de l'autre de ses puissants voisins. D'ailleurs, Hanell avait jadis souligné le manque d'uniformité des traditions antiques relatives à Mégare et à ses colonies. Ce qui nous est resté représente le résultat d'une longue évolution, un mélange de traditions authentiques et de constructions mythiques. Ce qui ne veut pas dire que la tradition manque de valeur, vu que certaines formules altérées dissimulent, bien souvent, une certaine réalité historique $^{24}$. Dans ces conditions, la prudence des conclusions s'impose pour plusieurs questions examinées.

Quant à l'étude de l'histoire des colonies, une difficulté majeure consiste dans le fait qu'on n'a pas conservé les récits qui avaient pour objet propre la Sicile, la Propontide ou le Pont-Euxin. À titre d'exemple,

Hanell, Megarische Studien, p. 15. 
les œuvres des historiens grecs ne concernent que marginalement les cités mégariennes de Sicile et les historiens locaux du $\mathrm{V}^{\mathrm{e}}$ siècle (tels qu'Antiochos de Syracuse, Philistos de Syracuse, Hellanicos de Lesbos) ne sont connus que par des citations. En outre, l'absence d'historiens d'origine mégarienne en Sicile fait que les notices historiques concernant Mégara dépendent d'un milieu syracusain ou chalcidien, rarement favorable aux Mégariens de Sicile ${ }^{25}$.

Pour l'étude des installations mégariennes, on dispose également de descriptions géographiques avec des citations à caractère historique, fournies par les périples du Ps.-Scylax (IV ${ }^{\mathrm{e}}$ siècle) et du Ps.-Scymnos (II siècle), la Géographie de Strabon et l'Anaplous Bospori de Denys de Byzance (II ${ }^{\mathrm{e}}$ siècle ap. J.-C.). Des informations dispersées concernant les sites mégariens sont conservées chez Stéphane de Byzance, auteur des Éthnika (VI ${ }^{\mathrm{e}}$ siècle ap. J.-C.), une longue liste de peuples et de cités antiques ${ }^{26}$.

Il convient par ailleurs de préciser que pour l'époque archaïque, la documentation archéologique émanant de Mégare et de ses colonies de la Propontide et du Pont-Euxin reste maigre. On ne dispose que de très peu de découvertes en mesure de nous offrir une image des premières fondations. Dans ces régions, des localités modernes ont entièrement occupé les sites grecs anciens, ce qui rend les fouilles difficiles (voir pl. I pour une vue de la ville moderne de Mégare $)^{27}$. En revanche, profitant de l'absence d'habitat moderne, les fouilles archéologiques effectuées à Mégara et à Sélinonte par des chercheurs italiens, français et allemands ont mis au jour des documents qui ont largement renouvelé nos connaissances sur la prise de possession du territoire, le développement urbain et les sanctuaires de ces cités ${ }^{28}$.

25 Voir infra, chapitre II.1.1.1.

26 Après l'édition qui a fait date de A. Meineke (éd.), Stephani Byzantii Ethnicorum quae supersunt, Berlin 1849 (réimpr. Chicago 1992), une partie de l'ouvrage de Stéphane de Byzance (jusqu'à la lettre iôta) vient d'être rééditée par M. Billerbeck (éd.), Stephani Byzantii Ethnika, vol. I-II, Berlin 2006-2011. Ce sont ces deux éditions que j'ai utilisées pour les Éthnika de Stéphane de Byzance.

27 Il y a aussi le cas d'Astacos, dont l'emplacement exact fait pour l'instant défaut: voir infra, chapitre II.2.1.1.

28 Mégara et Sélinonte sont d'ailleurs les seules colonies mégariennes pour lesquelles on dispose de séries de publications archéologiques (voir la bibliographie citée infra, chapitres II.1.1.4 et II.1.2.6). 
On constate que la situation est inverse dans le cas des données épigraphiques, beaucoup plus importantes dans les colonies de la Propontide et du Pont-Euxin que dans celles de l'Occident. L'indigence de la documentation épigraphique est l'une des raisons du peu d'informations que l'on possède sur les institutions de Mégara et de Sélinonte. Les plus amples informations dans ce domaine émanent des autres cités mégariennes. D'ailleurs, force est de constater que, de manière générale, l'épigraphie civique est peu représentée dans les cités grecques de Sicile $^{29}$. Cet état de la documentation découle de la destruction de plusieurs villes à la fin de l'époque classique, ainsi que de l'usage du plomb pour la gravure des inscriptions, un métal qui se détériore considérablement à travers le temps et est facilement réutilisable ${ }^{30}$. À cet égard, on rappellera qu'outre plusieurs tablettes de plomb portant des defixiones $^{31}$, Sélinonte a livré le plus long texte sur plomb conservé à ce jour. Il s'agit de la célèbre loi sacrée arrivée au Musée J. Paul Getty de Malibu en 1981 et restituée à l'Italie en 1992, et dont Jameson, Jordan et Kotansky ont donné la première édition ${ }^{32}$.

Enfin, pour ce qui est des sources, il ne faut pas oublier l'apport de la numismatique, car les types monétaires peuvent nous renseigner sur des traditions qui rattachent une apoikia à ses origines, et particulièrement sur les divinités principales et les héros des cités ${ }^{33}$.

29 L. Dubois, in IGDS, p. XI; S. Berger, Revolution and Society in Greek Sicily and Southern Italy, Historia Einzelschriften 71, Stuttgart 1992, p. 13.

30 Cf. M.L. Lazzarini, «Presentazione», MediterrAnt 7, 2, 2004, p. 594.

31 Voir le corpus des defixiones de Sélinonte publié par Bettarini, Defixiones (2005).

32 Jameson, Jordan, Kotansky, Lex sacra, p. 14-17 [republiée maintenant par E. Lupu, Greek Sacred Law. A Collection of New Documents (NGSL), Leiden-Boston 2005, $\mathrm{n}^{\circ} 27$, qui rassemble la riche bibliographie portant sur ce texte]. La lex sacra de Sélinonte, aujourd'hui exposée au Museo Civico del Castelvetrano (Trapani), fut reprise dans le catalogue de l'exposition édité par L. Godart, S. de Caro (éds.), Nostoi. Capolavori ritrovati (Roma, Pallazo del Quirinale, 21 dicembre 2007-2 marzo 2008), Loreto 2007, p. 152-153, n 39. Signalons aussi que pour le dialecte mégarien, Sélinonte offre au spécialiste de l'épigraphie archaïque un dossier linguistique assez riche. Voir à ce propos Dubois, Bilan dialect., p. 331-346. Lacroix, Monnaies et colon., p. 9-11. 


\section{Partie I}

\section{La cité de Mégare à l'époque archaïque}

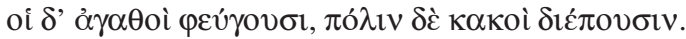

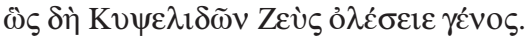

On bannit les honnêtes gens, les méchants gouvernent la ville; mais puisse Zeus anéantir de même la descendance de Cypsélos ${ }^{1}$.

Cette première partie de l'ouvrage est consacrée à l'étude des événements de l'histoire de la cité de Mégare susceptibles d'avoir provoqué le départ des Mégariens vers la Sicile, la Propontide et le Pont-Euxin. Il est dans mon intention de mettre en lumière le développement de la société mégarienne à l'époque archaïque et de discuter ici les causes invoquées par les modernes pour la colonisation, à savoir la surpopulation, les conflits extérieurs, les luttes internes et le commerce. Les chapitres de cette partie portent ainsi sur le synœcisme, les conflits des Mégariens avec leurs voisins de Corinthe et d'Athènes et sur les changements politiques qui eurent lieu à Mégare. Il s'agit en effet de questions qui ont fait l'objet de débats intenses parmi les chercheurs et qui, compte tenu de leur importance pour l'explication du mouvement de colonisation, réclament un réexamen approfondi.

\section{I.1 Le synœcisme mégarien}

Le synœcisme est le premier événement historique concernant la cité de Mégare dont l'on ait connaissance. Il y a lieu de se demander si cet événement ne serait pas responsable tant de l'apparition de l'État mégarien que du départ de Mégariens vers la Sicile et la Propontide. En effet, les récits suggèrent que le synœcisme a provoqué non seulement

1 Théognis, 893-894 (trad. de J. Carrière, CUF). 
l'unification politique, mais également des luttes internes. De plus, j'aimerais examiner dans ce chapitre les conflits entre Mégare et Corinthe et le rôle qu'ils ont joué à la fois dans la création de la cité de Mégare et dans la colonisation.

Pour l'analyse de ces événements du haut archaïsme, il est essentiel à mes yeux de tenir compte du fait que, très souvent, les témoignages datent des époques hellénistique et impériale. C'est notamment le cas de quelques passages de Plutarque, de Pausanias et de Strabon, qui se fondent sur la Constitution des Mégariens due à l'École d'Aristote, sur les écrits des historiens hellénistiques de Mégare ou sur des traditions orales que les auteurs antiques ont pu recueillir eux-mêmes. Il est important de rappeler que plusieurs traditions locales mégariennes sont des réponses tardives à des propos athéniens, béotiens et corinthiens et, par conséquent, elles revêtent un caractère polémique. Dans ces conditions, on ne sera pas surpris de constater que les situations décrites par ces récits contiennent davantage d'éléments de la Mégare hellénistique que de la Mégare archaïque.

Pour contrebalancer cela, l'archéologie permet de mieux connaître cette période archaïque. Les récentes trouvailles et les réinterprétations des données déjà connues émanant de la Mégaride, mais aussi de la Corinthie ou de l'Attique, renouvellent nos connaissances sur le territoire et les relations des Mégariens avec leurs voisins.

\section{I.1.1 La liste des cinq mérè («districts») mégariens de Plutarque}

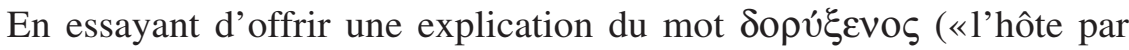

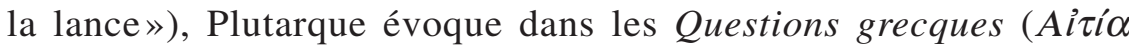

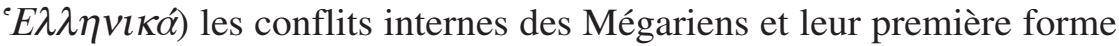
d'organisation politique. Il rapporte la tradition suivante:

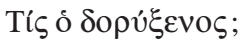

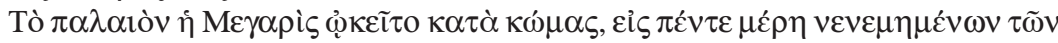

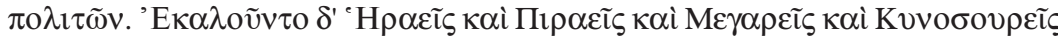

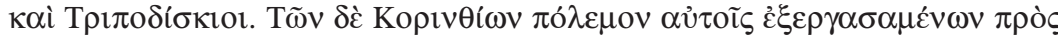

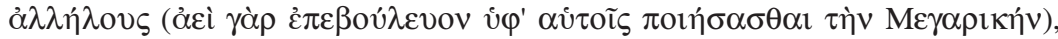

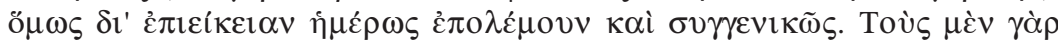

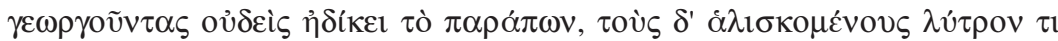

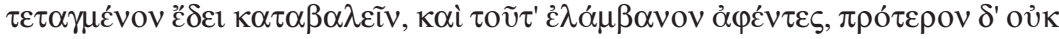




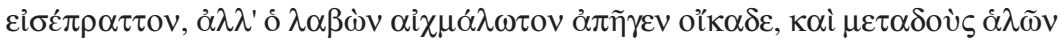

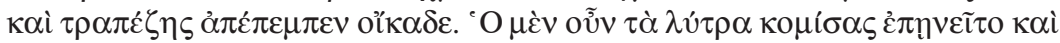

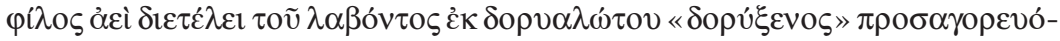

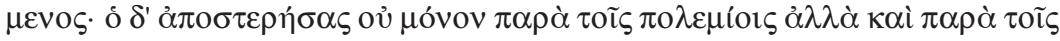

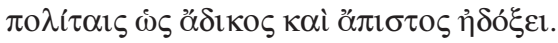

Qui est l'< hôte par la lance >?

Dans l'ancien temps, la population de la Mégaride était organisée en bourgs, les citoyens étant répartis en cinq districts. Ils s'appelaient Héraeis, Piraeis, Mégareis, Kynosoureis et Tripodiskioi. Les Corinthiens les firent entrer en guerre les uns contre les autres (ils ne cessaient, en effet, de comploter pour mettre la Mégaride sous leur pouvoir). Toutefois, leur douceur civilise la guerre et lui donne une tournure bon enfant. En effet, les cultivateurs ne furent les victimes d'absolument personne. Ceux qui étaient capturés devaient s'acquitter d'une rançon convenue et ce n'était qu'après les avoir relâchés qu'on la recevait. On ne l'exigeait pas avant. Celui qui faisait un prisonnier l'emmenait chez lui et, après avoir partagé avec lui son sel et sa table, il le renvoyait chez lui. Celui, donc, qui apportait sa rançon était loué et il ne cessait d'être l'ami de celui qui l'avait capturé sous le surnom d' < hôte par la lance >, tiré de l'adjectif < pris à la lance >. Mais celui qui y manquait avait non seulement auprès de l'ennemi, mais aussi auprès de ses concitoyens, une mauvaise réputation d'improbité et de perfidie ${ }^{2}$.

Les savants ont interprété ce passage comme un indice de l'existence d'une division territoriale en cinq kômai, antérieure à la création de la cité (polis) de Mégare. Mieux, en rattachant les Héraeis et les Piraeis à la péninsule de Pérachora, située au sud de l'isthme, on a inféré une participation des habitants de cette région au synœcisme mégarien. Cette péninsule aurait été ensuite annexée par les Corinthiens, et c'est justement cette perte territoriale qui aurait entraîné le départ des Mégariens vers la Sicile et la Propontide. Ainsi pour plusieurs chercheurs, l'afflux d'émigrés provoqué par la perte de la Pérachora fut-il la cause principale de la colonisation mégarienne aux VIII ${ }^{\mathrm{e}}-\mathrm{VII}^{\mathrm{e}}$ siècles $^{3}$. D'ailleurs, dans son ouvrage sur l'histoire de Mégare aux époques archaïque et

2 Plutarque, Questions grecques, XVII (= Moralia 295 B-C, trad. de J. Boulogne, CUF, partiellement modifiée).

3 Hammond, Heraeum, p. 98; idem, Peloponnese, p. 336; Burn, Lyric Age, p. 113; Legon, Megara Pol. Hist., p. 70; S. van de Maele, «Le réseau mégarien de défense territoriale contre l'Attique à l'époque classique ( $\mathrm{V}^{\mathrm{e}}$ et $\mathrm{IV}^{\mathrm{e}} \mathrm{s}$. av. J.-C.)», in Fortificationes antiquae, S. van de Maele et J.M. Fossey (éds.), Amsterdam 1992, p. 95; Paltseva, Mégare, p. 230-239; J.G. Devoto, «Two Megarian Colonies in

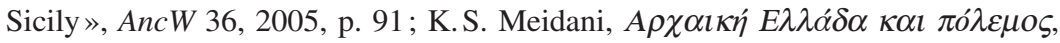
Athènes 2010, p. 36-40. 
classique, Legon intitulait de manière suggestive le chapitre sur la colonisation mégarienne: «Contraction at home - expansion abroad».

Néanmoins, la thèse qui considère la sténochôria («exiguïté des terres ») comme la cause principale de la colonisation présente plusieurs faiblesses. Commençons d'abord par une nouvelle analyse de la tradition fournie par Plutarque. On notera d'emblée que il n'est pas question dans la Question grecque XVII d'une division de la Mégaride en cinq kômai («bourgs»), mais en cinq unités portant le nom de mérè («districts $\gg)^{4}$. Sur la foi de cette tradition, on conclura que la polis de Mégare ne fut pas dès le début une agglomération urbaine mais qu'elle se constitua à partir d'un ensemble de bourgs dispersés; des communes qui originellement se regroupèrent en cinq unités territoriales, chaque méros pouvant contenir un ou plusieurs bourgs à la fois ${ }^{5}$.

Ensuite, il convient de se demander à quelle Mégare se réfère le texte de Plutarque: l'établissement dorien ou celui pré-dorien. Je rappelle que, selon plusieurs récits, Mégare fut originellement une terre ionienne, ayant appartenu à Athènes. Selon la tradition littéraire, la dorisation du pays aurait eu lieu pendant le règne de Codros à Athènes (1090/80-1070/60), lorsque les Péloponnésiens envahirent l'Attique. Sans pouvoir mettre la main sur Athènes, les Doriens occupèrent la Mégaride, dont les habitants changèrent alors de coutumes et de dialecte en devenant des Doriens ${ }^{6}$. D'après Hanell, les Doriens de Mégare seraient originaires d'Argos, preuve en étant les liens cultuels et mythologiques existant entre Argos et Mégare ${ }^{7}$. Cependant, la rareté des trouvailles datant de l'âge du Bronze ne permet pour l'instant aucune conclusion concernant l'origine des premiers habitants de Mégare ${ }^{8}$.

4 G. Huxley, $C R$ 32, 2, 1982, p. 228.

$5 \quad$ Sur le rapport entre mérè et kômai, voir infra, chapitre III.1.4.

6 Hérodote, V, 76; Pausanias, I, 19, 5; 39, 4-5; Strabon, VIII, 1, 2, C 333; IX, 1, 7, C 393. Pour les récits mentionnant une possession par Athènes de la Mégaride, voir aussi infra, chapitre I.2.2. Sur le roi athénien Codros, voir K. Scherling, s.v. «Kodros », RE XV, 1922, col. 984-994; P. Harding, The Story of Athens. The Fragments of the Local Chronicles of Attika, London-New York 2008, p. 78-81.

7 Hanell, Megarische Studien, p. 69-91. Même opinion chez Will, Korinthiaka, p. 290-291.

8 E.L. Highbarger, compte rendu de Hanell, Megarische Studien, AJPh 58, 1937, p. 119-121, estime que la documentation est soit peu nombreuse, soit trop tardive, pour que l'on puisse accepter l'origine argienne de Mégare. Voir aussi à cet égard Salmon, Heraeum, p. 192-193; Legon, Megara Pol. Hist., p. 42-46. 
S'appuyant sur les témoignages relatifs à l'organisation des États grecs par villages à une époque reculée ${ }^{9}$, Halliday considérait jadis que Plutarque présentait la situation d'une Mégare pré-dorienne ${ }^{10}$. Cependant, bien que l'on n'ait aucun indice que les kômai aient intégrées les institutions mégariennes, il est certain qu'elles étaient des unités géographiques de l'État dorien. En effet, un passage de la Poétique d'Aristote confirme que les Mégariens nomment kômai les bourgs qui sont aux environs des villes, tout comme les Athéniens les appellent dèmes ${ }^{11}$. On peut donc conclure que l'habitat kata kômas était spécifique aux Mégariens des époques classique et hellénistique et sans nul doute en allait-il de même à l'époque archaïque.

Du reste, un élément susceptible de nous aider à vérifier l'historicité du passage de Plutarque consiste dans la localisation des cinq mérè (voir carte 2 pour les sites de la Mégaride). On constate d'emblée que, parmi ces districts, il y en a deux qui peuvent être situés sans difficulté: les Mégareis et les Tripodiskioi. Les Mégareis doivent être associés à la ville de Mégare, qui devient, en raison de sa position au carrefour des routes principales de la Mégaride, le centre du nouvel État ${ }^{12}$. Plusieurs traditions coexistent à l'époque impériale pour expliquer le nom de la ville. Pausanias en connaît deux: l'une mégarienne et l'autre béotienne. Selon la première, la cité avait pris le nom de Mégare à l'époque du premier roi mégarien, Car, qui avait introduit le culte de Déméter, en bâtissant en son honneur un mégaron, une sorte d'enclos servant de

9 Thucydide, I, 10, 2; II, 15, 1-2; Strabon, VIII, 3, 2, C 336-337; cf. Aristote, Politique, I, 2, 6-8, 1252b 15-35; III, 9, 14, 1280b 40-1281a 4.

10 Halliday, Gr. Questions, p. 96-97.

11 Aristote, Poétique, III, 1448a 36-37. Sur ce passage, voir infra, chapitre III.1.4. L'habitat en villages est présent aussi dans d'autres cités doriennes, par exemple en Laconie, où l'un des quatre bourgs primitifs porte le nom de Kynosoura, tout comme

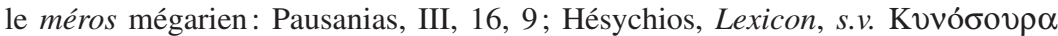
(éd. K. Latte); cf. Bursian, Geographie, vol. II, p. 121 ; Jones, Public Organization, p. 119.

12 Muller, De Nisée à Mégare, p. 626. Pour les routes qui traversent la Mégaride, voir Hammond, Main Road, p. 103-122, notamment p. 116; A. Muller, BCH 108, 1984, p. 249-256; S. van de Maele, «La route antique du port mégarien de Pagai à la forteresse d'Aigosthènes », EMC 33, 1989, p. 183-188; idem, «Pausanias et la route de Mégare vers Pagai et Éréneia», CEA 38, 2001, p. 113-118; Smith, Megaris,

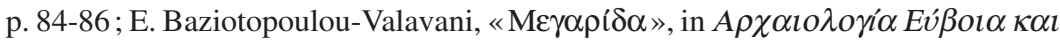

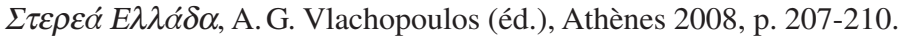


lieu de culte pour la déesse ${ }^{13}$. Une autre légende, mise en circulation par les Béotiens, soutenait que le nom de la cité était dû à Mégareus, le fils de Poséidon, venu d'Onchestos pour participer aux côtés du roi mégarien Nisos, son beau-frère, à la guerre contre Minos; mort dans la bataille, le héros béotien fut enterré dans la cité de l'isthme et en son honneur le nom de la cité fut changé de Nisa en Mégare ${ }^{14}$. Notons par ailleurs qu'un autre éponyme mythique de la cité pourrait être Mégaros, qui, selon les mythographes mégariens, fut le fils de Zeus et d'une nymphe locale. Le héros Mégaros échappa au déluge de Deucalion, en suivant un vol de grues, dont le cri lui indiqua un sommet qui en souvenir de ces oiseaux, fut appelé la Géranie (grue) ${ }^{15}$.

Les Tripodiskioi sont les ressortissants de Tripodiskos/Tripodiskoi, localité située sur les pentes nord-est des monts Géraniens, que Thucydide et Pausanias qualifient de bourg (kômè) et que Strabon considère comme le lieu du marché (agora) des Mégariens ${ }^{16}$. Sur la foi des récits et des trouvailles archéologiques (notamment des tombes), les modernes ont cherché l'emplacement de cette bourgade dans la région de Khani Derveni au nord-ouest de Mégare ${ }^{17}$. Ce site est connu pour avoir

13 Pausanias, I, 39, 5; 40, 6. D'après d'autres récits, les mégara seraient des cavités du sol où l'on jetait diverses offrandes en sacrifice à Déméter (notamment des porcelets): Scholie à Lucien, Dialogue des courtisanes, II, 1; Clément d'Alexandrie, Protreptique, II, 17, 1 ; $f$. A.-J. Festugière, «Les mystères de Dionysos », RBi 44, 3, 1935, p. 386-389; I. Patera, Offrir en Grèce ancienne. Gestes et contextes, Stuttgart 2012, p. 231-248.

14 Pausanias, I, 39, 5-6; 42, 1.

15 Pausanias, I, 40, 1; cf. l'Etymologicon Magnum, s.v. Гعрóveı $\alpha$ (éd. T. Gaisford), qui attribue cette généalogie à Mégareus. D'après Plutarque, Questions grecques, XVI (= Moralia 295 A-B), le roi Nisos avait épousé Habroté, fille d'Onchestos et sœur de Mégareus. En revanche, à en croire Pausanias (I, 39, 6), les Mégariens n'acceptaient pas la version de la prise de leur ville par Minos et soutenaient que Mégareus succéda à Nisos, en épousant sa fille Iphinoé. Sur les différentes généalogies de Mégareus et les étymologies du nom de la cité, voir Highbarger, Megara, p. 77-78, 88-94; P. Arbesmann, s.v. «Megareus», RE XV, 1932, col. 215-217; Piccirilli, MEGARIKA, p. 86-90; Antonetti, Megara e le sue colonie, p. 88.

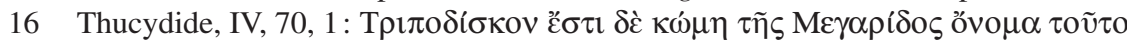

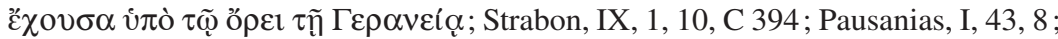
cf. E. Meyer, s.v. Tripodiskos, RE VII A, 1948, col. 201-202.

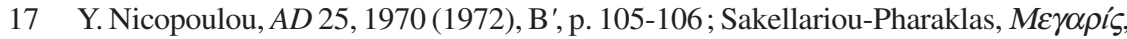
Appendice 2, p. 2-3; Legon, Megara Pol. Hist., p. 33; J. Travlos, Bildlexikon zur Topographie des antiken Attika, Tübingen 1988, p. 259, 282, fig. 356; Smith, Megaris, p. 30-31, 80 . 
été le lieu d'origine de Sousariôn, iambographe du $\mathrm{VI}^{\mathrm{e}}$ ou $\mathrm{V}^{\mathrm{e}}$ siècle qui, d'après une tradition hellénistique, fut l'inventeur de la comédie. Le poète se qualifie dans ses vers comme un Mégarien de Tripodiskos:

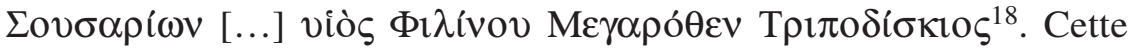
appellation confirme le statut de dépendance de Tripodiskos vis-à-vis de Mégare: Sousariôn, le fils de Philinos, même s'il est originaire de Tripodiskos, reste un Mégarien. Placé sur la route reliant Delphes au Péloponnèse, le bourg occupait une place importante du point de vue religieux chez les Mégariens. Car une tradition rapporte que le héros argien Coroibos était le fondateur mythique de Tripodiskos et du sanctuaire d'Apollon qui s'y trouvait. La légende de cette fondation se trouve chez Pausanias, qui raconte que Psamathée, la fille du roi argien Crotôpos, mit au monde un enfant conçu par Apollon. Mais, par peur de son père, la fille exposa l'enfant qui sera dévoré par les chiens du roi. Apollon envoie alors dans la ville d'Argos, Poiné («l'Expiation»), qui enlevait les enfants à leur mère. Coroibos tua Poiné, mais ce meurtre provoqua la peste. Ce deuxième fléau détermina le héros à se rendre à Delphes pour chercher la réparation du meurtre de Poiné. La Pythie ne permit pas à l'Argien de rentrer dans sa patrie et elle lui donna un trépied, en lui ordonnant de construire un temple d'Apollon à l'endroit où le trépied lui échapperait des mains. Lorsque Coroibos descendit de la montagne de Géraneia, le trépied lui tomba des mains et c'est à cet endroit même qu'il fonda Tripodiskoi (« Petits Trépieds») ${ }^{19}$. Le nom du bourg ferait ainsi référence au trépied que le héros emporta de Delphes. On notera aussi que l'importance de Coroibos pour les Mégariens est

18 West, Iambi et elegi Graeci ${ }^{2}$, p. 167. On attribuait aussi à Sousariôn une origine athénienne. Sur ce poète, voir aussi L. Breitholtz, Die dorische Farce im griechischen Mutterland vor dem 5. Jahrhundert. Hypothese oder Realität?, Upsala 1960, p. 7482 ; D. E. Gerber, Greek Iambic Poetry from the Seventh to the Fifth Century BC, Cambridge-London 1999, p. 510-511.

19 Pausanias, I, 43, 7-8. Pour la légende de Coroibos et de Psamathée, voir aussi Callimaque, fr. 31 (éd. R. Pfeiffer), l'épigramme de l'Anthologie Palatine, VII, 154 (= D. L. Page, Further Greek Epigrams, Cambridge 1981, p. 388-391, no 87) et le récit de Conon, FGrHist 26 F 19; cf. Piccirilli, MEGARIKA, p. 122-126; F. Chamoux, «Coroibos à Mégare», in Hommage à Lucien Lerat, H. Walter (éd.), Paris 1984, p. 181-187, qui estime que le poème de l'Anthologie Palatine n'est autre que l'épigramme lue par Pausanias sur le tombeau de Coroibos à Mégare; Antonetti, Megara e le sue colonie, p. 92-93. 
mise en évidence par le transfert de sa tombe sur l'agora de Mégare ${ }^{20}$. De surcroît, Rigsby estime que c'est dans le bourg de Tripodiskos que se déroulaient les Grands Pythia de Mégare, tandis que les Petits Pythia avaient lieu dans la ville même ${ }^{21}$.

Si la participation des mérè des Mégareis et des Tripodiskioi au synœcisme est assurée par l'existence à l'époque historique de deux sites homonymes, l'appartenance des mérè des Héraeis et des Piraeis à la cité de Mégare est en revanche un objet de dispute entre les spécialistes. En effet, ces deux districts devaient être situés au sud de la Mégaride, dans la péninsule de Pérachora, région qui appartenait à l'époque classique à la cité de Corinthe. Tout d'abord, le district de Piraeis devrait être associé au Peiraion, une bourgade corinthienne évoquée par un passage de Xénophon dans le contexte de la Guerre de Corinthe. Ce texte nous apprend que, menacés vers 390 par les Spartiates d'Agésilas, les Corinthiens mirent leur bétail en sûreté au Peiraion. Cependant, quand les troupes ennemies réussirent à occuper les hauteurs de cette région, les gens de Peiraion «se refugièrent à l'Héraion, hommes, femmes, esclaves, homme libres, avec la plus grande partie des troupeaux $»^{22}$. Il ressort de ce passage que le méros de Piraeis se situait au sud des montagnes de Géraneia, non loin du sanctuaire d'Héra Akraia de Pérachora. Cette localisation a été contestée par Salmon, qui a proposé de situer ce district au sud de l'isthme, dans la région de Kenchreai, au bord du golfe Saronique (voir carte 2). À son avis, pour

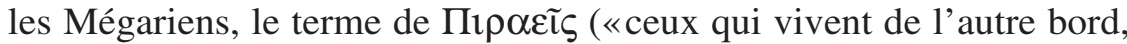
de l'autre côté», de l'adjectif $\pi \varepsilon \rho \alpha \operatorname{ITo}^{23}$ ) ne peut désigner que les habitants occupant une zone située de l'autre côté de leur territoire, qui ne

20 Pausanias, I, 43, 7 ; cf. Polignac, Naissance de la cité gr., p. 172.

21 Rigsby, Megara, p. 93-102; cf. Robu, Chalcédoine, p. 140-141. Selon Rigsby, le nom de Tripodiskos pourrait aussi provenir du carrefour de trois routes.

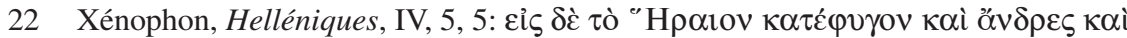

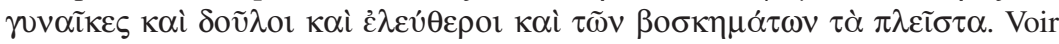

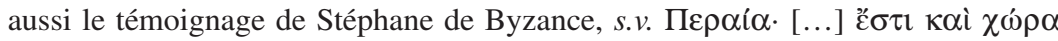

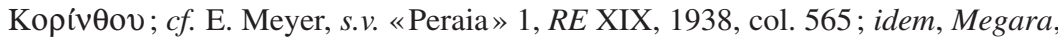
col. 168-169; Halliday, Gr. Questions, p. 97-98; Wiseman, Land, p. 32-33 ; U. Sinn, «La funzione dell'Heraion di Perachora nella peraía corinzia», in Geografia storica della Grecia Antica. Tradizioni e problemi, F. Prontera (éd.), Roma-Bari 1991, p. 216-228.

23 Chantraine, DELG, s.v. $\pi \dot{\varepsilon} \rho \bar{\alpha}$. 
peut être, dans ce cas, que la rive du golfe Saronique qui leur était opposée. Mieux, les ressources de Pérachora auraient été insuffisantes pour assurer l'existence de deux districts (des Piraeis et des Héraeis) ${ }^{24}$. Toutefois, il faut avouer que ce dernier argument a peu de valeur, car on n'a aucune information sur la grandeur des districts mentionnés par Plutarque. Quant à l'étymologie du nom des Piraeis, il est également possible que cette appellation ait été mise en circulation par les Corinthiens, et non par les Mégariens, et qu'elle ait originellement désigné les habitants se trouvant dans la région sud-est de la péninsule de Pérachora, près de l'isthme, en face de la ville de Corinthe ${ }^{25}$. Cette hypothèse gagne en vraisemblance si l'on admet que l'occupation corinthienne de cette péninsule ne connut aucune interruption à l'époque archaïque (voir ci-dessous). Je crois dès lors qu'il n'y a pas de raison de mettre en doute la localisation des Piraeis dans la péninsule de Pérachora. D'aucuns ont proposé de placer ce district (ou le Peiraion) au sud ${ }^{26}$ ou au nord-ouest de cette péninsule ${ }^{27}$. Mais en l'absence de témoignages détaillés, il reste difficile de choisir entre ces propositions ${ }^{28}$.

On signalera aussi ici l'opinion de Wachter, selon laquelle le Peiraion mentionné par Xénophon apparaîtrait dans une inscription peinte sur un pinax du VI ${ }^{\mathrm{e}}$ siècle consacré dans le sanctuaire de Poséidon et d'Amphitrite à Corinthe. Wachter propose de lire ce texte ainsi: Пع $\rho \alpha-$ $\varepsilon o ́ \theta \varepsilon v$ víõo $\mu \varepsilon \varsigma$, que l'on traduira par «nous avons vaincu (au concours)

24 Salmon, Heraeum, p. 195-196; cf. Coldstream, Geom. Gr. ${ }^{2}$, p. 105, n. 28.

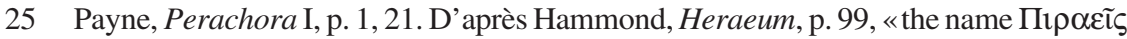

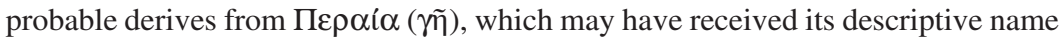
in the Bronze Age from any Greek-speaking people of the adjacent Peloponnese». Tout en réfutant l'hypothèse de Salmon concernant la localisation des Piraieis dans le Péloponnèse, Wiseman, Land, p. 41-42, n. 109, estime que ces derniers auraient pu être désignés ainsi par les Mégariens «if they had lived along the Halcyonic coast of the Perachoran peninsula».

26 Legon, Megara Pol. Hist., p. 50, 52.

27 Meyer, Megara, col. 168; H. N. Fowler, R. Sillwell, Corinth, vol. I. Introduction, Topography, Architecture, Cambridge, Mass. 1932, p. 42; Sakellariou-Pharaklas,

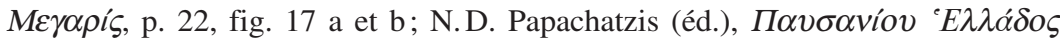

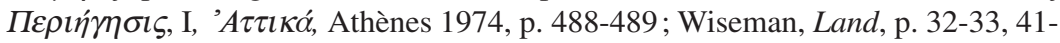
42, n. $107,109$.

28 Cf. Figueira, Chronological Table, p. 266-267. 
de Péraion ${ }^{29}$. On peut se demander si cette victoire n'avait pas été remportée lors d'un concours organisé en l'honneur d'Héra dans le sanctuaire de Pérachora. Si tel fut le cas, on aurait un argument supplémentaire en faveur de la proximité existant entre les Piraeis et les Héraeis dans la péninsule de Pérachora. Notons à cet égard qu'une fête en l'honneur d'Héra Akraia était célébrée à Corinthe, en association avec des cérémonies consacrées aux enfants de Médée. Les jeunes accomplissaient à ce moment-là plusieurs rites d'initiation ${ }^{30}$. Selon Will, la célébration de cette fête avait lieu dans le sanctuaire urbain d'Héra Akraia ${ }^{31}$. Mais l'existence d'un tel lieu de culte a été mise en doute par les chercheurs, qui estiment que les rites en l'honneur d'Héra Akraia se déroulaient, au moins en partie, à Pérachora ${ }^{32}$. Ces Héraia avaient peut-être eu à une certaine époque un caractère agonistique.

Comme son nom l'indique, le district des Héraeis se rattache au culte d'Héra, une divinité qui ne semble pas être célébrée à Mégare, mais seulement dans une région proche de cette cité, à Pérachora. Les fouilles menées par Payne de 1930 à 1933 sur ce site ont mis au jour deux lieux de culte distincts dédiés à Héra ${ }^{33}$. D'une part, il y avait un temple d'Héra Akraia, près du port, à une courte distance de la mer, auquel Payne attribue une période géométrique et une période couvrant le $\mathrm{VI}^{\mathrm{e}}$ siècle. L'épiclèse Akraia est attestée par une inscription du $\mathrm{V}^{\mathrm{e}}$ siècle et deux inscriptions du $\mathrm{IV}^{\mathrm{e}}$ siècle, mais en raison de la continuité du culte dans cette zone, on a considéré que le culte d'Héra Akraia

29 R. Wachter, Non-Attic Greek Vase Inscriptions, Oxford 2001, p. 151-152, traduit l'inscription peinte sur ce pinax corinthien par «we have won (a prize) from Peraion ».

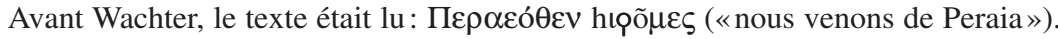
Voir à cet égard IG IV 329; E. Schwyzer, Dialectorum Graecorum exempla epigraphica potiora, Leipzig 1923, $\mathrm{n}^{\circ} 123,12$; C. D. Buck, The Greek Dialects. Grammar, Selected Inscriptions, Glosary, Chicago-London 1955, nº 92 d.

30 M.P. Nilsson, Griechische Feste von religiöser Bedeutung ${ }^{2}$, Leipzig 1906, p. 57-61.

31 Will, Korinthiaka, p. 84-103.

32 D. Novaro-Lefèvre, «Le culte d'Héra à Pérachora (VIII $-{ }^{\mathrm{V}} \mathrm{VI}^{\mathrm{e}} \mathrm{s}$.) : essai de bilan», REG 113, 2000, p. 60-62; B. Menadier, «The Sanctuary of Hera Akraia and its Religious Connections with Corinth», in Peloponnesian Sanctuaries and Cults. Proceedings of the Ninth International Symposium at the Swedish Institute at Athens, 11-13 June 1994, Stockholm 2002, p. 85-90.

33 Les découvertes de Pérachora ont été publiées par Payne, Perachora I, et Dunbabin, Perachora II. Dernièrement, plusieurs savants ont réexaminé ces trouvailles: Tomlinson, Perachora, p. 321-346; Sinn, Heraion; Menadier, Perachora. 
remontait à une époque plus ancienne. D'autre part, il existait un temple consacré à Héra Liménéia, dans la partie sud-ouest de la vallée, à une distance de $c a$. 200 mètres de la mer. D'après Payne, le temple d'Héra Akraia est à placer entre le $\mathrm{IX}^{\mathrm{e}}$ siècle et $c a$. 750-725; le temple d'Héra Liménéia, quant à lui, vers 750-72034.

L'identification de la céramique trouvée à Pérachora et l'appartenance politique de cette région ont généré un grand débat. En raison de l'importance du matériel archéologique argien, Payne et Dunbabin pensent que le culte d'Héra Akraia a été fondé par les Argiens. Mais considérant une partie de la céramique géométrique trouvée dans le sanctuaire comme corinthienne, ils localisent le sanctuaire dans le territoire de la cité de Corinthe ${ }^{35}$. En revanche, acceptant l'historicité de la participation du district des Héraeis au synœcisme mégarien, Hammond estime que la céramique géométrique identifiée par Payne comme argienne serait en réalité de la céramique mégarienne imitant la céramique d'Argos. Il soutient ainsi l'origine mégarienne du sanctuaire d'Héra Akraia (ca. 850-725) et considère que le temple d'Héra Liménéia fut fondé vers 740 par les Corinthiens après qu'ils eurent conquis la péninsule de Pérachora ${ }^{36}$. Cette thèse a été critiquée par Salmon, qui a montré de manière convaincante qu'il n'existait pas d'interruption de l'utilisation cultuelle dans le sanctuaire d'Héra Akraia et que les deux temples continuaient à être utilisés parallèlement jusqu'à l'époque hellénistique. Les noms d'Akraia et de Liménéia représentent en réalité deux épiclèses pour le même culte d'Héra ${ }^{37}$. La construction du temple

34 Payne, Perachora I, p. 25, 34, et pl. 27, 2 (dédicace à Héra Akraia du Ve siècle), pl. 29, 1-2, et pl. 131, 1-2 (dédicaces à Héra Akraia du IV siècle). Trois dédicaces datant du $\mathrm{VI}^{\mathrm{e}}$ siècle évoquent le culte d'Héra Liménéia: Payne, Perachora I, p. 136, pl. 43, 57; L. H. Jeffery, in Dunbabin, Perachora II, p. 395, nº 17, pl. 128 (3434), pl. 163; p. 398, no 101, pl. 151, pl. 167. Strabon, VIII, 6, 22, C 380, rapporte qu'il y avait jadis un oracle d'Héra Akraia à Pérachora; $c f$. T. J. Dunbabin, «The Oracle of Hera Akraia at Perachora», ABSA 46, 1951, p. 61-71; J. et L. Robert, Bull. ép., 1954, 51.

35 Payne, Perachora I, p. 20-23, 32-33; Dunbabin, Corinth, p. 59-69, suivis par Hanell, Megarische Studien, p. 77-79; Will, Korinthiaka, p. 36-38; Antonetti, Confini della Megaride, p. 547.

36 Hammond, Heraeum, p. 93-102; idem, Peloponnese, p. 334.

37 Salmon, Heraeum, p. 175-178; Menadier, Perachora, p. 136-142; R. A. Tomlinson, Greek Sanctuaries, London, 1976, p. 111-115; Coldstream, Geom. Gr. ${ }^{2}$, p. 327, 339, n. 6. Notons aussi que les plus anciennes dédicaces trouvées dans le sanctuaire (situées à des époques différentes par les spécialistes, entre $c a$. 750-ca.550) attestent 
d'Héra Liménéia se justifierait par des raisons topographiques, l'augmentation du nombre de dédicaces ayant imposé l'élargissement de la zone cultuelle et l'édification d'un deuxième lieu de culte. Salmon considère la plus grande partie des céramiques géométriques et archaïques de Pérachora comme corinthienne et note que l'occupation mégarienne du site à l'époque archaïque n'est pas attestée par les sources archéologiques. Le contrôle corinthien sur le sanctuaire doit commencer à partir de 800 , ce qui, à son avis, n'exclut pas une occupation mégarienne de l'Héraion à une date antérieure au VIII ${ }^{\mathrm{e}}$ siècle $^{38}$. Cette dernière hypothèse reste néanmoins difficile à prouver, car les trouvailles n'attestent pas une occupation de l'Héraion au $\mathrm{IX}^{\mathrm{e}}$ siècle ou auparavant. De fait, les spécialistes ont fait rabaisser la chronologie de Payne pour l'Héraion de Pérachora et ont montré que le premier temple (au plan absidal) ne remontait pas au-delà du VIII ${ }^{\mathrm{e}}$ siècle. Entre cet édifice de la haute époque archaïque et le temple dorique construit vers la fin du VI siècle, s'intercalerait un temple du VII ${ }^{\mathrm{e}}$ siècle dont l'existence est suggérée par la découverte de nombreuses céramiques. Mais sa localisation exacte reste sujette à caution ${ }^{39}$. Selon Tomlinson, l'édifice datant du VII ${ }^{\mathrm{e}}$ siècle

une autre épiclèse d'Héra, à savoir celle de Leukolenos («aux bras blancs »): H. T. Wade-Gery, in Payne, Perachora I, p. 256-267, pl. 36, pl. 132, 3-4; Guarducci, Epigrafia gr., I, p. 430 ; Jeffery, $L S A G^{2}$, p. 122-125, 131, nos 7, 12, 17 ; H. R. Immerwahr, Attic Script. A Survey, Oxford 1990, p. 16; D. Novaro-Lefèvre, op. cit., p. 45-52.

38 Salmon, Heraeum, p. 192-204; cf. R. A Tomlinson, «Perachora: the Remains outside two Sanctuaries », ABSA 64, 1969, p. 235, qui pensait initialement que le passage de Plutarque sur les cinq districts mégariens «derives from a Megarian attempt to justify a claim to this region, made perhaps in Hellenistic times ». Pourtant, la démonstration de Salmon lui a fait changer d'avis par la suite: Tomlinson, Perachora, p. 324, n. 5, 348. La thèse de Salmon est également acceptée par Coldstream, Geom. Gr. ${ }^{2}$, p. 85-86, 105, n. 28. De même, Antonetti-Lévêque, Devins, p. 197, n. 3 ; Antonetti, Confini della Megaride, p. 539-540, 546-549; eadem, Megara e le sue colonie, p. 90-92, estiment qu'avant l'appropriation par Corinthe en 750-700, l'Héraion de Pérachora avait appartenu à Mégare.

39 Salmon, Heraeum, p. 161-165; Coldstream, Gr. Geom. Pot., p. 352-353; idem, Geom. $G r^{2}$, p. 174, 321, 322; Tomlinson, Perachora, p. 321-346, considère le temple du $\mathrm{VII}^{\mathrm{e}}$ siècle «hypothetical, rather than archaeological» (p. 330); Sinn, Heraion, p. 58-61, 100-102 ; J. M. Fossey, «The Perakhóra Peninsula Survey », EMC 34, 1990, p. 201-211; Menadier, Perachora, p. 65-74, 77-78, 93-100, 105-120, 144-145; Freitag, Der Golf von Korinthos, p. 187-189. 
et dont émanent les dédicaces du $\mathrm{VI}^{\mathrm{e}}$ siècle à Héra Liménéia ne serait pas un temple, mais un hestiatorion ${ }^{40}$.

De plus, si l'on accepte une possession par Mégare de la Pérachora avant le VIII ${ }^{e}$ siècle, on devrait également situer à cette époque-là le synœcisme et l'élaboration des institutions de Mégare, ce qui n'est guère satisfaisant ${ }^{41}$. En réalité, il est évident aujourd'hui que la céramique trouvée à Pérachora - qui provient, rappelons-le, en grande majorité de Corinthe - ne peut pas être utilisée pour démontrer que l'occupation corinthienne a succédé à une phase d'occupation mégarienne. Car, d'une part, une céramique géométrique produite à Mégare n'a pas encore été identifiée ${ }^{42}$, et, d'autre part, une tradition littéraire confirme le contrôle corinthien non seulement de Pérachora mais aussi de la cité de Mégare (voir ci-dessous). Il serait alors en principe difficile de faire la différence, du point de vue de la céramique, entre deux territoires qui furent à l'origine corinthiens. En outre, les trouvailles confirment l'emploi de la céramique corinthienne par les Mégariens dans la deuxième moitié du VIII ${ }^{\mathrm{e}}$ siècle et au début du VII ${ }^{\mathrm{e}}$ siècle ${ }^{43}$, et l'on trouve en Mégaride et Corinthie à l'époque archaïque la même pratique funéraire, soit l'inhumation en sarcophages ${ }^{44}$.

40 R. A. Tomlinson, «The Upper Terraces at Perachora», ABSA 72, 1977, p. 197-202; idem, «The Chronology of the Perachora Hestiatorion and its Significance», in Sympotica. A Symposium on the Symposion, O. Murray (éd.), Oxford 1990, p. 95101 ; idem, Perachora, p. 330, 333-334 ; suivi par Sinn, Heraion, p. 60-66, 101-102 ; Salmon, Wealthy Corinth, p. 59, n. 15 ; cf. De Fidio, Corinto e l'Occidente, p. 78-80; B. Bergquist, in Le sanctuaire grec, Entretiens sur l'Antiquité classique 37, A. Schachter et J. Bingen (éds.), Genève 1990, p. 351 ; Mazarakis Ainian, From Rulers' Dwellings to Temples, p. 154-155.

41 Cf. Figueira, Chronological Table, p. 265-266.

42 C.W. Neeft, «Observations on the Thapsos Class», MEFRA 93, 1981, p. 54-55; J. Boardman, F. Schweizer, «Clay Analyses of Archaic Greek Pottery», ABSA 68, 1973, p. 278-280; A.P. Grimal et al., «Neutron Activation and X-Ray Analysis of «Thapsos Class» Vases. An Attempt to Identify their Origin», Journal of Archaeological Science 7, 1980, p. 228-229; cf. Boardman, Gr. Overseas ${ }^{3}$, p. 163.

43 Pour la présence des céramiques corinthiennes (géométriques et protocorinthiennes) en Mégaride, voir Dunbabin, Corinth, p. 65 ; Coldstream, Gr. Geom. Pot., p. 95, 353, 404 ; Morgan, Isthmia VIII, p. 476, 478.

44 G. Shepherd, «The Pride of Most Colonials: Burial and Religion in the Sicilian Colonies», ActaHyp 6, 1995, p. 56; I. Morris, «Archaeology and Archaic Greek History», in Archaic Greece: New Approaches and New Evidence, N. Fisher et H. van Wees (éds.), London 1998, p. 19. Pour l'attestation de l'inhumation en sarco- 
Du reste, il convient de noter que du point de vue géographique, la Pérachora est étroitement liée à Corinthe et non pas à Mégare: si les Mégariens sont séparés de cette péninsule par les monts Géraniens, cela n'est pas le cas pour la cité de Corinthe, que l'on arrive même à apercevoir depuis l'Héraion ${ }^{45}$. De plus, ce sanctuaire se trouve sur la route menant aux colonies d'Occident; c'est dès le milieu du VIII ${ }^{\mathrm{e}}$ siècle que l'on constate son développement ${ }^{46}$. Et l'on sait que ce sont surtout les Corinthiens qui ont profité des contacts entre la Grèce et l'Ouest ${ }^{47}$. On remarque de même que le culte d'Héra Akraia fut introduit dans la deuxième moitié du VIII ${ }^{\mathrm{e}}$ siècle à Corcyre par les Corinthiens qui avaient remplacé la première apoikia érétrienne, ce qui laisse penser qu'à cette époque l'Héraion de Pérachora était une possession de Corinthe ${ }^{48}$.

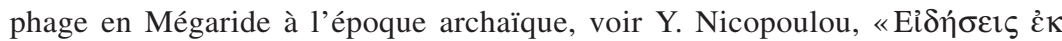

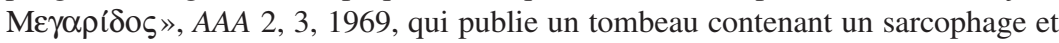
des céramiques protocorinthiennes, trouvés près de la route qui reliait Mégare, par les monts Géraniens et Tripodiskos, à l'isthme de Corinthe; P. Zoridis, «Mć $\gamma \alpha \rho \alpha »$,

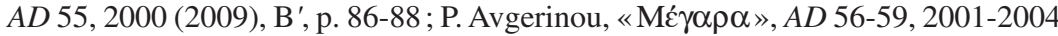
(2010), B', p. 303.

45 D'ailleurs, en constatant les difficultés d'accès des Mégariens à Pérachora, E. L. Highbarger, $A J P h$ 58, 1937, p. 120, notait déjà : «It seems to me that Perachora could never have been controlled by Megara». Cf. Menadier, Perachora, p. 145-146.

46 Payne, Perachora I, p. 25; T.J. Dunbabin, ABSA 46, 1951, p. 61-71; Tomlinson, Perachora, p. 331-332; G. Shepherd, «Greeks bearing Gifts : Religious Relationships between Sicily and Greece in the Archaic Period», in Sicily from Aeneas to Augustus. New Approches in Archaeology and History, C. Smith et J. Serreti (éds.), Edinburg 2000, p. 67-68; Menadier, Perachora, p. 156, 216-222; cf. aussi D. J. Blackman, «The Harbour at Perachora», ABSA 61, 1966, p. 192-194; D. Novaro-Lefèvre, op. cit., p. 65-66.

47 De Fidio, Corinto e l'Occidente, p. 47-141 (avec la bibliographie).

48 Salmon, Heraeum, p. 181-183, 200; De Fidio, Corinto e l'Occidente, p. 80; Menadier, Perachora, p. 148-151. L'épiclèse $A k r(a) i a$ est attestée à Corcyre par une borne du $\mathrm{V}^{\mathrm{e}}$ siècle: $I G$ IX 1, 698; $c f$. Jeffery, $L S A G^{2}$, p. 234, no 18 . Sur le culte d'Héra Akraia

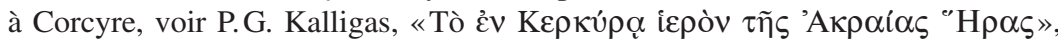
$A D$ 24, 1969 (1971), A', p. 51-58; G. Dontas, «Denkmäler und Geschichte eines kerkyräischen Heiligtums », in Neue Forschungen in griechischen Heiligtümern. Internationales Symposion in Olympia vom 10. bis 12. Oktober 1974, U. Jantzen (éd.), Tübingen 1976, p. 121-133. Plutarque, Questions grecques, XI (= Moralia 293 B), rapporte que les Érétriens furent remplacés à Corcyre par les Corinthiens de Charicrate (Chersicratès chez Timée, FGrHist 566 F 80, et chez Strabon, VI, 2, 4, C 269). Il existe deux dates pour l'établissement des Corinthiens à Corcyre: 733, 
Quant au culte d'Héra dans les colonies de Mégare, que Hammond mettait en relation avec des émigrés de Pérachora, il peut aussi témoigner de la présence des Corinthiens, des Argiens ou des Béotiens dans ces cités, des colons qui avaient pu emporter cette divinité de leurs métropoles respectives ${ }^{49}$. En tout état de cause, Héra n'est célébrée sous aucune épiclèse spécifique à Mégare et dans ses colonies. Pour l'introduction des divinités de souche non mégarienne dans les établissements fondés par les Mégariens et leurs synoikoi, on peut évoquer à titre de comparaison la célébration d'Héraclès à Héraclée du Pont, culte qui se rapporte aux traditions béotiennes présentes dans cette colonie ${ }^{50}$. Cela n'exclut pas que les Mégariens aient pu fréquenter l'Héraion de Pérachora, lieu de passage pour les navires traversant le golfe de Corinthe vers la Grande Grèce et la Sicile. En insistant sur les prérogatives d'Héra dans le domaine de la navigation, Antonetti estime à cet égard que Pérachora a pu être «le pivot du culte d'Héra pour l'Isthme entier» ${ }^{51}$.

D'autre part, le paysage religieux de la Mégaride à l'époque archaïque reste peu connu et l'existence dans cette région d'un sanctuaire d'Héra, que les fouilles n'ont pas encore mis au jour, reste toujours possible. Mieux, on sait que le mont Cithéron, à la frontière avec la

selon Strabon (VI, 2, 4, C 269, concordance avec la fondation de Syracuse), et 706/ 5, chez Eusèbe (Chron., St. Jérôme, éd. R. Helm, p. 91b; = éd. A. Schöne, p. 85). La dernière date semble être confirmée par les trouvailles archéologiques, mais la question reste à vrai dire ouverte. $C f$. Miller, Colony Dates, p. 23, 192-193; P. G. Kalligas,

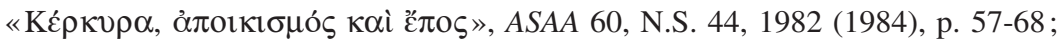

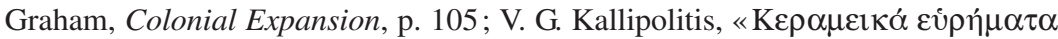

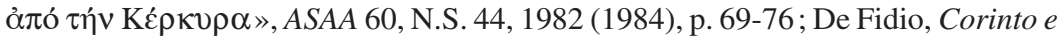
l'Occidente, p. 64-65, 90-92; V. Parker, Untersuchungen zum Lelantischen Krieg und verwandten Problemen der frühgriechischen Geschichte, Historia Einzelschriften 109, Stuttgart 1997, p. 55-57.

49 Hammond, Heraeum, p. 96, 98. Le culte d'Héra est sûrement attesté dans les colonies mégariennes à Sélinonte (voir infra, chapitre II.1.2.5), à Byzance et Chalcédoine (voir infra, chapitre II.2.4.1.5), à Mésambria (voir infra, chapitre II.3.2.1) et peut-être à Mégara de Sicile (voir infra, chapitre II.1.2.5) et à Héraclée du Pont (voir infra, chapitre II.3.1.1).

50 Voir infra, chapitre II.3.1.1.

51 Antonetti, Panthéon de Mégare,p. 37. Sur le tracé exact des frontières politiques dans la région de l'isthme à l'époque archaïque, voir aussi Morgan, Isthmia VIII, p. 421, qui écrit : «It is, however, important also to consider the fluidity of early < borders > and to question their real political significance even as late as the 8th century ». 
Béotie, était consacré à Héra ${ }^{52}$. La Ciris, œuvre attribuée à Virgile, évoque le sacrilège que Scylla, la fille du roi mégarien Nisos, avait commis durant la fête locale d'Héra; quoique la valeur historique de cette mention reste douteuse ${ }^{53}$.

Bref, on voit que la thèse selon laquelle la péninsule de Pérachora aurait d'abord appartenu à Mégare, avant d'être conquise par Corinthe, présente plusieurs faiblesses, et plusieurs savants ont d'ailleurs refusé de la suivre ${ }^{54}$. Or si les Piraeis et les Héraeis ont peu de chances d'avoir participé au synœcisme mégarien, il reste néanmoins à expliquer leur présence dans la liste de cinq mérè de Plutarque. À ce propos, Rigsby avait avancé l'hypothèse selon laquelle cette liste représente une tentative des Mégariens de l'époque classique de démontrer l'appartenance de la Pérachora à leur cité55. Selon moi, une explication analogue peut être avancée pour l'inclusion des Kynosoureis parmi les districts de la Mégaride. Pour localiser ce méros, les exégètes ont cherché différentes

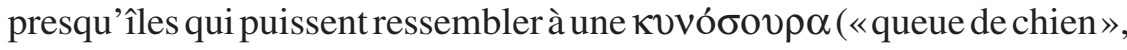
une dénomination fréquente pour une péninsule). On a ainsi proposé de situer les Kynosoureis soit dans la région nord-ouest de la Mégaride (près d'Aigosthènes) ${ }^{56}$, soit à l'est du port mégarien de Nisaia (la presqu'île

52 Euripide, Phéniciennes, 24; cf. A. Schachter, Cults of Boiotia, 1. Acheloos to Hera, BICS, Suppl. 38.1, London 1981, p. 242-246; Parisi Presice, L'importanza di Hera, p. 54.

53 Ps.-Virgile, Ciris, 133-150 (éd. D. Knecht). Ce poème raconte l'histoire de Scylla, qui tomba amoureuse de Minos, le roi de Crète, lorsque celui-ci assiégea Mégare. D’après R. O. A. L. Lyne (éd.), Ciris. A Poem Attributed to Virgil, Cambridge 1978, p. 154-155, l'histoire de la punition de Scylla par Héra est calquée sur celle d'Inô, la prêtresse d'Héra à Argos; $c f$. Antonetti, Megara e le sue colonie, p. 91-92.

54 C. A. Morgan, «Corinth, the Corinthian Gulf and Western Greece during the Eighth Century BC», ABSA 83, 1988, p. 335; eadem, «The Evolution of a Sacral 〈Landscape > : Isthmia, Perachora, and the Early Corinthian State», in Placing the God. Sanctuaries and Sacred Spaces in Ancient Greece, S. E. Alcock et R. Osborne (éds.), Oxford 1994, p. 135 ; C. K. Williams, «Archaic and Classical Corinth», in Corinto e l'Occidente. Atti del trentaquattresimo Convegno di studi sulla Magna Grecia (Taranto, 7-11 ottobre 1994), Taranto 1995, p. 34; Menadier, Perachora, p. 129-130, 150-152, 215-222; D. Novaro-Lefèvre, op. cit., p. 55-56. Rigsby, Megara, p. 101 ; cf. M. Gras, H. Tréziny, in Mégara 5, p. 557.

56 Bursian, Geographie, vol. I, p. 372; Meyer, Megara, col. 169, 182; Halliday, Gr. Questions, p. 98 ; Hammond, Main Road, p. 117; Legon, Megara Pol. Hist., p. 53. 
de Teicho) $)^{57}$ ou encore à Salamine ${ }^{58}$. Les deux premières localisations ont été rejetées par Sakellariou et Pharaklas, qui notaient l'absence de découvertes importantes de l'époque archaïque et de récits évoquant le nom d'un tel site dans ces régions. D'après eux, la troisième proposition serait aussi inacceptable, en raison de la présence d'une subdivision civique (hékatostys) appelée Kynosouris à Mégare au $\mathrm{III}^{\mathrm{e}}$ siècle, à une époque où l'île de Salamine n'appartenait plus aux Mégariens ${ }^{59}$. Par ailleurs, les deux savants suggèrent que tout comme dans le cas de la Kynosoura de Sparte, la dénomination du district homonyme mégarien n'aurait pas de sens topographique. Ainsi proposent-ils de situer les Kynosoureis dans la région du nord-est de la Mégaride, près de la frontière avec Éleusis, en raison de la trouvaille de céramiques d'époque archaïque et de la présence d'un fortin à l'époque hellénistique ${ }^{60}$. Cette dernière proposition reste toutefois difficile à accepter, car cette région de frontière entre Athènes et Mégare apparaît souvent dans les documents et l'on n'y trouve jamais la mention d'une Kynosoura.

En revanche, l'hypothèse de Toepffer, selon laquelle la désignation du «district» des Kynosoureis fait référence à Kvvóoovp $\alpha$, la longue et étroite presqu'île située à Salamine (en face du Pirée, voir carte 3), mérite davantage notre attention. L'attestation de la hékatostys Kynosouris à Mégare à l'époque hellénistique n'est pas un argument contre un lien avec Salamine, parce que le nom de cette subdivision civique était beaucoup

57 E. Kirsten, in A. Philippson, Die griechischen Landschaften, Band I, Teil III : Attika und Megaris, Frankfurt am Main 1952, p. 946, n. 2.

58 J. Toepffer, Quaestiones Pisistrateae, Dorpat 1886, p. 49; Beloch, Gr. Gesch. ${ }^{2}$, I, 2 , p. 310-311. Sur la Kynosoura de Salamine, voir E. Curtius, J. Kaupert (éds.), Karten von Attika. Text. Heft VII-VIII, Berlin 1895, p. 26-27; L. Bürchner, s.v. «Kynosura» 1, RE XII, 1925, col. 36; Bursian, Geographie, vol. I, p. 364; A. Philippson, op. cit., p. 870. Une péninsule appelée Kynosoura se trouvait aussi en Attique dans le golfe de Marathon: J. R. McCredie, Fortified Military Camps in Attica, Hesperia, Suppl. 11, Princeton 1966, p. 41-43.

$59 I G \mathrm{IV}^{2}$ 1, 42. Sur cette inscription, voir infra, chapitre III.1.2.1.

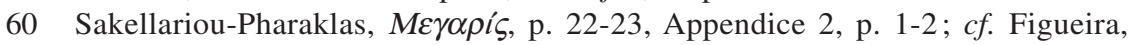
Chronological Table, p. 267; Smith, Megaris, p. 71. Dernièrement, P. Zoridis,

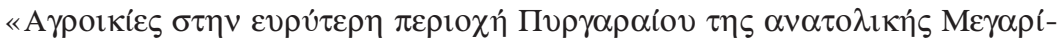
$\delta \alpha \varsigma », A D$ 57, 2002 (2010), A', p. 93-118, publie plusieurs vestiges (fermes, villa, tour) datant des $\mathrm{V}^{\mathrm{e}}-\mathrm{IV} \mathrm{V}^{\mathrm{e}}$ siècles, trouvées à Pyrgari, à environ $7 \mathrm{~km}$ au nord-est de Mégare. Sur la trace de Sakellariou et Pharaklas, Zoridis met en rapport ces découvertes avec les Kynosoureis. 
plus ancien et n'avait probablement plus à cette période un sens topographique. De fait, on peut rattacher la Kynosoura de Salamine à un héros Kynosouros, qui serait l'éponyme mythique de cette presqu'île. L'usage d'appeler différents endroits d'après les noms des héros est bien documenté, et l'on sait qu'un autre Kynosouros, le fils d'Hermès, était l'éponyme d'une montagne d'Arcadie (Kynosoura), tandis que la nymphe Kynosoura se retrouve dans un nom de lieu en Crète ${ }^{61}$. Mieux, il est très probable que le héros Kynosouros ait été honoré par les Mégariens car, fils de Pélops et d'Hippodamie ${ }^{62}$, il était le frère d'Alcathoos, le bâtisseur mythique des remparts et roi de Mégare, qui donna son nom à l'acropole occidentale ${ }^{63}$. Pausanias rapporte qu'Alcathoos et plusieurs membres de sa famille (son épouse et ses enfants) étaient célébrés par les Mégariens ${ }^{64}$. Au surplus, la présence de Kynosouros à Mégare semble être confirmée par la mention de ce héros dans une inscription émanant de la colonie mégarienne de Mésambria ${ }^{65}$. Tout comme d'autres héros

61 H. W. Stoll, s.v. «Kynosoura», in Roscher, Lexikon, II, 1, col. 1706.

62 O. Höfer, s.v. «Hippodameia» 1, in Roscher, Lexikon, I, 2, col. 2669; H. W. Stoll, s.v. «Kynosouros » 2, in Roscher, Lexikon, II, 1, col. 1706.

63 Théognis, 773-774; Pausanias, I, 42, 1-2. La scholie b à Pindare, Néméennes, V, 84, rapporte que les Mégariens tenaient des concours en l'honneur d'Alcathoos, des Alkathoia. Cf. Bernhardt, s.v. «Alkathoos» 1, in Roscher, Lexikon, I, 1, col. 232; Highbarger, Megara, p. 34, 55 ; Hanell, Megarische Studien, p. 27-30; Piccirilli, MEGARIKA, p. 38-41. Sur le héros Alcathoos en tant que véritable fondateur de la cite mégarienne, voir Bohringer, Mégare, p. 9-10; Muller, De Nisée à Mégare, p. 623-624 ; Polignac, Naissance de la cité gr., p. 171-172. La plus ancienne attestation de l'acropole d'Alcathoos est fournie par une stèle funéraire d'Athènes, qui mentionne la bravoure des cavaliers athéniens dans une bataille contre des soldats

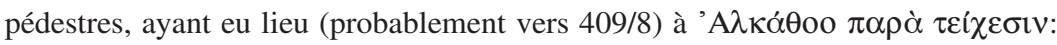
L. Parlama, «Palaiologou Shaft: Marble Memorial Stele», in The City Beneath the City. Antiquities from the Metropolitan Railway Excavations, L. Parlama et N. Chr. Stampolidis (éds.), Athens 2000, p. 396-399.

64 Selon Pausanias, à Mégare se trouvaient les tombes d'Alcathoos et de sa femme Pyrgo (I, 43, 4), de ses fils, Callipolis (I, 42, 6) et Ischépolis (I, 43, 2), de sa fille, Iphinoé $(\mathrm{I}, 43,4)$. On apprend aussi qu' avant leur mariage, les jeunes filles de Mégare faisaient des libations en l'honneur d'Iphinoé, en lui offrant une partie de leur chevelure.

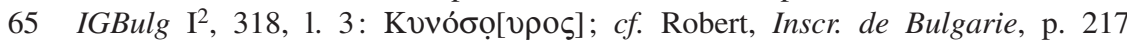
(=OpMinSel, V, p. 247), qui est le premier à avoir suggéré que cette inscription était un catalogue de héros. Les Kynosoureis, auquel se rapporte le nom du héros Kynosouros, ne sont pas les ressortissants d'un bourg mégarien, comme le pense Robert (suivi par G. Mihailov, IGBulg I², ad n ${ }^{\circ} 318$, p. 280 ; Nawotka, West. Pont. Cities, p. 96; Chiekova, Cultes, p. 280), mais, on l'a vu, d'un district. 
mégariens célébrés à Chalcédoine (Calchas) ${ }^{66}$ ou à Byzance (Polyeidos, Lakiadès, Ajax ${ }^{67}$, Kynosouros de Mésambria pourrait être originaire de Mégare.

Si l'on accepte la localisation des Kynosoureis à Salamine, il est fort probable que ce méros fut rattaché aux districts qui participèrent au synœcisme afin d'exprimer les prétentions de Mégare sur l'île voisine, objet de longues disputes avec Athènes. De la même manière, l'hékatostys Kynosouris témoignerait de la célébration du héros salaminien Kynosouros par les Mégariens de l'époque hellénistique. De fait, ce héros peut faire partie des divinités appartenant à l'horizon salaminien, que les Mégariens invoquaient pour qu'elles appuient leurs droits de possession sur l'île, telles que le héros Sciron (l'arrière-grand-père d'Ajax) et l'Athéna Aiantis ${ }^{68}$. On trouve un parallèle à Athènes, où Ajax de Salamine fut, parmi les dix éponymes des tribus clisthéniennes, le seul à venir de l'étranger ${ }^{69}$. En donnant le nom d'Aiantis ou de Kynosouris à leurs subdivisions civiques, les Athéniens et les Mégariens essayaient de légitimer leurs prétentions sur l'île de Salamine.

Sur la foi de cette démonstration, la liste de Plutarque serait à interpréter comme l'expression de la propagande des Mégariens vis-à-vis de leurs voisins de Corinthe et d'Athènes. La participation des Piraeis, des Héraeis et des Kynosoureis au synœcisme étayait les prétentions des Mégariens sur la région de Pérachora et sur l'île de Salamine. En revanche, la présence des Mégareis et des Tripodiskioi parmi les mérè de Plutarque se justifie par l'importance de Mégare, le centre politique de la Mégaride, et de Tripodiskos, le lieu d'un marché des Mégariens et un important centre religieux. Le recours des historiens mégariens à des mythes pour montrer l'extension de leur cité aux dépens des cités voisines est confirmé par une autre liste des cinq «unités» mythiques qu'il convient d'analyser par la suite.

66 Voir infra, chapitre II.2.2.1.

67 Voir infra, chapitre II.2.4.1.

68 Voir infra, chapitre I.2.2.

69 Hérodote, V, 66. 


\section{I.1.2 Le catalogue des vaisseaux mégariens chez Strabon}

Pour mettre un terme à leurs longs conflits pour l'île de Salamine, les Mégariens et les Athéniens ont fait appel vers le milieu ou la fin du $\mathrm{VI}^{\mathrm{e}}$ siècle à des arbitres spartiates. Pour appuyer leurs prétentions, les deux parties ont invoqué des vers de l'Iliade. Les Athéniens ont d'abord soutenu que les troupes d'Ajax de Salamine étaient rangées auprès de celles d'Athènes ${ }^{70}$. À leur tour, pour contrecarrer ces propos, les Mégariens ont répondu, selon Strabon, par l'interpolation des vers suivants:

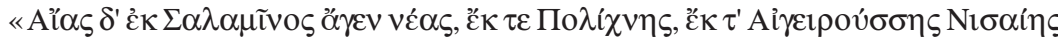

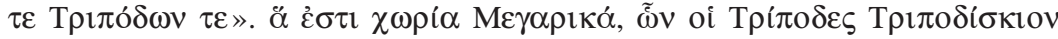

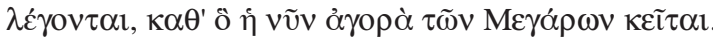

<Ajax amena des vaisseaux de Salamine, de Polichnè, d'Aigeiroussa, de Nisaia et de Tripodes \. Ce sont là des localités de Mégaride. Parmi elles, Tripodes se nomme maintenant Tripodiskion, à proximité de laquelle se tient de nos jours le marché des Mégariens ${ }^{71}$.

On constate d'emblée que la plupart des cinq sites qui auraient fourni les vaisseaux d'Ajax sont facilement identifiables: Salamine est l'île voisine de Mégare, l'objet de l'arbitrage; Tripodes, comme le note Strabon, est une variante de Tripodiskos; Nisaia est le nom du port de Mégare et, moins probablement, la dénomination archaïque de celle-ci ${ }^{72}$. En ce qui concerne Polichnè («petite ville»), les chercheurs ont d'abord considéré que sous le nom de cette localité il convient de reconnaître soit Mégare ${ }^{73}$, soit Pagai ${ }^{74}$. Ensuite, pensant que le mot polichnè désignait un fort, Figueira a placé Polichnè sur les versants de Géraneia, à la frontière mégaro-corinthienne, ou, mieux, au carrefour de la péninsule de Pérachora avec l'isthme, près du fort corinthien d'Oinoé (voir

70 Plutarque, Solon, 10, 1-2.

71 Strabon, IX, 1, 10, C 394 (trad. de R. Baladié, CUF); $c f$. Piccirilli, MEGARIKA, p. 133-134.

72 Figueira, Chronological Table, p. 268.

73 E. Kirsten, s.v. «Polichne», RE XXI, 2, 1952, col. 1371-1372; Bursian, Geographie, vol. I, p. 372, n. 2.

74 Hammond, Main Road, p. 120.

75 Figueira, Chronological Table, p. 268. Pour la localisation d'Oinoé, voir Xénophon, Helléniques, IV, 5, 5, et Strabon, VIII, 6, 22, C 380; cf. Wiseman, Land, p. 28-32. 
carte 2$)^{75}$. Du reste, la présence de Nisaia et l'absence de Mégare dans le catalogue de Strabon s'expliquent peut-être par le fait que les Mégariens considéraient que leur port était plus ancien que leur ville ${ }^{76}$. L'archéologie semble confirmer cette hypothèse, car les plus anciennes céramiques, datant de l'époque mycénienne, proviennent de Nisaia ${ }^{77}$. En revanche, les vestiges trouvés jusqu'à présent ne semblent pas remonter au-delà de l'époque géométrique ${ }^{78}$. Bref, il est possible que, pour donner crédit à leur catalogue des vaisseaux, les Mégariens aient introduit de vieux noms, une manière de rendre les choses plus anciennes qu'elles ne l'étaient. Par contraste avec l'antique Nisaia, Mégare aurait pu être considérée à l'époque hellénistique comme étant à l'origine une polichnè («petite ville»). Cependant cela n'est qu'une hypothèse dont il est impossible d'avoir la confirmation et, pour l'instant, on ne dispose pas d'autre indice permettant de situer avec certitude Polichnè dans la Mégaride. Quant à Aigeiroussa, appelée aussi Aigeiros chez Théopompe ${ }^{79}$, elle doit être identifiée avec le lieu-dit Aigeiroi, qui apparaît dans la

76 On a suggéré que Nisaia apparaîtrait dans le catalogue des vaisseaux de l'Iliade, parmi les sites de la Béotie (II, v. 508: Nĩ $\alpha \zeta \alpha \theta \varepsilon ́ \eta)$. Voir à cet égard Highbarger, Megara, p. 88-89; Hanell, Megarische Studien, p. 23, 55; Ehrhardt, Ktistai, p. 3839; idem, «Ilias B 508 und die Gründung von Heraclea Pontica», Hermes 124, 1996, p. 101-103. Mais, il peut aussi s'agir dans ce passage du site béotien appelé Nisa, que le géographe Dionysios, fils de Calliphon, GGM I, 101-102, situe aux alentours de Platée. D' après Strabon, IX, 2, 14, C 405, il faudrait remplacer Nisa par Isos dans l'Iliade; $c f$. R. Hope Simpson, J. F. Lazenby, The Catalogue of the Ships in Homer's Iliad, Oxford 1970, p. 32; Fossey, Topography, p. 257-261 ; E. Visser, Homers Katalog der Schiffe, Stuttgart-Leipzig 1997, p. 279-280; Smith, Megaris, p. 96.

77 F. Bölte, G. Weicker, «Nisaia und Minoa», MDAI(A) 29, 1904, p. 94-95; I. Threp-

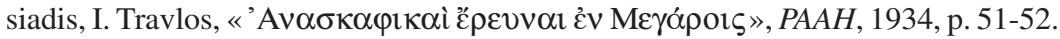
Muller, De Nisée à Mégare, p. 619-623, pense que l'occupation mycénienne se limitait à Nisaia et que Mégare ne l'a pas connue. L'abandon de Nisaia pour le site de Mégare serait à mettre en relation avec la conquête dorienne de la Mégaride, au tournant du $\mathrm{XI}^{\mathrm{e}}-\mathrm{X}^{\mathrm{e}}$ siècle. Contra $\mathrm{C}$. Bérard, «Urbanisation à Mégara Nisaea et l'urbanisme à Mégara Hyblaea», MEFRA 95, 2, 1983, p. 634-639, qui attribue un passé mycénien à la ville de Mégare.

78 Muller, De Nisée à Mégare, p. 620-623; Zoridis, Mégara, p. 200-201.

79 Théopompe, FGrHist 115 F 241, apud Stéphane de Byzance, s.v. Aiłzipoú $\sigma \alpha$.

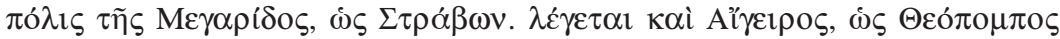

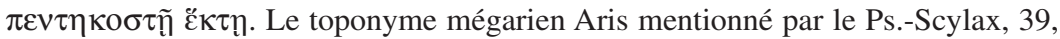
devrait être corrigé probablement en A〈geir〉ros. Voir à ce propos G. Shipley (éd.), Pseudo-Skylax's, Periplous. The Circumnavigation of the Inhabited World, Exeter 2011, p. 118. 
Question grecque LIX de Plutarque, consacrée à l'attaque d'une théorie des Péloponnésiens par le génos des «renverseurs de chariots». On apprend ainsi que des théores, qui traversaient la Mégaride en direction de Delphes, installèrent leur campement «à Aigeiroi, en bordure du

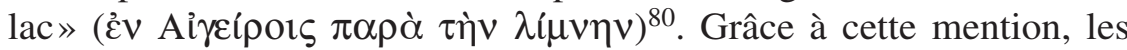
exégètes ont situé Aigeiroussa dans la région de Pérachora, sur la rive sud du lac moderne de Vouliasmeni, au nord-est de l'Héraion ${ }^{81}$. En revanche, Hammond propose de placer cette localité au nord de la Mégaride, près de Mégalo Vathychoria, là où passait la route qui menait vers Delphes, et où se trouvait semble-t-il un $\operatorname{lac}^{82}$. De même que dans le cas de Polichnè, en l'absence d'autres témoignages, il faut avouer qu'il reste difficile à attribuer un emplacement précis à Aigeiroussa.

En comparant la liste de Plutarque à celle de Strabon, Rigsby estime que la dernière est la plus crédible, car elle contient plus de sites dont on connaît l'existence à l'époque historique, à savoir Salamine, Nisaia, Tripodiskos, Aigeiroussa. Par conséquent, selon lui, il faudrait abandonner la liste des cinq districts de Plutarque pour ne se fier qu'à celle de Strabon ${ }^{83}$. Cependant, il serait erroné de rejeter la tradition de Plutarque qui exprime, on l'a vu, les prétentions mégariennes sur le sud de l'isthme et sur la Salamine, des territoires, qui à l'époque classique, étaient en la possession des Athéniens et des Corinthiens, alors que la liste de Strabon présente, me semble-t-il, les mêmes caractéristiques. En dépit de quelques différences, cette dernière tradition témoigne aussi d'une extension «maximale» de la Mégaride, telle qu'elle était conçue à l'époque classique ou hellénistique. C'est ainsi qu'on ne retrouve plus chez Strabon les Kynosoureis qui faisaient référence à Salamine, mais la mention de l'île elle-même. L'appartenance du sud de l'isthme à la Mégaride pourrait être soulignée par la mention d'Aigeiroussa ou de Polichnè, si ces sites devaient être localisés dans la péninsule de

80 Plutarque, Questions grecques, LIX (= Moralia 304 E-F). Sur ce récit, voir aussi infra, chapitre I.3.1.

81 Bursian, Geographie, vol. I, p. 383; Halliday, Gr. Questions, p. 219-220; Figueira, Chronological Table, p. 268.

82 Hammond, Main Road, p. 118-120, suivi par Salmon, Heraeum, p. 204, n. 258, et Wiseman, Land, p. 26-27. Cf. aussi H. Lohmann, «Antike Straßen und Saumpfade in Attika und der Megaris », in Stuttgarter Kolloquium zur historischen Geographie des Altertums 7, 1999. Zu Wasser und zu Land. Verkehrswege in der antiken Welt, E. Olshausen et H. Sonnabend (éds.), Stuttgart 2002, p. 116-117.

Rigsby, Megara, p. 100-101. 
Pérachora. Les deux traditions mentionnent par ailleurs deux sites fort importants du point de vue politique et religieux pour les Mégariens: Mégare (chez Plutarque) - Nisaia/Polichnè ? (chez Strabon), Tripodiskos (chez Plutarque) - Tripodes (chez Strabon). En somme, il me semble que la liste de Plutarque est d'une certaine manière analogue à celle de Strabon, les deux traditions mettant en lumière des divisions en cinq unités de la Mégaride. De même que la liste de Strabon a un but politique clairement délimité, dans la mesure où elle vise à établir que Salamine était mégarienne à une époque reculée, la liste utilisée par Plutarque a pu être conçue avec un but politique précis: justifier la possession de Pérachora et peut-être aussi de Salamine par les Mégariens.

Les deux traditions ont probablement été élaborées à l'époque classique ou hellénistique, quand il était d'usage de faire appel aux mythes dans le contexte des conflits de voisinage. De fait, bien que l'arbitrage spartiate soit traditionnellement daté de l'époque de Solon, on n'a en réalité aucune preuve que l'interpolation mégarienne de l'Iliade remonte aussi à cette période. Au contraire, il est fort probable que l'on ait affaire à une légende mise en circulation par les historiens locaux de Mégare. De fait, Strabon cite comme source de ce passage les témoi-

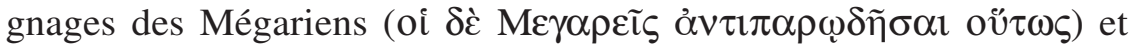
l'on peut penser que c'est l'un des historiens mégariens, Dieuchidas ou Héréas, qui a sans doute introduit les vers mentionnant les vaisseaux mégariens dans l'Iliade ${ }^{84}$. Car ces deux auteurs, célèbres pour leurs opinions anti-athéniennes, furent ceux qui accusèrent Solon ou Pisistrate de remaniement des poèmes homériques ${ }^{85}$.

84 E. Schwartz, s.v. «Apollodorus » 61, RE I, 1894, col. 2868, et F. Atenstädt, «Apollo-

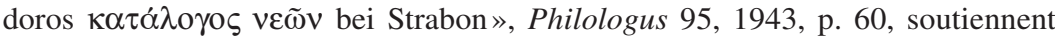
qu'Apollodore d'Athènes, auteur au $\mathrm{II}^{\mathrm{e}}$ siècle d'un commentaire sur le Catalogue des vaisseaux, est la source de ce passage de Strabon. Cette opinion est acceptée par Jacoby, FGrHist II B, p. 776, et Piccirilli, Tre ricerche, p. 407. En revanche, E. Heitsch, «Ilias B 557/8», Hermes 96, 1968, p. 649-651, 657, pense que c'est plutôt Aristarque de Samothrace, maître d'Apollodore à Alexandrie, qui est la source de Strabon-Apollodore. Mais Apollodore (ou Aristarque) s'appuya sans doute sur l'une des œuvres des mythographes mégariens.

85 Dieuchidas, FGrHist 485 F 6 (apud Diogène Laërce, I, 57), désigne Solon comme responsable du remaniement des poèmes homériques. Par ailleurs, Héréas, FGrHist 486 F 1 (apud Plutarque, Thésée, 20, 2), dénonce l'interpolation des vers dans l'Odyssée pratiquée à l'époque de Pisistrate (il s'agirait plus exactement du v. 631 du chant XI:

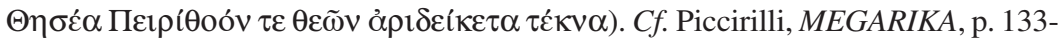
134 (avec la bibliographie). 
Quant à la source de la tradition de Plutarque, Giesen a jadis suggéré qu'il s'agissait de la Constitution des Mégariens, écrite par Aristote ou par l'un de ses élèves ${ }^{86}$. Cet ouvrage, connu par Strabon ${ }^{87}$, fut sans doute la source de quelques passages de la Politique d'Aristote et de deux des Questions grecques de Plutarque (XVIII et LIX) ${ }^{88}$. Mais l'on rappelle qu'il s'agit de textes qui relèvent de la situation politique de Mégare au VI ${ }^{\mathrm{e}}$ siècle, lors de la «démocratie sans retenue», et non pas de celle du VIII ${ }^{\mathrm{e}}$ siècle. Il n'est pas certain que la Question grecque XVII se fonde sur la même source et il est également possible que ce texte s'appuie sur les histoires locales de Mégare. On sait d'ailleurs que Plutarque connaissait les Mégarika de Dieuchidas et d'Héréas, puisqu'il les cite à plusieurs reprises ${ }^{89}$. Malheureusement, on ignore à quelle période remontent ces deux historiens, dont les fragments ne sont connus que par des citations à l'époque impériale. On a identifié Dieuchidas et Héréas avec des personnages homonymes attestés par des inscriptions à l'époque hellénistique ${ }^{90}$. Mais ces identi-

K. Giesen, «Plutarchs Quaestiones Graecae und Aristoteles' Politien», Philologus 60, 1901, p. 461-465, suivi par Figueira, Chronological Table, p. 262; Okin, Theognis, p. 11-14, suggère que Chamailéon d'Héraclée du Pont pourrait être l'auteur de la Constitution des Mégariens (p. 19, n. 2). Notons la prudence de Halliday, Gr. Questions, p. 92, 95, qui estime que bien que les Questions XVI et XVII puissent être tirées de la Constitution des Mégariens, une autre source ne serait pas à exclure.

87 Aristote, fr. 550 (éd. V. Rose ; apud Strabon, VII, 7, 2, C 322).

88 Voir aussi infra, chapitre I.3.1.

89 Plutarque cite Dieuchidas dans Lycurgue, 1, 8 (=FGrHist 485 F 5), et Héréas dans Thésée, 20, 2 (= FGrHist 486 F 1); 32, 7 (=FGrHist 486 F 2) et dans Solon, 10, 5 (=FGrHist 486 F 4). De même, il invoque dans Thésée, 10, 2 (= FGrHist 487 F 1)

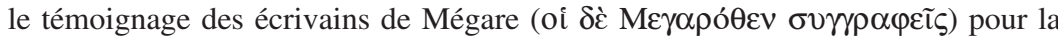
légende qui faisait de Sciron de Mégare un héros, arrière-grand-père d'Ajax. Sur la foi des Mégariens, Plutarque, Propos de table, V, 3, 1 (= Moralia 675 E; = Piccirilli, MEGARIKA, F 4b, p. 92), mentionne le passage d'Inô en Mégaride. De même, Plutarque, Périclès, 30, 4 (=FGrHist 487 F 13), évoque l'opinion des Mégariens concernant la cause de la guerre du Péloponnèse. On apprend ainsi que les Mégariens rejetaient l'inculpation de la mort du messager athénien Anthémocritos, et, en citant Aristophane (Acharniens, 524-529), ils attribuaient le déclenchement de la guerre à une affaire d'enlèvement de courtisanes.

90 D. W. Prakken, «A Note on the Megarian Historian Dieuchidas », AJPh 69, 1941, p. 348-351; idem, «On the Date of Hereas, the Megarian Historian», CW 37, 1943 1944, p. 122-123 ; J. A. Davison, «Dieuchidas of Megara», CQ 53, 1959, p. $216-$ 222 ; Okin, Theognis, p. 19. Pour K. J. Dover, «Anthemocritus and the Megarians », AJPh 87, 1966, p. 206, «there is not a particle of positive evidence for the existence 
fications sont très incertaines, en l'absence des patronymes des deux historiens ${ }^{91}$.

J'ajoute que pour la question des débats entre les mythographes mégariens et athéniens, la bibliographie de Philochore d'Athènes, né peu après 350 et mort vers 260, peut s'avérer intéressante. Car cet atthidographe a écrit un ouvrage consacré à la fondation de Salamine ( $\Sigma \alpha \lambda \alpha \mu \tilde{\imath} v \sigma \varsigma \kappa \tau i \sigma i \varsigma)$, dans lequel on peut penser qu'il faisait état des liens existant entre cette île et sa ville ${ }^{92}$. Il serait possible dans ce cadre que des Mégarika, écrits par Dieuchidas et/ou par Héréas, aient répondu aux propos de Philochore, en lançant les deux traditions de l'extension maximale de Mégare, dont Plutarque et Strabon se firent l'écho à l'époque impériale.

Même dans l'éventualité où l'on accepterait que la Question grecque XVII s'appuierait sur la Constitution des Mégariens, cet ouvrage du $\mathrm{IV}^{\mathrm{e}}$ siècle se fondait certainement, à son tour, sur des récits locaux, qui vraisemblablement exprimaient les prétentions des Mégariens sur Salamine et Pérachora, deux zones de confins qui étaient alors en la possession des Athéniens et des Corinthiens. Certes, on pourrait répondre que, tout comme Salamine a été mégarienne à une certaine époque, la Pérachora, elle aussi, a pu appartenir aux Mégariens. Mais à la différence de Salamine, pour laquelle plusieurs textes évoquent l'occupation mégarienne, aucun récit n'atteste que la région de l'Héraion ait été l'objet de contestation entre Mégare et Corinthe.

Finalement, deux autres arguments - certes ex silentio, mais non pas dépourvus d'importance - pourraient plaider contre l'historicité d'une organisation en cinq unités de la Mégaride à l'époque archaïque. En premier lieu, il est difficile d'expliquer pourquoi Pagai (Alepouchori) et Aigosthènes (Porto Germeno, voir pl. III), n'apparaissent pas dans les listes de Plutarque et de Strabon. Il s'agit là de deux localités

of any Megarian historian at any date later than the third century B. C. $C \mathrm{C}$. Piccirilli, MEGARIKA, p. 13-16 (sur Dieuchidas), 51-78 (sur Héréas).

91 J. et L. Robert, Bull. ép., 1944, 110.

92 Philochore, FGrHist 328, p. 121, n ${ }^{\text {os }} 7-9$; cf. Jacoby, FGrHist b Supplement (Text), p. 229; R. Laqueur, s.v. «Philochoros», RE XIX, 1938, col. 2435 ; D. Knoepfler, «Trois historiens hellénistiques : Douris de Samos, Hiéronymos de Cardia, Philochore d'Athènes », in Histoire et historiographie dans l'Antiquité. Actes du XI colloque de la Villa Kérylos (Beaulieux-sur-Mer, 13-14 octobre 2000), Cahiers de la Villa Kérylos 11, J. Leclant et F. Chamoux (éds.), Paris 2001, p. 40. 
mégariennes fort importantes ayant livré des céramiques géométriques et archaïques et qui changent de statut politique à l'époque hellénistique, en se transformant de bourgs en cités ${ }^{93}$. D'autre part, on ne retrouve pas chez Plutarque et Strabon les deux autres bourgs mégariens: Éréneia (que l'on place dans la région des Vathychoria, voir carte 2) ${ }^{94}$ et Krommyon, ce dernier étant annexé à l'époque archaïque ou classique par Corinthe (voir ci-dessous) ${ }^{95}$.

Le deuxième argument contre une organisation en cinq districts est de nature institutionnelle: la documentation émanant des colonies mégariennes et héracléotes n'atteste pas une division territoriale en mérè (ou éventuellement en kômai), mais uniquement les divisions traditionnelles du corps civique mégarien, par phylai («tribus») et par hékatostyes («centaines»). Si la Mégaride avait été divisée à l'époque archaïque en cinq mérè ou kômai, on s'attendrait à ce que les colonies - qui reproduisaient la majorité des institutions politiques de la métropole - aient préservé cet héritage.

Notons enfin que les listes de Plutarque et de Strabon ne sont pas les seules traditions qui nous renseignent sur la division de la Mégaride. Les mythographes soutenaient l'organisation de la Mégaride en plusieurs royaumes constitués autour de Mégare, d'Éleusis et de Pagai. Ainsi, Dioclès fut le chef (archôn) d'Éleusis et, chassé par Thésée, il trouva refuge à Mégare, où il fut honoré par des fêtes ${ }^{96}$. De même, Pausanias vit à Mégare le tombeau de Térée, que les Mégariens considéraient comme ayant été le roi d'un territoire aux abords de Pagai. Le Périégète rapporte la version la plus commune du mythe de Térée, qui régna sur les Thraces à Daulis, en Phocide, et qui fut le mari de Procné, la fille du roi athénien Pandion II. En poursuivant Procné et Philomèle

93 Smith, Megaris, p. 35-38, 45-49, 78-80; E. Baziotopoulou-Valavani, op. cit., p. 206207. On a trouvé près de Pagai, à Bouri Alepochoriou, un temple et des dépôts votifs

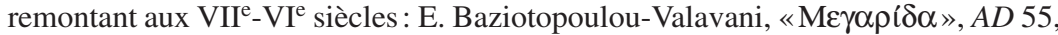
2000 (2009), B', p. 92-93.

94 Pausanias, I, 44, 5. Pour la localisation d'Éréneia, voir Van de Maele, Ereneia, p. 153-159; A. Muller, «Megarika», BCH 106, 1982, p. 379-405.

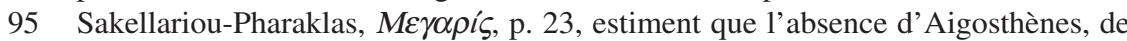
Pagai et peut-être aussi d'Éréneia dans la liste de Plutarque s'expliquerait par le fait que ces sites étaient semi-autonomes (notamment les deux premiers) ou qu'ils étaient trop petits pour être évoqués.

96 Anonyme de Mégare, FGrHist 487 F 1 (apud Plutarque, Thésée, 10, 4). Sur Dioclès, voir infra, chapitre I.2.2. 
pour la mort de son fils, Itys, Térée se serait suicidé à Mégare. Pausanias ajoute qu'en son honneur on fit élever dans la ville de Mégare un tombeau et on fit un sacrifice annuel, en utilisant des cailloux au lieu de grains ${ }^{97}$. La présence de ce mythe en Mégaride à l'époque hellénistique pourrait être confirmée par une tablette funéraire trouvée à Pagai, mentionnant un certain Tí $\rho \eta \varsigma$ (voir pl. VIII, fig. 2) ${ }^{98}$. Et l'on peut penser que la tombe de Térée servait originellement à renforcer le rattachement de Pagai à la cité de Mégare, tout comme la tombe de Coroibos rappelait les liens entre Tripodiskos et Mégare ${ }^{99}$.

\section{I.1.3 Les rapports entre Mégare et Corinthe à l'époque archaïque}

Bien que les traditions relatives à l'organisation des Mégariens en cinq districts datent vraisemblablement de l'époque classique ou hellénistique, cela ne met pas en doute l'historicité du synœcisme. La fondation des colonies après le milieu du VIII ${ }^{\mathrm{e}}$ siècle - des cités qui reproduisent les nomima mégariens - témoigne de l'existence en Mégaride d'une cité dotée de ses propres institutions politiques et religieuses. Concernant le synœcisme des cités grecques, il est utile d'évoquer ici l'opinion de Demand, qui propose d'interpréter cet événement non pas comme une étape dans la formation de la polis (explication qui serait tributaire d'Aristote), mais comme le résultat d'une situation exceptionnelle, conditionnée par un danger externe ${ }^{100}$. Or dans le cas précis de Mégare, la menace corinthienne aurait pu être l'une des causes du synœcisme. La Question grecque XVII nous apprend, on l'a vu, que ce sont les Corinthiens qui firent entrer en guerre les cinq districts et ne cessèrent de comploter pour s'emparer de la Mégaride. Le fait que les Corinthiens aient attisé des luttes intestines entre les Mégariens

97 Pausanias, I, 5, 4; 41, 8-9; cf. Highbarger, Megara, p. 54-55; Hanell, Megarische Studien, p. 37-39.

$98 \quad I G$ VII 205.

99 Bohringer, Mégare, p. 10-12.

100 Demand, Urban Relocation, p. 14-27, p. 181, n. 3. Sur le synœecisme des cités grecques, voir aussi Moggi, Sinecismi, surtout p. 30-32 pour le cas mégarien; Osborne, Classical Landscape, p. 55-56; I. Morris, «Village Society and the Rise of the Greek State», in Structures rurales et sociétés antiques. Actes du colloque de Corfu (14-16 mai 1992), P. N. Doukellis et L. Mendoni (éds.), Paris 1994, p. 49-53. 
s'inscrit dans une longue tradition de conflits entre les deux cités doriennes, dont l'opposition était proverbiale. Plutarque, qui évoque cette rivalité ailleurs, considère qu'il n'est plus nécessaire de préciser d'autres détails ${ }^{101}$. On peut penser que le système de rançon et d'hospitalité

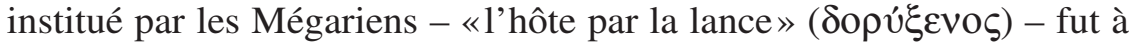
la fois une réponse à la menace corinthienne et une forme de solidarité, qui constitua la première étape dans la création de la cité de Mégare ${ }^{102}$.

Au demeurant, une légende soutenait que Mégare aurait même été une possession de Corinthe. Divers scholiastes en témoignent, en commentant deux expressions proverbiales: ó $\Delta$ iò $\zeta$ Kópıv $\theta 0 \varsigma$ ( «Korinthos,

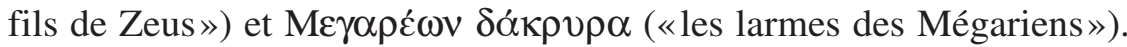
Les informations les plus détaillées sont fournies par une scholie de Pindare, qui cite Démon, l'auteur vers 300 de l'ouvrage Sur les proverbes $^{103}$. On apprend ainsi que les Mégariens, des colons (apoikoi) des Corinthiens ${ }^{104}$, furent obligés d'envoyer des pleureurs aux funé-

101 Plutarque, De la malignité d'Hérodote, XXXV (= Moralia 868 C), témoigne de l'inimitié proverbiale qui opposait à la veille des guerres médiques les Éginètes aux Athéniens, les Chalcidiens aux Érétriens et les Corinthiens aux Mégariens. Pareillement, Thucydide, I, 103, 4, indique que les conflits frontaliers entre Mégare et Corinthe ( $\pi \varepsilon \rho \grave{i} \gamma \tilde{\eta} \varsigma$ ö $\omega \nu)$ furent responsables de la sortie de Mégare de la Ligue péloponnésienne en 461 et de son alliance avec Athènes. Sur la rivalité entre Corinthe et Mégare, voir aussi Théognis, 894; Aristote, Politique, III, 9, 9, 1280b 1317; Plutarque, Cimon, 17, 2 ; cf. Will, Korinthiaka, p. 359; D. M. Lewis, «The Origins of the First Peloponnesian War», in Classical Contributions. Studies in honor of M. F. McGregor, G. S. Shrimpton et D. J. McCarger (éds.), Locust Valley N. Y. 1981, p. 73-74 [= Selected Papers in Greek and Near Eastern History, P. J. Rhodes (éd.), Cambridge 1997, p. 13-14].

102 Figueira, Chronological Table, p. 263.

103 Démon, FGrHist 327 F 19 (apud scholie à Pindare, Néméennes, VII, 155b); Scholie à Aristophane, Grenouilles, 439; Scholie à Platon, Euthydème, 292 e; Zénobios,

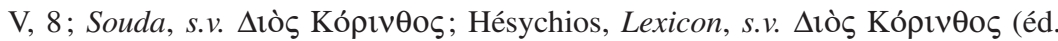
K. Latte); cf. Halliday, Gr. Questions, p. 100; Will, Korinthiaka, p. 359-360; Hammond, Heraeum, p. 97 ; Salmon, Heraeum, p. 197-198; idem, Wealthy Corinth, p. 70-71; Legon, Megara Pol. Hist., p. 60-62; De Fidio, Corinto e l'Occidente, p. 78; Figueira, Chronological Table, p. 263-265.

104 D'après Graham, Colony, p. 233-234, Mégare ne fut pas une véritable apoikia corinthienne, ne s'agissant que d'une domination des Corinthiens sur leurs voisins. Notons aussi que le Ps.-Scymnos, 502-503, rapporte que Mégare fut une fondation des Doriens, en particulier des Corinthiens et des Messéniens. Cf. Will, Korinthiaca, p. 290-291, qui estime que cette tradition est «le reflet d'une prétention ultérieure de Corinthe à l'égard de Mégare, l'argument pseudo-historique d'une revendication ». 
railles des Bacchiades, le groupe dominant à Corinthe du VIII ${ }^{\mathrm{e}}$ siècle au milieu de VII ${ }^{\mathrm{e}}$ siècle ${ }^{105}$. Suite à la révolte des Mégariens, une ambassade corinthienne vint à Mégare pour faire savoir que «Korinthos, fils de Zeus, s'irriterait s'il n'obtenait pas justice». Ces remarques provoquèrent la colère des Mégariens, qui lapidèrent les ambassadeurs. Dans la guerre qui suivit, les Mégariens triomphèrent et poursuivirent les Corinthiens au cri de «frappez, frappez Korinthos, fils de Zeus». Pour Diogénien en revanche, les «larmes des Mégariens», seraient des larmes aux funérailles des rois de Mégare ${ }^{106}$.

Les modernes ont suggéré que ces traditions avaient leur source dans la Constitution des Mégariens, voire même une origine plus ancienne, dans l'œuvre du poète corinthien de la deuxième moitié du VIII ${ }^{\mathrm{e}}$ siècle Eumélos ${ }^{107}$. L'habitude d'envoyer des pleureurs est rapportée par Hérodote à propos de Sparte, où les hilotes étaient obligés de participer aux funérailles des rois spartiates. Il s'agit d'une institution symbolique, créée pour mettre en évidence une dépendance politique ${ }^{108}$. Figueira propose pour les conflits pour la libération de Mégare de la domination corinthienne, la période avant le milieu du VIII ${ }^{\mathrm{e}}$ siècle, c'està-dire avant le synœcisme mégarien ${ }^{109}$. Sa datation est fort probable, car la création de l'État mégarien a sans doute entraîné la fin de la domination corinthienne.

Il convient de noter que les savants ont rattaché l'action militaire du Mégarien Orsippos au dossier des conflits frontaliers avec Corinthe ${ }^{110}$. D'après Pausanias, celui-ci fut le premier athlète à courir nu à Olympie, en gagnant la course du stade. On apprend aussi qu'il fut élu plus tard stratège de l'armée et qu'il s'empara d'un territoire au détriment des peuples voisins ${ }^{111}$. Une épigramme funéraire attribuée à Simonide

105 Sur l'aristocratie des Bacchiades à Corinthe, voir Will, Korinthiaca, p. 295-338, et Salmon, Wealthy Corinth, p. 55-74.

106 Diogénien, VI, 34; VII, 65 (éd. E. Lelli).

107 Halliday, Gr. Questions, p. 92; Hammond, Heraeum, p. 94-95.

108 Hérodote, VI, 58, 2-3; Pausanias, IV, 14, 4; $f$. Hammond, Peloponnese, p. 334 ; Figueira, Chronological Table, p. 264.

109 Figueira, Chronological Table, p. 262-265.

110 Hanell, Megarische Studien, p. 72, n. 3; Hammond, Heraeum, p. 97; idem, Peloponnese, p. 354; Burn, Lyric Age, p. 88-89; Piccirilli, MEGARIKA, p. 128-129; Legon, Megara Pol. Hist., p. 62-63, 69-70; Figueira, Chronological Table, p. 271273 ; K. S. Meidani, op. cit., p. 37.

111 Pausanias, I, 44, 1. 
rappelait les mêmes exploits du héros, à savoir la reconquête des nombreuses terres perdues par sa cité et la victoire olympique. L'inscription témoigne du fait que c'est l'oracle de Delphes qui demanda aux Mégariens d'élever la tombe d'Orsippos (appelé Orrhippos dans le dialecte mégarien $)^{112}$. Quant aux voisins vaincus par le héros, malgré l'avis de la plupart des historiens, vu le silence des sources sur l'origine des ennemis et le territoire conquis, l'identification avec les Corinthiens reste sujette à caution. Certes, elle ne peut pas être exclue, mais les Mégariens auraient aussi pu mettre la main sur les terres aux confins d'Athènes ou de la Béotie. L'étendue de ces terres ne peux être déterminée seulement sur la foi de l'épigramme mégarienne, qui les qualifie de «nombreuses» $(1.4: \pi \mathrm{o} \lambda \lambda \dot{\alpha} \mathrm{v})^{113}$. La prudence me semble d'autant plus s'imposer, que la victoire au stade d'Orsippos reste difficile à dater; d'après la tradition la plus commune, elle se placerait en 720 , lors de la $15^{\mathrm{e}}$ olympiade $^{114}$. Cependant, plusieurs légendes circulaient dans l'Antiquité concernant le premier athlète à se dénuder et la date de sa victoire olympique, et il est impossible de savoir laquelle de ces versions est vraie ${ }^{115}$.

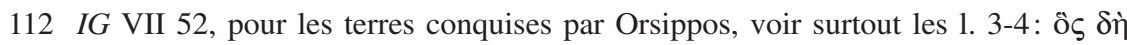

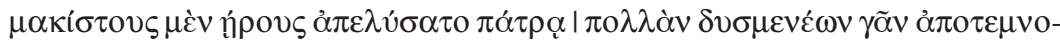
$\mu \varepsilon ́ v \omega v$. L'épigramme fut regravée à l'époque impériale tardive sur la tombe du héros, située sur l'agora. Cf. L'Homme-Wéry, Solon, p. 117-120; F. Chamoux, «Les épigrammes dans Pausanias », in Éditer, traduire, commenter Pausanias en l'an 2000. Actes du colloque de Neuchâtel et de Fribourg (18-22 septembre 1998), D. Knoepfler et M. Piérart (éds.), Genève 2001, p. 89; H. Schörner, Sepulturae Graecae intra urbem. Untersuchungen zum Phänomen der intraurbanen Bestattungen bei den Griechen, Boreas Beiheft 9, Möhnesee 2007, p. 60, 121, 260.

113 Salmon, Heraeum, p. 199.

114 Julius Africanus, F 65, 62 (éd. M. Wallraff et al., p. 196); Hésychios, Lexicon,

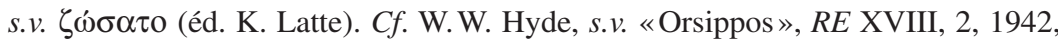
col. 1420-1422; L. Moretti, «Olympionikai, i vincitori negli antichi agoni olimpici», in Atti dell'Academia dei Lincei, Memorie, serie VIII, vol. VIII, 2, Roma 1957, p. 6162, nº 16; Piccirilli, MEGARIKA, p. 129; Figueira, Chronological Table, p. 271-272.

115 W. E. Sweet, «Protection of the Genitals in Greek Athletics », AncW 11, 1985, p. 43 45 ; $c$. SEG XXXV, 400. Denys d'Halicarnasse, VII, 72, 2-3, désigne le Spartiate Acanthos comme le premier athlète à courir nu lors de la $15^{\mathrm{e}}$ olympiade. D'autre

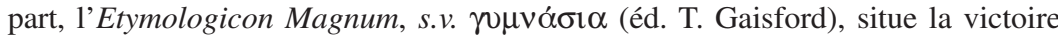
olympique d'Orsippos lors de la $32^{\mathrm{e}}$ olympiade, soit en 652, et attribue à Orsippos une origine spartiate. $C f$. F. Bohringer, «Cultes d'athlètes en Grèce classique: propos politiques, discours mythiques », REA 81, 1979, p. 8, 13-14 
Du reste, un conflit entre Mégare et Corinthe à l'époque archaïque est mentionné dans le passage que Pausanias consacre à la description du trésor mégarien d'Olympie:

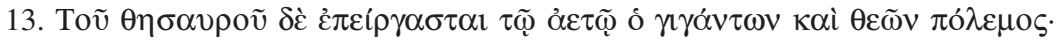

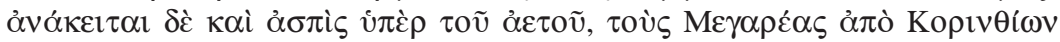

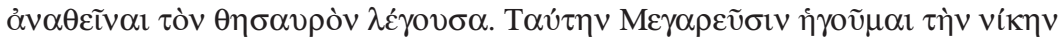

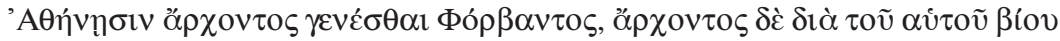

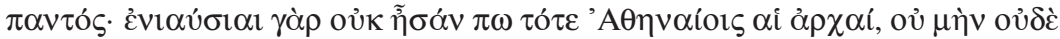

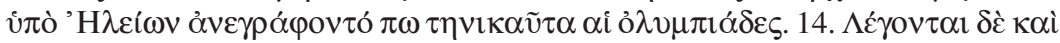

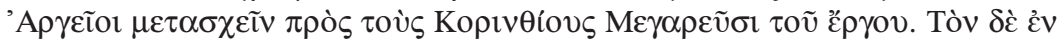

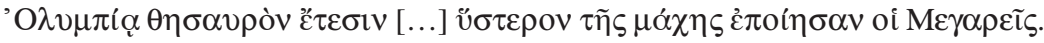

13. Au fronton du trésor on a sculpté la guerre des géants et des dieux: consacré aussi au-dessus du fronton, il y a un bouclier, avec des mots indiquant que les Mégariens ont consacré le trésor sur les dépouilles des Corinthiens. À mon avis, les Mégariens remportèrent cette victoire quand Phorbas était archonte à Athènes, et archonte à vie. En effet, les magistratures n'étaient pas encore annuelles à Athènes à cette époque, et les olympiades n'étaient assurément pas non plus encore inscrites par les Éléens. 14. On dit que les Argiens prirent part à l'action des Mégariens contre les Corinthiens, et les Mégariens firent leur trésor à Olympie [...] années après la bataille $^{116}$.

On notera à propos de ce récit que la représentation d'une Gigantomachie sur le fronton du trésor mégarien à Olympie n'est pas dépourvue d'une certaine symbolique. Car les Mégariens parvenaient ainsi à offrir une analogie visuelle et idéologique à leur propre victoire, en la comparant à celle des dieux olympiens sur les Géants ${ }^{117}$. Conformément au récit de Pausanias, la guerre de Corinthe contre Mégare (alliée à Argos) aurait eu lieu sous l'archontat de Phorbas à Athènes. Cette période ne saurait pourtant entrer en considération: selon la tradition, Phorbas aurait été archonte au $\mathrm{X}^{\mathrm{e}}$ siècle ${ }^{118}$, tandis que le trésor des Mégariens à Olympie a été bâti vers $510^{119}$. Ce dernier indice archéologique placerait la guerre

116 Pausanias, VI, 19, 13-14 (trad. de J. Pouilloux, Paris, CUF).

117 C. Marconi, «Mito e autorappresentazione nella decorazione figurate dei thesauroi di età arcaica», in Stranieri e non citadini nei santuari greci, A. Naso (éd.), Firenze 2006, p. 168.

118 Samuel, Chronology, p. 195.

119 A. Mallwitz, Olympia und seine Bauten, München 1972, p. 174-176; J. Heiden, Die Tondächer von Olympia, Berlin-New York 1995, p. 25 ; C. Marconi, op. cit., p. $165-$ 168. 
vers la fin du $\mathrm{VI}^{\mathrm{e}}$ siècle ou peut-être un peu avant si l'on acceptait la suggestion de Corbetta de remplacer dans ce texte l'archonte Phorbas par Phormion $(c a .546 / 5)^{120}$. Notons aussi que l'on a trouvé à Olympie des armes consacrées à l'époque archaïque par les Argiens après une victoire contre les Corinthiens. Pour des raisons archéologiques (style des casques, lieu de trouvaille), Jackson situe ces dédicaces dans le dernier tiers du $\mathrm{VI}^{\mathrm{e}}$ siècle ou au début du $\mathrm{V}^{\mathrm{e}}$ siècle et pense qu'elles peuvent corroborer le passage de Pausanias sur la guerre des Mégariens et des Argiens contre les Corinthiens, sans pour autant avoir des certitudes là-dessus ${ }^{121}$. Malheureusement, le nombre d'années qui séparent la victoire mégarienne de la construction du trésor d'Olympie n'est pas conservé dans le passage de Pausanias et cette lacune constitue une difficulté supplémentaire pour la datation de la guerre. Du reste, compte tenu de la mention de l'archontat à vie, il est possible que la source de Pausanias fasse allusion à un conflit plus ancien entre les Mégariens, les Argiens et les Corinthiens, remontant au $\mathrm{VIII}^{\mathrm{e}}$ ou $\mathrm{VII}^{\mathrm{e}}$ siècle ${ }^{122}$. Les Mégariens ont pu être soutenus dans la guerre par l'Argien Pheidon, si l'on accepte la datation du VII ${ }^{\mathrm{e}}$ siècle proposée pour ce tyran légendaire ${ }^{123}$.

120 C. Corbetta, «Il conflitto del VI secolo a.C. fra Corinto e Megara», RIL 112, 1998, p. 299-304; cf. Legon, Megara Pol. Hist., p. 144-145; Manni Piraino, Koiné alfabetica, p. 121-122. Figueira, Chronological Table, p. 292-294, situe un conflit entre les Mégariens et les Corinthiens dans la première moitié du VI ${ }^{\mathrm{e}}$ siècle, en raison du fait qu'Argos, après la défaite de 546 dans la guerre contre les Spartiates (la «bataille des Champions »), était incapable d'aider Mégare, et il en place un autre dans la deuxième moitié du VI ${ }^{\mathrm{e}}$ siècle, à cause de la date du trésor d'Olympie. Sur la datation de l'archontat de Phormion vers 546/5, voir D.W. Bradeen, «The FifthCentury Archon List», Hesperia 32, 1963, p. 191-192.

121 A.H. Jackson, «Argos' Victory over Corinth», ZPE 132, 2000, p. 295-311; $c$. M. Sève, Bull. ép., 2001, 82; SEG L, 464. Sur le lien qui pourrait exister entre l'exvoto des Argiens à Olympie et la guerre mentionnée par Pausanias, voir déjà Will, Korinthiaka, p. 644-645, n. 1.

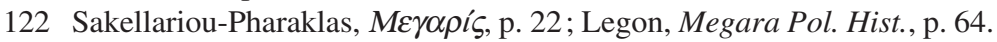

123 Sur la la tyrannie de Pheidon à Argos, voir Burn, Gr. Sea Power, p. 171; idem, «The So-called 〈Trade-Leagues > in Early Greek History and the Lelantine War», JHS 49, 1929, p. 22; A. Andrews, «The Corinthian Actaeon and Pheidon of Argos », CQ 43, 1949, p. 70-78; Will, Korinthiaka, p. 352-360; R. A. Tomlinson, Argos and the Argolid. From the End of the Bronze Age to the Roman Occupation, Ithaca-New York 1972, p. 79-86; E. Manni, «Fidone d'Argo, i Bacchiadi di Corinto e le fondazioni di Siracusa e di Megara Iblea», Kokalos 20, 1974, p. 85-87; Manni Piraino, Koiné alfabetica, p. 121-122; Salmon, Wealthy Corinth, p. 71-72. 
En effet, Pheidon, par sa volonté de contrôler l'isthme, fut la principale menace pour les Bacchiades et une tradition place même sa mort à Corinthe ${ }^{124}$.

Quant aux relations entre Argos et Mégare, force est de constater l'existence de liens étroits entre les deux peuples dans le domaine des mythes et de la religion. Ainsi, Car, le premier roi mégarien, était le fils de Phoroneus, le premier chef d'Argos ${ }^{125}$. Mieux, le nombre de onze générations qui séparent les rois Car et Lélex, pour lequel Pausanias (I, $39,6)$ ne fournit aucune explication, a été introduit par les mythographes mégariens pour établir une corrélation entre la liste des rois de Mégare et celle des rois d'Argos ${ }^{126}$. Grâce à une épigramme funéraire et à Pausanias, on sait aussi que la légende de Coroibos, le fondateur de Tripodiskos, était commune aux Mégariens et aux Argiens ${ }^{127}$. De même, on n'a pas manqué de noter les rapprochements qui existent entre les cultes des deux cités doriennes. Ainsi, Hanell estime que l'appellation

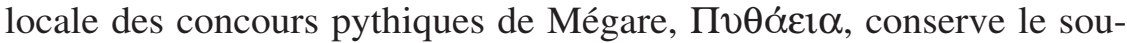
venir d'une épiclèse plus ancienne, Пv $\theta \alpha \varepsilon v ́ \varsigma$ (avec un thème en $-\alpha$ ). Cette forme serait d'origine argienne, étant donnée la présence à Argos

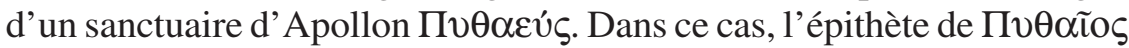
portée par Apollon à Chalcédoine, colonie de Mégare, renverrait également à l'épiclèse argienne d'Apollon. Le culte d'Apollon Pythien - le fondateur divin de Mégare, qui aide le héros Alcathoos à bâtir les remparts de la cité - aurait dans ce cas une origine argienne, tout comme le culte d'Apollon Lykeios, qui se retrouve, lui aussi, à Argos ${ }^{128}$. De surcroît, Pausanias situe à Mégare deux monuments qui se rattachent à Argos: l'hérôon d'Iphigénie et le sanctuaire d'Artémis, construit par Agamemnon ${ }^{129}$.

Du reste, on peut inférer sur la base de quelques récits de fondation que les Argiens ont pu accompagner les Mégariens en Sicile et dans la Propontide. Ainsi une légende cite-t-elle les Argiens parmi les fondateurs

124 Nicolas de Damas, FGrHist 90 F 35 ; Plutarque, Histoires d'amour, II (= Moralia 772 D-773 B); Scholie à Apollonios de Rhodes, IV, 1212.

125 Pausanias, II, 15, 5.

126 Highbarger, Megara, p. 69-70.

127 Pausanias, I, 43, 7; Anthologie Palatine, VII, 154.

128 Hanell, Megarische Studien, p. 84; $c f$. M. Piérart, «Un oracle d'Apollon à Argos », Kernos 3, 1990, p. 324 ; Robu, Chalcédoine, p. 137-155.

129 Pausanias, I, 43, 1; cf. A. Muller, «Megarika», BCH 105, 1981, p. 218-222. 
de Byzance ${ }^{130}$. Et des Argiens se sont probablement associés aux Mégariens de Lamis quand ceux-ci partirent pour la Sicile ${ }^{131}$. Une institution d'origine argienne (le hiéromnâmon), des divinités et des mythes argiens sont aussi présents dans les colonies mégariennes (à Byzance, à Chalcédoine, à Mésambria) ${ }^{132}$. Hanell pensait jadis que les cultes et les mythes argiens furent introduits dans les colonies par le biais de Mégare, tenue pour un établissement argien. L'origine des Doriens de Mégare reste pourtant difficile à établir et ces données argiennes peuvent aussi être dues à la collaboration entre les Argiens et les Mégariens dans le mouvement de colonisation. Cette collaboration, ainsi que l'aide argienne contre Corinthe évoquée par Pausanias, découlerait des liens de syngéneia existant entre les deux peuples. On rappelle à cet égard que, selon Aristote, les apoikiai étaient originairement le résultat d'une syngéneia, d'une «parenté» remontant à l'époque de la fondation $(\alpha i$

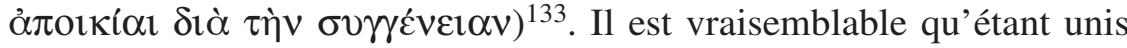
par des liens de parenté, les Mégariens et les Argiens avaient collaboré à l'époque archaïque dans des combats contre l'ennemi commun, Corinthe, aussi bien que dans l'installation de certaines apoikiai (notamment celle de Byzance).

Pour les rapports entre Mégare et Corinthe il est enfin intéressant de rappeler le témoignage de Strabon sur Krommyon (aujourd'hui Agioi Theodoroi), un bourg dans la Corinthie, qui avait auparavant appartenu aux Mégariens (voir carte 2) ${ }^{134}$. Figueira date la capture de cet établissement par les Corinthiens de ca. 625-600 et l'inclut parmi les actions du tyran Périandre visant à contrôler le golfe Saronique ${ }^{135}$. Salmon estime que le bourg est devenu corinthien avant la fin du $\mathrm{VI}^{\mathrm{e}}$ siècle ou le début

130 Hésychios, FGrHist 390 F 3, 4, 6.

131 Voir infra, chapitre II.1.1.1.

132 Voir infra, chapitres II.2.4.1.6. et III.2.1.2.

133 Aristote, Politique, I, 2, 6, 1252b 20-22. Sur la syngéneia, voir O. Curty, Les parentés légendaires entre cités grecques. Catalogue raisonné des inscriptions con-

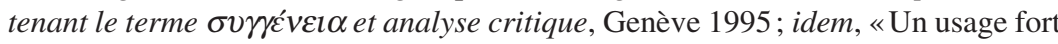
controversé: la parenté dans le langage diplomatique de l'époque hellénistique», AncSoc 35, 2005, p. 101-117 (avec les références antérieures).

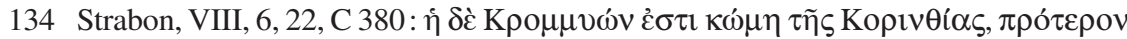

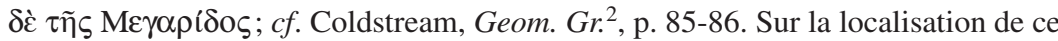

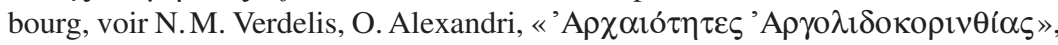
AD 17, 1961-1962, p. 52-54.

135 Figueira, Chronological Table, p. 277-278, suivi par K. S. Meidani, op. cit., p. 116. 
du $\mathrm{V}^{\mathrm{e}}$ siècle $^{136}$. Il s'appuie sur deux inscriptions trouvées à Agioi Theodoroi écrites dans un alphabet plus proche du corinthien que du mégarien ${ }^{137}$. Mais on ne peut exclure que les deux inscriptions - dont l'une funéraire et l'autre trop fragmentaire pour pouvoir en établir le caractère - témoignent de la présence des Corinthiens sur ce site, chose qui ne serait guère surprenante pour une localité de frontière. D'ailleurs, des inscriptions en alphabet corinthien apparaissent aussi dans la colonie mégarienne de Sélinonte ${ }^{138}$. On n'a donc pas les moyens de connaître la date exacte de la conquête de Krommyon. L'événement remonte en tout cas à la période avant le troisième quart du $\mathrm{IV}^{\mathrm{e}}$ siècle, la date du périple du Ps.-Scylax, qui qualifie Krommyon de fort (teichos) dans la Corinthie ${ }^{139}$. On notera par ailleurs que l'appel de la Ligue achéenne à des juges mégariens pour le conflit entre Corinthe et Épidaure suggère que, dans la deuxième moitié du $\mathrm{III}^{\mathrm{e}}$ siècle, la zonefrontière entre les deux cités doriennes de l'isthme n'était plus un sujet de dispute, car autrement les Corinthiens n'auraient pas accepté les Mégariens en tant que dikastai ${ }^{140}$.

En guise de conclusion, on notera qu'avant le milieu du VIII ${ }^{\mathrm{e}}$ siècle les Mégariens se trouvaient dans une situation de dépendance vis-à-vis de Corinthe. Pour échapper à cette domination et mettre fin à leurs conflits internes, les Mégariens ont institué le système d'alliance de «l'hôte par la lance». Ce système donnera lieu à une nouvelle cité, sans pour autant créer de solidarité parfaite entre les habitants de la Mégaride. De fait, comme on le verra dans le chapitre suivant, on a raison de

136 Salmon, Heraeum, p. 196-197 et n. 227, suivi par C. Corbetta, op. cit., p. 303.

137 J.H. Kent, Corinth, vol. VIII, part III. The Inscriptions (1926-1950), Princeton 1966,

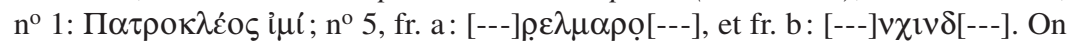
notera la présence de l'iota corinthien (sous la forme d'un sigma à quatre branches) dans la première inscription, et du san $(\mathrm{M})$ dans la deuxième, signe présent dans l'alphabet de Corinthe, mais absent dans celui de Mégare. En revanche, comme Salmon le note, l'épitaphe de Patroklès atteste un alpha spécifique à Mégare. Le premier éditeur de l'épitaphe de Patroklès, W. Peek, «Griechische Inschriften», $\operatorname{MDAI}(A) 59,1934$, p. 45, avait déjà conclu, sur la foi de cette inscription, que l'occupation mégarienne de Krommyon devait être antérieure à 500.

138 Voir infra, chapitre II.1.2.5.

139 Ps.-Scylax, 55; cf. H. N. Fowler, R. Sillwell, op. cit., p. 48. G. Shipley (éd.), op. cit., p. 6-8, assigne la date de 338-337 au périple du Ps.-Scylax. Sur Krommyon, voir aussi Xénophon, Helléniques, IV, 4, 13.

$140 I G \mathrm{IV}^{2}$ 1, 71 ; $c f$. Wiseman, Land, p. 136-138. 
penser qu'il existe un lien étroit entre le synœcisme, la création d'une nouvelle politeia et le début de la colonisation mégarienne vers le milieu du VIII' siècle.

\section{I.1.4 La colonisation et le synoecisme mégariens: deux phénomènes contemporains du haut archaïsme}

Les récits situent le synœcisme, la création des institutions politiques de Mégare et le début du mouvement colonial mégarien dans la deuxième moitié du VIII ${ }^{\mathrm{e}}$ siècle. Comme ailleurs, des traditions légendaires rapportent que Mégare fut d'abord gouvernée par des rois. Le premier d'entre eux, Car, le fils de Phoroneus, donna son nom à l'acropole orientale de la ville et son rôle civilisateur se manifeste dans la fondation du mégaron de Déméter ${ }^{141}$. Onze générations après Car, ce fut Lélex, le fils de Poséidon, venu d'Égypte, qui exerça la royauté. Il fut suivi par Cléson, Pylas, Nisos, Mégareus, Alcathoos, Ajax et Hypérion, fils d'Agamemnon ${ }^{142}$. Grâce à Pausanias, on apprend dans quelles circonstances les Mégariens remplacèrent leur dernier roi par un collège de magistrats élus.

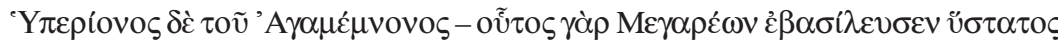

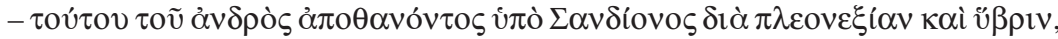

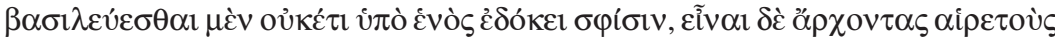

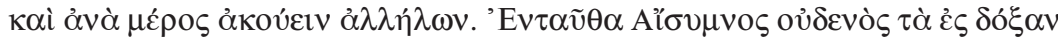

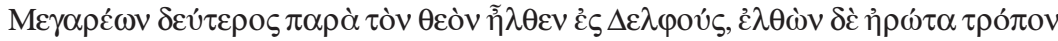

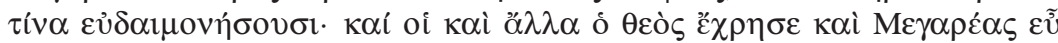

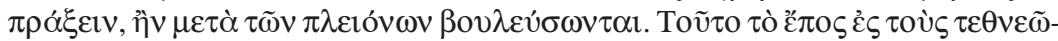

141 Pausanias, I, 39, 5 ; Stéphane de Byzance, s.v. Kapí $\alpha$. D’après Pausanias, I, 44, 6, le tombeau de Car se trouvait sur la route de Corinthe.

142 Pausanias, I, 39, 6; 41, 3-6; 42, 4; 43, 3. Sur les différentes versions des généalogies royales de Mégare, voir J. Holle, Megara im mythischen Zeitalter, in Programm des Gymnasiums zu Recklinghausen LI. Schuljahr 1880-1881, Recklinghausen 1881; K. Seeliger, «Alkathöos und die megarische Königliste. Eine Pausaniasstudie», in Festschrift für Johannes Overbeck, Leipzig 1893, p. 27-44; Highbarger, Megara, p. 66-94; Bohringer, Mégare, p. 6-22; Muller, De Nisée à Mégare, p. 619-628; Carlier, Royauté, p. 402-403. Pour la double fonction des généalogies mythiques (mesurer le temps historique et lier le présent de la cité à son passé légendaire), voir C. Calame, «Spartan Genealogies: the Mythological Representation of a Spatial Organisation», in Interpretation of Greek Mythology, J. Bremmer (éd.), LondonSydney 1987, p. 153-186. 


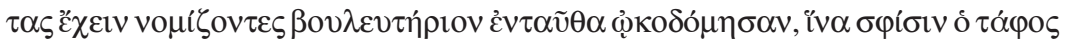

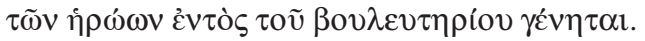

Hypérion, le fils d'Agamemnon, - ce fut le dernier roi de Mégare -, cet homme donc fut tué par Sandion à cause de sa cupidité et de sa démesure. Les Mégariens décidèrent alors de ne plus se laisser gouverner par un roi unique, mais d'avoir des magistrats élus et d'obéir à tour de rôle les uns aux autres. Alors Aisymnos, un Mégarien qui ne le cédait en réputation à aucun autre, vint à Delphes auprès du dieu et, une fois là, il lui demanda le moyen pour les Mégariens d'avoir la prospérité. Le dieu leur répondit entre autres que les gens de Mégare s'en trouveraient bien s'ils ouvraient leurs délibérations au plus grand nombre. Jugeant que cette parole désignait les morts, ils construisirent leur salle du Conseil en ce lieu, pour que le tombeau des héros fût à l'intérieur de la salle du Conseil ${ }^{143}$.

Sur la foi de Pausanias, on constate que le transfert du pouvoir politique conduit à Mégare à l'identification de l'espace politique avec l'espace sacré$^{144}$. De fait, tous les édifices publics sont placés sur des tombes anciennes ${ }^{145}$. Ainsi, comme le passage cité en témoigne, les Mégariens bâtirent leur Bouleutèrion sur les tombeaux des héros et le Périègete ajoute ailleurs que cet édifice se trouvait sur le tombeau de Timalcos, le fils de Mégareus ${ }^{146}$. De plus, le Prytanée était sur les tombeaux d'Euhippos, autre fils de Mégareus, et d'Ischépolis, le fils d'Alcathoos ${ }^{147}$. Les archives de la cité, quant à elles, sont implantées sur l'hérôon d'Alcathoos ${ }^{148}$.

S'il est impossible de démontrer l'existence historique des rois mégariens ${ }^{149}$, il est en revanche certain que l'on assiste dès le milieu du

143 Pausanias, I, 43, 3 (trad. de J. Pouilloux, CUF).

144 Bohringer, Mégare, p. 7.

145 Pour l'organisation de la description de Mégare par Pausanias, voir Highbarger, Megara, p. 1-31; A. Muller, «Megarika», BCH 105, 1981, p. 203-225.

146 Pausanias, I, 42, 4. Voir aussi infra, chapitre III.2.2.1, pour l'hypothèse selon laquelle l'Aisymnion mentionné par Pausanias, I, 43, 3, devrait être identifié au Bouleutèrion. Si l'on accepte cette hypothèse, cela signifierait que la salle du Conseil abritait aussi le tombeau d'Aisymnos.

147 Pausanias, I, 43, 2.

148 Pausanias, I, 43, 4; cf. Bohringer, Mégare, p. 7.

149 Voir notamment supra, chapitre I.1.3, pour l'influence argienne sur la liste des rois mégariens. De manière générale, pour la question de la royauté (dépourvue ou non d'un sens monarchique) dans la Grèce du haut archaïsme, voir R. Drews, Basileus. The Evidence for Kingship in Geometric Greece, New Haven-London 1983, p. 98131 ; Carlier, Royauté, surtout p. 503-514; idem, «Les basileis homériques sont-ils des rois ?», Ktèma 21, 1996, p. 5-21 ; D. Knoepfler, REG 99, 1986, p. 332-341. 
VIII ${ }^{\mathrm{e}}$ siècle en Mégaride, tout comme dans d'autres régions du monde grec, à la formation de la cité ${ }^{150}$. Conformément aux légendes locales, dorénavant, ce n'est pas «une institution monarchique» qui gouvernera les Mégariens, mais un pouvoir collégial électif, incarné très probablement par les aisimnatai ${ }^{151}$. Ce témoignage suggère qu'il y a eu vers le milieu du VIII ${ }^{\mathrm{e}}$ siècle un changement institutionnel, qui reste (en l'absence des données archéologiques) difficile à saisir dans toute sa complexité ${ }^{152}$, mais qui est sans doute étroitement lié au synœcisme ${ }^{153}$. En effet, le regroupement des Mégariens a imposé l'élaboration des nouvelles institutions afin d'assurer la médiation politique entre les aristocrates locaux. Il convient en même temps de remarquer que la légende d'Aisymnos cache une ruse: au lieu d'élargir le corps politique, comme le dieu de Delphes le leur avait conseillé («ouvrir les délibérations au plus grand nombre»), les Mégariens ont construit leur salle du Conseil sur des tombes héroïques. Cela suggère qu'en dépit du conseil de l'oracle de Delphes, certaines familles ont été exclues de l'exercice du pouvoir politique. Et l'on a vu que les luttes internes sont évoquées par Plutarque dans le passage relatif aux cinq mérè, déjà commenté: il y est question des conflits qui opposaient les Mégariens et auxquels le système de «l'hôte par la lance» était destiné à mettre fin. L'affirmation de Plutarque selon laquelle «les cultivateurs ne furent les victimes d'absolument personne» a incité Figueira à attribuer le passage à une

150 C. Bérard, «Récupérer la mort du prince : héroïsation et formation de la cité», in $L a$ mort, les morts dans les sociétés anciennes, G. Gnoli et J.-P. Vernant (éds.), Cambridge-Paris 1982, p. 89-105; Bohringer, Mégare, p. 17, rappelle que «l'appel aux héros et à leurs mythes, leur mise en terre, et l'apparition, pour quelques-uns, de leur culte, sont ainsi inhérents au processus de formation de la cité grecque». Voir aussi F. de Polignac, «Repenser la <cité > ? Rituels et société en Grèce archaïque », in Studies in the Ancient Greek Polis, M.H. Hansen et K. Raaflaub (éds.), Historia Einzelschriften 95, Stuttgart 1995, p. 7-19; Morris, The Eighth-century Revolution, p. 64-80.

151 Sur les aisimnatai, voir infra, chapitre III.2.2.1.

152 Même dans les régions où les découvertes sont plus abondantes qu'en Mégaride, notamment à Érétrie, l'identification des catégories sociales de la haute époque archaïque sur la base des vestiges archéologiques pose de difficultés. À cet égard, voir B. Blandin, Les pratiques funéraires d'époque géométrique à Érétrie. Espace des vivants, demeures des morts, Eretria. Fouilles et recherches XVII, Gollion 2007, p. 137-156 (avec les références).

153 Legon, Megara Pol. Hist., p. 53-55; Bohringer, Mégare, p. 14; Muller, De Nisée à Mégare, p. 627. 
situation où les aristocrates préservaient l'héritage d'un combat individuel, par opposition aux transformations politiques et militaires introduites par la phalange ${ }^{154}$. Il s'agit sans aucun doute d'une situation politique spécifique du haut archaïsme, caractérisée par des conflits entre différents groupements d'oikoi ou de clans; autrement dit, des conflits à l'intérieur de l'élite ${ }^{155}$.

Dans ce cadre, il est permis de supposer que des aristocrates qui ne trouvaient pas de place dans la nouvelle organisation politique, avaient été obligés d'abandonner la Mégaride pour aller s'installer ailleurs ${ }^{156}$. Ceux-ci suivaient l'exemple des Héraclides de Corinthe, plus précisément d'Archias, probablement originaire du bourg de Ténéa, qui avait fondé Syracuse ${ }^{157}$, et de Chersicratès, le fondateur de Corcyre. À cet égard, il n'est pas sans intérêt d'évoquer ici le témoignage de Timée de Tauromenium, selon lequel la cause du départ de Chersicratès fut sa privation des honneurs (timai) par les Corinthiens ${ }^{158}$. Nicolas de Damas rapporte aussi que vers le milieu du VII ${ }^{\mathrm{e}}$ siècle le tyran Cypsélos

154 Figueira, Chronological Table, p. 262-263.

$155 C f$. Morris, The Eighth-century Revolution, p. 72.

156 À propos du départ des apoikoi à l'époque archaïque, B. Helly, «Arithmétique et histoire. L'organisation militaire et politique des Ioniens en Achaïe à l'époque archaïque», Topoi(Lyon) 7, 1, 1997, p. 254, estime que «la communauté en place expulse les individus que la structure d'organisation qu'elle a adoptée ne lui permet pas d'intégrer comme il conviendrait».

157 Thucydide, VI, 3, 2; Strabon, VI, 1, 11, C 262; VI, 2, 4, C 269-270; VIII, 6, 22, C 380 ; Marmor Parium, FGrHist 239 A 31 ; cf. Malkin, Religion and Colon., p. 4143 ; C. K. Williams, op. cit., p. 41 ; De Fidio, Corinto e l'Occidente, p. 90-91, n. 152 ; F. Bernstein, Konflikt und Migration. Studien zu griechischen Fluchtbewegungen im Zeitalter der sogenannten Großen Kolonisation, St. Katharinen 2004, p. 45-77. D'après Strabon, VI, 2, 4, C 269, le bourg de Ténéa avait fourni la plupart des colons d'Archias.

158 Évoquant l'arrivée des Corinthiens à Corcyre, Timée, FGrHist 566 F 80, transmet:

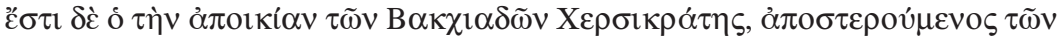

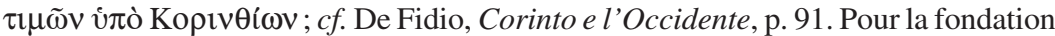
de Corcyre par les Corinthiens voir aussi les références citées ci-dessus. Les luttes internes (les périodes de stasis) qui divisaient les cités grecques furent responsables de la fondation d'autres colonies (Tarente, Cyrène, etc.): C. Dougherty, «It's Murder to found a Colony», in Cultural Poetics in Archaic Greece: Cult, Performance, Politics, C. Dougherty et L. Kurke (éds.), Cambridge 1993, p. 182-184; M. Moggi, «Emigrazioni forzate e divieti di ritorno nella colonizzazione greca die secoli VIIIVII a. C. », in Coercizione e mobilità umana nel mondo antico, M. Sordi (éd.), Milano 1995, p. 27-49, surtout p. 45 ; F. Bernstein, op. cit., p. 23-32. 
avait permis le retour des exilés et avait honoré (épitimoi) ceux que le régime des Bacchiades avait dépouillés de leurs privilèges (atimoi) ${ }^{159}$. Un passage d'Hérodote témoigne précisément du rôle de la timè (que l'on peut traduire non seulement par «honneur», mais aussi par «autorité» et «charge») pour l'accès des nouveaux colons à la pleine citoyenneté. On apprend ainsi qu'étant chassés de Lemnos par des Pélasges, les Minyens, descendants des Argonautes, demandèrent aux Lacédémoniens d'habiter parmi eux, à condition d'avoir leur part des timai et le droit de posséder un lot de terre. Outre ces deux privilèges, les Spartiates leur accordèrent aussi l'intégration dans une tribu et l'intermariage ${ }^{160}$. De même, le célèbre «Serment des Fondateurs» de Cyrène stipule que les Théréens qui arrivent par la suite comme colons supplémentaires (époikoi) devaient obtenir leur part de droits civiques (politéia), des honneurs (timai) et recevoir un lot de terre (gè) dans la nouvelle fondation ${ }^{161}$.

On peut ainsi conclure que de même qu'à Corinthe et dans d'autres cités, la perte de la timè, c'est-à-dire la perte d'une partie des droits que la citoyenneté impliquait, a pu déterminer aux $\mathrm{VIII}^{\mathrm{e}}-\mathrm{VII}{ }^{\mathrm{e}}$ siècles plusieurs habitants de la Mégaride à quitter leur pays. Ce fut d'abord le cas des Mégariens de Lamis, qui ne participent pas au synœcisme de Mégare en Grèce et fondent leur propre «Mégare» en Sicile. Le fait que les deux cités sont homonymes peut être interprété non seulement comme la volonté d'établir un lien avec la métropole, mais aussi comme un indice de l'hostilité des apoikoi de Sicile à l'égard de leur métropole.

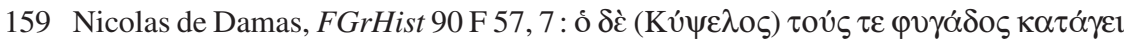

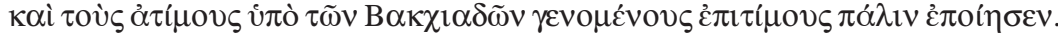

160 Hérodote, IV, 145 ; $c f$. F. Ruzé, Délibération et pouvoir dans la cité grecque de Nestor à Socrate, Paris 1997, p. 205-206.

$161 S E G$ IX, 3. On se rapportera pour ce texte à l'édition de C. Dobias-Lalou, «SEG IX, 3: un document composite ou inclassable?», Verbum 3-4, 1994, p. 243-256; cf. C. Calame, Mythe et histoire dans l'Antiquité grecque. La création symbolique d'une colonie $^{2}$, Paris 2011, p. 236-241. Les droits des époikoi sont mentionnés aux 1.31-33

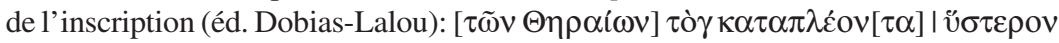

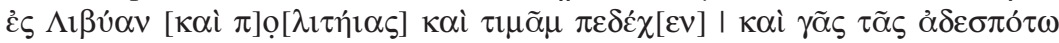
$[\dot{\alpha} \pi \mathrm{o} \lambda \alpha \gamma] \chi \alpha \dot{v} v \varepsilon v$. 


\section{I.2 Les conflits de Mégare avec Athènes pour la possession de l'île de Salamine: une affaire de néoi?}

Interea Megarenses, memores inlati Atheniensibus belli et deserti, ne frustra arma movisse viderentur, matronas Atheniensium in Eleusinis sacris noctu oppressuri naves conscendunt.

Cependant les Mégariens, qui n'avaient pas oublié la guerre contre les Athéniens (pour Salamine), qu'ils avaient entreprise puis abandonnée, craignant qu'on ne les blâmât d'avoir pris les armes pour rien, s'embarquent pour surprendre les matrones athéniennes aux fêtes nocturnes d'Éleusis ${ }^{162}$.

La guerre pour la possession de Salamine a été une longue guerre, qui a marqué les relations entre Mégare et Athènes au $\mathrm{VI}^{\mathrm{e}}$ siècle et aux époques ultérieures, et ce n'est que le recours à des arbitres de Sparte qui y a mis fin. Ce conflit a contribué en même temps à l'élaboration et à l'épanouissement des différentes traditions pour justifier la possession de l'île. Il s'agit de récits qui entremêlent mythe et histoire et qui prennent à la fois une dimension politique et religieuse, notamment avec la fondation de nouveaux cultes. J'aimerais d'abord faire état dans le cadre de ce chapitre des traditions et des mythes relatifs aux combats entre les Mégariens et les Athéniens. Cela me permettra d'examiner ensuite les enjeux de la guerre pour Salamine et notamment de m'interroger sur l'importance économique, commerciale et stratégique de l'île. Enfin, j'aborderai aussi la question du type de combats menés par les deux parties, ainsi que celle du rapport éventuel entre ces combats et la fondation de colonies mégariennes sur les rives du Pont-Euxin ${ }^{163}$.

162 Justin, II, 8, 1 (trad. E. Chambry et L. Thély-Chambry).

163 Ce chapitre reprend et développe des réflexions que j'ai faites dans A. Robu, «L'affaire de Salamine», Dacia N.S. 48-49, 2004-2005, p. 161-172. 


\section{I.2.1 Les traditions relatives aux combats menés par les Mégariens et les Athéniens à l'époque archaïque}

Les savants s'accordent pour situer le début de l'occupation mégarienne de Salamine avant ca. 600. Highbarger date cet événement du VIII ${ }^{\mathrm{e}}$ siècle et estime qu'il aurait dû se produire avant le départ des Mégariens pour la Sicile ${ }^{164}$. En revanche, pour Figueira, la conquête de l'île eut lieu après la fondation des colonies mégariennes en Propontide, à l'époque du tyran Théagène. L'arrêt du mouvement colonial mégarien vers 630625 s'expliquerait par les nouvelles terres acquises suite à l'occupation de l'île ${ }^{165}$. On a aussi suggéré que les Mégariens prirent possession de Salamine au cours du VII ${ }^{\mathrm{e}}$ siècle afin d'empêcher les attaques des pirates qui sévissaient dans l'île ${ }^{166}$.

En réalité, les récits, peu nombreux et souvent à caractère polémique, nous empêchent de connaître les circonstances du début de la guerre. À cet égard, le seul indice chronologique dont on dispose est un passage de Plutarque, qui rapporte que les Mégariens réoccupèrent Nisaia et Salamine, en profitant de la situation difficile d'Athènes, survenue après le sacrilège commis par les Alcméonides dans l'affaire de Cylon ${ }^{167}$. Il y aurait donc eu avant cet événement une occupation mégarienne de Salamine, suivie d'une conquête de l'île et du port de Nisaia par les Athéniens. Le terminus post quem pour le coup d'État de Cylon est la victoire de l'Athénien à la double course lors la $35^{\mathrm{e}}$ olympiade, c'est-à-dire en $640^{168}$, ou bien plus tard, en 598/7, à condition que l'on accepte l'opinion de Lenschau, selon laquelle les 49 premières olympiades furent annuelles ${ }^{169}$. On sait par ailleurs que le tyran Théagène

164 Highbarger, Megara, p. 127.

165 Figueira, Chronological Table, p. 280.

166 Legon, Megara Pol. Hist., p. 101, 122, 130-131.

167 Plutarque, Solon, 12, 5.

168 Julius Africanus, F 65, 99 (éd. M. Wallraff et al., p. 198); cf. Legon, Megara Pol. Hist., p. 93-95; Figueira, Chronological Table, p. 276; Okin, Theognis, p. 9-10; H. Berve, Die Tyrannis bei den Griechen, II, Darmstadt 1967, p. 536; L. de Libero, Die archaische Tyrannis, Stuttgart 1996, p. 225-230; Smith, Megaris, p. 99-100.

169 T. Lenschau, «Forschungen zur griechischen Geschichte im VII. und VI. Jahrhundert v. Chr., I, Die Tyrannis in den Isthmosstaaten», Philologus 91, 1936/7, p. 287-289, date la tyrannie de Théagène autour de 600. De même, E. Lévy, «Notes sur la chronologie athénienne au VI siècle», Historia 27, 1978, p. 513-521, se prononce en faveur de la date basse de la victoire olympique de Cylon. Il fut suivi par A. Muller, 
soutint Cylon, son gendre, dans son coup d'État ${ }^{170}$. Il ne serait dès lors pas surprenant que Théagène ait mené une attaque contre Athènes après l'échec de la tentative de Cylon de s'emparer de la tyrannie.

Quel que soit le rôle de Théagène dans la prise de Salamine, il est certain que la guerre entre les Mégariens et les Athéniens dura longtemps et que les premiers commencèrent par avoir le dessus. Selon une tradition athénienne très répandue, ce serait Solon qui aurait persuadé les Athéniens de reprendre la guerre, après que ceux-ci avaient interdit par un décret toute reprise des hostilités. Il aurait composé un poème élégiaque appelé «Salamine», qui rendit le courage à ces concitoyens ${ }^{171}$. La participation de Solon à la capture de l'île était rappelée à l'époque classique par la statue qui l'honorait sur l'agora de Salamine ${ }^{172}$. Et certains auteurs ont essayé de renforcer le lien entre le célèbre réformateur athénien et Salamine, en lui attribuant une origine salaminienne ${ }^{173}$, ou en soutenant que ses cendres avaient été dispersées dans l'île ${ }^{174}$. En revanche, Daïmachos de Platée rejette la participation de Solon à la

«Megarika», BCH 105, 1981, p. 212; A. Duplouy, Le prestige des élites. Recherches sur les modes de reconnaissances sociales en Grèce entre les $X^{e}$ et $V^{e}$ siècles avant J.-C., Paris 2006, p. 85-86. Cf. aussi A. Giuliani, «Il sacrilegio ciloniano: tradizioni e cronologia», Aevum 73, 1999, p. 21-42.

170 Thucydide, I, 126, 3-5; Pausanias, I, 28, 1 ; 40, 1. L'alliance entre Cylon et Théagène est mise en doute par M. Lang, «The Kylonian Conspiracy », CPh 62, 1967, p. 243249. D'après F. J. Frost, «The Athenian Military before Cleisthenes », Historia 33, 1984, p. 286, l'échec de la tentative de Cylon devrait être attribué en bonne partie à son alliance avec Mégare.

171 Démosthène, XIX, Sur les forfaitures de l'ambassade, 252; Scholie à Démosthène, XIX, 251 ; Plutarque, Solon, 8-9; Polyen, I, 20, 2 ; Diogène Laërce, I, 46-48; Justin, II, 7, 7-12; Élien, Histoire variée, VII, 19; Cicéron, De officiis, I, 30, 108.

172 Eschine, I, Contre Timarque, 25; Démosthène, XIX, Sur les forfaitures de l'ambassade, 251.

173 Diogène Laërce, I, 45, 1 ; Diodore, IX, 1, 1. La tradition de l'origine salaminienne de Solon est réfutée par M. Bakaoukas, «Solon's Forgotten Genealogy», ElectronAnt 6, 1, 2001-2002, non paginé (consulté sur <http://scholar.lib.vt.edu/ejournals/ElAnt/ V6N1/bakaoukas.html>, le $1^{\text {er }}$ mars 2004).

174 Aristote, fr. 392 (éd. V. Rose, apud Plutarque, Solon, 32, 4); Diogène Laërce, I, 62; contra Élien, Histoire variée, VIII, 16, qui estime que Solon fut enterré près des remparts, à côté des portes de la ville. $C f$. C. Higbie, «The Bones of a Hero, the Ashes of a Politician: Athens, Salamis, and the Usable Past», ClAnt 16, 1997, p. 303-304. 
guerre contre Mégare ${ }^{175}$, tandis qu'une autre tradition attribue la conquête de l'île à Solon et à Pisistrate ${ }^{176}$.

Les modernes ont proposé différentes chronologies des combats entre Mégare et Athènes ${ }^{177}$. Mais la confusion qui existe dans les sources entre les exploits de Solon et ceux de Pisistrate et le caractère quasimythique des combats rendent ces reconstructions très hypothétiques ${ }^{178}$. Il n'est donc pas dans mon intention de reprendre cette question de chronologie. Je me contenterai de noter que les Mégariens gardaient vivant à l'époque impériale le souvenir de leur victoire contre les Athéniens. Pausanias vit dans le temple local de Zeus Olympios l'éperon de bronze d'une trière que les Mégariens avaient capturée pendant la guerre.

Chose importante, il existait aussi une tradition mégarienne relative à la perte de Salamine, fort différente de celle des Athéniens. Le Périégète rapporte ainsi:

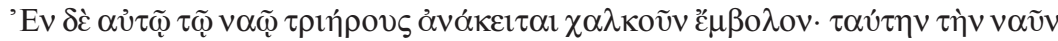

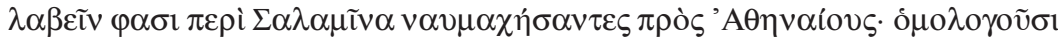

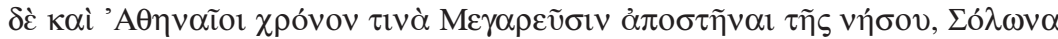

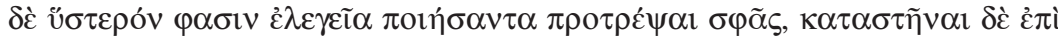

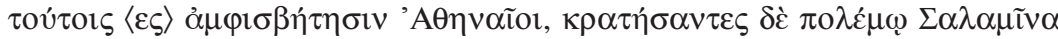

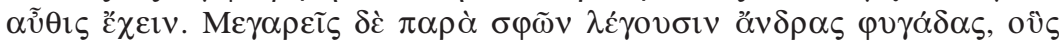

175 Daïmachos de Platées, FGrHist 65 F 7 (apud Plutarque, Comparatio Solonis et Publicolae, 4, 1). Les sources portant sur la vie et l'œuvre de Solon sont recueillies par A. Martina, Solone. Testimonianze sulla vita e l'opera, Roma 1968.

176 Plutarque, Solon, 8, 3. Contra Ps.-Aristote, Constitution d'Athènes, XVII, 2, qui critique cette version en s'appuyant sur la différence d'âge entre Solon et Pisistrate. Néanmoins, J. K. Davies, Athenian Properted Families 600-300 B. C., Oxford 1971, s.v. 8792 (II), s.v. 11793 (II), place la date de naissance de Solon vers 630-625 et de Pisistrate vers 605-600, ce qui peut rendre vraisemblable leur implication commune dans le conflit pour la possession de Salamine. À ce sujet, voir aussi A. Podlecki, «Solon or Peisistratus? A Case of Mistaken Identity», AncW 16, 1987, p. 3-10.

177 Pour les diverses chronologies des confrontations entre Mégare et Athènes, voir Beloch, Gr. Gesch. ${ }^{2}$, I, 2, p. 309-314; Highbarger, Megara, p. 133, n. 24 ; A. French, «Solon and the Megarian Question», JHS 77, 1957, p. 238-246; Legon, Megara Pol. Hist., p. 122-131; Piccirilli, Solone, p. 1-13; Figueira, Chronological Table, p. 270-286, 291-292, 298-303 ; M. C. Taylor, Salamis and the Salaminioi. The History of an unofficial Athenian Demos, Amsterdam 1997, p. 21-47.

$178 C f$. A. Andrews, «The Growth of the Athenian State», in Cambridge Ancient History ${ }^{2}$, III, 3, J. Boardman et N. G. L. Hammond (éds.), Cambridge 1982, p. 373 ; F. J. Frost, «Solon and Salamis, Peisistratos and Nisaia», AncW30, 1999, p. 133-139; Polignac, Divininités, p. 31-32. 


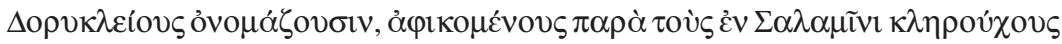

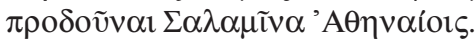

Dans le temple lui-même, on a consacré l'éperon de bronze d'une trière. C'est, diton, le bateau qu'ils prirent aux Athéniens dans un combat naval au large de Salamine. Les Athéniens conviennent, eux aussi, qu'ils se retirèrent de l'île un certain temps pour la laisser aux Mégariens; mais par la suite Solon, affirment-ils, composa un poème élégiaque et leur rendit courage. À la suite de quoi, disent-ils, ils engagèrent la lutte, et comme les Athéniens avaient été vainqueurs, ils reprirent possession de Salamine. Mais selon les Mégariens ce sont des fugitifs de chez eux, - ils les appellent Dorykleioi -, qui se rendirent près des clérouques et livrèrent Salamine aux Athéniens ${ }^{179}$.

Les Dorykleioi, «fameux par leurs lances», forment un groupe de guerriers, ou peut-être même une sorte de génos, qui fut expulsé pour des raisons impossibles à déterminer. Difficile à situer du point de vue chronologique, ce groupement remonte en tout cas au $\mathrm{VI}^{\mathrm{e}}$ siècle, et son existence nous montre la violence des conflits qui déchiraient Mégare à cette époque $^{180}$. Piccirilli met en doute l'historicité des Dorykleioi, en les considérant comme une invention mégarienne pour justifier a posteriori la prise de possession de Salamine par les Athéniens ${ }^{181}$. Cette hypothèse ne s'appuie sur rien et l'expulsion de divers groupes dans les cités de l'époque archaïque est connue ailleurs. On peut mentionner à titre d'exemple le groupe (génos?) des Mylétidai, qui, après avoir été expulsé de Syracuse, se joint aux Chalcidiens de Zancle pour fonder Himère $^{182}$. Mieux, une inscription athénienne atteste à l'époque impériale un téménos d'Athéna situé dans le dème attique de Lamptrai et portant le nom de Dorykleion ${ }^{183}$. On a là peut-être un écho de la tradition de Pausanias concernant l'exil du groupe des Dorykleoi en Attique ${ }^{184}$.

179 Pausanias, I, 40, 5 (trad. J. Pouilloux, CUF).

180 Figueira, Chronological Table, p. 285-286, considère que les Dorykleioi sont expulsés par Théagène ou, moins probablement, par l'oligarchie «modérée» de Mégare. Contra Legon, Megara Pol. Hist., p. 129, qui soutient que c'est la démocratie qui est à l'origine de l'écart des Dorykleioi.

181 Piccirilli, MEGARIKA, p. 132-133; cf. Legon, Megara Pol. Hist., p. 129.

182 Thucydide, VI, 5, 1. D'après S. Calderone, «Problemi storici relative alle «Apoikiai» siceliote in età protoarcaica», in Rizza (éd.), Insediamenti colon. gr., p. 17-18, les Mylétidai sont un «genos nobiliare».

$183 I G \mathrm{II}^{2} 1035,1.51$.

184 I. Bultrighini, «Dorykleion, Dorykleioi e Dorieis», RCCM 53, 1, 2011, p. 99-106, estime que le Dorykleion a pu être consacré à Athéna par les Dorykleioi de Mégare. 
D'autre part, d'aucuns estiment que le succès athénien a été favorisé par la défaite que les Samiens infligèrent aux Mégariens dans la Propontide ${ }^{185}$. Cette affaire, mentionnée par Plutarque, se situe après la fondation de Périnthe en 602 par les Samiens ${ }^{186}$. Néanmoins, les combats autour de Périnthe ont sans doute concerné les Mégariens des colonies et l'on ne connaît pas quelle fut la participation exacte de Mégare de Grèce ${ }^{187}$. Je crois dès lors qu'il est prudent de réfuter tout lien entre la guerre de Salamine et celle menée en Propontide.

L'affaire de Salamine fut définitivement réglée en faveur d'Athènes par l'arbitrage de Sparte ${ }^{188}$, un événement daté par les modernes soit vers le milieu du VI ${ }^{\mathrm{e}}$ siècle $^{189}$, soit lors de la période de $c a .520-510^{190}$. La première datation se fonde sur la mention de Solon comme défenseur de la cause athénienne devant les arbitres spartiates Critolaïdos, Amompharétos, Hypsichidas, Anaxilas et Cléomène. En revanche, la deuxième, qui est plus probable, se justifie par la mention parmi les cinq arbitres de Cléomène et d'Amompharétos. Le premier pourrait être le célèbre roi lacédémonien et le second l'un des commandants présents à Platée en 479. Dans ce cas, l'arbitrage sur Salamine se placerait entre $c a .520$, le début du règne de Cléomène, et $c a$. 510, l'intervention spartiate contre la tyrannie d'Hippias à Athènes. Comme Taylor le propose, une solution serait de considérer que l'arbitrage spartiate du dernier quart du $\mathrm{VI}^{\mathrm{e}}$ siècle fut associé de manière anachronique avec Solon ou Pisistrate ${ }^{191}$. Les noms de cinq arbitres se trouvaient probable-

185 Burn, Gr. Sea Power, p. 172-174; Legon, Megara Pol. Hist., p. 120-122; G. Shipley, A History of Samos, Oxford 1987, p. 52, n. 21.

186 Plutarque, Questions grecques, LVII (= Moralia 303 E-304 C).

187 Robu, Réseaux, p. 184-187. Voir aussi infra, chapitre II.2.1.2.

188 Plutarque, Solon, 10; Strabon, IX, 1, 10, C 394; Élien, Histoire variée, VII, 19; Quintilien, V, 11, 40.

189 Legon, Megara Pol. Hist., p. 138. Voir aussi A. Andrews, op. cit., p. 373, qui place l'arbitrage spartiate vers 560 .

190 Les savants ont aussi daté l'arbitrage au sujet de Salamine de ca. 519/8 (Piccirilli, Arbitrati, p. 46-56, $\mathrm{n}^{\circ} 10$, après la victoire de Sparte contre Argos à Sepeia, dont la date haute de 520/19 est soutenue par Piccirilli au détriment de celle de 494), ou de ca. 510, suite au renversement d'Hippias (Beloch, Gr. Gesch. ${ }^{2}$, I, 2, p. 312-314; R. Sealey, A History of the Greek City States ca. 700-338 B. C., Berkeley et al. 1976, p. 145-147; Figueira, Chronological Table, p. 300-303). Cf. Will, Korinthiaka, p. 642-645; T. Lenschau, op. cit., p. 289.

191 M. C. Taylor, op. cit., p. 46. 
ment mentionnés dans une inscription faisant état de la décision des Spartiates, qui était conservée dans les archives d'Athènes et qui fut par la suite utilisée par la tradition de Plutarque ${ }^{192}$.

Outre Salamine, les Athéniens semblent avoir réussi à mettre la main à deux reprises, certes pour une brève période, sur Nisaia. Une première conquête athénienne du port mégarien est placée avant l'affaire de Cylon. Plutarque rapporte que les Mégariens profitèrent des troubles créés par le procès des Alcméonides, pour reconquérir Nisaia et Salamine ${ }^{193}$. Plus tard, d'après Hérodote, Pisistrate acquit de la gloire dans une campagne contre les Mégariens, en s'emparant de Nisaia ${ }^{194}$. Mais il reste difficile de savoir si ce dernier événement constitue une attaque réussie ou une occupation effective du port mégarien ${ }^{195}$.

Au demeurant, Van Effenterre et L'Homme-Wéry estiment que les deux cités se seraient également opposées à l'époque archaïque à Éleusis. Car, à leurs avis, les bornes (horoi) arrachées par Solon sur la terre qu'il libère ne seraient pas des bornes hypothécaires, mais des bornes de frontière ${ }^{196}$. Cette hypothèse reste difficile à vérifier et elle semble d'ailleurs aller à l'encontre des trouvailles archéologiques: les céramiques archaïques découvertes à Éleusis sont essentiellement de provenance attique, tandis qu'à Mégare elles sont plutôt corinthiennes ${ }^{197}$.

192 R. Nicolai, «Solone e la conquista di Salamina: da guerre tradizionale a mito politico», in Costruzione e uso del passato storico nella cultura antica. Atti del convegno internazionale di studi (Firenze, 18-20 settembre 2003), P. Desideri et al. (éds.), Alessandria 2007, p. 11.

193 Plutarque, Solon, 12, 5.

194 Hérodote, I, 59; $c f$. Ps.-Aristote, Constitution d'Athènes, XIV, 1 ; Énée le Tacticien, Poliorcétique, IV, 8-11 ; Justin, II, 8, 1-5; Frontin, Strat., II, 9, 9.

195 Figueira, Chronological Table, p. 291-292; cf. Morgan, Isthmia VIII, p. 425.

196 H. van Effenterre, «Solon et la terre d'Eleusis», RIDA 24, 1977, p. 106-118; L'Homme-Wéry, Solon, p. 111-113; eadem, «Solon, libérateur d'Éleusis dans les 〈Histoires > d'Hérodote», REG 107, 1994, p. 362-380; eadem, «Eleusis and Solon's Seisachtheia», GRBS 40, 1999, p. 109-133. Cf. C. Picard, «Les luttes primitives d'Athènes et d'Éleusis », $R H$ 166, 1931, p. 13, 65. Sur les différentes interprétations des horoi que Solon enleva à Athènes, voir Van Wees, Mafia of Early Greece, p. 1624 ; J. Ober, «Solon and the Horoi: Facts on the Ground in the Archaic Athens », in Solon of Athens. New Historical and Philological Approaches, J. H. Blok et A.P. M.H. Lardinois (éds.), Leiden-Boston 2006, p. 441-456.

197 R. Osborne, «Archaeology, the Salaminioi, and the Politics of Sacred Spaces in Archaic Athens», in Placing the God. Sanctuaries and Sacred Spaces in Ancient Greece, S. E. Alcock et R. Osborne (éds.), Oxford 1994, p. 152-153; Parker, Athenian 
L'hypothèse des combats entre Athènes et Mégare dans la région d'Éleusis, bien que difficile à vérifier, ne doit pas être écartée pour autant. Elle semble être confortée par Hérodote, qui rapporte que pour Solon, le plus heureux des mortels fut l'Athénien Tellos, mort glorieusement à Éleusis en combattant contre des voisins ${ }^{198}$. En outre, on sait qu'à l'époque classique la «terre sacrée» d'Éleusis (la hiéra orgas des deux Déesses) fut l'objet de dispute entre les deux cités. Et plusieurs lexicographes considèrent la hiéra orgas comme mégarienne ${ }^{199}$. Cependant, faute d'autres informations, il est difficile d'établir les enjeux et la nature exacte de la guerre d'Éleusis à l'époque archaïque, qui pouvait aussi être un simple combat de frontière.

Les récits indiquent en somme que Mégare et Athènes se sont opposées dans plusieurs endroits, à Salamine, à Nisaia et peut-être aussi à Éleusis. Il est certain que les deux cités ont livré une longue guerre au sujet de Salamine et non pas de simples combats frontaliers, et il est vraisemblable que ce fut l'arbitrage spartiate qui fit cesser la dispute vers la fin $\mathrm{du} \mathrm{VI} \mathrm{VI}^{\mathrm{e}}$ siècle $^{200}$. Du reste, ce conflit provoqua l'élaboration de différents récits mythographiques: des vers d'Homère, des pratiques funéraires et des divinités furent appelées à appuyer les droits de telle ou telle partie. Ces récits, que je me propose d'analyser par la suite, ne s'avèrent pas moins intéressants pour la question des relations entre Athènes et Mégare dans l'Antiquité.

Religion, p. 13. Pour les céramiques découvertes à Éleusis et Mégare, voir de manière générale Coldstream, Gr. Geom. Pot., p. 402 (Éleusis), 404 (Mégare), ainsi que supra, chapitre I.1.1.

198 Hérodote, I, 30; $c f$. R. A. Padgug, «Eleusis and the Union of Attika», GRBS 13, 1972, p. 139-140.

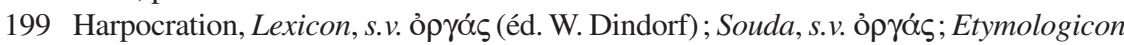
Magnum, s.v. ỏ $\rho \gamma \alpha ́ \delta \alpha \gamma \tilde{\eta} v$ (éd. T. Gaisford). Sur les conflits entre Athènes et Mégare aux $\mathrm{V}^{\mathrm{e}}-\mathrm{IV}^{\mathrm{e}}$ siècles pour la zone frontière d'Éleusis, voir G. Daverio Rocchi, Frontiera e confini, p. 186-194; eadem, «La hiera orgas e la frontiera atticomegarica», in Studi di antichità in memoria di C. Gatti, Quaderni di Acme 9, Milano 1987, p. 97-109; L'Homme-Wéry, Solon, p. 117-150; N. Papazarkadas, Sacred and Public Land in Ancient Athens, Oxford 2011, p. 244-259; P. Bonnechere, «Oracles et grande politique en Grèce ancienne. Le cas de l'orgas sacrée et de la consultation de Delphes en 352/351 avant J.-C. ( $1^{\text {re }}$ partie)», Métis N.S. 10, 2012, p. 261-286.

200 I. M. Linforth, Solon the Athenian, Berkeley 1919, p. 264; A. Masaracchia, Solone, Firenze 1958, p. 95-96; H. van Effenterre, op. cit., p. 105; H. A. Shapiro, «Exekias, Ajax, and Salamis: A Further Note», AJA 85, 2, 1981, p. 173-174. 


\section{I.2.2 Conflits et rivalités entre Mégare et Athènes: récits mythologiques et cultes}

Pour convaincre les cinq arbitres spartiates de leurs droits sur Salamine, les Athéniens et les Mégariens invoquèrent le catalogue des vaisseaux de l'Iliade ${ }^{201}$. Plutarque évoque les circonstances de la dispute et note que l'on soupçonnait Solon d'avoir modifié le texte homérique:

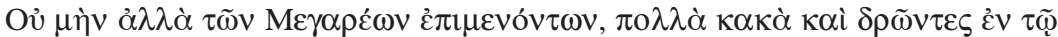

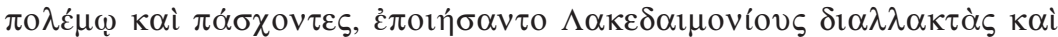

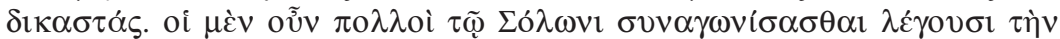

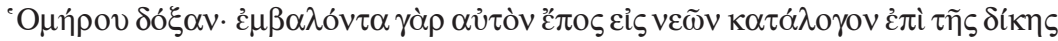

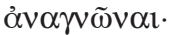

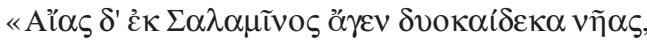

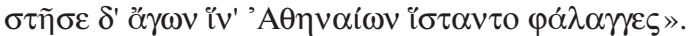

Cependant, les Mégariens ne renoncèrent pas à la guerre, et les deux parties en lutte, après avoir porté et reçu de nombreux coups, prirent les Lacédémoniens pour médiateurs et pour arbitres. On dit généralement que Solon, dans ce débat, s'appuya sur l'autorité d'Homère, et qu'ayant ajouté un vers dans le catalogue des vaisseaux, il lut ainsi le passage devant les juges:

$<$ De Salamine Ajax amenait douze nefs,

Qu'il a conduites là, près des troupes d'Athènes ${ }^{202}$.

L'appel à Homère dans l'affaire de Salamine est connu par Aristote et cette tradition connaît une large diffusion parmi les commentateurs antiques et byzantins ${ }^{203}$. Un scholiaste faisait déjà observer que le vers 558 (chant II) contredisait d'autres passages de l'Iliade, dans lesquels Ajax n'est pas rangé près des bataillons d'Athènes, mais sur un autre point de la ligne ${ }^{204}$. West interprète l'absence dans les vers cités par Solon d'un nom de lieu, à l'exception d'Athènes et de Salamine, comme l'indice d'une interpolation tardive. Sur la foi des témoignages antiques

201 Sur l'usage politique de la poésie dans l'Antiquité grecque, voir A.L. Ford, «The Seal of Theognis. The Politics of Autorship in Archaic Greece», in Theognis of Megara. Poetry and the Polis, T.J. Figueira et G. Nagy (éds.), Baltimore-London 1985, p. 82-95.

202 Plutarque, Solon, 10, 1-2 (trad. de R. Flacelière, E. Chambry et M. Juneaux, CUF).

203 Aristote, Rhétorique, I, 15, 1375b 29-30; Strabon, IX, 1, 10, C 394 ; Diogène Laërce, I, 48; 57; Scholie à Démosthène, XIX, 251; Scholie b à Homère, Iliade, II, 558; Eustathe, Commentaire à l'Iliade, II, 557 (éd. M. van der Valk).

204 Scholie a à Homère, Iliade, III, 230 ; cf. E. Heitsch, op. cit., p. 645-647. 
(notamment celui d'Héréas de Mégare ${ }^{205}$ ), les spécialistes estiment que l'interpolation athénienne remonterait à l'époque de Pisistrate ou de ses fils, lors du travail d'établissement du texte homérique ${ }^{206}$.

D'après Strabon, les Mégariens auraient répondu aux Athéniens, en intercalant, à leur tour, deux vers dans l'Iliade. Il s'agit des vers mentionnant les vaisseaux amenés par Ajax de cinq établissements de la Mégaride: Salamine, Polichnè, Aigeiroussa, Nisaia et Tripodes ${ }^{207}$. À ce propos, le fait que le nombre de vaisseaux commandés par Ajax n'apparaît pas dans ce passage amène Kirk à y voir une preuve de l'inauthenticité de l'interpolation des Mégariens ${ }^{208}$.

On notera par ailleurs qu'un Ajax hostile à Mégare apparaît dans le Catalogue des femmes du Ps.-Hésiode ${ }^{209}$. Selon West, l'auteur de cette œuvre serait un poète athénien de la fin du $\mathrm{VI}^{\mathrm{e}}$ siècle. Si tel fut le cas, cela expliquerait pourquoi Ajax dirige dans ce texte ses attaques vers Mégare et non pas vers Athènes ${ }^{210}$.

Pour étayer les prétentions de sa cité sur l'île, Solon aurait soutenu que Philaios et Eurysacès, les fils d'Ajax, se sont établis à Athènes. En outre, d'après lui, les cadavres étaient enterrés à Salamine le visage tourné vers l'occident, comme à Athènes, contrairement à l'habitude

205 Héréas, FGrHist 486 F 1 (apud Plutarque, Thésée, 20, 2).

206 R. Merkelbach, «Die pisistratische Redaktion der homerischen Gedichte», RhM 95, 1952, p. 23-47; Will, Korinthiaka, p. 642-643; Piccirilli, Tre ricerche, p. 398-415; M. L. West, Studies in the Text and Transmission of the Iliad, Munich-Leipzig 2001, p. 179-180; contra M. van der Valk, «Ajax and Diomede in the Iliad», Menmosyne 5, 1952, p. 281-283; idem, Researches on the Text and Scholia of the Iliad, vol. II, Leiden 1964, p. 487, 519-523, n. 43, qui soutient l'authenticité du vers II, 558 de l'Iliade. Cf. E. Heitsch, op. cit., p. 641-660; R. Hope Simpson, J. F. Lazenby, op. cit., p. 59-60; E. Visser, op. cit., p. 17-18, 447-454; D. Bouvier, Le sceptre et la lyre. L'Iliade ou les héros de la mémoire, Grenoble 2002, p. 144-147; J. Latacz, Homers Ilias. Gesamtkommentar, München-Leipzig 2003, p. 179-180.

207 Strabon, IX, 1, 10, C 394. Voir supra, chapitre I.1.2.

208 G.S. Kirk, The Iliad: A Commentary, I, Cambridge 1985, p. 207-208.

209 Ps.-Hésiode, Catalogue des femmes, fr. 204, 48 (éds. R. Merkelbach et M.L. West; = fr. 155, 48, éd. G.W. Most), présente Ajax de Salamine comme un brigand qui rapporte son butin, entre autres, de Mégare. Cf. Legon, Megara Pol. Hist., p. 101, n. 31 .

210 M.L. West, The Hesiodic Catalogue of Women. Its Nature, Structure and Origin, Oxford 1985, p. 169-171; contra M. Hirschberger, Gynaikōn Katalogos und Megalai Ehoiai. Ein Kommentar zu den Fragmenten zweier hesiodeischer Epen, Leipzig 2004, p. 42-51, qui attribue une origine éolienne à l'auteur du Catalogue des femmes. 
des Mégariens d'ensevelir les morts avec le visage vers l'orient ${ }^{211}$. À cette dernière preuve, Héréas de Mégare aurait répliqué que les visages des cadavres étaient aussi tournés dans sa cité vers l'occident ${ }^{212}$. En ce qui concerne les coutumes funéraires, Plutarque rapporte que Solon développa un argument encore plus important, à savoir qu'à Athènes chacun avait son propre tombeau, par opposition à Mégare où, dans le même tombeau, l'on pouvait enterrer trois ou quatre personnes ${ }^{213}$. Il aurait aussi ajouté que les noms gravés sur les tombes de Salamine indiquent les dèmes d'origine, conformément à la pratique athénienne ${ }^{214}$.

L'oracle de Delphes confirme que les Athéniens ont le droit d'oc-

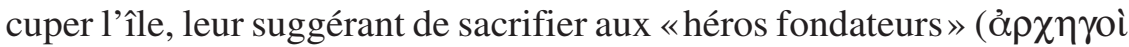
$\chi \omega ́ p \alpha \varsigma)$ de Salamine, que Solon identifie à Périphémos et à Cychreus ${ }^{215}$. Si Périphémos n'est pas connu par ailleurs, Cychreus, le fils de Poséidon et de la nymphe Salamis, fut le premier roi de l'île ${ }^{216}$. Il apparut aux Athéniens sous la forme d'un serpent au cours de la bataille de Salamine contre les Perses ${ }^{217}$. Mieux encore, Solon aurait même reçu des oracles de la Pythie donnant à Salamine l'appellation d'Ionienne ${ }^{218}$.

211 Plutarque, Solon, 10, 3-4. D'après Élien, Histoire variée, VII, 19, Solon démontra que les Athéniens sont enterrés vers l'occident, tandis que les Mégariens sont ensevelis au hasard et sans règle. $C f$. B. Aratowski, «Notes on Salamis», in Studies presented to D. M. Robinson, II, G. E. Mylonas et D. Raymond (éds.), Saint Louis 1953, p. 794-795 ; C. Higbie, op. cit., p. 299-301.

212 Héréas, FGrHist 486 F 4 (apud Plutarque, Solon, 10, 5). Piccirilli, Tre ricerche, p. 397-398, estime que le caractère antiathénien du fragment d'Héréas s'explique par la dispute de frontière entre Mégare et Athènes de 350/49, qui a ressuscité les anciens débats sur la possession de Salamine.

213 Plutarque, Solon, 10, 5.

214 Diogène Laërce, I, 48.

215 Plutarque, Solon, 9, 1. Cet oracle est considéré comme une invention athénienne, datée vers 300, par H.W. Parke, D.E.W. Wormell, The Delphic Oracle, Oxford 1956, vol. I, p. 110; vol. II, p. 130-131. Contra J. Fontenrose, The Delphic Oracle, Berkeley et al. 1978, p. 193, 290, 291, qui pense qu'il s'agit d'un oracle probablement authentique. À ce propos, voir aussi Kearns, Heroes, p. 46-47; idem, « Saving the City », in The Greek City from Homer to Alexander, O. Murray et S. Price (éds.), Oxford, 1990, p. 327 ; C. Higbie, op. cit., p. 301-303. Sur les héros locaux en tant que archegetai (fondateurs) d'une famille, d'une phylè, d'un peuple ou d'une cité, voir Leschhorn, Gründer, p. 180-182.

216 Apollodore, III, 12, 7.

217 Eschyle, Perses, 570 ; Pausanias, I, 36, 1; cf. Plutarque, Thésée, 10, 3. Sur Cychreus, voir Kearns, Heroes, p. 180.

218 Plutarque, Solon, 10, 6. 
Le statut particulier de Salamine dans la cité d'Athènes témoigne d'une intégration tardive de l'île dans le système institutionnel athénien. Salamine ne participa pas au synœcisme réalisé par Thésée: elle fut offerte aux Athéniens par Philaios et Eurysacès, les fils d'Ajax, en échange de la citoyenneté athénienne ${ }^{219}$. Assurément, on a là affaire à un autre mythe qui vise à appuyer les droits des Athéniens sur Salamine. Un fameux décret confirme l'intégration de Salamine vers la fin $\mathrm{du} \mathrm{VI}^{\mathrm{e}}$ siècle dans le système militaire et financier d'Athènes ${ }^{220}$. Mais aucun dème ne fut créé sur l'île à l'époque de Clisthène, les habitants étant rattachés aux dèmes et aux tribus de l'Attique ${ }^{221}$. Cela indiquerait, selon L'Homme-Wéry, «qu'elle n'était pas partie intégrante du territoire d'Athènes avant que Mégare ne s'en empare. Sinon, elle aurait vraisemblablement retrouvé ce statut quand les Athéniens l'avaient acquise à l'époque de Clisthène $»^{222}$.

Le fait que l'île était considérée comme distincte d'Athènes est corroboré par la scholie à Démosthène, XXIII, 71, qui rapporte que les meurtriers de Myrrhine, la fille de Pisistrate, furent obligés de s'établir à Salamine, même s'ils avaient reçu la citoyenneté athénienne. En effet, on interdisait à ceux qui avaient commis un crime de vivre en Attique ${ }^{223}$.

219 Plutarque, Solon, 10, 3. Par contre, pour Pausanias, I, 35, 2, Phliaios était le fils d'Eurysacès et le petit-fils d'Ajax et c'est lui qui a offert l'île aux Athéniens, recevant d'eux la citoyenneté. Les différentes traditions concernant le don de l'île de Salamine aux Athéniens par les héritiers d'Ajax sont examinées par W. S. Ferguson, «The Salaminioi of Heptaphylai and Sounion», Hesperia 7, 1938, p. 16, et M. C. Taylor, op. cit., p. 4, 74-82.

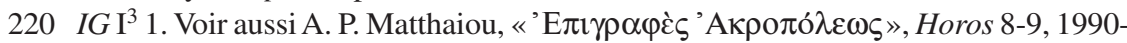
1991, p. 10-12, no 1 , qui publie un nouveau fragment de cette inscription.

221 M. C. Taylor, op. cit., p. 4-8, 62 et 95-101. À en croire R. Osborne, op. cit., p. 157158,1 'absence de mention de Salamine en tant que dème pourrait s'expliquer par le nombre réduit d'habitants qui résident sur l'île à l'époque géométrique et archaïque.

222 L'Homme-Wéry, Les héros de Salamine, p. 338.

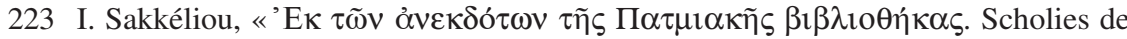
Démosthène et d'Eschine d'après un manuscrit inédit de Patmos », $B C H$ 1, 1877, p. 1-16, 137-155, notamment p. 138. Cf. M. Moggi, «L'insediamento a Salamina di Antidoro Lemnio e degli uccisori di Mirrina», ASNP serie iii, 8, 4, 1978, p. 13011312, qui considère les événements évoqués par cette scholie comme historiques. Suivant Figueira, Athens and Aigina, p. 146-148, la scholie à Démosthène, XXIII, 71, nous montre que les gens de Salamine étaient «citizens outside the deme system». M. C. Taylor, op. cit., p. 82-82, critique cette hypothèse et note que les meurtriers ont reçu la politeia athénienne et non pas «a second class citizenship», et que «the scholion shows that Salamis was perceived to be different from Attica but that is all». 
De même, le fait que la prêtresse d'Athéna Polias, qui s'abstient de toucher au fromage de l'Attique, mange toutefois du fromage de Salamine, était considéré par certains comme un indice que l'île était pour les Athéniens une terre étrangère ${ }^{224}$.

L'intégration de Salamine au territoire d'Athènes est mise en évidence symboliquement par le nom d'Ajax, que porte l'une des tribus établies par Clisthène. Les Athéniens, on le sait, envoyèrent à la Pythie une liste des cent héros fondateurs (archégetai), pour que celle-ci en choisisse dix. Bien qu'étant étranger aux Athéniens, Ajax fut inclus parmi eux, car, comme nous l'apprend Hérodote, il fut leur voisin et allié $^{225}$. En donnant à une des dix nouvelles tribus le nom d'Ajax, il fut créé artificiellement un groupe de parenté226. Il est intéressant de noter qu'au $\mathrm{II}^{\mathrm{e}}$ siècle les éphèbes participent lors de leur passage par Salamine à la fête locale des Aiantéia et font des sacrifices à Ajax ${ }^{227}$. De surcroît, le héros est célébré à Athènes même. De fait, Pausanias note qu'outre le temple d'Ajax à Salamine, il subsistait à son époque un culte d'Ajax à Athènes ${ }^{228}$.

Au surplus, d'autres cultes et mythes viennent renforcer à l'époque classique et hellénistique le rattachement de Salamine à Athènes. Tout d'abord, il y a le groupe des cultes célébrés par le génos des Salaminiens. Il importe peu ici si les membres de ce groupe avaient été des descendants des Salaminiens établis en Attique (hypothèse de Nilsson), voire même des Athéniens établis sur l'île (opinion de Lambert), ou s'ils n'entretenaient

224 Strabon, IX, 1, 11, C 394.

225 Hérodote, V, 66; Ps.-Aristote, Constitution d'Athènes, XXI, 6. Cf. U. Kron, Die zehn attischen Phylenheroen. Geschichte, Mythos, Kult und Darstellungen, Berlin 1976, p. 171-176; Parker, Athenian Religion, p. 118-119, 312; Kearns, Heroes, p. 82, 141-142.

$226 C f$. Finley, Sur l'hist. ancienne, p. 160.

$227 I G$ II $^{3}$ 1313, 1. 21-22; O. W. Reinmuth, «The Ephebic Inscription, Athenian Agora I $286 »$, Hesperia 24, 1955, p. 228, nº I, 1. 21-23 (SEG XV, 104); IG II ${ }^{2} 1008,1.22-23$, 76-77. Cf. Calame, Thésée ${ }^{2}$, p. 352; Polignac, Ajax l'Athénien, p. 121. Sur la fête des Aiantéia, voir L. Deubner, Attische Feste, Berlin 1932, p. 228 ; C. Pélékidis, Histoire de l'éphébie attique des origines à 31 avant Jésus-Christ, Paris 1962, p. 247-249; E. Perrin-Saminadayar, Éducation, culture et société à Athènes. Les acteurs de la vie culturelle athénienne (229-88): un tout petit monde, Paris 2007, p. 192. Signalons aussi que d'après H. A. Shapiro, op. cit., p. 174-175, «Ajax' appearance in Attic vase-painting in the course of the sixth century is a reflection of Athen's takeover of Salamis ».

228 Pausanias, I, 35, 3. 
qu'une relation symbolique avec l'île, à travers des cultes, comme la critique est prête aujourd'hui à les interpréter ${ }^{229}$. Grâce à un long décret émanant du génos des Salaminiens et datant de 363/2, on sait que cette association rendit un culte à plusieurs membres de la famille d'Ajax, notamment à son fils Eurysacès («large bouclier», allusion au bouclier de son père $)^{230}$. C'est dans le lieu de culte de ce héros, l'Eurysakeion, situé dans le dème de Mélitè, que l'on dressait les stèles portant les décrets de la tribu Aiantis (d'Ajax) ${ }^{231}$ et ceux du génos même ${ }^{232}$. On a aussi proposé d'identifier le sanctuaire d'Eurysacès à celui d'Ajax, qui figure dans deux inscriptions datant de la seconde moitié du $\mathrm{II}^{\mathrm{e}}$ siècle $^{233}$.

229 W.S. Ferguson, op. cit., p. 42, estime, à juste titre, que le génos des Salaminiens «came into being to promote and justify the claim of Athens to possession, on the basis of rightful ownership, of Salamis ». M.P. Nilsson, «The New Inscription of the Salaminioi », AJPh 59, 1938, p. 385-393, pense qu'au moment où les Athéniens occupèrent l'île, ils en transférèrent une partie des habitants en Attique. Cette population allait constituer par la suite le génos des Salaminiens. Cette opinion fut suivie, entre autres, par S. C. Humphreys, «Phrateres in Alopeke, and the Salaminioi », ZPE 83, 1990, p. 246-247. On lira, parmi les mises au point, sur le génos des Salaminiens: Parker, Athenian Religion, p. 308-316; M. C. Taylor, op. cit., p. 47-63 ; S. D. Lambert, «The Attic Genos Salaminioi and the Island of Salamis», ZPE 119, 1997,

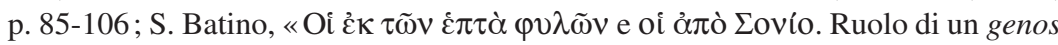
nella definizione degli spazi sacri nella città e nel suo territorio », ASAA 81, serie iii, 3, 1, 2003 (2004), p. 83-152; Polignac, Ajax l'Athénien, p. 121-122; P. Ismard, La cité des réseaux. Athènes et ses associations, $\mathrm{VI}^{e}-\mathrm{I}^{\text {er }}$ siècle av. J.-C., Paris 2010, p. 224-239.

230 W. S. Ferguson, op. cit., p. 5, nº 1,1.88 (SEG XXI, 527), texte repris dans P. J. Rhodes, R. Osborne (éds.), Greek Historical Inscriptions (404-323 BC), Oxford 2003, no 37.

231 B.D. Meritt, «Greek Inscriptions », Hesperia 7, 1938, p. 95, n 15 (=A. G. Woodhead, The Athenian Agora. Vol. XVI: Inscriptions. The Decrees, Princeton-New Jersey 1997, no 86), 1. 31-33; cf. W. S. Ferguson, op. cit., p. 18; Parker, Athenian Religion, p. 311.

232 P.J. Rhodes, R. Osborne (éds.), op. cit., nº 37, 1. 84-85; IG II ${ }^{2}$ 1232, 1. 21-22. Sur le culte et le sanctuaire d'Eurysacès à Athènes, voir R. E. Wycherly, The Athenian Agora. Vol. III: Literary and Epigraphical Testimonia, Princeton-New Jersey 1957, p. 90-93, nos 246-255; Kearns, Heroes, p. 70-71, 141-142, 164 ; N. Robertson, Festivals and Legends: the Formation of Greek Cities in the Light of Public Ritual, Toronto et al. 1992, p. 122, n. 7, 126-127 ; L’Homme-Wéry, Les héros de Salamine, p. 334-341.

$233 I G \mathrm{II}^{2}$ 1008, 1. 87; O. W. Reinmuth, op. cit., p. 231, n V, 1. 140-141 (SEG XV, 104). Pour l'identification de l'Eurysakeion à l'Aianteion, voir Kearns, Heroes, p. 141; N.F. Jones, «The Athenian Phylai as Association, Disposition, Function and Purpose», Hesperia 64, 1995, p. 509. 
Outre Eurysacès, le décret de 363/2 mentionne les sacrifices offerts par le génos à d'autres héros et divinités appartenant à un horizon salaminien: Phaiax, Teucros, Nauseiros, Athéna Skiras et $\operatorname{Sciros}^{234}$. On sait que Teucros fut le demi-frère d'Ajax ${ }^{235}$, et que les héros Phaiax et Nauseiros (à identifier avec Nausithoos, qui apparaît chez Plutarque) sont les deux pilotes que Sciros de Salamine envoya à Thésée, sur le point de s'embarquer pour aller tuer le Minotaure. De retour à Athènes après son expédition crétoise, Thésée institua en faveur de ses pilotes la fête des Kybernèsia et leur fit édifier des hérôa au Phalère, près du sanctuaire de Sciros ${ }^{236}$.

Quant à Athéna Skiras, elle avait des sanctuaires au Phalère en Attique, et, d'après Hérodote, à Salamine ${ }^{237}$. Ce dernier témoignage plaide en faveur d'une divinité ayant un ancrage dans l'île située en face d'Athènes ${ }^{238}$. Cependant, l'origine de l'épiclèse Skiras donnée à Athéna restait débattue dans l'Antiquité. Strabon met en rapport cette épiclèse avec Skiras, ancienne dénomination de Salamine ${ }^{239}$. Plutarque évoque dans l'île le promontoire de Sciradion, autour duquel il y aurait

234 P.J. Rhodes, R. Osborne (éds.), op. cit., no 37, 1. 91 (Phaiax, Teucros, Nauseiros), 1. 93 (Athéna Skiras et Sciros). Les décrets du génos des Salaminiens étaient aussi exposés dans le sanctuaire d'Athéna Skiras: $I G \mathrm{II}^{2}$ 1232, 1. 15-16.

235 F. Schmidt, s.v. «Teukros», RE V A, 1934, col. 1123-1131; Kearns, Heroes, p. 200.

236 Philochore, FGrHist 328 F 111 (apud Plutarque, Thésée, 17, 6-7). W. S. Ferguson, op. cit., p. 25, pense que le nom de Nausithoos mentionné chez Plutarque est une altération de la forme Nauseiros indiquée par le décret émanant du génos des Salaminiens. En revanche, Kearns, Heroes, p. 38-39, 106-107, 187, estime qu'il s'agit de deux noms différents, utilisés pour désigner le même héros. $C f$. Polignac, Ajax l'Athénien, p. 116-120.

237 Hérodote, VIII, 94. D’après Calame, Thésée $e^{2}$, p. 147-148, 337-348, il y aurait eu deux sanctuaires d'Athéna Skiras en Attique, l'un au Phalère et l'autre à Sciron, lieu situé au bord de la Voie Sacrée qui reliait Athènes à Éleusis. Sur le culte d'Athéna Skiras et la fête des Skira (ou Skirophoria), voir aussi Parker, Polytheism and Society, p. 172-177, 480; C. Sourvinou-Inwood, Athenian Myths and Festivals. Aglauros, Erechthus, Plynteria, Panathenia, Dionysia, Oxford 2011, p. 172-175.

238 Hanell, Megarische Studien, p. 40-41; J.N. Bremmer, «The Sacrifice of Pregnant Animals », in Greek Sacrificial Ritual, Olympian and Chtonian. Proceedings of the Sixth International Seminar on Ancient Greek Cult, organized by the Department of Classical Archaeology and Ancient History (Göteborg University, 25-27 April 1997), R. Hägg et B. Alroth (éds.), Stockholm 2005, p. 161. Contra N. Robertson, op. cit., p. 127, qui rejette la relation entre Athéna Skiras et Salamine. D'après Robertson, les divers sanctuaires d'Athéna Skiras auraient été fondés à une époque ancienne et de manière autonome.

239 Strabon, IX, 1, 9, C 393. 
eu une confrontation entre les Athéniens de Solon et les Mégariens. Cet événement était rappelé par divers rites à l'époque impériale ${ }^{240}$. Selon Philochore et Pausanias, Athéna Skiras tirerait son nom de Sciros, un devin de Dodone mort à Éleusis, en combattant contre Érechtée. Le Mégarien Praxiôn estime, quant à lui, que l'épiclèse Skiras vient de Sciron, sans doute le héros mégarien tué par Thésée ${ }^{241}$.

On connaît par ailleurs divers héros ayant des noms bâtis sur la racine skir- et qui ont des liens avec Salamine ou font l'objet de polémique entre les mythographes athéniens et mégariens. C'est le cas d'abord du héros Sciros, fils de Poséidon et époux de la nymphe Salamis, qui fut l'auteur du synœcisme de Salamine ${ }^{242}$. On trouve probablement une référence à ce héros salaminien dans un décret athénien de 213/2, qui honore les éphèbes de l'année précédente. Ce document atteste qu'étant arrivés à Salamine, les éphèbes firent un sacrifice lors des Aiantéia, menèrent une procession pour la Démocratie et honorèrent le héros éponyme de l'île par une course aux flambeaux ${ }^{243}$. On pourrait penser que ce héros n'est autre qu'Ajax ${ }^{244}$. Mais cette possibilité reste très incertaine, car Ajax n'est pas l'éponyme de l'île, mais celui de la tribu Aiantis. Selon moi, on n'aurait pas tort d'identifier l'éponyme en question à Sciros, l'île étant appelée, on l'a vu, ancienne-

240 Plutarque, Solon, 9, 6; cf. Polignac, Divinités, p. 29-30. F. Geyer, s.v. «Skiradion», RE III A, 1927, col. 533, localise le sanctuaire salaminien d'Athéna Skiras sur le cap de Sciradion. Sur un éventuel lien entre les rites évoqués par Plutarque aux abords de Sciradion et la célébration d'Athéna Skiras, d'Ajax et d'Enyalios, voir aussi L. Deubner, op. cit., p. 218-219; Parker, Polytheism and Society, p. 484.

241 Philochore, FGrHist 328 F 14; Pausanias, I, 36, 4 ; Praxiôn de Mégare, FGrHist 484 F 1. De même, une scholie nous apprend que ce fut Athéna Skiras qui tua le brigand Sciron : scholie à Clément d'Alexandrie, Protreptique, II, 17, p. 302 (éd. O. Stählin) :

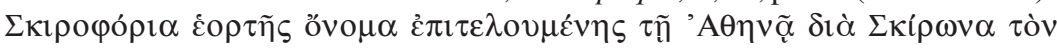

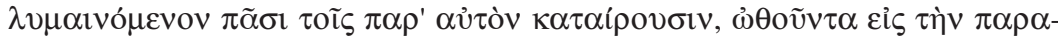

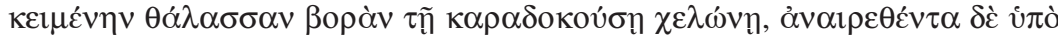
$\tau \tilde{\eta} \varsigma^{\prime} A \theta \eta \nu \tilde{\alpha} \varsigma$.

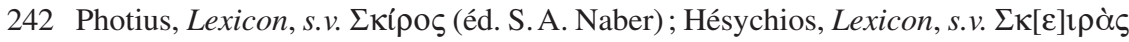
'A $\theta \eta v \tilde{\alpha}$ (éd. M. Schmidt).

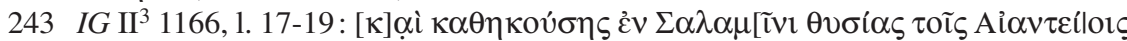

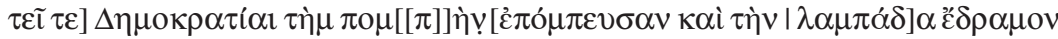

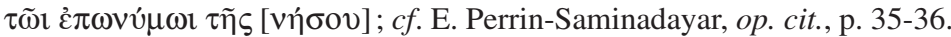

244 Cette identification est envisagée par V.N. Bardani et S. T. Tracy, qui notent dans

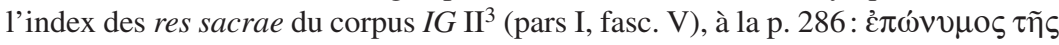
vท́бov scil. Aias. 
ment Skiras $^{245}$. On aura donc célébré à Salamine au II $^{\mathrm{e}}$ siècle les deux héros Sciros et Ajax à la fois, tout comme à Athènes même.

Il y a ensuite le héros mégarien Sciron, dont Athènes s'empare, en le reliant à la geste de Thésée. Sciron devient ainsi dans la mythologie athénienne le célèbre brigand, qui, après avoir dérobé les voyageurs, les précipitait dans la mer du haut des roches qui surplombent le golfe Saronique, entre Corinthe et Mégare (voir carte 2). Thésée, on le sait, lui fit subir le même sort, et les roches seront désormais appelées Scironiennes ${ }^{246}$. Cette étymologie laisse penser que le nom du héros serait issu de бкĩpos, terme qui désigne, entre autre, le gypse ou le calcaire $^{247}$.

D'autre part, les Mégariens tenaient Sciron pour un héros, tué par Thésée lorsque ce dernier s'emparait d'Éleusis. Il était le gendre de Cychreus, le premier roi de Salamine, beau-père d'Éaque, grand-père de Pélée et de Télamon, nés tous d'Endéis, fille de Sciron et de Chariclo. Ainsi, arrière-grand-père d'Ajax, ce Sciron peut être considéré comme l'incarnation des prétentions mégariennes sur Salamine ${ }^{248}$. Ces prétentions sont renforcées par la présence du sanctuaire d'Athéna Aiantis (d'Ajax) sur l'acropole d'Alcathoos. À en croire Pausanias, la statue qui abritait le temple d'Athéna Aiantis datait du règne d'Ajax sur la Mégaride, car celui-ci en tant que fils de Télamon et de Périboia (appelée aussi Ériboia ou Méliboia), fut le successeur d'Alcathoos, son grand-

245 Calame, Thésée $e^{2}$, p. 353.

246 Bacchylide, Dithyrambes, IV, 2, 24-25; Pausanias, I, 3, 1; 44, 8; Strabon, IX, 1, 4, C 391 ; Plutarque, Thésée, 10, 1; 25, 6; Diodore, IV, 59.

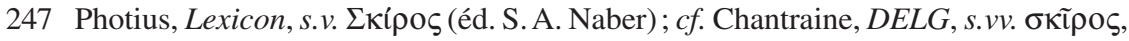

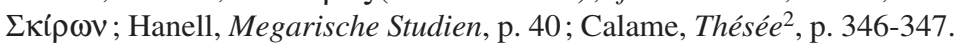

248 Anonyme de Mégare, FGrHist 487 F 1 (apud Plutarque, Thésée, 10, 1-4). Sur les héros Sciros et Sciron, voir Highbarger, Megara, p. 85; M.C. van der Kolf, s.v. «Skiron», RE III A, 1927, col. 537-545; Hanell, Megarische Studien, p. 40-48; F. Vian, «Génies des passes et des défilés», RA 39, 1952, p. 145-149; A. Brelich, «Theseus e i suoi avversari», SMSR 27, 1956, p. 139-140; Piccirilli, MEGARIKA, p. 98-103; Kearns, Heroes, p. 197-198; Antonetti, Confini della Megaride, p. 543544 ; Calame, Thésée ${ }^{2}$, p. 90-91, 340-346. En se rapportant explicitement aux cas de Thésée et de Sciron, A. Brelich, Gli eroi greci. Un problema storico-religioso, Roma 1978 , p. 40, remarquait « una tendenza a difendere il prestigio della propria città può anche contribuire alla «epurazione » di certi miti degli eroi locali e, viceversa, in una presentazione malevola dei loro avversari, campioni di città nemiche». 
père maternel ${ }^{249}$. À cette dernière légende, les Athéniens répondaient que Périboia, la mère d'Ajax, n'a pas été l'épouse de Télamon, mais de Thésée $\mathrm{e}^{250}$.

À l'image des Athéniens, les Mégariens célébrèrent d'autres héros plus ou moins directement associés à Salamine. Sur la foi de la documentation onomastique, on peut penser que Télamon, le petit-fils de Sciron et le père d'Ajax, fut honoré à Mégare à l'époque hellénistique ${ }^{251}$. On connaît aussi à la même époque un Kynosouros, héros éponyme d'une subdivision civique mégarienne (la «centaine» Kynosouris), ainsi que probablement de la presqu'île de Kynosoura à Salamine ${ }^{252}$. Une inscription du début du $\mathrm{V}^{\mathrm{e}}$ siècle mentionne le héros, Naustolos, le «conducteur de navire». Celui-ci rappelle le pilote Nauseiros, à qui le génos des Salaminiens offre un sacrifice. Dans l'inscription de Mégare, Naustolos apparaît en compagnie de cinq autres héros marins (Neôridès/Neôris, Limenouchos, Halirothios, Anchialos, Euryalos), indice du rapport étroit que les Mégariens entretenaient avec la mer et la navigation ${ }^{253}$. On notera que l'un de ces héros, Halirothios, est connu à Athènes sous le nom d'Halirrothios, en tant que fils de Poséidon et de la nymphe Eurytè ${ }^{254}$.

En outre, les mythographes gardèrent la trace des rivalités entre les Athéniens et les Mégariens au sujet d'Éleusis. Ainsi, selon Andron d'Halicarnasse, le roi mégarien Nisos eut en sa possession la plaine

249 Pausanias, I, 42, 4 ; cf. Antonetti, Panthéon de Mégare, p. 42. Périboia/Ériboia apparaît en tant que fille d'Alcathoos et épouse de Télamon chez Xénophon, Art de la chasse, I, 9; Apollodore, III, 12, 7; et Diodore, IV, 72 (qui attribue aussi à Ériboia une origine athénienne). Cf. Polignac, Ajax l'Athénien, p. 115.

250 Istros, FGrHist 334 F 10; Plutarque, Thésée, 29, 1 ; cf. J. Toepffer, Attische Genealogie, Berlin 1889, p. 271, 274; H. Lewy, s.v. «Periboia» 10, in Roscher, Lexikon, III, 2, col. 1961-1962.

251 Télamon est un nom très rare: on en dénombre une occurrence à Mégare ( $L G P N$ III B, s.v. Tع $\lambda \alpha \mu \omega ́ v$ 1, ca. 315-280) et cinq à Chersonèse Taurique ( $L G P N$ IV, s.v.

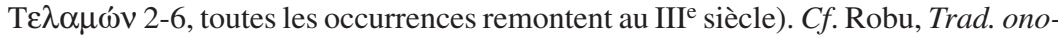
mastiques, p. 281-293.

252 Voir supra, chapitre I.1.1.

253 W. Peek, «Griechische Inschriften», $\operatorname{MDAI}(A)$ 59, 1934, p. 52-54, n ${ }^{\circ} 10$, pl. IV 3 (SEG XIII, 300); cf. Jeffery, $L S A G^{2}$, p. 136-137, pl. 22, n 4 ; D. Knoepfler, «Poséi-

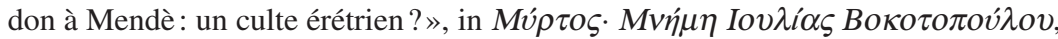
P. Adam-Veleni (éd.), Thessalonique 2000, p. 340-342; A. Robu, «Le culte de Poséidon à Mégare et dans ses colonies », Dacia N.S. 57, 2013, p. 72-74.

254 P. Friedländer, s.v. «Halirrhothios» 1, RE VII, 1912, col. 2268-2270; Kearns, Heroes, p. 19-20, 144-145. 
éleusienne de Thriasia. En revanche, pour l'atthidographe Philochore, Éleusis appartient à l'Attique depuis le règne de Cécrops I ${ }^{255}$. D'après une tradition mégarienne, Thésée s'empara d'Éleusis, qui était alors en la possession des Mégariens, après avoir trompé Dioclès, l'archôn de la région; et il tua aussi Sciron à ce moment ${ }^{256}$. L'Éleusinien Dioclès est honoré à Mégare: dans les Acharniens d'Aristophane un Mégarien jure par Dioclès, héros qui est célébré au début du printemps dans la cité de l'isthme par des fêtes, appelées les Diokleia $^{257}$. On connaît aussi un fils de Sciron, appelé Halykos, qui combattit aux cotés des Dioscures et périt à Aphidnai en Attique; il donna ensuite son nom à un lieu de la Mégaride. Héréas de Mégare attribua la responsabilité de sa mort à Thésée ${ }^{258}$.

Du reste, les généalogies royales font état des rivalités entre Athènes et Mégare et plusieurs traditions soutiennent une possession athénienne de la Mégaride pré-dorienne. Tout d'abord, les atthidographes insérèrent le roi athénien Pandion II dans la liste des rois mégariens. Chassé d'Athènes, Pandion II s'exila à Mégare, où il épousa la fille du roi Pylas, à qui il succéda. À la mort de Pandion II, Mégare revint à un de ses quatre fils, Nisos ${ }^{259}$. Sophocle, dans sa tragédie perdue Égée, faisait allusion à cette légende, en indiquant que, après le partage effectué par Pandion, Nisos avait régné sur la Mégaride ${ }^{260}$. Nisos lutte en tant que roi de Mégare à côté des Athéniens pendant la guerre légendaire contre Minos.

255 Andron, FGrHist 10 F 14 (apud Strabon, IX, 1, 6, C 392); Philochore, FGrHist 328 F 94 (apud Strabon, IX, 1, 20, C 397); cf. Piccirilli, MEGARIKA, p. 102; Daverio Rocchi, Frontiera e confini, p. 193.

256 Anonyme de Mégare, FGrHist 487 F 1 (apud Plutarque, Thésée, 10, 1-4).

257 Aristophane, Acharniens, 774; Théocrite, XII, 27-34; Scholie à Pindare, Olympiques, XIII, 156. Sur le culte de Dioclès à Mégare, voir Highbarger, Megara, p. 57-58; Calame, Thésée $e^{2}$, p. 421-422.

258 Plutarque, Thésée, 32, 6-7, conteste l'opinion d'Héréas, FGrHist 486 F 2 sur l'implication de Thésée dans la mort d'Halykos. Car, d'après lui, si le héros athénien était présent à Aphidnai, sa mère n'aurait pas été enlevée par les Dioscures.

259 Pausanias, I, 5, 3; 39, 4; II, 34, 7; Apollodore, III, 15, 5 et 8. Sur cette légende, voir aussi Strabon, IX, 1, 6, C 392; IX, 1, 11, C 394, qui cite parmi ses sources Philochore, FGrHist 328 F 107. On distingue, dans les listes de rois d'Athènes, Pandion I, fils d'Érichthonios, de son homonyme, Pandion II, fils de Cécrops II et père d'Égée. Un de ces rois donna son nom à l'une des dix tribus clisthéniennes, soit la Pandionis. Voir à cet égard, U. Kron, op. cit., p. 104-119.

260 Sophocle, Égée, fr. 24 (éd. S. Radt). 
Après sa mort, les Athéniens l'emmènent dans leur ville et l'enterrèrent derrière le Lycée ${ }^{261}$. Nisos est l'éponyme de Nisaia, le port de Mégare ${ }^{262}$, et l'on sait que ce héros archégète avait un lieu de culte à Nisaia ${ }^{263}$. Dans ce cadre, le transfert du corps de Nisos depuis Mégare à Athènes reflète une fois de plus les prétentions athéniennes sur la Mégaride ${ }^{264}$.

Les Mégariens tenaient Pandion pour un héros. Celui-ci avait un hérôon dans le secteur nord de la ville, au pied nord-est de l'acropole d'Alcathoos, sa tombe se trouvait en revanche sur le promontoire d'Athéna Aithyia ${ }^{265}$. On place habituellement ce cap aux abords de Nisaia, au pied de la colline de Saint-Georges ${ }^{266}$. On célébrait donc dans le port de Mégare deux héros unis par des liens de parenté, Pandion et son fils, Nisos. Les mythographes mégariens ne font en revanche aucune mention du règne de Pandion II sur Mégare. D'après eux, l'accès de Nisos à la royauté se passa ainsi: Sciron, fils du roi Pylas de Mégare, épousa la fille de Pandion d'Athènes et entra en conflit avec Nisos, le fils de Pandion, au sujet de l'héritage de son père. Suite à l'arbitrage d'Éaque d'Égine, Sciron devint chef des armées et Nisos roi de Mégare. On rejetait également à Mégare la tradition de la prise de la ville par Minos sous le règne de $\operatorname{Nisos}^{267}$. Ce qui n'est guère surprenant, car cette légende faisait de Mégare une dépendance athénienne ${ }^{268}$. D'ailleurs, pour les Athéniens, Mégare resta sujette d'Athènes même après le règne de Nisos. Preuve en serait le fait que le roi mégarien

261 Pausanias, I, 19, 4.

262 Pausanias, I, 39, 4; 44, 3. Sur Mégare en tant que ville de Nisos, voir la mention de

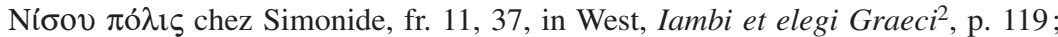

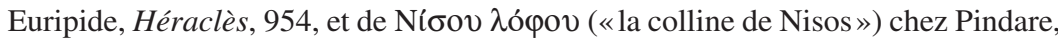
Pythiques, IX, 161; Néméennes, V, 85. Cf. Highbarger, Megara, p. 74, 88-94.

263 Thucydide, IV, 118, 4.

264 Kearns, Heroes, p. 116, 188.

265 Pausanias, I, 5, 3; 41, 6; Hésychios, Lexicon, s.v. ع̉v $\delta ’$ Al̈ $\theta v 1 \alpha$ (éd. K. Latte). Sur la localisation de l'hérôon de Pandion dans la ville de Mégare, voir A. Muller, «Megarika», BCH 105, 1981, p. 207-211.

266 M. Mayer, «Mythistorica. I. Megarische Sagen», Hermes 27, 1892, p. 484, n. 1; Highbarger, Megara, p. 45; Smith, Megaris, p. 21-24.

267 Pausanias, I, 39, 6; 44, 6. Sur les rois Pandion II et Nisos, voir Highbarger, Megara, p. 72-77, qui inclut Pandion II dans la liste de rois mégariens, et aussi Hanell, Megarische Studien, p. 18-21, 35-40; Kearns, Heroes, p. 188, 191-192; Legon, Megara Pol. Hist., p. 42.

$268 C f$. Piccirilli, MEGARIKA, p. 87. 
Alcathoos envoya sa fille Périboia pour se rendre aux côtés de Thésée en Crète: elle fit partie des sept jeunes filles qui avec les sept jeunes gens constituaient le tribut imposé par Minos à Athènes ${ }^{269}$.

Plutarque rapporte que ce fut Thésée qui unit solidement la Mégaride à l'Attique. Le héros athénien aurait aussi dressé la stèle dont l'inscription indiquait l'isthme comme frontière entre les Péloponnésiens et les Ioniens et il aurait été le premier à établir des jeux en l'honneur de Poséidon dans l'isthme. Selon cette tradition, les concours isthmiques avaient pour but d'expier la mort de Sciron, son parent, ce dernier étant le fils de Canéthos et d'Hénioché, fille de Pithée ${ }^{270}$.

D'après Taylor, le fait de soutenir l'appartenance de Mégare à l'Attique permettait aux mythographes de renforcer les prétentions d'Athènes sur Salamine et de combattre l'opinion selon laquelle l'île appartenait à Mégare. De fait, si les Athéniens avaient eu la Mégaride en leur possession, cela signifiait que Salamine leur revenait de droit, les deux territoires étant à l'origine des pays ioniens ${ }^{271}$. Néanmoins, il faut avouer qu'il reste difficile de mettre en relation les traditions relatives à la mainmise des Athéniens sur Mégare avec un épisode exact de la guerre entre les deux cités ${ }^{272}$. Car si les conflits de l'époque archaïque ont laissé des traces dans les mythologies des deux cités, les récits mentionnant les généalogies et les exploits des divers héros n'ont pas tous été rédigés

269 Bacchylide, Dithyrambes, III, 1, 14-15; Pausanias, I, 17, 3 ; 42, 2; Servius, ad Aen., VI, 21; $c f$. Hanell, Megarische Studien, p. 45-46.

270 Plutarque, Thésée, 25, 4-6. Sur l'isthme en tant que frontière de l'Attique, voir aussi les témoignages de Platon, Critias, 110 d-e, et de Strabon, IX, 1, 6, C 392. Pour l'analyse des mythes concernant les exploits de Thésée dans l'isthme, voir A. E. Raubitschek, "Theseus at the Isthmus», in Corinthiaca. Studies in Honor of Darrell A. Amyx, M. A. Del Chiaro (éd.), Columbia 1986, p. 1-2; E.R. Gebhard, «The Early Stadium at Isthmia and the Founding of the Isthmian Games», in Proceedings of an International Symposium on the Olympic Games (5-9 september 1988), W. Culson et H. Kyrieleis (éds.), Athens 1992, p. 73-79; Calame, Thésée ${ }^{2}$, p. 223-225 ; 421-424; Morgan, Isthmia VIII, p. 422-428.

271 M. C. Taylor, op. cit., p. 22-23. Cf. F. Jacoby, Atthis. The Local Chronicles of Ancient Athens, Oxford 1949, p. 122-123.

272 M.P. Nilsson, «Political Propaganda in Sixth Century Athens », in Studies presented to D. M. Robinson, vol. II, G. E. Mylonas et D. Raymond (éds.), Saint Louis 1953, p. 746-747; idem, Cults, Myths, Oracles, and Politics in Ancient Greece, New York 1972, p. 54-59, suggère que les mythes reliant l'Athénien Pandion et son fils, Nisos, à Mégare remontent à l'époque de la conquête de Nisaia par Pisistrate. $C f$. Jacoby, FGrHist III b Supplement (Text), p. 430-431. 
pour appuyer une action politique. Certains ne sont probablement que le résultat de l'émulation entre des cités voisines. Pour cet état des choses, on notera qu'au ${ }^{\text {er }}$ siècle, les Mégariens, désireux de montrer à MarcAntoine quelque chose qui aurait pu rivaliser avec Athènes, lui firent visiter la salle du Conseil. Mais sans succès, puisque le général romain qualifia cet édifice public de $\mu 1 \kappa \rho o ́ \varsigma$ («petit») et de $\sigma \alpha \pi \rho o ́ \varsigma$ («délabré») ${ }^{273}$. Les rivalités locales pourraient également expliquer la décision prise par les Mégariens, à l'époque d'Hadrien, d'interdire aux Athéniens la participation aux «Petits Pythia». À en croire Philostrate, les deux peuples se disputaient alors si violemment, comme si le célèbre «décret mégarien» (l'une des causes de la guerre du Péloponnèse) venait d'être promulgué à Athènes. Toutefois, grâce à l'intervention du sophiste Markos de Byzance, le conflit entre les deux cités voisines fut réglé. On peut se demander si cette dispute autour de la participation à un concours local ne serait pas vouée à renforcer une rivalité ancienne, en s'appuyant sur des références historiques et mythiques ${ }^{274}$.

\section{I.2.3 Les enjeux de la possession de Salamine}

Après avoir fait état des mythes engendrés par les conflits et les rivalités entre Mégare et Athènes, il convient de s'interroger maintenant sur les enjeux de la possession de Salamine. Il importe d'emblée d'éviter tout anachronisme dans l'interprétation de cette guerre. Ainsi, malgré l'avis de Trever, on n'a aucune raison de penser qu'en occupant Salamine, les Athéniens arrivèrent à contrôler le commerce des Mégariens, et que cette perte entraîna la décadence économique et politique de la cité de l'isthme ${ }^{275}$. De même, contrairement à ce qu' affirme Aratowski, la possession de l'île ne permettait pas à Athènes de bloquer le port

273 Plutarque, Marc-Antoine, 23, 3.

274 Philostrate, Vies des sophistes, I, 24, 529. Pour la référence aux origines ethniques et aux ancêtres dans les cités péloponnésiennes de l'époque impériale, voir Y. Lafond, La mémoire des cités dans le Péloponnèse d'époque romaine (II siècle avant J.-C.III ${ }^{e}$ siècle après J.-C.), Rennes 2006, p. 137-180.

275 Trever, Megara, p. 122, écrit: «The possession of Salamis determined which should dominate the Saronic Gulf, and therefore which should govern the trade of the other. [...] Whichever state held it would be a constant menace to the other, and the defeated state was fated to economic and political decadence». 
mégarien de Nisaia ${ }^{276}$; pour ce faire, on voit que pendant la guerre du Péloponnèse les Athéniens durent occuper l'île de Minôa, située en face de Nisaia ${ }^{277}$. Il ne faut pas oublier non plus qu'Athènes n'est pas une puissance maritime importante avant le programme de construction des trières initié par Thémistocle en $483^{278}$. De surcroît, bien que la nouvelle possession ait facilité le contrôle du golfe d'Éleusis par Athènes ${ }^{279}$, French a sans nul doute exagéré l'importance commerciale et stratégique de Salamine, en affirmant que la guerre visait à sécuriser l'accès aux ports du sud de l'Attique, ainsi qu'à ouvrir aux navires athéniens la route vers l'isthme de Corinthe ${ }^{280}$. De fait, si l'on pouvait depuis Salamine menacer plus facilement l'adversaire, l'occupation de l'île n'était

276 B. Aratowski, op. cit., p. 789, note: «If Athens controlled Salamis, the chief port of Megara, Nisaea, would be helpless; if Megara controlled Salamis, the straits could be effectively blockaded and a good part of Attic mainland rendered inaccessible from the sea». Contra A. Andrews, op. cit., p. 374, qui note «it may be an anachronism to suppose that an offshore island in enemy hands would severely inhibit the other maritime activity of an Archaic state». Cf. L. Piccirilli, ASNP serie iii, 8, 1, 1978, p. 12.

277 Thucydide, III, 51, 2-3; IV, 118, 4. La localisation de Minôa est objet de controverses, les modernes ayant situé cette île à différents endroits aux abords d'actuelle Pachi (l'antique Nisaia): sur la colline Paliokastro [T. Spratt, «Remarks on the Supposed Situation of Minoa and Nisaea», The Journal of the Royal Geographical Society 8, 1838, p. 205-209; = in Thucydides, The History of the Peloponnesian War, T. Arnold (éd.), Oxford 1847, p. 540-543; H. G. Lolling, «Nisäa und Minoa», $\operatorname{MDAI}(A)$ 5, 1880, p. 16], sur la petite île de Pachaki en face de Pachi (E. Burnof, «Nisée et Minoa», CRAI, 1875, 3, p. 209-221), sur la colline de Saint-Georges [F. Bölte, G. Weicker, «Nisaia und Minoa», MDAI(A) 29, 1904, p. 90-91], ou encore, comme on a tendance à privilégier aujourd' hui, à l'est de Pachi dans la région de la presqu'île de Teicho (W. M. Leake, Travels in Northern Greece, vol. II, London 1835, p. 401-402; A. J. Beattie, «Nisaea und Minoa», RhM 103, 1960, p. 27-28,

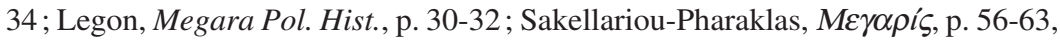
et fig. 31 ; Smith, Megaris, p. 153-154). Pour l'examen de ces hypothèses, voir Bernier, Ports de la Mégaride, p. 11-122; A. Robu, Dacia N. S. 57, 2013, p. 67-68.

278 C. J. Haas, «Athenian Naval Power before Themistocles», Historia 34, 1985, p. 2946; P. de Souza, «Towards Thalassocracy? Archaic Greek Naval Developments», in Archaic Greece: New Approaches and New Evidence, N. Fisher et H. van Wees (éds.), London 1998, p. 285 ; L. Scott, «Where the Polis Navies in Archaic Greece?», in The Sea in Antiquity, G. J. Olivier et al. (éds.), Oxford 2000, p. 93-115.

279 C.J. Haas, op. cit., p. 42.

280 A. French, op. cit., p. 238. L'hypothèse de French a été acceptée par Moggi, Salamina, p. 7, et par Piccirilli, Arbitrati, p. 49-50. Contra R. Sealey, op. cit., p. 127. 
pas en mesure de porter un coup majeur à l'activité navale d'aucune des deux cités ${ }^{281}$.

En réalité, plusieurs documents attestent que le partage de lots de terre par de jeunes mégariens ou athéniens constitue l'un des enjeux principaux de la dispute ${ }^{282}$. D'après Plutarque, ce sont surtout les jeunes hommes (véol) d'Athènes qui désirent recommencer la guerre avec Mégare et c'est à eux que Solon pense quand il prononce son discours sur Salamine ${ }^{283}$. Or les guerres et la fondation des apoikiai constituent autant de moyens pour la cité de se débarrasser de ces jeunes hommes ${ }^{284}$. D'ailleurs, l'une des versions de la prise de Salamine assimile Solon à un véritable fondateur (oikistès): il reçoit d'abord un oracle de Delphes qui lui demande de sacrifier aux héros fondateurs du pays. Il débarque ensuite à Salamine avec cinq cents volontaires auxquels un décret avait garanti la possession de l'île en cas de victoire ${ }^{285}$. La version mégarienne privilégie aussi l'idée de l'importance des terres dans la dispute: la mention des clérouques ( $\kappa \lambda \eta \rho о \tilde{\chi} \chi 01)$ de Mégare par Pausanias nous montre qu'il s'agissait d'une occupation de l'île, suivie d'un partage des lots de terre ${ }^{286}$. On rappelle que Salamine est vantée par Théophraste pour la richesse de ses récoltes qui, d'après lui, dépassent largement celles du reste de l'Attique et de la zone littorale de la Mégaride ${ }^{287}$.

On sait aussi qu'Athènes se confronte à la fin de l'époque archaïque avec un manque de terres. L'envoi des colons à Salamine, de même

281 Legon, Megara Pol. Hist., p. 130-131.

282 F. J. Frost, Historia 33, 1984, p. 293, note: «A review of all the wars fought in archaic Greece will show that virtually every battle was fought for land». $C f$. Trever, Megara, p. 122.

283 Plutarque, Solon, 8, 1.

284 Sur le danger potentiel constitué par des groupes de jeunes gens pour la paix sociale de la cité, voir E. Scheid-Tissinier, «Les prétendants de l'Odyssée, une génération perdue», in L'initiation. Actes du colloque de Montpellier (11-14 avril 1991), A. Moreau (éd.), Montpellier 1992, p. 115-118; eadem, «Télémaque et les prétendants. Les véor d'Ithaque», AC 62, 1993, p. 20-22. Cf. M. Steinrück, Iambos. Studien zum Publikum einer Gattung in der frühgriechischen Literatur, Zürich et al. 2000, p. 53-65; idem, The Suitors in the Odyssey. The Clash between Homer and Archilochus, New York et al. 2008, p. 15-17, 63-66.

285 Plutarque, Solon, 9, 1-2; cf. R. Nicolai, op. cit., p. 8.

286 Pausanias, I, 40, 5 ; $c f$. Figueira, Athens and Aigina, p. 44-46.

287 Théophraste, Recherches sur les plantes, II, 8, 11. 
qu'à Chalcis $(c a .506)^{288}$ et à Lemnos $(c a .499)^{289}$, peut être considéré comme une réponse aux problèmes fonciers de l'Attique ${ }^{290}$. À ce propos, Stahl considère que la colonisation de Salamine a offert aux Athéniens un moyen efficace de résoudre «ein Übervölkerungsproblem» et d'assurer en même temps la défense du sanctuaire d'Éleusis et du port d'Athènes ${ }^{291}$. Après l'arbitrage spartiate, le décret $I G \mathrm{I}^{3} 1$ (ca. 510-500) confirme l'attribution de lots de terres à des Athéniens qui résident sur l'île, mais ces derniers n'ont pas le droit de mettre en location leurs propriétés. Cette interdiction suggère une sorte de contrôle exercé par la cité sur la possession et la transmission des terres à Salamine. Figueira pense que cette mesure s'explique par le désir des Athéniens d'avoir davantage de soldats ${ }^{292}$. Cette hypothèse semble être appuyée par les clauses financières et militaires mentionnées par le décret: les allocataires de terres doivent payer leurs taxes et remplir leurs obligations militaires. La cité s'engage à son tour à distribuer aux résidents sur l'île des armes pour une valeur de trente drachmes. Ainsi, les Athéniens désirent d'une part avoir de nouveaux lots de terres et, d'autre part, préserver le contrôle de la distribution de ces lots et prévenir d'autres attaques mégariennes ${ }^{293}$.

Du reste, si l'on accepte la datation de la première «démocratie» mégarienne au $\mathrm{VI}^{\mathrm{e}}$ siècle (sans doute dans la première moitié du $\mathrm{VI}^{\mathrm{e}}$ siècle $)^{294}$, l'on observe que c'est sous ce régime qu'ont eu lieu les principaux combats entre Mégare et Athènes. C'était probablement une période de troubles internes et d'actions militaires externes. On voit chez Plutarque et dans le recueil du poète mégarien Théognis que le régime «démocratique» ne jouissait pas d'une bonne réputation et que la violence

288 Hérodote, V, 77; IG $\mathrm{I}^{3} 501 ; c f$. K. Reber, M.H. Hansen, P. Ducrey, s.v. «Chalkis », in Hansen-Nielsen (éds.), Inventory, p. 648.

289 Hérodote, VI, 136; 140; IG I $\mathrm{I}^{3} 522$ bis, 1466; cf. G. Reger, s.v. «Lemnos», in Hansen-Nielsen (éds.), Inventory, p. 756.

290 D. M. Lewis, «Cleisthenes and Attica», Historia 12, 1963, p. 38 (= Selected Papers in Greek and Near Eastern History, Oxford 1997, p. 96).

291 M. Stahl, Aristokraten und Tyrannen im archaischen Athen. Untersuchungen zur Überlieferung, zur Sozialstruktur und zur Entstehung des Staates, Stuttgart 1987, p. 205 ; $c f$. F. J. Frost, $A n c W 30,1999$, p. 133.

292 Figueira, Athens and Aigina, p. 184; cf. Moggi, Salamina, p. 3-5.

293 R. Sealey, op. cit., p. 147, et Figueira, Chronological Table, p. 302, considèrent le décret $I G \mathrm{I}^{3} 1$, comme une mesure athénienne pour défendre l'île.

294 Voir infra, chapitres I.3.1.-2. 
et les conflits entre les groupes de philoi étaient fréquents à Mégare au $\mathrm{VI}^{\mathrm{e}}$ siècle ${ }^{295}$. Rappelons que, suivant Pausanias, les Mégariens pensaient que ce fut la bande des Dorykleioi qui livra l'île à Athènes (voir ci-dessus). À cet égard, Figueira estime que si des bandes de guerriers conduisirent les opérations militaires, cela peut en partie expliquer l'insistance de Théognis sur les philoi ${ }^{296}$. Je pense à mon tour que l'on n'aurait pas tort de considérer que ce sont les groupes de philoi qui ont probablement fait la guerre pour Salamine, une guerre longue, qui a marqué les relations entre Athènes et Mégare pendant tout le $\mathrm{VI}^{\mathrm{e}}$ siècle.

Outre la terre, la gloire a sans doute constitué une autre raison de la guerre. Car la supériorité militaire acquise par des jeunes guerriers lors des combats contre leurs voisins était une preuve de prestige pour toute la communauté297. N'oublions pas que, selon Hérodote, l'occupation de Nisaia, le port de Mégare, par Pisistrate, valut à celui-ci la gloire nécessaire pour imposer sa tyrannie à Athènes ${ }^{298}$.

Il convient également de signaler ici une autre interprétation avancée par les modernes à propos de l'affaire de Salamine. Ainsi, Calame qualifie les guerres entre Athènes et Mégare de «presque rituelles» et Piccirilli leur attribue une composante religieuse et agonale ${ }^{299}$. De fait, les récits évoquant la victoire de Solon ${ }^{300}$ ou celle de Pisistrate ${ }^{301}$ contre les Mégariens rapportent que ces derniers furent capturés par de jeunes Athéniens déguisés en femmes. Or le thème du travestissement féminin des jeunes gens tient d'un contexte initiatique, faisant référence aux rites d'adolescence. Dans ce cadre, que ce soit par la participation des jeunes et l'usage du déguisement pour capturer l'ennemi (comme dans le cas du

295 Plutarque, Questions grecques, XVIII (= Moralia 295 D); LIX (= Moralia 304 EF). Théognis, 209-210, 333-350, 825-830, 1197-1202, indique que lui aussi a été dépossédé de ses biens et obligé de partir en exil. Pour la violence des conflits à Mégare, voir Van Wees, Megara's Mafiosi, p. 52-67.

296 Figueira, Chronological Table, p. 286. Pour la mention des philoi, voir Théognis, 93-100, 213-217, 309-312, 963-970, 1164 a-h.

297 H. van Wees, Status Warriors. War, Violence and Society in Homer and History, Amsterdam 1992, p. 255.

298 Hérodote, I, 59.

299 Calame, Thésée ${ }^{2}$, p. 225, 344-345; Piccirilli, Solone, p. 12. Cf. Polignac, Ajax l'Athénien, p. 129-130.

300 Plutarque, Solon, 8, 4-6; Polyen, I, 20, 2; cf. Élien, Histoire variée, VII, 19.

301 Justin, II, 8, 1-5; Énée le Tacticien, Poliorcétique, IV, 8-11; Frontin, Strat., II, 9, 9. Cf. M. C. Taylor, op. cit., p. 28-33. 
déguisement en filles des jeunes spartiates dans la guerre de Messénie), ou par le désir de faire des prisonniers pour les libérer ensuite en vertu d'accords ${ }^{302}$, ou encore par les cultes que les Athéniens et les Mégariens rendaient en l'honneur des héros et des divinités originaires de Salamine, la guerre du $\mathrm{VI}^{\mathrm{e}}$ siècle entre Athènes et Mégare rappelle les combats rituels à caractère initiatique examinés par Brelich ${ }^{303}$.

En somme, bien que les Mégariens aient eu le dessus au début des combats pour Salamine, les luttes internes ont très probablement affaibli la cité de l'isthme au $\mathrm{VI}^{\mathrm{e}}$ siècle. À l'époque impériale, on constate que la tradition faisant de la trahison la principale responsable de la perte de l'île est bien ancrée chez les Mégariens. Les défaites dans la guerre de Salamine et les conflits internes ont sans doute déterminé plusieurs Mégariens à aller s'installer ailleurs: songeons à la bande des Dorykleioi qui trouva refuge à Athènes. En s'associant à d'autres Grecs (les Béotiens à Héraclée du Pont) ou à leurs apoikoi de Propontide (les Chalcédoniens à Mésambria), les Mégariens de Grèce ont repris leur activité colonisatrice après un siècle environ. Les savants ont suggéré que la perte de l'île avait privé Mégare d'un territoire potentiel pour son expansion et avait accéléré la pénétration mégarienne en mer Noire: c'est vers 554 et 513/2 qu'Héraclée du Pont et Mésambria furent respectivement fondées ${ }^{304}$. Le fait que la date de fondation de Mésambria se situe à peu près à la même période que l'arbitrage spartiate qui mit fin à la dispute pour Salamine peut étayer cette hypothèse. Il faut néanmoins se méfier d'un déterminisme trop étroit, car, on le rappelle, les épisodes de la guerre sont difficiles à reconstituer et on n'est pas en mesure de connaître l'impact de cette perte sur le développement de Mégare. À mon sens, les défaites dans la guerre contre Athènes ne peuvent pas être dissociées des luttes internes (staseis), que Mégare connaît au VI ${ }^{\mathrm{e}}$ siècle et dont il sera question au chapitre suivant. Autrement dit, ce n'est qu'en associant défaite dans la guerre extérieure et conflits internes que l'on peut inclure la perte de Salamine parmi les causes de la fondation des colonies mégariennes du Pont-Euxin.

302 Plutarque, Solon, 9, 4-7; Énée le Tacticien, Poliorcétique, IV, 11.

303 A. Brelich, Guerre, agoni e culti nella Grecia arcaica, Bonn 1961, notamment p. 80-84. Sur le caractère rituel de la guerre pour Salamine, voir aussi R. Nicolai, op. cit., p. 3-19.

304 Burstein, Heraclea, p. 17; Hind, Megarian Colonization, p. 134. 


\section{I.3 Les luttes internes à Mégare au VI ${ }^{\mathrm{e}}$ siècle}

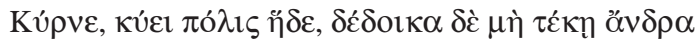

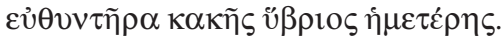

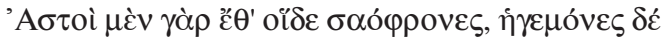

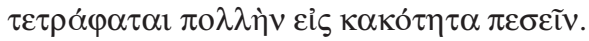

Cyrnos, notre ville est en travail, et je crains qu'elle n'enfante un redresseur de nos déplorables outrances; car, si nos concitoyens font preuve encore de sagesse, nos chefs, eux, sont engagés sur une fort mauvaise pente ${ }^{305}$.

Je me propose dans ce chapitre d'examiner les conflits qui traversèrent la Mégaride à l'époque archaïque et qui aboutirent à diverses solutions radicales: la palintokia (le «retour des intérêts»), la confiscation des biens, la limitation de l'accès aux magistratures à une seule faction politique. L'examen porte d'abord sur les mesures prises par les démocrates et les oligarques mégariens contre leurs adversaires, et ensuite sur les poèmes de Théognis, l'une des sources des tensions politiques et des bouleversements sociaux qui eurent lieu en Mégaride. Cette analyse permettra à mes yeux de déceler quelle a été la place des luttes internes parmi les causes de la colonisation mégarienne et en particulier de l'installation des Mégariens à Héraclée du Pont peu avant le milieu du $\mathrm{VI}^{\mathrm{e}}$ siècle.

\section{I.3.1 Mégare à l'époque archaïque: renversements politiques et troubles internes}

Après la chute des rois et le synœcisme, les historiens locaux de Mégare, dont Pausanias se fit l'écho, rapportent que la cité fut gouvernée par une oligarchie restreinte. La construction de la salle du Conseil sur les tombes héroïques montre le désir des aristocrates de s'assurer de la majorité sans augmenter le nombre des membres du conseil dirigeant ${ }^{306}$. Ce gouvernement fut renversé par le coup d'État de Théagène, que l'on

305 Théognis, 39-42 (trad. de J. Carrière, CUF).

306 Pausanias, I, 43, 3 ; cf. Figueira, Megarian Society, p. 140. Voir aussi supra, chapitre I.1.4. 
place, on l'a vu, après le milieu du VII siècle $^{307}$. L'instauration de la tyrannie fut préparée par la décision de l'assemblée d'accorder à Théagène une garde militaire, ce qui suppose l'existence d'une Assemblée du peuple à cette époque ${ }^{308}$. Le tyran est sans doute issu du milieu aristocratique, compte tenu du mariage de sa fille avec l'aristocrate athénien Cylon ${ }^{309}$. Selon Aristote, sa popularité fut déterminée par le massacre des troupeaux des riches (euporoi), qui se trouvaient près d'une rivière ${ }^{310}$. Ure pensait que Théagène voulut s'assurer par cette mesure le monopole de la production de laine, mais il s'agit là d'une vision certainement anachronique ${ }^{311}$. Les savants ont aussi pensé que cette action pouvait trahir un conflit entre des éleveurs et des petits fermiers ${ }^{312}$, ou entre de grands et de petits propriétaires de troupeaux ${ }^{313}$. Mais ces hypothèses restent elles aussi difficiles à vérifier. À mon sens, en massacrant les troupeaux des riches, Théagène cherchait à offrir de nouveaux pâturages à ses partisans, qu'ils fussent pauvres ou riches. Et l'on sait que, comme ailleurs, l'élevage et les pâturages constituaient une importante source de revenus pour les Mégariens ${ }^{314}$.

307 Voir supra, chapitre I.2.1.

308 Aristote, Rhétorique, I, 2, 1357b 30-36; cf. Figueira, Megarian Society, p. 143.

309 Thucydide, I, 126, 3 ; Pausanias, I, 28, 1; 40, 1.

310 Aristote, Politique, V, 5, 9 1305a 24-26. Figueira, Megarian Society, p. 143-145, estime qu'étant donné qu'une rivière fait défaut à la Mégaride, le mot potamos devrait désigner chez Aristote un lieu de culte appelé Potamos, où l'on célébrait la fête des Potamia. Les terres proches de Potamos auraient servi à faire pâturer les animaux pour les sacrifices et la nourriture commune, mais les riches se seraient approprié ces domaines. Cette reconstruction très hypothétique reste néanmoins difficile à suivre. Rappelons au passage qu'il existe à Pachi (le site de l'antique Nisaia) un cours d'eau qui se jette dans la mer et qui pourrait être le potamos d'Aristote. $C f$. A.J. Beattie, op. cit., p. 34. De même, un ruisseau se trouve aux abords de Pagai: J. A. Lebègue, De oppidis et portibus Megaridis ac Boeotiae in Corinthiaci sinus littore sitis, Paris 1875, p. 44; Bernier, Ports de la Megaride, p. 134-135.

311 P.N. Ure, The Origin of Tyranny, Cambridge 1922, p. 264-268. De même, Smith, Megara and her Colonies, p. 78; idem, Megaris, p. 100, estime que Théagène visait à imposer un contrôle, voire même un monopole, sur la production de laine.

312 Burn, Lyric Age, p. 188, suivi par A. J. Papalas, «Theagenes ans the Slaughter of the Livestock», AncW 38, 2007, p. 67-68.

313 Legon, Megara Pol. Hist., p. 95-96. Cf. Oost, Megara, p. 190; Forsdyke, Megara, p. 88 ; eadem, Exile, Ostracism, and Democracy. The Politics of Expulsion in Ancient Greece, Princeton 2005, p. 52.

314 Voir infra, chapitre I.4. 
Il faut du reste ajouter que Pausanias vit dans le secteur nord de la ville le site appelé Rhous (le «Courant»), où le tyran fit édifier un autel à Achéloos, divinité des eaux. Il note que par cet endroit s'écoulait l'eau descendant des montagnes après que Théagène l'avait détournée pour alimenter la fontaine qu'il fit construire au pied de l'acropole Caria. La fontaine dite de Théagène est l'un des rares monuments antiques encore en place aujourd'hui à Mégare. Mais du point de vue archéologique, sa

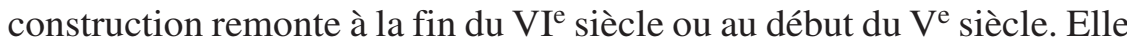
fut donc erronément attribuée à Théagène et il reste difficile de connaître quels furent les travaux hydrauliques entrepris par le tyran à Mégare ${ }^{315}$. Notons au passage que l'on a suggéré que les vers 39-52 de Théognis, cités en partie en exergue de ce chapitre, faisaient référence à Théagène. Chose intéressante, la tyrannie est annoncée dans ces vers par une période de troubles internes entre les Mégariens ${ }^{316}$.

La Question grecque XVIII de Plutarque rapporte que la tyrannie de Théagène fut remplacée par une oligarchie modérée, qui fut suivie par une démocratie ${ }^{317}$. Dans le passage cité ci-dessous, la période de la «démocratie» est caractérisée par des violences et des attaques menées par des pauvres contre des riches.

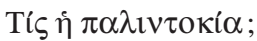

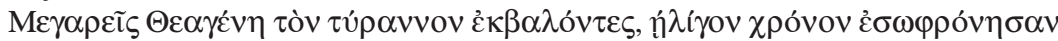

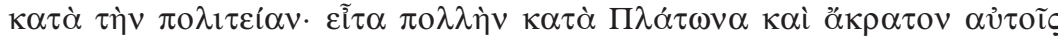

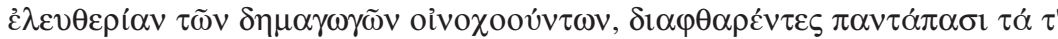

315 Pausanias, I, 40, 1; 41, 2. A. Muller, «Megarika», BCH 105, 1981, p. 208-218, estime que le dispositif de drainage des eaux vers Rhous peut être l'œuvre de Théagène. Sur la date de la fontaine dite de Théagène, voir G. Gruben, «Das Quellhaus

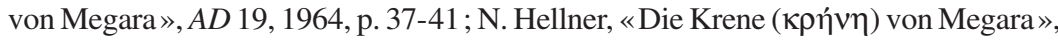

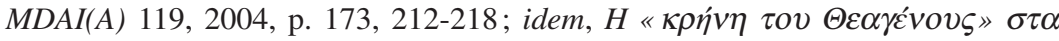

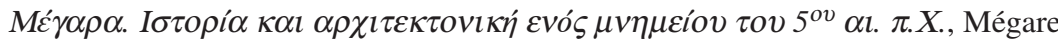
2009, p. 74-75. Sur le culte d'Achéloos à Mégare, voir Highbarger, Megara, p. 5960 ; A. Effenberger, «Zur Interpretation des megarischen Acheloos-Reliefs», Forschungen und Berichte 12, 1970, p. 77-96.

316 G. Nagy, «Poet and Tyrant: Theognidea 39-52, 1081-1082b», ClAnt 14, 1983, p. 82-91; Van Groningen, Theognis, p. 26-31; cf. L. de Libero, op. cit., p. 32-35; H. Selle, Theognis und die Theognidea, Berlin-New York 2008, p. 229-235.

317 La chute de Théagène est placée par Figueira, Chronological Table, p. 276-277, vers 600 et par Legon, Megara Pol. Hist., p. 102, avant 620. Ces dates devraient être abaissées si l'on place le début de la tyrannie de Théagène au début du VI ${ }^{\mathrm{e}}$ siècle: voir supra, chapitre I.2.1. 


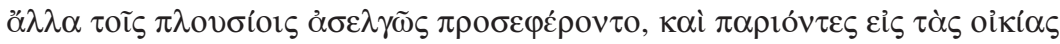

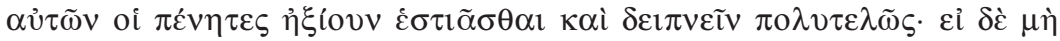

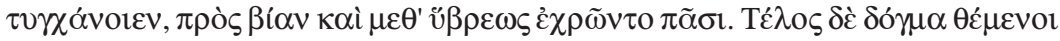

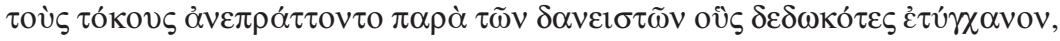

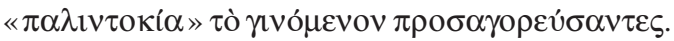

Qu'est-ce que le <retour des intérêts〉?

Une fois que les Mégariens eurent chassé le tyran Théagène, ils administrèrent leur cité pendant peu de temps avec sagesse. Puis, les démagogues, comme dit Platon, leur versèrent à boire la liberté en grande quantité et sans mélange ${ }^{318}$, si bien que les pauvres, complètement pervertis, se conduisaient en général avec grossièreté à l'égard des riches et, en particulier, ils entraient dans leurs maisons pour exiger d'être régalés par des dîners somptueux. S'ils n'obtenaient pas satisfaction, ils faisaient preuve de violence et d'insolence envers tout le monde. Ils finirent par prendre un décret pour se faire rembourser de leurs créanciers les intérêts qu'ils se trouvaient leur avoir versés, appelant l'opération 〈retour des intérêts ${ }^{319}$.

On notera d'emblée que ce texte, qui a sans doute son origine dans la Constitution des Mégariens, œuvre d'Aristote ou d'un de ses disciples ${ }^{320}$, témoigne d'une mesure prise par les Mégariens pour résoudre le problème des dettes. Suite à un décret (dogma), les créanciers furent obligés de rembourser les intérêts déjà versés par leurs débiteurs. Comme on n'a pas manqué de le remarquer, la palintokia (le «retour des intérêts») présente des similitudes avec la seisachtheia de Solon, les deux réformes s'attaquant aux problèmes posés par les dettes. Néanmoins, la palintokia était une réforme moins radicale que celle introduite à Athènes, car elle ne prévoyait que le remboursement des intérêts, tandis qu'à la même époque Solon imposait l'abolition des dettes ${ }^{321}$.

318 Pour l'application de cette métaphore au régime démocratique, voir Platon, République, VIII, 14, 562 d. Cf. D. B. Lewis, «Symposium and the Polis», in Theognis of Megara. Poetry and the Polis, T.J. Figueira et G. Nagy (éds.), Baltimore-London 1985, p. 176-196.

319 Plutarque, Questions grecques, XVIII (= Moralia 295 D, trad. de J. Boulogne, CUF).

320 K. Giesen, op. cit., p. 461-463; Halliday, Gr. Questions, p. 92 et 99.

321 Legon, Megara Pol. Hist., p. 115 ; Figueira, Megarian Society, p. 148; P. Millett, Lending and Borrowing in Ancient Athens, Cambridge 1991, p. 48-50; Van Wees, Mafia of Early Greece, p. 28-29, 34-35; idem, «<Stasis, Destroyer of Men〉. Mass, Elite, Political Violence and Security in Archaic Greece», in Sécurité collective et ordre public dans les sociétés anciennes, Entretiens sur l'Antiquité classique 54, C. Brélaz et P. Ducrey (éds.), Vandœuvres-Genève 2007, p. 30-31; Forsdyke, Megara,p. 77, 86. H. van Effenterre, op. cit., p. 121-122, rappelle les limites de notre connaissance de la seisachtheia, une mesure qui aurait pu viser l'abolition des dettes (Ps.-Aristote, 
Aristote offre des informations supplémentaires sur les mesures prises par les «démocrates » à Mégare et dans sa colonie, à Héraclée du Pont. On assiste dans les deux cités au bannissement des «notables» (gnôrimoi) et à la confiscation de leurs fortunes, des mesures qui conduisirent finalement à la chute des régimes «démocratiques».

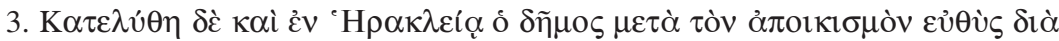

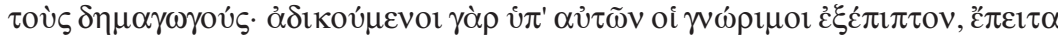

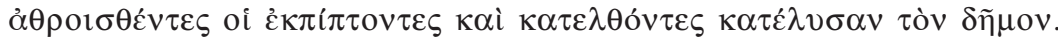

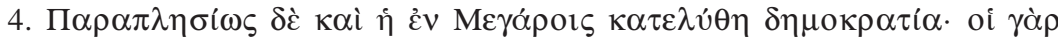

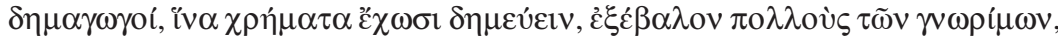

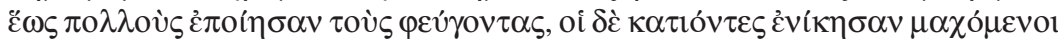
$\tau$

3. À Héraclée aussi, la démocratie fut renversée, aussitôt après la fondation de la colonie, à cause des démagogues : brimés par eux, les notablesétaient, d'ordinaire, bannis ; mais ensuite, les exilés se regroupèrent, revinrent et renversèrent le régime populaire. 4. C'est encore d'une manière presque identique qu'à Mégare la démocratie fut renversée : les démagogues expulsèrent un grand nombre de notables, pour confisquer leurs biens, jusqu' au moment où ces exilés furent assez nombreux; ceux-ci revinrent alors, menèrent une lutte victorieuse contre le peuple et installèrent l'oligarchie ${ }^{322}$.

Concernant la nature de la démocratie à Mégare et à Héraclée du Pont, il convient de noter que deux opinions s'affrontent. D'aucuns défendent la présence des institutions démocratiques dans les deux cités au $\mathrm{VI}^{\mathrm{e}}$ siècle, tout en notant qu'il pouvait s'agir d'une démocratie modérée ${ }^{323}$. En revanche, selon une autre opinion, l'opposition entre les «démocrates» et les «oligarques» est un anachronisme; en réalité, on a affaire à des luttes entre diverses factions dominées par des aristocrates dont certaines, pour attirer le peuple, proposent des mesures qui visent à résoudre des problèmes sociaux et économiques (notamment le pro-

Constitution d'Athènes, VI, 1; Plutarque, Solon, 25, 2), mais aussi seulement un allégement des charges, plus exactement une réduction des taux d'intérêt, selon Androtion, FGrHist 324 F 34 (apud Plutarque, Solon, 25, 3). Le témoignage d'Androtion est contesté par Van Wees, Mafia of Early Greece, p. 45, n. 60, qui considère qu'il ne s'agit là que d'une intention de diminuer le radicalisme de la réforme de Solon.

322 Aristote, Politique, V, 5, 3-4, 1304b 31-39 (trad. de J. Aubonnet, CUF).

323 Burstein, Heraclea, p. 17, 19; Legon, Megara Pol. Hist., p. 119-120; E. W. Robinson, The First Democracies. Early Popular Government outside Athens, Historia Einzelschriften 107, Stuttgart 1997, p. 112-113, 116-117; idem, Democracy beyond Athens. Popular Governement in the Greek Classical Age, Cambridge 2011, p. 44 et n. $130,157-158$. 
blème des dettes) $)^{324}$. Il me semble que c'est la thèse que l'on devrait privilégier. Car outre la palintokia, les récits ne témoignent pas d'autres réformes à caractère démocratique et l'on ne possède d'informations sur la procédure d'élection des magistrats et sur les mécanismes de la prise de décision ni à Mégare, ni dans sa colonie, à l'époque de la démocratie. Il faut ajouter que malgré le parallèle entre Mégare et Héraclée du Pont avancé par Aristote, la situation dans les deux cités était sans doute différente. Il est vraisemblable que dans la colonie pontique les confrontations concernaient non seulement les grandes familles aristocratiques, mais aussi des groupes de colons d'ethnies différentes ou appartenant à différentes vagues de colonisation (apoikoi, époikoi) (25. $^{325}$.

Assurément, la «démocratie» ne jouit pas d'une bonne renommée dans les histoires locales de Mégare. La Question grecque LIX de Plutarque évoque un sacrilège commis par le génos des «renverseurs de chariots» sous la «démocratie sans retenue» (akolastos démokratia). De même que dans le cas de la Question grecque XVIII, ce passage cité ci-dessous est probablement tiré de la Constitution des Mégariens de l'École d'Aristote ${ }^{326}$.

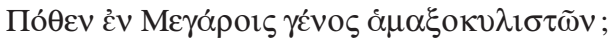

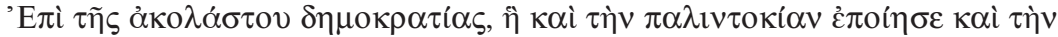

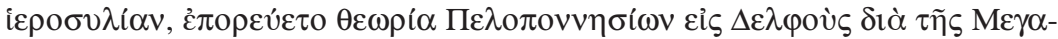

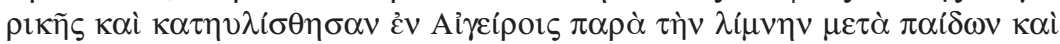

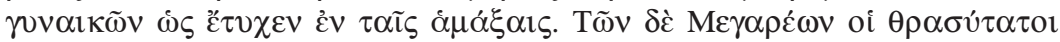

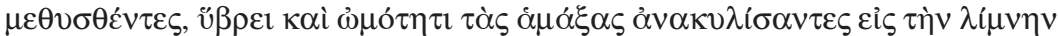

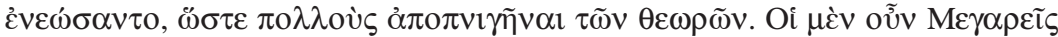

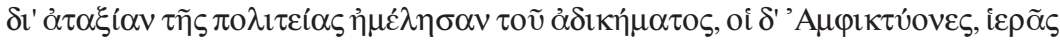

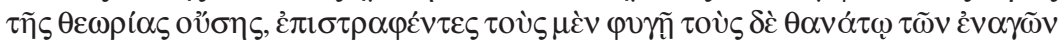

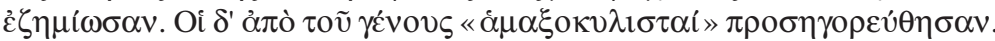

D’où vient, à Mégare, le groupe des 〈renverseurs de chariots〉?

À l'époque où la démocratie n'avait plus de frein et produisit aussi bien le retour des intérêts que le pillage des temples, une théorie de Péloponnésiens traversa la Mégaride en direction de Delphes et ils installèrent leur campement à Aigeiroi, le long du lac, leurs chariots abritant au gré du hasard des enfants et des femmes. Les plus arrogants des Mégariens, sous le coup de l'ivresse, firent par violence et cruauté rouler les

324 Oost, Megara, p. 193-194; Asheri, Herakleia, p. 29; Forsdyke, Megara, p. 73-92; Avram, Héraclée et ses colonies, p. 220-221.

325 Avram, Héraclée et ses colonies, p. 220-221. Voir aussi infra, chapitre II.3.1.1.

326 K. Giesen, op. cit., p. 463; Halliday, Gr. Questions, p. 92; Piccirilli, Arbitrati, p. 2627; Okin, Theognis, p. 18. 
chariots en arrière pour les pousser dans le lac, de façon que fussent noyés nombre des théores. Les Mégariens, à cause du désordre de leur régime, négligèrent le crime, mais les Amphictions, comme la théorie était sacrée, y prêtèrent attention et ils infligèrent à certains des coupables une peine d'exil et à d'autres la peine de mort. Quant aux descendants du groupe, ils reçurent le surnom de 〈renverseurs de chariots ${ }^{327}$.

L'événement rapporté par Plutarque montre l'insécurité qui règne en Mégaride à l'époque archaïque et qui, à en croire Aristote, fut responsable de la fin de la démocratie ${ }^{328}$. On accusa le régime de la «démocratie sans retenue» d'impiété, car il aurait permis le «pillage des temples»

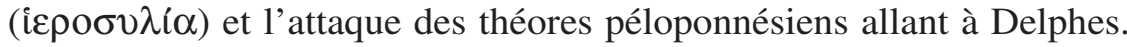
Même si l'acte de sacrilège fut de la responsabilité d'un groupement bien précis (le génos des $\alpha \mu \alpha \xi o \kappa v \lambda \imath \sigma \tau \alpha i^{329}$ ) et qui n'avait pas forcément de lien avec le régime politique en place ${ }^{330}$, cela témoigne de la présence de bandes de guerriers agissant pour leur propre compte. De la même manière, le groupe des Dorykleioi, qui avait livré l'île de Salamine à Athènes, constitue un autre indice de l'existence de bandes de guerriers indépendantes et de la violence des conflits internes à Mégare.

Il est probable que l'une des conséquences de l'intervention de l'Amphictionie pyléo-delphique en Mégaride fut la chute des «démocrates». À cet égard, force est de constater que plusieurs datations ont été proposées pour la période de la «démocratie» mégarienne: Legon la place entre $c a .600-580^{331}$, tandis que Figueira la situe entre $c a .580-510$.

327 Plutarque, Questions grecques, LIX (= Moralia 304 E-F, trad. de J. Boulogne, CUF).

328 Aristote, Politique, V, 3, 5, 1302b 31; cf. Oost, Megara, p. 194-195.

329 Suivant Antonetti, Confini della Megaride, p. 549, le fondateur mythique du génos des Hamaxokylistai serait Sciron, le malfaiteur qui précipitait les voyageurs dans la mer du haut des Roches Scironiennes. Mais cette hypothèse est peu probable, car la légende qui faisait de Sciron un brigand est d'origine athénienne. Les Mégariens considéraient Sciron comme un héros tué par Thésée au moment où ce dernier avait occupé Éleusis (voir supra, chapitre I.2.2). Cf. G. Daverio Rocchi, «La hiera orgas e la frontiera attico-megarica», in Studi di antichità in memoria di C. Gatti, Quaderni di Acme 9, Milano 1987, p. 106.

330 Forsdyke, Megara, p. 83-84; cf. M. Dillon, Pilgrims and Pilgrimage in Ancient Greece, London-New York 1997, p. 23-24, 56.

331 Legon, Megara Pol. Hist., p. 104-135. Sur la question du droit d'intervention de l'Amphictionie en Mégaride, voir Piccirilli, Arbitrati, p. 25-27, n 6; F. Lefèvre, L'Amphictionie pyléo-delphique: histoire et institutions, Athènes-Paris 1998, p. 242; P. Sánchez, L'Amphictionie des Pyles et de Delphes : recherches sur son rôle historique, des origines au $\mathrm{II}^{e}$ siècle de notre ère, Historia Einzelschriften 148, Stuttgart 2001, p. 81-82. 
Pour ce dernier chercheur, le récit d'Aristote (cité ci-dessus) appuierait l'idée que les «démocrates» étaient encore au pouvoir vers 554, lors de la fondation d'Héraclée du Pont. D'après lui, c'est Sparte qui aurait agi pour l'Amphictionie et aurait facilité le retour des oligarques. L'intervention se serait produite vers 510, au moment où les Spartiates passèrent par la Mégaride pour chasser les Pisistratides d'Athènes ${ }^{332}$. Cependant, rien ne permet d'attribuer la chute de la «démocratie» mégarienne à Sparte. Au contraire, sur la foi d'Aristote, on est autorisé à penser qu'Héraclée du Pont fut installée comme une «démocratie». Cela implique qu'il y avait un nombre important de «démocrates» parmi les fondateurs de cette colonie et l'on peut inférer que ceux-ci furent expulsés par les oligarques. On conclura donc que la «démocratie» fut renversée peu avant le milieu du $\mathrm{VI}^{\mathrm{e}}$ siècle, lorsque les Mégariens fondèrent Héraclée du Pont sur la côte sud de la mer Noire ${ }^{333}$.

Enfin, il est important de souligner que, à en croire Aristote, le gouvernement oligarchique prit à Mégare, tout comme le précédent, des mesures radicales contre les adversaires politiques. Les oligarques décidèrent que les magistrats ne seraient choisis que parmi ceux qui étaient revenus ensemble de l'exil et avaient combattu contre le dèmos ${ }^{334}$.

\section{I.3.2 Kakoi et agathoi chez Théognis}

Les poèmes élégiaques de Théognis nous renseignent davantage sur les bouleversements internes que la ville de Mégare connut à l'époque archaïque. Quoique la question de la composition du recueil théognidéen reste controversée, l'historicité du célèbre poète mégarien me semble

332 Figueira, Chronological Table, p. 296-302. D'autres savants ont daté l'attaque des théores péloponnésiens par le génos des «renverseurs de chariots» vers 570-560 (d'après Meyer, Megara, col. 186, suivi par Piccirilli, Arbitrati, p. 27), ou vers le milieu du VI ${ }^{\mathrm{e}}$ siècle (suivant H. Bürgel, Die pylaeisch-delphische Amphiktyonie, München 1877, p. 148).

333 Notons que Oost, Megara, p. 195, n. 33, situe la chute de la démocratie à une époque postérieure à 550.

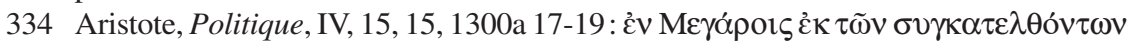

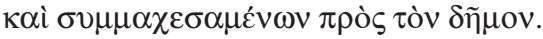


fort probable ${ }^{335}$. La Souda date le floruit de Théognis de la 59 $9^{\mathrm{e}}$ Oympiade (ca. 544-541); il serait donc contemporain de la période de la «démocratie», qui remonte, on l'a vu, à la première moitié du VI ${ }^{\mathrm{e}}$ siècle $^{336}$.

On a aussi suggéré que la relation entre Théognis et Mégare ne reposait pas sur une base historique et que la cité qu'il décrivait était une cité imaginaire ${ }^{337}$. Mais sans mettre en doute la portée panhellénique des poèmes de Théognis, il est vraisemblable que cet auteur a transposé dans certains de ses vers le cas particulier de sa cité et sa situation personnelle d'aristocrate déchu et exclu de l'exercice du pouvoir ${ }^{338}$.

Théognis évoque aux vers 667-680 la perte de sa fortune et se plaint du désordre qui règne parmi ces concitoyens. La répartition équitable

335 Les spécialistes ont placé les poèmes rassemblés sous le nom de Théognis à diverses dates entre l'époque de la tyrannie de Théagène et celle des guerres médiques, soit entre $c a$. 640-479. Sur la composition du corpus théognidéen, voir Carlier, Theognis, p. 8-19; West, Gr. Elegy and Iambus, p. 65-71; H. Selle, op. cit., p. 20-27, 228-246, 280-281, 373-381. D'après V. Cobb-Stevens et al., «Introduction », in Theognis of Megara. Poetry and the Polis, T.J. Figueira et G. Nagy (éds.), Baltimore-London 1985, p. 2; Nagy, Theognis and Megara, p. 33, le personnage de Théognis représente «a cumulative synthesis of Megarian poetic tradition».

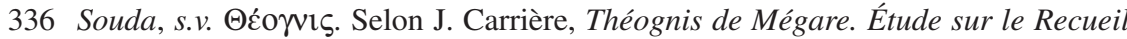
élégiaque attribué à ce poète, thèse de doctorat, Université de Paris, Paris 1948, p. 8-13, les événements politiques, auxquels Théognis fait référence, remontent à la première moitié du $\mathrm{VI}^{\mathrm{e}}$ siècle. La naissance de Théognis est située vers 630 par Legon, Megara Pol. Hist., p. 111, ou vers le début du VI ${ }^{\mathrm{e}}$ siècle par R. Lane Fox, «Theognis: an Alternative to Democracy», in Alternatives to Athens. Varieties of Political Organization and Community in Ancient Greece, R. Brock et S. Hodkinson (éds.), Oxford 2000, p. 35-51, ou entre 615-560 par H. Selle, op. cit., p. 26-27. Notons aussi que pour West, Gr. Elegy and Iambus, p. 68-70, l'exil de Théognis aurait eu lieu à l'époque de la tyrannie de Théagène, et non pas à celle de la « démocratie». $C f$. H. F. Johansen, «A Poem by Theognis (Thgn. 19-38), Part II», $C \& M 44$, 1993, p. 5-29.

337 A. Aloni, «Elegy», in The Cambridge Companion to Greek Lyric, F. Budelmann (éd.), Cambridge 2009, p. 175.

338 Nagy, Theognis and Megara, p. 22-81; A. Fouchard, Aristocratie et démocratie. Idéologies et sociétés en Grèce ancienne, Paris 1997, p. 23, 113, 143 ; H. Selle, op. cit., p. 271-280. Sur le caractère panhellénique de Théognis, voir aussi V. CobbStevens, «Opposites, Reversals and Ambiguities : the Unsettled World of Theognis », in Theognis of Megara. Poetry and the Polis, T.J. Figueira et G. Nagy (éds.), Baltimore-London 1985, p. 159-175; E. Stein-Hölkeskamp, «Adel und Volk bei Theognis », in Volk und Verfassung im vorhellenistischen Griechenland. Beiträge auf dem Symposium zu Ehren von Karl-Wilhelm Welwei in Bochum, 1-2 März. 1996, W. Eder et K.-J. Hölkeskamp (éds.), Stuttgart 1997, p. 22. 
des biens a disparu et ce n'est pas la justice (dikè) qui conduit à présent la cité, mais la déraison, la violence (hybris) ${ }^{339}$. Dépouillé de ses biens, le poète est obligé de partir, et la Sicile apparaît parmi les destinations de ses voyages ${ }^{340}$. Ce séjour sicilien donna probablement naissance à la controverse antique à propos de l'origine de Théognis. De fait, si Didymos et Stéphane de Byzance le présentent comme un ressortissant de Mégare de Grèce ${ }^{341}$, Platon et la Souda le considèrent comme originaire de Mégara de Sicile. Harpocration essaie déjà de concilier les deux traditions, en soutenant que le poète était un Mégarien de Grèce qui s'était rendu en Sicile, à Mégara, où il avait reçu la citoyenneté. D'après la Souda, Théognis aurait même écrit un poème sur le siège de Syracuse, aujourd'hui perdu ${ }^{342}$. Mais, comme Carrière l'a noté, l'Élégie syracusaine n'est sans doute pas l'œuvre de Théognis. D'après Carrière, Hésychios de Milet (la source probable de la note de la Souda) ou un autre grammairien aurait confondu le Mégarien avec un poète athénien du même nom qui vécut vers la fin $d u V^{e}$ siècle, étant l'un des Trente Tyrans d'Athènes. Ce Théognis d'Athènes fut donc l'auteur du poème qui traite d'un siège de Syracuse, événement qui ne serait autre que le siège entrepris par les Athéniens et leurs alliés en 414 lors de la guerre du Péloponnèse ${ }^{343}$. Toutefois, il convient de préciser que si l'on

339 Pour l'usage du mot hybris chez Théognis, voir L. Gernet, Recherches sur le développement de la pensée juridique et morale en Grèce (étude sémantique), Paris 1917, p. 19-24; A. Fouchard, op. cit., p. 69.

340 Théognis, 783-786. Concernant l'appropriation de la fortune de Théognis par ses adversaires, voir les vers 345-385, 833-836.

341 Didymos, apud scholie à Platon, Lois, I, 630 a; Stéphane de Byzance, s.v. Mé $\alpha \rho \alpha$.

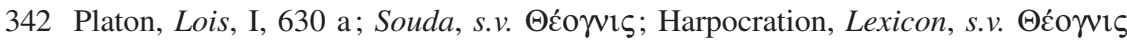
(éd. W. Dindorf). Cf. T. Hudson-Williams, «Theognis and his poems », JHS 23, 1903, p. 2-3; J. Carrière, op. cit., p. 3-8; Figueira, Megarian Society, p. 124-127; A. K. Gavrilov, «Les deux patries de Théognis », Hyperboreus 6, 2000, p. 279-295 (en russe); De Angelis, Megara Hyblaia and Selinous, p. 55-56; H. Selle, op. cit., p. 27-36, 247-253, 372-373.

343 J. Carrière, op. cit., p. 86. Sur le poète athénien Théognis, surnommé Xíwv (la

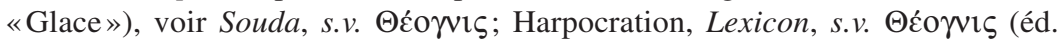
W. Dindorf). En revanche, E.L. Highbarger, «Suidas' Account of Theognis», in Studies presented to D. M. Robinson, vol. II, G. E. Mylonas et D. Raymond (éds.), Saint Louis 1953, p. 644-645, estime que si l'Élégie syracusaine avait été l'œuvre du poète mégarien, ce poème aurait pu porter sur la prise de Mégara par Gélon. $C f$. H. Selle, op. cit., p. 64-67, 372. 
a fait cette confusion, c'est non seulement à cause de l'homonymie, mais aussi parce que l'on associait Théognis à Mégara en particulier, et à un milieu sicilien en général. On sait que le tyran Gélon conquit Mégara en 483/2 et transféra les familles aristocratiques de cette cité à Syracuse $^{344}$. L'assimilation d'une partie de la population de Mégara par la cité de Syracuse aurait pu justifier, dans la tradition reprise par la Souda, l'association du poète mégarien à un événement de l'histoire de Syracuse. Bref, tous ces indices suggèrent que Théognis fut chassé de sa patrie, et que pendant son voyage il séjourna un certain temps dans la colonie mégarienne de la Sicile orientale.

Le poète met en évidence une violence extrême dans la société mégarienne qui aurait entraîné, selon lui, un changement des fortunes et des élites. Les kakoi ont remplacé les agathoi, et ils conduisent à présent la cité ${ }^{345}$. La cité en proie à la stasis est comparée à un navire, qui a perdu son pilote ${ }^{346}$ :

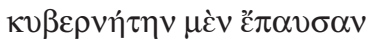

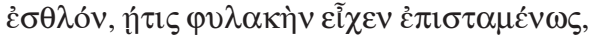

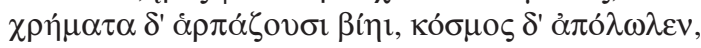

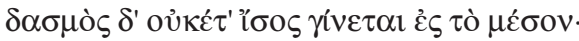

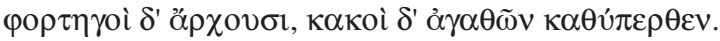

Ils ont relevé le pilote - un bon, et qui savait tenir la barre -; de vive force, ils pillent la cargaison; tout ordre a disparu; le butin ne fait plus l'objet d'un égal partage! Ce sont les faquins qui commandent; les méchants dominent les bons ${ }^{347}$.

Selon Figueira, les vers élégiaques de Théognis expriment l'idéologie oligarchique et répondent à la situation sociale créée par les actions des démocrates, mais aussi à l'idéologie «populiste», telle qu'elle est ex-

344 Hérodote, VII, 156-157.

345 Théognis, 39-58, 183-192, 833-836, 855-856; cf. Figueira, Megarian Society, p. $143-$ 158; V. Cobb-Stevens, op. cit., p. 159-175; S. von der Lahr, Dichter und Tyrannen im archaischen Griechenland. Das Corpus Theognideum als zeitgenössische Quelle politischer Wertvorstellungen archaisch-griechischer Aristokraten, München 1992, p. 19-22; A. T. Edwards, «Historicizing the Popular Grotesque: Bakhtin's Rabelais and Attic Old Comedy », in Theater and Society in the Classical Wolrd, R. Scodel (éd.), Ann Arbor 1993, p. 99; Van Wees, Megara's Mafiosi, p. 52-67.

346 G. Nagy, «Theognis of Megara: the Poet as Seer, Pilot and Revenant», Arethusa 15, 1982, p. 111-113; idem, Theognis and Megara, p. 23-24.

347 Théognis, 675-679 (trad. de J. Carrière, CUF). 
primée par la comédie mégarienne ${ }^{348}$. De fait, un passage d'Aristote associe la «démocratie» mégarienne à l'invention de la comédie. Le Stagirite note que la comédie fait son apparition dans un milieu rural et il fait dériver $\kappa \omega \mu \omega \delta i ́ \alpha$ de $\kappa \omega ́ \mu \eta$, le terme qui désigne le bourg chez les Mégariens ${ }^{349}$. Or dans un passage qui mérite d'être cité, Théognis indique que les kakoi sont venus des territoires hors de la ville; leur comportement fait référence à la comédie.

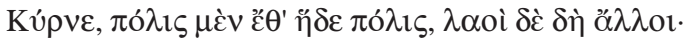

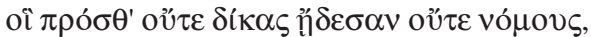

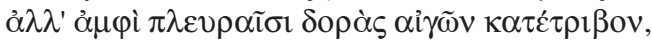

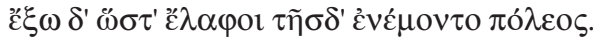

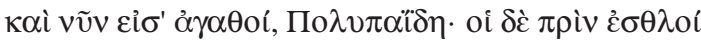

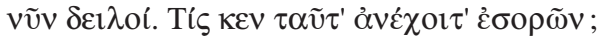

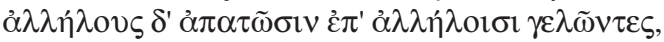

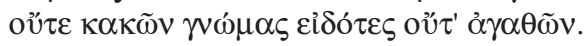

Cyrnos, cette ville est encore une ville, mais ses habitants ont changé: ceux qui autrefois ne connaissaient ni droit ni lois, juste bons à user autour de leurs flancs leurs peaux de chèvres ${ }^{350}$ et à pâturer hors des murs comme des cerfs, ce sont eux maintenant les bons, Polypaidès; les honnêtes gens d'autrefois sont devenus des gens de rien. Qui pourrait supporter ce spectacle ? Ils se jouent et se rient les uns des autres, sans voir où est le mal, où le bien ${ }^{351}$.

Si l'on accepte de placer l'invention de la comédie entre 580-560, on peut suggérer que la «démocratie» existait déjà à Mégare vers $580^{352}$. Cependant, cette date n'est pas certaine et il n'est pas possible de situer précisément la date du début de la «démocratie» à Mégare. De même, on n'est pas en mesure de savoir si les accusations de Théognis contre ceux «qui pâturent hors des murs», et qui à présent sont des agathoi, témoignent de l'arrivée des gens de la campagne dans la ville et de leur participation accrue dans la vie politique. La réponse est probablement

348 Figueira, Megarian Society, p. 140-141; cf. V. Cobb-Stevens, op. cit., p. 162-163; Forsdyke, Megara, p. 81-82.

349 Aristote, Poétique, III, 1448a 30-38; cf. A. Wartelle, Lexique de la «Poétique» d'Aris-

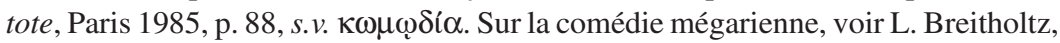
op. cit., p. 34-82, 87-95; Figueira, Megarian Society, p. 132-137. Voir aussi infra, chapitre III.1.4.

350 Figueira, Megarian Society, p. 141, note que «the skins that they wore on their sides correspond to the costumes appropriate to animal or satyr choruses ».

351 Théognis, 53-60 (trad. de J. Carrière, CUF, partiellement modifiée).

352 Marmor Parium, FGrHist 239 A 39; cf. Figueira, Chronological Table, p. 298. 
négative, le poète est plutôt préoccupé par les évolutions sociales et le mélange des élites ${ }^{353}$. Il se plaint ailleurs que les mésalliances entre les kakoi et les agathoi sont désormais dictées par la richesse et excluent les valeurs aristocratiques traditionnelles, la noble naissance ayant perdu de son importance ${ }^{354}$.

Il serait également erroné de considérer que l'opposition chez Théognis entre les agathoi et les kakoi traduit une confrontation des aristocrates avec les commerçants ou les moins fortunés de Mégare. De fait, contrairement à ce que pensait jadis Trever, on n'assiste pas aux $\mathrm{VII}^{\mathrm{e}}-\mathrm{VI}^{\mathrm{e}}$ siècles à un conflit entre «the Doric noble landholders» et «a new and growing class of industrials and merchants of common ancestry ${ }^{355}$. Celle-ci est sans nul doute une vision «modernisante» et on n'a aucune raison de penser que la colonisation ou le commerce ont provoqué l'émergence à Mégare d'une classe bourgeoise responsable de changements politiques tels que la tyrannie de Théagène et l'akolastos démokratia.

Théognis critique la politique des «chefs» de sa ville «engagés sur

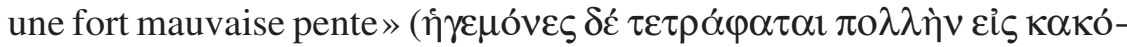
$\tau \eta \tau \alpha \pi \varepsilon \sigma \varepsilon \tau v)^{356}$. Et si ce sont les kakoi hégémones qui corrompent le peuple, il n'est pas nécessaire que ces derniers proviennent d'un milieu pauvre ${ }^{357}$. Il semble au contraire, on l'a vu, que tous les régimes de Mégare, qualifiés de «tyrannie», d' «oligarchie» ou de «démocratie» par la littérature antique postérieure au $\mathrm{VI}^{\mathrm{e}}$ siècle, se caractérisent par des combats entre des bandes menées par des aristocrates. Ceux-ci, pour vaincre leurs adversaires, se seraient attaché des représentants du peuple. Il s'agit de conflits violents qui visent à contrôler de nouvelles

353 H. van Wees, in Sécurité collective et ordre public dans les sociétés anciennes, Entretiens sur 1'Antiquité classique 54, C. Brélaz et P. Ducrey (éds.), VandœuvresGenève 2007, p. 43, écrit: «Theognis' resentment focuses on upward social mobility rather than geographical mobility».

354 Théognis, 183-196, 305-308; cf. Nagy, Theognis and Megara, p. 54-55; E. SteinHölkeskamp, op. cit., p. 29-32; F.-X. Ajavon, L'Eugénisme de Platon, Paris et al. 2001, p. 117-129.

355 Trever, Megara, p. 125-128. La même opinion chez Paltseva, Mégare, p. 239-247.

356 Théognis, 41-50.

357 E. Stein-Hölkeskamp, op. cit., p. 21-27, 32; A. Fouchard, op. cit., p. 51-53;Z. Papakonstantinou, «Theognis and the Late Archaic Greek Aristocracy», Dike 7, 2004, p. 9, n. 10. Cf. H. Selle, op. cit., p. 263-264. 
terres, notamment des terres de pâturage à l'époque de Théagène. De même, les diverses factions cherchent à s'assurer la suprématie politique, en limitant l'accès aux magistratures aux membres d'un seul groupe: par exemple, le groupe d'exilés lors de l'oligarchie. Comme on n'a pas manqué de le noter, ces confrontations engendrèrent des mesures à caractère économique et politique (le massacre des troupeaux des adversaires, la confiscation des biens, le «retour des intérêts», l'interdiction des droits civiques), qui auraient pu aussi être profitables aux Mégariens pauvres ${ }^{358}$.

Notons aussi ici l'opinion de Steinrück, qui pense que l'akolastos démokratia a privilégié les jeunes déshérités et estime que les critiques de Théognis aux nouveaux dirigeants de la cité étaient l'expression d'une opposition à l'accès élargi au pouvoir des jeunes gens. La situation de Mégare ressemblerait à celle décrite dans l'Odyssée à propos d'Ithaque, où en l'absence d'Ulysse, des prétendants, aveuglés par l'hybris, aspirent à la royauté et désirent épouser Pénélope. Ces jeunes adultes, fils d'aristocrates, mais n'étant pas les aînés ou étant issus de mariages illégitimes, rappelleraient par la violence et l'insolence de leurs actes les kakoi hégémones de Théognis. Or si les prétendants échouent à Ithaque, Ulysse et Télémaque leur ayant infligé la mort, les néoi seraient arrivés au pouvoir à Mégare avec la «démocratie». Cela expliquerait alors la brusque interruption de la colonisation mégarienne - un moyen efficace pour la communauté d'éliminer le surplus des jeunes hommes - dans la première moitié du $\mathrm{VI}^{\mathrm{e}}$ siècle $^{359}$. Cette reconstruction ingénieuse me semble être appuyée par le fait que les combats entre les Athéniens et les Mégariens furent menés par des groupes de jeunes guerriers, fort intéressés par la possession de nouveaux lots de terres à Salamine ${ }^{360}$. On conclura donc que les bouleversements so-

358 Van Wees, Mafia of Early Greece, p. 36; Forsdyke, Megara, p. 88-89.

359 M. Steinrück, Der neue Iambos. Studien zu den Formwegen eines griechischen Diskurses im Hellenismus und der Kaiserzeit, Zürich-New York 2009, p. 8-17. Voir surtout Théognis, 1123-1128, où le poète compare son sort à celui d'Ulysse, qui, de retour dans sa patrie, avait tué les prétendants de Pénélope. D'après Steinrück, l'élégie des hommes mariés de Théognis s'opposerait à l'iambe, dont le public est constitué de jeunes hommes. Rappelons qu'une tradition attribuait l'invention de l'iambe au Mégarien Sousariôn. Voir à cet égard West, Iambi et elegi Graeci ${ }^{2}$, p. 167-168 (avec les testimonia).

360 Voir supra, chapitre I.2.3. 
ciaux dans la Mégare du $\mathrm{VI}^{\mathrm{e}}$ siècle furent le résultat des confrontations entre diverses factions politiques, mais probablement aussi du désir des jeunes de s'emparer du pouvoir ${ }^{361}$.

Il est certain par ailleurs que les changements politiques violents produisirent un nombre important d'exilés ${ }^{362}$. Ce fut le cas des Dorykleioi, qui livrèrent, d'après la tradition locale de Mégare, l'île de Salamine à Athènes, ou celui de Théognis, le plus célèbre exilé de l'époque archaïque. On peut même penser que chaque renversement politique fut suivi par le bannissement d'une partie des adversaires du nouveau régime. Plusieurs auteurs antiques en témoignent: Aristote rapporte que le régime «démocratique» de Mégare a produit des exilés ${ }^{363}$, et d'après Plutarque, les Amphictions condamnèrent les Mégariens responsables de l'attaque des théores à l'exil ou à la mort ${ }^{364}$. Il est possible que cette décision se soit appuyée sur un oracle d'Apollon de Delphes qui demandait le départ hors de la cité du groupe d'hommes indésirables et la fondation d'une colonie. C'est peut-être dans ces circonstances que les Mégariens, accompagnés par des Béotiens, fondèrent kata chrèsmon la cité d'Héraclée du Pont ${ }^{365}$. Le cas de cette installation est digne d'intérêt pour une autre raison: cette cité fut établie comme une «démocratie», mais ce régime, aussitôt après la fondation, fut renversé, tout comme dans la métropole, par les oligarques ${ }^{366}$. Il se peut donc que les conflits internes de Mégare fussent exportés dans une certaine mesure dans le milieu colonial.

Finley a remarqué, et à juste titre, que dans les cités grecques «l'exil s'accompagnait régulièrement de la confiscation des biens, qui étaient redistribués d'une manière ou d'une autre aux membres de la faction victorieuse $»^{367}$. Dans ces conditions, le retour des exilés était difficile,

361 Sur les prétendants de l'Odyssée et les révoltes des jeunes gens dans les cités grecques, on lira avec profit E. Scheid-Tissinier, «Télémaque et les prétendants. Les véol d'Ithaque », AC 62, 1993, p. 1-22.

362 Van Wees, Megara's Mafiosi, p. 66.

363 Aristote, Politique, IV, 15, 15, 1300a 17-19; V, 5, 4, 1304b 35-39.

364 Plutarque, Questions grecques, LIX (= Moralia 304 E-F).

365 Sur le rôle de l'oracle de Delphes dans la fondation d'Héraclée du Pont, voir infra, chapitre II.3.1.1.

366 Aristote, Politique, V, 5, 3-4, 1304b 31-39.

367 Finley, Sur l'hist. ancienne, p. 85, qui note aussi les difficultés politiques et sociales posées par la proclamation d'Alexandre le Grand aux Jeux olympiques de 324, selon laquelle les cités grecques devaient rappeler tous leurs exilés. 
car il supposait une restitution de leurs biens, ce qui représentait une menace pour la stabilité politique et sociale de la communauté. À mon sens, il est très probable que le processus de colonisation ait joué à Mégare le rôle de «stabilisateur social». Autrement dit, les dirigeants ont poussé, par la politique de confiscation des biens et la suppression des droits politiques de leurs adversaires, plusieurs de leurs concitoyens à partir fonder de nouvelles cités. Pour cette raison je crois que les luttes internes constituent la cause principale du mouvement mégarien de colonisation, et surtout de la fondation d'Héraclée du Pont vers 554 ${ }^{368}$. De même, il est probable que les Mégariens bannis au VI ${ }^{\mathrm{e}}$ siècle par les démocrates ou les oligarques sont allés en tant que colons supplémentaires dans les fondations mégariennes de Sicile ou de la Propontide. Ce sont eux probablement les époikoi qui, suivant Aristote, provoquèrent des troubles internes à Byzance ${ }^{369}$.

Enfin, concernant la procédure de bannissement des adversaires politiques dans la Mégare archaïque, il convient de s'arrêter sur la présence de l'ostracisme à Mégare et à Chersonèse Taurique. Une scholie à Aristophane nous apprend que l'ostracisme était pratiqué non seulement par les Athéniens, mais aussi par les Argiens, les Milésiens et les Mégariens ${ }^{370}$. Ce témoignage est corroboré par la découverte d'un ostrakon dans un fossé sur l'acropole Caria de Mégare. Le bol fragmentaire portant l'inscription qui donne le nom du Mégarien ostracisé

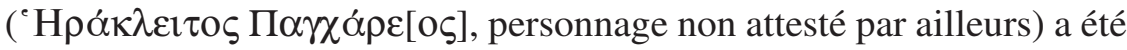
daté de la fin du $\mathrm{V}^{\mathrm{e}}$ ou du début du $\mathrm{IV}^{\mathrm{e}}$ siècle $^{371}$. Du reste, quelques dizaines d'ostraka datant du $\mathrm{V}^{\mathrm{e}}$ siècle ont été trouvés à Chersonèse Taurique, colonie pontique qui hérita, par le biais de sa métropole, Héraclée du Pont, de plusieurs institutions mégariennes. Ces tessons démontreraient, d'après Vinogradov et Zolotarev, que les Chersonésitains n'imitèrent pas l'ostracisme athénien, mais qu'ils importèrent la pratique de l'ostracisme depuis Mégare et Milet, les deux cités qui auraient

368 Cf. Smith, Megara and her Colonies, p. 76.

369 Aristote, Politique, V, 3, 11-12, 1303a 25-34.

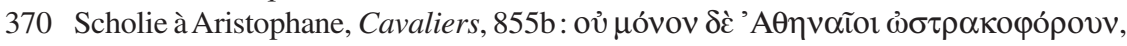

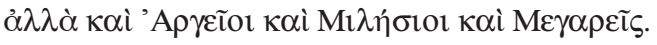

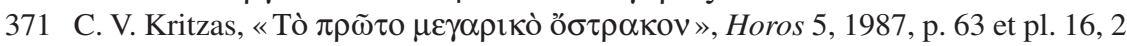
(SEG XXXVII, 371). 
participé, à leurs avis, à la fondation d'Héraclée du Pont ${ }^{372}$. Cette opinion fut suivie par d'autres chercheurs, qui voyaient là un indice de l'ancienneté de la procédure de l'ostracisme ${ }^{373}$. En analysant l'ostracisme et ses attestations en dehors d'Athènes, notamment à Argos, Milet, Mégare, Syracuse, Cyrène et peut-être aussi à Éphèse, Forsdyke estime que l'ostracisme athénien «was simply one elaboration of a more generalized Greek practice of using written ballots - whether leaves of potsherds - as a means of determining a penalty (removal from public office or exile) $»^{374}$.

Il convient néanmoins de préciser que l'interprétation de l'ostracisme à Chersonèse comme le développement d'une pratique spécifiquement mégarienne pose plusieurs difficultés. En premier lieu, la date exacte des plus anciens ostraka de Chersonèse est controversée: les premiers éditeurs les ont placés vers 500-480, mais Tokhtasyev estime récemment qu'ils remontent à la période de $480-450^{375}$. En second lieu, il n'est pas exclu que ces tessons soient des bulletins de vote utilisés

372 Vinogradov-Zolotarev, Ostracismo, p. 111-131; J. G. Vinogradov, «Ostrakismos als strenges Kampfmittel für Demokratie im Lichte der neuen Funde aus Chersonesos Taurike», in Gab es das Griechische Wunder? Griechenland zwischen dem Ende des 6. und der Mitte des 5. Jahrhunderts v. Chr., D. Papenfuß et M. Strocka (éds.), Mainz 2001, p. 379-386; M.I. Zolotarev, «Chersonesus Tauricus (sic). The Foundation and the Development of the Polis», in Ancient Greek Colonies in the Black Sea, D. V. Grammenos et E. K. Petropoulos (éds.), Thessaloniki 2003, p. 605606, 640, pl. 10. Cf. E.I. Solomonik, «Graffiti de l'antique Chersonèse», VDI, 1976, 3, p. 121-124 (en russe); eadem, «Une inscription fragmentaire de Chersonèse concernant des exilés politiques », VDI, 1984, 3, p. 77 (en russe); SEG XLIX, 1031 ; L. Dubois, Bull. ép., 2000, 487.

373 A. Napoleone, «La $\delta \eta \mu$ к $\rho \alpha \tau i ́ \alpha$ a Cirene: probleme e prospettive», AION(archeol) N. S. 5, 1998, p. 101 ; I. E. Surikov, «Ostracisme et ostraka à Athènes et en dehors de ses frontières », Hyperboreus 6, 1, 2000, p. 103-123 (en russe); S. Forsdyke, Exile, Ostracism, and Democracy. The Politics of Expulsion in Ancient Greece, Princeton 2005, p. 287-288.

374 S. Forsdyke, op. cit., p. 285.

375 Vinogradov-Zolotarev, Chersonèse, p. 407; S. R. Tokhtasyev, «Sur l'onomasticon et la datation des ostraka de Chersonèse», VDI 2007, 2, p. 110-125 (en russe). $C f$. A. Avram, Bull. ép., 2008, 409; SEG LVII, 702. On a aussi placé certains tessons inscrits de Chersonèse à la fin du $\mathrm{V}^{\mathrm{e}}$ ou au début du $\mathrm{IV}^{\mathrm{e}}$ siècle: Posamentir, Grave Stelai, p. 376; cf. I.E. Surikov, op. cit., p. 103-123; G. R. Mack, J. C. Carter (éds.), Crimean Chersonesos: City, Chora, Museum, and Environs, Austin 2003, p. 19, fig. 3.3. 
pour l'élection des magistrats (comme on les avait d'ailleurs interprétés dans un premier temps) ${ }^{376}$ ou lors de procédures à des fins juridiques (suggestion d'Avram) ${ }^{377}$. En conclusion, on ne peut pas se fier à la documentation de Chersonèse pour démontrer l'existence de l'ostracisme dans la Mégare archaïque. Il est nettement plus probable que l'introduction de ce procédé politique à Mégare se produit au cours du $\mathrm{V}^{\mathrm{e}}$ siècle, sous l'influence directe d'Athènes, comme Kritzas l'avait suggérée ${ }^{378}$. Cette opinion est confortée par les inscriptions qui attestent que les Mégariens imitent à l'époque hellénistique leurs voisins d'Athènes, tout comme ceux de Béotie et d'Achaïe, dans le domaine des institutions ou dans celui de la pratique épigraphique ${ }^{379}$.

376 Vinogradov-Zolotarev, Chersonèse, p. 406; cf. C. V. Kritzas, op. cit., p. 72; Hind, Megarian Colonization, p. 143, qui estime que l'on pourrait avoir affaire à des graffiti à caractère privé.

377 Avram, Héraclée et ses colonies, p. 212-214.

378 C. V. Kritzas, op. cit., p. 66-73, propose de dater l'introduction de l'ostracisme à Mégare vers 460, suite à l'alliance conclue par Mégare avec Athènes, ou pendant les années 427-424, lorsque Mégare fut gouvernée par une démocratie.

379 Liddel, Megarid, p. 416; Robu, Hellenistic Megara, à paraître. 


\section{I.4 Conclusions: les causes de la colonisation mégarienne}

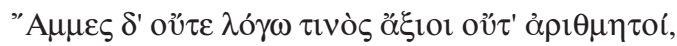

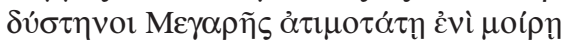

Nous, nous ne valons pas qu' on en parle et nous ne comptons pas, pauvres diables de Mégariens, au rang le plus méprisée ${ }^{380}$.

Les savants ont essayé d'expliquer la colonisation mégarienne de l'époque archaïque en faisant appel, avant tout, à des facteurs économiques et démographiques. Busolt faisait naguère observer que la Mégaride possédait un sol peu propice à l'agriculture, convenant plutôt à l'élevage des moutons. Et comme l'agriculture ne parvenait pas à couvrir les besoins de la population, une bonne partie des habitants ont cherché les moyens de leur subsistance dans la navigation, dans le commerce ou dans divers métiers d'artisans. Dans ces conditions, la colonisation s'avéra être pour les Mégariens la meilleure solution à leur problème démographique ${ }^{381}$. Pour Trever, les raisons du départ des apoikoi furent d'abord la surpopulation et la sténochôria («étroitesse du sol»), et ensuite, le commerce et l'esprit d'aventure ${ }^{382}$.

Rappelons que la surpopulation a été invoquée pour motiver d'autres mouvements de colonisation (par exemple corinthien), et, de manière générale, elle a été jadis considérée comme la cause principale de la co-

380 Théocrite, XIV, 48-49 (trad. de P.-E. Legrand, CUF).

381 Busolt, Gr. Gesch., I, p. 470-471. De même, Highbarger, Megara, p. 103, pense que la stérilité du sol rendait impossible aux habitants de vivre uniquement de produits locaux et fut la première cause de la colonisation mégarienne.

382 Trever, Megara, p. 117: «Megara, like Corinth, was very limited in territory, with poor, stony soil, and devoid of other natural resources. [...] Their land was fitted for little but grazing, and this could be pursued only on a very small scale. Doubtless Megara early failed to raise sufficient grain to feed her population». Il ajoute ensuite: «The dominating motive at first, as in other Greek states, was probably the pressure of population and the need for more arable land. [...] Of course, in addition to land hunger, a complex of motives was active from the first, such as the desire for trade and the spirit of adventure. Political and social revolution, however, was a latter factor» (p. 118). 
lonisation grecque ${ }^{383}$. Cette explication a suscité des critiques légitimes, de sorte que l'on ne saurait l'accepter pour Mégare sans analyse ${ }^{384}$.

Il convient d'emblée de souligner que la thèse moderne sur l'improductivité des terres de l'isthme de Corinthe ne fait que reprendre une opinion antique. Un passage d'Isocrate nous apprend que les Mégariens «n'ont ni terre, ni ports, ni mines d'argent et cultivent un sol pierreux ${ }^{385}$. Malgré ces inconvénients, ajoute Isocrate, ils gouvernent leur cité en se préservant des guerres internes et en profitant des avantages de la paix. Il est pourtant certain que l'on a affaire ici à des exagérations rhétoriques, preuve en est l'absence de mention des ports mégariens chez Isocrate. On en connaît en réalité plusieurs: Nisaia sur le golfe Saronique, et, sur le golfe de Corinthe, Aigosthènes, Pagai et Panormos ${ }^{386}$. Le but du rhéteur est de convaincre les Athéniens des malheurs entrâ̂nés par la politique expansionniste qui les avait menés à la guerre avec

383 A. Gwynn, «The Character of Greek Colonization», JHS 38, 1918, p. 88-123; J. Bérard, L'expansion et la colonisation grecques jusqu'aux guerres médiques, $\mathrm{Pa}-$ ris 1960, p. 60-61 (un ouvrage malheureusement inachevé à cause de la mort tragique de l'auteur dans un accident routier en 1957), estime que la surpopulation aurait été provoquée par la forte croissance démographique que la Grèce avait connue au VIII ${ }^{\mathrm{e}}$ siècle. En considérant ce facteur démographique et social comme responsable du grand mouvement de colonisation de l'époque archaïque, Bérard estime que «si des colons vont s'établir au loin, c'est que le sol de leur patrie ne suffit plus à les nourrir». À propos de la colonisation corinthienne, De Fidio, Corinto $e$ l'Occidente, p. 101, écrit: «all'origine dell'iniziativa coloniale corinzia dell'ultimo terzo del'VIII vi furono probabilmente spinte demografiche e bisogno di terre».

384 Pour la critique de la thèse qui considère la surpopulation comme principale cause de la colonisation grecque, voir J. Fossey, «Some Parameters of Archaic Greek Emigration", in Sur les traces des Argonautes. Actes du $\sigma^{e}$ symposium de Vani (Colchide), 22-29 septembre 1990, O. Lordkipanidzé et P. Lévêque (éds.), Paris 1996, p. 119-128; De Angelis, Found. of Selinous, p. 87-88 (avec les références); Morgan, Isthmia VIII, p. 420, qui note que «it is important to emphasize that overpopulation is as much a social as a biological construct, and that absolute population levels (even when they can be estimated) are no guide to a community's need or ability to colonize».

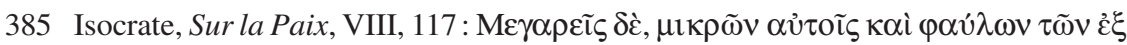

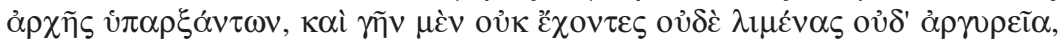
$\pi \varepsilon \dot{\tau} \rho \alpha \varsigma \delta \varepsilon \grave{\varepsilon} \gamma \varepsilon \omega \rho \gamma о \tilde{v} \nu \tau \varepsilon \varsigma, \kappa \tau \lambda$.

386 Sur le port de Panormos, l'objet d'un conflit entre Aigosthènes et Pagai, voir Robert, Inscr. de Pagai, p. 102-119 (= OpMinSel, II, p. 1255-1272). On trouve une mise au point récente sur l'histoire d'Aigosthènes et de Pagai chez Freitag, Der Golf von Korinthos, p. 174-186. 
Sparte au V $V^{\mathrm{e}}$ siècle. C'est dans ce cadre qu'il donne l'exemple des Mégariens qui, à son époque, en dépit de l'absence des ressources naturelles et de leur faible puissance militaire, ont su, grâce à leur modération (sôphrosynè), conserver la paix pour leur cité et bâtir les plus grandes demeures parmi les Grecs. À l'opposé se trouvent les Thessaliens, qui disposent d'un riche territoire et d'une importante armée, des avantages qui ne les ont pas empêchés d'avoir leurs citadelles (akropoleis) occupées par des armées ennemies et de connaître des luttes intestines ${ }^{387}$.

Quant à la pauvreté légendaire des Mégariens, il est probable qu' Isocrate se fait, dans ce passage, l'écho d'un oracle delphique dont l'authenticité reste contestée et qui était fort défavorable à la cité de l'isthme. Ainsi, un poème, repris par des scholiastes et des lexicographes byzantins, nous apprend que les gens de Mégare (ou, selon une autre version, d'Aigion d'Achaïe) allèrent à Delphes pour demander à Apollon quels étaient les meilleurs des Grecs, en espérant être nommés les premiers. Mais le dieu énuméra les vertus de beaucoup d'autres peuples et conclut par leur faire apprendre qu'ils «ne sont ni troisièmes, ni quatrièmes, ni douzièmes, ni en parole, ni en nombre ${ }^{388}$. On trouve des allusions à cette réponse de la Pythie, entre autres, chez Callimaque, Théocrite, Mnaséas de Patras et Plutarque ${ }^{389}$. Selon une tradition reprise par Photius et la Souda, la plus ancienne version de l'oracle était conservée chez Ion de Chios, qui pensait que la réponse était adressée aux gens d'Aigion d'Achaï ${ }^{390}$. Or

387 Isocrate, Sur la Paix, VIII, 116-119, avec les commentaires de Legon, Megara Pol. Hist., p. 278-280; cf. J. Salmon, JHS 103, 1983, p. 203; G. Mathieu (éd.), Isocrate, Discours, Tome III, Paris 1950, p. 44, n. 2, qui se demande à propos de ce passage d'Isocrate: «Cette admiration pour une cité aussi peu importante que Mégare (dont on dissimule la politique de bascule) s'expliquerait-elle en partie par des rapports avec les philosophes établis à Mégare au début du IV ${ }^{\mathrm{e}} \mathrm{s}$. autour d'Euclide?»

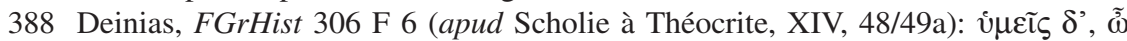

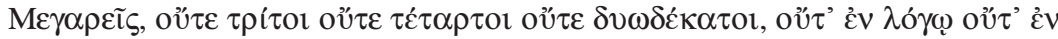

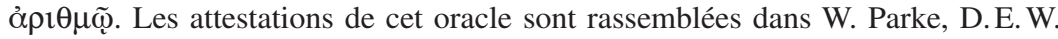
Wormell, The Delphic Oracle, vol. II, Oxford 1956, p. 1-2, no 1 ; J. Fontenrose, op. cit., p. 276-277, n 26.

389 Callimaque, Épigrammes, XXV (éd. R. Pfeiffer; = Anthologie Palatine, V, 6); Théocrite, XIV, 48-49; Mnaséas de Patras, fr. 59 (éd. P. Cappelletto); Plutarque, Propos de table, V, 7, 6 (= Moralia, 682 F); VIII, 8, 4 (= Moralia, 730 D).

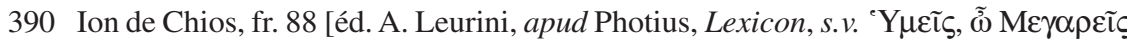

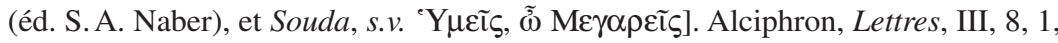
considère que ce proverbe concernait à la fois les gens de Mégare et d'Aigion. Selon 
si les Mégariens n'apparaissaient pas dans ce récit du $V^{\mathrm{e}}$ siècle, on peut penser qu'ils y furent insérés à la place des gens d'Aigion plus tard, au $\mathrm{IV}^{\mathrm{e}}$ siècle, sans doute suite à une influence athénienne ${ }^{391}$. On aurait ainsi une autre preuve des moqueries des Athéniens envers leurs voisins doriens, deux peuples qui étaient réputés, on l'a vu, pour leurs disputes ${ }^{392}$.

Mieux encore, Pausanias considère qu'il y a même une malédiction divine qui plane sur Mégare et qui avait empêché l'empereur Hadrien, malgré ses efforts, d'aider cette cité à se développer davantage. La malédiction découlerait de leurs actes d'impiété: les Mégariens, rappelle le Périégète, avaient tué, juste avant le début de la guerre du Péloponnèse, le héraut athénien Anthémocritos et, en outre, ils avaient mis en culture «la terre sacrée» d'Éleusis, en provoquant ainsi la colère des deux Déesses ${ }^{393}$. Il n'est pas difficile de reconnaître dans ce témoignage une vue des Athéniens qui accusaient, à plusieurs reprises, leurs voisins d'avoir empiété sur une partie de l'orgas sacrée ${ }^{394}$. On conclura donc que Mégare avait une bien mauvaise réputation dans l'Antiquité et que les Athéniens étaient en bonne partie responsables de cette situation. Dans ces conditions, il serait difficile de s'appuyer sur le texte d'Isocrate pour montrer que la prétendue pauvreté de l'isthme de Corinthe fut la cause principale du départ de ses habitants à l'époque

Clément d'Alexandrie, Stromates, VII, 18, 110, ces vers visaient les Mégariens et ils seraient de Théognis. Cf. E. Harrison, Studies in Theognis: together with a Text of the Poems, Cambridge 1902, p. 273-274; A. Le Boulluec (éd.), Clément d'Alexandrie, Les Stromates VII, Paris 1997, p. 328-329, n. 2, qui estime que Clément a pu trouver ces vers attribués à Théognis dans une anthologie. Contre l'attribution des vers à Théognis, il y a l'argument que l'oracle est connu sous forme d'hexamètres, tandis que l'on sait que le poète mégarien avait composé des élégies. En outre, même si Théognis se plaint de ses concitoyens, on n'a aucun indice que le poète avait porté un jugement si critique sur sa cité.

391 W. Parke, D.E.W. Wormell, op. cit., vol. I, p. 83, écrivent: «Our earliest authority, Ion of Chios, the fifth-century litterateur, gave Aegium. Also if the oracle had actually been delivered to the Megarians, it is hard to imagine who would have found it worth while to father it to tiny Aegium. The transfer from Aegium to Megara would have been satisfying to Athenian dislike of their neighbour». Contra J. Fontenrose, op. cit., p. 277, qui pense que c'était Mégare qui apparaissait dans la plus ancienne version du proverbe, qui aurait été transmise par Théognis.

392 Pour les moqueries des Athéniens à l'égard des Mégariens, il suffit de renvoyer à Aristophane, Acharniens, 729-835.

393 Pausanias, I, 36, 3. Cf. D. Knoepfler, Bull. ép., 2010, 337.

394 Voir la bibliographie citée supra, chapitre I.2.1. 
archaïque. De fait, on n'a aucun indice selon lequel ce territoire n'aurait pas offert assez de ressources agricoles à ses habitants.

Certes, étant traversée par des montagnes et des collines, la Mégaride n'a pas une vocation agricole. Il s'agit d'une région géographique bien délimitée: elle est séparée de la Béotie et de l'Attique principalement par les chaînes des montagnes du Cithéron, du Patéras et du Trikérato, tandis que les monts Géraniens forment la frontière avec la Corinthie (voir carte 2) ${ }^{395}$. Strabon rapporte que ce territoire est plutôt

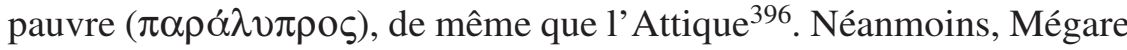
est installée dans une plaine fertile (voir pl. II) et les nombreuses chambres souterraines découvertes dans la ville ont été, à juste titre, mises en rapport avec le stockage de grains ${ }^{397}$. De plus, des céréales furent sans doute cultivées dans la plaine de Pagai, les vallées du littoral (à Aigosthènes, à Panormos/la moderne Psatha) et de l'arrière-pays (telles que celles de Mégalo et Mikro Vathychoria, où l'on situe l'antique Éréneia) ${ }^{398}$. Si les habitants de l'isthme de Corinthe ont importé des céréales dans des situations exceptionnelles, on ne peut pas affirmer qu'ils ne pouvaient pas en règle générale se fournir le nécessaire du blé dont ils avaient besoin ${ }^{399}$.

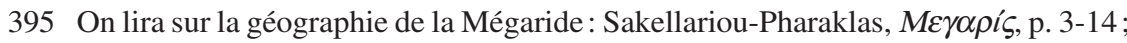
Van de Maele, Ereneia, p. 153-159; Legon, Megara Pol. Hist., p. 21-40; A. Muller, «Megarika», BCH 108, 1984, p. 249-253; Smith, Megaris, p. 5-10.

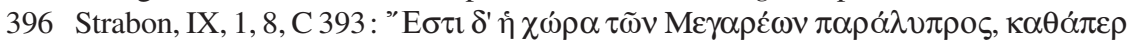

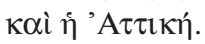

397 Zoridis, Mégara, p. 202, rapporte la découverte de plus de cent chambres souterraines qui auraient été utilisées lors de la fête des Thesmophories et pour le stockage des céréales. Pour la mention des céréales de Mégare, voir Athénée, III, $126 \mathrm{~F}$ et 127 B, qui cite Antiphane, Anteia, fr. 36 (éds. R. Kassel et C. Austin), poète comique du IV IV $^{\mathrm{e}} \mathrm{cle} ; c f$. Théophraste, Recherches sur les plantes, II, 8, 11.

398 Sur la région de Pagai à Aigosthènes, ainsi que sur les deux Vathychoria, voir J. A. Lebègue, op. cit., p. 43-81; Robert, Inscr. de Pagai, p. 118-119 (=OpMinSel, II,

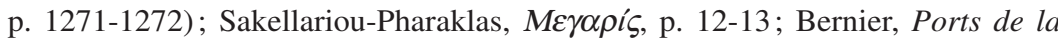
Mégaride, p. 123-124; A. Muller, «Megarika», BCH 106, 1982, p. 403; idem, «Mega-

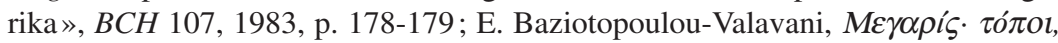
$\mu v \eta \mu \varepsilon i \alpha, \delta i \alpha \delta \rho o \mu \varepsilon ́ \varsigma$, Athènes 2008, p. 43-67.

399 Legon, Megara Pol. Hist., p. 23-24. Mégare figure dans la stèle de Cyrène (ca. 330326) parmi les cités qui, dans un contexte de famine, importèrent des céréales de Libye. Les Mégariens sont inscrits à deux reprises pour un total de 30.000 médimnes : SEG IX, 2, 1.14 (20.000 médimnes) et 1. 36 (10.000 médimnes). Cf. A. Laronde, Cyrène et la Libye hellénistique, Paris 1987, p. 30-36; G. Marasco, Economia e 
Il serait erroné par ailleurs, lorsque l'on traite des ressources naturelles d'un pays, de ne faire état que des paysages agricoles ${ }^{400}$. On sait que l'économie pastorale était particulièrement importante en Mégaride. Les vêtements de laine produits ici étaient renommés et Pline attribue à Nicias de Mégare l'invention de l'art du foulon ${ }^{401}$. Deux inventaires d'Éleusis de la seconde moitié du IV ${ }^{\mathrm{e}}$ siècle mentionnent trois commerçants mégariens à qui l'on avait acheté des tuniques (exômides, Kallias et Midas) et des manteaux (himatia, Antigénès) ${ }^{402}$. D'après Diogène Laërce, le philosophe Diogène le Cynique, de passage à Mégare, constata qu'il était plus avantageux d'être ici le bélier d'un habitant que le fils de celui-ci. En effet, les animaux étaient protégés par des peaux de cuir afin que l'on obtienne une laine de grande qualité, tandis que les enfants étaient nus ${ }^{403}$. Il ressort de ce récit que la laine utilisée pour les habits fabriqués à Mégare était de production locale, sans que l'on puisse pour autant exclure qu'elle fut en partie importée ${ }^{404}$. Un décret d'Aigosthènes octroie, dans la première moitié du $\mathrm{II}^{\mathrm{e}}$ siècle, l'épinomia (le «droit de pâturage») à un citoyen de Mégare, un certain Apollodôros, fils d'Alkimachos, confirmant ainsi l'importance de ce privilège pour les relations entre les Mégariens ${ }^{405}$. De même, les modernes ont suggéré

storia, Viterbo 1992, surtout p. 19-52; A. Bresson, «L'attentat d'Hiéron et le commerce grec», in Les échanges dans l'Antiquité: le rôle de l'État, Entretiens d'archéologie et d'histoire 1, P. Briant (éd.), Saint-Bertrand-de-Comminges 1994, p. 5052 (= La cité marchande, Paris 2000, p. 135-137), qui suggère que les licences d'exportation accordées par les Cyrénéens aux Grecs étaient accompagnées d'atélie.

$400 C f$. J. et L. Robert, Bull. ép., 1958, 320, p. 590-591.

401 Aristophane, Acharniens, 519; Paix, 1002; Xénophon, Mémorables, II, 7, 6; Pline, NH, VII, 196. Cf. M. I. Rostovtseff, Histoire économique et sociale du monde hellénistique, traduction O. Demange, Paris 1989, p. 69; Legon, Megara Pol. Hist., p. 24, 87-90, 280-283; Smith, Megara and her Colonies, p. 78.

402 K. Clinton, Eleusis. The Inscription on Stone. Documents of the Sanctuary of the Two Goddesses and Public Documents of the Deme, vol. I, Athens 2005, $\mathrm{n}^{\mathrm{o}} 159$, 1. 45-46 (IG II $\left.{ }^{2} 1673\right)$; n ${ }^{\circ} 177,1.165$ (IG II ${ }^{2}$ 1672); $c f$. M. Bettalli, «Note sulla produzione tessile ad Atene in età classica», Opus 1, 1982, p. 264, 271-272.

403 Diogène Laërce, VI, 41. Sur ce type d'élevage pratiqué à Mégare, voir C. Chandezon, L'élevage en Grèce ( fin $V^{e}$-fin I'r s. a. C.). L'apport des sources épigraphiques, Bordeaux 2003, p. 401.

$404 C f$. A. Bresson, «Greek Epigraphy and Ancient Economics», in Epigraphy and Historical Sciences, J. Davies et J. Wilkes (éds.), Oxford 2012, p. 230-231.

405 IG VII 223, 1. 18; cf. Robu, Décret d'Aigosthènes, p. 79-101. 
que les tours et les fortins situés dans le territoire, notamment à la frontière avec l'Attique, servaient de lieux de refuge pour la population locale et le bétail ${ }^{406}$.

Du reste, il y avait des possibilités de cultiver des oliviers, des arbres fruitiers, des légumes, des vignes autour des principaux habitats mégariens ${ }^{407}$. La vallée d'Aigosthènes est propice à la viticulture et Polybe évoque le vin doux produit dans cette cité ${ }^{408}$. Une autre ressource de la région est le bois: une partie de la Mégaride est aujourd'hui couverte de forêts de pins et l'on peut penser que cela fut aussi le cas dans l'Antiquité (voir pl. IV) ${ }^{409}$.

Bref, les ressources de l'isthme de Corinthe ne sont pas maigres et elles n'appuient pas a priori la thèse selon laquelle la colonisation ne fut pas autre chose qu'un remède à la pauvreté de la région. Pour contourner ce fait, les savants, dont certains d'excellents connaisseurs de l'économie de la région (tels que Hammond et Legon), ont considéré que ce furent les défaites des Mégariens dans les conflits avec Corinthe qui expliqueraient la fondation des colonies en Sicile et dans la Propontide. D'après eux, les pertes territoriales (notamment de Pérachora) provoquèrent un surplus de population. Et, étant dans l'impossibilité de trouver les terres nécessaires à leur subsistance, les émigrés des territoires

406 S. van de Maele, «Le réseau mégarien de défense territoriale contre l'Attique à l'époque classique ( $\mathrm{V}^{\mathrm{e}}$ et $\mathrm{IV}^{\mathrm{e}}$ s. av. J.-C.)», in Fortificationes Antiquae, S. van de Maele et J.M. Fossey (éds.), Amsterdam 1992, p. 93-107; H. Lohmann, «Antike Hirten in Westkleinasien und der Megaris: zur Archäologie der Mediterranen Weidewirtschaft», in Volk und Verfassung im vorhellenistischen Griechenland. Beiträge auf dem Symposium zu Ehren von Karl-Wilhelm Welwei in Bochum, 1-2 März 1996, W. Eder et K.-J. Hölkeskamp (éds.), Stuttgart 1997, p. 75-81; P. Zoridis, «А А $A D$ 57, 2002 (2010), A', p. 93-118.

407 À en croire Aristophane, Acharniens, 519-522, 761; Paix, 246, 1000-1002, les Mégariens fournissaient aux marchés d'Athènes de l'ail, des concombres, des coings, des grenades, du sel, des levreaux, des cochons et des mantelets pour les esclaves. Sur les divers produits de la Mégaride, voir Meyer, Megara, col. 171-174 (avec les

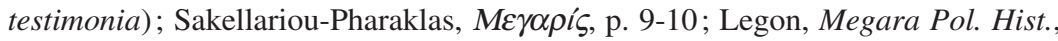
p. 24; A. Muller, «Megarika», BCH 106, 1982, p. 403-405.

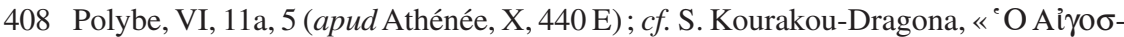

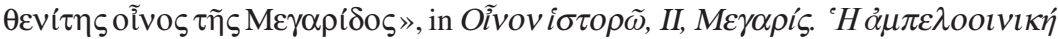

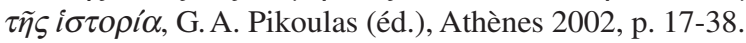

409 Meyer, Megara, col. 174; Robert, Inscr. de Pagai, p. 116-118 (= OpMinSel, II, p. 1269-1271). 
conquis par les Corinthiens furent obligés de quitter leur pays ${ }^{410}$. Pourtant, l'examen des documents entrepris dans le premier chapitre de l'ouvrage ne confirme pas de pertes mégariennes importantes aux VIII et VII ${ }^{\mathrm{e}}$ siècles. Il n'existe pas de trace archéologique d'une possession de Pérachora par les Mégariens à la haute époque archaïque. Et même si Corinthe a réussi à occuper quelques territoires de frontière (Krommyon), il est improbable que ce soit ces pertes - pour lesquelles on n'a pas de date précise - qui provoquèrent le départ des Mégariens. D'ailleurs, les conflits de voisinage sont un type de combat qui caractérise les rapports entre les cités et qui n'implique pas nécessairement un déplacement de population $^{411}$. En outre, les Mégariens ont aussi vaincu leurs voisins à l'époque archaïque: les sources témoignent de la conquête des terres de frontière par l'olympionique Orsippos et le trésor mégarien rappelle à Olympie une victoire contre Corinthe. La fondation de cinq cités (Mégara en Sicile, Astacos, Chalcédoine, Sélymbria et Byzance dans la Propontide) en l'espace de deux générations environ ne saurait donc pas être imputée à la surpopulation et aux défaites dans les guerres extérieures ${ }^{412}$.

Il est en revanche permis de supposer que la fondation de ces colonies fut l'œuvre des familles (oikoi) exclues du synœcisme et du nouveau système politique mis en place. On assiste dans la deuxième moitié du VIII ${ }^{\mathrm{e}}$ siècle et la première moitié du VII ${ }^{\mathrm{e}}$ siècle à deux phénomènes simultanés: le synœcisme, qui aboutit à la création de la cité, et la colonisation. À mon sens, les changements politiques du haut archaïsme ont provoqué non seulement la création d'institutions nouvelles, mais aussi l'exclusion de certains groupes de l'exercice du pouvoir. Le lien existant entre les luttes internes et l'expulsion est attesté plus tard, pour la Mégare du VI ${ }^{\mathrm{e}}$ siècle: les démocrates bannissent les oligarques et confisquent leurs biens. Si le régime «démocratique»s'appuyait sur une meilleure intégration des jeunes adultes dans la cité (hypothèse de Steinrück), cela expliquerait l'absence du phénomène de la colonisation dans la première moitié du $\mathrm{VI}^{\mathrm{e}}$ siècle. L'intervention des Amphictions

410 Hammond, Heraeum, p. 93-102; Legon, Megara Pol. Hist., p. 70; Hind, Megarian Colonization, p. 131, 133; Paltseva, Mégare, p. 230-239; cf. Highbarger, Megara, p. 66; Busolt, Gr. Gesch., I, p. 470-471, n. 4. Voir aussi supra, chapitre I.1.1.

411 Cf. Osborne, Classical Landscape, p. 145; Daverio Rocchi, Frontiera e confini, p. 28-30.

412 Figueira, Chronological Table, p. 275. 
de Delphes provoqua la chute de la «démocratie sans retenue» et le retour des oligarques. On enregistre alors de nouveaux bannissements et les magistratures sont réservées au groupe restreint des exilés du régime «démocratique». Ce renversement politique est probablement la cause de la fondation d'Héraclée du Pont vers 554 par les Mégariens et les Béotiens, qui avaient suivi le conseil de la Pythie. Comme Platon en témoigne, la colonisation reste le meilleur moyen de se débarrasser des hommes qui n'ont rien et qui sont prêts à suivre leurs chefs (hégémones) pour s'en prendre aux biens des possédants ${ }^{413}$.

Chose intéressante, des Mégariens bannis de leur cité font appel à l'oracle de Delphes, preuve en étant un passage du traité Sur l'exil de Favorin d'Arles, peu commenté par les spécialistes de la colonisation. Cet auteur du $\mathrm{II}^{\mathrm{e}}$ siècle ap. J.-C. atteste qu'un exilé mégarien, un certain Lampos/Lampôn, est allé consulter Apollon. À son arrivée, le dieu le salua ainsi: "un homme noble est venu pour chercher une descendance et une demeure ${ }^{414}$. Le personnage n'est pas connu par ailleurs, et l'hypothèse d'Amato selon laquelle il s'agirait du fondateur de Callatis nécessite plus de preuves pour que l'on puisse la suivre ${ }^{415}$. La réponse du dieu laisse penser qu'il s'agissait d'un jeune homme, issu d'une famille illustre (il est qualifié de kleinos), mais qui ne trouvait ni femme, ni terres dans sa patrie. Dans ces conditions, l'exilé se tourna vers l'oracle de Delphes qui recommanda sans doute la fondation d'une nouvelle cité.

Du reste, il est possible que les défaites de Mégare dans la guerre que celle-ci mena au $\mathrm{VI}^{\mathrm{e}}$ siècle contre Athènes pour la possession de Salamine aient joué un rôle dans la décision d'installer une apoikia dans le Pont-Euxin. Considérée comme athénienne par les cinq arbitres

413 Platon, Lois, V, 736 a; $c f$. C. Dougherty, The Poetics of Colonization. From City to Text in Ancient Greece, New York-Oxford 1993, p. 37.

414 Favorin d'Arles, Sur l'exil, 24, 7-9 (éd. A. Barigazzi; = XXII, 33-35, éd. A. Tepe-

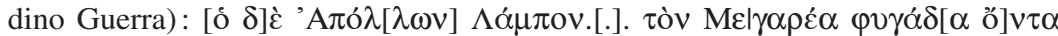

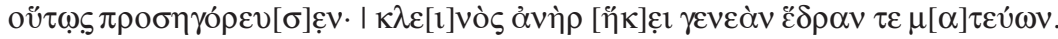
Bien que Favorin ne précise pas à quel Apollon nous avons affaire, il est certain que celui-ci est le dieu de Delphes, compte tenu du rôle de cette divinité dans la colonisation.

415 E. Amato, «Apollo, Lampos/Lampone e la fondazione di Callatis? (Nota a Pap. Vat. gr. 11v, col. 22, 33-35)», Emerita 75, 2, 2007, p. 319-338, réfute l'hypothèse selon laquelle le Mégarien mentionné par Favorin serait à identifier avec l'un des fondateurs de Thourioi, l'Athénien Lampôn. Il note avec raison que ce dernier ne fut pas un exilé. Voir infra, chapitre II.3.1.1, sur la fondation de Callatis. 
de Sparte, l'île n'offrait plus aux jeunes de Mégare la possibilité de guerroyer pour leur cité et pour l'espoir d'acquérir de nouvelles terres. Ainsi, l'expansion de Mégare dans le golfe Saronique prit fin et la cité resta à peu près dans les mêmes frontières jusqu'à l'époque hellénistique, lorsque Aigosthènes et Pagai obtinrent l'indépendance. Ce n'est peut-être pas un hasard si la fondation de Mésambria vers 513/2 par les Mégariens et les Chalcédoniens est contemporaine de l'arbitrage spartiate des années 520-510. Sans les terres de Salamine, certains Mégariens acceptèrent de se joindre à leurs anciens colons pour fonder une apoikia sur la rive ouest de la mer Noire.

En vérité, s'il est nécessaire de mettre en garde contre les excès de la thèse de la surpopulation comme seule explication du départ des colons, les facteurs fonciers, quant à eux, méritent d'être pris en compte $^{416}$. La division successorale, l'accumulation des terrains entre les mains d'une élite et la confiscation des biens des adversaires politiques produisirent d'inévitables inégalités foncières et économiques ${ }^{417}$. Or la fondation d'une cité offrait la possibilité de procéder à la fois à un nouveau lotissement des terres et à une meilleure distribution des honneurs. L'anecdote d'Aithiops, apoikos corinthien qui, en route pour la Sicile, vendit le lot (klèros) censé lui revenir dans la future Syracuse pour un gâteau de miel, révèle que la possession d'un terrain figure parmi les droits des colons ${ }^{418}$. Et, comme nous le verrons dans les chapitres suivants, le lot occupe une position centrale dans le premier urbanisme de Mégara et de Sélinonte.

D'autre part, on sait que les colonies connaissent aussi des inégalités de statut: une aristocratie foncière, les «gros» (pacheis), apparaît à Mégara quelques générations après la fondation ${ }^{419}$. Cette stratification sociale découlerait de la mainmise d'une partie des habitants sur les

416 Parmi les prises de position sur les facteurs fonciers dans la colonisation, on renvoie à J. Zurbach, "Question foncière et départs coloniaux. À propos des apoikiai archaïques », ASAA 86, serie III, 8, 2008 (2010), p. 87-103; D’Ercole, Colonisation grecque, p. 51-75.

417 Hésiode, Travaux et jours, 376-377, rapporte qu'avoir un seul fils permettra d'éviter la dispersion de l'héritage. Sur la tendance de l'élite à monopoliser la propriété foncière à l'époque archaïque, voir M. Detienne, Crise agraire et attitude religieuse chez Hésiode, Bruxelles 1963, p. 12-27; Van Wees, Mafia of Early Greece, p. 1-51.

418 Archiloque, fr. 216 (éd. F. Lasserre, CUF).

419 Hérodote, VII, 156; $c f$. A. Fouchard, op. cit., p. 84, 107. 
terres et des différences juridiques existant entre les descendants des premiers colons et les colons supplémentaires. Si le «Serments des Fondateurs » prévoit à Cyrène que les colons ultérieurs auront les mêmes droits que les premiers, c'est sans doute parce que cela n'était pas toujours le $\operatorname{cas}^{420}$. Aristote met en garde contre le risque de sédition qui existe dans les colonies ayant admis de nouveaux colons, et il cite le cas de Byzance, où les époikoi furent chassés de la ville à cause d'une rébellion. Les raisons de ce complot pouvaient bien être la revendication d'une meilleure distribution des terres et des droits civiques ${ }^{421}$.

Qu'en est-il des facteurs commerciaux dans la colonisation mégarienne? Bien que certaines cités soient fondées dans des régions qui deviendront des centres d'échanges importants (comme Byzance), il reste difficile d'établir le rôle du commerce dans le départ de colons ${ }^{422}$. À cet égard, les sources textuelles et archéologiques ne témoignent, du moins pour l'instant, ni de la présence d'une aristocratie commerçante ou maritime à Mégare (comme celle supposée à Égine ou à Érétrie), ni de réseaux d'échanges entre la métropole et ses colonies ${ }^{423}$. Assurément, cela n'exclut pas l'existence des contacts; on sait par exemple que les Mégariens collaborent avec leurs apoikoi dans la fondation des nouvelles cités (Sélinonte, Mésambria). Mais de manière générale, il faut avouer que par opposition aux relations existant entre Milet, Samos et leurs colonies respectives, les rapports de Mégare avec ses

420 Voir supra, chapitre I.1.4.

421 Aristote, Politique, V, 3, 11-12, 1303a 25-34.

422 Suivant Smith, Megara and her Colonies, p. 76-77; idem, Megaris, p. 78, 98, les raisons de la colonisation mégarienne furent la surpopulation, les luttes internes (dans le cas d'Héraclée du Pont) et surtout le commerce et la recherche des métaux. Il cite dans ce cadre l'exemple de la colonie de Chalcédoine, dont le nom suggérerait que cette cité possédait des mines de cuivre. Celle-ci n'est pourtant pas la seule étymologie et, selon d'autres traditions, Chalcédoine tirait son nom du prophète Calchas ou de son fils, Calchédon: Robu, Chalcédoine, p. 144-146, et infra, chapitre II.2.2.1.

$423 C f$. A. Robu, «Chronique mégarienne. À propos d'un livre récent portant sur les cités mégariennes de Sicile», AC 75, 2006, p. 208-209. Sur l'implication des élites d'Égine dans les activités commerciales qui firent la célébrité de l'île, voir Figueira, Aegina, p. 280-286. La présence d'une aristocratie maritime a aussi été supposée à Érétrie: J. et L. Robert, Bull. ép., 1965, 324 (à propos des aeinautai érétriens); P. Lévêque, «Le dynamisme d'Érétrie la Rameuse. La genèse précoce d'une cité », MEFRA 101, 1989, p. 739-750; idem, Les Grecs en Occident, p. 14. 
colonies restent peu documentés ${ }^{424}$. On constate par ailleurs que les colonies de la Propontide furent confrontées à des guerres difficiles contre les indigènes aussitôt après leur fondation. Leur salut fut en bonne partie rendu possible par leur alliance militaire - elles réussirent à mettre en place un véritable «réseau» mégarien - et aucun soutien de la métropole n'apparaît explicitement mentionné par les sources ${ }^{425}$. L'hypothèse, avancée jadis par Burn, d'une thalassocratie mégarienne entre ca. 660-599 est donc contestable ${ }^{426}$.

On ne saurait refuser pour autant toute vocation commerciale aux Mégariens, dont le territoire, situé entre deux golfes (le Golfe de Corinthe au nord-ouest et le Golfe Saronique au sud-est), fut toujours une zone d'échanges très actifs entre le Péloponnèse, l'Attique et la Grèce centrale ${ }^{427}$. Le passage de commerçants susceptibles d'offrir des informations sur des régions lointaines et la double ouverture sur la mer dont l'isthme de Corinthe bénéficie n'ont fait que favoriser le départ des colons. De même, il convient de rappeler que Mégare est une cité maritime dans l'Antiquité grecque. Selon Théocrite (début du III ${ }^{\mathrm{e}}$ siècle), ses habitants sont excellents au maniement des rames et leur art de la navigation (nautikè) aurait été célébré par Simonide ${ }^{428}$. Et si les guerres de Mégare avec Athènes sont à l'époque archaïque surtout des combats terrestres,

424 Je rappelle que Milet conclut des traités d'isopolitie au IV ${ }^{\mathrm{e}}$ siècle avec, entre autres, Olbia et Cyzique: A. Rehm (éd.), Das Delphinion in Milet, Berlin 1914, 136; 137 ; cf. Graham, Colony, p. 99-102; Ehrhardt, Die politischen Beziehungen, p. 85-87, 115-117 ; P. Herrmann (éd.), Milet VI. Inschriften von Milet, vol. I, Berlin-New York 1997, p. 170-171. Sur les rapports entre Milet et ses colonies pontiques au vu des trouvailles céramiques, voir Dupont, Le Pont-Euxin archaïque, p. 29-36. Voir infra, chapitre II.2.1.2, sur les rapports entre Samos et ses colonies.

425 Voir infra, chapitres II.2.1.2 et II.2.4.1.7.

426 Burn, Gr. Sea Power, p. 165-177, estime que la mention des Cariens dans la liste des puissances maritimes archaïques, transmise par Eusèbe, est une erreur, et propose le remplacement de KAPE $\Sigma$ par MEГAPEI $\Sigma$. Cette thèse est acceptée par W. G. Forrest, «Two Chronograpic Notes», CQ 19, 1969, p. 95-106. Contra Legon, Megara Pol. Hist., p. 89.

427 A. Muller, «Megarika», BCH 108, 1984, p. 249-251; Lévêque, Grecs en Occident, p. 15.

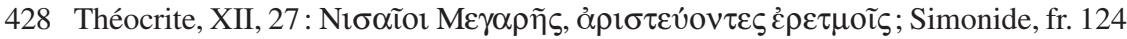

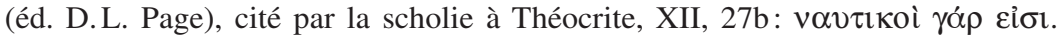

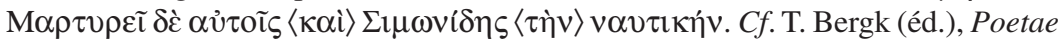
Lyrici Graeci ${ }^{4}$, vol. III, Leipzig 1882, ad fr. 199, p. 523 ; J. H. Molyneux, Simonides. A Historical Study, Wauconda IL 1992, p. 200. 
l'emploi des navires est parfois mentionné par les sources. Grâce à Pausanias, on apprend que les Mégariens consacrèrent dans le sanctuaire de Zeus Olympien, situé au pied de l'acropole Caria, l'éperon d'un navire pris aux ennemis dans un combat naval au large de Salamine ${ }^{429}$. La cité fournit 20 trières à la flotte des alliés qui affronte les Perses à Salamine, seuls les Athéniens (127 trières, plus les 20 vaisseaux athéniens armés par les Chalcidiens) et les Corinthiens (40 trières) avaient fait mieux ${ }^{430}$. Ensuite, elle appuie Corinthe dans la guerre contre Corcyre d' abord avec 8 trières (en 435),

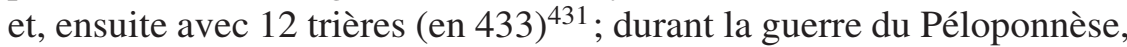
ses ressortissants (Hélixos, Komôn) participent en tant qu'amiraux aux batailles navales dans la Propontide en 411 et à Aigos Potamos en $405^{432}$.

En conclusion, on peut compter parmi les causes de la colonisation mégarienne, sans crainte de se tromper, la distribution inégale des droits civiques et des terres, les luttes intestines et le bannissement des adversaires politiques. On pourrait ajouter à celles-ci des facteurs conjoncturels, tels que la famine provoquée par une période prolongée de sécheresse et de mauvaises récoltes. À cet égard, nous ne disposons que de témoignages indirects et de trouvailles incomplètes. On peut citer notamment un passage de Pausanias, qui explique le culte rendu à Zeus Aphésios («Libérateur»), au sommet des Roches Sironiennes, par une sécheresse qui s'était abattue sur la Grèce. Après la consultation de l'oracle de Delphes, les Grecs s'adressèrent à Éaque d'Égine pour intercéder en leur faveur auprès de Zeus Panellénios. Malheureusement, le passage est ensuite corrompu et l'interprétation de l'épiclèse Aphésios, que le Périégète met en rapport avec ỏ $\varphi \imath \varepsilon ́ v \alpha l$, reste difficile ${ }^{433}$. Arrien rapporte que Deucalion consacra un autel à Zeus Aphésios sur le sommet de l'acropole d'Argos (le lieu de son refuge), en guise de remerciement pour avoir échappé au déluge ${ }^{434}$. La plupart des spécialistes

429 Pausanias, I, 40, 4-5 ; cf. A. Muller, «Megarika», BCH 108, 1984, p. 256-260. La proue qui orne les monnaies mégariennes en bronze d'époque hellénistique serait, d'après Head, $H N^{2}$, p. 394, celle de cet ancien navire pris par les Mégariens aux Athéniens.

430 Hérodote, VIII, 1.

431 Thucydide, I, 27, 2; 46, 1.

432 Legon, Megara Pol. Hist., p. 255-256 (avec les testimonia).

433 Pausanias, I, 44, 9; voir aussi II, 29, 7-8; cf. Piccirilli, MEGARIKA, p. 94-97.

434 Arrien, FGrHist 156 F 16. Pour Hanell, Megarische Studien, p. 79-83, le culte mégarien de Zeus Aphésios serait d'origine argienne et il serait, lui aussi, à mettre en rapport avec le mythe du déluge. 
pensent que Zeus Aphésios est une divinité «météorologique», qui apporte la pluie et frappe du tonnerre ${ }^{435}$. En revanche, Robert l'interprète comme un dieu qui guide les voyageurs et assure leur bon départ, en considérant la légende de Pausanias comme étiologique ${ }^{436}$. Le sanctuaire de Zeus Aphésios a été localisé sur une terrasse, au lieu-dit «Marmara», à deux heures environ au sud-ouest de Mégare, là où des fouilles de Philios ont mis au jour en 1889 un ensemble de plusieurs constructions (temple, autel, bases d'offrandes, divers bâtiments, voir pl. V et VI). Sur la foi de la brève description des céramiques donnée par le fouilleur, Muller suggère que le sanctuaire fut fondé vers la fin de l'époque géométrique et qu'il connut une fréquentation durant les époques archaïque et classique $^{437}$. Néanmoins, en l'absence d'une publication détaillée des trouvailles, les différentes phases du sanctuaire demeurent inconnues. Il serait en conséquence hasardeux de tirer une conclusion sur un éven-

435 L.R. Farnell, The Cults of the Greek States, vol. I, Oxford 1896 p. 51 ; A. B. Cook, Zeus. A Study in Ancient Religion, vol. II, part 1, Cambridge 1925, p. 179; J. McK. Camp II, «A Drought in the Late Eighth Century B.C.», Hesperia 48, 1979, p. 408; M.B. Sakellariou, Le peuplement de la Grèce et du bassin égéen aux hautes époques. 3. Les proto-Grecs, Athènes 1980, p. 214-216; A. Muller, «Megarika», BCH 107, 1983, p. 170-171; Antonetti, Panthéon de Mégare, p. 42.

436 L. Preller, Griechische Mythologie. Vierte Auflage bearbeitet von Carl Robert, vol. I, Berlin 1894, p. 118, n. 3. Cf. L. R. Farnell, op. cit., p. 45; Highbarger, Megara, p. 4142 ; M. K. Langdon, A Sanctuary of Zeus on Mount Hymettos, Hesperia, Suppl. 16, Princeton 1976, p. 82.

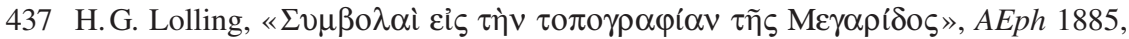
col. 213-216, a été le premier à reconnaître dans les vestiges de Marmara les restes

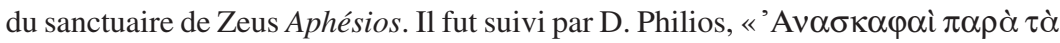
Mć $\alpha \rho \alpha », A E p h$ 1890, col. 21-64 (avec une lettre de H.G. Lolling, p. 55-62); A. B. Cook, op. cit., vol. II, part 2, p. 895-897. Contra N. Pharaklas, in Sakellariou-

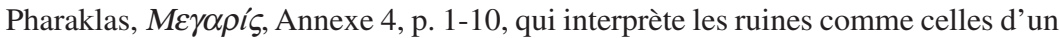

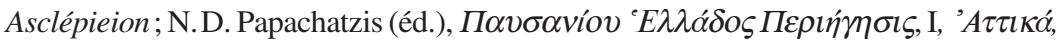
Athènes 1974, p. 518, n. 1, qui pense qu'il s'agissait des locaux d'une garnison qui devait surveiller le passage scironien. Ces deux opinions ont été rejetées par A. Muller, $B C H 107,1983$, p. 157-176, qui a apporté de nouveaux arguments en faveur de la première identification des constructions. Cf. Mazarakis Ainian, From Rulers' Dwellings to Temples, p. 318. Notons aussi que le graffito $\Phi \mathrm{E} \Sigma$ trouvé à Marmara donne peut-être l'épiclèse du dieu: D. Philios, op. cit., p. 46, pl. 6, nº 7; repris dans

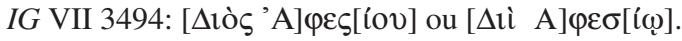


tuel lien entre le culte de Zeus Aphésios et le départ des colons à cause d'une sècheresse de longue durée ${ }^{438}$.

Pour les modalités de l'envoi des colons, force est de mentionner l'interprétation du culte mégarien d'Apollon Dékatèphoros, avancée par C. Antonetti. Selon cette savante, le surnom Dékatèphoros ferait référence à «l'éloignement d'une partie du corps civique vouée à un dieu», le mot dékatè (la «dîme») ayant acquis un sens technique dans le cadre de la colonisation ${ }^{439}$. La célébration d'Apollon Dékatèphoros dans l'ancien Apollônion de la ville aux côtés d'Apollon Archégète, divinité spécifique de la colonisation, appuierait aussi cette opinion ${ }^{440}$. On se rappelle aussi la tradition selon laquelle la cité de Rhégion fut fondée par des Chalcidiens consacrés comme dîme à Apollon à cause d'une famine ${ }^{441}$. Confrontés à des situations exceptionnelles (disettes, épidémies ou staseis), les Mégariens auraient offert, eux-aussi, une partie du corps civique à Apollon, célébré depuis comme Dékatèphoros. Bien que cette hypothèse soit séduisante, il faut avouer qu'elle n'est pas la seule explication possible. On doit peut-être privilégier un sens général pour Dékatèphoros, épiclèse qui renvoie à la qualité de «receveur de dîme»

438 J. McK. Camp, op. cit, p. 397-411, invoque divers témoignages archéologiques (surtout l'augmentation des puits vers 760-700 sur le site de la future agora d'Athènes) et textuels pour appuyer la légende de la sécheresse évoquée par Pausanias. D'après lui, cette sécheresse prolongée et la famine qui la suivit pourraient expliquer la colonisation grecque de la fin du VIII ${ }^{\mathrm{e}}$ et du début du VII ${ }^{\mathrm{e}}$ siècle. La thèse de Camp a été critiquée par A.M. Snodgrass, «Two Demographic Notes», in The Greek Rennaissance of the Eight Century B.C. Tradition and Innovation. Proceedings of the Second International Symposium at the Swedish Institute in Athens, 1-5 June 1981, R. Hägg (éd.), Stockholm 1983, p. 170, qui refuse de considérer le site de l'Agora comme représentatif de la situation en Attique au VIII ${ }^{\mathrm{e}}$ siècle. Car Athènes n'était à cette époque qu'un groupe de villages, peu centré sur l'Acropole. Un autre contreargument de Snodgrass, qui peut valoir aussi pour la Mégaride, est qu'il est difficile de croire qu'une sècheresse affecta l'Attique durant deux générations, un tel fléau étant limité dans la Méditerranée à des périodes de quelques années. $C f$. M. Sakellariou, ASAA 59, N.S. 43, 1981 (1983), p. 157-158; I. Morris «Archaeology and Archaic Greek History», in Archaic Greece : New Approaches and New Evidence, N. Fisher et H. van Wees (éds.), London 1998, p. 76-77.

439 Antonetti, Apollon, p. 20-21. Sur la pratique de consacrer une dîme d'hommes à Apollon de Delphes, voir Malkin, Religion and Colon., p. 37-41.

440 Pausanias, I, 42, 5, atteste que l'ancien temple d'Apollon abrita à Mégare les statues d'Apollon Pythien, d'Apollon Dékatèphoros et d'Apollon Archégète.

441 Strabon, VI, 1, 6, C 257. 
du dieu et que l'on célèbre notamment après une victoire militaire ${ }^{442}$. De fait, on constate que les Mégariens consacrèrent à Delphes, au cours du $\mathrm{V}^{\mathrm{e}}$ siècle, une statue d'Apollon tenant une lance, après une victoire contre des Athéniens à Nisaia ${ }^{443}$. Et Vatin pense avoir retrouvé la base de cette statue sur laquelle le mot dékatè apparaîtrait aussi ${ }^{444}$. Apollon n'est d'ailleurs pas la seule divinité à qui l'on apporte une dîme à Mégare et une inscription mentionne la consécration vers le milieu du $\mathrm{V}^{\mathrm{e}}$ siècle d'une dékatè à Athéna ${ }^{445}$.

Enfin, dans l'examen des raisons de la colonisation, je crois qu'une distinction entre les différentes vagues de colons s'impose. Car les conditions des départs dans la deuxième moitié du VIII ${ }^{\mathrm{e}}$ - première moitié du $\mathrm{VII}^{\mathrm{e}}$ siècle furent sans doute différentes de celles du $\mathrm{VI}^{\mathrm{e}}$ siècle. On retiendra dans ce cadre que les colonies de Sicile et de la Propontide furent le résultat d'un processus d'unification politique, que les anciens nommèrent synoikismos, et qui entraîna le départ du surplus d'hommes que la nouvelle cité oligarchique ne pouvait pas intégrer politiquement et économiquement. La fondation d'Héraclée du Pont vers le milieu du $\mathrm{VI}^{\mathrm{e}}$ siècle, quant à elle, découla des luttes entre diverses factions politiques et est à mettre en rapport avec le renversement de la «démocratie sans retenue». L'installation des Mégariens à Mésambria vers la fin du $\mathrm{VI}^{\mathrm{e}}$ siècle survint dans le contexte de l'attribution de l'île de Salamine par les arbitres spartiates à Athènes. Comme nous avons pu le constater, ce sont les jeunes hommes qui participent aux combats contre Athènes et qui sont habituellement recrutés pour fonder des apoikiai. La guerre et la colonisation peuvent apporter de la gloire à la cité et faire accroître

442 Highbarger, Megara, p. 32-33; Hanell, Megarische Studien, p. 89; Detienne, Apollon, p. 217; F. Chamoux (éd.), Pausanias, Description de la Grèce, Livre I, L'Attique, Paris 1992, ad I, 42, 5, p. 262, suggère que la statue d'Apollon Dékatèphoros fut érigée avec la dîme d'un butin ou d'une récolte.

443 Pausanias, X, 15, 1; Plutarque, Sur les oracles de la Pythie, 16 (= Moralia 402 A).

444 C. Vatin, «L'Apollon des Mégariens à Delphes», MEFRA 95, 2, 1983, p. 628-633 (SEG XXXIII, 438), date la dédicace de 446-445, lorsque les Mégariens abandonnèrent l'alliance athénienne et, appuyés par les Péloponnésiens, envahirent l'Attique. Le butin obtenu à cette occasion leur aurait permis d'ériger une statue d'Apollon à Delphes. En revanche, Legon, Megara Pol. Hist., p. 254-255, n. 70, estime que l'ex-voto se placerait dans le contexte de la reprise de Nisaia par les Mégariens, après 412.

445 IG VII 37; P. A. Hansen (éd.), Carmina epigraphica Graeca saecolorum VIIIVa.Chr.n., Berlin-New York 1983, $\mathrm{n}^{\circ} 361$. 
sa renommée ${ }^{446}$. Il est d'ailleurs vraisemblable qu'une compétition existait entre Mégare et d'autres cités (Corinthe, Samos, Milet) dans la colonisation et dans l'appropriation des territoires durant l'époque archaïque. Les récits témoignent des conflits entre les Mégariens et les Chalcidiens à Léontinoi en Sicile ${ }^{447}$, et entre les Mégariens et les Samiens dans la Propontide ${ }^{448}$.

Au surplus, il ne faut pas oublier que le succès des implantations coloniales tient aussi à la collaboration des Mégariens avec les habitants d'autres cités grecques (Béotiens, Argiens, Mégariens des colonies), et parfois à de bons contacts avec les tribus indigènes (voir le rôle du roi Hyblôn dans la fondation de Mégara). La participation des groupes de colons non mégariens à l'établissement et au développement des colonies ne relève pas nécessairement d'une décision d'État (à savoir de leur cité d'origine), mais souvent d'une implication individuelle. Il existait en Sicile, tout comme en Propontide, des alliances entre des groupes de colons menés par divers chefs (hégémones); ces derniers sont par la suite célébrés dans les colonies comme fondateurs de la cité (oikistai) ou de divers groupes gentilices.

Le départ des colons mégariens semble être néanmoins organisé dans le cadre de la cité, les grandes familles participent à cette entreprise collective et assurent le transfert des coutumes institutionnelles (nomima) de la cité-mère vers les apoikiai ${ }^{449}$. L'examen des traditions de fondation et des institutions politiques mégariennes, que j'ai prévu d'entreprendre dans les deux autres parties de l'ouvrage, montrera le désir des colonies de rappeler leur ancienne origine et de conserver l'héritage institutionnel de leur métropole.

446 Le cas de la fondation de Cyrène est particulièrement intéressant pour la participation des jeunes hommes dans la colonisation et leur modalité de désignation. Hérodote, IV, 153, rapporte que les Théréens décidèrent de recruter un frère sur deux, sans doute un fils par famille, choisi par le tirage au sort. Cette règle est mentionnée par le «Serment des Fondateurs » SEG IX, 3, voir les lignes 27-30 dans la nouvelle édition de l'inscription donnée par C. Dobias-Lalou, op. cit., p. 244-246. Cf. F. Chamoux, Cyrène sous la monarchie des Battiades, Paris 1953, p. 105-111; J. Zurbach, op. cit, p. 95-98.

447 Voir infra, chapitre II.1.1.1.

448 Voir infra, chapitre II.2.1.2.

449 À en croire une tradition transmise par Denys de Byzance, 53, p. 22-23 (éd. R. Güngerich), ce furent les sept maisons mégariennes les plus nobles qui s'installèrent sur la rive européenne du Bosphore thrace. Voir infra, chapitres II.2.4.1.1. 


\section{Les établissements mégariens de Sicile, de la Propontide et du Pont-Euxin}

La société archaïque n'est pas une simple collection d'individus mais une construction complexe de groupes familiaux que nous connaissons mal ${ }^{1}$.

Mon intention est d'entreprendre dans cette partie de l'ouvrage l'examen des récits et des trouvailles archéologiques en rapport avec la fondation des établissements mégariens de Sicile, de la Propontide et du Pont-Euxin. Installées en plusieurs temps, les colonies ont conservé des liens de parenté qu'il sera intéressant de relever pour des questions telles que la nature des rapports entre la métropole et les colonies, ou encore les coutumes institutionnelles des cités mégariennes. Dans cette deuxième partie, il s'agira de chercher les analogies et les différences concernant la prise de possession du territoire, les relations entre les différents groupes de colons et les rapports des colonies avec la métropole et les populations locales.

L'enquête sera menée en tenant compte des particularités de chaque fondation, chaque cité ayant des ressources et des territoires différents, ainsi qu'une évolution caractéristique ${ }^{2}$. On rappelle, par exemple, que la présence d'un grand nombre de defixiones à Sélinonte n'est pas due à une tradition mégarienne mais plutôt à un développement local. De fait, les defixiones font défaut autant à Mégara de Sicile qu'à Mégare de Grèce ${ }^{3}$. À cela s'ajoute le déséquilibre concernant la nature de la documentation conservée jusqu'à nous et qui peut varier sensiblement d'une cité à l'autre. Ainsi, l'inoccupation des sites de Mégara et de Sélinonte aux

$1 \quad$ M. Gras et H. Tréziny, in Mégara 5, p. 541.

2 Cf. Osborne, Classical Landscape, p. 193 ; Hansen-Nielsen (éds.), Inventory, p. 150153.

3 J. Curbera, «Defixiones», in Sicilia Epigraphica. Atti del convegno (Erice, 15-18 Ottobre 1998), ASNP serie iv, Quaderni 1, M. I. Gulletta (éd.), Pisa 1999, p. 160. 
époques médiévale et moderne a favorisé le progrès des explorations et l'identification, ne fût-elle que partielle, des premiers habitats. En revanche, on ne dispose pas de données architecturales fiables ni pour Mégare, ni pour ses colonies propontiques et pontiques car les sites connaissent une occupation ininterrompue. Il est donc impossible de comparer l'urbanisme mégarien archaïque de Sicile à celui des autres cités mégariennes et c'est la raison pour laquelle l'étude des habitats se limitera, dans les chapitres sur Mégara et Sélinonte, à relever les caractéristiques principales de la première occupation du territoire.

Par ailleurs, dans l'examen des données littéraires et archéologiques, l'important n'est pas d'arriver à des dates de fondation absolues, mais de comprendre le processus de la colonisation. À cet égard, l'approche utilisée par Gras dans un article paru en 1986 reste toujours valable: «L'archéologie a fait connaître la réalité des implantations; il est secondaire de savoir si Syracuse a été fondée quelques années avant ou après Mégara; mieux vaut tenter de comprendre, pour le moment, les caractères du développement des sociétés coloniales du haut archaïsme ${ }^{4}$. Notons aussi qu'une bonne partie des traditions de fondation attestent que les premiers contingents d'apoikoi n'étaient pas homogènes, des ressortissants d'autres cités grecques ayant pris part à l'installation des colonies à côté des Mégariens. En outre, il y a les colons additionnels, les époikoi, qui s'ajoutent à la première vague des colons et qui souvent laissent peu de traces dans la documentation. L'un des enjeux de l'étude est celui de comprendre comment ces populations mêlées ont réussi à créer de nouvelles communautés et quel fut le rôle des Mégariens dans ce processus.

En dernier lieu, il convient de s'interroger sur les apports particuliers des différents peuples non grecs à l'établissement et au développement des apoikiai ${ }^{5}$. Ma démarche diffère sur ce point de celle de Hanell, qui prêta peu d'attention à l'élément local dans son ouvrage sur Mégare et ses colonies (Megarische Studien) publié en 1934. La raison principale est que ce savant se proposa de reconstituer l'ensemble des traditions institutionnelles des Mégariens et, dans une moindre mesure,

4 M. Gras, «Aspects de la recherche sur la colonisation grecque. À propos du Congrès d'Athènes. Notes de lecture », RBPh 64, 1986, p. 16.

5 De manière générale, sur la problématique des contacts entre les indigènes et les Grecs et sur le rôle des populations locales dans le processus de colonisation, voir Domínguez, Colon. Gr., surtout p. 1-17, 91-95. 
d'expliquer le processus de colonisation. Cependant, il s'avère de plus en plus aujourd'hui que les populations locales ont marqué de leur empreinte l'évolution des colonies, et cela dès l'époque de la fondation. Il me semble donc utile de présenter ici l'état de la documentation concernant les rapports entre les Grecs et les indigènes, bien que celleci, avouons-le, reste encore assez maigre et difficile à interpréter.

\section{II.1 Les établissements mégariens de Sicile}

Je me propose de présenter dans ce chapitre les traditions de fondation de Mégara et de Sélinonte et de les confronter aux trouvailles archéologiques qui remontent à la génération des premiers colons. Dans le cas de Mégara, mon intention est de déceler l'individualité de l'entreprise mégarienne en Sicile orientale et les rapports des Mégariens de Lamis avec d'autres groupes de colons (Doriens, Chalcidiens). L'examen de la fondation de Sélinonte permet d'éclairer d'un jour particulier notamment la question des contacts précoloniaux et des relations avec la métropole. Les premiers rapports entre les Mégariens et les populations non grecques de Sicile occidentale et orientale font également partie de l'enquête.

Mon analyse portera enfin sur l'organisation des premiers habitats en Sicile orientale et occidentale afin de révéler les modalités de l'appropriation du territoire par les Grecs et les caractéristiques des premières implantations urbaines à Mégara et à Sélinonte.

\section{II.1.1 Mégara}

\section{II.1.1.1 Les récits et les découvertes archéologiques concernant la fondation de Mégara}

Il existe principalement deux traditions littéraires qui nous renseignent sur la fondation de Mégara: la première est fournie par Thucydide, tandis que la deuxième est conservée chez Éphore. Au début du livre VI de l'Histoire de la guerre du Péloponnèse, Thucydide fait un bref 
excursus sur les origines des cités grecques de Sicile, indiquant aussi les intervalles de temps qui séparent leurs fondations ${ }^{6}$. On apprend que les Chalcidiens d'Eubée sous la direction de Thouclès (Théoclès dans d'autres récits, voir ci-après) furent les premiers arrivés en Sicile, en fondant Naxos. Ils furent suivis l'année suivante par les Corinthiens d'Archias qui établirent Syracuse; cinq ans après, Thouclès et les Chalcidiens de Naxos s'installèrent d'abord à Léontinoi et ensuite à Catane.

C'est dans ce contexte d'expansion chalcidienne et corinthienne en Occident que, rapporte Thucydide, les Mégariens de Grèce fondèrent la cité de Mégara:

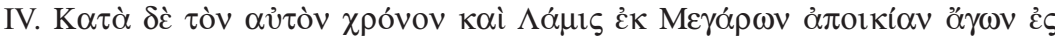

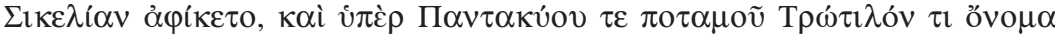

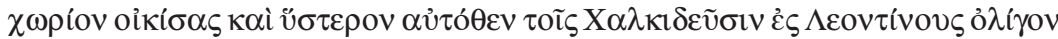

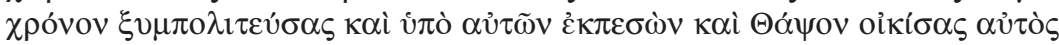

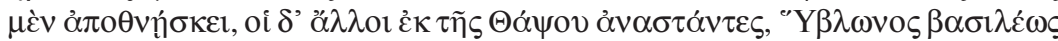

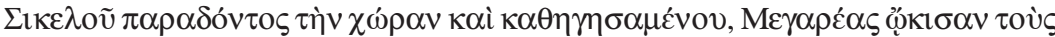

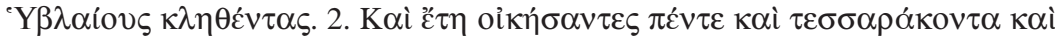

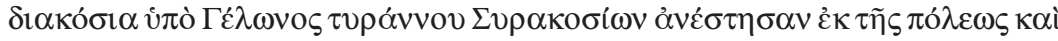

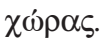

IV. Vers la même époque, Lamis, venu de Mégare, arriva en Sicile à la tête d'une colonie et l'établit au-dessus du fleuve Pantakyas, en un lieu nommé Trôtilon; de là, plus tard, passé à Léontinoi, il y fit quelque temps cité commune avec les Chalcidiens, et ensuite, chassé par eux, il s'installa à Thapsos. Mais il meurt, et ses compagnons sont forcés de quitter Thapsos. Conduits par Hyblôn, un roi sicule, qui leur avait concédé le territoire, ils fondèrent Mégara que l'on appela Hybléenne. 2. Après y avoir habité pendant deux cent quarante-cinq ans, ils furent forcés par Gélon, tyran de Syracuse, d'abandonner la ville et le pays ${ }^{7}$.

Le texte de Thucydide, tel qu'il est conservé, a permis aux savants d'interpréter différemment les premières relations entre les Mégariens et les Sicules. Dans une exégèse de ce passage, Graham estime qu'il

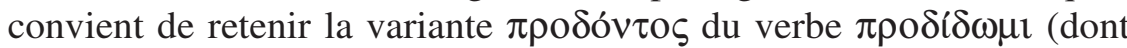
l'un des sens et celui de «livrer par trahison», «trahir»), offerte par les manuscrits, au lieu de $\pi \alpha \rho \alpha \delta o ́ v \tau o \zeta$ du verbe $\pi \alpha \rho \alpha \delta i \delta \omega \mu$ ( «concéder»), une émendation proposée par Classen et adoptée en général par

6 Thucydide, VI, 3-5; $c f$. K. J. Dover, in A. W. Gomme, A. Andrews, K. J. Dover, A Historical Commentary on Thucydides, IV, Oxford 1970, p. 198-219.

7 Thucydide, VI, 4, 1-2 (trad. de L. Bodin et J. de Romilly, CUF, partiellement modifiée). 
les éditeurs de Thucydide ${ }^{8}$. Selon Graham, les conflits entre les Grecs et les Sicules à Syracuse et à Léontinoi auraient poussé Thucydide à considérer le don des terres fait par le roi Hyblôn aux Mégariens comme une trahison de la cause sicule. Mieux encore, l'historien antique aurait eu à sa disposition des informations plus détaillées sur l'alliance des indigènes contre les Grecs et l'installation des Mégariens en Sicile ${ }^{9}$. Il faut avouer cependant que ce dernier argument est particulièrement faible, le contenu exact de la source utilisée par Thucydide pour ce passage restant pour nous inconnu ${ }^{10}$. En outre, même si l'on considère $\pi \rho o \delta o ́ v \tau o \varsigma$ comme la forme correcte, cela ne suppose pas nécessairement une trahison, le verbe $\pi \rho o \delta i \delta \omega \mu$ ayant aussi le sens de «renon-

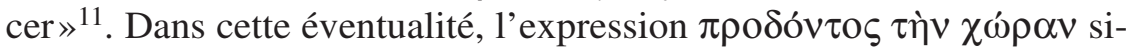
gnifierait que Hyblôn avait renoncé à un territoire au bénéfice de nouveaux venus. Plusieurs historiens estiment qu'en échange de ce don, les Grecs assimilèrent le roi sicule à un véritable œciste ${ }^{12}$. On précisera néanmoins que le rapport entre le nom du mythique Hyblôn et celui de Mégara reste obscur. Certes, Thucydide qualifie Mégara d'Hybléenne, mais cette appellation peut aussi s'expliquer par un souci de différencier la colonie de sa métropole. D'ailleurs, pour la même raison, les auteurs

8 J.Classen(éd.), Thukydides, Berlin 1876, p. 8, n. 7. Outre l'édition de Thucydide dans

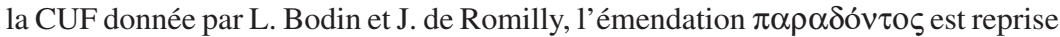
par C. Forster Smith (éd.), Thucydides, History of the Peloponnesian War, Books V and VI, Cambridge-London 1959 (réimpression de l'édition de 1921), et chez C. Hude (éd.), Thucydidis, Historiae, Leipzig 1925. Cf. S. Hornblower, A Commentary on Thucydides, volume III, Books 5.25-8.109, Oxford 2008, p. 286-288.

9 Graham, Megara Hyblaea, p. 158-160. Notons que Graham reprend ici l'opinion exprimée par K. J. Dover, in A. W. Gomme, A. Andrews, K. J. Dover, op. cit., p. 216; idem, Thukydides, p. 350-351, selon laquelle Thucydide en connaissait davantage sur la Sicile qu'il n'en dit. Cette affirmation peut être vraie, mais elle ne démontre rien.

10 R. van Compernolle, «Les dates de fondation des colonies siciliotes. À propos d'un article récent», $A C$ 25, 1956, p. 101.

11 S. Hornblower, op. cit., p. 287. Le verbe $\pi \rho \delta \delta i \delta \omega \mu$ est employé chez Eschine, Contre Timarque, I, 115, avec le sens de «renoncer à la lutte» ( $\tau$ òv $\alpha \hat{\gamma} \tilde{\omega} v \alpha$ ) et chez Sophocle, Antigone, 1165-1166, avec celui de «renoncer aux plaisirs» (íjovós). Cf. LSJ, s.v. $\pi \rho \circ \delta i ́ \delta \omega \mu \mathrm{III} 5$.

12 Casevitz, Vocabulaire, p. 105; Malkin, Megara Hyblaia, p. 220-222; S. de Vido, «I dinasti dei Siculi. Il caso di Archonides», Acme 50, 2, 1997, p. 18-19; V. La Rosa, «L'ospitalità del re di Sicilia: il Sicano Kokalos ed il Siculo Hyblon», SicGymn N.S. 45, 1992, p. 105-106; Veronese, Santuari greci, p. 231-232. 
antiques appellent habituellement les ressortissants de cette cité les

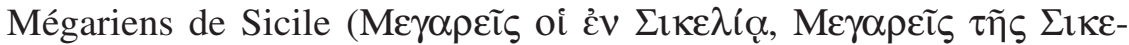
$\lambda i^{\prime} \alpha \varsigma^{13}{ }^{13}$. Le terme de Mégara Hyblaea/Hyblaia, qui est entré dans la littérature moderne n'apparaît pas dans les récits, et, à ma connaissance,

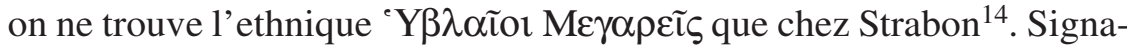
lons aussi ici l'hypothèse avancée par Tréziny selon laquelle les Hyblaioi pourraient aussi être un terme géographique, en rapport avec les monts Hybléens situés en Sicile sud-orientale ${ }^{15}$.

Pour ce qui est de la date de fondation, l'historien d'Athènes rapporte que Mégara fut créée 245 ans avant sa prise par Gélon. Étant donné que sur la foi d'Hérodote, cette conquête est placée vers 483/2, on peut supposer que la fondation de la cité eut lieu vers $728 / 7^{16}$.

Un fragment d'Éphore (FGrHist 70 F 137 a), repris par Strabon, donne une autre version de l'installation des Grecs en Sicile et attribue le mérite de cette entreprise à l'Athénien Théoclès.

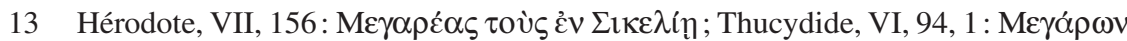

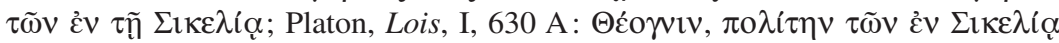

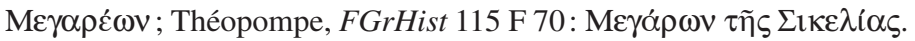

14 Strabon, VIII, 7, 5, C 387 (sur ce passage voir infra, chapitre II.1.2.1). Cf. Hanell, Megarische Studien, p. 116, n. 1, qui écrit: «Zu bemerken ist, dass ' $\mathrm{Y} \beta \lambda \alpha$ ĩot nur als

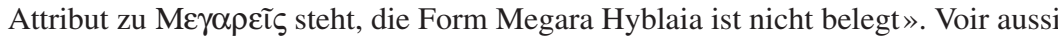
I. Malkin, «What's in a Name? The Eponymous Founder of Greek Colonies », Athenaeum 63, 1985, p. 118; K. Brodersen, «Männer, Frauen und Kinder in Großgriechenland: Quellen und Modelle zur frühen Siedler-Identität», Mnemosyne 47, 1994, p. 50-55.

15 Tréziny, Grecs et indigènes, p. 15. Sur les monts Hybléens (Hyblaei colles), voir Manni, Geog. della Sicilia, p. 89.

16 Hérodote, VII, 156-157; $c f$. Polyen, I, 27, 3. On admet que la conquête de Mégara doit se placer entre 484, la prise de Syracuse par Gélon, et 480, la bataille d'Himère, soit le plus probablement vers 483/2. Voir à ce sujet A. Holm, Geschichte Siziliens im Altertum, I, Leipzig 1870, p. 132; Dunbabin, Western Greeks, p. 435; Bérard, Colonisation, p. 89-91; Van Compernolle, Ét. de chronologie, p. 411, 417, 419-421; Vallet-Villard, Dates de fondation, p. 294-295; Legon, Megara Pol. Hist., p. 71; Danner, Megara, p. 19; De Angelis, Megara Hyblaia and Selinous, p. 66-67. Les données archéologiques attestent que le site de Mégara n'est pas resté inhabité à l'époque classique, une partie des exilés mégariens auraient donc pu retourner dans leur patrie. Voir à cet égard H. Tréziny, «L'agora de Mégara Hyblaea», in Agora greca e agorai di Sicilia, C. Ampolo (éd.), p. 120-121. 


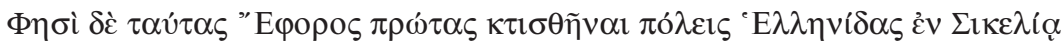

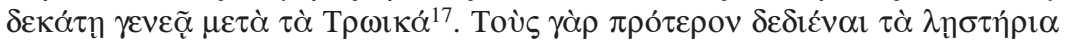

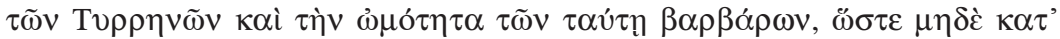

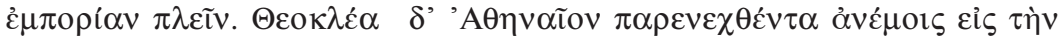

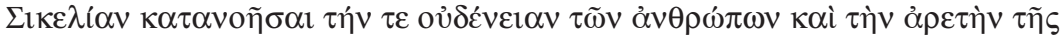

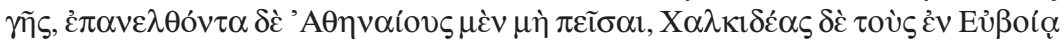

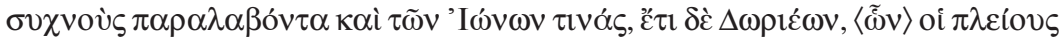

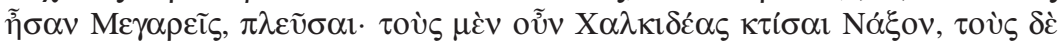

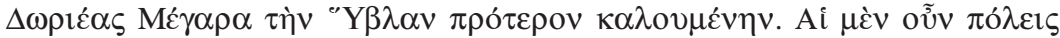

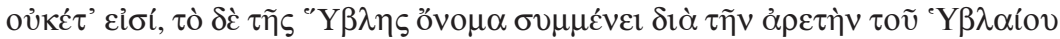
$\mu \varepsilon ́ \lambda \imath \tau O \varsigma^{18}$.

Éphore affirme que ces deux villes (Naxos et Mégara) furent les premières cités grecques bâties en Sicile, dix générations après la Guerre de Troie. Car jusque-là, par crainte des pirates tyrrhéniens et de la cruauté des barbares installés dans l'île, ils (les Grecs) n'avaient pas fait la traversée, même pour faire du commerce. Mais l'Athénien Théoclès, poussé par les vents jusqu'en Sicile, constata la faiblesse numérique des habitants et l'excellence du sol; de retour en son pays, il ne put convaincre les Athéniens, il prit alors comme compagnons des Chalcidiens d'Eubée en grand nombre, quelques Ioniens et, en outre, quelques Doriens, dont la plupart étaient des Mégariens, et navigua (vers la Sicile). Les Chalcidiens fondèrent Naxos et les Doriens, Mégara, qui s'appelait auparavant Hybla. Ces cités, comme on l'a dit, n'existent plus, mais le nom d'Hybla a survécu grâce à l'excellence du miel hybléen.

Strabon précise ailleurs que le groupe de Doriens ne fut pas homogène et qu'un certain nombre d'entre eux se séparèrent des Mégariens en Sicile et s'établirent au cap Zéphyrion (aujourd'hui Capo Bruzzano), un important point de passage pour les navires qui marque l'entrée dans le détroit de Sicile. Ceux-ci furent recueillis par Archias et fondèrent par la suite avec les Corinthiens la cité de Syracuse ${ }^{19}$.

L'identité des Doriens du cap Zéphyrion reste difficile à connaître avec exactitude. On exclut les Corinthiens qui ont leur propre mouvement de colonisation en Sicile, auquel les Doriens finissent par se joindre. Les Argiens sont en revanche de meilleurs candidats, car les récits

17 La période de dix générations qui sépare la guerre de Troie de l'installation des

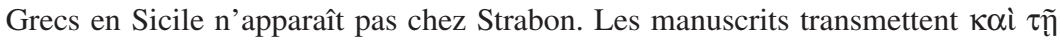

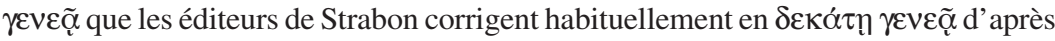
le Ps.-Scymnos, 272. Voir à cet égard G. Parmeggiani, Eforo di Cuma. Studi di storiografia greca, Studi di storia 14, Bologna 2011, p. 292, n. 728.

18 Strabon, VI, 2, 2, C 267 (éd. N. Biffi).

19 Strabon, VI, 2, 4, C 270. Sur les installations grecques du promontoire de Zéphyrion, voir Van Compernolle, Capo Zefirio, p. 761-780. 
suggèrent leur présence à Syracuse à l'époque archaïque. De fait, Hippys de Rhégion évoque un basileus syracusain appelé Pollis l'Argien, tandis que le Marbre de Paros mentionne la descendance d'Archias, l'œciste de Syracuse, de Téménos, le premier des Héraclides d'Argos ${ }^{20}$. D'aucuns estiment que ces témoignages seraient corroborés par la découverte à Syracuse de céramiques argiennes datant de la première moitié du $\mathrm{VII}^{\mathrm{e}}$ siècle ${ }^{21}$. L'hypothèse selon laquelle le groupe des Doriens fut constitué d'émigrés argiens est aussi appuyée par les relations étroites que Mégare entretenait avec Argos à l'époque archaïque. Les deux cités furent des alliées dans une guerre contre Corinthe et s'associèrent vraisemblablement dans la colonisation de Byzance ${ }^{22}$. Mais si des Argiens ont peut-être fait cité commune avec les Mégariens sur la rive européenne du Bosphore thrace, des représentants du même peuple ont dû en route vers la Sicile, en raison des diverses divergences, choisir de se séparer des Mégariens et de fonder ensuite avec les Corinthiens la cité de Syracuse.

On ajoutera que pour Gras et Tréziny, l'absence de la mention du groupe de Doriens chez Thucydide s'expliquerait par la source que l'historien athénien a utilisée pour ce passage, à savoir Antiochos de Syracuse. Ce dernier, auteur d'un ouvrage sur l'histoire de la Sicile depuis l'époque du roi mythique Kokalos jusque vers 424/3 ( $\Sigma \imath \kappa \varepsilon \lambda \imath \tilde{\omega} \tau \iota \varsigma$ $\left.\sigma v \gamma \gamma \rho \alpha \varphi \eta^{\prime}\right)$, aurait cherché à présenter sa cité d'origine comme une

20 Hippys de Rhégion, FGrHist 554 F 4; Marmor Parium, FGrHist 239 A 31. Les données «argiennes » présentes à Syracuse sont examinées par R. van Compernolle, «Syracuse, colonie d'Argos?», Kokalos 12, 1966, p. 75-101; E. Manni, «Fidone d'Argo, i Bacciadi di Corinto e le fondazioni di Syracusa e di Megara Iblea », Kokalos 20, 1974, p. 88-89, n. 61; Asheri, La colon. gr., p. 117 et 121; De Fidio, Corinto e l'Occidente, p. 98-99; Tréziny, Colonies gr. de Méditerranée, p. 55.

21 P. Courbin, La céramique géométrique de l'Argolide, Paris 1966, p. 34 ; Coldstream, Gr. Geom. Pot., p. 147; J. Boardman, Early Greek Vase Painting, 11th-6th Centuries B. C. : A Handbook, London 1998, p. 114, considèrent que les grands cratères découverts dans la nécropole du Fusco à Syracuse furent produits par des artisans argiens immigrés à Syracuse. Selon M. Gras et H. Tréziny, in Mégara 5, p. 548-549, n. 7, cette céramique témoignerait de la participation d'Argiens à la fondation de Syracuse.

22 Voir supra, chapitre I.1.3, à propos du passage de Pausanias, VI, 19, 13-14, qui évoque la guerre des Mégariens, appuyés par les Argiens, contre les Corinthiens. Pour la mention des Argiens parmi les fondateurs de Byzance, voir infra, chapitre II.2.4.1.6. 
fondation culturellement homogène ${ }^{23}$. La participation des Doriens du cap Zéphyrion, mais aussi d'Argiens et d'Arcadiens à la fondation de Syracuse serait ainsi passée sous silence ${ }^{24}$.

Il n'est pas inutile de rappeler, à ce stade de l'analyse, que les alliances ou les conflits entre des apoikoi provenant de différentes métropoles sont caractéristiques non seulement de la colonisation mégarienne ou corinthienne, mais aussi d'autres mouvements de colonisation. À titre d'exemple, on rappelle la «solidarité tyrrhénienne» qui existe entre les Eubéens, les Phocéens et les Poseidoniates, remarquable dans le cas de Vélia, cité fondée par des Phocéens avec l'aide des Chalcidiens sur le conseil d'un Poseidoniate ${ }^{25}$.

De même que Strabon, le Ps.-Scymnos présente au II ${ }^{\mathrm{e}}$ siècle l'arrivée des Grecs en Sicile sous la forme d'un groupe composite de colons sous la direction de Théoclès d'Athènes.

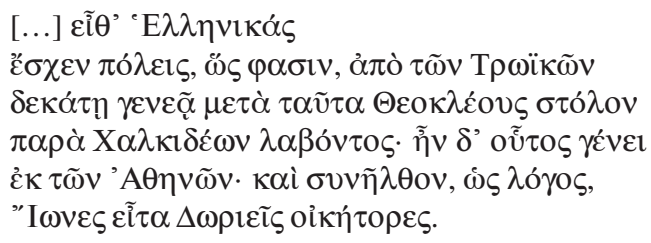

23 M. Gras et H. Tréziny, in Mégara 5, p. 548-549; cf. Sammartano, Tradizioni ecistiche, p. 91. Pour $\Sigma \imath \kappa \varepsilon \lambda \iota \tilde{\omega} \tau \iota \varsigma \sigma v \gamma \gamma \rho \alpha \varphi \eta \dot{~ d ' A n t i o c h o s ~ e n ~ t a n t ~ q u e ~ s o u r c e ~ d u ~ p a s s a g e ~ V I, ~ 3-~}$ 5 de Thucydide, voir aussi Dover, Thukydides, p. 344-368; M. T. Piraino, «Sulla cronologia della fondazioni siceliote», Kokalos 3, 1957, p. 123-128; Van Compernolle, La fond. de Sélinonte, p. 348-349, n. 1; idem, Ét. de chronologie, p. 1-48; F. W. Walbank, «The Historians of Greek Sicily», Kokalos 14-15, 1968-1969, p. 478-481 ; Miller, Colony Dates, p. 77-83 ; N. Luraghi, «Fonti e tradizioni nell'archaiologia siciliana (per una rilettura di Thuc. 6, 2-5)», in Hesperìa, 2 : studi sulla grecità di Occidente, L. Braccesi (éd.), Roma 1991, p. 41-62 ; Danner, Selinunt, p. 89; C. Cuscunà (éd.), I frammenti di Antioco di Siracusa. Introduzione, traduzione e commento, Alessandria 2003, p. 13-21.

24 Pindare, Olympiques, VI, 8-9, et les scholies a et b à Pindare, Olympiques, VI, 8, témoignent de la participation à la colonisation de Syracuse d'un cofondateur ( $\sigma \cup v o \iota \kappa \iota \sigma \tau \eta ́ \rho)$, membre de la famille sacerdotale des Iamides, originaire d'Arcadie et d'Olympie. Cf. P. Reichert-Südbeck, Kulte von Korinth und Syrakus. Vergleich zwischen einer Metropolis und ihrer Apoikia, Dettelbach 2000, p. 8-9.

25 J.-P. Morel, «Problématiques de la colonisation grecque en Méditerranée occidentale : l'exemple des réseaux », in Antonetti (éd.), Il dinam. della colon. gr., p. 59-70, surtout p. 59. 


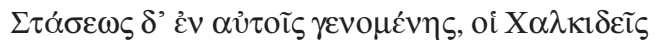

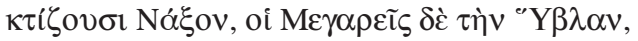

$\tau$

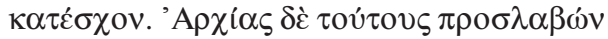

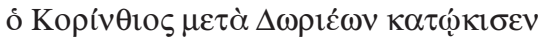

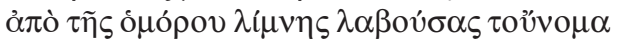

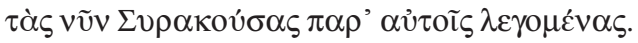

[...] Puis elle (la Sicile) reçut des cités grecques à la dixième génération après la guerre de Troie, dit-on, quand Théoclès y amena une troupe de Chalcidiens - luimême était issu d'Athènes. Avec lui, selon la tradition, arrivèrent comme colons des Ioniens, puis des Doriens. Une sédition éclatant entre eux, les Chalcidiens s'en vont fonder Naxos, les Mégariens Hybla, tandis que les Doriens prirent possession d'Épizéphyron en Italie. Le Corinthien Archias, qui avait pris ces derniers en charge, repeupla avec des Doriens l'endroit dont le nom vient d'un étang voisin, celle que de nos jours on nomme là-bas Syracuse ${ }^{26}$.

Le rapprochement qui existe entre ce passage et celui déjà cité de Strabon accrédite l'idée que le Ps.-Scymnos s'appuie aussi sur le récit d'Éphore ${ }^{27}$. Conformément à cette tradition, la fondation des premières colonies, et implicitement de Mégara, eut lieu à la dixième génération après la guerre de Troie. Sachant que le Ps.-Scymnos retenait la date d'Ératosthène pour la prise de Troie, soit 1184/3, et en estimant la durée moyenne d'une génération à 35 ans, la fondation de Mégara remonterait à la période $869 / 8-834 / 3^{28}$. La question se complique en revanche si l'on accepte que le Ps.-Scymnos et Éphore ne fixent pas la date de la prise de Troie de la même façon. Ainsi, certains estiment que cet événement aurait été daté par l'historien de Cumes autour de 1150/49; la durée d'une génération variant entre 30 et 40 ans, la dixième génération

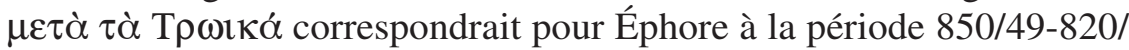
9 (génération de 30 ans) ou 790/89-750/49 (génération de 40 ans) ${ }^{29}$. Il

26 Ps.-Scymnos, 270-282 (trad. de D. Marcotte, CUF, partiellement modifiée).

27 Sur Éphore (FGrHist 70 F 137 b) en tant que source du Ps.-Scymnos, 270-282, voir Vallet-Villard, Dates de fondation, p. 310-311; Van Compernolle, La fond. de Sélinonte et de Syracuse, p. 189-190; idem, Capo Zefirio, p. 771-772 ; Bérard, Colonisation, p. 75-77.

28 Cf. Asheri, La colon. gr., p. 92; D. Marcotte (éd.), Les géographes grecs. Introduction générale, Tome I: Ps.-Scymnos, Circuit de la Terre, Paris 2000, p. 77.

29 Pour Graham, Megara Hyblaea, p. 151, Éphore date la chute de Troie de 1150, et en comptant 30 ans par génération, la colonie mégarienne aurait dû être fondée vers 850. D. Marcotte, op. cit., p. 77-79, 182-183, penche pour une datation dans le deuxième quart du VIII ${ }^{\mathrm{e}}$ siècle pour les plus anciennes colonies de Sicile, tandis que 
faut avouer que rien ne permet de préciser davantage cette chronologie, une datation de l'installation des Mégariens en Sicile avant le milieu du VIII ${ }^{\mathrm{e}}$ siècle reste pourtant improbable en l'absence d'une confirmation archéologique.

De même, on mentionnera ici l'hypothèse avancée par Vallet et Villard, selon laquelle le texte authentique d'Éphore ne portait pas $\delta \varepsilon \kappa \alpha ́ \tau \eta\rceil ~ \gamma \varepsilon v \varepsilon \tilde{\alpha}$, mais $\tau \rho i ́ \tau \eta ~ \kappa \alpha i ~ \delta \varepsilon \kappa \alpha ́ \tau \eta ฺ ~ \gamma \varepsilon v \varepsilon \tilde{\alpha}$ ou en chiffres $\imath \gamma^{\prime} \gamma \varepsilon v \varepsilon \tilde{\alpha}$. On serait ainsi dans la treizième génération après la prise de Troie, période qui correspond à une date dans le courant du VIII ${ }^{\mathrm{e}}$ siècle ${ }^{30}$. Du reste, dans cette étude, qui a fait couler beaucoup d'encre, Vallet et Villard essaient de montrer l'historicité de la tradition d'Éphore soutenant l'antériorité de la fondation de Mégara par rapport à celle de Syracuse, tradition reprise par Strabon (VI, 2, 2, C 267), mais non pas chez le Ps.-Scymnos. Les savants français estiment qu'Antiochos - la source de Thucydide, on l'a vu, pour le passage concernant les fondations grecques en Sicile - a rabaissé à cause de son patriotisme local les dates de Naxos et de Mégara, pour préserver la prééminence de sa ville natale, Syracuse. À défaut de pouvoir revendiquer le statut de cité grecque la plus ancienne de Sicile, car la prééminence de Naxos, marquée par le caractère panhellénique du sanctuaire naxien d'Apollon Archégète, était trop connue, Syracuse aurait tenté de s'approprier la deuxième place. Cela expliquerait l'ordre chronologique transmis par Thucydide pour les installations grecques de Sicile: Naxos (vers 734), Syracuse (vers 733), Mégara (vers 727). Du reste, s'appuyant sur la date de fondation de Sélinonte fournie par Diodore, soit 650, et sur les découvertes archéologiques provenant de ce site, Vallet et Villard considèrent que la

G. Parmeggiani, op. cit., p. 292 et n. 728, opte pour la période de 790/89 à 750/49. En revanche, Nicosia, Megara, p. 172-174, estime que l'historien de Cumes date la prise de Troie de 1070/69 et compte 35 ans pour une génération, et dans ce cas, la fondation de Mégara se situerait entre 755/4 et 720/19. Sur la place de Mégara dans le système chronologique fourni par Éphore, voir aussi A. R. Burn, «Dates in Early Greek History», JHS 55, 1935, p. 130-146, surtout p. 137; Miller, Colony Dates, p. 83-87; Sammartano, Tradizioni ecistiche, p. 51-52; Danner, Megara, p. 19-22.

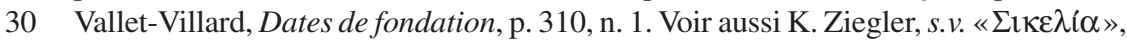
$R E$ II A, 1921, col. 2494-2495, pour l'hypothèse selon laquelle les dix générations devraient être remplacées par quinze, chose qui permettrait d'obtenir la date de 734 $(1184-15$ générations $\times 30$ ans $=734)$ pour l'installation des Grecs en Sicile. 
fondation de Mégara, réalisée cent ans avant celle de Sélinonte, d'après Thucydide, remonterait vers 750 . En revanche, la date de fondation de Syracuse serait celle donnée par Thucydide, soit 733. Selon eux, cette chronologie serait confirmée par les céramiques géométriques trouvées à Mégara, bien plus anciennes que celles trouvées à Syracuse; à l'époque où ils écrivaient, les coupes «de Thapsos» faisaient encore défaut dans la colonie corinthienne de Sicile ${ }^{31}$.

Les deux dates de 750 et de $728 / 7$, proposées pour la fondation de Mégara, ont longtemps divisé les chercheurs ${ }^{32}$. Il n'est pas question d'entrer dans ce débat de chronologie, on se bornera à noter que cette dispute a pris fin au moment où des fragments de coupes «de Thapsos» ont été découverts à Syracuse. De fait, les fouilles de Pelagatti ont mis au jour dans la colonie corinthienne une céramique similaire au matériel le plus ancien de Mégara ${ }^{33}$. Cette trouvaille a donc rendu caduque la base archéologique du système chronologique proposé par Vallet et Villard, et remis en question leur construction historique en faveur de

31 Vallet-Villard, Dates de fondation, p. 289-346, notamment p. 318-343. Pour cette thèse, voir aussi G. Vallet, F. Villard, «À propos des dates de fondation de Mégara Hyblaea, de Syracuse et de Sélinonte», BIBR 24, 1955, p. 199-214; iidem, «Céramique et histoire grecque», in Vallet, Le monde gr. colonial, p. 245; iidem, Mégara 2, p. 18-23; G. Vallet, «Céramique d'importation en Sicile avant 730», in Vallet, Le monde gr. colonial, p. 341-342.

32 Bernabò Brea, Re Hyblon, p. 176-177; E. Sjöqvist, Sicily and the Greeks. Studies in the Interrelationship between the Indigenous Populations and the Greek Colonists, Ann Arbor 1973, p. 17, se prononcent en faveur de la date de 750. L'antériorité de Mégara sur Syracuse est acceptée aussi par Bérard, Colonisation, p. 130. Contra Dunbabin, Western Greeks, p. 18-19, 45-46, 444 et 455; Coldstream, Gr. Geom. Pot., p. 322-325 ; K. Fittschen, Untersuchungen zum Beginn der Sagendarstellungen bei den Griechen, Berlin 1969, p. 204; Graham, Megara Hyblaea, p. 149-150 et 160; idem, Colonial Expansion, p. 106-108; cf. B. d'Agostino, ArchClass 17, 1, 1965, p. 160-162 ; P. E. Arias, «La civiltà italo-siceliota», in Popoli e civiltà dell'Italia antica, II, B. d'Agostino et al. (éds.), Roma 1974, p. 103.

33 P. Pelagatti, «Siracusa. Elementi dell'abitato di Ortigia nell'VIII e nel VII secolo a. C. », in Rizza (éd.), Insediamenti colon. gr., p. 127-132; eadem, «I più antichi materiali d'importazione a Siracusa, a Naxos e in altri siti della Sicilia orientale », in La céramique grecque ou de tradition grecque au VIII ${ }^{e}$ siècle en Italie centrale et méridionale, Cahiers du Centre Jean Bérard 3, G. Vallet (éd.), Naples 1982, p. 125 139; cf. C. Dehl, «Cronologia e diffusione della ceramica corinzia dell'VIII sec. a.C. in Italia», ArchClass 35, 1983, p. 200-201. 
l'antériorité de Mégara sur Syracuse ${ }^{34}$. En même temps, on a mis en évidence les limites de la documentation archéologique. Le court intervalle de temps entre la fondation de Mégara et celle de Syracuse ne peut pas être déterminé par la céramique et continuer sur cette voie serait une erreur de méthode ${ }^{35}$. Tout ce que l'on peut dire est que le matériel archéologique de Mégara date du troisième quart du VIII ${ }^{\mathrm{e}}$ siècle, ce qui est encore insuffisant pour dater la fondation de la ville à l'année près ${ }^{36}$.

Il convient également de rappeler que Thucydide ne transmet pas une date absolue pour la fondation de Mégara ou pour celles des autres colonies de Sicile. Il fournit seulement une chronologie relative à l'intérieur de laquelle la fondation de Syracuse devient une référence pour les autres installations grecques ${ }^{37}$. Ainsi, Naxos fut fondée un an avant Syracuse, et cinq ans après cette dernière fondation, les Chalcidiens de Naxos s'établirent à Léontinoi et ensuite à Catane. Ce fut «vers la même

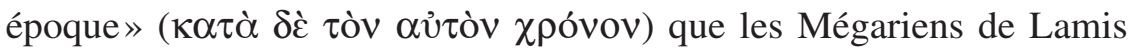

34 En raison de la trouvaille de fragments de coupes «de Thapsos » à Syracuse, Vallet a accepté le manque de données archéologiques pour mettre en cause la chronologie de Thucydide et pour démontrer l'antériorité de Mégara sur Syracuse: G. Vallet, «La céramique grecque ou de tradition grecque au VIII ${ }^{\mathrm{e}}$ siècle en Italie centrale et méridionale. Position des problèmes », in Vallet, Le monde gr. colonial, p. 365-369; idem, «Rhégion et Zancle, vingt ans après », in Vallet, Le monde gr. colonial, p. 390. Bien avant les découvertes de Syracuse, les difficultés et les contradictions du système chronologique proposé par Vallet et Villard pour la fondation de Mégara, Syracuse et Sélinonte, ont été signalées par Van Compernolle, La fond. de Sélinonte et de Syracuse, p. 195-200; idem, «À propos des dates de fondation de Syracuse, de Mégara Hyblaea et de Sélinonte», BIBR 24, 1955, p. 215-240, surtout p. 217-218; idem, Ét. de chronologie, p. 44-45; J. Ducat, «L'archaïsme à la recherche de points de repère chronologiques », $B C H 86,1962$, p. 166-170.

35 G. Vallet, in Rizza (éd.), Insediamenti colon. gr., p. 151; D. A. Amyx, Corinthian Vase-Painting of the Archaic Period, Berkeley 1988, p. 414; Van Compernolle, Capo Zefirio, p. 779; M. Gras et H. Tréziny, in Mégara 5, p. 548; cf. M. Gras, RBPh 64, 1986, p. 15-16; Tréziny, Colonies gr. de Méditerranée, p. 52-53; I. Morris, AArch 67, 1996, p. 54-55. On remarque qu'en 1951, F. Villard, «Mégara Hyblaea», MEFR 63,1951 , p. 7-52, s'appuyant sur la datation des céramiques les plus anciennes (du dernier quart du VIII ${ }^{\mathrm{e}}$ siècle), trouvées alors à Mégara, avait accepté la date de Thucydide pour la fondation de cette colonie mégarienne.

36 Holloway, Anc. Sicily, p. 54.

37 E. Luraghi, op. cit., p. 50-51. 
arrivèrent en Sicile. De même, bien que l'historien d'Athènes précise que les Mégariens occupèrent leur ville durant 245 ans avant qu'elle ne soit conquise par Gélon, il n'évoque jamais dans son œuvre la date de ce dernier événement ${ }^{38}$. De même, Strabon, en suivant Éphore, rapporte que Naxos et Mégara furent les premières colonies en Sicile, tout en ajoutant que Syracuse fut fondée «à peu près à la même époque»

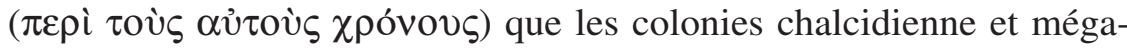
rienne $^{39}$. Bref, devant l'ambiguïté et les divergences entre les récits évoquant la fondation de Mégara et de Syracuse, il devient évident que l'on ne peut pas proposer de dates précises pour ces colonies. Sans parler du fait que le laps de temps séparant l'arrivée des Mégariens en Sicile, leur première installation à Trôtilon et la fondation de Mégara reste difficile à établir ${ }^{40}$.

Néanmoins, les traditions de Thucydide et d'Éphore ont, malgré leurs divergences, un élément en commun: l'accord initial entre les Mégariens et les Chalcidiens dans la colonisation de la Sicile, dont la rupture déboucha sur la fondation de Mégara ${ }^{41}$. Pour Thucydide, les Mégariens, après un séjour à Trôtilon (un site que les modernes identifient à la moderne Brucoli ${ }^{42}$ ou à la «Punta Castelluzzo» ${ }^{43}$ ), ont fait cité commune avec les Chalcidiens à Léontinoi. Ils en ont ensuite été expulsés, et ils vécurent un temps à Thapsos, où leur chef, Lamis, trouva

38 Cf. Van Compernolle, La fond. de Sélinonte, p. 349; Nicosia, Megara, p. 156-161.

39 Strabon, VI, 2, 4, C 269.

40 Cf. De Fidio, Corinto e l'Occidente, p. 92-93; Danner, Megara, p. 26-27. À en croire Polyen $(\mathrm{V}, 5,2)$, la période de cohabitation entre les Mégariens et les Chalcidiens à Léontinoi a été de six mois, tandis que le séjour des Mégariens à Trôtilon (qui doit probablement être corrigé en Thapsos, d'après Thucydide, voir ciaprès) s'est limité à un hiver.

41 Vallet-Villard, Dates de fondation, p. 316; Martin et al., Città greche, p. 601.

42 Manni, Geog. della Sicilia, p. 239; G. Vallet, s.v. «Brucoli», in BTCGI IV, 1985, p. 200-204.

43 L. Bernabò Brea, «Punta Castelluzzo», in Archeologia nella Sicilia Sud-Orientale, P. Pelagatti et G. Voza (éds.), Napoli 1973, p. 55, propose de localiser Trôtilon à «Punta Castelluzza (comune di Augusta)», un peu au nord de Brucoli, à cause de la découverte sur ce site de fragments céramiques grecs. Bernabò Brea souligne que même si Brucoli offre une meilleure position portuaire, ce site n'a pas encore livré des traces archéologiques qui pourraient confirmer la présence d'un habitat grec à l'époque archaïque. $C f$. Veronese, Santuari greci, p. 181. 
la mort ${ }^{44}$. Enfin, grâce à l'aide du roi sicule Hyblôn, ils fondèrent la cité de Mégara. Pour Éphore, les Mégariens arrivèrent en Sicile sous la direction de Théoclès et ils fondèrent leur cité, suite aux divergences avec les Chalcidiens.

Au surplus, Polyen nous fournit au $\mathrm{II}^{\mathrm{e}}$ siècle ap. J.-C. des détails supplémentaires sur la cohabitation des Chalcidiens et des Mégariens à Léontinoi $^{45}$. Dans la notice consacrée à Théoclès, il rapporte le stratagème militaire suivant ${ }^{46}$ :

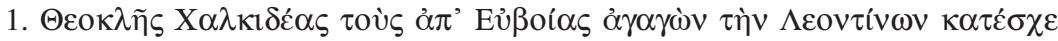

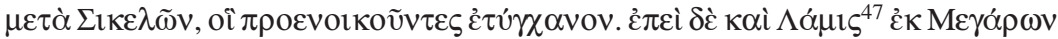

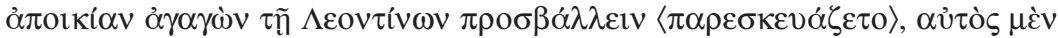

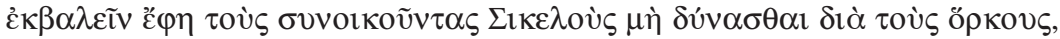

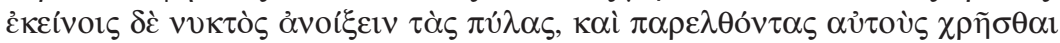

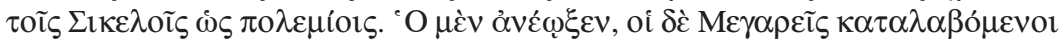

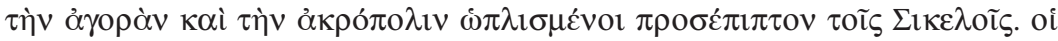

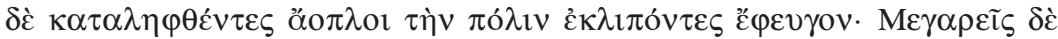

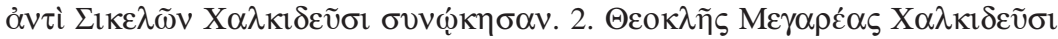

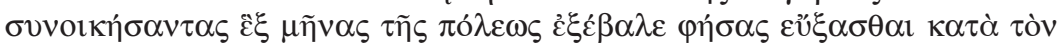

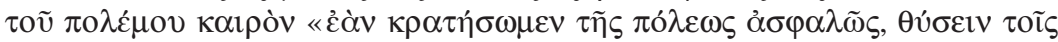

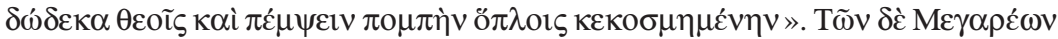

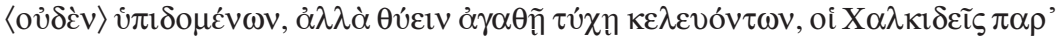

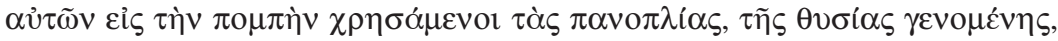

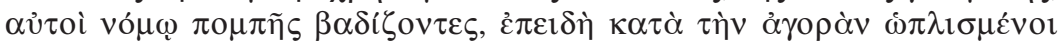

44 La découverte d'une tombe datée par son mobilier de la fin du VIII' siècle, quoiqu'il ne soit pas démontrable qu'elle appartienne à Lamis, confirme la présence des Grecs à Thapsos. À ce propos, voir P. Orsi, «Thapsos», MAL 6, 1895, col. 103-104. Pour l'hypothèse, avancée très prudemment par Orsi, que la tombe découverte à Thapsos appartenait à Lamis, voir aussi Dunbabin, Western Greeks, p. 19; Malkin, Religion and Colon., p. 213; Coldstream, Geom. Gr.2, p. 235; Holloway, Anc. Sicily, p. 50; Graham, Megara Hyblaea, p. 156; M. Gras, H. Tréziny, «Mégara Hyblaea. Retours sur l'agora», in Architettura, urbanistica, società nel mondo antico. Giornata di studi in ricordo di Roland Martin, Tekmeria 2, Paestum 2001, p. 60; De Angelis, Megara Hyblaia and Selinous, p. 16, n. 46; M. Adelaide Vaggioli, s.v. «Thapsos (penisola)», in BTCGI XX, 2011, p. 544-545.

45 Sur la date de composition des Strategemata de Polyen, voir M. T. Schettino, Introduzione a Polieno, Pisa 1998, p. 33-35.

46 Polyen, V, 5, 1-2. J.-P. Schneider m'a évité bien des erreurs dans la traduction de ce passage de Polyen.

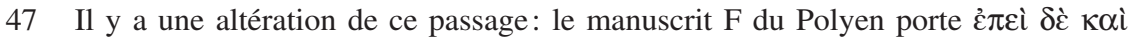

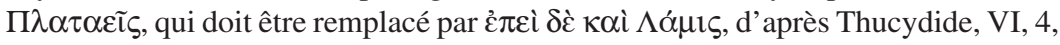
1. Voir à cet égard Graham, Megara Hyblaea, p. 156-157. 


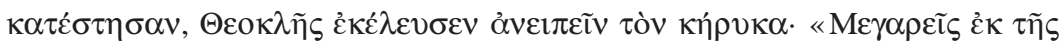

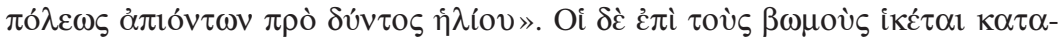

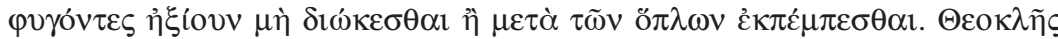

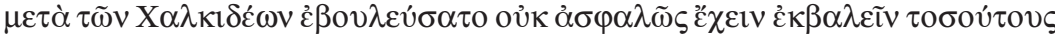

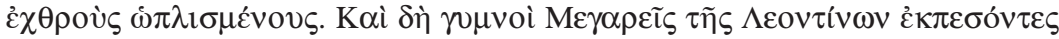

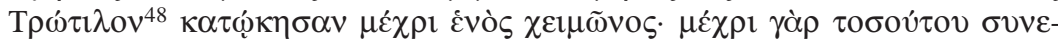
$\chi \omega ́ \rho \eta \sigma \alpha \nu$ oi $\mathrm{X} \alpha \lambda \kappa \imath \delta \varepsilon \tau \varsigma$.

1. Conduisant des Chalcidiens d'Eubée, Théoclès prit possession du territoire de Léontinoi ${ }^{49}$ avec des Sicules qui se trouvaient habiter le pays auparavant. Et, comme Lamis, conduisant à son tour une colonie de Mégare, se préparait à se diriger vers le territoire de Léontinoi, Théoclès dit qu'il ne pouvait chasser lui-même les Sicules qui vivaient avec eux à cause des serments, mais qu'il ouvrirait pendant la nuit les portes (aux Mégariens) et que, une fois à l'intérieur, ceux-ci pourraient traiter les Sicules en ennemis. Lorsqu'il fit ouvrir les portes, les Mégariens, après avoir occupé l'agora et l'acropole, se précipitèrent en armes sur les Sicules qui, surpris sans armes, abandonnèrent la cité et s'enfuirent. Les Mégariens résidèrent ainsi avec les Chalcidiens à la place des Sicules. 2. Théoclès chassa de la cité les Mégariens après qu'ils y avaient vécu six mois avec les Chalcidiens. Il prétendit avoir fait au moment de la guerre le vœu suivant: 〈Si nous exerçons le pouvoir sur la cité en toute sécurité, nous offrirons un sacrifice aux Douze Dieux et nous les honorerons en menant une procession (composée d'hommes) en armes >. Les Mégariens ne se méfiaient de rien, mais invitaient (les Chalcidiens) à sacrifier à la bonne fortune. Les Chalcidiens de leur côté, empruntant (aux Mégariens) leur panoplie en vue de la procession, une fois le sacrifice achevé, marchaient au pas à la façon d'une procession. Lorsqu'ils s'étaient arrêtés tout en armes sur l'agora, Théoclès ordonna au héraut de faire cette proclamation : <Que les Mégariens sortent de la cité avant le coucher du soleil !〉Ces derniers, s'étant réfugiés en suppliants auprès des autels, demandèrent de ne pas être chassés ou alors d'être renvoyés avec leurs armes. Théoclès réfléchit avec les Chalcidiens qu'il n'était pas sûr de chasser un si grand nombre d'ennemis avec leurs armes. Et exilés justement sans armes du territoire de Léontinoi, les Mégariens s'établirent à Trôtilon pour un hiver; en effet, c'est pour cette durée que les Chalcidiens leur avaient accordé (cette faveur).

Le récit de Polyen présente à coup sûr des inexactitudes ou des déformations, sans être pour autant dépourvu d'intérêt. Le parallélisme entre les Sicules surpris «sans armes» (aoploi) et les Mégariens expulsés de Léontinoi «sans armes» est suspect. Comme Cusumano l'a noté, ces

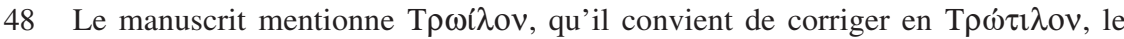
toponyme mentionné par Thucydide, VI, 4, 1. À ce sujet, voir Vallet-Villard, Dates de fondation, p. 314, n. 3 .

49 Tout comme E. Bianco (éd.), Gli Stratagemmi di Polieno. Introduzione, traduzione

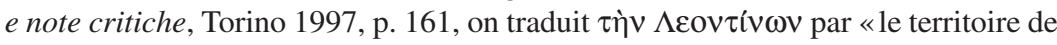

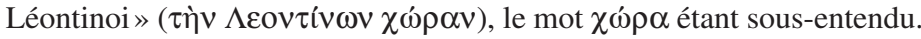


détails montrent d'une part la prétendue infériorité des indigènes vis-àvis des Grecs et, d'une autre, le processus de la «metamorfosi antropologica» des Mégariens armés, qui se transforment à la fin de leur séjour à Léontinoi en aoploi («sans armes»), à l'image des Sicules ${ }^{50}$. Le statut similaire des Mégariens et des indigènes, tous rejetés par les autres Grecs de Sicile, pouvait expliquer leur collaboration dans la fondation de la nouvelle cité.

La mention des Douze Dieux s'avère aussi intéressante à relever. Ce culte n'est pas attesté par d'autres documents à Léontinoi et il n'est pas non plus répertorié à Chalcis, tandis qu'à Mégare une statue des Douze Dieux, œuvre de Praxitèle, se trouvait à l'époque de Pausanias dans le sanctuaire d'Artémis Sôteira ${ }^{51}$. En Eubée, les mois du calendrier de la cité d'Histiée étaient formés sur les noms des Douze Dieux, mais on ne peut pas dire si ce calendrier remonte à l'époque archaïque ${ }^{52}$. Si l'on ne peut pas prouver l'existence d'un culte des Douze Dieux à l'époque de la fondation de Léontinoi, le contexte dans lequel ces divinités sont célébrées trouve des parallèles remontant à l'époque archaïque et classique. Tout d'abord, il ressort du passage de Polyen que le culte des Douze Dieux était célébré sur l'agora, ce qui rappelle la célébration de ces divinités à Athènes. Selon Thucydide, lorsque Pisistrate le Jeune, le fils du tyran Hippias, fut archonte, il consacra un autel aux Douze Dieux sur l'agora ${ }^{53}$. Ensuite, Théoclès intègre une liste de héros ou de chefs d'expédition, fondateurs mythiques d'autels des Douze Dieux,

50 N. Cusumano, Una terra splendida et facile da possedere. I Greci e la Sicilia, Roma 1994, p. 81-83, 86-91; cf. Sammartano, Tradizioni ecistiche, p. 64-66.

51 Pausanias, I, 40, 3. Notons que dans le monde mégarien, le culte des Douze Dieux est attesté à Hiéron, localité située sur la rive asiatique du Bosphore thrace dont Byzance et Chalcédoine se disputaient la possession: Apollonios de Rhodes, II, 531533 (et sa scholie); Polybe, IV, 39, 6; I. Kalchedon, 13; Denys de Byzance, 75, p. 27 (éd. R. Güngerich); Hésychios, FGrHist 390 F 33. Selon Polybe et Denys de Byzance, étant arrivé à Hiéron, Jason aurait été le premier à sacrifier aux Douze Dieux. Cf. C. R. Long, The Twelve Gods of Greece and Rome, Leiden et al. 1987, p. 55-57, 132-133, 153-154, 217-218.

52 La plus ancienne attestation d'un mois du calendrier d'Histiée, le mois Are(i)os, est fournie par l'inscription $I G$ XII 9, 1188, 1. 6, datant du IV ${ }^{\mathrm{e}}$ siècle. Voir à cet égard D. Knoepfler, «Le calendrier des Chalcidiens de Thrace. Essai de mise au point sur la liste et l'ordre des mois eubéens », JS, 1989, p. 32-33; Trümpy, Monatsnamen, p. $267-270$.

53 Thucydide, VI, 54, 6-7; cf. C. R. Long, op. cit., p. 157. 
tel que Deucalion en Thessalie, Héraclès à Olympie, Agamemnon sur le promontoire Lekton en Troade, Jason à Hiéron sur le Bosphore thrace ${ }^{54}$. On sait aussi qu'à Athènes l'autel des Douze Dieux était particulièrement recherché par les suppliants et il est vraisemblable que, sur le point d'être chassés par les Chalcidiens, les Mégariens se refugièrent aussi auprès de l'autel de ces divinités ${ }^{55}$. Compte tenu de ces analogies, il est permis de supposer que Polyen se fit l'écho d'une tradition locale selon laquelle Théoclès fut le fondateur du culte des Douze Dieux à Léontinoi.

Revenons à la question de l'installation des Grecs en Sicile pour noter que l'auteur des Stratagèmes corrobore Thucydide sur plusieurs points: il rapporte que les Mégariens sont arrivés seuls en Sicile et qu'ils ont cohabité avec les Chalcidiens à Léontinoi, pendant une brève période $^{56}$. Il existe une contradiction entre Thucydide et Polyen concernant la présence des Mégariens à Trôtilon: le premier la situe avant l'arrivée des Mégariens à Léontinoi, le deuxième après. Mais cette divergence peut s'expliquer par une confusion faite par Polyen entre Trôtilon et Thapsos. Polyen, comme Thucydide, omet d'indiquer que les Mégariens furent menés par l'Athénien Théoclès; c'est seulement la tradi-

54 Hellanicos, FGrHist 4 F 6 a-b, mentionne l'autel des Douze Dieux bâti par Deucalion en Thessalie. Pour les autels des Douze Dieux construits par Héraclès à Olympie, voir Pindare, Olympiques, X, 43-50 (et les scholies). Grâce à Strabon, XIII, 1, 48, C 605, on apprend qu'Agamemnon consacra un autel aux Douze Dieux sur le mont Lekton. Cf. C. R. Long, op. cit., p. 153, 159; S. Georgoudi, «Les Douze Dieux et les autres dans l'espace cultuel grec », Kernos 11, 1998, p. 73-83.

55 Hérodote, VI, 108, rapporte que, menacés par les Thébains, les Platéens vinrent demander l'aide aux Athéniens, en se réfugiant sur l'autel des Douze Dieux. D'après Lycurgue, Contre Léocrate, 93, Callistratos, homme politique athénien de la première moitié du $\mathrm{IV}^{\mathrm{e}}$ siècle, partit en exil afin d'échapper à la condamnation à mort prononcée par la cité contre lui. De retour à Athènes, il chercha le salut auprès des Douze Dieux, mais sans succès, le peuple l'ayant mis à mort.

56 Bérard, Colonisation, p. 77-78; Vallet-Villard, Dates de fondation, p. 314; Graham, Megara Hyblaea, p. 156. Selon Dunbabin, Western Greeks, p. 45, le récit de Polyen se fonde probablement sur l'œuvre que Thucydide a abrégée dans le chapitre sur les fondations grecques de la Sicile. En revanche, pour Sammartano, Tradizioni ecistiche, p. 64, 87-89, la source de Polyen est probablement Timée, auteur qui aurait présenté une version favorable aux Chalcidiens, en rendant les Mégariens responsables de l'élimination des Sicules à Léontinoi. Sur Timée en tant que source de Polyen, voir aussi M. T. Schettino, op. cit., p. 181-184. Cf. Manni, Sicilia preromana, p. 197-198; Tréziny, Grecs et indigènes, p. 24. 
tion d'Éphore qui transmet cette information ${ }^{57}$. L'absence de la mention de l'origine athénienne de Théoclès par Thucydide ne peut guère surprendre, car celui-ci connaissait sans doute l'opinion d'Hellanicos de Lesbos, auteur d'une Histoire de l'Attique ${ }^{58}$, selon laquelle Théoclès venait de Chalcis ${ }^{59}$. Bérard a été le premier à soutenir que l'origine athénienne de Théoclès, qui apparaît chez Éphore, était une invention de la propagande athénienne au cours du $\mathrm{V}^{\mathrm{e}}$ siècle, soit à l'époque de la fondation de Thourioi, soit plus probablement à celle de l'expédition athénienne en Sicile. Car l'Eubée était alors une dépendance d'Athènes, Naxos un membre de la Ligue de Délos et Athènes s'arrogeait des droits panhelléniques sur l'Occident ${ }^{60}$. Que cette tradition date de l'époque de l'empire athénien ou qu'elle fut une création postérieure reste néanmoins

57 Graham, Megara Hyblaea, p. 151-152, réfute la tradition d'Éphore. Contra Malkin, Megara Hyblaia, p. 212-214, qui démontre que, en dépit de ses topoi classiques, Éphore a une valeur historique.

58 Cette œuvre est citée par Thucydide, I, 97, 2.

59 Hellanicos, FGrHist 4 F 82 (cité par Stéphane de Byzance, s.v. X $\alpha \lambda \kappa i \varsigma$ ); $c f$. G. Vanotti, «L'idea di colonizzazione in Elanico e in Tucidide», in Antonetti (éd.), Il dinam. della colon. gr., p. 97-107, notamment p. 104. Sur Hellanicos de Lesbos, voir A. Gudeman, s.v. «Hellanikos» 7, RE VIII, 1913, col. 104-155; Jacoby, FGrHist III b Supplement (Text), p. 1-21. L'origine chalcidienne de Théoclès est rapportée aussi par Conon, FGrHist $26 \mathrm{~F}$ 1, XX. En revanche, Théoclès est considéré comme

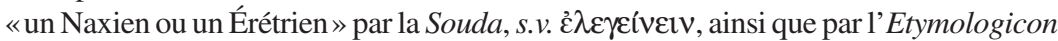

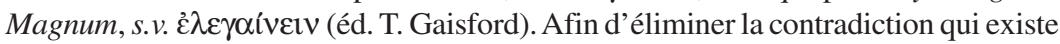
entre le récit d'Éphore et les autres récits relatifs à l'origine de Théoclès, M. Vaglio, «L'ecista ateniese. Una nota su Teocle, il fondatore di Nasso», Hesperìa, 17: studi sulla grecità di Occidente, L. Braccesi (éd.), Roma 2003, p. 159-164, estime que cet œciste était originaire d'Athènes Diades, cité située en Eubée. Pour l'examen des traditions concernant l'origine de Théoclès, voir aussi R. van Compernolle, «La fondation de Naxos et les sources littéraires. Contribution à l'histoire de la colonisation grecque», BIBR 26, 1950, p. 163-185.

60 Bérard, Colonisation, p. 78-79, suivi par G. Vallet, «Les cités chalcidiennes du Détroit et de Sicile», in Vallet, Le monde gr. colonial, p. 120; Asheri, La colon. gr., p. 106-107; Leschhorn, Gründer, p. 9; R. van Compernolle, «La Sicilia e la Grecia arcaica fino alle fine del VI secolo: 1'apporto delle fonti letterarie», Kokalos 30-31, 1984-1985, p. 27 ; F. Cordano, Antiche fondazioni greche. Sicilia e Italia meridionale, Palermo 1986, p. 32-33; Fischer-Hansen, Nielsen, Ampolo, Megara, p. 213. Cf. A. Mele, «Cuma in Opicia tra Greci e Romani», in Cuma. Atti del quarantottesimo Convegno di studi sulla Magna Grecia (Taranto, 27 settembre-1 ottobre 2008), Taranto 2009, p. 100-101. 
impossible à savoir, faute d'une documentation explicite ${ }^{61}$. Force est de constater à cet égard que l'absence de la mention d'un œciste mégarien chez Éphore faisait de l'Athénien Théoclès le véritable fondateur de Mégara. On se demande alors si le rôle de Théoclès dans l'installation des Mégariens en Sicile ne fait pas partie des thèmes de propagande athéniens vis-à-vis de leurs voisins de Mégare. Les Athéniens pouvaient soutenir à l'époque classique non seulement le droit de possession sur la Mégaride, mais aussi que les Mégariens avaient été conduits en Sicile par un Athénien ${ }^{62}$.

Le parti pris par Vallet et Villard en faveur de la tradition d'Éphore concernant la fondation de Mégara, au détriment de celle de Thucydide, a eu comme résultat l'acceptation de la thèse selon laquelle les apoikoi des Mégariens et des Chalcidiens étaient unies au départ ${ }^{63}$. Il y a cependant de sérieux doutes vis-à-vis de cette interprétation et il vaut mieux considérer l'expédition menée par Lamis comme une initiative propre aux Mégariens. En effet, je pense qu'il n'y a pas eu une subordination des Mégariens aux Chalcidiens ${ }^{64}$ ou des Doriens aux Ioniens ${ }^{65}$,

61 Selon G. Parmeggiani, op. cit., p. 292, Éphore récupère la tradition qui faisait du Chalcidien Théoclès un Athénien, pour porter un jugement critique sur Athènes et non pas pour la glorifier. Car si les Athéniens avaient répondu à l'appel de Théoclès de coloniser la Sicile, cela les aurait mis aux Ve-IV siècles à l'abri de biens des erreurs.

62 Pour les récits soutenant l'appartenance de la Mégaride à l'Attique, voir supra, chapitre I.2.2.

63 N. M. Kontoleon, «Zur Gründung von Naxos und Megara», in Europa. Studien zur Geschichte und Epigraphik der frühen Aegaeis. Festschrift für Ernst Grumach, W.C. Brice (éd.), Berlin 1967, p. 183-187; Legon, Megara Pol. Hist., p. 75; Figueira, Chronological Table, p. 269-270; Domínguez, Colon. Gr., p. 255 ; J.-L. Lamboley, Les Grecs d'Occident. La période archaïque, Paris 1996, p. 71-72; Polignac, Mégara Hyblaea, p. 225-226.

64 Figueira, Chronological Table, p. 270, note: «The Megarians were not free agents in Sicily. It may be that even in their settlement of Trotilon, they were acting as auxiliaries of the Khalkidians ».

65 M. Gras, H. Tréziny, in Mégara 5, p. 549, pensent que l'emploi du terme oỉń pour les Doriens par le Ps.-Scymnos, 275, indique le fait que ceux-ci sont en «position subalterne » par rapport aux autres colons. Mais le passage en question me semble être surinterprété, oíkń $о \rho \varepsilon \varsigma$ pouvant désigner à la fois les Ioniens et les Doriens (voir la traduction de Marcotte dans la CUF). De plus, rien ne permet d'affirmer que les оíń colons. Comme le rappelle Casevitz, Vocabulaire, p. 84-85, oißń $\tau \omega \rho$ signifie résident associé aux colons officiels, sans avoir toujours un sens juridique précis. 
mais plutôt une collaboration temporaire entre les Mégariens et les Chalcidiens ${ }^{66}$, similaire à celle qui unissait les Mégariens et les «Doriens» (des Argiens?) en route vers la Sicile. De fait, plusieurs alliances ad hoc se sont constituées entre différents groupes d'apoikoi menés par un ou plusieurs chefs. Ce fut le cas des alliances entre les Mégariens de Lamis et les Chalcidiens de Théoclès à Léontinoi, entre les Corinthiens d'Archias et les «Doriens » à Syracuse, ou encore entre les Chalcidiens (partis de Zancle sous la conduite d'Euclide, de Simos et de Sacon) et les Mylétidai (expulsés de Syracuse) à Himère ${ }^{67}$.

Quant aux premières relations entre les Mégariens et les Chalcidiens, les savants n'accordent pas de crédit au texte de Polyen qui rapporte que les Mégariens agirent par eux-mêmes ou peut-être même voulaient attaquer ( $\pi \rho \circ \sigma \beta \alpha ́ \alpha \lambda \lambda \varepsilon \imath v)$ la cité de Léontinoi ${ }^{68}$. Mais rien ne justifie le rejet de ce témoignage et il est envisageable que les Chalcidiens se soient confrontés à la pression des Mégariens et que ce ne soit pas Théoclès qui invita les Mégariens à Léontinoi. Autrement dit, les Chalcidiens ont fait le choix d'intégrer les Mégariens, au moins pour une brève période, plutôt que de les affronter ${ }^{69}$.

Si l'on considère que la tradition selon laquelle les Mégariens et les Chalcidiens sont arrivés ensemble en Sicile n'est pas fiable, étant due à la propagande athénienne, il ressort que les Mégariens ont eu en Sicile leur propre mouvement de colonisation. Ils n'étaient donc pas, comme on a pu l'écrire, un «misero gruppo di Megaresi vagabondi» qui, d'une manière inattendue, aurait réussi à créer les premiers éléments de

$66 C f$. E. Manni, «Greci in Sicilia fra l'VIII e il VI secolo», in E. Manni, $\Sigma \imath \kappa \varepsilon \lambda \iota \kappa \dot{\alpha} \kappa \alpha i$ 'I $\tau \alpha \lambda \iota \kappa \alpha ́$. Scritti minori di storia antica della Sicilia e dell'Italia meridionale, Roma 1990, p. 94.

67 Malkin, Megara Hyblaia, p. 214-215. R. Osborne, «Early Greek Colonization? The Nature of Greek Settlement in the West», in Archaic Greece : New Approaches and New Evidence, N. Fisher et H. van Wees (éds.), London 1998, p. 251-269, insiste sur le caractère «privé» des apoikiai («private enterprises») et sur le rôle des «charismatic individuals» dans la fondation des établissements grecs d'Italie et de Sicile. Voir à cet égard aussi A. Morakis, «Thucydides and the Character of Greek Colonisation in Sicily», $C Q$ 61, 2, 2011, p. 460-492.

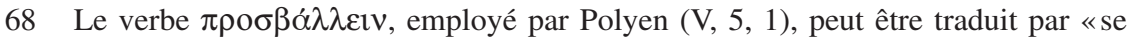
diriger vers » ou « venir dans », mais aussi par «attaquer». Voir à ce propos LSJ, s.v. $\pi \rho о \sigma \beta \alpha ́ \alpha \lambda \lambda \omega$ II 1 ; Graham, Megara Hyblaea, p. 156-157.

69 Dunbabin, Western Greeks, p. 18. 
l'urbanisme $\operatorname{grec}^{70}$. D'ailleurs, on rappelle que l'apoikia de Lamis avait au début un caractère composite, d'autres Doriens s'étant associés aux Mégariens pour partir vers la Sicile. On rappellera du reste qu'en l'absence d'une historiographie qui leur soit propre, la marginalité des Mégariens dans les sources littéraires s'explique par l'origine syracusaine, chalcidienne ou athénienne de ces sources ${ }^{71}$.

Suite à la mort de leur chef à Thapsos, les apoikoi choisirent probablement un autre ociste pour effectuer la fondation de leur ville (que celui-ci soit le roi Hyblôn ou non, voir ci-dessus), comme cela se produisit dans le cas de Catane. À cet égard, Thucydide (VI, 3, 3) atteste que les Chalcidiens menés par Théoclès fondèrent Naxos, Léontinoi et Catane. Pourtant, même s'ils étaient arrivés en Sicile sous la conduite de Théoclès, les habitants de Catane se donnèrent eux-mêmes Évarchos pour œciste. Ce témoignage montre qu'au VIII ${ }^{\mathrm{e}}$ siècle le changement de l'œciste était envisageable pour les apoikoi.

En conclusion, ces considérations rendent, à mon sens, difficile à accepter l'opinion selon laquelle les Mégariens n'étaient à leur arrivée en Sicile qu'un élément rapporté aux Eubéens et plaide au contraire pour la spécificité du mouvement mégarien de colonisation.

\section{II.1.1.2 Les rapports entre les Mégariens et les Sicules}

À leur arrivée en Sicile, les Grecs rencontrèrent les Sicules dans les parties orientales et septentrionales de l'île, les Sicanes, les Élymes et les Phéniciens dans les parties méridionales et occidentales ${ }^{72}$. Pour la

70 D. Asheri, Athenaeum N.S. 56, 1978, p. 401, écrit: «È quindi veramente straordinario constatare come riuscì questo misero gruppo di Megaresi vagabondi, senza ecista, ad 〈organizzare lo spazio〉 secondo regole ben definite, che segnano la data di nascita dell'urbanistica pianificata greca in occidente».

71 Sammartano, Tradizioni ecistiche, p. 57-58, 64, 66, 88-89; Gras, Tréziny, Megara Iblea, p. 257. Pour la place de Mégara dans les historiographies syracusaine et chalcidienne, voir également M. Gras, H. Tréziny, in Mégara 5, p. 548-550.

72 Thucydide, VI, 2, 2-6. On renverra parmi les nombreuses études sur les populations locales de Sicile à l'époque de la colonisation grecque à Manni, Sicilia preromana, p. 181-211; R. Ambrosini, «L'elemento indigeno », in La Sicilia antica, I, 1, E. Gabba et G. Vallet (éds.), Napoli 1980, p. 43-51 ; L. Braccesi, «Trattazione storica», in La Sicilia antica, I, 1, E. Gabba et G. Vallet (éds.), Napoli 1980, p. 53-86; Domínguez, Colon. Gr.,p. 19-82, 507-632; R. van Compernolle, « Segesta e gli Elimi, quarant' anni dopo », in Gli Elimi e l'area elima fino all'inizio della prima guerra punica. Atti del 
Sicile orientale, les trouvailles archéologiques corroborent les récits attestant la présence à la haute époque archaïque de communautés sicules à Léontinoi ${ }^{73}$ et à Syracuse ${ }^{74}$. Bien que Mégara n'ait pas fourni jusqu'à présent de telles trouvailles, on notera la présence d'un site indigène près de Villasmundo, dans la vallée du fleuve Marcellino, à $8 \mathrm{~km}$ au nord-ouest de la ville mégarienne. Explorée par Vozza, la nécropole de ce site a livré des céramiques de fabrication locale et d'importation datant de la première moitié du VIII ${ }^{\mathrm{e}}$ siècle, la localité étant abandonnée probablement dans la première moitié du VII ${ }^{\mathrm{e}}$ siècle ${ }^{75}$. En dépit du

seminario di studi (Palermo-Contessa Entellina, 25-28 maggio 1989), G. Nenci et al. (éds.), Palermo 1990, p. 73-98; V. La Rosa, «Le popolazioni della Sicilia: Sicani, Siculi, Elimi », in Italia omnium terrarum parens $^{2}$, G. Pugliese Carratelli (éd.), Milano 1991,p. 3-110; R. Sammartano, Origines gentium Siciliae. Ellanico, Antioco, Tucidide, Roma 1998; Leighton, Sicily before History, p. 215-268; R. M. Albanese Procelli, Sicani, Siculi, Elimi. Forme di identità, modi di contatto e processi di trasformazione, Milano 2003, surtout p. 131-145; A. Willi, Sikelismos : Sprache, Literatur und Gesellschaft im griechischen Sizilien (8.-5. Jh. v. Chr.), Basel 2008, p. 331-349.

73 Polyen, V, 5, 1; Thucydide, VI, 3, 3. Sur les sites sicules des alentours de Léontinoi et les rapports entre les Sicules et les Chalcidiens, voir G. Vallet, «La colonisation chalcidienne et l'hellénisation de la Sicile orientale», in Vallet, Le monde gr. colonial, p. 87-105 ; G. Rizza, «Siculi e Greci sui colli di Leontini », Cronache di Archeologia 1, 1962, p. 3-27; E. Procelli, «Aspetti e problemi dell'ellenizzazione calcidese nella Sicilia orientale», MEFRA 101, 1989, p. 679-689; Sammartano, Tradizioni ecistiche, p. 61-64; I. Morris, AArch, 67, 1996, p. 56; M. Frasca, «Leontinoi alla luce delle nuove indagini», in La Sicilia in età arcaica. Dalle apoikiai al 480 a.C. Contributi dalle recenti indagini archeologiche, R. Panvini et L. Sole (éds.), Palermo 2009, p. 75-76; Frasca, Leontinoi, p. 25-35, 41-44.

74 Thucydide, VI, 3, 2. Pour les découvertes archéologiques qui attestent la présence des indigènes à Syracuse et dans son territoire au moment de l'arrivée des Grecs, voir G. Voza, «Ricerche in Ortigia. Esplorazioni nell' area delle necropoli e dell'abitato», in Archeologia nella Sicilia Sud-Orientale, P. Pelagatti et G. Voza (éds.), Napoli 1973, p. 81-82 ; M. Frasca, «Iron Age Settlements and Cemeteries in Southeastern Sicily : An Introduction Survey », in Early Societies in Sicily: New Developments in Archaeological Research, R. Leighton (éd.), London 1996, p. 140-141; idem, «Una nuova capanna 〈sicula > Siracusa, in Ortigia: tipologia dei materiali», MEFRA 95, 1983, p. 565-598; V. La Rosa, op. cit., p. 36; R. Sammartano, Tradizioni ecistiche, p. 91-93; Tréziny, De Mégara à Sélinonte, p. 162.

75 G. Voza, «Villasmundo-Necropoli in contrada Fossa», in Archeologia nella Sicilia Sud-Orientale, P. Pelagatti et G. Voza (éds.), Napoli 1973, p. 57-63 ; idem, «La necropoli della valle del Marcellino presso Villasmundo», in Rizza (éd.), Insediamenti colon. gr., p. 104-110; idem, «Evidenze archeologiche di VIII e VII secolo a. C. nel territorio di Siracusa: la necropoli di Villasmundo, nella valle del Marcellino », ASAA 60, 
fait qu'elles ne sont que partiellement publiées, les trouvailles de Villasmundo font de ce site un meilleur candidat à l'identification avec Hybla (la capitale du roi Hyblôn) que Pantalica ${ }^{76}$. Cette opinion, qui est actuellement partagée par plusieurs chercheurs, est soutenue par les parallèles établis entre le matériel céramique de Villasmundo et celui de Mégara, et par l'absence de la céramique géométrique à Pantalica, un site qui semble se trouver plutôt dans l'aire d'influence de Syracuse $^{77}$. Pourtant, il reste douteux que les trouvailles de Villasmundo, qui sont selon Voza la conséquence des contacts précoloniaux entre les Grecs et la Sicile, puissent être mises en relation directe avec la fondation de Mégara ${ }^{78}$. Dernièrement, Tréziny estime que les plus anciens vases seraient d'origine eubéo-cycladique, ou «chalcidienne», chose qui plaiderait en faveur des Chalcidiens comme responsables des contacts avec les indigènes durant cette phase précoloniale ${ }^{79}$. Ajoutons que les difficultés rencontrées par les Mégariens à trouver un emplacement convenable pour leur apoikia indiquent qu'ils n'avaient pas acquis une bonne connaissance de la Sicile orientale, comme on l'aurait attendu d'une cité qui avait développé des échanges précoloniaux avec les habitants de cette région ${ }^{80}$.

N. S. 44, 1982 (1984), p. 169-171 ; idem, «I contatti precoloniali col mondo greco», in SIKANIE. Storia e civiltà della Sicilia antica, G. Pugliese Carratelli (éd.), Milano 1986, p. 560 ; cf. Domínguez, Colon. Gr., p. 54-55; Coldstream, Geom. Gr. ${ }^{2}$, p. 233; R. M. Albanese Procelli, op. cit., p. 132-133; Tréziny, Grecs et indigènes, p. 19-21.

76 L'identification d'Hybla, le chef-lieu du roi sicule, avec Pantalica a été proposée par Bernabò Brea, Re Hyblon, p. 163-164; idem, «Pantalica», in Archeologia nella Sicilia Sud-Orientale, P. Pelagatti et G. Voza (éds.), Napoli 1973, p. 53, suivi par G. Vallet, «Espace privé et espace public dans une cité coloniale d'Occident (Mégara Hyblaea)», in Vallet, Le monde gr. colonial, p. 464 ; V. La Rosa, op. cit., p. 35 ; Coldstream, Geom. Gr. ${ }^{2}$, p. 235 ; Boardman, Gr. Overseas ${ }^{3}$, p. 189.

77 R. M. Albanese Procelli, «Greek and Indigenous People in Eastern Sicily: Forms of Interaction and Acculturation », in Early Societies in Sicily: New Developments in Archaeological Research, R. Leighton (éd.), London 1996, p. 168; M. Gras, H. Tréziny, in Mégara 5, p. 338, n. 151; Tréziny, Grecs et indigènes, p. 18, 21.

78 Danner, Megara, p. 30-32; De Angelis, Megara Hyblaia and Selinous, p. 10-11; Leighton, Sicily before History, p. 225. Cf. Martin et al., Città greche, p. 611; R. Leighton, «Sicily during the Centuries of Darkness», CArchJ 3, 2, 1993, p. 274-275.

79 Tréziny, Grecs et indigènes, p. 20-21; cf. M. Denoyelle, M. Iozzo, La céramique grecque d'Italie méridionale et de Sicile. Productions locales et apparentées du VIII au III ${ }^{e}$ siècle av. J.-C., Paris 2009, p. 42.

80 C. W. Neeft, «Observations on the Thapsos Class», MEFRA 93, 1981, p. 55, n. 204. 
On notera du reste qu'il est improbable que le roi Hyblôn ait concédé une partie de son territoire sans être convaincu de la possibilité de recevoir une aide militaire de la part des Mégariens. Comme on n'a pas manqué de le suggérer, les Sicules comptaient sans doute sur l'appui des Mégariens contre la menace des apoikoi chalcidiens et corinthiens ${ }^{81}$. Même si les Mégariens furent chassés de Léontinoi par les Chalcidiens, il ne faut pas sous-estimer leur capacité militaire. Il est difficile de croire que des colons désarmés (aoploi) aient occupé un endroit dépourvu de défenses naturelles tel que le site de la future Mégara ${ }^{82}$. L'absence d'une véritable fortification naturelle et les éventuelles menaces de leurs voisins grecs ont probablement déterminé les Mégariens à bâtir leur premier rempart à une date relativement haute, autour de $700^{83}$.

Du reste, les sources textuelles témoignent de l'existence d'un rapport ambigu entre Mégara et le site sicule d'Hybla. Éphore, dans le passage cité par Strabon (VI, 2, 2, C 267), rapporte que Mégara s'appe-

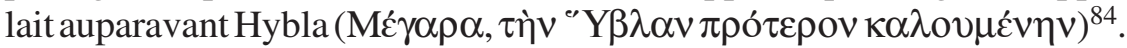
Il résulte de cette tradition, reprise aussi par Servius et Stéphane de Byzance $^{85}$, que les Grecs ont colonisé Hybla, la cité grecque remplaçant par la suite le site sicule ${ }^{86}$. Certes, la présence indigène fait encore défaut à Mégara, mais rien n'empêche qu'Éphore ait pu transmettre une tradition locale selon laquelle la cité grecque fut le successeur du royaume d'Hyblôn. Il n'est d'ailleurs pas nécessaire que la ville ait été fondée sur un site sicule pour faire apparaître une telle tradition. Il suffit que la localité indigène ait été englobée dans le territoire de la nouvelle fondation

81 Bernabò Brea, Re Hyblon, p. 172-173; Graham, Megara Hyblaea, p. 159-163; Holloway, Anc. Sicily, p. 50; Coldstream, Geom. Gr. ${ }^{2}$, p. 235-236 et 242 ; Leighton, Sicily before History, p. 232-233; P. G. Guzzo, Fondazioni greche. L'Italia meridionale e la Sicilia (VIII e VII sec. a.C.), Roma 2011, p. 177-180.

82 G. Vallet, F. Villard, «Mégara Hyblaea IX. Les problèmes de l'agora et de la cité archaïque», MEFR 81, 1969, p. 10; Vallet, Bilan, p. 454.

83 H. Tréziny, in Mégara 5, p. 301 ; idem, Colonies gr. de Méditerranée, p. 59.

84 L'autre texte (Ps.-Scymnos, 276-277) qui transmet la tradition d'Éphore présente

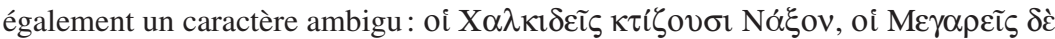

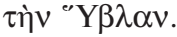

85 Servius, ad Buc., I, 54 : Hybla, quae postea Megara, oppidum Siciliae; Stéphane de

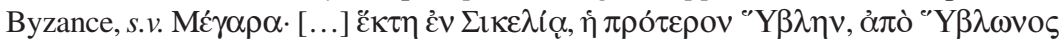

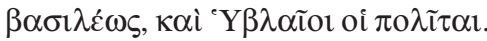

86 N. Cusumano, op. cit., p. 91; cf. M. Gras, H. Tréziny, in Mégara 5, p. 338. 
pour que les auteurs antiques aient pu considérer Mégara comme le substitut de l'établissement sicule ${ }^{87}$. Je rappelle que la cité d'Histria (Istros) portait le nom du célèbre fleuve, parce que celui-ci était aux confins de son territoire, la ville n'étant pas installée aux embouchures de l'Istros ${ }^{88}$.

Le développement rapide et la croissance démographique de Mégara durant le VII ${ }^{\text {e }}$ siècle seraient dus, selon De Angelis, à l'afflux de Sicules, menacés par l'expansion de Syracuse ${ }^{89}$. Il estime que l'arrivée des indigènes en ville expliquerait la disparition des sites sicules de l'arrière-pays de Mégara vers le milieu du VII ${ }^{\mathrm{e}}$ siècle. Mais cette hypothèse est difficile à prouver en l'absence d'une prospection systématique de la chôra, peu connue actuellement, et du caractère lacunaire des publications. D'ailleurs, Sammartano arrive à une conclusion opposée à celle de De Angelis, en suggérant que l'abandon de Villasmundo dans les premières décennies du VII ${ }^{\mathrm{e}}$ siècle serait un indice de la détérioration des rapports entre les Mégariens et les Sicules ${ }^{90}$. De surcroît, les chercheurs ont suggéré qu'une série de pratiques funéraires qui apparaissent dans les nécropoles - la position fotale (rannicchiata), la décapitation des cadavres, l'inhumation multiple - témoignerait d'une présence ou d'une influence sicule dans le domaine funéraire à Mégara ${ }^{91}$.

87 Cf. Sammartano, Tradizioni ecistiche, p. 71-72.

88 P. Alexandrescu, «Colonisation occidentale et colonisation pontique», in Die Ägäis und das westliche Mittelmeer. Beziehungen und Wechselwirkungen 8. bis 5. Jh. v. Chr. Akten des Symposions, Wien, 24. bis 27. März 1999, F. Krinzinger (éd.), Wien 2000, p. 520 (= L'aigle et le dauphin. Études d'archéologie pontique, Bucarest-Paris 1999, p. 24); cf. Avram, Les territoires d'Istros et de Callatis, p. 610-612.

89 De Angelis, Megara Hyblaia and Selinous, p. 52-54, voir également p. 1-10 pour l'analyse de la culture indigène rencontrée par les Mégariens à leur arrivée en Sicile, avec une présentation détaillée de la bibliographie à ce sujet. De même, la présence des Sicules dans la cité de Mégara est soutenue par Pugliese Carratelli, Selinunte, p. 17; Domínguez, Colon. Gr., p. 94, 107, 271-272; cf. M. Gras, H. Tréziny, in Mégara 5, p. 523-524. Pour les rapports entre les Grecs et les indigènes de Sicile, voir aussi F. de Angelis, «Equations of Culture: the Meeting of Natives and Greeks in Sicily (ca. 750-450 BC)», Ancient West \& East 2, 1, 2003, p. 19-50.

90 Sammartano, Tradizioni ecistiche, p. 67-68.

91 M. Gras, «Nécropole et histoire : quelques réflexions à propos de Mégara Hyblaea», Kokalos 21, 1975, p. 48; L. Mercuri, «Tête sans corps, corps sans tête. De certaines pratiques funéraires en Italie méridionale et en Sicile (VIII ${ }^{-}-V^{\mathrm{e}}$ siècles avant J.-C.) », MEFRA 113, 2001, p. 10; cf. Vallet-Voza, Augusta, p. 57; L. M. Guglielmino, «La necropoli di Entella», in Nécropoles et sociétés antiques (Grèce, Italie, Languedoc), 
Cependant, la datation de ces tombes de l'époque archaïque et le caractère indigène de ces pratiques funéraires ont été contestés, de sorte que l'on ne peut pas s'appuyer sur ces trouvailles, du moins avant leur publication intégrale ${ }^{92}$.

Malheureusement, la documentation onomastique ne permet pas de compléter l'image des rapports entre les Mégariens et les Sicules, ce qui n'est guère surprenant, tant la moisson des inscriptions est maigre pour cette cité. Un seul nom semble avoir une origine sicule, soit l'anthroponyme $* \mathrm{Kv} \beta \mathrm{ou}[\mathrm{o} \varsigma]$, qui apparaît dans une inscription funéraire fragmentaire ${ }^{93}$. On connaît par ailleurs le nom d'un site de la chôra: il s'agit de Styella, établissement qualifié de phrourion par Stéphane de Byzance, et qui s'appelais aussi Hybla, selon Philistos de Syracuse ${ }^{94}$. Cette localité, qui englobe un ancien centre sicule et qui, après l'abandon de Mégara, commence à frapper des monnaies, se trouverait selon

J. de la Genière (éd.), Naples 1994, p. 207-209; R. M. Albanese Procelli, «Le etnie dell' età del ferro e le prime fondazioni coloniali », in Prima Sicilia, alle origini della società siciliana, Albergo dei Poveri, Palermo, 18 ottobre-22 dicembre 1997, S. Tusa (éd.), Siracusa-Palermo 1997, p. 519-520; Leighton, Sicily before History, p. 234-237.

92 Tréziny, Grecs et indigènes, p. 26.

93 M. Lejeune, «Notes d'épigraphie sicilienne», Kokalos 16, 1970, p. 23-24; contra C. Gallavotti, «Scritture arcaiche della Sicilia e di Rodi», Helikon 15-16, 1975-

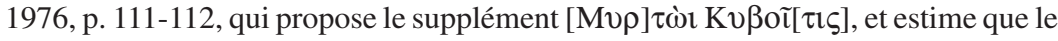
dernier mot serait l'ethnique d'une femme, formée à partir de Kúßos, une localité punique en Afrique, près d'Utique, mentionnée par Stéphane de Byzance, s.v. Kúßos; $c f$. R. Arena, IGASM I ${ }^{2}, a d \mathrm{n}^{\circ}$ 11, p. 22-23; M. Gras, H. Tréziny, in Mégara 5, p. 572.

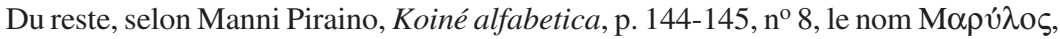
mentionné par une inscription funéraire de Mégara, peut être d'origine sicule. Con-

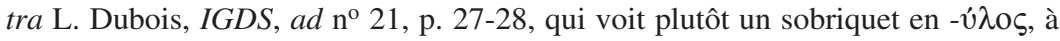

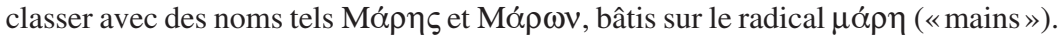
$C f$. aussi L. Agostiniani, in Gli Elimi e l'area elima fino all'inizio della prima guerra punica. Atti del seminario di studi (Palermo-Contessa Entellina, 25-28 maggio 1989), G. Nenci et al. (éds.), Palermo 1990, p. 357.

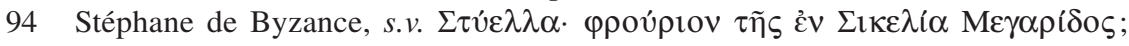
Philistos, FGrHist 556 F 20 (apud Stéphane de Byzance, s.v. "Y $\beta \lambda \alpha \imath$ ): $\mu i ́ \alpha \delta \dot{\varepsilon} \tau \tilde{\omega} v$

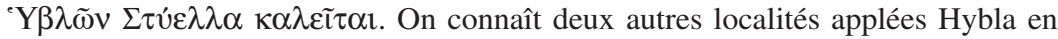
Sicile orientale, soit Hybla Géléatis/Géréatis et Hybla Héraia: Thucydide, VI, 62, 5 ; Pausanias, V, 23, 6; Stéphane de Byzance, s.v. ${ }^{\text {YY }} \beta \lambda \alpha \mathrm{l} ;$ cf. Manni, Geog. della Sicilia, p. 184-186; Sammartano, Tradizioni ecistiche, p. 73-83; Manganaro, Hybla, p. 149154. 
Bernabò Brea dans la partie ouest du territoire de Mégara, «nella contrada Pezza Grande presso l'attuale Pedagaggi» ${ }^{95}$.

Les contacts entre les cités mégariennes de Sicile et les Sicules sont aussi visibles dans la répartition géographique du formulaire funéraire à apostrophe oĭhot. Ce formulaire apparaît dans les épitaphes des Sélinontins trouvées à Delphes ${ }^{96}$ et dans les colonies grecques de $\mathrm{Si}$ cile, il n'est guère attesté qu'à Sélinonte, vers $600^{97}$. Or on retrouve la formule par olıor dans une épitaphe de la fin du VI siècle ou du début $\mathrm{du} \mathrm{V}^{\mathrm{e}}$ siècle trouvée à Raguse, localité de la Sicile orientale que l'on identifie avec l'antique Hybla Héraia ${ }^{98}$. Lejeune propose de voir dans cette inscription une influence exercée par Mégara sur l'Hybla sicule ${ }^{99}$.

95 Bernabò Brea, Re Hyblon, p. 178-185; idem, «Che cosa conosciamo dei centri indigeni della Sicilia che hanno coniato moneta prima dell'età di Timoleonte », in Le emissioni dei centri siculi fino all'epoca di Timoleonte e $i$ loro rapporti con la monetazione della colonie greche in Sicilia, AIIN, Suppl. 20, Roma 1975, p. 49-51 ; cf. De Angelis, Megara Hyblaia and Selinous, p. 73-75. Pour les différentes localisations de Styella proposées par les modernes, voir G. Manganaro, «Iscrizioni greche del V sec. a. C. della Sicilia», ZPE 144, 2003, p. 153-156; A. Facella, s.v. «Styella», in BTCGI XIX, 2005, p. 730-732, qui considère le site comme non identifié. Pour les émissions monétaires de Styella ( $V^{\mathrm{e}}$ siècle), voir S. Mirone, «Stiela, topografia e numismatica», Zeitschrift für Numismatik 38, 1928, p. 29-55 ; R. R. Holloway, «Le monetazioni di Agyrion, Aluntion, Entella, Hipana, Nakone, Stiela», in Le emissioni dei centri siculi fino all'epoca di Timoleonte e i loro rapporti con la monetazione della colonie greche in Sicilia, AIIN, Suppl. 20, Roma 1975, p. 142-143; T. FischerHansen, T.H. Nielsen, C. Ampolo, s.v. «Stielanaioi», in Hansen-Nielsen (éds.), Inventory, p. 224-225.

$96 S I G^{3} 11$; J. Bousquet, «Inscriptions de Delphes», BCH 88, 1964, p. 380-382; G. Rougemont, «Delphes et les cités grecques d'Italie du Sud et de Sicile», in $L a$ Magna Grecia e i grandi santuari della madrepatria. Atti del trentunesimo convegno di studi sulla Magna Grecia (Taranto, 4-8 ottobre 1991), Taranto 1992, p. 169-170. La formule par ol̆ $\mathrm{oot}$ apparaît aussi vers la fin du $\mathrm{VI}^{\mathrm{e}}$ siècle dans les inscriptions attiques: $I G \mathrm{I}^{3} 1248,1267$.

97 IGDS, 63-69; II, 21 ; IGASM I $\mathrm{I}^{2}, 26-34,33$ bis; Brugnone, Note epigrafiche, p. 5964, 91-94; eadem, «A proposito di un'epigrafe sepolcrale da Selinunte», MEFRA 120, 2008, p. 21-28; G. Rocca, Nuove iscrizioni da Selinunte, Alessandria 2009, p. 1-16; cf. C. Sourvinou-Inwood, 〈Reading $>$ Greek Death to the End of the Classical Period, Oxford 1995, p. 152-160.

98 R. Arena (éd.), Iscrizioni greche arcaiche di Sicilia e Magna Grecia. Vol. V: Iscrizioni di Taranto, Locri Epizefiri, Velia e Siracusa, Alessandria 1998, 98; cf. Jeffery, LSAG ${ }^{2}$, p. 269.

99 M. Lejeune, op. cit., p. 19-20. 
Mais étant donné que le formulaire ol̆hor n'est pas connu pour l'instant à Mégara, et compte tenu également du caractère isolé de cette trouvaille, on ne peut pas exclure que l'on ait là une influence directe de l'épigraphie funéraire sélinontine.

Sur la foi des documents examinés jusqu'ici, on conclura que les contacts avec les Sicules du roi Hyblôn eurent un rôle important dans l'établissement de Mégara, et sans doute dans le développement ultérieur de la cité. Il reste à espérer que les nouvelles découvertes et la publication du matériel archéologique existant dans les collections des musées italiens viendront compléter l'image des rapports entre les Grecs et la population locale durant l'époque archaïque.

\section{II.1.1.3 Les causes de la fondation de Mégara et les rapports avec la métropole}

La rareté des découvertes archéologiques datant du $\mathrm{VIII}^{\mathrm{e}}$ siècle et l'absence de récits détaillés concernant l'histoire archaïque de Mégare Nisaia et de Mégara Hyblaea rendent difficile l'identification des causes exactes (stasis, sténochôria, commerce, conflits externes, une période de famine prolongée) qui provoquèrent le départ des colons vers l'ouest ${ }^{100}$. L'examen des événements de l'histoire de Mégare, entrepris dans la première partie de l'ouvrage, suggère que la raison principale de ce mouvement colonial furent les luttes intestines, qui eurent lieu à l'époque du synœcisme. En revanche, l'opinion selon laquelle la perte de Pérachora aurait été la cause principale du départ des Mégariens vers l'Occident est dénuée de fondement, puisque la péninsule n'a jamais été contrôlée par les Mégariens, si du moins notre démonstration est exacte ${ }^{101}$.

Quant aux rapports entre Mégare et ses apoikoi de Sicile, d'aucuns estiment que l'expulsion des Mégariens de Léontinoi fut l'un des résultats de la guerre lélantine, et plus précisément une conséquence, d'une part, des conflits entre Mégare et Corinthe et, de l'autre, de la coopération

100 De manière générale, pour les causes de la colonisation grecque en Sicile, voir Boardman, Gr. Overseas ${ }^{3}$, p. 162-164.

101 Voir supra, chapitres I.1.1. et I.4. 
entre Chalcis et Corinthe ${ }^{102}$. Mais en réalité aucun récit n'appuie ces conjectures, et les conflits entre les Chalcidiens et les Mégariens entrent dans la catégorie des luttes internes spécifiques aux cités ayant admis des étrangers comme cofondateurs ou comme colons supplémentaires, ce dont témoigne Aristote ${ }^{103}$. De même, l'hypothèse selon laquelle les conflits entre Mégare et Corinthe auraient provoqué une confrontation entre Mégara et Syracuse pêche par son «modernisme» 104 . Même si les Mégariens avaient été forcés par les Corinthiens à quitter Thapsos $^{105}$ - ce que le texte de Thucydide $(\mathrm{VI}, 4,2)$ ne mentionne pas et qui paraît être en contradiction avec Polyen $(\mathrm{V}, 5,2)^{106}$ - cette expulsion s'explique par la compétition entre les apoikiai pour prendre possession des terres et des voies de communication de Sicile plutôt que par les conflits entre les métropoles de Grèce.

On notera également qu'outre la collaboration pour la fondation de Sélinonte (voir ci-dessous), on ne connaît pas d'autres rapports politiques entre Mégara et sa métropole. Les contacts commerciaux entre les deux cités seraient mis en évidence, à en croire De Angelis, par les silos trouvés à Mégara et datant de la haute époque archaïque. Ceux-ci témoigneraient de l'intérêt de l'élite locale à établir une route commerciale qui aurait permis d'acheminer des céréales de Sicile en Mégaride ${ }^{107}$.

102 A. Blakeway, «Prolegomena to the Study of Greek Commerce with Italy, Sicily and France in the Eighth and Seventh Centuries B.C.», ABSA 33, 1932-1933, p. 205206; Forrest, Colonization, p. 161 ; N. M. Kontoleon, op. cit., p. 186-187; De Angelis, Megara Hyblaia and Selinous, p. 69, n. 87, 201 ; Coldstream, Geom. Gr. ${ }^{2}$, p. 200, 235 ; Smith, Megaris, p. 98; contra Asheri, La colon. gr., p. 111. Sur l'hypothétique participation de Mégare à la guerre lélantine, voir infra, chapitre II.2.4.1.3.

103 Aristote, Politique, V, 3, 11, 1303a 25-28 (passage cité infra, chapitre II.2.4.1.7).

104 F. de Angelis, «Equations of Culture: the Meeting of Natives and Greeks in Sicily (ca. 750-450 BC)», Ancient West \& East 2, 1, 2003, p. 34.

105 Cette hypothèse est soutenue par Pugliese Carratelli, Selinunte, p. 17; Figueira, Chronological Table, p. 269; cf. Graham, Megara Hyblaea, p. 159.

106 Si l'on accepte que Polyen a fait une erreur en mentionnant Trôtilon à la place de Thapsos quant au lieu de séjour des Mégariens après leur expulsion de Léontinoi, alors ce serait les Chalcidiens qui auraient permis aux Mégariens de rester un hiver à Thapsos. Dans ce cas, les Chalcidiens seraient les responsables du départ des Mégariens de Thapsos et non pas les Corinthiens de Syracuse. À ce propos, voir Sammartano, Tradizioni ecistiche, p. 66, 70.

107 F. de Angelis, «Trade and Agriculture at Megara Hyblaea», OJA 21, 2002, p. 299 310; idem, Megara Hyblaia and Selinous, p. 51, suivi par Morris, The Eighth-century Revolution, p. 68 ; contra A. Robu, AC 75, 2006, p. 209-210. 
Cependant, il est bien difficile de prouver que ces silos - dont les dimensions sont variées, pouvant atteindre en diamètre $1 \mathrm{~m}$ environ et une profondeur de 2,70 $\mathrm{m}$ - appartenaient aux aristocrates et non pas à de simples citoyens ou éventuellement à des groupements plus larges par exemple à des patriai ou à d'autres groupes gentilices attestés ailleurs dans le monde mégarien (voir ci-dessous) ${ }^{108}$. Dernièrement, Gras et Tréziny ont rejeté eux aussi l'interprétation proposée par De Angelis et ont interprété les silos localisés au nord-est de l'agora comme «des restes de la phase des campements et des cabanes », la première forme d'implantation grecque à Mégara ${ }^{109}$. Bref, si l'on peut s'accorder avec De Angelis sur le fait que l'agriculture était l'une des préoccupations principales des apoikoi ${ }^{110}$, l'hypothèse de l'exportation des céréales depuis Mégara vers la Mégare de Grèce demeure fragile. Il faut avouer que cette opinion se fait l'écho d'une thèse contestable, selon laquelle la première finalité des apoikiai était l'acquisition des terres à blé qui pussent diminuer les insuffisances du ravitaillement des métropoles ${ }^{111}$.

S'agissant des liens entre les Mégariens de Sicile et ceux de Grèce, il convient d'évoquer l'exil de Théognis en Sicile ${ }^{112}$. Comme on l'a

108 G. Vallet, F. Villard, P. Auberson notent dans Mégara 1 la présence des silos 38, 13 , p. $101 ; 47,6$, p. 118 , et 58,18 , p. 144 , qui ont une terre de remplissage contenant un matériel daté de la fin du VIII ${ }^{\mathrm{e}}$ ou du VII ${ }^{\mathrm{e}}$ siècle. Selon Mégara 1, il existe aussi deux silos du VII ${ }^{\mathrm{e}}$ siècle, situés sur la place et la stoa qui borde l'agora au nord (les silos 41, 2 et 3, p. 110-111), qui ont probablement une fonction publique. Sur les silos de Mégara, voir également M. Gras, H. Tréziny, in Mégara 5, p. 497-502, 524526. Pour Gras et Tréziny le silo 58, 18 est un «puits inachevé». En plus, ils pensent que la structure 41, 4 initialement définie dans Mégara 1, p. 111, comme un «bothros» est en fait un silo, qui doit être associé aux deux autres silos de l'agora (41,2 et 3) et qui devient un lieu de culte seulement après son comblement.

109 M. Gras, H. Tréziny, in Mégara 5, p. 526; H. Tréziny, «Aux origines de Mégara Hyblaea», in The 〈Dark Ages> revisited. Acts of an International Symposium in Memory of William D. E. Coulson (University of Thessaly, Volos, 14-17 June 2007), A. Mazarakis Ainian (éd.), Volos 2011, p. 543-545. Cf. aussi H. Tréziny, Gnomon 78, 2006, p. 713, qui note: «Il est probable en réalité que ces silos sont publics, et sans doute antérieurs à la mise en place du plan urbain».

110 L'agriculture constitue la base économique de toutes les colonies grecques de Sicile à l'époque archaïque. À cet égard, voir surtoutF. de Angelis, «Estimating the Agricultural Base of Greek Sicily », PBSR 68, 2000,p. 111-148; $c f$. D. Fusaro, «Note di architettura domestica greca nel periodo tardo-geometrico ed arcaico», DdA N. S. 4, 1982, p. 21.

111 Contre cette thèse, voir Lévêque, Grecs en Occident, p. 14.

112 Théognis, 783-786. 
suggéré plus haut, c'est probablement ce voyage qui est à la base de la tradition selon laquelle le célèbre poète mégarien était originaire de Mégara Hyblaea. Chassé par les «démocrates» de Mégare Nisaia, Théognis aurait vécu un certain temps à Mégara, où il aurait reçu aussi la citoyenneté ${ }^{113}$.

\section{II.1.1.4 Les caractéristiques de la première implantation urbaine de Mégara}

Le site de Mégara, situé en bordure de mer et à $22 \mathrm{~km}$ de Syracuse, au fond du golfe d'Augusta, est dépourvu de défenses naturelles mais se trouve néanmoins dans une région riche en sources d'eau, à l'embouchure du fleuve Cantera, ce qui contraste avec la situation de Thapsos, que les Mégariens avaient occupé auparavant (voir carte 4) ${ }^{114}$. Cet avantage, auquel s'ajoutent sans doute les bons rapports avec les Sicules du roi Hyblôn, a dû jouer un rôle important dans le choix du site. On a longtemps pensé que la nouvelle cité fut installée dans une zone inoccupée depuis longtemps ${ }^{115}$. Cependant, le hiatus entre le village néolithique et l'occupation grecque est aujourd'hui partiellement comblé par la découverte en 2006, au nord-est de la porte ouest de la cité, de niveaux de l'âge du Bronze. Quelques siècles avant l'installation des Grecs, le site était donc occupé116.

Les premières fouilles archéologiques de Mégara, menées de manière discontinue par Cavallari (1879-1889) puis par Orsi (1889-1921), ont fait apparaître plusieurs centaines de tombes appartenant aux nécro-

113 Voir supra, chapitre I.3.2.

114 Vallet-Voza, Augusta, p. 26; F. Villard, «Mégara Hyblaea», MEFR 63, 1951, p. 10; Martin et al., Città greche, p. 603-604. Voir aussi M. Gras, «Mégara Hyblaea avant Augusta. Une fontaine dans l'histoire», in 〈Alla Signorina〉. Mélanges Noëlle de La Blanchardière, Rome 1995, p. 141-166, sur le ravitaillement en eau de Mégara. Pour le creusement et la répartition des puits (très nombreux), à Mégara, voir M. Gras, H. Tréziny, in Mégara 5, p. 486-512. Sur les premières implantations urbaines de Mégare et de Sélinonte, j'enverrai aussi à A. Robu, «Les fondations mégariennes de Sicile: origine des colons et appropriation du territoire», Cahiers «Mondes anciens » 2, 2011 (<http ://mondesanciens.revues.org/index347.html>).

115 M. Gras, H. Tréziny, in Mégara 5, p. 339-341, 347-348.

116 H. Tréziny, «Chronique, Mégara Hyblaea», MEFRA 120, 1, 2008, p. 256-260; idem, Grecs et indigènes, p. 24; idem, De Mégara à Sélinonte, p. 162-163. 
poles, ainsi que les traces du rempart ouest de la ville archaïque ${ }^{117}$. L'archéologie mégarienne a connu un tournant à partir de 1949, lorsque Villard et Vallet entreprirent des fouilles portant essentiellement sur la partie nord du site. La plus spectaculaire de leurs trouvailles est l'agora avec le quartier attenant. Les résultats de ces recherches ont révélé une organisation urbaine sans précédent dans le monde colonial grec $^{118}$. En parallèle, plusieurs fouilles de sauvetage se sont déroulées dans les nécropoles méridionale et occidentale de Mégara ${ }^{119}$, et une équipe composée de Tréziny, Gras et Broise a conduit des recherches sur le plateau sud de la ville ${ }^{120}$. Les membres de cette équipe française ont publié récemment une mise au point sur la genèse et l'évolution globale de la ville, tout en présentant une image nouvelle de la société mégarienne, telle qu'elle ressort de la documentation archéologique ${ }^{121}$.

Bénéficiant de l'avantage de fouiller dans une ville grecque abandonnée depuis l'Antiquité, Vallet et Villard ont pu montrer que le «quartier de l'Agora», correspondant à la première phase d'occupation, était

117 Sur les premières campagnes de fouilles à Mégara, voir M. Cébeillac-Gervasoni, «Les nécropoles de Mégara Hyblaea», Kokalos 21, 1975, p. 4-5 ; Mégara 3, p. 134139; A. Iacovella, «Les premières fouilles à Mégara Hyblaea (1860-1897)», MEFRA 113, 2001, p. 401-469. Pour une présentation générale de l'évolution des fouilles de Mégara, voir G. Vallet, s.v. «Megara Iblea», in BTCGI IX, 1991, p. 516-520; Gras, Tréziny, Megara Iblea, p. 251-256; iidem, in Mégara 5, p. 32-49.

118 Pour la publication des résultats des fouilles du plateau nord de Mégara, voir surtout Mégara 1; Mégara 2 ; Mégara 3 ; G. Vallet, F. Villard, Mégara Hyblaea 4. Le temple du IVe siècle, Paris 1966; et dernièrement Mégara 5. L'importance des découvertes de Mégara est mise aussi en évidence par les nombreux comptes rendus de Mégara 1, realisés par G. Gullini, PP 183, 1978, p. 427-469; E. Manni, Kokalos 24-25, 19781979, p. 220-223 ; N. Bonacasa, Kokalos 24-25, 1978-1979, p. 223-227 ; R. R. Holloway, AJA 82, 1978, p. 560-562 ; D. Asheri, Athenaeum N.S. 56, 1978, p. 399-402; E. Will, RH 261, 1979, p. 463-466. Sur Mégara 2, voir le compte rendu de B. d'Agostino, ArchClass 17, 1, 1965, p. 159-167, et sur Mégara 3, voir les comptes rendus de C. Ampolo, Opus 3, 1984, p. 203-207, et de P. Vanicelli, RFIC 115, 2, 1987, p. 335339.

119 M. Cébeillac-Gervasoni, op. cit., p. 3-36; M. Gras, «Nécropole et histoire: quelques réflexions à propos de Mégara Hyblaea», Kokalos 21, 1975, p. 37-53.

120 Broise, Gras, Tréziny, Bilan des fouilles, p. 647-650; Gras, Ricerche, p. 801-804. H. Broise, M. Gras, H. Tréziny, in Mégara 5, p. 53-155, offrent maintenant la publication détaillée de leurs recherches sur l'habitat du plateau sud.

121 H. Broise, M. Gras, H. Tréziny, Mégara 5. Ces savants annoncent également le prochain volume Mégara Hyblaea 6 portant sur les nécropoles de la cité. 
organisé en fonction des principales voies de communication. Les lots sont alignés sur les rues, les premières maisons construites à l'intérieur du lotissement sont modestes, se limitant à une seule pièce de 15 à $18 \mathrm{~m}^{2}$. La grande phase d'expansion commence vers le milieu du $\mathrm{VII}^{\mathrm{e}}$ siècle. En effet, on assiste au cours du $\mathrm{VII}^{\mathrm{e}}$ et du $\mathrm{VI}^{\mathrm{e}}$ siècle à la véritable «urbanisation» de la ville par la réalisation des structures spatiales de la cité (les principaux monuments publics, les rues). On trouve ainsi, à partir de la deuxième moitié du $\mathrm{VII}^{\mathrm{e}}$ siècle, un aménagement d'ensemble, cohérent et chronologiquement unitaire, qui reflète la transformation de la structure éclatée du premier habitat en une organisation plus centrée, avec des fonctions précises. Les maisons s'agrandissent par la juxtaposition de deux ou trois nouvelles pièces et les espaces vides entre les maisons se rétrécissent. On pense aussi que l'agora, initialement lieu de rassemblement des premiers colons, présente maintenant ses fonctions essentielles: religieuse, civique, politique, judiciaire. En étroite liaison avec l'agora, un réseau de rues conçues comme tel s'aménage entre le milieu et la fin du VII ${ }^{\mathrm{e}}$ siècle ${ }^{122}$. On notera aussi que les zones artisanales sont dispersées dans la ville et elles ne sont pas concentrées dans le secteur de l'agora ${ }^{123}$.

La question est de savoir si cette division cohérente de l'espace du «quartier de l'Agora», qui n'est qu'une partie du territoire urbain, remonte à la première génération d'émigrés. Étant donné que toutes les maisons primitives sont orientées conformément à l'alignement des rues

122 Mégara 1, p. 269-270, 284, 301-302 (sur les maisons des VIII ${ }^{\mathrm{e}-\mathrm{VII}} \mathrm{e}^{\mathrm{e}}$ siècles), 413421 ; G. Vallet, F. Villard, «Mégara Hyblaea IX. Les problèmes de l'agora et de la cité archaïque», MEFR 81, 1969, p. 12-27; Vallet, Bilan, p. 453-462; Polignac, Mégara Hyblaea, p. 222-224. Voir aussi R. Martin, «Problèmes d'urbanisme dans les cités grecques de Sicile», Kokalos 18-19, 1972-1973, p. 351-352; M. Gras, H. Tréziny, in Mégara 5, p. 465-471, sur les maisons archaïques de Mégara. Pour l'inventaire et la date des monuments trouvés sur l'agora, voir Mégara 1, p. 184240; De Angelis, Megara Hyblaia and Selinous, p. 17-35, avec la figure 20. Sur l'édification des constructions de l'agora et la mise en place des rues, voir les nouvelles interprétations proposées par M. Gras, H. Tréziny, in Mégara 5, p. 391-457 (les édifices du secteur de l'agora), 471-481 (les rues).

123 Plusieurs fours de l'époque archaïque ont été découverts sur le plateau nord et les fouilleurs ont également signalé la présence d'installations d'artisanales sur le plateau sud. À cet égard, voir Broise, Gras, Tréziny, Bilan des fouilles, p. 650; iidem, in Mégara 5, p. 82-83; M. Tréziny, in Mégara 5, p. 170-175; M. Gras, H. Tréziny, in Mégara 5, p. 481-485. 
du VII ${ }^{\mathrm{e}}$ siècle, et que l'emplacement de l'agora et de toutes les rues est «réservé» dès le début, on peut accepter l'opinion des fouilleurs, selon laquelle, même si l'on ne peut pas parler d'un «plan directeur» original, le schéma fondamental du quartier est contemporain de l'installation des apoikoi. Ce n'est qu'au VII ${ }^{\mathrm{e}}$ siècle que l'on assiste à une spécialisation des lieux ${ }^{124}$.

De surcroît, sur le plateau sud de Mégara les fouilles ont mis au jour plusieurs fragments de coupes «de Thapsos», ce qui signifie que l'occupation de ce secteur remonte à la fin du VIII ${ }^{\mathrm{e}}$ siècle, tout comme pour le plateau nord. Les recherches ont identifié de même un réseau de rues datant du VII siècle. Le fait que quelques constructions (une maison, un petit enclos) de la fin du VIII ${ }^{\mathrm{e}}$ siècle respectent dans ce secteur les orientations des rues montre que celles-ci avaient été mises en place à la même période ${ }^{125}$. Par ailleurs, dans la dépression centrale de l'Arenella, une zone située en bordure de mer, séparant les plateaux nord et sud de la ville, on a découvert un mur qui est daté, par sa technique et son contexte stratigraphique, de la fin du VIII ${ }^{\mathrm{e}}$-début du VII ${ }^{\mathrm{e}}$ siècle ${ }^{126}$. De même, des tessons archaïques remontant à la seconde moitié du VIII siècle ont été trouvés lors des sondages effectués dans le secteur nord-ouest de la ville ${ }^{127}$.

Selon les dernières recherches, le «rempart primitif» de Mégara (un mur à agger) date probablement de 700 environ, soit de l'époque où l'habitat se mettait en place (voir carte 4). Cela suggère que l'enceinte

124 Mégara 1, p. 384, 388, 399; Mégara 3, p. 146; G. Vallet, F. Villard, P. Auberson, «Expériences coloniales en Occident et urbanisme grec. Les fouilles de Mégara Hyblaea», in Vallet, Le monde gr. colonial, p. 449-450; E. Will, RH 261, 1979, p. 464-465; Vallet, Bilan, p. 458-460; M. Gras, RBPh 64, 1986, p. 10; F. de Polignac, «Héritage, rupture et projection: aspects du rapport au temps dans les fondations grecques », in La fundación de la ciudad. Mitos y ritos en el mundo antiguo, P. Azare et al. (éds.), Barcelona 2000, p. 113-114; Tréziny, Lots et îlots à Mégara, p. 176-177; De Angelis, Megara Hyblaia and Selinous, p. 20.

125 Broise, Gras, Tréziny, Bilan des fouilles, p. 649-650; Gras, Ricerche, p. 802; Mégara 5, p. 59-64, 86-88, 151-152; H. Tréziny, «Mégara Hyblaea vers 600 av. J.-C. », in Une Odyssée gauloise. Parures de femmes à l'origine des premiers échanges entre la Grèce et la Gaule, S. Verger et L. Pernet (éds.), Arles 2013, p. 288-289.

126 G. Vallet, «Chronique, Mégara Hyblaea», MEFRA 105, 1993, p. 464-465 ; H. Tréziny, in Mégara 5, p. 289-290.

127 F. Villard, G. Vallet, «Mégara Hyblaea II : les fouilles de 1950 », MEFR 64, 1952, p. 11-12; iidem, «Mégara Hyblaea III : les fouilles de 1951 » MEFR 65, 1953, p. $12-$ 13. 
joue un rôle très important dans le processus d'implantation de l'apoikia et dans l'organisation de l'espace urbain. On remarque également que l'aménagement urbain s'adapte au terrain et notamment à des axes de circulation datant parfois de l'époque précoloniale ${ }^{128}$.

Par ailleurs, à la place de la notion d'îlot et de la vision d'un paysage rural progressivement aménagé qui apparaît dans Mégara 1 , les auteurs de Mégara 5 mettent le lot au centre de l'urbanisme mégarien, ou plus précisément les files de lots. Ils constatent ainsi que «Mégara Hyblaea a été urbanisée très rapidement et si tous les lots n'ont pas été occupés et donc matérialisés au même moment, ils ont été définis très vite». D'après eux, la mise en place du plan d'urbanisme est «d'abord un processus de lotissement, visant à construire des lots d'une superficie égale ou équivalente». Et les lots, construits en files le long d'axes de circulation, ne sont plus des subdivisions de l'îlot. Conformément à cette restitution, l' «îlot» est créé seulement par la juxtaposition de deux files de lots, de deux rangées de lots, et il n'existe plus en tant que référence sur le plan social ${ }^{129}$. Chose importante, l'existence des lots urbains égaux ne signifie pas une égalité sur le plan social, car, ajoutent Gras et Tréziny, «il est probable que ces lots sont en fait regroupés en entités plus vastes, en 〈groupes de lots〉 qui reflètent une réalité sociale» ${ }^{130}$. Il faut souligner que Mégara ne constitue pas un unicum: tout comme d'autres villes archaïques, elle présente un plan «régulier hétérogène», c'est-àdire qu'il n'est régulier que par secteurs, et non pas dans son ensemble ${ }^{131}$.

128 Tréziny, Urbanisme et voirie, p. 267-282 ; M. Gras, H. Tréziny, in Mégara 5, p. $527-$ 531. Pour les fortifications archaïques de Mégara, voir les études de Tréziny, Enceintes de Mégara, p. 160-161, 225; idem, in Mégara 5, p. 237-301; idem, «Les fortifications archaïques dans le monde grec colonial d'Occident», in Guerra e pace in Sicilia e nel Mediterraneo antico (VIII-III sec. a. C.). Arte, prassi e teoria della pace e della guerra, vol. I, Pisa 2006, p. 257-259.

129 M. Gras, H. Tréziny, in Mégara 5, p. 532-546, 561-563 (voir les p. 532 et 546 pour les passages cités); M. Gras, H. Tréziny, «Mégara Hyblaea: le domande e le risposte», in Alle origini della Magna Grecia. Mobilità, migrazioni, fondazioni. Atti del cinquantesimo convegno di studi sulla Magna Grecia (Taranto, 1-4 ottobre 2010), Taranto 2012, p. 1137-1139.

130 M. Gras, H. Tréziny, in Mégara 5, p. 546; H. Tréziny, «Nouvelles recherches à Mégara Hyblaea», RA, 2007, 1, p. 185. Cf. M. Fitzjohn, «Equality in the Colonies: Concepts of Equality in Sicily during the Eighth to Sixth Centuries BC», World Archeology 39, 2, 2007, p. 215-228.

131 Tréziny, Urbanisme et voirie, p. 267. 
En somme, les données archéologiques disponibles indiquent que le site a été occupé dans plusieurs secteurs à une époque proche de la fondation de la cité, chose qui met en lumière la cohérence du mouvement colonial mégarien ${ }^{132}$. Les fouilleurs de l'agora soulignent que «du $\mathrm{VIII}^{\mathrm{e}}$ au $\mathrm{VI}^{\mathrm{e}}$ siècle, ce n'est pas l'extension de la ville qui change, mais la densité de l'habitat» ${ }^{133}$. De fait, dans un espace urbain de 60 hectares, la dimension moyenne des lots mégariens oscille entre 120 et $140 \mathrm{~m}^{2}$. Dans ces conditions, sans pour autant pouvoir déterminer exactement le nombre des premiers colons, il existe sûrement des espaces laissés libres soit pour les futurs arrivants, soit pour les héritiers des premiers colons ${ }^{134}$. Suivant Vallet, le «gaspillage de l'espace» est une caractéristique du premier habitat mégarien de Sicile ${ }^{135}$.

Au demeurant, il est utile d'évoquer ici la thèse de l'éventuelle représentation des cinq bourgs (kômai) originels de Mégare de Grèce dans l'espace urbain de Mégara. Ainsi, Svenbro estime que les axes de l'organisation urbaine délimitent dans le quartier de l'agora cinq zones. Cela appuierait l'idée, d'après lui, que la division en cinq kômai de la

132 G. Vallet, «Travaux et recherches à Mégara Hyblaea», Kokalos 26-27, 2, 19801981, p. 801 ; Tréziny, Lots et îlots à Mégara, p. 177; De Angelis, Megara Hyblaia and Selinous, p. 33 ; M. Gras, H. Tréziny, in Mégara 5, p. 527.

133 G. Vallet, F. Villard, P. Auberson, «Expériences coloniales en Occident et urbanisme grec. Les fouilles de Mégara Hyblaea», in Vallet, Le monde gr. colonial, p. 450. À partir du début du $\mathrm{VII}^{\mathrm{e}}$ siècle, on assiste à une augmentation à la fois du nombre des pièces dans une maison et du nombre de maisons. À cet égard, voir Mégara 1, p. 410-412.

134 Tréziny, Lots et îlots à Mégara, p. 141-183, surtout p. 174 sur la superficie des lots ; M. Gras, H. Tréziny, in Mégara 5, p. 535-537 (sur la dimension des lots), 569-571 (sur la densité d'occupation à Mégara), 575-576 (sur l'arrivée des époikoi à Mégara); M. Gras, «Megara Hyblaea et la naissance de l'urbanisme grec en Occident », RPAA 79, 2006-2007, p. 9. D'aucuns ont suggéré d'autres dimensions pour les lots mégariens: G. Vallet, F. Villard, P. Auberson, in Mégara 3, p. 146-147, et G. Vallet, «Topographie historique de Mégara Hyblaea et problèmes d'urbanisme colonial », MEFRA 95, 2, 1983, p. 643 (lots urbains de 100-120 m²); F. Villard, «Le cas de Mégara Hyblaea: est-il exemplaire? », in La colonisation grecque en Méditerranée Occidentale. Actes de la rencontre scientifique en hommage à Georges Vallet organisée par le Centre Jean-Bérard, l'École française de Rome, l'Istituto universitario orientale et l'Università degli studi di Napoli «Federico II»(Rome-Naples, 15-18 novembre 1995), Rome 1999, p 138-139 (envisage l'existence d'un grand klèros d'environ 750 à $800 \mathrm{~m}^{2}$ ).

135 Vallet, Urbanisation, p. 490. 
métropole se trouvait reproduite dans le plan du quartier de l'agora ${ }^{136}$. La possibilité de l'organisation de l'habitat de Mégara en fonction de cinq kômai a été acceptée par Vallet, Villard et Auberson. Pourtant, les archéologues français ont contesté la présence de ces cinq secteurs dans le quartier de l'agora et le fait que le plan avancé par Svenbro ait été le même que le leur. Ils ont supposé en revanche l'existence primordiale de cinq orientations ou cinq «quartiers» dans la structure de la ville, l'ensemble du site étant occupé dans ce cas par cinq «quartiers» primitifs ${ }^{137}$. On constate que cette reconstitution a été accueillie favorablement par les savants ${ }^{138}$. Elle est, à mon sens, contestable pour plusieurs raisons. Tout d'abord, comme je m'efforcerai de le montrer dans la partie sur les institutions, l'hypothèse d'une division mégarienne en cinq kômai manque de fondement. D'autre part, comme les modernes l'ont déjà noté, au milieu du VIII ${ }^{\mathrm{e}}$ siècle, Mégare Nisaia a une «expérience urbaine» limitée et la cohésion interne de la société n'est pas encore réalisée ${ }^{139}$.

Ensuite, les recherches entreprises par Gras et Tréziny montrent qu'il y a plus de cinq orientations dans l'espace urbain de Mégara et qu'il n'existe pas cinq «quartiers» contigus à l'agora ${ }^{140}$. Mieux, on ne connaît pas encore quel est, à l'époque des premiers apoikoi, le rapport entre la zone d'habitat du plateau nord et celle du plateau sud du point de vue de la répartition des terres ${ }^{141}$. En outre, une grande partie de la ville a été très peu fouillée ou n'est pas encore explorée, ce qui em-

136 J. Svenbro, «À Mégara Hyblaea: le corps géomètre», Annales (HSS) 37, 1982, p. $958-960$.

137 G. Vallet, F. Villard, P. Auberson, in Mégara 3, p. 145-146; G. Vallet, «Topographie historique de Mégara Hyblaea et problèmes d'urbanisme colonial», MEFRA 95, 2, 1983, p. 642-643; cf. P. Auberson, Kokalos 14-15, 1968-1969, p. 426-427.

138 De Angelis, Megara Hyblaia and Selinous, p. 49; J.-L. Lamboley, Les Grecs d'Occident. La période archaïque, Paris 1996, p. 168, 170; Fischer-Hansen, Town Planning, p. 34; Fischer-Hansen, Nielsen, Ampolo, Megara, p. 214.

139 Muller, De Nisée à Mégare, p. 628; G. Vallet, «Topographie historique de Mégara Hyblaea et problèmes d'urbanisme colonial», MEFRA 95, 2, 1983, p. 646-647; $c f$. C. Bérard, «Urbanisation à Mégara Nisaea et l'urbanisme à Mégara Hyblaea», MEFRA 95, 2, 1983, p. 634-640.

140 Tréziny, Urbanisme et voirie, p. 267-271; idem, Colonies gr. de Méditerranée, p. 57-59; M. Gras, H. Tréziny, in Mégara 5, p. 531, 556-557, 582-583.

141 Gras, Ricerche, p. 802, souligne que sur le plateau nord de Mégara le rapport entre l'organisation de l'habitat et une possible division en cinq kômai reste encore à démontrer. 
pêche d'avoir une image plus détaillée de la mise en place et de l'évolution urbanistique de la cité mégarienne ${ }^{142}$. Enfin, il serait dangereux d'appliquer des spéculations d'arithmétique sociale à une organisation urbaine qui ne s'est accomplie que deux ou trois générations après l'arrivée des premiers colons ${ }^{143}$.

Quant à la prise de possession et la division du territoire, un passage de Denys de Byzance au regard de la colonisation du Bosphore thrace s'avère particulièrement intéressant pour le cas de Mégara. Selon une tradition recueillie par cet auteur du $\mathrm{II}^{\mathrm{e}}$ siècle ap. J.-C., ce furent les sept

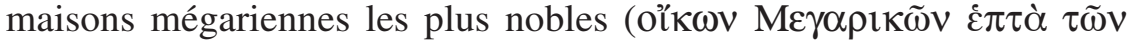
ópí $\tau \tau \omega v)$ qui participèrent à la fondation d'Hestiai, un site dans le territoire de la future Byzance ${ }^{144}$. L'installation des Grecs se fit donc par oikoi («familles»), et non pas par kômai ${ }^{145}$. Il faut avouer que du point de vue juridique, le concept d'une apoikia implique la reproduction d'un oikos et la possession d'un klèros ${ }^{146}$. On suppose l'existence à Mégara, au moment de la fondation, de plusieurs noyaux d'installation ${ }^{147}$, les groupes de lotissements étant probablement des groupes d'oikoi ${ }^{148}$. Il est impossible de savoir si ces groupes se constituent en respectant une division par phylai ou par hékatostyes (les deux subdivisions civiques attestées dans le monde mégarien), ou simplement en fonction des liens ou des solidarités qui existaient entre leurs membres.

142 H. Broise, M. Gras, H. Tréziny, in Mégara 5, p. 57, signalent que sur une superficie de la ville archaïque estimée à environ $600.000 \mathrm{~m}^{2}$, les recherches sur le « quartier de l'Agora » ont porté sur $22.500 \mathrm{~m}^{2}$ et celles sur le plateau sud sur $1.000 \mathrm{~m}^{2}$. Ces chiffres suffisent pour montrer l'image très partielle que l'on a de l'espace urbain mégarien.

143 Holloway, Anc. Sicily, p. 52; Polignac, Mégara Hyblaea, p. 225.

144 Denys de Byzance, 53, p. 22-23 (éd. R. Güngerich). Sur ce passage, voir infra, chapitre II.2.4.1.1.

145 Voir E. Scheid-Tissinier, «Laos et dèmos, le peuple de l'épopée», AC 71, 2002, p. 39, pour l'emploi chez Homère du mot oikos avec le sens de famille plus ou moins restreinte.

146 Asheri, La colon. gr., p. 100; G. Vallet, «Le fait urbain en Grèce et en Sicile à l'époque archaïque», in Vallet, Le monde gr. colonial, p. 504-505, 508.

147 G. Vallet, F. Villard, P. Auberson, «Expérience coloniale en Occident et urbanisme grec. Les fouilles de Mégara Hyblaea», Annales (HSS) 25, 1970, p. 1112 (= Vallet, Le monde gr. colonial, p. 450).

148 M. Gras, H. Tréziny, in Mégara 5, p. 533, 564-566. Voir aussi A. di Vita Gafà, «L'urbanistica», in SIKANIE. Storia e civiltà della Sicilia antica, G. Pugliese Carratelli (éd.), Milano 1985, p. 368, qui estime que «i diversi orientamenti dei lotti possano riflettere l'attribuzione ad appartenenti a una stessa fratria, o a uno stesso ghenos ». 
Chose importante, les documents révèlent la présence des groupements familiaux ou pseudo-familiaux (de type génos) à la fois dans les colonies mégariennes et dans leur métropole. Ainsi, les spécialistes ont attiré l'attention sur les plates-formes généralement circulaires observées à Mégara ${ }^{149}$ et à Sélinonte ${ }^{150}$, qui ne seraient pas à identifier à des structures domestiques, mais plutôt à des lieux de culte privés (autels) appartenant à un groupe familial ${ }^{151}$. Quoique la nature de ces groupements et du culte qu'ils pratiquaient reste impossible à déterminer, ces plates-formes rappellent la structure cylindrique employée à Érétrie, dès le milieu du VIII ${ }^{\mathrm{e}}$ siècle jusqu'à la fin du VI $\mathrm{e}^{\mathrm{e}}$ siècle, comme autel au centre de l'aire sacrificielle située au nord du sanctuaire d'Apollon Daphnèphoros ${ }^{152}$. Mieux, comme il a été suggéré ci-dessus, les silos de Mégara datant des $\mathrm{VIII}^{\mathrm{e}}-\mathrm{VII}{ }^{\mathrm{e}}$ siècles appartenaient peut-être à des groupements familiaux plus larges. Et il est possible qu'au moins à partir de la seconde moitié du $\mathrm{VI}^{\mathrm{e}}$ siècle, les tombes monumentales regroupées, décelées au nord, à l'ouest et au sud du site, mettent en lumière l'existence de liens familiaux entre leurs occupants ${ }^{153}$.

On remarque qu'à Sélinonte, le lieu de culte datant du début du $\mathrm{VI}^{\mathrm{e}}$ siècle, les dépôts votifs et l'hérôon retrouvés en bordure de l'agora sont

149 Mégara 5, p. 512-521, 541-543; H. Tréziny, MEFRA 123, 2011, p. 325 ; cf. Mertens, Selinus 1, p. 226.

150 A. Henning, in Mertens et al., Agora, p. 413-418; D. Mertens, «Raumgestaltung in westgriechischen Kolonialstädten », GeogrAnt 18, 2009, p. 79-82.

151 M. Gras, H. Tréziny, «Mégara Hyblaea. Retours sur l'agora», in Architettura, urbanistica, società nel mondo antico. Giornata di studi in ricordo di Roland Martin, Tekmeria 2, Paestum 2001, p. 51-63, surtout p. 57; Tréziny, Colonies gr. de Méditerranée, p. 60.

152 S. Huber, «Une aire sacrificielle proche du sanctuaire d'Apollon Daphnéphoros à Érétrie. Approches d'un rituel archaïque», in Ancient Greek Cult Practice from the Archaeological Evidence. Proceedings of the Fourth International Seminaron Ancient Greek Cult, organized by the Swedish Institute at Athens, 22-24 October 1993, R. Hägg (éd.), Stockholm 1998, p. 141-155; eadem, L'Aire sacrificielle au nord du sanctuaire d'Apollon Daphnéphoros, vol. I, Eretria. Fouilles et recherches XIV, Montreux 2003, p. 22, 27-36, 163-174. De manière générale, sur les divers usages des plates-formes circulaires de l'époque géométrique trouvées dans le monde méditerranéen, on lira Mazarakis Ainian, From Rulers'Dwellings to Temples, p. 114-124.

153 M. Cébeillac-Gervasoni, «Les nécropoles de Mégara Hyblaea», Kokalos 21, 1975, p. 32-33; M. Gras, «Nécropole et histoire: quelques réflexions à propos de Mégara Hyblaea», Kokalos 21, 1975, p. 50-51. 
peut-être en rapport avec la célébration du culte des ancêtres ${ }^{154}$. En faveur d'une participation active des oikoi et des groupements d'oikoi dans la vie civique et religieuse des cités, il y a surtout le témoignage de la célèbre loi sacrée de Sélinonte ( $\mathrm{V}^{\mathrm{e}}$ siècle), qui décrit des rites de purification et stipule que les homosépyoi («ceux qui ont la même huche à pain») offrent des sacrifices ensemble ${ }^{155}$. Or grâce à Aristote, on sait que Charondas, le législateur de Catane, appela les homosipyoi les membres d'un même oikos ${ }^{156}$.

De plus, une inscription sélinontine $\mathrm{du} \mathrm{V}^{\mathrm{e}}$ siècle mentionne une organisation gentilice nommée patria, qui rassemblait plusieurs oikoi et à laquelle les femmes aussi pouvaient être associées ${ }^{157}$. Le rôle des groupements pseudo-familiaux dans la distribution et l'administration

154 À propos des découvertes de l'agora de Sélinonte, N. Hoesch, in Mertens et al., Agora, p. 437, note: «Die enge Einbindung in ein eher inoffiziell wirkendes Wohnumfeld, die relativ bescheidenen und nahezu auf Keramik beschränkten Weihungen sowie die geringe Ausdehnung des Platzes könnte andererseits aber auch an Aktivitäten einer privaten oder familiären Kultgemeinschaft aus den Anfängen der Besiedlung denken lassen».

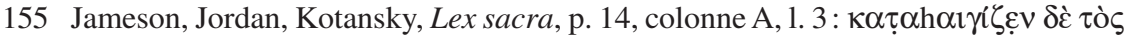

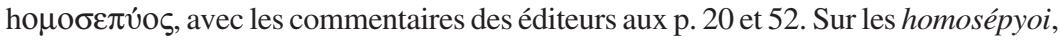
voir aussi A. Brugnone, «Una lamineta iscrita da Selinunte», SicArch XXX, 93-95, 1997, p. 123-124; Dubois, Loi sacrée, p. 110-111; G. Camassa, «La lex sacra di Selinunte», in Sicilia Epigraphica. Atti del convegno (Erice, 15-18 Ottobre 1998), ASNP serie iv, Quaderni 1, M.I. Gulletta (éd.), Pisa 1999, p. 141; A. Dimartino, «Omicidio, contaminazione, purificazione : il <caso > della lex sacra di Selinunte», ANSP 8, 2003 (2006), p. 312-313; N. Cusumano, «Polivalenze funzionale figurative. Osservazioni su Zeus Meilichios», Mètis N. S. 4, 2006, p. 178-180.

156 Aristote, Politique, I, 2, 5, $1252 \mathrm{~b}$ 14. Sur Charondas en tant que législateur des villes chalcidiennes d'Italie et de Sicile, voir aussi Aristote, Politique, II, 12, 6, 1274a 23.

157 IGDS, 47 (=IGASM I², 51 ; M.L. Famà, V. Tusa, Le stele del Meilichios di Selinunte, Padova 2000, $\mathrm{n}^{\circ}$ 11); cf. Jameson, Jordan, Kotansky, Lex sacra, p. 97-98; F. Ghinatti, «Le organizzazioni civiche siceliote», Kokalos 46, 1, 2000 (2004), p. 60-61 ; R. Parker, « $\pi \alpha \tau \rho \tilde{\omega} o 1$ $\theta \varepsilon o$ i: The Cults of Sub-Groups and Identity in the Greek World», in Religion and Society. Rituals, Resources and Identity in the Ancient Graeco-Roman World. The BOMOS-Conferences 2002-2005, A. Holm Rasmussen et S.W. Rasmussen (éds.), Rome 2008, p. 207-208. Pour la présence des groupements familiaux à Sélinonte, voir aussi la stèle $I G D S, 45\left(=I G A S M \mathrm{I}^{2}, 41\right)$ consacrée à Zeus Meilichios et évoquant le Meı $\lambda i ́ \chi \imath o \zeta \mid \tau o ̀ v ~ K \lambda \varepsilon v \lambda \imath \delta \tilde{\alpha} v$ («je suis le Meilichios des Kleulidai»). Les Kleulidai réuniraient les membres d'un groupe descendant d'un ancêtre commun nommé Kleulos : E. Gabrici, «Il santuario della Malophoros a Selinunte», MAL 32, 1927, p. 382-383, 405; Hanell, Megarische Studien, p. 178; C. Grotta, Zeus Meilichios a Selinunte, Roma 2010, p. 102-103. 
des lots de terre est attesté à Byzance. Le Ps.-Aristote rapporte qu'à cause de leurs difficultés financières, les Byzantins ont mis en vente les domaines sacrés gérés par les associations cultuelles (thiasoi) et les groupements gentilices (patriai) ${ }^{158}$. On conclura que la patria faisait partie tant à Byzance qu'à Sélinonte de l'héritage mégarien. À mon sens, la présence des patriai et des cultes gentilices dans les colonies (Zeus Meilichios à Sélinonte, Dionysos Patrôos à Callatis) illustre l'importance que les groupements familiaux et pseudo-familiaux eurent dans la colonisation. D'ailleurs, on se souvient que de tels groupements sont connus dans la métropole (le génos des «renverseurs des chariots», les Dorykleioi) ${ }^{159}$.

Pour conclure, on notera que l'occupation globale du site et la cohérence de l'aménagement urbain témoignent de l'individualité et de l'originalité de l'entreprise mégarienne en Sicile ${ }^{160}$. La cité fut conçue comme une «fondation composite», mais à cause des séditions entre les apoikoi, elle fut finalement établie à l'aide d'un chef sicule ${ }^{161}$. En effet, ce furent les conflits avec les autres Doriens puis avec les Chalcidiens qui déterminèrent les Mégariens à s'allier avec les Sicules pour installer leur apoikia. Cela montre que la politique d'alliance dépasse à la haute époque archaïque le clivage Grecs-barbares, tel qu'il apparaît dans les récits des époques ultérieures. Quant à la date de fondation de Mégara, elle se place dans le troisième quart du VIII ${ }^{\mathrm{e}}$ siècle, sans pour autant pouvoir être précisée davantage.

158 Ps.-Aristote, Économique, II, 2, 3a, 1346b 13-16, avec les commentaires de

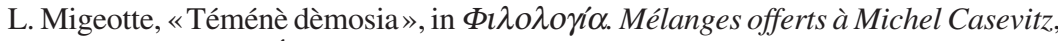
P. Brillet-Dubois et É. Parmentier (éds.), Lyon 2006, p. 187-195. Sur ce passage dont l'interprétation pose des difficultés, voir aussi B. A. van Groningen, Aristote: Le second livre de l'Économique, Leyde 1933, p. 55-56; E. Will, REA 71, 1969, p. 495 (= Historica Graeco-Hellenistica. Choix d'écrits, 1953-1993, Paris 1998, p. 440); J. Velissaropoulos-Karakostas, Droit grec d'Alexandre à Auguste (323 av. J.-C.-14 ap. J.-C.). Personnes-Biens-Justices, vol. II, MEAETHMATA 66, Athènes 2010, p. 34.

159 Robu, Zeus Meilichios, p. 277-291.

$160 C f$. Pugliese Carratelli, Selinunte, p. 18.

161 Sur les «fondations composites», voir M. Gras, H. Tréziny, in Mégara 5, p. 551552. 


\section{II.1.2 Sélinonte}

\section{II.1.2.1 Les récits et les découvertes archéologiques concernant la fondation de Sélinonte}

On dispose pour la date de fondation de Sélinonte de deux traditions antiques. La première, fournie par Thucydide, atteste que l'installation de la ville eut lieu cent ans après la fondation de Mégara. Étant donné que la date de fondation de Mégara remonte, on l'a vu, vers 728/7, la fondation de Sélinonte se place vers $628 / 7^{162}$. L'interprétation du passage de Thucydide reste en revanche controversée quant à l'origine de l'œciste :

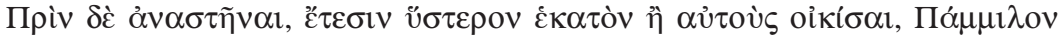

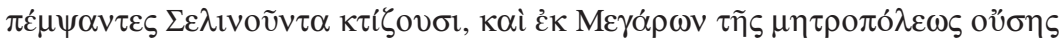

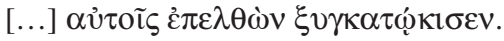

Mais, avant d'en être expulsés (par Gélon), et cent ans après leur installation, ils (les Mégariens de Sicile) avaient envoyé Pammilos fonder Sélinonte: de Mégare, leur métropole, leur était venu [...], qui présida avec lui à la fondation ${ }^{163}$.

La traduction proposée par Bodin et De Romilly, citée ci-dessus, suggère l'existence de deux oikistai à Sélinonte: Pammilos de Mégara Hyblaea et un œciste non identifié envoyé par Mégare Nisaia ${ }^{164}$. Cependant, une autre interprétation de ce passage est possible. Les éditeurs français du texte de Thucydide estiment que si l'on renonce à la lacune,

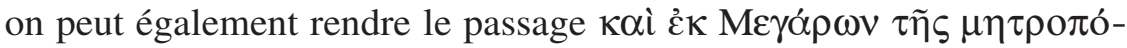

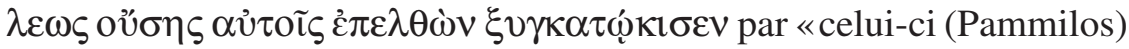

162 En raison du fait que 3 générations de 35 ans séparent la fondation de Sélinonte de celle de Syracuse, Van Compernolle, La fond. de Sélinonte, p. 351-352; idem, Lafond. de Sélinonte et de Syracuse, p. 197-198; idem, Ét. de chronologie, p. 425-426, est d'avis que la fondation de Sélinonte (628/7) est datée dans le système de Thucydide d'après celle de Syracuse (733/2). Ce qui serait un indice du fait que la chronologie de Thucydide offre une date artificielle, sans valeur, pour la fondation de Sélinonte. Sur les différents calculs des générations proposés pour expliquer la date de fondation de Sélinonte, voir également Danner, Selinunt, p. 11-13 (avec les références).

163 Thucydide, VI, 4, 2 (trad. de L. Bodin et J. de Romilly, CUF).

164 Vallet-Villard, Dates de fondations, p. 293 ; K. J. Dover, in A. W. Gomme, A. Andrews, K. J. Dover, op. cit., p. 217 ; L. Braccesi, «Appunti su katoikizein in Tucidide VI, 3, 5 », Kokalos 41, 1995, p. 342. 
était venu de Mégare, leur métropole, pour participer à la fondation ${ }^{165}$. Cette dernière traduction a l'avantage d'éviter l'émendation du texte et élimine du même coup l'idée de deux oikistai ${ }^{166}$. La fondation de Sélinonte serait ainsi analogue à celle d'Épidamne. Dans ce dernier cas, Thucydide rapporte que, en suivant la règle ancienne, Corcyre avait demandé à sa métropole Corinthe de lui envoyer un œciste pour présider à la fondation d'Épidamne. On apprend également que l'œciste corinthien n'est pas arrivé seul et que des apoikoi venus de Corinthe et d'autres pays doriens ont participé à l'expédition ${ }^{167}$.

La fondation de Sélinonte par les Mégariens de Sicile est également évoquée par le Ps.-Scymnos (qui la situe avant celle d'Agrigente) ${ }^{168}$ et par Strabon ${ }^{169}$, mais sans aucune mention de l'œciste. Par ailleurs, on retrouve une autre date de fondation de Sélinonte chez Diodore, qui transmet que la cité fut établie 242 ans avant sa prise par les Carthaginois ${ }^{170}$. On sait que la destruction carthaginoise remonte à 409/8, et si l'on y ajoute 242 ans, on obtient la date de 651/0, pour la fondation de Sélinonte ${ }^{171}$. Les modernes ont suggéré que l'origine de cette tradition

165 L. Bodin, J. de Romilly (éd.), Thucydide, La guerre du Péloponnèse, Livres VI-VII, Paris 1955, p. 4, n. 1. L'absence d'une lacune et l'existence d'un seul oeciste, Pammilos, venu de Mégare, sont acceptées par C. Forster Smith (éd.), Thucydides, History of the Peloponnesian War, Books V and VI, Cambridge-London 1959 (réimpression de l'édition de 1921); D. Roussel (éd.), Thucydide, La guerre du Péloponnèse, Paris 1964 (qui traduit le passage par: «Celui-ci était venu de Mégare, leur métropole, pour fonder avec eux cette cité»); $c f$. De Wever-Van Compernolle, Colonisation, p. 491 ; M. Costanzi, «Les colonies de deuxième degré de l'Italie du Sud et de Sicile: une analyse lexicographique», Ancient West \& East 9, 2010, p. 96-97; A. Morakis, op. cit., p. 478-480.

166 Malkin, Religion and Colon., p. 132, 256.

167 Thucydide, I, 24, 2; cf. S. Mazzarino, «Metropoli e colonie», in Metropoli e colonie di Magna Grecia. Atti del terzo convegno di studi sulla Magna Grecia (Taranto 1963), Napoli 1964, p. 65-67; T. Stickler, Korinth und seine Kolonien. Die Stadt im Mächtegefüge des klassischen Griechenland, Berlin 2010, p. 227.

168 Ps.-Scymnos, 292.

169 Strabon, VI, 2, 6, C 272.

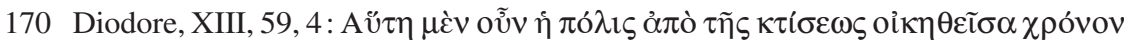

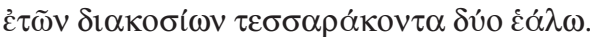

171 Diodore, XIII, $54 ; c f$. Bérard, Colonisation, p. 246. Sur la destruction de Sélinonte par les Carthaginois, voir N. Cusumano, «Il massacro dei Selinuntini nel 409: alcune osservazioni», in Atti de V Congresso Internazionale di Studi Fenici e Punici (Marsala-Palermo, 2-8 ottobre 2000), A. Spanò Giammellaro (éd.), Palermo 2005, p. 823-828. 
remonte à Timée de Tauroménion, qui, à son tour, avait utilisé pour les fondations grecques d'Occident l'Histoire de Sicile de Philistos ${ }^{172}$. Il faut ajouter que la Chronologie d'Eusèbe place l'installation de Sélinonte aussi autour de $650^{173}$.

Pour concilier les traditions de Diodore/Eusèbe et de Thucydide, Dunbabin et Bérard ont expliqué la date haute de la fondation de Sélinonte par une confusion avec celle d'Himère, installée selon la tradition vers 649/8. La date de 627 attribuée à la colonisation de Lipara, qui apparaît erronément dans un passage d'Eusèbe, représenterait, selon eux, la date basse de la fondation de Sélinonte ${ }^{174}$. Mais cette hypothèse n'est pas tenable: une confusion chez Diodore sur ce point est difficile à envisager, étant donné que celui-ci transmet deux dates différentes de fondation pour Himère et Sélinonte et situe la fondation de Lipara autour de $580^{175}$.

En revanche, tout en acceptant la date de Diodore, Van Compernolle pense qu'elle doit être considérée comme approximative, à une marge de dix à quinze ans près, ce qui placerait la fondation de Sélinonte vers 665-635. Contrairement à Vallet et Villard, ce savant pense que les auteurs antiques ne disposaient pas pour les VIII ${ }^{\mathrm{e}}-\mathrm{VII}{ }^{\mathrm{e}}$ siècles de chronologies fondées sur l'ère de la cité, et qu'ils utilisaient des calculs par générations pour établir les dates de fondation des colonies ${ }^{176}$.

172 Van Compernolle, La fond. de Sélinonte, p. 339-344, 352-356; G. Vallet, F. Villard, «À propos des dates de fondation de Mégara Hyblaea, de Syracuse et de Sélinonte », BIBR 24, 1955, p. 212; Danner, Selinunt, p. 9. Sur Philistos de Syracuse et son œuvre, on lira G. de Sanctis, Ricerche sulla storiografia siceliota, Palermo 1958, p. 17-40; Miller, Colony Dates, p. 89-96; G. Vanotti, «L'archaiologhia siciliana di Filisto», in Hesperìa, 3 : studi sulla grecità di Occidente, L. Braccesi (éd.), Roma 1993, p. 115-135.

173 Eusèbe, Chron., St. Jérôme: Ol. 32.3 (=650/49, éd. R. Helm, p. 95b). On remarque aussi que la version arménienne d'Eusèbe indique erronément la quatrième année de la $5^{\mathrm{e}}$ olympiade (=757/6, éd. J. Karst, p. 181$)$ pour la fondation de Sélinonte. $C f$. Bérard, Colonisation, p. 246; Van Compernolle, La fond. de Sélinonte, p. 318 ; Miller, Colony Dates, p. 18, 26.

174 Dunbabin, Western Greeks, p. 437; Bérard, Colonisation, p. 246.

175 Vallet-Villard, Dates de fondation, p. 319-320. Voir Diodore, XIII, 62, et V, 9, pour la date de fondation d'Himère (648), respectivement de Lipara (entre 580-576 av J.-C.).

176 Van Compernolle, La fond. de Sélinonte, p. 317-356; idem, La fond. de Sélinonte et de Syracuse, p. 195-198; idem, «À propos des dates de fondation de Syracuse, de Mégara Hyblaea et de Sélinonte», BIBR 24, 1955, p. 225-227, 233-234. Contra G. Vallet, F. Villard, BIBR 24, 1955, p. 207-210. 
Au deumeurant, les archéologues ont invoqué le matériel archéologique pour appuyer la date de fondation haute ou basse de la cité. L'absence des vases protocorinthiens, la rareté des vases appartenant au style de transition et la masse assez considérable de céramiques corinthiennes découvertes à cette époque-là à Sélinonte ont amené autrefois Payne à placer le début du Corinthien ancien vers une date proche de la fondation, laquelle était selon lui la date de Thucydide ${ }^{177}$. Cette thèse a été critiquée par Vallet et Villard, pour qui la présence des céramiques appartenant au Protocorinthien récent ou au style de transition dans le sanctuaire de Déméter Malophoros confirmait plutôt la date haute de fondation ${ }^{178}$. Ultérieurement, ces trouvailles se sont avérées être moins anciennes que ne l'avaient pensé les savants français ${ }^{179}$. Toutefois, les spécialistes constatent encore aujourd'hui la présence dans l'aire sacrée de la Malophoros de quelques céramiques antérieures au Corinthien ancien, bien que ces découvertes soient isolées et dépourvues de contexte archéologique ${ }^{180}$.

Notons du reste que c'est la nécropole de Manuzza qui a livré le plus ancien matériel céramique de Sélinonte. Les fouilles entreprises par Rallo dans cette nécropole ont permis la découverte de céramiques grecques remontant autour du milieu du VII ${ }^{\mathrm{e}}$ siècle ${ }^{181}$. Les plus an-

177 H. Payne, Necrocorinthia: a Study of Corinthian Art in the Archaic Period, Oxford 1931, p. 22-23; idem, Protokorinthische Vasenmalerei, Berlin 1933, p. 20, suivi par Dunbabin, Western Greeks, p. 437-438, 457.

178 Vallet-Villard, Dates de fondation, p. 325-328; iidem, Lafond. de Sélinonte, p. 16-26. Contra La Genière, Saggi sull'Acropoli, p. 102-107; cf. D. A. Amyx, op. cit., p. 408409.

179 J. Ducat, op. cit., p. 170-174; D. A. Amyx, op. cit., p. 418-419; C. Dehl-von Kaenel, «Keramik als Handelsware. Zum Vertrieb korinthischer Keramik in das Malophoros Heiligtum in Selinunt», MBAH 13, 1994, p. 55-82; eadem, «Le importazioni corinzie nel santuario della Malophoros di Selinunte e le strutture della distribuzione della ceramica corinzia in Sicilia e in Magna Grecia», in Corinto e l'Occidente. Atti del trentaquattresimo Convegno di studi sulla Magna Grecia (Taranto, 7-11 ottobre 1994), Taranto 1995, p. 345-366; eadem, Keramik aus Malophoros, p. 32-42.

180 S. Tusa, «Introduzione», in S. Tusa et al., «Selinunte-Malophoros : rapporto preliminare sulla II campagna di scavi», SicArch XIX, 60-61, 1986, p. 21, publie une kotyle appartenant au style protocorinthien moyen; $c f$. aussi Dehl-von Kaenel, Keramik aus Malophoros, p. 305, 314, pour trois fragments de céramique antérieurs au Corinthien ancien.

181 Rallo, Selinunte, p. 720-733; eadem, Ceramiche di Manuzza, p. 203-218; Dehl-von Kaenel, Keramik aus Malophoros, p. 32-37; Mertens, Städte und Bauten, p. 83-84. 
ciennes céramiques trouvées dans la nécropole de Buffa (située au nordest du site antique) se placent au troisième et quatrième quart du VII $^{\mathrm{e}}$ siècle (période de transition, début du Corinthien ancien) ${ }^{182}$. En revanche, les fouilles récentes de l'agora et dans la vallée du Gorgo Cottone n'ont pas livré de fragments céramiques antérieurs à la fin du VII ${ }^{\mathrm{e}}$ siècle (voir ci-après). D'aucuns ont suggéré que les vases les plus anciens, remontant au-delà du dernier quart du VII ${ }^{\mathrm{e}}$ siècle, auraient été amenés à Sélinonte grâce aux contacts des Élymes avec les Grecs de Géla ${ }^{183}$, ou même par des apoikoi de Géla installés sur le site avant de céder la place aux Mégariens ${ }^{184}$. Mais ces opinions ne se fondent que sur le rapprochement géographique entre Géla et Sélinonte. De plus, elles ne tiennent pas compte du fait qu'une partie de ces céramiques ont été fabriquées à Mégara ${ }^{185}$.

En dépit des trouvailles de Sélinonte, le système chronologique proposé par Payne - qui, rappelons-le, s'appuyait sur les dates de fondation fournies par Thucydide - n'a pas été abandonné par les spécialistes. Car il est confirmé par d'autres repères, indépendants du matériel céramique découvert en Sicile occidentale, qui montrent que le début du style corinthien ancien se place au dernier quart du VII ${ }^{e}$ siècle ${ }^{186}$. En revanche, il est probable que la date de la première arrivée des Grecs à Sélinonte est plus ancienne que celle que l'on peut tirer du récit de Thucydide. Les céramiques trouvées dans la nécropole de Manuzza, mais aussi quelques trouvailles provenant du sanctuaire de la Malophoros et de la nécropole de Buffa, laissent penser qu'autour de 651/0

182 La Genière, Saggi sull'Acropoli, p. 106-107; V. Tusa, «Ricerche e scavi nelle necropoli selinuntine», ASAA 60, N.S. 44, 1982 (1984), p. 189-202; E. Meola, Necropoli di Selinunte, I: Buffa, Palermo 1996-1997, vol. I, p. 279-298, vol. II, p. 62, 8990, 105-107, 199, 232-233, 258, 277, 290, 336, 369, 381-382, 420.

183 J. G. Devoto, «Two Megarian Colonies in Sicily», AncW 36, 2005, p. 94.

184 Boardman, Gr. Overseas ${ }^{3}$, p. 187.

185 Rallo, Ceramiche di Manuzza, p. 215 ; Dehl-von Kaenel, Keramik aus Malophoros, p. 400 ; M. Denoyelle, M. Iozzo, op. cit., p. 58-63.

186 Vallet-Villard, La fond. de Sélinonte, p. 22-26; D. A. Amyx, op. cit., p. 428; Danner, Selinunt, p. 20-26; Dehl-von Kaenel, Keramik aus Malophoros, p. 19-20, 32-42; I. Morris, «The Absolute Chronology of the Greek Colonies in Sicily», AArch 67, 1996, p. 51-59; De Angelis, Megara Hyblaia and Selinous, p. 126-127, n. 183 ; C. W. Neeft, «Absolute Chronology and Corinthian Pottery», in La Sicilia in età arcaica, R. A. Panvini et L. Sole (éds.), à paraître. 
les Grecs étaient déjà arrivés à Sélinonte ${ }^{187}$. En se fondant sur une documentation archéologique encore peu convaincante à son époque, Atkinson avait jadis avancé l'hypothèse selon laquelle la fondation de Sélinonte aurait été précédée par une phase d'investigations préliminaires et de contacts avec les indigènes ${ }^{188}$. Si tel fut le cas, l'année 651/0 désignerait alors la date de ces premiers contacts, tandis que la date transmise par Thucydide (628/7) ne représenterait pas une erreur, mais constituerait la date «officielle» de la fondation de Sélinonte. Cette opinion semble être appuyée par les trouvailles de la zone nord de Manuzza, de l'acropole et de l'agora qui montrent que les Grecs ne se sont établis en nombre sur le site qu'à partir du dernier quart du $\mathrm{VII}^{\mathrm{e}}$ siècle ${ }^{189}$. Il est donc probable qu'après une période de contacts ou une étape de reconnaissance, - on évitera de parler d'une véritable installation, en l'absence d'un contexte archéologique attestant un habitat grec -, les Mégariens de Sicile ont décidé d'installer une apoikia en Sicile occidentale, en sollicitant leur métropole de Grèce pour l'envoi d'un œciste.

Signalons aussi que l'on a cherché à trouver par le biais d'une étude sémantique du passage de Thucydide (VI, 4, 2) l'indice de l'existence de deux étapes successives dans la fondation de la ville, qui correspondraient aux deux dates de fondation (651/0 et 628/7) transmises par les auteurs antiques. De fait, Wentker estime que chez Thucydide, le verbe

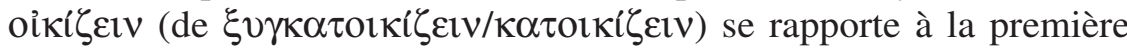

187 Asheri, La colon. gr., p. 129; P. E. Arias, op. cit., p. 107-108; E. Østby, «Chronological problems of archaic Selinus », ActaHyp 6, 1995, p. 83 ; Fischer-Hansen, Town Planning, p. 346; Veronese, Santuari greci, p. 497-498; contra Mertens, Selinus I, p. 226, 273, qui considère que les trouvailles antérieures au dernier quart du $\mathrm{VII}^{\mathrm{e}}$ siècle sont trop peu nombreuses pour que l'on puisse accepter une date de fondation antérieure à 628 .

188 K. M. T. Atkinson, «Two Tomb-Groups from Selinus», PBSR 14, 1938, p. 131. Contra T. J. Dunbabin, «Two Tomb-Groups from Selinus», PBSR 16, 1948, p. 23 ; idem, Western Greeks, p. 438; Van Compernolle, La fond. de Sélinonte, p. 322; Danner, Town Planning, p. 150. Cf. aussi Cook, Ionian and Greece, p. 73.

189 Nicosia, Megara, p. 174-175; R. J. A. Wilson, «Archaeology in Sicily, 1977-1981», AR for 1981-1982, p. 101; Parisi Presicce, Selinunte, p. 125; Tusa, Greci e punici, p. 19-22; Tréziny, Enceintes de Mégara, p. 187-188; De Angelis, Megara Hyblaia and Selinous, p. 124; C. Parisi Presicce, «Selinunte dalla scelta del sito alle prime fasi di vita», $\operatorname{MDAI}(R)$ 110, 2003, p. 267-269; contra Martin et al., Città greche, p. 637 ; $c f$. Martin, Sélinonte, p. 186-187; Mertens, Städte und Bauten, p. 83-85. 
étape de colonisation, à savoir à la prise de possession du site et à l'installation des colons. Le verbe $\kappa \tau i \zeta \varepsilon ı 1 v$ exprimerait une action postérieure à celle de oikí̧દıv, et porterait sur la deuxième étape: la fondation «officielle» de la cité accompagnée des mesures caractéristiques d'une $\kappa \tau i ́ \sigma ı \zeta$ (construction de l'enceinte, institution des cultes, etc.) ${ }^{190}$. En revanche, Nicosia a défendu une thèse diamétralement opposée à celle de Wentker. Pour lui, le verbe $\kappa \tau i \zeta \varepsilon \imath v$ signifie «occuper», se référant à la première étape de colonisation, tandis que le verbe oikí̧દıv a le sens de «fonder», et concerne ainsi la deuxième étape ${ }^{191}$. Mieux, Braccesi considère qu'après l'échec d'une première fondation de Sélinonte par les Mégariens de Sicile vers 651, les Mégariens de Grèce et de Sicile

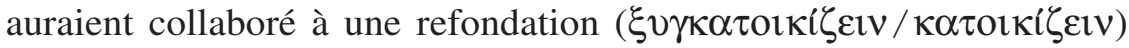
de la cité vers $628^{192}$.

Les thèses de Wentker et Nicosia, qui auraient le mérite d'expliquer la différence chronologique existant entre les dates de fondation transmises par Diodore et Thucydide ne sont néanmoins pas recevables, pour la simple raison qu'elles mènent à des contradictions et s'excluent

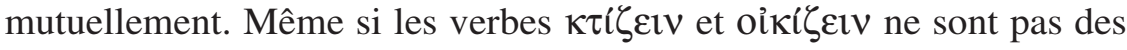
synonymes au sens strict, ils évoquent chez Thucydide deux actions étroitement liées et impossibles à dissocier dans le temps ${ }^{193}$. De sucroît, les trouvailles ne confirment pas l'opinion de Braccesi concernant «un fallimento del primo esperimento coloniario » à Sélinonte ${ }^{194}$. D'ailleurs, dans le passage de Thucydide concernant la fondation de Sélinonte, c'est le sens de «participer à la fondation», préféré par la plupart des

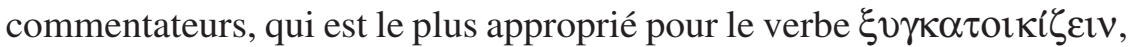
et non pas celui de «refonder» ou «repeupler» ${ }^{195}$. Braccesi croit même pouvoir arguer de l'aide que Pentathlos, le chef d'un contingent des

190 H. Wentker, «Die Ktisis von Gela bei Thukydides », $\operatorname{MDAI}(R)$ 63, 1956, p. 130-131, 137-138.

191 Nicosia, Megara, p. 163-165, 168, 181.

192 L. Braccesi, «Appunti su katoikizein in Tucidide VI, 3, 5 », Kokalos 41, 1995, p. 342-343 ; L. Braccesi, G. Millino, La Sicilia greca, Roma 2000, p. 35.

193 De Wever-Van Compernolle, Colonisation, p. 477-492, 504-505, 522 ; $c f$. K. J. Dover, in A. W. Gomme, A. Andrews, K. J. Dover, op. cit., p. 207 ; Danner, Selinunt, p. 1718.

194 L. Braccesi, op. cit., p. 342-343.

195 De Wever-Van Compernolle, Colonisation, p. 510-517; Casevitz, Vocabulaire, p. 218. 
colons cnidiens et rhodiens, accorda vers 580 aux Sélinontins pendant la guerre contre les Ségestins, pour établir la participation des apoikoi de Cnide à la deuxième fondation de Sélinonte ${ }^{196}$. Mais il est impossible de suivre cette opinion, aucune source ne témoignant de la présence des Cnidiens à Sélinonte.

Après avoir passé en revue les différentes opinions vis-à-vis des traditions de fondation, il me semble utile de formuler ici une remarque sur le nom donné par les Mégariens à leur colonie. L'appellation Sélinous, qui désigne à la fois la cité et l'une des rivières qui traversait son territoire (aujourd'hui Modione ${ }^{197}$ ), vient du sélinon («ache»), une plante que l'on trouvait en abondance dans les environs ${ }^{198}$. Dans son Commentaire à Denys le Périégète, Eustathe rapporte que beaucoup de toponymes grecs dérivent de la végétation ${ }^{199}$. Strabon localise le fleuve

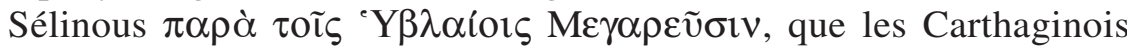
avaient chassés de leur cité ${ }^{200}$. On peut penser qu'il s'agit dans ce passage d'une confusion avec Sélinonte ou que le terme des Hyblaioi Mégareis désigne les Sélinontins, les colons des Mégariens de Sicile ${ }^{201}$. Quoi qu'il en soit, force est de constater que la feuille de d'ache devient un véritable emblème de Sélinonte ${ }^{202}$. Elle figure sur les plus anciennes monnaies (qui datent de la première moitié du $\mathrm{VI}^{\mathrm{e}}$ siècle et du début du $\mathrm{V}^{\mathrm{e}}$ siècle) ${ }^{203}$, et accompagne, au revers des monnaies du $\mathrm{V}^{\mathrm{e}}$ siècle, les

196 L. Braccesi, «Cronologia e fondazioni coloniarie, 1 (Pentatlo, gli Cnidi e la fondazione di Lipari)», in Hesperìa, 7 : studi sulla grecità di Occidente, L. Braccesi (éd.), Roma 1996, p. 35-36.

197 Manni, Geog. della Sicilia, p. 122; J. Curbera, «Onomastics and River-Gods in Sicily», Philologus 142, 1998, p. 55.

198 Douris de Samos, FGrHist 76 F 59, rapporte que Sélinonte, comme dans le cas des autres cités de Sicile, reçut son nom d'un fleuve. Mais en réalité, il est probable que le nom de l'ache est responsable autant du nom du fleuve que de celui de la ville.

199 Eustathe, GGM II, 453, p. 302.

200 Strabon, VIII, 7, 5, C 387.

201 Manganaro, Hybla, p. 149. Pour l'emploi de l'ethnique de la métropole pour nommer les apoikiai, voir Vatin, Citoyenneté et ethnique, p. 71-80; Robu, Réseaux, p. 184-186.

202 Lacroix, Monnaies et colon., p. 151-154.

203 E. Babelon, Traité des monnaies grecques et romaines, II 1, Paris 1907, p. 15511554, nos 2338-2348, pl. LXXIX, n ${ }^{\text {os }} 1-11$; Head, $H N^{2}$, p. 167; W. Schwabacher, «Die Tetradrachmenprägung von Selinunt», MBNG 43, 1925, p. 28; SNG Cop. Sicily, pl. 13, $\mathrm{n}^{\text {os }}$ 591-596; G. E. Rizzo, Monete greche della Sicilia, Roma 1946, p. 166, pl. XXXI, nos 1-6; P. R. Franke, M. Hirmer, Die griechische Münze, München 1972, 
images des dieux fleuves Sélinous ${ }^{204}$ et Hypsas (aujourd'hui le fleuve Belice $)^{205}$. De plus, la cité émet au $\mathrm{V}^{\mathrm{e}}$ siècle des didrachmes et une série de fractions ornées d'une feuille de sélinon, et les ateliers monétaires utilisent cette feuille en tant que contremarque ${ }^{206}$. Au surplus, on sait que pour montrer leur dévotion à Apollon Pythien, les Sélinontins envoyèrent à Delphes un sélinon en or ${ }^{207}$. Cette consécration n'est pas depouvue de signification, car l'ache est une plante chère à Apollon. Le dieu porte en Eubée une épiclèse dérivée du nom de la plante: il y avait un sanctuaire d'Apollon Sélinaios/Sélinountios, à Orobiai, dans le territoire d'Histiée ${ }^{208}$. La conclusion qui me semble s'imposer est que le

$\mathrm{n}^{\text {os }}$ 184-185; A. Tusa Cutroni, «Aspetti e problemi della monetazione arcaica di Selinunte (inizi-480 a.C.). Natura, metrologia, organizzazione, circolazione », Kokalos 21, 1975, p. 154-173; SNG Amer. Sicily, pl. 23, nº 665-687; C. Boehringer, «Der Beitrag der Numismatik zur Kenntnis Siziliens im VI. Jahrhundert v. Chr.», Kokalos 30-31, 1984-1985, p. 116-119, pl. XII, n ${ }^{\text {os }} 5-10$; SNG 6, pl. 26, nos 873-879; H. Baumann, Pflanzenbilder auf griechischen Münzen, München 2000, p. 54-55.

204 F. Imhoof-Blumer, «Fluss- und Meergötter auf griechischen und römischen Münzen», SNR 23, 1923, p. 208-209, nos 86-89; Head, $H N^{2}$, p. 168-169; W. Schwabacher, op. cit., p. 5-26, $\mathrm{n}^{\mathrm{os}}$ 1-45; SNG Cop. Sicily, pl. 13, $\mathrm{n}^{\mathrm{os}}$ 597-600; SNG Amer. Sicily, pl. 23-24, $\mathrm{n}^{\text {os }}$ 688-701; P. R. Franke, M. Hirmer, op. cit., $\mathrm{n}^{\text {os }} 186,188-191$.

205 F. Imhoof-Blumer, op. cit., p. 210, n ${ }^{\text {os }}$ 90-91; Head, $H N^{2}$, p. 168; SNG Cop. Sicily, pl. 13, n ${ }^{\circ} 601$; G.E. Rizzo, op. cit., pl. XXXI, n ${ }^{\text {os }} 15-17$; pl. XXXIII, no 8 ; P.R. Franke, M. Hirmer, op. cit., $\mathrm{n}^{\circ} 187$; SNG Amer. Sicily, pl. 24, $\mathrm{n}^{\text {os }}$ 702-710. Pour la représentation des dieux-fleuves Sélinous et Hypsas sur les monnaies sélinontines, on verra aussi C. Weiss, Griechische Flussgottheiten in vorhellenistischer Zeit. Ikonographie und Bedeutung, Würzburg 1984, p. 24-49, 55-56.

206 Pour la présence habituelle de la feuille de sélinon sur l'avers et le revers des didrachmes et des différentes fractions de Sélinonte et également pour l'usage de cette feuille en tant que contremarque, voir C. Arnold-Biucchi, «Litras en argent contremarquées en Sicile et les fractions de Sélinonte», in Pour Denyse. Divertissements numismatiques, S. Mani Hurter et C. Arnold-Biucchi (éds.), Bern 2000, p. 1317, pl. 1, $\mathrm{n}^{\text {os }} 1-3$ (contremarques), ${ }^{\text {os }}$ 5-7 (fractions); L. Lazzarini, «Monete arcaiche inedite di Selinunte e nuove considerazioni sul tipo della foglia», NAC 32, 2003, p. 11-22.

207 Plutarque, Sur les oracles de la Pythie, 12 (= Moralia 399 F).

208 Strabon, X, 1, 3, C 445, localise un oracle d'Apollon Sélinountios à Orobiai. On a trouvé en Eubée, aux abords de la moderne Rovies, un acte d'affranchissement par consécration à Apollon Sélinaios ( $\mathrm{II}^{\mathrm{e}}-\mathrm{I}^{\mathrm{er}}$ siècle). Comme on n'a pas manqué de le noter, la divinité mentionnée par cette inscription ne fait qu'une avec celle évoquée

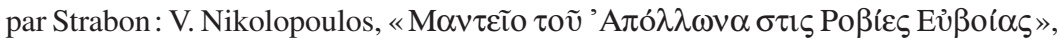

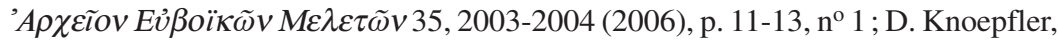
Bull. ép., 2007, 333; cf. SEG LVI, 1030. 
sélinon fut choisi pour donner son nom à la cité de Sélinonte en raison de ses liens avec Apollon, la divinité principale des Mégariens, et de son rôle dans les pratiques rituelles locales.

\section{II.1.2.2 Les premiers rapports entre les Sélinontins et les indigènes}

La cité de Sélinonte fut installée entre les vallées des fleuves Gorgo Cottone à l'est et Modione à l'ouest dans une région habitée par les Sicanes. Les résultats des fouilles menées sur le plateau de Manuzza, dans la partie nord de la ville, ont accrédité l'opinion selon laquelle les premiers contacts entre les Mégariens et les populations locales n'avaient pas été violents, l'occupation grecque du site s'étant faite de manière pacifique. D'après Rallo, le niveau indigène serait suivi dans ce secteur par une couche mixte gréco-indigène, laquelle aurait été finalement remplacée par une couche purement grecque, sans traces de destruction $^{209}$. Mais ce matériel est en bonne partie inédit, chose qui rend sa datation et son interprétation controversées, d'autant plus que l'on n'a pas trouvé un habitat indigène dans les autres secteurs de la ville ${ }^{210}$.

En dehors de Manuzza, Tusa a aussi supposé l'existence d'une phase pré-grecque dans le sanctuaire de Déméter Malophoros ${ }^{211}$. Mais son opinion ne se fonde que sur quelques fragments de céramique indigène dépourvus de contexte archéologique, ce qui n'est guère suffisant. L'absence de stratigraphie et le nombre réduit de ces tessons découverts dans ce secteur (remontant à une période très large, VIII $-\mathrm{V}^{\mathrm{e}}$ siècles)

209 Rallo, Selinunte, p. 730, suivie par R. Martin, Histoire de Sélinonte, p. 53; idem, «Recherches sur l'acropole de Sélinonte», Kokalos 26-27, 1980-1981, p. 1013; A. J. Graham, «The Western Greeks», in Cambridge Ancient History ${ }^{2}$, III, 3, J. Boardman et N.G.L. Hammond (éds.), Cambridge 1982, p. 168; Tusa, Greci e punici, p. 19; Di Vita, Selinunte, p. 9-10; Domínguez, Colon. Gr., p. 373; S. Collin Bouffier, «Sélinonte à la frontière punique», Dossiers d'Archéologie 225, 1997, p. 47; J. G. Devoto, op. cit., p. 91; Tusa, Prima di Selinunte, p. 37-38.

210 Mertens, Städte und Bauten, p. 83; Tréziny, De Mégara à Sélinonte, p. 163.

211 S. Tusa, «Presenze indigene nel territorio selinuntino», SicArch XV, 49-50, 1982, p. 111-118. L'impossibilité d'identifier les éléments indigènes dans le culte de la Malophoros à cause surtout du manque d'informations concernant la religion des communautés indigènes de Sicile a été soulignée par Jameson, Jordan, Kotansky, Lex sacra, p. 140, n. 8. Cf. M. Riotto, «Il santuario della Malophoros a Selinunte: spunti per una discussione storico-religiosa», SicArch XVIII, 59, 1985, p. 25-51, notamment p. 34-35 ; C. Parisi Presicce, $\operatorname{MDAI}(R)$ 110, 2003, p. 279. 
rend impossible à accepter la comparaison faite par Tusa entre les trouvailles de l'aire de la Malophoros et celles de Manuzza.

La découverte isolée de fragments de coupes indigènes sur l'acropole ne peut pas non plus être considérée comme un argument décisif pour la présence indigène dans cette aire ${ }^{212}$. De même, les fouilles menées sur l'agora et dans la vallée du fleuve Gorgo Cottone n'ont pas confirmé l'existence d'une éventuelle occupation des Sicanes dans ces zones $^{213}$. Ainsi, l'hypothèse de Parisi Presicce sur l'existence à Sélinonte d'un village sicane constitué avant l'arrivée des Grecs par plusieurs noyaux d'habitation reste encore à être prouvée par les fouilles à venir ${ }^{214}$.

Par ailleurs, des confrontations semblent avoir eu lieu entre les Grecs et les indigènes: preuve en sont les découvertes de Montagnoli, une localité située à la périphérie orientale du territoire de Sélinonte, dans la vallée du fleuve Belice (l'antique Hypsas), et que l'on considère comme appartenant à l'aire élyme. On a trouvé ici des traces de destruction par incendie remontant au milieu du VII ${ }^{\mathrm{e}}$ siècle $^{215}$. En s'appuyant sur ces découvertes, De Angelis estime que les contacts avec les populations locales, pacifiques à l'origine, sont ensuite devenus violents $^{216}$. Bien que cette possibilité ne soit pas à exclure, on peut aussi envisager une autre solution. Si la fondation de Sélinonte découle d'une politique d'alliance avec certains chefs indigènes, cela n'exclut pas des

212 Pour la céramique indigène trouvée sur l'acropole, voir M. H. Fourmont, «Sélinonte: fouille dans la région nord-ouest de la rue F», SicArch XIV, 46-47, 1981, p. 8-9. Par ailleurs, I. Tamburello, «La Montagnola di Marineo», SicArch III, 10, 1970, p. 35, n. 11, évoque la présence au Musée de Palerme des céramiques indigènes de l'époque archaïque provenant des nécropoles de Sélinonte, céramiques trouvées lors des fouilles de 1963-1967.

213 Mertens, Selinus I, p. 226, 273; idem, Städte und Bauten, p. 83.

214 Parisi Presicce, Selinunte, p. 27, suivi par De Angelis, Megara Hyblaia and Selinous, p. 151.

215 G. Castellana, «L'insediamento di Montagnoli nei pressi di Selinunte. Un contributo per la conoscenza delle popolazioni anelleniche lungo il corso finale del Belice», in Gli Elimi e l'area elima fino all'inizio della prima guerra punica. Atti del seminario di studi (Palermo-Contessa Entellina, 25-28 maggio 1989), G. Nenci et al. (éds.), Palermo 1990, p. 326-330; idem, «Nuovi dati sull'insediamento di Montagnoli presso Menfi», in Terze giornate internazionali di studi sull'area elima (Gebellina-EriceContessa-Entellina, 23-26 ottobre 1997). Atti, vol. I, S. de Vido (éd.), Pisa-Gibellina 2000, p. 263-271. Sur Montagnoli, voir aussi G. Castellana, s.v. «Montagnoli», in BTCGI X, 1992, p. 235-236; Tusa, Prima di Selinunte, p. 38.

216 De Angelis, Megara Hyblaia and Selinous, p. 151-152, 201. 
luttes avec d'autres, moins attirés par le profit qu'ils pouvaient tirer des échanges avec les Grecs. Une telle reconstruction peut expliquer l'absence de traces de destruction à Manuzza et leur présence à Montagnoli. Tout cela est d'autant plus probable si l'on accepte que l'installation des Grecs s'est déroulée en plusieurs étapes et qu'il y a eu plusieurs vagues de colons. Comme dans le cas de Mégara, le succès de l'entreprise coloniale en Sicile occidentale a pu être favorisé par l'existence de bonnes relations entre les Grecs et diverses tribus locales ${ }^{217}$.

Du reste, la documentation onomastique confirme l'existence des rapports entre les Sélinontins et les Sicanes aux $\mathrm{VI}^{\mathrm{e}}-\mathrm{V}^{\mathrm{e}}$ siècles. Les tablettes de malédiction sur plomb (defixiones) attestent au $\mathrm{V}^{\mathrm{e}}$ siècle la présence de plusieurs noms d'aspect indigène dans la colonie mégarienne

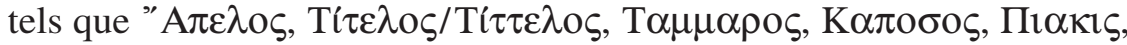
Apo $\theta 1 \varsigma^{218}$. Les inscriptions confirment également l'emploi de l'ethnique des Sicanes comme anthroponyme (le féminin $\Sigma \mathfrak{i} \alpha \alpha^{2} \alpha^{219}$ et le masculin $\Sigma i ́ \kappa \bar{o} v^{220}$, qui est sans doute une Kurzform de $\Sigma \imath \kappa \varepsilon \lambda$ ó $^{221}$. Si

217 Pippidi, Gètes, Grecs et Romains en Scythie, p. 445-446, établit trois catégories de relations possibles entre les apoikoi grecs et les indigènes : l'accueil généreux des Grecs par les indigènes (voir l'exemple de la fondation de Massalia: Justin, XLIII, 3, 4-13), la version héroïque de la colonisation avec la conquête du territoire indigène et les accords en vertu desquels les Grecs recevaient des dynastes locaux les terres nécessaires à l'établissement de leur apoikia. $C f$. F. de Angelis, «Re-assessing the Earliest Social and Economic Developments in Greek Sicily », $\operatorname{MDAI}(R)$ 116, 2010, p. 21-53.

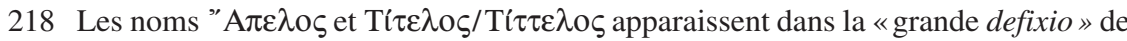
Sélinonte: IGDS, 38 (=IGASM $\mathrm{I}^{2}, 63$; Bettarini, Defixiones, $\left.\mathrm{n}^{\circ} 23\right)$; cf. Masson, L'imprécation de Sélinonte, p. 386-387. C'est aussi grâce à une defixio que l'on con-

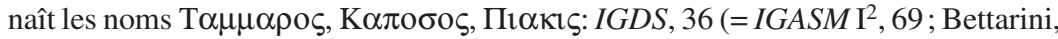
Defixiones, $\left.\mathrm{n}^{\mathrm{0}} 24\right)$; $c f$. O. Masson, «La Sicile et le monde grec archaïque : 1'apport de la linguistique», Kokalos 30-31, 1984-1985, p. 75; Antonetti-De Vido, Cittadini, p. 421. Dernièrement, une defixio du V $\mathrm{V}^{\mathrm{e}}$ siècle publiée par R. Kotansky, J. Curbera, «Unpublished Lead Tablets in the Getty Museum», MediterrAnt 7, 2, 2004, p. 686-

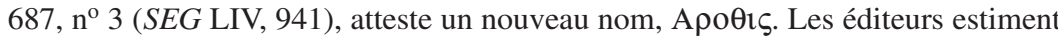
qu'il pourrait s'agir d'un anthroponyme italique ou étrusque. D'après L. Dubois, Bull. ép., 2006, 516, on aurait affaire à un nom indigène.

219 IGDS, 29 (=IGASM $\mathrm{I}^{2}, 59$; Bettarini, Defixiones, $\left.\mathrm{n}^{\circ} 15\right)$.

220 G. Manganaro, «Una defixio giudiziaria in alfabeto selinuntino », REG 116, 2003, p. 685 (SEG LIII, 1038); L. Bettarini, «Una nuova defixio di Selinunte ?», ZPE 151, 2005, p. 257.

221 M. Lambertz, Die griechischen Sklavennamen, in 57. Jahres-Bericht über das $k . k$. Staatsgymnasium im VIII. Bezirke Wiens für das Schuljahr 1906/1907, Wien 1907, p. 15, n. 25 . 
l'on ne peut pas se prononcer sur l'importance de l'intégration de l'élément local dans la colonie à partir du seul domaine de l'onomastique, les noms évoqués révèlent cependant l'existence des contacts avec le monde sicane.

\section{II.1.2.3 L'expansion de Sélinonte dans la Sicile occidentale à l'époque archaïque}

Il me semble utile de se pencher ici sur plusieurs documents archéologiques qui témoignent de l'expansion des Sélinontins en Sicile occidentale à la fin du VII ${ }^{\mathrm{e}}$ siècle et dans la première moitié du $\mathrm{VI}^{\mathrm{e}}$ siècle. Cela peut compléter, à mon sens, l'image des premiers rapports entre Grecs et indigènes et le processus de la colonisation mégarienne en Sicile.

Outre les trouvailles de Montagnoli évoquées dans le chapitre précédent, la pénétration des Grecs vers l'intérieur du pays, passant par la vallée du Belice, est attestée dès la fin du VII ${ }^{\mathrm{e}}$ siècle par les céramiques grecques trouvées à Monte Castellazzo di Poggioreale ${ }^{222}$. Aux VII ${ }^{\mathrm{e}}-\mathrm{VI}^{\mathrm{e}}$ siècles, Sélinonte semble de même être le centre de diffusion des céramiques grecques et étrusques le long de la vallée du Belice, notamment vers les sites de Poggioreale et de Monte Iato ${ }^{223}$.

222 V. Tusa, «Materiali greci dell'VIII e del VII secolo a. C. nella Sicilia Occidentale», in Rizza (éd.), Insediamenti colon. gr., p. 49; G. Falsone in G. Falsone et al., «Quatro campagne di scavo a Castellazzo di Poggioreale», Kokalos 36-37, 1980-1981, p. 936-937; La Genière, Sélinonte, p. 252-253. Sur les découvertes de Poggioreale, voir aussi V. Tusa, «La zona archeologica di Poggioreale», SicArch V, 18-20, 1972, p. 57-60; G. Falsone, s.v. «Monte Castellazzo di Poggioreale», in BTCGI X, 1992, p. 307-312. Sur les sites indigènes de la Sicile occidentale, voir la description détaillée fournie par De Angelis, Megara Hyblaia and Selinous, p. 101-115, et surtout p. 173-178, pour les sites indigènes qui se trouvaient dans le territoire de Sélinonte.

223 Rallo, Considerazioni, p. 545-546, n. 20, p. 549; F. Spatafora, «L'alta e media Valle del Belice tra la Media Età del Bronzo e l'età arcaica», Kokalos 42, 1996, p. 188198 ; $c f$. R. Panvini di Stefano, QuadMess 2, 1986-87, p. 107. Sur l'arrivé des céramiques grecques à Monte Iato dès la fin du VII ${ }^{\mathrm{e}}$ siècle, voir H.P. Isler, «Indigeni e Greci nella Sicilia Occidentale : le più antiche importazioni greche a Monte Iato », in KOINA : miscellanea di studi archeologici in onore di Piero Orlandini, Milano 1999, p. 143-156 (avec les références); idem, Monte Iato. Guida archeologica, Palermo 2000, p. 19. 
Une épitaphe datant de la fin du VII ${ }^{\mathrm{e}}$ siècle ou du début du VI ${ }^{\mathrm{e}}$ siècle, découverte au nord de Sélinonte, dans la «Contrada Vallesecco», où se trouve l'une des nécropoles de la cité, confirme la rapidité de la pénétration des Sélinontins vers l'intérieur du territoire ${ }^{224}$. De plus, on a trouvé dans une région proche de Poggioreale une dédicace à Héraclès, en dialecte dorien, datée de la première moitié $\mathrm{du} \mathrm{VI}^{\mathrm{e}}$ siècle. Il existait donc très probablement dans cet endroit une aire sacrée dédiée à Héraclès, que l'on pourrait mettre en liaison avec l'expédition de Pentathlos en Sicile $^{225}$. Grâce à Diodore, on sait que Pentathlos se tenait pour un descendant d'Héraclès et qu'il a aidé vers 580 la cité de Sélinonte dans son conflit avec Ségeste, et probablement aussi avec les Phéniciens ${ }^{226}$. D'autre part, la dédicace découverte à Poggioreale peut être interprétée comme un indice de la fréquentation de cette région par les Sélinontins et des rapports qu'ils entretenaient avec les populations locales, et non pas comme la preuve d'une expansion militaire ${ }^{227}$. On rappelle que, tout comme dans d'autres cités siciliotes, Héraclès bénéficie d'un culte à

224 A. Brugnone, «Epigrafia greca», Kokalos 34-35, 1988-1989, p. 339-341 (= IGDS II, 20).

225 IGLMP, 35; IGDS, 84; IGASM $\mathrm{I}^{2}, 35$; $c f$. M. Giangiulio, «Greci e non-Greci in Sicilia alla luce dei culti e delle leggende di Eracle», in Modes de contacts et processus de transformation dans les sociétés anciennes (Actes du colloque de Cortone, mai 1981), Pise-Rome 1983, p. 803-807; idem, Memorie coloniali, Hesperia, 27: studi sulla grecità di Occidente, Roma 2010, p. 104-105; De Vido, Gli Elimi, p. $129-139$.

226 Diodore, V, 9. À en croire, Antiochos de Syracuse, FGrHist 555 F 1 (= F. 14, éd. C. Cuscunà ; apud Pausanias, X, 11, 3), les troupes de Pentathlos menèrent une guerre contre les Élymes et les Phéniciens. Sur l'expédition de Pentathlos en Sicile, voir Bérard, Colonisation, p. 254-257; Dunbabin, Western Greeks, p. 328-329; Martin, Histoire de Sélinonte, p. 53-54 ; L.-M. Hans, Karthago und Sizilien. Die Entstehung und Gestaltung der Epikratie auf dem Hintergrund der Beziehungen der Karthager $z u$ den Griechen und den nichtgriechischen Völkern Siziliens (VI.-III. Jahrhundert v. Chr.), Hildesheim et al. 1983, p. 6.

227 L. Gallo, «Per un riesame dei rapporti tra Segesta e Selinunte», in Terze giornate internazionali di studi sull'area elima (Gebellina, Erice, Contessa Entellina, 23-26 ottobre 1997). Atti, S. De Vido (éd.), Pisa-Gibellina 2000, p. 519; F. Persolja, «L'espansionismo selinuntino di VI secolo alle luce delle testimonianze epigrafiche e letterarie», ZPE 167, 2008, p. 113-116; M. de Bernardin, «Per un'analisi della figura di Eracle in Sicilia: dal VII sec. a.C. all'età romana», in Sicilia occidentale. Studi, rassegne, ricerche, C. Ampolo (éd.), Pisa 2012, p. 305-306. 
Sélinonte: il est mentionné par l'inscription dite du temple $\mathrm{G}^{228}$ et il apparaît sur les métopes du temple Y (appelé aussi le «tempietto delle piccole metope») et sur celles du temple $\mathrm{C}^{229}$, ainsi que sur les monnaies ${ }^{230}$. Notons au passage que le temple $\mathbf{M}$, situé sur la colline de la Gaggera, au nord-ouest du sanctuaire de la Malaphoros a été attribué à Héraclès ${ }^{231}$.

La présence grecque à l'ouest de Sélinonte, en direction du fleuve Mazaro, est confirmée par une épitaphe en alphabet corintho-mégarien, découverte dans l'aire de Campobello di Mazaro et datée de la fin du $\mathrm{VII}^{\mathrm{e}}$ siècle $^{232}$. Ultérieurement, vers le milieu du $\mathrm{VI}^{\mathrm{e}}$ siècle, une autre inscription funéraire de Sélinonte évoque la mort d'Aristogeitos, le fils

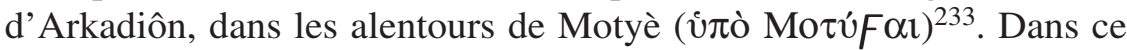
cadre, on rappellera qu'un conflit opposant les Sélinontins aux Carthaginois eut lieu durant le $\mathrm{VI}^{\mathrm{e}}$ siècle, à la suite duquel Théron, le fils de Miltiade, s'empara de la tyrannie à Sélinonte ${ }^{234}$.

$228 I G A S M \mathrm{I}^{2}$, 53. Sur la popularité du culte d'Héraclès en Sicile, on verra C. JourdainAnnequin, Héraclès aux portes du soir. Mythe et histoire, Paris 1989, p. 301-356; eadem, «Être un Grec en Sicile: le mythe d'Héraclès », Kokalos 34-35, 1, 1993, p. 143-166; Malkin, A Small Greek World, p. 119-141; M. de Bernardin, op. cit., p. $305-312$.

229 C. Marconi, Temple Decoration and Cultural Identity in the Archaic Greece. The Metopes of Selinus, Cambridge 2007, p. 229, 238-239.

230 A. Tusa Cutroni, «La monetazione di Selinunte», in Selinunte, S. Tusa (éd.), Roma 2010, p. 161. Voir aussi infra, chapitre III.1.2.4 sur le clan (ou l'hékatostys?) des Héraclides à Sélinonte.

231 L. Pompeo, Il complesso architettonico del Tempio M di Selinunte: analisi tecnica e storia del monumento, Studi e materiali di archeologia 12, Torino 1999, p. 74-83.

232 G. Nenci, «Una nuova iscrizione greca arcaica dall' area selinuntina », ASNP serie iii, 25, 3, 1995, p. 1329-1331 (SEG XLV, 1415); cf. P. Anello, «Grecità periferica in Sicilia: Himeráioi e Selinóuntioi », in Hesperìa, 10: studi sulla grecità di Occidente, L. Braccesi (éd.), Roma 2000, p. 105; S. de Vido in C. Antonetti, S. de Vido, «Conflitti locali e integrazione culturale a Selinunte : il nouvo profilo della polis nell' iscrizione della vittoria», in Guerra e pace in Sicilia e nel Mediterraneo antico (VIII-III sec. a.C.). Arte, prassi e teoria della pace e della guerra, vol. I, Pisa 2006, p. 146.

$233 I G L M P, 80$ (=IGDS, 73; IGASM $\left.\mathrm{I}^{2}, 18\right)$; $c f$. Jeffery, $L S A G^{2}$, p. 461.

234 Polyen, I, 28, 2; cf. De Angelis, Megara Hyblaia and Selinous, p. 156-159. Pour l'expansion de Sélinonte aux $\mathrm{VI}^{\mathrm{e}}-\mathrm{V}^{\mathrm{e}}$ siècles vers l'ouest, dans la direction du fleuve Mazaro, voir aussi V. Merante, «Sui rapporti greco-punici nel Mediterraneo occidentale nel VI secolo a. C. », Kokalos 16, 1970, p. 112; L. Gallo, op. cit., p. 517-531, qui estime que l'expansion militaire de Sélinonte fut principalement dirigée vers l'ouest et non pas vers les cités élymes du nord. 
Les fouilles ont par ailleurs révélé à l'est de Sélinonte, dans la région de Caltabellotta, une céramique grecque archaïque et une statuette féminine en terre cuite, très proche des statuettes découvertes dans le sanctuaire de la Malophoros. Papadopoulos pense que cette figurine de style dédalique, datant de la fin du VII ${ }^{\mathrm{e}}$ siècle ou du début du $\mathrm{VI}^{\mathrm{e}}$ siècle, indique «la precoce presenza greca in un centro sicano, non limitata a semplici scambi di natura commerciale, giacché se deve presupporre l'esistenza di un santuario greco dal cui materiale votivo certamente proviene la statuetta ${ }^{235}$. Toujours dans la partie orientale du territoire de Sélinonte, le site indigène de Monte Adranone, situé à 1000 m d'altitude et dominant la vallée du Belice, connaît une occupation grecque au $\mathrm{VI}^{\mathrm{e}}$ siècle et il est utilisé comme place fortifiée jusqu'à la fin du $\mathrm{V}^{\mathrm{e}}$ siècle ${ }^{236}$.

Du reste, on est bien informé par les sources textuelles sur l'expansion côtière de la cité mégarienne. À l'ouest, les récits attestent l'existence de Mazare, un emporion, d'après Diodore, ou un phrourion sélinontin, selon Stéphane de Byzance, aux embouchures de l'antique fleuve Mazaros ${ }^{237}$. Cette localité antique est occupée par la ville ac-

235 J. Papadopoulos, «Una terracotta dedalica da Caltabellotta», Xenia 2, 1981, p. 10. Notons que pour R. Panvini di Stefano, «Contributo alla conoscenza di un centro indigeno ellenizzato presso Caltabellotta (Agrigento)», QuadMess 2, 1986-87, p. 109, le site de Caltabellotta ne commence à être hellénisé qu'à partir du milieu du $\mathrm{VI}^{\mathrm{e}}$ siècle, la présence de la statuette de style dédalique n'étant que le résultat des contacts avec les Grecs. Mieux, ce site serait à identifier à la cité de Triokola, qui apparaît dans la documentation littéraire. $C f$. R. Panvini, s.v. «Caltabellotta», in BTCGI IV, 1985, p. 269-270; eadem, «Scavi e ricerche a Caltabellotta», Kokalos 34-35, 1988-89, p. 559-572 ; Leighton, Sicily before History, p. 261 ; Veronese, Santuari greci, p. 502, 532-533.

236 E. de Miro, «Monte Adranone, antico centro di età greca», Kokalos 13, 1967, p. 180-185; E. de Miro, G. Fiorentini, «Attività della Soprintendeza alle Antichità della Sicilia centro-meridionale negli anni 1968-1972», Kokalos 18-19, 1972-1973, p. 241-244; iidem, «Relazione sull'attività della Soprintendeza alle Antichità di Agrigento (1972-1976)», Kokalos 22-23, 1976-1977, p. 454-455; E. de Miro, «Nuovi dati del problema relativo all'ellenizzazione dei centri indigeni della Sicilia centrooccidentale», BA 60, 3-4, 1975, p. 126-128; Domínguez, Colon. Gr., p. 410-412; C. A. di Noto, s.v. «Monte Adranone», in BTCGI X, 1992, p. 260. Les trouvailles indiquent qu'après la destruction de la fin du $\mathrm{V}^{\mathrm{e}}$ siècle (qui fut une conséquence de la conquête punique de Sélinonte), la localité de Monte Adranone fut rebâtie au $\mathrm{IV}^{\mathrm{e}}$ siècle et qu'elle continua son existence jusqu'au milieu du $\mathrm{III}^{\mathrm{e}}$ siècle.

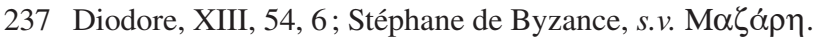


tuelle de Mazara del Vallo, ce qui rend difficiles les fouilles archéologiques, seules capables de mieux préciser la date de l'installation des Sélinontins à Mazare ${ }^{238}$.

Les Sélinontins ont poursuivi leur expansion côtière également à l'est, en installant Minôa sur la rive gauche du fleuve Halykos (l'actuel Platani) ${ }^{239}$, à la place d'un ancien centre sicane appelé Makara ${ }^{240}$. Les trouvailles dans la nécropole archaïque confirment la fondation de cet établissement vers le milieu du $\mathrm{VI}^{\mathrm{e}}$ siècle $^{241}$. Il importe de noter que le héros éponyme du fleuve Halykos n'est autre que le fils de Sciron, héros éponyme d'un site en Mégaride ${ }^{242}$. En outre, le nom même de Minôa reflète un héritage mégarien puisqu' on trouve une petite île ayant ce nom (qui serait là un souvenir de la conquête de Mégare par Minos), près de Nisaia, le port de Mégare de Grèce ${ }^{243}$. Le nom de la colonie sélinontine n'a été très probablement mis en rapport qu'à une époque postérieure avec la légende de Dédale et de Minos en Sicile ${ }^{244}$. On sait qu'après la défaite et la mort du spartiate Dorieus, pendant sa campagne contre les Phéniciens et les Ségestins (vers 520), ses compagnons, commandés par Euryléon, ont occupé Minôa. La cité changera de nom

238 Sur l'emplacement et l'histoire de Mazare, voir Manni, Geog. della Sicilia, p. 115116; S. de Vido, s.v. «Mazara del Vallo», in BTCGI IX, 1991, p. 502-508; De Angelis, Megara Hyblaia and Selinous, p. 196, n. 249; F. Persolja, op. cit, p. 116-117.

239 Hérodote, V, 46, 2.

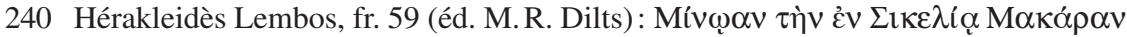

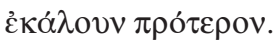

241 E. de Miro, «La fondazione di Agrigento e l'ellenizzazione del territorio fra il Salso e il Platani», Kokalos 8, 1962, p. 144-146; idem, L'Antiquarium e la zona archeologica di Eraclea Minoa, Roma 1965, p. 5, 10-11 ; R. J. A. Wilson, A. Jr. Leonard, «Field Survey at Heraclea Minoa (Agrigento), Sicily», JFA 7, 1980, p. 224-226.

242 Voir supra, chapitre I.2.2. Sur le fleuve Halykos, voir Manni, Geog. della Sicilia, p. 107.

243 E. Pais, Storia della Sicilia e della Magna Grecia, Torino-Palermo 1894, p. 136. Sur l'île mégarienne de Minôa, voir supra, chapitre I.2.3.

244 L'association entre le roi Minos et Minôa de Sicile se trouve chez Diodore, IV, 79. Cf. E. Sjöqvist, op. cit., p. 9; Martin et al., Città greche, p. 556; G. Manganaro, «Mondo religioso greco e mondo < indigeno > in Sicilia», in Antonetti (éd.), Il dinam. della colon. gr., p. 73 et aussi p. 157. Pour les traditions concernant l'expédition et la mort du roi Minos en Sicile, voir aussi G. Pugliese Carratelli, «Minos e Cocalos», Kokalos 2, 1956, p. 89-103 (= Tra Cadmo e Orfeo. Contributi alla storia civile e religiosa dei Greci d'Occidente, Bologna 1990, p. 43-57); F. P. Rizzo, «Akragas e la fondazione di Minoa», Kokalos 13, 1967, p. 117-142; R. Sammartano, «Dedalo, Minosse e Cocalo in Sicilia», Mythos 1, 1989, p. 201-229. 
et deviendra Héraclée Minôa soit après l'occupation d'Euryléon ${ }^{245}$, soit beaucoup plus tard, entre 357 et 313 , à l'époque de la nouvelle colonisation faite par Timoléon ${ }^{246}$. Fondée avec le dessein de bloquer l'expansion du tyran agrigentin Phalaris, Minôa finit par être occupée au début $\mathrm{du} \mathrm{V}^{\mathrm{e}}$ siècle par Agrigente ${ }^{247}$.

Enfin, grâce à Pomponius Mela et Pline, on connaît l'existence en Sicile occidentale d'une localité appelée Thermae Selinuntiae ${ }^{248}$. On a proposé d'identifier Thermae Selinuntiae à la grotte du «Monte S. Calogero» située aux abords de Sciacca, où l'on a trouvé des statuettes et des céramiques datant du $\mathrm{VI}^{\mathrm{e}}$ siècle. Cette localité serait en outre à associer au mythe de Dédale en Sicile, personnage responsable, d'après Diodore, de l'aménagement d'une source d'eaux thermales dans le territoire de Sélinonte ${ }^{249}$.

245 Bérard, Colonisation, p. 265 ; Pugliese Carratelli, Selinunte, p. 23; D. Musti, «Le tradizioni ecistiche di Agrigento », in Agrigento e la Sicilia greca. Atti della settimana di studio (Agrigento, 2-8 maggio 1988), L. Bracessi et E. de Miro (éds.), Roma 1992, p. 43; L. Braccesi, L'enigma Dorieo, Hesperìa, 11 : studi sulla grecità di Occidente, Roma 1999, p. 46; T. Fischer-Hansen, T. H. Nielsen, C. Ampolo, s.v. «Herakleia (1)», in Hansen-Nielsen (éds.), Inventory, p. 196; Malkin, A Small Greek World, p. 138-141.

246 E. de Miro, «Eraclea Minoa e l'época di Timoleonte», Kokalos 4, 1958, p. 69-81, surtout p. 78; Martin et al., Città greche, p. 555 ; R. Descat, «Gélon et les emporia de Sicile», Messana 13, 1992, p. 10, n. 1.

247 Chronique de Lindos, FGrHist 532 C 30. Sur l'occupation de Minôa par Agrigente, voir E. de Miro, «Agrigento arcaica e la politica di Falaride», PP 11, 1956, p. 272 273 ; J. A. de Waele, Acragas Graeca. Die historische Topographie des griechischen Akragas auf Sizilien, Den Haag 1971, p. 108; De Angelis, Megara Hyblaia and Selinous, p. 161-162; Veronese, Santuari greci, p. 436-437, 502. Notons ici que selon S. Bianchetti, Falaride e Pseudofalaride: storia e leggenda, Roma 1987, p. 90-91, Minôa fut établie par les Sélinontins avec l'accord du tyran Phalaris, les Agrigentins et les Sélinontins étant unis par leur adversité vis-à-vis des Sicanes. La même opinion chez F. Persolja, op. cit., p. 113 et n. 3. On comprend mal néanmoins pourquoi les Agrigentins auraient accueilli favorablement l'installation d'un établissement sélinontin à leurs frontières.

248 Pomponius Mela, II, 7, 118 ; Pline, NH, III, 90; cf. Bérard, Colonisation, p. 247-248; D. Zirone, s.v. «Sciacca», in BTCGI XVIII, 2010, p. 457-463; idem, s.v. «Terme Selinuntine», in BTCGI XX, 2011, p. 440-442.

249 Diodore, IV, 78, 3 ; $c f$. G. Bejor, «Ricerche di topografia e di archeologia romana nella Sicilia sud-occidentale», ASNP serie iii, 5, 2, 1975, p. 1294-1295, qui estime que le nom de Thermae Selinuntiae pourrait dériver d'une confusion avec le nom de la colonie de Thermae Himeraeae sur la côte nord de Sicile; Veronese, Santuari greci, p. 502-503, 534, 585-586. 
On conclura que les découvertes archéologiques et épigraphiques témoignent de l'évolution rapide des contacts entre les Grecs et les populations locales de l'arrières-pays. Il faut cependant avouer la difficulté à distinguer entre le contrôle des voies de communication et de commerce, la possession réelle de tel ou tel endroit par les Sélinontins et les initiatives privées menées par des individus attirés par les possibilités d'échanges offertes par la Sicile occidentale. Quoi qu'il en soit, la rapidité de l'expansion côtière et vers l'intérieur du pays menée par les Sélinontins aux $\mathrm{VII}^{\mathrm{e}}-\mathrm{VI}^{\mathrm{e}}$ siècles laisse penser que ceux-ci avaient acquis une connaissance des lieux bien avant la fondation de la cité vers la fin du VII ${ }^{\mathrm{e}}$ siècle. L'arrivée des colons en plusieurs étapes à Sélinonte a favorisé les contacts et les échanges avec les indigènes, tout en assurant le succès de l'entreprise grecque. D'ailleurs, cette reconstruction correspond bien au schéma des fondations mégariennes en Propontide, où l'on rencontre aussi une colonisation par étapes, cohérente et conditionnée par les relations avec les Thraces et les Bithyniens ${ }^{250}$.

\section{II.1.2.4 Les causes de la fondation de Sélinonte}

Les raisons de l'installation des Mégariens en Sicile occidentale ont fait l'objet de débats intenses parmi les savants. La croissance de la population mégarienne vers le milieu du VII ${ }^{\mathrm{e}}$ siècle et l'incapacité du territoire de Mégara à fournir le nécessaire à ses habitants ont longtemps été considérées comme les causes les plus probables de la fondation de Sélinonte ${ }^{251}$. En revanche, De Angelis estime que le territoire de Mégara était largement suffisant pour compenser la croissance démographique.

250 Voir infra, chapitre II.2.1.2.

251 P. Orsi, «Megara Hyblaea. Storia, topografia, necropoli e anathemata », MAL 1, 1890, col. 695 ; Asheri, La colon. gr., p. 113; K. H. Water, «The Rise and Decline of Some Greek Colonies in Sicily », AncSoc 5, 1974, p. 1, 7; Domínguez, Colon. Gr., p. 107, 363 ; S. Berger, «Great and Small Poleis in Sicily: Syracuse and Leontinoi », Historia 40, 1991, p. 132; S. Collin Bouffier, op. cit., p. 46; F. Villard, «Le cas de Mégara Hyblaea: est-il exemplaire?», in La colonisation grecque en Méditerranée Occidentale. Actes de la rencontre scientifique en hommage à Georges Vallet organisée par le Centre Jean-Bérard, l'École française de Rome, l'Istituto universitario orientale et l'Università degli studi di Napoli «Federico II» (Rome-Naples, 15-18 novembre 1995), Rome 1999, p. 139; M. Gras, H. Tréziny, in Mégara 5, p. 576, 588. Voir aussi Martin et al., Città greche, p. 637, qui considèrent Sélinonte comme une colonie «de peuplement» à caractère agricole. 
Selon lui, le départ des apoikoi n'a pas été provoqué par la surpopulation, mais par le désir de prendre possession de nouvelles terres et de participer à la colonisation de la Sicile ${ }^{252}$. Il ajoute à ce raisonnement le fait que la croissance démographique compte parmi les raisons de la fondation de Sélinonte non pas en tant que surpopulation (c'est-à-dire trop de gens pour peu de terre), mais comme un stimulus social. Ainsi, plusieurs individus furent attirés par les possibilités d'acquérir de ressources offertes par la nouvelle installation ${ }^{253}$. Cette opinion, qui est a priori recevable, est confrontée au caractère lacunaire de la documentation. Les fouilles ont porté surtout sur la ville et la prospection du territoire de Mégara reste limitée 254 .

Une autre hypothèse a été avancée par Parisi Presicce, qui pense que la quête de minerais par les Mégariens, exclus du trafic tyrrhénien par les Chalcidiens, a pu déterminer leur départ pour la Sicile occidentale. Selon lui, l'acquisition de ces richesses, antérieure à la fondation de Sélinonte, serait également responsable du développement urbain de Mégara vers le milieu du VII ${ }^{\mathrm{e}}$ siècle $^{255}$. Bien que cette solution ne soit pas, elle non plus, improbable, on peut difficilement en trouver une confirmation dans les sources littéraires ou archéologiques dont l'on dispose.

Ce qui est certain c'est que l'expansion mégarienne vers l'ouest coïncide avec une période florissante du développement de la ville de Mégara, lorsque, dans la deuxième moitié du VII ${ }^{\mathrm{e}}$ siècle, se réalise une véritable unité urbaine, l'expression du passage de la cité à un niveau supérieur d'intégration et d'organisation ${ }^{256}$. Même s'ils ne luttaient pas

252 De Angelis, Found. of Selinous, p. 87-110. Outre l'étude de De Angelis, pour la reconstitution du territoire de Mégara, voir aussi Bernabò Brea, Re Hyblon, p. 178186; Vallet-Voza, Augusta, p. 55-59; Gras, Tréziny, Megara Iblea, p. 258-260; Veronese, Santuari greci, p. 233-238.

253 De Angelis, Megara Hyblaia and Selinous, p. 62, écrit: «What population growth may have done is to induce social stress, creating a desire amongst certain individuals to branch out elsewhere in Sicily. I suggest that the population growth detectable at Megara Hyblaia around the mid-seventh century may have similarly played some part in creating a need for expansion, a need for certain individuals to break away and acquire new resources and spaces elsewhere».

$254 C f$. Gras, Tréziny, Megara Iblea, p. 260.

255 Parisi Presicce, Selinunte, p. 57-58.

256 Ibidem, p. 42-43; Polignac, Mégara Hyblaea, p. 227; De Angelis, Found. of Selinous, p. 101; idem, Megara Hyblaia and Selinous, p. 51-63; Veronese, Santuari greci, p. 498. 
pour leur survie, comme l'estime Berger ${ }^{257}$, les Mégariens se sont probablement rendu compte que leurs possibilités d'expansion étaient limitées par le voisinage avec Syracuse et Léontinoi et que seuls les territoires de la Sicile occidentale étaient disponibles à ce moment-là ${ }^{258}$. D'ailleurs, il existe un témoignage faisant état de conflits de frontière entre Mégara et ses voisins. Polyen nous apprend que le polémarque Panaitios s'empara de la tyrannie à Léontinoi (vers 615), dans le contexte d'une guerre au sujet des terres de confins ( $\pi \varepsilon \rho \grave{~} \gamma \tilde{\eta} \varsigma$ ö $\rho \omega v)$ qui opposa sa cité à Mégara ${ }^{259}$.

On peut aussi penser que les difficultés rencontrées par l'apoikia de Lamis quelques générations auparavant auraient fait comprendre aux Mégariens qu'ils devaient s'approprier assez vite un territoire situé à la limite du monde hellénique de Sicile. À cette époque-là, il y avait un mouvement d'expansion des Grecs en Sicile. Les auteurs antiques rapportent que vers le milieu du VII ${ }^{\mathrm{e}}$ siècle la cité d'Himère fut fondée par les Chalcidiens de Zancle et par les Mylétidai, une faction de Syracusains fugitifs ${ }^{260}$. La présence de la cité de Géla dans la partie sud-ouest de la Sicile, fondée vers 688 (ou même avant) par Antiphémos de Rhodes et Entimos de Crète ${ }^{261}$, a sans doute conduit les Mégariens à pousser plus à l'ouest ${ }^{262}$.

Au demeurant, pour la question des causes de la colonisation mégarienne en Sicile, il n'est pas sans intérêt de s'interroger sur les possibilités agricoles et commerciales du site de Sélinonte. La cité s'est dotée d'un riche territoire à l'époque archaïque, qui, on l'a vu, s'étendait le

257 S. Berger, op. cit., p. 132.

258 La Genière, Sélinonte, p. 259; De Angelis, Found. of Selinous, p. 104.

259 Polyen, V, 47; cf. Frasca, Leontinoi, p. 39-40.

260 Sur la fondation d'Himère, voir Thucydide, VI, 5, 1, et Diodore, XIII, 62, qui rapporte que la cité d'Himère est fondée 240 ans avant sa destruction en 408, soit vers 648 .

261 Thucydide, VI, 4, 3, note que la fondation de Géla eut lieu 45 ans avant celle de Syracuse, soit vers 688 . Une date plus ancienne est supposée par H. Wentker, op . cit., p. 130-131, qui traduit le terme époikoi, employé par Thucydide pour les apoikoi de Rhodes et de Crète, par colons additionnels. Contra De Wever-Van Compernolle, Colonisation, p. 503-504. Notons qu'une date de fondation plus haute est soutenue par la trouvaille à Géla de céramiques du VIII ${ }^{\mathrm{e}}$ siècle. À ce sujet, voir E. de Miro, G. Fiorentini, «Gela nell’ VIII e VII secolo a.C.», in Rizza (éd.), Insediamenti colon.

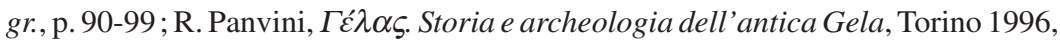
p. 24-32; M. Pizzo, «Sulla ceramica più antica di Gela e la topografia della città », in KOINA : miscellanea di studi archeologici in onore di Piero Orlandini, Milano 1999, p. $157-168$.

262 De Angelis, Found. of Selinous, p. 107, n. 18. 
long de la vallée du Belice et dont les limites côtières sont sans doute représentées à l'ouest, par Mazare, et à l'est, par Minôa. Assurément, la campagne de Sélinonte constitua une source d'importantes richesses pour ses habitants ${ }^{263}$. Les auteurs antiques témoignent de la place de la culture des céréales à Sélinonte ${ }^{264}$ et le grain d'orge et l'épi de blé figurent sur les monnaies de la cité 265 .

Quant aux activités commerciales, il est permis de supposer que la position très favorable dont bénéficiait le site pour développer de telles entreprises n'est pas passée inaperçue des Mégariens ${ }^{266}$. Il existe dans ce sens quelques éléments qui indiquent que les Sélinontins se sont impliqués dans le commerce en Sicile et en Méditerranée occidentale. En effet, un lingot d'argent, associé à des monnaies archaïques sélinontines dans un trésor de Tarente, peut constituer la preuve d'un commerce de l'argent espagnol à Sélinonte ${ }^{267}$. Ce lingot porte comme marque le carré creux qui se retrouve au revers des monnaies sélinontines ${ }^{268}$, ces dernières ayant par ailleurs été découvertes jusqu'en Espagne ${ }^{269}$. On notera par ailleurs que les trouvailles témoignent, dès les premières générations, d'une activité artisanale, ainsi que d'une production de terres cuites et d'un mobilier métallique de bonne qualité 270 .

263 M. Torelli, in Rizza (éd.), Insediamenti colon. gr., p. 70. Contra Gullini, in Rizza (éd.), Insediamenti colon. gr., p. 73, qui soutient que la vallée du Belice n'était pas sous la domination directe de Sélinonte.

264 Thucydide, VI, 20, 4; Pline, NH, XVIII, 12, 64; cf. De Angelis, Megara Hyblaia and Selinous, p. 186-187.

265 Lacroix, Monnaies et colon., p. 111; SNG Cop. Sicily, pl. 13, nº 604.

266 Veronese, Santuari greci, p. 498.

267 La Genière, Sélinonte, p. 255.

268 E. Babelon, Mélanges numismatiques, vol. 4, Paris 1912, p. 304-343, surtout p. 326, $\mathrm{n}^{\text {os }}$ 53-55 (les monnaies de Sélinonte), et p. 335-336, $\mathrm{n}^{\circ} 83$ (le lingot); $c f$. M. Thompson, O. Mørkholm, C.M. Kraay, An Inventory of Greek Coin Hoards, New York 1973, p. 274-275, nº 1874.

269 M. Thompson, O. Mørkholm, C. M. Kraay, op. cit., p. 352-353, nos 2312 (Mongó), 2314 (Tarragona); cf. L. Gallo, op. cit., p. 519.

270 M. H. Fourmont, «Un moule pour le travail du bronze à Sélinonte», in Studi sulla Sicilia Occidentale in onore di V. Tusa, Padova 1993, p. 57-60; T. Fischer-Hansen, «Ergasteria in the Western Greek Colonies», in Polis and Politics. Studies in Ancient Greek History. Presented to M. H. Hansen on his Sixtieth Birthday, August 20, 2000, P. Flensted-Jensen (éd.), Copenhagen 2000, p. 106-107; cf. M. H. Fourmont, «Recherches sur les activités artisanales d'un quartier de Sélinonte», SicArch XXIV, 7677, 1991, p. 7-41. 
Il convient de signaler aussi l'hypothèse avancée par Verger selon laquelle Sélinonte constituait le point d'arrivée d'une route maritime directe qui, dès la seconde moitié du VII ${ }^{\mathrm{e}}$ siècle (soit avant la fondation de Massalia), permettait d'acheminer sur les lieux de culte grecs de Sicile méridionale des objets métalliques du Languedoc ${ }^{271}$. Ce savant pense que les Mégariens jouaient pendant la seconde moitié du VII et la première moitié du $\mathrm{VI}^{\mathrm{e}}$ siècle un rôle très important en Méditerranée dans l'organisation du trafic d'offrandes fabriquées en Gaule (bracelets, anneaux, pendentifs, diverses pièces d'ornement, etc.). Mais les arguments invoqués par Verger, qui sont la fondation par Mégare des établissements en Sicile, dans la Propontide et dans le Pont-Euxin et la trouvaille d'objets gaulois en métal en Sicile (dans les sanctuaires de Sélinonte et de Mégara), mais aussi en Grèce même (dans l'Héraion de Pérachora), restent faibles. En effet, on ne peut guère mettre en relation directe les parures féminines originaires du nord-ouest de la Méditerranée trouvées à Pérachora avec Mégare, car ce sont les Corinthiens qui possèdent ce sanctuaire, comme l'auteur le souligne lui-même ${ }^{272}$. Pour l'instant, il est en outre bien difficile de savoir ce que fut la présence des Mégariens dans la région de Pérachora à l'époque archaïque. De plus, c'est la cité de Corinthe et non pas Mégare qui domine largement les échanges maritimes aux $\mathrm{VIII}^{\mathrm{e}}-\mathrm{VII}^{\mathrm{e}}$ siècles, en produisant et en exportant des céramiques de qualitée ${ }^{73}$. Mieux, les sources ne confirment pas que Mégare contrôle ou coordonne par l'intermédiaire de ses colonies une partie des trafics venant de la mer Noire. D'ailleurs, la Question grecque LVII de Plutarque, invoquée à l'appui de cette opinion, qui mentionne l'expédition menée par les Mégariens contre la colonie samienne de Périnthe, concerne les colons mégariens de Propontide plutôt que les Mégariens de Grèce ${ }^{274}$. Il est donc impossible de savoir

271 S. Verger, «Des objets gaulois dans les sanctuaires archaïques de Grèce, de Sicile et d'Italie», CRAI, 2003, 1, p. 545-546, 551-552; idem, «Les objets gaulois dans la Sicile méridionale grecque», in Une Odyssée gauloise. Parures de femmes à l'origine des premiers échanges entre la Grèce et la Gaule, S. Verger et L. Pernet (éds.), Arles 2013, p. 234-236.

272 Voir supra, chapitre I.1.1.

273 A. Blakeway, op. cit., p. 203 ; Coldstream, Geom. Gr.2. p. 167, 186-188; H. Tréziny, «Navires attiques et navires corinthiens à la fin du VIII ${ }^{\mathrm{e}}$ siècle. À propos d'un cratère géométrique de Mégara Hyblaea», MEFRA 92, 1980, p. 33 (avec la bibliographie).

274 Robu, Réseaux, p. 184-186; voir aussi infra, chapitre II.2.1.2. 
si les objets des Balkans trouvés à Sélinonte, à Mégara ou à Pérachora ont été transportés par les colons mégariens et non pas, par exemple, par les Corinthiens ${ }^{275}$.

À mon sens, le rôle de Sélinonte dans l'organisation du trafic sicilien d'objets produits en Gaule doit être examiné indépendamment des Mégariens de Grèce ou de la Propontide. La participation des Mégariens de Sicile au développement d'une voie maritime passant par la côte méridionale de la Sicile peut être mise en évidence par les vases étrusques qui arrivent à Sélinonte et à Mégara à partir de la deuxième moitié du $\mathrm{VII}^{\mathrm{e}}$ siècle $^{276}$. L'importation de bucchero étrusque est attestée dans toute la Sicile, mais les trois sites qui ont fourni la plus grande quantité de ce type de céramique sont les cités de Sélinonte, de Mégara et de Syracuse $^{277}$. Dunbabin pensait naguère que ces vases étaient arrivés à Sélinonte par le biais des Carthaginois ${ }^{278}$. Et selon Tusa Cutroni, l'absence de monnaies de Sélinonte en Étrurie refléterait l'absence d'échanges commerciaux directs des Sélinontins avec cette région ${ }^{279}$. Cependant,

275 Il convient de rappeler que la documentation qui atteste l'existence des relations commerciales entre les cités doriennes du golfe Saronique et les colonies grecques de la mer Noire à l'époque archaïque est assez maigre. Pour les céramiques corinthiennes d'époque archaïque provenant de la mer Noire, voir S. Boriskovskaja, «On Trade Connections between the Greek Cities of the Northern Black Sea Coast and Corinth in the Archaic Period», WissZRostock 16, 7-8, 1967, p. 425-429; P. Dupont, «Amphores archaïques de Grèce propre en mer Noire. État de la question », Il Mar Nero 2, 1995-1996 (1996), p. 85-98; idem, «Note d'épigraphie amphorique. Addendum à Il Mar Nero II (1995-96), 85-98», in Civilisation grecque et cultures antiques périphériques. Hommage à Petre Alexandrescu à son $70^{e}$ anniversaire, A. Avram et M. Babeş (éds.), Bucarest 2000, p. 205-209.

276 Pour le rôle des Mégariens dans l'organisation de la route maritime passant par la côte méridionale de la Sicile, voir Pugliese Carratelli, Selinunte, p. 20; P. Anello, op. cit., p. 106-107; L. Gallo, op. cit., p. 517-519.

277 K. M. T. Atkinson, op. cit., p. 116-119; M. Gras, Trafics tyrrhéniens archä̈ques, Rome 1985, p. 490-491; Rallo, Considerazioni, p. 537-549, notamment p. 542-546, avec la bibliographie concernant la présence de buccheros à Sélinonte. Pour les canthares étrusques découverts dans le sanctuaire de la Malophoros, voir aussi Dehlvon Kaenel, Keramik aus Malophoros, p. 396-399.

278 Dunbabin, Western Greeks, p. 253. En dernier lieu, voir Rallo, Considerazioni, p. 546, qui note: «È possibile che Selinunte avesse la funzione di centro di smistamento delle merci greche verso Mozia e il mondo punico, e che alcuni dei materiali etruschi ivi presenti facessero parte del carico di ritorno del circuito commerciale fenicio».

279 A. Tusa Cutroni, «La presenza del bucchero a Selinunte: suo significato », Kokalos 12, 1966, p. 247. 
une defixio judiciaire, datant du premier quart du $\mathrm{V}^{\mathrm{e}}$ siècle, mentionne

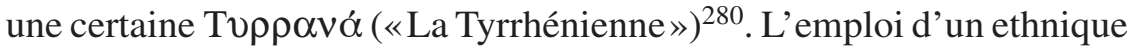
régional comme anthroponyme suggère que les parents de cette femme étaient en relations d'hospitalité ou de commerce avec les Étrusques ${ }^{281}$. En outre, Masson a identifié parmi les anthroponymes attestés par la «grande defixio» de Sélinonte un groupe de noms d'aspect «italique»

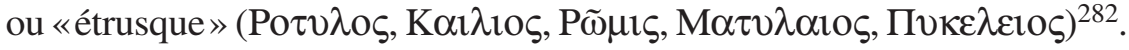
On connaît aujourd'hui les stèles funéraires d'une $\Lambda \varepsilon v \kappa \alpha v \alpha ́$ («La Lucanienne», vers 600) ${ }^{283}$ et d'un certain Latinos de Rhégion (ca. 550$500)$, à condition que cette dernière inscription ne soit pas un faux ${ }^{284}$. Des bronzes de production ou de provenance étrusque (bassins à rebord perlé, chaudrons) ont été découverts dans les cités mégariennes de Sicile, et l'on connaît des graffiti étrusques sur deux canthares trouvés à Sélinonte ${ }^{285}$. Ces attestations sont en mesure de témoigner des contacts directs établis entre Sélinonte et l'Étrurie. L'arrivée d'importations étrusques à Mégara dès 650 jusqu'au début du $\mathrm{VI}^{\mathrm{e}}$ siècle serait ainsi une conséquence de ces rapports ${ }^{286}$. La cité de Sélinonte constituait

280 IGDS, 37; IGASM I², 61; Bettarini, Defixiones, n ${ }^{\circ} 20$; $c f$. Jeffery, $L S A G^{2}$, p. 271, $277, \mathrm{n}^{\circ} 38$ a.

$281 C f$. L. Dubois, IGDS II, ad n ${ }^{\circ} 24$, p. 71.

282 IGDS, 38; IGASM I ${ }^{2}$, 63; Bettarini, Defixiones, $\mathrm{n}^{\circ}$ 23, avec les commentaires de Masson, L'imprécation de Sélinonte, p. 386-388. Notons que selon Bettarini,

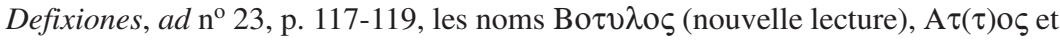
$\Sigma \alpha \rho ı \varsigma$, attestés par cette defixio de Sélinonte, auraient aussi une origine italique. Pour la présence de non-Grecs à Sélinonte, on renverra à la mise au point d'AntonettiDe Vido, Cittadini, p. 410-451, surtout p. 421.

283 IGDS II, 20; cf. L. Dubois, Bull. ép., 1993, 714.

284 L'épitaphe de Latinos IGDS II, 24 est conservée au musée Paul Getty de Malibu. Elle serait de provenance sélinontine, en raison de la nature de la pierre et de l'acheminement vers le musée de Malibu d'autres pièces issues des fouilles clandestines de Sélinonte (telles que la célèbre lex sacra). Pour G. Manganaro, in «L'epigrafia greca di Sicilia», in Sicilia Epigraphica. Atti del convegno (Erice, 15-18 Ottobre 1998), ASNP serie iv, Quaderni 2, M.I. Gulletta (éd.), Pisa 1999, p. 420, ce texte serait un faux.

285 M. Gras, op. cit., p. 498 (graffiti étrusques), p. 500-512 (bronzes d'origine étrusque), p. 525-526 (onomastique étrusque); De Angelis, Megara Hyblaia and Selinous, p. 191.

286 Pour le matériel étrusque à Mégara, voir F. Villard, G. Vallet, «Mégara Hyblaea III : les fouilles de 1951 », MEFR 65, 1953, p. 35-36; Mégara 2, p. 131-132; Boardman, Gr. Overseas ${ }^{3}$, p. 176; M. Gras, op. cit., p. 488-512, 526-529. En dernier lieu, 
probablement un point important sur une route commerciale qui partait d'Étrurie et qui, traversant les centres phéniciens de Sicile, menait ensuite vers les cités grecques de la Sicile méridionale ainsi que vers les sites de la vallée du Belice.

On remarque de même que Sélinonte joue un rôle dans le développement d'un commerce direct avec la Grèce. Ce rôle est mis en évidence par la trouvaille aux abords de Sélinonte d'un trésor datant de la fin du $\mathrm{VI}^{\mathrm{e}}$ siècle, composé de 4 fragments de lingots d'argent non monnayés et de 165 monnaies d'argent. En ce qui concerne l'origine de ces pièces, 81 viennent d'Égine, 39 de Corinthe, 35 de Sélinonte, 5 de Sybaris, 2 de Métaponte, 1 d'Himère, 1 de Poseidonie, 1 d'Abdère. On voit que ce ne sont pas les monnaies locales qui dominent mais celles de Grèce; les monnaies d'Égine et de Corinthe représentent presque les trois quarts des pièces (120 monnaies), ce qui supposerait des échanges entre Sélinonte et ces cités de la Grèce ${ }^{287}$.

Pour ce qui est des relations commerciales des Sélinontins avec les trois cités phéniciennes de Sicile (Motyè, Panormos et Solonte), on constate que le bilan des trouvailles est plutôt modeste. La découverte de céramiques protocorinthiennes dans la nécropole archaïque de Motyè suggère que les Phéniciens auraient pu établir des contacts avec les Grecs dès la fin du VIII ${ }^{\mathrm{e}}$ siècle ou le début du VII ${ }^{\mathrm{e}}$ siècle $^{288}$. Des vases puniques utilisés comme urnes apparaissent au $\mathrm{VI}^{\mathrm{e}}$ siècle dans les né-

M. Gras, H. Tréziny, in Mégara 5, p. 572, pensent que les vases étrusques découverts dans le sanctuaire nord-ouest, dans les tombes et dans les maisons «rendent également plausible la présence d'Étrusques à Mégara Hyblaea».

287 C. Arnold-Biucchi, L. Beer Tobey, N. M. Waggoner, «A Greek Archaic Silver Hoard from Selinus », ANSMN 33, 1988, p. 1-35; A. Tusa Cutroni, «Recenti studi e ricerche sulla monetazione della Sicilia antica», Kokalos 34, 1988-1989, p. 397-398; R. Descat, op. cit., p. 11-12; P. Anello, op. cit., p. 107-108.

288 V. Tusa, «La necropoli arcaica e adiacenze. I. Relazione preliminare degli scavi eseguiti a Mozzi negli anni 1972, 1973, $1974 »$, in Mozia IX, Roma 1972, p. 7-98; idem, «Materiali greci dell'VIII e del VII secolo a. C. nella Sicilia Occidentale», in Rizza (éd.), Insediamenti colon. gr., p. 47-48. Pour les contacts entre les Grecs et les Puniques dans la Sicile occidentale, voir aussi Tusa, Greci e punici, p. 19-28; S. Moscati, «Fenici e Greci in Sicilia: alle origini di un confronto », Kokalos 30-31, 1984-1985, p. 1-19; G. Pugliese Carratelli, «Storia civile», in SIKANIE. Storia e civiltà della Sicilia antica, G. Pugliese Carratelli (éd.), Milano 1986, p. 14; E. Manni,

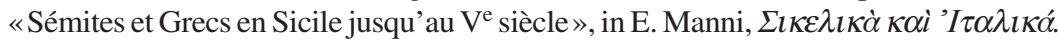
Scritti minori di storia antica della Sicilia e dell'Italia meridionale, Roma 1990, p. 151-174, notamment p. 173. 
cropoles de Gaggera et de Timpone Nero ${ }^{289}$. Bien plus tard, la «grande defixio » de Sélinonte, datant du $\mathrm{V}^{\mathrm{e}}$ siècle, cite le nom sémitique Mó $\gamma \omega v$, ainsi que $\Phi$ Ф̃vı $\xi$, ethnique employé dans ce document à trois reprises comme anthroponyme ${ }^{290}$. Dans un milieu punique, à Motyè, trois épitaphes fragmentaires, datées des $\mathrm{VI}^{\mathrm{e}}-\mathrm{V}^{\mathrm{e}}$ siècles, sont écrites en alphabet sélinontin ${ }^{291}$. Faute d'une documentation littéraire et épigraphique plus détaillée, les circonstances dans lesquelles les contacts et les échanges entre les Sélinontins et les Phéniciens se sont déroulés demeurent inconnues. Dans l'attente de nouvelles trouvailles, on doit néanmoins éviter de regarder la cité de Sélinonte comme un avant-poste des Grecs de Sicile contre l'expansion punique ${ }^{292}$. L'appui offert par les Sélinontins aux Carthaginois lors de la bataille d'Himère (en 480, voir ci-après) et l'exil de Giscon, le père d'Hannibal, à Sélinonte constituent des preuves du fait que les relations entre les deux peuples ne furent pas toujours belliqueuses ${ }^{293}$.

Du reste, la découverte de vases sélinontins à Ségeste montre que les Grecs ont développé dès leur arrivée en Sicile occidentale des relations commerciales avec les Élymes, peuple auquel les Anciens attribuaient une origine italiote ou troyenne ${ }^{294}$. En dépit de ses conflits avec

289 A. Kustermann Graff, «DANIMS 16. Necropoli di Selinunte (necropoli Manicalunga, gruppo di tombe Gaggera)», ASNP serie iii, 21, 1, 1991, p. 109; D. Leibundgut Wieland, «DANIMS 25. Necropoli di Manicalunga. Tombe della contrada Timpone Nero (Selinunte)», ASNP serie iii, 25, 1, 1995, p. 200, 217; De Angelis, Megara Hyblaia and Selinous, p. 191.

290 IGDS, 38; IGASM I², 63; Bettarini, Defixiones, $\mathrm{n}^{\circ} 23$; $f f$. R. de Simone, « Riflessioni sull'onomastica punica», in Sicilia Epigraphica. Atti del convegno (Erice, 15-18 Ottobre 1998), ASNP serie iv, Quaderni 1, M.I. Gulletta (éd.), Pisa 1999, p. 211. Pour une analyse onomastique des noms mentionnés par cette defixio, voir Masson, L'imprécation de Sélinonte, p. 375-388.

291 Jeffery, $L S A G^{2}$, p. 272, 277, $\mathrm{n}^{\circ} 45 ; I_{\text {IGASM }}^{2}, 72$.

292 Di Vita, Selinunte, p. 10; idem, Siracusa, Camarina, Selinunte, p. 374-379; Parisi Presicce, Selinunte, p. 46-47; E. Østby, op. cit., p. 83-84; cf. S. Calderone, «Problemi storici relative alle <Apoikiai > siceliote in età protoarcaica », in Rizza (éd.), Insediamenti colon. gr., p. 12

293 Diodore, XIII, 43, 5 ; cf. L. M. Hans, op. cit., p. 40-41.

294 La Genière, Sélinonte, p. 251-264; eadem, «Ségeste et l'hellénisme », MEFRA 90, 1978, p. 33-49; eadem, «Una divinità femminile sull' acropoli di Segesta ?», Kokalos 32-33, 1976-1977, p. 685; cf. A. J. Graham, «The Western Greeks », in Cambridge Ancient History ${ }^{2}$, III, 3, J. Boardman et N. G. L. Hammond (éds.), Cambridge 1982, p. 167-168. Sur l'origine des Élymes, on verra De Vido, Gli Elimi, p. 1-114. 
les Grecs, Ségeste connaît une hellénisation progressive à partir du VII ${ }^{\mathrm{e}}$ siècle jusqu'à l'époque classique ${ }^{295}$. On a suggéré que des architectes sélinontins prirent part au $\mathrm{VI}^{\mathrm{e}}$ siècle aux travaux des temples de Ségeste $^{296}$; et le célèbre temple bâti dans le dernier quart du $\mathrm{V}^{\mathrm{e}}$ siècle est l'un des meilleurs exemples d'architecture dorique de l'île ${ }^{297}$. On sait aussi que l'alphabet de Sélinonte fut utilisé dans l'aire élyme: le bêta sélinontin, à la forme d'un $n u$ renversé (И), apparaît dans les graffites de la fin du $\mathrm{VI}^{\mathrm{e}}$ siècle ou du début du $\mathrm{V}^{\mathrm{e}}$ siècle, mis au jour à Ségeste ${ }^{298}$. De même, comme Dubois l'a noté, l'epsilon en forme de bêta panhellénique, qui figure dans les légendes monétaires des cités d'Éryx et de

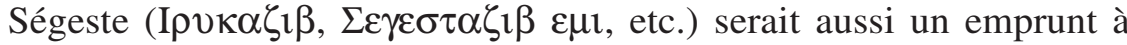
l'alphabet mégarien hérité de Sélinonte ${ }^{299}$. Il en témoigne l'attestation récente de ce signe à Sélinonte par la stèle d'Euphronès ${ }^{300}$. On signale

295 Pour l'évolution des rapports entre les Élymes et les Grecs de Sicile aux époques archaïque et classique, voir De Vido, Gli Elimi, p. 115-298; S. N. Consolo Langher, «Gli Elimi tra Greci e Cartaginesi nella storia della Sicilia occidentale e nei trattati interstatali tra VI e IV sec. a.C.», in Guerra e pace in Sicilia e nel Mediterraneo antico (VIII-III sec. a. C.). Arte, prassi e teoria della pace e della guerra, vol. I, Pisa 2006, p. 191-212 (avec les références).

296 Fischer-Hansen, Nielsen, Ampolo, Selinous, p. 221. Voir V. Tusa, «Il santuario arcaico di Segesta», in Atti del settimo congresso internazionale di archeologia classica, vol. 2, Roma 1961, p. 31-40, sur la découverte à Ségeste d'un temple du début du $\mathrm{VI}^{\mathrm{e}}$ siècle.

297 D. Mertens, Der Tempel von Segesta und die dorische Tempelbaukunst des griechischen Westen in klassischer Zeit, Mainz am Rhein 1984, p. 203-205 ; Domínguez, Colon. Gr., p. 392-396.

298 L. Agostiniani, Iscrizioni anelleniche di Sicilia. Le iscrizioni elime, Firenze 1977, $\mathrm{n}^{\text {os }} 222,277,281,289,317$. Sur le rôle de Sélinonte dans l'introduction de l'alphabet grec dans l'aire élyme, voir L. Agostiniani, «La lingua degli Elimi. Per uno stato della questione», in Gli Elimi e l'area elima fino all'inizio della prima guerra punica. Atti del seminario di studi (Palermo-Contessa Entellina, 25-28 maggio 1989), G. Nenci et al. (éds.), Palermo 1990, p. 353-354; idem, «L'epigrafia elima», in Sicilia Epigraphica. Atti del convegno (Erice, 15-18 Ottobre 1998), ASNP serie iv, Quaderni 1, M.I. Gulletta (éd.), Pisa 1999, p. 1-13; idem, «Alfabetizzazione della Sicilia pregreca», Aristonothos 4, 2012, p. 140-141; M. T. Manni Piraino, «L'apporto dell'epigrafia», Kokalos 30-31, 1984-1985, p. 94; S. Marchesini, «Il segno И in Elimo: una nuova proposta», ASNP serie iv, 3, 1-2, 1998, p. 289-299; Dubois, Des Grecs aux Élymes, p. 107-111.

299 Dubois, Des Grecs aux Élymes, p. 108-111.

300 IGDS II, 21. Voir aussi infra, chapitre II.1.2.5. 
aussi la trouvaille d'une inscription gravée boustrophédon en alphabet sélinontin à Entella ${ }^{301}$.

Les transferts entre les Sélinontins et les Élymes concernent également le domaine du religieux, preuve en étant le culte des Euménides. Les décrets d'Entella citent le mois Euménideios ${ }^{302}$ et la loi sacrée de Sélinonte évoque les Euménides et un Zeus Euménès ${ }^{303}$. De plus, Nenci a souligné les parallèles qui existent entre l'onomastique de Sélinonte

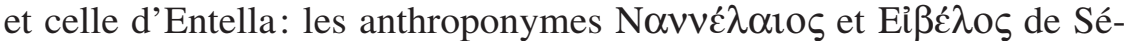

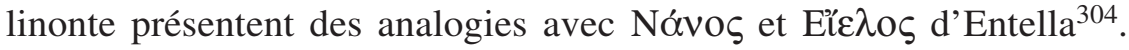
La colonie mégarienne exerce également une influence sur l'émission des monnaies de Ségeste, qui, après avoir été en usage pendant tout le $\mathrm{V}^{\mathrm{e}}$ siècle, disparaissent brusquement dans la dernière décennie du même siècle ou au début du $\mathrm{IV}^{\mathrm{e}}$ siècle, peu après la destruction de Sélinonte et d'Himère par les Carthaginois ${ }^{305}$. Enfin, il ne faut pas oublier que, selon Thucydide, les rapports de Ségeste avec Sélinonte avaient même permis un accord d'intermariage (épigamia) ${ }^{306}$.

En conclusion, s'il reste difficile, dans l'examen des raisons de la colonisation, de se fier à une documentation postérieure d'une ou plusieurs générations aux premières vagues de colons, force est de constater que les Sélinontins réussirent à se constituer un réseau d'alliances, qui dépassa la barrière ethnique, et surent tirer profit des avantages de leur position aux confins du monde grec de Sicile. Assurément, les relations entre les

301 G. Nenci, in M. G. Canzanella et al., «Entella. Relazione preliminare della campagna di scavo $1988 », A S N P$ serie iii, 20, 1, 1990, p. 548, n 2, estime que l'inscription peut mentionner des Sélinontins refugiés à Entella. Mais le caractère fragmentaire de ce texte (seul indice les lettres $\varphi \varepsilon v-$ ) empêche d'avoir une confirmation de cette hypothèse. $C f$. SEG XL, 786; F. Spatafora, «L'alta e media Valle del Belice tra la Media Età del Bronzo e l'età arcaica », Kokalos 42,1996, p. 198; Brugnone, Note epigrafiche, p. 52.

302 IGDS, 204, 205, 207.

303 Jameson, Jordan, Kotansky, Lex sacra, p. 14, colonne A, 1. 8 (Zeus Eủ

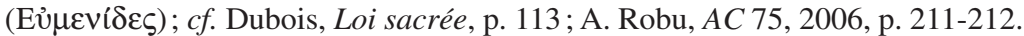

304 G. Nenci, ASNP serie iii, 25, 3, 1995, p. 1330-1331; idem, «Novità epigrafiche dall'area elima», in Seconde giornate internazionali di studi sull'area elima (Gibelina, 22-26 ottobre 1994). Atti, vol. III, Pisa-Gebellina 1997, p. 1187-1188. Cf. Bettarini, Defixiones, p. 118, 120-121.

305 A. Tusa Cutroni, «Riflessioni sulla monetazione di Segesta ed Erice», in AПAPХAI. Nuove ricerche e studi sulla Magna Grecia e la Sicilia antica in onore di Paolo Enrico Arias, vol. I, M.L. Gualandi et al. (éds.), Pisa 1982, p. 240.

306 Thucydide, VI, 6, 2. 
Grecs, les Puniques et les Élymes furent plus pacifiques que l'on peut le supposer sur la foi des sources textuelles. Les échanges culturels dont il a été question ci-dessus découlent en bonne partie des rapports de commerce, d'hospitalité et d'intermariage qui unissaient les habitants des cités siciliotes. On n'aurait pas tort par conséquent de considérer que la fondation de Sélinonte résulta d'une conjonction de facteurs fonciers et commerciaux, les possibilités agricoles et commerciales des terres de la Sicile occidentale comptant parmi les causes du départ des Mégariens.

\section{II.1.2.5 Les rapports de Sélinonte avec Mégara de Sicile et Mégare de Grèce}

Thucydide rapporte, on l'a vu, que l'apoikia installée par les Mégariens Hybléens à Sélinonte était placée sous la conduite de Pammilos de Mégare. Cet acte de fondation représente la preuve de la persistance des rapports entre Mégara et sa métropole ${ }^{307}$. L'archéologie corrobore les sources littéraires: on a trouvé à Sélinonte des grands stamnoi produits à Mégara Hyblaea et appartenant à la deuxième phase de la céramique polychrome (ca.660-640). On a là un indice de l'existence des exportations céramiques depuis la cité-mère siciliote vers sa colonie, et cela dès l'époque de la première génération des colons ${ }^{308}$.

Du reste, il est vraisemblable que d'autres Mégariens de Grèce ont accompagné l'œciste Pammilos en Sicile occidentale ${ }^{309}$. Ceux-ci ont contribué au développement des liens étroits qui existent entre Sélinonte et Mégare, visibles notamment dans l'alphabet des deux cités. Il existe à Sélinonte des signes typiquement mégariens, qui au moins pour l'instant ne se retrouvent pas à Mégara Hyblaea. Le bêta de forme $И$, présent dans deux inscriptions officielles de Sélinonte ${ }^{310}$, dans une épitaphe ${ }^{311}$

307 Finley, Anc. Sicily, p. 22, 31; Dewailly, Statuettes, p. 1.

308 Rallo, Ceramiche di Manuzza, p. 203-218; M. Denoyelle, M. Iozzo, op. cit., p. 58-63.

309 La Genière, Sélinonte, p. 257; Asheri, La colon. gr., p. 129-130.

310 Cette forme rarissime de bêta apparaît dans deux inscriptions célèbres de Sélinonte: la loi sacrée (Jameson, Jordan, Kotansky, Lex sacra, p. 14, colonne A, 1. 14 et p. 16, colonne B, 1. 10) et l'inscription du temple $\mathrm{G}\left(I G A S M \mathrm{I}^{2}, 53,1.2\right)$.

311 A. Brugnone, «A proposito di un'epigrafe sepolcrale da Selinunte», MEFRA 120, 2008, p. 21-28, surtout p. 22 ; cf. SEG LVII, 889. Pour les différences entre les caractères de l'alphabet de Mégare, de Mégara et de Sélinonte, voir Guarducci, Epigrafia gr., I, p. 317-321. 
et peut-être aussi dans deux defixiones ${ }^{312}$, est un signe archaïque de l'alphabet mégarien ${ }^{313}$. De fait, ce bêta sélinontin, tout comme celui qui apparaît sur les monnaies de Byzance, dérive du bêta de forme $\sqrt{ }$ attesté dans un obituaire de Mégare ${ }^{314}$. Mieux encore, une inscription funéraire de Sélinonte transmet le nom Eủ $\varphi \rho o ́ v \bar{\varepsilon} \varsigma$, écrit avec un epsilon à la forme de bêta pangrec et un rho à la forme d'un triangle renversé. Or il s'agit là aussi de deux signes typiques de l'alphabet mégarien ${ }^{315}$. On rappelle que les mêmes caractères sont utilisés pour inscrire le même nom (un certain Ev̉ $\varphi \rho o ́ v \bar{\varepsilon} \varsigma$, fils de ${ }^{~} P i ́ v \omega v$ ) sur une tablette funéraire de Mégare datant du $\mathrm{V}^{\mathrm{e}}$ siècle $\mathrm{e}^{316}$.

Pour la question des rapports entre métropole et colonies, il faut s'arrêter sur une inscription très fragmentaire découverte à Olympie et datée, sur la foi des critères paléographiques, de la fin du $\mathrm{VI}^{\mathrm{e}}$ siècle ou du début $\mathrm{du} \mathrm{V}^{\mathrm{e}}$ siècle $\mathrm{e}^{317}$. Gravé sur une plaque de bronze, ce texte fait mention de Sélinonte, des Mégariens (considérés par la plupart des commentateurs comme originaires de Mégara de Sicile plutôt que de Mégare de Grèce), des groupes de bannis (pheugontes) et de leurs biens (chrémata). Il fut d'abord interprété comme un décret de Mégara portant sur la réintégration des exilés qui avaient cherché refuge à Sélinonte $^{318}$. En revanche, Asheri estime qu'il s'agissait plutôt d'un accord entre la cité de Sélinonte et un groupe de Sélinontins réfugiés à

312 IGASM I², 67 (= IGDS, 33; Bettarini, Defixiones, $\mathrm{n}^{\circ}$ 22). Selon Bettarini, Defixio$n e s, a d \mathrm{n}^{\circ} 23$, p. 114, ce type de bêta apparaît aussi dans la «grande defixio » de

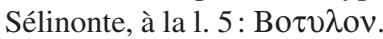

313 M. Guarducci, «Gli alfabeti della Sicilia arcaica», Kokalos 10-11, 1964-1965, p. 471-472; eadem, Epigrafia gr., I, p. 307-310; eadem, «Epigrafi arcaiche di Siracusa e di Megara Iblea», ArchClass 38-40, 1986-1988, p. 3-4; L. Dubois, «La nouvelle loi sacrée de Sélinonte. Bilan dialectologique», AION(ling) 19, 1997, p. 336; idem, Des Grecs aux Élymes, p. 108-109. Cf. Jeffery, $L S A G^{2}$, p. 262, 269; Brugnone, Alfabeti arcaici, p. 1309-1311.

314 Pour l'attestation de ces types de bêta à Byzance et à Mégare, voir infra, chapitres II.2.4.1.5 et III.1.1.1.

315 IGASM I², 81; IGDS II, 21.

316 M. Guarducci, «Note di epigrafia sepolcrale», $R A L$ 25, 1970, p. 389; $c f$. Jeffery, $L S A G^{2}$, p. 136, n. $5,138, \mathrm{n}^{\circ} 9$.

317 IvO, 22; IGDS, 28; IGASM I², 52.

318 Dunbabin, Western Greeks, p. 417; Bérard, Colonisation, p. 245 ; Graham, Colony, p. 112-113; G. Manganaro, «Ricerche di antichità e di epigrafia siceliota», ArchClass 17, 2, 1965, p. 196-197; Martin, Histoire de Sélinonte, p. 56; Mégara 1, p. 422-423. 
Mégara $^{319}$. Malheureusement, les éléments nous manquent pour trancher de manière définitive entre les différentes interprétations proposées $^{320}$. On se bornera à souligner que le document confirme le maintien des relations entre les cités mégariennes, et nous fait voir les luttes qui opposaient les différentes factions politiques au sein des poleis à l'époque archaïque ${ }^{321}$. Il est intéressant de remarquer que le texte évoque plusieurs vagues d'exilés et seule une partie d'entre eux est visée par la convention ${ }^{322}$. Le document fournit aussi la plus ancienne mention d'aisimnatai, une ancienne archè d'origine mégarienne. Ces magistrats semblent jouer un certain rôle dans le règlement de l'affaire, ayant probablement des pouvoirs de sanction ou juridiques ${ }^{323}$. Pour garantir le respect de l'accord, les Sélinontins envoyèrent une copie de l'inscription afin qu'elle fût exposée dans le sanctuaire de Zeus d'Olympie: c'est le texte qui nous est parvenu.

Par ailleurs, un événement révélateur des liens entre les Sélinontins et les Mégariens de Grèce pourrait être l'exil du tyran d'Agrigente, Thrasydée, à Mégare (après 472/1). Diodore rapporte que les Mégariens, profitant de l'arrivée de l'Agrigentin dans leur cité, le condamnèrent à mort et l'exécutèrent ${ }^{324}$. Il est fort probable que cette décision inattendue des Mégariens réponde à l'occupation au début du $\mathrm{V}^{\mathrm{e}}$ siècle de Minôa, une installation sélinontine, par Agrigente (voir ci-dessus). D'ailleurs, il n'est pas exclu que le père de Thrasydée, le tyran Théron (488/7-472/1),

319 D. Asheri, «Rimpatrio di esuli a Selinunte», ASNP serie iii, 9, 2, 1977, p. 479-497, suivi par R. Arena, IGASM I ${ }^{2}, a d \mathrm{n}^{0}$ 50, p. 50, 52; S. Berger, Revolution and Society in Greek Sicily and Southern Italy, Historia Einzelschriften 71, Stuttgart 1992, p. 31 ; Van Effenterre-Ruzé, NOMIMA, vol. I, p. 80; De Angelis, Megara Hyblaia and Selinous, p. 160-161; M. Gras, H. Tréziny, in Mégara 5, p. 576, n. 220.

320 L. Dubois, IGDS, ad n ${ }^{\circ}$ 28, p. 34; Fischer-Hansen, Nielsen, Ampolo, Selinous, p. 220-221.

321 Cf. H.-J. Gehrke, Stasis. Untersuchungen zu den inneren Kriegen in den griechischen Staaten des 5. und 4. Jahrhunderts v. Chr., München 1985, p. 216-236.

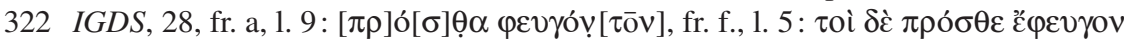

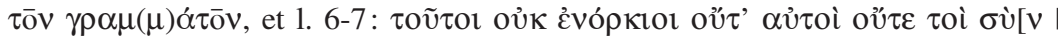

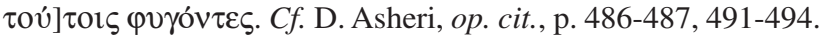

323 D. Asheri, op. cit., p. 490. Sur les $\alpha i \sigma u \mu \nu \tilde{\alpha} \tau \alpha$ à Mégare et dans ses colonies, voir infra, chapitre III.2.2.1.

324 Diodore, XI, 53, 5. 
ait joué un rôle dans la prise de cette colonie ${ }^{325}$. Il ne faut pas oublier que Sélinonte est la seule cité grecque de Sicile alliée des Carthaginois lors de la bataille d'Himère (480) contre les troupes de Théron d'Agrigente et de Gélon de Syracuse ${ }^{326}$. Il est permis de supposer qu'en raison de leurs conflits avec les Agrigentins et pour venger l'occupation de Minôa, les Sélinontins ont persuadé leurs syngéneis de Grèce d'exécuter Thrasydée ${ }^{327}$.

De même, on trouve chez Thucydide une allusion aux rapports de parenté unissant les Mégariens de Grèce et les Sélinontins: l'historien évoque le «malheur» qui frappa les exilés de Mégare, alliés des Athéniens au moment de l'expédition en Sicile en 415, lorsqu'ils durent combattre d'autres Mégariens, les Sélinontins ${ }^{328}$.

$\mathrm{Au}$ demeurant, sur la foi des inscriptions, on a supposé la présence de colons non mégariens à Sélinonte dans les premières années de vie de la cité. Un iota brisé en forme de sigma à quatre branches apparaît dans l'épitaphe d'Eukritos, datée de la deuxième moitié du VII siècle $^{329}$,

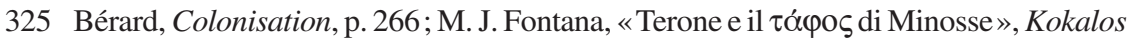
24, 1978, p. 201-219; R. Descat, op. cit., p. 10; Fischer-Hansen, Nielsen, Ampolo, Selinous, p. 224. Pour les tyrannies de Théron et de Thrasydée à Agrigente, voir Dunbabin, Western Greeks, p. 412-414; J. A. de Waele, op. cit., p. 109-115 ; S. Berger, op. cit., p. 17; D. Asheri, «Agrigento libera: rivolgimenti interni e problemi costituzionali, ca. 471-446», in Agrigento e la Sicilia greca. Atti della settimana di studio (Agrigento, 2-8 maggio 1988), L. Bracessi et E. de Miro (éds.), Roma 1992, p. 95-111, surtout p. 96-97; N. Luraghi, Tirannidi arcaiche in Sicilia e Magna Grecia da Panezio di Leontini alla caduta dei Dinomenidi, Firenze 1994, p. 41, 231-272, qui écrit: «Le ragioni dell'uccisione di Trasideo a Megara (Diod. 11, 53, 5) sono piuttosto enigmatiche» (p. 262, n. 151).

326 Diodore, XI, 21, 4-5; XIII, 55, 1; cf. L.-M. Hans, op. cit., p. 40.

327 O. Curty, Les parentés légendaires entre cités grecques. Catalogue raisonné des

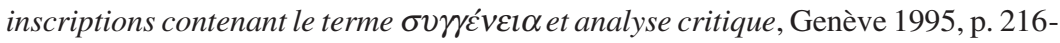
217, note que pour avoir droit au titre de syngénès d'une cité, il faut «le plus souvent que les fondateurs de chaque cité soient parents. Une fois ce lien originel établi, la parenté peut être reconnue ainsi que les obligations morales qu'elle implique». À mon sens, ces obligations morales pourraient bien expliquer la condamnation de Thrasydée par les Mégariens.

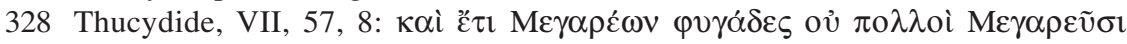

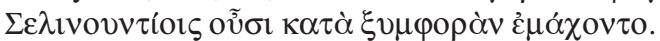

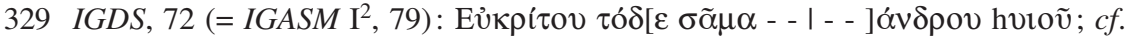
C. Gallavotti, op. cit., p. 90-93, note que le géntif en -ov (au lieu de ō) est attésté à Corcyre plutôt qu'à Corinthe. Cela prouverait, d'après Gallavotti, que l'épitaphe d'Eukritos est celle d'un Corcyréen. Cf. Brugnone, Alfabeti arcaici, p. 1309; eadem, Note epigrafiche, p. 47. 
et dans une inscription incisée sur un alabastron corinthien de la fin du $\mathrm{VII}^{\mathrm{e}}$ siècle $^{330}$. Or cette lettre est caractéristique de l'alphabet corinthien et elle n'est pas documentée ailleurs dans le monde mégarien. Mais on ne saurait dire si la présence de cet élément corinthien à Sélinonte doit être mise en relation avec des ressortissants de Corinthe ou plutôt avec ceux des apoikiai corinthiennes ${ }^{331}$. Dans ce cadre, quelques parallèles entre le panthéon de Sélinonte et celui de Corinthe méritent également d'être signalés. La fête des Kotyttia, qui apparaît vers le milieu du $\mathrm{V}^{\mathrm{e}}$ siècle dans la lex sacra ${ }^{332}$, renvoie à $\operatorname{Kotyt}(\mathrm{t}) \hat{\mathrm{o}}$, une divinité honorée à Corinthe ${ }^{333}$. On ajoutera que l'attestation des noms théophores Kotytis à Callatis et Kotytiôn à Callatis et à Chersonèse Taurique laisse penser que la fête des Kotyttia existait aussi dans ces colonies de la mer Noire ${ }^{334}$. Kotyt(t)ô semble être à l'origine une divinité thrace, car, à en croire Strabon, ce sont les Thraces qui célèbrent les Kotyteia et les Bendideia ${ }^{335}$. Si tel fut le cas, il n'est pas exclu que ce soit depuis les colonies pontiques

$330 I G D S, 79 ; I G A S M \mathrm{I}^{2}, 80$. D'aucuns estiment que cette inscription a pu être originellement inscrite à Corinthe: L. Agostiniani, «I modi del contatto linguistico tra Greci e indigeni nella Sicilia antica», Kokalos 34-35, 1988-89, p. 183, n. 135 ; Brugnone, Note epigrafiche, p. 49.

331 La Genière, Sélinonte, p. 257; M. Guarducci, «Note di epigrafia selinuntina arcaica», Kokalos 12, 1966, p. 182-183; Brugnonte, Note epigrafiche, p. 54, écrit : «In assenza di qualsiasi riferimento nelle fonti letterarie a fatti specifici, è impossibile stabilire se l'uso di segni corinzi sia riconducibile a presenze occasionali o alla participazione di gruppi provenienti dall'area di colonizzazione corinzia all'apoikia dei Megaresi Iblei ».

332 Jameson, Jordan, Kotansky, Lex sacra, p. 14, colonne A, 1. 7, avec les commentaires des éditeurs aux p. 23-26.

333 Eupolis, Baptai, fr. 93 (éds. R. Kassel et C. Austin), cité par Hésychios, Lexicon, s.v. Ko $\tau \tau \tau \omega \dot{~(e ́ d . ~ K . ~ L a t t e) . ~}$

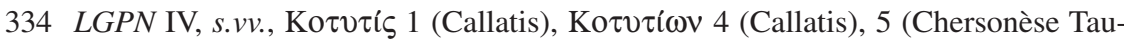
rique); $c f$. V. F. Stolba, «Quelques noms dans les inscriptions sur des céramiques de Chersonèse», Archeologičeski Vesti 2, 1993, p. 107-112 (en russe); M. Dana, «Lettres grecques dialectales nord-pontiques (sauf IGDOP 23-26)», REA 109, 2007, p. 82-83.

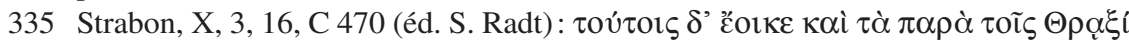

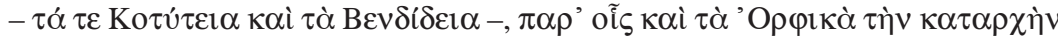
¿゙ $\sigma \chi \varepsilon$. Pour la fête en l'honneur de Kotyt $(\mathrm{t}) \hat{o}$, Strabon renvoie à un passage d'Edônoi d'Eschyle, fr. 57 (éd. S. Radt). Cf. S. Srebrny, « Kult der thrakischen Göttin Kotyto in Korinth und Sicilien», in Mélanges Franz Cumont, vol. I, Bruxelles 1936, p. 423 447. 
que le culte de $\operatorname{Kotyt}(\mathrm{t}) \hat{\text { ô }}$ passa en Grèce, à Corinthe, et en Sicile, à Sélinonte ${ }^{336}$.

Mieux encore, la célébration d'Héra par les Sélinontins illustre peutêtre les échanges cultuels qui se sont produits entre les Mégariens et les Corinthiens dans le milieu colonial. Le temple E, situé sur la colline orientale de la Marinella, a été identifié avec un Héraion, en raison de la découverte dans son adyton d'une dédicace à Héra datant de l'époque hellénistique ${ }^{337}$. La présence d'un deuxième sanctuaire d'Héra a été supposée sur la colline occidentale de la Gaggera, au sud du téménos de la Malophoros, près du port occidental de la ville ${ }^{338}$. Or si le culte d'Héra n'est pas documenté de manière certaine à Mégare de Grèce, il est en revanche célébré en Corinthie, à Pérachora ${ }^{339}$. On pourrait donc se demander si le culte d'Héra ne reflétait pas une influence corinthienne à Sélinonte. Certes, on a suggéré que cette divinité était présente à Mégara Hyblaea. Diodore (XX, 32,4), évoque dans le contexte d'événements datant de $c a .309$ un sanctuaire d'Héra dans les alentours de Mégara et les commentateurs estiment que ce lieu de culte datait de l'époque archaïque $^{340}$. Chose possible, mais pas certaine. À l'époque à laquelle se

336 Robu, Trad. onomastiques, p. 287-298. Pour une autre interprétation, voir L. Dubois, IGDS II, $a d \mathrm{n}^{\circ} 18$, p. 45, qui écrit: «Le culte de Ko $\tau \tau \tau \tau \omega ́$ aurait été très tôt importé, en tout cas avant la colonisation occidentale et peut-être par les Héraclides, de Thrace à Corinthe et à Mégare, puis dans les colonies de cette dernière». En revanche, N. Robertson, Religion and Reconciliation in Greek Cities. The Sacred Laws of Selinus and Cyrene, Oxford 2010, p. 53-68, préfère attribuer une origine grecque à Kotyt(t)ô. Cf. S. I. Johnston, Restless Dead. Encounters between the Living and the Dead in Ancient Greece, Berkeley et al. 1999, p. 57-58.

337 IGDS, 56; cf. Parisi Presice, L'importanza di Hera, p. 55-56; C. Marconi, Selinunte. Le metope dell'Heraion, Modena 1994, p. 137; Mertens, Selinus, p. 235 ; Veronese, Santuari greci, p. 508-509.

338 C. Parisi Presice, «La struturra», in S. Tusa et al., «Selinunte-Malophoros : rapporto preliminare sulla II campagna di scavi », SicArch XIX, 60-61, 1986, p. 52-53; idem, L'importanza di Hera, p. 50-58; identifie ce sanctuaire avec un Héraion en raison de la trouvaille d'un graffite portant les lettres EPA, que l'auteur propose de restituer

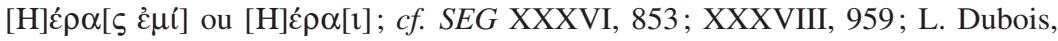
Bull. ép., 1989, 857; Antonetti, Megara e le sue colonie, p. 88, 91-92; Veronese, Santuari greci, p. 521-522.

339 Voir supra, chapitre I.1.1.

340 Hammond, Heraeum, p. 96, 98; G. Vallet, F. Villard, «Le repeuplement du site de Mégara Hyblaea à l'époque de Timoléon», Kokalos 4, 1958, p. 100-106; Parisi Presice, L'importanza di Hera, p. 55; Veronese, Santuari greci, p. 265-266. 
réfère Diodore, l'Héraion appartenait au territoire de Syracuse et il aurait pu être bâti après la conquête de Mégara par les troupes de Gélon (en 483/2), peut-être à l'époque de Timoléon. Notons au passage que le culte d'Héra est attesté à Syracuse, ainsi que dans la colonie syracusaine d'Acrai ${ }^{341}$. L'interprétation du passage de Diodore reste en tout état de cause sujette à caution et l'on ne peut proposer une date précise à un sanctuaire qui n'est mentionné que par un auteur de l'époque romaine dans un contexte historique de l'époque hellénistique, lorsque Mégara n'existait plus comme cité.

On conclura qu'outre les Mégariens de Sicile, des Mégariens de Grèce et probablement aussi des Corinthiens (provenant de Corinthe même ou de colonies corinthiennes) étaient présents à Sélinonte. Ceuxci figuraient parmi les premiers apoikoi ou ils y sont arrivés en tant que époikoi («colons additionnels») après la fondation de la cité ${ }^{342}$. Ainsi, Sélinonte attira, dès les premières années de son existence, des Grecs originaires d'autres cités que Mégara et l'on peut supposer que l'une des raisons de ce fait furent les contacts commerciaux que la cité entretenait avec les peuples non grecs de la région ${ }^{343}$.

341 P. Reichert-Südbeck, op. cit., p. 113-115 (avec les testimonia).

342 Sur le caractère mélangé que les colonies de Sicile présentaient au moment de leur fondation, voir Asheri, La colon. gr., p. 136-137; Vallet, Urbanisation, p. 486; idem, «Rhégion et Zancle, vingt ans après », in Vallet, Le monde gr. colonial, p. 396-397. Plusieurs chercheurs ont souligné l'importance de la politique de ravitaillement des colonies de l'Occident: E. Lepore, «Rapporti ed analogie di collonizzazione tra Sicilia e Magna Grecia», Kokalos 14-15, 1968-1969, p. 79; Finley, Anc. Sicily, p. 30; M. Gras, «La Méditerranée occidentale, milieu d'échanges. Un regard historiographique», in Les Grecs et l'Occident. Actes du colloque de la Villa Kérylos (1991), Collection de l'École française de Rome 208, Rome 1995, p. 113-114.

343 Di Vita, Siracusa, Camarina, Selinunte, p. 375-376; P. Anello, op. cit., p. 102-103. Voir le discours prononcé par Gélon en 481 face aux ambassadeurs des Grecs venus à Syracuse pour demander de l'aide contre les Perses, reproduit par Hérodote (VII, 158), qui évoque les profits que les cités de Grèce tiraient des emporia de Sicile. R. Descat, op. cit., p. 5-17, estime que la colonie sélinontine de Minôa devrait figurer parmi ces emporia. 


\section{II.1.2.6 Les caractéristiques de la première implantation urbaine de Sélinonte}

L'évolution de l'habitat de Sélinonte a été mise en évidence par les recherches faites sur la colline sud (dite «acropole»), sur le plateau nord de Manuzza et en bordure de l'agora (voir carte 5) ${ }^{344}$. Il convient d'emblée de souligner que c'est seulement après la conquête de Sélinonte par les Carthaginois en 409/8 que la ville s'est limitée à un petit habitat fortifié sur la colline sud, qui deviendra l'acropole visible aujourd'hui. La vie de cet habitat s'étala jusqu'en 250, lorsque les Carthaginois transférèrent la population, alors majoritairement punique, à Lilybée (l'actuelle Marsala) ${ }^{345}$.

À l'époque archaïque, on constate que l'espace intra-muros de Sélinonte, d'une superficie de 110 hectares, était considérablement plus grand que celui de sa métropole de Sicile (60 hectares). De même, les lots urbains de Sélinonte, avec leur surface moyenne de $220 \mathrm{~m}^{2}$, font à peu près le double de ceux de Mégara (d'une surface moyenne de $\left.125 \mathrm{~m}^{2}\right)^{346}$. Sans entrer dans la question de l'évolution du plan d'urbanisme à Sélinonte à l'époque archaïque et classique, on notera que celui-ci se fonde, comme dans la métropole siciliote, sur le lotissement, l'innovation principale étant le recours systématique à l'angle droit ${ }^{347}$.

344 Pour l'histoire des diverses étapes de la recherche à Sélinonte, voir R. Martin, «Rapport sur l'urbanisme de Sélinonte», Kokalos 21, 1975, p. 54-57; Parisi Presicce, Selinunte, p. 127-132; Mertens, Selinus I, p. 1-29.

345 R. de Simone, «Selinunte punica», in Selinunte, V. Tusa (éd.), Roma 2010, p. 181190; S. Helas, Selinus II. Die punische Stadt auf der Akropolis, Wiesbaden 2011, p. 32-36.

346 On trouve une présentation détaillée du site de Sélinonte chez Mertens, Selinus I, p. 31-32. Concernant la surface des lots urbains de Sélinonte, voir Mertens, Selinus I, p. 57, 263-264, 274; idem, Städte und Bauten, p. 178-179; Mégara 5, p. 588-589; Tréziny, De Mégara à Sélinonte, p. 165-167. Voir aussi D. Mertens, «Die Planstadt Selinunt. Entwurf und Realisierung», in Die Stadt als Großbaustelle. Von der Antike bis zur Neuzeit. Internationaler Kongress vom 7. bis 11. November 2001 im Auswärtigen Amt, Berlin, Berlin, 2003, p. 25; idem, Städte und Bauten, p. 173, pour l'espace intra-muros de 110 hectares de Sélinonte; $c f$. De Angelis, Megara Hyblaia and Selinous, p. 140-143.

347 Tréziny, De Mégara à Sélinonte, p. 165-167, 176-177. Pour les parallèles entre l'espace urbain de Mégara et celui de Sélinonte, on verra aussi Danner, Town Planning, p. 143-165; Mégara 5, p. 588-589; Mertens, Von Megara nach Selinunt, p. 55-103. 
La cité est conçue autour d'une agora, qui se trouve entre le quartier de l'acropole et celui situé au sud-ouest de Manuzza, et dont la forme trapézoïdale rappelle celle de l'agora de Mégara. La place publique est reliée par deux rues principales aux grands sanctuaires extra-urbains situés sur les collines opposées de la Gaggera et de la Marinella ${ }^{348}$. Comme on l'a déjà noté, les plus anciens vestiges de ce secteur de la ville datent de la fin du $\mathrm{VII}^{\mathrm{e}}$ siècle. En bordure est de l'agora, non loin de la nécropole de Manuzza, il existe un lieu de culte et des dépôts votifs remontant au début du $\mathrm{VI}^{\mathrm{e}}$ siècle, ainsi que des maisons et des installations commerciales ${ }^{349}$. Plusieurs structures trouvent ici des parallèles dans la métropole siciliote de Sélinonte: les plates-formes circulaires à buts cultuels ${ }^{350}$; l'hestiatorion édifié vers le milieu du VI $\mathrm{VI}^{\mathrm{e}}$ siècle et succédant à un ensemble d'habitations privées, plus anciennes ${ }^{351}$, tout comme à Mégara ${ }^{352}$.

De Vito estimait que l'endroit de la première implantation coloniale devrait être situé au sud de la colline de l'acropole, là où ultérieurement les Sélinontins allaient bâtir les temples A et $\mathrm{O}^{353}$. Dans ce cadre, on évoquera la découverte, au sud de l'acropole, des restes d'une maison ayant livré des céramiques qui pourraient remonter, à en croire Fourmont, au Protocorinthien et au style de transition (le milieu et le

348 D. Mertens, «Verso l'agora di Selinunte», in La colonisation grecque en Méditerranée Occidentale. Actes de la rencontre scientifique en hommage à Georges Vallet organisée par le Centre Jean-Bérard, l'École française de Rome, l'Istituto universitario orientale et l'Università degli studi di Napoli «Federico II " (RomeNaples, 15-18 novembre 1995), Rome 1999, p. 185-193, surtout p. 191; idem, in Mertens et al., Agora, p. 389-390; idem, Selinus, p. 226 idem, Städte und Bauten, p. 177; idem, «Raumgestaltung in westgriechischen Kolonialstädten», GeogrAnt 18, 2009, p. 80-81. Cf. A. Rallo, «Nuovi aspetti dell'urbanistica di Selinunte», ASAA 62, N.S. 46, 1984 (1988), p. 88-89, 91 ; De Angelis, Megara Hyblaia and Selinous, p. 133.

349 D. Mertens, in Mertens et al., Agora, p. 407-408; N. Hoesch, in Mertens et al., Agora, p. 429-438.

350 Voir supra, chapitre II.1.1.4.

351 D. Mertens, in Mertens et al., Agora, p. 408-410; idem, Selinus I, p. 230. La substitution à Mégara et à Sélinonte d'un groupe de maisons par un hestiatorion est un exemple de passage d'un espace privé à un espace public.

352 Mégara 1, p. 198-202; M. Gras, H. Tréziny, in Mégara 5, p. 423-424.

353 A. di Rallo, «Urbanistica della Sicilia greca», in I Greci in Occidente, G. Pugliese Caratelli (éd.), Milano 1996, p. 282. Cf. Mertens, Selinus I, p. 226-227; idem, Städte und Bauten, p. 85, 173, 326. 
troisième quart du VII ${ }^{\mathrm{e}}$ siècle); mais ces trouvailles restent, à ma connaissance, en bonne partie inédites ${ }^{354}$. En ce qui concerne le développement urbain, le secteur de l'acropole présente deux grandes zones séparées par la rue Sf, de direction est-ouest (voir carte 5). On trouve une zone d'habitat au nord de la rue Sf, avec une organisation d'îlots selon un système per strigas, et une aire située au sud de la rue $\mathrm{Sf}$, qui semble avoir été réservée à la zone sacrée, avec le grand téménos des temples $\mathrm{C}$ et $\mathrm{D}$. Les spécialistes ont remarqué qu'après une première occupation dispersée de l'acropole par les premiers colons, se produit au premier quart du $\mathrm{VI}^{\mathrm{e}}$ siècle la véritable extension de la ville: l'habitat devient plus dense et on assiste au quadrillage de l'ensemble du site, qui se fait par la mise en place d'un système de division du territoire et d'un réseau de rues au tracé régulier, dont l'alignement est respecté par les maisons ${ }^{355}$. De plus, d'après les plus récentes découvertes, le premier rempart remonte à la première moitié $\mathrm{du} \mathrm{VI}^{\mathrm{e}}$ siècle. Cette datation met en évidence le rapport étroit qui existe à Sélinonte entre la construction de l'enceinte et la mise en place du grand plan urbain, un fait déjà constaté à Mégara ${ }^{356}$.

Par ailleurs, les fouilles effectuées par Rallo sur le plateau de Manuzza seraient les seules à révéler les traces d'un site indigène pré-grec. Celuici aurait été remplacé dans le dernier quart du VII ${ }^{\mathrm{e}}$ siècle par un habitat

354 M.H. Fourmont, «Rapport d'activité pour les travaux à Sélinonte: 1980-1984», in V. Tusa, «L'attività della Soprintendenza alle Antichità della Sicilia Occidentale nel quadriennio maggio 1980-aprile 1984», Kokalos 30-31, 1984-1985, p. 559, estime que ces découvertes de l'acropole seraient comparables au matériel de la nécropole de Manuzza. Cf. Danner, Selinunt, p. 19-20.

355 Martin, Sélinonte, p. 183-188; La Genière, Saggi sull'Acropoli, p. 68-107; eadem, «Nuove ricerche sulla topografia di Selinunte», $R A L$ 36, 1981, p. 211-217; eadem, «Sélinonte. Recherches sur la topographie urbaine (1975-1981)», ASNP serie iii, 12, 1, 1982, p. 469-479; J. de la Genière, J. Rougetet, « Recherches sur la topographie de Selinonte. Campagne 1985 », RAL 40, 1985, p. 289-297; Di Vita, Selinunte, p. 11-53; Fischer-Hansen, Town Planning, p. 345-349; Danner, Town Planning, p. 151-155; De Angelis, Megara Hyblaia and Selinous, p. 128-140; D. Mertens, «Selinunte :l'eredità di Megara Hyblaea e tante domande aperte», in Alle origini della Magna Grecia. Mobilità, migrazioni, fondazioni. Attidel cinquantesimo convegno di studi sulla Magna Grecia (Taranto, 1-4 ottobre 2010), Taranto 2012, p. 1152-1158.

356 Mertens, Selinus I, p. 233-234, 264-270; cf. H. Tréziny, «Les fortifications archaïques dans le monde grec colonial d'Occident», in Guerra e pace in Sicilia e nel Mediterraneo antico (VIII-III sec. a.C.). Arte, prassi e teoria della pace e della guerra, vol. I, Pisa 2006, p. 257. 
grec dont le plan urbain, avec un réseau de rues bien défini, datait du milieu du $\mathrm{VI}^{\mathrm{e}}$ siècle ${ }^{357}$. Il faut signaler aussi la trouvaille sur les versants sud-est de Manuzza d'un groupe de tombes contenant des céramiques de la seconde moitié du VII ${ }^{\mathrm{e}}$ siècle, des offrandes votives allant jusqu'au début du $\mathrm{V}^{\mathrm{e}}$ siècle, ainsi qu'un lieu de culte consacré à la déesse Tanit à l'époque hellénistique. D'après Rallo, ces données accréditeraient l'idée de l'existence dans ce secteur d'un lieu de vénération des héros ${ }^{358}$. En attendant la publication exhaustive du matériel archéologique de Manuzza, on notera que le culte des héros semble avoir été célébré en bordure de l'agora. Preuve en sont deux tombes découvertes l'une à côté de l'autre et sans mobilier funéraire, que Mertens interprète comme un hérôon, voire le monument du fondateur (ou des fondateurs) de la cité ${ }^{359}$. La pratique d'ensevelir des héros à l'intérieur de la ville est attestée dans plusieurs cités, et, plus particulièrement dans le monde mégarien, elle est présente à Mégare Nisaia, ainsi qu'à Héraclée du Pont ${ }^{360}$. Notons que même dans la métropole siciliote de Sélinonte, les archéologues ont découvert une tombe à incinération datant de la première moitié du VII ${ }^{\mathrm{e}}$ siècle, située dans la dépression d'Arenella, à l'intérieur de l'enceinte archaïque ${ }^{361}$.

357 Rallo, Selinunte, p. 720-733; eadem, «Nuovi aspetti dell'urbanistica di Selinunte», ASAA 62, N.S. 46, 1984 (1988), p. 81-91; cf. J. de la Genière, ASNP serie iii, 12, 1, 1982, p. 469-479; E. Greco, Gnomon 73, 2001, p. 334 ; De Angelis, Megara Hyblaia and Selinous, p. 140.

358 Rallo, Contributions, p. 194-198; eadem, «Considerazioni su un gruppo di tombe protoarcaiche di Selinunte», in Atti del Convegno Internazionale. Sepolti tra $i$ vivi. Buried among the Living (Roma, 26-29 Aprilie 2006), G. Bartoloni et M. G. Benedettini (éds.), Scienze dell'Anntichità 14/1, Roma 2008, p. 489-496.

359 Mertens, Städte und Bauten, p. 178; idem, «L'<heroon〉 sull' agora di Selinunte. Note preliminare», in Atti del Convegno Internazionale. Sepolti tra $i$ vivi. Buried among the Living (Roma, 26-29 Aprilie 2006), G. Bartoloni et M. G. Benedettini (éds.), Scienze dell'Antichità 14/1, Roma 2008, p. 489-496; idem, Von Megara nach Selinunt, p. 80-84; D. Mertens et al., «Die Agora von Selinunt. Der Platz und die Hallen», $\operatorname{MDAI}(R)$ 118, 2012, p. 58-64, 153-165; cf. C. Antonetti, «Riflessioni su Zeus Agoraios a Selinunte», in Temi selinuntini, C. Antonetti et S. de Vido (éds.), Pisa 2008, p. 36-42; R. Giglio, «Selinous. Recenti attività di ricerca archeologica», in La Sicilia in età arcaica. Dalle apoikiai al 480 a. C. Contributi dalle recenti indagini archeologiche, R. Panvini et L. Sole (éds.), Palermo 2009, p. 209-210.

360 Comme en témoigne Pausanias, I, 42-43, plusieurs tombes de héros se trouvaient à l'intérieur de la ville de Mégare (voir supra, chapitre I.1.4). Pour la tombe du héros Idmôn sur l'agora d'Héraclée du Pont, voir infra, chapitre II.3.1.1.

361 H. Tréziny, in Mégara 5, p. 290 ; M. Gras, H. Tréziny, in Mégara 5, p. 558; Tréziny, Colonies gr. de Méditerranée, p. 54. 
Il faut du reste ajouter que l'on a trouvé ailleurs à Sélinonte des vestiges datant de la fin du VII ${ }^{\mathrm{e}}$ siècle: c'est notamment le cas des plus anciennes céramiques trouvées dans la vallée du fleuve Gorgo Cottone et dans les nouveaux sondages effectués sur le plateau de Manuzza ${ }^{362}$. Sur la colline occidentale de la Gaggera, même si le «premier mégaron » consacré à Déméter Malophoros date de 590-580, un autel primitif, situé au centre du futur téménos de la Malophoros, et deux foyers (4 et 11) confirment l'existence d'un lieu de culte, œuvre de la première génération de colons ${ }^{363}$. Dans le même secteur, mais un peu plus au sud, les fouilles ont fait apparaître un nouveau temple (identifié à un Héraion), bâti vers le milieu du $\mathrm{VI}^{\mathrm{e}}$ siècle, et des céramiques de la fin du $\mathrm{VII}^{\mathrm{e}}$-début $\mathrm{du} \mathrm{VI} \mathrm{I}^{\mathrm{e}}$ siècle, qui indiquent une fréquentation antérieure du lieu ${ }^{364}$. Au secteur opposé, sur la colline orientale de Marinella, on a proposé que la construction du temple E (phase E 1, qui serait un Héraion, voir cidessus) avait eu lieu à la fin du VII ${ }^{\mathrm{e}}$ ou au début du VI ${ }^{\mathrm{e}}$ siècle $^{365}$.

362 Mertens, Selinus I, p. 226. Voir aussi dans ce volume les résultats des fouilles de la vallée du Gorgo Cottone et du plateau de Manuzza publiés par V. Hinz et E. CancikKirschbaum (p. 281-433); Mertens, Städte und Bauten, p. 83-84.

363 E. Gabrici, op. cit., col. 144-154; Dewailly, Sanct. de la Malophoros, p. 14-27; eadem, Statuettes, p. 3-9; M. Dewailly, C. Parisi-Presicce, S. Tusa, «Selinunte, Malophoros : campagne di scavo 1982-1983», in V. Tusa, «L'attività della Soprintendenza alle Antichità della Sicilia Occidentale nel quadriennio maggio 1980-aprile 1984 », Kokalos 30-31, 1984-1985, p. 577; C. Dehl, M. Dewailly, «Area 〈muro nord »», in S. Tusa et al., «Selinunte-Malophoros: rapporto preliminare sulla II campagna di scavi », SicArch XIX, 60-61, 1986, p. 59-66; Antonetti-De Vido, Cittadini, p. 411414; Veronese, Santuari greci, p. 524-526.

364 S. Tusa, «Introduzione», in S. Tusa et al., «Selinunte-Malophoros : rapporto preliminare sulla II campagna di scavi», SicArch XIX, 60-61, 1986, p. 17; Veronese, Santuari greci, p. 522. Pour la date de fondation de ce sanctuaire, voir Mertens, Selinus, p. 234-235.

365 G. Gullini, «Il tempio E1 e l'architettura protoarcaica di Selinunte», in Rizza (éd.), Insediamenti colon. gr., p. 52-61 et 72-74, surtout p. 53 et 73; idem, «L'architettura templare greca in Sicilia del primo arcaismo alla fine del V secolo», in Il tempio greco in Sicilia. Architettura e culti. Atti della $1^{a}$ riunione scientifica della Scuola di perfezionamento in archeologia classica dell'Università di Catania (Siracusa, 2427 novembre 1976), Cronache di Archeologia 16/1977, Catania 1980, p. 23-30; idem, «L'architettura», in SIKANIE. Storia e civiltà della Sicilia antica, G. Pugliese Carratelli (éd.), Milano 1986, p. 431-434; Veronese, Santuari greci, p. 508-510; Mertens, Von Megara nach Selinunt, p. 84. 
Toutes ces trouvailles appuient l'idée que même si les Grecs n'avaient pas pensé à un ordre spatial qui comprenne le grand territoire comme un tout, ils avaient fréquenté vers la fin du VII ${ }^{\mathrm{e}}$ siècle une bonne partie de l'aire sur laquelle la ville de Sélinonte se développe aux $\mathrm{VI}^{\mathrm{e}}$ $\mathrm{V}^{\mathrm{e}}$ siècles ${ }^{366}$. La première intention des Mégariens, semble-t-il, fut de marquer la possession du territoire et de contrôler celui-ci à travers leur habitat et leurs sanctuaires, et ensuite, dans le premier quart du VI siècle, de procéder à une division régulière du sol. La distribution des sanctuaires extra-urbains et la localisation de la nécropole de Manicalunga à 4-5 km de Sélinonte (à l'ouest du fleuve Modione), à proximité de laquelle devait exister un village ${ }^{367}$, ont même permis de supposer l'existence à Sélinonte d'un habitat kata kômas, chaque village étant rattaché à un centre religieux ${ }^{368}$.

En conclusion, les données archéologiques et urbanistiques montrent que les apoikoi ont occupé, certes sous une forme dispersée, tant à Sélinonte qu'à Mégara dès le début les principales zones d'habitation. Les similitudes que l'on a relevées entre l'organisation urbaine des deux cités (l'importance du lot dans la mise en place du plan urbain, la forme de l'agora, l'analogie entre diverses structures) plaident en faveur de l'individualité et de l'originalité du mouvement mégarien de colonisation. Cela confirme que les Mégariens furent des acteurs importants dans la colonisation de Sicile; leur rôle fut comparable dans ce processus à celui des apoikoi chalcidiens et corinthiens.

366 Di Vita, Selinunte, p. 11; Parisi Presicce, Selinunte, p. 25-26; V. Tusa, «Ricerche e scavi nelle necropoli selinuntine», ASAA 60, N.S. 44, 1982 (1984), p. 195-196; E. Østby, op. cit., p. 84; De Angelis, Megara Hyblaia and Selinous, p. 140; Mertens, Selinus I, p. 226-228, 273-274; Veronese, Santuari greci, p. 505.

367 V. Tusa, «Le necropoli di Selinunte», in Odeon ed altri «monumenti » archeologici, A. Adriani et al., Palermo 1971, p. 177. Sur les nécropoles de Sélinonte, voir aussi H.P. Isler, «Les nécropoles de Sélinonte», in Nécropoles et sociétés antiques (Grèce, Italie, Languedoc), J. de la Genière (éd.), Naples 1994, p. 165-168.

368 G. Manganaro, «Mondo religioso greco e mondo 〈indigeno〉 in Sicilia», in Antonetti (éd.), Il dinam. della colon. gr., p. 72; cf. De Angelis, Megara Hyblaia and Selinous, p. 152; Mertens, Selinus I, p. 226. 


\section{II.2 Les établissements mégariens de la Propontide}

Throughout Greece in the seventh century there was much colonization, and, on the whole, generally little in the fifth century. To colonize was, for the most part, a sign of vitality ${ }^{369}$.

Les Mégariens installèrent à la fin du VIII ${ }^{\mathrm{e}}$ siècle et dans la première moitié du VII ${ }^{\mathrm{e}}$ siècle quatre cités sur les rives de la Propontide: Astacos, Chalcédoine, Sélymbria et Byzance. Faute de découvertes archéologiques importantes provenant de ces sites, l'enquête se fonde essentiellement sur l'analyse des récits de fondation. Mon intention est de mettre en évidence dans les chapitres suivants les rapports entre les cités-sœurs mégariennes et les réseaux qu'elles ont mis en place en Propontide. Il convient également de s'interroger si des ressortissants d'autres cités grecques ont participé au mouvement de colonisation mégarien. De fait, dans le cas de Byzance, les sources textuelles évoquent la participation des colons non mégariens à cette fondation. Par ailleurs, de même que dans le cas des installations mégariennes de Sicile, les rapports entre les Mégariens et les non-Grecs (les Mysiens, les Bithyniens, les Thraces) font partie de l'étude.

\section{II.2.1 Astacos}

La cité d'Astacos fut fondée sur la côte asiatique de la Propontide dans la partie sud du golfe moderne d'İzmit. Chez les auteurs antiques,

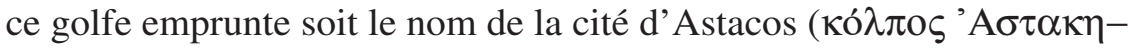

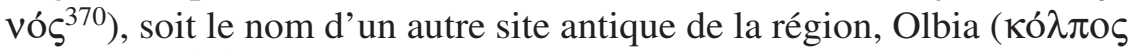
'O $\left.\lambda \beta 1 \alpha v o ́ \zeta^{371}\right)$. La colonie faisait sans doute partie de la région antique

369 Figueira, Chronological Table, p. 275.

370 Strabon, X, 2, 21, C 459; XII, 4, 2, C 563; Mennipi Pergameni Periplus, 5812 (éd.

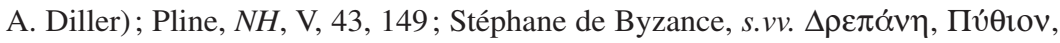
T $\rho \alpha \lambda \lambda i \alpha$; Constantin Porphyrogénète, De Thematibus, I, p. 25 (éd. I. Bekker).

371 Ps.-Scylax, 92; Pomponius Mela, I, 19, 100. Sur Olbia, voir infra, chapitre II.2.1.4. 
de Mysie, ultérieurement annexée par le royaume bithynien ${ }^{372}$. Cependant, en l'absence de fouilles archéologiques, il est difficile de connaître l'emplacement exact de la ville. Ruge suggère qu'Astacos était située près de la ville turque de Yuvadjyk (Yuvacik) ${ }^{373}$. En revanche, Şahin pense que la ville se trouvait plus près de la côte, à Baş Iskele, dans la zone du port militaire de Gölcük, où les travaux militaires ont mis au jour des céramiques grecques qui restent malheureusement encore inédites. Ce site, qui se trouve en face de l'antique Nicomédie, correspondrait bien à la description de Memnon, selon qui Nicomède $\mathrm{I}^{\mathrm{er}}$ aurait bâti sa nouvelle

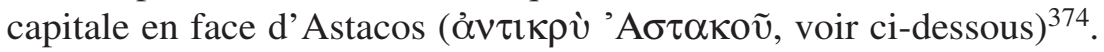

\section{II.2.1.1 Les récits concernant la fondation d'Astacos}

Au sujet de la fondation d'Astacos, on dispose de deux traditions littéraires. La première, fournie par Memnon d'Héraclée du Pont, attribue la fondation de la cité aux Mégariens, suite à un oracle. Il convient d'emblée de souligner que cette tradition a pour source un autre chroniqueur d'Héraclée, Nymphis ${ }^{375}$. Historien et homme politique de la première moitié du III ${ }^{e}$ siècle, Nymphis a écrit un ouvrage (en treize livres), aujourd'hui perdu, portant sur l'histoire de sa cité, et qui est utilisé à l'époque

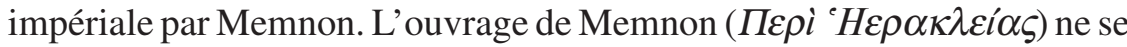
conserve que sous la forme d'extraits compilés au IX ${ }^{\mathrm{e}}$ siècle ap. J.-C. par le célèbre patriarche de Constantinople, Photius, dans sa Bibliothèque ${ }^{376}$.

372 Astacos n'apparaît pas dans la description de la Bithynie et de la Mysie fournie par le Ps.-Scylax, 92-93. Mais, étant donné que ce périple localise Olbia dans la Mysie et que ce site fut très probablement situé aux alentours d'Astacos (voir ci-dessous), il est très probable qu'Astacos faisait partie de la Mysie plutôt que de la Bithynie. Pour l'appartenance originelle de la péninsule située entre Nicomédie et Cios à la Mysie, voir Robert, Hellenica, VII, p. 37-38; cf. Debord, Mysiens, p. 142; A. Avram, s.v. «The Propontic Coast of Asia Minor, I. The Region», in Hansen-Nielsen (éds.), Inventory, p. 974-975, qui situe en revanche Astacos et Olbia en Bithynie.

373 Ruge, Astakos, col. 1774.

374 Şahin, Nikomedia, p. 66-70. Cf. J. et L. Robert, Bull. ép., 1974, 574.

375 J. Toepffer, «Astakos», Hermes 31, 1896, p. 126.

376 Burstein, Heraclea, p. 2-4. Sur Nymphis, Memnon, Photius et les rapports qui existent entre leurs œuvres voir aussi R. Laqueur, s.v. «Nymphis von Herakleia», $R E$ XVII, 1937, col. 1608-1623 ; Jacoby, FGrHist III B, p. 259-261 (Nymphis), 267-271 (Memnon); M. Janke, Untersuchungen zu Memnon von Herakleia, Diss. Würzburg 1963, p. 1-14; Desideri, Storiografia eracleota, p. 366-416; K. Meister, Die 
Memnon évoque l'installation des Mégariens à Astacos, suite à un oracle, dans le cadre du récit de l'alliance entre le roi bithynien Nicomède $\mathrm{I}^{\mathrm{er}}$ et les Galates et de la fondation de Nicomédie.

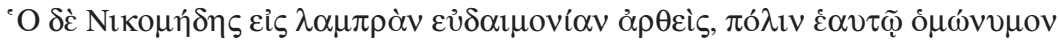

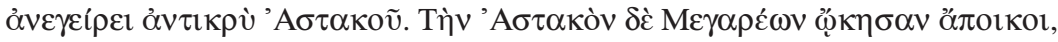

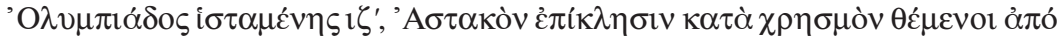

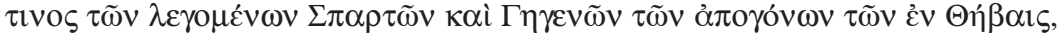

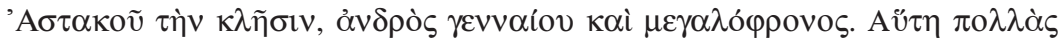

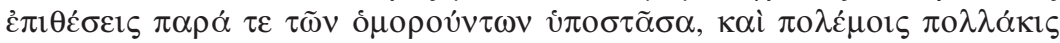

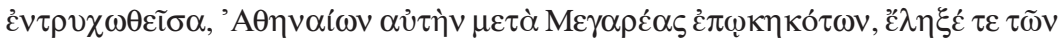

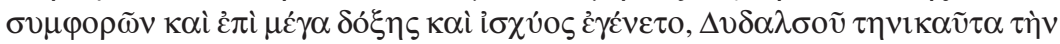

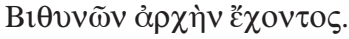

Nicomède s'éleva à une fortune éclatante et il bâtit en face d'Astacos une ville qui porta son nom. Astacos avait été fondée par des colons mégariens au début de la $17^{\mathrm{e}}$ olympiade; ils lui avaient donné le nom d'Astacos, sur l'ordre d'un oracle, d'après celui d'un descendant de ceux qu'on appelait à Thèbes les «Spartes» et les Fils de la Terre; il s'appelait Astacos; c'était un homme noble et magnanime. Cette ville soutint nombre d'attaques de ses voisins; elle s'épuisa à plusieurs reprises dans les guerres et elle accueillit, après les Mégariens, des colons athéniens; elle atteignit un haut degré de gloire et de puissance et Dœdalsès, qui régnait alors sur les Bithyniens, mit alors fin à ses malheurs ${ }^{377}$.

Sur la foi de ce passage, on remarque que la fondation d'Astacos aurait eu lieu au début de la $17^{\mathrm{e}}$ olympiade, soit vers $712 / 1$. La Chronique d'Eusèbe offre une date proche: la deuxième année de la $17^{\mathrm{e}} \mathrm{olym}-$ piade $(=711 / 0)$, ce qui fait d'Astacos une des premières installations grecques en Propontide ${ }^{378}$.

À son tour, Strabon avait repris, bien avant Memnon, la même tradition, dans les termes suivants:

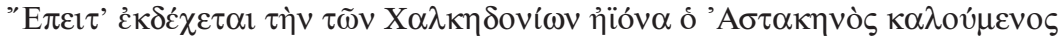

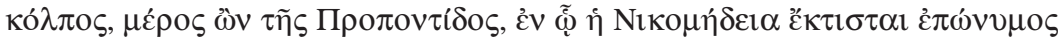

griechische Geschichtsschreibung. Von den Anfängen bis zum Ende des Hellenismus, Stuttgart et al. 1990, p. 127-128.

377 Memnon, FGrHist 434 F 12 (apud Photius, Bibliothèque, 228 a, trad. de R. Henry, CUF, partiellement modifiée).

378 Eusèbe, Chron., St. Jérôme: Ol. 17. 2 (= 711/0, éd. R. Helm, p. 91b). On remarque que la version arménienne d'Eusèbe indique la troisième année de la $18^{\mathrm{e}}$ olympiade (=706/5, éd. J. Karst, p. 183). Miller, Colony Dates, p. 22, préfère néanmoins la date de 711/0 offerte par Saint Jérôme pour la fondation d'Astacos, car elle a l'avantage d'être plus proche de la date fournie par Memnon. 


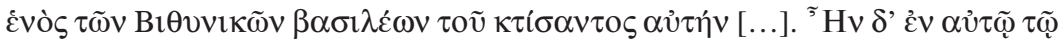

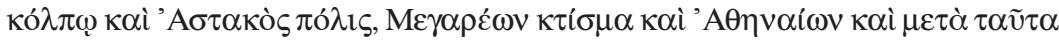

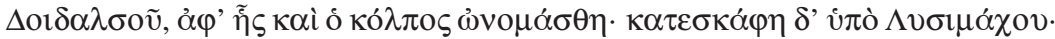

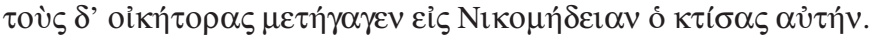

Au littoral chalcédonien fait suite ce qu'on appelle le golfe d'Astacène: c'est la partie de la Propontide au bord de laquelle a été fondée Nicomédie, ainsi nommée d'après son fondateur, l'un des rois de Bithynie [...]. Dans le golfe encore se trouve la ville d'Astacos, fondée par les Mégariens et les Athéniens, puis par Dœdalsès; c'est d'elle que le golfe tient son nom. Elle fut détruite par Lysimaque, et ses habitants furent transférés à Nicomédie par le fondateur de cette dernière ${ }^{379}$.

Outre les passages de Memnon et de Strabon, la Chorographie de Pomponius Mela, un ouvrage géographique rédigé sous l'empereur Claude, en utilisant une source grecque (Nymphis?), mentionne également l'origine mégarienne d'Astacos ${ }^{380}$.

Du reste, selon une autre tradition, transmise par Charon de Lamp-

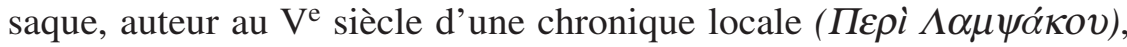
ce sont les Chalcédoniens qui avaient établi Astacos ${ }^{381}$. Ce récit implique, du même coup, que la date de la fondation d'Astacos doit être postérieure à celle de Chalcédoine, soit $685^{382}$.

En analysant ces traditions littéraires, Hanell accordait sa préférence au témoignage de Charon et estimait que c'étaient les Chalcédoniens qui avaient fondé Astacos, peut-être avec une participation des Mégariens. De fait, le concours des Mégariens de Grèce était confirmé par la présence d'un polichnion Mégarikon dans le territoire d'Astacos ${ }^{383}$. Hanell

379 Strabon, XII, 4, 2, C 563 (trad. de F. Lasserre, CUF).

380 Pomponius Mela, I, 19, 100: Duo sunt inde modici sinus. Alter sine nomine Cion amplectitur, Phrygiae haud longe iacentis opportunissimum emporium, alter Olbianos in promunturio fert Neptuni fanum, in gremio Astacon, a Megarensibus conditam. Comme Alexandru Avram a eu l'amablité de me le suggérer, il n'y a pas de doute que la source de ce passage soit grecque, car les toponymes Cion, Astacon (en non pas Cium, Astacum) sont grecs, tout comme le nom du golfe d'Olbia, Olbianos (et non pas Olbianus). Étant donné que Pomponius Mela, tout comme Strabon et Memnon, considère Astacos comme une colonie mégarienne, on est autorisé à penser que la source de ce passage est peut-être aussi Nymphis d'Héraclée.

381 Charon de Lampsaque, FGrHist 262 F 6 (apud Photius, Lexicon, s.v. ỏ $\sigma \alpha \alpha$ kó , éd.

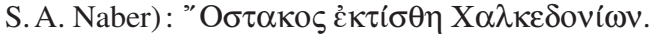

382 Voir infra, chapitre II.2.2.3.

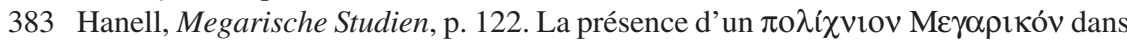
la région d'Astacos est attestée par Arrien (FGrHist 156 F 18) et Pline (NH, V, 43, 148: promunturium, in quo Megarice oppidum fuit). 
acceptait la suggestion de Toepffer, selon laquelle le rapport entre Mégare, Chalcédoine et Astacos était analogue à la relation entre Corinthe, Corcyre et Épidamne ${ }^{384}$. Par ce subterfuge, la tradition de la participation de Mégare à la colonisation d'Astacos n'était pas complètement écartée. La plupart des modernes ont accepté cette reconstruction, qui avait le mérite de combiner les deux traditions littéraires ${ }^{385}$. Mieux, Loukopoulou suggère qu'Astacos aurait servi d'avant-poste à Chalcédoine, comme Sélymbria à Byzance ${ }^{386}$. On pourrait accepter cette dernière proposition, mais cela n'exclut pas le fait qu'Astacos ait pu être fondée avant Chalcédoine, tout comme Sélymbria a été fondée par les Mégariens avant Byzance ${ }^{387}$.

En réalité, la thèse de Hanell concernant la fondation d'Astacos n'est pas recevable pour plusieurs raisons. D'abord, il n'est pas certain que le récit de Charon, du seul fait qu'il est le plus ancien (vers 400), soit nécessairement plus crédible que celui de Nymphis (repris par Memnon et Strabon $)^{388}$. Il paraît exclu que Nymphis et Memnon, tous les deux originaires d'Héraclée du Pont, une cité d'origine mégarienne, aient inventé eux-mêmes une tradition de fondation pour Astacos ou, tout simplement, qu'ils aient méconnu l'identité de sa métropole. Certes, l'hypothèse d'une confusion dans les sources antiques, qui auraient qualifié de «Mégariens» non seulement les Mégariens de Grèce, mais aussi les Chalcédoniens ou les Byzantins, doit être prise en compte (voir ci-après). Mais dans le cas d'Astacos, il est difficile de croire avec

384 J. Toepffer, op. cit., p. 127.

385 Jacoby, FGrHist III A, p. 11; R. Merkelbach, I. Kalchedon, p. 91; Legon, Megara Pol. Hist., p. 79, n. 45; Graham, Colonial Expansion, p. 119-120; Malkin-Shmueli, City of the Blind, p. 32. Avram, Astacos, p. 977, estime qu'Astacos a été fondée par Chalcédoine et qu'elle a été ultérieurement renforcée par des Mégariens de Grèce.

386 Loukopoulou, Thrace propontique, p. 51, 53.

387 Voir infra, chapitre II.2.3.

388 Busolt, Gr. Gesch., I, p. 471, écrit: «Doch nach einer älteren, glaubwürdigeren Überlieferung wurde Astakos von den Kalchadoniern, also nicht vor 677 begründet». On retrouve cette opinion chez J. Toepffer, op. cit., p. 127; Hanell, Megarische Studien, p. 120, et Graham, Colonial Expansion, p. 119. Beloch, Gr. Gesch. ${ }^{2}$, I, 1, p. 234 ; I, 2, p. 233, estime, lui aussi, que la date de 712/1 est trop haute pour la fondation d'Astacos et considère ce dernier établissement comme une fondation de Chalcédoine. 
Toepffer et Loukopoulou ${ }^{389}$ que des historiens originaires d'Héraclée du Pont aient été incapables de faire la différence entre Mégare et Chalcédoine; d'autant plus que les extraits de Photius montrent que les historiens héracléotes étaient bien informés sur l'histoire de la Bithynie ${ }^{390}$. À mon sens, leur intérêt pour Astacos venait notamment du fait que le célèbre tyran d'Héraclée du Pont, Cléarque, avait assiégé sans succès cette ville vers le milieu du IV $^{\mathrm{e}}$ siècle $^{391}$.

Il existe du reste une autre contradiction chez Hanell, car il écarte la date de 712/1 pour la fondation d'Astacos, attestée chez Memnon et Eusèbe, tout en acceptant la date de 685 fournie par la même chronologie d'Eusèbe pour la fondation de Chalcédoine. On a ici le sentiment que l'historien suédois ne considère Astacos comme une installation chalcédonienne que pour mieux asseoir l'une des thèses essentielles de son ouvrage, à savoir la prééminence de Chalcédoine, aux dépens de Mégare, dans la fondation de cités mégariennes en Propontide (Astacos, Sélymbria, Byzance) et dans le Pont-Euxin (Mésambria) ${ }^{392}$. Pourtant, même si Chalcédoine joua un rôle dans l'installation de Byzance et de Mésambria, je pense qu'il est préférable de parler d'une collaboration ou d'une solidarité mégarienne plutôt que d'une hégémonie chalcédonienne dans la colonisation mégarienne des rives de la Propontide ${ }^{393}$.

\section{II.2.1.2 Le «réseau» mégarien et la fondation d'Astacos}

Tout en rejetant donc l'opinion de Hanell selon laquelle Astacos était une colonie principalement chalcédonienne, je crois qu'il faut intégrer cette fondation dans le cadre plus large de l'installation des Mégariens en Propontide. Selon moi, les quatre cités mégariennes attestées dans cette région - Astacos et Chalcédoine sur la côte asiatique, Sélymbria

389 Loukopoulou, Thrace propontique, p. 53, qui, sans s'en apercevoir, suit l'hypothèse

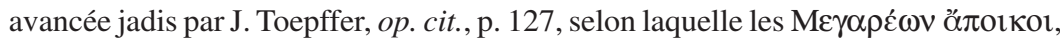
pouvaient aussi bien provenir de Chalcédoine que de Mégare. Voir aussi Beloch, $G r$. Gesch. $^{2}$, I, 1, p. 257, n. 4, qui accepte la tradition de Charon pour la fondation d'Astacos, en notant: «Daß die Stadt von Memnon (c. 20, FHG. III 536) als megarische Gründung bezeichnet wird, steht damit nicht im Widerspruch ».

390 M.I. Rostovtseff, op. cit., p. 400.

391 Polyen, II, 30, 3.

392 Hanell, Megarische Studien, p. 132-136; cf. Loukopoulou, Thrace propontique, p. 52-53.

393 Robu, Réseaux, p. 183-189. 
et Byzance sur la côte européenne - font partie d'un «projet» cohérent de colonisation. Je crois que l'on peut appliquer la notion moderne de «projet» de colonisation à une entreprise qui, bien qu'elle puisse être culturellement hétérogène, se déroule en suivant une logique propre et réussit à mettre en place un «réseau» ou des «réseaux» permettant d'exploiter les ressources d'une région plus vaste ${ }^{394}$. Certes, on n'a pas affaire à un «projet» d'occupation du territoire figé dans le temps, mais à un «projet» qui connaît des évolutions et des adaptations ultérieures. L'idée de plan, qui se trouve derrière la notion de «projet», est soutenue, me semble-t-il, par l'occupation par les Mégariens des positionsclefs sur la route reliant la Méditerranée à la mer Noire (notamment le détroit du Bosphore), et cela dans l'espace d'une ou deux générations, entre la fin du VIII ${ }^{\mathrm{e}}$ siècle et le milieu du VII ${ }^{\mathrm{e}}$ siècle. L'importance de ces sites en tant que points de contrôle du passage vers le Pont est mise en évidence ultérieurement par l'occupation de ces endroits par Athènes à l'époque de son hégémonie. Dans le cas d'Astacos, sa position très favorable a été remarquée par les Athéniens, qui installèrent une colonie vers $435 / 4^{395}$. Comme on n'a pas manqué de le noter, le golfe d'Astacos pouvait constituer un refuge idéal pour les navires qui naviguaient dans la direction de la mer Noire ${ }^{396}$.

Notons par ailleurs que l'on trouve aux abords d'Astacos d'autres localités liées à un héritage mégarien et qui suggèrent une occupation de la région par les Mégariens en plusieurs endroits. Il y a la mention, on l'a vu, d'un polichnion Mégarikon, mais aussi d'Olbia, probablement elle aussi une fondation mégarienne (voir ci-après). De même, le site de Pythion, placé par Stéphane de Byzance dans la région du golfe d'Astacos, a été sans doute installé par les Mégariens, car son appellation renvoie à Apollon Pythios, la principale divinité mégarienne ${ }^{397}$. On ne dispose d'aucune information permettant d'affirmer que le polichnion Mégarikon, Olbia et Pythion soient devenus des centres politiques, il

394 Pour la notion de «projet» colonial, voir Lévêque, Grecs en Occident, p. 14-15.

395 Voir infra, chapitre II.2.1.3.

396 Sur les routes maritimes en Propontide, voir Malkin-Shmueli, City of the Blind, p. 24-31 (avec les références).

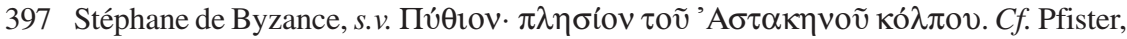
Mythische Königsliste, p. 46. Sur le culte d'Apollon Pythien à Mégare et dans ses colonies, voir Antonetti, Apollon, p. 17-24; Robu, Chalcédoine, p. 137-143 (avec la bibliographie). 
n'existe ni émissions monétaires, ni décrets émanant de ces établissements. Il est donc permis de penser que ces trois sites n'ont pas dépassé le niveau de centres urbains secondaires dans le territoire d'Astacos.

Du reste, l'installation des Mégariens dans le golfe d'Astacos peut être considérée comme une étape importante avant la colonisation des abords du détroit de Bosphore. On a là affaire à une colonisation par étapes, entièrement compréhensible si l'on envisage l'hypothèse que les apoikiai mégariennes constituaient un véritable «réseau», comparable par exemple au «réseau» chalcidien à l'ouest (voir la relation entre Zancle, Rhégion et Mylai pour le détroit de Messine $)^{398}$. L'installation des Mégariens sur la côte asiatique de la Propontide fut analogue à celle qu'ils accompliront sur la côte européenne: Astacos précéda la fondation de Chalcédoine, tandis que Byzance fut précédée par Sélymbria.

Un tel «réseau» unitaire liant les établissements mégariens entre eux ne visait pas strictement un but commercial à long terme, thèse toujours suspecte de pécher par excès de modernisme. En effet, même si l'on ne peut pas exclure complètement un intérêt commercial dans la colonisation mégarienne ${ }^{399}$, ce qui compte au VII siècle c'est surtout la capacité des apoikoi de s'établir dans des régions occupées par des populations qui pouvaient leur être hostiles, et de réussir à délimiter des territoires suffisants pour leurs habitants ${ }^{400}$. La solidarité entre les cités, très souvent sous-estimée par les savants modernes, jouait à l'époque un rôle essentiel dans cette entreprise, et elle a été l'une des raisons pour lesquelles les Mégariens ont réussi à implanter avec succès leurs colonies en Propontide. Les auteurs antiques attestent que les populations indigènes (les Thraces, les Mysiens, les Bithyniens), qui entouraient les territoires des colonies, constituaient une menace permanente. Dans le cas de la fondation de Byzance, les colons, confrontés à une forte opposition des tribus thraces, ont dû faire appel à leurs voisins de

398 Pour la notion des «réseaux ethniques » et le contrôle des détroits par des établissements d'une même métropole, voir J.-P. Morel, «La colonisation grecque jusqu'à la fin de l'archaïsme», L'information historique 57, 1995, p. 200; idem, «Problématiques de la colonisation grecque en Méditerranée occidentale: l'exemple des réseaux », in Antonetti (éd.), Il dinam. della colon. gr., p. 64 ; Malkin, Networks, p. 5674 ; Robu, Réseaux, p. 183-189.

399 Voir supra, chapitre I.4.

400 Finley, Sur l'hist. ancienne, p. 122, rappelle, à juste titre, que «dans l'Antiquité, la première chose à faire quand on fonde une cité, c'est d'établir les nouveaux venus sur le sol». 
l'autre rive du Bosphore. Grâce à l'aide qu'il prêta aux Byzantins, Deinias de Chalcédoine est perçu comme un nouveau fondateur de la citét01.

De plus, on sait qu'il y avait aussi des mouvements de colonisation concurrents (milésien, samien) en Propontide. À cet égard, il convient d'évoquer la Question grecque LVII de Plutarque, qui témoigne d'un conflit ayant opposé les Mégariens aux Samiens ${ }^{402}$. Cette guerre, provoquée par la fondation de Périnthe vers 602 par les Samiens, constitue un exemple de solidarité des Mégariens face à un ennemi qui menaçait leur hégémonie sur la côte nord-est de la Propontide ${ }^{403}$. En me penchant ailleurs sur ce passage, j'ai essayé de montrer que les Mégariens en question n'étaient pas nécessairement les Mégariens de Grèce, comme on l'a souvent $\mathrm{cru}^{404}$, mais surtout les Mégariens de Propontide ${ }^{405}$. Car ce sont les colonies de Byzance et de Sélymbria qui étaient les cités directement menacées par la fondation de Périnthe, la nouvelle installation samienne étant située dans leur voisinage. Plutarque utilise le terme générique de Mégareis pour désigner les combattants contre les Samiens et ce terme pouvait aussi être employé pour des colons de Mégare. De fait, Vatin a bien montré que les colons grecs manifestaient une volonté de se rapporter à l'ethnique de leur métropole pour définir leur propre identité, et cela notamment à une époque proche de la fondation de la colonie $^{406}$. Il va de soi que l'on ne peut pas exclure que des Mégariens de Grèce, en suivant l'exemple des Samiens, aient envoyé des renforts à leurs apoikoi, mais rien n'est moins sûr.

401 Voir infra, chapitre II.2.4.1.7.

402 Plutarque, Questions grecques, LVII (= Moralia 303 E-304 C).

403 Pour la date de fondation de Périnthe, voir Eusèbe, Chron., St. Jérôme (éd. A. Schoene, p. 91 ; = éd. R. Helm, p. 98b); cf. G. Shipley, A History of Samos, Oxford 1987, p. 51-52; Loukopoulou, Thrace propontique, p. 53-56; Sayar, Perinthos-Herakleia, p. 71 ; Veligianni-Terzi, Hellenides poleis, p. 50-51.

404 Burn, Gr. Sea Power, p. 172-174; Halliday, Gr. Questions, p. 212; Graham, Colony, p. 74; idem, Colonial Expansion, p. 120; E. Schönert, «Zur Geschichte der Stadt Perinthos», Altertum 8, 2, 1962, p. 73; Legon, Megara Pol. Hist., p. 120-122; Figueira, Chronological Table, p. 287-288; G. Shipley, op. cit., p. 52-53; S. Verger, CRAI, 2003, 1, p. 552.

405 Beloch, Gr. Gesch. ${ }^{2}$, I, 1, p. 359-360, n. 3 ; Loukopoulou, Thrace propontique, p. 55; L. Loukopoulou, A. Lajtar, s.v. «Perinthos», in Hansen-Nielsen (éds.), Inventory, p. 920. Pour la guerre de Périnthe, je renverrai à Robu, Réseaux, p. 184-187. Une explication similaire peut être fournie pour la guerre entre les Mégariens et les Milésiens, mentionnée par une inscription de Milet: voir infra, chapitre II.2.4.1.3.

406 Vatin, Citoyenneté et ethnique, p. 71-80. 
Comme j'ai rejeté plus haut l'hypothèse selon laquelle les «Mégariens », désignés par les auteurs antiques en tant que fondateurs d'Astacos, étaient des Chalcédoniens, il peut paraître surprenant que je considère les «Mégariens» qui se sont opposés aux Samiens comme originaires des colonies de Propontide, et non pas de Mégare de Grèce. Ce qui fait, à mes yeux, la différence entre les deux situations, c'est la nature des sources. Dans le premier cas, il s'agit d'une tradition fournie par des historiens d'Héraclée du Pont, de bons connaisseurs de l'histoire des colonies mégariennes, dans le deuxième, d'une tradition samienne. Pour bien comprendre notre passage il ne faut pas oublier que Plutarque mentionne une tradition de Samos et non pas de Mégare: la Question grecque LVII vise à offrir au lecteur une explication du nom d'un bâtiment samien célèbre, le «dépôt des entraves ${ }^{407}$. On apprend que cette appellation était due aux entraves des prisonniers mégariens qui avaient aidé les Samiens dans leur coup d'État contre les aristocrates. La tradition samienne a tendance à offrir une image homogène des Mégariens. Le texte n'évoque que le conflit entre les Samiens et les Mégariens, sans mentionner le rôle des Byzantins et des Sélymbriens dans cette guerre, assurément les principales parties concernées par la dispute. Cela s'explique par le fait que ce qui comptait à Samos, c'était l'aide prêtée par les Mégariens au renversement de l'«oligarchie des propriétaires terriens» ( $\gamma \varepsilon \omega \mu$ ó $\rho \omega v$ ỏ $\lambda \imath \gamma \alpha \rho \chi i ́ \alpha)$, et non pas l'action militaire menée en Propontide $^{408}$. En honorant les Mégariens par un bâtiment où les entraves de ceux-ci étaient consacrées, les Samiens n'envisageaient pas de fournir un témoignage d'une action politique externe (la guerre de Périnthe), mais de garder le souvenir de l'appui des «Mégariens» dans une affaire interne (le changement de régime politique). Bref, toutes ces

407 Okin, Theognis, p. 11-13, suggère deux sources possibles pour la Question grecque LVII : la Constitution des Samiens d'Aristote, déjà utilisée par Plutarque dans sa Vie de Solon, et la Chronique samienne de Douris de Samos. À cet égard, voir aussi Halliday, Gr. Questions, p. 212; P. Payen, «Rhétorique et géographie dans les Questions romaines et Questions grecques de Plutarque», in Plutarque: Grecs et Romains en Questions, Entretiens d'archéologie et d'histoire 4, P. Payen (éd.), SaintBertand-de-Comminges 1998, p. 54, 68, n. 40.

408 Pour les liens entre Périnthe et sa métropole à l'époque archaïque, on rappellera ici l'inscription (datant de $c a$. 580-570) qui atteste que deux Périnthiens ont consacré comme dîme à Héra de Samos divers objets : IG XII 6, 577 ; $c f$. J. et L. Robert, Bull. ép., 1954, 205; Loukopoulou, Thrace propontique, p. 96-103. 
raisons me font croire que le passage de Plutarque ne peut pas être utilisé pour montrer une domination ou un protectorat exercé par la métropole mégarienne sur ses colonies, mais qu'il doit être interprété comme un indice de la solidarité entre les Mégariens de la Propontide face à la menace d'un mouvement de colonisation concurrent.

Revenons maintenant à la tradition de Charon de Lampsaque portant sur la fondation d'Astacos par Chalcédoine, qui par ailleurs, nous

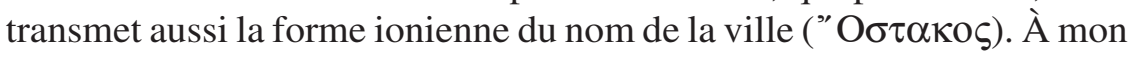
sens, ce récit pourrait faire référence à des époikoi de Chalcédoine venus ultérieurement s'adjoindre aux premiers colons mégariens, probablement confrontés aux incursions des indigènes des alentours ${ }^{409}$. Cela n'a rien d'exceptionnel pour deux cités voisines ${ }^{410}$. Le passage de Memnon atteste que la cité d'Astacos a dû subir fréquemment les attaques de ses voisins (les homorountes sont sans aucun doute des Mysiens et/ou des Bithyniens). La réduction de la contribution qu'Astacos devait payer en tant que membre de la Ligue de Délos de 11/2 talent à 1.000 drachmes en 450/49 est expliquée par De Sanctis comme une conséquence de la guerre que la cité a dû mener contre ses voisins bithyniens ${ }^{411}$.

D'autres récits confirment que les relations entre les Grecs et les $\mathrm{Bi}$ thyniens étaient très tendues. Ainsi, Xénophon rapporte que les Bithyniens traitaient cruellement tous les Grecs qui abordaient sur leur côte ${ }^{412}$. Diodore atteste que les Byzantins et les Chalcédoniens ont dévasté vers 416 le territoire bithynien et, après avoir occupé plusieurs villages, ils ont massacré tous les prisonniers, hommes, femmes et enfants ${ }^{413}$. En outre, on sait que le dynaste bithynien Zypoitès assiège en 315 simultanément Astacos et Chalcédoine, qui étaient alliées dans cette guerre. Le stratège d'Antigone Monophthalmos, Polémaios, est intervenu pour

409 De même, Roebuck, Ionian Trade, p. 115, estime que la tradition de Charon «may, of course, only indicate a Chalcedonian reinforcement».

410 Sur la foi de Strabon, XII, 4, 2, C 563, qui atteste que le littoral chalcédonien fait suite au golfe d'Astacos, on est autorisé à penser que les territoires des deux cités étaient contigus. $C f$. Fernoux, Notables, p. 28.

411 De Sanctis, Astakos, p. 480; cf. ATL, I, p. 472; III, p. 39, p. 288, n. 68. Sur l'appartenance d'Astacos à la Ligue de Délos, voir aussi infra, chapitre II.2.1.3.

412 Xénophon, Anabase, VI, 4, 2.

413 Diodore, XII, 82, 2. Un passage de Plutarque, Alcibiade, 29, 6, suggère pourtant l'existence à cette époque d'une alliance entre les Chalcédoniens et certains chefs bithyniens. $C f$. H.-L. Fernoux, «Guerres, cités et mondes indigènes du Pont-Euxin et de la Propontide aux V ${ }^{\mathrm{e}}$ et IV ${ }^{\mathrm{e}}$ siècles av. J.-C.», Pallas 51, 1999, p. 188. 
mettre fin aux hostilités et faire entrer les belligérants dans une alliance avec Antigone ${ }^{414}$. Pourtant, ceci ne fut qu' un épisode de cette guerre, car Plutarque évoque une autre incursion des Chalcédoniens dans le royaume de Zypoitès. Les Chalcédoniens sont vaincus dans la bataille de Phalion et ce n'est que grâce à l'intervention de Byzance qu'ils ne sont pas complètement anéantis, ce qui représente un exemple de plus de la solidarité mégarienne en Propontide ${ }^{415}$. Tous ces combats entre les Bithyniens et les Grecs nous montrent que l'alliance entre les cités mégariennes était un élément important pour leur survie. Dans ces conditions, il est probable que le renforcement de la cité par Chalcédoine s'est déroulé dans le contexte des guerres entre Astacos et les Bithyniens. Ces renforts ont pu être considérés par les auteurs antiques comme une nouvelle fondation de la cité. On aurait ainsi une situation similaire à celle de Byzance qui, à cause d'une forte opposition thrace, a reçu des colons supplémentaires de Chalcédoine ${ }^{416}$.

Par ailleurs, il convient de dire qu'une autre cité mégarienne, Héraclée du Pont, a manifesté de l'intérêt pour la cité d'Astacos, à l'époque de la tyrannie de Cléarque. De fait, grâce au récit du Polyen, on sait que Cléarque a mené entre 363-352 une campagne d'été contre Astacos ${ }^{417}$. Ce siège, qui a d'ailleurs échoué, n'est pas facile à interpréter, d'autant plus qu'il s'agit de la seule expédition militaire attribuée par les sources au tyran héracléote. Burstein a repoussé, avec raison, l'opinion de Polyen, selon laquelle la campagne de Cléarque était destinée à anéantir un grand nombre de citoyens d'Héraclée. Ceci est sans nul doute une explication créée a posteriori pour incriminer le tyran. Burstein considère que par l'occupation d'Astacos, Cléarque a cherché à obtenir des points d'appui sur la côte méridionale de la Propontide ${ }^{418}$. Sans

414 Diodore, XIX, 60, 3 ; cf. D. Glew, «Nicomedes' Name», EA 38, 2005, p. 136-137.

415 Plutarque, Questions grecques, XLIX (= Moralia 302 E-F), rapporte que 8.000 Chalcédoniens périrent dans la bataille de Phalion. Sur les combats entre Zypoitès et Chalcédoine, alliée à Astacos, voir Vitucci, Regno di Bitinia, p. 14-16.

416 Voir infra, chapitre II.2.4.1.7.

417 Polyen, II, 30, 3.

418 Burstein, Heraclea, p. 55-56. Bittner, Herakleia, p. 29, 31, estime que l'attaque d'Astacos constitue aussi une mesure prise par Cléarque pour légitimer sa tyrannie. Bien que possible, cette interprétation n'explique pas le choix du tyran héracléote, qui pouvait toujours trouver une légitimité militaire dans les guerres avec les voisins indigènes ou grecs d'Héraclée du Pont. 
rejeter cette interprétation, je crois qu'il faut prendre aussi en compte les liens de parenté (syngéneia) qui unissent les deux cités mégariennes. En vertu de ces liens, il est possible qu'une faction politique d'Astacos ait fait appel au tyran d'Héraclée. Cette faction pouvait ne pas être favorable au protectorat bithynien sur la colonie mégarienne et c'est peut-être la raison pour laquelle elle cherchait l'aide de sa cité-sœur du Pont-Euxin face aux indigènes. Car Polyen rapporte que les Bithyniens étaient les alliés d'Astacos dans la guerre contre les Héracléotes de Cléarque (voir ci-après).

En conclusion, les événements analysés ci-dessus appuient l'idée qu'il n'y a pas de raisons pour rejeter la tradition de Memnon sur la fondation d'Astacos par Mégare vers la fin du VIII siècle. Quant à la tradition de Charon de Lampsaque, elle peut être expliquée soit par l'envoi de colons supplémentaires (époikoi) par Chalcédoine pour aider les habitants d'Astacos dans leurs guerres contre les Mysiens et les Bithyniens, soit éventuellement par une occupation chalcédonienne d'Astacos ${ }^{419}$. Il est hautement probable qu'en raison de ses difficultés à préserver son territoire, Astacos ait souvent fait appel à ses cités-sœurs plus puissantes, Chalcédoine et Héraclée du Pont. Comme nous le verrons dans le chapitre suivant, la proximité du royaume bithynien entraîne la perte de l'indépendance d'Astacos, qui, après avoir connu une colonisation athénienne, finit par être annexée à la nouvelle cité de Nicomédie.

\section{II.2.1.3 L'occupation athénienne et bithynienne d'Astacos}

Outre la fondation d'Astacos par les Mégariens, les sources textuelles témoignent de deux autres événements fort importants pour l'histoire de la cité: l'occupation athénienne d'une part, et la refondation bithynienne, d'autre part.

En ce qui concerne les rapports entre Astacos et Athènes, les inscriptions confirment que la colonie mégarienne a été membre de la Ligue de Délos. Le montant de la contribution versée par Astacos au trésor de

419 Asheri, Astakos, p. 94, suggère qu'après la destruction d'une première colonie mégarienne par les Cimmériens, les Chalcédoniens ont refondé la ville d'Astacos. Une hypothèse difficile à accepter, étant donné que cette destruction cimmérienne d'Astacos n'est pas attestée par les sources antiques. 
la Ligue est connu pour quatre ou cinq ans (entre $454 / 3$ et $444 / 3)^{420}$. Suivant le texte de Memnon (FGrHist 434 F 12) déjà cité, Astacos a été colonisée par les Athéniens, qui s'y sont installés après les Mégariens

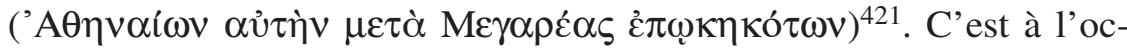
cupation athénienne que fait aussi référence Strabon (sur les traces du même Nymphis) quand il désigne les Athéniens et les Mégariens en tant que fondateurs de la cité. Sur la foi d'une émendation proposée par Niese à un passage de Diodore ${ }^{422}$, l'installation des Athéniens à Astacos est datée de 435-434 ${ }^{423}$. Une colonie athénienne en Propontide avait un double avantage pour Athènes: fournir à ses citoyens des lots de terres et protéger le passage du blé venant du Pont.

Les rapports entre Astacos et les Bithyniens constituent un autre élément qui a influencé le développement de la colonie mégarienne. Comme il a déjà été signalé, la cité semble avoir été confrontée à plusieurs reprises aux attaques de ses voisins indigènes. Mieux, Dœdalsès, le souverain bithynien de la deuxième moitié $\mathrm{du} \mathrm{V}^{\mathrm{e}}$ siècle, est inclus par Strabon parmi les fondateurs d'Astacos, après les Mégariens et les Athé-

420 Les années pour lesquelles nous savons qu' Astacos paye sa contribution à la Ligue de Délos sont les suivantes: 454/3 (IG I ${ }^{3}$ 259, III, $27: 1$ talent et 3.000 drachmes), 453/2 (IG I $\mathrm{I}^{3} 260$, VII, 18 : 1 talent et 3.000 drachmes), 450/49 (IG I ${ }^{3} 263$, IV, 16 : 1.000 drachmes), 445/4 (IG I $\mathrm{I}^{3}$ 267, I, 33 : 1.000 drachmes), 444/3 (IG I $\mathrm{I}^{3}$ 268, I, 33 : 1.000 drachmes). $C f$. ATL, I, p. 238 ; III, p. 21, 56, 270, 288, n. 68. Il convient de rappeler, toutefois, que pour l'année 444/3 le nom de la ville d'Astacos est presque entièrement restitué.

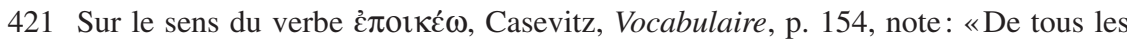

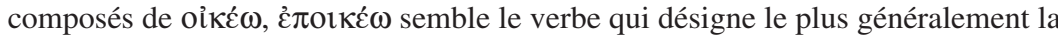
colonisation en tant qu'installation dans un pays soit avec d'autres habitants soit après de précédents colonisateurs ».

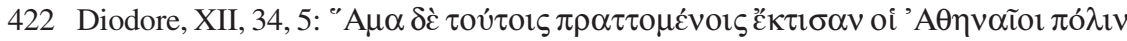

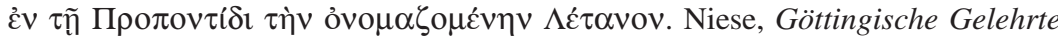

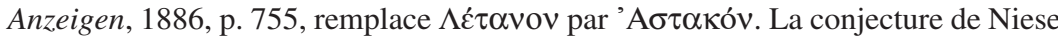
est acceptée par C. H. Oldfather (éd.), Diodorus of Sicily. Books IX-XII, 40, London 1970. Cf. M. Casevitz (éd.), Diodore de Sicile, Bibliothèque historique, Livres XII, Paris 1972, p. 36, n. 1.

423 De Sanctis, Astakos, p. 479; J. Toepffer, op. cit., p. 129; H. Nesselhauf, Untersuchungen zur Geschichte der delisch-attischen Symmachie, Klio Beiheft 30, Leipzig 1933, p. 55, n. 1 ; ATL, I, p. 471-472, 603; III, p. 288; IV, p. 151, s.v. «Astakos »; R. Meiggs, The Athenian Empire, Oxford 1972, p. 198; W. Schuller, Die Herrschaft der Athener im Ersten Attischen Seebund, Berlin-New York 1974, p. 30-31, 155; P. Debord, L'Asie Mineure au IV e siècle (412-323 a.C.). Pouvoirs et jeux politiques, Paris-Bordeaux 1999, p. 91 ; Avram, Astakos, p. 977. 
niens ${ }^{424}$. Memnon atteste que sous le protectorat de Dœedalsès, les attaques des voisins sur Astacos ont cessé et la cité a connu une période d'épanouissement ${ }^{425}$. Ces témoignages suggèrent qu'après l'occupation athénienne, les Bithyniens de Dodalsès ont réussi, vers la fin du $\mathrm{V}^{\mathrm{e}}$ siècle, à imposer leur protectorat sur Astacos ${ }^{426}$. D'ailleurs, on remarque que vers le milieu du IV ${ }^{\mathrm{e}}$ siècle, au moment du siège d'Astacos par Cléarque, le tyran d'Héraclée du Pont, les Bithyniens sont probablement les alliés, voire même les protecteurs de la cité ${ }^{427}$.

D'autre part, une tradition transmise par Pausanias établit un lien entre Zypoitès et Astacos:

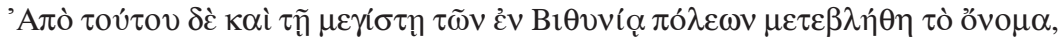

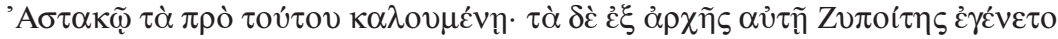

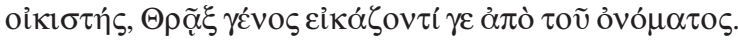

C'est à partir de son règne (le règne de Nicomède) que l'on changea le nom de la capitale de Bithynie, que l'on appelait auparavant Astacos. Son fondateur fut Zypoitès, un Thrace d'origine si on peut l'inférer d'après son nom ${ }^{428}$.

En ce qui concerne l'historicité de ce récit, Leschhorn estime qu'après la destruction de Lysimaque, attestée par Strabon (XII, 4, 2, C 563), le souverain bithynien a reconstruit la ville. Et c'est effectivement cet exploit qui a pu déterminer les habitants à le regarder comme un nouveau fondateur ${ }^{429}$. On aurait ainsi une situation similaire à celle de Byzance, lorsque le général spartiate Pausanias, après avoir libéré la cité de l'occupation perse, fut honoré en tant que nouveau fondateur ${ }^{430}$.

424 Strabon, XII, 4, 2, C 563. Sur Dœdalsès de Bithynie, voir E. Meyer, s.v. «Bithynia», RE III, 1899, col. 515.

425 Memnon, FGrHist 434 F 12; cf. J. Toepffer, op. cit., p. 127, n. 1, qui note au sujet du

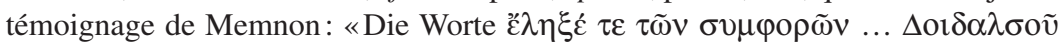

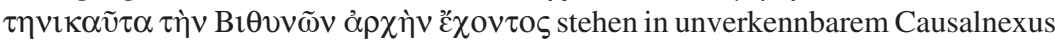
miteinander, während der vorausgehende Genitivus absolutus bloß temporale Bedeutung hat».

426 Meritt, Wade-Gery, McGregor, ATL, I, p. 472, pensent que l'occupation d'Astacos par Dœdalsès date de $c a$. 405, au moment de l'effondrement de l'empire athénien. Cf. P. Debord, op. cit., p. 91.

427 Polyen, II, 30, 3, note que Cléarque, au moment du siège d'Astacos, craignait une attaque des Thraces, c'est-à-dire des Bithyniens.

428 Pausanias, V, 12, 7 (trad. J. Pouilloux, CUF).

429 Leschhorn, Gründer, p. 269-270; cf. Jacoby, FGrHist III B, p. 277.

430 Voir infra, chapitre II.2.4.1.2. 
Pour la reconstruction des faits, on peut ainsi envisager qu'après un siège raté de Zypoitès en $315^{431}$ et probablement à cause de la défaite des Chalcédoniens à Phalion, Astacos aurait été obligée de se soumettre aux Bithyniens. Dans ces conditions, la destruction d'Astacos par Lysimaque (avant 281) serait l'une des conséquences des conflits entre Zypoitès et Lysimaque ${ }^{432}$. Après cet événement, le roi bithynien a probablement rebâti la ville, un exploit qui lui a valu aux yeux de certains le titre d'œciste.

On sait par ailleurs que Zypoitès a été le premier des dynastes bithyniens à avoir pris le titre de roi (en 297/6), en essayant d'imiter les diadoques dans leur rôle de fondateurs (ktistai) de cités. Il créa ainsi au pied du mont Lypéros une ville à laquelle il donna son nom

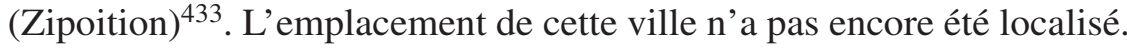
En s'appuyant sur le récit de Pausanias qui considère Zypoitès comme le fondateur d'Astacos/Nicomédie, Jones suggère que la cité de Zipoition est à identifier avec la cité qui est connue plus tard sous le nom de Nicomédie ${ }^{434}$. En faveur d'une telle hypothèse, on peut invoquer la notice d'Eusèbe sur la fondation de Nicomédie, selon laquelle Nicomède $\mathrm{I}^{\mathrm{er}} \mathrm{n}$ 'a fait qu'élargir la ville et en changer le nom ${ }^{435}$. Cependant, étant donnée l'absence d'une documentation archéologique, l'identification de Zipoition avec Nicomédie reste encore à être confirmée par de futures trouvailles.

En revanche, l'opinion de Beloch selon laquelle ce n'est pas la prise du titre de roi par Zypoitès, mais l'occupation d'Astacos qui marque le début de l'ère bithynienne, est moins probable et elle n'a pas été

431 Diodore, XIX, 60, 3.

432 B. Niese, Geschichte der griechischen und makedonischen Staaten seit der Schlacht bei Chaeronea, I, Gotha 1893 (rémpr. Darmstadt 1963), p. 399; E. Meyer, Die Grenzen der hellenistischen Staaten in Kleinasien, Zürich-Leipzig 1925, p. 109; Fernoux, Notables, p. 34-35.

433 Memnon, FGrHist 434 F 12; Stéphane de Byzance, s.v. Zıлoí $\imath$ ov. Pour la fondation de Zipoition et l'imitation de dynastes hellénistiques par le roi bithynien, voir Vitucci, Regno di Bitinia, p. 20-21.

434 A.H.M. Jones, The Cities of the Eastern Roman Provinces ${ }^{2}$, Oxford 1971, p. 419, n. 6.

435 Eusèbe, Chron. (éd. R. Helm, p. 131): Nicomedes rex Bithyniae urbem amplians Nicomediam nuncupauit. Sur l'historicité de ce récit, voir Jacoby, FGrHist III B, p. 277. 
généralement retenue par les modernes ${ }^{436}$. Car cette conquête n'est pas considérée comme un événement suffisamment important pour provoquer la prise d'une telle mesure ${ }^{437}$. Il convient finalement de souligner qu'une reconstruction bithynienne de la ville mégarienne par Zypoitès, après la destruction de Lysimaque, rend aussi plus compréhensible un transfert de la population d'Astacos à Nicomédie, ce dont Strabon témoigne. Le Géographe rapporte que les habitants d'Astacos furent transférés par le fils de Zypoitès, le roi Nicomède $\mathrm{I}^{\mathrm{er}}$, dans sa nouvelle capitale, fondée vers $265-261^{438}$.

\section{II.2.1.4 Les rapports entre Astacos, Olbia et Nicomédie}

Même si l'histoire d'Astacos en tant que polis cessa après 261, la nouvelle fondation de Nicomédie assura à la cité mégarienne une certaine continuité. Je me propose d'examiner ici les liens qui unissent Astacos, Olbia et Nicomédie, trois établissements situés dans la même région géographique, à savoir le golfe dit d'Astacos ou d'Olbia (actuellement le golfe d'İzmit).

Tout d'abord, il est intéressant de s'arrêter sur les traditions littéraires à propos de l'origine du héros éponyme d'Astacos. Une généalogie fournie par Memnon signale que le fondateur de la cité était un descendant de ceux que l'on nommait à Thèbes les «Spartes» et les

436 Beloch, Gr. Gesch. ${ }^{2}$, IV, 1, p. 234, n. 1: «Es ist möglich, daß das Epochenjahr der bithynischen Ära 297 eben an die Eroberung von Astakos anknüpft». Cf. aussi W. Leschhorn, Antike Ären. Zeitrechnung, Politik und Geschichte im Schwarzmeerraum und in Kleinasien nördlich des Tauros, Historia Einzelschriften 81, Stuttgart 1993, p. 185-187, sur la possibilité que Zypoitès ait pris le titre de roi suite à une victoire contre Lysimaque, événement connu grâce à Memnon, FGrHist $434 \mathrm{~F}$ 12, 5.

437 Vitucci, Regno di Bitinia, p. 16, n. 3; C. Habicht, s.v. «Zipoites» 1, RE XIX A, 1972, col. 452. À propos du choix de la date d'une conquête pour inaugurer une ère, on rappellera le cas de l'ère séleucide, qui commence en 312, quand Séleucos ${ }^{\mathrm{er}}$ a conquis les satrapies orientales (ou iraniennes), et non pas en 306/5, quand il a pris le titre de roi. Cf. Will, Histoire ${ }^{2}$, I, p. 66-67, 76. Les documents dont on dispose ne permettent pas de savoir si le début de l'ère bithynienne est aussi marqué par une annexion territoriale (Astacos?).

438 Strabon, XII, 4, 2, C 563. Pour la datation du synœcisme de Nicomédie peu avant 260, voir Vitucci, Regno di Bitinia, p. 27-28, et Leschhorn, Gründer, p. 271 (avec les références). 
Fils de la Terre ${ }^{439}$. Asheri interprète ce mythe comme un indice d'une participation béotienne à la colonisation du golfe d'Astacos ${ }^{440}$. Pourtant, cette hypothèse, tout séduisante qu'elle puisse paraître, se heurte au silence des sources. Et l'on ne peut pas exclure que la généalogie prestigieuse du héros Astacos ne soit qu'un signe des relations étroites qui existaient entre les Mégariens et les Béotiens dans le domaine de la mythologie. On rappelle que le héros éponyme de Mégare était, lui aussi, un Béotien, venu d'Onchestos ${ }^{441}$.

Par ailleurs, Arrien transmet une deuxième tradition, probablement plus locale, selon laquelle le nom de la cité venait du héros Astacos, fils de Poséidon et de la nymphe Olbia ${ }^{442}$. En ce qui concerne cette dernière divinité, on sait, grâce sans doute aux mêmes Bithyniaka d'Arrien qui ont été repris par Stéphane de Byzance au VI siècle ap. J.-C., qu'elle était considérée comme l'éponyme d'une autre cité de Bithynie ${ }^{443}$. Ces récits établissent clairement une liaison mythologique entre Astacos et Olbia. Conformément à cette tradition, l'œciste d'Astacos était le fils de Poséidon et de la nymphe éponyme de la cité d'Olbia. Ce dernier site se trouvait dans le golfe moderne d'İzmit, un golfe qui, on l'a vu, dans l'Antiquité était souvent désigné comme le golfe d'Olbia. Malheureusement, on ne connaît rien sur l'histoire d'Olbia. Celle-ci apparaît dans le Périple du Ps.-Scylax (au IV ${ }^{\mathrm{e}}$ siècle) comme un établissement indépen-

439 Memnon, FGrHist $434 \mathrm{~F} 12$.

440 Asheri, Astakos, p. 94-98. La même opinion chez Fossey, Boiotia and the Pontic Cities, p. 109. Cf. H. W. Stoll, s.v. «Astakos» 2, in Roscher, Lexikon, I, 1, col. 645, sur le héros Astacos, originaire de Thèbes.

441 Voir supra, chapitres I.1.1.

442 Arrien, FGrHist 156 F 26, cité par Stéphane de Byzance, s.v. 'A $\sigma \tau \alpha \kappa o ́ \varsigma \cdot \pi o ́ \lambda \imath \varsigma$

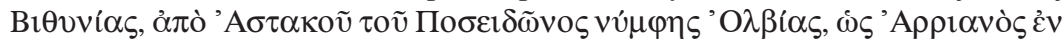

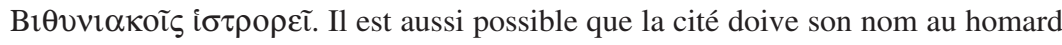
( $\alpha \sigma \tau \alpha \kappa o ́ \varsigma)$ représenté sur ses monnaies : J. Toepffer, op. cit., p. 129-134. Par ailleurs, en s'appuyant sur l'incorporation des noms thraces dans la dénomination d'autres colonies mégariennes (Byzance, Sélymbria, Mésambria), K. Boshnakov, Die Thraker südlich vom Balkan in den Geographica Strabos. Quellenkritische Untersuchungen, Stuttgart 2003, p. 194, et Porozhanov, Founders, p. 515, suggèrent que le nom de la cité d'Astacos émane de celui de la tribu thrace des Astes (voir infra, chapitre II.3.2.2, sur cette tribu). Toutefois, ce rapprochement ne me semble guère nécessaire et les étymologies grecques, évoquées par les documents littéraires et numismatiques (du homard ou d'un fondateur grec mythique, Astacos), sont plus probables (voir aussi la présence d'une cité grecque homonyme en Acarnanie).

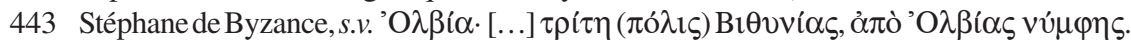


dant équipé d'un port, faisant partie de la Mysie ${ }^{444}$. En revanche, Stéphane de Byzance la considère comme une polis de la Bithynie ${ }^{445}$. La différence de localisation entre les deux auteurs s'explique par le fait que la Mysie sera englobée à l'époque hellénistique dans le royaume bithynien et ultérieurement dans la province romaine de Bithynie ${ }^{446}$.

Olbia n'apparaît pas dans les listes de tributs athéniens et elle ne frappe pas de monnaie. Bien que l'origine de ses fondateurs ne soit pas mentionnée par les sources littéraires, il est probable que cet établissement a été aussi une installation mégarienne, car elle se trouve dans une région occupée par les Mégariens (le golfe d'Astacos/Olbia) ${ }^{447}$. En fait, on a déjà signalé la présence dans cette zone non seulement d'Astacos, mais aussi de deux autres établissements mégariens, le polichnion Mégarikon et Pythion.

Pour expliquer les rapports entre Astacos et Olbia, Vogt et Ruge ont jadis considéré qu'Astacos était le nom initial de la cité, lequel aurait été changé en Olbia après l'installation des Athéniens dans la cité en 435/ $4^{448}$. Pourtant, Ruge a ultérieurement abandonné cette opinion, qui ne se fondait sur rien, tout en préférant l'existence de deux cités ${ }^{449}$. Il est plus probable qu'Olbia a été intégrée dans le territoire d'Astacos, ce qui pourrait expliquer la double appellation de ce golfe ${ }^{450}$. La généalogie qui faisait de l'œciste d'Astacos le fils de Poséidon et de la nymphe d'Olbia aurait alors été créée pour justifier l'absorption d'Olbia par Astacos à une date qu'il est impossible de préciser. Les monnaies frappées au $\mathrm{V}^{\mathrm{e}}$ siècle par Astacos portent au droit un homard, en référence au nom de la cité, et au revers une tête de femme dans un carré creux ${ }^{451}$. Étant donné que l'image des dieux-fleuves ou des nymphes apparaît souvent sur les monnaies des cités grecques, on peut supposer que la divinité représentée

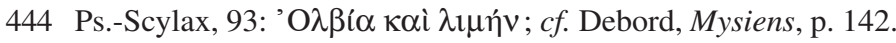

445 Stéphane de Byzance, s.v. 'O $\lambda \beta i ́ \alpha$.

446 Robert, Hellenica, VII, p. 37-38.

447 Avram, Olbia, p. 990.

448 G. Vogt, De rebus Megarensium usque ad bella Persica, Cassel 1857, p. 63 ; Ruge, Astakos, col. 1774.

449 W. Ruge, s.v. «Olbia» 1, RE XVII, 1937, col. 2404: «Nach alledem erscheint mir die Identität von $\mathrm{O}$. und Astakos nicht mehr so wahrscheinlich wie früher ». Contra Jacoby, FGrHist II D, p. 565-566, qui suppose l'identité entre Astacos et Olbia.

450 Avram, Olbia, p. 990.

451 Waddington-Babelon-Reinach, Recueil, I, 2, p. 266, n ${ }^{\text {os }} 1$-6, pl. XLI, n ${ }^{\text {os }}$ 1-6; Head, $H N^{2}$, p. 510. 
sur les monnaies d'Astacos est probablement la nymphe Olbia ${ }^{452}$. Le rôle de Poséidon en tant que père du fondateur d'Astacos est renforcé par la présence d'un sanctuaire consacré à cette divinité, situé sur un promontoire du golfe d'Astacos/Olbia ${ }^{453}$.

Au demeurant, selon une autre tradition fournie par Stéphane de Byzance, la cité de Nicomédie était appelée Olbia ${ }^{454}$. Cependant, sur la foi de ce témoignage, il est difficile d'établir si Nicomédie a été bâtie sur le site d'Olbia ${ }^{455}$ ou si la nouvelle fondation hellénistique a simplement englobé Olbia dans son territoire.

En ce qui concerne la relation entre Astacos et Nicomédie, le passage de Memnon (FGrHist 434 F 12) suggère que Nicomédie ne fut

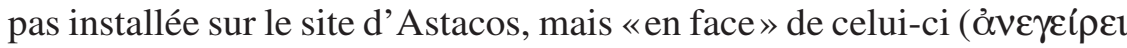

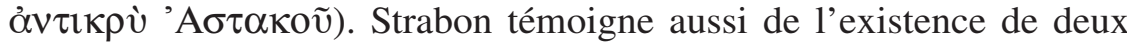
établissements distincts, les habitants d'Astacos étant transférés par Nicomède $\mathrm{I}^{\mathrm{er}}$ dans sa nouvelle capitale ${ }^{456}$. Le même auteur évoque ailleurs la cité acarnanienne d'Astacos comme étant «homonyme de la cité voisine de Nicomédie sur le golfe Astacène ${ }^{457}$. Le changement du nom d'Astacos

452 J. Toepffer, op. cit., p. 133; J. Sölch, «Bithynische Städte im Altertum», Klio 19, 1925, p. 144. Sur la représentation des nymphes locales sur les monnaies des cités grecques, voir F. Imhoof-Blumer, «Nymphen und Chariten auf griechischen Münzen », JIArchNum 11, 1908, p. 7-119, surtout p. 45-47 (Sélinonte), 107 (Astacos); Lacroix, Monnaies et colon., p. 115-129.

453 Pomponius Mela, I, 19, 100: Duo sunt inde modici sinus. Alter sine nomine Cion amplectitur [...], alter Olbianos in promunturio fert Neptuni fanum, in gremio Astacon, a Megarensibus conditam. De même, Ptolémée, Géographie, V, 1, 4, localise dans

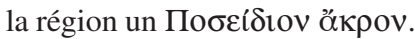

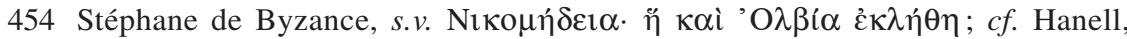
Megarische Studien, p. 121.

455 L'identité entre Olbia et Nicomédie est acceptée par J. Toepffer, op. cit., p. 127; Waddington-Babelon-Reinach, Recueil, I, 2, p. 265, n. 1; V. Tscherikower, Die hellenistischen Städtegründungen von Alexander dem Großen bis auf die Römerzeit, Leipzig 1927, p. 46; A.H. M. Jones, op. cit., p. 150-151; C. Marek, Stadt, Ära und Territorium in Pontus-Bithynia und Nord-Galatia, Tübingen 1993, p. 15 ; P. Debord, «Comment devenir le siège d'une capitale impériale: le <parcours > de la Bithynie», REA 100, 1-2, 1998, p. 144; Fernoux, Notables, p. 36, qui suggère que le choix d'Olbia peut s'expliquer par la proximité des marais pestillentiels qui, à en croire Polyen, II, 30, 3, se trouvaient aux abords d'Astacos.

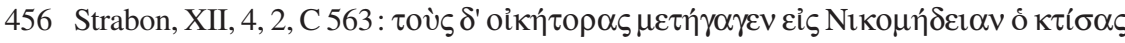
$\alpha$ $\tau$ ๆ́v.

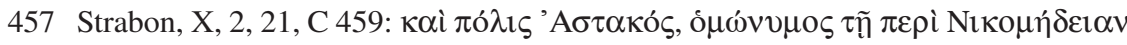

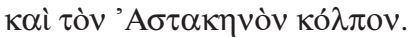


en Nicomédie est signalé par Pausanias ${ }^{458}$ et par la Chronique d'Eusèbe ${ }^{459}$. Et on trouve la même information chez Ammien Marcellin, dans l'Histoire Auguste ${ }^{460}$ et le Chronicon Paschale (VII ${ }^{\mathrm{e}}$ siècle ap. J.-C.) ${ }^{461}$.

En se fondant sur les récits de Ptolémée ${ }^{462}$ et de Constantin Porphyrogénète ${ }^{463}$, qui mentionnent Astacos près de Nicomédie, Ruge suppose qu'une nouvelle localité se développe probablement à l'époque impériale sur le site d'Astacos ${ }^{464}$. Un texte byzantin, la Vie de Théodore de Sykéôn, énumère au VII ${ }^{\mathrm{e}}$ siècle ap. J.-C. Astacos parmi les localités de la région de Nicomédie ${ }^{465}$. La persistance de ce nom ancien rend probable l'hypothèse qu'un site habité, portant le même nom d'Astacos et dépendant de la nouvelle ville bithynienne, ait pu persister, après la fondation de Nicomédie ${ }^{466}$. En effet, on voit que Ptolémée (Géographie, V, 1, 3) cite les trois établissements, Astacos, Olbia, Nicomé-

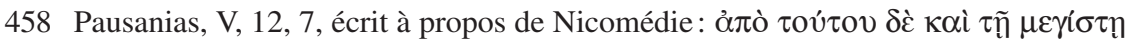

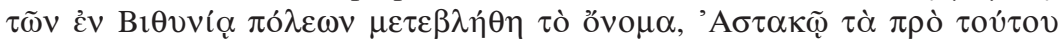

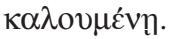

459 Eusèbe, Chron., St. Jérôme (éd. R. Helm, p. 91b): Nicomedia condita, quae prius Astacus uocabatur. La même information est transmise aussi par la version arménienne de cette chronique: éd. J. Karst, p. 183. Voir pourtant un autre passage d'Eusèbe, Chron. (éd. R. Helm, p. 131), qui transmet: Nicomedes rex Bithyniae urbem amplians Nicomediam nuncupauit (voir supra, chapitre II.2.1.3).

460 Ammien Marcellin, Histoires, XXII, 8, 5: <et Astacum>, secuto tempore Nicomediam a rege cognominatam; Histoire auguste. Les deux Galliens, IV, 8: Astacon [...] quae Nicomedia postea dicta est.

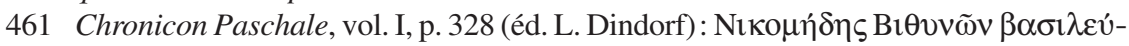

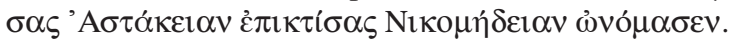

462 Ptolémée, Géographie, V, 1, 3.

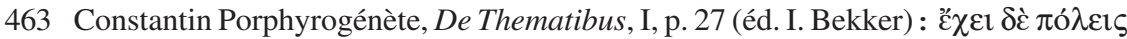

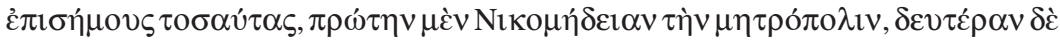

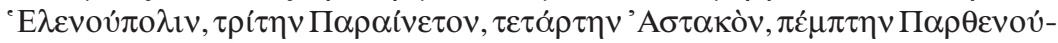
$\pi \mathrm{o} \lambda \mathrm{lv}$.

464 Ruge, Astakos, col. 1774: « vielleicht hat sich später an der Stelle von Astacos wieder eine Ortschaft entwickelt»; $f f$. J. Sölch, op. cit., p. 146, qui envisage aussi cette possibilité.

465 Ce texte dont l'édition est donnée par A. J. Festugière (éd.), Vie de Théodore de Sykéôn, Bruxelles 1970, XXVIII, 157, p. 130, évoque le séjour dans la région de Nicomédie de Théodore, un célèbre thaumaturge et exorciste de la deuxième moitié

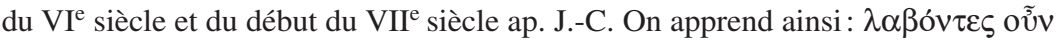

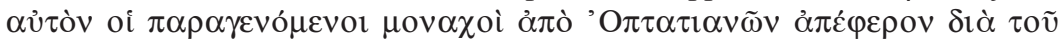

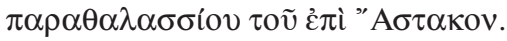

466 J. et L. Robert, Bull. ép., 1974, 574. 
die. Ainsi, la mention d'Olbia et d'Astacos par les auteurs d'époque romaine ou byzantine s'expliquerait d'une manière plutôt satisfaisante par le fait que ces deux sites aient subsisté en tant que bourgs (kômai) dans le territoire de Nicomédie.

Enfin, il convient de préciser que Nicomédie non seulement a accueilli les habitants d'Astacos, mais qu'elle a aussi - afin de se prévaloir d'une ancienneté manifestement plus prestigieuse - fait siennes les traditions et les légendes de cette ville. Preuve en sont quelques épi-

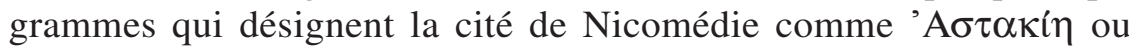
'A $\sigma \alpha \kappa i \eta \eta \gamma \tilde{\eta}^{467}$. En analysant ces textes, Robert note à juste titre que «le nom d'Astacos évoquait une antiquité bien plus reculée que celui de Nikomedes, une origine hellénique et héroïque». Pour prouver son eugeneia («noble origine»), la cité de Nicomédie s'est approprié ainsi les divinités, les héros et les légendes de la colonie mégarienne et il est possible que même le héros Astacos ait été honoré parmi les ktistai («fondateurs») de Nicomédie ${ }^{468}$. On a là un bel exemple d'intégration d'une vieille cité grecque, de ses mythes et de ses cultes dans les nouvelles cités bâties par les souverains hellénistiques.

\section{II.2.2 Chalcédoine}

\section{II.2.2.1 Les récits concernant la fondation de Chalcédoine}

La ville antique de Chalcédoine (X $\alpha \lambda \kappa \eta \delta \omega ́ v$ ou K $\alpha \lambda \chi \eta \delta \omega \dot{v} /$ en dorien K $\alpha \lambda \chi \alpha \delta \omega v^{469}$ ) fut bâtie sur la rive asiatique du Bosphore thrace, sur l'actuel promontoire Kadiköy de la ville turque d'Istanbul. Thucydide est le premier auteur antique à nommer Chalcédoine comme apoikia des Mégariens ${ }^{470}$. En tant que fondation mégarienne, Chalcédoine est

467 IG II ${ }^{2} 8395$; SEG IV, 105 ; Anthologie Palatine, VII, 627 ; 701 (éds. F. Conzia et al.).

468 L. Robert, Rev. Phil. 65, 1939, p. 166-170 (=OpMinSel, II, p. 1319-1323, le passage cité se trouve à la page 1322); idem, À travers l'Asie Mineure, p. 418; cf. C. Habicht, s.v. «Zipoites» 1, RE XIX A, 1972, col. 451. Pour la présence d'Astacos parmi les ktistai de la ville de Nicomédie, voir Leschhorn, Gründer, p. 271-275.

469 Pour la mention de ces trois variantes du nom de Chalcédoine par les sources antiques, voir Avram, Kalchedon, p. 979.

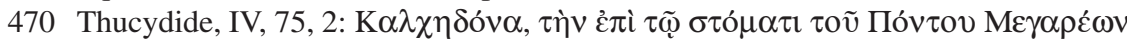

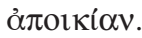


mentionnée aussi par Strabon et par Eustathe ${ }^{471}$; et Archias de Mégare figure comme l'œciste de la cité chez Pomponius Mela ${ }^{472}$. On pourrait identifier ce personnage avec Archias, fils d'Aristônymos, originaire de Thasos, qui, après avoir été repoussé par les Chalcédoniens, aurait fondé, à en croire Denys de Byzance, un site appelé Archeion (aujourd'hui Ortaköy), sur la côte européenne du Bosphore ${ }^{473}$.

Même si la plupart des auteurs attestent l'origine mégarienne de Chalcédoine, une tradition de fondation différente est fournie au VI ${ }^{\mathrm{e}}$ siècle ap. J.-C. par Hésychios de Milet. La mention de l'aide offerte par les Chalcédoniens aux Byzantins dans leur guerre contre les Thraces est une occasion pour Hésychios de faire état des étymologies du nom de Chalcédoine. On apprend ainsi:

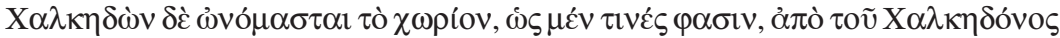

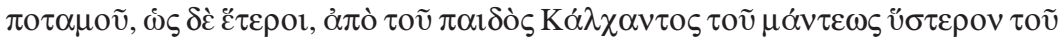

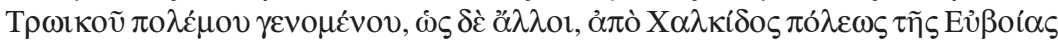

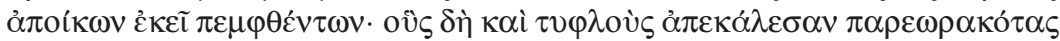

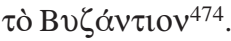

Le pays est appelé Chalcédoine, appellation qui dérive, selon d'aucuns, du nom du fleuve Chalcédoine ${ }^{475}$, selon d'autres, du nom du fils du prophète Calchas qui avait vécu après la guerre de Troie, selon d'autres encore, de la cité de Chalcis d'Eubée, qui y avait envoyé des colons; on avait appelé ceux-là aveugles parce qu'ils avaient délaissé Byzance.

Hanell rejette ce récit attribuant la fondation de Chalcédoine aux Chalcidiens, en considérant qu'il s'agit d'une des nombreuses explications

471 Strabon, VII, 6, 2, C 320; XII, 4, 2, C 563 ; Eustathe, GGM II, 764, p. 349.

472 Pomponius Mela, I, 19, 101 : oppidi nomen Calchedon, auctor Archias Megarensium princeps; $f f$. J. Hind, «Pomponius Mela on colonies in West and East», in Ancient Greeks West and East, G. R. Tsetskhladze (éd.), Leiden et al. 1999, p. 82, suggère qu'il s'agit d'une information erronée et que Pomponius Mela avait peut-être confondu le fondateur de Chalcédoine avec le Corinthien Archias, l'œciste de Syracuse.

473 Denys de Byzance, 48, p. 19-20 (éd. R. Güngerich). Oberhummer, Bosporos, col. 747, identifie Archeion avec la moderne Ortaköy. Cf. Loukopoulou, Thrace propontique, p. $64-65, \mathrm{n} .7$.

474 Hésychios, FGrHist 390 F 21.

475 Denys de Byzance, 111, p. 34 (éd. R. Güngerich), atteste aussi la présence du fleuve Chalcédoine dans la ville mégarienne homonyme. Cette information se trouve aussi

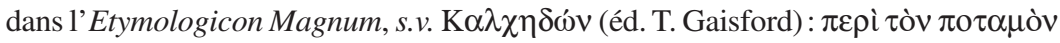

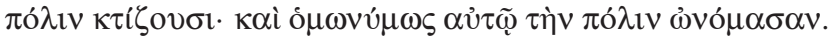


artificielles du nom de la citét76. À part les étymologies légendaires de Chalcédoine mentionnées par Hésychios, il faut ajouter que d'autres variantes circulaient aussi dans l'Antiquité. D'après Arrien, la cité tirait son nom de Calchédon, fils de $\operatorname{Cronos}^{477}$, et selon la tradition retenue par Stéphane de Byzance, du fleuve Chalcis ${ }^{478}$. Une légende transmise au $\mathrm{X}^{\mathrm{e}}$ siècle ap. J.-C. par Syméon Magister et Logothète rapporte que Chalcédoine devait son nom soit au cuivre/bronze ( $\chi \alpha \lambda \kappa o ́ \varsigma)$, soit à la fille de Nicomède, Chalcis ${ }^{479}$. De même, une variante différente de cette légende, fournie par un autre manuscrit byzantin attribué à Syméon, indique que le nom de Chalcédoine dérive de Calchas, un exilé d'Attique, ou, selon d'autres, de la sœur de Nicomède ${ }^{480}$.

Par ailleurs, à en croire Pline, la cité s'appelait auparavant Proce-

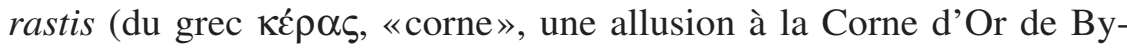

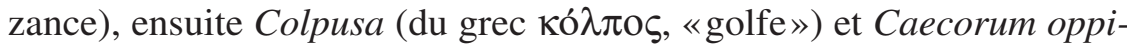
dum («Cité des Aveugles») ${ }^{481}$. Ces appellations, utilisées probablement en tant qu'épithètes poétiques ${ }^{482}$, ont une certaine vocation topographique, deux d'entre elles situant la ville de Chalcédoine par rapport à sa voisine plus célèbre, Byzance.

En analysant les étymologies du nom de Chalcédoine, on remarque d'abord que celles qui attribuent le nom de la cité à un fleuve (Chalcédoine, Chalcis) ne nous sont pas d'un grand secours, car elles ne font que déplacer le problème. Si Chalcédoine reprend le nom d'un fleuve,

476 Hanell, Megarische Studien, p. 122-123. Pour les différentes étymologies du nom de la ville de Chalcédoine, on renverra aussi à Müller, in GGM II, p. XXI, 94-95, n. 6-8; W. Ruge, s.v. «Kalchedon» 1, RE X, 1919, col. 1555.

477 Arrien, FGrHist 156 F 78 (apud Eustathe, GGM II, 803, p. 356).

478 Stéphane de Byzance, s.v. X $\alpha \lambda \kappa \eta \delta \omega ́ v ; ~ c f$. E. Oberhummer, s.v. «Kalchedon» 2, RE X, 1919, col. 1559.

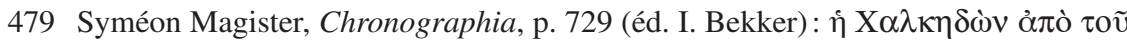

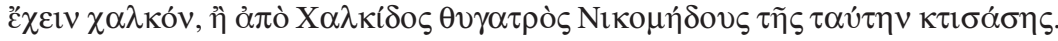

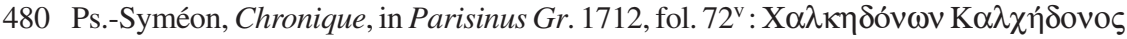

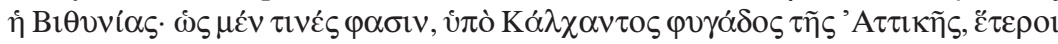

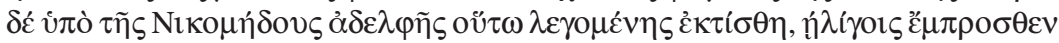

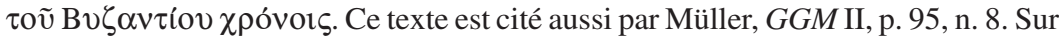
les différents manuscrits de Syméon, voir K. Krumbacher, Geschichte der byzantinischen Literatur von Justinian bis zum Ende des oströmischen Reiches (527-1453) ${ }^{2}$, vol. I, München 1897 (réimpr. New York 1958), p. 200-203, 358-361.

481 Pline, $N H, \mathrm{~V}, 43,149$.

482 Hanell, Megarische Studien, p. 123. 
il reste à s'interroger sur l'origine de ce dernier. Encore faudrait-il trouver le héros éponyme de ces fleuves. Pour ce qui est de la dérivation du nom de Chalcédoine du nom de la fille ou de la sœur de Nicomède $\mathrm{I}^{\mathrm{er}}$, elle est manifestement anachronique et s'explique par l'activité de ce souverain dans la région et par sa célébrité.

Quant à l'attribution du nom de la cité à un éponyme légendaire (Calchas, le fils de Calchas ou le fils de Cronos), je pense qu'il s'agit dans ce cas d'une intention des Chalcédoniens d'assurer à leur cité une antiquité plus reculée et une ascendance prestigieuse ${ }^{483}$. Le cas de Calchas est très éloquent. L'introduction du célèbre prophète dans la généalogie de Chalcédoine venait sans nul doute renforcer le caractère oraculaire du principal sanctuaire de la cité, à savoir le sanctuaire d'Apollon Pythien et Chrestèrios ${ }^{484}$. De surcroît, Camassa considère que Calchas peut être interprété comme le véritable Kurzname de la cité, car si pour la cité de Chalcédoine les appellations X $\alpha \lambda \kappa \eta \delta \omega ́ v$ et K $\alpha \lambda \kappa \eta \delta \omega ́ v$ sont attestées, pour le nom du devin de l'Iliade les formes Kó $\lambda \chi \alpha \varsigma$ et $\mathrm{X} \alpha \dot{\lambda} \kappa \alpha \varsigma$ sont également mentionnées ${ }^{485}$. Les modernes ont même pensé que la tête barbue qui orne les premières monnaies de Chalcédoine, datant de la première moitié du $\mathrm{IV}^{\mathrm{e}}$ siècle, pouvait représenter Calchas ${ }^{486}$.

483 Robu, Chalcédoine, p. 144-146. Un rhéteur de la fin du III ${ }^{\mathrm{e}}$ siècle ap. J.-C., Ménandre, rapporte dans son traité Sur l'éloge des pays, I, 3, 353, 5-19 (éds. D. A. Russell et N. G. Wilson), que la plus haute distinction pour une cité était d'avoir un œciste divin. Ensuite, la deuxième place revenait aux cités fondées par des héros, et finalement, la dernière place aux cités fondées par des mortels.

484 Sur le culte oraculaire d'Apollon de Chalcédoine, voir L. Robert, «Hellenica », RPh 13, 1939, p. 188 (=OpMinSel, II, p. 1341); Rigsby, Megara, p. 94-96; idem, Asylia, p. 164-167; Robu, Chalcédoine, p. 137-155.

485 G. Camassa, «Calcante, la cecità dei Calcedoni e il destino dell'eroe del bronzo miceneo», ASNP serie iii, 10, 1, 1980, p. 28. Contra T. S. Scheer, Mythische Vorväter. Zur Bedeutung griechischer Heroenmythen im Selbstverständnis kleinasiatischer Städte, München 1993, p. 175. Sur Calchas, voir aussi H. W. Stoll, O. Immisch, s.v. «Kalchas », in Roscher, Lexikon, II, 1, col. 921-924; J. Heckenbach, s.v. «Kalchas », RE X, 1919, col. 1552-1555. Le père de Calchas, Thestor, était le fils d'Apollon: G. Türk, s.v. «Thestor» 1, RE VI A, 1, 1936, col. 185.

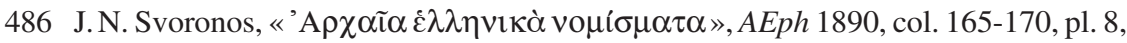
$\mathrm{n}^{\text {os }} 29-31$, identifie la tête d'homme qui orne le droit des premières monnaies frappées par Chalcédoine soit avec Calchas ( ${ }^{\circ} 29$, la tête barbue), soit avec son fils, Calchédon ( $n^{\text {os }} 30-31$, la tête imberbe). Néanmoins, si les savants ont accepté comme probable l'identification avec Calchas, la tête imberbe, elle, est considérée comme une représentation d'Apollon plutôt que du fils de Calchas. À ce propos, voir 
Mieux encore, il est possible que cette tradition qui faisait de Calchas le fondateur mythique de Chalcédoine ait une origine mégarienne et qu'elle ait été apportée par les premiers apoikoi, car, selon Pausanias, les Mégariens de Grèce prétendaient que le devin de l'Iliade était originaire de leur citét87. La légende de Calchédon, fils de Calchas, éponyme de Chalcédoine, établissait pour la nouvelle cité une liaison évidente avec une grande famille de manteis d'origine mégarienne. Une situation analogue se présente à Byzance, où Denys de Byzance atteste le culte rendu par les Byzantins au devin mégarien Polyeidos et à ses fils $^{488}$, ainsi qu'au devin mégarien Lakiadès ${ }^{489}$.

Du reste, la tradition selon laquelle Calchédon, fils de Cronos, était à l'origine du nom de la cité souligne l'intention des Chalcédoniens de s'intégrer aux généalogies locales et de mettre en place des rapports de parenté avec le milieu indigène. Ces rapports auraient pu justifier l'occupation du territoire indigène par les Mégariens. On sait, en effet, que Cronos jouait un rôle important dans les généalogies du peuple thrace $\mathrm{e}^{490}$

G. Camassa, op. cit., p. 31, n. 25 (avec les références). Ces émissions de Chalcédoine sont datées par Waddington-Babelon-Reinach, Recueil, I, 2, p. 290, n ${ }^{\text {os }} 1-5$; Head, $H N^{2}$, p. 511, vers $480\left(n^{\circ} 1\right)$ et de 450 à $400\left(n^{\text {os }} 2-5\right)$. En revanche, suivant M. Price (éd.), SNG 9, pl. IV, ${ }^{\text {os }} 84-85$, ces monnaies ne datent que de 387/6-340.

487 Pausanias, I, 43, 1; cf. Pfister, Mythische Königsliste, p. 34-35. Sur la tradition qui localise le devin Calchas à Mégare, voir Highbarger, Megara, p. 38; Piccirilli, MEGARIKA, p. 118-119; Antonetti-Lévêque, Devins, p. 197-200. Il convient aussi de mentionner l'opinion de E. Maass, «Mythische Kurznamen», Hermes 23, 1888, p. 619-620, selon laquelle cette tradition de Mégare se fonde sur une confusion tardive avec Calchédon, fils de Calchas, le nom de l'œciste de Chalcédoine. Cependant, il me semble que la piste de l'origine mégarienne de la légende de Calchas, fondateur de Chalcédoine, est plus probable, car elle a le mérite de tenir compte des liens cultuels qui existaient entre Chalcédoine et sa métropole (voir à titre d'exemple le transfert du culte d'Apollon Pythien de Mégare à Chalcédoine).

488 Denys de Byzance, 14, p. 7 (éd. R. Güngerich); $c f$. Scholie à Denys de Byzance, 19 (ad 7, 1), p. 37 (éd. R. Güngerich). Par ailleurs, Pausanias, I, 43, 5, rapporte que Polyeidos, descendant de Mélampous, a introduit à Mégare le culte de Dionysos Patrôos. Sur ce devin, voir Hanell, Megarische Studien, p. 100-101, 188; Piccirilli, MEGARIKA,p. 112-113; Antonetti-Lévêque, Devins, p. 201,203;Antonetti, Megara e le sue colonie, p. 94.

489 Denys de Byzance, 49, p. 20 (éd. R. Güngerich).

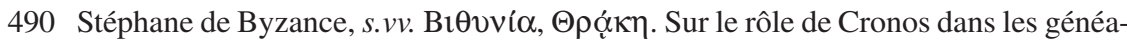
logies des Thraces, voir M. Pohlenz, s.v. «Kronos», RE XI, 1922, col. 2012-2013; Jacoby, FGrHist II D, p. 583. 
et que Cronia était l'un des noms de la Bithynie ${ }^{491}$. En somme, les étymologies qui renvoyaient l'origine du nom de la colonie mégarienne à Calchas, au fils de Calchas ou au fils de Cronos ont été créées par les Chalcédoniens, soit pour renforcer les liens avec leur métropole et les puissances mantiques locales, soit pour englober leur ville dans la mythologie des populations indigènes de la région.

Mais revenons au récit qui atteste la participation des colons d'Eubée à la fondation de Chalcédoine, pour constater que cette tradition ne fait pas sa première apparition chez Hésychios, mais probablement déjà chez Denys le Périégète. Originaire d'Alexandrie et contemporain de l'empereur Hadrien, Denys a écrit un poème intitulé Description de la

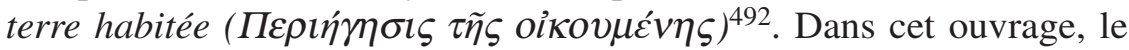
Périégète alexandrin, remarquable pour la langue riche en archaïsmes et pour les formes rares ou désuètes, indique (GGM II, 764) la présence aux abords du Bosphore de la X $\alpha \lambda$ кi Chalcis»). Ensuite, il tient à ajouter:

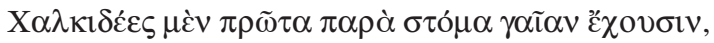

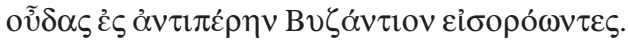

Les Chalcidiens en premier occupent une terre près de l'embouchure et regardent sur la rive opposée le sol de Byzance ${ }^{493}$.

On ne connaît pas la source de ce passage, ce qui n'est pas une exception pour Denys, qui passe habituellement sous silence les auteurs qu'il utilise. En faveur de l'authenticité de cette tradition, Alexandrescu invoque les trouvailles de céramique eubéenne géométrique tardive à Histria (Istros) et à Bérézan (Olbia), ce qui suggérerait l'intérêt des marchands eubéens pour le Pont-Euxin (dès la seconde moitié du

491 Pline, $N H, \mathrm{~V}, 40,142$.

492 Ce n'est qu'en 1884 que G. Leue, «Zeit und Heimat des Periegeten Dionysios », Philologus 42, 1884, p. 175-178, a établi l'origine alexandrine et la datation de Denys le Périégète. À cet égard, voir également C. Jacob, «L'œil et la mémoire: sur la Périégèse de la Terre habitée de Denys », in Arts et légendes d'espace. Figures du voyage et rhétoriques du monde, C. Jacob et F. Lestringant (éds.), Paris 1981, p. 2930, et dernièrement E. Amato (éd.), Dionisio di Alessandria, Descrizione della Terra abitata, Milano 2005, p. 51-67.

493 Denys le Périégète, GGM II, 803-804 (trad. de C. Jacob). 
VIII' siècle $)^{494}$. Pourtant, il convient de rappeler que l'origine histrienne de ces fragments de céramique est incertaine, car il s'agit de pièces qui se trouvent à Cambridge, suite à un don de Lambrino à Rodewald lors d'une visite de ce dernier à Histria. On notera aussi que les fouilles ultérieures n'ont pas mis au jour une telle céramique, ce qui rende suspecte la provenance histrienne du lot de Cambridge ${ }^{495}$. Quoi qu'il en soit, il convient de souligner que la trouvaille d'une telle céramique n'implique pas nécessairement la présence des Chalcidiens à Istros ou à Olbia, des commerçants d'autres origines ayant pu être responsables de l'acheminement de ces objets vers la mer Noire.

Un argument supplémentaire pour la participation des Chalcidiens à la fondation de Chalcédoine serait, d'après Alexandrescu, l'emploi de l'alphabet ionien dans une inscription funéraire de Chalcédoine (datée par Jeffery vers le milieu du VI ${ }^{\mathrm{e}}$ siècle $)^{496}$, ainsi qu'à Mésambria, une colonie des Mégariens et des Chalcédoniens ${ }^{497}$. La légende META qui apparaît sur des monnaies d'argent et de bronze frappées par Mésambria contient un caractère ionien, le sampi avec la valeur de $\sigma$ ou $\sigma \sigma^{498}$. Signalons aussi au passage la similitude qui existe entre le revers des premières monnaies émises à Chalcédoine et à Mésambria, qui présentent dans les deux cas des lettres (KA $\Lambda \mathrm{X}$ ou KA $\Lambda$ et META) intercalées entre les rayons d'une roue ${ }^{499}$. En dépit de ce rapprochement, la présence de l'alphabet ionien dans les deux cités n'a aucune

494 Alexandrescu-Morintz, Mésambria, p. 8. Sur la présence des Eubéens en mer Noire, voir aussi P. Alexandrescu, «Les Eubéens et le début de la navigation en Mer Noire», in Mélanges Pierre Lévêque, vol. 5, M.-M. Mactoux et E. Geny (éds.), Paris 1990, p. 1-7 (= L'aigle et le dauphin. Études d'archéologie pontique, Bucarest-Paris 1999, p. 1-7).

495 Coldstream, Gr. Geom. Pot., p. 377; Alexandrescu, Histria IV, p. 21, n. 15; Dupont, Le Pont-Euxin archaïque, p. 29, n. 1; A. I. Ivantchik, ACSS 12, 3-4, p. 333.

496 I. Kalchedon, 30 ; cf. Jeffery, $L S A G^{2}$, p. 366, 371, no 41.

497 Sur la fondation de Mésambria, voir infra, chapitre II.3.2.1.

498 Head, $H N^{2}$, p. 278-279; SNG 9, pl. X, n ${ }^{\text {os }}$ 266-275, 277, 279; Karayotov, Coinage of Mesambria I, p. 18-19, pl. I, nos 1-6; idem, Coinage of Mesambria II, pl. I-XXIII; SNG 11, pl. X, n ${ }^{\text {os }} 218-228$.

499 Pour ces types de revers avec l'abréviation du nom de la cité intercalée entre les rayons d'une roue, voir Waddington-Babelon-Reinach, Recueil, I, 2, p. 289, 297 $298, \mathrm{n}^{\text {os }} 1-7$; Head, $H N^{2}$, p. 511 ; SNG Cop. Bosporus-Bithynia, pl. 9, $\mathrm{n}^{\text {os }} 346-347$; $S N G$ 9, pl. IV, n ${ }^{\text {os }} 84-92$; SNG 11, pl. I, n ${ }^{\text {os }} 10,13$ (Chalcédoine), et Head, $H N^{2}$, p. 278; SNG 9, pl. X, n ${ }^{\text {os }}$ 266-275, 277, 279; Karayotov, Coinage of Mesambria I, p. 18 , pl. I, nos 2 et 3 ; SNG 11, pl. X, n ${ }^{\text {os }} 218-228$ (Mésambria). 
valeur pour la question de la fondation des colonies. Remontant à plus d'un siècle après l'installation des Mégariens, l'épitaphe de Chalcédoine atteste uniquement qu'un ressortissant d'une cité ionienne trouva sa mort sur la rive asiatique du Bosphore, ce qui est tout à fait compréhensible, si l'on songe à la multitude des colons milésiens ayant traversé le Bosphore pour arriver en mer Noire. L'alphabet ionien apparaît d'ailleurs employé à l'époque archaïque dans une inscription de Byzance $^{500}$. Il y avait sans aucun doute à l'époque archaïque des étrangers de passage ou établis de façon permanente dans les colonies mégariennes. C'est par exemple le cas du médecin ionien dont l'épitaphe est gravée, vers le milieu du $\mathrm{VI}^{\mathrm{e}}$ siècle, sur la cuisse d'un kouros trouvé à Mégara de Sicile ${ }^{501}$.

Quant au sampi de Mésambria, on n'a aucune preuve que l'on a là un signe hérité de Chalcédoine, comme l'avait proposé Jeffery ${ }^{502}$. La solution la plus simple qui vient à l'esprit est de penser que ce caractère représente un emprunt de la colonie mégarienne du Pont Gauche à une des colonies milésiennes voisines (Apollonia ou Odessos) ${ }^{503}$. On rappellera aussi que le sampi est attesté à Milet et dans ses colonies (comme Cyzique), ainsi que dans d'autres cités ioniennes de l'Asie mineure (Éphèse, Érythrée, Téos, Halicarnasse) ${ }^{504}$.

Au demeurant, la thèse qui attribue aux Chalcidiens un rôle dans la fondation de Chalcédoine présente d'autres points faibles, difficiles à surmonter. Ainsi, il est très probable que la présence de l'île de Chalcitis dans la région du Bosphore (voir ci-dessous) et le rapprochement entre

500 I. Byzantion, 42.

$501 I G D S, 22 ; I G A S M \mathrm{I}^{2}, 3$.

502 Jeffery, $L S A G^{2}$, p. 39, 366, 368, croit que ce furent les Chalcédoniens qui avaient adopté l'écriture ionienne des colonies milésiennes et que ce furent toujours eux qui la transmirent à Mésambria; $c f$. Isaac, Gr. Settlem. in Thrace, p. 211; Loukopoulou, Thrace propontique, p. 159.

503 Head, $H N^{2}$, p. 278. S'appuyant sur l'attestation du sampi à Cyzique, la colonie milésienne de Propontide, A. Gercke, «Zur Geschichte des ältesten griechischen Alphabets », Hermes 41, 1906, p. 542, estime que le sampi de Mésambria serait un emprunt à sa voisine, Apollonia, une colonie milésienne. Cf. F. W. G. Foat, «Tsade and Sampi », JHS 25, 1905, p. 345-348.

504 F.W.G. Foat, «Fresh Evidence for T», JHS 26, 1906, p. 286-287; Guarducci, Epigrafia gr., I, p. 102; Jeffery, $L S A G^{2}$, p. 38-39, 325, 338, 339, 367. Pour l'attestation de sampi à Milet, voir R. Wachter, «Eine Weihung an Athena von Assesos », EA 30, 1998, p. 1-8. 
le nom des Chalcédoniens (oi X $\alpha \lambda \kappa \eta \delta$ óvılor) et le nom des Chalcidiens (oi X $\alpha \lambda \kappa \imath \delta \varepsilon ́ \varepsilon \varsigma / X \alpha \lambda \kappa \imath \delta \varepsilon \tau \varsigma$ ) aient pu produire une confusion ou une déformation dans le poème géographique de Denys le Périégète. On trouve dans ce texte de nombreuses déformations de toponymes, par exemple Samatai, au lieu de Sarmatai (GGM II, 304), Brentioi pour Brettioi (GGM II, 362), Taskoi pour Taokoi (GGM II, 1069) ${ }^{505}$. Rappelons que l'ouvrage de Denys, un véritable manuel de géographie, a connu un grand succès dans le monde gréco-romain et, afin de le rendre plus accessible, deux traducteurs, Avienus, vers 370 ap. J.-C., et Priscien, vers 512 ap. J.-C., l'adaptèrent en latin ${ }^{506}$. On voit que dans ces deux versions latines, Chalcis et les Chalcidiens n'apparaissent plus, la mention de Chalcédoine figurant seule à leur place, comme si les auteurs latins avaient corrigé le texte grec original ${ }^{507}$. D'ailleurs, la X $\alpha \lambda \kappa i \varsigma$

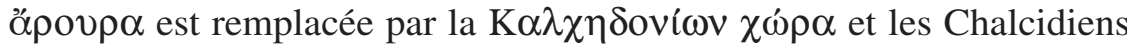
par les Chalcédoniens chez l'auteur byzantin ayant paraphrasé le poème de Denys en prose ${ }^{508}$. On remarque aussi que l'exégète Eustathe, auteur au XII ${ }^{\mathrm{e}}$ siècle ap. J.-C. d'un Commentaire consacré à Denys, atteste que la X $\alpha \lambda$ кì öpov $\alpha \alpha$ se trouvait dans la région de Chalcédoine. L'archevêque de Thessalonique, lecteur attentif de Denys et excellent connaisseur de la littérature antique, évoque ensuite l'occupation du site localisé en face de Byzance par les Mégariens ${ }^{509}$.

On conclura que la thèse de la participation des Chalcidiens à l'installation de Chalcédoine n'est pas recevable et que, dans l'état actuel de la documentation, rien ne permet de mettre en doute le caractère

505 Pour ces déformations, voir Müller, in GGM II, p. XXV.

506 C. Jacob (éd.), La Description de la terre habitée de Denys d'Alexandrie ou la leçon de géographie, Paris 1990, p. 25.

507 Avienus, GGM II, 972-974: Chalcedon tumulus flucta circumdatus alto eminus Europen proceraque mœnia Byzae aspicit; Priscien, GGM II, 737: Chalcedonis arua ; 770-771: Sunt Chalcedonii primi, post ostia Ponti, monia Byzantis qui cernut optima contra.

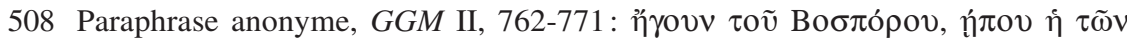

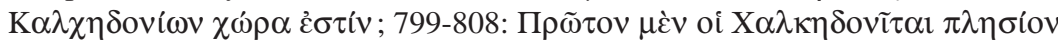

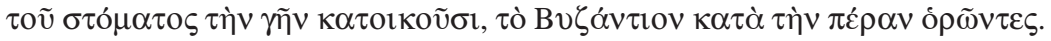

509 Eustathe, GGM II, 764, p. 348-349; voir aussi 803, p. 356. Sur Eustathe en tant que commentateur de Denys, voir C. Jacob, op. cit., p. 62-70, qui note (p. 64) : «Eustathe, bien que confrontant des opinions parfois divergentes, reste néanmoins < positiviste > il ne s'agit pas tant de corriger et de rectifier les descriptions de Denys que de les compléter, de leur apporter l'éclairage de nouveaux témoignages». 
mégarien de cette fondation. À mon sens, il est très probable que la large diffusion du poème de Denys le Périégète est responsable de la notice étymologique écrite au VI ${ }^{\mathrm{e}}$ siècle ap. J.-C. par Hésychios de Milet reliant Chalcédoine à Chalcis d'Eubée.

\section{II.2.2.2 Chalcédoine ou la "Cité des Aveugles»: les raisons de l'installation des Mégariens sur la rive asiatique du Bosphore}

Depuis Hérodote jusqu'à Tacite et Pline, l'aveuglement des Mégariens au moment où ils ont préféré la rive asiatique du Bosphore à la rive européenne pour installer leur apoikia, était l'objet de moquerie. On peut néanmoins se demander si le choix des Mégariens tenait de l'ignorance ou s'il ne se fondait pas en réalité sur de bonnes raisons. Ce sont les causes de cette entreprise que je me propose d'analyser dans ce chapitre.

Hérodote rapporte que celui qui avait attribué pour la première fois le qualificatif d' «aveugles» aux Chalcédoniens aurait été le général perse Mégabaze, après avoir appris que la fondation de Chalcédoine avait précédé celle de Byzance:

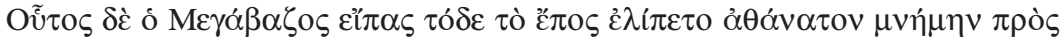

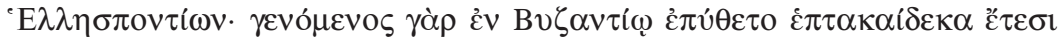

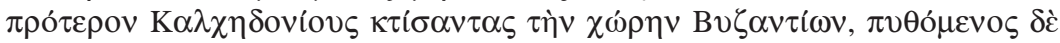

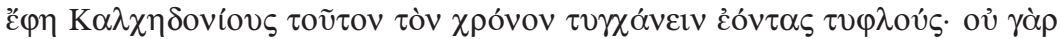

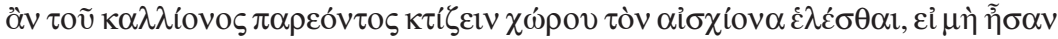
$\tau v \varphi \lambda o^{\prime}$.

Ce même Mégabaze, pour avoir tenu le propos que je vais rapporter, a laissé un souvenir impérissable chez les Hellespontins: étant à Byzance, il apprit que les Chalcédoniens s'étaient établis dans le pays dix-sept ans avant les Byzantins; et quand il l'eut appris, il déclara qu'en ce temps les Chalcédoniens étaient aveugles; car s'ils n'avaient pas été aveugles, ils n'auraient pas choisi pour s'y établir le moins bon emplacement, alors que le meilleur s'offrait à eux ${ }^{510}$.

De même, Pline rapporte que l'un des noms de Chalcédoine était la «Cité des Aveugles» (Caecorum Oppidum), car ses fondateurs n'avaient pas choisi le site de Byzance, beaucoup plus avantageux et situé à une

510 Hérodote, Histoires, IV, 144 (trad. de P.-E. Legrand, CUF). 
distance de seulement sept stades de Chalcédoine ${ }^{511}$. On trouve un écho de cette tradition chez Hésychios ${ }^{512}$. On constate aussi qu'une version différente de cette légende circulait à l'époque impériale. Selon cette variante, c'est le dieu de Delphes qui a conseillé aux Mégariens d'aller fonder une colonie en face des «aveugles».

Une présentation détaillée de cette tradition apparaît chez Strabon, au moment où le géographe évoque le revenu important procuré aux Byzantins et au peuple romain par la pêche des pélamides (une sorte de thon):

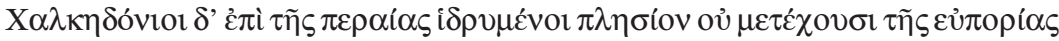

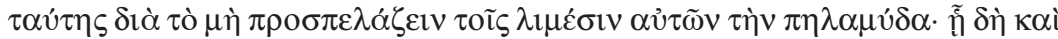

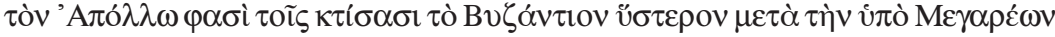

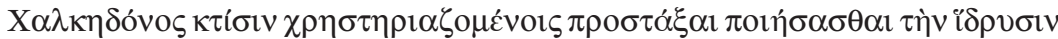

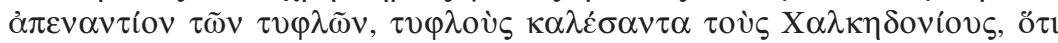

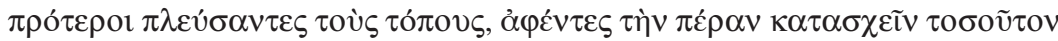

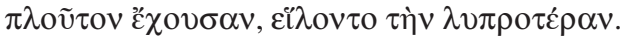

Les Chalcédoniens, qui sont installés sur la rive opposée, malgré leur proximité, n'ont aucune part à cette richesse, du fait que la pélamide n'approche pas de leurs ports; ainsi s'explique qu'Apollon ait enjoint à ceux qui le consultaient avant de fonder Byzance - fondation qui vint après celle de Chalcédoine par les Mégariens -, d'installer leur ville «en face des aveugles». Il désignait ainsi les Chalcédoniens parce qu'après avoir été les premiers à venir par mer dans ces parages, ils avaient laissé passer l'occasion d'occuper le site de la rive opposée qui bénéficiait d'une telle richesse et avaient préféré des deux l'emplacement le plus déshérité ${ }^{513}$.

Cette tradition, qui fait de l'oracle de Delphes le responsable de l'attribution du qualificatif de «terre des aveugles» à Chalcédoine, est reproduite aussi chez Tacite:

Namque artissimo inter Europam Asiamque diuortio Byzantium in extremo Europae posuere Graeci, quibus, Pythium Apollonem consulentibus, ubi conderent urbem, redditum oraculum est, quaererent sedem caecorum terris aduersam. Ea ambage Chalcedonii monstrabantur, quod priores illuc aduecti, praeuisa locorum utilitate, peiora legissent. Quippe Byzantium fertili solo, fecundo mari, quia uis piscium immensa, Pontum erumpens et obliquis subter undas saxis exterrita, omisso alterius litoris flexu, hos ad portus defertur.

511 Pline, $N H, \mathrm{~V}, 43,149$ : Calchadon [...] postea Caecorum Oppidum, quod locumeligere nescissant, septem stadiis distante Byzantio, tanto feliciore omnibus modis sede.

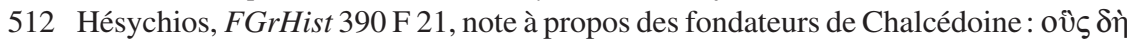

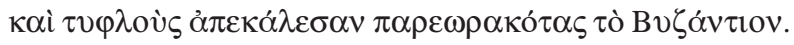

513 Strabon, VII, 6, 2, C 320 (trad. de R. Baladié, CUF). 
De fait, c'est à l'endroit où l'Europe et l'Asie sont séparées par l'intervalle le plus étroit, à l'extrémité de l'Europe, que Byzance fut établie par les Grecs; ayant consulté Apollon Pythien sur le lieu où fonder la ville, ils reçurent de l'oracle la réponse de chercher un emplacement face à la terre des aveugles. Cette énigme désignait les Chalcédoniens, qui, arrivés les premiers à cet endroit et ayant vu l'avantage de la position, en avaient choisi une autre plus mauvaise. En effet, Byzance a un sol fertile et une mer féconde, parce que des bancs énormes de poissons, se précipitant hors de l'Euxin et apercevant une barre de roches obliques sous les eaux, s'écartent effrayés de l'autre rive et refluent vers ce port ${ }^{514}$.

On remarque que même au XII ${ }^{\mathrm{e}}$ siècle ap. J.-C., Eustathe, dans son commentaire à Denys le Périégète, connaît les deux variantes de cette tradition. Il évoque ainsi l'oracle fourni par Apollon aux fondateurs de Byzance, qui nommait les Chalcédoniens les «aveugles». Et l'illustre exégète juge nécessaire de citer Hérodote pour l'appellation d' «aveugles» donnée par Mégabaze aux Chalcédoniens ${ }^{515}$.

En ce qui concerne l'oracle livré par l'Apollon de Delphes aux fondateurs de Byzance, qui qualifie les Chalcédoniens d' «aveugles», il est certain que parmi les variantes d'oracles qui circulaient dans l'Antiquité à propos de la fondation de Byzance, celle-ci est la plus douteuse. En effet, dans la version la plus ancienne de cette légende, fournie par Hérodote, ce n'est pas le dieu de Delphes qui est à l'origine de cette anecdote, mais Mégabaze. Ultérieurement, on remarque que chez Strabon et Tacite, le général perse est remplacé par l'oracle d'Apollon, une autorité en matière de colonisation ${ }^{516}$. Cette tradition, que l'on trouve pour la première fois chez Hérodote, est sans doute à l'origine d'une autre prophétie d'Apollon. Celle-ci, sans évoquer les Chalcédoniens, révèle aussi aux fondateurs de Byzance (Mégariens ou Argiens, selon les différentes variantes de la tradition) les richesses halieutiques de la future colonie ${ }^{517}$. Il existe même une résurgence tardive de la légende qui faisait de Chalcédoine la ville des aveugles, cette fois à propos de Constantinople. Dans ce sens, selon une tradition qui circulait aux $\mathrm{XI}^{\mathrm{e}}-\mathrm{XII}^{\mathrm{e}}$ siècles ap. J.-C., Constantin le Grand était aussi un «aveugle», car il avait initialement choisi le site de Chalcédoine à la place de celui de

514 Tacite, Annales, XII, 63, 1-2 (trad. de P. Wuilleumier, CUF).

515 Eustathe, GGM II, 764, p. 349.

516 Miller, Byzantion, col. 1128; W. Parke, D.E. W. Wormell, The Delphic Oracle, Oxford 1956, vol. I, p. 60-61, vol. II, p. 230, n 594; Malkin, Religion and Colon., p. 22.

517 Voir infra, chapitre II.2.4.1. 
Byzance pour sa nouvelle capitale. Des aigles (ou selon d'autres versions, les pierres elles-mêmes) enlevèrent les cordages et les portèrent à Byzance, l'intervention divine ayant ainsi éclairé l'empereur ${ }^{518}$.

Quant aux avantages exceptionnels de la position géographique de Byzance (les importantes ressources issues de la pêche et du commerce) par rapport à Chalcédoine, ils sont perçus par les auteurs antiques dans la perspective du développement ultérieur de la cité519. Mais il convient de noter que du point de vue des exigences de la navigation maritime (les criques, les ports, les courants), Malkin et Shmueli ont montré que la rive asiatique de la Propontide jouissait d'une position plus favorable que la rive européenne. De fait, le point de départ préféré pour entreprendre un voyage en direction de la mer Noire était la côte asiatique du Bosphore et non pas la côte opposée, les courants marins pouvant être défiés plus facilement depuis Chalcédoine que depuis Byzance ${ }^{520}$. En revanche,

518 Georgius Cedrenus, Historiarum compendium, I, p. 496 (éd. I. Bekker); Zonaras, Annales, XIII, 3, 1-4, p. 13-14 (éd. T. Büttner-Wobst). Cf. Dagron, Naissance d'une capitale, p. 30-31; A. Kazdan, «〈Constantin imaginaire〉. Byzantin Legends of the Ninth Century about Constantine the Great», Byzantion 57, 1987, p. 236-237.

519 Sur les avantages de la position privilégiée de Byzance, outre les récits signalés cidessus, voir aussi Polybe, IV, 38, 43-44; Dion Cassius, LXXV, 10, 1; Zosime, II, 30; Procope, De aedificiis, I, 5. D'après Pline, NH, IX, 20, 50-51, le nom de la Corne d'Or venait des richesses halieutiques de Byzance. Les bancs de poissons dont les plus célèbres, les pélamides, ornaient souvent à l'époque impériale le revers des monnaies byzantines (Schönert-Geiss, Byzantion, vol. I, p. 2 ; vol. II, p. 34) étaient conduits vers la ville par les courants du Bosphore. Sur l'abondance de cette espèce de thon à Byzance, voir Ps.-Hésiode, fr. 372 (éds. R. Merkelbach et M.L. West ; apud Athénée, III, 116 B) ; Archéstratos, fr. 38 (éds. S. Douglas Olson et A. Sens); Dion Chrysostome, XXXIII, 24. Aristote, Politique, IV, 4, 21, 1291b 2223, mentionne l'importance du groupe des pêcheurs à Byzance, tandis que le Ps.Aristote, Économique, II, 2, 3a, 1346b 20, évoque la vente du droit de pêche par la cité. Cf. B. A. van Groningen, Aristote: Le second livre de l'Économique, Leyde 1933, p. 58. Sur la pêche sur le Bosphore à l'époque ancienne et moderne, on renverra à Robert, Documents, p. 227-231; J. Dumont, Halieutika. Recherches sur la pêche dans l'Antiquité grecque, thèse de doctorat, Université de Paris IV, Paris 1981, vol. I, p 249-250, vol. III, p. 788-790.

520 Malkin-Shmueli, City of the Blind, p. 21-36. À l'été 1985, Shmueli a entrepris une expédition dans une petite embarcation afin de trouver la meilleure route maritime dans la Propontide. Celle-ci a montré que, malgré l'opinion de Polybe (IV, 44, 5-8), la direction des courants et la présence de plusieurs abris pour les navires (il y a un nombre important de petites îles) rendent la navigation plus facile en suivant la rive asiatique de la Propontide qu'en suivant la rive européenne. 
Byzance, grâce à la direction des courants sortant du Bosphore thrace, pouvait contrôler le passage des navires venant du Pont ${ }^{521}$. Cet état des choses est confirmé par l'Économique du Ps.-Aristote, qui nous apprend qu'étant confrontés à des situations économiques difficiles, les Chalcédoniens saisirent les vaisseaux de commerce en partance pour le

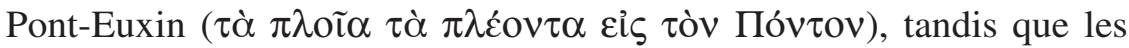
Byzantins mirent la main sur ceux qui venaient du Pont-Euxin ( $\tau \grave{\alpha} \pi \lambda \circ \tau \tilde{\imath} \alpha$

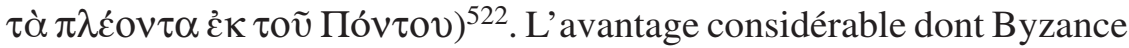
jouissait à l'époque classique ne pouvait pas être valorisé au VII ${ }^{\mathrm{e}}$ siècle, car le commerce avec les régions de la mer Noire n'avait pas alors acquis une importance majeure pour les Grecs ${ }^{523}$. Il est clair que la cité de Byzance du VII ${ }^{\mathrm{e}}$ siècle ne pouvait pas être le véritable «emporion»du $\mathrm{IV}^{\mathrm{e}}$ siècle, selon le terme utilisé par Théopompe, dont les citoyens passent la plupart de leur temps sur l'agora et dans le port ${ }^{524}$.

En outre, il faut mentionner parmi les sites du territoire de Chalcédoine, Chrysopolis (aujourd'hui Üsküdar/Skutari), qui se trouvait sur la rive asiatique du Bosphore et qui était un établissement fort important pour le passage des navires par le détroit. Preuve en est la décision prise par les Athéniens d'Alcibiade d'occuper et de fortifier ce site en 410/9. Ils l'utilisent ensuite pour prélever une taxe de dix pour cent sur toutes les marchandises qui transitaient par le Bosphore, non seulement sur celles originaires du Pont-Euxin, mais aussi sur celles qui y allaient ${ }^{525}$.

521 Voir le passage de Polybe, IV, 39, 7-44, 10, consacré aux courants du Pont et de la Propontide, avec les commentaires de Malkin-Shmueli, City of the Blind, p. 27-31.

522 Ps.-Aristote, Économique, II, 2, 3c, 1346b 29-33 (Byzance) ; II, 3, 10, 1347b 20-30 (Chalcédoine); $c f$. V. Gabrielsen, «Trade and Tribute: Byzantion and the Black Sea Straits », in The Black Sea in Antiquity. Regional and Interregional Economic Exchanges, Black Sea Studies 6, V. Gabrielsen et J. Lund (éds.), Aarhus 2007, p. 312313.

523 Beloch, Gr. Gesch. ${ }^{2}$, I, 1, p. 257; Cook, Ionian and Greece, p. 72, 85; Roebuck, Ionian Trade, p. 114-115; Legon, Megara Pol. Hist., p. 79-81; Isaac, Gr. Settlem. in Thrace, p. 220.

524 Théopompe, FGrHist 115 F 62 (apud Athénée, XII, 526 D-E). Pour le commerce pratiqué par les Byzantins aux époques classique et hellénistique, voir Merle, Byzantion und Kalchedon, p. 63-67; Isaac, Gr. Settlem. in Thrace, p. 215-230; V. Gabrielsen, op. cit., p. 287-324.

525 Xénophon, Helléniques, I, 1, 22, mentionne l'établissement d'un dékateutèrion («bureau de perception de la dîme») à Chrysopolis; Polybe, IV, 44, 3-4; Diodore, XIII, 64, 2-3; cf. Théopompe, FGrHist 115 F 7 (apud Stéphane de Byzance, s.v.

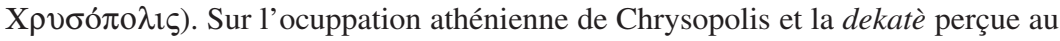


La fondation et le contrôle de Chrysopolis par Chalcédoine et non par Byzance montre que les Chalcédoniens étaient conscients de l'importance du trafic commercial par le Bosphore et des avantages qui en découlaient.

Du reste, on constate que la situation politique de la rive européenne n'a pas favorisé l'installation des Grecs. La cité de Byzance est implantée dans une région occupée par les tribus de guerriers thraces qui manifestèrent une opposition farouche à l'installation des Grecs ${ }^{526}$. Pour assurer le succès de la fondation de Byzance, les Mégariens firent appel aux synoikoi et aux époikoi provenant d'autres cités grecques (Argos, Chalcédoine, les cités de la Béotie, Carystos, Corinthe?, voir ci-après) $)^{527}$. Ceci revient à souligner que les Thraces constituaient un danger redoutable et que sans l'assistance fournie par les autres Grecs, et surtout par les Chalcédoniens, le succès de l'entreprise mégarienne sur la rive européenne du Bosphore aurait été compromis.

En revanche, l'invasion cimmérienne, qui a provoqué vers 670 l'effondrement du royaume phrygien et l'apparition de la dynastie lydienne des Mermnades, faisait peut-être de l'Asie mineure une région politiquement moins organisée et plus favorable à l'installation des Grecs ${ }^{528}$. On peut penser que la menace des tribus indigènes était moins forte à Chalcédoine, ce qui constituait un élément d'attractivité supplémentaire pour les premiers apoikoi ${ }^{529}$.

Néanmoins, ce serait une erreur d'interpréter la fondation de Chalcédoine avant celle de Byzance selon un raisonnement fondé uniquement sur l'importance des terres ou du commerce, en considérant le premier établissement comme une «colonie agricole» et le deuxième comme

passage du Bosphore thrace, voir R. Meiggs, op. cit., p. 372; A. Rubel, «Hellespontophylakes - Zöllner am Bosporos? Überlegungen zur Fiskalpolitik des attischen Seebundes (IG I ${ }^{3}$ 61)», Klio 83, 1, 2001, p. 39-51, qui estime qu'une taxe de passage fut imposée par la Ligue de Délos aux navires traversant le Bosphore bien avant la guerre du Péloponnèse, les Athéniens ne faisant que l'augmenter en 410/9, contraints par leur situation financière désastreuse; N. Jefremow, $M B A H$ 24, 1, 2005, p. 69-70; V. Gabrielsen, op. cit., p. 293-297.

526 Voir infra, chapitre II.2.4.2.

527 Graham, Colonial Expansion, p. 120.

528 Malkin-Shmueli, City of the Blind, p. 32; A. I. Ivantchik, Les Cimmériens au ProcheOrient, Fribourg-Goettingue 1993, p. 73.

529 Cf. Boardman, Gr. Overseas ${ }^{3}$, p. 241-242. 
une «colonie commerciale ${ }^{530}$. Je pense que la division en «colonies commerciales» et «colonies agraires» ou de «peuplement» ne peut pas être appliquée à la colonisation mégarienne en général, et à la colonisation des rives du Bosphore thrace en particulier ${ }^{531}$. Car sur la foi de la documentation conservée jusqu'à nous, on ne peut guère affirmer que les Mégariens ont fondé des apoikiai à vocation strictement commerciale ou agraire.

Concernant la colonisation des rives du Bosphore, il est permis de supposer que, pour pouvoir bénéficier des avantages offerts par la rive européenne, les Grecs ont dû d'abord consolider leur position sur la rive asiatique. Si l'on tient pour historique la tradition selon laquelle l'installation des Mégariens dans le golfe d'Astacos a précédé la fondation des cités de l'embouchure du Bosphore, il est clair que ceuxci connaissaient bien la région et les avantages de chaque site. Par la fondation de leurs établissements de la Propontide, ils ont réussi à mettre en œuvre un système fort élaboré. Il s'agit d'une colonisation par étapes, et pour le succès de cette entreprise, il fallait d'abord occuper les sites les mieux placés sur une route qui menait vers le Pont-Euxin. Ces sites devaient également disposer de territoires suffisants pour leurs habitants.

D'aucuns ont invoqué, parmi les causes de la fondation de Chalcédoine avant Byzance, les gisements de cuivre qui auraient pu se trouver dans la proximité de la colonie mégarienne ${ }^{532}$. Et il a été déjà question de la légende, transmise par Syméon, selon laquelle l'appellation de Chalcédoine vient de $\chi \alpha \lambda \kappa o ́ \varsigma$. Les récits évoquent l'exploitation des mines de cuivre de l'île de Chalcitis, appelée aussi Démonèsos dans l'Antiquité (la moderne Heybeliada). Située en face de Chalcédoine,

530 E.H. Minns, Scythians and Greeks, Cambridge 1913, p. 438-439. Voir de même Hanell, Megarische Studien, p. 134, qui note à propos de Chalcédoine: «Die Lage dieser Stadt zeigt, dass eine Ackerbaukolonie und nicht eine Handelsstation beabsichtigt war».

$531 C f$. Lepore, Grande Grèce, p. 41, qui écrit: «Les tentatives modernes pour individualiser quelques traits spécifiques de cités < agricoles > et < commerciales > - et même pour reconnaître, en terme de chronologie et de périodisation, une prétendue priorité à l'une ou à l'autre de ces deux catégories, ou le choix de tel ou tel schéma dans l'implantation - semblent destinées à être abandonnées au fur et à mesure que les fouilles progressent».

532 Roebuck, Ionian Trade, p. 114; Legon, Megara Pol. Hist., p. 79; cf. Magie, Roman Rule, vol. I, p. 304, vol. II, p. 1183, n. 7. 
cette île était riche en gisements de cuivre et en pierres semi-précieuses ${ }^{533}$. La recherche des métaux comme l'une des causes de la fondation de Chalcédoine est une hypothèse possible, même probable, mais l'état actuel des sources ne permet pas d'avoir une confirmation de l'exploitation déjà au VII ${ }^{\mathrm{e}}$ siècle des mines de l'île de Chalcitis par les Chalcédoniens ${ }^{534}$.

À l'issue de cette analyse, la conclusion qui s'impose est que l'attribution de l'épithète d' «aveugles» aux Chalcédoniens ne correspond point aux réalités de l'époque archaïque. Les Mégariens connaissaient les excellents ports de Byzance, mais ils n'ignoraient pas non plus les difficultés qu'il y avait à s'installer dans cette région et à se tailler une chôra. La fondation de Chalcédoine avant celle de Byzance met en lumière l'importance de la possibilité de distribuer aisément des lots de terre aux apoikoi, mais ce n'est pas la seule motivation de l'installation des Mégariens. Car il est difficile d'accepter que ce soit uniquement le besoin de nouvelles terres ou la surpopulation qui aient déterminé les Mégariens à installer au VII ${ }^{\mathrm{e}}$ siècle quatre colonies en Propontide et à se joindre aux Mégariens de Sicile pour la fondation de Sélinonte. À cet égard, il convient de remarquer qu'il y avait sans nul doute une concurrence entre les Grecs dans la colonisation. Vers le milieu du VII ${ }^{\mathrm{e}}$ siècle, les Milésiens ont installé leurs premiers établissements en mer Noire (Istros, Orgamé, Borysthène/Olbia) et vers la fin du même siècle les Samiens, malgré l'opposition des Mégariens, ont installé Périnthe à proximité de

533 Ps.-Aristote, De mirabilibus auscultationibus, LVIII, 834b 18-31; Théophraste, Des pierres, IV, 25; Pline, NH, XXXVII, 72; Stéphane de Byzance, s.vv. X $\alpha \lambda \kappa i \tau \imath \varsigma$.

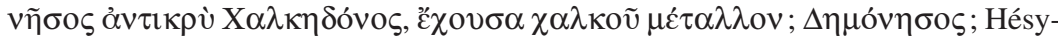

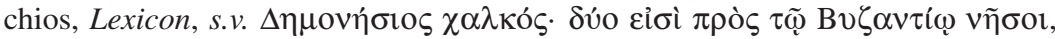

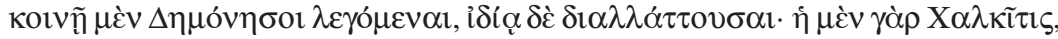

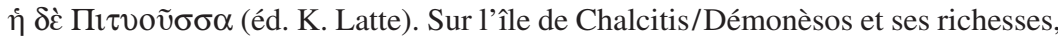
voir L. Bürchner, s.v. «Chalkitis» 2, RE III, 1899, col. 2093; H. Blümner, s.v. «Kupfer», RE XI, 1922, col. 2197; Magie, Roman Rule, vol. I, p. 304, vol. II, p. 1183, n. 7; Janin, Constantinople ${ }^{2}$, p. 506-508; H. Flashar (éd.), in Aristoteles Werke, XVIII, 2-3. Mirabilia, Berlin 1972, p. 94.

534 G. Camassa, op. cit., p. 25-69, considère que Chalcédoine avait, à l'âge du Bronze, un rôle important dans l'approvisionnement en métaux, attribuant aussi un passé mycénien à la tradition qui localise Calchas à Chalcédoine. De plus, Camassa estime que les Mégariens se seraient approprié cette légende pour donner à leur ville un passé précolonial. Pourtant, ces opinions restent difficiles à vérifier en l'absence de découvertes qui puissent attester un habitat mycénien à Chalcédoine. Voir toutefois infra, chapitre II.2.4.1.1, la tradition qui mentionne les Mycéniens parmi les fondateurs de Byzance. 
Byzance. Selon une expression de Figueira, pour toutes ces cités «to colonize was, for the most part, a sign of vitality ${ }^{535}$. On peut penser que de la même façon que la victoire remportée par de jeunes guerriers dans des combats avec les voisins conférait du prestige à la communauté tout entière, l'installation avec succès d'un nouvel établissement constituait un objet de gloire pour la cité ayant envoyé ces apoikoi ${ }^{536}$.

Dans l'espace de moins d'une génération, une expédition presque «internationale», au sein de laquelle les Mégariens ont joué le rôle principal, aboutit à la fondation d'une cité sur la rive européenne du Bosphore thrace. Pour l'installation de Byzance, comme nous le constaterons, l'aide donnée par les Chalcédoniens dans les conflits byzantins avec les Thraces a été déterminante. Cet appui souligne l'importance de la solidarité entre les établissements mégariens face à leurs voisins indigènes ou grecs. Il n'est pas erroné de considérer que c'est cette solidarité qui est à la base du «réseau» mégarien de la Propontide et qui a assuré le succès de l'installation des Mégariens et de leurs synoikoi (cofondateurs) dans la région. On remarque enfin qu'à l'époque hellénistique les cités mégariennes de la Propontide (Chalcédoine, Byzance) et de la mer Noire (Héraclée du Pont) collaborèrent entre elles au moment des incursions des Galates ${ }^{537}$ ou contre l'influence des rois séleucides sur la côte méridionale de la mer Noire. Ainsi, Héraclée du Pont, Byzance et Chalcédoine concluent-elles vers 281 une alliance contre le royaume séleucide. Cette symmachie qui, par l'adhésion d'autres villes et dynastes micrasiatiques, deviendra la soi-disant «Ligue du Nord», peut être également interprétée comme l'expression d'une solidarité mégarienne. On rappellera pour finir qu'à en croire Memnon, ce fut la flotte de 40 trières envoyées par Héraclée du Pont qui sauva Byzance lors de la guerre contre Antiochos II $^{538}$.

535 Figueira, Chronological Table, p. 275.

536 Voir aussi supra, chapitre I.4.

537 Memnon, FGrHist 434 F 11, mentionne l'argent envoyé par les Héracléotes (4.000 statères) et par d'autres symmachoi aux Byzantins au moment où leur territoire fut envahi par les Galates (vers 280/79). À cet égard, voir Habicht, Gottmenschentum ${ }^{2}$, p. 118; Seyrig, Monnaies, p. 191-192.

538 Memnon, FGrHist 434 F 15. Sur la «Ligue du Nord», voir Desideri, Storiografia eracleota, p. 409-412; S. J. Saprykin, «The Northern League: International Relations in the Southern Euxine Seaboard in the Early Hellenistic Period», in The Black Sea Littoral in the Hellenistic Times. Materials of the $3^{\text {rd }}$ All-Union Symposium on 


\section{II.2.2.3 La date de fondation de Chalcédoine et la chronologie des installations mégariennes en Propontide}

La Chronique d'Eusèbe transmet les dates de $685 / 4$ et $659 / 8$ pour les fondations respectives de Chalcédoine et de Byzance ${ }^{539}$. On remarque d'emblée que ces dates ne correspondent pas aux intervalles donnés par Hérodote ou par Hésychios pour les fondations des deux colonies mégariennes du Bosphore thrace. Hérodote rapporte que Chalcédoine a été fondée dix-sept ans avant Byzance ${ }^{540}$, alors que Hésychios établit un intervalle de dix-neuf ans entre les deux installations ${ }^{541}$. Dernièrement, les fouilles ont mis au jour à Chrysopolis, dans le territoire de Chalcédoine, des céramiques datant de la deuxième moitié du VII ${ }^{\mathrm{e}}$ siècle ${ }^{542}$.

D'aucuns ont essayé de rabaisser les dates de fondation de ces deux colonies dans la deuxième moitié du $\mathrm{VII}^{\mathrm{e}}$ siècle. Cette thèse a comme point de départ la date de 628 , transmise au $\mathrm{VI}^{\mathrm{e}}$ siècle ap. J.-C. par Jean le Lydien pour la fondation de Byzance ${ }^{543}$. Roebuck pense qu'une date

the Ancient History of the Black Sea Littoral, Tsqaltubo-1982, Tbilisi 1985, p. 49-61 (en russe); Bittner, Herakleia, p. 63-69; Avram, Divinisation de Ptolémée, p. 830, n. 16; idem, CRAI, 2003 (2005), 3, p. 1186-1187.

539 Pour la date de Chalcédoine, voir Eusèbe, Chron., St. Jérôme: Ol. 23.4 (=685/4, éd. R. Helm, p. 93b). Pour la date de Byzance, voir Eusèbe, Chron., St. Jérôme: O1. 30. 2 (=659/8, éd. R. Helm, p. 94b); Version arménienne: Ol. 30.2 (=659/8, éd. J. Karst, p. 185). Cf. Cook, Ionian and Greece, p. 71; Miller, Colony Dates, p. 23-24.

540 Hérodote, IV, 144. L'intervalle de dix-sept ans mentionné par Hérodote a été considéré par Dover, Thukydides, p. 364-368, comme une preuve de l'existence des traditions locales concernant la date de fondation des apoikiai. Contra R. van Compernolle, «Les dates de fondation des colonies siciliotes. À propos d'un article récent», $A C$ 25,1956 , p. 102, qui pense que cet intervalle n'est qu'une indication de chronologie relative, les dix-sept ans pouvant d'ailleurs être introduits dans l'anecdote de Mégabaze à la suite des préoccupations chronologiques du $\mathrm{V}^{\mathrm{e}}$ siècle.

541 Hésychios, FGrHist 390 F 20.

542 Karagöz, Khrysopolis, p. 34-35; eadem, «Byzance. Les périodes archaïque, hellénistique et romaine», in De Byzance à Istanbul : un port pour deux continents, Paris 2009, p. 45-46.

543 En s'appuyant sur le témoignage de Jean le Lydien (Des Magistratures de l'État romain, III, 70, 4), Burn, Lyric Age, p. 114, propose les dates de 645 et de 628 pour les fondations de Chalcédoine et de Byzance. Ces dates avaient l'avantage de bien s'intégrer dans le système chronologique qu'A. R. Burn, «Dates in Early Greek History », JHS 55, 1935, p. 130-146, surtout p. 132-133, avait auparavant proposé et selon lequel les dates traditionnelles de fondations coloniales devraient être généralement abaissées. $C f$. à cet égard aussi Cook, Ionian and Greece, p. 73-74. 
à court terme après le milieu du $\mathrm{VII}^{\mathrm{e}}$ siècle est davantage conforme à la documentation qui atteste l'arrivée des Grecs en mer Noire ${ }^{544}$. Mais cette opinion est contredite par les trouvailles de la mer Noire, qui indiquent que les premières céramiques grecques arrivent dans cette région à partir du troisième quart du $\mathrm{VII}^{\mathrm{e}}$ siècle, ce qui dénote l'existence d'un commerce précolonial ${ }^{545}$.

Dans ces conditions, l'information isolée de Jean le Lydien me paraît insuffisante pour abandonner la chronologie traditionnelle d'Eusèbe et pour adopter un nouveau système chronologique qui ferait descendre la fondation des colonies mégariennes en Propontide dans la deuxième moitié du VII ${ }^{\mathrm{e}}$ siècle.

La cité de Mégare, dont les habitants avaient installé Mégara en Sicile dans la deuxième moitié du VIII ${ }^{\mathrm{e}}$ siècle et participé à la fondation de Sélinonte vers 650-628, avait sans nul doute les moyens nécessaires pour installer des établissements en Propontide déjà à la fin du VIII siècle et dans la première moitié du VII ${ }^{\mathrm{e}}$ siècle. Certes, les dates d'Eusèbe ne doivent pas être considérées comme absolues, mais seulement comme des indications de chronologie relative qui suggèrent que les Mégariens furent parmi les premiers Grecs à fonder des apoikiai dans la région du Bosphore thrace ${ }^{546}$. Une colonisation des rives du Bosphore dès la première moitié du VII ${ }^{\mathrm{e}}$ siècle est d'ailleurs conforme au tableau de l'expansion grecque dans la Propontide et en mer Noire. Les trouvailles les plus anciennes de Cyzique datent du premier quart du VII ${ }^{\mathrm{e}}$ siècle, ce qui confirme la deuxième date (vers 679) fournie par Eusèbe pour cette installation ${ }^{547}$.

544 Roebuck, Ionian Trade, p. 114, suivi par Isaac, Gr. Settlem. in Thrace, p. 218. Cf. Figueira, Chronological Table, p. 274-275.

545 S. L. Solovyov, Ancient Berezan. The Architecture, History and Culture of the First Greek Colony in the Northern Black Sea, Leiden et al. 1999, p. 3-4; Dupont, Le Pont-Euxin archaïque, p. 29-31. De même, pour les céramiques remontant à la première moitié du VII ${ }^{\mathrm{e}}$ siècle découvertes dans différents sites de la mer Noire, voir Petropoulos, Emporion, p. 3-4, 15-16, 24-74 (avec les références), avec le compterendu de cet ouvrage rédigé par A. I. Ivantchik, ACSS 12, 3-4, p. 333-334.

546 Sur la chronologie d'Eusèbe, voir A. A. Mosshammer, The Chronicle of Eusebius and Greek Chronographic Tradition, London 1979, p. 84-112.

547 Pour Cyzique, Eusèbe, Chron. (éd. R. Helm, p. 88b, 93b), transmet deux dates de fondation (756, respectivement 679). Pourtant, seule la deuxième date est confirmée par les découvertes archéologiques. À ce propos, voir Loukopoulou, Thrace propontique, p. 44 ; A. Avram, s.v. «Kyzikos», in Hansen-Nielsen (éds.), Inventory, p. 984 (avec les références). 
Notons aussi que les sources littéraires et archéologiques attestent la fondation des colonies milésiennes dans le Pont-Euxin vers le milieu ou la deuxième moitié du VII ${ }^{\mathrm{e}}$ siècle. À cet égard, on peut mentionner à titre d'exemple le rapport chronologique étroit qui existe entre la date de fondation d'Histria (Istros), 657/6, donnée par Eusèbe (Chron., éd. R. Helm, p. 95b), et les découvertes archéologiques d'Orgamé et d'Histria (Istros), datant du milieu ou du dernier quart du $\mathrm{VII}^{\mathrm{e}}$ siècle ${ }^{548}$. Ce ne sont probablement que les fouilles très limitées qui nous empêchent d'avoir un synchronisme analogue entre les sources textuelles et les données matérielles pour les fondations mégariennes.

En ce qui concerne les causes du départ des Mégariens, il est improbable que ce mouvement ait été provoqué par la surpopulation ou par des pertes territoriales suite aux conflits entre Mégare et Corinthe (notamment dans la région de Pérachora). En revanche, c'est plutôt aux conflits internes qu'il convient d'accorder un rôle important dans le début de la colonisation mégarienne. Le synœeisme mégarien et les conflits entre les familles aristocratiques sont, à mon avis, les responsables de la fondation à une date assez ancienne (entre la fin du VIII ${ }^{\mathrm{e}}$ siècle et le milieu du VII ${ }^{\mathrm{e}}$ siècle) des établissements mégariens de la Propontide ${ }^{549}$.

548 Selon Alexandrescu, Histria IV, p. 19-21; idem, «Histria in archaischer Zeit», in Histria: Eine Griechenstadt an der rumänischen Schwarzmeerküste, Xenia 25, P. Alexandrescu et W. Schuller (éds.), Konstanz 1990, p. 50-51, les plus anciens documents céramiques d'Histria (Istros) remontent au dernier quart du VII ${ }^{\mathrm{e}}$ siècle. Les trouvailles d'Orgamé témoignent de l'arrivée des Grecs aux embouchures du fleuve Istros vers le milieu du VII ${ }^{\mathrm{e}}$ siècle. À ce propos, voir V. Lungu, «La tombe d'un "HPO $\Sigma$ et l'organisation de la nécropole d'une cité milésienne du Pont-Euxin: le tumulus T-A95 d'Orgamé», Talanta 32-33, 2000-2001 (2002), p. 171-188 (= in Actes du III Colloque international d'archéologie funéraire, Tulcea, 1997, Tulcea 2000, p. 67-86); Avram, Les territoires d'Istros et de Callatis, p. 610-611; M. MănucuAdameşteanu, «Orgame», in Ancient Greek Colonies in the Black Sea, D. V. Grammenos et E. K. Petropoulos (éds.), Thessaloniki 2003, p. 344-346; Dupont, Le PontEuxin archaïque, p. 30.

549 Voir aussi supra, chapitre I.4. 


\section{II.2.3 Sélymbria}

La cité antique de Sélymbria $(\Sigma \eta \lambda v \mu \beta \rho i ́ \alpha$ ou $\Sigma \eta \lambda v \beta \rho i ́ \alpha /$ en dorien $\Sigma \alpha \lambda v \mu \beta \rho i \alpha)$ se trouvait sur la côte nord de la Propontide, entre Périnthe et Byzance, sur le site de l'actuelle Silivri, un nom turc qui conserve les traces de l'appellation grecque de la cité ${ }^{550}$.

Le seul texte antique qui nous renseigne sur l'origine des fondateurs de cette apoikia est celui du Ps.-Scymnos, qui note brièvement que Sélymbria fut installée avant Byzance par les Mégariens ${ }^{551}$. Le terme de «Mégariens» employé par le Ps.-Scymnos a été différemment interprété par les modernes. Hanell pense qu'il s'agit de Chalcédoniens, tout comme dans le cas d'Astacos ${ }^{552}$. Selon une autre hypothèse, avancée par Loukopoulou, le mot «Mégariens» ne serait utilisé par certains auteurs que pour marquer la distinction entre les fondations mégariennes et milésiennes. Le terme «Mégariens» dans le passage du Ps.-Scymnos se référerait, d' après elle, aux Byzantins, sans pour autant annuler la participation des Mégariens ou des Chalcédoniens ${ }^{553}$. Mais cette opinion ne peut guère se concilier avec le témoignage du Ps.-Scymnos, qui situe la fondation de Sélymbria avant ( $\pi \rho i ́ v)$ celle de Byzance.

En réalité, il est difficile d'accepter que le Ps.-Scymnos ait fait une confusion en désignant les fondateurs de Sélymbria comme «Mégariens » au lieu de Byzantins ou de Chalcédoniens, car quelques vers plus loin seulement, le même auteur (ou sa source) distingue Mégare et Chalcédoine, en désignant les deux cités comme les métropoles de Mésambria ${ }^{554}$. Par conséquent, bien que l'on ne puisse pas exclure une participation d'apoikoi originaires des autres cités mégariennes de la Propontide (Chalcédoine, Astacos ?) à la fondation de Sélymbria, ce n'est pas par la confusion qu'on peut expliquer le passage du Ps.-Scymnos. Il n'existe

550 On rappelle que la cité de Sélymbria a porté, au V $\mathrm{V}^{\mathrm{e}}$ siècle ap. J.-C., pour une brève période, le nom d'Eudoxiopolis, en l'honneur d'Eudoxie, l'épouse de l'empereur Arcadius. Sur les différentes appellations de la ville, voir Oberhummer, Selymbria, col. 1324-1327.

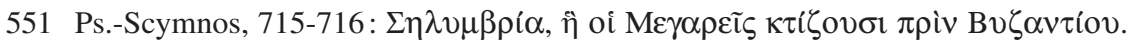
Voir sur le Ps.-Scymnos la notice détaillée que lui a consacrée D. Marcotte, Les géographes grecs. Introduction générale, Tome I: Ps.-Scymnos, Circuit de la Terre, Paris 2000, p. 1-100.

552 Hanell, Megarische Studien, p. 134 ; cf. Isaac, Gr. Settlem. in Thrace, p. 210.

553 Loukopoulou, Thrace propontique, p. 53.

554 Ps.-Scymnos, 741-742. 
rien dans ce récit qui appuierait les opinions émises par Hanell ou Loukopoulou, et il est bien douteux qu'on puisse y voir autre chose qu'une allusion à la fondation de Sélymbria par les Mégariens de Grèce.

D'autre part, l'opinion de Loukopoulou selon laquelle Sélymbria et Astacos ont servi d'avant-postes respectifs à Byzance et à Chalcédoine, me parait quelque peu trop «moderniste ${ }^{555}$. Il y avait sans nul doute une collaboration entre les colonies, mais ces établissements furent fondés en tant que poleis autonomes, un statut qu'ils gardent longtemps ${ }^{556}$. Même si à l'époque impériale les inscriptions attestent que Sélymbria a perdu le statut de polis et qu'elle est devenue un bourg (kômè) faisant partie du territoire de Byzance, il n'en ressort pas qu'à l'époque archaïque il y ait eu un rapport de dépendance entre ces deux cités ${ }^{557}$.

En ce qui concerne la date de fondation de Sélymbria, le Ps.-Scymnos atteste que celle-ci se situe avant celle de Byzance, c'est-à-dire avant $659 / 8$. D'une manière générale, il est probable que la cité a été fondée dans la première moitié du VII ${ }^{\mathrm{e}}$ siècle, période de l'expansion mégarienne en Propontide. Le premier avantage du site semble être celui de répondre aux besoins fonciers des premiers colons: le territoire de Sélymbria est favorable à la culture des céréales ${ }^{558}$ et l'on note aussi que l'épi de blé orne le revers des monnaies frappées par la cité vers 425/20-411/10559.

555 Loukopoulou, Thrace propontique, p. 51.

556 Pour la mention d'Astacos et de Sélymbria en tant que poleis par les sources antiques, voir Avram, Astakos, p. 977, et L. Loukopoulou, A. Lajtar, s.v. «Selymbria», in Hansen-Nielsen (éds.), Inventory, p. 921.

557 Oberhummer, Selymbria, col. 1325; L. Robert, in Firatl, Stèles de Byzance, p. 148; idem, Hellenica, II, p. 64, VII, p. 39. L. Loukopoulou, A. Lajtar, op. cit., p. 921, estiment que Sélymbria «may have lost its autonomy at the time of the formation of the sympoliteia between Byzantion and Perinthos, tentatively dated to the period of Philip II's unsuccessful efforts in 340 to bring the area under Makedonian control ». Sur le statut de komè de Sélymbria à l'époque impériale, voir aussi infra, chapitre III.1.2.2.

558 J. Crow, S. Turner, «Silivri and the Thracian Hinterland of Istanbul: An Historical Landscape», AS 59, 2009, p. 167-181. Cf. Legon, Megara Pol. Hist., p. 79.

559 E. Schönert-Geiss, Die Münzprägung von Bisanthe, Dikaia, Selymbria, Berlin 1977, p. 48-49, pl. 8, $\mathrm{n}^{\text {os }}$ 59-73. Cf. P. Delev, «Bevölkerung und Siedlungssystem an der bulgarischen Schwarzmeerküste », in Die bulgarische Schwarzmeerküste im Altertum, Xenia 16, W. Schuller (éd.), Konstanz 1985, p. 16-17, qui met en doute le lien entre la présence des épis de blé ou de Déméter sur le numéraire des colonies pontiques et le caractère originairement agricole de ces fondations. Selon le savant bulgare, ces symboles montreraient que ces cités pratiquaient un commerce de grains, et non pas qu'elles disposaient d'une production agricole importante. 
Par ailleurs, si l'on compare le territoire de Byzance avec celui de Sélymbria, on remarque que le territoire byzantin était tout aussi fertile. Ce sont les attaques des Thraces qui empêchent, rappelle Polybe, les Byzantins de bénéficier de leurs récoltes ${ }^{560}$. On peut alors se demander si ce ne fut pas la menace des tribus thraces, moins forte à Sélymbria qu'à Byzance, qui a déterminé avant tout les Mégariens à choisir ce site avant la rive européenne du Bosphore. Il n'est pas exclu que les Mégariens aient installé Sélymbria suite à un accord avec les indigènes, tout comme ils ont fondé leur établissement en Sicile grâce à l'aide du roi sicule Hyblôn ${ }^{561}$. Dans ce sens, Strabon et Stéphane de Byzance rapportent que le nom de Sélymbria est d'origine thrace, étant formé du nom du fondateur, Sélys, et «Bria», le dernier élément désignant dans les idiomes thraces la «ville» 562 ou le «village» 563 . Le nom de Sélymbria pourrait faire penser à l'existence d'un ancien site thrace qui se serait trouvé quelque part aux environs de la future fondation mégarienne ${ }^{564}$. Malheureusement, l'absence de fouilles nous empêche de savoir si un habitat thrace se trouvait aux abords de Sélymbria au moment de l'arrivée des Grecs. Malgré ce constat, le fait que les Mégariens aient choisi de célébrer le thrace Sélys comme œciste et qu'ils aient donné un nom indigène à leur cité dénote leur intention d'intégrer l'élément local dans le nouvel établissement, au moins au niveau mythologique ${ }^{565}$. Un œciste indigène légitimait la fondation de la colonie et ses éventuelles revendications territoriales. À cet égard, on peut avancer comme parallèle le récit d'Apollonios de Rhodes concernant Héraclée du Pont, qui évoque les bonnes relations établies entre

560 Polybe, IV, 45.

561 Pour les accords entres les apoikoi grecs et les dynastes indigènes, en vertu desquels les Grecs recevaient les terres nécessaires pour la fondation de leur ville, voir Pippidi, Gètes, Grecs et Romains en Scythie, p. 445-446; Domínguez, Colon. Gr., p. 91-95.

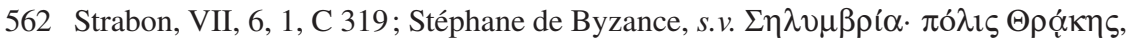

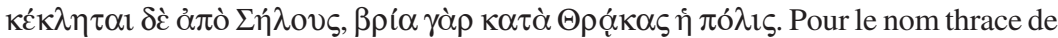
Sélymbria, voir Detschew, Thrak. Sprachreste ${ }^{2}$, p. 437-438.

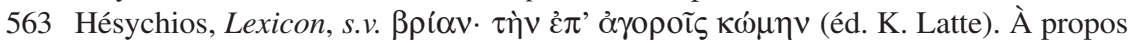
des sens de «village» ou de «ville» du mot thrace bria, voir I. Russu, La langue des Thraco-Daces ${ }^{2}$, Bucarest 1967, p. 96 (en roumain); G. Mihailov, IGBulg $\mathrm{I}^{2}$, ad no 345, p. 307-308; Detschew, Thrak. Sprachreste 2 , p. 86.

564 Oberhummer, Selymbria, col. 1325; Hanell, Megarische Studien, p. 122.

565 Sur Sélys, voir J. Zwicker, s.v. $\Sigma \tilde{\eta} \lambda v \varsigma, R E$ II A, 1923, col. 1327; Detschew, Thrak. Sprachreste $^{2}$, p. 438. 
les Mariandyniens et les Mégariens ou entre les Mariandyniens et le héros Héraclès ${ }^{566}$. Ces traditions ont été interprétées aussi comme une expression des revendications territoriales ultérieures de la part d'Héraclée du Pont ${ }^{567}$.

Les inscriptions font mention de noms thraces, par exemple A $\lambda^{2}-$

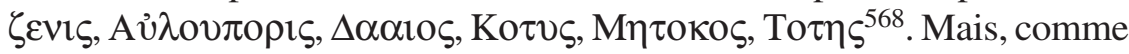
l'a noté Loukopoulou, leur nombre est restreint dans l'onomastique de

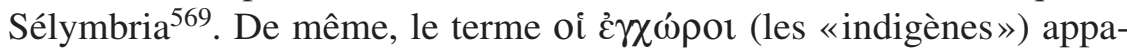
raît dans une inscription de l'époque impériale, sans que l'on puisse pour autant savoir si ce terme se réfère à des habitants d'origine grecque ou thrace résidant sur place ${ }^{570}$.

Observons en passant que Gökyildirim met en rapport le coq qui orne le droit des monnaies de Sélymbria avec la légende du jeune Alectryon, transformé par Arès en coq. Selon lui, Arès aurait eu une origine thrace et aurait été la divinité tutélaire des Sélymbriens ${ }^{571}$. Sans entrer dans la question des rapports d'Arès avec le monde thrace, il faut avouer que cette hypothèse reste spéculative, les cultes d'Arès ou d'Alectryon n'étant pas attestés par ailleurs à Sélymbria. Les légendes monétaires en question s'expliquent, à mes yeux, autrement. Étant donné que le coq figure parmi les animaux consacrés à Déméter et à Perséphone ${ }^{572}$, sa présence sur les monnaies peut témoigner de la célébration de ces divinités par les Sélymbriens. Cette interprétation est confortée par la représentation sur le revers de certaines de ces monnaies d'un épi de blé, attribut de Déméter. Rappelons aussi que le coq est le symbole de la fécondité et que son chant annonce la fin de la nuit et le lever du

566 Apollonios de Rhodes, II, 746-750.

567 Desideri, Storiografia eracleota, p. 402. Voir aussi infra, chapitre II.3.1.2.

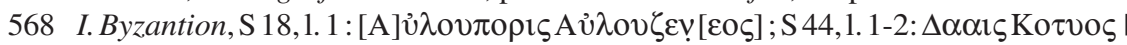
[’A]

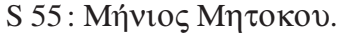

569 Loukopoulou, Thrace propontique, p. 207-209. Pour différentes explications de la présence des noms thraces dans les cités grecques à l'époque impériale, voir infra, chapitre II.2.4.2.

570 I. Byzantion, S 24; cf. G. Seure, «Antiquités thraces de la Propontide», BCH 36, 1912, p. 557; L. Robert, J. Robert, La Carie. Histoire et géographie historique, II, Paris 1954 , p. 307 , n. 3.

571 T. Gökyildirim, «Vth c. B. C. Coin Hoard from Thrace-Örcünlü(1970)», in Stephanos nomismatikos. Edith Schönert-Geiss zum 65. Geburtstag, Berlin 1998, p. 282-283.

572 Porphyre, De l'Abstinence, IV, 16. 
jour. Animal psychopompe, il renvoie au passage de Perséphone du monde des vivants à celui des morts et de l'état virginal au mariage ${ }^{573}$. Les célèbres pinakes de Locres Épizéphyrienne représentent à plusieurs reprises la fille de Déméter tenant dans sa main un coq ou recevant cet animal de la part d'un adorateur ou d'un dieu (Hermès, Arès) ${ }^{574}$. Ces analogies appuient l'idée que le coq et l'épi de blé sont en rapport avec la célébration de Déméter et de Perséphone à Sélymbria, deux divinités dont le culte est attesté ailleurs dans le monde mégarien ${ }^{575}$.

Quant aux liens entre Mégare et Sélymbria, on peut évoquer le cas du sophiste Hérodicos, qualifié de «Sélymbrien, et Mégarien à l'origine» par Platon, et de Sélymbrien par la Souda ${ }^{576}$. Ces récits laissent penser que Hérodicos fut originaire de Mégare et qu'il s'établit par la suite à Sélymbria, où il aurait reçu le droit de cité577. Ce cas rappellerait celui de Théognis, considéré par deux traditions différentes comme originaire de Mégare de Grèce ou de Mégara de Sicile ${ }^{578}$. Du reste, Vatin propose une autre interprétation des mots to archaion Mégareus de Platon, ceux-ci pouvant faire allusion à l'origine mégarienne de Sélymbria, et signaler que «par son ethnie, Hérodicos est apparenté à une école célèbre», soit à l'école philosophique de Mégare ${ }^{579}$.

573 L. Bodson, 'Iع $\rho \dot{\alpha} \zeta \tilde{\omega} \alpha$. Contribution à l'étude de la place de l'animal dans la religion grecque ancienne, Bruxelles 1978, p. 99-100; I. Paladino, «Il gallo e i riti di passaggio in Grecia», in Transition Rites. Cosmic, Social and Individual Order, Proceedings of the Finnish-Swedish-Italian seminar held at the University of Rome «La Sapienza» (24 ${ }^{\text {th }}-28^{\text {th }}$ March 1984), U. Bianchi (éd.), Rome 1986, p. 241; R. Schenal Pileggi, I pinakes di Locri Epizefiri, Reggio Calabria 2011, p. 23.

574 M. Rubinich, in I pinakes di Locri Epizefiri. Musei di Reggio Calabria e di Locri, ASMG, Quarta Serie I (1996-1999), E. Lissi Caronna et al. (éds.), Roma 1999, p. 6163 ; R. Schenal Pileggi, in I pinakes di Locri Epizefiri. Musei di Reggio Calabria e di Locri, ASMG, Quarta Serie III (2004-2007), E. Lissi Caronna et al. (éds.), Roma 2007, p. 41-42; eadem, op. cit., p. 17, 18, 25, 27, 36-40.

575 Sur le culte de Déméter et de Perséphone à Mégare et dans les colonies mégariennes, voir Hanell, Megarische Studien, p. 180-181; Antonetti, Megara e le sue colonie, p. 85-85; V. Hinz, Der Kult von Demeter und Kore auf Sizilien und in der Magna Grecia, Wiesbaden 1998, p. 144-154; Chiekova, Cultes, p. 119-124.

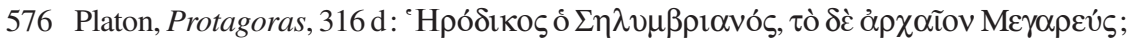

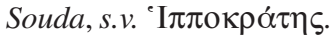

577 Graham, Colony, p. 66.

578 Voir supra, chapitre I.3.2.

579 Vatin, Citoyenneté et ethnique, p. 79. 


\section{II.2.4 Byzance}

\section{II.2.4.1 Les récits concernant la fondation de Byzance}

Byzance (l'actuelle Istanbul), située à l'entrée européenne du Bosphore sur un promontoire délimité par la Corne d'Or, le Bosphore et la Propontide, est la dernière colonie fondée par les Mégariens que les rives de la mer de Marmara ${ }^{580}$.

Il est à remarquer que les Mégariens ne sont jamais désignés comme les fondateurs de Byzance à l'époque classique, mais seulement dès la

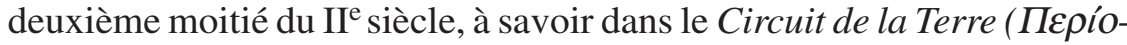
$\delta o \varsigma)$ du Ps.-Scymnos ${ }^{581}$. Aux époques impériale et byzantine, la tradition de la fondation de Byzance par Mégare est bien enracinée, étant évoquée par Denys de Byzance ${ }^{582}$, Philostrate ${ }^{583}$, Jean le Lydien ${ }^{584}$, Hésychios $^{585}$, Georgius Cedrenus ${ }^{586}$, par des manuscrits attribués à Sy-

580 Pour une description du site de Byzance, voir E. Oberhummer, s.v. «Byzantion», RE III, 1899, col. 1116-1120; Janin, Constantinople ${ }^{2}$, p. 1-8.

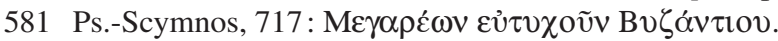

582 Denys de Byzance (éd. R. Güngerich) évoque des devins et des héros mégariens qui ont donné leurs noms à différents endroits du Bosphore ou qui font l'objet d'un culte: les devins Polyeidos [14, p. 7 ; $c f$. Scholie à Denys de Byzance, $19(\operatorname{ad~7,1),}$ p. 37, éd. R. Güngerich] et Lakiadès (49, p. 20); les héros Hipposthénès (32, p. 15), Schoiniklos (34, p. 15, ce héros est en réalité béotien, voir infra, chapitre II.2.4.1.4), Ajax (39, p. 17) et Saron (71, p. 26). Sur le culte des héros mégariens dans les colonies fondées par Mégare, voir Hanell, Megarische Studien, p. 188-190. Selon une tradition recueillie par Denys, les Mégariens ont fondé sur la rive européenne du Bosphore l'endroit appelé Hestiai (53, p. 23, éd. R. Güngerich, voir infra, chapitre II.2.4.1.1). De plus, toujours selon ce géographe de Byzance, les golfes de Lasthénès (63, p. 25, éd. R. Güngerich) et de Lykadion (104, p. 32, éd. R. Güngerich) sont nommés d'après des Mégariens.

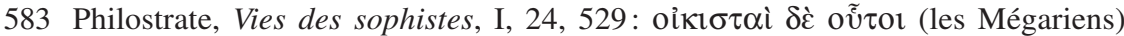

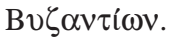

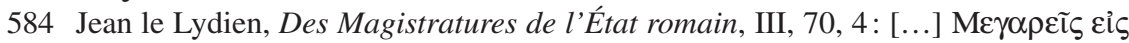

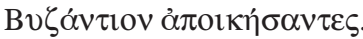

585 Hésychios de Milet, FGrHist 390 F 5 (voir infra, chapitre II.2.4.1.6).

586 Georgius Cedrenus, Historiarum compendium, I, p. 197 (éd. I. Bekker), rapporte que Byzance fut fondée par le roi thrace Byzas ou, selon d'autres, par les Mégariens :

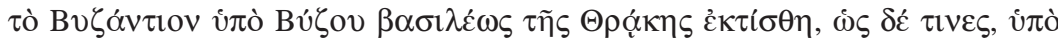

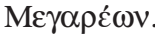


méon $^{587}$ et à Josephus Genesius ${ }^{588}$, par une scholie à Démosthène ${ }^{589}$ ou encore par la Narratio historica in depositione vestis $S$. Mariae in Blachernis $^{590}$.

De plus, selon une tradition mentionnée par Stéphane de Byzance et par Eustathe, c'était l'oracle de Delphes qui avait conseillé aux Mégariens de fonder leur apoikia sur la rive thrace du Bosphore, leur précisant les bienfaits de la future colonie (l'abondance de poissons et du gibier $)^{591}$. Une autre tradition, recueillie par Hésychios, mentionne le même oracle intimé cette fois non pas aux Mégariens, mais aux Argiens ${ }^{592}$. Cet «oracle» était assurément une contrefaçon postérieure à la fondation de la cité, au moment où Byzance était déjà célèbre pour ses richesses halieutiques ${ }^{593}$.

Par ailleurs, on remarque que même si plusieurs auteurs antiques se sont penchés sur l'histoire de Byzance et sur les avantages de sa position, ils ont gardé le silence à propos des fondateurs de cette colonie. Hérodote (IV, 144), lorsqu'il reprend les propos de Mégabaze, ne mentionne pas

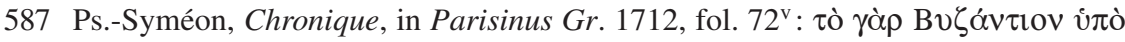

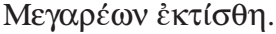

588 Josephus Genesius, in J.-P. Migne (éd.), Patrologia Graeca, vol. 109, Paris 1887,

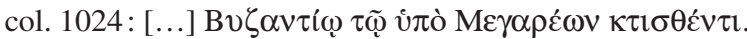

589 Scholie à Démosthène, V, 25: Bvל̧́์

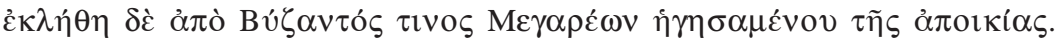

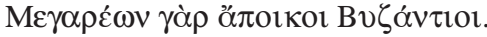

590 On trouve ce manuscrit reproduit chez F. Combefis (éd.), Historia haeresis Monothelitarum, Paris 1648, col. 755 D-E (voir infra, chapitre II.2.4.1.7).

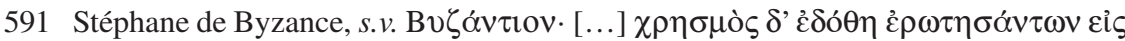

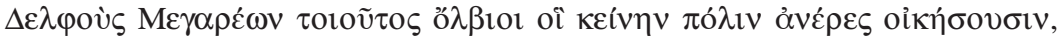

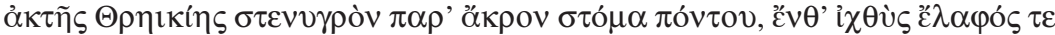

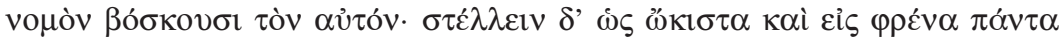
$\lambda \alpha \beta o ́ v \tau \alpha$. Le même oracle est reproduit par Eustathe, GGM II, 803, p. 357, et, sans l'indication de l'origine des fondateurs, par Denys de Byzance, 23, p. 11 (éd. R. Güngerich), et la scholie à Denys de Byzance, 28 ( $a d 11,9)$, p. 37 (éd. R. Güngerich). La même prophétie apparaît aussi dans l'Anthologie Palatine, XIV, 115, mais adressée cette fois à Constantin le Grand. L'oracle conseilla à l'empereur de ne pas bâtir sa capitale sur les ruines d'Ilion, mais sur l'emplacement de la ville mégarienne du Bosphore.

592 Hésychios, FGrHist 390 F 3.

593 Voir supra, chapitre II.2.2.2. Cet oracle est repertorié par W. Parke, D.E. W. Wormell, op. cit., vol. II, p. 201-202, nos 497-498; ainsi que par J. Fontenrose, The Delphic Oracle, Berkeley et al. 1978, p. 283, nº 44, qui ne le considère pas comme authentique. $C f$. Dagron, Naissance d'une capitale, p. 14. 
les fondateurs de Byzance, tout en évoquant pourtant la fondation de Chalcédoine par les Mégariens. De même, Strabon (VII, 6, 2, C 320), qui rapporte que les Mégariens ont installé Chalcédoine, parle seule-

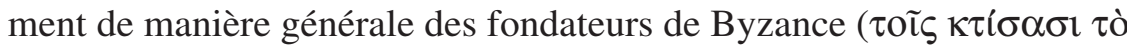

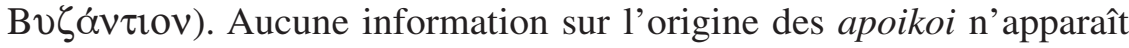
non plus dans le célèbre excursus que Polybe (IV, 38; 43-52) a consacré à la cité du Bosphore. Or rappelons que Byzance jouait un rôle important dans l'économie antique, elle contrôlait la route commerciale qui passait par le Bosphore en direction de la mer Noire, et il est certain qu'une telle cité conférait un prestige important à la métropole l'ayant fondée. L'absence dans les récits de l'époque classique de la mention de l'origine de Byzance s'explique peut-être par le fait qu'il existait différentes traditions de fondation, et non pas une seule. Autrement dit, il est possible que plusieurs auteurs se soient trouvés vraiment dans l'embarras du choix et aient préféré ne rien dire plutôt que de se compliquer la tâche ${ }^{594}$. Je me propose d'examiner dans les chapitres suivants les nombreuses traditions qui circulaient à l'époque impériale à propos de l'origine des fondateurs de Byzance.

\section{II.2.4.1.1 La fondation d'Hestiai}

L'analyse des récits concernant la fondation de Byzance doit commen-

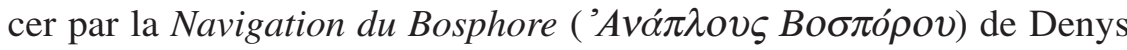
de Byzance (II ${ }^{\mathrm{e}}$ siècle ap. J.-C.). Cet ouvrage, une véritable «promenade mythologique ${ }^{595}$, transmet plusieurs traditions portant sur la fondation des différents sites et lieux de culte situés sur les rives européenne et asiatique du Bosphore. Il évoque aussi les ports, les mouillages utiles pour le passage des navires par le détroit. Il nous reste de cette description géographique des fragments en grec et des citations traduites en latin par le moine français Petrus Gillius (Pierre Gilles d’Albi),

594 Hanell, Megarische Studien, p. 127, note «dass neben den Megaren auch Angehörige anderer Staaten an der Siedlung teilnahmen, ist doch vielleicht den Griechen immer klar gewesen». Cette suggestion est acceptée aussi par Legon, Megara Pol. Hist., p. 81.

595 Dagron, Recueil des Patria, p. 12, qui confond pourtant les commentaires d'Eustathe de Thessalonique à Denys d'Alexandrie avec ceux de Pierre Gille à Denys de Byzance. 
dans ses ouvrages parus à titre posthume en 1561, De Bosporo Thracio et De Topographia Constantinopoleos ${ }^{596}$.

Pour la colonisation du Bosphore, la mention la plus intéressante de Denys de Byzance est de loin celle qui concerne la fondation du lieu-dit des Hestiai sur la rive européenne du Bosphore. En essayant de fournir une explication pour le nom de ce site, Denys rapporte deux légendes. Selon la première, lorsque les apoikoi grecs voulurent installer Byzance, sur le promontoire du Bosphore thrace, ils constatèrent que les lieux étaient tenus par une grande foule de soldats barbares.

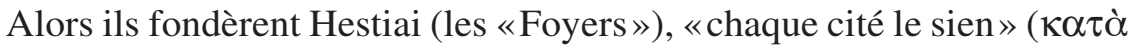
$\pi$ ó $\lambda \iota v \varepsilon \varepsilon \kappa o ́ \sigma \tau \eta v)$, à l'endroit où ils avaient d'abord débarqué. Les barbares sortirent de leur cité et attaquèrent par terre la nouvel établissement, mais cela offrit l'occasion aux Grecs d'aborder avec leur flotte le promontoire du Bosphore, qui se trouvait sans protection, et de fonder la future Byzance. Car pour les Grecs le trajet par mer n'était pas long en coupant les golfes, tandis que pour les barbares la voie terrestre suivait une courbe. Ils réussirent ainsi à tromper leurs adversaires par une ruse de guerre. Mais, selon une autre légende, «les Hestiai (les 〈Foyers >) n'appartiennent pas aux cités, mais aux sept maisons mégariennes les plus nobles». Devant la divergence des sources, le géographe finit par noter: «Plaise à chacun de croire ce qu'il veut» 597 .

596 La première édition complète de Denys de Byzance a été publiée par C. Wescher (éd.), Dionysii Byzantii, De Bospori navigatione, Paris 1874. Cependant, l'édition de référence est celle de R. Güngerich (éd.), Dionysii Byzantii, Anaplus Bospori. Una cum scholiis X saeculi ${ }^{2}$, Berlin 1958, qui a le mérite de donner à la fois le texte grec de l'auteur, les passages de Gillius ayant valeur de testimonia et l'editio princeps des scholies à Denys. Sur Denys de Byzance, voir aussi C. Müller, GGM II, p. I-XIV; E. Miller, JS, 1874, p. 200-218; Merle, Byzantion und Kalchedon, p. 3 ; R. Güngerich, op. cit., p. V-XLIV; idem, Die Künstenbeschreibung in der griechischen Literatur $^{2}$, Orbis antiquus, Heft 4, Münster 1975, p. 21-22; F. Jacoby, Gnomon 4, 1928, p. 262-268; D. Marcotte, op. cit., p. XXXVIII, CVI-CVII. Pour la paraphrase de Pierre Gilles, on renvoie à C. Müller (éd.), GGM II, Paris 1861, p. 1-101, et surtout à J.-P. Grélois (éd.), Pierre Gilles. Itinéraires byzantins. Lettre à un ami. Du Bosphore de Thrace. De la Topographie de Constantinople et de ses antiquités, Paris 2007, qui offre une traduction en français des ouvrages de Gilles.

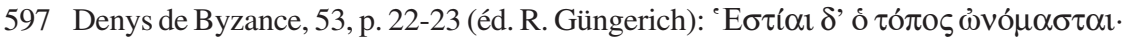

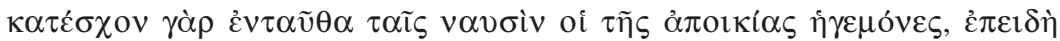

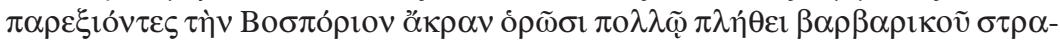

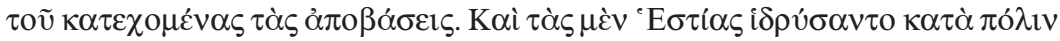

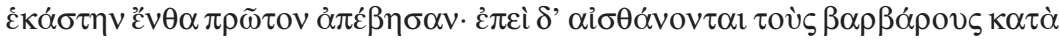


Il ressort de ce récit qu'Hestiai est le nom du site sur la rive européenne du Bosphore où les Grecs ont débarqué pour la première fois ${ }^{598}$. Il n'est pas erroné de considérer que les traditions recueillies par Denys de Byzance concernent la fondation de Byzance ${ }^{599}$. De fait, la fondation d'Hestiai, dont le nom fait référence à la fois à la mise en commun des foyers grecs et à la déesse Hestia, la protectrice du feu sacré du Prytanée, symbolise la fondation de Byzance ${ }^{600}$. Mieux encore, Denys utilise dans ce passage un vocabulaire spécifique à un synœcisme et l'on se souvient des mythes athéniens qui rapportent que Thésée a substitué les Prytanées de chaque village par un seul Prytanée commun. En remplaçant les foyers dispersés de l'Attique par un seul, Thésée a fondé une nouvelle ville et en l'honneur de cet événement les Athéniens ont organisé la fête des Synoikia ${ }^{601}$. De la même manière, les apoikoi originaires de différentes cités ou de sept familles mégariennes ont regroupé à Hestiai leurs feux sacrés pour pouvoir fonder une nouvelle ville. L'installation d'une apoikia grecque suppose la réalisation d'un rassemblement de plusieurs groupes de colons, c'est-à-dire l'existence

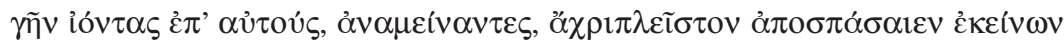

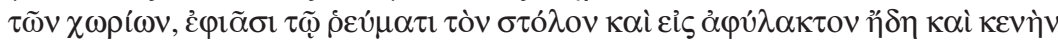

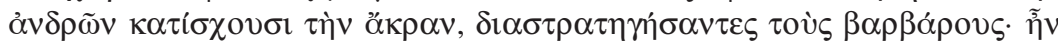

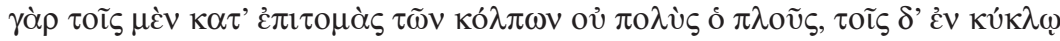

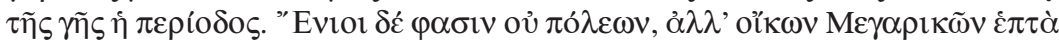

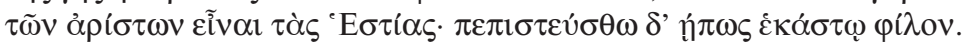

598 Polybe, IV, 43, 5, évoque «les hauteurs appelées Hestiai, du côté de l'Europe » ( $\tau$ ò

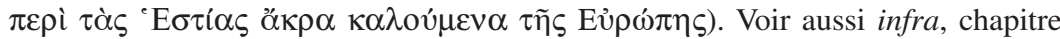
II.2.4.1.7, pour la mention d'une autre tradition de fondation d'Hestiai chez Hésychios, FGrHist 390 F 22. Pline, $N H$, V, 43, 150, rapporte aussi la présence d'Hestiae sur la rive européenne du Bosphore. Sur cet endroit, voir Oberhummer, Bosporos, col. 747-748.

599 Contra Pfister, Mythische Königsliste, p. 38-39, qui estime que le passage de Denys ne porte pas sur la fondation de Byzance en particulier, mais sur la colonisation des rives européennes et asiatiques du Bosphore thrace en général, lieu de passage de plusieurs Grecs.

600 Sur le caractère politique du culte d'Hestia, voir R. Merkelbach, «Der Kult der Hestia im Prytaneion der griechischen Städte», ZPE 37, 1980, p. 77-92; J.-P. Vernant, Mythe et pensée chez les Grecs. Études de psychologie historique ${ }^{3}$, Paris 1985, p. 155-201, 214-215 ; D. Gneisz, Das antike Rathaus. Das griechische Bouleuterion und die frührömische Curia, Wien 1990, p. 208-211.

601 Thucydide, II, 15, 2; Plutarque, Thésée, 24, 3. 
d'un synœcisme initial. À mon sens, le terme de synoikismos peut s'appliquer au phénomène de la colonisation grecque, car par son sens technique, à savoir une «réunion de plusieurs oikoi», ce mot exprime, si l'on citait Casevitz, «un processus unificateur d'où résulte une ville nouvelle ${ }^{602}$. Il indique donc la réunion en cité d'individus de diverses provenances ou de la même origine.

Comme Vernant l'a rappelé, l'Hestia, le Foyer commun, n'est pas seulement un symbole religieux, mais avant tout un symbole politique: il exprime l'unité des citoyens ${ }^{603}$. Dans ce cadre, le transfert du feu sacré d'une métropole dans une colonie exprime la continuité et les liens de parenté qui existent entre les deux communautés et qui peuvent appuyer a priori des relations au niveau politique ${ }^{604}$. On note aussi que chez Hésychios l'installation des Grecs sur la rive européenne du Bosphore a été accompagnée par la célébration des rites de fondation et par des sacrifices aux divinités grecques et locales ${ }^{605}$.

Un parallèle pour Hestiai de Byzance est fourni par Pausanias, qui évoque la présence à Mégare d'un autel-foyer des dieux Prodomeis

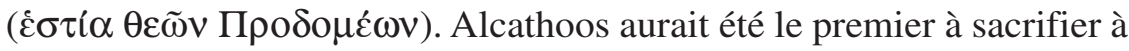
ces divinités au moment où il avait commencé la construction du rempart. Près d'Hestia de Mégare, ajoute le Périégète, se trouvait la pierre sur laquelle le dieu Apollon aurait déposé sa cithare, le temps d'aider le héros mégarien dans son entreprise ${ }^{606}$. Ces données nous montrent que la fondation de Mégare était célébrée par des sacrifices dans ce véritable foyer de la ville. Les Prodomeis («Premiers Constructeurs») sont des dieux bâtisseurs qui aidèrent à la construction de l'enceinte, à savoir à l'acte de naissance de la cité. Il existe dans ce sens une liaison étroite entre les protagonistes de cette fondation: le héros Alcathoos, les dieux Prodomeis et la principale divinité mégarienne Apollon

602 Casevitz, Vocabulaire, p. 205-205; Robu, Réseaux, p. 182-183. Cf. M. Moggi,

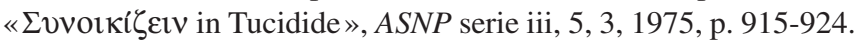

603 J.-P. Vernant, op. cit., p. 186-187, 214-215, 241. Cf. S. G. Miller, The Prytaneion. Its Function and Architectural Form, Berkeley et al. 1978, p. 13-15.

604 Voir Malkin, Religion and Colon., p. 114-134, pour les témoignages concernant le transfert du feu sacré du Prytanée de la métropole dans la colonie et pour les symboles de cette vieille tradition grecque.

605 Hésychios, FGrHist 390 F 3.

606 Pausanias, I, 42, 1-2. Sur Alcathoos, voir aussi supra, chapitre I.1.1. 
Archégète ${ }^{607}$. Pareillement, Hestiai de Byzance renvoie aux temps du début de la cité et aux sacrifices accomplis par les premiers fondateurs ayant abordé la rive européenne du Bosphore.

Force est de constater par ailleurs que Denys transmet deux traditions pour la fondation d'Hestiai/Byzance. La première rapporte que les «Foyers» (Hestiai) appartenaient aux cités qui ont envoyé les colons. On a affaire dans ce cas à une colonie qui a plusieurs métropoles, ce qui implique le transfert de plusieurs feux sacrés ${ }^{608}$. La deuxième tradition atteste que les «Foyers» appartenaient aux sept familles mégariennes les plus notables. On assignait ainsi aux aristocrates l'honneur de cette fondation, et plus haut Denys de Byzance mentionne les

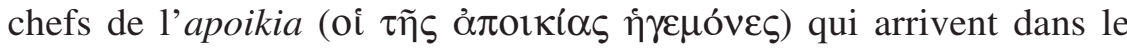
Bosphore avec leurs navires ${ }^{609}$. Bref, il n'était pas possible au $\mathrm{II}^{\mathrm{e}}$ siècle ap. J.-C. de faire un choix entre ces deux légendes, et le chroniqueur invite ses lecteurs à en penser ce qu'ils veulent. Cette difficulté conforte l'opinion exprimée plus haut qu'à Byzance il existait plusieurs traditions de fondation et que, par conséquent, pour certains auteurs, il n'était pas facile d'en choisir une.

Le rôle principal joué par Mégare dans la fondation de Byzance est néanmoins incontestable ${ }^{610}$. Il est confirmé par la plupart des récits qui attribuent cette colonie à Mégare et aussi par l'alphabet mégarien ${ }^{611}$, par l'onomastique et le dialecte ${ }^{612}$, par les institutions mégariennes pré-

607 Pour le culte des dieux Prodomeis à Mégare, voir Highbarger, Megara, p. 50-51; A. Alvino, «I Prodomeis nel culto megarese: divinità senza volto?», Religione $e$ città nel mondo antico. Atti. Centro ricerche e documentazione sull'antichità classica 11, 1980-1981, Roma 1984, p. 7-8 ; F. Chamoux (éd.), Pausanias, Description de la Grèce, Livre I, L'Attique, Paris 1992, ad I, 42, 1, p. 260-261 ; Detienne, Apollon, p. 94.

608 Cf. Malkin, Religion and Colon., p. 131.

609 Pour l'implication de l'aristocratie à l'époque archaïque dans la colonisation et dans les activités commerciales, voir A. Mele, Il commercio greco arcaico. Prexis ed emporie, Cahiers du Centre Jean Bérard 4, Napoli 1979, surtout p. 58-78.

610 Merle, Byzantion und Kalchedon, p. 6-7; Legon, Megara Pol. Hist., p. 81-82; Graham, Colonial Expansion, p. 120.

611 Jeffery, $L S A G^{2}$, p. 134-135, 366; K. Hallof, K. Herrmann, S. Prignitz, «Alte und neue Inschriften aus Olympia I», Chiron 42, 2012, p. 216-222.

612 L. Robert, in Firatlt, Stèles de Byzance, p. 135-136; O. Masson, «L'onomastique de l'ancienne Byzance (épithaphes et monnaies)», EA 23, 1994 (1995), p. 137-144 (= Onomastica Graeca selecta, vol. III, Genève 2000, p. 206-213); Loukopoulou, Thrace propontique, p. 203-205. 
sentes à Byzance (mais avec une exception notable, le hiéromnamôn éponyme ${ }^{613}$ ), par les cultes et le calendrier, qui sont également d'origine mégarienne ${ }^{614}$. Cette constatation n'exclut pas que d'autres Grecs aient pu collaborer avec les Mégariens dans cette entreprise. En effet, il n'était pas inhabituel que deux ou plusieurs métropoles s'unissent pour fonder ensemble une apoikia ou qu'une cité invitât ceux qui le désiraient à se joindre à l'apoikia qu'elle envoyait à l'étranger ${ }^{615}$. Les sources littéraires évoquent la présence à Byzance non seulement des Mégariens, mais aussi des Arcadiens, des Mycéniens, des Carystiens, des Athéniens, des Spartiates, des Milésiens, des Béotiens, des Corinthiens, des Argiens et des Chalcédoniens. Selon Merle, cette longue liste s'explique par le développement ultérieur de la cité de Byzance. L'auteur qui transmet l'information attribue l'honneur de la fondation à différentes métropoles en fonction de son patriotisme, ou bien de sa sympathie pour l'une des cités mentionnées ${ }^{616}$. Cette liste confirme en tout cas l'absence d'une tradition sans équivoque à l'égard de l'orgine des fondateurs de Byzance.

Il faut avouer notre difficulté à faire fond sur certains témoignages, faute d'analogies ou d'informations explicites. Ainsi, Denys de Byzance localise sur la rive de la Corne d'Or un temple de Zeus Hapsasios fondé par un Arcadien ${ }^{617}$. Mais hormis ce récit, on ne dispose pas d'autres

\section{Voir infra, chapitre III.2.1.2.}

614 Hanell, Megarische Studien, p. 161-204; Loukopoulou, Thrace propontique, p. 103 109, 120-122; Trümpy, Monatsnamen, p. 147-149. Même si en principe les nomima mégariens pouvaient être introduits à Byzance par des colons de Chalcédoine, ceci est improbable, car aucune tradition antique ne mentionne Byzance comme une fondation chalcédonienne (voir infra, chapitre II.2.4.1.7).

615 De Wever-Van Compernolle, Colonisation, p. 472, n. 26.

616 Merle, Byzantion und Kalchedon, p. 6: «Bei dem bunten Gemisch der Auswanderer ist es zu verstehen, daß die Quellen, besonders wenn die neue Siedelung sich zu einem bedeutenden Platz auswuchs, bald diesen, bald jenen die Ehre der Gründung zuerkennen, je nachdem bei dem Schreiber lokalpatriotische Gefühle mitsprachen, oder er sonstwie eine gewisse Sympathie für diesen oder jenen Staat hegte».

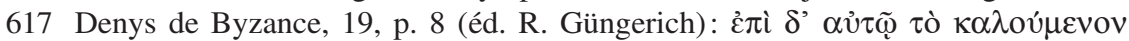

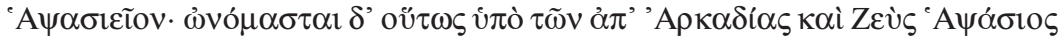

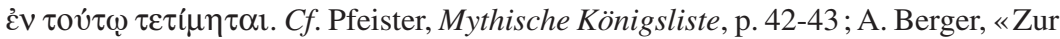
Topographie der Ufergegend am Goldenen Horn in der byzantinischen Zeit», MDAI(I) 45, 1995, p. 150-151, qui place le Hapsasieion à l'église Saint-Nicolas, aux abords d'Ayakapt. 
données qui pourraient confirmer la présence des Arcadiens sur les rives du Bosphore. La participation des Mycéniens et des Carystiens, à côté des Mégariens et des Corinthiens, évoquée par un manuscrit byzantin du IX ${ }^{\mathrm{e}}$ siècle ap. J.-C., n'est pas non plus attestée par d'autres sources ${ }^{618}$. Il n'est pas exclu que l'antiquité reculée et la célébrité des Arcadiens et des Mycéniens soient les seules responsables de ces attestations tardives. Avoir ces vieux peuples parmi ses ancêtres pouvait constituer un objet de gloire à l'époque impériale ou byzantine. Quant à la participation de Carystos à la fondation de Byzance, on rappellera que cette cité était une escale importante sur la voie reliant le golfe Saronique au nord de la mer Égée ${ }^{619}$. On peut penser que des apoikoi ou des époikoi mégariens partis pour la Propontide firent escale en Eubée, où ils prirent en route quelques Carystiens.

Par ailleurs, on dispose de sources littéraires et documentaires plus nombreuses relatives à la participation des Spartiates, des Athéniens, des Béotiens, des Milésiens, des Corinthiens, des Argiens et des Chalcédoniens à la colonisation de la rive européenne du Bosphore thrace. Je me propose maintenant de faire état de ces récits de fondation et de fournir pour chaque cas l'explication qui me semble convenir le mieux.

\section{II.2.4.1.2 Les Spartiates et les Athéniens: les fondateurs de Byzance?}

À en croire Justin, Pausanias, le célèbre chef spartiate qui triompha dans les guerres contre les Perses, fut le premier fondateur de Byzance. Ensuite, après que la cité fut restée sept ans sous le pouvoir du Spartiate, elle fut occupée alternativement par les Lacédémoniens et par les

618 Josephus Genesius, in J.-P. Migne (éd.), Patrologia Graeca, vol. 109, Paris 1887,

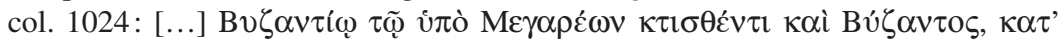

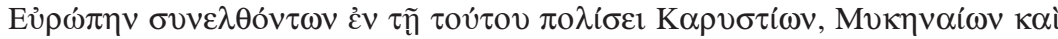

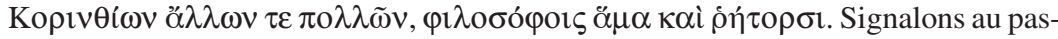
sage l'apparition de Carystos dans les archives mycéniennes de Thèbes. À ce propos, voir C. Pitéros, J.-P. Oliver, J. L. Melena, «Les inscriptions en linéaire B des nodules de Thèbes (1982): la fouille, les documents, les possibilités d'interprétation », BCH 114, 1990, p. 153-154; D. Knoepfler, Décrets érétriens de proxénie et de citoyenneté, Eretria. Fouilles et recherches XI, Lausanne 2001, p. 240.

619 J.-M. Kowalski, Navigation et géographie dans l'Antiquité gréco-romaine. La terre vue de la mer, Paris 2012, p. 70-71. Sur Carystos, voir dernièrement K. Reber, M.H. Hansen, P. Ducrey, s.v. «Karystos», in Hansen-Nielsen (éds.), Inventory, p. 658-659 (avec les références). 
Athéniens ${ }^{620}$. Cette information est reprise par Orose qui, lui aussi, désigne Pausanias comme le fondateur de la cité621. En revanche, Ammien Marcellin attribue la fondation de Byzance aux Athéniens ${ }^{622}$ et, chez Constantin Porphyrogénète, «Byzance est une colonie des Mégariens, des Lacédémoniens et des Béotiens, les plus anciens des Grecs ${ }^{623}$.

Comme on n'a pas manqué de le noter, ces traditions découlent du rôle important que les deux cités de la Grèce ont joué dans l'histoire de Byzance à l'époque classique ${ }^{624}$. En effet, la mention de Pausanias en tant que fondateur de Byzance s'avère être une confusion provoquée par le fait que le général spartiate avait délivré la ville de l'occupation perse. On sait en effet que la flotte grecque, commandée par Pausanias, est arrivée en Propontide vers 478-477 et a réussi à prendre Byzance ${ }^{625}$. La conquête de la ville par le régent spartiate a été suivie par le retour des Byzantins, réfugiés en 493 avec des Chalcédoniens à Mésambria ${ }^{626}$. Dans ce contexte, la restitution de la ville aux Byzantins a pu être perçue comme une seconde fondation, Pausanias étant honoré par la suite comme un nouveau fondateur de la cité627.

620 Justin, IX, 1, 3 : Haec namque urbs condita primo a Pausania, rege Spartanorum, et per septem annos possessa fuit; deinde, uariante uictoria, nunc Lacedaemoniorum, nunc Atheniensium iuris habita est.

621 Orose, Histoires contre les païens, III, 13, 2: Haec autem Byzantium quondam a Pausanias rege Spartanorum condita.

622 Ammien Marcellin, Histoires, XXII, 8, 8: Constantinopolis, uetus Byzantium, Atticorum colonia.

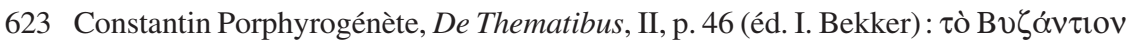

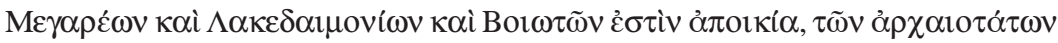

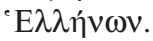

624 Legon, Megara Pol. Hist., p. 82.

625 La prise de Byzance par Pausanias est datée soit de l'automne 478, soit du printemps 477. À ce propos voir C. W. Fornara, «Some Aspects of the Career of Pausanias of Sparta», Historia 15, 1966, p. 261-271; W. T. Loomis, «Pausanias, Byzantion and the Formation of the Delian League. A Chronological Note», Historia 39, 1990, p. 487-492; P. Ellinger, La fin des maux. D'un Pausanias à l'autre, Paris 2005, p. 44-45, 245, n. 42.

626 Voir infra, chapitre II.3.2.1.

627 C.F. Lehmann-Haupt, «Pausanias, Heros Ktistes von Byzanz», Klio 17, 1921, p. 59-66; Leschhorn, Gründer, p. 157-159; cf. Janin, Constantinople ${ }^{2}$, p. 13. 
Quant à la tradition qui fait de Byzance une colonie athénienne, elle s'explique par l'appartenance de la cité du Bosphore autant à la première qu'à la seconde Ligue athénienne ou, plus probablement, par l'alliance conclue vers 340/39 entre les Byzantins et les Athéniens contre le roi de Macédoine Philippe II $^{628}$. À l'appui de cette dernière hypothèse, on peut invoquer le fait que Charès - le stratège athénien envoyé au secours des Byzantins assiégés par Philippe -, est inséré par Hésychios dans la liste des sept stratèges ayant gouverné la cité de Byzance ${ }^{629}$.

Pour les rapports entre les cités du Bosphore thrace et Athènes, il n'est pas sans intérêt de constater que les noms de certaines subdivi-

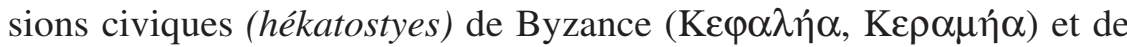
Chalcédoine ('A ${ }^{\prime} \theta i ́ \varsigma$ ) portent la marque d'un héritage athénien ${ }^{630}$.

\section{II.2.4.1.3 Y a-t-il eu une participation des Milésiens à la fondation de Byzance? À propos du soi-disant accord entre les Mégariens et les Milésiens dans la colonisation}

Au début du $\mathrm{I}^{\mathrm{er}}$ siècle ap. J.-C., dans l'Histoire romaine de Velleius Paterculus, la cité de Milet apparaît comme métropole de Byzance et de Cyzique $^{631}$.En s'appuyant sur ce récit, Hanell considère que les Milésiens avaient participé avec les Chalcédoniens et les Mégariens à la fondation de Byzance. Cette participation milésienne appuierait l'idée d'un accord entre Mégare et Milet, en vertu duquel les deux cités se seraient assurées le monopole de la colonisation en mer Noire ${ }^{632}$. Selon lui, cet accord serait aussi illustré par la mention des Milésiens en tant que fondateurs

628 Sur les rapports entre Byzance et Athènes au Ve-IVe siècles, voir Miller, Byzantion, col. 1130-1136; Merle, Byzantion und Kalchedon, p. 17-49; Loukopoulou- -ajtar, Byzantion, p. 916-917; Merkelbach, I. Kalchedon, p. 92-94.

629 Hésychios, FGrHist 390 F 28. On connaît aussi une épigramme composée en l'honneur de Boidion, morte au cours de l'expédition de son époux, Charès, et enterrée sur la côte asiatique du Bosphore: Anthologie Palatine, VII, 169 (=I. Kalchedon, 35).

630 Voir infra, chapitre III.1.2.6.

631 Velleius Paterculus, II, 7, 7: Id maiores, cum uiderunt tanto potentiorem Tyro Carthaginem, Massiliam Phocaea, Syracusas Corintho, Cyzicum ac Byzantium Mileto, genitali solo.

632 Hanell, Megarische Studien, p. 132-136, suivi par Legon, Megara Pol. Hist., p. 8284 (avec pourtant quelques réserves); M. R. Alföldi, «Zur Gründung von Kyzikos », in Studien zum antiken Kleinasien. Asia Minor Studien, Band 3, Bonn 1991, p. 137; Antonetti, Megara e le sue colonie, p. 85-85; Hind, Megarian Colonization, p. 134. Cf. Malkin-Shmueli, City of the Blind, p. 32 
d'Héraclée du Pont ${ }^{633}$ et de Callatis ${ }^{634}$. Dernièrement, Vinogradov a essayé d'apporter des arguments supplémentaires en faveur d'une collaboration entre Mégare et Milet dans la colonisation. Il invoque notamment des ostraka de Chersonèse Taurique, qui transmettent au $\mathrm{V}^{\mathrm{e}}$ siècle

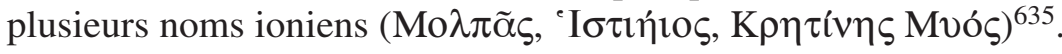

Cependant, force est de constater qu'Hanell écrit dans son ouvrage de 1934 comme s'il avait traité des relations entre les États européens dans la première moitié $\mathrm{du} \mathrm{XX}^{\mathrm{e}}$ siècle. L'image de Milet et Mégare est celle de deux métropoles puissantes qui négocient leurs sphères d'intérêt de la même manière que l'Angleterre l'a fait avec l'Allemagne ou la France à l'époque contemporaine. Le contrôle du Bosphore, un élément-clé pendant la Grande Guerre, aurait joui déjà à l'époque archaïque de la même importance ${ }^{636}$. Il y a plusieurs indices qui suggèrent qu'on a affaire à un modèle erroné. Tout d'abord, on rappellera le danger de la transposition de l'attitude de l'Angleterre ou de l'Allemagne dans la Grèce antique, sur lequel Finley a attiré l'attention ${ }^{637}$. Ensuite, il faut avouer que rien ne permet d'affirmer que les Mégariens, dans le contexte des combats qu'ils ont dû mener contre les tribus thraces au moment de la fondation de Byzance, furent capables de réaliser «le blocus de l'entrée du Bosphore». Il est d'ailleurs très douteux que cette entreprise ait été possible à l'époque archaïque ${ }^{638}$. Preuve en est la guerre de Périnthe, qui opposa autour de 600 les Mégariens de Propontide aux Samiens, et qui est une guerre pour l'hégémonie sur la côte nord-est de

633 Strabon, XII, 3, 4, C 542.

634 Pomponius Mela, II, 2, 22.

635 Vinogradov, Milet und Megara, p. 465-473.

636 Hanell, Megarische Studien, p. 135: «Nach der Gründung von Byzantion beherrschten die Megarer die Einfahrt zum Pontus. Es ist nun, wie oben bemerkt wurde, eine historische Tatsache, dass fast sämtliche Griechenstädte am Pontus milesisch oder megarisch sind. Dies setzt ein Bündnis der beiden Städte voraus, wodurch der Zugang zum Pontos Milesiern und Megaren vorbehalten war».

637 Finley, Sur l'hist. ancienne, p. 152-153.

638 Contra Loukopoulou, Thrace propontique, p. 59, qui rejette la thèse de Hanell, en considérant que cet accord, très utile aux Milésiens qui traversaient le Bosphore, ne présentait aucun intérêt pour les Mégariens. Pourtant, ce raisonnement est construit selon la même logique que celui de Hanell, mais d'une manière inverse. C'est d'ailleurs la raison pour laquelle Loukopoulou arrive à une conclusion tout aussi anachronique: «Toute réaction des Milésiens à la fondation des colonies mégariennes en mer Noire entrainerait, en représailles, le blocus de l'entrée du Bosphore, ce qui sonnerait la fin des colonies milésiennes du Pont-Euxin». 
la Propontide. La perte de cette guerre par les Mégariens montre que ceux-ci n'avaient pas les ressources nécessaires pour empêcher d'autres mouvements grecs de colonisation concurrents dans la région ${ }^{639}$.

Pour les époques postérieures, on remarque que le contrôle du trafic à travers le Bosphore ne se réalisa que lors de très brèves périodes: ce fut notamment le cas à l'époque de la guerre du Péloponnèse, lorsque les Athéniens occupèrent Chrysopolis et décidèrent de taxer les bateaux de commerce passant par le détroit ${ }^{640}$. On sait aussi que les Byzantins et les Chalcédoniens saisirent à plusieurs reprises au $\mathrm{IV}^{\mathrm{e}}$ siècle des cargaisons de navires venant ou allant vers le Pont-Euxin, ou qu'ils avaient introduit des taxes supplémentaires pour les commerçants se trouvant dans leurs ports ${ }^{641}$. Cependant, l'essai de Byzance, affaiblie par le tribut qu'elle devait payer aux Galates, de taxer vers 220 les navires traversant le Bosphore provoqua la guerre avec Rhodes, à la fin de laquelle la mesure fut abandonnée ${ }^{642}$. Cela montre la difficulté que les Byzantins avaient à établir à long terme un monopole commercial sur les marchandises qui transitaient par le détroit ${ }^{643}$.

Quant à l'attestation épigraphique d'une présence ionienne à Chersonèse et la mention des Milésiens parmi les fondateurs de Callatis, celles-ci ne constituent pas des preuves de l'existence d'un accord entre les Mégariens et les Milésiens. Car il faut rappeler que Chersonèse et

639 Voir supra, chapitre II.2.1.2.

640 Voir supra, chapitre II.2.2.2.

641 Démosthène, L, Contre Polyclès, 4-6 et 17-19, rapporte que les Byzantins, les Chalcédoniens et les Cyzicéniens s'attaquèrent en 362 aux navires de commerce parce qu'ils manquaient de blé; ensuite, en 361, les attaques des navires furent reprises par les Byzantins et les Chalcédoniens. De même, Démosthène, V, Sur la Paix, 25, mentionne l'habitude des Byzantins d'arrêter les vaisseaux marchands. Ps.-Aristote, Économique, II, 2, 3c, 1346b 29-33, atteste que Byzance saisit les navires sortant du Pont-Euxin et obligea les marchands à payer une taxe de dix pour cent sur la valeur de la cargaison. De même, toujours selon le Ps.-Aristote, Économique, II, 3, 10, 1347b 20-30, afin de payer la solde restante aux mercenaires étrangers se trouvant dans leur ville, les Chalcédoniens saisirent les navires qui étaient en partance pour le Pont-Euxin.

642 Voir infra, chapitre II.2.4.2.

643 V. Gabrielsen, op. cit., p. 287-317. Cf. A. Robu, «Les relations de Byzance avec les cités du Pont Gauche à l'époque hellénistique : la guerre pour l'emporion de Tomis », in Actes du colloque Die Außenbeziehungen pontischer und kleinasiatischer Städte in hellenistischer und römischer Zeit (Constantza, 20-24 septembre 2010), V. Cojocaru et C. Schuler (éds.), à paraître. 
Callatis ne sont pas des colonies de Mégare, mais d'Héraclée du Pont. Or du point de vue méthodologique, la distinction entre la colonisation mégarienne et héracléote s'impose. Il s'agit de deux mouvements de colonisation qui ont des causes et des buts différents ${ }^{644}$. Par ailleurs, comme on l'a déjà suggéré, les noms ioniens attestés à Chersonèse pourraient témoigner de la présence de ressortissants des colonies milésiennes dans cette cité, et notamment des colons de Sinope, la voisine d'Héraclée du Pont ${ }^{645}$.

Au demeurant, contre l'opinion de l'existence d'un accord entre les Mégariens et les Milésiens, il y a une épigramme gravée à Milet vers 200 sur un polyandrion. Le document fait l'éloge des Milésiens morts au cours d'une guerre contre les Mégariens ${ }^{646}$ :

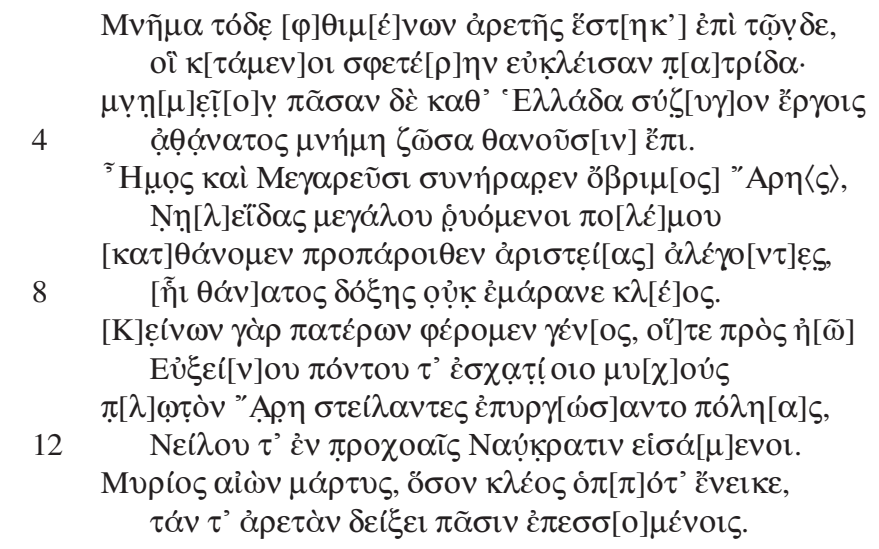

Ce monument du courage se dresse pour les défunts que voici, qui par leur mort ont rendu leur patrie illustre; par toute l'Hellade ils ont associé un monument à leurs exploits, souvenir immortel vivant pour les morts.

Quand la guerre puissante éclata contre les Mégariens, nous sommes morts au premier rang, en protégeant les Néléides (à savoir les Milésiens) pendant la grande guerre, avec pour (unique ?) souci la vaillance: grâce à elle la mort n'a pas fané la

644 Sur la colonisation héracléote, qui ne fait pas l'objet de cette enquête, on verra Burstein, Heraclea, p. 25-26; Saprykin, Heracleia and Chersonesus, p. 57-87; Avram, Héraclée et ses colonies, p. 209-227. Voir aussi infra, chapitre II.3.1.1.

645 Vinogradov-Zolotarev, Chersonèse, p. 409-410; Avram, Héraclée et ses colonies, p. 215-216.

646 W. Peek, «Ein milesisches Polyandrion», WS 79, 1966, p. 218-230 [P. Herrmann (éd.), Milet VI. Inschriften von Milet, vol. II, Berlin-New York 1998, $\mathrm{n}^{\circ}$ 732; R. Merkelbach, J. Stauber (éds.), Steinepigramme aus dem griechischen Osten, Band I, Stuttgart-Leipzig 1998, nº 01/20/08]. Cf. Peek, Gr. Vers-Inschriften, $\mathrm{n}^{\circ} 33$. 
gloire de notre renommée. Car nous portons la race de ces pères, eux, qui vers l'est et vers l'extrémité du Pont-Euxin lointain emportèrent la guerre avec eux sur les mers, élevèrent des cités avec des remparts et établirent Naucratis à l'embouchure du Nil. De cela est témoin l'éternité infinie quand elle apporte une gloire bien grande, et qui montrera notre valeur à tous ceux qui viendront ${ }^{647}$.

En se penchant sur ce texte, J. et L. Robert ont repoussé l'opinion du premier éditeur, Peek, selon laquelle le conflit entre Mégare et Milet serait une falsification de l'histoire (une «Geschichtsfälschung») ${ }^{648}$. De plus, ils ont noté à juste titre que pour une guerre entre les deux cités «il n'y a pas d'occasion ni possibilité dans la période hellénistique ni classique». Ils ont proposé que l'on pourrait avoir affaire à un épisode de la guerre lélantine $^{649}$. Pourtant, cette hypothèse semble peu probable, car si Mégare s'était impliquée dans cette guerre - une participation qui, rappelons-le, n'est pas certaine -, elle ne l'aurait pas fait en tant qu'ennemie de Milet et alliée de Chalcis. En effet, dans sa dispute avec la cité d'Érétrie, Chalcis est soutenue par Corinthe, la rivale de Mégare. Par conséquent, dans l'éventualité d'une participation de Mégare à la guerre lélantine, cette cité devrait être placée à côté d'Érétrie, Milet, Égine, Chios contre Chalcis, Samos, Corinthe, Érythrée et les Thessaliens ${ }^{650}$. Certes, J. et L. Robert n'ignoraient pas ce réseau d'alliance de l'époque

647 Trad. de T. Boulay, «La mémoire des faits d'armes dans les cités d'Asie Mineure à l'époque hellénistique: un polyandrion à Milet et Lichas fils d'Hermophantos », in Pratiques et identités culturelles des armées hellénistiques du monde méditerranéen, J.-C. Couvenhes et al. (éds.), Bordeaux 2011, p. 214 (partiellement modifiée).

648 W. Peek, WS 79, 1966, p. 218-230.

649 J. et L. Robert, Bull. ép., 1967, 528, p. 536-538.

650 Trever, Megara, p. 120-121; A. R. Burn, «The So-called 〈Trade-Leagues〉 in Early Greek History and the Lelantine War», JHS 49, 1929, p. 14-37; Highbarger, Megara, p. 108-109; Forrest, Colonization, p. 160-171 ; Legon, Megara Pol. Hist., p. 83-84 ; Coldstream, Geom. Gr.2 ${ }^{2}$, p. 200 ; Bérard, Colonisation, p. 45-46, 125 ; L. Antonelli, «Sulle navi degli Eubei (immaginario mitico e traffici di età arcaica)», in Hesperìa, 5: studi sulla grecità di Occidente, L. Braccesi (éd.), Roma 1995, p. 13-14, n. 7 ; V. Parker, Untersuchungen zum Lelantischen Krieg und verwandten Problemen der frühgriechischen Geschichte, Historia Einzelschriften 109, Stuttgart 1997, p. 133 144 ; L. Ferreri, «Teognide e la guerra lelantina», GIF 57, 2005, p. 71-102. Sur la guerre lélantine, voir aussi B. d'Agostino, «Osservazioni a proposito della guerra lelantina », $D d A$ 1, 1967, p. 20-37; G. Tedeschi, «La guerra lelantina e la cronologia esiodea», in Studi triestini di antichità in onore di L. A. Stella, Trieste 1975, p. 149167 ; K. Tausend, Amphiktyonie und Symmachie. Formen zwischenstaatlicher Beziehungen im archaischen Griechenland, Stuttgart 1992, p. 137-145. 
archaïque, mais ils pensaient contourner cette difficulté, en suggérant que Mégare a pu changer d'alliance durant la guerre.

Je pense qu'une solution plus simple mérite de retenir notre attention. De fait, comme on l'a déjà proposé, il y a plus de chances que le conflit mentionné par l'épigramme de Milet soit en rapport avec l'antagonisme qui a peut-être opposé les Mégariens aux Milésiens dans la Propontide ou dans le Pont-Euxin ${ }^{651}$. Cette opinion est appuyée par le fait que les autres événements rapportés par l'inscription sont tous en rapport avec la colonisation. On évoque ainsi l'installation des Milésiens dans le Pont-Euxin et la fondation de Naucratis. On apprend également que les Milésiens emmenèrent Arès (à savoir la guerre) avec eux sur la mer, dans le lointain Pont Euxin. Le contexte oriente donc vers un conflit dans un milieu colonial. Les sources ne permettent pas de savoir quelle est cette «grande guerre» dont le souvenir est gardé «par toute l'Hellade» (les vers 3 et 6 ). Mais je ne suis pas certain qu'il faille voir, avec Boulay, une guerre "à l'échelle du bassin égéen», qui, en l'occurrence, dans le sillage de J. et L. Robert, serait la guerre lélantine ${ }^{652}$. Il est probable que cette information témoigne du désir des Milésiens d'agrandir les exploits de leurs concitoyens morts contre les Mégariens et d'embellir l'héroïsme de ceux-ci afin de forger la mémoire civique et le prestige de la cité. Cette volonté d'amplifier la gloire des ancêtres ressort aussi du vers 12, évoquant Naucratis comme fondation milésienne. On a là l'écho d'une tradition de l'époque hellénistique, contraire au récit d'Hérodote (II, 178-179) et aux données archéologiques, qui n'appuient pas l'idée d'une primauté des Milésiens dans l'installation de Naucratis ${ }^{653}$.

651 Figueira, Chronological Table, p. 262, 294-296, place le conflit à l'époque de la fondation d'Héraclée du Pont par les Mégariens, en le datant de 575-550; Loukopoulou, Thrace propontique, p. 60, n. 3. R. Merkelbach, J. Stauber, op. cit., p. 124125, pensent que les Milésiens auraient mené une guerre contre les colons mégariens de Byzance et de Chalcédoine, qui auraient pu bloquer le Bosphore. Vinogradov, Milet und Megara, p. 470-471, estime que le conflit en question n'est autre que la guerre de Périnthe (sur cette guerre voir supra, chapitre II.2.1.2). En outre, à en croire Vinogradov, les Milésiens et les Mégariens ne seraient pas ennemis lors de cette guerre, mais des alliés. Cf. Petropoulos, Emporion, p. 100-101.

652 T. Boulay, op. cit., p. 215.

653 A. Bresson, «Rhodes, l'Hellénion et le statut de Naucratis (VI ${ }^{\mathrm{e}}-\mathrm{IV}^{\mathrm{e}}$ siècle a.C.)», DHA 6, 1980, p. 315-316 (= La cité marchande, Paris 2000, p. 51-52); M. Austin, s.v. «Naukratis», in Hansen-Nielsen (éds.), Inventory, p. 1239. 
En conclusion, sans rejeter l'existence de relations et d'échanges entre les Milésiens et les Mégariens du Bosphore thrace à certaines périodes ${ }^{654}$, le témoignage de Velleius Paterculus est insuffisant pour que l'on puisse accepter une participation milésienne à la fondation de Byzance, et encore moins l'existence d'un accord entre Mégare et Milet à l'époque archaïque. Je préfère accorder plus de crédit à l'hypothèse avancée jadis par Merle, selon laquelle cette mention était due à la célébrité dont Milet jouissait en tant que métropole à l'époque hellénistique et impériale ${ }^{655}$. On remarque que dans la deuxième moitié du $\mathrm{IV}^{\mathrm{e}}$ siècle, l'opinion antique concernant la suprématie milésienne dans la colonisation était bien établie. De fait, on voit que chez Anaximène de Lampsaque, la cité de Milet était déjà considérée comme la métropole de nombreuses apoikiai de la Propontide et du Pont-Euxin ${ }^{656}$.

\section{II.2.4.1.4 La participation des Béotiens à la fondation de Byzance}

Selon le passage de Constantin Porphyrogénète, déjà évoqué, les Béotiens furent, avec les Mégariens et les Spartiates, les fondateurs de Byzance $^{657}$. Il existe plusieurs indices qui suggèrent que cette tradition ne

654 Il convient de citer ici le décret I. Byzantion, 2, qui accorde au $\mathrm{II}^{\mathrm{e}}$ siècle la citoyenneté byzantine au juge milésien Apollônidas, fils de Memnôn. On apprend qu'étant confrontés à des troubles sociaux, les Byzantins firent appel à Milet pour envoyer un juge pour leurs procès publics et privés. On invoque dans ce cadre les liens d'amitié qui unissent depuis longtemps les deux villes.

655 Merle, Byzantion und Kalchedon, p. 9; Hind, Megarian Colonization, p. 134. Voir aussi l'erreur «à l'inverse» faite par Jean le Lydien, Des Magistratures de l'État romain, III, 70, 4, quand il attribue la fondation de Cyzique aux Mégariens, aux dépens des Milésiens. La fondation de Cyzique par Milet est attestée par Anaximène de Lampsaque, FGrHist 72 F 26. On voit que chez Pline, V, 31, 112, la cité de Milet est désignée comme la capitale de l'Ionie et la métropole de plus de 90 cités disséminées sur toutes les mers. Pour la confusion faite par les auteurs d'époque romaine entre les diverses métropoles, voir aussi J. Hind, «Pomponius Mela on colonies in West and East», in Ancient Greeks West and East, G. R. Tsetskhladze (éd.), Leiden et al. 1999, p. 82, qui note: «It is certain that authors of the Roman period and later had conflicting and confused views about the origins of the cities on the Bosporus and in the Propontis».

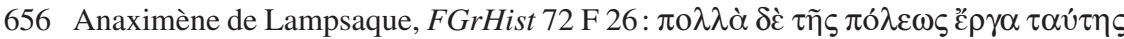

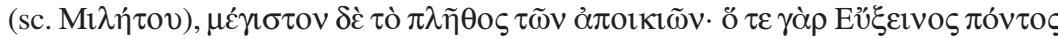

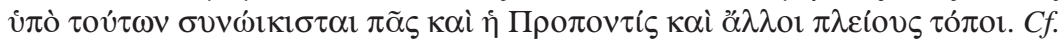
Burstein, Heraclea, p. 14-15.

657 Constantin Porphyrogénète, De Thematibus, II, p. 46 (éd. I. Bekker). 
doit pas être écartée d'emblée, comme Hanell l'avait fait ${ }^{658}$. La participation des Mégariens est, on l'a vu, certaine et celle des Spartiates s'explique par le rôle que Pausanias a eu dans la libération de Byzance. Ceci montre que le chroniqueur byzantin se fondait sur des récits dignes de foi et qu'en conséquence, sa mention des Béotiens ne doit pas être considérée a priori comme une erreur.

En fait, on trouve des données béotiennes à Byzance. Denys de Byzance témoigne de la célébration dans cette cité du héros béotien Amphiaraos et de son aurige Schoiniklos ${ }^{659}$. De même, un manuscrit de Diodore (XIV, 12,3) évoque la présence à Byzance d'un collège appelé Boiôtoi («Béotiens») composé de trente magistrats ( $\tau \rho \imath \alpha ́$ Kov $\tau \alpha$

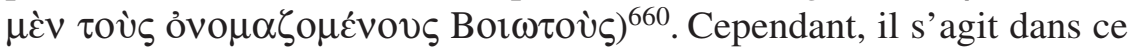

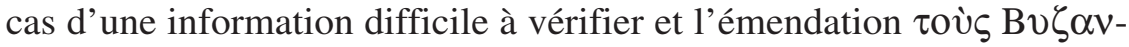

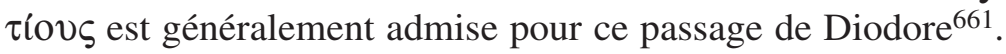

On notera aussi que l'on attribuait au célèbre philosophe byzantin de la seconde moitié du $\mathrm{IV}^{\mathrm{e}}$ siècle, Léôn, un ouvrage intitulé Histoires béotiennes ${ }^{662}$. Comme M. Dana le suggère, il n'est pas exclu que l'intérêt du Byzantin pour ce sujet ait son origine dans le rôle que les Béotiens avaient joué dans la fondation de Byzance ${ }^{663}$.

658 Hanell, Megarische Studien, p. 125-126. Contra Miller, Ist Byzanz eine megar. Colonie?, p. 332-333; idem, Byzantion, col. 1129; Highbarger, Byzantium und Kalchedon, p. 8; Neswkaja, Byzanz, p. 21, Malkin-Shmueli, City of the Blind, p. 32, qui acceptent la présence des Béotiens à Byzance.

659 Denys de Byzance, 34, p. 15; 63, p. 25 (éd. R. Güngerich); Hésychios, FGrHist 390 F 16. Sur l'origine béotienne d'Amphiaraos et Schoiniklos, voir Pfeister, Mythische Königsliste, p. 36-37, 43-44; Hanell, Megarische Studien, p. 189-190. Pour le célèbre sanctuaire oraculaire d'Amphiaraos situé dans le territoire d'Oropos, voir A. Schachter, Cults of Boiotia, 1. Acheloos to Hera, BICS, Suppl. 38.1, London 1981, p. 19-25 (avec les références).

660 Voir aussi infra, chapitre III.1.1.2.

661 F. Vogel (éd.), Diodori Bibliotheca historica, Leipzig 1893, p. VII, avec l'apparat critique de la p. 199; Highbarger, Byzantium und Kalchedon, p. 8, n. 2; cf. aussi Fossey, Boiotia and the Pontic Cities, p. 109, qui estime qu'outre les Boiôtoi, les

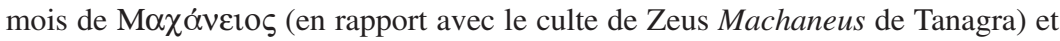

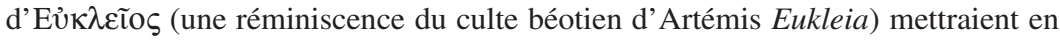
lumière la présence béotienne à Byzance. Mais ces mois ne constituent pas une spécificité byzantine, car ils étaient présents très probablement aussi à Mégare, tout comme à Corinthe (voir infra, chapitre II.2.4.1.5).

662 Léôn de Byzance, FGrHist 132 F 2.

663 Dana, Culture, p. 274. 
De manière générale, la collaboration des Béotiens et des Mégariens dans la colonisation à l'époque archaïque est confirmée par leur participation commune à la fondation d'Héraclée du Pont. Ce n'est d'ailleurs pas un hasard si les Mégariens ont bâti vers la fin du VI ${ }^{\mathrm{e}}$ siècle leur trésor à Delphes, le centre oraculaire spécialisé dans la colonisation, près de celui des Béotiens. C'était peut-être le symbole de leur alliance étroite dans la colonisation ${ }^{664}$. Dans le cas de Byzance, un autre indice qui atteste la présence des Béotiens sur les rives du Bosphore ressort des quelques distiques contenant une recette contre la cataracte du médecin byzantin Aglaïas, dont le nom est à corriger en Aglaïdas (proposition de Dana). Grâce à ce texte, on apprend qu'au I ${ }^{\text {er }}$ siècle ap. J.-C. cet illustre médecin faisait remonter l'origine de sa famille à Héraclès, ce qui laisse penser, comme l'a noté Robert, que ce héros aurait joué quelque rôle dans les légendes de fondation de Byzance ${ }^{665}$. On peut ajouter qu'à Byzance il y avait un temple ${ }^{666}$ et un ö $\lambda \sigma o \varsigma$ («bois sacré») d'Héraclès ${ }^{667}$. On sait aussi qu'un «Herculis K $\lambda i ́ v \eta »$ se trouvait sur la rive asiatique du Bosphore ${ }^{668}$. De plus, le héros était représenté sur les monnaies d'époque impériale émises par Byzance, par Sélymbria ou par Chalcédoine, et dans cette dernière cité il y avait un prêtre d'Héraclès à l'époque hellénistique ${ }^{669}$. Or l'on sait qu'Héraclès est un étranger à

664 Voir infra, chapitre II.3.1.1.

665 U.C. Bussemaker (éd.), Carminum medicorum reliquiae, in Poetae bucolici et

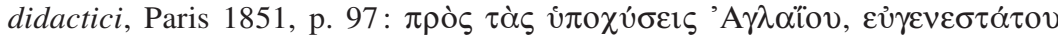

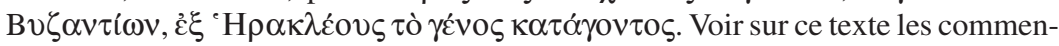
taires de L. Robert, in Firatl, Stèles de Byzance, p. 137, et de Dana, Culture, p. $193-$ 194. Si Aglaïas semble être un hapax, le nom Aglaïdas est en revanche attesté à Byzance à l'époque hellénistique par l'inscription funéraire I. Byzantion, 219. Pour la date d'Aglaïdas à l'époque de Néron, voir aussi M. Wellmann, s.v. «Demosthenes » 11, RE V, 1905, col. 189.

666 Syméon Magister, Chronographia, p. 704 (éd. I. Bekker). Rappelons qu'Hermès et Héraclès sont honorés à Byzance en tant que dieux du gymnase: I. Byzantion, 11. Cf. Dana, Culture, p. 110-114.

667 Hésychios, FGrHist 390 F 37 ; cf. Miller, Byzantion, col. 1147.

668 Denys de Byzance, 95, p. 30 (éd. R. Güngerich); $c f$. Oberhummer, Bosporos, col. 753.

669 Voir I. Kalchedon, 10, 1. 4 et 11, pour le prêtre d'Héraclès à Chalcédoine. Pour la représentation d'Héraclès sur les monnaies de Byzance, voir Schönert-Geiss, Byzantion, vol. II, p. 35, et pl. 78, $\mathrm{n}^{\text {os }} 1469-1474$, pl. 79, $\mathrm{n}^{\mathrm{o}} 1495$, pl. 95, $\mathrm{n}^{\text {os }} 1685$ 1686, pl. 104, no 1785, pl. 123, n ${ }^{\text {os }}$ 2009-2011; pour celles de Sélymbria: SNG Cop. Thrace, pl. 16, $\mathrm{n}^{\circ} 790$; et pour celles de Chalcédoine, voir Waddington-BabelonReinach, Recueil, I, 2, p. 295, n 30, p. 303, nº 82. 
Mégare: il reçoit de la part des Mégariens le droit de cité670. À sa place dans le panthéon mégarien traditionnel, on trouve Alcathoos, le tueur du lion du mont Cithéron ${ }^{671}$. Comme nous le constaterons ci-dessous, le fait que le héros soit l'éponyme d'Héraclée du Pont s'explique par la participation des Béotiens à la fondation de cette cité672. Pareillement, la présence d'Héraclès à Byzance peut aussi refléter la présence des Béotiens dans cette cité. Quant au culte d'Héraclès à Chalcédoine et à Sélymbria, il peut s'expliquer soit par les échanges cultuels qui se sont produits entre ces deux colonies mégariennes et Byzance, soit par la célébrité que le héros connaît à l'époque hellénistique et impériale ${ }^{673}$.

Concernant la présence d'éléments béotiens sur les rives du Bosphore, on notera aussi que le nom d'une subdivision civique de Chalcédoine, l'hékatostys 'A $\sigma \omega \pi \mathrm{\sigma} \omega(\rho \eta \dot{\alpha})$, renvoie à Asôpos, dieu-fleuve de Béotie $^{674}$. D'ailleurs, on constate que le nom 'A $\sigma \omega \pi$ ó $\omega \omega \rho \varsigma$ ऽ n'est pas présent en Mégaride, mais qu'il est bien documenté en Béotie ${ }^{675}$. Au groupe de noms «béotiens» en 'A $\sigma \omega \dot{\pi} \pi$ - se rattache également le nom 'A $\sigma \omega ́ \pi ı \zeta$, attesté au III' siècle à Byzance ${ }^{676}$. La présence d'une subdivision civique portant un nom à résonance béotienne à Chalcédoine est

670 Plutarque, Sur la monarchie, la démocratie et l'oligarchie, 2 (= Moralia, 826 C-D). Le culte d'Héraclès est attesté à Pagai (à l'époque impériale) et à Aigosthènes (deuxième moitié du III ${ }^{\mathrm{e}}$ siècle) par les inscriptions IG VII 192 et 213. Dans ces cas, on peut penser que la proximité avec la Béotie explique la diffusion du culte d'Héraclès dans ces deux établissements de la Mégaride occidentale. $C f$. Highbarger, Megara, p. 65, n. 246; Smith, Megaris, p. 123.

671 Hanell, Megarische Studien, p. 28-31, 203; Lacroix, Monnaies et colon., p. 36; Piccirilli, MEGARIKA, p. 38-41; cf. Jacoby, FGrHist III B Noten, p. 233, n. 40. Signalons ici qu'Héraclès apparaît sur le revers d'une monnaie frappée par Mégare à l'époque de Septime Sevère: BCD Pelop., p. 30, no 49.3.

672 Voir infra, chapitre II.3.1.1.

673 De même, le culte d'Héraclès à Sélinonte est sans doute un développement spécifique à cette colonie mégarienne, en rapport avec la célébrité dont le héros jouissait chez les Grecs de Sicile: voir supra, chapitre II.1.2.5.

674 I. Kalchedon, 7, 1. 16. Voir infra, chapitre III.1.2.2.

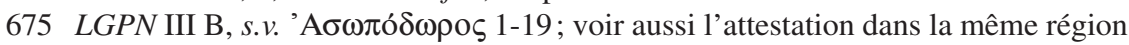

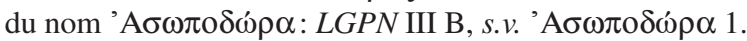

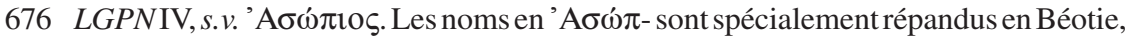
et rarement en Mégaride. À ce propos, voir Bechtel, Hist. Personennamen, p. 88, et

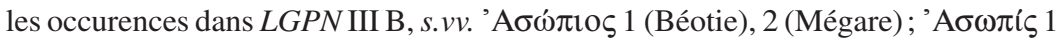

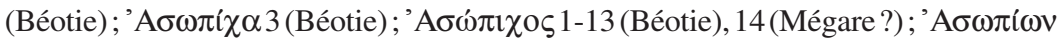

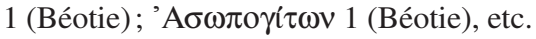


peut-être due aux transferts institutionnels qui se produisirent entre les deux cités mégariennes du Bosphore ${ }^{677}$.

$\mathrm{Au}$ surplus, quelques événements de la guerre du Péloponnèse me semblent être révélateurs des rapports de parenté entre les Byzantins, d'une part, et les Mégariens et les Béotiens, de l'autre. On constate que lorsque Sparte décida d'appuyer en 411 la révolte de Byzance contre Athènes, elle envoya une escadre de navires placée sous le commandement d'Hélixos de Mégare ${ }^{678}$. On voit aussi que, plus tard, en 408, assiégée par les Athéniens, la cité de Byzance est défendue par les troupes de Cléarque, harmoste de Sparte, parmi lesquels se trouvaient des contingents mégariens et béotiens, conduits par Hélixos et Koiratadas ${ }^{679}$. Il est vraisemblable que l'envoi des Mégariens et des Béotiens dans la Propontide avait pour but de renforcer l'alliance entre la Ligue du Péloponnèse et Byzance.

En dernier lieu, il n'est pas sans intérêt de s'arrêter ici sur les dernières lignes d'un décret par lequel les Delphiens reconnaissaient l'inviolabilité du sanctuaire oraculaire d'Apollon de Chalcédoine. À la fin de l'inscription, on apprend que le commissaire chargé de l'affaire à Delphes fut un certain Rhodoklès, fils d'Hérodôros, de Béotie ${ }^{680}$. Les spécialistes suggèrent que l'inscription de Delphes devrait se situer vers la fin du III ${ }^{\mathrm{e}}$ siècle, à l'époque de l'alliance entre la Ligue étolienne et Chalcédoine; une datation qui serait aussi appuyée par l'écriture. Selon Pouilloux, la mention de Rhodoklès daterait le texte plus précisément de 217-212, la seule période entre la guerre des Alliés et la première guerre de Macédoine où les Béotiens avaient envoyé des représentants

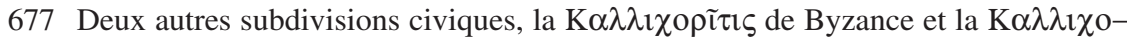
$\rho \varepsilon \tilde{\alpha} \tau(1 \varsigma)$ de Chalcédoine, ont peut-être comme éponyme un héros béotien, Kallichoros: voir infra, chapitre III.1.2.6.

678 Thucydide, VIII, 80, 3.

679 Xénophon, Helléniques, I, 1, 35 ; III, 15-21; cf. Legon, Megara, p. 255.

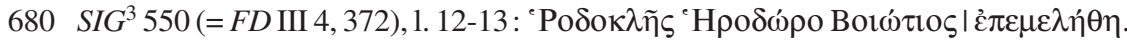
L'inscription est reprise dans Rigsby, Asylia, n 62 , et chez A. Jacquemin, D. Mulliez, D. Rougemont, Choix d'inscriptions de Delphes traduites et commentées, Paris 2012, $\mathrm{n}^{\mathrm{o}}$ 75. Selon H. Pomtow, $S I G^{3}, a d \mathrm{n}^{\circ} 550$, p. 38, n. 6, les dernières lignes (1. 12-13) du décret furent ajoutées ultérieurement. Mais l'examen de la photographie de l'inscription (voir Pouilloux, FD III 4, pl. 8, A) permet de constater qu'il n'y a pas de différences entre les caractères des deux dernières lignes et ceux du reste du texte, les premiers étant juste à peine plus petits. 
siéger à l'Amphictionie ${ }^{681}$. À cet égard, il faut ajouter que le Conseil amphictionique pouvait désigner un de ses membres pour graver le texte d'une inscription ${ }^{682}$. Néanmoins, il convient de souligner que le décret qui reconnaît l'asylia de l'Apollônion de Chalcédoine n'émane pas de l'Amphictionie, mais de la cité de Delphes ${ }^{683}$. Cela étant, je pense que la présence inhabituelle d'un Béotien dans un décret de Delphes s'explique aisément par la collaboration entre les Mégariens et les Béotiens dans la colonisation. Il est possible qu'à cause des liens de syngéneia qui unissaient Rhodoklès de Béotie avec les Chalcédoniens, la cité de Delphes ait désigné ce personnage pour se charger de l'affaire de l'inviolabilité du sanctuaire oraculaire d'Apollon de Chalcédoine.

En conclusion, les données examinées jusqu'ici étayent la tradition littéraire qui évoque le rôle des Béotiens dans la colonisation de la rive européenne du Bosphore thrace. Il n'est pas possible néanmoins de savoir si ceux-ci ont déjà figuré parmi les premiers apoikoi ou s'ils sont arrivés ultérieurement à Byzance en tant qu'époikoi. Quant à l'opinion de Figueira, selon laquelle les Mégariens étaient l'élite dominante et les Béotiens constituaient des citoyens de seconde classe dans les colonies mégariennes, elle n'est pas confirmée par les sources antiques ${ }^{684}$.

681 H. Pomtow, $S I G^{3}, a d n^{\circ}$ 550, p. 38 ; Pouilloux, FD III 4, $a d$ n $^{\circ}$ 372, p. 52-53. D'après Polybe, XV, 23, 7-9, à l'époque de la mainmise de Philippe V sur Lysimacheia,

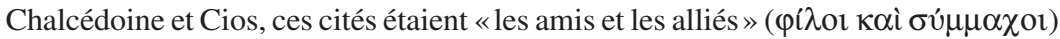
des Étoliens. À ce propos, voir Flacelière, Aitoliens, p. 312, n. 3; J.A. O. Larsen, «The Aetolians and the Cleomenic War», in The Classical Tradition. Literary and Historical Studies in Honor of Harry Caplan, L. Wallach (éd.), Ithaca-New York 1966, p. 53 ; Walbank, Commentary, vol. II, p. 477-479; Rigsby, Asylia, p. 167.

682 Rigsby, Asylia, $\mathrm{n}^{\circ} 3,1.16-17$.

683 Pouilloux, $F D$ III 4, ad $\mathrm{n}^{\circ} 372$, p. 53, estime que la présence du Béotien dans le décret de Delphes «peut être indépendante des considérations de politique générale». De même, Rigsby, Asylia, p. 169, pense que Rhodoklès pouvait être «a private citizen acting as a friend to Chalcedon or Delphi».

684 Figueira, Chronological Table, p. 276, écrit: «Colonial power sought to encapsulate citizens of their own city as a ruling elite surrounded by second-class citizens and dependent classes made up of immigrants from other poleis as well as natives. From Megara, a pool of those anxious to emigrate may have been available in nearby Boiotia». 


\section{II.2.4.1.5 La participation des Corinthiens à la fondation de Byzance}

La mention des Corinthiens comme les fondateurs de Byzance apparaît dans un fragment de Denys de Byzance.

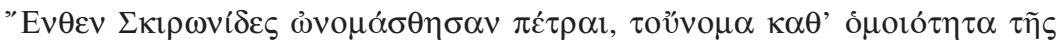

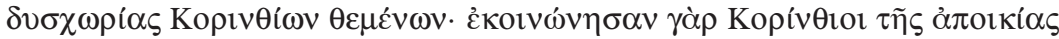

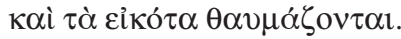

Ensuite, il y a les Roches dites Scironiennes, dont le nom est dû à la ressemblance avec le passage difficile des Corinthiens: en effet, les Corinthiens qui prirent part à la fondation de la colonie, furent surpris par cette similitude ${ }^{685}$.

À l'évidence, le géographe commet ici une erreur, en localisant les Roches Scironiennes dans la Corinthie et non pas dans la Mégaride (voir carte 2). La question qui se pose est si cette confusion est aussi responsable de la tradition qui fait de Byzance une colonie corinthienne. Signalons aussi que cette information est reprise par un manuscrit byzantin du $\mathrm{IX}^{\mathrm{e}}$ siècle ap. J.-C., attribué à un auteur conventionnellement désigné comme Josephus Genesius. Ce texte inclut, on l'a vu, les Corinthiens parmi les fondateurs de Byzance à côté des Mégariens, des Carystiens et des Mycéniens ${ }^{686}$.

Pour appuyer ces récits de fondation, Miller invoquait jadis l'attes-

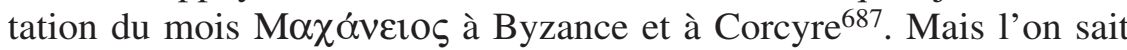
aujourd'hui que l'apparition de ce mois dans les deux cités est due aux rapprochements originels qui existent entre les calendriers mégarien et

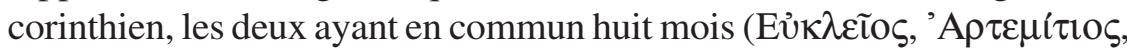

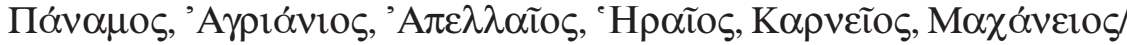

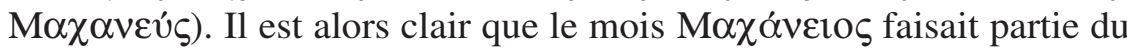

685 Denys de Byzance, 15, p. 7 (éd. R. Güngerich). Voir aussi la paraphrase de Gillius à Denys de Byzance, 15, p. 7 (éd. R. Güngerich): Post acram Plutonis et Junonis Dionysius ponit Scironias petras nuncupatas a Corinthiis participibus coloniae deductae Byzantium, qui his petris nomen imposuerunt a similitudine loci difficilis, qualem habebant petrae Scironiae, sitae inter Megaram et Isthmum Corinthiacum. De même, la scholie à Denys de Byzance, 20 ( $a d$ 7, 4), p. 37 (éd. R. Güngerich),

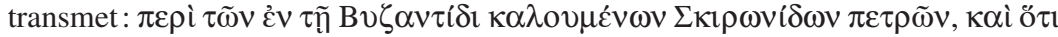

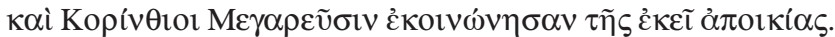

686 Josephus Genesius, in J.-P. Migne (éd.), Patrologia Graeca, vol. 109, Paris 1887, col. 1024.

687 Miller, Ist Byzanz eine megar. Colonie?, p. 332; idem, Byzantion, col. 1129. 
bagage initial des apoikoi mégariens ayant fondé Byzance ${ }^{688}$. De même, notons au passage que l'ancien type de bêta qui apparaît sur les monnaies de Byzance ne dérive pas d'un bêta corinthien, comme le pensait Newskaja, mais il est un signe typique de l'alphabet mégarien, pour lequel on a maintenant une attestation à Mégare même ${ }^{689}$.

L'antagonisme qui oppose Mégare à Corinthe à l'époque archaïque et classique peut constituer un argument contre la collaboration entre les deux cités dans la colonisation ${ }^{690}$. Mais cela n'exclut pas que des Corinthiens bannis de leur cité aient pu trouver refuge à Mégare et dans ses colonies. Car il y avait sans aucun doute des liens entre les familles aristocratiques mégariennes et corinthiennes. Le régime des Bacchiades, de même que la tyrannie de Cypsélos, qui, selon la chronologie d'Eusèbe (Chron., éd. R. Helm, p. 94b), commence vers 660, une date proche de celle de la fondation de Byzance, ont pu provoquer l'exil de certains Corinthiens ${ }^{691}$.

De même, on relèvera dans ce cadre les parallèles qui existent entre Byzance et Sélinonte, deux colonies mégariennes fondées presque à la même époque selon la chronologie d'Eusèbe (vers 659 et respectivement vers 650). La présence des Corinthiens est attestée par les sources littéraires à Byzance et par les sources épigraphiques à Sélinonte. De plus, il y avait sur un promontoire de la Corne d'Or un ancien sanctuaire d'Héra (Akraia?), détruit par les Perses de Darius au moment de leur campagne contre les Scythes ${ }^{692}$. D'autre part, on a vu qu'il y avait un, voire même deux temples d'Héra à Sélinonte ${ }^{693}$. Il est possible qu'à

688 Voir dernièrement Trümpy, Monatsnamen, p. 147-155, pour le calendrier mégarien, et p. 155-164, pour le calendrier corinthien. Pour les calendriers de Mégare et des établissements mégariens, voir les études citées supra dans l'introduction, ii.

689 Newskaja, Byzanz, p. 21 ; contra Loukopoulou, Thrace propontique, p. 158, n. 4. On trouve une nouvelle attestation de ce type de bêta dans la dédicace des Byzantins à Olympie (autour de 500) : K. Hallof, K. Herrmann, S. Prignitz, op. cit., p. 217-218. Pour l'attestation d'un bêta semblable à Mégare, voir infra, chapitre III.1.1.1.

690 Voir supra, chapitre I.1.3.

691 Pour la chronologie des Cypsélides, voir Will, Korinthiaca, p. 363-440.

692 Denys de Byzance, 14, p. 6-7 (éd. R. Güngerich). Cf. Hanell, Megarische Studien, p. 195; Hammond, Heraeum, p. 96, 98 ; Menadier, Perachora, p. 147. On constate par ailleurs que le mois Héraios est présent dans le calendrier de Byzance: Trümpy, Monatsnamen, p. 147. En outre, une inscription d'époque impériale (I. Byzantion, 33) mentionne la déesse Héra comme hiéromnamôn éponyme de Byzance.

693 Voir supra, chapitre II.1.2.5. 
Byzance aussi bien qu'à Sélinonte le culte d'Héra, une divinité qui a un rôle important dans le domaine de la navigation et dans les expéditions coloniales, soit en rapport avec une présence des Corinthiens dans ces cités $^{694}$. De fait, si le culte d'Héra semble être absent à Mégare, cette divinité occupe une place importante dans le panthéon corinthien et il est possible que le sanctuaire d'Héra Akraia de Pérachora ait servi de modèle aux Byzantins et aux Sélinontins. En revanche, je ne crois pas que le culte d'Héra puisse confirmer la présence des émigrés mégariens de Pérachora dans les colonies de Mégare. En réalité, cette région de l'isthme semble être sous contrôle corinthien à l'époque archaïque, une possession mégarienne de Pérachora n'étant pas attestée par la documentation antique $^{695}$. Signalons que le culte d'Héra était aussi célébré à Chalcédoine, un Héraion se trouvant ici sur un cap situé en face de la ville ${ }^{696}$.

694 Pour le rôle d'Héra comme protectrice de la navigation, voir Parisi Pressicce, L'importanza di Hera, p. 44-83; Antonetti, Confini della Megaride, p. 546-549; eadem, Megara e le sue colonie, p. 90-92; Menadier, Perachora, p. 217; F. de Polignac, «Héra, le navire et la demeure: offrandes, divinité et société en Grèce archaïque», in Héra. Images, espaces, cultes. Actes du colloque international (Lille, 29-30 novembre 1993), J. de la Genière (éd.), Naples 1997, p. 113-122; idem, Divinités, p. 25-26; C. Jourdain-Annequin, «I Greci - Les Grecs», in Ethne e religioni nella Sicilia antica. Atti del convegno (Palermo, 6-7 dicembre 2000), P. Anello et al. (éds.), Kokalos, Suppl. 18, Roma 2006, p. 197.

695 Sur le culte d'Héra à Corinthe et sur le contrôle corinthien de Pérachora, voir supra, chapitre I.1.1. Voir aussi les commentaires de Müller, ad Denys de Byzance, GGM II, fr. 9, p. 23, à propos des liens entre le culte d'Héra de Byzance et celui d'Héra Akraia de Corinthe. Par ailleurs, J. Christien-Trégaro, «Les Péloponnésiens et la mer Noire», in Sur les traces des Argonautes. Actes du $\sigma^{e}$ symposium de Vani (Colchide), 22-29 septembre 1990, O. Lordkipanidzé et P. Lévêque (éds.), Paris 1996, p. 146-147, estime que le culte d'Hélios, attesté à Byzance par des sources tardives, aurait aussi une origine corinthienne. Pour le culte byzantin d'Hélios, voir Malalas, Chronographia, XII, 20, 62-67, p. 221 (éd. J. Thurn); Chronicon Paschale, vol. I, p. 494-495 (éd. L. Dindorf); $c f$. W. Kubitschek, s.v. «Byzantion», RE III, 1899, col. 1146. Ayant un autel sur l'Acrocorinthe, Hélios est une divinité particulièrement célébrée par les Corinthiens : Pausanias, II, 4, 6; $c f$. O. Jessen, s.v. «Helios» 1, RE VIII, 1913, col. 64; P. Reichert-Südbeck, op. cit., p. 156-158.

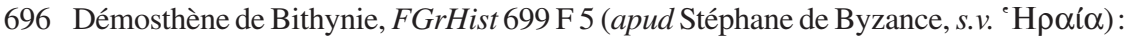

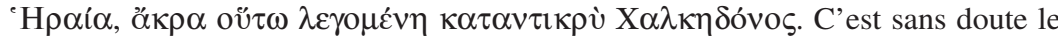
même sanctuaire qui est mentionné chez Arrien, FGrHist 156 F 18. On sait aussi que l'empereur Justinien fit bâtir pour sa femme Théodora un palais sur le cap de Hiéria (le moderne Fenerbahçe). Voir à ce propos Janin, Constantinople ${ }^{2}$, p. 148 150. 
On évoquera par ailleurs le récit de Pline, selon lequel la cité de Byzance a été appelée auparavant Lygos ${ }^{697}$. Ce nom, qui appartient probablement à l'un des fondateurs de la cité ${ }^{698}$, est rarement attesté dans le monde grec et il est à rapprocher du nom Lygôn, qui semble être gravé sur un graffite trouvé lors des fouilles de l'Héraion de Pérachora et datant de $c a .675^{699}$. Certes, ce rapprochement onomastique ne constitue pas un indice solide en faveur de la participation des Corinthiens à la fondation de Byzance, mais il a néanmoins le mérite de signaler les rapports étroits qui existent entre le monde mégarien et corinthien à l'époque archaïque. En conclusion, bien qu'un doute doive subsister vis-à-vis de la tradition de la participation des Corinthiens à la fondation de Byzance, il n'est pas exclu que des familles corinthiennes, indépendamment de leur cité-mère, aient accompagné les Mégariens sur les rives du Bosphore.

\section{II.2.4.1.6 La participation des Argiens à la fondation de Byzance}

Il convient maintenant de se pencher sur le récit d'Hésychios de Milet, qui évoque la participation tantôt des Argiens, tantôt des Mégariens à la fondation de Byzance. Auteur, au VI ${ }^{\mathrm{e}}$ siècle ap. J.-C., d'une chronique universelle en six «sections», dont l'on ne conserve qu'un extrait (résumé ou adapté), Hésychios a consacré la sixième section de son ouvrage

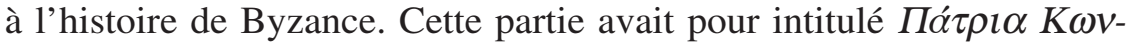
$\sigma v \tau \alpha \nu \tau \iota v o v \pi o ́ \lambda \varepsilon \omega \varsigma$; elle commençait par la fondation de la cité et continuait jusqu'à l'époque de Constantin le Grand. L'œuvre d'Hésychios

697 Pline, NH, IV, 9, 46: promunturium Chryseon Ceras in quo oppidum Byzantium libera condicionis antea Lygos dictum.

698 Janin, Constantinople ${ }^{2}$, p. 9-10, estime que le bourg de Lygos se rapporte à l'occupation pré-grecque, thrace, de la rive européenne du Bosphore. Mais, il est probable que le nom est grec et qu'il vient de $\lambda u ́ \gamma o \zeta$ («osier», "gattilier»). On connaît une Artémis Lygodesma, l'épithète faisant référence aux branches d'agnus castus, sym-

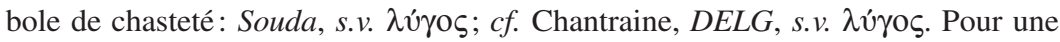
autre opinion, voir B. Sergent, «Les premiers Celtes d'Anatolie», REA 90, 3-4, 1988, p. 340, qui estime que le nom Lygos a une origine anatolienne et n'appartient pas à la tradition grecque.

699 Payne, Perachora I, 98, pl. 131, 7; Jeffery, $L S A G^{2}$, p. 131, no 5 (voir errata); $L G P N$ III A, s.v. $\Lambda$ $\gamma \omega v ; c f$. W. Pape, Wörterbuch der griechischen Eigennamen, 3. Auflage

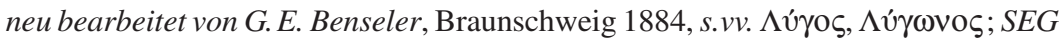

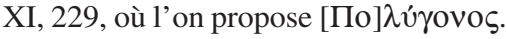


fait partie d'un genre littéraire à part, les patria, les « récits d'origine ${ }^{700}$. Tout au début de son chapitre sur Byzance, le patriographe précise que pour établir l'origine de la cité, il s'est fondé sur des écrits poétiques et historiques anciens ${ }^{701}$. On a remarqué une proximité de plusieurs passages d'Hésychios avec l'Anaplus Bospori de Denys de Byzance, mais il est bien difficile d'identifier toutes les sources d'Hésychios ${ }^{702}$.

La première tradition recueillie par Hésychios (FGrHist $390 \mathrm{~F} 3$ ) transmet que les Argiens, en suivant un oracle de la Pythie, furent les premiers fondateurs de Byzance. Néanmoins, selon d'autres légendes, l'origine de la cité remonte soit aux Mégariens de Byzas, soit à Iô, la fille du roi argien Inachos.

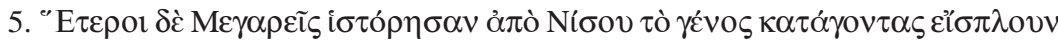

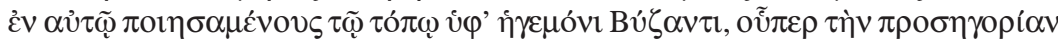

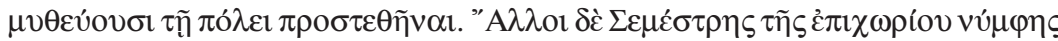

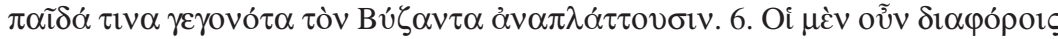

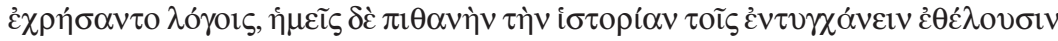

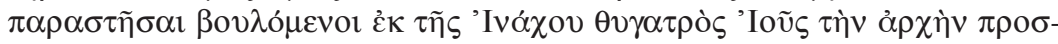

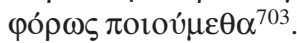

5. Les uns rapportent que des Mégariens descendant de la lignée de Nisos vinrent en ce lieu par mer sous la conduite de Byzas, dont, comme ils racontent, le nom fut donné à la cité; pourtant, d'autres imaginent que Sémestrè, une nymphe indigène, eut pour fils Byzas. 6. Les uns adoptent précisément ces récits différents, mais nous, comme nous voulons fournir aux lecteurs une histoire crédible, nous tirons l'origine (de la cité de Byzance) d'Iô, fille d'Inachos.

700 Sur les patria de Constantinople et Hésychios de Milet, voir K. Krumbacher, op. cit., p. 323-325; H. Schultz, s.v. «Hesychios» 10, RE VIII, 1913, col. 1322-1327; Dagron, Recueil des Patria, p. 12-13, 21-29; A. Berger, Untersuchungen zu den Patria Konstantinupoleos, Bonn 1988, p. 38-39. Pour un recueil des patria, voir l'édition donnée par T. Preger (éd.), Scriptores originum Constantinopolitanarum, vol. I-II, Leipzig 1901-1907.

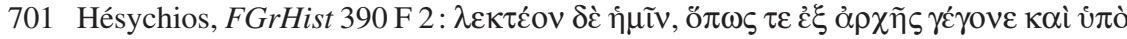

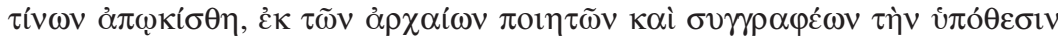

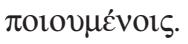

702 Pour les emprunts faits par Hésychios au texte de Denys de Byzance, voir Dagron, Recueil des Patria, p. 25. À propos des différentes sources utilisées par le patriographe, Dagron note: «Hésychios avait encore à sa disposition une tradition large et diffuse, peut-être déjà épaissie de commentaires ou découpée en excerpta, que sa brève synthèse a oblitérée, et c'est un jeu pour lui de discuter les opinions de devanciers qu'il ne cite pas».

703 Hésychios, FGrHist 390 F 5-6. 
La préférence du chroniqueur byzantin pour la légende d'Iô s'explique par le fait que cette tradition avait l'avantage de donner à Byzance un passé mythologique comparable à celui de Rome. On a constaté les faits calqués par Hésychios sur l'histoire romaine: la lutte entre les frères Byzas et Strombos est comparable à celle entre Romulus et Rémus ${ }^{704}$; Byzance a été gouvernée successivement par sept stratèges, de la même manière que Rome a été dirigée par sept rois ${ }^{705}$; la cité grecque a été sauvée par l'aboiement des chiens au moment du siège de Philippe II, tout comme Rome face aux Gaulois grâce au cri des oies ${ }^{706}$.

À première vue, le prestige légendaire dont Argos jouit à l'époque historique peut constituer une explication possible de la mention de cette cité par Hésychios comme métropole de Byzance ${ }^{707}$. D'aucuns pensent en revanche que cette tradition ne doit pas être écartée et qu'elle mérite au contraire d'être prise en compte ${ }^{708}$. De fait, quelques données appuient l'idée d'une participation des Argiens à la colonisation de la rive européenne du Bosphore thrace.

Tout d'abord, la légende d'Iô met en lumière l'existence de liens mythologiques entre Byzance et Argos. Rappelons qu'Iô, fille du roi argien Inachos et prêtresse d'Héra, suscita l'amour de Zeus. Métamorphosée en génisse par Héra et poursuivie par la déesse à travers la Thrace, Iô passa en Asie dans la région de la future Byzance et le lieu de sa tra-

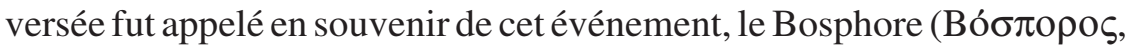

704 Hésychios, FGrHist 390 F 20.

705 Les sept stratèges nommés par Hésychios sont: Byzas, suivi par Dinéos de Chalcédoine, ensuite à l'époque des guerres avec Philippe II le byzantin Léôn et Charès d'Athènes, et finalement Prôtomachos, Timèsios d'Argos, Kalliadès.

706 Hésychios, FGrHist 390 F 27 ; cf. Janin, Constantinople ${ }^{2}$, p. 11; Dagron, Naissance d'une capitale, p. 15 ; idem, Recueil des Patria, p. 26.

707 Sur le prestige d'Argos, voir M. Piérart, G. Touchais, Argos. Une ville grecque de 6000 ans, Paris 1996, p. 30.

708 Head, $H N^{2}$, p. 266 ; Merle, Byzantion und Kalchedon, p. 7 ; Newskaja, Byzanz, p. 21. En s'appuyant sur les deux dates de fondation transmises par Jean le Lydien et Eusèbe, Svoronos, Nomism. Analekta, p. 77, suggérait qu'il y avait eu deux fondations de Byzance, la première en 658, par les Argiens, et la deuxième en 628, par les Mégariens. Contra Miller, Ist Byzanz eine megar. Colonie?, p. 326-327. Dernièrement, VeligianniTerzi, Hellenides poleis, p. 51-55, accepte aussi une double fondation de la cité, d'abord par les Argiens et ensuite par les Mégariens. 
«passage de la vache» ${ }^{709}$. D'après Polybe, le toponyme La Vache (i் Boṽ $)$, une localité située aux abords de Chrysopolis, sur la rive asiatique du Bosphore, se rattache à la traversée d' Iô $^{710}$. Une épigramme d'un acteur, un certain Euelpistos, fils de Sôsos, enterré à Tomis, offre au II siècle ap. J.-C. une confirmation épigraphique de la popularité des légendes rapportées par Hésychios. Le premier vers de ce poème qualifie Byzance, la patrie d'Euelpistos, de «terre d'Inachos » ${ }^{711}$. Cette appellation peut être interprétée comme une allusion soit à l'origine argienne de la cité du Bosphore ${ }^{712}$, soit à la généalogie qui faisait de Byzas, le fondateur de Byzance, un petit-fils d'Iô, la fille d'Inachos ${ }^{713}$.

Ensuite, on notera l'analogie qui existe entre le magistrat hiéromnamôn de Byzance et le collège argien des hiaromnamones. Les inscriptions attestent que l'Héraion d'Argos était administré au $\mathrm{V}^{\mathrm{e}}$ siècle par un collège de quatre hiaromnamones, chacun désigné par une

709 Denys le Périégète, GGM II, 140-142; Denys de Byzance, 7, p. 4; 24, p. 12 (éd. R. Güngerich); I. Kalchedon, 35; Hésychios, FGrHist 390 F 6; cf. Pfeister, Mythische Königsliste, p. 41-42. Pour les mésaventures d'Iô, voir aussi Hérodote, I, 1-2, et Eschyle, Prométhée, 635-686; cf. R. Engelmann, «Die Jo-Sage», JDAI 18, 1903, p. 37-58; T.S. Scheer, op. cit., p. 273-274. Sur l'étymologie du Bosphore, voir Oberhummer, Bosporos, col. 741-742. D'après Svoronos, Nomism. Analekta, p. 7477 , pl. 1, n ${ }^{\text {os }} 1-2$, le bovidé représenté sur les monnaies de Byzance fait référence à Iô. Contra Miller, Ist Byzanz eine megar. Colonie?, p. 326-327; E. Schönert-Geiss, «Der Io-Mythos auf den Silbermünzen von Byzanz», Helikon 6, 1966, p. 174-182, qui pensent que ce bovidé n'a rien à voir avec la légende d'Iô et qu'il symbolise seulement la richesse des élevages byzantins. Voir néanmoins Le Rider, Monnayage de Byzance, p. 146, qui, tout en acceptant la dernière interprétation, note que «comme la légende d'Iô était bien connue à Byzance (Byzas, le fondateur de la cité, était en effet le petit-fils d'Iô), plus d'un Byzantin devait se plaire à trouver dans le type monétaire de la ville une allusion à cette légende et à l'origine du nom du Bosphore». Cf. Antonetti, Panthéon de Mégare, p. 38; T. Russell, «<The Land of Inachus >, Byzantium's Early Coinage and Two Bosporus Toponyms », ZPE 180, 2012, p. 133-138.

710 Polybe, IV, 43, 6-7; 44, 3 ; cf. Oberhummer, Bosporos, col. 744, 754-755.

711 A. Avram, C.P. Jones, «An Actor from Byzantium in a New Epigram from Tomis », ZPE 178, 2011, p. 126-134. Voir aussi l'édition de cette inscription donnée par G. Staab, «Das Grabepigramm des Euelpistos aus Tomi», ZPE 179, 2011, p. 97102. Cf. A. Avram, Bull. ép., 2012, 301 et 302.

712 A. Avram, C.P. Jones, op. cit., p. 130-131.

713 T. Russell, op. cit., p. 134-135. Voir infra, chapitre II.2.4.2, sur les généalogies de Byzas. 
tribu $^{714}$. En revanche, on n'a pas la mention d'un hiéromnamôn à Mégare, mais seulement d'un mnamôn. Il est possible que la première place occupée par le hiéromnamôn dans la hiérarchie des magistrats de Byzance et la deuxième place occupée par ce magistrat à Chalcédoine découle d'une collaboration des Argiens avec les Mégariens dans la colonisation $^{715}$.

Signalons au passage aussi la mention du nom Noĩo $\varsigma$ dans une épitaphe de Mésambria, une colonie fondée par Mégare et Chalcédoine et qui a reçu aussi des habitants de Byzance et de Chalcédoine. Au moment de la publication de cette inscription funéraire datant du $\mathrm{III}^{\mathrm{e}}$ siècle, Mihailov a considéré que Noĩos était un anthroponyme nouveau ${ }^{716}$. Le nom Noĩos est certes rare, mais il est pourtant attesté, comme aussi Noí $\omega v$, à $\operatorname{Argos}^{717}$. Ce rapprochement me fait croire qu'il peut s'agir d'un nom argien à Mésambria, ce qui montre de nouveau les liens existant entre les Argiens et les Mégariens des colonies.

Par ailleurs, on peut penser que l'introduction du culte d'Héra à Byzance, évoquée ci-dessus, a pu aussi être favorisée non seulement par la présence des Corinthiens, mais aussi par celle des Argiens ${ }^{718}$.

Enfin, il convient de rappeler les rapports étroits qui existent entre les Mégariens de Grèce et les Argiens, tant dans les généalogies mythiques que dans le domaine politique. Une tradition mégarienne, évoquée par Pausanias (I, 39, 5), atteste que les Mégariens se considéraient les syngéneis des Argiens. Selon le Périégète, les Mégariens croyaient qu'ils étaient devenus des Doriens au moment où chez eux régnait Car, le fils du roi d'Argos, Phoroneus. C'est à ce moment que leur cité a pris le nom de Mégare et que le culte de Déméter a commencé à être

714 IG IV, 517; SEG XXXIII, 275. Dernièrement, de nouvelles inscriptions d'Argos viennent confirmer que le collège des quatre hiaromnamones représente l'une des magistratures principales de la cité: C. Kritzas, «Nouvelles inscriptions d'Argos: les archives des comptes du Trésor sacré (IV' s. av. J.-C.)», CRAI, 2006 (2008), 1, p. 397-434, surtout p. 412 .

715 Pour l'attestation du hiéromnamôn à Byzance et à Chalcédoine, et du mnamôn à Mégare, voir infra, chapitre III.2.1.2.

716 G. Mihailov, «Epigraphica», Bulletin de l'Institut d'archéologie de Sofia 25, 1956, p. 210, $\mathrm{n}^{\mathrm{o}} 11$ (= IGBulg $\mathrm{I}^{2}, 335$ bis); LGPN IV, s.v. Noĩos.

$717 L G P N$ III A, s.vv. Noĩos, Noíwv.

$718 \mathrm{Head}, H N^{2}$, p. 266, attribue une origine argienne au culte d'Héra à Byzance. 
célébré ${ }^{719}$. Cette légende était la réponse des Mégariens aux traditions des Athéniens, des Béotiens et des Corinthiens, qui faisaient de la Mégaride leur terre. Une allusion au rôle des Argiens dans l'établissement de Mégare ressort aussi d'un passage de Strabon, qui rapporte qu'une partie des Doriens ayant fondé Mégare repartirent ensuite pour la Crète sous la conduite de l'Argien Althaiménès ${ }^{720}$. Les rapprochements entre les deux peuples ne se limitent pas au seul domaine de la mythologie, car on trouve chez Pausanias la mention d'une alliance militaire entre Argos et Mégare contre Corinthe à l'époque archaïque ${ }^{721}$. À mon sens, il n'est pas exclu que cette alliance ait fonctionné aussi pendant la colonisation. De fait, des Argiens figuraient très probablement parmi les Doriens partis avec les Mégariens en Occident et qui, après s'être détachés de ces derniers, rejoignirent les Corinthiens d'Archias et fondèrent Syracuse ${ }^{722}$. Sur la foi du récit d'Hésychios et des données argiennes présentes dans les colonies mégariennes, il est, par conséquent, légitime de penser que des Argiens accompagnèrent aussi les Mégariens sur les rives du Bosphore thrace.

\section{II.2.4.1.7 Les époikoi de Chalcédoine}

La difficulté d'implanter une apoikia sur la rive européenne du Bosphore est confirmée par l'arrivée à Byzance des époikoi de Chalcédoine. Un passage d'Hésychios mentionne l'aide prêtée par un chef chalcédonien, un certain Dinéos, peu de temps après la fondation de la colonie mégarienne, à Byzas, l'œciste légendaire de la cité, dans les guerres avec les tribus thraces.

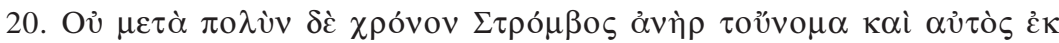

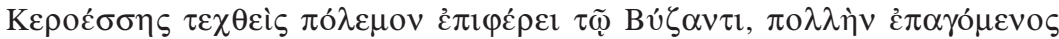

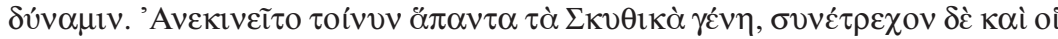

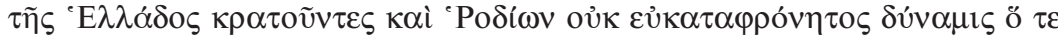

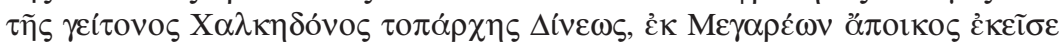

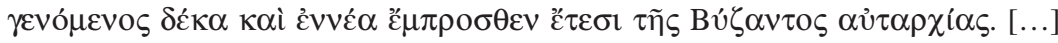

719 Voir supra, chapitre I.1.3.

720 Strabon, XIV, 2, 6, C 653; cf. Will, Korinthiaka, p. 291, qui voit dans ce passage une référence à une fondation argienne de Mégare. Sur les liens entre Argos et Mégare, on verra Hanell, Megarische Studien, p. 69-91. Voir aussi supra, chapitre I.1.1.

721 Pausanias, VI, 19, 13-14. Voir supra, chapitre I.1.3.

722 Voir supra, chapitre II.1.1.1. 


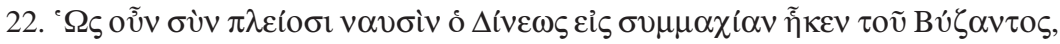

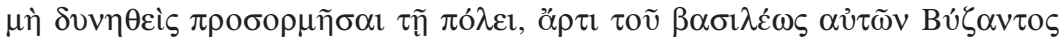

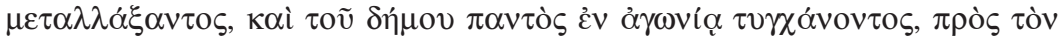

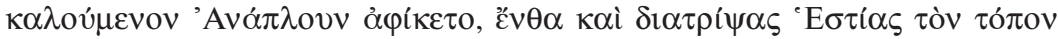

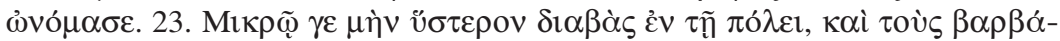

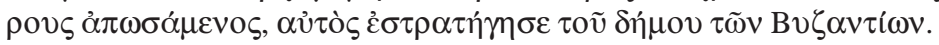

20. Peu de temps après, un homme appelé Strombos, lui-aussi né de Céroessa, fit la guerre à Byzas à la tête d'une nombreuse armée. Toutes les peuplades des Scythes se mirent en mouvement; se rassemblèrent aussi ceux qui avaient le pouvoir en Grèce, l'armée non méprisable des Rhodiens et Dinéos, le chef de la voisine Chalcédoine, qui, colon de Mégare, y était venu, dix-neuf ans avant le gouvernement de Byzas. [...] 22. Lorsque Dinéos arriva donc avec plusieurs navires pour conclure une alliance avec Byzas, ne pouvant pas débarquer dans la ville, car le roi Byzas venait de mourir et la population était éplorée, il se dirigea vers un endroit appelé Anaplous et comme il y avait passé du temps, il donna à cet endroit le nom d'Hestiai. 23. Peu de temps après, étant entré dans la cité et ayant chassé les barbares, il devint lui-même le stratège du peuple byzantin ${ }^{723}$.

On remarque que selon ce récit, Dinéos a changé le nom du site Anaplous en Hestiai au moment de son premier débarquement sur la rive européenne du Bosphore. Cette mention montre que Hestiai avait une importance dans la colonisation du Bosphore et que, comme je l'ai suggéré, cet endroit était lié à la fondation symbolique de la cité de Byzance. Il est possible que cette variante de la légende de fondation d'Hestiai ait une origine chalcédonienne. En effet, même si l'aide des autres Grecs et des Scythes est, elle aussi, mentionnée par Hésychios, ce sont finalement les Chalcédoniens qui ont sauvé les Byzantins ${ }^{724}$. L'élection de Dinéos comme deuxième stratège de la cité (après Byzas) et le changement du nom de l'endroit Anaplous en Hestiai suggèrent l'existence d'une tradition qui attribuait aux Chalcédoniens une deuxième fondation de Byzance.

Hésychios situe le conflit entre Byzas et Strombos et l'arrivée des

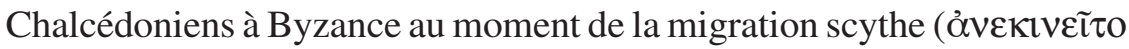

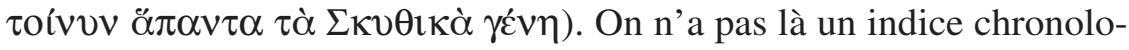
gique très précis, mais en le rapportant à l'arrivée des Scythes dans les

723 Hésychios, FGrHist 390 F 20-23.

724 L'aide que les Rhodiens auraient prêtée aux Byzantins dans la guerre est sans nul doute un anachronisme, celui-ci s'expliquant par le rôle important que la cité de Rhodes joua dans les relations entre cités à l'époque hellénistique. 
régions du nord et de l'ouest de la mer Noire, on serait amené à situer les renforts chalcédoniens au plus tôt vers le milieu du VII ${ }^{\mathrm{e}}$ siècle ${ }^{725}$.

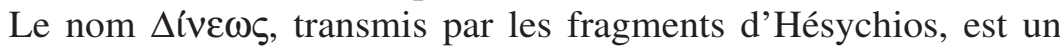
hapax. Hanell pensait que ce chef chalcédonien était la même personne que le chef mégarien $\Delta \varepsilon i v i ́ \alpha \varsigma$, qui figure dans un manuscrit d'époque byzantine ${ }^{726}$. Étant donné que Byzas est l'éponyme mythique de la cité, le savant suédois croyait que $\Delta i ́ v \varepsilon \omega \varsigma / \Delta \varepsilon \imath v i ́ \alpha \varsigma$ était le véritable œciste, ce qui aurait confirmé sa thèse sur le rôle principal joué par Chalcédoine dans la fondation de Byzance ${ }^{727}$. Si le rôle des Chalcédoniens dans la colonisation de la Propontide me semble avoir été surévalué par

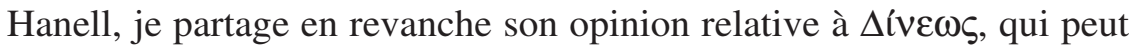
en effet être une corruption du nom $\Delta(\varepsilon) \imath v i ́ \alpha \varsigma$ connu notamment en Béotie, en Mégaride et en Thrace ${ }^{728}$.

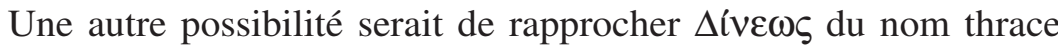
$\Delta \imath v \imath \varsigma$, dont le génitif est $\Delta \imath v \varepsilon \omega \varsigma^{729}$. Dans ce dernier cas, l'origine chalcédonienne/mégarienne de ce chef pourrait refléter l'essai des Grecs des cités du Bosphore de s'approprier un héros indigène. Une situation analogue se présente pour Byzas, considéré par différentes légendes tantôt comme un chef mégarien, tantôt comme un roi thrace ${ }^{730}$. Quoi

725 Sur la présence des Scythes au nord et à l'ouest de la mer Noire aux VII ${ }^{\mathrm{e}}-\mathrm{VI}^{\mathrm{e}}$ siècles, voir V. Y. Murzin, S. A. Skory, «An Essay of Scythian History», Il Mar Nero 1, 1994, p. 55-73; A. Vulpe, «En marge de Ps.-Scymnos 766-770», in La première époque du fer à l'embouchure du Danube et dans les régions pontiques. Actes du colloque international, Tulcea, septembre 1993, Tulcea 1997, p. 181-185; Petropoulos, Emporion, p. 23-24.

726 Il s'agit du manuscrit Narratio historica in depositione vestis S. Mariae in Blachernis, in F. Combefis (éd.), op. cit., col. 755 D-E.

727 Hanell, Megarische Studien, p. 127-128. Cf. Malkin-Shmueli, City of the Blind, p. 32-33.

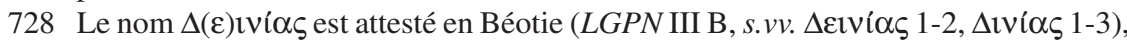
en Mégaride ( $L G P N$ III B, s.v. $\Delta$ tví $\varsigma_{\varsigma} 4$ : Aigosthènes ; 6 : Mégare), en Thrace ( $L G P N$

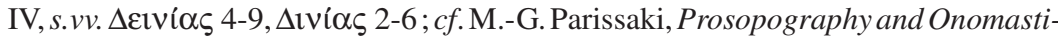
con of Aegean Thrace, ME AETHMATA49, Athens 2007, p. 157), dans le Pont-Euxin

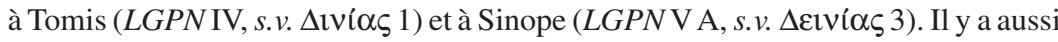
le nom $\Delta$ tví $\alpha$ qui est mentionné en Argolide, à Hermioné (LGPN III A, s.v. $\Delta$ tví $\alpha$ ).

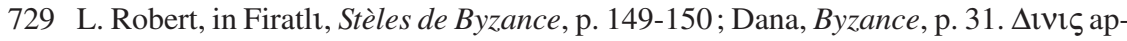
paraît à Byzance à l'époque impériale dans l'inscription I. Byzantion, 340 (LGPNIV,

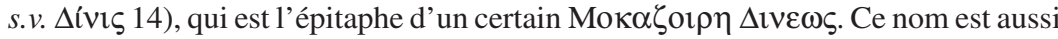
abondamment attesté en Thrace: LGPNIV, s.v. $\Delta$ ívıs 3-27; cf. M.-G. Parissaki, op. cit., p. 161. Sur l'origine thrace de $\Delta \mathrm{tvi \varsigma}$, voir Detschew, Thrak. Sprachreste ${ }^{2}$, p. 137-138.

730 Voir infra, chapitre II.2.4.2. 
qu'il en soit, force est de constater que les passages d'Hésychios font la différence entre une première vague de colons d'origine argienne ou mégarienne, et une deuxième, en provenance de Chalcédoine.

La présence des époikoi à Byzance est confirmée aussi par Aristote, qui cite la colonie mégarienne comme un exemple de conflits entre les premiers colons et ceux qui sont venus par la suite.

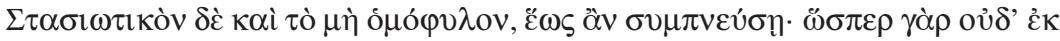

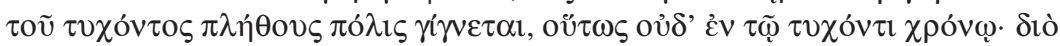

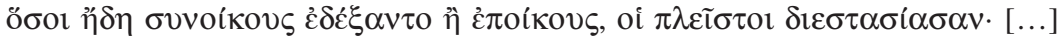

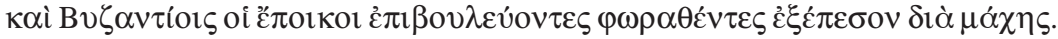

Un autre facteur de sédition, c'est l'absence de communauté raciale, tant qu'il n'y a pas une communauté d'aspiration: en effet, de même qu'une cité ne connaît pas de n'importe quelle foule, ainsi ne se forme-t-elle pas non plus en n'importe quel laps de temps. C'est pourquoi les États qui jusqu'à présent ont admis des étrangers comme cofondateurs ou ensuite comme colons ont, pour la plupart, connu des séditions: [...] à Byzance, les nouveaux colons, pris en flagrant délit de complot, furent chassés de vive force ${ }^{731}$.

Ce passage d'Aristote indique que l'apoikia de Byzance était composée de groupes hétérogènes de colons et qu'à cause de leurs rivalités la cité avait connu une période de stasis $^{732}$. On n'a pas de moyen de connaître l'identité des époikoi en question, qui pouvaient être les Chalcédoniens de Deinias, mais aussi l'un des groupes de colons mentionnés par les récits comme les fondateurs de la cité (les Mégariens, les Carystiens, les Béotiens, les Corinthiens, les Argiens).

La participation des Chalcédoniens à la fondation de Byzance serait confirmée, selon Loukopoulou et Avram, par la présence dans les deux cités du hiéromnamôn, un magistrat qui est une exception parmi les institutions des établissements mégariens ${ }^{733}$. Ce magistrat, qui occupe la

731 Aristote, Politique, V, 3, 11-12 1303a 25-34 (trad. de J. Aubonnet, CUF).

732 Pour les luttes internes à Byzance, voir aussi le passage de Diodore, XIV, 12, 2, qui atteste que vers 403-402, les Byzantins, afin d'établir l'ordre dans la ville, ont demandé un stratège à Sparte (voir infra, chapitre III.1.1.2).

733 Loukopoulou, Thrace propontique, p. 146: «Or, le fait que l'hiéromnamon occupe une place importante - bien que différente - dans la constitution de Byzance et de Chalcédoine corrobore l'hypothèse que Byzance fut une colonie directe de Chalcédoine». Avram, Kalchedon, p. 981, est plus prudent à propos de cette reconstruction, en notant: «Nevertheless, the idea of a direct foundation of Byzantion by Kalchedon remains a hypothesis ». 
deuxième place à Chalcédoine, aurait gagné la première place à Byzance après l'arrivée dans cette cité des époikoi de Deinias. Cette hypothèse séduisante présente néanmoins un défaut: elle n'explique pas comment le hiéromnamôn est arrivé à Chalcédoine. C'est la raison pour laquelle je pense qu'il vaut mieux privilégier la piste de l'origine argienne de ce magistrat ${ }^{734}$. Ultérieurement, étant donnés les étroits rapports politiques existant entre les deux cités du Bosphore, le hiéromnamôn de Byzance a pu entrer dans la hiérarchie des magistrats de Chalcédoine. On serait ainsi face à une situation semblable à celle de Périnthe, la colonie samienne de Propontide, qui reçut de Byzance le hiéromnamôn comme magistrat éponyme ${ }^{735}$.

\section{II.2.4.1.8 Conclusions sur l'origine des fondateurs de Byzance}

La fondation de Byzance peut être considérée comme l'œuvre principalement des Mégariens, mais ceux-ci furent aussi appuyés par des groupes de colons d'autre origine (argienne, béotienne, carystienne, voire même corinthienne) ${ }^{736}$. Il s'agissait d'une expédition qui devait faire face aux tribus de guerriers thraces et que l'on pourrait qualifier d' «internationale». Les colons non mégariens arrivèrent à Byzance soit parmi les premiers apoikoi, soit parmi les époikoi. Cette entreprise a ensuite bénéficié du support des Chalcédoniens qui aidèrent les Byzantins dans leurs conflits avec les Thraces ${ }^{737}$. Même si Aristote évoque les luttes intestines entre les premiers venus et les colons supplémentaires, il est fort probable que le succès de la colonisation mégarienne sur les rives du Bosphore ait été dû, au moins dans une première étape, à l'assimi-

734 Voir supra, chapitre II.2.4.1.6.

735 Voir infra, chapitre III.2.1.2.

736 Cette hypothèse est acceptée maintenant aussi par Loukopoulou-Lajtar, Byzantion, p. 915, qui notent: «Probably, the majority of colonists came from Megara, while some contingents were supplied by their immediate neighbours, especially Argos, Corinth and Boiotia». Cf. Graham, Colonial Expansion, p. 120.

737 L'hypothèse ingénieuse de Hanell, Megarische Studien, p. 127-128, 132-138, suivi par Loukopoulou, Thrace propontique, p. 52, 146, selon laquelle l'arrivée de Deinias montre que Byzance a été une colonie principalement de Chalcédoine est contredite par le témoignage d'Hésychios, qui fait la différence entre les premiers fondateurs et les époikoi chalcédoniens, et aussi par la plupart des auteurs antiques qui attribuent l'origine de cette ville aux Mégariens. Hanell, ne pouvant pas exclure toutes les données mégariennes qui existaient à Byzance, accordait ausssi un rôle dans cette fondation aux Mégariens de Grèce et, comme on l'a vu, aux Milésiens. 
lation des vagues ultérieures ou des groupes simultanés de colons d'autres communautés grecques par le noyau mégarien le plus important.

En ce qui concerne la date de fondation de la cité, il n'existe pas de fortes raisons pour rejeter la date de 659/8, fournie par la Chronique d'Eusèbe (éd. R. Helm, p. 94b). Néanmoins, elle n'est qu'un indice de chronologie relative et la meilleure solution est de considérer que la cité de Byzance a été installée dans la première moitié du VII siècle, après la fondation d'Astacos, de Chalcédoine et de Sélymbria.

Notons du reste qu'à en croire Jean le Lydien, l'installation de Byzance eut lieu lors de la $38^{\mathrm{e}}$ olympiade, soit vers 628 :

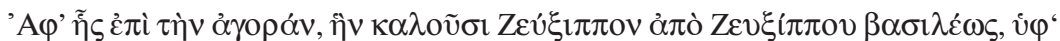

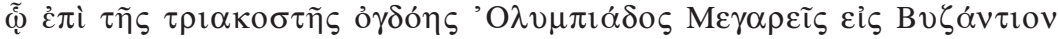

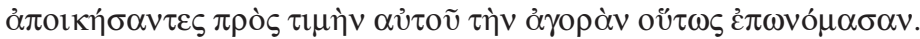

Ensuite l'agora, que l'on appelle le Zeuxippe, d'après le roi Zeuxippos, sous le règne de qui, au cours de la $38^{\mathrm{e}}$ olympiade, les Mégariens colonisateurs de Byzance avaient donné son nom à l'agora pour lui faire honneur ${ }^{738}$.

Cette date basse de fondation peut se rapporter à l'arrivée d'une nouvelle vague de colons mégariens. Leur chef pouvait bien être Zeuxippos, le basileus mentionné par cet auteur du $\mathrm{VI}^{\mathrm{e}}$ siècle ap. J.-C., et dont le nom fut aussi donné aux thermes bâtis vers la fin du II ${ }^{\mathrm{e}}$ siècle ap. J.-C. par Septime Sévère ${ }^{739}$. La découverte de fragments de céramique protocorinthienne dans les sondages au Sérail n'apporte pas une confirmation archéologique ni pour la chronologie haute, ni pour la chronologie basse de la fondation de la cité ${ }^{740}$. Ce serait en effet une erreur d'accorder

738 Jean le Lydien, Des Magistratures de l'État romain, III, 70, 4 (trad. de J. Schamp, CUF); $c f$. A. Ogan, «Les fouilles de Topkapu Saray», Belleten 4, 1940, p. 329.

739 L'agora de Zeuxippos n'est mentionnée que par Jean le Lydien, et son nom provient des bains homonymes qui se trouvaient dans les alentours. Sur les thermes de Zeuxippos bâtis vers la fin du $\mathrm{II}^{\mathrm{e}}$ siècle ap. J.-C. par Septime Sévère, voir H. von Geissau, s.v. «Zeuxippos» 1, RE XIX A, 1972, col. 379; H. Beckby (éd.), Anthologia Graeca, vol. I, München 1957, p. 166; J. Schamp (éd.), Jean le Lydien, Des Magistratures de l'État romain, Tome II, Livres II et III, Paris 2006, p. CLVI-CLIX; A. Kaldellis, «Christodoros on the Statues of Zeuxippos Baths: A New Reading of the Ekphrasis», GRBS 47, 2007, p. 361-362 (avec les références).

740 A. Ogan, op. cit., p. 329-335, surtout p. 332, fig. 2-3; E. Akurgal, «Recherches faites à Cyzique et à Ergili», Anatolia 1, 1956, p. 19-20, et pl. X, aryballes protocorinthiennes tardives (datant de ca. 650-610: I. Morris, AArch 67, 1996, p. 53, Table 2, et aussi p. 57); M. J. Mellink, «Archaeology in Asia Minor», AJA 60, 4, 
trop de crédit à ces données matérielles en l'absence d'une stratigraphie archaïque dans cette cité.

Enfin, je crois qu'une explication des nombreuses traditions de fondation qui circulaient à l'époque romaine à propos de Byzance mérite d'être proposée. Il ne serait pas erroné de considérer que toutes ces versions ont été mises en circulation par les différentes familles (oikoi) ou groupements familiaux, qui soutenaient avoir des héros ou des ancêtres d'origine mégarienne, argienne, corinthienne, béotienne ou chalcédonienne. Se flattant d'avoir un ancêtre illustre ayant fondé des sites ou des sanctuaires dans cette région, ces familles essayaient de faire valoir leur primauté dans la fondation de la cité. L'usage d'intégrer les fondateurs mythiques dans les généalogies locales est mis en évidence au $\mathrm{II}^{\mathrm{e}}$ siècle ap. J.-C. par le cas du sophiste Markos de Byzance, qui se tenait pour un descendant de Byzas, et qui, chose intéressante, prêta son aide dans un conflit entre les Mégariens et les Athéniens. Markos fut envoyé par les Byzantins comme ambassadeur à Rome, où il s'attira l'admiration de l'empereur Hadrien ${ }^{741}$. Et les monnaies attestent qu'il remplit dans sa cité à deux reprises la charge d'hiéromnamôn, dont une fois à titre posthume. Il reçut le titre de «héros» (ñ $\rho \omega \varsigma)$, sans doute suite à une donation que lui ou sa famille avait faite $^{742}$. D'autre part, on a déjà mentionné le cas du médecin Aglaïdas

1956, p. 383; N. Firatlt, "New Discoveries concerning the First Settlement of Ancient Istanbul-Byzantion", in Proceedings of the $X^{\text {th }}$ International Congress of Classical Archaeology, Ankara-Izmir 1973, p. 571-574; Loukopoulou, Thrace propontique, p. 52-53. Les céramiques grecques livrées par les fouilles du métro d'Istanbul (à Sultanahmet Eski Cezaevi, à Yenipari) ne semblent pas remonter au-delà du dernier quart du VII" siècle: A. Denkar, G. Yağct, A. B. Akay, "Büyük Saray kazıst”, in Gün Işı̆̆ında İstanbul'un 8000 Yılı-Marmaray, Metro, Sultanahmet Kazllari, Istanbul 2007, p. 144, no SC2; R. Asal, "İstanbul'un ticareti ve Theodosius Limant”, in Gün Işı̆̆ında İstanbul'un 8000 Yllt-Marmaray, Metro, Sultanahmet Kazllari, Istanbul 2007, p. $180-181$, p. $248, \mathrm{n}^{\circ} \mathrm{Y} 1$. Voir aussi supra, chapitres II.2.2.3, les trouvailles de Chyrsopolis.

741 Philostrate, Vies des sophistes, I, 24, 528-529.

742 L. Robert, in Firatl, Stèles de Byzance, p. 137 et 171; J. et L. Robert, Bull. ép., 1968, 342 , p. $482 ; c f$. B. Puech, Orateurs et sophistes grecs dans les inscriptions d'époque impériale, Paris 2002, p. 344-345; Dana, Culture, p. 253-254. Pour les monnaies frappées avec le nom de Memmios Markos comme éponyme, voir Schönert-Geiss, Byzantion, vol. II, p. 8-12, 17-18, 20-21, et pl. 70-71, $\mathrm{n}^{\text {os }} 1384,1395-1398,1402-$ 1404, pl. 74-75, nos $1424-1426,1433-1440$, pl. 125-126, nos $2046-2048$. 
de Byzance, qui prétendait que sa famille remontait au héros Héraclès. Ces témoignages montrent, selon Robert, qu'à Byzance «il y avait con-

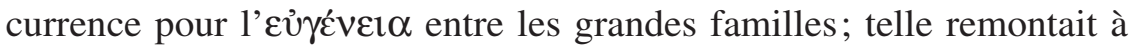
Byzas, telle autre à Héraclès ${ }^{743}$. Ainsi, on conclura que certains oikoi, afin de prouver leur ancienneté, avaient l'habitude de faire remonter leur généalogie jusqu' aux fondateurs de la cité. En conséquence, Byzas, Lygos, Deinias ou Zeuxippos pourraient bien être les différents œcistes revendiqués par autant de familles byzantines.

\section{II.2.4.2 Byzas, l'œeciste de Byzance, et les rapports entre les Byzantins et les Thraces}

La rareté des témoignages antiques et des trouvailles rend pratiquement impossible autant l'identification exacte des limites des territoires des colonies mégariennes de Propontide à l'époque archaïque et classique, que le repérage des sites indigènes qui faisaient partie de ces chôrai ${ }^{744}$. On retiendra que l'archéologie n'a pas confirmé pour l'instant la présence d'un site thrace sur les rives du Bosphore au moment de l'arrivée des Grecs ${ }^{745}$. En revanche, des témoignages littéraires et épigraphiques nous renseignent sur les rapports entre les Thraces et les Grecs de Byzance. Dans ce sens, un premier indice de la présence d'éléments thraces

743 L. Robert, in Firatll, Stèles de Byzance, p. 137. Pour l'invention des légendes de fondation dans les colonies grecques, voir aussi D. Braund, «Reflections on Eumelus' Black Sea Regions », in Pont-Euxin et polis. Polis hellenis et polis barbaron. Actes du Xe Symposium de Vani, 23-26 septembre 2002. Hommage à Otar Lodkinapidzé et Pierre Lévêque, D. Kacharava et al. (éds.), Besançon 2005, p. 101.

744 En se fondant sur les témoignages épigraphiques, Robert, Hellenica, VII, p. 39, estime que «le territoire de Byzance s'étendait en Thrace jusqu'à Derkos au moins, sur la rive du Pont-Euxin, jusqu'à Rhégion (Küçük Çekmece) au moins, sur la rive nord de la Propontide; peut-être, de ce côté, s'étendait-il, à l'époque impériale, jusqu'à Salymbria (Selivri)». Il convient de rappeler que ces limites sont tracées par les découvertes de stèles d'époque impériale datées par le hiéromnamôn éponyme de Byzance, à Derkos, Rhégion et Sélymbria (voir infra, chapitre III.2.1.2). Sur le territoire de Byzance, voir aussi Isaac, Gr. Settlem. in Thrace, p. 232-233; Robert, Hellenica, VII, p. 30-44. Voir aussi ci-dessous sur la pérée byzantine en Asie aux époques hellénistique et impériale.

745 N. Firatl, op. cit., p. 570, note à propos des plus anciennes découvertes de Byzance: «we do not possess any archaeological evidence from the period between the end of the second millennium B.C. and the middle of the seventh century, when the Greeks came to settle here». 
est l'appellation même de la cité; le fondateur mythique est Byzas, d'où

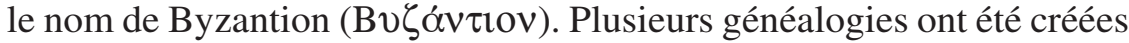
pour Byzas à l'époque romaine et byzantine: il est tour à tour un chef mégarien, le fils de la nymphe indigène Sémestrè, le fils de Poséidon et Céroessa, héroïne éponyme de la Corne d'Or et fille de Zeus et d'Iô, un roi thrace ayant épousé Phidaleia, la fille de Barbysès, le maitre thrace de la région de Byzance ${ }^{746}$. Assurément, le nom Byzas appartient à l'onomastique thrace. On connaît un dynaste thrace d'époque hellénistique, qui porte le même nom que celui du fondateur de Byzance ${ }^{747}$. De même, il est présent en Thrace égéenne à l'époque impériale sous les

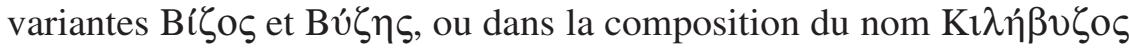
(attesté déjà au $\mathrm{IV}^{\mathrm{e}}$ siècle $)^{748}$.

Pour montrer leur origine mythique, les Byzantins représentent, aux $\mathrm{II}^{\mathrm{e}}$-III ${ }^{\mathrm{e}}$ siècles ap. J.-C., Byzas et sa mère Céroessa sur leurs monnaies de bronze ${ }^{749}$. De même, une statue de ces deux personnages hé-

746 Diodore, IV, 49, 1, situe le roi indigène Byzas à l'époque mythique des Argonautes. Pour les légendes qui attribuent à Byzas une origine divine, semi-divine ou mégarienne, voir Denys de Byzance, 24, p. 12 (éd. R. Güngerich); Hésychios,

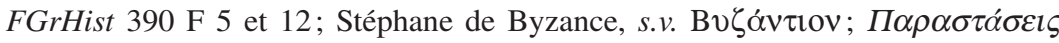

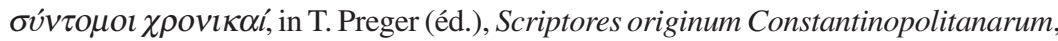
vol. I, Leipzig 1901, 38, p. 42 et 41, p. 48 ; Scholie à Démosthène, V, 25. Selon une tradition rapportée par Georgius Cedrenus, Historiarum compendium, I, p. 197 (éd. I. Bekker), Byzas aurait été un roi thrace. Notons que le Chronicon Paschale, vol. I, p. 493-495 (éd. L. Dindorf), transmet au VII ${ }^{\mathrm{e}}$ siècle ap. J.-C. que Byzance fut originellement un emporion thrace dont le chef fut Barbysès, remplacé par Byzas, qui avait épousé Phidaleia, la fille de son prédécesseur. La même légende se trouve chez Malalas, Chronographia, VII, 7, 86-94, p. 246 (éd. J. Thurn). Les attestations concernant les différentes généalogies de Byzas sont recueillies par Stoll, Byzas, col. 841 ; J. Miller, s.v. «Byzas», RE III, 1899, col. 1158-1159; A. Pavlopoulou, «Légende et culte des héros fondateurs dans les colonies grecques de Thrace», in Thrace, Athènes 1994, p. 126-127; Porozhanov, Founders, p. 518-520.

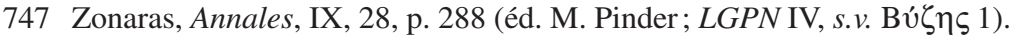

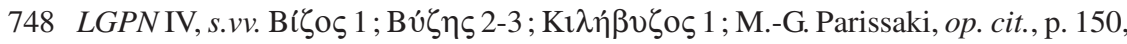

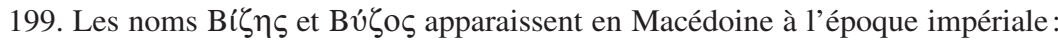

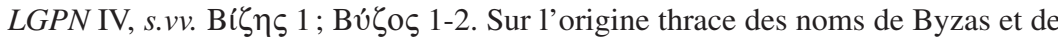
Byzance, voir Detschew, Thrak. Sprachreste 2 , p. 94-95.

749 Svoronos, Nomism. Analekta, p. 71-73, pl. 1, n ${ }^{\text {os }}$ 7-9 (Céroessa), p. 79-80, pl. 1, $\mathrm{n}^{\text {os }} 16-17$ (Byzas); Head, $H N^{2}$, p. 269-270; E. Schönert-Geiss, Helikon 6, 1966, p. 177-178; eadem, Byzantion, vol. II, p. 34, et pl. 123-124, n ${ }^{\text {os }}$ 2012-2022 (Céroessa), pl. 125-127, nos 2032-2074 (Byzas). 
roïques semble se trouver à la même époque dans la cité ${ }^{750}$. Il n'y a pas lieu d'analyser ici les nombreuses mentions de Byzas dans les récits d'époque impériale ou les patria d'époque byzantine, qui utilisent le héros pour établir, d'une part, des liens avec la terre de Thrace et, d'autre part, avec un passé préromain et préchrétien ${ }^{751}$. De manière générale, on rappelle qu'un œciste indigène constituait un moyen pour les Mégariens de justifier la prise de possession des terres nécessaires à leur apoikia $^{752}$. L'intégration de Byzas dans les généalogies locales, tout comme dans le cas de la tradition attribuant l'origine de Chalcédoine à Calchédon, fils de Cronos $^{753}$, révèle ainsi l'intention des Byzantins d'engager des rapports de parenté avec les Thraces.

À cette logique de rapprochement avec le monde thrace, visible à l'époque impériale, correspond aussi la tradition fournie par Hésychios, selon laquelle les fondateurs de Byzance accomplirent des sacrifices aux dieux et aux héros du lieu ${ }^{754}$. Les divinités locales devaient ainsi approuver la nouvelle installation. En même temps, les dieux grecs appuient également les Mégariens. Comme dans le cas de l'aide offerte par Apollon et Poséidon au roi Laomédon de Troie ${ }^{755}$, les deux divinités aidèrent Byzas à bâtir les murs de la cité ${ }^{756}$. Et on se souvient qu'Apollon est aussi le dieu qui aida Alcathoos à bâtir les murs de la métropole de Byzance, Mégare ${ }^{757}$.

En dépit de la tentative d'intégrer l'élément indigène dans la mythologie de leur cité (comme le montre l'exemple de Byzas), plusieurs auteurs attestent que les premiers rapports entre les Mégariens et les

750 Stoll, Byzas, col. 841.

751 Dagron, Recueil des Patria, p. 18-19; A. Pavlopoulou, op. cit., p. 127; V. Fol, «ByzasByzantion: une métaphore historico-culturelle», in Thracia 13. Studia in memoriam Velizari Velkov, Sofia 2000, p. 101-106.

752 Voir supra, chapitre II.2.3.

753 Voir supra, chapitre II.2.2.1.

754 Hésychios, FGrHist 390 F 4. G. Nenci, «Les rapports internationaux dans la Grèce archaïque (650-550 av. J.-C.)», in Studi sui rapporti interstatali nel mondo antico, Pisa 1981, p. 59-60, note que le sacrifice aux divinités locales rendait possible l'intégration de ces dieux épichorioi dans le panthéon de la nouvelle cité.

755 Homère, Iliade, VII, 452-453; XXI, 441-449; $c f$. M. Detienne, «Apollon Archégète. Un modèle politique de la territorialisation», in Tracés de fondation, M. Detienne (éd.), Louvain-Paris 1998, p. 307-308.

756 Hésychios, FGrHist 390 F 12.

757 Voir supra, chapitre I.1.1. 
Thraces ont été violents. Les fragments de Denys de Byzance évoquent les luttes menées par les premiers fondateurs de Byzance contre les populations locales ${ }^{758}$. Hésychios de Milet, quant à lui, témoigne des guerres entre les Grecs et les Thraces, même s'il note aussi que ces derniers ont été dans un premier temps les alliés de Byzas ${ }^{759}$. Cependant, étant donné que cette dernière mention se place à l'époque mythique de Byzas, on ne saurait dire si les Grecs ont été appuyés par certains chefs thraces; il est bien plus probable qu'Hésychios n'évoque cette alliance que pour expliquer la tradition sur l'origine thrace de Byzas.

Par ailleurs, les luttes internes et la guerre avec les Thraces sont les causes invoquées par Diodore pour l'appel adressé par les Byzantins aux Lacédémoniens vers la fin du $\mathrm{V}^{\mathrm{e}}$ siècle, afin que ceux-ci envoient un stratège capable d'établir l'ordre dans la ville ${ }^{760}$. De même, Polybe nous apprend que les Byzantins payaient de lourds tributs aux différents dynastes thraces pour «racheter» ou préserver la chôra ${ }^{761}$. Il est d'ailleurs possible que ce soient les razzias répétées des Thraces qui ont déterminé les Byzantins à se tailler une chôra en Asie. À cet égard, Polybe transmet que les Byzantins occupaient «depuis longtemps» la Mysie au moment de la guerre avec les Rhodiens et le roi bithynien Prusias Ir (vers 220 ${ }^{762}$. À la fin de cette guerre, le traité de paix stipulait que les terres de Mysie, occupées pendant la guerre par les Bithyniens, devaient être retournées aux Byzantins ${ }^{763}$. Ce témoignage peut

758 Denys de Byzance, 8, p. 4-5; 16, p. 7; 53, p. 22-23 (éd. R. Güngerich; voir aussi supra, chapitre II.2.4.1.1). Pour les conflits entre les Byzantins et les Thraces, voir Miller, Byzantion, col. 1129, 1141; Newskaja, Byzanz, p. 19-20; Isaac, Gr. Settlem. in Thrace, p. 223, 230-231.

759 Hésychios, FGrHist 390 F 10, 17-23 (voir aussi supra, chapitre II.2.4.1.6). Cf. Merle, Byzantion und Kalchedon, p. 10; V. Fol, op. cit., p. 102-103.

760 Diodore, XIV, 12, 2 (voir infra, chapitre III.1.1.2). Le témoignage de Diodore est corroboré par celui de Polyen, II, 2, 7, qui atteste aussi que ce sont les attaques des Thraces qui ont déterminé les Byzantins à envoyer leurs stratèges pour demander l'aide du Spartiate Cléarque.

761 Polybe, IV, 45-46.

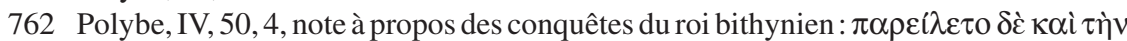

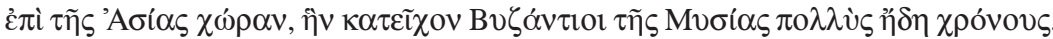

763 Polybe, IV, 52. Sur la guerre des Byzantins avec les Rhodiens et Prusias I ${ }^{\mathrm{er}}$, voir Merle, Byzantion und Kalchedon, p. 56-59; Vitucci, Regno di Bitinia, p. 37-42; C. Habicht, s.v. «Prusias» 1, RE XXIII, 1, 1957, col. 1088-1091; Will, Histoire ${ }^{2}$, II, p. 45-46; N. Jefremow, «Der rhodisch-byzantinische Krieg von 220 v. Chr.: ein Handelskrieg im Hellenismus?», MBAH 24, 1, 2005, p. 51-98. 
être corroboré par un passage de Denys de Byzance, qui rapporte que les Byzantins avaient consacré un temple à Ptolémée II Philadelphe (283-246). Il s'agissait d'une expression de reconnaissance de la part des Grecs du Bosphore, car le roi d'Égypte les avait gratifiés de terres en Asie, de céréales, d'armes (projectiles?) et d'argent ${ }^{764}$. Un passage des Oracles Sibyllins ${ }^{765}$ évoque probablement les pertes territoriales subies par les Byzantins et les peines que les Bithyniens infligèrent à ceux-ci en Asie lors de la guerre de $220^{766}$. Il faut ajouter à cela une notice de Strabon, qui confirme l'existence de possessions byzantines en Asie, dans la région du lac de Daskylion ${ }^{767}$.

On signalera aussi ici un autel d'époque impériale découvert au nord-ouest de Nicomédie, dans le village de Yağcilar, qui porte une dédi-

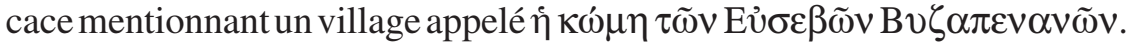

764 Denys de Byzance, 41, p. 17 (éd. R. Güngerich). Cf. K. Bringmann, H. von Steuben (éds.), Schenkungen hellenistischer Herrscher an griechische Städte und Heiligtümer, Teil I: Zeugnisse und Kommentare, Berlin 1995, p. 271. Sur la pérée de Byzance à l'époque hellénistique et impériale, on renverra à Robert, Hellenica, VII, p. 38-44; idem, in Firatlı, Stèles de Byzance, p. 134-135 ; J. et L. Robert, Bull. ép., 1949, 183 a; C. Habicht, s.v. «Prusias» 1, RE XXIII, 1, 1957, col. 1089; Isaac, Gr. Settlem. in Thrace, p. 232; T. Corsten (éd.), I. Apameia und Pylai, p. 47-48, 162; idem, «Neue Denkmäler aus Bithynien », EA 17, 1991, p. 79; O. L. Gabelko, «Zur Lokalisierung und Chronologie der asiatischen Besitzungen von Byzanz», OTerr 2, 1996, p. 121128. Voir aussi infra, chapitre III.2.1.2 pour les documents trouvés dans la région de Yalova, qui sont datés par le hiéromnamôn, le magistrat éponyme de Byzance. Pour les relations entre Ptolémée II et Byzance, voir surtout W. Otto, «Zu den syrischen Kriegen der Ptolemäer», Philologus 86, 1931, p. 408-409; Habicht, Gottmenschentum $^{2}$, p. 116-121, et dernièrement Avram, Divinisation de Ptolémée, p. 828-833, qui estime que les possessions asiatiques ont été accordées à Byzance «lors du traité de 279 av. J.-C. entre le roi de Bithynie, Nicomède ${ }^{\text {er }}$, et les Galates (Memnon, F 11, 2), quasiment contemporain de la trêve conclue entre Philadelphe et Antiochos $\mathrm{I}^{\mathrm{er}}$ » (p. 829); idem, «Antiochos II Théos, Ptolémée II Philadelphe et la mer Noire», CRAI, 2003 (2005), 3, p. 1203-1213; P. Gauthier, Bull. ép., 2006, 277.

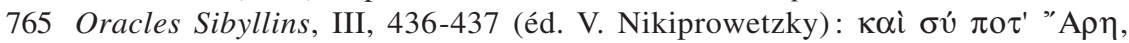

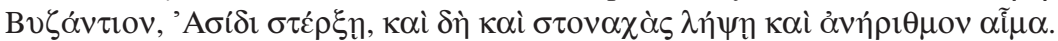

766 Contra R. Buitenwerf (éd.), Book III of the Sibylline Oracles and Its Social Setting, with an Introduction, Translation, and Commentary, Leiden-Boston 2003, p. 233, qui suggère que ce passage se rapporte aux guerres contre Mithridate, quand Byzance était l'alliée de Rome.

767 Strabon, XII, 8, 11, C 576. 
Comme l'avaient déjà suggéré J. et L. Robert, on peut rapprocher la première partie du toponyme du nom du fondateur mythique de Byzance, Byzas ${ }^{768}$. La présence d'un village portant un nom tiré de celui du héros éponyme de Byzance montre l'influence byzantine dans cette région asiatique de la Propontide orientale.

En ce qui concerne le statut des indigènes, on notera qu'une des conditions de la paix conclue entre les Byzantins et Prusias I ${ }^{\mathrm{er}}$ stipulait que le roi bithynien devait rendre aux premiers sans rançon leurs laoi et les autres prisonniers (citoyens?) ${ }^{769}$. On voit ainsi que les laoi sont différenciés des autres prisonniers, sans doute en raison de leur condition juridique. Polybe rapporte que Prusias ${ }^{\text {er }}$ obligea les Bithyniens à rendre aux «cultivateurs» ( $\gamma \varepsilon \omega \rho \gamma o i ́)$ qui se trouvaient dans le territoire asiatique de Byzance (en Mysie) ce qu'ils avaient enlevé ${ }^{770}$. Mais ce dernier récit n'autorise pas l'équivalence entre les laoi, prisonniers de Prusias, et les geôrgoi de la Mysie ${ }^{771}$. Et il n'est pas exclu que les laoi soient les habitants thraces de la chôra européenne de Byzance, qui avaient été peut-être capturés au moment du siège de la ville par Prusias et ses mercenaires thraces ${ }^{772}$. Quoi qu'il en soit, un statut servile pour les Bithyniens de la chôra byzantine est confirmé par Phylarque qui estime, à l'époque hellénistique, que les Byzantins exercent leur

768 Şahin, Nikomedia, $\mathrm{n}^{\circ} 67 ;$ TAM IV 1,72. On lit sur le côté droit de l'autel: $[\hat{\varepsilon}] \kappa \tau \tilde{\omega} \mathrm{V}$

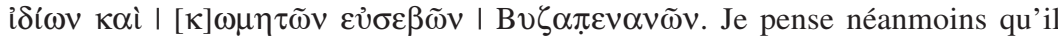

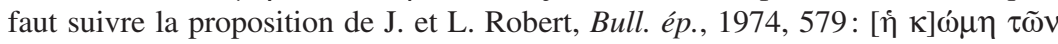

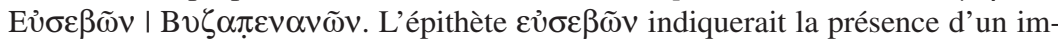
portant sanctuaire dans ce village. L'autel présente aussi trois reliefs : un de Zeus, un d'Hermès et un croissant lunaire qui serait à mettre en relation avec le culte du dieu Men. Voir également Şahin, Nikomedia, $\mathrm{n}^{\circ} 68$, pour un autel découvert dans le même village, datant de l'époque d'Hadrien et mis en relation avec Men.

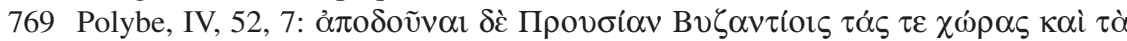

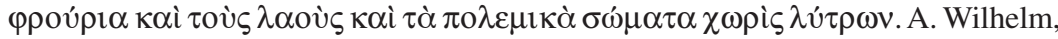
Wiener Eranos, 1909, p. 131 (non vidi), corrige ce passage, en remplaçant $\pi \mathrm{o} \lambda \varepsilon \mu 1 \kappa \alpha ́$

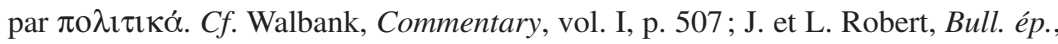
1958, 320, p. 274; L. Robert, «Reliefs votifs et cultes d'Anatolie», Anatolia 3, 1958, p. 107, n. 12 (=OpMinSel, I, p. 406, n. 12); Papazoglou, Laoi et paroikoi, p. 51, n. 108.

770 Polybe, IV, 52, 9.

771 Cette équivalence est soutenue par C. Habicht, s.v. «Prusias » 1, RE XXIII, 1, 1957, col. 1089. Contra Papazoglou, Laoi et paroikoi, p. 52.

772 Polybe, IV, 51, 8. 
pouvoir sur les Bithyniens de la même façon que les Spartiates sur les hilotes ${ }^{773}$.

Notons au passage que Xénophon atteste la présence à Byzance d'un endroit de rassemblement appelé Thrakion (voisin de l'actuelle Sainte-Sophie) $)^{774}$. D'aucuns ont proposé que ce Thrakion aurait constitué un lieu de refuge pour la population rurale lors des périodes de guerre $^{775}$.

Un domaine susceptible de révéler les composantes de la population de Byzance est l'onomastique. En l'absence des documents, on ne peut pas se prononcer sur la présence des Thraces à Byzance aux époques archaïque ou classique. En revanche, on constate la présence dans cette cité à l'époque hellénistique et romaine de plusieurs noms thraces, tels

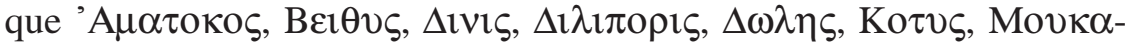

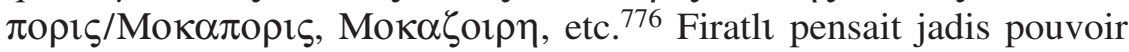
s'appuyer sur ces noms, ainsi que sur la représentation du cavalier thrace et des symboles de Bendis sur des stèles funéraires de Byzance, pour soutenir le caractère thrace de la ville ${ }^{777}$. Robert a repoussé cette opinion, en notant que: «Si intéressants que soient ces noms, leur proportion reste très faible dans l'ensemble de l'onomastique de Byzance; ce n'est pas une invasion transformant cette cité en une ville <en réalité thrace »». Mieux, le savant français a suggéré qu'une source possible

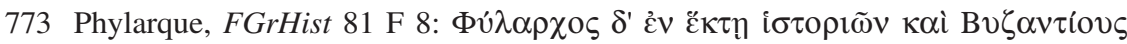

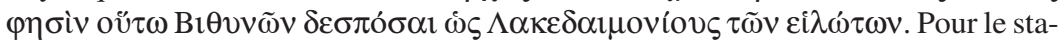
tut de ces sujets bithyniens, voir Walbank, Commentary, vol. I, p. 507; D. Lotze,

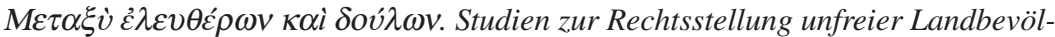
kerungen in Griechenland bis zum 4. Jahrhundert v. Chr., Berlin 1959, p. 57-58; D. M. Pippidi, «Le problème de la main-d'œuvre agricole dans les colonies grecques de la mer Noire», in Problèmes de la terre en Grèce ancienne, M. I. Finley (éd.), Paris 1973, p. 68 ; Papazoglou, Laoi et paroikoi, p. 50-52; C. Schuler, Ländliche Siedlungen und Gemeinden im hellenistischen und römischen Kleinasien, Vestigia 50, München 1998, p. 198; Avram, Divinisation de Ptolémée, p. 829, n. 9.

774 Xénophon, Helléniques, I, 3, 20; Anabase, VII, 1, 24. Cf. Janin, Constatinople ${ }^{2}$, p. 14 ; C. Emereau, «Notes sur les origines et la formation de Constantinople. Les grands centres historiques de la ville», RA 21, 1925, p. 9.

775 Loukopoulou-Lajtar, Byzantion, p. 918.

776 Sur l'onomastique thrace à Byzance, voir L. Robert, in Firatl, Stèles de Byzance, p. 133-135, 148-150, 173-174; Loukopoulou, Thrace propontique, p. 199-203; O. Masson, op. cit., p. 137-144; cf. C. Brixhe, Bull. ép., 2001, 308.

777 Firatl, Stèles de Byzance, p. 26-27, 45. 
pour cette onomastique est le domaine détenu par Byzance en Mysie, une région occupée par une population indigène d'origine thrace ${ }^{778}$.

Il faut néanmoins avouer que si la pénétration thrace peut apparâ̂tre restreinte, au vu de la documentation onomastique disponible, cela peut être finalement un argument trompeur. Il n'est pas dans mon intention d'aborder ici ce sujet, qui nécessite une enquête plus approfondie. Je me contenterai de souligner la complexité des stratégies de dénomination dans la Byzance de l'époque impériale. Car les inscriptions attestent tous les cas de figures: des porteurs de noms thraces qui donnent à leurs enfants des noms thraces ${ }^{779}$ ou grecs (que l'on avait tendance à qualifier de plus prestigieux $)^{780}$, et on a aussi des exemples de noms thraces suivis d'un patronyme grec ${ }^{781}$. Cette dernière pratique onomastique illustre peut-être un procédé de dénomination typiquement grec: on aurait pu donner à l'enfant le nom thrace du grand-père. Mais il n'est pas exclu que l'on ait là un phénomène culturel spécifique à l'époque impériale, en rapport avec le désir des Byzantins de renouer avec le passé thrace de leur ville (voir ci-dessus). On rappellera enfin qu'un nom thrace peut témoigner non seulement de l'origine thrace de son détenteur ou des membres de sa famille, mais simplement des rapports que sa famille entretenait avec les populations thraces situées aux abords de Byzance. Concernant la nature des contacts entre les Thraces et les ressortissants des cités mégariennes du Bosphore thrace, on finira par évoquer l'épitaphe d'Odessos, mentionnant à l'époque impériale le

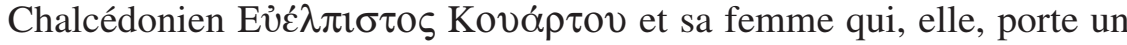
nom thrace, $\mathrm{K} \alpha \rho 1 \delta \alpha \beta \alpha^{782}$.

778 L. Robert, in Firatl, Stèles de Byzance, p. 134; suivi par Loukopoulou, Thrace propontique, p. 201-202. Selon Strabon, VII, 3, 2, C 295 ; XII, 3, 3, C 541-542; 4, 8, C 566, les Mysiens étaient des Thraces; $c f$. Hérodote, VII, 75. Sur les Mysiens, voir Debord, Mysiens, p. 135-146. Voir aussi T. Corsten, «The Role and Status of the Indigenous Population in Bithynia», in Rome and the Black Sea Region. Domination, Romanisation, Resistance, Black Sea Studies 5, T. Bekker-Nielsen (éd.), Aarhus 2006, p. 85-92, sur l'origine thrace de la population indigène de la Bithynie.

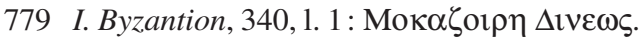

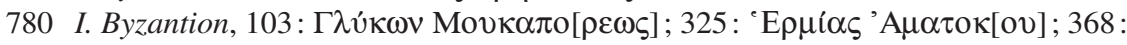

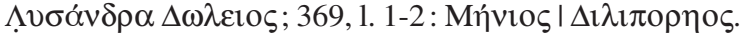

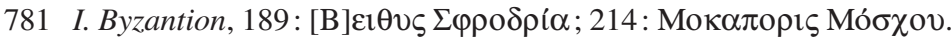

782 IGBulg $\mathrm{I}^{2}$, 172; cf. Robert, Inscr. de Bulgarie, p. 182, n. 4 (= OpMinSel, V, p. 212, n. 4). Pour l'origine thrace du nom K $\alpha \rho 1 \delta \alpha \beta \alpha$, voir Detschew, Thrak. Sprachreste ${ }^{2}$, p. 229. 


\section{II.3 Les établissements mégariens du Pont-Euxin}

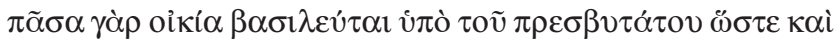

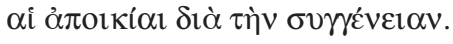

[...] toute famille, en effet, est soumise à la royauté du plus âgé, et les colonies sont dans le même cas par suite de la communauté d'origine ${ }^{783}$.

Les récits de fondation témoignent de l'hétérogénéité culturelle du mouvement de colonisation mégarien dans le Pont-Euxin: on retrouve des Béotiens à Héraclée du Pont et des Chalcédoniens et des Byzantins à Mésambria. De même que dans le cas des colonies de Sicile et de la Propontide, mon intention est de me pencher dans les chapitres suivants, d'une part, sur les rapports entre les Mégariens et les autres Grecs ayant participé à l'entreprise coloniale mégarienne et, d'autre part, sur les relations entre les Grecs et les populations locales (les Mariandyniens à Héraclée du Pont et les Thraces à Mésambria).

\section{II.3.1 Héraclée du Pont}

\section{II.3.1.1 Les récits concernant la fondation d'Héraclée du Pont}

Les relations actives entre les Mégariens et les Béotiens sont illustrées à l'époque archaïque par la fondation d'Héraclée du Pont (l'actuelle Ereğli, sur la rive méridionale de la mer Noire). D'après le Ps.-Scymnos (II ${ }^{\mathrm{e}}$ siècle), des apoikoi mégariens et béotiens fondèrent Héraclée à l'époque de la conquête de la Médie par Cyrus ${ }^{784}$. La Chronique d'Eusèbe date cet événement de 560/59785. Mais, en s'appuyant sur des chroniques orientales, les exégètes modernes placent la conquête de la Médie plutôt

783 Aristote, Politique, I, 2, 6, 1252b 20-22 (trad. de J. Aubonnet, CUF).

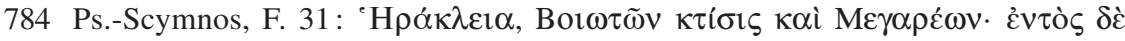

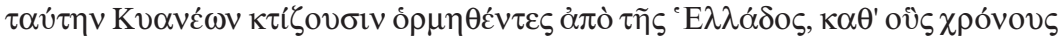

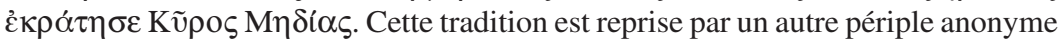
de la mer Noire, œuvre d'un compilateur byzantin: Anonymus, Periplus Ponti Euxini, 10-11 (éd. A. Diller).

785 Eusèbe, Chron., St. Jérôme: Ol. 55.1 (éd. A. Schoene, p. 95 ; = éd. R. Helm, p. 102a). 
dans la période 554/3-550/49, le plus probablement en 554 (l'opinion de Drews) ou en 550/49 (selon Frye) ${ }^{786}$.

Bien que certains auteurs (Xénophon, Diodore, Arrien) rapportent que la fondation d'Héraclée a été l'œuvre des seuls Mégariens ${ }^{787}$, on constate que la tradition de l'origine mégarienne et béotienne de la cité est bien ancrée dans les sources antiques. Cette double origine est évoquée par Éphore $^{788}$ et dans les Argonautiques d'Apollonios de Rhodes ${ }^{789}$. Pour Euphorion (III ${ }^{\mathrm{e}}$ siècle), Héraclée est une colonie des Béotiens avec un œciste mégarien, Gnésiochos ${ }^{790}$, tandis que Pausanias atteste que la cité fut installée par des Mégariens et des Tanagréens ${ }^{791}$. En revanche, la Souda indique Thèbes comme métropole d'Héraclée du Pont et mentionne comme l'un des chefs des colons un certain Damis, fondateur d'un génos auquel au IV ${ }^{\mathrm{e}}$ siècle le philosophe Héraclide le Pontique se vantait d'appartenir ${ }^{792}$. Notons au passage que le récit de la Souda serait appuyé par les noms de Thébais et de Mégaris, portés à l'époque impériale par deux tribus de Prusias de l'Hypios. Car l'on sait que Prusias de l'Hypios fut bâtie sur le site de Kiéros, ancienne colonie d'Héraclée du Pont (voir ci-après) ${ }^{793}$.

786 R. Drews, «The Fall of Astyages and Herodotus' Chronology of the Eastern Kingdoms », Historia 18, 1969, p. 1-11, surtout p. 4; R. N. Frye, The History of Ancient Iran, Munich 1984, p. 91-92.

787 Xénophon, Anabase, VI, 2, 1; Diodore de Sicile, XIV, 31, 3; Arrien, Périple du Pont-Euxin, XIII, 3.

788 Éphore, FGrHist $70 \mathrm{~F} 44$ a (apud scholie à Apollonios de Rhodes, II, 845): Ö $\tau \imath ~ \delta \dot{\varepsilon}$

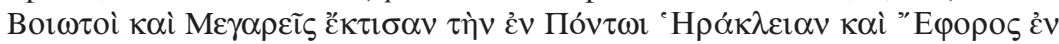

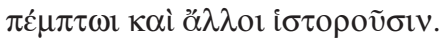

789 Apollonios de Rhodes, II, 743-749, rapporte d'abord que ce furent les Mégariens de Nisaia qui s'établirent dans le pays des Mariandyniens. Ensuite, le même auteur évoque (II, 846-850) l'oracle rendu par Apollon aux Béotiens et aux Mégariens pour que ceux-ci célèbrent l'Argonaute Idmôn comme protecteur de leur cité (voir cidessous).

790 Euphorion, fr. 177 (éd. J. U. Powel; apud scholie à Apollonios de Rhodes, II, 351 -

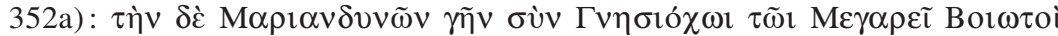

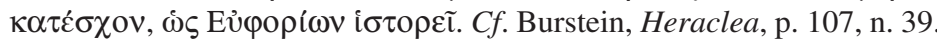

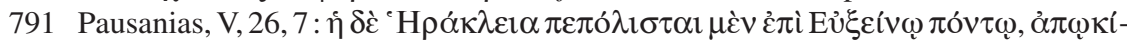

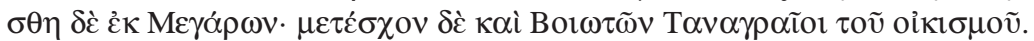

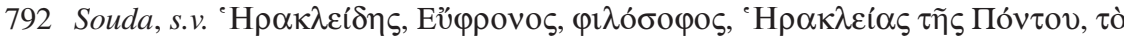

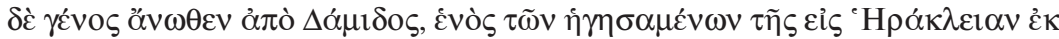

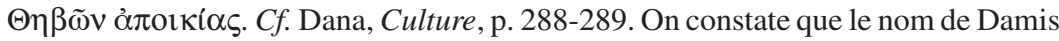
est présent en Béotie, à Tanagra et à Thespies: LGPN III B, s.v. $\Delta \widetilde{\alpha} \mu 1 \varsigma$ 1-2.

793 Sur les tribus de Prusias de l'Hypios, voir infra, chapitre III.1.1.3. 
Les modernes ont suggéré que des Béotiens originaires de Siphai avaient rejoint aussi les Mégariens en mer Noire. Preuve en serait le culte rendu par les Héracléotes à Tiphys, héros éponyme de la petite cité béotienne ${ }^{794}$. Chose intéressante, les relations des Mégariens avec cette cité sont confirmées par un décret d'Aigosthènes, qui accorde au $\mathrm{III}^{\mathrm{e}}$ siècle aux gens de Siphai la proedria et le droit de participer aux sacrifices communs à l'instar des citoyens, en vertu du «dévouement» (eunoia) et de la «concorde» (homonoia) qui existent, depuis les ancêtres (ek progonôn), entre les deux communautés ${ }^{795}$. On ne serait pas surpris si ces liens d'amitiés ancestraux dataient de l'époque de la colonisation, car la mer unissait les deux établissements du golfe Halcyonique, qui autrement n'étaient pas voisins sur terre (voire carte 2) ) $^{796}$.

Au demeurant, une tradition différente, fournie par Justin, fait d'Héraclée du Pont une colonie béotienne. On apprend ainsi que les Béotiens, décimés par la peste et la guerre, fondèrent une colonie en mer Noire en l'honneur d'Héraclès, suite à deux oracles de la Pythie.

\section{Quippe Boeotiis pestilentia laborantibus oraculum Delphis responderant coloniam in Ponti regione sacram Herculi conderent. 5. Cum, propter metum longae ac periculosae navigationis, mortem in patria omnibus praeoptantibus, res omissa esset, bellum his Phocenses intulerunt, 6. quorum cum adversa proelia paterentur, iterato ad oraculum decurrunt; responsum idem belli quod pestilentiae remedium fore. 7. Igitur, conscripta colonorummanu, in Pontum delati urbem Heracleam condiderunt, et quoniam fatorum auspiciis in eas sedes delati errant, brevi tempore magnas opes paravere.}

4. L'oracle de Delphes avait ordonné aux Béotiens désolés par la peste de fonder dans la région du Pont une colonie consacrée à Hercule. 5. Mais ils eurent peur d'une

794 U. von Willamowitz-Moellendorff, «Oropos und die Graer», Hermes 21, 1886, p. 111, n. 3 ; Burstein, Heraclea, p. 17; Asheri, Herakleia, p. 26; Fossey, Boiotia and the Pontic Cities, p. 108, 110. Apollonios de Rhodes, II, 854, atteste la présence de la tombe de Tiphys à Héraclée du Pont; $c f$. Malkin, Religion and Colonization, p. 75. Selon une autre légende transmise par Pherekydes, FGrHist 3 F 107, ce héros béotien serait originaire de Potniai. Voir Fossey, Topography, p. 167-165, sur l'emplacement et les trouvailles de Siphai.

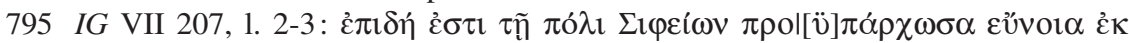

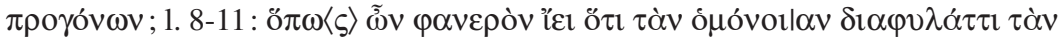

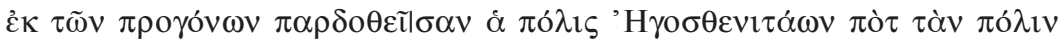
$\Sigma 1 \varphi \varepsilon l i ́ \omega v ; c f$. P. Roesch, Thespies et la confédération béotienne, Paris 1965, p. 55 ; Liddel, Megarid, p. 427.

796 Robert, Inscr. de Pagai, p. 116 (=OpMinSel, II, p. 1270). 
longue et dangereuse navigation et préférèrent tous mourir dans leur patrie; aussi ne tinrent-ils pas compte de l'oracle. Alors les Phocidiens portèrent la guerre dans leur pays 6 . et leur infligèrent plusieurs défaites. Ils recoururent de nouveau à l'oracle, qui leur répondit qu'ils remédieraient à la guerre par le même moyen qu'à la peste. 7 . En conséquence, ils enrôlèrent une troupe de colons qui, transportés dans le Pont, y fondèrent la ville d'Héraclée, et, comme ils avaient fondé cet établissement sous les auspices de l'oracle, ils acquirent une grande puissance en peu de temps ${ }^{797}$.

Il est fort probable que cette tradition, dont la source originelle est peutêtre Nymphis ${ }^{798}$, est un développement tardif, car elle contient tous les thèmes de la «propagande» delphique vis-à-vis de la colonisation: le peuple décimé par une maladie fait appel à Delphes, l'ignorance en premier lieu du terrible oracle, suivie par d'autres fléaux (la guerre contre les gens de Phocide), et finalement l'accomplissement de l'oracle du dieu par la fondation d'une colonie prospère. Ces détails rendent, à mes yeux, très suspecte la tradition rapportée par Justin ${ }^{799}$.

D'autre part, il faut ajouter qu'Apollonios nous on a conservé un autre oracle accordé par Apollon, cette fois-ci, aux Béotiens et aux Mégariens.

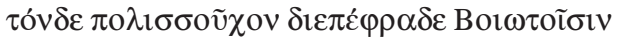

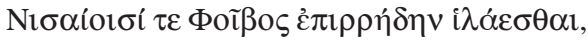

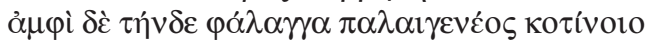

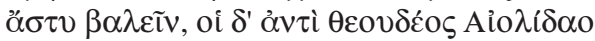

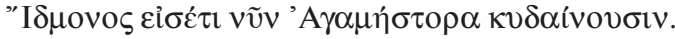

Phoibos prescrivit aux Béotiens et aux Nisaiens de donner à ce héros (Idmôn) dans leurs invocations le titre de protecteur de leur cité et, autour de cet antique rouleau d'olivier sauvage, d'établir leur ville; mais, à la place du pieux Éolide Idmôn, c'est Agamestor qu'ils vénèrent aujourd'hui encore ${ }^{800}$.

Conformément à cette légende, Apollon conseilla aux Béotiens et aux Nisaiens ${ }^{801}$ de célébrer le devin Idmôn et de fonder leur cité auprès de

797 Justin, XVI, 3, 4-8 (trad. d'E. Chambry et L. Thély-Chambry).

798 Desideri, Storiografia eracleota, p. 391, n. 123.

$799 C f$. A. Schachter, «Boiotia in the Sixth Century B.C.», in Boiotika. Vorträge vom 5. internationalen Böotien-Kolloquim (Institut für alte Geschichte LudwigMaximilians-Universität München, 13.-17. Juni 1986), H. Beister et J. Buckler (éds.), München 1989, p. 82.

800 Apollonios de Rhodes, II, 846-850 (trad. d'É. Delage, CUF).

801 L'ethnique Nisaioi vient de Nisos, le héros éponyme du port de Mégare: Pausanias, I, 39, 4; voir supra, chapitre I.2.2. 
l'olivier sauvage, dont Apollonios (II, 842-844), juste avant, rapportait qu'il poussait sur la tombe du héros argonaute. Grâce à Hérodoros, on sait que cette tombe se trouvait sur l'agora de la ville ${ }^{802}$, une localisation qui rappelle l'habitude des Mégariens de Grèce d'ensevelir leurs héros à l'intérieur des remparts de la cité ${ }^{803}$. À l'image des Mégariens, qui ensevelirent intra muros les soldats tombés dans la seconde guerre médique $^{804}$, les Héracléotes firent élever un tombeau à l'intérieur de l'espace civique pour leurs concitoyens morts en 280/79, lors de la guerre contre les Bithyniens de Zypoitès ${ }^{805}$. On relèvera aussi un autre parallèle avec la métropole: un olivier sacré était vénéré sur l'agora de Mégare, et un oracle aurait prédit la conquête de la cité lorsque l'arbre auraitété abattu ${ }^{806}$.

Quant au rapport entre Idmôn et Agamestor, le récit de Promathidas d'Héraclée vient à l'appui de la tradition d'Apollonios, selon laquelle on aurait affaire à un seul héros, adoré sous deux noms différents. Car, rapporte ce chroniqueur local, les Héracléotes, méconnaissant l'identité de ce héros (à savoir Idmôn), lui donnèrent le nom d'Agamestor ${ }^{807}$. Il résulte de ces récits qu'Agamestor fut l'un des héros fondateurs de la colonie, et l'on peut penser que les mythographes locaux lui substituèrent Idmôn, en raison de la qualité d'Argonaute de ce dernier ${ }^{808}$. De fait, la tombe d'Idmôn/Agamestor, tout comme celle d'un autre Argonaute, le héros béotien Tiphys, et de l'ami d'Héraclès, Sthénélos, offrait aux Héracléotes la possibilité de justifier leur droit sur les terres prises aux Mariandyniens et de montrer leur lignée prestigieuse ${ }^{809}$.

802 Hérodoros, FGrHist 31 F 51 (apud scholie à Apollonios de Rhodes, II, 848).

803 Voir supra, chapitres I.1.4. et II.1.2.6.

804 Pausanias, I, 43, 3. Voir aussi l'épigramme $I G$ VII 53, qui a été regravée à la fin de l'Antiquité sur le tombeau des héros de la seconde guerre médique et que l'on attribuait à Simonide.

805 Memnon, FGrHist 434 F 9, 5 ; cf. T. Boulay, op. cit., p. 214.

806 Théophraste, Recherches sur les plantes, V, 2, 4; Pline, NH, XVI, 76, 199; cf. Antonetti, Megara e le sue colonie, p. 91.

807 Promathidas d'Héraclée, FGrHist 430 F 3 (apud scholie à Apollonios de Rhodes, II,

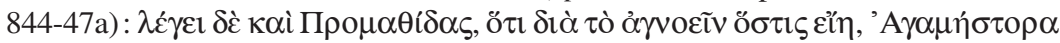

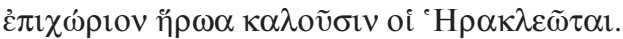

808 F. Jacoby, FGrHist III B, p. 257; F. Vian, «Notice», in Apollonios de Rhodes, Argonautiques, Tome I, Chants I-II, Paris 1976, p. 162 et n. 1; Malkin, Religion and Colonization, p. 75-76; idem, Networks, p. 54; Ehrhardt, Ktistai, p. 36-40.

809 Asheri, Herakleia, p. 25-26. La tombe de Sthénélos est évoquée par Apollonios de Rhodes, II, 911. 
Bref, je ne crois pas que l'on ait tort de considérer les deux oracles relatifs à la fondation d'Héraclée du Pont comme le fruit d'élaborations tardives, dont le but est de relier la colonie pontique à Delphes, une autorité reconnue en matière de colonisation, ainsi qu'à la saga des Argonautes ${ }^{810}$. Sans pouvoir établir la place de l'oracle d'Apollon dans la fondation de la colonie mégaro-béotienne, on notera que les Héracléotes firent appel à Delphes pour l'envoi de leurs propres apoikiai. Le Ps.-

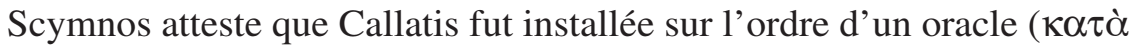
$\chi \rho \eta \sigma \mu o ́ v)^{811}$ et cette tradition est appuyée par une série de réponses oraculaires transcrites aux $\mathrm{IV}^{\mathrm{e}}$ et II ${ }^{\mathrm{e}}$ siècles sur plusieurs pierres à Callatis ${ }^{812}$. Le Ps.-Scymnos rapporte également qu'un oracle conseilla aux Héracléotes et aux Déliens de fonder la cité de Chersonèse en Tauride ${ }^{813}$. À en croire Pline, le premier nom de cette colonie aurait été Mégarice, appellation qui rappelle l'origine mégarienne des fondateurs d'Héraclée du Pont ${ }^{814}$. Signalons aussi que Chersonèse est nommé à l'époque impériale dans une inscription comme la ville du héros Dôros, l'éponyme des

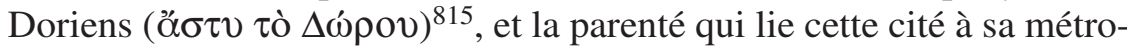
pole est évoquée à la même époque par les documents épigraphiques ${ }^{816}$.

810 Contra Malkin, Religion and Colonization, p. 75, qui plaide pour l'authenticité des deux oracles. Pour la fabrication d'oracle voir l'exemple des propos de Mégabaze vis-à-vis des fondateurs de Chalcédoine, ultérieurement attribués à la Pythie (voir supra, chapitre II.2.2.2).

811 Ps.-Scymnos, F 4; cf. Hanell, Megarische Studien, p. 170-171.

812 ISM III, 48-50; $c f$. A. Avram, F. Lefèvre, «Les cultes de Callatis et l'oracle de Delphes », REG 108, 1995, p. 7-23.

813 Ps.-Scymnos, F 12.

814 Pline, NH, IV, 12, 85 ; cf. S. J. Saprykin, «Megarice-Heracleia-Chersonesus: Three Names of a Greek City-State in South-Western Taurica», OTerr 1, 1995, p. 25-38. Le nom des Mégariens apparaîtrait dans une inscription fragmentaire de Chersonèse

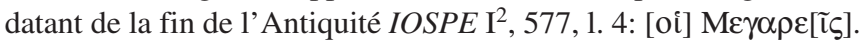

815 IOSPE $\mathrm{I}^{2}, 436$; $c f$. Robert, Hellenica, XIII, p. 131. De plus, une épitaphe du II $^{\mathrm{e}}$ siècle ap. J.-C. qualifie une autre fondation héracléote de la côte sud du Pont-Euxin de « ville de Dôros » : Peek, Gr. Vers-Inschriften, $\mathrm{n}^{\circ} 788$; L. Robert, « Griechische VersInschriften hrsg. von Peek. 1. Grabepigramme», Gnomon 31, 1959, p. 21-22, n. 4. Robert, À travers l'Asie-Mineure, p. 413-414, propose d'identifier la « ville de Dôros » avec Kytoros, une localité qui, selon Strabon, XII, 3, 10, C 544, participa au synœcisme d'Amastris.

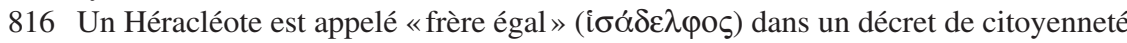
octroyé par Chersonèse: IOSPE $\mathrm{I}^{2}, 359$. Dans d'autres inscriptions émanant de la même cité, les rapports entre les deux peuples sont considérés comme ceux qui 
Malgré la tradition fournie par Justin, il n'y a pas de raison de penser que l'installation d'Héraclée du Pont ne fut pas l'exploit commun des Mégariens et des Béotiens. En effet, la collaboration des deux peuples dans la colonisation, attestée par plusieurs récits, est certaine. Dans ce sens, bien que les institutions d'Héraclée du Pont aient gardé le caractère mégarien ${ }^{817}$, les fondateurs ont préféré consacrer leur cité à Héraclès, une divinité peu vénérée en Mégaride, mais bien présente en Béotie $^{818}$. Héraclès figure sur les premières monnaies frappées par la cité de la mer Noire à la fin du $\mathrm{V}^{\mathrm{e}}$ siècle ${ }^{819}$ et il porte le titre de ktistès sur des monnaies de l'époque impériale ${ }^{820}$. On sait aussi que les sujets choisis par les Héracléotes pour décorer leurs offrandes à Olympie furent quatre des travaux d'Héraclès (les épisodes du lion de Némée, de l'Hydre, de Cerbère, du sanglier d'Érymanthe) ${ }^{821}$. Mieux, les récits témoignent de l'existence au nord d'Héraclée du Pont, sur le Cap Achéron, de la «grotte d'Hadès», qui, pour une tradition locale, n'est autre que l'endroit où Héraclès serait descendu aux Enfers pour chercher le chien Cerbère $^{822}$. C'est à cette légende que se rattache le culte d'Héraclès

existent entre un fils (viós pour Chersonèse) et un père ( $\pi \alpha ́ \tau \eta \rho$ pour Héraclée): IOSPE $\mathrm{I}^{2}, 357,362 ; c f$. M. Dana, D. Dana, «Histoires locales dans le Pont-Euxin Ouest et Nord. Identité grecque et construction du passé », Il Mar Nero 5, 2001-2003 (2006), p. 104; I. Makarov, «La <Première Eleutheria 〉 de Chersonèse Taurique dans les sources épigraphiques», VDI 2005, 2, p. 82-93 (en russe). On retrouve dans tous ces titres la «passion» du passé et l'éloge de l'origine illustre qui caractérise à l'époque impériale les Grecs de la mer Noire et que Robert, À travers l'Asie-Mineure, p. 412, avait bien relevés.

817 Voir infra, chapitres III.1.1.3, III.1.2.3, III.2.1.1, III.2.2.5.

818 L.R. Farnell, Greek Hero Cults and Ideas of Immortality, Oxford 1921, p. 132; Highbarger, Megara, p. 65, n. 246; Burstein, Heraclea, p. 17; Ehrhardt, Ktistai, p. 37, 40-41. Pour le culte d'Héraclès dans les cités de la Béotie, voir A. Schachter, Cults of Boiotia, 2. Herakles to Poseidon, BICS, Suppl. 38.2, London 1986, p. 1-37. Sur la célébration d'Héraclès par les Mégariens, voir supra, chapitre II.2.4.1.4.

819 Waddington-Babelon-Reinach, Recueil, I, 2, p. 345, n ${ }^{\text {os }} 1-4$; SNG Cop. BosporusBithynia, pl. 10, nos 405-411; SNG 9, pl. LVII, no ${ }^{\text {os }} 1566-1572$; SNG 11, pl. XXXVI, $\mathrm{n}^{\mathrm{o}} 808$.

820 Waddington-Babelon-Reinach, Recueil, I, 2, p. 356, nos $69-70$, p. 357, no 74.

821 Pausanias, V, 26, 7.

822 Xénophon, Anabase, VI, 2, 2 ; Apollonios de Rhodes, II, 353-356, 728-736; Scholie à Apollonios de Rhodes, II, 353-56; Diodore, XIV, 31, 3. 
$\Phi \alpha \rho \alpha \gamma \gamma \varepsilon i ́ \tau \eta \varsigma$ (de $\varphi \alpha ́ \rho \alpha \gamma \xi$, le «ravin») attesté par l'inscription de Callatis ISM III, 72, émanant d'une association d'Héracléotes ${ }^{823}$.

Tout comme à Héraclée du Pont, Héraclès apparaît avec le titre de ktistès sur les monnaies frappées à l'époque impériale par Callatis ${ }^{824}$ et par Prusias de l'Hypios, cité qui prit la place de Kiéros ${ }^{825}$. Pareillement, le culte d'Héraclès fut transmis à Chersonèse Taurique ${ }^{826}$. De même, il n'est pas exclu que le culte d'Héra, dont témoignent les monnaies d'Héraclée du Pont et de Callatis, se rattache aux groupes de colons d'origine béotienne. En effet ce culte est attesté à plusieurs reprises en Béotie, mais il n'est pas répertorié à Mégare ${ }^{827}$.

La présence des traditions béotiennes dans les colonies héracléotes est confirmée aussi dans le cas de Panélos, un site non localisé, mais que Stéphane de Byzance qualifie de polis, en précisant que son héros

823 E. Chirica, «Le culte d'Héraclès Pharangeitès à Héraclée du Pont», REG 111, 1998, p. 722-731; cf. J. et L. Robert, Bull. ép., 1964, 290. Pour le culte d'Héraclès à Callatis, voir A. Avram, in ISM III, p. 95, 382-383 ; Chiekova, Cultes, p. 227-229; G. Talmaţchi, The Coinage of the West-Pontic Cities of Histria, Callatis and Tomis during the Autonomous Era. Iconography, Legend, Metrology, Chronology and Countermarking, Cluj-Napoca 2011, p. 345-347 (en roumain).

824 Pick, Münzen von Dacien und Moesien, p. 84, 111, $\mathrm{n}^{\text {os }} 290-296$.

825 Waddington-Babelon-Reinach, Recueil, I, 4, p. 604, no 8; cf. Magie, Roman Rule, vol. II, p. 1190, n. 21.

826 S. J. Saprykin, «Le culte d'Héraclès à Chersonèse et à Héraclée à l'époque de l'hellénisme», SovArch 1, 1978, p. 38-52 (en russe); A. Wasowicz, «Les lieux de culte des cités pontiques », in Religione e città nel mondo antico. Atti, Centro di ricerche e documentazione sull'antichità classica 11, 1980-1981, Roma 1984,p. 207-208;V.F. Stolba, «Une nouvelle dédicace de la Crimée du Nord-Ouest et les aspects du culte d'Héraclès à Chersonèse », VDI, 1989, 4, p. 55-70 (en russe); E. A. Popova, S. A. Kovalenko, «On the Cult of Herakles in the North-Western Crimea: Recent Finds from the Chaika Settlement», in New Studies on the Black Sea Littoral, Colloquia Pontica 1, G. R. Tsetskhladze (éd.), Oxford 1996, p. 63-71; iidem, «ANew Relief with Heracles in the North-Western Crimea», Talanta 32-33, 2000-2001 (2002), p. 103-108.

827 La déesse Héra figure sur les monnaies d'Héraclée du Pont du IV siècle: SNG Cop. Bosporus-Bithynia, pl. 10, $\mathrm{n}^{\text {os }} 412-418$; SNG 9, pl. LVIII, $\mathrm{n}^{\text {os }} 1588-1592,1603$; SNG 11, pl. XXXVI, n ${ }^{\text {os }}$ 815-816 (contra Waddington-Babelon-Reinach, Recueil, I, 2, p. 347-349, $n^{\text {os }} 16-28$, qui estiment que la tête de femme qui apparaît sur ces monnaies appartient à la Tychè de la ville), et de Callatis (à l'époque impériale): Pick, Münzen von Dacien und Moesien, p. 316, $\mathrm{n}^{\circ}$ 316. Pour le culte d'Héra en Béotie, on renverra à A. Schachter, Cults of Boiotia, 1. Acheloos to Hera, BICS, Suppl. 38.1, London 1981, p. 238-251; E. Simon, «Héra en Béotie et en Thessalie», in Héra. Images, espaces, cultes. Actes du colloque international (Lille, 29-30 novembre 1993), J. de la Genière (éd.), Naples 1997, p. 83-86. 
éponyme fut un Héracléote qui descendait d'un chef béotien participant à la guerre de Troie ${ }^{828}$. Du reste, Asheri remarque que l'hydronyme Kôralios et l'oronyme Orminion de Bithynie portent les noms d'un fleuve béotien (situé près du sanctuaire d'Athéna Itônia de Coronée) et d'une localité thessalienne (Orminion, ville qui apparaît dans le catalogue des vaisseaux de l'Iliade et qui, plus tard, est attestée comme komè dans le territoire de Démétrias). D'après Asheri, les données béotiennes et thessaliennes sont aussi mises en évidence par les noms des sites pontiques de Kiéros, Thibais, Orchomène (les deux derniers non localisés), Krénides (entre Héraclée et Tiéion), qui renvoient à des localités homonymes situées en Thessalie (Kiérion) et en Béotie (Thèbes, Orchomène) et, dans le cas de Krénides, à l'une des sept portes de Thèbes $(\mathrm{K} \rho \eta v \alpha \tilde{\imath} \alpha \imath \pi \dot{\imath} \lambda \alpha \mathrm{l})^{829}$. En revanche, on trouve une réminiscence mégarienne dans le nom de la localité Gérania, située par Pline aux environs de Callatis, et à laquelle correspond la montagne Géraneia de la Mégaride $^{830}$. Cette ancienne appellation mégarienne fut sans doute introduite dans la colonie du Pont-Gauche par le biais d'Héraclée ${ }^{831}$.

La collaboration des Mégariens et des Béotiens dans la colonisation est peut-être illustrée par l'aménagement à Delphes des Trésors des deux peuples l'un à côté de l'autre ${ }^{832}$. Dans ce cadre, on notera que

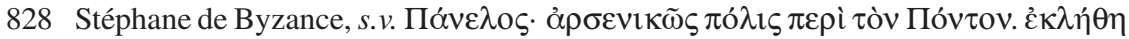

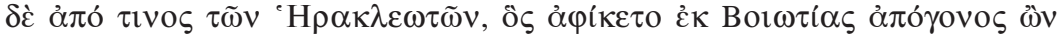

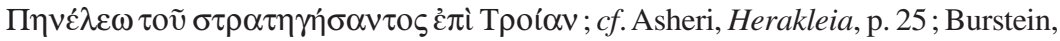
Heraclea, p. 25.

829 Asheri, Herakleia, p. 14-15, 26 (avec les testimonia). Voir infra, chapitre III.1.2.6, pour l'éventuelle origine béotienne de Kallichoros, héros éponyme d'un fleuve situé à l'est d'Héraclée du Pont.

830 Pline, $N H, \mathrm{IV}, 18,44$.

831 I. von Bredow, «Karer im Pontos?», in Alte Geschichte: Wege-Einsichten-Horizonte, Festschrift für E. Olshausen, Hildesheim 1998, p. 4-5; A. Avram, in ISM III, p. 15-16, note aussi que les noms des trois autres localités du territoire callatien, soit Nymphaion, Parthénopolis et Héracléa, renvoient à un héritage héracléote. Car l'on connaît dans le territoire d'Héraclée du Pont des sites portant le nom de Nymphaion et de Parthénopolis.

832 E. C. Partida, The Treasuries at Delphi : an Architectural Study, Jonsered 2000, p. 185 191,195 , suggère que «the Archaic Megarian treasury near the Boeotian one symbolized a state/political consortium for the colonization of Herakleia in Pontus » (p. 191). Sur le trésor dédié à Delphes par les Mégariens à la fin du $\mathrm{VI}^{\mathrm{e}}$ ou au début du $\mathrm{V}^{\mathrm{e}}$ siècle, voir aussi F. Bommelaer, Guide de Delphes. Le site, Athènes-Paris 1991, p. 126-127; A. Jacquemin, Offrandes monumentales à Delphes, Athènes-Paris 1999, p. 54. 
la décision des Delphiens de graver un décret de proxénie pour deux Callatiens (FD III 1, 158) sur le socle du Trésor de Mégare fut peut-être prise en tenant compte de la syngéneia («parenté») qui liait Callatis à Mégare $^{833}$.

Au demeurant, Strabon fournit une tradition de fondation différente: selon cet auteur, ce seraient des apoikoi originaires de Milet qui fondèrent Héraclée du Pont ${ }^{834}$. En suivant probablement Théopompe ${ }^{835}$, cet auteur évoque aussi l'accord conclu entre les Milésiens, en tant que premiers fondateurs, et les Mariandyniens.

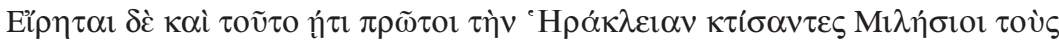

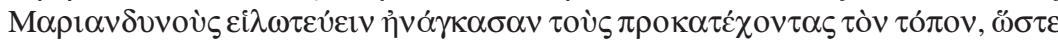

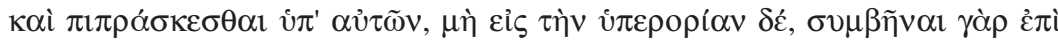

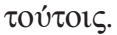

On a dit aussi que les Milésiens, comme premiers fondateurs d'Héraclée, contraignirent les Mariandyniens habitant ce lieu avant eux à les servir comme des hilotes et qu'ils allèrent jusqu'à les vendre comme esclaves, mais à l'intérieur de leurs frontières seulement, en vertu d'une convention sur ce point ${ }^{836}$.

Burstein pense qu'il n'existe pas d'indices qui pourraient appuyer cette légende et que la source de Strabon a attribué la fondation d'Héraclée du Pont aux Milésiens à cause de la célébrité de Milet en tant que métropole ${ }^{837}$. Faute d'autres indices, je crois qu'il est prudent de suivre cette interprétation. La tradition d'un accord des Grecs avec les indigènes est d'ailleurs, elle aussi, suspecte. On la trouve aussi chez Posidonios, et là sans aucune mention des Milésiens, mais uniquement des Héracléotes ${ }^{838}$. D'autre part, il y a lieu de se demander si le récit de la fondation fournie par Strabon n'est pas une réminiscence de la concurrence dans la colonisation entre les Milésiens et les Mégariens, dont une inscription semble, on l'a vu, garder la trace ${ }^{839}$. Ainsi, en lançant

833 A. Avram, F. Lefèvre, op. cit., p. 16.

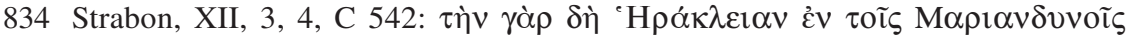

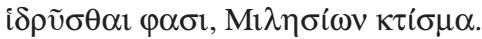

835 F. Jacoby, FGrHist II D, p. 400; Asheri, Herakleia, p. 12.

836 Strabon, XII, 3, 4, C 542 (trad. de F. Lasserre, CUF).

837 Burstein, Heraclea, p. 13-15; A. Avram, J. Hind, G., Tsetskhladze, s.v. «Herakleia», in Hansen-Nielsen (éds.), Inventory, p. 956; contra Asheri, Herakleia, p. 12-17; Vinogradov, Milet und Megara, p. 465-473.

838 Posidonios, FGrHist 87 F 8. Voir infra, chapitre II.3.1.2.

839 Voir supra, chapitre II.2.4.1.3. 
l'opinion selon laquelle la cité d'Héraclée avait été originellement une installation de Milet, la source de Strabon ne faisait que contester le droit de terre des Mégariens et des Béotiens en mer Noire.

En somme, on constate que, tout comme dans le cas du départ vers la Sicile et vers la Propontide, les Mégariens firent appel aux ressortissants d'autres cités pour la fondation d'Héraclée du Pont. Le fait que la colonie pontique ait été fondée à une époque plus récente et mieux documentée (milieu du VI ${ }^{\mathrm{e}}$ siècle), et qu'elle ait été aussi le lieu d'origine d'un nombre important de philosophes et d'historiens explique pourquoi l'on possède plus d'informations sur l'origine exacte des fondateurs de la cité. Les sources textuelles évoquent des colons de Mégare, de Tanagra, de Thèbes. Mais des colons d'autres établissements de la Béotie, comme Siphai, auraient également participé à cette entreprise. Il est bien possible que plusieurs groupes de colons soient venus ultérieurement à Héraclée du Pont, en tant que colons additionnels (époikoi). Suivant Avram, les conflits internes que la cité connaît à l'époque archaïque, évoqués par Aristote d'une manière anachronique comme des luttes entre des «oligarques» et des «démocrates», seraient le reflet des luttes entre différents groupes de colons - des apoikoi ou des époikoi - pour le partage des terres ${ }^{840}$.

On connaît également les noms de quelques chefs des colons, l'œciste Gnésiochos de Mégare, Damis de Thèbes, le Béotien Panélos. De même qu'à Byzance ${ }^{841}$, ces chefs deviendront à Héraclée du Pont des ancêtres héroïsés des familles ou des groupes pseudo-familiaux de type génos ou patria (voir ci-dessus le cas de Damis considéré comme fondateur d'un génos). Au surplus, les Héracléotes célébraient aussi le héros argonaute Idmôn/Agamestor, que le dieu de Delphes aurait choisi en tant que «protecteur» $(\pi 01 \sigma \sigma o \tilde{v} \chi 0 \varsigma)$ de la cité, et surtout Héraclès, l'éponyme mythique.

840 Avram, Cités gr., p. 299; idem, Héraclée et ses colonies, p. 220-221. On rappelle que d'après Aristote, Politique, V, 5, 3-4, 1304b 31-39, la «démocratie» fut renversée à Héraclée du Pont aussitôt après la fondation - et d'une manière identique à Mégare - par les exilés du régime «démocratique». Sur ce passage, voir supra, chapitre I.3.1. Justin, XVI, 3, 8, témoigne aussi des conflits externes et internes auxquels était confrontée la cité d'Héraclée du Pont. Pour les époikoi qui provoquent la stasis dans une colonie, voir supra, chapitre II.2.4.1.7.

841 Voir supra, chapitre II.2.4.1.8. 
Quant aux causes de la fondation d'Héraclée du Pont par les Mégariens, il convient d'évoquer en premier lieu les luttes internes qui entraînèrent d'importants bouleversements politiques dans la cité de l'isthme ${ }^{842}$. En second lieu, il n'est pas exclu que les défaites des Mégariens dans les guerres contre les Athéniens aient eu comme résultat le départ d'apoikoi mégariens pour la mer Noire ${ }^{843}$. Pour Justin (XVI, 3, 5-6), les raisons de l'installation d'Héraclée du Pont par les Béotiens furent la peste et les défaites dans la guerre contre les gens de Phocide. Mais comme il a été suggéré plus haut, cet auteur ne fait en réalité que transposer dans son récit la structure classique du mythe d'une fondation selon laquelle le recours à la colonisation, prédit par le dieu de Delphes, doit être préfiguré par des calamités naturelles et/ou des guerres. Parmi les causes de la participation des Béotiens au mouvement de colonisation mégarien, il y avait peut-être les problèmes économiques et sociaux posés par l'accumulation et la distribution des terres et des privilèges à l'intérieur d'un nombre limité de familles ${ }^{844}$. De même, on peut penser, mais sans pouvoir le prouver, que la richesse des gisements de minerais qui se trouvaient dans le territoire des Mariandyniens et dont les documents littéraires et archéologiques ont confirmé la trace, avait également attiré les Grecs ${ }^{845}$.

Quelles que soient les raisons de l'installation des premiers apoikoi mégariens et béotiens, on retiendra que la cité fut établie dans une région fertile, mais qui n'est réellement dominée qu'au prix de plusieurs guerres avec les indigènes (voir ci-après). De plus, les Héracléotes se sont révélés des commerçants redoutables et leur expansion est mise en

842 Voir supra, chapitre I.3.2.

843 Burstein, Heraclea, p. 14; Hind, Megarian Colonization, p. 134. Voir supra, chapitre I.2.3.

844 Voir R. J. Buck, A History of Boeotia, Edmonton 1979, p. 91-101, sur la question de la possession des lots de terre et des rapports entre les différentes communautés de la Béotie à l'époque archaïque.

845 Apollonios de Rhodes, II, 141, rapporte que les Bébryces et les Mariandyniens «combattaient sans cesse pour un territoire riche en fer». On note qu'une exploitation ancienne des gisements de minerai de fer a été découverte dans la région située à l'est du fleuve Sangarios, dans le massif du Çamdağ: Robert, À travers l'Asie Mineure, p. 5-10; B. Sergent, «Les premiers Celtes d'Anatolie», REA 90, 3-4, 1988, p. 342. Cf. Fossey, Boiotia and the Pontic Cities, p. 113, qui pense que la recherche des métaux constituait la cause du départ des Béotiens vers la Propontide et le PontEuxin. 
évidence aussi par la fondation de plusieurs établissements en mer Noire $^{846}$. Ils installèrent Callatis sur la côte ouest (dans la deuxième moitié du VI ${ }^{\mathrm{e}}$ siècle ou au début du $\mathrm{IV}^{\mathrm{e}}$ siècle ${ }^{847}$, aujourd'hui Mangalia), Chersonèse sur la côte nord (dans la première moitié du $\mathrm{V}^{\mathrm{e}}$ siècle ${ }^{848}$, près de l'actuelle Sébastopol) et Kiéros, vers l'intérieur de l'Asie Mineure $^{849}$. Les récits font aussi de Panélos (voir ci-dessus) et de l'île de Thynias (appelée aussi Apollonia, l'actuelle île de Kefken) des installations héracléotes ${ }^{850}$.

846 Sur l'activité commerciale des Héracléotes, voir Burstein, Heraclea, p. 12-13; Bittner, Herakleia, p. 125-145.

847 La date de fondation de Callatis, transmise par le Ps.-Scymos (F. 4: à l'époque où «Amyntas prit le pouvoir en Macédoine»), n’est pas très précise, car trois rois macédoniens portaient ce nom, notamment Amyntas ${ }^{\text {er }}$ et Amyntas III (le père de Philippe II). Les plus anciennes découvertes de Callatis remontent au $\mathrm{IV}^{\mathrm{e}}$ siècle: Avram, in ISM, p. 9-11 (avec les références antérieures).

848 Ps.-Scymnos, F 12. Bien que la date de la fondation de la cité traditionnellement admise par les modernes soit de 422/1, l'année où les Déliens furent expulsés par les Athéniens de l'île et allèrent s'installer sur la côte nord-ouest de l'Asie Mineure, à Adramyttion (H. Schneiderwirth, Das pontische Heraklea, Heiligenstadt 1882, p. 15 ; Burstein, Heraclea, p. 34-35, p. 119, n. 109), les découvertes archéologiques suggèrent l'existence d'un établissement grec à Chersonèse déjà dans la première moitié du V $\mathrm{V}^{\mathrm{e}}$ siècle: R. V. Stoyanov, «Quelques notes sur l'époque et les causes de la fondation de Chersonèse Taurique», VDI, 2007, 2, p. 125-144 (en russe, avec la bibliographie). Sur la fondation de Chersonèse, voir aussi A. A. Zedgenidze, «La date de fondation de Chersonèse Taurique», KSIA 159, 1979, p. 26-34 (en russe); Saprykin, Heracleia and Chersonesus, p. 57-87; idem, «The Foundation of Tauric Chersonesus », in The Greek Colonisation of the Black Sea Area, Historia Einzelschriften 121, G. Tsetskhladze (éd.), Stuttgart 1998, p. 227-248; M. I. Zolotarev, «Sur la chronologie de Chersonèse à l'époque archaïque», in Sur les traces des Argonautes. Actes du 6e symposium de Vani (Colchide), 22-29 septembre 1990, O. Lordkipanidzé et P. Lévêque (éds.), Paris 1996, p. 311-317.

849 Sur la colonie héracléote de Kiéros, devenue Prusias de l'Hypios après la conquête par le roi bityhinien Prusias ${ }^{\mathrm{er}}$, voir Magie, Roman Rule, vol. I, p. 307, vol. II, p. 1190, n. 21; F. K. Dörner, s.v. «Prusias ad Hypium» 5, RE XXIII, 1, 1957, col. 1128-1148; Robert, À travers l'Asie-Mineure, p. 61-62; Ameling, I. Prusias ad Hyp., p. 1-4 ; P. Debord, REA 100, 1-2, 1998, p. 143, 146; H.-L. Fernoux, Pallas 51, 1999 , p. 187. Concernant les combats entre Héraclée du Pont et les Bithyniens pour le contrôle de Kiéros, voir aussi Vitucci, Regno di Bitinia, p. 22-23.

850 Ps.-Scymnos, F 34; cf. Asheri, Herakleia, p. 14, 34; F. K. Dörner, W. Hoepfner, «Das Einland Thynias-Apollonia», MDAI(I) 39, 1989, p. 103-106. 
À l'image des Mégariens de Grèce, les Héracléotes firent, à leur tour, appel à des synoikoi - des Ioniens ${ }^{851}$, des Déliens ou des ressortissants du polichnion béotien de Délion ${ }^{852}$ - pour la fondation de Chersonèse Taurique. Ultérieurement, ils rappellent à l'époque impériale leur glorieux passé, en désignant fièrement leur ville sur une émission monétaire comme «la métropole de nombreuses colonies ${ }^{853}$.

\section{II.3.1.2 Les rapports entre les Héracléotes et les Mariandyniens}

Les Mariandyniens, la population barbare située dans le territoire d'Héraclée du Pont, avaient une origine controversée dans l'Antiquité. Strabon les place dans la liste des peuples d'origine thrace, tandis que des scholies à Apollonios de Rhodes considèrent qu'ils s'apparentaient aux Cimmériens. En revanche, en avançant plusieurs parallèles mytholo-

851 Étant donné que l'on trouve dans les premières inscriptions de Chersonèse (les ostraka, voir supra, chapitre I.3.2) des noms à la fois d'origine dorienne et ionienne, Vinogradov et Zolotarev estiment que des colons ioniens se trouvaient déjà à Héraclée du Pont (voir ci-dessus la tradition de la fondation milésienne d'Héraclée) et que ceuxci avaient ensuite participé avec les Mégariens, les Béotiens et les Déliens à la fondation de Chersonèse: Vinogradov-Zolotarev, Ostracismo, p. 111-131, surtout p. 130; Vinogradov, Milet und Megara, p. 465-467; cf. L. Dubois, Bull. ép., 1991, 420; 2000, 487; A. Avram, Bull. ép., 2008, 409. Une autre solution serait que des colons milésiens de la mer Noire (de Sinope ?) se soient adjoints aux Héracléotes pour la fondation de Chersonèse: Vinogradov-Zolotarev, Chersonèse, p. 409, suivi par Avram, Héraclée et ses colonies, p. 215-216. Voir aussi supra, chapitre II.2.4.1.3.

852 Hind, Megarian Colonization, p. 145, suggère que dans le texte du Ps.-Scymnos (F 12, mentionnant la fondation de Chersonèse par les Héracléotes et les Déliens), il y aurait une confusion entre les ressortissants de Délos ( $\Delta \eta \dot{\lambda} \lambda \mathrm{lol})$ et ceux de $\Delta \eta \dot{\lambda} \lambda$ เov, un polichnion situé dans le territoire de Tanagra. Sur le Délion béotien, voir Fossey, Topography, p. 62-65.

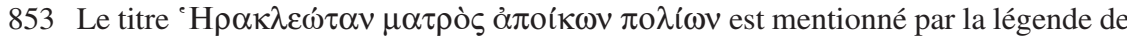
plusieurs monnaies frappées par Héraclée: Waddington-Babelon-Reinach, Recueil, I, 2, p. 345, 357-358, n $^{\text {os }} 72,76-78$, qui estiment aussi que sur le revers d'une de ces monnaies (le $\mathrm{n}^{\mathrm{O}} 72$ ), les trois petits personnages représentés debout devant Zeus (ou le Démos) seraient soit les Charites, soit, plus probablement, trois colonies héracléotes. La dernière identification, qui fut acceptée aussi par Robert, À travers l'Asie Mineure, p. 6, n. 3, reste difficile à suivre, en raison, d'une part, de l'absence de parallèles, et, d'autre part, du fait qu'il a existé plus de trois établissements héracléotes (voir ci-dessus). 
giques et onomastiques, Sergent n'hésite pas à les introduire dans la liste des peuples celtes d'Anatolie ${ }^{854}$.

Contrairement à la question de l'origine des Mariandyniens, les récits s'accordent sur leur statut servile et les comparent aux hilotes de Sparte, aux pénestes de Thessalie, à la population dépendante de Crète et de Syracuse ${ }^{855}$. Ils sont aussi désignés comme des «porteurs de dons » $(\delta \omega \rho о \varphi o ́ \rho 01)^{856}$. Aristote les inclut dans la catégorie «des périèques et

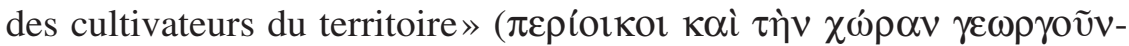
$\tau \eta \zeta)$, en ajoutant que ce peuple fournissait aux Héracléotes les équipages pour un grand nombre de trières ${ }^{857}$. Cette documentation autorise à intégrer les Mariandyniens parmi les peuples dépendants de l'Antiquitée ${ }^{858}$. Et on note que, dans les colonies mégariennes, ce sont

854 Strabon, XII, 3, 4, C 542 (cite Théopompe, FGrHist 115 F 388); VII, 3, 2, C 295 ; Scholie à Apollonios de Rhodes, I, 1126/31a (cite Promathidas d'Héraclée, FGrHist 430 F 1); II, 140a; II, 723; II, 780-783a. Pour les sources antiques évoquant les Mariandyniens, leur origine et la localisation de leur territoire, voir surtout W. Ruge, s.v. «Mariandynoi », RE XIV, 1930, col. 1747-1749; Jacoby, FGrHist I A, p. 355 ; Burstein, Heracleia, p. 6-11; Asheri, Herakleia, p. 17-19; B. Sergent, op. cit., p. 336-345 ; Ivantchik, Am Vorabend der Kolon., p. 129-132. Le peu d'informations dont l'on dispose sur les indigènes du territoire d'Héraclée du Pont ne nous permet pas d'identifier une onomastique mariandynienne. $C f$. A. Avram, «Indigenous Names in Heraclea Pontica», in Personal Names in Ancient Anatolia, PBA 191, R. Parker (éd.), Oxford 2013, p. 51-62.

855 Platon, Lois, VI, 776 c-d; Kallistratos, FGrHist 348 F 4 (apud Athénée, VI, 263 E);

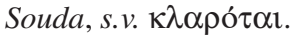

856 Pollux, III, 83; Euphorion, fr. 78 (éd. J. U. Powel; apud Athénée, VI, 263 D-E);

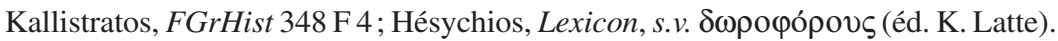

857 Aristote, Politique, VII, 6, 8, 1327a 10-15.

858 D. Lotze, op. cit., p. 56-57; Vidal-Naquet, L'historiographie gr. de l'esclavage, p. 37-38; D. M. Pippidi, «Le problème de la main-d'œuvre agricole dans les colonies grecques de la mer Noire», in Problèmes de la terre en Grèce ancienne, M.I. Finley (éd.), Paris 1973, p. 67; E.D. Frolov, «Les Mariandyniens d’Héraclée (les relations entre les colons grecs et les tribus indigènes dans l'aire de la colonisation dorienne)», in La situation démographique dans la région de la mer Noire durant la période de la grande colonisation grecque, Tbilisi 1981, p. 22-33 (en russe); Avram, Mariandyner, p. 19-28; idem, Gesch. des Territ. von Kallatis, p. 123-125; Papazoglou, Laoi et paroikoi, p. 95-96; C. Schuler, op. cit., p. 200; S. Gallotta, «Tra integrazione ed emarginazione: gli indigeni nelle poleis greche del Mar Nero", in Serta antiqua et mediaevalia VII. Il cittadino, lo straniero, il barbaro, fra integrazione ed emarginazione nell'antichità. Atti del I incontro internazionale di storia antica (Genova 22-24 maggio 2003), M. G. Angeli Bertinelli et A. Donati (éds.), Roma 2005, p. 427-431. 
les laoi et les geôrgoi mysiens de Byzance qui semblent avoir eu un statut analogue aux Mariandyniens d'Héraclée ${ }^{859}$.

À en croire certains récits, les Héracléotes auraient même conclu un accord originel avec les indigènes, selon lequel ces derniers travaillaient à la solde des Grecs qui, quant à eux, subvenaient à leurs besoins et n'avaient pas le droit de les vendre à l'étranger ${ }^{860}$. Il est toutefois difficile de savoir si cette tradition a un caractère historique ou si elle n'est pas une idéalisation des premières relations avec les Mariandyniens ${ }^{861}$. Et cela d'autant plus que l'on dispose d'autres légendes qui évoquent l'entente existant primitivement entre les Grecs et les indigènes. Ainsi, Apollonios de Rhodes (II, 746-750) mentionne à la fois le bon accueil fait aux Mégariens par les Mariandyniens et fait d'Héraclès, l'éponyme mythique de la cité grecque, un allié des Mariandyniens contre la tribu indigène des Bébryces (II, 752-810). À ce propos, Desideri estime que la source des légendes d'Apollonios est Nymphis, qui les aurait inventées afin de: «1) creare un fondamento mitologico alla politica tirannica e poi aristocratica di collaborazione fra Eracleoti e Mariandini; 2) dare una legittimazione postuma, mitologico anch'essa, delle rivendicazioni territoriali di Eraclea» ${ }^{862}$.

$\mathrm{Au}$ demeurant, les Mariandyniens n'auraient pas été soumis tous en même temps par les fondateurs d'Héraclée du Pont, mais probablement d'abord ceux d'entre eux qui se trouvaient dans la proximité de la

859 Voir supra, chapitre II.2.4.2.

860 Posidonios, FGrHist 87 F 8 (apud Athénée, VI, 263 C-D); Strabon, XII, 3, 4, C 542 (qui note pourtant que le contrat de servitude fut établi entre les Milésiens et les Mariandyniens). Selon S. J. Saprykin, «Les poleis et la population locale du littoral sud de la mer Noire à l'époque archaïque et classique: Héraclée et les Mariandyniens », in La situation démographique dans la région de la mer Noire durant la période de la grande colonisation grecque, Tbilisi 1981, p. 9-22 (en russe), les accords conclus entre les Grecs des colonies de la mer Noire et les indigènes visaient aussi la protection commune contre les attaques d'autres tribus barbares. Voir aussi Hind, Megarian Colonization, p. 135, qui estime que «the native people, the Mariandyni, may have initially ceded some costal territory fairly peacefully, being in need of protection from more powerful neighbours, the Bebrykes and Paphlagones ».

861 C. Schuler, op. cit., p. 199-200; cf. B. Sergent, op. cit., p. 344-345, qui considère que ce contrat de servage est une institution d'origine celtique.

862 Desideri, Storiografia eracleota, p. 402, ajoute aussi : «Il punto di collegamento fra i due motivi è ovvio: una rivendicazione territoriale in tanto aveva senso, in quanto poteva appoggiarsi ad un ethnos, di cui i Greci della città fungevano da protettori e rappresentanti, fin dall'epoca del loro eponimo mitico». 
nouvelle cité863. On remarque en effet que selon Hérodote, il y avait des Mariandyniens qui payaient tribut aux Perses et qui servaient indépendamment dans l'armée de Xerxès ${ }^{864}$. Grâce aux récits d'Hécatée ${ }^{865}$ et de Théophraste ${ }^{866}$, on apprend aussi le nom d'une cité (Stephanis) et d'un bourg (Acones) des Mariandyniens.

En ce qui concerne les luttes avec les indigènes, Pausanias évoque des consécrations faites par les Héracléotes à Olympie, après des incursions sur le territoire des Mariandyniens ${ }^{867}$. De même, Justin témoigne, on l'a vu, des nombreuses guerres menées par les Héracléotes contre les peuples voisins ${ }^{868}$. Ces conflits pourraient s'expliquer par la nécessité de distribuer des lots de terre aux nouveaux colons ${ }^{869}$, phénomène auquel Chersonèse, la colonie d'Héraclée du Pont, semble avoir aussi été confrontée ${ }^{870}$.

Il faut ajouter que la mainmise des Héracléotes sur les territoires des Mariandyniens et l'occupation des terres des Taures par des Chersonésitains ont été considérées par certains chercheurs comme des indices en faveur de l'opinion que la colonisation dorienne, par opposition à la colonisation ionienne, aurait eu un caractère violent, visant principalement l'exploitation des populations locales ${ }^{871}$. Cette vision moderniste, qui

863 Burstein, Heraclea, p. 29-30; Asheri, Herakleia, p. 18; Papazoglou, Laoi et paroikoi, p. 95 .

864 Hérodote, I, 28; III, 90; VII, 72.

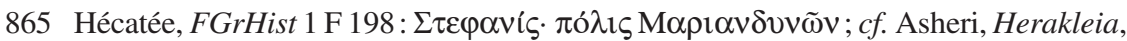
p. 20; Avram, Mariandyner, p. 23-24; idem, Gesch. des Territ. von Kallatis, p. 125.

866 Théophraste, Recherches sur les plantes, IX, 16, 4, note que la plante appelée akoniton

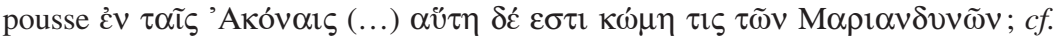
A. Ivantchik, «Les Thraces et les Mariandynes dans la tradition locale d'Héraclée $\mathrm{du}$ Pont», in The Thracian World at the Crossroads of Civilizations. Proceedings of the Seventh International Congress of Thracology (Constanta-Mangalia-Tulcea, 2026 May 1996), vol. I, P. Roman et al. (éds.), Bucarest 1997, p. 329-331; idem, Am Vorabend der Kolon., p. 127-129.

867 Pausanias, V, 26, 7.

868 Justin, XVI, $3,8$.

869 Burstein, Heraclea, p. 23-24.

870 Saprykin, Heracleia and Chersonesus, p. 78.

871 E. D. Frolov, op. cit., p. 22-33 (en russe); G. R. Tsetskhladze, «Greek Colonisation of the Black Sea Area. Historical Interpretation of Archaeology », in The Greek Colonisation of the Black Sea Area, Historia Einzelschriften 121, G. Tsetskhladze (éd.), Stuttgart 1998, p. 47-48. 
veut attribuer des caractéristiques aux apoikiai grecques en fonction de l'origine de leurs fondateurs, est sans nul doute erronée. Car, comme on l'a vu, ni Héraclée du Pont, ni Chersonèse, ne furent l'œuvre des seuls colons mégariens et il y eut dans les deux cités des Béotiens, mais également des Ioniens dans le cas de Chersonèse. Mieux, on ne possède pas d'indices selon lesquels, dans les établissements mégariens de la mer Noire, les Grecs exploitaient d'une manière générale la population indigène de leurs territoires, et les conclusions relatives à Héraclée du Pont et à Chersonèse ne peuvent pas être extrapolées pour Callatis et Mésambria.

Du reste, d'aucuns estiment que les Mariandyniens auraient pu être intégrés dans le démos héracléote lors des situations de crise, notamment au moment de la réforme démocratique du $\mathrm{IV}^{\mathrm{e}}$ siècle, qui avait entraîné une augmentation du nombre des subdivisions civiques (des hékatostyes) de douze à soixante ${ }^{872}$, ou de la tyrannie de Cléarque (en 364), quand on avait assisté à une redistribution des terres et à l'affranchissement des esclaves des riches. Le tyran aurait même imposé des mariages entre ces esclaves et les filles de leurs anciens maîtres ${ }^{873}$. Ces témoignages suggèrent que la condition servile des Mariandyniens aurait pu changer au fil du temps et que certains d'entre eux auraient pu être affranchis, voire recevoir le droit de cité.

872 Avram, Mariandyner, p. 25-26; idem, Gesch. des Territ. von Kallatis, p. 124-125. En se fondant sur le témoignage d'Aristote (Politique, VII, 6, 8, 1327a 10-15), Avram suggère que les Mariandyniens étaient divisés en deux catégories: les périoikoi, bénéficiaires d'une condition sociale plus avantageuse, qui pouvaient être intégrés dans le démos, et les «cultivateurs», ayant un statut d'esclavage, similaire à celui des hilotes. Sur l' augmentation du nombre des «centaines » à Héraclée du Pont, voir infra, chapitre III.1.2.3.

873 Justin, XVI, 5, 1-4; cf. Asheri, Herakleia, p. 23, 30-31; idem, «Tyrannie et mariage forcé. Essai d'histoire sociale grecque», Annales (HSS) 32, 1, 1977, p. 25-26; VidalNaquet, L'historiographie gr. de l'esclavage, p. 38; Papazoglou, Laoi et paroikoi, p. 96, n. 211. 


\section{II.3.2 Mésambria}

\section{II.3.2.1 Les récits concernant la fondation de Mésambria}

La cité de Mésambria (la médiévale Mesemvria/Misevria, la moderne Nessèbre ${ }^{874}$ ) fut installée sur une petite presqu'île ( 25 ha. aujourd'hui, mais probablement environ 40 ha. à l'époque classique) dans la partie nord du golfe moderne de Bourgas, en Bulgarie. À cause du changement du niveau de la mer Noire et des transformations géomorphologiques, une grande partie de la ville antique, y compris de son acropole, fut submergée, et c'est grâce aux recherches sous-marines qu'on a pu délimiter le tracé exact des remparts urbains ${ }^{875}$.

Le Ps.-Scymnos rapporte que les Mégariens et les Chalcédoniens établirent la cité de Mésambria lors de la guerre de Darius contre les Scythes.

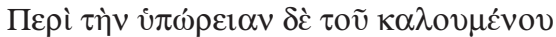

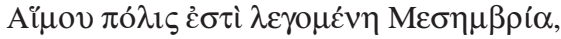

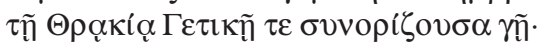

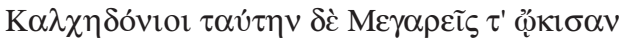

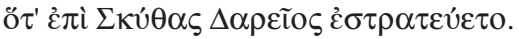

Au pied de la montagne qu'on appelle l'Haimos, on a la ville de Mésambria, qui confine à la Thrace et au pays de Gètes. Des Chalcédoniens et des Mégariens l'ont colonisée au temps où Darius guerroyait contre les Scythes ${ }^{876}$.

874 Sur les différentes variantes du nom de la ville depuis l'Antiquité jusqu'au Moyen Âge, voir Velkov, Mesambria, p. 27.

875 Sur le site de Mésambria et sur l'extension de la ville antique, voir Velkov, Mesambria, p. 9; Ognenova-Marinova, Mesambria, p. 34, 36-37; eadem, «Le système de défense hellénique de Mesambria du côté nord à la lumière des recherches sousmarines», in Nessèbre II, Sofia 1980, p. 96-109; J. Hind, "Greek and Barbarian Peoples on the Shores of the Black Sea», AR 30, 1983-1984, p. 73; H. Preshlenov, «Mesambria», in Ancient Greek Colonies in the Black Sea, D. V. Grammenos et E. K. Petropoulos (éds.), Thessaloniki 2003, p. 158-164 ; M. Oppermann, Die westpontischen Poleis und ihr indigenes Umfeld in vorrömischer Zeit, Langenweißbach 2004, p. 28, 84. Pour les recherches sous-marines à Mésambria, voir notamment L. Ognenova Marinova, "Nesebăr: trent' anni di ricerche di terra e subacque", $B A 75$, 59, 1990, p. 125-129. Les différentes graphies du nom de la cité depuis l'Antiquité jusqu'à aujourd'hui sont rassemblées chez Velkov, Mesambria, p. 27-28.

876 Ps.-Scymnos, 738-742 (trad. D. Marcotte, CUF). La tradition du Ps.-Scymnos est reprise chez Anonymus, Periplus Ponti Euxini, 84-85 (éd. A. Diller). 
Ce récit, dont la source est probablement Démétrios de Callatis ${ }^{877}$, implique que la fondation de Mésambria eut lieu entre 514 et 510 (peutêtre plus exactement vers 513/2) ${ }^{878}$. De même, l'origine mégarienne de la cité est évoquée aussi par Strabon ${ }^{879}$.

Par ailleurs, Hérodote rapporte que les Byzantins et les Chalcédoniens, menacés en 493 par la flotte phénicienne au service des Perses, s'installèrent à Mésambria. ${ }^{880}$

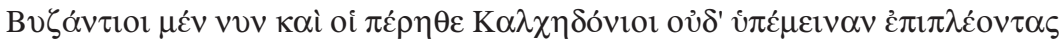

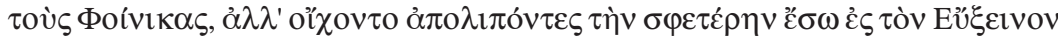

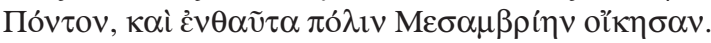

Les Byzantins et les Chalcédoniens, qui habitent en face, n'attendirent même pas l'arrivée de la flotte phénicienne; ils partirent, abandonnant leur patrie, et pénétrèrent dans le Pont-Euxin, où ils s'établirent dans la ville de Mésambria ${ }^{881}$.

En suivant ce récit, Eustathe, dans son commentaire à Denys le Périégète (et non pas à Denys de Byzance, comme il apparaît à tort chez certains modernes ${ }^{882}$ ) indique aussi que les Byzantins et les Chalcédoniens, qui avaient été vaincus dans un combat, fondèrent Mésambria ${ }^{883}$.

877 Velkov, Mesambria, p. 16; Avram, Cités gr., p. 291. Sur Démétrios de Callatis, voir E. Schwartz, s.v. «Demetrios» 77, RE IV, 1901, col. 2806-2807; Dana, Culture, p. 239.

878 H. Bengston, Griechische Geschichte: von den Anfängen bis in die römische Kaiserzeit, 5. durchgesehene und ergänzte Auflage, München 1977, p. 139-140; M. A. Dandamaev, A Political History of the Achemenid Empire, Leiden 1989, p. 136-140.

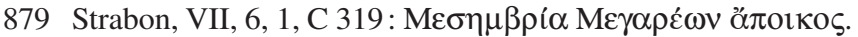

880 Sur le rôle de Byzance et de Chalcédoine dans la révolte des Grecs contre les Perses, on verra Merle, Byzantion und Kalchedon, p. 12-16.

881 Hérodote, VI, 33 (trad. de P.-E. Legrand, CUF).

882 Voir par exemple G. Mihailov, IGBulg $\mathrm{I}^{2}$, p. 255, qui renvoie pour le passage d'Eustathe à «schol. ad Dionysium Periegetam, cuius editionem novam non vidi : Dionysii Byzantii Anaplus Bospori una cum scholiis, ed. R. Güngerich, Berolini 1927 ». La même confusion chez Velkov, Mesambria, p. 15; idem, «Mesambria Pontica», in Die bulgarische Schwarzmerküste im Altertum, Xenia 16, W. Schuller (éd.), Konstanz 1985, p. 38 ; A. Bresson, «Sur une inscription de Mesembria (IGBulg, $\mathrm{I}^{2}, 335$ septies) », in Tarih Boyunca Karadeniz Kongresi Bildirileri-Congrès International sur la mer Noire (1-3 Juin 1988), Samsun 1990, p. 501.

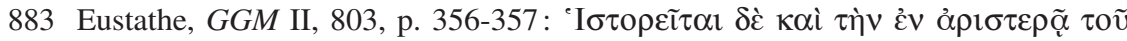

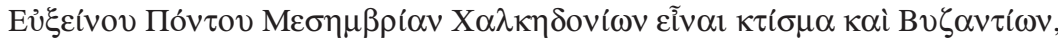

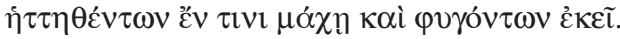


En constatant les divergences entre les récits d'Hérodote et du Ps.Scymnos portant sur la fondation de Mésambria, plusieurs savants ont préféré la première tradition en raison de son ancienneté ${ }^{884}$. Cependant, on a pu démontrer que les deux récits de fondation ne sont pas en contradiction et qu'il n'y a pas de raisons de privilégier une variante en faveur

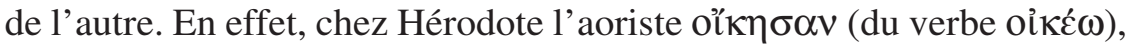

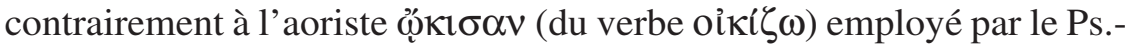
Scymnos, n'implique pas une fondation $(\kappa \tau i ́ \sigma \varsigma)$ ), mais une installation

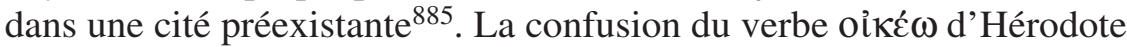
avec oiki $\zeta \omega$ expliquerait pourquoi Eustathe parle de la fondation $(\kappa \tau i \sigma \mu \alpha)$ de Mésambria par les Byzantins et les Chalcédoniens ${ }^{886}$. Par conséquent, la tradition d'Hérodote ne témoigne pas de la fondation de Mésambria, mais de l'arrivée dans cette cité d'un groupe de colons supplémentaires, originaires de Byzance et de Chalcédoine. Il est d'ailleurs probable que plusieurs Byzantins et Chalcédoniens retournèrent dans leur patrie après que la flotte grecque, sous la conduite du Spartiate Pausanias, libéra vers 478-477 les cités du Bosphore de la domination perse ${ }^{887}$.

Du reste, on remarque qu'Hérodote mentionne la cité de Mésambria dans le chapitre concernant l'expédition de Darius contre les Scythes, ce qui suggérerait que la cité existait déjà à ce moment-là 888 .

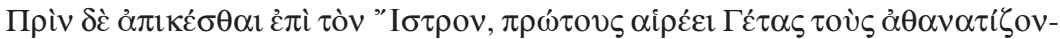

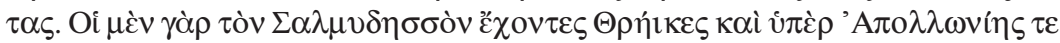

884 Isaac, Gr. Settlem. in Thrace, p. 250-251; Demand, Urban Relocation, p. 42-43; Hind, Megarian Colonisation, p. 138.

885 C'est à Casevitz, Vocabulaire, p. 75-81, qu'appartient le mérite d'avoir démontré de manière convaincante que le verbe oik $\varepsilon ́ \omega$ («avoir résidence», «habiter») ne se réfère pas spécifiquement au processus de la colonisation. À propos du passage d'Hérodote, VI, 33, le savant français estime qu'il concerne « une installation accidentelle et précaire aux temps historiques, sans intention colonisatrice» (p. 77). Cependant, bien avant lui, W. W. How, J. Wells, A Commentary on Herodotus, vol. II, Oxford 1912 (réimpr. Oxford 1961), ad VI, 33, p. 75, notaient déjà « oľkn $\sigma \alpha V$ < took up their abode in, > not olk $\kappa \alpha \nu$ <founded >, the previous existence of Mesembria is implied in iv. 93 ». L'enquête de Casevitz a été suivie par Ehrhardt, Die politischen Beziehungen, p. 92; D. Marcotte, op. cit., p. 237-238; Avram, Cités gr., p. 291 ; T. Miller, Die griechische Kolonisation im Spiegel literarischer Zeugnisse, Tübingen 1997, p. 67-68; contra Hind, Megarian Colonisation, p. 137-138.

886 Avram, Cités gr., p. 291

887 Voir supra, chapitre II.2.4.1.2.

888 W. W. How, J. Wells, op. cit., ad VI, 33, p. 75. 


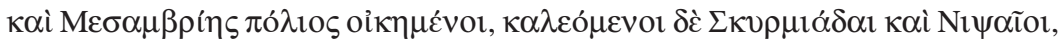

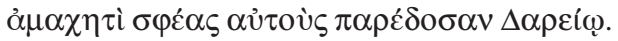

Avant d'arriver à l'Istros, Darius soumit en premier lieu les Gètes, qui croient à leur immortalité. Car les Thraces qui occupent Salmydessos et qui habitent au-dessus d'Apollonia et de la ville de Mésambria, ceux qu'on appelle Skyrmiades et Nipséens, s'étaient rendus à lui sans combats ${ }^{889}$.

L'opinion d'aucuns selon laquelle la colonie mégarienne n'est évoquée dans ce passage que pour situer géographiquement les tribus thraces n'est pas convaincante ${ }^{890}$. Car il est peu probable que vers le milieu du $\mathrm{V}^{\mathrm{e}}$ siècle des cités pontiques telles que Mésambria ou Apollonia aient pu être facilement localisées par les lecteurs de l'historien d'Halicarnasse. Il convient aussi de repousser l'idée que l'on aurait chez Hérodote la mention d'un site thrace homonyme que les Grecs avaient occupé par la suite ${ }^{891}$, car les découvertes archéologiques ne confirment pas une présence thrace à Mésambria à l'époque de la colonisation grecque (voir ci-après).

On conclura donc que Mésambria accueillit plusieurs vagues de colons originaires de Mégare, de Chalcédoine et de Byzance ${ }^{892}$. Sur la foi des récits du Ps.-Scymnos et d'Hérodote, on doit identifier deux événements distincts: tout d'abord, la fondation de la cité vers 513/2 par les Mégariens et les Chalcédoniens, ensuite l'arrivée des Byzantins et des Chalcédoniens, sous la pression du danger perse, comme époikoi en $493^{893}$.

889 Hérodote, IV, 93 (trad. de P.-E. Legrand, CUF).

890 Demand, Urban Relocation, p. 186-187, n. 4, estime que la mention de Mésambria par Hérodote dans le contexte de la description de la campagne de Darius contre les Scythes, « could simply be a mean of identifying the location in terms a fifth-century audience would understand». Pareillement, Hind, Megarian Colonisation, p. 138, note: «However, the mention of Apollonia and Mesambria, at 4.93, is in a parenthesis, describing the location of two minor Thracian tribes on Darius' route. It may simply reflect the situation by Herodotus' own time, and should not be taken to discredit historian's later description of the circumstances and time of foundation ».

891 B. Lenk, s.v. «Mesambria» 1, RE XV, 1931, col. 1073, note «Herod. IV 93 erwähnt zwar die Stadt schon gelegentlich des Skythenzuges, aber nur um die Wohnsitze eines Thrakerstammes seiner Lesern zu bezeichnen, widerspricht sich also nicht». L'opinion de Lenk est acceptée par Hanell, Megarische Studien, p. 128.

892 C. M. Danov, s.v. «Pontos Euxeinos», in RE Suppl. IX, 1962, col. 1071; Velkov, Mesambria, p. 16.

893 Beloch, Gr. Gesch. ${ }^{2}$,I, 2, p. 234 ;Ognenova-Marinova,Mesambria, p. 36;AlexandrescuMorintz, Mesambria, p. 8 ; A. Bresson, op. cit., p. 501 ; Avram, Cités gr., p. 291-292; M. Oppermann, op. cit., p. 16; Veligianni-Terzi, Hellenides poleis, p. 56-57. 
À cet égard, force est de constater que cette fondation présente les deux caractéristiques principales du mouvement de colonisation mégarien: l'association des ressortissants d'autres cités grecques à l'entreprise colonisatrice des Mégariens - des synoikoi, les Chalcédoniens - et l'arrivée ultérieure des colons supplémentaires - des époikoi, les Byzantins et les Chalcédoniens.

Quant aux plus anciennes céramiques grecques découvertes à Mésambria, Lazarov estime qu' elles ne remonteraient pas au-delà de $500^{894}$. Du reste, Ognenova a récemment publié quelques figurines grecques, qui, selon elle, dateraient de la deuxième moitié ou de la fin du VI ${ }^{\mathrm{e}}$ siècle ${ }^{895}$. Ces trouvailles offriraient une confirmation archéologique de la date de fondation de la cité fournie par le Ps.-Skymnos (vers 513/2).

Notons que la participation des Chalcédoniens et des Byzantins en tant que synoikoi ou époikoi à la colonisation de Mésambria est confirmée par la présence dans la cité du Pont-Gauche d'un hiéromnamôn, une magistrature qui fait défaut à Mégare, mais qui est en revanche présente dans les cités du Bosphore thrace ${ }^{896}$. De même, le culte d'Héra a pu être introduit à Mésambria par les Byzantins et/ou les Chalcédoniens, car ces derniers, on l'a vu, célébraient cette divinité dans leurs patries ${ }^{897}$.

894 M. Lazarov, «Notizen zur griechischen Kolonisation am westlichen Schwarzen Meer. Schriftquellen und archäologische Denkmäler», in The Greek Colonisation of the Black Sea Area, Historia Einzelschriften 121, G. Tsetskhladze (éd.), Stuttgart 1998, p. 90, écrit: «das früheste Material, darunter eine schwarzfigurige Oinochoe und eine Amphora von Chios, kann nicht vor 500 v. Chr. datiert werden». Cf. L. Ognenova, «Les fouilles de Mésambria», BCH 84, 1960, p. 221-232; Karayotov, Coinage of Mesambria I, p. 14; Hind, Megarian Colonization, p. 138; M. Gyuzelev, The West Pontic Coast between Emine Cape and Byzantion during the First Millennium BC, Burgas 2008, p. 82-83.

895 L. Ognenova, «Terres cuites de Messambria», in Nessèbre III, Burgas 2005, p. 5152 , p. 56, $\mathrm{n}^{\mathrm{O}} 1$ : une miniature de Koré/Aphrodite à la colombe, datée de la fin du $\mathrm{VI}^{\mathrm{e}}$ siècle; p. $56, \mathrm{n}^{\circ} 2$ : une tête de Koré située dans la deuxième moitié du $\mathrm{VI}^{\mathrm{e}}$ siècle.

896 Voir infra, chapitre III.2.1.2.

897 Les graffiti avec la mention de $\Delta \mathrm{IO} \Sigma$, respectivement de HPA trouvés dans un bothros daté des $\mathrm{V}^{\mathrm{e}}-\mathrm{III}^{\mathrm{e}}$ siècles, ont été mis en rapport avec un temple dédié à Zeus et à Héra: L. Ognenova, $B C H$ 84, 1960, p. 229, 231 ; eadem, «L'architecture domestique à Messambria IV ${ }^{\mathrm{e}}-\mathrm{II}^{\mathrm{e}}$ s. av. J.-C.», in Nessebre III, Burgas 2005, p. 14; $c f$. V. Velkov, «Inscriptions antiques de Messambria», in Nessebre III, Burgas 2005, p. 171-172; Chiekova, Cultes, p. 164. On a trouvé aux abords de Mésambria une dédicace à Héra datant de l'époque impériale: IGBulg $\mathrm{I}^{2}, 352$. La déesse apparaît aussi sur des monnaies de bronze émises par Mésambria au $\mathrm{III}^{\mathrm{e}}$ siècle: Karayotov, Coinage of 
Il faut avouer que les raisons exactes de l'installation des Mégariens dans le Pont-Gauche restent difficiles à connaître. Comme il a été déjà suggéré, on devrait compter parmi celles-ci la perte de Salamine (dans les années 520-510, suite à l'arbitrage spartiate), qui mit fin à l'expansion mégarienne dans le golfe Saronique ${ }^{898}$. D'autre part, compte tenu du début des émissions mésambriennes en argent à une date assez haute (dès le milieu du $\mathrm{V}^{\mathrm{e}}$ siècle déjà ${ }^{899}$ ), et de la découverte de monnaies de bronze datant d'une période proche de la fondation, les savants ont suggéré comme causes de la fondation de Mésambria la piste du commerce avec les Thraces et la recherche des métaux (notamment cuivre) ${ }^{900}$. On notera que la cité de Mésambria bénéficiait aussi d'une position géographique favorable; elle était située sur une presqu'île facile à défendre - sans doute l'une des raisons de l'établissement des Byzantins et des Chalcédoniens en 493 - et flanquée de deux golfes au nord et au sud, qui avaient servi de ports aux Thraces, aux âges du Bronze et du Fer, aussi bien qu'aux Grecs, à l'époque historique ${ }^{901}$.

Mesambria II, p. 109, pl. CXLVI, nos 289-293, pl. CLVI, nos 476-478. Pour le culte d'Héra à Byzance et à Chalcédoine, voir supra, chapitre II.2.4.1.5.

898 Voir supra, chapitre I.2.3.

899 Pour les premières monnaies en argent de Mésambria, voir Karayotov, Coinage of Mesambria I, p. 18, pl. I, nos 1-2; SNG 9, pl. X, no $265 ; S N G$ 11, pl. X, no 217.

900 Velkov, Mesambria, p. 16; P. Delev, «Bevölkerung und Siedlungssystem an der bulgarischen Schwarzmeerküste», in Die bulgarische Schwarzmeerküste im Altertum, Xenia 16, W. Schuller (éd.), Konstanz 1985, p. 16-17; J. Stronk, «Wreckage at Salmydessos », in Thracia Pontica III. Les Thraces et les colonies grecques, VII-Vs. av. n. è. (Sozopol, 6-12 octobre 1985), Sofia 1986, p. 203-215; L. OgnenovaMarinova, «Mesambria et le monde thrace entre le VII et le Ve s. av. n. è», Thracia Pontica III. Les Thraces et les colonies grecques, VII-V s. av. n. è. (Sozopol, 6-12 octobre 1985), Sofia 1986, p. 242-243; Demand, Urban Relocation, p. 43. Sur l'exploitation des gisements de cuivre par les Thraces, voir aussi C. M. Danov, op. cit., col. 1047; J. Hind, AR 30, 1983-1984, p. 74.

901 Sur les deux ports naturels de Mésambria, voir L. Ognenova-Marinova, «Mesembriacus portus », in Thracia Pontica V, 1994, p. 139-142. Il convient d'évoquer la découverte de plusieurs ancres en pierre, qui témoignent de l'utilisation des ports de Mésambria aux âges du Bronze et du Fer. Pour ces trouvailles, voir L. Ognenova-Marinova, «Thracia Pontica», in Thracia Pontica I. La mer Noire et le monde méditerranéen (Sozopol, 9-12 octobre 1979), Sofia 1982, p. 69-81; P. Delev, op. cit., p. 13-15; K. Porozhanov, «La ville thrace de Mesembria sur la côte de la mer Noire», in Thracia 13. Studia in memoriam Velizari Velkov, Sofia 2000, p. 347-348. 
Quant à la chôra de Mésambria, bien qu'elle soit encore difficile à situer $^{902}$, les sources antiques attestent que la colonie mégarienne fonda d'autres établissements dans le Pont-Gauche. Elle installa Naulochos (aujourd'hui Obzor) et réussit ainsi à élargir son territoire vers le nord ${ }^{903}$. En revanche, la tradition qui faisait de Bizonè (entre Dionysopolis et Callatis, l'actuelle Kavarna) une installation mésambrienne reste encore douteuse, les quelques documents épigraphiques émanant de ce site n'étant pas rédigés en dorien, mais en koinè ${ }^{904}$. Enfin, grâce à une inscription, on apprend que Mésambria mena à l'époque hellénistique une guerre contre Apollonia au sujet de la possession d'Anchialos ${ }^{905}$. Strabon considère cette dernière localité comme un polichnion des Apolloniates $^{906}$, mais la présence d'un héros homonyme à Mégare laisse penser qu'Anchialos aurait été à l'origine une installation mésambrienne ${ }^{907}$.

\section{II.3.2.2 Les rapports entre les Mésambriens et les Thraces}

Les antiques attribuèrent au nom de Mésambria une origine thrace. De fait, Strabon et Nicolas de Damas rapportent au Ir siècle que le premier élément provient de Ména ou Melsos, le fondateur mythique de la cité,

902 Pour la localisation du territoire de Mésambria, voir I. Karayotov, «La $\chi \omega ́ \rho \alpha$ de Mesambria Pontika d'après les données archéologiques et numismatiques », in Studies on Settlement Life in Ancient Thrace. Proceedings of the IIIrd International Symposium «Cabyle», 17-21 Mai 1993, D. Draganov (éd.), Jambol 1994, p. 283-292; M. Oppermann, op. cit., p. 28-29, 84-86, 175-177, 256-258.

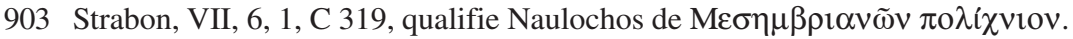

904 Le Ps.-Scymnos, F 3, note que le polichnion Bizonè fut selon certains une installation barbare, selon d'autres une apoikia des Mésambriens. L'occupation thrace de Bizonè avant l'arrivée des Grecs semble être attestée par les trouvailles. Sur Bizonè, dont le nom est certainement thrace, voir G. Mihailov, IGBulg $\mathrm{I}^{2}$, p. 35-37; Detschew, Thrak. Sprachreste ${ }^{2}$, p. 61; A. Salkin, «Evidence for the Earlier Foundation of Bizone Colony », in Thracia Pontica III. Les Thraces et les colonies grecques, VII-V s. av. n.è. (Sozopol, 6-12 octobre 1985), Sofia 1986, p. 251-255; Isaac, Gr. Settlem. in Thrace, p. 259-261; Ehrhardt, Milet und seine Kolonien², p. 66-67; Avram, Gesch. des Territ. von Kallatis, p. 107; D. Marcotte, op. cit., p. 240; H. Preshlenov, op. cit., p. 165 ; M. Oppermann, op. cit., p. 168-169, 253-254.

905 ISM I, 64.

906 Strabon, VII, 6, 1, C 319.

907 A. Robu, «Le culte de Poséidon à Mégare et dans ses colonies », Dacia N.S. 57, 2013 , p. 74. 
et que le deuxième, $\beta \rho i ́ \alpha$, est le nom thrace pour désigner une ville ${ }^{908}$. Les deux auteurs donnent très probablement une forme corrompue du nom de l'œeciste, la forme correcte étant, comme Kramer l'a jadis prôné, Melsas ${ }^{909}$. Il existe du reste une attestation épigraphique de cette tradition littéraire. L'épigramme funéraire d'Iulia, fille de Nikias, qualifie à

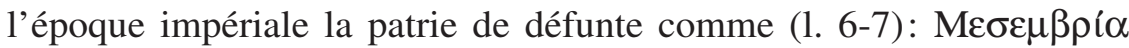

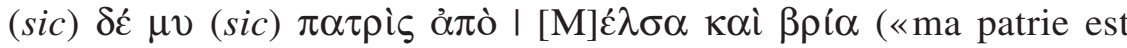
Mésambria - de Melsas et bria») ${ }^{910}$. Mais on a aussi suggéré que le rapprochement phonétique entre le terme thrace $\beta \rho i ́ \alpha$ et la désinence du mot grec $\mu \varepsilon \sigma \eta \mu \beta \rho i ́ \alpha$ («le midi») est en réalité à l'origine de la fausse étymologie thrace de la citég11. Quoi qu'il en soit, la légende qui attri-

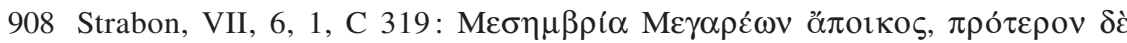

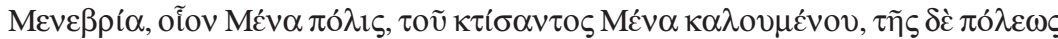

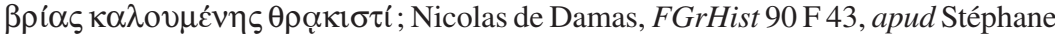

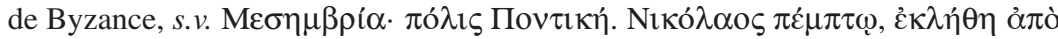

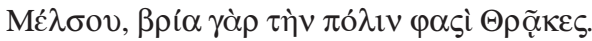

909 En accordant sa préférence au témoignage de Nicolas de Damas, G. Kramer (éd.), Strabonis Geographica recensuit commentario critico instruxit, vol. II, Berlin 1847,

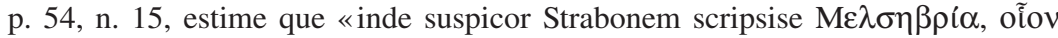

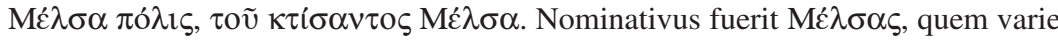
declinavit uterque: $\Lambda$ et $\Sigma$ (forma rotunda) facile coaluerunt in $N »$. On trouve d'autres variantes du nom de l'œciste, sans doute elles aussi corrompues, chez Pline, $N H$, IV, 11, 45: nunc in ora Mesembria, Anchialum, ubi Messa fuerat; et dans la Chrestomathie

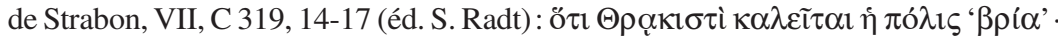

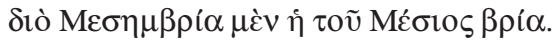

910 IGBulg $\mathrm{I}^{2}, 345$. Les étymologies de Mésambria ont fait l'objet d'une littérature abondante: Detschew, Thrak. Sprachreste ${ }^{2}$,p. 86, 295-296; Mihalov, IGBulg $\mathrm{I}^{2}, a d \mathrm{n}^{\circ} 345$, p. 307-308; D. Bojadziev, «Un cas de contact entre la langue thrace et la langue grecque», in Thracia Pontica III. Les Thraces et les colonies grecques, VII-V s. av. n. è. (Sozopol, 6-12 octobre 1985), Sofia 1986, p. 183-185 (SEG LVIII, 705); K. A. Vlahov, «Die thrakische Herkunft der Ortsnamen an der Schwarzmeerküste während und nach der griechischen Kolonisation », in Thracia Pontica III. Les Thraces et les colonies grecques, VII-V s. av. n. è. (Sozopol, 6-12 octobre 1985), Sofia 1986, p. 176-177; K. Boshnakov, «Strabo VII 6, 1 », Thracia Pontica V, 1994, p. 92 ; K. Nawotka, «Melsas, the Founder of Mesambria», Hermes 122, 1994, p. 320-326; idem, West Pont. Cities, p. 13-15; A. Fol, «Thracia Pontica - Twenty Years Later», in New Studies on the Black Sea Littoral, Colloquia Pontica 1, G. R. Tsetskhladze (éd.), Oxford 1996, p. 3-4; A. Avram, J. Hind, G. Tsetskhladze, s.v. «Mesambria », in Hansen-Nielsen (éds.), Inventory, p. 934-935; Veligianni-Terzi, Hellenides poleis, p. 56-58; Porozhanov, Founders, p. 516-517; M. Dana, D. Dana, op. cit., p. 104-105.

911 G. Mihailov, IGBulg $\mathrm{I}^{2}, a d \mathrm{n}^{\mathrm{o}} 345$, p. 307-308; Veligianni-Terzi, Hellenides poleis, p. 57. 
buait la fondation de la cité du Pont-Gauche à Melsas date au moins de l'époque hellénistique, car on constate que le radical du nom de l'œciste fait partie de l'onomastique mésambrienne aux III $^{\mathrm{e}}-\mathrm{II}^{\mathrm{e}}$ siècles $^{912}$.

Pour ce qui est de l'hypothèse de la présence d'un site thrace à la fin du $\mathrm{VI}^{\mathrm{e}}$ siècle, les recherches archéologiques ont mis au jour une couche précoloniale thrace - appartenant à la civilisation Babadag de l'époque hallstattienne - et dont d'aucuns ont attribué la destruction aux Grecs ${ }^{913}$. Néanmoins, les recherches ultérieures menées par Alexandrescu et Morintz ont infirmé cette supposition, en montrant qu'il existait un «hiatus d'environ trois siècles entre l'abandon du site hallstattien et la fondation de la cité dorienne ${ }^{914}$. À propos du nom thrace de la cité, Alexandrescu estime qu' on pourrait aussi «admettre un transfert toponymique d'une place portant un nom avec l'élément $\beta \rho i ́ \alpha$, et se trouvant quelque part aux environs de la future fondation dorienne» ${ }^{915}$. À mon sens, le nom de Mésambria, tout comme celui de Byzance et de

912 Le décret du $\mathrm{III}^{\mathrm{e}}$ siècle IGBulg $\mathrm{I}^{2}, 308$ sexies (Velkov, Inscr. de Mésambria, p. 165,

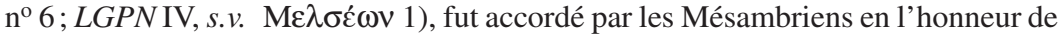

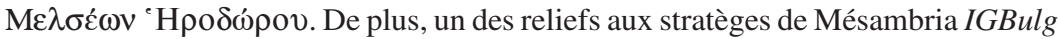

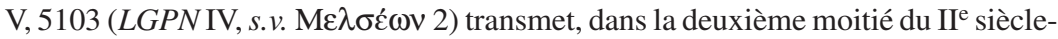

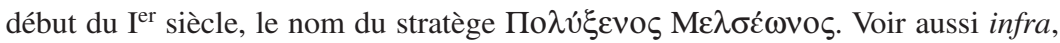
chapitre III.2.2.4 sur ce stratège. Cf. A. Avram, Bull. ép., 2010, 434.

913 I. Venedikov, «La Mésambria thrace», in Nessèbre II, Sofia 1980, p. 7-22 (pour la céramique indigène); idem, «Les fortifications dans la partie nord-ouest de Nessèbre», in Nessèbre II, Sofia 1980, p. 75-80 (pour les remparts thraces); Ognenova-Marinova, Mesambria, p. 34-40; eadem, «Thracia Pontica», in Thracia Pontica I. La mer Noire et le monde méditerranéen (Sozopol, 9-12 octobre 1979), Sofia 1982, p. 69-81; eadem, «Mesambria et le monde thrace entre le VII et le Ve s. av. n. è», in Thracia Pontica III. Les Thraces et les colonies grecques, VII-V s. av. n. è. (Sozopol, 6-12 octobre 1985), Sofia 1986, p. 142-156, situent l'habitat thrace du XII ${ }^{\mathrm{e}}$ au VI $\mathrm{VI}^{\mathrm{e}}$ siècle; $c f$. Hind, Greeks and Barbarian Peoples, p. 86, idem, Megarian Colonization, p. 138, qui, en suivant l'opinion des archéologues bulgares, estime que la présence d'un site thrace expliquerait la date tardive de la fondation de Mésambria par les Grecs. Sur l'habitat thrace de Mésambria, voir aussi L. Ognenova-Marinova, «La <bria > thrace d'après les recherches archéologiques à Nessèbre», in Thracia Pontica IV, Sofia 1991, p. 133-136.

914 Alexandrescu-Morintz, Mesambria, p. 8-16, le passage cité se trouve à la p. 15; cf. Avram, Gesch. des Territ. von Kallatis, p. 127; M. Lazarov, op. cit., p. 90-91; M. Oppermann, op. cit., p. 15-16.

915 Alexandrescu-Morintz, Mesambria, p. 15; cf. C. Danov, «The Penetration of the Thracians into the Greek Colonies of the Western Shore of the Black Sea», Klio 38, 1960, p. 75. 
Sélymbria, peut aussi témoigner de l'intention des Grecs de chercher un passé thrace à leur cité. En effet, comme on l'a constaté dans le cas de l'une des étymologies de Chalcédoine (celle qui renvoyait à Calchédon, fils de Cronos), donner un nom indigène à une apoikia était un moyen d'intégrer les Grecs dans les généalogies mythiques locales ${ }^{916}$.

On constate par ailleurs que l'étymologie thrace de Mésambria a généré différentes opinions dans l'historiographie moderne vis-à-vis des oikistai de la cité. Selon d'aucuns, le fondateur Melsas serait représenté sur les monnaies en bronze de Mésambria du $\mathrm{IV}^{\mathrm{e}}$ siècle. De plus, le casque corinthien, qui figure sur d'autres monnaies frappées par la cité et sur un relief votif de Mésambria (IGBulg V, 5102), ferait référence à l'œciste héroïsé ${ }^{917}$. En réalité, si la première hypothèse est recevable compte tenu du parallèle avec les représentations de Calchas et de Byzas sur les monnaies respectives de Chalcédoine et de Byzance ${ }^{918}$-, il est en revanche plus difficile d'accepter que le casque figuré sur les monnaies de Mésambria appartienne au fondateur mythique de la cité. Ce véritable symbole de la cité pontique, qui est employé aussi comme monogramme $^{919}$, fait plus probablement référence à Athéna, divinité qui apparaît sur les plus anciennes émissions monétaires ${ }^{920}$. On trouve un parallèle à cet égard dans le casque corinthien d'Athéna qui orne à l'époque impériale les monnaies de Byzance, une des cités qui ont participé à la colonisation de Mésambria ${ }^{921}$. Le casque témoignerait alors,

916 Voir supra, chapitre II.2.2.1.

917 T. Gerasimov, «Monnaies autonomes inédites de Mésambria sur la mer Noire», $B M N B$ 1, 1950, p. 26, nº 15 (en bulgare); Karayotov, Coinage of Mesambria I, p. 13, 14, 19, 55; idem, Coinage of Mesambria II, p. 20-21, 99-100, pl. V-VII (monnaies au type de «Melsas»); K. Dimitrov, «Hoard of Hellenistic Bronze Coins from Mesambria Pontica in the Depository of the National Archaeological Museum in Sofia (IGCH 884)», in Studia in honorem A. Fol, Sofia 1995, p. 409-418, surtout p. 413, 415; Chiekova, Cultes, p. 274-275 ; cf. Hind, Greeks and Barbarian Peoples, p. 86; Veligianni-Terzi, Hellenides poleis, p. 58.

918 Voir supra, chapitres II.2.2.1. et II.2.4.2.

919 Pour des exemplaires de monnaies contremarquées avec le casque, voir SNG 11, pl. 10, nos 231-234 (tétradrachmes au type d'Alexandre); $c f$. Robert, Hellenica II, p. 151 ; VII, p. 239.

920 Karayotov, Coinage of Mesambria I, p. 18-19, pl. I, $\mathrm{n}^{\mathrm{os}} 1,4,5$; idem, Coinage of Mesambria II, p. 94-96, pl. I-IV. Cf. Chiekova, Cultes, p. 224-225.

921 Schönert-Geiss, Byzantion, vol. II, p. 35, et pl. 64-70, $\mathrm{n}^{\text {os }}$ 1322-1328, 1330-1333, 1345-1346, 1369-1373, 1383-1384, pl. 75-76, nos 1433-1443, 1447-1453. De même, 
à Byzance aussi bien qu'à Mésambria, du culte d'Athéna et non pas du culte de l'œciste ${ }^{922}$.

Quant à la représentation des armes (deux casques, six boucliers, une paire de cnémides et une cuirasse) sur le relief aux stratèges IGBulg $\mathrm{V}, 5102$, il pourrait s'agir dans ce cas de panoplies dédiées dans un sanctuaire. Pausanias atteste, on le rappelle, que l'entablement du temple portait des boucliers à Olympie ${ }^{923}$. D'autre part, les Mésambriens pourraient aussi faire allusion, par la représentation des armes, à un banquet funèbre, à un symposium héroïque. En effet, il existait une coutume antique selon laquelle les panoplies ornaient les salles de banquets, et on remarque que sur un cratère corinthien du Louvre des armes sont représentées à côté de personnages couchés ${ }^{924}$. Mieux, on peut évoquer à titre de parallèle un relief funéraire de l'époque hellénistique en provenance d'une cité de la Propontide ou du Pont-Euxin et décoré d'une scène de banquet héroïque. Au centre, on a représenté deux personnages masculins allongés sur une klinè et entourés de plusieurs personnes (une femme, plusieurs enfants), tandis que le tiers supérieur du relief illustre une tête de cheval et différentes armes (casque corinthien, bouclier, armure $)^{925}$.

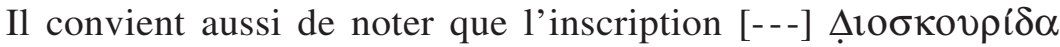
ท๊ $\rho \omega \sigma$, qui apparaît sur un relief fragmentaire (IGBulg $\mathrm{I}^{2}, 335$ septies), a été considérée par Ognenova-Marinova comme un témoignage de l'existence d'un culte des oikistai. En invoquant le datif pluriel ñ $\rho \omega \sigma$,

le casque corinthien accompagne la déesse Nikè sur d'autres monnaies byzantines de l'époque impériale: Schönert-Geiss, Byzantion, vol. II, pl. 74, n 1423 , pl. 94, $\mathrm{n}^{\mathrm{o}} 1651$, pl. 95-96, n ${ }^{\text {os }} 1694-1696,1700-1703$.

922 Rappelons aussi ici la ressemblance qui existe entre les légendes monétaires de Mésambria et celles d'une autre cité mégarienne du Bosphore thrace, Chalcédoine. Sur plusieurs émissions monétaires, les noms de ces deux cités sont intercalés entre les rayons d'une roue: voir supra, chapitre II.2.2.1.

923 Pausanias, V, 10, 5.

924 Hérodote I, 34; III, 78; $f f$. H. van Wees, «Greeks bearing Arms. The State, the Leisure Class, and the Display of Weapons in Archaic Greece», in Archaic Greece: New Approaches and New Evidence, N. Fisher et H. van Wees (éds.), London 1998, p. 362-364.

925 M. Lubos, «Zu einem hellenistischen Grabrelief», in Pontos Euxeinos. Beiträge zur Archäologie und Geschichte des antiken Schwarzmeer- und Balkanraumes. Manfred Oppermann zum 65. Geburtstag, S. Conrad et al. (éds.), Langenweißbach 2006, p. 181-188. 
la savante bulgare pense que ce relief représenterait un sacrifice en l'honneur des deux fondateurs héroïsés de la cité, l'indigène Melsas et le grec Dioskouridas. En conséquence, elle propose la restitution sui-

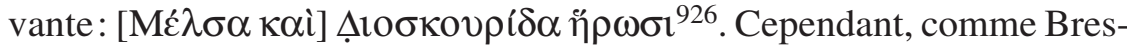
son l'a noté, l'interprétation proposée par Ognenova-Marinova n'est

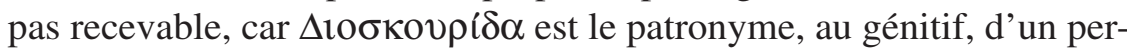
sonnage ou le père de deux frères dont le(s) nom(s) ont disparu. Ainsi, ce fragment de relief serait une dédicace aux héros, type de documents dont l'on a d'autres exemples à Mésambria ${ }^{927}$.

$\mathrm{Au}$ demeurant, les documents épigraphiques nous renseignent sur le protectorat exercé par des dynastes thraces sur la colonie mégarienne. Comme d'autres Grecs de la mer Noire, étant confrontés aux razzias des tribus barbares, les Mésambriens firent souvent appel aux princes indigènes pour assurer la sécurité de leur territoire ${ }^{928}$. Dans ce sens, on remarque qu'ils ont décerné à l'époque hellénistique ( $\mathrm{III}^{\mathrm{e}}-\mathrm{II}^{\mathrm{e}}$ siècles) le droit de cité à un Thrace de la tribu des Astes, et à ses descendants, pour les services rendus à la cité ${ }^{929}$. Les récits rapportent que ce peuple thrace occupait le territoire situé au nord de Byzance, entre Périnthe et Apollonia du Pont, dans la région montagneuse de l'Istranca ${ }^{930}$.

926 L. Ognenova-Marinova, «Au sujet de Dioskouridas de Mesambria», in Actes du IX $X^{e}$ Congrès international d'épigraphie grecque et latine (31.08-7.09.1987). Acta Centri Historiae. Terra Antiqua Balcanica II, A. Fol (éd.), Veliko Tărnovo-Sofia 1987, p. 262-263; cf. SEG XXXVII, 614; Karayotov, Coinage of Mesambria I, p. 54-55; Velkov, Inscr. de Messambria, p. 168, no 11.

927 A. Bresson, op. cit., p. 501-504. Même opinion chez G. Mihailov, IGBulg V, ad

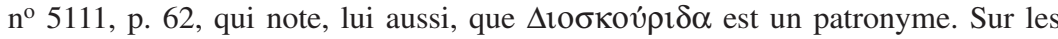
reliefs représentant des stratèges de Mésambria qui sacrifient aux héros, voir infra, chapitre III.2.2.4.

928 Pour les ambassades des cités grecques de la mer Noire auprès des chefs barbares, voir la documentation rassemblée récemment chez Avram, Défense des cités en mer Noire, p. 163-182.

929 IGBulg $\mathrm{I}^{2}, 312$.

930 Sur les Astes et leur territoire, voir Polybe, XIII, 10, 10; Ps.-Scymnos, 728-729; Tite-Live, XXXVIII, 40, 7; Strabon, VII, 6, 1-2, C 319-320; fr. 47; Pline, NH, IV, 11, 45 ; Ptolémée, Géographie, III, 11, 10; $f$. E. Oberhummer, s.v. «Astai », RE II, 1896, col. 1772-1773; C.M. Danov, Altthrakien, Berlin-New York 1976, p. 122, 129; K. Boshnakov, Die Thraker südlich vom Balkan in den Geographica Strabos. Quellenkritische Untersuchungen, Stuttgart 2003, p. 94, 188-194; A. Avram, CRAI, 2003 (2005), 3, p. 1191-1192. 
Au surplus, les Mésambriens octroient au III ${ }^{\mathrm{e}}$ siècle la citoyenneté à un chef thrace appelé Sadalas et à ses descendants et ils s'engagent aussi à lui accorder chaque année une couronne d'or de 50 statères. Le décret pour Sadalas est suivi par un traité conclu entre les Grecs et le dynaste thrace, contenant un règlement sur le droit d'épaves, qui n'est que partiellement conservé ${ }^{931}$. Comme le notent J. et L. Robert, «au lieu que les indigènes de la côte aient la propriété des navires échoués ou de leurs restes, ils recevront une somme (sans doute proportionnelle) pour chaque navire échoué en dédommagement du droit qu'ils exerçaient auparavant ${ }^{932}$. On apprend aussi (1. 11-16) que le trésorier

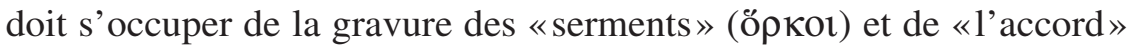

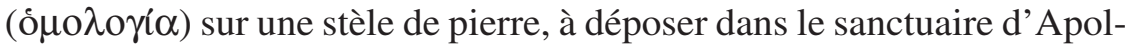

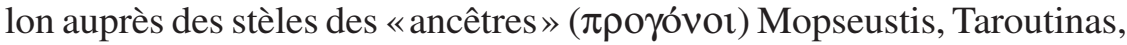
Medistas et Kotys. Il s'agit là d'une véritable liste de dynastes thraces, «ancêtres» de Sadalas, que les Grecs avaient honorés au fil du temps.

Des relations conflictuelles sont également attestées entre les Mésambriens et diverses tribus thraces au ${ }^{\mathrm{er}}$ siècle. Une inscription évoque une guerre contre Byrébistas, le roi des Gètes ${ }^{933}$, et une épigramme

931 IGBulg $\mathrm{I}^{2}, 307$ (= L. Moretti, Iscrizioni storiche ellenistiche, vol. II, Florence 1976, $\mathrm{n}^{\mathrm{o}}$ 123); cf. IGBulg V, 5086. Sur cette inscription, voir notamment les commentaires de J. et L. Robert, Bull. ép., 1953, 133 ; 1963, 175 ; Robert, Inscr. de Bulgarie, p. 216 (=OpMinSel, V, p. 246); C. Danov, op. cit., p. 77-78; H. Bengston, «Neues zur Geschichte des Hellenismus in Thrakien und in der Dobroudscha», Historia 11, 1962, p. 25-26; Velkov, Mesambria, p. 13, 17; idem, «Mesambria Pontica», in Die bulgarische Schwarzmerküste im Altertum, Xenia 16, W. Schuller (éd.), Konstanz 1985, p. 33 (= Geschichte und Kultur Thrakiens und Mösiens, Amsterdam 1988, p. 85); Ognenova-Marinova, Mesambria, p. 37-39; P. Balabanov, «Trois inscriptions du littoral sud-est de la mer Noire», in Studia in honorem Georgii Mihailov, Sofia 1985, p. 37-39; P. Delev, op. cit., p. 19; Hind, Greeks and Barbarian Peoples, p. 86-87; H. Preshlenov, op. cit., p. 172, 179; M. Mainardi, «Mesambria Pontica e i Traci », Acme 64, 3, 2011, p. 14-23. Pour le pillage des navires échoués sur les rives pontiques par les Thraces (notamment dans la région de Salmydessos), voir les témoignages de Xénophon, Anabase, VII, 5, 12-14, et de Strabon, VII, 6, 1, C 319.

932 J. et L. Robert, Bull. ép., 1953, 133, p. 39.

933 IGBulg $\mathrm{I}^{2}, 323$; cf. Avram, Défense des cités en mer Noire, p. 179. Sur les rapports entre les Grecs et les Gètes, voir aussi A. Avram, «Modes de contacts entre Grecs et Gètes à Histria à l'époque archaïque», in Sur les traces des Argonautes. Actes du $6^{e}$ symposium de Vani (Colchide), 22-29 septembre 1990, O. Lordkipanidzé et P. Lévêque (éds.), Paris 1996, p. 241-251; idem, Les territoires d'Istros et de Callatis, p. 602-603. 
mentionne les couronnes décernées par le peuple à un certain Ariston, mort lors d'une campagne militaire contre une autre tribu thrace, les Besses $^{934}$.

On finira par noter que tout comme à Sélymbria et à Byzance, l'onomastique thrace est peu représentée à Mésambria, les noms grecs étant largement majoritaires ${ }^{935}$. À titre d'exemple, les inscriptions attestent à l'époque hellénistique et impériale des noms thraces tels que A $\theta 0 \varsigma$,

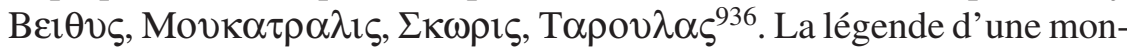

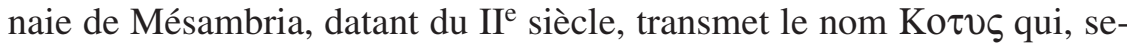
lon Karayotov, ne serait pas le roi thrace homonyme, mais un stratège de la cité 937 .

934 IGBulg $\mathrm{I}^{2}, 344$; cf. Robert, Inscr. de Bulgarie, p. 219 (=OpMinSel, V, p. 249); J. et L. Robert, 1960, 245 ; Velkov, Mesambria, p. 18-19.

935 Pour l'origine grecque des noms de femmes évoqués par les inscriptions de Mésambria, voir F. Cordano, «Le donne di Mesambria», in Heros Hephaistos. Studia in honorem Liubae Ognenova-Marinova, T. Stoyanov et al. (éds.), Veliko Tărnovo 2005, p. 42-44; cf. A. Avram, Bull. ép., 2006, 284. Notons que C. Danov, op. cit., p. 77, signale la présence de tombes thraces dans la nécropole hellénistique de Mésambria.

936 IGBulg $\mathrm{I}^{2}, 322$ ter; 354 ; 354 quater $; 355 ; 363$.

937 Karayotov, Coinage of Mesambria I, p. 55. 


\section{Partie III}

\section{Les institutions politiques mégariennes}

\section{III.1 Les subdivisions du corps civique à Mégare et dans ses colonies}

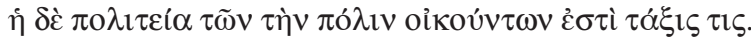

Ce qui fait la cité, c'est un certain ordre dans lequel sont rangés les citoyens ${ }^{1}$.

L'inscription des ressortissants des établissements mégariens dans les subdivisions civiques rendait possible leur accès aux privilèges fournis par la citoyenneté ${ }^{2}$. Les sources littéraires et épigraphiques attestent que les citoyens de Mégare étaient regroupés dans les trois phylai («tribus») doriennes et en plusieurs hékatostyes («centaines»). D'aucuns ont supposé la présence d'une troisième division civique, la division en kômai («villages»); mais, comme j'essaierai de le montrer, il faut abandonner cette hypothèse invétérée.

On notera d'emblée que la documentation qui nous renseigne sur les subdivisions du corps civique est essentiellement épigraphique. Les auteurs anciens ont été peu intéressés par l'organisation civique, ce qui, bien entendu, limite notre connaissance de cet aspect très important de la vie des cités ${ }^{3}$. Par ailleurs, les colonies grecques reproduisent traditionnellement, on le sait, les institutions de leurs métropoles. C'est pourquoi, pour avoir une image complète des subdivisions civiques, on peut utiliser les renseignements provenant non seulement de Mégare, mais aussi de ses colonies de la Propontide et du Pont-Euxin ${ }^{4}$. De même, on

1 Aristote, Politique, III, 1, 1, $1274 \mathrm{~b} 38$.

2 Jones, Enrollement Clauses, p. 79; F. Ruzé, «Les tribus et la décision politique dans les cités grecques archaïques et classiques », Ktèma 8, 1983, p. 299-300 (=Eunomia. À la recherche de l'équité, Boulogne-sur-Mer-Paris 2003, p. 55-56).

3 Hanell, Megarische Studien, p. 137; Debord, Chiliastys, p. 201-202. 
trouve d'autres informations sur les institutions d'origine mégarienne dans les documents émanant des colonies d'Héraclée du Pont (Chersonèse Taurique, Callatis, Kiéros/Prusias de l'Hypios), car ces cités reçurent, par le biais de leur métropole, les nomima mégariens. En revanche, nonobstant le grand nombre de fouilles effectuées à Mégara de Sicile et à Sélinonte, la moisson des inscriptions qui évoquent les institutions de ces cités reste maigre ${ }^{5}$. Comme je l'ai déjà signalé plus haut, cet état de la documentation s'explique en bonne partie par l'absence d'une épigraphie hellénistique et romaine à caractère public, les deux cités mégariennes de Sicile ayant subi des conquêtes destructrices, l'une vers 483/2 et l'autre en 409/8. À cela s'ajoute, notamment à Sélinonte, le fait que les inscriptions sont souvent gravées sur des tablettes de plomb, un matériel facilement réutilisable ${ }^{6}$.

\section{III.1.1 La division par phylai («tribus»)}

\section{III.1.1.1 Mégare}

La répartition des citoyens dans les trois tribus doriennes traditionnelles (Hylleis, Dymanes, Pamphyloi) est attestée à Mégare déjà à l'époque classique par un catalogue de soldats morts à la guerre. Il s'agit d'une liste de noms qui a été trouvée à proximité de l'agora et dont je reproduis ci-dessous le texte ${ }^{7}$.

4 Loukopoulou, Thrace propontique, p. 123.

5 L. Dubois, in IGDS, p. 23.

6 Voir supra, introduction, iv.

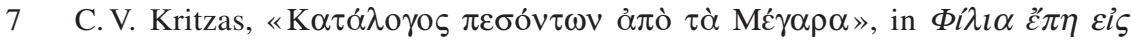

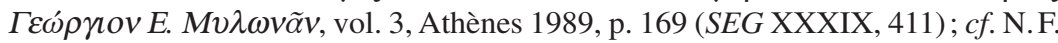
Jones, «The Order of the Dorian Phylai», $C P h$ 75, 3, 1980, p. 208; idem, Public Organization, p. 94-95; Jeffery, $L S A G^{2}$, p. 442; P. Gauthier, Bull. ép., 1990, 267; O. Masson, Bull. ép., 1990, 365 ; Smith, Megaris, p. 114-115; P. Low, «Remembering War in the Fifth-Century Greece: Ideologies, Societies, and Commemoration beyond Democratic Athens», World Archaeology 35, 1, 2003, p. 101-103; D. Knoepfler, A. Robu, Bull. ép., 2010, 338; SEG LVIII, 426. 


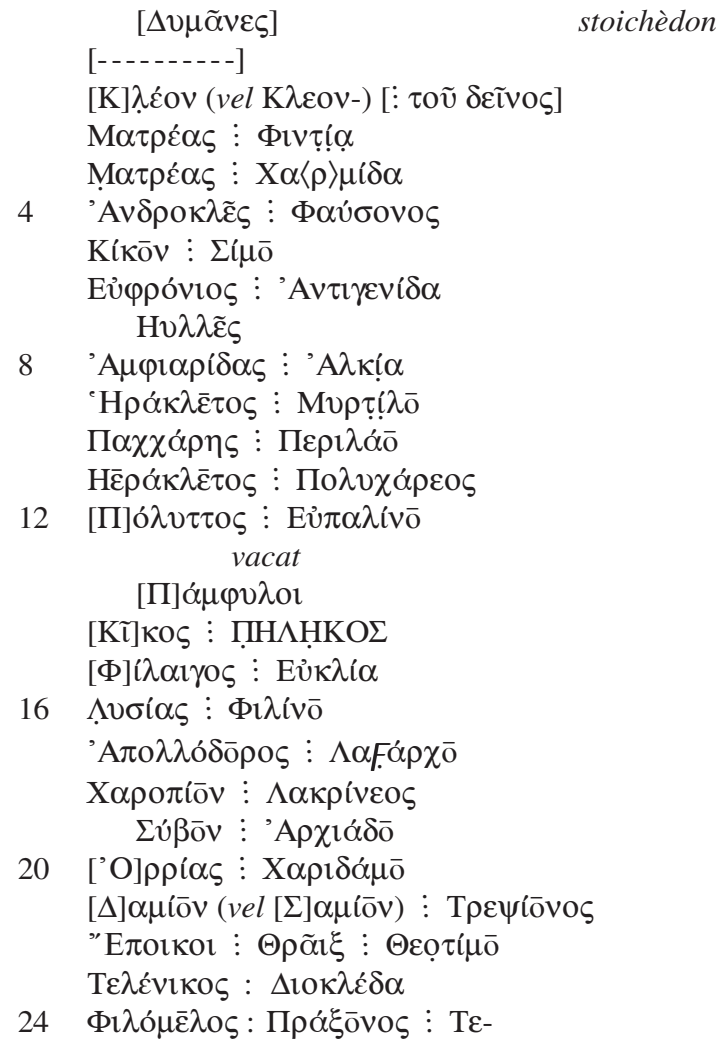

En latéral, à droite, de bas en haut:

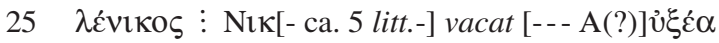

Sur le bord droit de la stèle:

(b)

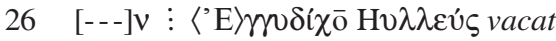

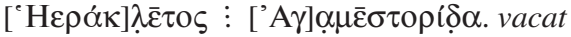

En se fondant sur l'écriture, Kritzas, date cet obituaire de $c a$. 425-400 et le considère comme une liste des victimes de la guerre du Péloponnèse. La partie (a) est la partie principale de l'inscription. Elle regroupe les noms des Mégariens, suivis de leurs patronymes, sur une seule colonne, sous les rubriques Dymanes, Hylleis et Pamphyloi, écrites en 
caractères plus grands. De plus, une liste des époikoi (1. 22-25) est présente à la fin de l'inscription. Faute d'espace, cette liste continue sur le bord de la pierre, à droite, de bas en haut. La partie (b), écrite sur le bord droit de la stèle, conserve encore la mention de deux défunts, ultérieurement ajoutés à la liste (1. 26-27). Pour le premier d'entre eux, seuls le patronyme et l'indication de l'affiliation civique sont conservés,

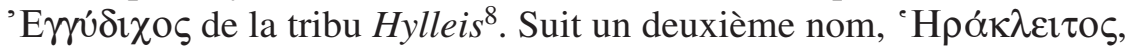
fils de 'A $\gamma \alpha \mu \varepsilon \sigma \tau o \rho i ́ \delta \alpha \varsigma$.

Il faut ajouter qu'à la ligne 19 ( $\Sigma u ́ \beta \bar{v} v)$, on trouve la première attestation à Mégare d'un ancien type de bêta, qui est sans aucun doute à l'origine des types de bêta «mégarien» attestés par les inscriptions de Sélinonte et les monnaies de Byzance ${ }^{9}$.

Rappelons que l'usage d'inscrire kata phylas sur des stèles les noms des soldats morts à la guerre n'est pas sans parallèles: il est aussi attesté dans des cités telles qu'Athènes ${ }^{10}$ et $\operatorname{Argos}^{11}$. En revanche, on trouve pour la première fois dans un obituaire le mot époikoi. Comme on n'a pas manqué de le noter, ce terme désigne soit des résidents permanents qui ne jouissent pas de tous les droits civiques, soit des étrangers réfugiés à Mégare et qui par la suite ont été recrutés dans l'armée ${ }^{12}$.

8 On constate qu'au lieu d'écrire ce nom sous la rubrique de la tribu Hylleis où il y avait encore suffisamment de place, le graveur a préféré l'écrire sur le bord, en indiquant son affiliation tribale.

9 Voir supra, chapitres II.1.2.5. et II.2.4.1.5.

10 Voir par exemple les inscriptions $I G \mathrm{I}^{3} 1162,1164,1165,1168,1184$, et le témoignage de Pausanias, I, 29, 4; 32, 3.

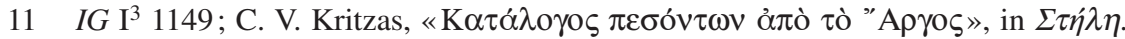

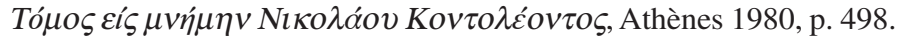

12 C. V. Kritzas, op. cit. (p. 326, n. 7), p. 178; SEG XXXIX, 411,p. 143 ; P. Gauthier, Bull. ép., 1990, 267 ; Legon, Megara, p. 464. La mention d'un «Thrace», un nom commun pour les esclaves, à la ligne 22, incite P. Low, op. cit., p. 102, à soutenir la présence d'esclaves parmi les époikoi. Il est plus probable pourtant que ce Thrace est un affranchi, devenu métèque. Contre l'opinion de Smith, Megaris, p. 113-114, 132, selon laquelle les époikoi constituaient une quatrième tribu mixte, composée soit de non Doriens, soit de réfugiés de Pérachora ou de Salamine, voir D. Knoepfler, A. Robu, Bull.ép., 2010, 338. Le statut des métèques à Mégare semble être analogue à l'époque classique à celui des métèques à Athènes (paiement du métoikion, obligation d'être représenté par un prostatès). Voir à cet égard P. Gauthier, «Métèques, périèques et paroikoi : bilan et points d'interrogation », in L'étranger dans le monde grec. Actes du colloque organisé par l'Institut d'études anciennes, Nancy 1987, Nancy 1988, p. 29 (=Études d'histoire et d'institutions grecques. Choix d'écrits, Genève 2011, p. 63-64). 
Du reste, il convient de s'arrêter sur une inscription du $\mathrm{V}^{\mathrm{e}}$ siècle, qui

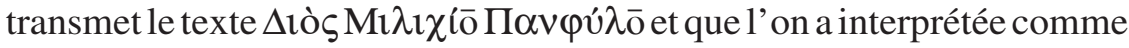
une attestation indirecte de la présence des tribus doriennes à Mégare. Cette inscription (aujourd'hui perdue) a été découverte par Lambros (près de la colline de Saint-Georges, dans la région de l'antique Nisaia), elle a été signalée par Richards, qui l'a qualifiée de borne de sanctuaire ${ }^{13}$. Mais il n'est pas exclu que l'on ait affaire à une dédicace votive ${ }^{14}$, car l'on connaît à Mégare et ailleurs (à Selinonte, à Athènes, etc.) des cippes ou des pierres grossières consacrées à Zeus Meilichios ou à Apollon Lykeios dont la formule dédicatoire comporte le nom du dieu au génitif ${ }^{15}$. Sur la foi de ce document, on a pensé que le culte de Zeus Meilichios appartenait soit à la tribu des Pamphyloi ${ }^{16}$, soit à toutes les tribus ${ }^{17}$. Le terme Panphylos fait plus particulièrement allusion, à mes yeux, au culte rendu par les Mégariens au héros Pamphylos. Dans ce sens, un parallèle est fourni par la loi sacrée de Sélinonte, qui témoigne de la célébration de Zeus Meilichios dans les chapelles ou les sanctuaires des héros Myskos et Euthydamos ${ }^{18}$. On peut ainsi penser que les Mégariens rendaient un culte à la même divinité dans la chapelle du héros dorien Pamphylos, l'éponyme de la tribu des Pamphylo ${ }^{19}$. Cette interprétation est appuyée par un passage de Pausanias, qui atteste que l'éponyme d'une autre tribu dorienne, Hyllos, le fils d'Héraclès, était honoré par les Mégariens ${ }^{20}$. Il

13 G.C. Richards, «Archaeology in Greece, 1897-8», JHS 18, 1898, p. 332 (SEG XXXVII, 370); $c f$. Jeffery, $L S A G^{2}$, p. 138, $\mathrm{n}^{\mathrm{o}} 12$, qui date l'inscription du $\mathrm{V}^{\mathrm{e}}$ siècle; Dewailly, Statuettes, p. 148-150; Jones et al., Lex sacra, p. 84; C. Grotta, Zeus Meilichios a Selinunte, Roma 2010, p. 165-166, 283, n 25.

14 N. Cusumano, «Zeus Meilichios», $M Y \Theta O \Sigma 3,1991$, p. 34, n. 57 ; C. Grotta, op. cit., p. 165.

15 M.L. Lazzarini, Le formule delle dediche votive nella Grecia arcaica, Roma 1976, p. 149-152, 303-304, $\mathrm{n}^{\text {os }} 877-884$. Voir pour Mégare, l'inscription IG VII 35 : 'А

16 Hanell, Megarische Studien, p. 178.

17 Jones, Public Organization, p. 94; cf. SEG XXXVII, 370; Jones et al., Lex sacra, p. 84, 92; Antonetti, Megara e le sue colonie, p. 89.

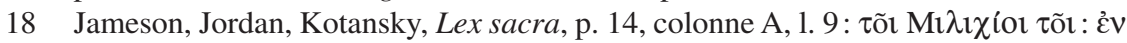

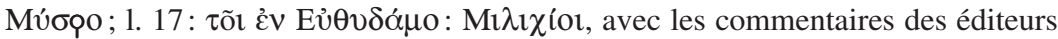
aux p. 28-29, 37, 52-53, 93 ; L. Dubois, IGDS II, $a d \mathrm{n}^{\circ} 18$, p. 47 ; $c f$. C. Grotta, op. cit., p. 199-201.

19 Robu, Zeus Meilichios, p. 285-286. Sur le héros Pamphylos, voir G. Türk, s.v. «Pamphylos» 2, RE XVIII, 3, 1949, col. 408.

20 Pausanias, I, 41, 2-3; cf. Smith, Megaris, p. 97. 
est donc permis de supposer que les héros éponymes des trois tribus doriennes faisaient l'objet d'un culte à Mégare, tout comme cela se passait avec les éponymes des dix tribus à Athènes ${ }^{21}$. On ne dispose pas de données suffisantes pour savoir si ce culte était pratiqué uniquement par les membres de la tribu des Pamphyloi, ou s'il s'agissait d'un culte célébré par l'ensemble de la communauté.

L'existence des tribus doriennes dans la Mégare classique et hellénistique est révélée par la structure tripartite des diverses institutions. On constate que Démosthène évoque un tribunal mégarien composé de trois cents juges, dont les membres étaient peut-être désignés par tribus $^{22}$. La structure tripartite du corps civique mégarien est mise en évidence au $\mathrm{III}^{\mathrm{e}}$ siècle par le collège de six stratèges, qui reste en place pour une période d'au moins quatre ans ${ }^{23}$. Il est probable que chaque tribu élisait deux stratèges dans ce collège. De même, les six théaroi, qui avaient fait au $\mathrm{III}^{\mathrm{e}}$ siècle une dédicace à l'Apollon Prostatèrios, ont pu être désignés par tribus ${ }^{24}$.

Les noms des trois tribus apparaissent dans une inscription hellénistique trouvée à Épidaure, qui mentionne des Mégariens en tant que juges (dikastai) lors d'une dispute territoriale entre Épidaure et Corinthe ${ }^{25}$. Le stratège Aigialeus, désigné par la Confédération achéenne pour qu'il s'occupe de ce conflit, est situé par Beloch entre 242/1 et 236/526. Après la mention de la décision prise, le document cite les cent cinquante et un juges de Mégare. Leurs noms, suivis des patronymes, sont classés par

21 U. Kron, Die zehn attischen Phylenheroen. Geschichte, Mythos, Kult und Darstellungen, Berlin 1976, passim.

22 Démosthène, XIX, Sur les forfaitures de l'ambassade, 295. Legon, Megara Pol. Hist., p. 48, n. 23, suppose que ce tribunal est le même que le Conseil oligarchique qui gouvernait Mégare au IV siècle. D. M. MacDowell (éd.), Demosthenes, On the False Embassy (Oratio 19), Oxford 2000, p. 335, garde pourtant pour «les Trois Cents » le sens de cour judiciaire.

23 IG VII 1-7; Heath, Proxeny Decrees, p. 85, $\mathrm{n}^{\circ}$ III. Voir infra, chapitre III.2.2.4.

$24 I G$ VII 39. Il est néanmoins possible que dans la dédicace fragmentaire $I G$ VII 40 à Apollon Prostatèrios, le nombre des théaroi soit de sept. Si tel fut le cas, on doit alors admettre que l'élection des théaroi n'était pas faite par les tribus, mais en fonction d'autres procédures, que nous ignorons.

$25 I G \mathrm{IV}^{2} 1,71$ (= K. Harter-Uibopuu, Das zwischenstaatliche Schiedsverfahren im achäischen Koinon, Köln et al. 1998, $\mathrm{n}^{\circ} 3$; S. L. Ager, Interstate Arbitrations in the Greek World, 337-90 B.C., Berkeley et al. 1996, no 38) ; cf. Wiseman, Land, p. 136138 ; Osborne, Classical Landscape, p. 162-164. Beloch, Gr. Gesch. ${ }^{2}$, IV, 2, p. 224. 


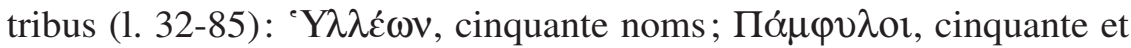
un noms; $\Delta \nu \mu \tilde{\alpha} v \varepsilon \varsigma$, cinquante noms. La procédure selon laquelle les cent cinquante et un dikastai furent désignés (élection ou tirage au sort) n'est pas précisée ${ }^{27}$. Bien que les Corinthiens aient accepté la décision donnant à Épidaure la propriété des terres disputées, ils contestèrent le tracé de la frontière. Les Mégariens envoyèrent alors une nouvelle commission plus restreinte, composée de trente et un termastères (leurs noms apparaissent aux 1. 85-96). Celle-ci fut chargée de procéder à une nouvelle délimitation de la ligne séparatrice entre Épidaure et Corinthe ${ }^{28}$. Les «commissaires de borne» sont choisis parmi les cent cinquante et un juges déjà mentionnés dans l'inscription et leurs noms observent le classement par phylai: dix noms pour les Hylleis, onze noms pour les Pamphyloi et dix noms pour les Dymanes ${ }^{29}$. Notons que, pour éviter le ballottage, la tribu des Pamphyloi compte un dikastès et un termastès de plus.

Enfin, la division par tribus est attestée à Mégare par des inscriptions à l'époque impériale, quand une quatrième tribu, celle des Hadrianidai, créée en l'honneur de l'empereur Hadrien, vint s'ajouter aux trois tribus primitives. Les quatre tribus dédient vers 135-137 ap. J.-C. des statues à Hadrien et à son épouse. L'empereur est honoré par les tribus des Dymanes $^{30}$, des Hadrianidai ${ }^{31}$ et par une tribu (des Hylleis ou des

27 Pour S.L. Ager, op. cit., p. 117, la réapparition des noms de quelques juges dans la souscription pour le temple d'Apollon IG VII 42 laisserait penser que ces Mégariens au moins étaient des riches, et peut-être des personnes prééminentes dans la cité. Si l'on accepte cette hypothèse, il en découlerait que les cent cinquante et un juges furent élus à Mégare.

28 Ces commissaires sont des magistrats analogues aux termastai mentionnés par le règlement frontalier entre deux cités d'Épire, Ambracie et Charadros : P. Cabanes et J. Andréou, «Le règlement frontalier entre les cités d'Ambracie et de Charadros », $B C H$ 109, 1985, p. 501-505, le terme apparaît dans le fragment B, 1.35 (SEG XXXV, 665). Sur les fonctions des termastères et des termastai, on verra D. Rousset, «Les frontières des cités grecques. Premières réflexions à partir du recueil des documents épigraphiques », CCG 5, 1994, p. 104-106.

29 Jones, Public Organization, p. 95.

$30 I G$ VII $70\left(I G I^{2} 2,1124\right)$. La date de cette série d'inscriptions est indiquée par la mention du proconsul d'Achaïe, Iulius Candidus, qui, selon B. E. Thomasson, Laterculi Praesidum, vol. I, Göteborg 1984, p. 194, n 33, a exercé sa fonction vers 135137 ap. J.-C. Selon E. Groag, Die römischen Reichsbeamten von Achaia bis auf Diokletian, Wien-Leipzig 1939, col. 69-70, ce proconsul date de 136/7; cf. W. Weber, Untersuchungen zur Geschichte des Kaisers Hadrianus, Leipzig 1907, p. 180.

$31 I G$ VII $72\left(I G\right.$ IV $\left.^{2} 2,1125\right)$. 
Pamphyloi ?) dont le nom n'est pas conservé ${ }^{32}$, tandis que Sabine l'est par les tribus des Pamphyloi ${ }^{33}$ et des Hadrianidai ${ }^{34}$. Comme Jones l'a proposé, on est autorisé à penser que chacune des quatre tribus a consacré une statue à Hadrien et une autre à Sabine, et qu'à l'origine, il y avait huit statues honorant le couple impérial. Le même savant considère que le titre ktistès ( «fondateur») avec lequel Hadrien apparaît dans ces inscriptions émanant des tribus serait un argument en faveur de la recréation de la division kata phylas par l'empereur ${ }^{35}$. Mais cette opinion se fonde sur un argument ex silentio trompeur, à savoir le manque d'attestations de tribus après le $\mathrm{III}^{\mathrm{e}}$ siècle.

Mieux, j'ai formulé ailleurs l'hypothèse que le titre de ktistès fut octroyé par les Mégariens à l'empereur en raison de son évergétisme édilitaire $^{36}$. Pausanias nous apprend à cet égard qu'Hadrien s'est illustré dans la cité de l'isthme par la reconstruction en pierre de l'ancien temple d'Apollon, originellement en briques ${ }^{37}$, et par l'élargissement de la route côtière dite de $\operatorname{Sciron}^{38}$. Or l'on sait qu'à partir de l'époque hellénistique, le mot ktistès peut désigner le fondateur d'une cité, mais aussi celui qui a entrepris la reconstruction d'une cité ou d'un bâtiment ou qui a accordé certains privilèges à une cité ${ }^{39}$. Ce fut sans doute aussi le cas d'Hadrien à Mégare, qui fut assimilé ici à Apollon Pythios, le bâtisseur mythique des remparts de la citét ${ }^{40}$. Les inscriptions honori-

$32 I G$ VII 71.

$33 I G$ VII $73\left(I G \mathrm{IV}^{2} 2,1126\right)$.

34 IG VII 76.

35 Jones, Public Organization, p. 97; cf. SEG XXXVII, 369.

36 A. Robu, «Notes sur les dédicaces mégariennes pour Hadrien et Sabine», Dacia N. S. 51, 2007, p. 171-176; cf. SEG LVII, 415; D. Knoepfler, Bull. ép., 2010, 337.

37 Pausanias, I, 42, 5.

38 Pausanias, I, 44, 6.

39 J. et L. Robert, Bull. ép., 1956, 317; Robert, Hellenica, IV, p. 116; Leschhorn, Gründer, p. 334-335 ; Casevitz, Vocabulaire, p. 232-235; S. Follet, «Hadrien ktistès kai oikistès: lexicographie et realia», in La langue et les textes en grec ancien. Actes du colloque Pierre Chantraine (Grenoble, 5-8 septembre 1989), F. Létoublon (éd.), Amsterdam 1992, p. 241-254. D'après A.-V. Pont, «L'empereur <fondateur > : enquête sur les motifs de la reconnaissance civique», REG 120, 2007, p. 526-552, le titre de ktistès, décerné par les cités grecques aux empereurs, a essentiellement gardé un sens politique en Asie Mineure.

40 Hadrien est appelé Pythios dans IG VII 70-72, et «le nouveau Pythios» dans IG VII 3491. Cf. J. Beaujeu, La religion romaine à l'apogée de l'empire. I, La politique religieuse des Antonins (96-192), Paris 1955, p. 184-186; M. T. Boatwright, Hadrian 
fiques émanent des tribus sans doute en raison du fait que ce sont ces groupements civiques qui payèrent la consécration des statues. Une autre inscription de Mégare confirme que les tribus avaient leurs propres revenus: celle-ci atteste que la tribu des Hadrianidai offrit une statue, «à ses propres frais » ( $\dot{\varepsilon} \kappa \tau \tilde{\omega} \vee i ̉ i ́ \omega v)$, à son bienfaiteur Tyranniôn, le fils de Nisiôn ${ }^{41}$.

\section{III.1.1.2 Byzance, Chalcédoine et Mésambria}

Les tribus sont des divisions traditionnelles, elles constituent une structure archaïque qui a été transmise dans plusieurs colonies mégariennes. Par conséquent, même si les noms des trois tribus doriennes ne sont attestés dans aucun des établissements mégariens de la Propontide et du Pont-Euxin, on peut en supposer l'existence compte tenu de la présence d'une structure tripartite de certaines institutions.

Ainsi, la division tripartite du corps civique byzantin se déduit d'un passage de Diodore, qui évoque la mise en place vers 403 d'un collège de trente magistrats par le Lacédémonien Cléarque ${ }^{42}$. Cette mention est faite dans le contexte de la demande par les Byzantins d'un stratège à Sparte pour mettre fin aux luttes internes qui divisaient la cité et pour repousser les attaques des Thraces. Les Lacédémoniens ont envoyé Cléarque, qui recruta des mercenaires et utilisa son pouvoir non seulement pour rétablir l'ordre, mais aussi pour imposer sa tyrannie à Byzance. Le Spartiate élimina les magistrats réguliers et les remplaça par un collège extraordinaire composé de trente Byzantins, qui furent probablement choisis parmi les citoyens les plus connus ou les plus riches, à raison de dix personnes par tribu ${ }^{43}$. Cependant, rapporte Diodore, à

and the Cities of the Roman Empire, Princeton-Oxford 2003, p. 128-129; F. Camia, Theoi Sebastoi. Il culto degli imperatori romani in Grecia (Provincia Achaia) nel secondo secolo D.C., MEAETHMATA 65, Atene 2011, p. 74-75.

41 IG VII 101; cf. Meyer, Megara, col. 200. Sur les revenus des phylai et les honneurs qu'elles décernent à l'époque impériale, voir maintenant U. Kunnert, Bürger unter sich. Phylen in den Städten des kaiserzeitlichen Ostens, Basel 2012, p. 270-289.

42 Hanell, Megarische Studien, p. 142.

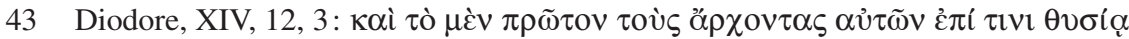

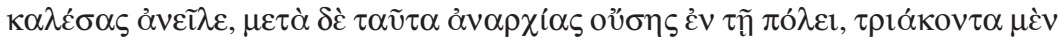

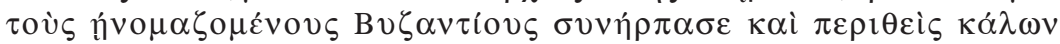

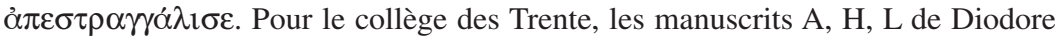


l'image des autres magistrats, Cléarque les fit tuer peu de temps après leur installation, afin d'instaurer son gouvernement autoritaire sur Byzance $^{44}$.

On connaît par ailleurs à Byzance de l'époque hellénistique un collège de Quinze (pentékaidéka), dont les membres auraient pu être choisis à raison de cinq par tribu ${ }^{45}$.

La présence parmi les magistratures de Chalcédoine des trois nomophylakes ${ }^{46}$ et des trois ankritères ${ }^{47}$ témoigne également d'une division tripartite du corps civique en tribus doriennes ${ }^{48}$. De la même manière, il est vraisemblable qu'à Mésambria les six stratèges ${ }^{49}$ et les six taxiarques (commandants de contingents d'infanterie) $)^{50}$ étaient recrutés par tribus.

De plus, on remarque que même si les décrets de Byzance stipulent seulement l'obligation des nouveaux citoyens de s'inscrire dans les hékatostyes, il est probable qu'il existait dans cette cité une division par phylai. De fait, comme les hékatostyes étaient réparties entre les phylai (voir ci-après), l'appartenance à une hékatostys signifiait automatiquement l'adhésion à une tribu ${ }^{51}$. Autrement dit, il suffisait au nouveau citoyen d'être inscrit dans une hékatostys pour pouvoir exercer ses droits au sein d'une tribu déterminée. Un parallèle à cela est fourni par Lamp-

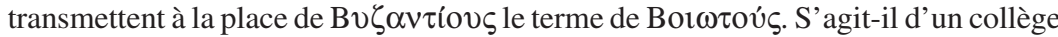
nommé Boiôtoi, un nom qui pourrait faire référence aux colons béotiens établis à

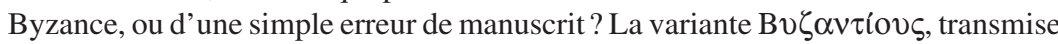
par les manuscrits P, F, J, K, M de Diodore, est préférée par l'édition de F. Vogel, T. Fischer (éds.), Diodori Bibliotheca historica, vol. III, Leipzig 1893 ; elle est retenue aussi par l'édition anglaise de C.H. Oldfather (éd.), Diodorus of Sicily. Books XIV-XV, London 1963, et l'édition française de M. Bonnet, E.R. Bennett (éds.), Diodore de Sicile, Bibliothèque historique, Livre XIV, Paris 1997. Sur le coup d'État de Cléarque à Byzance, voir aussi Polyen, II, 2, 7.

44 Il n'est pas exclu qu'en nommant un collège de Trente à la tête de la cité, Cléarque se soit peut-être inspiré de la mesure similaire imposée peu de temps avant, en 404, par un autre général spartiate, Lysandre, à Athènes.

45 Voir infra, chapitre III.2.2.3.

46 I. Kalchedon, 7. Voir infra, chapitre III.2.2.6.

47 I. Kalchedon, 8.

48 Hanell, Megarische Studien, p. 144.

49 IGBulg $\mathrm{I}^{2}, 323,324,326$. Sur les stratèges de Mésambria, voir infra, chapitre III.2.2.4.

$50 \quad$ IGBulg $\mathrm{I}^{2}, 325$.

51 Jones, Public Organization, p. 285. 
saque, où un décret stipule que les nouveaux citoyens sont répartis dans les hékatostyes, alors qu'un autre décret atteste que les magistrats épimènioi recevaient de la part du secrétaire de la cité une liste de «tous les citoyens écrite $\kappa \alpha \tau \alpha \grave{\alpha} \varphi v \lambda \grave{\alpha} \varsigma \kappa \alpha i ̀ ~ \varepsilon \kappa \alpha \tau o \sigma \tau \grave{\zeta} »^{52}$. L'obligation pour le nouveau citoyen d'être inscrit dans toutes les subdivisions de la cité apparaît ailleurs. Le décret d'Argos octroyant la citoyenneté à Alexandre de Sicyone prévoit l'enregistrement de ce dernier, tout comme dans le cas des autres citoyens, dans les subdivisions civiques: la tribu, la phratrie et la pentékostys ${ }^{53}$. Les décrets accordant le droit de cité à Athènes stipulent pour le nouveau citoyen l'obligation d'être inscrit dans la phratrie et les subdivisions civiques (tribu, dème) de son choix ${ }^{54}$.

\section{III.1.1.3 Héraclée du Pont et ses colonies}

Énée le Tacticien nous informe qu'à Héraclée du Pont, les citoyens étaient originellement répartis en trois tribus ${ }^{55}$. On a reconnu à juste titre dans ces subdivisions civiques les Hylleis, les Dymanes et les Pamphyloi $^{56}$. Cette identification a été mise en cause par Burstein, qui estime que la structure tripartite devait refléter les différents groupes ethniques ayant participé à l'installation de la colonie, notamment les Mégariens et les Béotiens. Pour étayer son hypothèse, il invoque la présence à l'époque impériale parmi les douze tribus de Prusias de l'Hypios (le nom ultérieur de la colonie héracléote de Kiéros), de trois

52 P. Frisch (éd.), Die Inschriften von Lampsakos, Bonn 1978 (IK, 6), 6, 1. 16, respectivement le décret no 9, 1. 39-40. Cf. Jones, Public Organization, p. 298; F. Ferraioli, L'Hekatostys : analisi della documentazione, Roma 2012, p. 103-115.

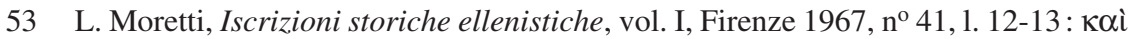

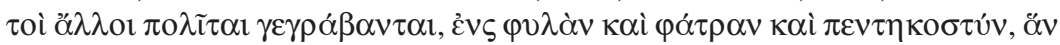
$\kappa \alpha \alpha u ̉ \tau o ̀ \varsigma ~ \pi \rho o \alpha i \rho \tilde{\eta} \tau \alpha$ l. Cf. SEG XXV, 362. Sur les subdivisons de la population d'Argos, voir M. Wörrle, Untersuchungen zur Verfassungsgeschichte von Argos im 5 Jhdt. v. Chr., Diss. Friedrich-Alexander-Universität, Erlangen-Nürnberg 1964, p. 11-31; M. Piérart, «Argos. Une autre démocratie», in Polis and Politics. Studies in Ancient Greek History. Presented to M. H. Hansen on his Sixtieth Birthday, August 20, 2000, Copenhagen 2000, p. 297-301.

54 M. Osborne, Naturalization in Athens, vol. I, Brussel 1981, p. 16-17.

55 Énée le Tacticien, Poliorcétique, XI, 10 bis.

56 H. Schneiderwirth, Das pontische Heraklea, Heiligenstadt 1882, p. 19; Hanell, Megarische Studien, p. 141; Pippidi, Héraclée, p. 238; Jones, Public Organization, p. 282 ; Rhodes-Lewis, Decrees, p. 424. 


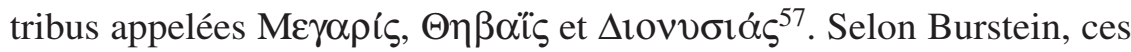
trois phylai dateraient de l'époque de la fondation de Kiéros par Héraclée et ne seraient autres que les tribus mentionnées par Énée le Tacticien. Les membres de ces tribus se seraient réunis déjà à Héraclée du Pont en fonction de leur origine, les Mégariens s'étant regroupés dans

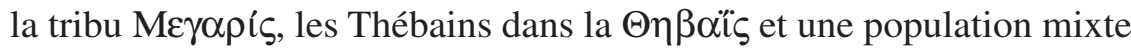
de Béotiens et d'autres colons provenant de la Grèce du Nord dans la $\Delta$ iovvolós $\varsigma^{58}$.

Néanmoins, l'hypothèse de Burstein, qui ne s'appuie pas sur d'autres témoignages et parallèles, ne peut guère emporter la conviction. Je crois

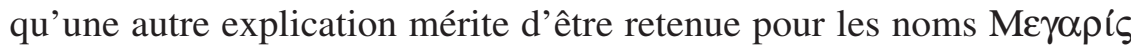
et $\Theta \eta \beta \alpha i ̈ \zeta:$ ces deux tribus ne reflètent pas l'organisation civique d'Héraclée du Pont, mais le désir des ressortissants de Prusias de l'Hypios de rappeler leur origine noble et ancienne. On sait que la cité de Kiéros a été fondée par Héraclée, colonie mégaro-béotienne, et ces deux tribus font assurément référence à cet ancien héritage héracléote ${ }^{59}$. Robert a bien noté qu'à l'époque impériale «les villes ont partout une passion de leur passé, de leur antiquité, et cela se traduit par des légendes et par

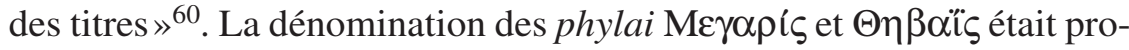
bablement la modalité par laquelle les membres de ces tribus indiquaient leur noble naissance $(\varepsilon \cup ̉ \gamma \varepsilon ́ v \varepsilon i \alpha)^{61}$.

I. Prusias ad Hyp., 1-12, 14, 149; M. Adak, K. Stauner, «Zur Stellung von Armeeangehörigen in ihren Heimatstädten: Der Fall M. Aur. Antoninus aus Prusias ad Hypium», Gephyra 3, 2006, p. 136-137, n 2 (SEG LVI, 1406). Cf. Magie, Roman Rule, vol. II, p. 1190, n. 21 ; F. K. Dörner, op. cit., col. 1137-1138; U. Kunnert, op. cit., p. 84-89.

58 Burstein, Heraclea, p. 21, suivi par Nawotka, West. Pont. Cities, p. 93-94. Contra Jones, Public Organization, p. 293, n. 1, qui estime que cette thèse est «wholly speculative».

59 T. Reinach, in Waddington-Babelon-Reinach, Recueil, I, 4, p. 602, n. 2. Robert, Hellenica, VIII, p. 76-77; idem, À travers l'Asie Mineure, p. 62.

60 Robert, À travers l'Asie Mineure, p. 412.

61 W.H. Wadington, $L B W, a d n^{\circ} 1176$, p. 286, note, à tort, que «le nom de la tribu Mégaris indique qu'il y avait parmi les premiers habitants des familles originaires de Byzance ou de Chalcédoine, toutes les deux colonies de Mégare ». Il n'y a aucune raison non plus d'expliquer ce nom par la présence à Prusias de l'Hypios d'une population mégarienne, comme le propose W. Tscherikower, Die hellenistischen Städtegründungen von Alexander dem Großen bis auf die Römerzeit, Leipzig 1927, p. 45. À cet égard, voir Robert, À travers l'Asie Mineure, p. 62. 
Quant à la $\Delta$ lovvolós, même si cette tribu était également présente à Héraclée du Pont, rien n'indique qu'elle ait contenu dans cette cité une population mixte ou qu' on puisse associer spécialement cette tribu avec Thèbes (opinion d'Ameling) ${ }^{62}$ ou la Béotie (suggestion de Reinach) ${ }^{63}$. Mieux, l'origine héracléote de la $\Delta$ tovvoiós de Prusias de l'Hypios n'est pas certaine, car Dionysos était célébré non seulement en Béotie et à Mégare, mais aussi en Bithynie, comme l'indiquent certains calendriers bithyniens ${ }^{64}$. Dans ces conditions, cette tribu pouvait aussi être introduite après la conquête de l'ancienne Kiéros par Prusias $\mathrm{I}^{\mathrm{er}}$, et

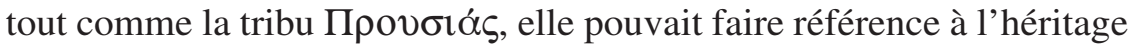
bithynien de la cité. Cette interprétation me semble être appuyée par la présence d'une tribu $\Delta$ tovvolós parmi les douze tribus de BithynionClaudiopolis, une cité fondée par Prusias ${ }^{\mathrm{er} 65}$.

En conclusion, il est certain que les Mégariens ou les Béotiens ayant fondé Héraclée du Pont étaient répartis dans les trois tribus doriennes ${ }^{66}$. La fondation d'une apoikia devait aboutir à la création d'une polis unifiée, et l'on n'a pas de témoignages qui pourraient confirmer que la société héracléote était divisée selon des critères ethniques.

Du reste, les récits témoignent de la structure tripartite du corps civique d'Héraclée du Pont à l'époque classique. Aristote atteste que les charges et les honneurs furent réservés à six cents citoyens lors du

62 W. Ameling (éd.), I. Prusias ad Hyp., p. 25.

63 T. Reinach, in Waddington-Babelon-Reinach, Recueil, I, 4, p. 602, n. 2. Magie, Ro-

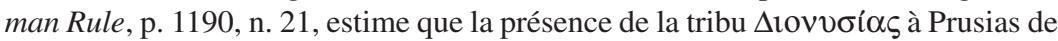
l'Hypios est due à l'héritage héracléote.

64 F. K. Dörner, op. cit., col. 1137; cf. Robert, À travers l'Asie Mineure, p. 62, n. 366.

65 C. Marek, «Die Phylen von Klaudiupolis, die Geschichte der Stadt und die Topographie Ostbithyniens », MH 59, 2002, p. 32-33 (SEG LII, 1231); $c f$. U. Kunnert, op. cit., p. 81-84. Sur la fondation de Bithynion par Prusias $\mathrm{I}^{\mathrm{er}}$, voir Robert, $\grave{A}$ travers l'Asie, p. 129-132; Fernoux, Notables, p. 40, 66; C. Marek, Geschichte Kleinasiens in der Antike, München 2010, p. 295.

66 Saprykin, Heracleia and Chersonesos, p. 40-41. L'opinion de Hanell, Megarische Studien, p. 141-142, selon laquelle les Héracléotes étaient divisés à l'époque impériale en cinq tribus, est une erreur. En effet, l'inscription attestant les cinq phylai sur laquelle s' appuyait le savant suédois a été faussement attribuée par G. Doublet, «Inscriptions de Paphlagonie», $B C H 13,1889$, p. 316-317, n 26, à Héraclée du Pont. On sait aujourd'hui qu'elle provient en réalité d'Héraclée-Périnthe. À ce propos, voir L. Robert, «Études d'épigraphie grecque. XL. Inscriptions d'Hérakleia», $R P h 10$, 1936, p. 113-115. 
gouvernement de la cité par l'oligarchie ${ }^{67}$. Suivant Polyen, un Conseil de trois cents membres fut renversé en 364 par Cléarque lors du coup d'État qui permit à ce dernier d'imposer sa tyrannie ${ }^{68}$.

Dans les colonies fondées par Héraclée du Pont, le regroupement des citoyens en trois tribus n'est pas confirmé de manière certaine par la documentation littéraire ou épigraphique. On évoquera ici une inscription de Chersonèse publiée par Vinogradov, qui fait mention à deux reprises du mot $\pi \rho v ́ \tau \alpha v \imath \varsigma^{69}$. L'éditeur date ce texte de fin du $\mathrm{IV}^{\mathrm{e}}$-début du III ${ }^{\mathrm{e}}$ siècle et l'interprète comme une liste des prytanes. Ces magistrats, conformément au modèle athénien, auraient été élus par chaque tribu pour préparer les sessions du Conseil et de l'Assemblée. Le savant russe estime que les prytanes ont été introduits à Héraclée du Pont à l'époque de l'adhésion de la cité à la première Ligue athénienne et ultérieurement transférés à Chersonèse. Malheureusement, le texte est trop mutilé pour que l'on puisse accepter sans réserve la restitution extensive de Vinogradov et la présence des prytanes à Chersonèse doit être confirmée par d'autres trouvailles ${ }^{70}$.

Toutefois, la présence d'une organisation tribale à Chersonèse semble être suggérée par l'attestation des trois nomophylakes par des décrets d'époques hellénistique et impériale ${ }^{71}$. Il s'agirait dans ce cas de magistrats élus par les trois tribus. On remarque aussi qu'à l'époque impériale, les magistrats qui apposaient leur sceau aux décrets de Chersonèse se répartissaient en trois rangs $(\sigma \tau i ́ \chi 01)$. Cette distribution pourrait

67 Aristote, Politique, V, 6, 3, 1305b 11-12. D'aucuns estiment que les six cents constituaient le Conseil (H. Schneiderwirth, op. cti., p. 19; Saprykin, Heracleia and Chersonesos, p. 46-48) ou l'Assemblée du peuple à Héraclée du Pont (V. Ehrenberg, The Greek States ${ }^{2}$, London 1969, p. 53). Mais, comme l'a noté Burstein, Heraclea, p. 109-110, n. 80, ces suggestions s'appuient sur une fausse interprétation du passage d'Aristote. $C f$. Figueira, Megarian Society, p. 154.

68 Polyen, II, 30, 2 ; cf. Burstein, Heraclea, p. 19; Bittner, Herakleia, p. 24-34.

69 Vinogradov, Les tribus doriennes, p. 64 (SEG XLIII, 497); cf. J. G. Vinogradov, Bull. ép., 1996, 290.

70 I. Makarov, qui prépare le nouveau corpus des inscriptions de Chersonèse, a eu l'amabilité de me suggérer que le mot $\pi \rho u ́ \tau \alpha v \imath \varsigma$, restitué aux 1.3-4, ne renvoie pas nécessairement à l'institution athénienne, mais serait plus probablement une nou-

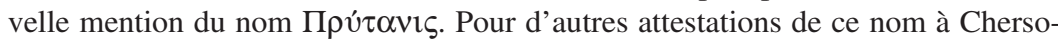

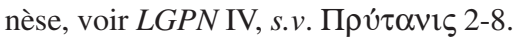

71 Voir les inscriptions citées infra, chapitre III.2.2.6. 
se rattacher à la présence des tribus dans la cité 72 . Une autre possibilité serait que les trois $\sigma \tau i ́ \chi 01$ se rapportent au regroupement des magistrats dans le document original par trois colonnes ${ }^{73}$.

En dernier lieu, on aurait aussi une division par tribus à Callatis, à condition d'accepter la restitution $\varphi v ́ \lambda[\alpha \rho \chi 0 \varsigma]$ proposée dans une inscription du $\mathrm{II}^{\mathrm{e}}$ s. ap. J.-C. ${ }^{74}$

\section{III.1.2 La division par hékatostyes («centaines»)}

\section{III.1.2.1 Mégare}

Outre les tribus, les sources antiques témoignent de l'existence dans les établissements mégariens d'une autre division civique, à savoir la division par hékatostyes («centaines»). Celle-ci est attestée à Mégare par une inscription d'Épidaure. Il s'agit d'un prêt datant de ca. 221/0. À la fin de l'inscription (1. 18-20) figurent les noms des témoins, l'un d'eux

72 Saprykin, Institutions et rapports fonciers, p. 105, 113; idem, Proxénie de Chersonèse, p. 41-65. Pour la mention de trois $\sigma \tau i ́ \chi 01$ dans les inscriptions de Chersonèse, voir IOSPE I $\mathrm{I}^{2}$, 359; Sourov, Inscr. de Chersonèse, p. 154-155 ; J. G. Vinogradov, «Un nouveau dossier documentaire de l'époque impériale de Chersonèse », VDI 1996, 1, p. 54-55 (L. Dubois, Bull. ép., 1997, 425; SEG XLV, 985 ; AE 1996, 1359). On ne suivra pas l'opinion de Saprykin, selon laquelle la nomination des archontes était elle aussi faite par tribus, car le nombre des archontes varie souvent à Chersonèse. On trouve six personnes portant le titre d'archonte dans les décrets publiés par Sourov, Inscr. de Chersonèse, p. 154-155, et Solomonik, Épigraph. Chersonèse II, 112; cinq dans les décrets IOSPE I², 359; Solomonik, Épigraph. Chersonèse II, 111; quatre dans le décret pour un Sinopéen publié par Saprykin, Proxénie de Chersonèse, p. 43 (SEG XLVIII, 999); et trois dans le décret publié par J. G. Vinogradov, VDI, 1996, 1, p. 54-55. Le lien entre le nombre d'archontes, les trois $\sigma \tau i ́ \chi 01$ et les tribus doriennes a été contesté par Vinogradov, Les tribus doriennes, p. 61-63. Un nouveau décret de Chersonèse atteste que les archontes étaient des magistrats annuels et qu'ils étaient responsables de la composition des tribunaux: I. Makarov, «La ville libre grecque et l'administration romaine: le cas de Chersonèse Taurique», in Une koinè pontique. Cités grecques, sociétés indigènes et empires mondiaux sur le littoral nord de la mer Noire (VII ${ }^{e}$ s. a.C.-III ${ }^{e}$. p.C.), A. Bresson et al. (éds.), Bordeaux 2007, p. 327-342; cf. A. Avram, Bull. ép., 2008, 411; SEG LV, 838.

73 V. Latyshev, ПONTIKA, Saint-Pétersbourg 1909, p. 327; cf. SEG XLV, 984.

74 ISM III, 70, voir aussi les commentaires d'Avram à la p. 85 du corpus callatien. 


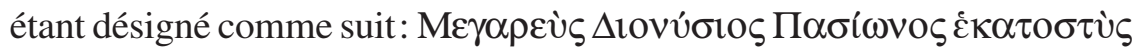
Kvvoбovpí[s $]^{75}$.

Bien que ce document soit daté de la période hellénistique, la présence des hékatostyes dans les colonies mégariennes (Héraclée du Pont, Byzance et Chalcédoine, voir ci-après) confirme que cette division civique remonte à l'époque archaïque ${ }^{76}$. Étant donné que les colonies de Propontide sont fondées dans la première moitié du VII ${ }^{\mathrm{e}}$ siècle, il y a tout lieu de croire que les hékatostyes figuraient dès cette époque parmi les institutions politiques de Mégare. Les doutes de Debord sur la diffusion de la division par hékatostyes de Mégare dans ses colonies ne me paraissent donc pas fondés ${ }^{77}$.

S'appuyant sur la mention des Kynosoureis dans la liste des cinq mérè primitifs de Mégare transmise par Plutarque (Questions grecques, XVII), les savants ont considéré l'hékatostys Kynosouris comme une preuve que les kômai ont survécu dans les hékatostyes qui en conservent les noms ${ }^{78}$. Pourtant, le texte de Plutarque ne parle pas de cinq kômai, mais de cinq mérè ${ }^{79}$. De plus, au cas où il y aurait eu un changement de cinq kômai en cinq hékatostyes, cet événement aurait dû avoir lieu au VIII ${ }^{\mathrm{e}}$ ou au début du $\mathrm{VII}^{\mathrm{e}}$ siècle, avant la fondation des colonies mégariennes de Propontide, car, dans ces cités, seule est attestée la division par hékatostyes. Or il est improbable que les Mégariens aient changé leurs subdivisions civiques à une date aussi haute. En réalité, il est plus probable que l'hékatostys Kynosouris ne témoigne pas d'une transformation à une certaine époque du méros des Kynosoureis en hékatostys, mais du culte rendu par les Mégariens au héros Kynosouros ${ }^{80}$.

$I G \mathrm{IV}^{2} 1,42,1.19-20$.

76 Hanell, Megarische Studien, p. 140-144; Jones, Public Organization, p. 12, 94, 266; Loukopoulou, Thrace propontique, p. 140; P. Gauthier, Bull. ép., 1987, 230, p. 313 $314 ; 1989,233$, p. 390; M. H. Hansen, «The Use of Sub-Ethnics as Part of the Name of a Greek Citizens of the Classical Period: the Full Name of a Greek Citizen », in Once Again: Studies in the Ancient Greek Poleis, T. H. Nielsen (éd.), Stuttgart 2004, p. 126 ; cf. G. Manganaro, «Epigrafia e istituzioni di Creta», in Antichità cretesi. Studi in onore di Doro Levi, vol. II, Cronache di Archeologia 13/1974, Catania 1978, p. 45.

77 Debord, Chiliastys, p. 208-209.

78 Burstein, Heraclea, p. 21 ; Legon, Megara. Pol. Hist., p. 47, n. 21, 48, n. 23 ; Loukopoulou, Thrace propontique, p. 139; Malkin, Foundations, p. 389; cf. Hanell, Megarische Studien, p. 140.

79 Voir infra, chapitre III.1.4.

80 Voir supra, chapitre I.1.1. 
Cette situation trouve des analogies à Byzance et à Chalcédoine, où les éponymes de plusieurs hékatostyes sont des héros ${ }^{81}$.

D'autre part, une attestation d'une «centaine» apparaîtrait dans un décret de proxénie de Delphes pour un Mégarien, un certain Пú $\theta \omega \mathrm{v}$ M $\alpha \tau \rho \varepsilon ́ \alpha[.] \theta 0 \varsigma^{82}$. En suivant la supposition erronée de Bechtel, selon laquelle ce sont les noms de phylai qui sont abrégés à Chalcédoine ${ }^{83}$, Baunack pensait que l'élément - $\theta$ os représentait l'abréviation d'un nom de tribu ${ }^{84}$. Mais comme à Chalcédoine il s'agit d'abréviations de noms de «centaines» et non de phylai (voir ci-après), notre - $\theta 0 \varsigma$ pourrait faire référence au nom d'une hékatostys. Notons que Bourguet a aussi

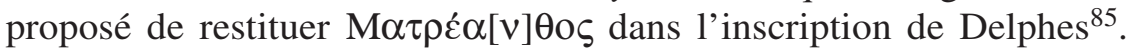
Ce dernier nom n'est guère satisfaisant, n'étant pas attesté par ailleurs.

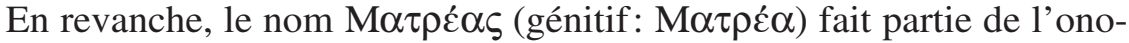
mastique mégarienne ${ }^{86}$. Il n'est donc pas exclu que la séquence - $\theta$ o $\varsigma$ ne soit pas la terminaison du patronyme, mais l'abréviation, voire même la fin (quoique il semble qu'il n'y a de l'espace que pour une lettre sur la pierre), de l'appellation d'une «centaine» à laquelle le Mégarien

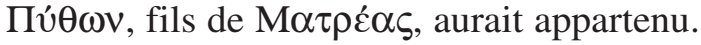

Le caractère très lacunaire de la documentation épigraphique empêche de connaître le rapport entre les tribus et les hékatostyes à Mégare. Sur la foi des exemples de Chalcédoine et d'Héraclée du Pont (voir ciaprès), où les hékatostyes étaient très probablement des subdivisions à l'intérieur des phylai doriennes, il n'est pas exclu non plus que chaque tribu de Mégare ait compté plusieurs «centaines». D'aucuns n'ont pas hésité à mettre en rapport les collèges mégariens composés de cinq magistrats (stratèges, polémarques, damiorgoi) ${ }^{87}$ avec la division par hékatostyes, en supposant l'existence de cinq «centaines» (voir aussi ci-

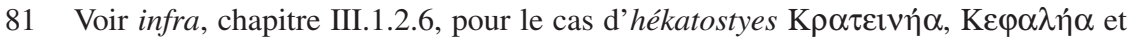

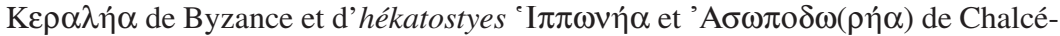
doine.

82 FD III 1, 177.

83 F. Bechtel, SGDI, ad no 3053, p. 31

84 J. Baunack, SGDI, ad n ${ }^{\circ} 2838$, p. 922.

85 É. Bourguet, FD III 1, ad n 177 , p. 101.

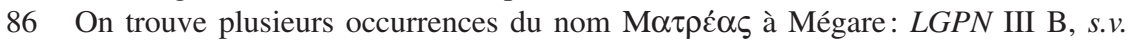
M $\alpha \tau \rho \varepsilon \alpha \varsigma$ 3-10.

87 Voir infra, chapitres III.2.2.4.-5. 
après $)^{88}$. Cependant, on n'a affaire ici qu'à des conjectures modernes et aucun document n'appuie l'idée selon laquelle les membres de ces collèges furent désignés par «centaines».

\section{III.1.2.2 Byzance et Chalcédoine $e^{89}$}

Par rapport à Mégare, il existe plus de documents attestant la division par hékatostyes dans les colonies mégariennes de la Propontide et du Pont-Euxin. Les «centaines» apparaissent ainsi à Byzance, Chalcédoine, Héraclée du Pont et peut-être aussi à Chersonèse. L'appartenance à une tribu ou à une hékatostys servait à définir l'identité du citoyen dans les colonies tout comme dans la métropole.

Trois décrets accordant le droit de cité attestent que les Byzantins se regroupaient en hékatostyes et que les nouveaux citoyens avaient la possibilité de choisir dans quelle hékatostys ils voulaient s'inscrire ${ }^{90}$. Dans ce sens, le décret (datant de ca. 175-171) en l'honneur d'Eudémos, fils de Nikôn, originaire de Séleucie du Kalykadnos et Ami du roi Antiochos IV stipule que le titulaire serait admis dans l'hékatostys qu'il voudra $^{91}$. Les Byzantins accordent la citoyenneté vers le milieu du $\mathrm{II}^{\mathrm{e}}$ siècle au juge milésien Apollônidas, fils de Memnôn, et à ses descendants, en même temps que la possibilité de s'inscrire dans les hékatostyes de leur choix ${ }^{92}$. On remarque que les descendants d'Apollônidas ont aussi le privilège de choisir leur hékatostys. Enfin, la possibilité de choisir son hékatostys est mentionnée dans le décret octroyant vers le milieu du $\mathrm{I}^{\mathrm{er}}$ siècle ap. J.-C. la citoyenneté à l'Olbiopolitain Orontas, fils d'Ababos ${ }^{93}$. Ces trois décrets nous montrent que l'obligation des ci-

88 Hanell, Megarische Studien, p. 141; Saprykin, Institutions et rapports fonciers, p. 108-110; Smith, Megaris, p. 112-113, 115.

89 Je me suis aussi penché sur l'organisation civique de Byzance et de Chalcédoine dans Robu, Organisation civique, p. 149-166.

90 Sur la mention de ce privilège dans les décrets des cités grecques, voir Jones, Enrollement Clauses, p. 97-110, surtout p. 84 (le cas de Byzance); $c f$. P. Gauthier, Bull. ép., 1992, 160.

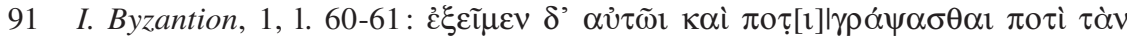

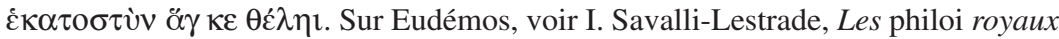
dans l'Asie hellénistique, Genève 1998, p. 54.

92 I. Byzantion, 2, 1. 29-32.

93 I. Byzantion, 3, 1. 27-30. 
toyens d'être inscrits dans une hékatostys s'est maintenue à Byzance entre le $\mathrm{II}^{\mathrm{e}}$ siècle av. J.-C. et le $\mathrm{I}^{\mathrm{er}}$ siècle ap. J.-C.

D'autre part, certains termes qui accompagnent les noms des citoyens dans des inscriptions provenant surtout de la nécropole de Byzance ont été considérés comme désignant des hékatostyes. Ils sont au génitif singulier et se trouvent à la même place que le démotique à Athènes et les noms de tribus dans d'autres cités grecques. Ainsi, en s'appuyant sur l'identification des noms figurant en troisième position dans deux inscriptions de Chalcédoine avec des noms d'hékatostyes, proposée par Hanell (voir ci-après), Robert a été le premier à remarquer que dans une inscription trouvée aux abords de Sélymbria, le mot $B \alpha \theta \omega v \eta ́ \alpha$ ne désignait pas le fleuve B $\alpha \theta v v i ́ \alpha \varsigma$, qui se jette en Propontide entre Sélymbria et Byzance (l'opinion du premier éditeur, Seure), mais d'une hékatostys. À la ligne 3 de la même inscription, $\Pi \alpha \rho[---]$ est le commencement du nom soit d'une hékatostys, soit d'un autre personnage honoré. La présence d'une «centaine» abrégée $\Pi \alpha \rho \tau \varepsilon-$ à Chalcédoine (voir ci-après) pourrait être un argument en faveur de la première possibilité. Il faut ajouter que l'inscription honorifique de Sélymbria remonte au $\mathrm{I}^{\text {er }}$ ou au $\mathrm{II}^{\mathrm{e}}$ siècle ap. J.-C., à une époque où cet établissement avait perdu le statut poliade. De fait, grâce à une inscription, on sait que Sélymbria était alors une kômè dans le territoire de Byzance, étant administrée par un kômarchès. Pour Robert, cela indiquerait que l'hékatostyes $\mathrm{B} \alpha \theta \omega \mathrm{v} \eta \dot{\alpha}$ (et peut-être aussi $\Pi \alpha \rho[---])$ appartenait alors à l'organisation civique byzantine ${ }^{94}$. Cette proposition a été ultérieurement confirmée par une inscription du $\mathrm{I}^{\mathrm{er}}$ siècle ap. J.-C. attestant la présence de l'hékatostys B $\alpha \theta \omega v \eta ́ \alpha$ à Byzance $^{95}$.

Les inscriptions témoignent également du fait que plusieurs noms de citoyens de Byzance sont suivis, après le patronyme, d'appellations

94 G. Seure, «Antiquités thraces de la Propontide», $B C H$ 36, 1912, p. 559-560, $\mathrm{n}^{\mathrm{o}}$ 14; Robert, Hellenica, II, p. 61-64; idem, in Firatl, Stèles de Byzance, p. 148. L'inscription publiée par Seure est reprise dans Sayar, Perinthos-Herakleia, 304, et dans I. Byzantion, S 23. Voir aussi l'inscription de l'époque impériale

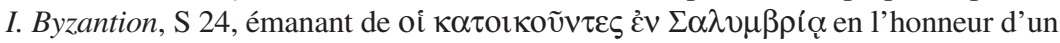

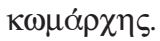

95 I. Byzantion, $315 \mathrm{c}$. 


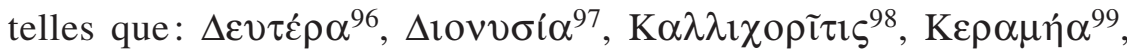

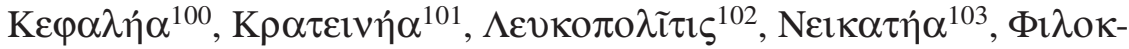
$\tau \varepsilon \rho \eta \alpha^{104}$ (ou $\Phi ı \lambda о \kappa \tau o \rho \eta ́ \alpha^{105}$ ). Signalons que parmi ces subdivisions, la seule qui pourrait dater de l'époque hellénistique est l'hékatostys $\Delta$ iovvoí $\alpha$, toutes les autres «centaines» étant attestées par des documents de l'époque impériale.

Par ailleurs, J. et L. Robert ont proposé, à titre d'hypothèse, que

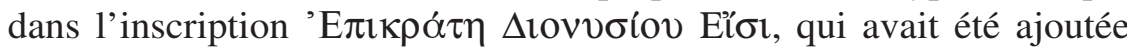
au-dessous d'un relief d'une stèle funéraire de Byzance, le dernier mot était l'abréviation du nom d'une hékatostys ${ }^{106}$. Une autre interprétation

I. Byzantion, 318 .

97 Bien que sa provenance ne soit pas connue, la stèle I. Byzantion, 378, mentionnant l'hékatostys $\Delta$ tovvoí $\alpha$, qui se trouve aujourd'hui dans le musée archéologique d'Istanbul, provient probablement de Byzance. Voir à cet égard J. et L. Robert, Bull. ép., 1970, 422, p. 423.

98 I. Byzantion, 320 a. Cette inscription a été attribuée par J. H. Mordtmann, «Inschriften aus dem Tschinili Kiösk», MDAI(A) 10, 1885, p. 19, nº 6, suivi par Hanell, Megarische Studien, p. 142-143, à Chalcédoine. Mais J. et L. Robert, Bull. ép., 1959, 252, p. 208, ont démontré que la pierre provenait de Byzance, en dépit de l'attestation d'une hékatostys K $\alpha \lambda \lambda$ ı $\chi 0 \rho \varepsilon \alpha \tau$ - à Chalcédoine. Cf. L. Robert, in Firatlı, Stèles de Byzance, p. 165.

99 I. Byzantion, 318.

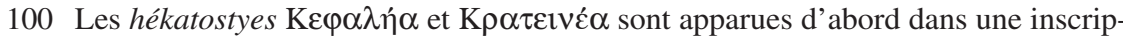
tion, connue seulement par une copie que J. H. Mordtmann avait donnée à Bechtel (voir ses commentaires dans SGDI, $a d \mathrm{n}^{\circ} 3053$, p. 31): I. Byzantion, 43. Ce sont J. et L. Robert, Bull. ép., 1959, 252, p. 208, qui ont soutenu l'origine byzantine de ces deux subdivisions civiques. Leur hypothèse est maintenant confirmée par un décret de l'époque impériale publié par T. Corsten, «Neue Denkmäler aus Bithynien », $E A$ 17, 1991, p. 81, no 1 (SEG XLI, 1102); cf. Debord, Mysiens, p. 142. Ce texte, qui émane d'un bourg du territoire asiatique de Byzance (le damos des Pratomyseitai),

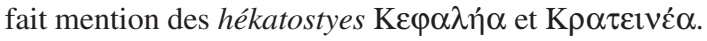

101 I. Byzantion, 43;319 b; T. Corsten, op. cit., p. 81, $\mathrm{n}^{\circ} 1$.

102 Robert, Documents, p. 227, n. 25, mentionne une dédicace à Zeus Brontaios qui

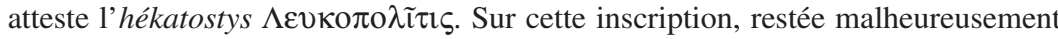
inédite, voir aussi Robert, Inscr. de Bulgarie, p. 202, n. 5 (=OpMinSel, V, p. 232, n. 5); idem, Hellenica, XI-XII, p. 580, n. 6; A. Lajtar, I. Byzantion, p. 22.

103 I. Byzantion, 248.

104 I. Byzantion, 30.

105 I. Byzantion, 319 a.

106 J. et L. Robert, Bull. ép., 1962, 196, p. 174; Firatl, Stèles de Byzance, p. 59, no 41, pl. XI, avec le commentaire de L. Robert aux p. 159-160. Le terme Eı $\sigma$ l est interprétée comme désignant une hékatostys aussi par Jones, Public Organization, p. 285, et 
a été proposée par Vatin, et soutenue aussi par Daux, qui considère la forme 'E déesse ${ }^{\widetilde{\tau}} \mathrm{I} \sigma \iota \zeta$. Dans ce cas, il ne s'agirait pas d'une épitaphe, mais d'une dédicace faite par une femme de Byzance à Isis ${ }^{107}$. J. et L. Robert ont

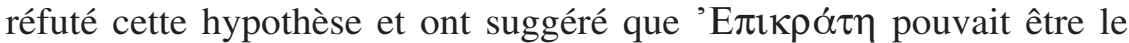

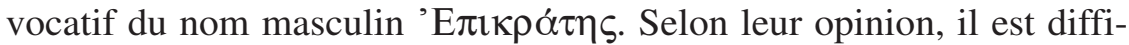
cile d'accepter qu'une dévote d'Isis ait utilisé pour faire une offrande une stèle funéraire ayant déjà été employée deux fois et représentant, de surcroît, un banquet funèbre ${ }^{108}$. Sur ce point, en revanche, Dunand estime que c'est «le motif représenté sur la stèle qui a pu lui-même favoriser une nouvelle utilisation: une confusion entre le thème du banquet funèbre et celui du banquet d'Isis et de Sarapis n'est certainement pas improbable, et on connaît des représentations grecques ou grécoégyptiennes de la klinè des dieux égyptiens ${ }^{109}$.

Il est important de souligner que l'abréviation des noms de subdivisions civiques n'est attestée pour aucune des hékatostyes byzantines déjà connues, et que dans les colonies mégariennes cet usage n'est présent avec certitude que dans les inscriptions de Chalcédoine, mais dans ce dernier cas sans doute pour des raisons d'espace ${ }^{110}$. Or comme l'a noté G. Daux, le graveur a choisi dans l'inscription de Byzance des lettres de grandes dimensions et il n'a pas utilisé toute la place dont il disposait, un grand espace ayant été laissé libre à gauche sous la

Loukopoulou, Thrace propontique, p. 141. Il convient de dire que cette stèle de

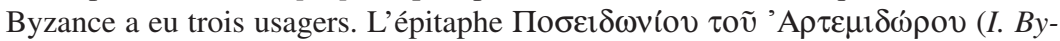
zantion, 190) a été gravée à l'époque hellénistique au-dessus du relief représentant le banquet funèbre sur un texte martelé. Ensuite, on a ajouté à l'époque romaine sur

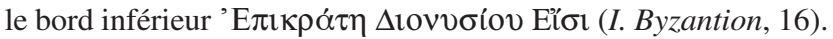

107 C. Vatin, «La stèle funéraire de Byzance n. 41 », BCH 92, 1968, p. 220-225, avec la lettre de G. Daux à la page 223, n. 5, dans laquelle ce dernier accepte l'interpréta-

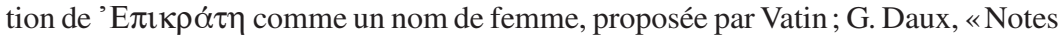
de lecture», $B C H$ 94, 1970, p. 599-600; idem, «Notes de lecture», $B C H$ 103, 1979 , p. $465-467$.

108 J. et L. Robert, Bull. ép., 1969, 385.

109 F. Dunand, Le culte d'Isis dans le bassin oriental de la Méditerranée II. Le culte d'Isis en Grèce, Leiden 1973, p. 65 ; cf. C. Vatin, op. cit., p. 225. A. Lajtar, I. Byzantion, ad $\mathrm{n}^{\circ} 16$, p. 46-47, et L. Bricault, Recueil des inscriptions concernant les cultes isiaques, vol. I, Paris 2005, ad $\mathrm{n}^{\circ}$ 114/0702, p. 183, considèrent cette inscription comme une dédicace à Isis.

110 Robu, Organisation civique, p. 154. 
dernière ligne ${ }^{111}$. Il y avait alors largement de la place pour écrire le nom complet de la subdivision civique, comme il était d'usage à Byzance. En somme, toutes ces données appuient l'idée que cette stèle a servi au culte isiaque et que le mot Eỉol est le datif du nom de la déesse Isis, et non pas l'abréviation du nom d'une «centaine». On ajoutera que le culte de cette déesse est attesté à Byzance par une stèle funéraire d'époque impériale qui porte la représentation d'une isiaque ${ }^{112}$ et peut-être par une dédicace à Isis et à Sarapis ${ }^{113}$. De même, Isis au voile décore le revers d'une monnaie de Byzance frappée à l'époque de Caracalla ${ }^{114}$.

Du reste, plusieurs hékatostyes sont attestées à Chalcédoine à l'époque hellénistique par deux inscriptions publiant les décisions de deux collèges d' $\alpha i \sigma ı \mu v \tilde{\alpha} \tau \alpha l$ de couronner leur chef respectif, le $\alpha \gamma \varepsilon \mu \omega \nu v$ $\beta o v \lambda \tilde{\alpha}$ s. On constate que la plupart des noms de ces magistrats sont suivis non seulement de patronymes, mais aussi d'appellations identifiées par Hanell comme des noms d'hékatostyes ${ }^{115}$. Dans la plupart des cas, ces noms sont abrégés; toutefois, pour quelques personnes, on trouve la formule onomastique complète, avec le nom de la subdivision civique au génitif, comme pour les hékatostyes de Byzance.

La première inscription atteste les appellations de huit subdivisions

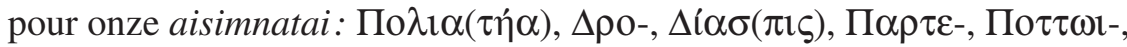

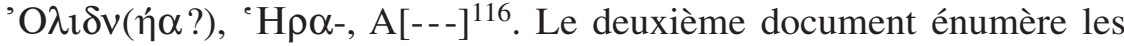
principaux magistrats de la cité (successivement le basileus, le hiéromnamôn, le prophètas, les trois nomophylakes) et mentionne la subdivision civique uniquement pour sept des neuf aisimnatai : По $\eta \tau \eta \dot{\eta} \alpha$, K $\alpha \lambda \lambda \imath \chi 0-$

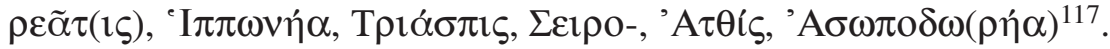

111 G. Daux, «Notes de lecture», BCH 91, 1967, p. 481.

112 I. Byzantion, 138 (= L. Bricault, op. cit., $\mathrm{n}^{\circ}$ 114/0704). Voir aussi I. Byzantion, 139, pour une autre stèle funéraire qui est aujourd'hui égarée et qui aurait représenté une isiaque.

113 I. Byzantion, 324 (= L. Bricault, op. cit., $\mathrm{n}^{\mathrm{o}}$ 114/0703). Cette inscription mentionnerait le roi des Odryses Rhoimétalkès $\mathrm{I}^{\mathrm{er}}$, mort en 14 ap. J.-C. Contra M. TachevaHitova, Eastern Cults in Moesia inferior and Thracia (5th cent. BC-4th cent. AD), Leiden 1983, p. 32-35, qui estime que cette inscription date du règne de Rhoimétalkès III (37-45 ap. J.-C.) et qu'elle provient de Périnthe ou de Mésambria.

114 Schönert-Geiss, Byzantion, vol. II, p. 82, pl. 87, nº 1587.

115 Hanell, Megarische Studien, p. 144.

116 I. Kalchedon, 6.

117 I. Kalchedon, 7. J'ai produit une nouvelle édition de ces deux inscriptions de Chalcédoine dans Robu, Organisation civique, p. 151-153. 
Chose importante, on estime que les aisimnatai constituaient à Chalcédoine une commission qui était la partie active du Conseil pour une période déterminée, comme les prytanes à Athènes pour un mois ${ }^{118}$. Par conséquent, il est vraisemblable que les aisimnatai de chaque liste, même s'ils provenaient généralement d'hékatostyes différentes, appartenaient, selon l'exemple des prytanes athéniens, à une seule tribu. Il y aurait eu ainsi une tribu composée de huit hékatostyes (I. Kalchedon, 7) et une autre peut-être de sept hékatostyes (I. Kalchedon, 6, mais il semble que cette inscription n'est pas complète). Je ne reprendrai pas ici la question du système de représentation des «centaines» dans la commission des aisimnatai, qui reste difficile à reconstituer, faute d'une documentation exhaustive ${ }^{119}$. On retiendra qu'à Chalcédoine, tout comme à Byzance et à Mégare, la nomenclature complète d'un personnage comprenait le nom, le patronyme et l' hékatostys à laquelle appartenait le citoyen.

\section{III.1.2.3 Héraclée du Pont et ses colonies}

Le seul témoignage d'un auteur antique concernant la division par tribus et par «centaines» d'une colonie mégarienne est celui d'Énée le Tacticien. Dans le chapitre sur les conspirations dans les cités grecques, celuici évoque les conflits entre les oligarques et les démocrates à Héraclée du Pont.

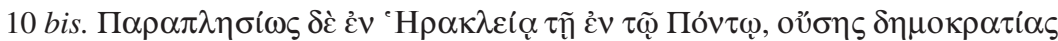

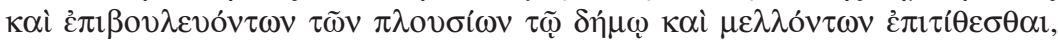

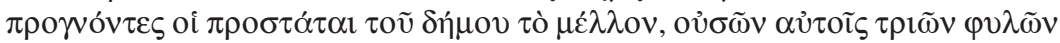

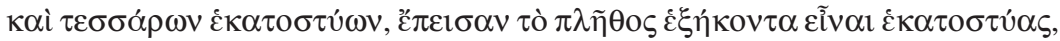

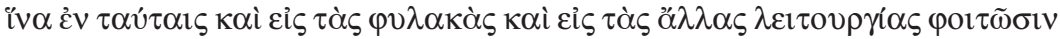

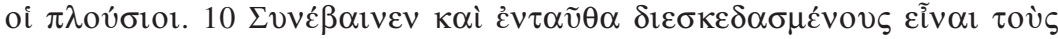

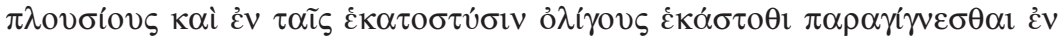

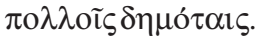

10 bis. Un cas similaire se présenta à Héraclée du Pont quand, sous la démocratie, les riches conspirèrent contre le peuple et furent prêts à l'attaquer. Les chefs du parti populaire, prévoyant ce qui allait se passer, persuadèrent la masse, alors qu'il existait trois tribus et quatre centaines, de créer soixante centaines dans le cadre des-

118 Böckh, CIG, ad n 3794, p. 973; Hanell, Megarische Studien, p. 146; Loukopoulou, Thrace propontique, p. 145. Voir infra, chapitre III.2.2.1.

119 Pour les différentes modalités d'élection et de représentation des citoyens dans les magistratures à Chalcédoine, je renvoie à Robu, Organisation civique, p. 151-153. 
quelles les riches viendraient régulièrement accomplir leur tour de garde et les autres services publics. 11. Là aussi, il arriva que les riches furent disséminés et que, dans les centaines, ils se trouvèrent chaque fois peu nombreux au milieu d'un grand nombre de leurs compatriotes ${ }^{120}$.

Ce récit confirme qu'à Héraclée du Pont, le corps civique était divisé en phylai et en hékatostyes, tout comme à Mégare. En ce qui concerne les tribus, même si le passage n'indique pas leurs noms, il s'agit sans nul doute des trois tribus doriennes (Hylleis, Dymanes, Pamphyloi, voir cidessus). Il n'a pas lieu de penser que cette réforme, datant probablement de $c a .370^{121}$, ait affecté leur nombre ou leur nature à Héraclée du Pont ${ }^{122}$.

Le rapport qui existe entre la division par tribus et celle par hékatostyes ne ressort pas clairement du texte d'Énée. À cet égard, les exégètes ont depuis longtemps formulé l'hypothèse selon laquelle on aurait affaire à un passage corrompu. Parmi les solutions avancées, la plus probable à mes yeux est celle qui considère que chaque tribu était divisée en quatre hékatostyes. Il existerait ainsi douze hékatostyes primitives à Héraclée, dont le nombre a été porté à soixante lors de la réforme du IV ${ }^{\mathrm{e}}$ siècle $^{123}$.

120 Énée le Tacticien, Poliorcétique, XI, 10 bis-11 (trad. d'A.-M. Bon, CUF, partiellement modifiée).

121 En soutenant que les événements sont présentés dans le chapitre XI de la Poliorcétique par ordre chronologique, Burstein, Heraclea, p. 20, 125, n 62, date la réforme d'Héraclée de ca. 370, avant l'instauration de la tyrannie de Cléarque en 364. Cependant, Saprykin, Heracleia and Chersonesus, p. 47, préfère situer ces événements à la fin du $\mathrm{V}^{\mathrm{e}}$ ou au début du $\mathrm{IV}^{\mathrm{e}}$ siècle. Voir aussi Bittner, Herakleia, p. 14, pour une possible datation de la réforme évoquée par Énée dans la deuxième moitié du $\mathrm{V}^{\mathrm{e}}$ siècle.

122 D. Whitehead (éd.), Aineias the Tactician, How to survive under Siege, Oxford 1990, p. 132.

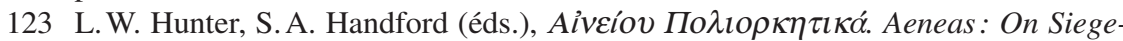
craft, Oxford 1927, p. 140; Pippidi, Héraclée, p. 237 ; A.-M. Bon, Énée le Tacticien, Poliorcétique, Paris 1967, p. 23, n. 1; D. Whitehead, op. cit., p. 132; M. Bettalli (éd.), Enea Tattico, La difesa di una città assediata (Poliorketika), Pisa 1990, p. 250; P. Villard, «Sociétés et armées civiques en Grèce: de l'union à la subversion», RH 266, 1981, p. 307, n. 76; Debord, Chiliastys, p. 207; cf. D. Barends, Lexicon Aeneium. A Lexicon and Index to Aeneas Tacticus' Military Manual <On the

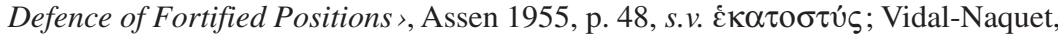
L'historiographie gr. de l'esclavage, p. 37-38; A. Avram, J. Hind, G., Tsetskhladze, s.v. «Herakleia», in Hansen-Nielsen (éds.), Inventory, p. 957. Pour une meilleure compréhension du texte, Busolt, Staatskunde, I, p. 261, n. 1, pense qu'il faut ajouter

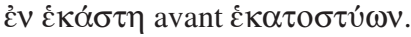


Cette possibilité est cependant rejetée par Jones, qui soutient qu'il faut garder le sens numérique pour le mot hékatostys («centaine»). Comme il ne peut pas y avoir seulement quatre cents citoyens à Héraclée, il

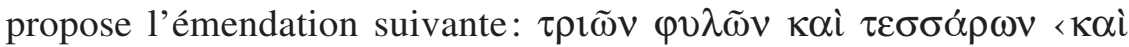

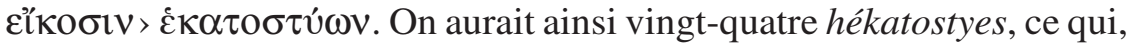
selon lui, permettrait d'abord d'avoir un nombre acceptable de «centaines», serait ensuite conforme à l'idée qui fait des «centaines» des subdivisions de tribus, et offrirait enfin une explication raisonnable de l'augmentation de leur nombre à soixante ${ }^{124}$. Étant donné que l'hypothèse de Jones se fonde principalement sur le sens numérique du mot hékatostys, probablement perdu à cette époque (voir ci-après), sa restitution du passage d'Énée ne me semble guère s'imposer. L'existence d'une tribu à Chalcédoine qui compte sept hékatostyes n'est pas une preuve pour que l'on suppose la présence de sept hékatostyes par tribu à Héraclée aussi, comme le pensait Jones. En réalité, on peut supposer que le nombre des hékatostyes variait dans chaque cité mégarienne en fonction de son propre corps civique.

En s'appuyant sur le texte d'Énée, Saprykin tend à prouver que les tribus constituaient le support de l'action politique de l'aristocratie, tandis que les hékatostyes représentaient la base de la démocratie. Il pense aussi qu'à Héraclée du Pont et dans sa colonie, Chersonèse, la citoyenneté était déterminée, pendant l'oligarchie, par l'appartenance aux tribus et, durant la démocratie, par l'appartenance aux hékatostyes ${ }^{125}$. Je ne partage pas cette opinion et je constate qu'au contraire, la division du corps civique héracléote en soixante hékatostyes n'a pas été spécifique au seul régime démocratique. De fait, Aristote atteste que l'accès aux magistratures était limité aux six cents citoyens lors de l'oligarchie, et l'on peut supposer que la désignation de ceux-ci se faisait au niveau de soixante «centaines», à raison de dix personnes par «centaine ${ }^{126}$. De même, il n'est pas exclu que les soixante membres du Conseil, arrêtés par Cléarque en 364, soient des représentants des soixante hékatostyes mentionnées par Énée ${ }^{127}$.

124 Jones, Public Organization, p. 282.

125 Saprykin, Institutions et rapports fonciers, p. 103-117; idem, Heracleia and Chersonesus, p. 41-48.

126 Aristote, Politique, V, 6, 2-3, 1305b 1-12.

127 Justin XVI, 4, 17. Cf. Saprykin, Institutions et rapports fonciers, p. 105-109; idem, «La boulè de Chersonèse», Archeologija (Kiev), 1995, 1, p. 75-82 (en russe; SEG 
Au demeurant, sur la foi du passage d'Énée le Tacticien, Pippidi a argumenté que les démocrates avaient effectué au $\mathrm{IV}^{\mathrm{e}}$ siècle à Héraclée du Pont une réforme du corps civique analogue à celle entreprise vers la fin du VI $\mathrm{VI}^{\mathrm{e}}$ siècle par Clisthène à Athènes. On assisterait ainsi au remplacement des trois tribus doriennes, le lieu du pouvoir des aristocrates héracléotes, par des tribus territoriales. Il y aurait ainsi à Héraclée du Pont, après la réforme démocratique, soit six tribus ayant chacune dix «centaines», soit dix tribus ayant chacune six «centaines» ${ }^{128}$. Il faut avouer néanmoins que le seul fait que les «centaines» soient multipliées n'est pas une preuve pour conclure que le principe d'organisation selon la parenté aurait été remplacé par celui selon la résidence. Comme le passage d'Énée le Tacticien l'atteste, le but des chefs des démocrates, en augmentant le nombre des hékatostyes, a été de disperser les riches dans un nombre plus grand de subdivisions civiques et de limiter ainsi leur possibilité d'action politique. D'ailleurs, Aristote con-

XLII, 689; XLV, 984), qui essaie, sans pour autant convaincre, de relier le nombre des membres du Conseil de Chersonèse à l'époque impériale à l'existence, dans un premier temps, de quatre ou de cinq hékatostyes. En réalité, le savant russe invoque des parallèles trompeurs, à savoir la présence à Héraclée du Pont de quatre hékatostyes (en fait plus probablement douze, voir ci-dessus) et à Mégare de cinq hékatostyeskômai (non attestée par les sources antiques, voir infra, chapitre III.1.4). Cependant, le nombre de magistrats varie trop souvent dans les décrets de Chersonèse pour que nous puissions accepter toutes ces hypothèses: il y en a 24 dans les décrets IOSPE I², 359; Sourov, Inscr. de Chersonèse, p. 154-155; 25 dans le décret publié par Solomonik, Épigraph. Chersonèse II, 111, et dans le décret SEG XLV, 985, et finalement 18 dans le décret publié par Saprykin, Proxénie de Chersonèse, p. 43. Cf. Y. G. Vinogradov, VDI, 1975, 1, p. 172. De même, Vinogradov, Les tribus doriennes, p. 61-63; idem, VDI 1996, 1, p. 48-60, met en doute les spéculations arithmétiques que Saprykin avance afin d'expliquer la désignation des conseillers de Chersonèse par tribus ou par hékatostyes. Selon Vinogradov, les dignitaires qui apparaissent à la fin des décrets «ayant apposé leurs sceaux» ( $\varepsilon \sigma \rho \rho \alpha ́ \gamma l \sigma \alpha \nu \tau o)$, ne représentaient pas tous les membres du Conseil, mais seulement ceux qui étaient présents au moment de l'adoption de la disposition. Ceci expliquerait bien pourquoi il existe dans les décrets un nombre différent de conseillers. $C f$. F. Gschnitzer, «Zwischen Denkmal und Urkunde. Kaiserzeitliche Neuerungen im Formular der Psephismata», in E fontibus haurire. Beiträge zur römischen Geschichte und zu ihren Hilfswissenschaften, R. Günther et S. Rebenich (éds.), Paderborn 1994, p. 283, 291-292; Rhodes-Lewis, Decrees, p. 556-557.

128 Pippidi, Héraclée, p. 237-238; Vidal-Naquet, L'historiographie gr. de l'esclavage, p. 37-38; Bittner, Herakleia, p. 14, n. 88; contra D. Whitehead, op. cit., p. 132; cf. aussi P. Villard, $R H$ 266, 1981, p. 307-308, n. 78. 
firme que l'augmentation du nombre des subdivisions civiques était un procédé utile afin que l'on consolide la démocratie et que l'on mélange les groupes sociaux ${ }^{129}$. On n'a donc aucun indice que les Héracléotes auraient pris une mesure visant à remplacer les tribus doriennes par des tribus territoriales ou par des «centaines»; ils ne choisirent qu' une formule ayant tendance à briser les solidarités entre les oligarques. On rappellera les propos de Villard sur ce point: «La précaution était alors d'intégrer le citoyen dans un cadre collectif où précisément les distinctions sociales n'étaient que peu ou pas prises en compte ${ }^{130}$.

D'autre part, l'essai de Burstein de montrer que les hékatostyes n'étaient pas des subdivisions civiques de tribus mais seulement des divisions territoriales se fonde sur deux arguments discutables. Le premier résulte de son opinion relative à l'absence des tribus doriennes, et par conséquent de leurs subdivisions (hékatostyes), à Héraclée du Pont; une opinion qui est, à mon sens, erronée (voir ci-dessus). Ensuite, Burstein estime que les kômai étaient à Mégare des unités territoriales ayant survécu dans les hékatostyes ${ }^{131}$. En réalité, dans l'état actuel de nos connaissances, il est difficile de prouver que les hékatostyes étaient des divisions territoriales dans le monde mégarien. On a attribué une base territoriale aux hékatostyes en raison du fait que la kômè (en réalité un méros) des Kynosoureis attestée par la liste de Plutarque était aussi connue comme une hékatostys à l'époque hellénistique (Kynosouris). On pensait donc que les cinq kômai de l'époque archaïque s'étaient transformées en cinq hékatostyes à l'époque hellénistique ${ }^{132}$. Mais si l'on considère que la liste de Plutarque est une création de l'époque classique ou hellénistique ${ }^{133}$, et que l'on renonce à identifier les kômai avec les hékatostyes, toute cette argumentation perd sa valeur.

Certains savants modernes ont soutenu que dans les colonies héracléotes de Chersonèse et de Callatis, la configuration des lots faisait référence à la division par hékatostyes. Ainsi, Shcheglov suggère qu'il existe à Chersonèse un lien entre le groupe de 100 klèroi identifiés

129 Aristote, Politique, VI, 4, 19, 1319b 23-27.

130 P. Villard, op. cit., p. 307.

131 Burstein, Heraclea, p. 21. Voir également G. Manganaro, op. cit., p. 45-46, qui considère, à tort, les hékatostyes mégariennes comme des divisions «di tipo territoriale», équivalentes aux kômai.

132 Voir supra, chapitre III.1.2.1.

133 Voir supra, chapitre I.1.1. 
dans la péninsule de Majačnij, et la division par hékatostyes ${ }^{134}$. Saprykin développe cette thèse d'une manière beaucoup plus compliquée: s'appuyant sur de nouvelles études de terrain, il estime que l'on aurait eu au $\mathrm{IV}^{\mathrm{e}}$ siècle à Majačnij non pas 100 lots avec des maisons rurales, mais seulement 25 lots, tous divisés en quatre parcelles. Pour chaque parcelle, il y aurait eu un représentant de l'une des quatre hékatostyes primitives. Ainsi, les terrains n'auraient été accordés qu'à 100 citoyens (25 de chacune des quatre hékatostyes $)^{135}$. Assurément, cette reconstruction est trop hasardeuse pour être acceptée et elle soulève des problèmes méthodologiques insurmontables ${ }^{136}$. D'ailleurs, comme on l'a $\mathrm{vu}$, il est fort probable qu'initialement les hékatostyes d'Héraclée du Pont n'étaient pas au nombre de quatre, mais de douze.

Quant à la cité de Callatis, Avram note que les distances entre les bornes données par les fragments d'une limitatio d'une partie du territoire, exécutée très probablement sous le règne de Trajan (ISM III, 5155), sont de 1.000, 2.000 et (une seule fois) de 2.400 pieds; c'est-à-dire des multiples de 100 et de 120 . D'après ce savant, cette combinaison entre un système décimal et duodécimal, qui semble être révélée par la délimitation de l'époque impériale, suggère que la division mégarienne

134 A. N. Shcheglov, Polis et chora. Cité et territoire dans le Pont-Euxin, Paris 1992, p. 224-228; cf. Avram, Gesch. des Territ. von Kallatis, p. 125-126. Située à l'extrémité nord-ouest de la péninsule «héracléote» de Chersonèse, la péninsule de Majačnij semble être la «vieille» Chersonèse de Strabon (VII, 4, 2, C 308), et selon certains, le site de la première implantation héracléote: Hind, Megarian Colonization, p. 146150 (avec les références).

135 Saprykin, Heracleia and Chersonesus, p. 77; idem, Institutions et rapports fonciers, p. 111-116; idem, Ancient Farms and Land-Plots on the Khora of Kersonesos Taurike (Research in the Herakleian Peninsula 1974-1990), Amsterdam 1994, p. 85-86. D'autre part, le savant russe estime que les 400 lots de la péninsule d'Héraclée, délimités à la fin du IV et au début du $\mathrm{III}^{\mathrm{e}}$ siècle dans la chôra de Chersonèse, appartenaient probablement à 4 hékatostyes, chaque «centaine» ayant 100 lots. Pour le lotissement du territoire de Chersonèse, voir aussi Latyshev, IOSPE $\mathrm{I}^{2}, a d \mathrm{n}^{\circ} 403$, p. 360-364; A. Wasowicz, «Traces de lotissements anciens en Crimée», MEFRA 84, 1972, p. 199-229; E. I. Solomonik, G. M. Nikolaenko, «Les lots agraires de Chersonèse au début du III ${ }^{\mathrm{e}}$ siècle av. J.C. (ad IOSPE I² 403)», VDI, 1990, 2, p. 79-99 (en russe); J. G. Vinogradov, «Greek Epigraphy of the North Black Sea Coast, the Caucasus and Central Asia (1985-1990)», ACSS 1, 1, 1994, p. 66-67. Pour les analogies et les différences entre la délimitation du territoire de Callatis et celui de Chersonèse, voir A. Avram, in ISM III, p. 360-362 (avec la bibliographie).

136 Voir les critiques de Hind, Megarian Colonization, p. 151, et de Müller, D'Olbia à Tanaïs, p. 146-147. 
du corps civique par hékatostyes aurait été aussi transmise à Callatis ${ }^{137}$. Cela reste très hypothétique et, comme dans le cas de Chersonèse, il s'avère dangereux de relier les données fournies par le cadastre du territoire et l'organisation civique.

Il faut donc admettre que l'on ne dispose pas de témoignages solides permettant d'accepter l'existence d'un lien entre les hékatostyes et la présence d'une division centésimale dans les territoires de Chersonèse ou de Callatis. Cela n'exclut pas la présence des hékatostyes dans les colonies d'Héraclée du Pont. On constate qu'un ostrakon de Cher-

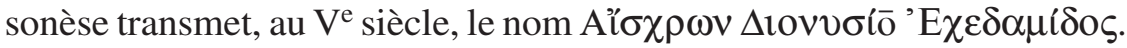
Comme l'ont proposé Vinogradov et Zolotarev, le dernier élément représente très probablement le nom d'une subdivision civique, soit la «centaine» ${ }^{\prime} \mathrm{E} \chi \varepsilon \delta \alpha \mu i \varsigma^{138}$.

\section{III.1.2.4 Un cas douteux: Sélinonte}

Bien que les documents de Sélinonte ne mentionnent jamais l'appellation d'hékatostys, on a interprété le troisième nom de certains citoyens comme appartenant à une subdivision civique. C'est le cas, d'après

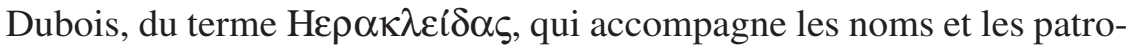
nymiques de plusieurs personnes dans une defixio ${ }^{139}$. D'autres savants estiment en revanche que cette appellation est celle d'un groupe familial ou gentilice, de tels groupes étant déjà attestés par les inscriptions de Sélinonte ${ }^{140}$.

137 Avram, Gesch. des Territ. von Kallatis, p. 133-134, 137; idem, Zur Verfassung von Kallatis, p. 175; idem, ISM III, p. 16-17, 85; idem, Les territoires d'Istros et de Callatis, p. 627.

138 Vinogradov-Zolotarev, Ostracismo, p. 119, n III, 8, pl. IV, 11 (SEG XLXI, 1031);

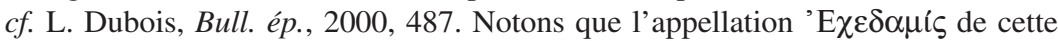
hékatostys est rare; on peut la rapprocher du nom 'E $\chi \varepsilon \delta \alpha \mu i \delta \alpha \zeta$ attesté au $\mathrm{VI}^{\mathrm{e}}$ siècle à $\operatorname{Argos}(L G P N$ III A, s.v. 'E $\chi \varepsilon \delta \alpha \mu i ́ \delta \alpha \varsigma)$.

$139 I G D S, 36$, avec le commentaire de L. Dubois à la p. 47. Cf. Bettarini, Defixiones, ad $\mathrm{n}^{\circ} 24$, p. 127; Brugnone, Note epigrafiche, p. 72.

140 L. H. Jeffery, «Further Comments on Archaic Greek Inscriptions », ABSA 50, 1955 , p. 73; R. Arena, «Di una defixio selinuntina», PP 41, 1986, p. 117-119; eadem, IGASM $\mathrm{I}^{2}, a d \mathrm{n}^{\circ} 69$, p. 70; F. Cordano, «Considerazioni sull'uso greco del terzo nome in Sicilia», in Seconde giornate internazionali di studi sull'area elima (Gibellina, 22-26 settembre 1994). Atti, Pisa-Gibellina 1997, p. 403; F. Ghinatti, «Le organizzazioni civiche siceliote», Kokalos 46, 1, 2000 (2004), p. 59-60. 
Par ailleurs, une épitaphe fragmentaire de la fin du $\mathrm{VI}^{\mathrm{e}}$ siècle a été,

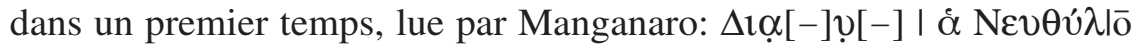

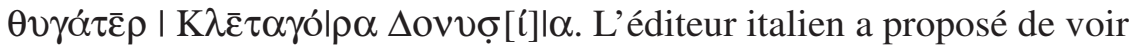
dans $\Delta o v v \sigma ̣[i] \alpha$ le nom d'une subdivision civique de type hékatostys. On comprendrait alors l'inscription: «Dia-, fille de Neuthylos, épouse de Kléthagoras de l'hékatostys Donysia» ${ }^{141}$. On a aussi suggéré que le nom de la subdivision civique renverrait à l'île de l'Égée appelée $\Delta$ ovovoí $\alpha$, qui fut en possession des Rhodiens, et dont l'ethnique était,

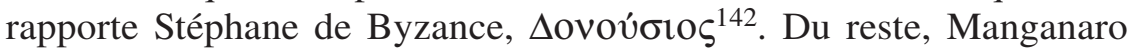
est revenu, dans un deuxième temps, sur ce texte et a proposé de recon-

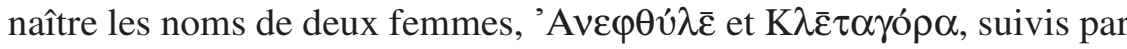
un patronyme, $\Delta$ ovvọ[.] $\alpha^{143}$.

Si l'on retient la première interprétation de $\Delta o v v \sigma ̣[i] \alpha$, il est possible que le graveur ait oublié un iôta après le delta et que le nom de la «centaine» puisse être corrigé en $\Delta\langle i\rangle$ ovvọ [í]l $\alpha$. L'attestation d'une subdivision civique appelée Dionysia dans une autre colonie mégarienne, à Byzance, me semble appuyer cette proposition ${ }^{144}$. Il faut avouer néanmoins que le caractère fragmentaire de l'inscription et la lecture difficile des lettres conservées empêchent de choisir de manière définitive entre les diverses restitutions.

Dans ces conditions, on conclura que, sur la base des deux exemples évoqués, il est difficile de prouver la présence des hékatostyes à Sélinonte et leur existence reste à être confirmée par les découvertes futures.

141 Manganaro, Studi di epigrafia, p. 30; IGASM I², 25 bis; IGDS II, 23. L. Dubois, Bull. ép., 1997, 729; idem, IGDS II, $a d \mathrm{n}^{\circ} 23$, p. 70, suggère de lire ơ Me $\theta \theta u ́ \lambda \bar{o}$ à

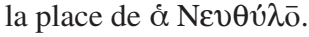

142 Manganaro, Studi di epigrafia, p. 30, n. 8; R. Arena, IGASM $\mathrm{I}^{2}$, ad n ${ }^{\circ} 25$ bis, p. 102; eadem, «Interferenze linguistiche e grafiche nell'epigrafia greca di Sicilia», in Sicilia Epigraphica. Atti del convegno (Erice, 15-18 Ottobre 1998), M. I. Gulletta (éd.),

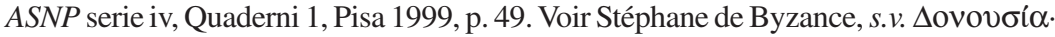

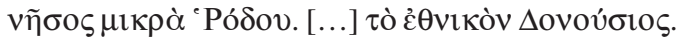

143 G. Manganaro, «Epigrafia greca dell'Occidente», in XI Congresso Internazionale di Epigrafia Greca e Latina (Roma 18-24 settembre 1997). Atti I, Roma 1999, p. 149 (SEG XLIX, 1326); cf. Brugnone, Note epigrafiche, p. 59, 88.

144 Voir supra, chapitre III.1.2.2. 


\section{III.1.2.5 La valeur numérique du mot hékatostys}

Suivant Jones, le terme d'hékatostys aurait conservé dans les cités mégariennes son sens numérique de «centaine». Cette idée avait l'avantage, on l'a vu, d'offrir une base de calcul pour le corps civique d'Héraclée du Pont. De même, Jones invoque la valeur numérique du terme hékatostys pour réfuter l'hypothèse de la transformation des cinq kômai de la Mégaride en cinq hékatostyes. Car, selon lui, la population civique de Mégare ne pouvait pas compter que cinq cents personnes ${ }^{145}$. Même si, à mon tour, je tiens pour erronée l'opinion d'une transformation des kômai en hékatostyes (voir ci-après), je crois que ce dernier argument de Jones est dépourvu de valeur.

De fait, plusieurs indices nous suggèrent qu'une division par hékatostyes ne suppose pas nécessairement que chaque hékatostys ait inclus une centaine de personnes ${ }^{146}$. Tout d'abord, on remarque qu'à Héraclée du Pont les hékatostyes ont augmenté d'une manière exceptionnelle de douze à soixante. Or il est difficile d'accepter une augmentation exceptionnelle du nombre des citoyens de mille deux cents à six mille. D'ailleurs, le passage d'Énée le Tacticien ne permet pas d'affirmer que la réforme démocratique fut accompagnée de l'augmentation du nombre des citoyens ${ }^{147}$. La réforme d'Héraclée du Pont montre en

145 Jones, Public Organization, p. 96 (pour les hékatostyes de Mégare), et p. 9-10, 282 (pour les hékatostyes d'Héraclée du Pont). De même, Debord, Chiliastys, p. 207, donne aussi une valeur numérique au mot hékatostys. Contra A.-M. Bon, op. cit., p. 23, n. 1; D. Whitehead, op. cit., p. 133; M. Bettalli, op. cit., p. 250 ; cf. P. Gauthier, Bull. ép., 1987, 230, p. 313-314.

$146 C f$. H. Francotte, La polis grecque. Recherches sur la formation et l'organisation des cités, des ligues et des confédérations dans la Grèce ancienne, Paderborn 1907, p. 125-126, qui se demande aussi à juste titre s'il faut prendre les dénominations numériques (chiliastys, hékatostys) au pied de la lettre, en notant: «de toute façon, les mathématiciens qui ont tracé ces belles figures n'ont eu qu'une satisfaction d'un moment, puisque la régularité parfaite des nombres n'a pas tardé à être dérangée par les morts et les naissances ».

147 Contra Vidal-Naquet, L'historiographie gr. de l'esclavage, p. 38, qui suggère que la réforme mentionnée par Énée le Tacticien a été accompagnée d'un élargissement du corps civique. Avram, Mariandyner, p. 25-26; idem, Gesch. des Territ. von Kallatis, p. 124-125, estime qu'à la suite de cette réforme du IV ${ }^{\mathrm{e}}$ siècle plusieurs Mariandyniens hellénisés furent intégrés dans le démos d'Héraclée du Pont. Voir supra, chapitre II.3.1.2. 
réalité la désinvolture avec laquelle les Anciens utilisaient les termes institutionnels ${ }^{148}$.

Ensuite, on constate que l'on laisse à Byzance au bon gré des nouveaux citoyens le choix de l'hékatostys à laquelle ils veulent appartenir ${ }^{149}$. Ceci implique que les Byzantins ne tenaient pas à garder à tout prix pour chaque subdivision civique un nombre fixe de cent citoyens. Et rien n'indique que l'Assemblée, le Conseil ou divers magistrats aient contrôlé dans la cité du Bosphore, comme ailleurs, l'enrôlement des citoyens dans les subdivisions civiques ${ }^{150}$. De surcroît, comme on l'a vu, deux des trois tribus doriennes de Chalcédoine étaient très probablement composées respectivement de sept et huit hékatostyes, or il est impossible que ces tribus aient compté seulement sept cents ou huit cents citoyens. En conclusion, les testimonia des colonies me portent à croire que le mot hékatostys avait perdu à l'époque classique et hellénistique son ancien sens numérique et que l'on ne peut pas connaître le nombre des citoyens des cités mégariennes en s'appuyant sur les attestations de cette division civique.

\section{III.1.2.6 Les fonctions des hékatostyes}

La communis opinio est que les hékatostyes, compte tenu de leur nom («centaines»), avaient originellement dans les cités doriennes un rôle militaire (voir aussi le cas analogue des pentékostyes), l'organisation militaire ayant servi de modèle à l'organisation civique ${ }^{151}$. Cette fonction est attestée à l'époque classique à Héraclée du Pont par Énée le Tacticien, qui note que les riches ( $\pi \lambda$ ov́бıol) devaient accomplir leurs tours de garde ( $\varphi v \lambda \alpha \kappa \alpha i ́)$ et les autres services publics ( $\lambda \varepsilon \imath \tau o v \rho \gamma i \alpha \imath)$ dans les hékatostyes ${ }^{152}$. Il ne faut pas retenir de ce récit que seuls les oligarques accomplissaient les obligations militaires, ou qu'avant la

148 M. Piérart, «Phratries et 〈kômai〉 d'Argos», BCH 107, 1983, p. 274 , n. 32.

149 Voir supra, chapitre III.1.2.2.

150 Le contrôle du nombre des citoyens par phylai est attesté par exemple à Milet, où seules les tribus désignées par le démos pouvaient être tirées au sort pour l'enrôlement des nouveaux citoyens: A. Rehm (éd.), Das Delphinion in Milet, Berlin 1914,

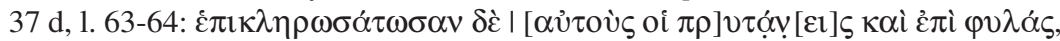

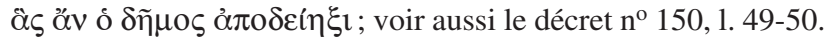

151 Debord, Chiliastys, p. 201 ; Jones, Public Organization, p. 93; M. Gras, H. Tréziny, in Mégara 5, p. 565.

152 Énée le Tacticien, Poliorcétique, XI, 10 bis. 
réforme mise en place par les démocrates ces obligations étaient accomplies dans les tribus. Énée mentionne les riches uniquement parce qu'il tient à insister sur le but principal de la réforme: la dissémination des riches dans un nombre plus grand de subdivisions civiques.

On remarque qu'à Chalcédoine, les dénominations des hékatostyes

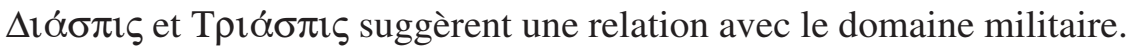
Car le mot ỏotí désigne le rang de soldats ${ }^{153}$ et les particules $\delta 1-$ et $\tau \rho 1$ - indiquent l'existence d'un ordre numérique spécifique à une organisation militaire. Le nom de l'hékatostys $\Delta \varepsilon v \tau \varepsilon ́ \rho \alpha$ (la «Seconde») de Byzance provient aussi d'un numéro d'ordre ${ }^{154}$. Mieux, les hékatostyes de Chalcédoine avaient un rôle dans la désignation des magistrats: dans cette cité, les aisimnatai étaient choisis par hékatostyes ${ }^{155}$.

Les «centaines» ont aussi un rapport avec le domaine du religieux, quelques-unes d'entre elles ayant des dieux ou des héros comme éponymes.

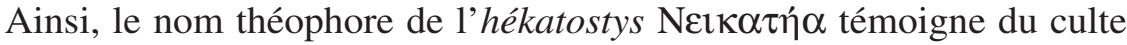
rendu par les Byzantins à la déesse Nikè ${ }^{156}$. Une inscription du début du II ${ }^{\mathrm{e}}$ siècle ap. J.-C. mentionne la déesse Nikè en tant que hiéromnamôn, le magistrat éponyme byzantin ${ }^{157}$, et les monnaies confirment qu'elle a détenu à l'époque impériale pendant plusieurs années l'éponymie de Byzance $^{158}$. L'hékatostys $\Delta$ tovv $\sigma i ́ \alpha$ met en lumière la célébration de Dionysos à Byzance, culte attesté dans cette cité par d'autres documents ${ }^{159}$.

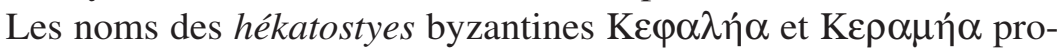

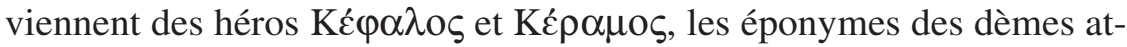

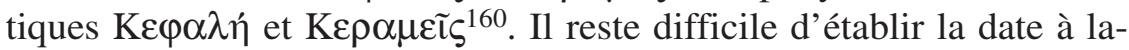
quelle remonte l'héritage athénien visible dans la dénomination de ces deux hékatostyes, ainsi que dans le nom 'A $\tau \theta i ́ \zeta$, porté par une «centaine» de Chalcédoine. À mon sens, cet héritage pourrait remonter autour de

153 Pour des exemples de l'emploi du mot ỏ $\sigma \pi i \zeta$ avec le sens de «rang de soldats », voir Thucydide, IV, 93, 4; VII, 79, 1; Aristophane, fr. 72 (éds. R. Kassel et C. Austin).

154 L. Robert dans Firatli, Stèles de Byzance, p. 143.

155 Voir supra, chapitre III.1.2.2.

156 A. Lajtar, I. Byzantion, ad no 248, p. 180.

157 I. Byzantion, 35.

158 Pour les monnaies qui attestent la déesse Nikè en tant qu'éponyme à Byzance, voir Schönert-Geiss, Byzantion, vol. II, p. 7, 15, 17, et pl. 66-67, $\mathrm{n}^{\mathrm{os}}$ 1343-1360, pl. 91, $\mathrm{n}^{\text {os }} 1634-1637,1639-1642$.

159 Voir infra, chapitres III.2.1.2.

160 Sur la présence de ces deux héros en Attique, voir Kearns, Heroes, p. 176 (Kéramos), 95 et 177 (Képhalos). 
390/89, lorsque l'intervention des troupes athéniennes de Thrasybule joua un rôle décisif dans l'établissement de la démocratie à Byzance ${ }^{161}$. Je n'exclus pas pour autant que les données athéniennes aient été introduites plus tard, vers 340, suite à l'alliance conclue entre les Byzantins et les Athéniens contre Philippe $\mathrm{II}^{162}$. L'appui accordé par le stratège athénien Charès à la cité de Byzance dans la guerre contre ce roi de Macédoine eut comme résultat l'intégration de l'Athénien dans la liste locale des stratèges. Cette alliance explique très probablement aussi la mention des Athéniens, chez certains auteurs tardifs, comme les fondateurs de Byzance ${ }^{163}$.

L'attestation à l'époque hellénistique à Chalcédoine de l'hékatostys 'A $\sigma \omega \pi \mathrm{o} \delta \omega \rho \eta \dot{\alpha} \alpha$, dont le nom est en rapport avec le dieu-fleuve béotien Asôpos, révèle la présence des traditions béotiennes sur les rives du Bosphore $^{164}$. Cette hékatostys a pu être importée à Chalcédoine depuis Byzance, où il y avait une tradition qui énumérait les Béotiens parmi les fondateurs de la cité ${ }^{165}$. On aurait ainsi une situation similaire à celle des hékatostyes $\mathrm{K} \alpha \lambda \lambda \imath \chi 0 \rho \tau \tau \imath \varsigma$ et $\mathrm{K} \alpha \lambda \lambda \imath \chi 0 \rho \varepsilon \tilde{\alpha} \tau \imath \varsigma$, attestées respectivement à Byzance et à Chalcédoine.

De même, les noms de l'hékatostys chalcédonienne 'I I $\pi \omega v \eta ́ \alpha$ et

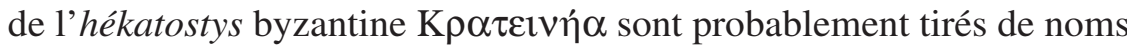
de héros ou d'héroïnes ${ }^{166}$. L'hékatostys Kynosouris de Mégare a, quant à lui, comme éponyme le héros Kynosouros ${ }^{167}$.

161 Xénophon, Helléniques, IV, 8, 27-28.

162 Robu, Organisation civique, p. 159-163.

163 Voir supra, chapitre II.2.4.1.2.

164 Hanell, Megarische Studien, p. 143; Jones, Public Organization, p. 284; Fossey, Boiotia and the Pontic Cities, p. 109. Sur le dieu-fleuve Asôpos, voir E. Wilisch, s.v. «Asopos», in Roscher, Lexikon, I, 1, col. 642-644; R. Wagner, s.v. «Asopos» 8, RE II 2, 1896, col. 1706-1708.

165 Voir aussi supra, chapitre II.2.4.1.4.

166 Böckh, CIG, ad n 3794, p. 974; Hanell, Megarische Studien, p. 143. On trouve de nombreuses attestations du nom "I $\pi \pi \omega v$ dans le monde grec, y compris à Chalcédoine ( $L G P N, \mathrm{~V}$, s.v. $\left.{ }^{\circ} \mathrm{I} \pi \pi \omega \vee 1-2\right)$ et à Byzance ( $L G P N, \mathrm{IV}$, s.v. $\left.{ }^{\prime \prime} \mathrm{I} \pi \pi \omega \vee 7-8\right)$. De

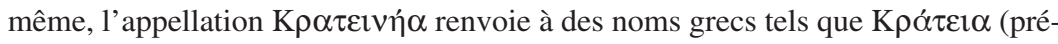

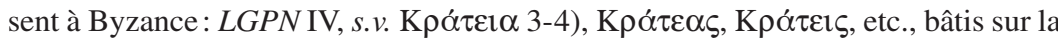

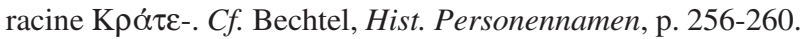

167 Voir supra, chapitre I.1.1. Pour la formation des noms de subdivisions civiques à partir d'anthroponymes (dont certains sont des héros) ou de toponymes, voir le récit du Ps.Aristote, Constitution d'Athènes, XXI, 5, à propos des réformes de Clisthène: $\pi \rho 0$ -

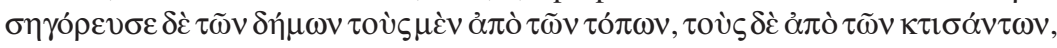

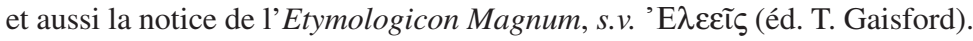




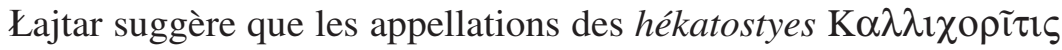
de Byzance et $\mathrm{K} \alpha \lambda \lambda \imath \chi 0 \rho \varepsilon \tilde{\alpha} \tau \imath \varsigma \zeta$ de Chalcédoine font référence à l'épi-

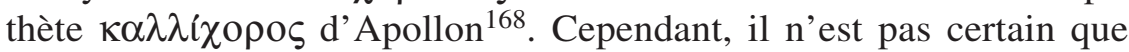
le culte d'Apollon avec l'épiclèse de Kallichoros ait existé à Mégare ou dans d'autres cités grecques. D'ailleurs, le texte d'Euripide (Héraclès, 687-690) invoqué par Lajtar n'attribue pas cette épithète de manière directe à Apollon. Dans ce passage, le mot $\kappa \alpha \lambda \lambda i ́ \chi 0 \rho \circ \varsigma$ semble se rapporter aux jeunes filles de Délos. Celles-ci chantent leur péan et exécutent

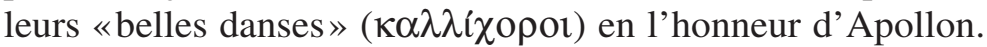

Selon une autre opinion, les deux «centaines» tireraient leurs noms

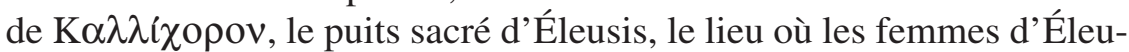
sis ont formé le premier chœur pour consacrer des chants à Déméter ${ }^{169}$. On aurait alors affaire à des noms à résonance athénienne. De telles appellations sont connues, on l'a vu, pour d'autres subdivisions civiques:

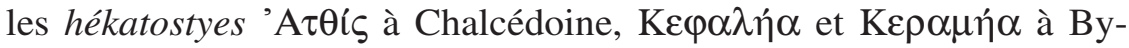
zance portent des noms qui se rattachent à l'Attique.

On peut par ailleurs envisager une troisième solution: l'éponyme de deux «centaines» pourrait être un héros nommé Kallichoros. Mieux, ce héros pourrait avoir une origine béotienne, car le nom Kallichoros, fort rare, est attesté à Thèbes (à la haute époque hellénistique) ${ }^{170}$. Il pourrait aussi avoir donné son nom au fleuve Kallichoros (le «fleuve des belles danses») qui se trouvait aux abords d'Héraclée du Pont, colonie mégaro-béotienne ${ }^{171}$.

Notons enfin que la ressemblance entre les dénominations de l'hékatostys byzantine K $\alpha \lambda \lambda \imath \chi 0 \rho \tilde{\imath} \tau \varsigma \varsigma$ et de l'hékatostys chalcédonienne K $\alpha \lambda \lambda \imath \chi 0 \rho \varepsilon \tilde{\alpha} \tau \imath \varsigma$ s'explique, selon J. et L. Robert, par la sympolitie qui aurait uni à l'époque hellénistique, pendant une certaine période du moins, Byzance et Chalcédoine ${ }^{172}$. On ne doit pas exclure en même temps que les concordances institutionnelles existant entre les deux

168 A. Lajtar, I. Byzantion, $a d \mathrm{n}^{\circ} 320$ a, p. 224.

169 Böckh, $C I G, a d \mathrm{n}^{\circ} 3794$, p. 974 ; Hanell, Megarische Studien, p. 143 ; G. Huxley, CR

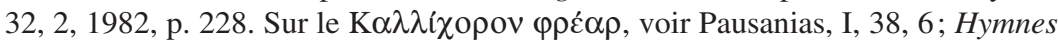
homériques à Déméter, 272; Euripide, Ion, 1075; Suppliantes, 392 et 619; Callimaque, Hymnes, VI, 15; Apollodore, I, 5, 1.

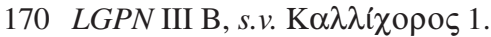

171 Ps.-Scylax, 90; Callimaque, fr. 600 (éd. R. Pfeiffer; apud scholie à Apollonios de Rhodes, II, 904-10a). Cf. Robu, Trad. onomastiques, p. 284-285.

172 J. et L. Robert, Bull. ép., 1959, 252, p. 208. 
colonies découlent des traditions communes présentes dans les deux cités-sœurs du Bosphore ${ }^{173}$.

\section{III.1.3 Les ikadeis de Mésambria}

Il convient d'évoquer brièvement ici l'hypothèse de Nawotka, selon laquelle il existait à Mésambria une division par ikadeis («vingtaines»). Cette institution apparaît dans deux inscriptions fragmentaires de l'époque hellénistique: grâce à l'une d'entre elles, on apprend que les ikadeis décernèrent une couronne à des bienfaiteurs, ceux-ci étant couronnés pendant la fête des Dioscures ${ }^{174}$. En s'appuyant sur une notice du Lexicon d'Hésychios, qui qualifie le terme éikadès de «part d'une tribu»175, Nawotka estime que les ikadeis pouvaient constituer une subdivision civique, soit un groupe de vingt hommes, soit $1 / 20$ d'une tribu ${ }^{176}$.

Cependant, l'opinion initiale de Mihailov, qui considère les ík $\alpha \delta \varepsilon \tilde{\iota} \zeta$ comme un collège de magistrats, les Vingt (vigintiviri), est plus vraisemblable ${ }^{177}$. Car cette thèse est soutenue par la présence dans les cités pontiques d'autres collèges similaires, à savoir à Mésambria ${ }^{178}$ et à Olbia d'un collège des Neuf ${ }^{179}$, à Olbia d'un collège des $\operatorname{Sept}^{180}$ et à Istros d'un collège de Dix ${ }^{181}$. Mieux, on trouve à Byzance, une cité qui avait envoyé des époikoi à Mésambria, un autre collège dont la désignation est déterminée par le nombre des membres, les Quinze (pentékaidéka) ${ }^{182}$.

173 Le magistrat hiéromnamôn, présent autant à Byzance qu'à Chalcédoine, est un autre exemple d'échange institutionnel entre ces deux cités mégariennes de la Propontide: voir infra, chapitre III.2.1.2.

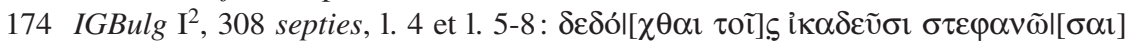

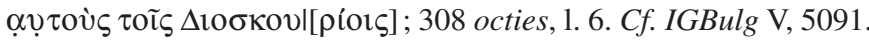

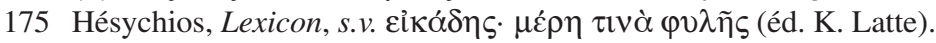

176 Nawotka, West. Pont. Cities, p. 94-96.

177 G. Mihailov, IGBulg $\mathrm{I}^{2}$, ad $\mathrm{n}^{\mathrm{o}} 308$ septies, p. 266; no 314, p. 274-275; cf. J. et L. Robert, Bull. ép., 1972, 298; Velkov, Inscr. de Messambria, p. 166; Chiekova, Cultes, p. 155-156.

178 IGBulg $\mathrm{I}^{2}, 314$ b, 1. 1; cf. Velkov, Mesambria, p. 19-20.

179 IOSPE $\mathrm{I}^{2}, 32 \mathrm{~A}, 1.39$.

180 IOSPE I $\mathrm{I}^{2}, 26,1.4 ; 31,1.1 ; 32 \mathrm{~A}, 1.2 ; 76,1.1$ [L. Dubois (éd.), Inscriptions grecques dialectales d'Olbia du Pont, Genève 1996, $\mathrm{n}^{\circ}$ 88]; cf. Ehrhardt, Milet und seine Kolonien $^{2}$, p. 218, 525, n. 1367.

181 ISM I, 28, 1. 7.

182 Voir infra, chapitre III.2.2.3. 
La thèse soutenant l'existence d'une division mégarienne en kômai («bourgs ») fait depuis longtemps l'unanimité des savants. Elle se fonde principalement sur le passage de Plutarque qui évoque l'ancienne division de la Mégaride en cinq parties (mérè) avant le synœcisme ${ }^{183}$. En outre, l'importance du nombre cinq pour les institutions mégariennes a été considéré comme un argument en faveur de la tradition de Plutarque. À l'époque hellénistique, il y avait à Mégare cinq stratèges, cinq polémarques ${ }^{184}$, cinq damiorgoi ${ }^{185}$. Pour ces magistratures, l'organisation civique suivrait, selon d'aucuns, non pas la division par tribus, mais celle en cinq kômai (ou mérè selon Moggi) ${ }^{186}$.

183 Plutarque, Questions grecques, XVII (= Moralia 295 B), passage cité supra, chapitre I.1.1. On peut citer parmi ceux qui, en s'appuyant sur le texte de Plutarque, ont soutenu l'existence de cinq kômai à Mégare: H. Reinganum, Das alte Megaris. Ein Beitrag zur Alterthumskunde Griechenlands, Berlin 1825, p. 69; Bursian, Geographie, vol. I, p. 372; Foucart, Inscr. de la Mégaride, p. 13, 34; E. Szanto, Die griechischen Phylen, Wien 1901, p. 18; Heath, Proxeny Decrees, p. 87; Busolt, Gr. Gesch. I, p. 221 ; idem, Staatskunde, I, p. 257; Highbarger, Megara, p. 66; Hanell, Megarische

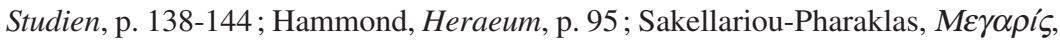
p. 22-23; Legon, Megara Pol. Hist., p. 47-55; idem, Megara, p. 464; D. Roussel, Tribu et cité. Études sur les groupes sociaux dans les cités grecques aux époques archaïque et classique, Paris 1976, p. 253; M. Piérart, «Phratries et < kômai > d'Argos», BCH 107, 1983, p. 274; Muller, De Nisée à Mégare, p. 627; Figueira, Chronological Table, p. 265 ; Loukopoulou, Thrace propontique, p. 139; Polignac, Naissance de la cité gr., p. 147; Saprykin, Heracleia and Chersonesus, p. 42; Nawotka, West. Pont. Cities, p. 96, 124; Paltseva, Mégare, p. 230; Smith, Megaris, p. 97, 112, 115; De Angelis, Megara Hyblaia and Selinous, p. 47; Malkin, Networks, p. 70; Fischer-Hansen, Nielsen, Ampolo, Megara, p. 214 ; Liddel, Megarid, p. 425.

184 Voir infra, chapitre III.2.2.4.

185 Voir infra, chapitre III.2.2.5.

186 Böckh, $C I G, a d \mathrm{n}^{\circ} 1052$, p. 558; Foucart, Inscr. de la Mégaride, p. 13, 34 ; Swoboda, Gr. Volksbeschlüsse, p. 140; Latyshev, Const. de Chersonèse, p. 287, 293; Busolt, Staatskunde, I, p. 257 ; Hanell, Megarische Studien, p. 139; N. G. L. Hammond, «The Lycurgean Reform at Sparta», JHS 70, 1950, p. 64 (= Studies in Greek History, Oxford 1973, p. 89-90); Legon, Megara Pol. Hist., p. 47-48; Moggi, Sinecismi, p. 31 ; idem, «Sinecismi arcaici del Peloponneso», in La transizione dal miceneo all'alto arcaismo. Dal palazzo alla città. Atti del Convegno Internazionale (Roma, 14-19 marzo 1988), D. Musti et al. (éds.), Roma 1991, p. 157; Figueira, Chronological Table, p. 268 ; Loukopoulou, Thrace propontique, p. 139; Malkin, Networks, p. 70. 
Jones a déjà soulevé quelques problèmes concernant l'historicité de cette reconstitution ${ }^{187}$. D'abord, il a noté que l'habitat kata kômas précède la naissance de nombreuses cités et que le terme politai est employé sans nul doute de manière anachronique chez Plutarque ${ }^{188}$. Il ajoute ensuite que le peu d'informations dont l'on dispose sur la localisation des cinq kômai ne nous autorise pas à les considérer comme des unités administratives de la Mégaride ${ }^{189}$.

Sans mettre en doute le fractionnement politique de la Mégaride au moment du synœcisme, je crois que la division en cinq kômai ne trouve pas d'écho dans la documentation antique. Outre les arguments de Jones, il existe d'autres indices. En premier lieu, il ne faut pas perdre de vue que le passage de Plutarque constitue une explication étymologique. Ce n'est pas la division de la Mégaride qui est au centre de la Question grecque XVII, mais plutôt les conflits entre les Mégariens qui ont donné finalement naissance au mot $\delta o \rho v ́ \xi \varepsilon v o \varsigma$, le point de départ du récit. Il ne s'agit donc pas d'un texte qui se propose d'examiner l'organisation civique de la cité ou la constitution mégarienne.

En second lieu, Plutarque n'affirme pas qu'il y a eu une division territoriale de la Mégaride en cinq bourgs. Il note que les Mégariens, qui habitaient autrefois $\kappa \alpha \tau \grave{\alpha} \kappa \omega ́ \mu \alpha \varsigma$ étaient divisés en cinq parties ou

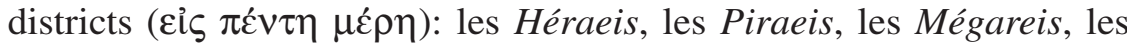
Kynosoureis et les Tripodiskioi ${ }^{190}$. Il est abusif d'identifier les kômai avec les cinq mérè en question et, comme l'a déjà souligné Moggi, il est vraisemblable que plusieurs kômai appartenaient à un méros ${ }^{191}$. Cette observation est corroborée par Strabon, qui rapporte qu'à l'origine les localités du Péloponnèse «étaient, à l'exception d'un petit nombre, non

187 Jones, Public Organization, p. 95-96.

188 Sur l'habitat kata kômas des Grecs, voir Osborne, Classical Landscape, p. 55-56.

189 Jones, Public Organization, p. 96. Jones estime aussi qu'à Sparte, à Mégare et à Argos, «the army had gradually abandoned all ties with the strictly public division in favour of other, more efficient or sophisticated arrangements of its own» (p. 120).

190 G. Huxley, CR 32, 2, 1982, p. 228.

191 Moggi, Sinecismi, p. 30. On peut évoquer comme parallèle le cas des douze mérè achéens de l'époque classique (Hérodote, I, 145), dont plusieurs comptaient, selon Strabon, VIII, 7, 5, C 386, sept ou huit bourgs à la fois. $C f$. B. Helly, «Arithmétique et histoire. L'organisation militaire et politique des Ioniens en Achaïe à l'époque archaïque », Topoi(Lyon) 7, 1, 1997, p. 213-215; Corsten, Vom Stamm zum Bund, p. $160-163$. 
des cités, mais des districts ruraux comprenant chacun plusieurs groupements de communes ${ }^{192}$.

Dans le but de montrer que les kômai mégariennes étaient des divisions territoriales similaires aux dèmes athéniens, Legon a initialement invoqué un passage d'Aristote portant sur l'invention de la comédie à Mégare pendant le régime «démocratique» ${ }^{193}$.

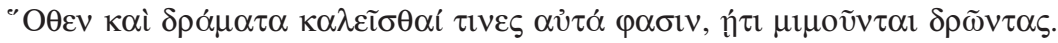

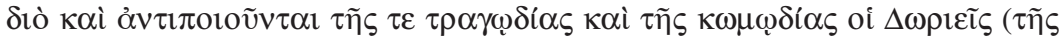

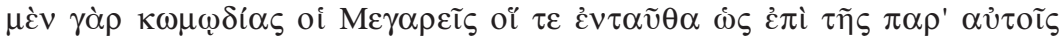

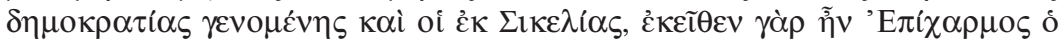

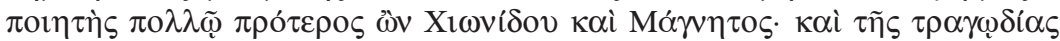

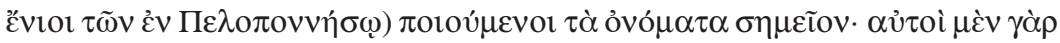

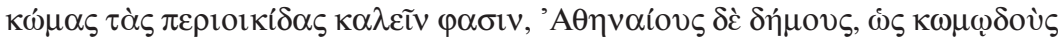

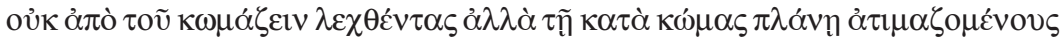

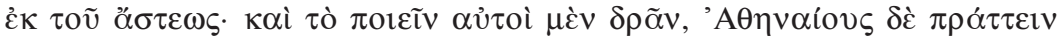
$\pi \rho о \sigma \alpha \gamma о \rho \varepsilon v ́ \varepsilon t v$.

C'est ce qui, au dire de certains, a fait appeler leurs œuvres des drames, parce qu'ils imitent des personnages agissant. C'est pour cette raison aussi que les Doriens revendiquent la tragédie et la comédie (la comédie est revendiquée par les Mégariens; par ceux d'ici, suivant qui elle serait née du temps où ils étaient en démocratie, et par ceux de Sicile: c'est de Sicile en effet que provenait le poète Épicharme, antérieur de beaucoup à Chionidès et à Magnès; la tragédie est revendiquée par quelques Doriens du Péloponnèse); et ils tirent un indice des termes employés. Ils disent qu'ils donnent eux le nom de $\kappa \tilde{\omega} \mu \alpha$ aux bourgades qui sont aux environs des villes tandis que les Athéniens les appellent dèmes, et que les comédiens tirent leur nom

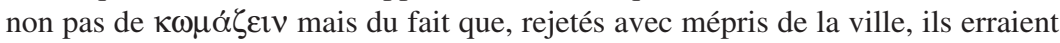
dans les $\kappa \tilde{\omega} \mu \alpha \mathrm{l}$. Ils allèguent aussi que pour dire «faire» ils emploient le mot $\delta \rho \tilde{\alpha} \nu$, tandis que les Athéniens disent $\pi \rho \alpha ́ \tau \tau \varepsilon \iota^{194}$.

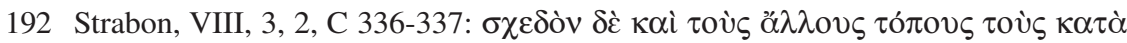

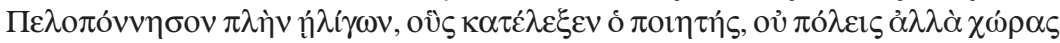

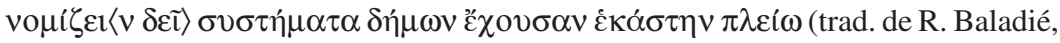
CUF); cf. B. Helly, op. cit., p. 220.

193 Legon, Megara Pol. Hist., p. 48; cf. Hammond, Heraeum, p. 95-96. Dernièrement, Legon, Megara, p. 454, accepte qu'il n'y a pas suffisamment de témoignages pour démontrer que les kômai étaient à Mégare des subdivisions civiques. Néanmoins, il soutient toujours que le texte de Plutarque, Questions grecques, XVII, mentionne cinq kômai.

194 Aristote, Poétique, III, 1448a 28-40 (trad. de J. Hardy, CUF). Sur la comédie mégarienne à l'époque classique et son caractère proverbial, voir Aristophane, Guêpes, 57, et Aristote, Éthique à Nicomaque, IV, 2, 1123a 23-24, et supra, chapitre I.3.2. 
Pourtant, ce passage ne laisse pas entendre que les kômai étaient à Mégare des subdivisions civiques, comme les dèmes à Athènes après la réforme de Clisthène. Pour la source mégarienne d'Aristote, les kômai sont de simples villages ( $\pi \varepsilon \rho ı \imath \kappa i ́ \delta \varepsilon ı)$ ) par opposition à la ville (ő $\sigma \tau v)$. En mettant en parallèle les kômai et les dèmes, c'est à l'ancien sens du mot $\delta \tilde{\eta} \mu \circ \varsigma$, celui de «bourg» et non pas à celui d'unité administrative, que le récit fait référence.

D'autres part, les documents ne confirment pas que les kômai aient fait partie de la structure institutionnelle de Mégare, comme ce fut le cas des dèmes à Athènes. Le mot $\kappa \omega ́ \mu \eta$ apparaît dans une seule inscription mégarienne datant probablement de ca. 235-229. Il s'agit d'un décret émis par Mégare, suite à une demande des Aigosthénitains, accordant la citoyenneté au Béotien Zôilos, fils de Kélainos, le chef de la garnison placée dans le bourg d'Aigosthènes par le roi macédonien Démétrios II. À la fin de l'inscription, les Mégariens indiquent avoir voulu honorer par là «ceux qui accomplissent un bien par la parole ou par l'action en faveur de la cité ou des bourgs ${ }^{195}$. Cette formule atteste le statut de dépendance d'Aigosthènes et la présence de plusieurs bourgs

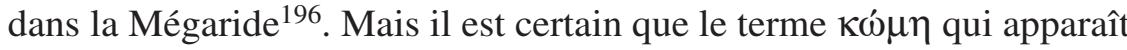
dans ce document officiel n'est pas utilisé pour désigner une subdivision civique à caractère topographique.

La localisation des Héraeis, des Piraeis, des Mégareis, des Kynosoureis et des Tripodiskioi ne confirme pas non plus l'hypothèse d'une ancienne division territoriale en cinq parties de la Mégaride, comme Jones l'a bien deviné. Au contraire, l'identification de ces mérè suggère que la liste de Plutarque est l'expression de la propagande des Mégariens vis-à-vis de leurs voisins, les Athéniens et les Corinthiens. Comme j'ai essayé de le montrer dans la première partie du livre, la tradition de la division de la Mégaride en cinq mérè a très probable-

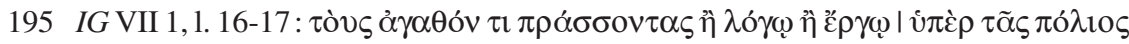

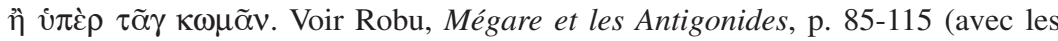
références), sur la date de cette inscription.

196 D'après M.H. Hansen, «Kome. A Study in How the Greek Designated and Classified Settlements which were not Poleis», in Studies in the Ancient Greek Polis, M.H. Hansen et K. Raaflaub (éds.), Historia Einzelschriften 95, Stuttgart 1995, p. 74, la dépendance d'Aigosthènes de Mégare est également indiquée par l'emploi

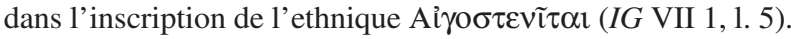


ment été fabriquée dans le contexte des conflits ancestraux avec Athènes et Corinthe. Elle a un caractère fictif, en présentant une extension maximale de la Mégaride (comprenant l'île de Salamine et la presqu'île de Pérachora). Autrement dit, l'on a affaire à un texte à caractère polémique (tout comme la liste de cinq sites de la Mégaride fournie par Strabon ${ }^{197}$ ), créé par des historiens locaux afin d'appuyer les prétentions de leurs cités sur des territoires de frontière. Il serait dès lors erroné de s'appuyer sur la Question grecque XVII pour soutenir une division de la Mégaride en cinq unités à l'époque archaïque. En réalité, il est plus facile d'admettre que la division en cinq unités fut une création de l'époque classique ou hellénistique que de soutenir que la division originelle en cinq mérè a été conservée en Mégaride pendant plusieurs siècles, depuis le VIII ${ }^{\mathrm{e}}$ siècle (l'époque du synœcisme) jusqu'au III ${ }^{\mathrm{e}}$ siècle (la période durant laquelle sont attestés des collèges comptant cinq magistrats).

197 Voir supra, chapitre I.1.2. 


\section{III.2 Les magistratures mégariennes}

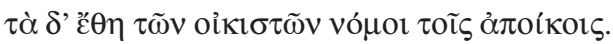

Les coutumes des fondateurs sont devenues des lois pour les colons ${ }^{198}$.

Ce chapitre se propose de donner un catalogue commenté des magistrats éponymes (le basileus, le hiéromnamôn) et des plus anciens collèges de magistrats d'origine mégarienne (les aisimnatai, les probouloi, les stratèges, les damiorgoi, les nomophylakes), attestés à Mégare et dans les colonies mégariennes et héracléotes. Bien que l'essentiel de la documentation date de l'époque hellénistique et impériale, il est permis de penser que les structures politiques, comme le reste des nomima, ont été introduites dans les colonies par les premiers apoikoi. Certes, on ne peut pas exclure l'introduction de certaines archai par des colons ultérieurs, mais cette possibilité reste très hypothétique, car la fondation d'une colonie supposait l'existence d'institutions politiques spécifiques à la cité grecque (subdivisions civiques et magistratures).

Il faut avouer que dans l'état actuel de nos connaissances, les modalités de fonctionnement des institutions ou les changements opérés au fil du temps dans telle ou telle cité nous échappent en grande partie; dans plusieurs cas l'on est réduit à des hypothèses. De fait, les documents épigraphiques ne mentionnent souvent que les titres des magistrats, sans préciser leurs fonctions exactes. Pour déterminer les fonctions de certains magistrats, on est amené dès lors à faire des rapprochements avec d'autres constitutions grecques, sans pour autant savoir si telle ou telle magistrature d'une cité mégarienne correspondait complètement à une magistrature homonyme d'une autre cité199.

Je tiens à ajouter que, sauf pour les cas du hiéromnamôn et des pentékaidéka, il ne sera pas question ici des magistratures n'ayant pas une origine mégarienne. Dans ces cas, je considère qu'il s'agit tantôt d'institutions panhelléniques (comme le Conseil, l'Assemblée ou le secrétaire du Conseil et de l'Assemblée), tantôt de développements institutionnels ultérieurs, sans lien avec l'origine des colonies (voir, à titre d'exemple, le prophètas de Chalcédoine, ou les archontes présents dans les différents établissements mégariens).

198 Denys de Byzance, 39, p. 17 (éd. R. Güngerich).

199 Latyshev, Const. de Chersonèse, p. 276-277. 


\section{III.2.1 Les magistrats éponymes}

\section{III.2.1.1 Le basileus}

Plusieurs décrets de proxénie de Mégare attestent que le basileus donne son nom à l'année dans la seconde moitié du $\mathrm{III}^{\mathrm{e}}$ siècle; à cette époque, la cité fait partie de la Ligue achéenne ${ }^{200}$. Il perd sa fonction d'éponyme seulement quand Mégare appartient à la Ligue béotienne (de 224 à probablement $206 / 5)^{201}$, puisqu'il est remplacé par un ö $\rho \chi \omega v$, selon le modèle béotien ${ }^{202}$.

Un $\beta \alpha \sigma \imath \lambda \varepsilon v$ $\varsigma$ Apollônidas apparaît dans un décret trouvé à Pagai ${ }^{203}$. Les deux fragments de cette stèle ont été publiés séparément et attribués par Dittenberger à Pagai (IG VII 188 et 189). Pourtant, comme l'a

200 IG VII 1-14, 3473 (?); Heath, Proxeny Decrees, p. 84-85, n ${ }^{\text {os }}$ I-III ; Kaloyéropoulou,

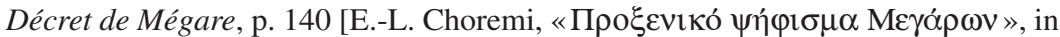

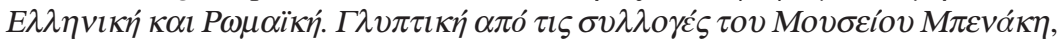
S. Vlizos (éd.), Athènes 2004, p. 211-213]; cf. Rhodes-Lewis, Decrees, p. 109-111. Voir infra, chapitre III.2.2.4, sur la date de ces décrets.

201 Chez les modernes prévaut l'opinion que la cité de Mégare fit partie à deux reprises, entre 243 et 224 et entre 192 et 146, de la Confédération achéenne, et entre 224 et 192, de la Ligue béotienne: Foucart, Inscr. de la Mégaride, ad no 34 a, p. 19-20; Beloch, Gr. Gesch. ${ }^{2}$, IV, 2, p. 433-434; Highbarger, Megara, p. 209-212; Meyer, Megara, col. 195-197; Feyel, Polybe, p. 30-32, p. 62, n. 1, 92; Wiseman, Land, p. 136. Cependant, A. Aymard, Les premiers rapports de Rome et de la confédération achaienne (198-189 avant J.-C.), Bordeaux 1938, p. 14-15, n. 7, 322, n. 38 ; idem, $R H 196,1946$, p. 290, a donné de bons arguments pour la date de 206/5, au lieu de la date de 192, traditionnellement admise, pour le retour de Mégare à la Ligue achéenne. Cf. Robert, Inscr. de Pagai, p. 113-115 (= OpMinSel, II, p. 12661268); Robu, Décret d'Aigosthènes, p. 92. Il est en même temps fort probable que la première période achéenne de la Mégaride ait été interrompue par une brève occupation de cette région par l'armée de Démétrios II, entre ca. 235-229: voir infra, chapitre III.2.2.4.

202 Les catalogues militaires de Mégare IG VII 27 et 28, sont datés par l'archonte de la cité, suivi par l'archonte béotien; $c f$. Étienne-Knoepfler, Hyettos de Béotie, p. 303. Sur le remplacement de leur magistrat éponyme par un archonte dans les cités entrées dans la Confédération béotienne, dont Mégare et Aigosthènes, voir P. Roesch, op. cit., p. 161; Robert, Inscr. de Pagai, p. 114-116 (=OpMinSel, II, p. 1267-1269).

203 IG VII 188, 1. 1-3. Carlier, Royauté, p. 404, suggère qu'Apollônidas, qui apparaît dans cette inscription, serait le même que le «roi» homonyme attesté par le décret de Mégare $I G$ VII 14. Mais l'absence du patronyme pour les deux Apollônidas nous empêche de vérifier cette hypothèse. 
démontré de manière convaincante Robert, il s'agit d'un seul décret émanant de Mégare, conservé en deux fragments, et exposé à Pagai. Selon le savant français, cette inscription date du début du $\mathrm{II}^{\mathrm{e}}$ siècle et porte sur le conflit entre Pagai et Aigosthènes au sujet de la possession du port de Panormos (dans la petite plaine du Psatho d'aujourd'hui, voir carte 2). Le litige a été réglé par l'intervention des Confédérations béotienne et achéenne, l'une pour appuyer Aigosthènes et l'autre pour soutenir le couple Mégare-Pagai. On apprend également que, pour assurer l'impartialité de la décision, l'on a choisi comme arbitres des citoyens des cités lointaines de Thyrreion d'Acarnanie et de Kassopée d'Épire. Qui plus est, ce décret atteste que Pagai est une communauté politique autonome, mais étroitement liée à Mégare ${ }^{204}$.

La formule ċđí, suivie du nom du secrétaire de l'Assemblée ou du Conseil (synédrion) figure en tête de deux listes d'éphèbes ${ }^{205}$. On a probablement dans ces deux cas l'influence du formulaire achéen, qui se caractérise par la mention du secrétaire fédéral comme éponyme, les catalogues remontant ainsi à la deuxième période achéenne de Mégare (de 206/5 à 146) ${ }^{206}$. Signalons aussi que deux monnaies rarissimes en bronze transmettent à l'époque hellénistique les noms des deux magistrats monétaires (Nikios et Dionysios), précédés par le mot $\dot{\varepsilon} \pi i^{207}$. Faute d'autre précision, on ne peut pas établir l'identité de cette magistrature.

204 Robert, Inscr. de Pagai, p. 107-108 (= OpMinSel, II, p. 1260-1261; SEG XIII, 327; S. L. Ager, op. cit., $\mathrm{n}^{\circ}$ 85); cf. E. Meyer, s.v. «Panormos», RE XVIII, 2, 1949, col. 658; Smith, Megaris, p. 40-41; K. Harter-Uibopuu, op. cit., p. 110-111; Freitag, Der Golf von Korinthos, p. 179-180; D. Knoepfler, A. Robu, Bull. ép., 2010, 325.

205 IG VII 29, 31. Cf. Robert, Inscr. de Pagai, p. 109 (= OpMinSel, II, p. 1262). La mention du synédrion permet de situer le catalogue IG VII 31 après 167, car l'on peut supposer qu'à l'image des Béotiens et des Eubéens, les Mégariens introduisirent cette institution après Pydna. $C f$. D. Knoepfler, «Contribution à l'épigraphie de Chalcis », BCH 114, 1990, p. 497; C. Müller, «La procédure d'adoption des décrets en Béotie de la fin du $\mathrm{III}^{\mathrm{e}}$ s. av. J.-C. au I ${ }^{\mathrm{er}}$ s. apr. J.-C.», in Citoyenneté et participation à la basse époque hellénistique, P. Fröhlich et C. Müller (éds.), Genève 2005, p. 114-115; D. Knoepfler, A. Robu, Bull. ép., 2010, 348.

206 Robu, Hellenistic Megara, à paraître. Pour le secrétaire fédéral achéen, on verra A. Aymard, «Recherches sur les secrétaires des Confédérations aitolienne et achaienne», in Mélanges offerts à Nicolae Iorga, Paris 1933, p. 95-108.

207 BCDPelop., p. 27, $\mathrm{n}^{\text {os }} 34$ (deuxième moitié du $\mathrm{II}^{\mathrm{e}}$-début du $\mathrm{I}^{\mathrm{er}}$ siècle) et 36 (fin du $\mathrm{II}^{\mathrm{e}}$ - début du $\mathrm{I}^{\mathrm{er}}$ siècle). Un troisième monétaire de Mégare, un certain Grammateus, dont le nom apparaît sur une monnaie inédite (Paris, $B N, 1227)$, est signalé dans

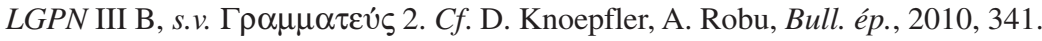


Une inscription honorifique mentionne encore un $\beta \alpha \sigma \imath \lambda \varepsilon u ́ \varsigma$ à Mégare à l'époque impériale, mais à cette période-là on sait que l'éponymie est

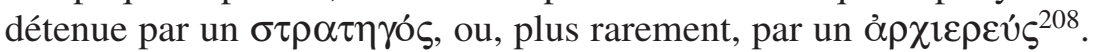

Un $\beta \alpha \sigma \imath \lambda \varepsilon u ́ \varsigma$ éponyme apparaît dans un site de la Mégaride, à Aigosthènes. Il en témoigne le décret pour le Mégarien Apollodôros, fils d'Alkimachos, datant de la première moitié du $\mathrm{II}^{\mathrm{e}}$ siècle. Ce document atteste qu'Aigosthènes, qui, dans le décret $I G$ VII 1 de l'époque de Démétrios II était un bourg (kômè) mégarien, est maintenant une cité indépendante ${ }^{209}$. Ce statut fut acquis par Aigosthènes au plus tard en 224 , lorsque ce bourg se rattache en tant que polis à la Confédération béotienne. À cette époque, les décrets sont datés à la fois par l'archonte fédéral béotien et par un magistrat de la cité210. Ce dernier est un archonte, compte tenu du parallèle avec Mégare, où, pendant la période béotienne, un archonte remplace le «roi» dans la fonction d'éponyme. Les inscriptions et les monnaies attestent que la cité du golfe Halcyonique garda son indépendance à la basse époque hellénistique et à l'époque impériale ${ }^{211}$.

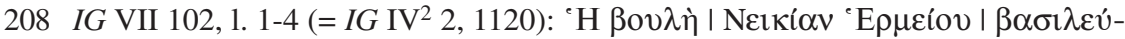

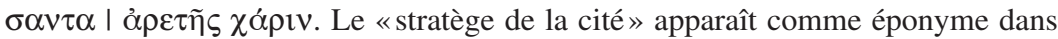
les inscriptions $I G$ VII 25 et 90 (voir aussi infra, chapitre III.2.2.4). Voir $I G$ VII 107 $\left(=I G \mathrm{IV}^{2} 2,1121\right)$, pour la mention d'un archiereus éponyme à Mégare à l'époque impériale. Cf. Hanell, Megarische Studien, p. 145-146.

209 IG VII 223. J'ai proposé ailleurs de dater ce décret d'Aigosthènes de $c a$. 171-146: Robu, Décret d'Aigosthènes, p. 79-101; cf. D. Knoepfler, Bull. ép., 2012, 188. Une date pour ce texte dans la première moitié du $\mathrm{II}^{\mathrm{e}}$ siècle est suggérée aussi par Liddel, Megarid, p. 427.

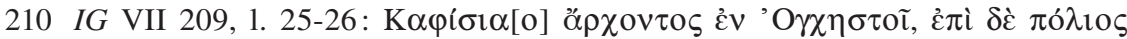
$\mathrm{K} \lambda \varepsilon \circ \delta \rho o ́ \mu o v$. L'archonte fédéral béotien et l'éponyme local datent aussi les décrets d'Aigosthènes $I G$ VII 212, 214-218, 220-222; cf. Étienne-Knoepfler, Hyettos de Béotie, p. 301-305, 323-331. Il n'est pas exclu qu'Aigosthènes, tout comme Pagai, aient bénéficié du statut de cité déjà dès 243 , suite à l'entrée de la Mégaride dans la Ligue achéenne. Voir à cetégard W. W. Tarn, «The Greeks Leagues and Macedonia», in The Cambridge Ancient History, vol. VII, The Hellenistic Monarchies and the Rise of Rome, S. A. Cook et al. (éds.), Cambridge 1928, p. 736; N. D. Papachatzis (éd.),

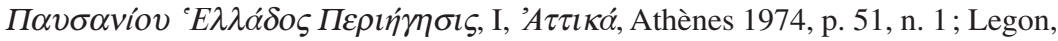
Megara Pol. Hist., p. 301-302; Freitag, Der Golf von Korinthos, p. 177-179, 185.

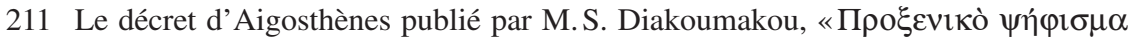

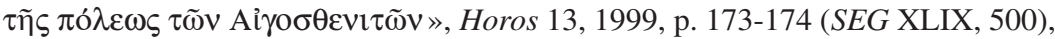
atteste que cet établissement garde le statut poliade au $\mathrm{I}^{\text {er }}$ siècle. $C f$. D. Knoepfler, A. Robu, Bull. ép., 2010, 348. Aigosthènes frappa des monnaies aux types de Septime Sèvere et Géta: Head, $H N^{2}$, p. 392-393; BCDPelop., p. 34, nos 62-63. Pour 
Si l'on ne trouve en revanche aucun «roi» dans les inscriptions émanant de Pagai, sa présence est néanmoins probable, étant donnée l'indépendance de cet établissement à l'époque hellénistique et impériale. De fait, un décret de proxénie émanant de Thisbé pour un ressortissant de Pagai atteste que ce bourg acquit le statut de cité à un certain moment après le milieu du $\mathrm{III}^{\mathrm{e}}$ siècle (la date exacte de l'inscription de Thisbé reste difficile à établir) ${ }^{212}$. Les monnaies de bronze 'A $\chi \alpha \alpha \tilde{\omega} \mathrm{V}$ $\Pi \alpha \gamma \alpha i \omega v$ confirment en tout cas que Pagai est indépendante dans la première moitié du $\mathrm{II}^{\mathrm{e}}$ siècle, lors de son intégration à la Confédération achéenne ${ }^{213}$; ce statut est maintenu au ${ }^{\mathrm{er}}$ siècle, au vu d'un décret honorifique $^{214}$. Ultérieurement, les inscriptions et les monnaies attestent que cette localité a gardé le statut de cité à l'époque impériale ${ }^{215}$.

D'autre part, le $\beta \alpha \sigma \imath \lambda \varepsilon v ́ \zeta$ est présent dans la plupart des apoikiai mégariennes. Ceci confirme l'ancienneté de son éponymie. Il s'agit évidemment d'une institution empruntée par les colonies à la métropole de Grèce; une archè de beaucoup antérieure à sa première attesta-

l'attestation du statut de cité d'Aigosthènes, voir aussi les inscriptions honorifiques IG VII 226-227 et les deux bases de statues, l'une de Constantin le Grand et de Licinius, et l'autre de Constantin II, publiées par C. Vatin, «Quelques inscriptions d'époque impériale», $B C H$ 90, 1966, p. 242-244 (SEG XXIII, 266, 267).

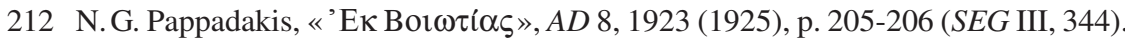
Sur ce décret de Thisbé, voir Étienne-Knoepfler, Hyettos de Béotie, p. 329-330, n. 242 ; D. Knoepfler, «La royauté grecque», REG 99, 1986, p. 333; idem, «L'épigraphie de la Grèce centro-méridionale (Eubée, Béotie, Phocide et pays voisins, Delphes): publications récentes, documents inédits, travaux en cours », in XI Congresso Internazionale di Epigrafia Greca e Latina (Roma 18-24 settembre 1997). Atti I, Roma 1999, p. 242 et n. 68; idem, Bull. ép., 2012, 189; C. Müller, «La dissolution du koinon béotien en 171 av. J.-C. et ses conséquences territoriales », in Pouvoir et territoire. Actes du colloque de Saint-Étienne (novembre 2005), P. Rodriguez (éd.), Saint-Étienne 2007, p. 35-37.

213 Head, $H N^{2}$, p. 417 ; BCDPelop., p. 35, nº 64; J. W. A. Warren, The Bronze Coinage of the Achaian Koinon. The Currency of a Federal Ideal, London 2007, p. 31-32, n ${ }^{\text {os }} 516$ 532, p. 120, 152, 163. Cf. Robert, Inscr. de Pagai, p. 113 (=OpMinSel, II, p. 1266).

$214 I G$ VII 190. Malheureusement, dans ce décret de Pagai, dont une nouvelle édition a été donnée par A. Wilhelm, «Inschrift aus Pagai», JÖAI 10, 1907, p. 19-20 (= Kleine Schriften, vol. II, 1, Leipzig 1984, p. 263-264), le passage où devait figurer l'éponyme n'est pas conservé.

$215 I G$ VII 193-196. Pour le monnayage de Pagai à l'époque impériale, voir Head, $H N^{2}$, p. 394 ; BCDPelop., p. 35, n ${ }^{\text {os }}$ 65-66. Le témoignage de Pline, NH, IV, 7, 23, selon lequel Pagai et Aigosthènes étaient des dépendances de Mégare à l'époque impériale, est erroné. 
tion épigraphique à Mégare au $\mathrm{III}^{\mathrm{e}}$ siècle. Ainsi, on retrouve un $\beta \alpha \sigma \mathrm{l} \lambda \varepsilon v ́ \varsigma$ éponyme à l'époque hellénistique et impériale à Chalcédoine ${ }^{216}$ et à Héraclée du Pont ${ }^{217}$. De plus, une inscription honorifique d'Héraclée du Pont, gravée sur la base d'une statue, mentionne une prêtresse de l'empereur Antonin le Pieux, qui fut également $\beta \alpha \sigma i ́ \lambda \iota \sigma \sigma \alpha(« \text { reine» })^{218}$.

La cité de Mésambria fournit la mention d'un autre basileus. Dans cette colonie mégarienne du Pont Gauche, les documents publics ne sont pas datés par la mention d'un éponyme. On connaît en revanche une dédicace du $\mathrm{III}^{\mathrm{e}}$ siècle à Zeus Hyperdexios, faite par Laios, fils de Boiôtos, un personnage qui a été à la fois «roi» et gymnasiarque ${ }^{219}$.

De même, les apoikiai fondées par Héraclée du Pont ont été fidèles aux nomima mégariens. Dans ce sens, le «roi» donne son nom à l'année autant à Callatis ${ }^{220}$ qu'à Chersonèse ${ }^{221}$. Les inscriptions et les monnaies de Chersonèse attestent qu'à l'époque impériale la magistrature éponyme est assumée de façon quasi permanente et fictive par la grande déesse locale, la Parthénos ${ }^{222}$.

216 IG XII 4, 226; I. Kalchedon, 7; 8; 10; 19. Karagöz, Khrysopolis, p. 77, n Ü11, publie la photo d'une base de statue de Cybèle de l'époque impériale, trouvée à Chrysopolis et consacrée par un certain Kointos Lollios Katos. Je lis aux lignes 1-2:

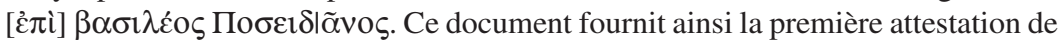
l'éponymie divine à Chalcédoine (en l'occurence le dieu Poséidon), dont l'on a plusieurs exemples à Byzance à la même époque (voir infra, chapitre III.2.1.2).

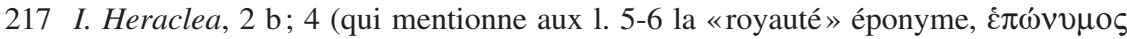
$\beta \alpha \sigma \imath \lambda \varepsilon i ́ \alpha)$; cf. J. et L. Robert, Bull. ép., 1963, 265; Carlier, Royauté, p. 480.

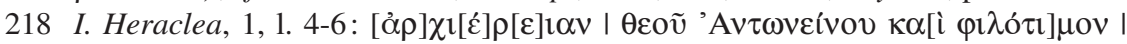

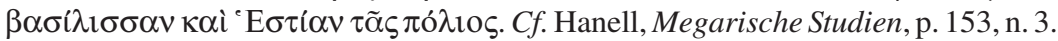

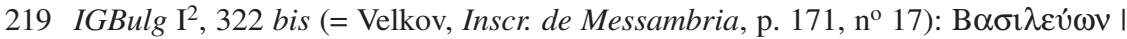

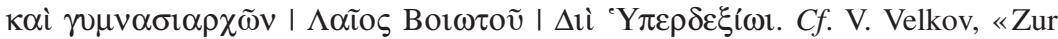
Geschichte der Mesambria Pontica im III. Jh. v. u. Z.», in Acta of the Fifth International Congress of Greek and Latin Epigraphy, Cambridge 1967, Oxford 1971, p. 110; J. et L. Robert, Bull. ép., 1971, 428; Carlier, Royauté, p. 481; Nawotka, West. Pont. Cities, p. 132-133.

220 ISM III, 6, 10-12, 30, 35, 38, 44, 46. Les inscriptions de Callatis, ISM III, 75, 112, 122, mentionnent trois citoyens ayant rempli la charge de basileus. Cf. ISM III, 3 et 7.

221 IOSPE I², 352, 353, 354, 384, 403 B ; cf. SEG XL, 615. Voir aussi les épitaphes IOSPE $\mathrm{I}^{2}, 410,414,415$, pour la mention de plusieurs personnes qui ont exercé la «royauté» à Chersonèse. $C f$. Latyshev, Const. de Chersonèse, p. 286.

222 IOSPE I ${ }^{2}, 357-361,365,376,384,699$; Sourov, Inscr. de Chersonèse, p. 154; Solomonik, Épigraph. Chersonèse II, 111, 112; Saprykin, Proxénie de Chersonèse, p. 43 ; SEG XLV, 985. Pour l'exercice de la «royauté» par la déesse Parthénos de Chersonèse,

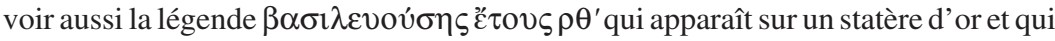


On ajoutera qu'à Prusias de l'Hypios, qui n'est autre, on l'a vu, que l'ancienne colonie héracléote Kiéros, deux inscriptions honorifiques mentionnent à l'époque impériale des basileis ${ }^{223}$. Dans cette cité, la «royauté» a pourtant changé de nature, elle n'est pas une magistrature annuelle, mais elle est assimilée à un titre honorifique. De fait, on remarque que dans l'une de ces deux inscriptions, le personnage honoré

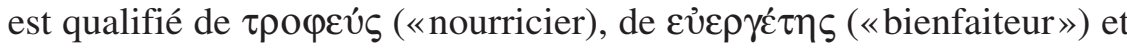
de $\beta \alpha \sigma \imath \lambda \varepsilon ́ v \zeta$ ( «roi»), la «royauté»n'étant pas mentionnée parmi les charges qu'il a remplies ${ }^{224}$.

Enfin, quelques monnaies frappées par Byzance vers 222-235 ap.

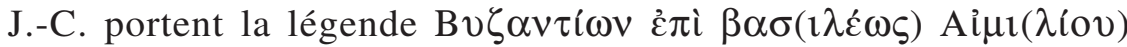
$\Sigma \varepsilon v \eta ́ p o v^{225}$. Il est même possible que, tout comme à Héraclée du Pont, le $\beta \alpha \sigma \imath \lambda \varepsilon v ́ \varsigma$ ait été accompagné à cette époque par une $\beta \alpha \sigma i ́ \lambda \imath \sigma \sigma \alpha$, car d'autres légendes monétaires transmettent le nom d'Aemilius Severus, assorti de celui sa femme, Iulia Severa ${ }^{226}$. On aurait affaire dans ce cas à une femme qui remplit aussi une fonction officielle. D' autre part, quelques monnaies de Byzance attestent qu'un autre titre, celui d'ỏ $\rho \imath \varepsilon \rho \varepsilon u ́ \varsigma$,

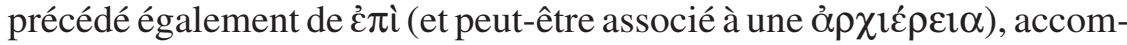

reprend le formulaire des décrets de la cité : A.von Sallet, «Ein Goldstater der taurischen Chersonesus mit dem Beinamen BA $\Sigma \mathrm{I} \Lambda \mathrm{EYOY} \Sigma \mathrm{A}$ und einer Jahreszahl der Chersonesischen Aera», Zeitschrift für Numismatik 4, 1877, p. 273-277; idem, «Beiträge zur antiken Münz- und Altertumskunde», Zeitschrift für Numismatik 9, 1882, p. 143. Comme le montre Robert, Hellenica, II, p. 56, le participe $\beta \alpha \sigma \imath \lambda \varepsilon v o v ́ \sigma \eta \varsigma$ se rapporte

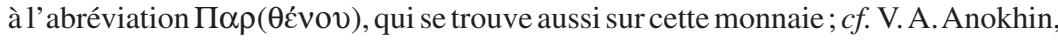
The Coinage of Chersonesus IV Century B. C. - XII Century A. D., BAR International Series 69, Oxford 1980, p. 6-7, 61. Voir aussi la liste des éponymes de l'époque impériale publiée par S. J. Saprykin, «Inscriptions grecques de Chersonèse », VDI, 1996, 4, p. 49-50, no 9 (en russe), où l'on trouve à deux reprises la Parthénos. Pour la place de cette déesse dans le panthéon de Chersonèse, voir A. S. Rusjaeva, «Le culte de la Parthénos à Chersonèse Taurique à l'époque de sa fondation », in Religions $d u$ Pont-Euxin. Actes du VIII Symposium de Vani (Colchide)-1997, O. Lordkipanidzé et P. Lévêque (éds.), Besançon-Paris 1999, p. 99-104 ; M. Dana, «Entre Crimée et Bosphore: d'une Parthenos à l'autre», Mètis N. S. 10, 2012, p. 289-308.

223 I. Prusias ad Hyp., 18, 19; cf. Robert, Hellenica, VIII, p. 76.

224 I. Prusias ad Hyp., 19, 1. 12-13. Cf. Carlier, Royauté, p. 481.

225 A. von Sallet, «Beiträge zur antiken Münz- und Altertumskunde», Zeitschrift für Numismatik 9, 1882, p. 145-146; Schönert-Geiss, Byzantion, vol. II, p. 98-99, pl. $96, \mathrm{n}^{\text {os }} 1700-1706$; p. 100, pl. 97, $\mathrm{n}^{\text {os }} 1710$.

226 Schönert-Geiss, Byzantion, vol. II, p. 99-100, pl. 97, n $^{\text {os }} 1707-1709$; p. 100-101, pl. $98, \mathrm{n}^{\text {os }} 1715-1721$; p. 101-102, pl. $99, \mathrm{n}^{\text {os }} 1724-1725$. 
pagne à l'époque impériale le nom de plusieurs magistrats ${ }^{227}$. Les inscriptions mentionnent aussi des archiereis (charge remplie, dans un cas, par un homme et une femme), ce sont des prêtres du culte impérial ${ }^{228}$.

Le fait que le mot ė $\pi$ í précède ces titres pourrait suggérer que l'on a affaire à des magistrats éponymes. Néanmoins, les sources épigraphiques et numismatiques attestent que l'éponymie à Byzance continue à

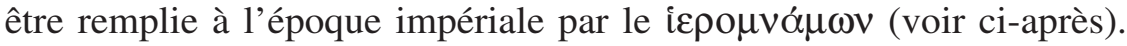
Pour expliquer cette situation, les savants ont pensé que le $\beta \alpha \sigma \imath \lambda \varepsilon v ́ \zeta$ et l'ỏ $\chi 1 \varepsilon \rho \varepsilon v ́ \varsigma$ étaient des charges à caractère religieux ou des fonctions honorifiques que les magistrats mentionnés par les monnaies avaient remplies outre leur charge d'éponyme ${ }^{229}$. Mais comme l'a noté R. van Bremen, l'usage d'éđí suivi par le nom d'un magistrat, outre que l'éponyme habituel, peut aussi signifier que le magistrat en question fut responsable de l'émission lors de l'année où il avait rempli sa charge; il n'y a donc pas toujours un rapport avec l'éponymie ${ }^{230}$.

227 Voir Schönert-Geiss, Byzantion, vol. II, p. 64, pl. 77, n $^{\text {os }} 1462-1463$; p. 70, pl. 80,

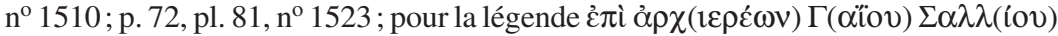

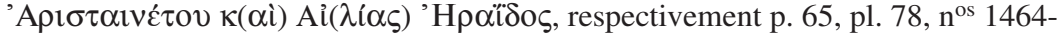
1467; p. 73-74, pl. 82, nos $1525-1529$; p. 83-84, pl. 88, $n^{\text {os }} 1597-1598$, pour la lé-

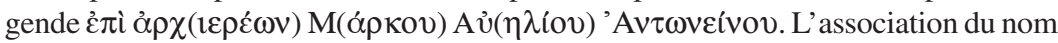
de C. Sallius Aristaenetus avec le nom d'une femme, Aelia Heraïs, est expliquée par B. Pick, «Personen- und Götternamen auf Kaisermünzen von Byzantion», NZ 27, 1895 , p. 50-55, par le fait que dans ce cas il s'agirait d'une paire de magistrats,

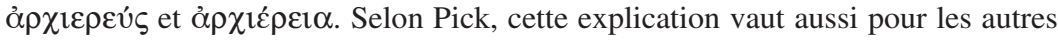
associations de noms de femmes et d'hommes, sans titres, transmises par les monnaies byzantines de l'époque impériale (Aemilius Severus et Iulia Severa, M. Aurelius Fronto et Aelia Festa, M. Aurelius Domitianus et Aurelia Alypiane, M. Aurelius Dionysius et P. Alexandra, Isauricus et Béronikè). Cf. Hanell, Megarische Studien, p. 156-157; Schönert-Geiss, Byzantion, vol. II, p. 18.

228 I. Byzantion, 32, 34, 36, avec le commentaire d'A. Lajtar, $a d \mathrm{n}^{\mathrm{o}}$ 34, p. 68; $c f$. R. van Bremen, The Limits of Participation. Women and Civic Life in the Greek East in the Hellenistic and Roman Periods, Amsterdam 1996, p. 117-125.

229 Hanell, Megarische Studien, p. 156-158; Schönert-Geiss, Byzantion, vol. II, p. 1819; Carlier, Royauté, p. 479-480; Loukopoulou, Thrace propontique, p. 146. Contra B. Pick, op. cit., p. 40-42, 55, qui estime que, tout comme à Mégare et dans d'autres colonies mégariennes, le basileus était à l'époque impériale le magistrat éponyme de Byzance. D'autre part, Robert, Documents, p. 225, n. 9, estime qu'à Byzance «l'éponyme changea lors de la nouvelle fondation de la ville sous les auspices de Caracalla,

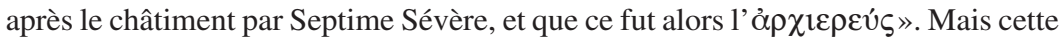
explication ne vaut pas pour le cas où c'est le basileus qui est précédé du mot ċंì.

230 R. van Bremen, op. cit., p. 132. 
D'après Carlier, le caractère honorifique du titre de $\beta \alpha \sigma \imath \lambda \varepsilon u ́ \varsigma$ à Byzance ressortirait aussi d'une inscription du III $^{\mathrm{e}}$ siècle ap. J.-C., qui mentionne une Aurélia Euphémia, «fille du très vénérable basileus» ${ }^{231}$.

Quant aux fonctions du $\beta \alpha \sigma i \lambda \varepsilon v ́ \zeta$, on notera qu'en dehors de celle d'éponyme, le «roi» accomplit généralement des tâches essentiellement religieuses à Mégare. Preuve en est un passage de Dieuchidas, qui indique que le roi était, à l'époque mythique, le responsable de la célébration des sacrifices aux dieux. De fait, le roi était celui qui accomplissait primitivement le rituel suivant: il terminait les sacrifices en plaçant la langue de la victime sur l'autel, une coutume qui, selon ce chroniqueur local, était encore en usage chez les Mégariens ${ }^{232}$. Ce témoignage permet de penser que le «roi»-magistrat, héritier du roi mythique (dont l'existence, on l'a vu, reste incertaine à l'époque géométrique), était en réalité celui qui célébrait à l'époque historique ce rite spécifique mégarien ${ }^{233}$.

De surcroît, un règlement sacré de Chalcédoine atteste que le «roi» s'occupe de l'installation des prêtres après que ces derniers ont payé leur sacerdoce ${ }^{234}$. D'autre part, grâce au décret de Chalcédoine, qui

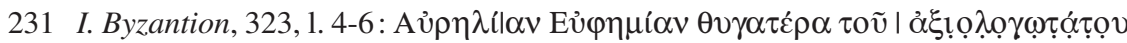

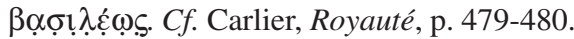

232 Dieuchidas, FGrHist 485 F 10 (= F 8, éd. L. Piccirilli ; apud scholie à Apollonios de Rhodes, I, 516-18c). Selon Dieuchidas, ce rituel était lié à la légende du héros Alcathoos, fils de Pélops, le bâtisseur mythique des murs de Mégare. En effet, après avoir tué le lion du mont Cithéron, le héros a mis dans sa besace la langue de l'animal. Au moment où les autres chasseurs ont prétendu à Mégare avoir tué le lion, Alcathoos les confondit, en montrant la langue. C'est la raison pour laquelle le roi faisait à la fin des sacrifices l'offrande de la langue de l'animal sacrifié, une cou-

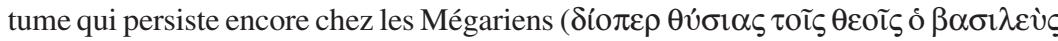

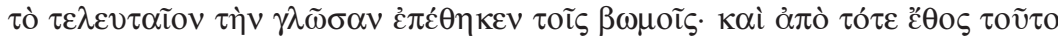

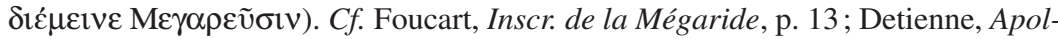
lon, p. 93-94; Smith, Megaris, p. 109.

233 Oost, Megara, p. 186; Piccirilli, MEGARIKA, p. 41; Carlier, Royauté, p. 401-402, n. 157. Sur les rois mythiques de Mégare, voir supra, chapitre I.1.4.

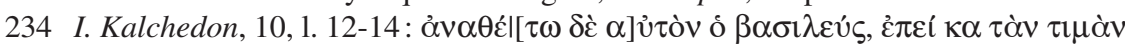

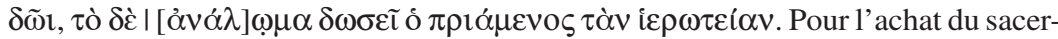
doce à Chalcédoine, voir aussi, I. Kalchedon, 11 et $12 ; c f$. E. Stavrianopoulou, «Normes of Public Behaviour towards Greek Priests: Some Insights from the Leges Sacrae», in La norme en matière religieuse en Grèce ancienne. Actes du XII ${ }^{e} \mathrm{col}$ loque international du CIERGA (Rennes, septembre 2007), P. Brulé (éd.), Kernos, Suppl. 21, 2009, p. 224-225. 
accepte l'asylia du sanctuaire d'Asclépios à Cos ( $c a$. 242), on apprend que le basileus est celui qui invite les théores à recevoir les «présents d'hospitalité» $(\xi \dot{\varepsilon} v i \alpha)^{235}$. Le même magistrat détient aussi une charge représentative à Callatis: les décrets stipulent que c'est à lui d'adresser à un honorandus l'invitation à se rendre au banquet au Prytanée ${ }^{236}$.

\section{III.2.1.2 Le hiéromnamôn}

Contrairement à la plupart des colonies mégariennes, l'éponymie n'était pas remplie à Byzance par le basileus, mais par le hiéromnamôn. Ainsi, Polybe rapporte-t-il que le traité des Byzantins avec les Rhodiens et le roi des Bithyniens, Prusias $\mathrm{I}^{\mathrm{er}}(c a$. 220) a été conclu «alors que Kôthôn, fils de Kalligeitôn, était le hiéromnémôn à Byzance» ${ }^{237}$. Comme on n'a pas manqué de le relever, cette formule correspond à celle d'un document officiel ${ }^{238}$. Pareillement, un décret apocryphe inséré dans le discours Sur la couronne de Démosthène (XVIII, 90) est daté par un

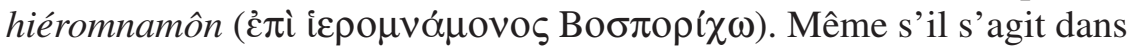
ce cas d'un faux, ce document montre que, pour faire vrai, il fallait que ce magistrat soit mentionné dans le formulaire du décret «byzantin ${ }^{239}$.

Mieux, plusieurs documents épigraphiques sont datés à l'époque hellénistique et impériale par un hiéromnamôn. C'est le cas d'un décret du II ${ }^{\mathrm{e}}$ siècle pour le juge Apollônidas, fils de Memnôn, trouvé au Delphinion de Milet. Grâce à ce texte, on apprend que le hiéromnamôn est le magistrat chargé de faire, lors du concours des Dionysies, la proclamation de la couronne d'or décernée par les Byzantins au juge milésien, à son secrétaire et au peuple de Milet ${ }^{240}$.

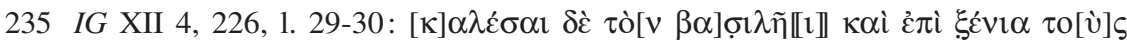
$\theta \varepsilon \alpha \mid[\rho o u ́ \zeta]$.

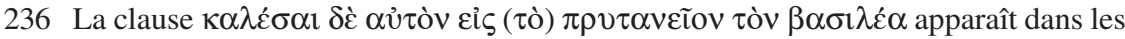
décrets $I S M$ III, 3 et 7.

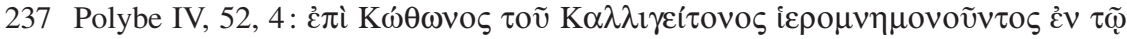

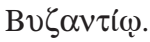

238 Robert, Hellenica, X, p. 18, n. 1; Walbank, Commentary, vol. I, p. 506. Sur la guerre de Byzance avec les Rhodiens et le roi bithynien Prusias ${ }^{\text {er }}$, voir supra, chapitre II.2.4.2.

239 Robert, Hellenica, X, p. 18, n. 2; cf. P. Treves, «Les documents apocryphes du Pro Corona », LEC 9, 1940, p. 157-158; L. Bettarini, «Un falso in Kotvó: il decreto di Bisanzio in Demosth. De corona 90 sg. », RFIC 130, 2002, p. 406-429.

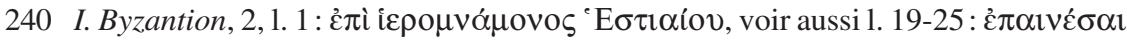

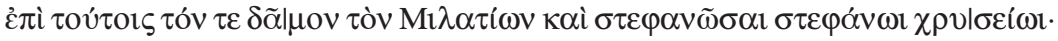


Le hiéromnamôn apparaît comme éponyme dans une dédicace du $\mathrm{I}^{\mathrm{er}}$ siècle à Zeus Aithrios ${ }^{241}$, ainsi que sur des stèles d'époque impériale provenant des bourgs du territoire européen et asiatique de Byzance. Ce magistrat date une dédicace à Zeus Kômatikos faite par les $\kappa \omega \mu \tilde{\eta} \tau \alpha 1$ $\Delta \varepsilon \lambda \kappa \alpha v o i^{242}$. Cette communauté villageoise se situait dans le Derkoz/ Derkos moderne, une bourgade qui a conservé son nom antique avec une légère variante phonétique, localisée par les auteurs d'époque byzantine au bord de la mer Noire, sur le territoire européen de Byzance. C'est effectivement dans cette région qu'a été trouvée notre dédicace ${ }^{243}$. Par ailleurs, une inscription d'époque impériale de Sélymbria, qui était alors un village byzantin, mentionne la déesse Hygie comme hiéromnamôn éponyme ${ }^{244}$.

La région de Yalova, sur la côte sud du golfe d'İzmit, où se trouvait la pérée de Byzance, a fourni également les noms de quelques éponymes byzantins ${ }^{245}$. Une inscription honorifique mentionnant Zeus Pratomysios, découverte dans le village de Çiftlik Köy, près de Yalova, où se trouvait l'antique Strobilos, est datée par l'éponymie de Bruttia Crispina, l'épouse de l'empereur Commode ${ }^{246}$.

Un autre texte honorifique émanant du damos des Pratomyseitai, la communauté à laquelle se rattache le culte de Zeus Pratomysios,

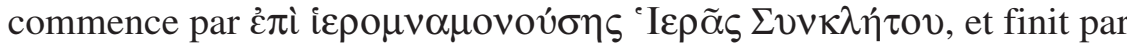

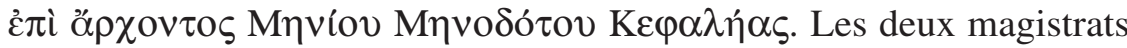
offrent une double datation de l'inscription: la première est fournie par le hiéromnamôn de Byzance, et la deuxième par l'archonte, le haut dignitaire du village. Dans le premier cas, l'éponyme est le «Sénat di-

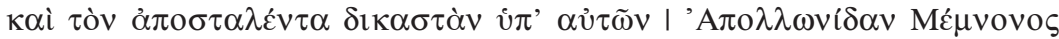

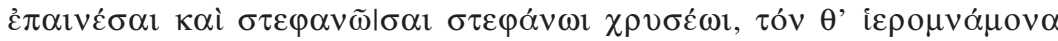

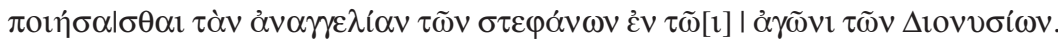

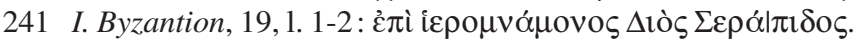

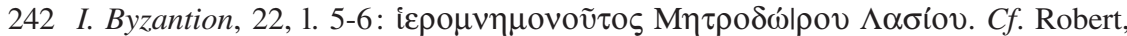

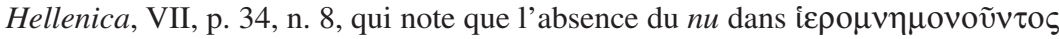
est un vulgarisme phonétique.

243 Sur la localisation de Derkoz et sur les inscriptions trouvées là, voir Robert, Hellenica, X, p. 38-46.

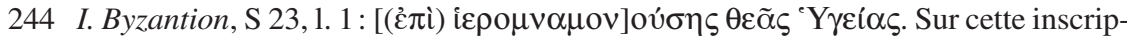
tion honorifique qui mentionne aussi l'hékatostys byzantine $\mathrm{B} \alpha \theta \omega v \eta \dot{ } \alpha$, voir supra, chapitre III.1.2.2.

245 Voir supra, chapitre II.2.4.2, sur la chôra asiatique de Byzance.

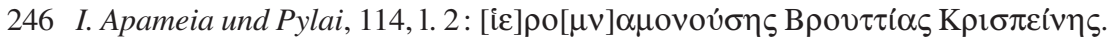


vin», une institution romaine célébrée par les Byzantins de la même manière que le culte impérial ${ }^{247}$.

De même, il convient d'évoquer la découverte sur le territoire européen de Byzance, à Küçük Çekmece, d'une série d'inscriptions honorifiques émanant des mystes de Dionysos Kallôn et datant du $\mathrm{I}^{\mathrm{er}}$ ou $\mathrm{II}^{\mathrm{e}}$ siècle ap.

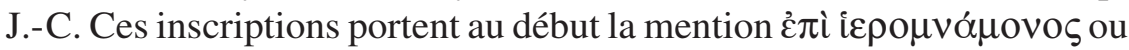

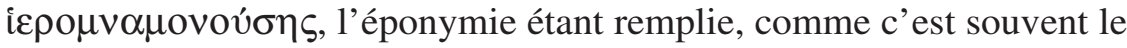
cas à l'époque impériale, soit par un empereur (Domitien) ${ }^{248}$, soit par des divinités (Déméter, Héra, Némésis, Nikè). Pour les éponymes divins, les textes attestent qu'un dignitaire, le hiérope, assistait la divinité, souvent à ses frais ${ }^{249}$. En revanche, on pense que dans le cas de l'éponymie des empereurs, de même que dans celle du Sénat romain, les frais requis par cette fonction étaient payés par l'empereur ou par le sénat, ou encore par la caisse du temple du culte impérial ou celle du temple du Sénat à Byzance ${ }^{250}$.

Le hiéromnamôn date aussi d'autres documents émanant des thiases de Byzance. À cause de l'état fragmentaire de ces textes, on apprend seulement dans deux cas le nom de la divinité célébrée par ces collèges. Il s'agit de deux collèges dionysiaques datant de l'époque d'Hadrien: le thiase de Dionysos Parabolos et le thiase des Dionysoboleitai ${ }^{251}$.

247 T. Corsten, «Neue Denkmäler aus Bithynien», EA 17, 1991, p. 81, n 1 (SEG XLI, 1102).

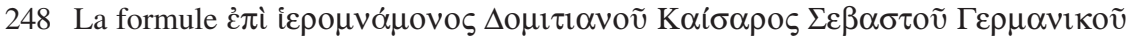

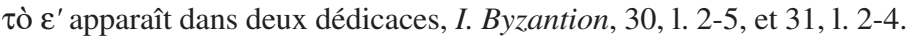

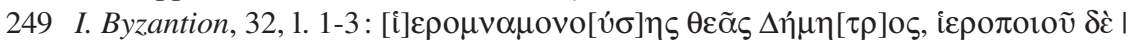

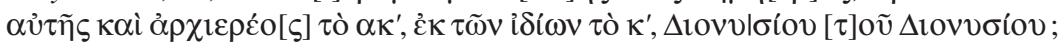

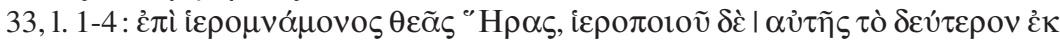

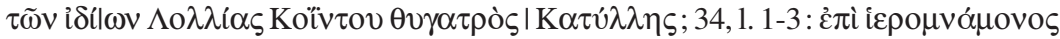

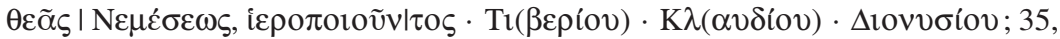

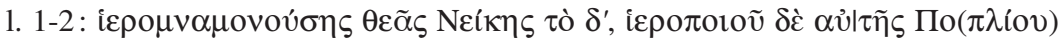

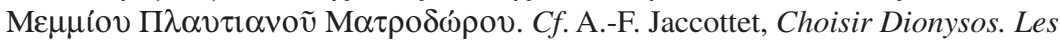
associations dionysiaques ou la face cachée du dionysisme, vol. II, Zurich 2003, p. 78-82, $\mathrm{n}^{\circ} 38$, qui reproduit et commente ces documents. Les sources épigraphiques et numismatiques attestent comme éponymes à Byzance à l'époque impériale plusieurs dieux et déesses: Déméter (deux fois), Dionysos (six fois), Héra, Némésis, Nikè (sept fois), Sarapis, Tychè Poléôs («de la Ville») et Hygie. À ce propos, voir Robert, Hellenica, II, p. 56, 154-155; X, p. 18-19; idem, Inscr. de Bulgarie, p. 202 (= OpMinSel, V, p. 232); Schönert-Geiss, Byzantion, vol. II, p. 17, 35; A. Lajtar, I. Byzantion, $a d \mathrm{n}^{\circ} 19$, p. 50.

250 T. Corsten, op. cit., p. 82; SEG XLI, 1102.

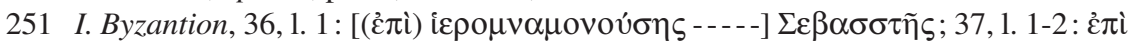

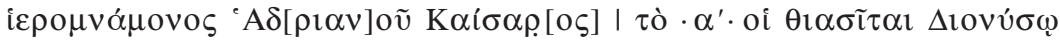


De plus, on constate que des monnaies de l'époque hellénistique et impériale portent le nom d'un magistrat au génitif, précédé de ėंì. Étant donné que le hiéromnamôn éponyme est attesté à Byzance, le magistrat qui apparaît sur ces monnaies a été identifié avec le hiéromnamôn ${ }^{252}$. Cela est vrai pour les émissions qui portent le nom abrégé du hiéromnamôn, mais pour les autres noms de magistrats, sans mention de la fonction sur les monnaies, on n'a pas moyen de connaître l'archè qu'ils avaient remplie (voir aussi ci-dessus) ${ }^{253}$. On signale par ailleurs que la formule غ̇ंì, suivie par le nom de l'éponyme au génitif apparaît aussi dans des inscriptions funéraires ${ }^{254}$.

Un hiéromnamôn éponyme figure dans une liste de mystes trouvée à Samothrace, après la mention du basileus éponyme local. Dimitrova considère récemment ces personnages comme originaires soit de Byzance, soit de Chalcédoine. Mais leur origine byzantine est hors de doute, car si le hiéromnamôn est aussi présent à Chalcédoine, il est

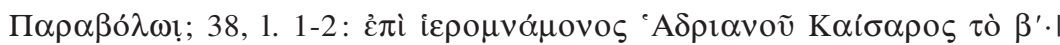

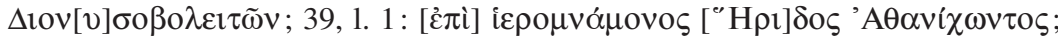

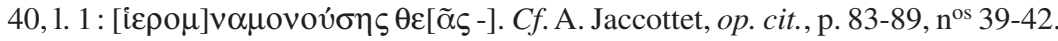
Outre les éponymies impériales attestées par les témoignages épigraphiques (Hadrien deux fois, Domitien cinq fois, Bruttia Crispina), les émissions monétaires attestent aussi les éponymies de Trajan (trois fois), Faustine l'Ancienne déesse, Faustine la Jeune déesse et peut-être Caracalla (Marcus Aurelius Antoninus). Pour les empereurs éponymes à Byzance, on verra L. Robert, Études épigraphiques et philologiques, Paris 1938, p. 146; idem, Documents, p. 225, n. 10 et 11; Schönert-Geiss, Byzantion, vol. II, p. 17; A. Lajtar, I. Byzantion, $a d \mathrm{n}^{0}$ 30, p. 62-63. Sur les collèges dionysiaques de Byzance, voir aussi Robert, Documents, p. 218-234.

252 Hanell, Megarische Studien, p. 156-157; Seyrig, Monnaies, p. 186; Schönert-Geiss, Byzantion, vol. I, p. 56-57; vol. II, p. 17-19 (qui fournit des listes des hiéromnamones éponymes mentionnés par les monnaies); G. Le Rider, «Sur le monnayage de Byzance au $\mathrm{IV}^{\mathrm{e}}$ siècle», $R N 13,1971$, p. 153. On trouvera aussi une liste des magistrats monétaires de Byzance chez R. Münsterberg, Die Beamtennamen auf den griechischen Münzen : geographisch und alphabetisch geordnet, Hildesheim-New York 1973 (Wien 1911-1927), p. 24-25.

253 Voir Schönert-Geiss, Byzantion, vol. II, p. 53-54, pl. 70-71, ${ }^{\text {os }} 1395-1398$, pour les

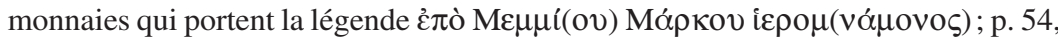

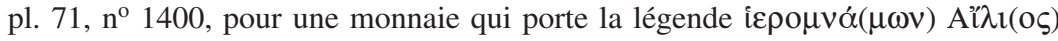

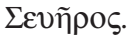

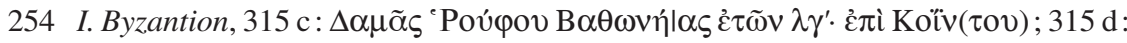

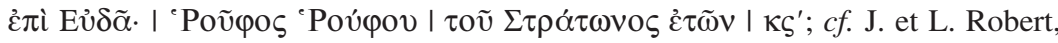
Bull. ép., 1959, 252. 
uniquement à Byzance en position d'éponyme. Cette opinion est d'ailleurs corroborée par la mention à la ligne 5 de l'inscription du nom

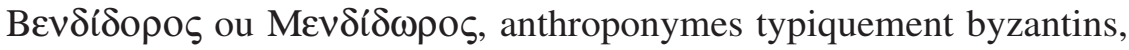
comme l'a remarqué Robert ${ }^{255}$.

On constate qu'à la fin du $\mathrm{II}^{\mathrm{e}}$ siècle ap. J.-C., une dédicace des mystes de Dionysos, provenant de Périnthe, est datée, selon l'exemple byzantin, par un hiéromnamôn ${ }^{256}$. Ce texte suggère que la colonie samienne a hérité du magistrat éponyme de sa voisine mégarienne. Il n'est pas sans intérêt de noter que l'inscription remonte à l'époque où Byzance fut réduite par Séptime Sèvere au statut de bourgade dans le territoire de Périnthe, en raison de l'appui que la ville avait accordé à l'usurpateur Pescennius Niger. Ce transfert institutionnel aurait survenu lors de ces années ${ }^{257}$, ou, comme le propose Loukoupoulou, il se serait produit vers la fin du III siècle, à l'époque où les cités de Byzance et de Périnthe étaient liées par une union politique (sympolitie) ${ }^{258}$.

Il est particulièrement intéressant de noter que le hiéromnamôn éponyme constitue une exception parmi les institutions des cités mégariennes $^{259}$. Outre Byzance, les seules colonies où il est sûrement présent sont Chalcédoine et Mésambria. Grâce à une inscription hellénistique, on sait que le hiéromnamôn occupe la deuxième place dans la hiérarchie des magistrats de Chalcédoine, il figure entre le basileus et le prophètas ${ }^{260}$.

255 N. M. Dimitrova, Theoroi and Initiates in Samothrace. The Epigraphical Evidence, Hesperia, Suppl. 37, Athens 2008, p. 216-217, no 134; cf. L. Robert, Gnomon 35, 1963, p. 65-65 (=OpMinSel, VI, p. 603-605); Robu, Trad. onomastiques, p. 290.

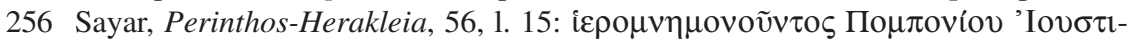

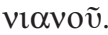

257 Sayar, Perinthos-Herakleia, ad $\mathrm{n}^{\circ}$ 56, p. 237.

258 Loukopoulou, Thrace propontique, p. 146-148. Sur l'éponymie du hiéromnamôn à Périnthe, voir aussi Robert, Hellenica, X, p. 19, n. 1 ; R. K. Sherk, «The Eponymous Officials of Greek Cities. IV», ZPE 93, 1992, p. 240, n 150. Au moment des négociations de 198 entre le roi macédonien Philippe V et Titus Quinctius Flamininus, les ambassadeurs rhodiens ont demandé que le roi macédonien rétablît la sympolitie entre les Périnthiens et les Byzantins, selon Polybe, XVIII, 2, 4 ( $\alpha \pi \circ \kappa \alpha \tau \alpha \sigma \tau \tilde{\eta} \sigma \alpha \mathrm{l}$

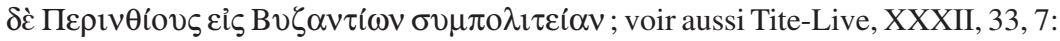
et Perinthium Byzantiis in antiqui formulam iuris restitui). Sur les campagnes de Philippe V dans la Propontide orientale, on renverra à A. Dumitru, «Byzance et les Philippe de Macédoine», REG 119, 2006, p. 139-156.

259 Isaac, Gr. Settlem. in Thrace, p. 235.

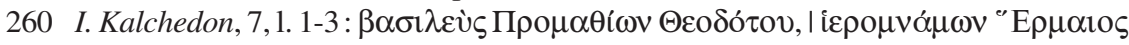

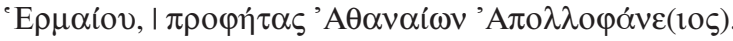


Quant à ses pouvoirs, le décret sur l'asylie du sanctuaire de l'Asclépios de Cos atteste vers 242 que, conformément à la loi, le hiéromnamôn est le magistrat chargé d'introduire la proposition de décret devant le Conseil $^{261}$. Cette compétence revient plus tard, au $\mathrm{II}^{\mathrm{e}}$ siècle, aux stratèges ${ }^{262}$. De plus, un règlement mentionne le hiéromnamôn en tant que magistrat responsable de la publication de la liste de proxènes ${ }^{263}$. On connaît enfin la stèle funéraire d'un Chalcédonien ayant rempli à la fois les charges de hiéromnamôn et de prophètas ${ }^{264}$.

D'autre part, un décret de Mésambria mentionne un certain Ompha-

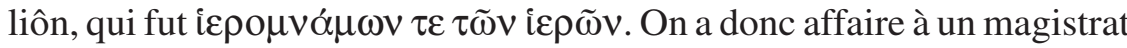
qui fut en charge soit des «sanctuaires», soit des «choses sacrées» de la cité $^{265}$. Cela confirmerait l'opinion de certains savants, selon laquelle les

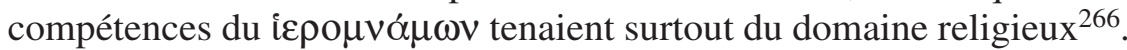

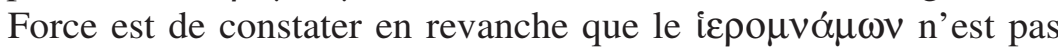
documenté à Mégare. On ne rencontre dans cette cité qu'un $\mu v \alpha ́ \mu \omega v$ à l'époque romaine, un magistrat dont les fonctions ne sont pas mentionnées, mais qui dans d'autres cités a des attributions dans la sphère de la rédaction de divers documents ou du respect des lois ${ }^{267}$. De surcroît, les

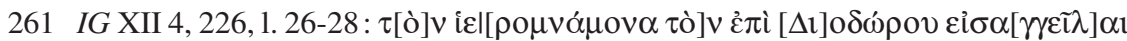

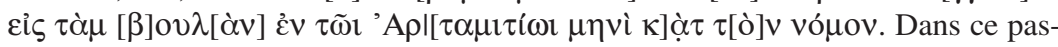
sage, le Diodôros est l'éponyme de Chalcédoine, soit le basileus (voir ci-dessus).

262 Voir infra, chapitre III.2.2.4.

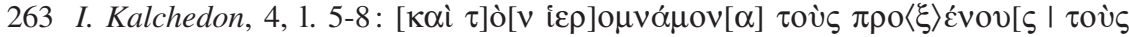

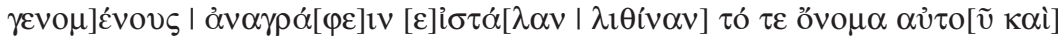

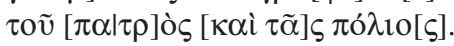

264 I. Kalchedon, 42. Rappelons que le prophètas est probablement à Chalcédoine en rapport avec le culte d'Apollon Pythaios et Chrestèrios. Une stèle funéraire fait aussi

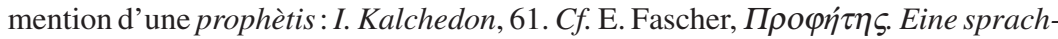
und religionsgeschichtliche Untersuchung, Gießen 1927, p. 48; Hanell, Megarische Studien, p. 150; L. Robert, «Hellenica», RPh 13, 1939, p. 187-188 (= OpMinSel, II, p. 1340-1341); J. et L. Robert, Bull. ép., 1978, 480; Robu, Chalcédoine, p. 143.

265 Velkov, Inscr. de Messambria, p. 164, no 5; cf. A. Avram, Bull. ép., 2006, 283.

266 H. Hepding, s.v. «Hieromnemones», RE VIII, 1913, col. 1490; Latyshev, Const. de Chersonèse, p. 296-298; Merle, Byzantion und Kalchedon, p. 72; Hanell, Megarische Studien, p. 150-151; A. Lajtar, I. Byzantion, $a d \mathrm{n}^{\circ} 2$, p. 25.

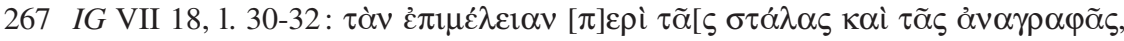

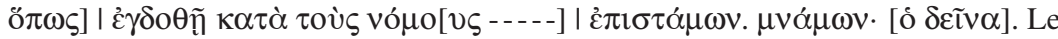
mnamôn est responsable à l'époque classique dans plusieurs cités de la rédaction des lois, en veillant aussi à leur respect; ses fonctions sont en rapport avec le domaine juridique. Il est souvent chargé à l'époque hellénistique de la rédaction de divers documents. À ce propos, voir M. Wörrle in W. Lambrinudakis, M. Wörrle, «Ein 
décrets d'époque hellénistique attestent à Chersonèse la présence des $\sigma v \mu \mu \nu \alpha ́ \mu 0 v \varepsilon \varsigma^{268}$. En analysant ces témoignages, Hanell a repoussé à

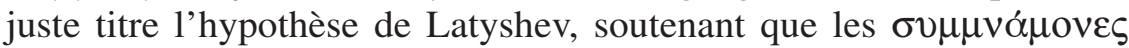

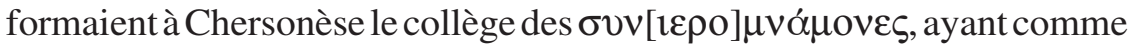

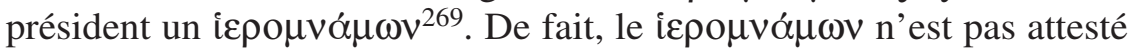

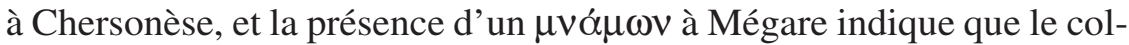

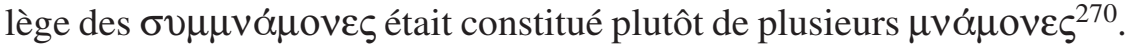
On n'a aucune raison de penser que le $\mu v o ́ \alpha \omega v$ de Mégare coïncide avec

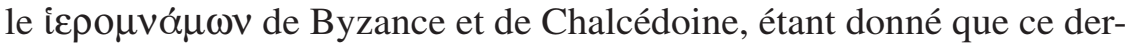
nier est un magistrat très répandu dans le monde grec, ayant des attributions variées ${ }^{271}$. Selon moi, au lieu de chercher une origine mégarienne

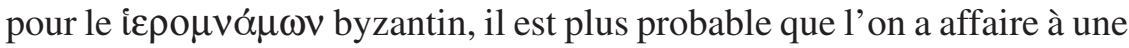
magistrature argienne. En faveur de cette hypothèse il y a, d'une part,

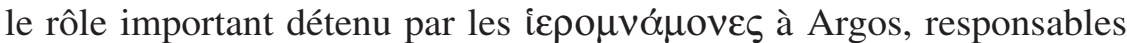
du culte d'Héra, l'une des divinités principales de la cité, et, de l'autre, la mention des Argiens parmi les fondateurs de Byzance ${ }^{272}$.

hellenistisches Reformgesetz über das öffentliche Urkundenwesen von Paros (mit. Taf. 5-13)», Chiron 13, 1983, p. 328-344; R. Thomas, Literacy and Orality in Ancient Greece, Cambridge 1992, p. 69-71; idem, «Written in Stone? Liberty, Equality, Orality, and the Codification of Law », BICS 40, 1995, p. 66-71 (SEG XLV, 2262); M. Gagarin, Writing Greek Law, Cambridge 2008, p. 117-121.

268 IOSPE $\mathrm{I}^{2}, 344,349,352$.

269 Latyshev, Const. de Chersonèse, p. 296-299.

270 Hanell, Megarische Studien, p. 151, 154; cf. R. A. Novikova, «Les symnamons et les nomophylaques de la Chersonèse Taurique», VDI, 1961, 2, p. 102-104 (en russe); Loukoupoulou, Thrace propontique, p. 146.

271 L'origine mégarienne du ípouvó $\mu \omega v$ est soutenue par H. Hepding, op. cit., col. 1492, qui renvoie à Plutarque, Propos de table, VIII, 8, 4 (= Moralia, 730 D-E), ainsi que par E. Fascher, op. cit., p. 48. Pourtant, comme Latyshev, Const. de Chersonèse, p. 298, l'a jadis noté, il ne ressort pas de ce texte que le ípouvó $\mu \omega v$ soit le prêtre de Poséidon à Mégare. Malgré ces évidences, on constate que R. K. Sherk, «The Eponymous Officials of Greek Cities. III», ZPE 88, 1991, p. 235, n 79, écrit «Byzantium was a colony of Megara back in the seventh century and inherited the institutions of its mother-city, including the office of hieromnemon [...]». De même, A. Lajtar, I. Byzantion, $a d \mathrm{n}^{\circ} 2$, p. 25, commet une erreur en écrivant que les

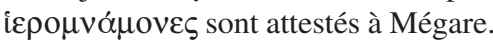

272 Voir supra, chapitre II.2.4.1.6. En revanche, F. Cordano, «Alcune caratteristiche delle colonie megaresi », in Argumenta Antiquitatis, G. Zanetto et M. Ornaghi (éds.), Milano 2009, p. 8, considère le hiéromnamôn de Byzance comme une nouveauté institutionnelle spécifique à l'époque hellénistique, sans rapport avec la tradition de la métropole. 


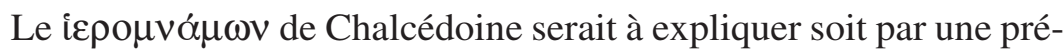
sence argienne, soit par les échanges institutionnels qui se sont produits entre les deux colonies mégariennes du Bosphore. Un cas similaire des rapprochements institutionnels entre les cités mégariennes du Bosphore est l'attestation de la hékatostys K $\alpha \lambda \lambda \imath \chi 0 p i \tau \imath \varsigma$ à Byzance et de la $K \alpha \lambda \lambda \imath \chi 0 \rho \varepsilon \tilde{\alpha} \tau \imath \varsigma$ à Chalcédoine ${ }^{273}$. Les liens politiques étroits entre ces deux cités pourraient être en effet responsables de certains transferts

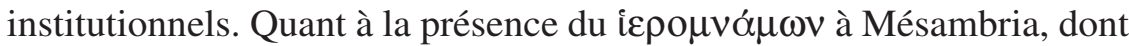
les charges cultuelles sont manifestes, elle est due soit aux Chalcédoniens ayant participé avec les Mégariens à la fondation de la cité, soit aux époikoi byzantins et chalcédoniens qui, menacés par les Perses, sont arrivés vers 493 dans la colonie mégarienne du Pont-Gauche ${ }^{274}$.

\section{III.2.2 Les collèges de magistrats}

\section{III.2.2.1 Les aisimnatai}

Les $\alpha i \sigma l \mu v \tilde{\alpha} \tau \alpha$ constituent l'un des collèges mégariens les plus anciens $^{275}$. Il faut rappeler que cette institution n'est pas propre uniquement au monde mégarien et qu'elle est connue dans des cités ioniennes telles que Milet et ses colonies (Sinope, Olbia) ${ }^{276}$. Pour expliquer cette

273 Voir supra, chapitre III.1.2.2.

274 A. Avram, Bull. ép., 2006, 283. Sur les récits de fondation de Mésambria, voir supra, chapitre II.3.2.1. Signalons aussi que le hiéromnamôn est attesté comme éponyme en Sicile, à Ségeste et à Entella: IG XIV, 291; IGDS, 204-206, 216; $c f$. L. Gallo, «Problemi istituzionali di Entella», in Seconde giornate internazionali di studi sull'area elima (Gibelina, 22-26 ottobre 1994). Atti, vol. II, Pisa-Gebellina 1997, p. 771-789; Cordano, Istituzioni, p. 155. Il n'est pas exclu que le hiéromnamôn ait été introduit dans ces cités par le biais de Sélinonte. On aurait alors un autre exemple des échanges institutionnels qui se sont produits entre les Sélinontins et les Élymes. Voir à ce propos A. Robu, «Chronique mégarienne. À propos d'un livre récent portant sur les cités mégariennes de Sicile», AC 75, 2006, p. 211-212.

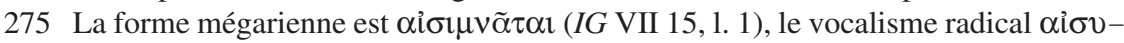
étant plutôt ionien. À ce propos, voir F. Solmsen, Beiträge zur griechischen Wort-

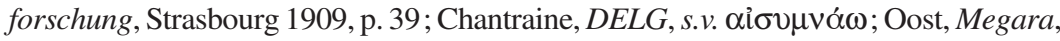
p. 186, n. 4; Piccirilli, MEGARIKA, p. 163, n. 7; L. Dubois, in IGDS, p. 35. Dans mon texte, j'ai choisi d'employer la forme mégarienne aisimnatai.

276 On peut citer parmi les études qui traitent des aisimnatai: F. Bilabel, Die ionische Kolonisation. Untersuchungen über die Gründungen der Ionier, deren staatliche 
concordance institutionnelle, nous en sommes réduits à des conjectures. D'aucuns estiment que les aisimnatai mégariens seraient à mettre en rapport avec un arbitre de l'Ionie (un aisymnetès) auquel les Mégariens avaient fait appel au $\mathrm{VI}^{\mathrm{e}}$ siècle, après la tyrannie de Théagène, pour mettre fin aux luttes internes ${ }^{277}$. La présence des aisimnatai dans les colonies mégariennes de Sicile et de la Propontide implique pourtant une introduction de cette magistrature à Mégare à une époque antérieure au milieu du VII ${ }^{\mathrm{e}}$ siècle.

Quoi qu'il en soit de l'origine de cette institution, on notera que les aisimnatai sont attestés par les inscriptions à Mégare, à Chalcédoine, à Sélinonte (la seule magistrature dont on a connaissance) et à Sélymbria. Dans les deux dernières cités, le caractère fragmentaire de la documentation nous empêche de connaître la nature exacte de cette magistrature. Les aisimnatai apparaissent à deux reprises dans l'accord trouvé à Olympie concernant les exilés sélinontins (datant de $c a$. 500), et ils avaient probablement des compétences relevant du domaine juridique et/ou de celui de la sanction ${ }^{278}$. De même, une inscription témoigne de la présence des aisimnatai parmi les magistrats de Sélymbria ${ }^{279}$.

Le décret de Mégare pour Hikésios d'Éphèse, gouverneur du roi de Pergame Eumène II (197-158) à Égine, atteste vers la fin du III ${ }^{\mathrm{e}}$ siècle ou dans le premier quart du $\mathrm{II}^{\mathrm{e}}$ siècle que les aisimnatai examinent avec le Conseil et l'Assemblée le «projet de décret» (probouleuma) que les synarchiai (les collèges de magistrats réunis) ont préalablement

und kultische Organisation und Beziehungen zu den Mutterstädten, Philologus, Suppl. 14, 1, Leipzig 1920, p. 124-125 ; G. Pugliese Carratelli, «Note di storia greca arcaica, I: Aisymnatai », RAAN21, 1941, p. 295-308; D. Hegyi, «Der Ursprung der Aisymneteia», ACD 13, 1977, p. 7-10; Ehrhardt, Milet und seine Kolonien², p. 200-202, 508, n. 1197 ; M. Faraguna, «La figura dell'asymnetes tra realità storica e teoria politica », in Symposion 2001. Vorträge zur griechischen und hellenistischen Rechtsgeschichte (Evanston, Illinois, 5.-8. September 2001), R. W. Walace et M. Gagarin (éds.), Wien 2005, p. 321-338.

277 G. Pugliese Carratelli, RAAN 21, 1941, p. 305-306; Piccirilli, MEGARIKA, p. 163.

278 IGDS, 28, fr. h, 1. 6; fr. b, 1. 5-6; cf. Cordano, Istituzioni, p. 151. Voir aussi supra, chapitre II.1.2.5.

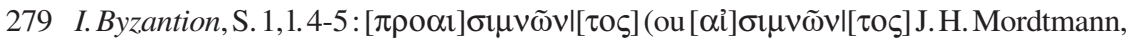

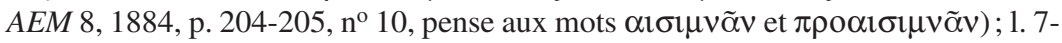

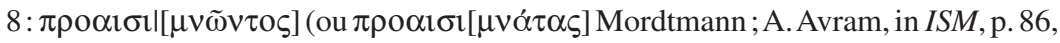
n. 360, suggère aussi $\left.\pi \rho \alpha_{1} \sigma \mathrm{l}[\mu \nu \alpha ́ \sigma \eta 1]\right) ; c f$. Hanell, Megarische Studien, p. 149. 
préparé $^{280}$. Malgré l'avis de certains, il ne ressort pas de notre décret que les aisimnatai aient été des magistrats similaires aux prytanes athéniens, comme cela fut le cas à Chalcédoine (voir ci-après) ${ }^{281}$.

D'autre part, les modernes ont aussi invoqué la légende d'Aisymnos, le bâtisseur mythique du Bouleutèrion mégarien, pour étayer l'hypothèse que les aisimnatai étaient un élément du Conseil. Pausanias (I, 43, 3) rapporte que l'Aisymnion est le nom d'un tombeau de héros. Il ajoute que le nom de cet édifice dérive d'Aisymnos, le nom du citoyen qui, au moment du remplacement du dernier roi mégarien, Hypérion, fils d'Aga-

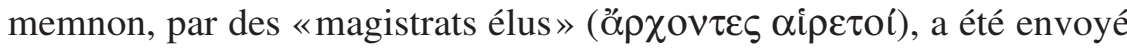
à Delphes pour demander au dieu ce que les Mégariens devaient faire pour connaître la prospérité. À cette question, l'oracle répond que les Mégariens doivent être plus nombreux lors de leurs délibérations. Afin de respecter la volonté du dieu et de préserver le gouvernement oligarchique, Aisymnos prend la décision de construire la salle du Conseil sur les tombes des héros de la cité282. Selon d'aucuns, l'Aisymnion serait le nom local du Bouleutèrion de la ville, la tradition recueillie par Pausanias n'étant qu'un aition ${ }^{283}$. Mieux encore, Hanell estime que l'on devrait

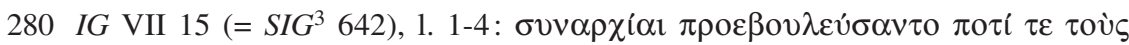

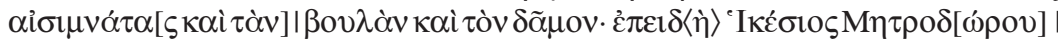

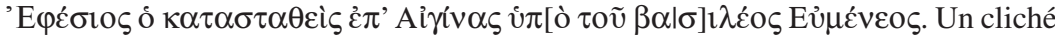
de cette inscription fragmentaire est reproduit en couverture. Sur les synarchiai, on renverra à Rhodes-Lewis, Decrees, p. 111-112; Robu, Décret d'Aigosthènes, p. 8889. Le décret $I G$ VII 15 se place après l'abandon de la Ligue béotienne par les Mégariens (ca. 206/5, voir ci-dessus); son terminus ante quem remonte autour de 174, date à laquelle l'on suppose qu'Hikésios d'Éphèse quitta sa fonction de gouverneur d'Égine. Voir à cet égard I. Savalli-Lestrade, op. cit., p. 165-166.

281 Robu, Organisation civique, p. 157-158. Pour l'opinion qui considère que les attributions des aisimnatai étaient à Mégare similaires aux prytanes d'Athènes, voir Foucart, Inscr. de la Mégaride, ad no 35 a, p. 26; Meyer, Megara, col. 199; Hanell, Megarische Studien, p. 146; F. Sokolowski, Lois sacrées de l'Asie Mineure, Paris, 1955, p. 15; Merkelbach, I. Kalchedon, ad $\mathrm{n}^{\circ}$ 6, p. 12. Cf. aussi Swoboda, Gr. Volksbeschlüsse, p. 140 ; idem, «Studien zu den griechischen Bünden», Klio 12, 1912, p. 46, n. 1.

282 Sur la légende d'Aisymnos et la construction de différents bâtiments publics sur des tombes de héros, voir aussi supra, chapitre I.1.4.

283 J. Toepffer, s.v. «Aisymnetes» 1, RE I, 1, 1893, col. 1090; J. G. Frazer (éd.), Pausanias's Description of Greece ${ }^{2}$, vol. II, London 1913, p. 534; Hanell, Megarische Studien,

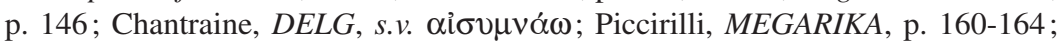

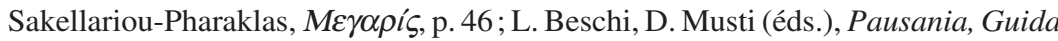
della Grecia. Libro I, L’Attica, Milano 1982, p. 433; K.-W. Welwei, «Heroenkult und 
identifier le Bouleutèrion avec le Prytanée ${ }^{284}$. Mais cette opinion est invraisemblable, car Pausanias (I, 43, 2) évoque, juste avant la mention de la salle du Conseil, le Prytanée, un édifice construit par les Mégariens aussi sur des tombes héroïques (celle d'Euhippos, fils de Mégareus, et celle d'Ischépolis, fils d'Alcathoos). Ce témoignage laisse penser que le Bouleutèrion et le Prytanée étaient deux bâtiments distincts à Mégare ${ }^{285}$. Bref, le récit de Pausanias atteste que les Mégariens honoraient à l'époque impériale le héros Aisymnos, l'éponyme mythique de leur ancien collège des aisimnatai, mais il ne transmet rien sur les charges de ces magistrats. Il est permis de penser que ce collège appartenait primitivement à Mégare aux institutions oligarchiques ${ }^{286}$. La tradition imputait au héros éponyme de la magistrature (Aisymnos) une mesure spécifique à un régime oligarchique. En bâtissant le Bouleutèrion sur les tombes des héros, il a gardé le nombre limité de conseillers mégariens, tout en respectant la volonté du dieu de Delphes d'élargir le corps politique de la cité. On a donc affaire à une décision à caractère oligarchique.

Du reste, les inscriptions de l'époque hellénistique attestent que les aisimnatai remplissaient à Chalcédoine des fonctions similaires à celles des prytanes d'Athènes. Grâce à deux inscriptions honorifiques, on sait que ces magistrats avaient des charges mensuelles et qu'ils étaient désignés par tirage au sort ${ }^{287}$. Le nombre des aisimnatai varie de neuf

Gefallenenehrung im antiken Griechenland», in Tod und Jenseits im Altertum, G. Binder et B. Effe (éds.), Trier 1991, p. 54-55 (= Polis und Arché, Historia Einzelschriften 146, Stuttgart 2000, p. 138-139). Voir aussi F. Chamoux (éd.), Pausanias, Description de la Grèce, Livre I, L'Attique, Paris 1992, ad I, 43, 3, p. 265-266, qui cite comme parallèle pour l'équivalence entre le Bouleutèrion et l'Aisymnion de Mégare, le cas du Bouleutèrion de Mégalopolis, qui, suivant Pausanias, VIII, 32, 1, était également appelé Thersilion, du nom de son fondateur. Contra H. Hitzig, H. Blümner (éds.), Pausaniae Graeciae Descriptio, vol. I, Berlin 1896, p. 371, qui croient qu'il faudrait distinguer à Mégare deux bâtiments, l'Aisymnion et le Bouleutèrion.

284 Hanell, Megarische Studien, p. 147, n. 6. Contra C. Robert, Pausanias als Schriftsteller. Studien und Beobachtungen, Berlin 1909, p. 182; Highbarger, Megara, p. 17-18, qui pensent qu'on a affaire à trois édifices : le Prytanée, l'Aisymnion et le Bouleutèrion.

285 Plutarque, Marc-Antoine, 23, 3, mentionne aussi le Bouleutèrion mégarien.

$286 C f$. R. L. Fox, «Theognis: an Alternative to Democracy», in Alternatives to Athens. Varieties of Political Organization and Community in Ancient Greece, R. Brock et S. Hodkinson (éds.), Oxford 2000, p. 41.

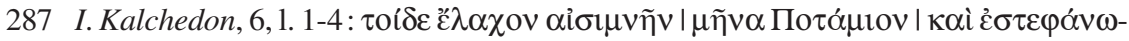

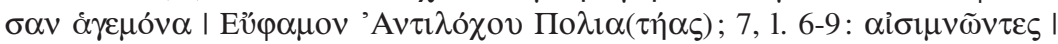

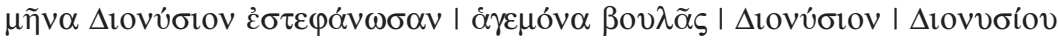


(I. Kalchedon, 7, 1. 8-17) à peut-être onze (I. Kalchedon, 6, 1. 4-14) $)^{288}$; ce sont là les seules attestations du nombre des aisimnatai dans une cité mégarienne ${ }^{289}$. À l'instar de l'épistate des prytanes athéniens, le chef des aisimnatai, le $\alpha \gamma \varepsilon \mu \omega ̀ v \beta o v \lambda \tilde{\alpha} \varsigma$, présidait le Conseil et l'Assemblée du peuple, ses fonctions administratives étant sans doute désignées par le verbe $\pi \rho o \alpha 1 \sigma 1 \mu v \alpha \omega^{290}$. Il convient de souligner que ces attributions sont spécifiques aux aisimnatai chalcédoniens et n'ont rien à voir avec les fonctions initiales des magistrats homonymes de la métropole ${ }^{291}$. Autrement dit, l'institution oligarchique de la métropole a changé de nature au fil du temps, en se transformant en une magistrature démocratique dans la colonie du Bosphore thrace.

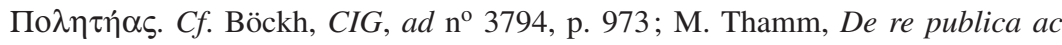
magistratibus Megarensium, Dissertation Halle 1885, p. 15-16; J. Toepffer, op. cit., col. 1090; Merle, Byzantion und Kalchedon, p. 74; Loukopoulou, Thrace propontique, p. 145 ; Robu, Organisation civique, p. 151-159.

288 Il n'est pas exclu que le nombre des aisimnatai mentionné dans I. Kalchedon, 6, soit supérieur à onze, car les dernières lignes de l'inscription ne semblent pas être préservées et d'autres noms de magistrats pouvaient y figurer, notamment le nom du secrétaire du Conseil et de l'Assemblée du peuple (comme dans I. Kalchedon, 7, 1. 18-19).

289 En estimant que les aisimnatai étaient élus par les cinq kômai primitives de la Mégaride, Loukopoulou, Thrace propontique, p. 143, suivie par Smith, Megaris, p. 114-115; Malkin, Foundations, p. 389, soutient la présence de cinq aisimnatai à Mégare. En réalité, il n'existe aucun témoignage attestant que le collège des aisimnatai était composé à Mégare de cinq membres. Voir supra, chapitre III.1.4, sur les cinq districts primitifs de la Mégaride.

290 En se fondant sur la présence d'un $\pi \rho 0 \alpha 1 \sigma v \mu v \tilde{\omega} v$ à Chersonèse (voir ci-après), Latyshev, Const. de Chersonèse, p. 282-283, estime que le verbe $\pi \rho 0 \alpha 1 \sigma 1 \mu v \alpha ́ \omega$ ne désigne pas les fonctions administratives de tous les aisimnatai, comme le pensait Dittenberger $\left(S I G^{3}, a d \mathrm{n}^{\circ} 709\right.$, p. 346, n. $29 ; \mathrm{n}^{\circ} 1009$, p. 145, n. 8; idem, «Kritische Bemerkungen zu griechischen Inschriften», Hermes 16, 1881, p. 167, n. 1, 173), en faisant équivaloir $\pi \rho \circ \alpha \iota \sigma \iota \nu \nu \widetilde{\alpha} v$ avec $\alpha i \sigma \iota \mu \nu \widetilde{\alpha} v$ et avec les attiques $\pi \rho v \tau \alpha v \varepsilon v ́ \varepsilon \imath v$ ou $\pi \rho \circ \beta о v \lambda \varepsilon v ́ \varepsilon ı v$, mais seulement du président des aisimnatai. $C f$. Busolt, Staatskunde, I, p. 374, 478; Hanell, Megarische Studien, p. 150; F. Sokolowski, op. cit.,

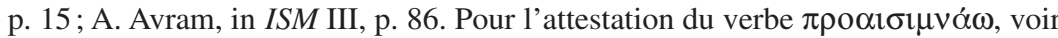
les règlements de Chalcédoine concernant la vente des sacerdoces I. Kalchedon, 10,

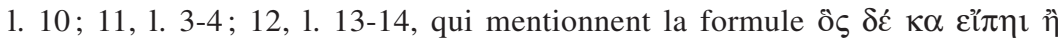

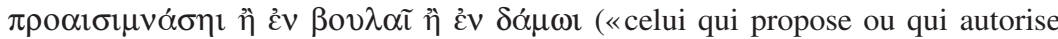
une proposition en tant que président des aisimnatai que ce soit devant le Conseil ou devant l'Assemblée»). Ces inscriptions transmettent également le passif $\tau \grave{\alpha}$

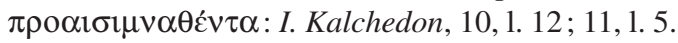

291 Oost, Megara, p. 186, n. 4 ; Piccirilli, MEGARIKA, p. 163 ; cf. Malkin, A Small Greek World, p. 195. 
Il faudrait finalement se demander si la fonction «probouleumatique» acquise par les aisimnatai de Chalcédoine ne témoigne pas de l'influence exercée à différentes reprises à l'époque classique par Athènes sur les cités du détroit du Bosphore thrace. En faveur de cette hypothèse, il y aurait les noms d'inspiration athénienne portés par quelques subdivisions civiques de Chalcédoine (la «centaine» 'A $\tau \theta i ́ \varsigma)$ et de By-

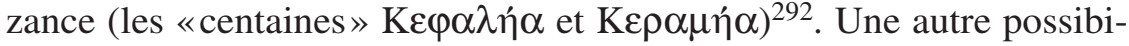
lité serait que le caractère démocratique de l'institution des aisimnatai fut importé depuis Byzance, la cité qui appuie vers 357 l'introduction d'un régime démocratique à Chalcédoine ${ }^{293}$.

\section{III.2.2.2 Les probouloi}

Dans les colonies fondées par Héraclée du Pont, à Chersonèse et à Callatis, les documents ne font pas mention des $\alpha i \sigma \mu \nu \tilde{\alpha} \tau \alpha 1$, mais seulement d'un $\pi \rho o \alpha \imath \sigma v \mu \nu \tilde{\omega} \nu$ (orthographié $\pi \rho \alpha \iota \sigma \iota \nu \nu \tilde{\omega} v$ à Callatis) ${ }^{294}$. Bon nombre de savants considèrent que le $\pi \rho 0 \alpha \imath \sigma v \mu \nu \tilde{\omega} v$ était le président du collège des $\alpha i \sigma ı \mu v \tilde{\alpha} \tau \alpha l$, en pensant que ce magistrat était analogue à l'épistate

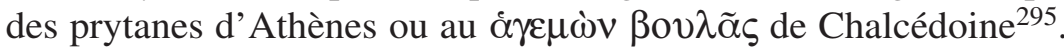

En revanche, Avram envisage une autre solution. Selon lui, les $\alpha i \sigma ı \nu v \tilde{\alpha} \tau \alpha \imath$ furent remplacés à Callatis (et peut-être déjà dans sa métropole Héraclée du Pont) par des $\pi \rho o ́ \beta o v \lambda o t^{296}$. De fait, les inscriptions

292 Voir supra, chapitre III.1.2.6.

293 Théopompe, FGrHist 115 F 62 ; Démosthène, XV, Pour la liberté des Rhodiens, 26; cf. Merle, Byzantion und Kalchedon, p. 43 ; Robu, Organisation civique, p. 161-162.

294 Le $\pi \rho \alpha_{1} \sigma 0 \mu \nu \tilde{\omega} \nu$ apparaît dans le célèbre décret de Chersonèse en l'honneur de Diophante, le stratège de Mithridate VI Eupatôr, IOSPE I ${ }^{2}, 352$, 1. 57: $\pi \rho 0 \alpha 1 \sigma v-$

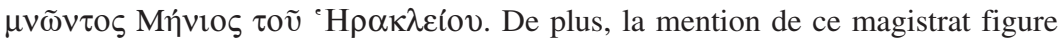

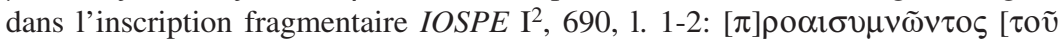

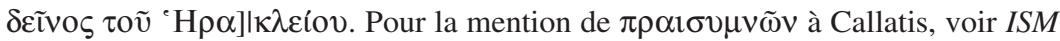

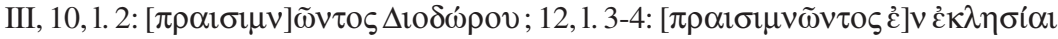

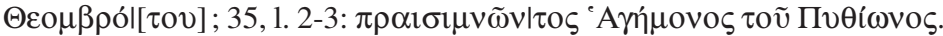

295 P. Foucart, $B C H$ 5, 1881, p. 87; J. Toepffer, op. cit., col. 1091; Latyshev, Const. de Chersonèse, p. 283; Dittenberger, $S I G^{3}$, ad n $\mathrm{n}^{0} 709$, p. 346, n. 29; Swoboda, Gr. Volksbeschlüsse, p. 98 ; Busolt, Staatskunde, I, p. 374, 478; Hanell, Megarische Studien, p. 152-155; Loukopoulou, Thrace propontique, p. 145; Antonetti, Megara e le sue colonie, p. 84.

296 Avram, Zur Verfassung von Kallatis, p. 167-174; idem, ISM III, p. 86-87. L'équivalence des probouloi de Callatis avec les aisimnatai était déjà supposée par Hanell, Megarische Studien, p. 155. 
attestent que dans la cité du Pont-Gauche ce sont les probouloi qui exercent à l'époque hellénistique des charges mensuelles et constituent, à l'image des prytanes à Athènes, la partie active du Conseil ${ }^{297}$. Dans ces conditions, le $\pi \rho 0 \alpha \imath \sigma v \mu \nu \tilde{\omega} v$ désignerait le président de l'Assemblée ${ }^{298}$ et il n'aurait plus rien à voir avec le collège des $\alpha i \sigma l \mu \nu \tilde{\alpha} \tau \alpha$ l, étant seulement l'un des $\pi \rho o ́ \beta o v \lambda o r$. Le magistrat $\pi \rho \circ \alpha \iota \sigma v \mu v \tilde{\omega} v$ ne serait alors dans les colonies héracléotes qu'une réminiscence de l'institution mégarienne des $\alpha i \sigma 1 \mu v \tilde{\alpha} \tau \alpha \mathrm{l}$. Signalons que les probouloi remplissent également d'autres fonctions à Callatis. Une clause d'un décret de citoyenneté mentionne les probouloi comme magistrats responsables d'accorder dans le théâtre au personnage honoré, lors de la fête de Dionysos, une couronne d'or et de proclamer son bénéficiaire comme un «homme de bien, zélé et dévoué à la cité» ${ }^{299}$. De même, les probouloi sont ceux qui doivent indiquer l'endroit d'exposition de certains décrets dans le sanctuaire des Dieux de Samothrace ${ }^{300}$.

D'autre part, les $\pi \rho$ óßov $\lambda$ or sont sans doute des magistrats d'origine mégarienne: preuve en serait un passage d'Aristophane (Acharniens, 754-756), où l'on voit un Mégarien appeler les chefs de sa ville

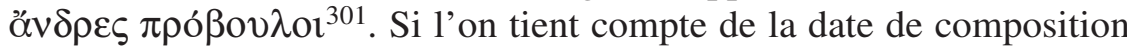
des Acharniens d'Aristophane, à savoir vers $425^{302}$, il résulte que les

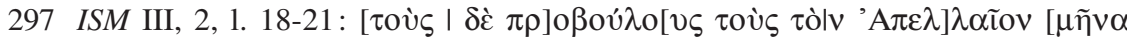

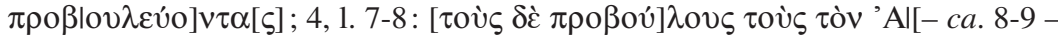

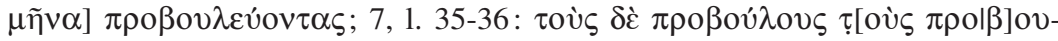

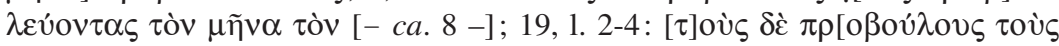

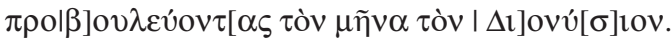

298 La même opinion chez D. M. Pippidi, Scythica Minora. Recherches sur les colonies grecques du littoral roumain de la mer Noire, Bucarest-Amsterdam 1975, p. 124.

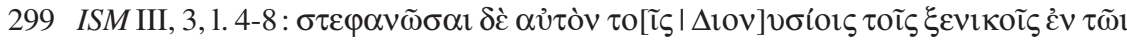

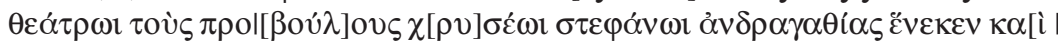

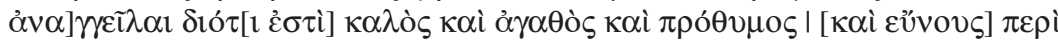
$\tau \grave{\alpha} \mu \pi$ ó $\lambda \iota v$.

300 ISM III, 4, 1. 7-11; 7, 1. 35-39; 19, 1. 2-6. Sur les probouloi des différentes cités grecques et leurs fonctions, voir F. Ruzé, «La fonction des probouloi dans le monde grec antique», in Mélanges d'histoire ancienne offerts à William Seston, Paris 1974, p. 443-462 (= Eunomia. À la recherche de l'équité, Boulogne-sur-Mer-Paris 2003, p. 11-29); J. Tréheux, «Sur les probouloi en Grèce», BCH 113, 1989, p. 241-247.

301 A. Avram, in ISM III, p. 87. Contra H. Schaefer, RE XXIII, 1, 1957, col. 1223, qui estime que le terme de probouloi n'a pas, dans ce passage, un sens technique.

302 W. J. M. Starkie (éd.), The Acharnians of Aristophanes, with Introduction, English Prose Translation, Critical Notes and Commentary, Amsterdam 1968, p. XXVII. 
probouloi appartiendraient alors au régime démocratique au pouvoir à Mégare entre 427 et $424^{303}$.

Il importe de retenir enfin que l'explication des attributions des probouloi et du proaisymnôn de Callatis, avancée par Avram, ne vaut pas encore aussi pour Chersonèse. Car les probouloi ne sont pas attestés dans la colonie héracléote du nord de la mer Noire et les fonctions du proaisymnôn ne sont pas mentionnées ici dans les inscriptions. Signalons aussi que pour Latyshev, la place des aisimnatai dans le Conseil serait prise l'époque impériale à Chersonèse par les proèdres, des magistrats qui proposent plusieurs décrets au Conseil et à l'Assemblée du peuple ${ }^{304}$. Cette interprétation est contredite maintenant par un nouveau décret, qui suggère que ces magistrats constituent à l'époque impériale une véritable classe à Chersonèse, sans rapport avec les aisimnatai. Cette inscription nous apprend que le personnage honoré aurait «le droit d'être conseiller et de voter avec ceux qui sont depuis les origines les proèdres des Chersonésitains ${ }^{305}$.

\section{III.2.2.3 Les pentékaidéka}

L'une des spécificités des institutions de Byzance est la présence d'un collège des Quinze, les $\pi \varepsilon \nu \tau \varepsilon \kappa \alpha i ́ \delta \varepsilon \kappa \alpha$. D'aucuns estiment que ces magistrats auraient pris dans la cité du Bosphore thrace les fonctions d'aisimnatai ou de prytanes athéniens, étant une commission du Conseil $^{306}$. Cette opinion se fonde, à mon sens, sur une surinterprétation de la documentation. Deux inscriptions attestent que les pentékaidéka sont les magistrats chargés d'exposer les décrets dans le sanctuaire d'Apollon ou

303 Highbarger, Megara, p. 176-179; Legon, Megara Pol. Hist., p. 231-237.

304 Latyshev, Const. de Chersonèse, p. 283-284. Pour la mention des proèdres dans les inscriptions de Chersonèse, voir IOSPE $\mathrm{I}^{2}, 357,359,362$, 364, 366, 367 ; Sourov, Inscr. de Chersonèse, p. 154-155; Saprykin, Proxénie de Chersonèse, p. 43. Cf. Hanell, Megarische Studien, p. 154.

305 J.G. Vinogradov, «Un nouveau dossier documentaire de l'époque impériale de Cher-

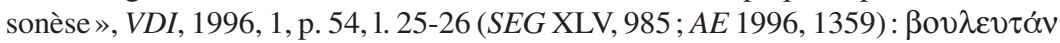

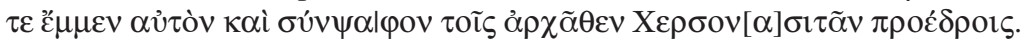

306 Merle, Byzantion und Kalchedon, p. 71; Hanell, Megarische Studien, p. 158; Newskaja, Byzanz, p. 62; A. Lajtar, I. Byzantion, ad n ${ }^{\circ}$ 1, p. 21. De plus, les pentékaidéka sont considérés comme une commission du Conseil par Dittenberger, $S_{1}{ }^{3}, a d$ $\mathrm{n}^{\circ}$ 644, p. 201, n. 23 («viri senatus pars»); cf. Rhodes-Lewis, Decrees, p. 197; Isaac, Gr. Settlem. in Thrace, p. 235. 


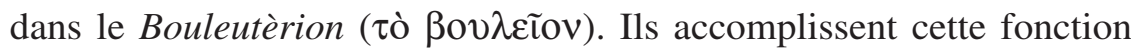
avec l'aide des synagoroi du Conseil et, occasionnellement, du secrétaire du Conseil ${ }^{307}$. Étant donné que ces derniers magistrats occupaient des charges administratives et financières, je pense qu'il convient de chercher les fonctions des pentékaidéka également dans le domaine de l'administration, sans un rapport direct avec le Conseil de la cité ${ }^{308}$.

Certes, on ignore la totalité des charges remplies par les pentékaidéka, et il n'est pas exclu que celles-ci aient tenu aussi du domaine politique. Mais le fait que dans les deux décrets le collège n'a qu'une tâche administrative, la publication des décisions du Conseil et de l'Assemblée du peuple, n'indique point qu'on aurait affaire à une commission analogue à celle des aisimnatai de Chalcédoine, des probouloi de Callatis ou des prytanes d'Athènes ${ }^{309}$.

Par ailleurs, si l'on compare les charges des probouloi de Callatis à celles des pentékaidéka de Byzance, on constate qu'il existe une différence entre les attributions des deux collèges: dans la colonie héracléote, les probouloi sont appelés à indiquer l'endroit où le décret sera exposé (ISM III, 7, 1. 35-39). En revanche, les pentékaidéka sont chargés à Byzance soit de la gravure du décret et de son dépôt dans le Bouleutèrion, soit simplement du dépôt du décret dans le sanctuaire d'Apollon. On ajoutera enfin qu'il est vraisemblable que les Quinze étaient choisis à Byzance au niveau des trois tribus doriennes, chaque phylè ayant le droit de désigner cinq magistrats dans ce collège ${ }^{310}$.

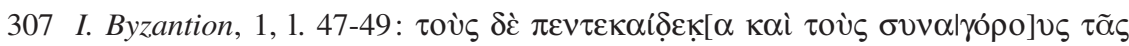

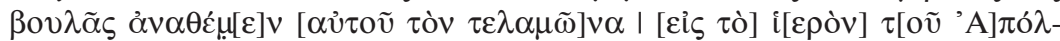

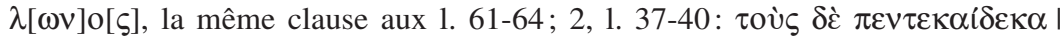

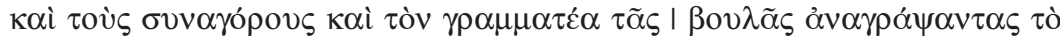

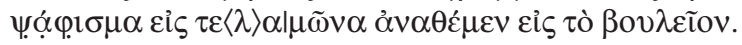

308 En invoquant comme parallèles les synégoroi d'Athènes (IG XII 2, 526 b, 1. 2), d'Iasos [W. Blümel (éd.), Die Inschriften von Iasos, vol. I, Bonn 1985, 1, 1. 11] et d'Oropos (IG VII 303, 1. 26), A. Lajtar, I. Byzantion, $a d \mathrm{n}^{\circ} 1$, p. 21, suppose que les synagoroi de Byzance étaient des magistrats chargés du contrôle des finances de l'État.

309 Il convient de dire que ni les pentékaidéka de Delphes $\left(S I G^{2} 438,1\right.$. 187 : des dignitaires de la phratrie des Labyades), ni ceux de Massalia (Strabon, IV, 1, 5, C 180, atteste qu'ils sont choisis parmi les 600 timouques, des conseillers nommés à vie, pour s'occuper des affaires courantes) ou de Chios [H. Röhl (éd.), Inscriptiones Graecae antiquissimae praeter Atticas in Attica repertas, Berlin 1882, no 381 a, 1. 18-19], ne sont pas des magistrats analogues aux prytanes d'Athènes. $C f$. A. Łajtar, I. Byzantion, ad n $\mathrm{n}^{\mathrm{O}} 1$, p. 21.

310 Voir supra, chapitre III.1.1.2. 


\section{III.2.2.4 Les stratèges}

Le décret de Mégare reconnaissant l'asylia de l'Asclépieion de Cos mentionne vers 242 les stratèges. Leur nombre n'est pas connu, car l'intitulé du document se présente sous une forme abrégée, on n'en trouve que la forme $[\sigma \tau \rho] \alpha \tau \alpha \gamma \tilde{\omega} \nu$, sans mention ni du «roi» éponyme, ni du secrétaire du Conseil et de l'Assemblée du peuple, comme il aurait été habituel à l'époque dans les décrets mégariens ${ }^{311}$.

Grâce à une série de dix-huit décrets, on sait que dans la seconde moitié du $\mathrm{III}^{\mathrm{e}}$ siècle le nombre des stratèges varie de cinq à six. Il existe ainsi un collège de six stratèges, qui demeure en charge pendant une période d'au moins quatre années (sous quatre basileis éponymes) ${ }^{312}$. Un autre collège composé, en revanche, de cinq stratèges et renouvelé chaque année est attesté pour cinq années différentes (lors de l'éponymie des cinq basileis) ${ }^{313}$. Concernant la date de ces documents, je pense avoir fourni ailleurs des arguments supplémentaires en faveur de l'opinion avancée jadis par Feyel selon laquelle le roi Démétrios, qui figure dans trois des huit décrets mentionnant les six stratèges (IG VII 1, 5 et 6),

311 D. Bosnakis, K. Hallof, «Alte und neue Inschriften aus Kos I», Chiron 33, 2003,

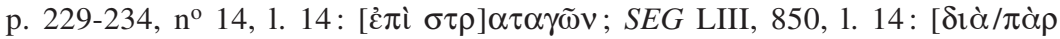

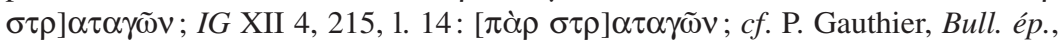
2004,238 , qui suggère simplement $[\sigma \tau \rho] \alpha \tau \alpha \gamma \tilde{\omega} \nu$.

312 IG VII 1-7; Heath, Proxeny Decrees, p. 85, $\mathrm{n}^{\circ}$ III.

313 IG VII 8-14; Heath, Proxeny Decrees, p. 84-85, n ${ }^{\text {os }}$ I-II ; Kaloyéropoulou, Décret de Mégare, p. 140. La série comprendrait même dix-neuf textes si l'on prenait aussi en compte le décret $I G$ VII 3473 (mentionnant six stratèges), dont l'authenticité reste pourtant douteuse. Plusieurs stratèges apparaissent probablement dans le préambule du décret $I G$ VII 188-189 trouvé à Pagai, mais leur nombre n'est pas certain et le nom de leur magistrature n'est pas conservé sur la pierre : Robert, Inscr. de Pagai, p. 107110 (= OpMinSel, II, p. 1260). De même, le décret publié par P. Graindor, «Inscriptions grecques (Athènes, Mégare, Ténos)», RA, 1917, 6, p. 49-51, n 30 (corr. 31), est trop fragmentaire pour savoir si les noms des magistrats qui apparaissent dans l'intitulé appartiennent aux stratèges et pour connaître éventuellement le nombre exact des membres de ce collège. L'attribution de ce document à Mégare a été d'ailleurs contesté par P. Paschidis, Between City and King. Prosopographical Studies on the Intermediaries between the Cities of the Greek Mainland and the Aegean and the Royal Courts in the Hellenistic Period (322-190 BC), MEAETHMATA 59, Athens 2008, p. 300, n. 1 (SEG LVIII, 423). 
est à identifier avec le roi Démétrios $\mathrm{II}^{314}$, et non pas avec son grandpère Démétrios Poliorcète, comme une bonne partie de la critique l'avait compris $^{315}$. On peut citer ici un indice de nature paléographique en faveur de cette thèse: dans les décrets mégariens publiés par Heath et Kaloyéropouolou (les seuls textes de la série encore conservés), la for-

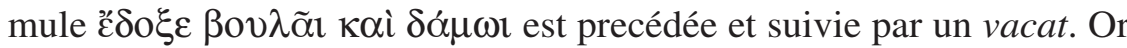
cette pratique est habituelle à Athènes après le milieu du $\mathrm{III}^{\mathrm{e}}$ siècle. Il est donc permis de penser que les Mégariens étaient influencés par leurs voisins dans la façon d'inscrire leurs décrets sur pierre ${ }^{316}$.

Il importe aussi de s'arrêter sur la procédure de désignation des stratèges à Mégare hellénistique. De fait, les décrets qui honorent des personnages faisant partie de l'entourage du roi Démétrios II ont été affichés lors d'une magistrature extraordinaire: le collège de six stratèges qui, contrairement au collège annuel de cinq stratèges, reste en place au moins quatre années consécutives dans la période 236/5-229. On a là l'indice d'une situation exceptionnelle, sans doute l'arrivée de l'armée macédonienne dans la Mégaride. Les six stratèges furent alors choisis au niveau des trois tribus doriennes, à raison de deux stratèges par tribu.

En revanche, les cinq stratèges sont peut-être en rapport avec une division en cinq unités (à caractère territorial ou tout simplement civique, la question reste ouverte), introduite après l'adhésion de la cité en 243 à la Ligue achéenne ${ }^{317}$. Car les Achéens semblent, eux aussi, se

314 Feyel, Polybe, p. 31-32, 85-100; Robu, Mégare et les Antigonides, p. 85-115. De même, pour la datation des décrets mégariens sous Démétrios II, voir maintenant P. Paschidis, op. cit., p. 295-392.

315 On peut citer parmi ceux qui défendent la datation haute des décrets (fin du $\mathrm{IV}^{\mathrm{e}}$ siècle-début du $\mathrm{III}^{\mathrm{e}}$ siècle): A.-R. Rangabé, Antiquités helléniques ou répertoire d'inscriptions et d'autres antiquités découvertes depuis l'affranchissement de la Grèce, vol. II, Athènes 1855, p. 295; Foucart, Inscr. de la Mégaride, p. 13-14; ad $\mathrm{n}^{\circ}$ 31, p. 17; Dittenberger, IG VII, ad n n $^{\circ}$, p. 2; no 11, p. 7; Highbarger, Megara, p. 202, n. 2; Meyer, Megara, col. 195; Hanell, Megarische Studien, p. 138-139, 144-145; et en dernier lieu R. Urban, Wachstum und Krise des achäischen Bundes. Quellenstudien zur Entwicklung des Bundes von 280 bis 222 v. Chr., Historia Einzelschriften 35, Wiesbaden 1979, p. 66-70; G. Marasco, «Note ellenistiche», Prometheus 9, 3, 1983, p. 221 ; C. Habicht, «Personenkundliches», in Festschrift für Nikolaus Himmelmann, H.-U. Cain et al. (éds.), Mainz am Rhein 1989, p. 321-322.

316 Robu, Hellenistic Megara, à paraître.

317 Robu, Mégare et les Antigonides, p. 100-104. 
répartir en cinq « districts » territoriaux à l'époque hellénistique ${ }^{318}$. Autrement dit, les Mégariens auraient adapté leur organisation militaire à la division en cinq «districts» (mérè), qui était alors en usage chez les Achéens. Certes, vu que l'organisation en cinq mérè de la Ligue achéenne concernait tout le Péloponnèse, les Mégariens avaient intégré un de ces districts. Mais ils auraient aussi pu introduire à cette époque un autre système d'élection pour les collèges de stratèges et de damiorgoi, plus conforme à la structure en cinq «districts» de la Ligue achéenne. Cette hypothèse est confortée par l'attestation d'autres transferts institutionnels lors des périodes d'appartenance des cités de la Mégaride (Mégare, Aigosthènes) aux États fédéraux hellénistiques, à savoir les synarchiai lors de la période achéenne, et l'archonte éponyme et les polémarques lors de la période béotienne ${ }^{319}$. Les tribus sont maintenues après 243, mais elles ne jouent plus le rôle principal dans l'élection des principaux magistrats de la cité. Elles sont utilisées pour la désignation des arbitres $^{320}$, c'est-à-dire dans des questions d'affaires étrangères, et, en outre, dans une situation de crise: lors de l'occupation de la Mégaride par Démétrios II, quand l'on a désigné un collège extraordinaire de six stratèges. Après la mort du roi macédonien en 229, les Mégariens se sont sans doute retournés dans la Ligue achéenne, en y restant jusqu'en 224. Ils renoncèrent aussi après 229 à désigner les stratèges par les trois tribus

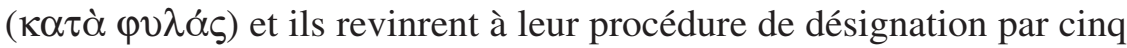

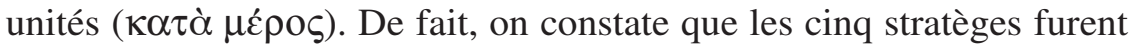
remplacés par cinq polémarques, suite à l'entrée de Mégare en 224 dans la Confédération béotienne ${ }^{321}$.

318 Corsten, Vom Stamm zum Bund, p. 171-173. Les dix damiorgoi de la Ligue achéenne (Tite-Live, XXXII, 22, 2) seraient en rapport avec ces cinq districts. On sait aussi que les communes du territoire d'Érétrie se distribuaient en cinq districts aux époques classique et hellénistique: D. Knoepfler, «Le territoire d'Érétrie et l'organisation politique de la cité (dêmoi, chôroi, phylai)», in The Polis as an Urban Centre and as a Political Community (Symposium, August 29-31 1996), Acts of the Copenhagen Polis Centre 3, M.H. Hansen (éd.), Copenhagen 1997, p. 352-449.

319 Robu, Décret d'Aigosthènes, p. 88-90.

320 Voir aussi supra, chapitre III.1.1.1.

321 Les cinq polémarques sont attestés à Mégare par deux catalogues militaires $I G$ VII 27 et 28. Sur le remplacement des stratèges de Mégare par des polémarques, voir Foucart, Inscr. de la Mégaride, ad no 34 a, p. 19-20; Dittenberger, IG VII, ad n ${ }^{\circ} 1$, p. 2; n 27, p. 22; Meyer, Megara, col. 199; Hanell, Megarische Studien, p. 145. 
On ignore combien de temps encore a duré la division en cinq du corps civique mégarien ou, si cela fut le cas, comment les Mégariens avaient procédé à la réorganisation de leur ville et de leur territoire en cinq districts. Toutefois, le fait que cette structure ne soit plus évoquée par les documents après la fin du $\mathrm{III}^{\mathrm{e}}$ siècle suggère son éventuel abandon. Il est possible que le fait que les Achéens aient renoncé au $\mathrm{II}^{\mathrm{e}}$ siècle aux cinq mérè ${ }^{322}$ ait aussi entraîné la disparition de cette organisation en Mégaride. Assurément, la thèse de l'existence d'une division en cinq unités dans la Mégare de l'époque hellénistique, indépendante de la division par tribus et par hékatostyes, a encore un caractère hypothètique, mais elle a pour le moins l'avantage d'offrir une explication au nombre (cinq) des stratèges. Le système selon lequel la cité de l'isthme s'est organisée à l'époque hellénistique serait ainsi beaucoup plus complexe et rigoureux que les modernes ne l'avaient envisagé jusqu'à présent.

On constate par ailleurs que les stratèges réapparaissent avec des fonctions nouvelles à Mégare à l'époque romaine. Plusieurs documents épigraphiques nous indiquent en effet que le «stratège de la cité» (ó $\sigma \tau \rho \alpha \tau \eta \gamma o ̀ \varsigma \tau \tilde{\eta} \varsigma \pi o ́ \lambda \varepsilon \omega \varsigma$ ) devient à l'époque impériale l'éponyme de la cité ${ }^{323}$. Celui-ci n'était probablement que le chef du collège de stratèges, car une inscription de Mégare honore un personnage qui, parmi

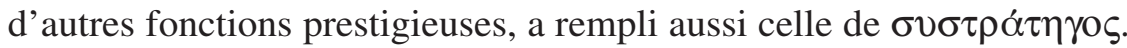
Cette mention suggère la présence, encore sous le Haut-Empire, d'une organisation collégiale des stratèges ${ }^{324}$.

322 Corsten, Vom Stamm zum Bund, p. 174-177.

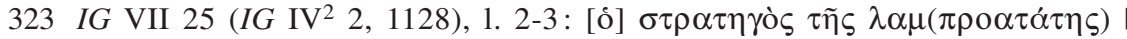

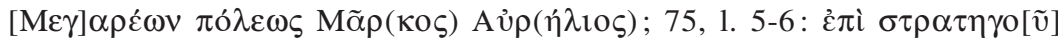

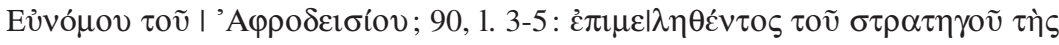

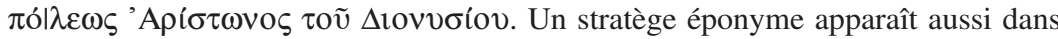
les inscriptions $I G$ VII 70-74, 3475 (?), 3491. Le personnage honoré dans $I G$ VII 4236 est peut-être aussi un stratège. Cf. Foucart, Inscr. de la Mégaride, ad $\mathrm{n}^{\mathrm{o}} 37$, p. 27 ; no 49, p. 35; Hanell, Megarische Studien, p. 145-146.

324 IG VII 106 (J. H. Oliver, Marcus Aurelius. Aspects of Civic and Cultural Policy in the East, Hesperia, Suppl. 13, Princeton 1970, p. 122, n $42 ; I G I^{2} 2$ 2, 1122). Gaius Curtius Proculus (Proklos), le Mégarien honoré par cette inscription, a eu une carrière exceptionnelle, ayant assumé non seulement des fonctions dans sa cité (agonothète, stratège, agoranome), mais aussi dans les organismes fédéraux de l'époque (béotarque, représentant de sa cité au Panhellénion, hiéromnémôn ou membre du Conseil de l'Amphictionie). Sur la carrière de ce personnage, on verra D. Knoepfler, 
Au demeurant, force est de constater que les stratèges apparaissent également dans plusieurs colonies mégariennes, soit à Mésambria, à Byzance, à Chalcédoine, à Sélymbria, à Héraclée du Pont et dans sa colonie de Callatis. La documentation la plus riche provient de Mésambria, elle témoigne de la présence dans cette cité d'un collège annuel de six stratèges, assortis d'un secrétaire. Trois reliefs du type naiskos (deux complets et l'un fragmentaire) datant de la deuxième moitié du $\mathrm{II}^{\mathrm{e}}$ siècle ou du début du $\mathrm{I}^{\mathrm{er}}$ siècle représentent les six stratèges et le secrétaire en train d'accomplir des sacrifices. Ils sont accompagnés par des membres de leurs familles ${ }^{325}$. Le destinataire de la consécration n'est mentionné que dans un seul cas: il s'agit du Héros Sôsipolis. La dédicace est faite par Déinoménès, fils de Hérotimos, et par les stratèges. Déinoménès est le premier stratège, c'est sans doute le chef du collège. On a associé à la consécration le secrétaire des stratèges ( $\gamma \rho \alpha \mu \mu \alpha \tau \varepsilon v ́ \varsigma)$, ainsi que les «gardes» ( $\varphi v ́ \lambda \alpha \kappa \varepsilon \varsigma$ ), divisés en deux groupes, les «gar-

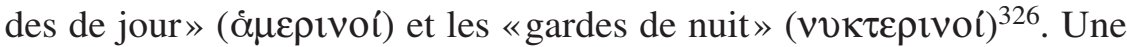

«L'exercice de la magistrature fédérale béotienne par des «étrangers » à l'époque impériale: conséquence de l'extension du Koinon en dehors des frontières de la Béotie ou simple effet d'une multi-citoyenneté individuelle?», in Patrie d'origine et patries électives: les citoyennetés multiples dans le monde grec d'époque romaine. Actes du colloque international de Tours, 6-7 novembre 2009, A. Heller et A.-V. Pont (éds.), Paris 2012, p. 228-231.

325 I. Venedikov, «Trois reliefs surprenants de Mésambria», in Nessèbre II, Sofia 1980, p. 83-95 (SEG XXX, 702-704); IGBulg V, 5102-5104; cf. J. et L. Robert, Bull. ép., 1983, 273 ; V. Velkov, «Mesambria Pontica», in Die bulgarische Schwarzmeerküste im Altertum, Xenia 16, W. Schuller (éd.), Konstanz 1985, p. 35.

326 IGBulg V, 5103. Le bord supérieur du relief porte l'inscription: $\Sigma \tau \rho \alpha \tau \alpha$ yoì $\tau$ oì

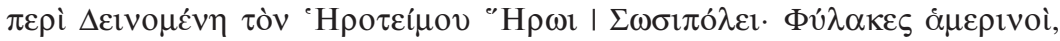

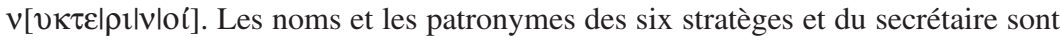
gravés sous les figures. Le titre $\gamma \rho \alpha \mu \mu \alpha \tau \varepsilon v ́ \varsigma$ est gravé sur un pilastre. On lit aussi les noms de quelques membres des familles des stratèges. En outre, on trouve un nom, accompagné d'un patronyme, sur l'édicule qui se trouve au milieu du relief et que I. Venedikov, op. cit., p. 85-88, considère comme un sarcophage. M. Alexandrescu Vianu, «L'iconographie des reliefs aux stratèges de Mésambria», StudClas 24, 1986, p. 100-105, propose que la scène de sacrifice se déroule au moment de l'enterrement d'un stratège décédé. D'après elle, on aurait affaire à un culte héroïque, créé par les stratèges en l'honneur d'un collègue décédé. En revanche, F. T. van Straten, SEG XXX, 703, p. 214-215, interprète l'objet central comme un autel. C'est sans doute l'interprétation qu'il convient de retenir. $C f$. Chiekova, Cultes, p. 277-278. Notons au passage qu'un autel de ce type (quadrangulaire) apparaît sur les monnaies de 
dédicace à Dionysos Éleuthéreus atteste que les six stratèges étaient aussi escortés par une troisième catégorie de «gardes», soit les «soldats de ronde» $(\pi \varepsilon \rho 10 \delta o \text { í })^{327}$.

L'autre relief aux stratèges conservé en entier ne nous fournit que le nom du premier stratège, un certain Oinias. On note aussi qu'une scène de banquet héroïque avec deux hommes allongés sur une klinè est représentée dans un édicule au-dessus des magistrats et de l'autel central. Ces deux personnages ont été considérés comme les bénéficiaires du sacrifice et ils ont été interprétés par Venedikov comme des victimes de guerre héroïsées, par Van Straten comme des héros et par Alexandrescu Vianu comme deux héros oikistai ou archégétai ${ }^{328}$. Le troisième relief est composé de deux fragments, on y trouve gravés les noms et les patronymes des six stratèges et d'un secrétaire. La partie supérieure, qui devait porter la dédicace, n'est pas conservés ${ }^{329}$. Du

Sélinonte: A. Tusa Cutroni, «La monetazione di Selinunte», in Selinunte, S. Tusa (éd.), Roma 2010, p. 159-162. P. Fröhlich revient sur les dédicaces des stratèges de Mésambria dans le cadre d'un mémoire inédit sur les magistratures des démocraties grecques $\left(\mathrm{IV}^{\mathrm{e}}-\mathrm{I}^{\mathrm{er}}\right.$ siecle av. J.-C.).

327 IGBulg $\mathrm{I}^{2}, 324$ : dédicace à Dionysos Éleuthéreus faite par les stratèges, le secrétaire

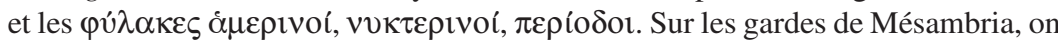
verra G. Seure, «Archéologie thrace. Documents inédits ou peu connus », RA, 1911, 2, p. 427; Velkov, Mesambria, p. 20; Nawotka, West. Pont. Cities, p. 187-188; Avram, Défense des cités en mer Noire, p. 168; C. Brélaz, La sécurité publique en Asie Mineure sous le Principat (I ${ }^{e r}-I I I^{e}$ s. ap. J.-C.). Institutions municipales et institutions impériales dans l'Orient romain, Bâle 2005, p. 83.

328 IGBulg V, 5102. La pierre portait sur le bandeau inférieur d'abord l'inscription

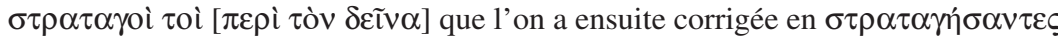
Oivíạ[s-ca. 12 -]; cf. I. Venedikov, op. cit., p. 84-85; F. T. van Straten, SEG XXX, 702, p. 214; M. Alexandrescu Vianu, op. cit., p. 99-104. De même, OgnenovaMarinova, Mesambria, p. 38; eadem, «Mesambria Pontica», in Mesambria, Mesemvria, Nessebur, Sofia 1987, p. 44, 46, pense qu'il s'agirait des deux œeistes, l'un grec et l'autre indigène, qu'elle supposait à tort exister à Mésambria (voir supra, chapitre II.3.2.2). Sur la pratique de l'héroïsation des différents personnages de la cité aux époques hellénistique et romaine, voir D. D. Hughes, «Hero Cult, Heroic Honnors, Heroic Dead: Some Developments in the Hellenistic and Roman Periods », in Ancient Greek Hero Cult. Proceedings of the Fifth International Seminar on Ancient Greek Cult (Göteborg University, 21-23 April 1995), R. Hägg (éd.), Stockholm 1999, p. 167-175.

329 IGBulg V, 5104. Les noms et les patronymes des six stratèges apparaissent sur le bandeau inférieur du relief, sous les figures. Le nom et le patronyme du secrétaire, ainsi que son titre sont inscrits sur la tête du plus petit personnage, à droite. 
reste, comme l'a suggéré Venedikov, il convient d'intégrer dans la même série le fragment de relief qui porte une dédicace aux héros et qui représente un personnage sur une klinè et deux boucliers ${ }^{330}$.

Les stratèges ont des compétences militaires: en témoigne une dédicace faite par les six stratèges et le secrétaire et qui évoque la guerre menée vers 55 par les Mésambriens contre le roi gète Byrébistas ${ }^{331}$. Les mêmes magistrats font au $\mathrm{I}^{\mathrm{er}}$ siècle une consécration à Athéna Sôtei$r a$, divinité protectrice de la cité ${ }^{332}$.

Mieux, on constate que les stratèges pouvaient acquérir une prééminence politique à la basse époque hellénistique. Cela ressort de deux décrets de Dionysopolis, partiellement publiés, qui honorent un certain Polyxénos, fils de Melséôn. Celui-ci n'est autre que l'un des stratèges mésambriens qui apparaît sur le relief IGBulg. V, 5103. Le premier décret fut affiché dans le sanctuaire local de la Métèr Pontia. Il évoque les séjours du Mésambrien à Dionysopolis et atteste qu'on lui accorda, à lui et à ses descendants, entre autres, la proxénie, la citoyenneté, l'égalité fiscale (isotéleia), l'inviolabilité (asylia). Le deuxième décret, affiché dans le sanctuaire des Dieux de Samothrace, confirme que Polyxénos tira profit de la citoyenneté dionysopolitaine, tout en conservant des liens avec sa patrie d'origine. Il reçoit le privilège d'être couronné à vie d'une couronne d'or en raison de son activité dans l'Assemblée (de Mésambria, d'après Sharankov). On apprend que Polyxénos remplit la charge de stéphanophore à Mésambria, sa première patrie ( $\dot{\varepsilon} \vee \tau \tilde{\eta} 1$ $\pi \rho \omega ́ \tau \eta \imath ~ \sigma \tau \varepsilon \varphi \alpha \nu о \varphi о \rho \tilde{\omega} \nu \pi \alpha \tau \rho i ́ \delta \imath)$. De plus, il prêta de l'argent sans intérêt à la cité de Dionysopolis et il s'occupa de la réparation du gymnase et de la fourniture en huile. Pour tous ces services, l'honorandus obtint aussi une statue de bronze dans le gymnase, une couronne de la part des éphèbes, l'inviolabilité pour lui et ses descendants. Mieux, un membre du Conseil fut élu par l'Assemblée de Dionysopolis pour aller annoncer les honneurs accordés à Polyxénos à Mésambria et pour déposer une copie du décret dans les archives locales ${ }^{333}$.

330 IGBulg $\mathrm{I}^{2}$, 335 septies; cf. I. Venedikov, op. cit., p. 85, 95. Voir supra, chapitre II.3.2.2.

331 IGBulg $\mathrm{I}^{2}, 323$ : la dédicace conserve les noms de trois stratèges, accompagnés d'un secrétaire dont le nom n'est pas conservé.

332 IGBulg $\mathrm{I}^{2}, 326 ;$ cf. Chiekova, Cultes, p. 225.

333 Pour ces deux décrets, voir le commentaire de N. Sharankov, dans I. Lazarenko et al., «The Temple of the Pontic Mother of Gods in Dionysopolis », in Ancient Sacral 
Par ailleurs, signalons ici l'opinion de Karayotov, selon laquelle les magistrats monétaires seraient élus à Mésambria parmi les membres sortants du collège de stratèges. Pour étayer sa thèse, le savant bulgare s'appuie sur l'identification de plusieurs noms gravés en monogramme sur les monnaies avec des noms de stratèges ${ }^{334}$.

De même, un collège de stratèges est documenté à Callatis à partir du milieu du III $^{\mathrm{e}}$ siècle $^{335}$. Leur nombre n'est pas mentionné dans les documents, mais d'après Avram, les stratèges seraient aussi ici au nombre de six. Preuve en serait un relief fragmentaire représentant un homme reposant sur une klinè, accompagné d'une femme et d'un serviteur. On trouve au-dessous du relief les noms et les patronymes de sept personnes. Tout comme à Mésambria, ceux-ci seraient les six stratèges et leur secrétaire $^{336}$. La présence de six stratèges aussi bien à Mégare qu'à Mésambria et à Callatis détermine Avram à estimer que le collège composé de six stratèges et d'un secrétaire serait une formule d'origine mégarienne ${ }^{337}$. Mais il convient de retenir que, contrairement aux six stratèges et à leur secrétaire de Mésambria, les stratèges de Mégare ne sont jamais accompagnés d'un secrétaire. D' ailleurs, seul le collège mégarien des damiorgoi a un secrétaire, mais dans ce cas il n'est pas certain que les damiorgoi aient remplacé à Mégare les stratèges ${ }^{338}$. En réalité, le nombre de six stratèges était très probablement déterminé par la modalité d'élection de ces magistrats par les trois tribus doriennes, les Mégariens et les Mésambriens et peut-être aussi les Callatiens ayant choisi deux stratèges par tribu.

Le domaine des compétences des stratèges de Callatis semble aussi être militaire. Un monument honorifique fragmentaire évoque sans doute un stratège qui a défendu le territoire ${ }^{339}$. Du reste, le décret pour l'A polloniate

Monuments in the Black Sea, E. K. Petropoulos et A. A. Maslennikov (éds.), Thessaloniki 2010, p. 34-36, 62, fig. 31 (avec un cliché du décret trouvé dans le sanctuaire de la Métèr Pontia). N. Sharankov donne aussi une traduction en bulgare du décret affiché dans le sanctuaire des Dieux de Samothrace dans L. F. Vagalinski, Blood and Entertainments. Sports and Gladiatorial Games in Hellenistic and Roman Thrace, Sofia 2009, p. 214-215, n 154. Cf. A. Avram, Bull. ép., 2011, 448.

334 Karayotov, Coinage of Mesambria I, p. 42-60, 64.

335 Le pluriel $\sigma \tau \rho \alpha \tau \alpha \gamma o$ á apparaît dans les décrets ISM III, 7, 1. 29, et 30, 1. 5, et le mot

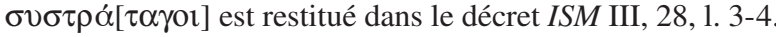

336 ISM III, 161.

337 A. Avram, in ISM III, p. 88-89.

338 Voir infra, chapitre III.2.2.5.

339 ISM III, 106. 
Stratônax, fils de Lygdamis, mentionne les stratèges comme responsables de l'envoi d'une copie du décret aux magistrats de la cité d'Apollonia ${ }^{340}$. Plus tard, à l'époque impériale, les stratèges sont nommés, avec les synèdres, comme les rogatores d'un décret de Callatis ${ }^{341}$.

Les stratèges étaient aussi présents dans la métropole de Callatis, à Héraclée du Pont. L'Économique du Ps.-Aristote les mentionne lors de la guerre menée dans le premier quart du $\mathrm{IV}^{\mathrm{e}}$ siècle par les Héracléotes contre le royaume du Bosphore cimmérien ${ }^{342}$.

On ajoute que le nombre de stratèges et la durée de leur magistrature pouvaient varier dans les établissements mégariens. Les stratèges de Byzance formaient aux époques hellénistique et impériale une organisation collégiale, ayant, tout comme à Callatis, une fonction politique, en tant que rogatores ${ }^{343}$. Grâce au décret pour Orontas, fils d'Ababos, on apprend que ce fut le Peuple qui donna l'ordre aux stratèges d'honorer cet Olbiopolitain ${ }^{344}$.

Sur la foi des récits, on peut supposer que le collège des stratèges comptait deux membres à Byzance, du moins à l'époque classique et hellénistique. De fait, Polyen nous apprend que pour s'emparer de Byzance, le Spartiate Cléarque tua vers la fin $\mathrm{du} \mathrm{V}^{\mathrm{e}}$ siècle les deux stratèges que la cité avait envoyés pour demander son aide dans les combats contre les Thraces $^{345}$. D'autre part, les personnages Hékatôdoros et Olympiodôros, évoqués par Polybe comme prostatai des Byzantins lors de la guerre contre Rhodes et les Bithyniens de Prusias ${ }^{\text {er }}$ (vers 220), étaient très

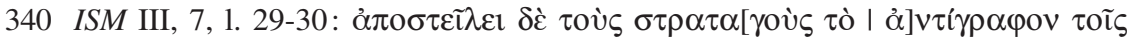

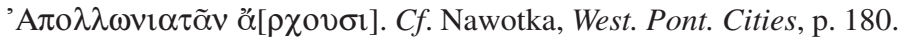

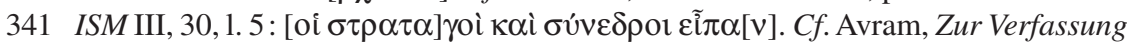
von Kallatis, p. 177.

342 Ps.-Aristote, Économique, II, 2, 8, 1347b 3-15. Cf. Bittner, Herakleia, p. 15-16.

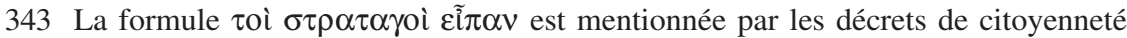
I. Byzantion, 2, 1.3-4;3,1.2-3. Les stratèges apparaîtraient aussi dans l'inscription par laquelle les Byzantins honorent Antigone et Démétrios (ca.302/1) trouvée à Olympie :

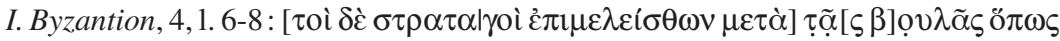

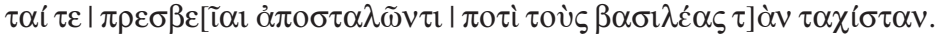

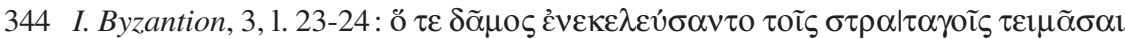
$\tau$ đòv öv $\delta \rho \alpha . C f$. Rhodes-Lewis, Decrees, p. 197.

345 Polyen, II, 2, 7. Sur le coup d'État de Cléarque à Byzance, voir aussi supra, chapitre III.1.1.2. 
probablement les deux stratèges de la cité $e^{346}$. On trouve aussi la mention des deux stratèges byzantins dans le Roman de Leucippé et Clitophôn d'Achille Tatius. Cette œuvre d'époque impériale évoque les guerres de Byzance contre les Thraces et transmet les noms de deux stratèges de la cité, chargés de la guerre, Sôstratos (l'oncle de Clitophôn et père de Leucippé) et Chairéphôn. On apprend aussi que les deux stratèges n'avaient pas les mêmes pouvoirs, Chairéphôn étant supérieur en grade à Sôstratos ${ }^{347}$. Bien que l'on ait affaire à un récit fictif, on peut se demander si Achille Tatius n'a pas voulu respecter une certaine authenticité concernant l'histoire (voir la guerre contre les Thraces) et les institutions de Byzance.

La présentation de l'histoire de Byzance par la chronique d'Hésychios de Milet (FGrHist 390 F 12-34) sous la forme d'une liste chronologique de sept stratèges (Byzas, Dinéos/Deinias, Léôn, Charès d'Athènes, Prôtomachos, Timèsios d'Argos, Kalliadès), confirme le rôle important rempli par les stratèges dans la cité mégarienne du Bosphore thrace ${ }^{348}$. Un passage de Damon, auteur méconnu d'un ouvrage Sur Byzance, sans doute de l'époque hellénistique, atteste le nom d'un autre stratège byzantin, Léônidas ${ }^{349}$. On ignore cependant si le terme $\sigma \tau \rho \alpha \tau \eta \gamma o ́ \varsigma$ a chez cet auteur une acception technique ou s'il désigne de manière générale l'un des commandants de l'armée byzantine.

Du reste, des récits de l'Antiquité tardive et de l'époque byzantine évoquent la présence à Byzance d'un Stratègion ${ }^{350}$ et d'aucuns estiment que c'est dans ce bâtiment que les stratèges tenaient leurs séances ${ }^{351}$.

346 Polybe, IV, 47, 5; cf. Merle, Byzantion und Kalchedon, p. 72; Newskaja, Byzanz, p. 62-63; Walbank, Commentary, vol. I, p. 500; L. Robert, in Firatl, Stèles de Byzance, p. 151; Seyrig, Monnaies, p. 186-187; A. Lajtar, I. Byzantion, ad no 2, p. 26.

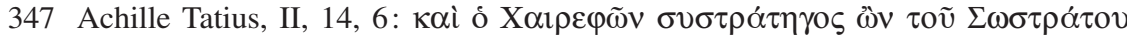
$\mu \varepsilon i \zeta \omega v$. Voir aussi II, 14, 2; VI, 16, 5.

348 Hanell, Megarische Studien, p. 159; A. Lajtar, I. Byzantion, ad nº 2, p. 25-26. La liste des sept stratèges de Byzance a été créée artificiellement par Hésychios selon le modèle de la liste des sept rois de Rome (voir supra, chapitre II.2.4.1.6). Sur le stratège Léon, qui ne serait autre que le célèbre philosophe homonyme, élève de Platon et ami du stratège athénien Phocion, voir Dana, Culture, p. 272-274; eadem, Byzance, p. 31.

349 Damon, FGrHist 389 F 1 (cité chez Athénée, X, 442 C, et Élien, Histoire variée, III, 14). Cf. Dana, Culture, p. 240-241, qui suggère que ce Léônidas serait à identifier avec Léôn, le stratège qui apparaît dans la liste d'Hésychios.

350 Hésychios, FGrHist 390 F 16; Chronicon Paschale, vol. I, p. 495 (éd. L. Dindorf);

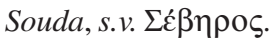

351 Merle, Byzantion und Kalchedon, p. 72; A. Łajtar, I. Byzantion, ad n ${ }^{\circ}$ 2, p. 26. Selon

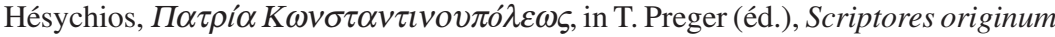


Les stratèges figuraient à l'époque hellénistique parmi les magistrats des deux autres colonies mégariennes, à savoir ceux de Sélymbria ${ }^{352}$ et de Chalcédoine. Grâce au décret de proxénie en l'honneur d'Eudémos, fils de Nikôn, on sait que les stratèges de Chalcédoine étaient élus vers 172 pour une durée de quatre mois. Ce document atteste que ces magistrats ont des compétences civiles et entretiennent des rapports avec le Conseil: pour l'octroi de la proxénie, les stratèges devaient faire une proposition devant le Conseil, conformément à la loi ${ }^{353}$.

\section{III.2.2.5 Les damiorgoi}

Cinq damiorgoi, accompagnés d'un secrétaire, font à Mégare à l'époque hellénistique une dédicace à Aphrodite ${ }^{354}$. En s'appuyant sur le nombre de dignitaires de ce collège et sur l'existence d'un collège fé-

Constantinopolitanarum, vol. I, Leipzig 1901, 39, p. 17, les stratèges de la cité recevaient les honneurs à l'époque de Constantin dans le Stratègion. En s'appuyant sur ce témoignage, C. Emereau, «Notes sur les origines et la formation de Constantinople. Les grands centres historiques de la ville», $R A$ 21, 1925, p. 9, et Janin, Constantinople $^{2}$, p. 13, estiment en revanche que le Stratègion de Byzance était un endroit analogue au «Champ de Mars» de Rome.

352 I. Byzantion, S. 3 A, 1. 4.

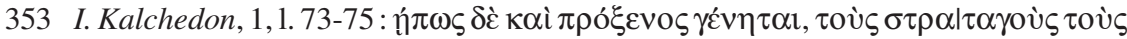

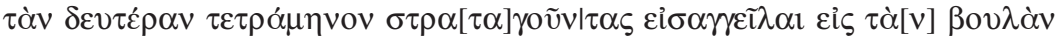

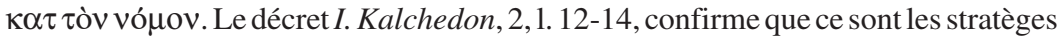
qui font la proposition d'octroi de la proxénie devant le Conseil. $C f$. Merle, Byzantion und Kalchedon, p. 74; Hanell, Megarische Studien, p. 151-152; Rhodes-Lewis, Decrees, p. 422-423, 494, 498. Sur la foi des inscriptions, on sait qu'à Érythrée aussi, la durée de la magistrature des stratèges était limitée à quatre mois : H. Engelmann, R. Merkelbach (éds.), Die Inschriften von Erythrai und Klazomenai, Bonn 1972

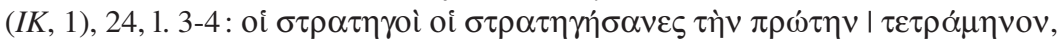
voir aussi les $n^{\text {os }} 29,32,33,103,104,112,114,119$. La durée semestrielle de plusieurs magistratures, y compris celle des stratèges, est attestée aussi à Argos: C. Kritzas, CRAI, 2006 (2008), 1, p. 416, 421-422. Sur la durée semestrielle des magistratures voir le témoignage d'Aristote, Politique, V, 8, 6, 1308a 13-16, qui note que cette limitation assure dans les régimes démocratiques la participation de plusieurs citoyens aux affaires publiques et constitue un obstacle à la tyrannie.

354 IG VII 41. Les dédicaces des magistrats à Aphrodite et les liens de cette déesse avec la sphère civique sont examinés par J. Wallensten, «Resources for Manpower: Magistrates' Dedications to Aphrodite», in Religion and Society. Rituals, Resources and Identity in the Ancient Graeco-Roman World. The BOMOS-Conferences 20022005, A. Holm Rasmussen et S. W. Rasmussen (éds.), Rome 2008, p. 139-150. 
déral achéen de dix damiurges ${ }^{355}$, plusieurs savants ont conclu que les cinq damiorgoi avaient remplacé les cinq stratèges lors de l'appartenance de Mégare à la Ligue achéenne. Il s'agissait dans ce cas d'une situation analogue à celle du remplacement des stratèges par les polémarques, suite à l'entrée de Mégare dans la Ligue béotienne ${ }^{356}$. Si l'on accepte que les décrets mentionnant les stratèges remontent à la seconde moitié du III ${ }^{\mathrm{e}}$ siècle, les damiorgoi ne se seraient substitués aux stratèges qu'après 206/5, lorsque les Mégariens quittèrent les Béotiens et rejoignirent de nouveau les Achéens ${ }^{357}$.

Cependant, cette hypothèse n'est pas à l'abri de toute critique. En premier lieu, on devrait se demander pourquoi les Mégariens auraient remplacé au $\mathrm{II}^{\mathrm{e}}$ siècle les stratèges par les damiorgoi, compte tenu du fait que les Achéens avaient aussi la magistrature de stratège parmi leurs $\operatorname{archai}^{358}$. D'ailleurs, les damiorgoi ne semblent pas avoir des pouvoirs militaires dans l'autre cité de la Mégaride où ils sont attestés, à Aigosthènes. Ils sont chargés ici de la gravure d'un décret de proxénie et de son dépôt dans le sanctuaire du héros Mélampous ${ }^{359}$.

En second lieu, on constate que les damiorgoi apparaissent au $\mathrm{III}^{\mathrm{e}}$ siècle dans une position politique centrale (aux côtés des bouleutes) dans

355 Tite-Live, XXXII, 22, 2. Sur les damiorgoi de l'État fédéral achéen, voir BusoltSwoboda, Staatskunde, II, p. 1566; Aymard, Assemblées, p. 173-174; J. A. O. Larsen, Greek Federal States. Their Institutions and History, Oxford 1968, p. 221 ; Corsten, Vom Stamm zum Bund, p. 172-173.

356 Dittenberger, $I G$ VII, $a d \mathrm{n}^{\circ} 1$, p. 2 ; no 41, p. 28 ; idem, $S I G^{3}$, $a d \mathrm{n}^{\circ} 331$, p. 551, n. 3 ; W. W. Tarn, op. cit., p. 736; P. Graindor, op. cit., p. 51; W. Schönfelder, Die städtischen und Bundesbeamten des griechischen Festlandes vom 4. Jahrhundert vor Chr. Geb. bis in die römische Kaiserzeit, Diss. Leipzig 1917, p. 49-51; Feyel, Polybe, p. 92; Kaloyéropoulou, Décret de Mégare, p. 144 ; R. Urban, op. cit., p. 69; E.-L. Choremi, op. cit., p. 211.

357 Voir supra, chapitre III.2.1.1.

358 En dehors des dix damiorgoi, le gouvernement central de la Confédération achéenne était constitué notamment d'une Assemblée, d'un Conseil et d'un président annuel appelé stratège. Voir à cet égard Busolt-Swoboda, Staatskunde, II, p. 1566; Aymard, Assemblées, p. 322 ; J. A. O. Larsen, op. cit., p. 220 ; A. Giovannini, Les relations entre États dans la Grèce antique du temps d'Homère à l'intervention romaine (ca. 700-200 av. J.-C.), Historia Einzelschriften 193, Stuttgart 2007, p. 407.

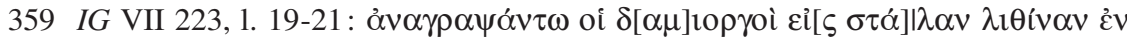

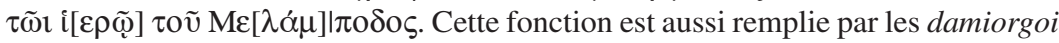
fédéraux, chose qui appuie l'idée qu'à Aigosthènes du moins, on peut avoir une influence achéenne. Voir à cet égard Robu, Décret d'Aigosthènes, p. 88-90. 
le célèbre Serment des citoyens de Chersonèse Taurique ${ }^{360}$. S'appuyant sur cette attestation, les modernes ont suggéré que ces magistrats figuraient parmi les institutions de Mégare à l'époque archaïque ${ }^{361}$. Du reste, étant donnée la présence des damiorgoi parmi les magistratures argiennes les plus anciennes ${ }^{362}$ et les liens existants entre Argos et Mégare à l'époque archaïque, Hanell estime que les damiorgoi auraient pu être introduits à Mégare par Argos lors de la conquête de la Mégaride par les Doriens ${ }^{363}$.

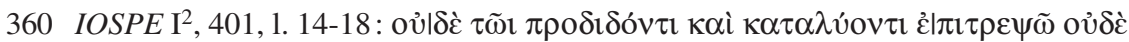

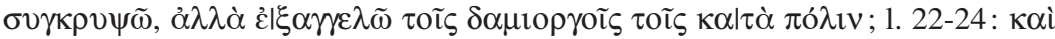

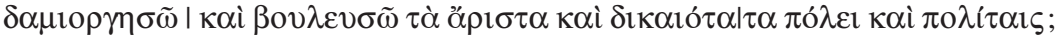

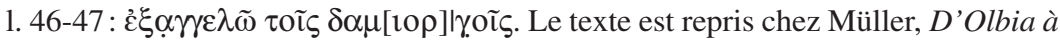

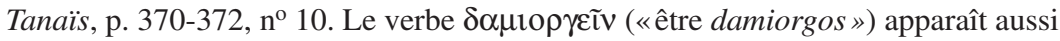
dans les inscriptions de Chersonèse à l'époque impériale, voir IOSPE $\mathrm{I}^{2}, 420 ; 423$; 424; 429; cf. Latyshev, Const. de Chersonèse, p. 292-293; C. Veligianni-Terzi, Damiurgen. Zur Entwicklung einer Magistratur, Diss. Heidelberg 1977, p. 88-89. Pour L. A. Paltseva, «Sur les notables du Conseil de Chersonèse durant les premiers siècles de notre ère », VDI, 1977, 3, p. 176 (en russe), les conseillers de Chersonèse, antérieurement appelés aisimnatai, auraient été désignés dès la fin du $\mathrm{I}^{\mathrm{er}}$ siècle, suite à une réforme du Conseil, par le terme de damiorgoi. Mais cette hypothèse est difficile à vérifier en l'absence d'autres informations concernant le rôle exact des damiorgoi à Chersonèse à l'époque impériale. Il faudrait aussi rappeler que dans les colonies héracléotes les aisimnatai ne sont pour l'instant pas attestés (voir supra, chapitre III.2.2.1).

361 Latyshev, Const. de Chersonèse, p. 292-293; Meyer, Megara, col. 199; Hanell, Megarische Studien, p. 145, 148; Robert, Inscr. de Pagai, p. 110, n. 2 (= OpMinSel, II, p. 1263, n. 2). Cf. C. Veligianni-Terzi, op. cit., p. 77-78, 86-89, qui considère aussi comme possible l'hypothèse d'une date archaïque pour les damiorgoi de Mégare.

362 IGIV 506;614(SEG XI, 336; Van Effenterre-Ruzé, NOMIMA, I, 87 : neuf damiorgoi); SEG XI, 314 (Van Effenterre-Ruzé, NOMIMA, I, 88: six damiorgoi) ; $f$. aussi IG IV 493, pour les damiorgoi de Mycènes (époque archaïque). Sur les damiorgoi argiens qui constituent sans doute au $\mathrm{VI}^{\mathrm{e}}$ siècle le principal collège de la cité, voir M. Wörrle, Untersuchungen zur Verfassungsgeschichte von Argos im 5. Jhdt. v. Chr., Diss. Friedrich-Alexander-Universität, Erlangen-Nürnberg 1964, p. 61-70; M. Piérart, s.v. «Argos », in Hansen-Nielsen (éds.), Inventory, p. 604. Pour la présence des damiorgoi et leurs fonctions dans différentes cités grecques, voir Latyshev, Const. de Chersonèse, p. 290-292; E. Swoboda, «Studien zu den griechischen Bünden», Klio 12, 1912, p. 41-43 ; L. H. Jeffery, «Demiourgoi in the Archaic Period», ArchClass 25-26, 19731974, p. 319-330; et surtout le livre de C. Veligianni-Terzi déjà cité.

363 Hanell, Megarische Studien, p. 148, 154; cf. C. Veligianni-Terzi, op. cit., p. 87; Smith, Megaris, p. 113-114. Sur la tradition qui fait de Mégare une fondation argienne, voir supra, chapitre I.I.1. Si les damiorgoi n'apparaissent plus après le VI $\mathrm{V}^{\mathrm{e}}$ siècle 
Quoique cette thèse reste difficile à prouver, la publication récente d'une dédicace émanant du collège de cinq damiorgoi d'Héraclée du Pont de l'époque impériale confirme, me semble-t-il, l'origine mégarienne de cette magistrature ${ }^{364}$. Les damiorgoi intègrent donc la liste d'archai d'origine mégarienne qui furent transmises aux colonies mégariennes et héracléotes de la mer Noire.

\section{III.2.2.6 Les nomophylakes}

Il convient de préciser que les nomophylakes (les «gardiens de lois») ne sont pas attestés par les sources antiques parmi les magistrats de Mégare. Leur présence à Mésambria, à Chalcédoine et à Chersonèse laisse penser toutefois que cette magistrature est de souche mégarienne, ayant été introduite par les premiers apoikoi ${ }^{365}$.

Une inscription hellénistique de Mésambria associe les nomophylakes à des éklogistai (des magistrats ayant un rôle financier), les deux fonctions étant très probablement des magistratures de contrôle ${ }^{366}$.

dans les documents émanant d'Argos, ces magistrats sont attestés à l'époque hellénistique dans d'autres cités de l'Argolide (Épidaure, Hermioné, Trézène) et dans le bourg argien de Mycènes. À ce propos, voir M. Wörrle, op. cit., p. 70 ; C. VeligianniTerzi, op. cit., p. 74-80.

364 B. Öztürk, İ. F. Sönmez, « New Inscriptions from the Karadeniz Ereğli Museum II », Arkeoloji Sanat 137, 2011, p. 156-157, n 1 . Faute de parallèles, il reste difficile de savoir si le fait que les damiorgoi sont au nombre de cinq correspond également à un héritage mégarien. Compte tenu de la date tardive à laquelle ces magistrats sont attestés, il est plus prudent de réfuter l'idée d'un lien direct entre le collège héracléote de cinq damiorgoi et celui de Mégare, qui comptait à l'époque hellénistique cinq damiorgoi et un secrétaire.

365 Le collège des nomophylakes est attesté dans de nombreuses cités, de l'époque clas-

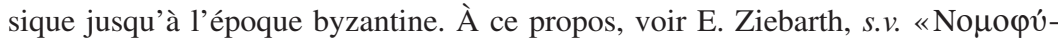
$\lambda \alpha \kappa \varepsilon \varsigma », R E$ XVII, 1937, col. 832-833; F. Tinnefeld, s.v. «Nomophylakes», in Der neue Pauly. Enzyklopädie der Antike, vol. 8, Stuttgart-Weimar 2000, col. 981-982.

366 IGBulg $\mathrm{I}^{2}, 314$ b; cf. J. et L. Robert, Bull. ép., 1952, 87; Nawotka, West. Pont. Cities, p. 194-195; H. Preshlenov, «Die mesambrische Politeia», in Thracia 15. In honour of A. Fol's $70^{\text {th }}$ Anniversary, K. Jordanov et al. (éds.), Sofia 2003, p. 524-525; $\mathrm{P}$. Fröhlich, Les cités grecques et le contrôle des magistrats $\left(I V^{e}-I^{\text {er }}\right.$ siècle avant J.C.), Genève 2004, p. 224-225, 382, qui estime que «les éklogistai seraient à Mésambria des magistrats contrôleurs de délits financiers, différents des délits signalés aux nomophylakes » (p. 225). 
Le collège des nomophylakes de Chalcédoine compte à l'époque hellénistique trois dignitaires ${ }^{367}$. Le même nombre de nomophylakes se retrouve aux époques hellénistique et impériale à Chersonèse, une magistrature que la cité de Crimée a assurément empruntée à sa métropole, Héraclée du Pont ${ }^{368}$. Ces magistrats ont une fonction politique dans la Chersonèse hellénistique, car ils sont évoqués en tant que rogatores en

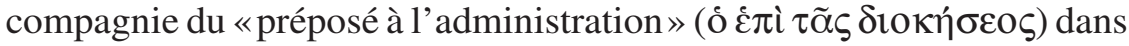
plusieurs décrets de la cité ${ }^{369}$. En outre, Anokhin estime qu'originellement, pendant la période d'autonomie de la cité, les nomophylakes auraient eu parmi leurs prérogatives l'émission du numéraire de Chersonèse; une charge qui, selon le savant russe, serait ultérieurement remplie par le «préposé à l'administration» et ensuite, à partir du Ir siècle ap. J.-C., par le premier archonte de la cité370. Enfin, il convient de retenir que les trois nomophylakes étaient sans doute désignés autant à Chalcédoine qu'à Chersonèse par les trois tribus doriennes ${ }^{371}$.

367 I. Kalchedon, 7, 1. 4-6; cf. aussi $\mathrm{n}^{\mathrm{o}} 11,1.8$.

368 IOSPE I², 351; 359; Sourov, Inscr. de Chersonèse, p. 154-155; Solomonik, Épigraph. Chersonèse II, 111 ; Saprykin, Proxénie de Chersonèse, p. 43. Voir aussi

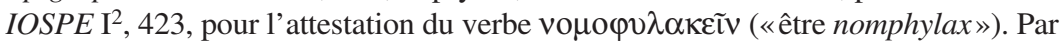
ailleurs, dans le décret fragmentaire publié par Solomonik, Épigraph. Chersonèse

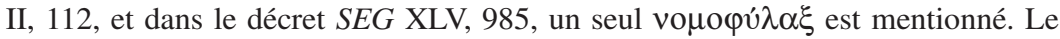

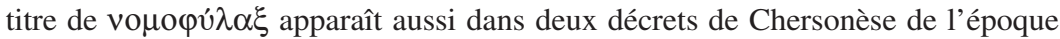
impériale: IOSPE $\mathrm{I}^{2}, 364 \mathrm{c}$, et le décret publié par I. Makarov, «Nouvelles inscriptions de Chersonèse Taurique », VDI 2006, 4, p. 92-94, no 4 (en russe); $c f$. SEG LVI, 873.

369 IOSPE $\mathrm{I}^{2}, 342 ; 343 ; 347 ; 351 ; 691$. Quant au dignitaire nommé par ces décrets

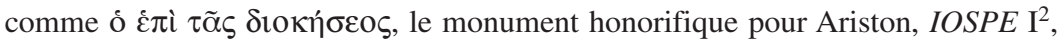
423, indique que ce magistrat était chargé à Chersonèse des finances de la cité; $c f$. Latyshev, Const. de Chersonèse, p. 295-296.

370 V. Anokhin, op. cit., p. 37-38, 42, 50, 65-66, 83-85, 123. De même, en suivant l'opinion d'Anokhin, Saprykin, Institutions et rapports fonciers, p. 113, considère les nomophylakes comme des magistrats monétaires. D'après R. A. Novikova, op. cit., p. 104-108 (en russe), le collège de nomophylakes serait la plus importante magistrature de Chersonèse.

371 Voir supra, chapitres III.1.1.2.-3. 


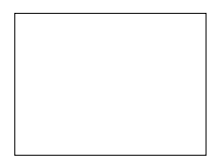




\section{Annexe \\ Une coutume épigraphique de Mégare attestée à Chersonèse Taurique et à Callatis}

Comme il a été relevé plusieurs fois dans les chapitres précédents, les cités fondées par Héraclée du Pont sur les rives de la mer Noire (Chersonèse Taurique, Callatis) ont gardé les principaux nomima mégariens (institutions politiques, cultes, calendrier) ${ }^{1}$. Mais, outre les correspondances institutionnelles qui existent entre les cités mégariennes et héracléotes, force est de constater les liens existant entre ces établissements dans le domaine de l'épigraphie. On remarque de fait que plusieurs stèles funéraires de l'époque classique de Chersonèse Taurique présentent dans la partie supérieure un espace destiné à l'insertion d'une tablette sur laquelle étaient gravés le nom et le patronyme du défunt. On a parfois trouvé à la fois la stèle et la tablette inscrite qui lui correspondait (voir pl. VII) ${ }^{2}$. Or, il existe dans l'épigraphie de la Mégaride une série bien définie constituée de tablettes ou de plaques, de forme rectangulaire, en marbre ou en calcaire, sur laquelle on inscrivait le nom du défunt, accompagné souvent de son patronyme (voir pl. VIII, fig. 12). Ce type d'épitaphes connaît ses débuts au $V^{\mathrm{e}}$ siècle et continue jusqu'à l'époque hellénistique ${ }^{3}$.

1 Pour les cultes et le calendrier d'origine mégarienne attestés à Héraclée du Pont et dans ses colonies, on renverra à Hanell, Megarische Studien, p. 166-167, 182-185, 190-204; Antonetti, Megara e le sue colonie, p. 83-94; A. Avram, in ISM III, p. 91 95, 110-115; Chiekova, Cultes, passim.

2 Posamentir, Grave Stelai, p. 31, n ${ }^{\circ} 20 ;$ p. 87, n ${ }^{\circ}$ C 6 ; p. 89, no C 8; p. 93, no C 12; p. $99, n^{\circ}$ C 23 ; p. $101, n^{\circ}$ C 25 ; p. $103-111, n^{\text {os }}$ C $28-36$; p. $114, n^{\circ}$ C 40.

3 P. Graindor, «Inscriptions grecques (Athènes, Mégare, Ténos)», RA, 1917, 6, p. 33 48, $\mathrm{n}^{\text {os }} 1-29$; W. Peek, «Griechische Inschriften», MDAI(A) 59, 1934, p. 54-56, $\mathrm{n}^{\text {os }} 12$ a-h (SEG XIII, 317); L. Robert, Collection Froehner I. Inscriptions grecques, Paris 1936, p. 23-24, nos 19 (SEG XIII, 330) et 20 (SEG XIII, 316); M. Guarducci, «Note di epigrafia sepolcrale», RAL 25, 1970, p. 389-393; D. Knoepfler, «Autour d'une stèle mégarienne», in Mélanges d'histoire ancienne et d'archéologie offerts à Paul Collart, Lausanne 1976, p. 269-270, n. 6; J. et L. Robert, Bull. ép., 1976, 290. Je reviendrai ailleurs sur la chronologie des tablettes funéraires de Mégare. 
À ma connaissance, des inscriptions funéraires de telle forme et avec un tel usage sont très peu répandues dans le monde grec. La découverte des tablettes en Mégaride et en mer Noire laisse donc penser que l'on est en présence d'une pratique épigraphique typiquement mégarienne qui fut introduite à partir de Mégare, directement ou indirectement (par le biais d'Héraclée du Pont), à Chersonèse.

Selon moi, il existerait même dans les corpus des inscriptions de Callatis une tablette funéraire de type mégarien (voir pl. VIII, fig. 3). Cela est suggéré par les dimensions de la pierre, la taille des lettres et le materiel employé (en l'occurrence le marbre), qui trouvent des similitudes dans les séries de tablettes de Mégare et de Chersonèse. Notons au passage que, d'après l'écriture, l'inscription callatienne remonterait au $\mathrm{IV}^{\mathrm{e}}$ siècle, étant l'un des plus anciens documents épigraphiques émanant de cette cité du Pont-Gauche ${ }^{4}$.

En conclusion, les tablettes de Chersonèse et de Callatis offrent la preuve de la diffusion d'une coutume épigraphique de Mégare dans les colonies pontiques. Cette analogie, qui, à ma connaissance, n'a pas été répertoriée par les historiens spécialistes de la colonisation grecque, témoigne des liens existant entre Mégare et les cités pontiques dans le domaine de l'épigraphie, plus exactement en ce qui concerne la gravure et l'affichage des inscriptions funéraires. Musée d'histoire et d'archéologie de Constantza», Pontica 25, 1992, p. 182-183, $\mathrm{n}^{0} 7$ (avec photo et dessin fig. 7, en roumain; = ISM III, 152). Les dimensions de cette tablette et des lettres inscrites (Ht. : 8,5 cm; Lg. 16,5 cm; Lettres : 1,7-2 cm) correspondent à celles des tablettes de Mégare. Seule l'épaisseur de l'inscription de Callatis (Ép. 11,5 cm) dépasse celle des tablettes mégariennes, dont l'épaisseur ne semble pas aller au-delà de $8 \mathrm{~cm}$ environ. 


\section{Conclusions générales}

Les Mégariens et leur synoikoi eurent à l'époque archaïque, sans l'ombre d'un doute, leurs propres mouvements indépendants de colonisation en Sicile, en Propontide et dans le Pont-Euxin. Tout d'abord, constatant l'échec des tentatives de coexistence avec les autres «Doriens» (qui, après s'être détachés des Mégariens de Lamis, participent à la fondation de Syracuse) et les Chalcidiens de Léontinoi, les Mégariens collaborèrent vers le milieu du VIII ${ }^{\mathrm{e}}$ siècle avec les Sicules du roi Hyblôn pour installer leur cité en Sicile orientale. Concernant les premières apoikiai, il est utile de rappeler les propos de Polignac, qui note à juste titre que les premiers colons qui arrivent dans la deuxième moitié du $\mathrm{VIII}^{\mathrm{e}}$ siècle en Sicile sont «des groupes hétérogènes dont le problème n'était pas seulement de trouver le site où s'établir, mais aussi de définir les contours de la collectivité qui s'y établirait» ${ }^{1}$.

Assurément, les liens entre les Mégariens de Grèce et ceux de Sicile se sont maintenus à l'époque archaïque, les deux cités ayant fondé ensemble Sélinonte, vers le milieu du VII ${ }^{\mathrm{e}}$ siècle. Cette dernière installation nous montre l'ambition de Mégara de participer à la colonisation de la Sicile occidentale, afin de rivaliser avec les autres cités grecques, mais aussi d'établir des relations commerciales avec les Carthaginois et la population indigène de Sicile. Ultérieurement, la condamnation et la mise à mort après 472/1 du tyran Thrasydée d'Agrigente, fils de Théron (qui avait probablement dépossédé les Sélinontins de Minôa), par les Mégariens de Grèce indiquent que ces derniers gardaient des contacts politiques avec leurs apoikoi de l'Ouest sicilien.

En outre, force est de constater que les Mégariens collaborèrent avec des habitants originaires d'autres cités grecques (des Béotiens, des Argiens, des Chalcédoniens, des Carystiens, et peut-être des Corinthiens à Byzance, des Mégariens de Sicile et probablement des Corinthiens à Sélinonte, des Chalcédoniens à Astacos, des Béotiens à Héraclée du Pont, des Chalcédoniens et des Byzantins à Mésambria) afin d'assurer le succès de leurs installations et de faciliter le développement de leurs

1 Polignac, Mégara Hyblaea, p. 225. 
établissements. Ces Grecs sont souvent venus en tant que colons additionnels dans les apoikiai et ce sont eux qui ont assuré la survivance et l'expansion des cités. Le fait que les Grecs aient linguistiquement marqué une différence entre les premiers colons (apoikoi) et les colons ultérieurs (époikoi), ces derniers ne jouissant pas toujours de la même considération et des mêmes droits que les premiers arrivés, met en évidence une réalité connue par les auteurs antiques et dont la recherche moderne doit tenir compte. À cet égard, on n' aurait pas tort de considérer la colonisation mégarienne comme un bon exemple de l'assimilation des vagues ultérieures ou des groupes simultanés de colons d'autres communautés grecques par le noyau (mégarien) le plus important.

Du reste, les relations entre les apoikoi et les indigènes de Sicile, de la Propontide et du Pont-Euxin varient d'une cité à l'autre en fonction des spécificités régionales (la présence effective des indigènes sur place ou l'absence de ceux-ci) et des moyens dont les colons disposaient ${ }^{2}$. Elles semblent être généralement bonnes au moment de la fondation de Mégara et peut-être dans une certaine mesure de la fondation de Sélinonte. En revanche, face à la menace des Thraces, des Mysiens et des Bithyniens, les Mégariens des colonies semblent avoir instauré de véritables «réseaux» sur les rives de la Propontide et c'est une certaine «solidarité» mégarienne qui prend naissance. D'autre part, les Mariandyniens de la chôra d'Héraclée du Pont seront asservis par les Grecs et les sources indiquent qu'au moins une partie d'entre eux furent maintenus dans un état de dépendance (analogue au statut des laoi et des geôrgoi mysiens de Byzance). Le fait que la quasi-totalité de nos documents émane du milieu grec limite malheureusement l'analyse des rapports entre les colons grecs et les populations locales. Bien que les auteurs antiques insistent sur les conflits entre les Grecs et les barbares, les modernes n'ont pas hésité à suggérer la possibilité que les indigènes aient été admis en tant que citoyens dans certaines colonies (par exemple à Mégara $^{3}$ ou à Héraclée du Pont ${ }^{4}$ ). Mieux, on retrouve des noms indi-

2 Cf. B. Helly, op. cit., p. 256.

3 Domínguez, Colon. Gr., p. 94, 107, 271-272; Pugliese Carratelli, Selinunte, p. 17; De Angelis, Megara Hyblaia and Selinous, p. 52-54.

4 D. Asheri, «Tyrannie et mariage forcé. Essai d'histoire sociale grecque», Annales (HSS) 32, 1, 1977, p. 25-26; Vidal-Naquet, L'historiographie gr. de l'esclavage, p. 38 ; Avram, Mariandyner, p. 25-26; idem, Gesch. des Territ. von Kallatis, p. 124; Papazoglou, Laoi et paroikoi, p. 96, n. 211. 
gènes à Sélinonte à l'époque archaïque et classique, ainsi qu'à Sélymbria, à Byzance et à Mésambria à l'époque hellénistique et surtout impériale. Cependant, sur la foi de la documentation existante, il est encore difficile d'établir le degré d'intégration des non-Grecs dans les colonies; il ne nous reste qu'à espérer que les futures trouvailles éclaireront davantage le phénomène.

Quant aux causes du mouvement de colonisation mégarien, j'espère avoir pu montrer dans la première partie de l'ouvrage que l'on ne dispose pas de témoignages solides permettant d'établir la possession mégarienne de l'Héraion de Pérachora. L'étude des données archéologiques et littéraires appuie l'idée que l'occupation corinthienne de ce sanctuaire régional fut ininterrompue à l'époque archaïque. Ainsi, contrairement à l'opinion communément admise, je ne crois pas que la perte de Pérachora, et par conséquent la sténochôria («exiguïté des terres »), puissent figurer parmi les causes de la colonisation mégarienne des VIII ${ }^{\mathrm{e}}-\mathrm{VII}{ }^{\mathrm{e}}$ siècles. En revanche, la compétition et les conflits entre les oikoi aristocratiques, les inégalités foncières et politiques, le désir d'expansion et l'espoir de profiter des avantages offerts par la colonisation ont joué un rôle dans le départ des Mégariens vers la Sicile et la Propontide ${ }^{5}$. Les défaites dans la guerre de Salamine et les luttes internes violentes du $\mathrm{VI}^{\mathrm{e}}$ siècle expliquent que les Mégariens, absents pendant un siècle du mouvement de colonisation, aient accepté de repartir fonder d'autres cités, cette fois-ci dans le lointain Pont-Euxin.

L'étude des institutions des colonies m'a permis de constater l'importance de l'héritage de la métropole dans ce domaine. On a là un indice du degré d'organisation de l'expédition et un argument contre l'opinion de certains chercheurs qui mettent en doute l'existence du phénomène de la colonisation grecque à l'époque archaïque. De fait, les subdivisions civiques (les trois tribus doriennes, les hékatostyes) et les principales magistratures de Mégare (le basileus, les aisimnatai, les probouloi, les stratèges, les damiorgoi, les nomophylakes, le mnamôn) furent reproduites dans les colonies mégariennes et héracléotes. Cela indique que l'élément non-mégarien fut très vite supplanté par l'élément mégarien dans les colonies. Il y a toutefois une exception notable, à savoir le hiéromnamôn attesté à Byzance et à Chalcédoine, une ma-

5 Cf. Figueira, Chronological Table, p. 275; De Angelis, Foundation of Selinous, p. 105. 
gistrature qui serait d'origine argienne. De surcroît, une inscription témoigne de la présence d'un hiéromnamôn parmi les institutions de Mésambria. Cette attestation n'est pas sans importance, car elle confirme que des transferts institutionnels pouvaient survenir suite à la participation des synoikoi ou à l'arrivée de nouveaux colons (époikoi). En effet, les Chalcédoniens, qui participent avec les Mégariens à la fondation de Mésambria, ou les Byzantins et les Chalcédoniens, qui, menacés par les Perses, trouvent ensuite refuge dans cette cité pontique, sont responsables de l'introduction de la magistrature du hiéromnamôn dans la colonie mégarienne de la mer Noire.

Par ailleurs, on constate que les institutions politiques faisant partie du bagage originaire des colons se sont transformées au fil du temps: les aisimnatai de Chalcédoine, ancienne archè à caractère oligarchique, appartiennent à l'époque hellénistique aux institutions démocratiques. De même, on enregistre des transformations de la division civique par hékatostyes ( «centaines»): c'est le cas de la désignation des aisimnatai de Chalcédoine par «centaines» et sans doute par tribus (selon le modèle des prytanes athéniens), ou encore de l'augmentation des «centaines» de douze à soixante à Héraclée du Pont.

Non sans importance, mon enquête démontre qu'il n'existait de divisions territoriales kata kômas («en bourgs») ni à Mégare, ni dans sa colonie, à Mégara. Les ouvrages de Plutarque et de Strabon, qui évoquent une organisation en cinq districts (mérè) dans la Mégaride d'avant le synœcisme, se fondent sur des textes à caractère polémique, fabriqués par des chroniqueurs locaux dans le contexte des disputes avec leurs voisins d'Athènes et de Corinthe.

L'étude des inscriptions a rendu possible un autre acquis: le transferts culturels depuis Mégare vers les colonies concernaient non seulement le domaine des institutions, mais aussi celui des pratiques épigraphiques. En témoigne la découverte à Mégare, à Chersonèse Taurique et à Callatis de tablettes inscrites de même type. De forme rectangulaire, ces tablettes étaient insérées dans des stèles funéraires. Cette pratique épigraphique qui fut introduite depuis Mégare, directement ou indirectement (par le biais d'Héraclée du Pont), dans les colonies héracléotes de la mer Noire est un élément nouveau pour la question des rapports entre métropole et colonies.

Enfin, il importe d'insister sur la célébration du culte des premiers fondateurs/ancêtres dans les colonies. Les documents épigraphiques et 
littéraires attestent que ces ancêtres deviennent, à côté des héros importés de la métropole, les fondateurs des groupes pseudo-familiaux de type génos ou patria. Il est fort probable que ce sont les membres de ces groupes qui lancèrent les différentes traditions locales de fondation, des textes privilégiant leurs héros ou leurs ancêtres. Il me semble qu'il serait erroné d'interpréter toutes les généalogies mythiques renvoyant aux fondateurs de la cité comme des développements tardifs de l'époque hellénistique ou romaine: cela n'a pas toujours été le cas, et les inscriptions de Sélinonte (notamment la lex sacra) confirment aujourd'hui que les groupements familiaux et pseudo-familiaux (les homosépyoi, les patriai) ont joué un rôle important dans les cités aux époques archaïque et classique.

En fin de compte, je considère que les colonies mégariennes sont le résultat d'un «synœecisme primitif», d'un rassemblement de plusieurs groupes d'apoikoi, qui, le plus souvent, n'étaient pas culturellement homogènes. De ce point de vue, le témoignage de Denys de Byzance est, à mes yeux, capital: la fondation de Byzance est symboliquement mise en évidence par le regroupement originel des «foyers» (hestiai) des cités ou des sept familles (oikoi) mégariennes ayant participé à la colonisation des rives européennes du Bosphore thrace. De même que la construction de l'autel-foyer des dieux Prodomeis («Premiers Constructeurs») à Mégare, ou que le remplacement des Prytanées des villages par un seul Prytanée commun à Athènes, symbolisaient la naissance de la cité, la mise en commun des foyers des différents groupes de colons indiquait la fondation de la nouvelle cité de Byzance. Cette constatation ne fait que renforcer l'idée du rapport étroit qui existe entre l'émergence de la polis - avec ses nouvelles institutions politiques et le début, vers le milieu du VIII ${ }^{\mathrm{e}}$ siècle, du mouvement de la colonisation grecque, deux phénomènes simultanés du haut archaïsme, dont l'importance historique a souvent été soulignée ${ }^{6}$.

6 Sur le rapport entre la colonisation et la naissance de la polis, on verra Malkin, Religion and Colon., p. 12; idem, Foundations, p. 373-394; Vatin, Citoyenneté et ethnique, p. 79-80 ; M. H. Hansen, Polis. An Introduction to the Ancient Greek CityState, Oxford 2006, p. 44-45; A. Morakis, «Thucydides and the Character of Greek Colonisation in Sicily », CQ 61, 2, 2011, p. 488-490; A. J. Domínguez, «The Origins of the Greek Colonisation and the Greek Polis : Some Observations », Ancient West \& East 10, 2011, p. 195-207. 


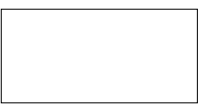




\section{Bibliographie}

\section{Sigles}

Les titres des revues sont abrégés conformément au système de L'Année philologique. Pour les périodiques qui ne sont pas repris par l'Année philologique, j'ai établi une liste particulière d'abréviations. On trouve de même ci-dessous une liste des sigles des instruments de travail fréquemment cités, notamment des recueils épigraphiques et numismatiques.

\section{I.1 Sigles des revues}

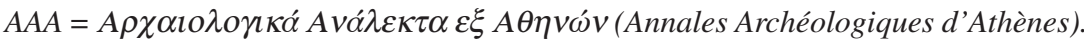

ACSS $=$ Ancient Civilizations from Scythia to Siberia .

AEM = Archäologish-Epigraphische Mitteilungen aus Österreich-Ungarn .

ANSMN = The American Numismatic Society. Museum Notes.

$B M N B=$ Bulletin du Musée National de Bourgas.

$D L Z=$ Deutsche Literaturzeitung für Kritik der internationalen Wissenschaft.

JIArchNum = Journal International d'Archéologie Numismatique.

KSIA = Kratkie soobshcheniya Instituta Arkheologii Akademii Nauk SSSR (BrefBulletin de

l'Institut d'Archéologie de l'Académie des Sciences de l'URSS).

$M A L=$ Monumenti Antichi dei Lincei.

$M B N G=$ Mitteilungen der Bayerischen Numismatischen Gesellschaft.

MEP = Minima Epigraphica et Papyrologica .

QuadMess = Quaderni dell'Istituto di archeologia della Facoltà di lettere e filosofia della Università di Messina .

SicArch = Sicilia Archaeologica .

SovArch = Sovestskaya arkheologiya (Archéologie Soviétique).

WissZRostock $=$ Wissenschaftliche Zeitschrift der Universität Rostock. 


\section{I.2 Sigles des ouvrages et des collections}

$A E=$ L'Année épigraphique, Paris 1888-.

$A T L=$ B. D. Meritt, H. T. Wade-Gery, M. F. McGregor, The Athenian Tribute Lists, Cambridge (Mass.), puis Princeton, I-IV, 1939-1953.

BCD Pelop. $=$ Coins of Peloponnesos. The BCD Collection. Auction LHS 96, Zurich 2006.

BTCGI = Bibliografia Topografica della Colonizzazione Greca in Italia e nelle Isole Tirreniche, G. Nenci et G. Vallet (éds.), Pisa et al. 1977-.

Bull. ép. = Bulletin épigraphique de la Revue des Études grecques, par J. et L. Robert (1938-1984), puis par divers auteurs sous la direction de P. Gauthier de 1987 à 2005, puis sous la direction de L. Dubois.

$C I G=$ A. Böckh (éd., vol. I-II), J. Franz (éd., vol. III), E. Curtius, A. Kirchhoff (éds., vol. IV), Corpus Inscriptionum Graecarum, Berlin 1828-1877.

$\mathrm{CUF}=$ Collection des Universités de France, Paris, Les Belles Lettres.

FD III, 4 = J. Pouilloux (éd.), Fouilles de Delphes. III. Épigraphie 4. Les inscriptions de la terrasse du temple et de la région nord du sanctuaire (nos. 351-516), Paris 1976.

FGrHist = F. Jacoby (éd.), Die Fragmente der griechischen Historiker, Berlin (et Leyde) 1923-.

$G G M=$ K. Müller (éd.), Geographi Graeci minores, I-II, Paris 1855-1861.

I. Apameia und Pylai = T. Corsten (éd.), Die Inschriften von Apameia (Bithynien) und Pylai, Bonn 1987 (IK, 32).

I. Byzantion = A. Lajtar (éd.), Die Inschriften von Byzantion, I. Die Inschriften, Bonn $2000(I K, 58,1)$.

I. Heraclea = L. Jonnes (éd.), The Inscriptions of Heraclea Pontica, with a Prosopographia Heracleotica by W. Ameling, Bonn 1994 (IK, 47).

I. Kalchedon = R. Merkelbach, F. K. Dörner, S. Şahin (éds.), Die Inschriften von Kalchedon, Bonn $1980(I K, 20)$.

I. Prusias ad Hyp. = W. Ameling (éd.), Die Inschriften von Prusias ad Hypium, Bonn 1985 (IK, 27).

$I G=$ Inscriptiones Graecae, Berlin 1873-.

IGASM $\mathrm{I}^{2}=\mathrm{R}$. Arena (éd.), Iscrizioni greche arcaiche di Sicilia e Magna Grecia. Iscrizioni di Sicilia, I. Iscrizioni di Megara Iblea e Selinunte ${ }^{2}$, Pisa 1996.

IGBulg = G. Mihailov (éd.), Inscriptiones Graecae in Bulgaria repertae, Sofia, $\mathrm{I}^{2}, 1970$; II, 1958; III/ 1, 1961 ; III/2, 1964; IV, 1966; V, 1997.

IGDS = L. Dubois (éd.), Inscriptions grecques dialectales de Sicile. Contribution à l'étude du vocabulaire colonial, Rome 1989; Tome II, Genève 2008.

$I G L M P=$ M. T. Manni Piraino (éd.), Iscrizioni greche lapidarie del museo di Palermo, Palermo 1973.

IK = Inschriften griechischer Städte aus Kleinasien, Bonn 1972-. 
IOSPE = V. Latyshev (éd.), Inscriptiones antiquae orae septentrionalis Ponti Euxini Graecae et Latinae, I, II, IV, Saint-Pétersbourg 1885-1901, I², Saint-Pétersbourg 1916 (réimpr. Hildesheim 1965).

$I S M=$ D. M. Pippidi (éd., vol. I: Histria et vicinia), I. Stoian (éd., vol. II : Tomis et son territoire), A. Avram (éd., vol. III : Callatis et son territoire), Inscriptions grecques et latines de Scythie Mineure, Bucarest-Paris 1983-1999.

$I v O=$ W. Dittenberger, K. Purgold (éds.), Die Inschriften von Olympia, Berlin 1896.

$L B W=\mathrm{P}$. Le Bas, W. H. Waddington (éds.), Inscriptions grecques et latines recueillies en Grèce et en Asie Mineure, Paris 1870.

$L G P N$ I-V A = P.M. Fraser, E. Matthews (éds., vol. I, III A-B, IV), M. J. Osborne et S. B. Byrne (éds., vol. II), T. Corsten (éd., vol. V A), A Lexicon of Greek Personal Names, Oxford 1987-2010.

$L S J=$ H. G. Liddel, R. Scott, H. S. Jones (éds.), A Greek-English Lexikon, Oxford 1996.

$R E=$ A. Pauly, G. Wissowa, W. Kroll, K. Ziegler (éds.), Realencyclopädie der classischen Altertumswissenschaft, Stuttgart 1894-1980.

SEG = Supplementum epigraphicum graecum, Leiden 1923-1971, Alphen aan den Rijn 1979-1980, Amsterdam 1979-2005, Boston 2006-.

$S G D I=$ H. Collitz, F. Bechtel et al. (éds.), Sammlung der griechischen Dialekt-Inschriften, Göttingen 1899-1915.

$S I G^{3}=$ W. Dittenberger (éd.), Sylloge inscriptionum Graecarum ${ }^{3}$, Leipzig 1915-1924.

SNG 6= H. Küthmann, U. Pause-Dreyer (éds.), Sylloge Nummorum Graecorum. Staatliche Münzsammlung München, 6. Heft (Sikelia - Punier in Sizilien - Lipara-SardiniaPunier in Sardinien - Nachträge), Berlin 1980.

SNG 9 = M. Price (éd.), Sylloge Nummorum Graecorum. The British Museum, Volume IX, Part 1: The Black Sea, London 1993.

SNG 11 = W. Stancomb (éd.), Sylloge Nummorum Graecorum, Volume XI: The William Stancomb Collection of Coins of the Black Sea Region, Oxford 2000.

SNG 14 = J.M. Kroll (éd.), Sylloge Nummorum Graecorum, Deutschland. Staatliche Münzsammlung München, 14. Heft (Attika, Megaris, Ägina, Nr. 1-601), München 2002.

SNG Amer. Sicily = Sylloge Nummorum Graecorum. The Collection of the American Numismatic Society, Part 4. Sicily II: Galaria Styella, New York 1977.

SNG Cop. Bosporus-Bithynia = Sylloge Nummorum Graecorum. The Royal Collection of Coins and Medals, Danish National Museum, Bosporus-Bithynia, Copenhagen 1944.

SNG Cop. Sicily = Sylloge Nummorum Graecorum. The Royal Collection of Coins and Medals, Danish National Museum, Sicily, Copenhagen 1942.

SNG Cop. Thrace = Sylloge Nummorum Graecorum. The Royal Collection of Coins and Medals, Danish National Museum, Thrace, Copenhagen 1942.

TAM = Tituli Asiae Minoris, Vienna 1901-. 


\section{Sources littéraires}

Les éditions des auteurs antiques utilisées sont en règle générale celles de la Collection des Universités de France, de la Bibliotheca Teubneriana, The Loeb Classical Library, Die Fragmente der griechischen Historiker (FGrHist) et Geographi Graeci minores (GGM). Pour les textes qui ne sont pas repris dans ces collections ou lorsque l'usage d'une autre édition s'imposait, je me suis rapporté aux publications signalées ci-dessous, en mentionnant habituellement dans les notes de bas de page le(s) nom(s) de l'éditeur(s).

Amato, E. (éd.), Dionisio di Alessandria, Descrizione della Terra abitata, Milano 2005.

Barigazzi, A. (éd.), Favorine di Arelate. Opere. Introduzione, testo critico e commento, Firenze 1966.

Bekker, I. (éd.), Georgius Cedrenus, Historiarum compendium, vol. I, Bonn 1838.

Bekker, I. (éd.), Theophanes Continuatus, Ioannes Cameniata, Symeon Magister, Georgius Monachus, Bonn 1838.

Bekker, I. (éd.), Constantinus Porphyrogenitus, De Thematibus, vol. I-II, Bonn 1840.

Beschi, L., Musti, D. (éds.), Pausania, Guida della Grecia. Libro I, L'Attica, Milano 1982

Bettalli, M. (éd.), Enea Tattico, La difesa di una città assediata (Poliorketika), Pisa 1990.

Bianco, E. (éd.), Gli Stratagemmi di Polieno. Introduzione, traduzione e note critiche, Torino 1997.

Biffi, N. (éd.), Strabone di Amasea, Magna Grecia e dintorni (Geografia, 5,4,3-6,3,11), Bari 2006.

Billerbeck, M. (éd.), Stephani Byzantii Ethnika, vol. I-II, Berlin 2006-2011.

Buitenwerf, R. (éd.), Book III of the Sibylline Oracles and Its Social Setting, with an Introduction, Translation, and Commentary, Leiden-Boston 2003.

Bussemaker, U.C. (éd.), Carminum medicorum reliquiae, in Poetae bucolici et didactici, Paris 1851.

Büttner-Wobst, T. (éd.), Ioannis Zonarae Annales, vol. III, Bonn 1897.

Cappelletto, P. (éd.), I frammenti di Mnasea. Introduzione, testo e commento, Milano 2003.

Chambry, E., Thély-Chambry, L. (éds.), Justin, Abrégé des histoires philippiques de Trogue Pompée et prologues de Trogue Pompée, Paris 1936.

Classen, J. (éd.), Thukydides, Berlin 1876.

Combefis, F. (éd.), Historia haeresis Monothelitarum, Paris 1648.

Conzia, F. et al. (éds.), Anthologia Palatina, vol. I, Libri I-VII, Torino 2005.

Cuscunà, C. (éd.), I frammenti di Antioco di Siracusa. Introduzione, traduzione e commento, Alessandria 2003.

Diller, A. (éd.), The Tradition of the Minor Greek Geographers, Lancaster-Oxford 1952.

Dilts, M. R. (éd.), Heraclidis Lembi. Excerpta Politiarum, Durham 1971.

Dindorf, L. (éd.), Chronicon Paschale, vol. I, Bonn 1832. 
Dindorf, W. (éd.), Harpocrationis Lexicon in decem oratores atticos, Oxford 1953.

Douglas Olson, S., Sens, A. (éds.), Archestratos of Gela, Greek Culture and Cuisine in the Fourth Century BCE. Text, Translation, and Commentary, Oxford 2000.

Festugière, A. J. (éd.), Vie de Théodore de Sykéôn, Bruxelles 1970.

Frazer, J. G. (éd.), Pausanias's Description of Greece², vol. II, London 1913.

Gaisford, T. (éd.), Etymologicon Magnum, Oxford 1948.

Grélois, J.-P. (éd.), Pierre Gilles. Itinéraires byzantins. Lettre à un ami. Du Bosphore de Thrace. De la Topographie de Constantinople et de ses antiquités, Paris 2007.

Güngerich, R. (éd.), Dionysii Byzantii, Anaplus Bospori una cum scholiis X saeculi² ${ }^{2}$ Berlin 1958.

Helm, R. (éd.), Eusebius Werke 7. Die Chronik des Hieronymus, Berlin 1956 (réimpr. Berlin 1984).

Hitzig, H., Blümner, H. (éds.), Pausaniae Graeciae Descriptio, vol. I, Berlin 1896.

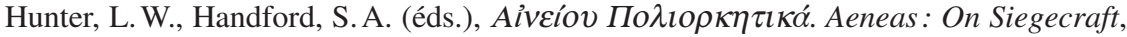
Oxford 1927.

Jacob, C. (éd.), La Description de la terre habitée de Denys d'Alexandrie ou la leçon de géographie, Paris 1990.

Karst, J. (éd.), Eusebius Werke 5. Die Chronik aus dem armenischen übersetzt mit textkritischem Commentar, Leipzig 1911.

Kassel, R., Austin, C. (éds.), Poetae Comici Graeci (PCG), vol. I-VIII, Berlin-New York 1983-2001.

Knecht, D. (éd.), Ciris. Authenticité, histoire du texte, édition et commentaire critique, Bruges 1970.

Kramer, G. (éd.), Strabonis Geographica recensuit commentario critico instruxit, vol. II, Berlin 1847.

Latte, K. (éd.), Hesychii Alexandrini Lexicon, vol. I-II, Copenhagen 1953-1966.

Le Boulluec, A. (éd.), Clément d'Alexandrie, Les Stromates VII, Paris 1997.

Lelli, E. (éd.), I proverbi greci. Le raccolte di Zenobio e Diogeniano, Soveria Mannelli 2006.

Leurini, A. (éd.), Ionis Chii. Testimonia e fragmenta ${ }^{2}$, Amsterdam 2000.

Lyne, R. O. A. L. (éd.), Ciris. A Poem Attributed to Virgil, Cambridge 1978.

MacDowell, D. M. (éd.), Demosthenes, On the False Embassy (Oratio 19), Oxford 2000.

Meineke, A. (éd.), Stephani Byzantii Ethnicorum quae supersunt, Berlin 1849 (réimpr. Chicago 1992).

Merkelbach, R., West, M. L. (éds.), Fragmenta Hesiodea, Oxford 1967.

Migne, J.-P. (éd.), Patrologia Graeca, vol. 109, Paris 1887.

Most, G. W. (éd.), Hesiod. The Shield, Catalogue of Women, other Fragments, London 2007.

Naber, S. A. (éd.), Photii Patriarchae Lexicon, vol. I-II, Leiden 1864-1865 (réimpr. Amsterdam 1965).

Nikiprowetzky, V. (éd.), La troisième Sibylle, Études juives IX, Paris-La Haye 1970.

Page, D. L. (éd.), Poetae Melici Graeci, Oxford 1962.

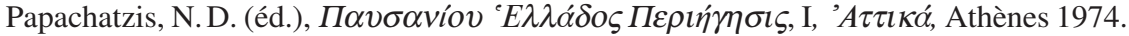

Pfeiffer, R. (éd.), Callimachus, vol. I-II, Oxford 1949-1953.

Pinder, M. (éd.), Ioannis Zonarae Annales, vol. II, Bonn 1844. 
Powel, J.U. (éd.), Collectanea Alexandrina: Reliquiae minores Poetarum Graecorum Aetatis Ptolemaicae 323-146 A.C. Epicorum, Elegiacorum, Lyricorum, Ethicorum, Oxford 1925.

Radt, S. (éd.), Tragicorum Graecorum Fragmenta, vol. 3, Aeschylus, Göttingen 1985.

Radt, S. (éd.), Strabons Geographika, vol. I-X, Göttingen 2002-2011.

Roussel, D. (éd.), Thucydide, La guerre du Péloponnèse, Paris 1964.

Russell, D. A., Wilson, N. G. (éds.), Menander Rhetor, Oxford 1981.

Schimdt, M. (éd.), Hesychii Alexandrini Lexicon, vol. IV, Jena 1862.

Shipley, G. (éd.), Pseudo-Skylax's, Periplous. The Circumnavigation of the Inhabited World, Exeter 2011.

Stählin, O. (éd.), Clemens Alexandrinus. I. Protrepticus und Paedagogus, Leipzig 1905.

Starkie, W. J. M. (éd.), The Acharnians of Aristophanes, with Introduction, English Prose Translation, Critical Notes and Commentary, Amsterdam 1968.

Tepedino Guerra, A. (éd.), L'esilio (Pap. Vat. Gr. 11 verso). Favorino di Arelate. Edizione critica, traduzione e commento, Roma 2007.

Thurn, J. (éd.), Ioannis Malalae Chronographia, Berlin 2000.

Valk, M. van der (éd.), Eustathii archiepiscopi Thessalonicensis comentarii ad Homeri Iliadem pertinentes, vol. I-IV, Leiden 1971-1987.

Wallraff, W. et al. (éds.), Iulius Africanus Chronographiae. The Extant Fragments, Berlin-New York 2007.

Wescher, C. (éd.), Dionysii Byzantii, De Bospori navigatione, Paris 1874.

Whitehead, D. (éd.), Aineias the Tactician, How to survive under Siege, Oxford 1990, p. 132.

\section{Liste bibliographique et abréviations}

Les abréviations des ouvrages et des articles fréquemment cités figurent dans la liste bibliographique, elles sont indiquées entre parenthèses et en gras après chaque étude.

Adak, M., Stauner, K., «Zur Stellung von Armeeangehörigen in ihren Heimatstädten:

Der Fall M. Aur. Antoninus aus Prusias ad Hypium », Gephyra 3, 2006, p. 133-168.

Adelaide Vaggioli, M., s.v. «Thapsos (penisola)», in BTCGI XX, 2011, p. 517-569.

Ager, S. L., Interstate Arbitrations in the Greek World, 337-90 B.C., Berkeley et al. 1996. Agostiniani, L., Iscrizioni anelleniche di Sicilia. Le iscrizioni elime, Firenze 1977.

Agostiniani, L., «I modi del contatto linguistico tra Greci e indigeni nella Sicilia antica», Kokalos 34-35, 1988-89, p. 167-206.

Agostiniani, L., «La lingua degli Elimi. Per uno stato della questione», in Gli Elimi e l'area elima fino all'inizio della prima guerra punica. Atti del seminario di studi (Palermo-Contessa Entellina, 25-28 maggio 1989), G. Nenci et al. (éds.), Palermo 1990, p. 345-368. 
Agostiniani, L., «L'epigrafia elima», in Sicilia Epigraphica. Atti del convegno (Erice, 15-18 Ottobre 1998), ASNP serie iv, Quaderni 1, M.I. Gulletta (éd.), Pisa 1999, p. 1-13.

Agostiniani, L., «Alfabetizzazione della Sicilia pregreca», Aristonothos 4, 2012, p. 139164.

Ajavon, F.-X., L'Eugénisme de Platon, Paris et al. 2001.

Akurgal, E., «Recherches faites à Cyzique et à Ergili», Anatolia 1, 1956, p. 15-20.

Albanese Procelli, R. M., «Greek and Indigenous People in Eastern Sicily : Forms of Interaction and Acculturation», in Early Societies in Sicily: New Developments in Archaeological Research, R. Leighton (éd.), London 1996, p. 167-176.

Albanese Procelli, R. M., «Le etnie dell'età del ferro e le prime fondazioni coloniali », in Prima Sicilia, alle origini della società siciliana, Albergo dei Poveri, Palermo, 18 ottobre-22 dicembre 1997, S. Tusa (éd.), Siracusa-Palermo 1997, p. 511-520.

Albanese Procelli, R. M., Sicani, Siculi, Elimi. Forme di identità, modi di contatto e processi di trasformazione, Milano 2003.

Alexandrescu, P., Histria IV: La céramique d'époque archäqque et classique (VII $-I V^{e}$ s.), Paris-Bucarest 1978 (= Alexandrescu, Histria IV).

Alexandrescu, P., «Histria in archaischer Zeit», in Histria: Eine Griechenstadt an der rumänischen Schwarzmeerküste, Xenia 25, P. Alexandrescu et W. Schuller (éds.), Konstanz 1990, p. 47-101.

Alexandrescu, P., «Les Eubéens et le début de la navigation en Mer Noire», in Mélanges Pierre Lévêque, vol. 5, M.-M. Mactoux et E. Geny (éds.), Paris 1990, p. 1-7 (=L'aigle et le dauphin. Études d'archéologie pontique, Bucarest-Paris 1999, p. 1-7).

Alexandrescu, P., «Colonisation occidentale et colonisation pontique», in Die Ägäis und das westliche Mittelmeer. Beziehungen und Wechselwirkungen 8. bis 5. Jh. v. Chr. Akten des Symposions, Wien, 24. bis 27. März 1999, F. Krinzinger (éd.), Wien 2000, p. 515-520 (= L'aigle et le dauphin. Études d'archéologie pontique, Bucarest-Paris 1999, p. 17-24).

Alexandrescu, P., Morintz, S., «À propos de la couche précoloniale de Mésambria», Pontica 15, 1982, p. 47-55 (= L'aigle et le dauphin. Études d'archéologie pontique, Bucarest-Paris 1999, p. 8-16; = Alexandrescu-Morintz, Mésambria).

Alexandrescu Vianu, M., «L'iconographie des reliefs aux stratèges de Mésambria», StudClas 24, 1986, p. 99-107.

Alföldi, M.R., «Zur Gründung von Kyzikos», in Studien zum antiken Kleinasien. Asia Minor Studien, Band 3, Bonn 1991, p. 129-148.

Aloni, A., «Elegy», in The Cambridge Companion to Greek Lyric, F. Budelmann (éd.), Cambridge 2009, p. 168-188.

Alvino, A., «I Prodomeis nel culto megarese: divinità senza volto? », in Atti. Centro ricerche e documentazione sull'antichità classica 11, 1980-1981, p. 3-8.

Amato, E., «Apollo, Lampos/Lampone e la fondazione di Callatis? (Nota a Pap. Vat. gr. $11 v$, col. 22, 33-35)», Emerita 75, 2, 2007, p. 319-338.

Ambrosini, R., «L'elemento indigeno», in La Sicilia antica, I, 1, E. Gabba et G. Vallet (éds.), Napoli 1980, p. 43-51.

Ampolo, C., «Le ricchezze dei Selinuntini : Tucidide VI, 20, 4 e l'iscrizione det tempio G di Selinunte», PP 39, 1984, p. 81-89. 
Ampolo, C., Compte rendu de Megara 3, Opus 3, 1984, p. 203-207.

Amyx, D. A., Corinthian Vase-Painting of the Archaic Period, Berkeley 1988.

Andrews, A., "The Corinthian Actaeon and Pheidon of Argos», CQ 43, 1949, p. 70-78.

Andrews, A., «The Growth of the Athenian State», in Cambridge Ancient History ${ }^{2}$, III, 3, J. Boardman et N. G.L. Hammond (éds.), Cambridge 1982, p. 360-391.

Anello, P., «Grecità periferica in Sicilia: Himeráioi e Selinóuntioi », in Hesperia, 10: studi sulla grecità di Occidente, L. Braccesi (éd.), Roma 2000, p. 99-115.

Anokhin, V.A., The Coinage of Chersonesus IV Century B.C. -XII Century A.D., BAR International Series 69, Oxford 1980.

Antonelli, L., «Sulle navi degli Eubei (immaginario mitico e traffici di età arcaica)», in Hesperìa, 5 : studi sulla grecità di Occidente, L. Braccesi (éd.), Roma 1995, p. 11 24.

Antonetti, C., «I confini della Megaride : incontri cultuali e culturali», in Stuttgarter Kolloquium zur historischen Geographie des Altertums 4, 1990, E. Olshausen et H. Sonnabend (éds.), Amsterdam 1994, p. 540-551 (= Antonetti, Confini della Megaride).

Antonetti, C. (éd.), Il dinamismo della colonizzazione greca. Atti della tavola rotonda: Espansione e colonizzazione greca di età arcaica, metodologie e problemi a confronto (Venezia, 10-11.11.1995), C. Antonetti (éd.), Napoli 1997 [= Antonetti (éd.), Il dinam. della colon. gr.].

Antonetti, C., «Megara e le sue colonie : un'unità storico-culturale ?», in Antonetti (éd.), Il dinam. della colon. gr., p. 83-94 (= Antonetti, Megara e le sue colonie).

Antonetti, C., «Le développement du panthéon d'une métropole: Mégare», in Les Panthéons des cités des origines à la Périegèse de Pausanias. Actes du Colloque organisé à l'Université de Liège du 15 au 17 mai 1997 (2e partie), Kernos, Suppl. 8, V. Pirenne-Delforge (éd.), Liège 1998, p. 35-46 (= Antonetti, Panthéon de Mégare).

Antonetti, C., «Le culte d'Apollon entre Mégare et ses colonies du Pont», in Religions du Pont-Euxin. Actes du VIII ${ }^{e}$ Symposium de Vani (Colchide)-1997, O. Lordkipanidzé et P. Lévêque (éds.), Besançon-Paris 1999, p. 17-24 (= Antonetti, Apollon).

Antonetti, C., «Riflessioni su Zeus Agoraios a Selinunte», in Temi selinuntini, C. Antonetti et $\mathrm{S}$ de Vido (éds.), Pisa 2008, p. 29-51.

Antonetti, C., De Vido, S., «Cittadini, non cittadini e stranieri nei santuari della Malophoros e del Meilichios di Selinunte », in Stranieri e non cittadini nei santuari greci. Atti del Convegno internazionale, A. Nasso (éd.), Firenze 2006, p. 410-451 (= AntonettiDe Vido, Cittadini).

Antonetti, C., De Vido, S., «Conflitti locali e integrazione culturale a Selinunte: il nouvo profilo della polis nell'iscrizione della vittoria», in Guerra e pace in Sicilia e nel Mediterraneo antico (VIII-III sec. a. C.). Arte, prassi e teoria della pace e della guerra, vol. I, Pisa 2006, p. 143-180.

Antonetti, C., Lévêque, P., «Au carrefour de la Mégaride. Devins et oracles », Kernos 3, 1990, p. 197-209 (= Antonetti-Lévêque, Devins).

Aratowski, B., «Notes on Salamis», in Studies presented to D. M. Robinson, II, G.E. Mylonas et D. Raymond (éds.), Saint Louis 1953, p. 789-796.

Arbesmann, P., s.v. «Megareus», RE XV, 1932, col. 215-217.

Arena, R., «Di una defixio selinuntina », PP 41, 1986, p. 114-119. 
Arena, R. (éd.), Iscrizioni greche arcaiche di Sicilia e Magna Grecia. Vol. V: Iscrizioni di Taranto, Locri Epizefiri, Velia e Siracusa, Alessandria 1998.

Arena, R., «Interferenze linguistiche e grafiche nell'epigrafia greca di Sicilia », in Sicilia Epigraphica. Atti del convegno (Erice, 15-18 Ottobre 1998), ASNP serie iv, Quaderni 1, M. I. Gulletta (éd.), Pisa 1999, p. 47-51.

Arias, P.E., «La civiltà italo-siceliota», in Popoli e civiltà dell' Italia antica, II, B. d'Agostino et al. (éds.), Roma 1974, p. 95-176.

Arnold-Biucchi, C., «The Beginnings of Coinage in the West: Archaic Selinus », in Florilegium Numismatica. Studia in honorem U. Westermark edita, Stockholm 1992, p. 13-19.

Arnold-Biucchi, C., «Litras en argent contremarquées en Sicile et les fractions de Sélinonte», in Pour Denyse. Divertissements numismatiques, S. Mani Hurter et C. Arnold-Biucchi (éds.), Berne 2000, p. 13-17.

Arnold-Biucchi, C., Beer Tobey, L., Waggoner, N.M., «A Greek Archaic Silver Hoard from Selinus », ANSMN 33, 1988, p. 1-35.

Asal, R., «İstanbul'un ticareti ve Theodosius Limanı », in Gün Işığında İstanbul'un 8000 Yllı-Marmaray, Metro, Sultanahmet Kazılari, Istanbul 2007, p. 180-189.

Asheri, D., «Supplementi coloniari e condizione giuridica della terra nel mondo greco», RSA 1, 1971, p. 77-91.

Asheri, D., «Über die Frühgeschichte von Herakleia Pontike», in Forschungen an der Nordküste Kleinasien, I, F. K. Dörner (éd.), Wien 1972, p. 9-34 (=Asheri, Herakleia).

Asheri, D., «Rimpatrio di esuli a Selinunte», ASNP serie iii, 9, 2, 1977, p. 479-497.

Asheri, D., «Tyrannie et marriage forcé. Essai d'histoire sociale grecque », Annales (HSS) $32,1,1977$, p. 21-48.

Asheri, D., «On the «Holy Family» of Astakos», in Studien zur Religion und Kultur Kleinasiens. Festschrift für Friedrich Karl Dörner zum 65. Geburtstag am 28. Februar 1976, I, Leiden 1978, p. 93-98 (= Asheri, Astakos).

Asheri, D., Compte rendu de Mégara 1, Athenaeum N.S. 56, 1978, p. 399-402.

Asheri, D., «La colonizzazione greca», in La Sicilia antica, I, 1, E. Gabba et G. Vallet (éds.), Napoli 1980, p. 89-142 (= Asheri, La colon. gr.).

Asheri, D., «Agrigento libera: rivolgimenti interni e problemi costituzionali, ca. 471$446 »$, in Agrigento e la Sicilia greca. Atti della settimana di studio (Agrigento, 2-8 maggio 1988), L. Bracessi et E. de Miro (éds.), Roma 1992, p. 95-111.

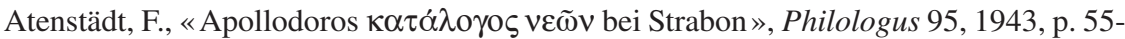
78.

Atkinson, K. M. T., «Two Tomb-Groups from Selinus», PBSR 14, 1938, p. 115-136.

Austin, M., s.v. «Naukratis», in Hansen-Nielsen (éds.), Inventory, p. 1238-1240.

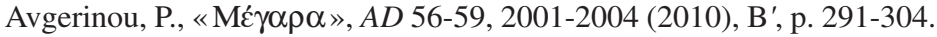

Avram, A., «Bemerkungen zu den Mariandynern von Herakleia am Pontos», StudClas 22, 1984, p. 19-28 (= Avram, Mariandyner).

Avram, A., «Untersuchungen zur Geschichte des Territoriums von Kallatis in griechischer Zeit», Dacia N.S. 35, 1991, p. 103-137 (= Avram, Gesch. des Territ. von Kallatis).

Avram, A., «Zur Verfassung von Kallatis in hellenistischer Zeit», Il Mar Nero 1, 1994, p. 167-177 (= Avram, Zur Verfassung von Kallatis). 
Avram, A., «Les cités grecques de la côte Ouest du Pont-Euxin», in Introduction to an Inventory of Poleis, Acts of the Copenhagen Polis Centre 3, M.H. Hansen (éd.), Copenhagen 1996, p. 288-316 (= Avram, Cités gr.).

Avram, A., "Modes de contacts entre Grecs et Gètes à Histria à l'époque archaïque», in Sur les traces des Argonautes. Actes du $\sigma^{e}$ symposium de Vani (Colchide), 22-29 septembre 1990, O. Lordkipanidzé et P. Lévêque (éds.), Paris 1996, p. 241 251.

Avram, A., «Les calendriers de Mégare et de ses colonies pontiques», in Religions du Pont-Euxin. Actes du VIII ${ }^{e}$ Symposium de Vani (Colchide)-1997, O. Lordkipanidzé et P. Lévêque (éds.), Besançon-Paris 1999, p. 25-31.

Avram, A., «Les territoires d'Istros et de Callatis », in Problemi della «chora » coloniale dall'Occidente al Mar Nero. Atti del quarantesimo convegno di studi sulla Magna Grecia (Taranto, 29 settembre-3 ottobre 2000), Taranto 2001, p. 593-633 (= Avram, Les territoires d'Istros et de Callatis).

Avram, A., «Sur la date de la divinisation de Ptolémée II Philadelphe à Byzance», in Orbis antiquus. Studia in honorem Ioannis Pisonis, L. Ruscu et al. (éds.), ClujNapoca 2004, p. 828-833 (= Avram, Divinisation de Ptolémée).

Avram, A., s.v. «Astakos», in Hansen-Nielsen (éds.), Inventory, p. 977-978 (= Avram, Astakos).

Avram, A., s.v. « Kalchedon», in Hansen-Nielsen (éds.), Inventory, p. 979-981 (= Avram, Kalchedon).

Avram, A., s.v. «Kyzikos», in Hansen-Nielsen (éds.), Inventory, p. 983-986.

Avram, A., s.v. «Olbia», in Hansen-Nielsen (éds.), Inventory, p. 990 (= Avram, Olbia).

Avram, A., «Antiochos II Théos, Ptolémée II Philadelphe et la mer Noire», CRAI, 2003 (2005), 3, p. 1181-1213.

Avram, A., «Héraclée du Pont et ses colonies pontiques. Antécédents milésiens (?) et empreinte mégarienne », in Colonie di colonie. Le fondazioni sub-coloniali greche tra colonizzazione e colonialismo. Atti del Convegno Internazionale (Lecce, 2224 giugno 2006), M. Lombardo et F. Frisone (éds.), Galatina 2009, p. 209-227 (= Avram, Héraclée et ses colonies).

Avram, A., «Indigenous Names in Heraclea Pontica», in Personal Names in Ancient Anatolia, PBA 191, R. Parker (éd.), Oxford 2013, p. 51-62.

Avram, A., Bărbulescu, M., «Inscriptions inédites de Callatis dans les collections du Musée d'histoire et d'archéologie de Constantza », Pontica 25, 1992, p. 167-205 (en roumain).

Avram, A., Hind, J., Tsetskhladze, G., s.v. «Herakleia», in Hansen-Nielsen (éds.), Inventory, p. 955-958.

Avram, A., Hind, J., Tsetskhladze, G., s.v. «Mesambria», in Hansen-Nielsen (éds.), Inventory, p. 934-935.

Avram, A., Jones, C.P., «An Actor from Byzantium in a New Epigram from Tomis », ZPE 178, 2011, p. 126-134.

Avram, A., Lefèvre, F., «Les cultes de Callatis et l'oracle de Delphes», REG 108, 1995, p. 7-23.

Aymard, A., «Recherches sur les secrétaires des Confédérations aitolienne et achaienne», in Mélanges offerts à Nicolae Iorga, Paris 1933, p. 71-108. 
Aymard, A., Les Assemblées de la Confédération achaienne. Étude critique d'institutions et d'histoire, Bordeaux 1938 (= Aymard, Assemblées).

Aymard, A., Les premiers rapports de Rome et de la confédération achaienne (198-189 avant J.-C.), Bordeaux 1938.

Babelon, E., Mélanges numismatiques, vol. 1-4, Paris 1892-1912.

Babelon, E., Traité des monnaies grecques et romaines, II 1, Paris 1907.

Bakaoukas, M., «Solon's Forgotten Genealogy », ElectronAnt 6, 1, 2001-2002, non paginé (<http://scholar.lib.vt.edu/ejournals/ElAnt/V6N1/bakaoukas.html>).

Balabanov, P., «Trois inscriptions du littoral sud-est de la mer Noire», in Studia in honorem Georgii Mihailov, Sofia 1985, p. 37-40.

Barends, D., Lexicon Aeneium. A Lexicon and Index to Aeneas Tacticus' Military Manual 〈On the Defence of Fortified Positions 〉, Assen 1955.

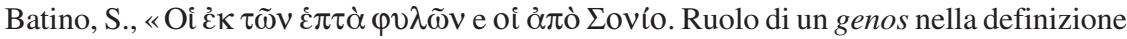
degli spazi sacri nella città e nel suo territorio », ASAA 81, serie iii, 3, 1, 2003 (2004), p. 83-152.

Baumann, H., Pflanzenbilder auf griechischen Münzen, München 2000.

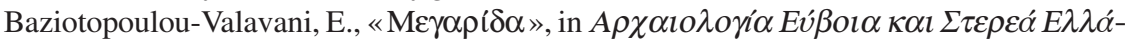
$\delta \alpha$, A. G. Vlachopoulos (éd.), Athènes 2008, p. 206-211.

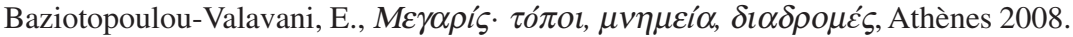

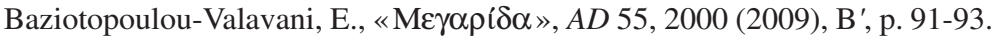

Beattie, A. J., «Nisaea und Minoa», RhM 103, 1960, p. 21-43.

Beaujeu, J., La religion romaine à l'apogée de l'empire. I, La politique religieuse des Antonins (96-192), Paris 1955.

Bechtel, F., Die historischen Personennamen des Griechischen bis zur Kaiserzeit, Halle 1917 (réimpr. Hildesheim et al., 1982 ; = Bechtel, Hist. Personennamen).

Bejor, G., «Ricerche di topografia e di archeologia romana nella Sicilia sud-occidentale», ASNP serie iii, 5, 2, 1975, p. 1275-1303.

Bejor, G., «Problemi di localizzazione di culti a Selinunte», ASNP serie iii, 7, 2, 1977, p. 439-457.

Beloch, K. J., Griechische Geschichte ${ }^{2}$, I, 1-IV, 2, Strasbourg, puis Berlin-Leipzig 19121927 (= Beloch, Gr. Gesch. ${ }^{2}$ ).

Bengston, H., «Neues zur Geschichte des Hellenismus in Thrakien und in der Dobroudscha», Historia 11, 1962, p. 18-28.

Bengston, H., Griechische Geschichte : von den Anfängen bis in die römische Kaiserzeit, 5. durchgesehene und ergänzte Auflage, München 1977.

Bérard, C., «Récupérer la mort du prince : héroïsation et formation de la cité», in La mort, les morts dans les sociétés anciennes, G. Gnoli et J.-P. Vernant (éds.), CambridgeParis 1982, p. 89-105.

Bérard, C., «Urbanisation à Mégara Nisaea et l'urbanisme à Mégara Hyblaea», MEFRA 95, 2, 1983, p. 634-640.

Bérard, J., La colonisation grecque de l'Italie méridionale et de la Sicile dans l'Antiquité, Paris 1957 (= Bérard, Colonisation).

Bérard, J., L'expansion et la colonisation grecques jusqu'aux guerres médiques, Paris 1960.

Berger, A., Untersuchungen zu den Patria Konstantinupoleos, Bonn 1988. 
Berger, A., «Zur Topographie der Ufergegend am Goldenen Horn in der byzantinischen Zeit», $\operatorname{MDAI}(I)$ 45, 1995, p. 149-165.

Berger, S., «Great and Small Poleis in Sicily: Syracuse and Leontinoi», Historia 40, 1991, p. 129-142.

Berger, S., Revolution and Society in Greek Sicily and Southern Italy, Historia Einzelschriften 71, Stuttgart 1992.

Bernabò Brea, L., «Il crepuscolo del re Hyblon», PP 23, 1968, p. 161-186 (= Bernabò Brea, Re Hyblon).

Bernabò Brea, L., «Pantalica», in Archeologia nella Sicilia Sud-Orientale, P. Pelagatti et G. Voza (éds.), Napoli 1973, p. 53-54.

Bernabò Brea, L., «Punta Castelluzzo», in Archeologia nella Sicilia Sud-Orientale, P. Pelagatti et G. Voza (eds), Napoli 1973, p. 55-56.

Bernabò Brea, L., «Che cosa conosciamo dei centri indigeni della Sicilia che hanno coniato moneta prima dell'età di Timoleonte », in Le emissioni dei centri siculi fino all'epoca di Timoleonte e i loro rapporti con la monetazione della colonie greche in Sicilia, AIIN, Suppl. 20, Roma 1975, p. 3-51.

Bernier, M.-A., Études topographique sur les ports de la Mégaride antique, thèse de maîtrise présentée à l'École des Études Supérieures de l'Université d'Ottawa, Ottawa 1990 (= Bernier, Ports de la Mégaride).

Bernstein, F., Konflikt und Migration. Studien zu griechischen Fluchtbewegungen im Zeitalter der sogenannten Großen Kolonisation, St. Katharinen 2004.

Berve, H., Die Tyrannis bei den Griechen, II, Darmstadt 1967.

Bettalli, M., «Note sulla produzione tessile ad Atene in età classica», Opus 1, 1982, p. 261-278.

Bettarini, L., «Un falso in Kolvó: il decreto di Bisanzio in Demosth. De corona 90 sg. », RFIC 130, 2002, p. 406-429.

Bettarini, L., «Una nuova defixio di Selinunte?», ZPE 151, 2005, p. 253-258.

Bettarini, L., Corpus delle defixiones di Selinunte. Edizione e commento, Alessandria 2005 (= Bettarini, Defixiones).

Bianchetti, S., Falaride e Pseudofalaride: storia e leggenda, Roma 1987.

Bilabel, F., Die ionische Kolonisation. Untersuchungen über die Gründungen der Ionier, deren staatliche und kultische Organisation und Beziehungen zu den Mutterstädten, Philologus, Suppl. 14, 1, Leipzig 1920.

Bittner, A., Gesellschaft und Wirtschaft in Herakleia Pontike. Eine Polis zwischen Tyrannis und Selbstverwaltung, Bonn 1998 (= Bittner, Herakleia).

Blackman, D. J., «The Harbour at Perachora», ABSA 61, 1966, p. 192-194.

Blakeway, A., «Prolegomena to the Study of Greek Commerce with Italy, Sicily and France in the Eighth and Seventh Centuries B.C.», ABSA 33, 1932-1933, p. 170208.

Blandin, B., Les pratiques funéraires d'époque géométrique à Érétrie. Espace des vivants, demeures des morts, Eretria. Fouilles et recherches XVII, Gollion 2007.

Blümel, W. (éd.), Die Inschriften von Iasos, vol. I, Bonn 1985.

Blümner, H., s.v. «Kupfer», RE XI, 1922, col. 2194-2200.

Boardman, J., The Greeks Overseas: their Early Colonies and Trade ${ }^{3}$, London 1988 (= Boardman, Gr. Overseas $\left.{ }^{3}\right)$. 
Boardman, J., Early Greek Vase Painting, 11th-6th Centuries B. C. : A Handbook, London 1998.

Boardman, J., Schweizer, F., «Clay Analysis of Archaic Greek Pottery», ABSA 68, 1973, p. 268-283.

Boatwright, M.T., Hadrian and the Cities of the Roman Empire, Princeton-Oxford 2003.

Bodson, L., 'I $\varepsilon \rho \dot{\alpha} \zeta \tilde{\omega} \alpha$. Contribution à l'étude de la place de l'animal dans la religion grecque ancienne, Bruxelles 1978.

Boehringer, C., «Der Beitrag der Numismatik zur Kenntnis Siziliens im VI. Jahrhundert v. Chr. », Kokalos 30-31, 1984-1985, p. 103-131.

Bohringer, F., «Cultes d'athlètes en Grèce classique: propos politiques, discours mythiques », REA 81, 1979, p. 5-18.

Bohringer, F., «Mégare. Traditions mythiques, espace sacré et naissance de la cité», $A C$ 69, 1980, p. 6-22 (= Bohringer, Mégare).

Bojadziev, D., «Un cas de contact entre la langue thrace et la langue grecque », in Thracia Pontica III. Les Thraces et les colonies grecques, VII-V s. av. n. è. (Sozopol, 6-12 octobre 1985), Sofia 1986, p. 182-185.

Bölte, F., Weicker, G., «Nisaia und Minoa», MDAI(A) 29, 1904, p. 79-100.

Bommelaer, J.-F., Guide de Delphes. Le site, Athènes-Paris 1991.

Bonacasa, N., Compte rendu de Mégara 1, Kokalos 24-25, 1978-1979, p. 223-227.

Bonnechere, P., «Oracles et grande politique en Grèce ancienne. Le cas de l'orgas sacrée et de la consultation de Delphes en 352/351 avant J.-C. ( $1^{\text {re }}$ partie)», Métis N.S. 10, 2012, p. 261-286.

Boriskovskaja, S., «On Trade Connections between the Greek Cities of the Northern Black Sea Coast and Corinth in the Archaic Period», WissZRostock 16, 7-8, 1967, p. $425-429$.

Boshnakov, K., «Strabo VII 6, 1 », Thracia Pontica V, 1994, p. 87-94.

Boshnakov, K., Die Thraker südlich vom Balkan in den Geographica Strabos. Quellenkritische Untersuchungen, Stuttgart 2003.

Bosnakis, D., Hallof, K., «Alte und neue Inschriften aus Kos I», Chiron 33, 2003, p. 203 262.

Boulay, T., «La mémoire des faits d'armes dans les cités d'Asie Mineure à l'époque hellénistique : un polyandrion à Milet et Lichas fils d'Hermophantos », in Pratiques et identités culturelles des armées hellénistiques du monde méditerranéen, J.-C. Couvenhes et al. (éds.), Bordeaux 2011, p. 213-225.

Bouvier, D., Le sceptre et la lyre. L'Iliade ou les héros de la mémoire, Grenoble 2002.

Braccesi, L., «Trattazione storica», in La Sicilia antica, I, 1, E. Gabba et G. Vallet (éds.), Napoli 1980, p. 53-86.

Braccesi, L., «Appunti su katoikizein in Tucidide VI, 3, 5 », Kokalos 41, 1995, p. 339-344.

Braccesi, L., «Cronologia e fondazioni coloniarie, 1 (Pentatlo, gli Cnidi e la fondazione di Lipari)», in Hesperìa, 7: studi sulla grecità di Occidente, L. Braccesi (éd.), Roma 1996, p. 33-36.

Braccesi, L., L'enigma Dorieo, Hesperìa, 11 : studi sulla grecità di Occidente, Roma 1999.

Braccesi, L., Millino, G., La Sicilia greca, Roma 2000.

Bradeen, D. W., «The Fifth-Century Archon List», Hesperia 32, 1963, p. 187-208. 
Braund, D., «Reflections on Eumelus' Black Sea Regions», in Pont-Euxin et polis. Polis hellenis et polis barbaron. Actes du Xe Symposium de Vani, 23-26 septembre 2002. Hommage à Otar Lodkinapidzé et Pierre Lévêque, D. Kacharava et al. (éds.), Besançon 2005, p. 99-112.

Bredow, I. von, «Karer im Pontos?», in Alte Geschichte: Wege-Einsichten-Horizonte, Festschrift für E. Olshausen, Hildesheim 1998, p. 1-6.

Breitholtz, L., Die dorische Farce im griechischen Mutterland vor dem 5. Jahrhundert. Hypothese oder Realität?, Upsala 1960.

Brélaz, C., La sécurité publique en Asie Mineure sour le Principat (I ${ }^{e r}-I I I^{e}$ s. ap. J.-C.). Institutions municipales et institutions impériales dans l'Orient romain, Bâle 2005.

Brelich, A., «Theseus e i suoi avversari », SMSR 27, 1956, p. 135-141.

Brelich, A., Guerre, agoni e culti nella Grecia arcaica, Bonn 1961.

Brelich, A., Gli eroi greci. Un problema storico-religioso, Roma 1978.

Bremen, R. van, The Limits of Participation. Women and Civic Life in the Greek East in the Hellenistic and Roman Periods, Amsterdam 1996.

Bremmer, J.N., «The Sacrifice of Pregnant Animals », in Greek Sacrificial Ritual, Olympian and Chtonian. Proceedings of the Sixth International Seminar on Ancient Greek Cult, organized by the Department of Classical Archaeology and Ancient History (Göteborg University, 25-27 April 1997), R. Hägg et B. Alroth (éds.), Stockholm 2005, p. 155-165.

Bresson, A., «Rhodes, l'Hellénion et le statut de Naucratis (VI ${ }^{\mathrm{e}}-\mathrm{IV}^{\mathrm{e}}$ siècle a. C.) », DHA 6, 1980, p. 291-349 (= La cité marchande, Paris 2000, p. 13-63).

Bresson, A., «Sur une inscription de Mesembria (IGBulg, $\mathrm{I}^{2}, 335$ septies)», in Tarih Boyunca Karadeniz Kongresi Bildirileri - Congrès International sur la mer Noire (1-3 Juin 1988), Samsun 1990, p. 501-504.

Bresson, A., «L'attentat d'Hiéron et le commerce grec », in Les échanges dans l'Antiquité: le rôle de l'État, Entretiens d'archéologie et d'histoire 1, P. Briant (éd.), SaintBertrand-de-Comminges 1994, p. 47-68 (=La cité marchande, Paris 2000, p. 131-149).

Bresson, A., «Greek Epigraphy and Ancient Economics», in Epigraphy and Historical Sciences, J. Davies et J. Wilkes (éds.), Oxford 2012, p. 223-247.

Bricault, L., Recueil des inscriptions concernant les cultes isiaques, vol. I-III, Paris 2005.

Bringmann, K., Steuben, H. von, (éds.), Schenkungen hellenistischer Herrscher an griechische Städte und Heiligtümer, Teil I: Zeugnisse und Kommentare, Berlin 1995.

Brodersen, K., «Männer, Frauen und Kinder in Großgriechenland: Quellen und Modelle zur frühen Siedler-Identität», Mnemosyne 47, 1994, p. 47-63.

Broise, H., Gras, M., Tréziny, H., «Mégara Hyblaea: bilan des fouilles récentes sur le plateau sud (1977-1982)», MEFRA 95, 1983, p. 647-650 (= Broise, Gras, Tréziny, Bilan des fouilles).

Brugnone, A., «Epigrafia greca», Kokalos 34-35, 1988-1989, p. 336-362.

Brugnone, A., «Gli alfabeti arcaici delle poleis siceliote e l'introduzione dell'alfabeto milesio», ANSP serie iii, 25, 1995, p. 1297-1327 (= Brugnone, Alfabeti arcaici).

Brugnone, A., «Una lamineta iscrita da Selinunte», SicArch XXX, 93-95, 1997, p. 121-130.

Brugnone, A., «Nomima chalkidika. Una laminetta iscritta da Himera», in Quarte giornate internazionali di studi sull'area elima (Erice, 1-4 dicembre 2000). Atti, vol. I, Pisa 2003, p. 77-89. 
Brugnone, A., «Note epigrafiche selinuntine», Thalassa 3, 2006 (2007), p. 45-123 (= Brugnone, Note epigrafiche).

Brugnone, A., «A proposito di un'epigrafe sepolcrale da Selinunte», MEFRA 120, 2008, p. 21-28.

Buck, C.D., The Greek Dialects. Grammar, Selected Inscriptions, Glosary, ChicagoLondon 1955.

Buck, R. J., A History of Boeotia, Edmonton 1979.

Bultrighini, I., «Dorykleion, Dorykleioi e Dorieis », RCCM 53, 1, 2011, p. 99-106.

Bürchner, L., s.v. «Chalkitis» 2, RE III, 1899, col. 2093.

Bürchner, L., s.v. «Kynosura» 1, RE XII, 1925, col. 36.

Bürgel, H., Die pylaeisch-delphische Amphiktyonie, München 1877.

Burn, A. R., «Greek Sea Power, 776-540 B. C., and the «Carian» Entry in the Eusebian Thalssocracy-List», JHS 47, 1927, p. 165-177 (= Burn, Gr. Sea Power).

Burn, A.R., "The So-called <Trade-Leagues > in Early Greek History and the Lelantine War», JHS 49, 1929, p. 14-37.

Burn, A. R., «Dates in Early Greek History », JHS 55, 1935, p. 130-146.

Burn, A. R., The Lyric Age of Greece, London 1960 (= Burn, Lyric Age).

Burnof, E., «Nisée et Minoa», CRAI, 1875, 3, p. 209-221.

Bursian, K., Geographie von Griechenland, vol. I-II, Leipzig 1862 (réimpr. Hildesheim 1977; = Bursian, Geographie).

Burstein, S.M., Outpost of Hellenism. The Emergence of Heraclea on the Black Sea, Berkeley-Los Angeles-London 1976 (= Burstein, Heraclea).

Busolt, G., Griechische Geschichte bis zur Schlacht bei Chaeroneia, I-IV, Gotha 18931904 (= Busolt, Gr. Gesch.).

Busolt, G., Griechische Staatskunde, vol. I-II (vol. II, bearbeitet von H. Swoboda), München 1920-1926 (= Busolt, Staatskunde).

Calame, C., «Spartan Genealogies : the Mythological Representation of a Spatial Organisation », in Interpretation of Greek Mythology, J. Bremmer (éd.), London-Sydney 1987, p. 153-186.

Calame, C., Thésée et l'imaginaire athénien. Légende et culte en Grèce antique ${ }^{2}$, Lau-

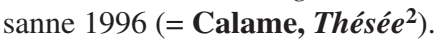

Calame, C., Mythe et histoire dans l'Antiquité grecque. La création symbolique d'une colonie $^{2}$, Paris 2011.

Calderone, S., «Problemi storici relative alle <Apoikiai > siceliote in età protoarcaica », in Rizza (éd.), Insediamenti colon. gr., p. 11-20.

Camassa, G., «Calcante, la cecità dei Calcedoni e il destino dell'eroe del bronzo miceneo », ASNP serie iii, 10, 1, 1980, p. 25-69.

Camassa, G., «La lex sacra di Selinunte», in Sicilia Epigraphica. Atti del convegno (Erice, 15-18 Ottobre 1998), ASNP serie iv, Quaderni 1, M.I. Gulletta (éd.), Pisa 1999, p. 141-148.

Camia, F., Theoi Sebastoi. Il culto degli imperatori romani in Grecia (Provincia Achaia) nel secondo secolo D.C., MEAETHMATA 65, Atene 2011.

Camp II, J. McK., «A Drought in the Late Eighth Century B.C.», Hesperia 48, 1979, p. 397-411. 
Canzanella, M. G. et al., «Entella. Relazione preliminare della campagna di scavo 1988 », ASNP serie iii, 20, 1, 1990, p. 429-552.

Carlier, P., La royauté en Grèce avant Alexandre, Strasbourg 1984 (= Carlier, Royauté).

Carlier, P., «Les basileis homériques sont-ils des rois ?», Ktèma 21, 1996, p. 5-21.

Carrière, J., Théognis de Mégare. Étude sur le Recueil élégiaque attribué à ce poète, thèse de doctorat, Université de Paris, Paris 1948.

Carry, M., Compte rendu de Hanell, Megarische Studien, JHS 55, 1935, p. 96.

Casevitz, M., Le vocabulaire de la colonisation en grec ancien, Paris 1995 (= Casevitz, Vocabulaire).

Castellana, G., s.v. «Montagnoli », in BTCGI X, 1992, p. 235-236.

Castellana, G., «Nuovi dati sull'insediamento di Montagnoli presso Menfi», in Terze giornate internazionali di studi sull'area elima (Gebellina-Erice-Contessa-Entellina, 23-26 ottobre 1997). Atti, vol. I, S. de Vido (éd.), Pisa-Gibellina 2000, p. 263-271.

Cauer, F., Parteien und Politiker in Megara und Athen. Studien zur Geschichte Griechenlands im Zeitalter der Tyrannis, Stuttgart 1890.

Cébeillac-Gervasoni, M., «Les nécropoles de Mégara Hyblaea», Kokalos 21, 1975, p. 3 36.

Chamoux, F., Cyrène sous la monarchie des Battiades, Paris 1953.

Chamoux, F., «Coroibos à Mégare», in Hommage à Lucien Lerat, H. Walter (éd.), Paris 1984, p. 181-187.

Chamoux, F., «Les épigrammes dans Pausanias», in Éditer, traduire, commenter Pausanias en l'an 2000. Actes du colloque de Neuchâtel et de Fribourg (18-22 septembre 1998), D. Knoepfler et M. Piérart (éds.), Genève 2001, p. 79-91.

Chandezon, C., L'élevage en Grèce (fin $V^{e}$-fin I ${ }^{e r}$ s.a.C.). L'apport des sources épigraphiques, Bordeaux 2003.

Chantraine, P., Dictionnaire étymologique de la langue grecque, Paris 1968 (= Chantraine, DELG)

Chiekova, D., Cultes et vie religieuse des cités grecques du Pont Gauche (VII ${ }^{e}$ I $^{\text {er }}$ siècle avant J.-C.), Berne 2008 (= Chiekova, Cultes).

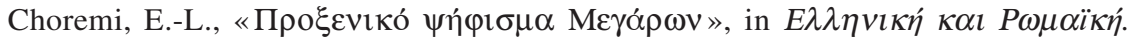

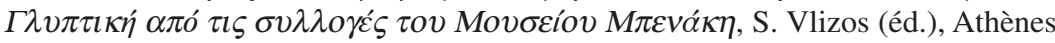
2004, p. 211-213.

Christien-Trégaro, J., «Les Péloponnésiens et la mer Noire», in Sur les traces des Argonautes. Actes du $6^{e}$ symposium de Vani (Colchide), 22-29 septembre 1990, O. Lordkipanidzé et P. Lévêque (éds.), Paris 1996, p. 141-150.

Clinton, K., Eleusis. The Inscription on Stone. Documents of the Sanctuary of the Two Goddesses and Public Documents of the Deme, vol. I-II, Athens 2005-2008.

Cobb-Stevens, V., «Opposites, Reversals and Ambiguities: the Unsettled World of Theognis », in Theognis of Megara. Poetry and the Polis, T. J. Figueira et G. Nagy (éds.), Baltimore-London 1985, p. 159-175.

Cobb-Stevens, V. et al., «Introduction», in Theognis of Megara. Poetry and the Polis, T. J. Figueira et G. Nagy (éds.), Baltimore-London 1985, p. 1-8.

Coldstream, J. N., Greek Geometric Pottery, London 1968 (= Coldstream, Gr. Geom. Pot.). Coldstream, J.N., Geometric Greece ${ }^{2}$, London-New York 2003 (= Coldstream, Geom. $\left.G r^{2}\right)$. 
Collin Bouffier, S., «Sélinonte à la frontière punique», Dossiers d'Archéologie 225, 1997, p. $46-56$.

Compernolle, R. van, «La fondation de Naxos et les sources littéraires. Contribution à l'histoire de la colonisation grecque», BIBR 26, 1950, p. 163-185.

Compernolle, R. van, «La date de fondation de Sélinonte (circa 650 avant notre ère)», BIBR 27, 1952, p. 317-356 (= Van Compernolle, La fond. de Sélinonte).

Compernolle, R. van, «À propos des dates de fondation de Sélinonte et de Syracuse», BIBR 28, 1953, p. 165-200 (= Van Compernolle, La fond. de Sélinonte et de Syracuse).

Compernolle, R. van, «À propos des dates de fondation de Syracuse, de Mégara Hyblaea et de Sélinonte», BIBR 24, 1955, p. 215-240.

Compernolle, R. van, «Les dates de fondation des colonies siciliotes. À propos d'un article récent », $A C 25,1956$, p. 100-105.

Compernolle, R. van, Étude de chronologie et d'historiographie siciliotes. Recherches sur le système chronologique des sources de Thucydide concernant la fondation des colonies siciliotes, Bruxelles-Rome 1959 (= Van Compernolle, Ét. de chronologie).

Compernolle, R. van, «Syracuse, colonie d'Argos?», Kokalos 12, 1966, p. 75-101.

Compernolle, R. van, «La Sicilia e la Grecia arcaica fino alle fine del VI secolo: 1'apporto delle fonti letterarie», Kokalos 30-31, 1984-1985, p. 23-53.

Compernolle, R. van, «Segesta e gli Elimi, quarant'anni dopo », in Gli Elimi e l'area elima fino all'inizio della prima guerra punica. Attidel seminario di studi (Palermo-Contessa Entellina, 25-28 maggio 1989), G. Nenci et al. (éds.), Palermo 1990, p. 73-98.

Compernolle, R. van, «Lo stanziamento di apoikoi greci presso Capo Zefirio (Capo Bruzzano) nell'ultimo terzo dell'VIII secolo a.C.», ASNP serie iii, 22, 3, 1992, p. 761-780 (= Van Compernolle, Capo Zefirio).

Consolo Langher, S. N., «Gli Elimi tra Greci e Cartaginesi nella storia della Sicilia occidentale e nei trattati interstatali tra VI e IV sec. a. C. », in Guerra e pace in Sicilia e nel Mediterraneo antico (VIII-III sec. a.C.). Arte, prassi e teoria della pace e della guerra, vol. I, Pisa 2006, p. 191-212.

Costanzi, M., «Les colonies de deuxième degré de l'Italie du Sud et de Sicile: une analyse lexicographique», Ancient West \& East 9, 2010, p. 87-107.

Cook, A. B., Zeus. A Study in Ancient Religion, vol. I-III, Cambridge 1914-1940.

Cook, R. M., "Ionian and Greece in the Eighth and Seventh Century B. C.», JHS 66, 1946, p. 67-98 (= Cook, Ionian and Greece).

Corbetta, C., «Il conflitto del VI secolo a.C. fra Corinto e Megara», RIL 112, 1998, p. 299-304.

Cordano, F., Antiche fondazioni greche. Sicilia e Italia meridionale, Palermo 1986.

Cordano, F., «Considerazioni sull'uso greco del terzo nome in Sicilia», in Seconde giornate internazionali di studi sull'area elima (Gibellina, 22-26 settembre 1994). Atti, PisaGibellina 1997, p. 401-413.

Cordano, F., «Le istituzioni delle città greche di Sicilia nelle fonti epigrafiche», in Sicilia Epigraphica. Atti del convegno (Erice, 15-18 Ottobre 1998), ASNP serie iv, Quaderni 1, M. I. Gulletta (éd.), Pisa 1999, p. 148-158 (= Cordano, Istituzioni).

Cordano, F., «Le donne di Mesambria», in Heros Hephaistos. Studia in honorem Liubae Ognenova-Marinova, T. Stoyanov et al. (éds.), Veliko Tărnovo 2005, p. 42-44. 
Cordano, F., «Alcune caratteristiche delle colonie megaresi », in Argumenta Antiquitatis,

G. Zanetto et M. Ornaghi (éds.), Milano 2009, p. 3-9.

Corsten, T., «Neue Denkmäler aus Bithynien», EA 17, 1991, p. 79-100.

Corsten, T., Vom Stamm zum Bund. Gründung und territoriale Organisation griechischer Bundesstaten, München 1999 (= Corsten, Vom Stamm zum Bund).

Corsten, T., «The Role and Status of the Indigenous Population in Bithynia», in Rome and the Black Sea Region. Domination, Romanisation, Resistance, Black Sea Studies 5, T. Bekker-Nielsen (éd.), Aarhus 2006, p. 85-92.

Courbin, P., La céramique géométrique de l'Argolide, Paris 1966.

Crow, J., Turner, S., «Silivri and the Thracian Hinterland of Istanbul: An Historical Landscape», AS 59, 2009, p. 167-181.

Curbera, J., «Onomastics and River-Gods in Sicily», Philologus 142, 1998, p. 52-60.

Curbera, J., «Defixiones», in Sicilia Epigraphica. Atti del convegno (Erice, 15-18 Ottobre 1998), ASNP serie iv, Quaderni 1, M.I. Gulletta (éd.), Pisa 1999, p. 159-186.

Curtius, E., Kaupert, J. (éds.), Karten von Attika. Text. Heft VII-VIII, Berlin 1895.

Curty, O., Les parentés légendaires entre cités grecques. Catalogue raisonné des inscrip-

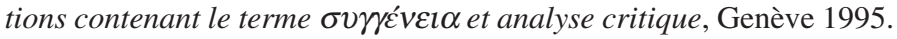

Curty, O., «Un usage fort controversé: la parenté dans le langage diplomatique de l'époque hellénistique», AncSoc 35, 2005, p. 101-117.

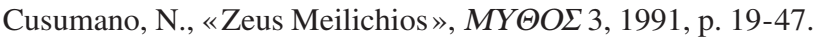

Cusumano, N., Una terra splendida et facile da possedere. I Greci e la Sicilia, Roma 1994.

Cusumano, N., «Il massacro dei Selinuntini nel 409: alcune osservazioni», in Atti del $V$ Congresso Internazionale di Studi Fenici e Punici (Marsala-Palermo, 2-8 ottobre 2000), A. Spanò Giammellaro (éd.), Palermo 2005, p. 823-828.

Cusumano, N., «Polivalenze funzionali e figurative. Osservazioni su Zeus Meilichios», Mètis N.S. 4, 2006, p. 165-192.

D’Agostino, B., Compte rendu de Mégara 2, ArchClass 17, 1, 1965, p. 159-167.

D’Agostino, B., «Osservazioni a proposito della guerra lelantina», DdA 1, 1967, p. 20 37.

D’Ercole, M. C., Histoires méditerranéennes. Aspects de la colonisation grecque de l'Occident à la mer Noire (VIII ${ }^{e}-I V^{e}$ siècles av. J.-C.), Paris 2012 (= D'Ercole, Colonisation grecque).

Dagron, G., Naissance d'une capitale. Constantinople et ses institutions de 330 à 451, Paris 1974 (= Dagron, Naissance d'une capitale).

Dagron, G., Constantinople imaginaire. Études sur le recueil des Patria, Paris 1984 (= Dagron, Recueil des Patria).

Dana, M., «Lettres grecques dialectales nord-pontiques (sauf IGDOP 23-26) », REA 109, 2007, p. 67-97.

Dana, M., Culture et mobilité dans le Pont-Euxin, Bordeaux 2011 (= Dana, Culture).

Dana, M., «Entre Crimée et Bosphore: d'une Parthenos à l'autre», Mètis N.S. 10, 2012, p. 289-308.

Dana, M., «Byzance hellénistique et impériale: un centre culturel avant Constantinople ?», in The Bosporus: Gateway between the Ancient West and Est (1st Millennium BC5th Century AD). Proceedings of the Fourth International Congress on Black 
Sea Antiquities Istanbul, 14th-18th September 2009, BAR International Series 2517, G. Tsetskhladze et al. (éds.), Oxford 2013, p. 29-38 (= Dana, Byzance).

Dana, M., Dana, D., «Histoires locales dans le Pont-Euxin Ouest et Nord. Identité grecque et construction du passé», Il Mar Nero 5, 2001-2003 (2006), p. 91-111.

Dandamaev, M. A., A Political History of the Achemenid Empire, Leiden 1989.

Danner, P., «Die Gründung von Selinunt», GB 21, 1995, p. 7-27 (= Danner, Selinunt).

Danner, P., «Das Gründungsdatum von Megara Hyblaea», Römische historische Mitteilungen 38, 1996, p. 17-34 (= Danner, Megara).

Danner, P., «Megara, Megara Hyblaea and Selinus: the Relationship between the Town Planning of a Mother City, a Colony and a Sub-Colony in the Archaic Period», ActaHyp 7, 1997, p. 143-165 (= Danner, Town Planning).

Danov, C., «The Penetration of the Thracians into the Greek Colonies of the Western Shore of the Black Sea», Klio 38, 1960, p. 75-80.

Danov, C. M., s.v. «Pontos Euxeinos », in RE Suppl. IX, 1962, col. 866-1175.

Danov, C.M., Altthrakien, Berlin-New York 1976.

Daux, G., «Notes de lecture», BCH 91, 1967, p. 469-482.

Daux, G., «Notes de lecture», $B C H$ 94, 1970, p. 595-623.

Daux, G., «Notes de lecture», BCH 103, 1979, p. 461-475.

Daverio Rocchi, G., «La hiera orgas e la frontiera attico-megarica», in Studi di antichità in memoria di C. Gatti, Quaderni di Acme 9, Milano 1987, p. 97-109.

Daverio Rocchi, G., Frontiera e confini nella Grecia antica, Roma 1988 (= Daverio Rocchi, Frontiera e confini).

Davies, J. K., Athenian Properted Families 600-300 B. C., Oxford 1971.

Davison, J.A., «Dieuchidas of Megara», CQ 53, 1959, p. 216-222.

De Angelis, F., «The Foundation of Selinous: Overpopulation or Opportunities?», in The Archaeology of Greek Colonisation. Essays dedicated to Sir John Boardman, G. Tsetskhladze etF. de Angelis (éds.), Oxford 1994, p. 87-110 (=DeAngelis, Found. of Selinous).

De Angelis, F., «Ancient Past, Imperial Present: the British Empire in T. J. Dunbabin's The Western Greeks», Antiquity 72, 1998, p. 539-549.

De Angelis, F., «Estimating the Agricultural Base of Greek Sicily», PBSR 68, 2000, p. 111-148.

De Angelis, F., «Trade and Agriculture at Megara Hyblaea», OJA 21, 2002, p. 299-310.

De Angelis, F., «Equations of Culture: the Meeting of Natives and Greeks in Sicily ( $c a$. 750-450 BC)», Ancient West \& East 2, 1, 2003, p. 19-50.

De Angelis, F., Megara Hyblaia and Selinous. The Development of Two Greek City-States in Archaic Sicily, Oxford 2003 (= De Angelis, Megara Hyblaia and Selinous).

De Angelis, F., «Re-assessing the Earliest Social and Economic Developments in Greek Sicily», $\operatorname{MDAI}(R)$ 116, 2010, p. 21-53.

De Bernardin, M., «Per un' analisi della figura di Eracle in Sicilia: dal VII sec. a.C. all'età romana», in Sicilia occidentale. Studi, rassegne, ricerche, C. Ampolo (éd.), Pisa 2012, p. 305-312.

De Fidio, P., «Corinto e l'Occidente tra VIII e VI secolo a.C.», in Corinto e l'Occidente. Atti del trentaquattresimo Convegno di studi sulla Magna Grecia (Taranto, 7-11 ottobre 1994), Taranto 1995, p. 47-141 (= De Fidio, Corinto e l'Occidente). 
De Libero, L., Die archaische Tyrannis, Stuttgart 1996.

De Miro, E., «Agrigento arcaica e la politica di Falaride», PP 11, 1956, p. 263-273.

De Miro, E., «Eraclea Minoa e l'época di Timoleonte», Kokalos 4, 1958, p. 69-81.

De Miro, E., «La fondazione di Agrigento e l'ellenizzazione del territorio fra il Salso e il Platani», Kokalos 8, 1962, p. 122-152.

De Miro, E., L'Antiquarium e la zona archeologica di Eraclea Minoa, Roma 1965.

De Miro, E., «Monte Adranone, antico centro di età greca», Kokalos 13, 1967, p. 180 185.

De Miro, E., « Nuovi dati del problema relativo all'ellenizzazione dei centri indigeni della Sicilia centro-occidentale», BA 60, 3-4, 1975, p. 123-128.

De Miro, E., Fiorentini, G., «Attività della Soprintendeza alle Antichità della Sicilia centromeridionale negli anni 1968-1972», Kokalos 18-19, 1972-1973, p. 228-250.

De Miro, E., Fiorentini, G., «Relazione sull'attività della Soprintendeza alle Antichità di Agrigento (1972-1976)», Kokalos 22-23, 1976-1977, p. 423-456.

De Miro, E., Fiorentini, G., «Gela nell’VIII e VII secolo a. C.», in Rizza (éd.), Insediamenti colon. gr., p. 90-99.

De Sanctis, G., «Die attische Ansiedlung in Astakos», Hermes 29, 1894, p. 479-480 (= De Sanctis, Astakos).

De Sanctis, G., Ricerche sulla storiografia siceliota, Palermo 1958.

De Simone, R., «Riflessioni sull'onomastica punica», in Sicilia Epigraphica. Atti del convegno (Erice, 15-18 Ottobre 1998), ASNP serie iv, Quaderni 1, M.I. Gulletta (éd.), Pisa 1999, p. 205-219.

De Simone, R., «Selinunte punica», in Selinunte, V. Tusa (éd.), Roma 2010, p. 181190.

De Souza, P., «Towards Thalassocracy? Archaic Greek Naval Developments », in Archaic Greece: New Approaches and New Evidence, N. Fisher et H. van Wees (éds.), London 1998, p. 271-293.

De Vido, S., s.v. «Mazara del Vallo», in BTCGI IX, 1991, p. 502-508.

De Vido, S., Gli Elimi. Storie di contatti e di rappresentazioni, Pisa 1997 (= De Vido, Gli Elimi).

De Vido, S., «I dinasti dei Siculi. Il caso di Archonides», Acme 50, 2, 1997, p. 7-37.

De Waele, J. A., Acragas Graeca. Die historische Topographie des griechischen Akragas auf Sizilien, Den Haag 1971.

De Wever, J., Van Compernolle, R., «La valeur des termes de «colonisation » chez Thucydide», AntCl36, 1966, p. 461-523 (=De Wever-Van Compernolle, Colonisation).

Debord, P., «Chiliastys», REA 86, 1984, p. 201-211 (= Centre G. Radet, Cahier No. 3, 1983, p. 17-31; = Debord, Chiliastys).

Debord, P., «Comment devenir le siège d'une capitale impériale: le 〈parcours〉 de la Bithynie», REA 100, 1-2, 1998, p. 139-165.

Debord, P., L'Asie Mineure au IVe siècle (412-323 a.C.). Pouvoirs et jeux politiques, Paris-Bordeaux 1999.

Debord, P., «Les Mysiens du mythe à l'histoire», in Origines Gentium, V. Fromentin et S. Gotteland (éds.), Bordeaux 2001, p. 135-146 (= Debord, Mysiens).

Dehl, C., «Cronologia e diffusione della ceramica corinzia dell'VIII sec. a. C. in Italia», ArchClass 35, 1983, p. 186-210. 
Dehl-von Kaenel, C., «Keramik als Handelsware. Zum Vertrieb korinthischer Keramik in das Malophoros Heiligtum in Selinunt», MBAH 13, 1994, p. 55-82.

Dehl-von Kaenel, C., Die archaische Keramik aus dem Malophoros-Heiligtum in Selinunt. Die korinthischen, lakonischen, ostgriechischen, etruskischen und megarischen Importe sowie die <argivisch-monochrome > und lokale Keramik aus den alten Grabungen, Berlin 1995 (= Dehl-von Kaenel, Keramik aus Malophoros).

Dehl-von Kaenel, C., «Le importazioni corinzie nel santuario della Malophoros di Selinunte e le strutture della distribuzione della ceramica corinzia in Sicilia e in Magna Grecia», in Corinto e l'Occidente. Atti del trentaquattresimo Convegno di studi sulla Magna Grecia (Taranto, 7-11 ottobre 1994), Taranto 1995, p. 345-366.

Delev, P., «Bevölkerung und Siedlungssystem an der bulgarischen Schwarzmeerküste», in Die bulgarische Schwarzmeerküste im Altertum, Xenia 16, W. Schuller (éd.), Konstanz 1985, p. 9-27.

Demand, N.H., Urban Relocation in Archaic and Classical Greece, Norman-London 1990 (= Demand, Urban Relocation).

Denkar, A., Yağcı, G., Akay, A. B., "Büyük Saray kazısý”, in Gün Işığında İstanbul'un 8000 Yll-Marmaray, Metro, Sultanahmet Kazllari, Istanbul 2007, p. 124-163.

Denoyelle, M., Iozzo, M., La céramique grecque d'Italie méridionale et de Sicile. Productions locales et apparentées du VIII e au III e siècle av. J.-C., Paris 2009.

Descat, R., «Gélon et les emporia de Sicile», Messana 13, 1992, p. 5-17.

Desideri, P., «Studi di storiografia eracleota, I: Promathidas e Nymphis », SCO 16, 1967, p. 366-416 (= Desideri, Storiografia eracleota).

Detienne, M., Crise agraire et attitude religieuse chez. Hésiode, Bruxelles 1963.

Detienne, M., «Apollon Archégète. Un modèle politique de la territorialisation », in Tracés de fondation, M. Detienne (éd.), Louvain-Paris 1998, p. 301-311.

Detienne, M., Apollon le couteau à la main, Paris 1998 (= Detienne, Apollon).

Detschew, D., Die thrakischen Sprachreste ${ }^{2}$, Wien 1976 (= Detschew, Thrak. Sprachreste $^{2}$ ).

Deubner, L., Attische Feste, Berlin 1932.

Devoto, J. G., «Two Megarian Colonies in Sicily», AncW 36, 2005, p. 90-106.

Dewailly, M., Histoire du culte dans le sanctuaire de la Malophoros à Sélinonte, thèse de doctorat, Université de Lille III, Lille 1987 (= Dewailly, Sanct. de la Malophoros).

Dewailly, M., Les statuettes aux parures du sanctuaire de la Malophoros à Sélinonte. Contexte, typologie et interprétation d'une catégorie d'offrandes, Cahiers Centre Jean Bérard 17, Naples 1992 (= Dewailly, Statuettes).

Dewailly, M., Parisi-Presicce, C., Tusa, S., «Selinunte, Malophoros: campagne di scavo 1982-1983 », in V. Tusa, «L'attività della Soprintendenza alle Antichità della Sicilia Occidentale nel quadriennio maggio 1980-aprile 1984», Kokalos 30-31, 1984-1985, p. 574-581.

Di Noto, C. A., s.v. «Monte Adranone», in BTCGI X, 1992, p. 257-265.

Di Vita, A., «Selinunte fra il 650 ed il 409: un modello urbanistico coloniale», ASAA 62, N.S. 46, 1984 (1988), p. 7-68 (= Da Siracusa a Mozia. Scritti di archeologia siciliana, Padova 1998, p. 315-363; = Di Vita, Selinunte $)$.

Di Vita, A., «Urbanistica della Sicilia greca », in I Greci in Occidente, G. Pugliese Caratelli (éd.), Milano 1996, p. 263-308. 
Di Vita, A., «Siracusa, Camarina, Selinunte: quale frontiera?», in Confini e frontiera nella grecità d'Occidente. Atti del trentasettesimo convegno di studi sulla Magna Grecia (Taranto, 3-6 ottobre 1997), Taranto 1999, p. 361-379 (= Da Siracusa a Mozia. Scritti di archeologia siciliana, Padova 1998, p. 373-379; = Di Vita, Siracusa, Camarina, Selinunte).

Di Vita Gafà, A., «L'urbanistica», in SIKANIE. Storia e civiltà della Sicilia antica, G. Pugliese Carratelli (éd.), Milano 1986, p. 359-414.

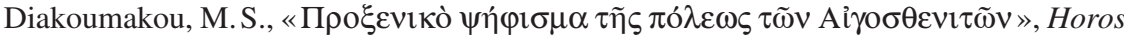
13, 1999, p. 173-175.

Dillon, M., Pilgrims and Pilgrimage in Ancient Greece, London-New York 1997.

Dimartino, A., «Omicidio, contaminazione, purificazione: il <caso〉 della lex sacra di Selinunte», ANSP 8, 2003 (2006), p. 305-347.

Dimitrov, K., «Hoard of Hellenistic Bronze Coins from Mesambria Pontica in the Depository of the National Archaeological Museum in Sofia (IGCH 884) », in Studia in honorem A. Fol, Sofia 1995, p. 409-418.

Dimitrova, N.M., Theoroi and Initiates in Samothrace. The Epigraphical Evidence, Hesperia, Suppl. 37, Athens 2008.

Dittenberger, W., «Kritische Bemerkungen zu griechischen Inschriften », Hermes 16, 1881, p. 161-200.

Dobias-Lalou, C., «SEG IX, 3: un document composite ou inclassable?», Verbum 3-4, 1994, p. 243-256.

Domínguez, A. J., La Colonización Griega en Sicilia. Griegos, Indígenas y Púnicos en la Sicilia Arcáica: Interacción y Aculturación, Oxford 1989 (=Domínguez, Colon. Gr.).

Domínguez, A.J., «The Origins of the Greek Colonisation and the Greek Polis: Some Observations », Ancient West \& East 10, 2011, p. 195-207.

Dontas, G., «Denkmäler und Geschichte eines kerkyräischen Heiligtums », in Neue Forschungen in griechischen Heiligtümern. Internationales Symposion in Olympia vom 10. bis 12. Oktober 1974, U. Jantzen (éd.), Tübingen 1976, p. 121-133.

Dörner, F. K., s.v. «Prusias ad Hypium» 5, RE XXIII, 1, 1957, col. 1128-1148.

Dörner, F. K., Hoepfner, W., «Das Einland Thynias - Apollonia», MDAI(I) 39, 1989, p. 103-106.

Doublet, G., «Inscriptions de Paphlagonie», BCH 13, 1889, p. 293-319.

Dougherty, C., The Poetics of Colonization. From City to Text in Ancient Greece, New York-Oxford 1993.

Dover, K. J., «Anthemocritus and the Megarians », AJPh 87, 1966, p. 203-209.

Dover, K. J., «Über die Kolonisierung Siziliens bei Thukydides», in Thukydides, H. Herter (éd.), Darmstadt 1968, p. 344-368 (= «La colonizzazione della Sicilia in Tucidide», Maia 6, 1953, p. 1-20; = Dover, Thukydides .

Drews, R., «The Fall of Astyages and Herodotus' Chronology of the Eastern Kingdoms », Historia 18, 1969, p. 1-11.

Drews, R., Basileus. The Evidence for Kingship in Geometric Greece, New HavenLondon 1983.

Dubois, L. (éd.), Inscriptions grecques dialectales d'Olbia du Pont, Genève 1996.

Dubois, L., «La nouvelle loi sacrée de Sélinonte. Bilan dialectologique», AION(ling) 19, 1997, p. 331-346. 
Dubois, L., «La nouvelle loi sacrée de Sélinonte», CRAI, 2003, 1, p. 105-125 (= Dubois, Loi sacrée).

Dubois, L., «Des Grecs aux Élymes: emprunts alphabétiques en Sicile occidentale à l'époque archaïque», in Traduire, transposer, transmettre dans l'Antiquité grécoromaine, B. Bortolussi et al. (éds.), Paris 2009, p. 107-111 (= Dubois, Des Grecs aux Élymes).

Ducat, J., «L'archaïsme à la recherche de points de repère chronologiques », $B C H 86$, 1962, p. 165-184.

Dumitru, A., «Byzance et les Philippe de Macédoine», REG 119, 2006, p. 139-156.

Dumont, J., Halieutika. Recherches sur la pêche dans l'Antiquité grecque, thèse de doctorat, Université de Paris IV, Paris 1981.

Dunand, F., Le culte d'Isis dans le bassin oriental de la Méditerranée II. Le culte d'Isis en Grèce, Leiden 1973.

Dunbabin, T. J., «The Early History of Corinth», JHS 68, 1948, p. 59-69 (= Dunbabin, Corinth).

Dunbabin, T. J., «Two Tomb-Groups from Selinus », PBSR 16, 1948, p. 19-23.

Dunbabin, T. J., «The Oracle of Hera Akraia at Perachora», ABSA 46, 1951, p. 61-71.

Dunbabin, T. J., Perachora: the Sanctuaries of Hera Akraia and Limenia. Excavations of the British School of Archaeology at Athens, 1930-1933. 2, Pottery, Ivories, Scarabs, and other Objects from the Votive Deposit of Hera Limenia excavated by Humfry Payne, Oxford 1962 (= Dunbabin, Perachora II).

Dunbabin, T.J., The Western Greeks. The History of Sicily and South Italy from the Foundation of the Greek Colonies to 480 B. C., Oxford 1968 (= Dunbabin, Western Greeks).

Duplouy, A., Le prestige des élites. Recherches sur les modes de reconnaissances sociales en Grèce entre les $X^{e}$ et $V^{e}$ siècles avant J.-C., Paris 2006.

Dupont, P., «Amphores archaïques de Grèce propre en mer Noire. État de la question », Il Mar Nero 2, 1995-1996 (1996), p. 85-98.

Dupont, P., «Note d'épigraphie amphorique. Addendum à Il Mar Nero II (1995-96), 8598 », in Civilisation grecque et cultures antiques périphériques. Hommage à Petre Alexandrescu à son $70^{e}$ anniversaire, A. Avram et M. Babeş (éds.), Bucarest 2000, p. 205-209.

Dupont, P., «Le Pont-Euxin archaïque : lac milésien ou lac nord-ionien? Un point de vue de céramologue », in Une koinè pontique. Cités grecques, sociétés indigènes et empires mondiaux sur le littoral nord de la mer Noire (VII e s. a.C.-III e s. p.C.), A. Bresson et al. (éds.), Bordeaux 2007, p. 29-36 (= Dupont, Le Pont-Euxin archä̈que).

Edwards, A. T., «Historicizing the Popular Grotesque: Bakhtin's Rabelais and Attic Old Comedy », in Theater and Society in the Classical Wolrd, R. Scodel (éd.), Ann Arbor 1993, p. 89-117.

Effenberger, A., «Zur Interpretation des megarischen Acheloos-Reliefs », Forschungen und Berichte 12, 1970, p. 77-96.

Effenterre, H. van, «Solon et la terre d'Eleusis », RIDA 24, 1977, p. 91-130.

Effenterre, H. van, Ruzé, F., NOMIMA. Recueil d'inscriptions politiques et juridiques de l'archaïsme grec, vol. I-II, Rome 1994-1995 (= Van Effenterre-Ruzé, NOMIMA). 
Ehrenberg, V., The Greek States ${ }^{2}$, London 1969.

Ehrhardt, N., «Die politischen Beziehungen zwischen den griechischen Schwarzmeergründungen und ihren Mutterstädten. Ein Beitrag zur Bedeutung von Kolonialverhältnissen in Griechenland», in Actes du IX congrès international d'épigraphie grecque et latine (31.08-7.09.1987), Acta Centri Historiae, Terra Antiqua Balcanica II, A. Fol (éd.), Veliko Tărnovo-Sofia 1987, p. 78-117 (= Ehrhardt, Die politischen Beziehungen).

Ehrhardt, N., Milet und seine Kolonien. Vergleichende Untersuchung der kultischen und politischen Einrichtungen ${ }^{2}$, Frankfurt am Main et al. 1988 (= Ehrhardt, Milet und seine Kolonien ${ }^{2}$ ).

Ehrhardt, N., «Ktistai in den Argonautika des Apollonios Rhodios. Beobachtungen zur Entwicklung von Gründungstraditionen in Kyzikos, Kios, Herakleia Pontike und Sinope», in Asia Minor Studien, Band 16. Studien zum antiken Kleinasien III, Bonn 1995, p. 23-46 (= Ehrhardt, Ktistai).

Ehrhardt, N., «Ilias B 508 und die Gründung von Heraclea Pontica», Hermes 124, 1996, p. 101-103.

Ekroth, G., The Sacrificial Rituals of Greek Hero-Cults, Kernos, Suppl. 12, Liège 2002.

Elderkin, G. W., Compte rendu de Hanell, Megarische Studien, AJA 39, 1935, p. 629.

Ellinger, P., La fin des maux. D’un Pausanias à l'autre, Paris 2005.

Emereau, C., «Notes sur les origines et la formation de Constantinople. Les grands centres historiques de la ville», $R A$ 21, 1925, p. 1-25.

Engelmann, R., «Die Jo-Sage», JDAI 18, 1903, p. 37-58.

Engelmann, H., Merkelbach, R. (éds.), Die Inschriften von Erythrai und Klazomenai, Bonn 1972 (IK, 1 et 2).

Étienne, R., Knoepfler, D., Hyettos de Béotie et la chronologie des archontes fédéraux entre 250 et 171 avant J.-C., BCH, Suppl. 3, Athènes-Paris 1976 (= ÉtienneKnoepfler, Hyettos de Béotie).

Facella, A., s.v. «Styella», in BTCGI XIX, 2005, p. 730-734.

Falsone, G., s.v. «Monte Castellazzo di Poggioreale», in BTCGI X, 1992, p. 307-312.

Falsone, G. et al., «Quatro campagne di scavo a Castellazzo di Poggioreale », Kokalos 3637, 1980-1981, p. 931-972.

Famà, M.L., Tusa, V., Le stele del Meilichios di Selinunte, Padova 2000.

Faraguna, M., «La figura dell' asymnetes tra realità storica e teoria politica», in Symposion 2001. Vorträge zur griechischen und hellenistischen Rechtsgeschichte (Evanston, Illinois, 5.-8. September 2001), R. W. Walace et M. Gagarin (éds.), Wien 2005, p. 321-338.

Farnell, L. R., The Cults of the Greek States, vol. I-V, Oxford 1896-1909.

Farnell, L. R., Greek Hero Cults and Ideas of Immortality, Oxford 1921.

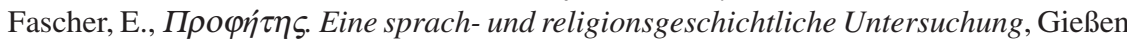
1927.

Ferguson, W. S., «The Salaminioi of Heptaphylai and Sounion», Hesperia 7, 1938, p. 174.

Fernoux, H.-L., «Guerres, cités et mondes indigènes du Pont-Euxin et de la Propontide aux Ve $\mathrm{V}^{\mathrm{e}}$ et $\mathrm{IV}^{\mathrm{e}}$ siècles av. J.-C.», Pallas 51, 1999, p. 173-204. 
Fernoux, H.-L., Notables et élites des cités de Bithynie aux époques hellénistique et romaine (III ${ }^{e}$ siècle av. J.-C.-III e siècle ap. J.-C.). Essai d'histoire sociale, Lyon 2004 (= Fernoux, Notables).

Ferraioli, F., L'Hekatostys : analisi della documentazione, Roma 2012.

Ferreri, L., «Teognide e la guerra lelantina», GIF 57, 2005, p. 71-102.

Festugière, A.-J., «Les mystères de Dionysos », RBi 44, 3, 1935, p. 366-396.

Feyel, M., Polybe et l'histoire de Béotie au III siècle avant notre ère, Paris 1942 (= Feyel, Polybe $)$.

Figueira, T.J., «Chronological Table. Archaic Megara», in Theognis of Megara. Poetry and the Polis, T. J. Figueira et G. Nagy (éds.), Baltimore-London 1985, p. 261-303 (= Figueira, Chronological Table).

Figueira, T. J., «The Theognidea and Megarian Society », in Theognis of Megara. Poetry and the Polis, T. J. Figueira et G. Nagy (éds.), Baltimore-London 1985, p. 112-158 (= Figueira, Megarian Society).

Figueira, T. J., Athens and Aigina in the Age of Imperial Colonization, Baltimore-London 1991 (= Figueira, Athens and Aigina).

Fink, J., «Der politische Gehalt in Darstellungen von Theseus' Abenteuer mit Skiron», Welt als Geschichte 20, 1960, p. 10-15.

Finley, M.I., A History of Sicily. Ancient Sicily to the Arab Conquest, London 1968 (= Finley, Anc. Sicily).

Finley, M.I., Sur l'histoire ancienne. La matière, la forme et la méthode, Paris 1987 (= Finley, Sur l'hist. ancienne).

Firatl, N., Les stèles funéraires de Byzance gréco-romaine, avec l'édition et l'index commenté des épitaphes par L. Robert, Paris 1964 (= Firatlı, Stèles de Byzance).

Firatl, N., «New Discoveries concerning the First Settlement of Ancient IstanbulByzantion », in Proceedings of the $X^{\text {th }}$ International Congress of Classical Archaeology, Ankara-Izmir 1973, p. 565-574.

Fischer-Hansen, T., «The Earliest Town Planning of the Western Greek Colonies, with Special Regard to Sicily», in Introduction to an Inventory of Poleis, Acts of the Copenhagen Polis Centre 3, M.H. Hansen (éd.), Copenhagen 1996, p. 317-373 (= Fischer-Hansen, Town Planning).

Fischer-Hansen, T., «Ergasteria in the Western Greek Colonies», in Polis and Politics. Studies in Ancient Greek History. Presented to M. H. Hansen on his Sixtieth Birthday, August 20, 2000, P. Flensted-Jensen (éd.), Copenhagen 2000, p. 91-120.

Fischer-Hansen, T., Nielsen, T.H., Ampolo, C., s.v. «Herakleia (1)», in Hansen-Nielsen (éds.), Inventory, p. 196-197.

Fischer-Hansen, T., Nielsen, T.H., Ampolo, C., s.v. «Megara», in Hansen-Nielsen (éds.), Inventory, p. 213-215 (= Fischer-Hansen, Nielsen, Ampolo, Megara).

Fischer-Hansen, T., Nielsen, T.H., Ampolo, C., s.v. «Selinous », in Hansen-Nielsen (éds.), Inventory, p. 220-224 (= Fischer-Hansen, Nielsen, Ampolo, Selinous).

Fischer-Hansen, T., Nielsen, T.H., Ampolo, C., s.v. «Stielanaioi », in Hansen-Nielsen (éds.), Inventory, p. 224-225.

Fittschen, K., Untersuchungen zum Beginn der Sagendarstellungen bei den Griechen, Berlin 1969. 
Fitzjohn, M., «Equality in the Colonies : Concepts of Equality in Sicily during the Eighth to Sixth Centuries BC», World Archeology 39, 2, 2007, p. 215-228.

Flensted-Jansen, P., Hansen, M.H., "Pseudo-Skylax», in The Return of the Polis: The Use and Meanings of the Word Polis in Archaic and Classical Sources, Historia Einzelschriften 198, M. H. Hansen (éd.), Stuttgart 2007, p. 204-242.

Foat, F. W. G., «Tsade and Sampi », JHS 25, 1905, p. 338-365.

Foat, F. W. G., «Fresh Evidence for T», JHS 26, 1906, p. 286-287.

Fol, A., «Thracia Pontica - Twenty Years Later», in New Studies on the Black Sea Littoral, Colloquia Pontica 1, G. R. Tsetskhladze (éd.), Oxford 1996, p. 1-12.

Fol, V., «Byzas-Byzantion: une métaphore historico-culturelle», in Thracia 13. Studia in memoriam Velizari Velkov, Sofia 2000, p. 101-106.

Follet, S., «Hadrien ktistès kai oikistès: lexicographie et realia», in La langue et les textes en grec ancien. Actes du colloque Pierre Chantraine (Grenoble, 5-8 septembre 1989), F. Létoublon (éd.), Amsterdam 1992, p. 241-254.

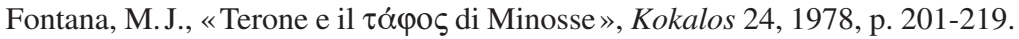

Fontenrose, J., The Delphic Oracle, Berkeley et al. 1978.

Ford, A.L., «The Seal of Theognis. The Politics of Autorship in Archaic Greece», in Theognis of Megara. Poetry and the Polis, T.J. Figueira et G. Nagy (éds.), Baltimore-London 1985, p. 82-95.

Fornara, C. W., «Some Aspects of the Career of Pausanias of Sparta », Historia 15, 1966, p. 257-271.

Forrest, W.G., «Colonization and the Rise of Delphi», Historia 6, 1957, p. 160-175 (= Forrest, Colonization).

Forrest, W. G., «Two Chronographic Notes », CQ 19, 1969, p. 95-110.

Forsdyke, S., Exile, Ostracism, and Democracy. The Politics of Expulsion in Ancient Greece, Princeton 2005.

Forsdyke, S., «Revelry and Riot in Archaic Megara: Democratic Disorder or Ritual Reversal ?», JHS 125, 2005, p. 73-92 (= Forsdyke, Megara).

Fossey, J. M., The Topography and Population of Ancient Boiotia, vol. I, Chicago 1988 (= Fossey, Topography).

Fossey, J. M., «The Perakhóra Peninsula Survey», EMC 34, 1990, p. 201-211.

Fossey, J.M., «Boiotia and the Pontic Cities in the Archaic to Hellenistic Periods», in Boeotia antiqua IV. Proceedings of the $7^{\text {th }}$ International Congress on Boiotian Antiquities, Boiotian (and Other) Epigraphy, J. M. Fossey (éd.), Amsterdam 1994, p. 107-115 (= Fossey, Boiotia and the Pontic Cities).

Fossey, J.M., «Some Parameters of Archaic Greek Emigration», in Sur les traces des Argonautes. Actes du $6^{e}$ symposium de Vani (Colchide), 22-29 septembre 1990, O. Lordkipanidzé et P. Lévêque (éds.), Paris 1996, p. 119-128.

Foucart, P., Explication des inscriptions grecques et latines recueillies en Grèce et en Asie Mineure, Paris 1873 ?, Supplément à Ph. Le Bas, Inscriptions grecques et latines recueillies en Grèce et en Asie Mineure. Deuxième partie: Mégaride et Péloponnèse. Section I: Mégaride, Paris 1848 (= Foucart, Inscr. de la Mégaride).

Foucart, P., «Décret de la ville de Chersonésos en l'honneur de Diophantos, général de Mithridate», $B C H 5,1881$, p. 70-87. 
Fouchard, A., Aristocratie et démocratie. Idéologies et sociétés en Grèce ancienne, Paris 1997.

Fourmont, M.H., «Sélinonte: fouille dans la région nord-ouest de la rue F », SicArch XIV, 46-47, 1981, p. 5-26.

Fourmont, M.H., «Rapport d'activité pour les travaux à Sélinonte: 1980-1984», in V. Tusa, «L'attività della Soprintendenza alle Antichità della Sicilia Occidentale nel quadriennio maggio 1980-aprile 1984», Kokalos 30-31, 1984-1985, p. 558-564.

Fourmont, M.H., «Recherches sur les activités artisanales d'un quartier de Sélinonte», SicArch XXIV, 76-77, 1991, p. 7-41.

Fourmont, M.H., «Un moule pour le travail du bronze à Sélinonte», in Studi sulla Sicilia Occidentale in onore di V. Tusa, Padova 1993, p. 57-60.

Fowler, H. N., Sillwell, R., Corinth, vol. I. Introduction, Topography, Architecture, Cambridge, Mass. 1932.

Francotte, H., La polis grecque. Recherches sur la formation et l'organisation des cités, des ligues et des confédérations dans la Grèce ancienne, Paderborn 1907.

Franke, P. R., Hirmer, M., Die griechische Münze, München 1972.

Frasca, M., «Una nuova capanna < sicula > a Siracusa, in Ortigia : tipologia dei materiali », MEFRA 95, 1983, p. 565-598.

Frasca, M., «Iron Age Settlements and Cemeteries in Southeastern Sicily: An Introduction Survey», in Early Societies in Sicily: New Developments in Archaeological Research, R. Leighton (éd.), London 1996, p. 138-145.

Frasca, M., «Leontinoi alla luce delle nuove indagini», in La Sicilia in età arcaica. Dalle apoikiai al 480 a.C. Contributi dalle recenti indagini archeologiche, $\mathrm{R}$. Panvini et L. Sole (éds.), Palermo 2009, p. 75-77.

Frasca, M., Leontinoi. Archeologia di una colonia greca, Roma 2009 (= Frasca, Leontinoi).

Freitag, K., Der Golf von Korinth. Historisch-topographische Untersuchungen von der Archaik bis in das erste Jh. v. Chr., München 2005 (= Freitag, Der Golf von Korinthos).

French, A., «Solon and the Megarian Questions », JHS 77, 1957, p. 238-246.

Frisch, P. (éd.), Die Inschriften von Lampsakos, Bonn 1978 (IK, 6).

Fröhlich, P., Les cités grecques et le contrôle des magistrats (IV ${ }^{e} I^{e r}$ siècle avant J.-C.), Genève 2004.

Frolov, E.D., «Les Mariandyniens d'Héraclée (les relations entre les colons grecs et les tribus indigènes dans l'aire de la colonisation dorienne)», in La situation démographique dans la région de la mer Noire durant la période de la grande colonisation grecque, Tbilisi 1981, p. 22-33 (en russe).

Frost, F. J., «The Athenian Military before Cleisthenes », Historia 33, 1984, p. 283-294. Frost, F. J., «Solon and Salamis, Peisistratos and Nisaia», AncW 30, 1999, p. 133-139.

Frye, R. N., The History of Ancient Iran, Munich 1984.

Fusaro, D., «Note di architettura domestica greca nel periodo tardo-geometrico ed arcaico», DdA N. S. 4, 1982, p. 5-30.

Gabelko, O.L., «Zur Lokalisierung und Chronologie der asiatischen Besitzungen von Byzanz», OTerr 2, 1996, p. 121-128.

Gabrici, E., «Il santuario della Malophoros a Selinunte», MAL 32, 1927, col. 6-419. 
Gabrielsen, V., «Trade and Tribute: Byzantion and the Black Sea Straits», in The Black Sea in Antiquity. Regional and Interregional Economic Exchanges, Black Sea Studies 6, V. Gabrielsen et J. Lund (éds.), Aarhus 2007, p. 287-324.

Gagarin, M., Writing Greek Law, Cambridge 2008.

Gallavotti, C., «Scritture arcaiche della Sicilia e di Rodi», Helikon 15-16, 1975-1976, p. 71-117.

Gallo, L., «Problemi istituzionali di Entella», in Seconde giornate internazionali di studi sull'area elima (Gibelina, 22-26 ottobre 1994). Atti, vol. II, Pisa-Gebellina 1997, p. 771-789.

Gallo, L., «Per un riesame dei rapporti tra Segesta e Selinunte», in Terze giornate internazionali di studi sull'area elima (Gebellina, Erice, Contessa Entellina, 23-26 ottobre 1997). Atti, S. De Vido (éd.), Pisa-Gibellina 2000, p. 517-531.

Gallotta, S., «Tra integrazione ed emarginazione: gli indigeni nelle poleis greche del Mar Nero », in Serta antiqua et mediaevalia VII. Il cittadino, lo straniero, il barbaro, fra integrazione ed emarginazione nell'antichità. Atti del I incontro internazionale di storia antica (Genova 22-24 maggio 2003), M. G. Angeli Bertinelli et A. Donati (éds.), Roma 2005, p. 427-436.

Garnsey, F. D. A., Famine and Food Supply in the Graeco-Roman World, Cambridge 1988.

Gauthier, P., «Métèques, périèques et paroikoi: bilan et points d'interrogation », in L'étranger dans le monde grec. Actes du colloque organisé par l'Institut d'études anciennes, Nancy 1987, Nancy 1988, p. 23-46 (= Études d'histoire et d'institutions grecques. Choix d'écrits, Genève 2011, p. 55-77).

Gavrilov, A. K., «Les deux patries de Théognis », Hyperboreus 6, 2000, p. 279-295 (en russe).

Gebhard, E. R., «The Early Stadium at Isthmia and the Founding of the Isthmian Games », in Proceedings of an International Symposium on the Olympic Games (5-9 september 1988), W. Culson et H. Kyrieleis (éds.), Athens 1992, p. 73-79.

Gehrke, H.-J., Stasis. Untersuchungen zu den inneren Kriegen in den griechischen Staaten des 5. und 4. Jahrhunderts v. Chr., München 1985.

Geissau, H. von, s.v. «Zeuxippos» 1, RE XIX A, 1972, col. 379.

Georgoudi, S., «Les Douze Dieux et les autres dans l'espace cultuel grec», Kernos 11, 1998, p. 73-83.

Gerasimov, T., «Monnaies autonomes inédites de Mésambria sur la mer Noire», $B M N B$ 1, 1950, p. 23-34.

Gerber, D.E., Greek Iambic Poetry from the Seventh to the Fifth Century BC, CambridgeLondon 1999.

Gercke, A., «Zur Geschichte des ältesten griechischen Alphabets», Hermes 41, 1906, p. $540-561$.

Gernet, L., Recherches sur le développement de la pensée juridique et morale en Grèce (étude sémantique), Paris 1917.

Geyer, F., s.v. «Skiradion», RE III A, 1927, col. 533.

Ghinatti, F., «Le organizzazioni civiche siceliote», Kokalos 46, 1, 2000 (2004), p. 31-73.

Giangiulio, M., «Greci e non-Greci in Sicilia alla luce dei culti e delle leggende di Eracle», in Modes de contacts et processus de transformation dans les sociétés anciennes (Actes du colloque de Cortone, mai 1981), Pise-Rome 1983, p. 785-845. 
Giangiulio, M., Memorie coloniali, Hesperìa, 27: studi sulla grecità di Occidente, Roma 2010.

Giesen, K., «Plutarchs Questiones Graecae und Aristoteles’ Politien», Philologus 60, 1901, p. 446-471.

Giglio, R., «Selinous. Recenti attività di ricerca archeologica», in La Sicilia in età arcaica.

Dalle apoikiai al 480 a.C. Contributi dalle recenti indagini archeologiche, $\mathrm{R}$. Panvini et L. Sole (éds.), Palermo 2009, p. 209-212.

Giovannini, A., Les relations entre États dans la Grèce antique du temps d'Homère à l'intervention romaine (ca. 700-200 av. J.-C.), Historia Einzelschriften 193, Stuttgart 2007, p. 407.

Giuliani, A., «Il sacrilegio ciloniano : tradizioni e cronologia», Aevum 73, 1999, p. 21-42. Glew, D., «Nicomedes' Name», EA 38, 2005, p. 131-139.

Gneisz, D., Das antike Rathaus. Das griechische Bouleuterion und die frührömische Curia, Wien 1990.

Godart, L., De Caro, S. (éds.), Nostoi. Capolavori ritrovati (Roma, Pallazo del Quirinale, 21 dicembre 2007-2 marzo 2008), Loreto 2007.

Gökyildirim, T., «Vth c. B.C. Coin Hoard from Thrace - Örcünlü (1970)», in Stephanos nomismatikos. Edith Schönert-Geiss zum 65. Geburtstag, Berlin 1998, p. 279-293.

Gomme, A. W., Andrews, A., Dover, K. J., A Historical Commentary on Thucydides, IV, Oxford 1970.

Graham, A. J., Colony and Mother City in Ancient Greece, Manchester 1964 (= Graham, Colony).

Graham, A. J., «The Colonial Expansion of Greece», in Cambridge Ancient History ${ }^{2}$, III, 3, J. Boardman et N. G. L. Hammond (éds.), Cambridge 1982, p. 83-162 (= Graham, Colonial Expansion).

Graham, A. J., «The Western Greeks », in Cambridge Ancient History², III, 3, J. Boardman et N. G. L. Hammond (éds.), Cambridge 1982, p. 163-195.

Graham, A. J., «Megara Hyblaea and the Sicels», in A. J. Graham, Collected Papers on Greek Colonisation, Leiden-Boston-Köln 2001,p. 149-164 (=in LocalEthno-political Entities of the Black Sea Area in the $7^{\text {th }}-4^{\text {th }}$ Centuries B. C. Materials of the $4^{\text {th }}$ All Union Symposium dedicated to the Problems of the Ancient History of the Black Sea Littoral Tsqaltubo-Vani-1985, Tbilisi 1988, p. 304-321;=Graham,Megara Hyblaea).

Graindor, P., «Inscriptions grecques (Athènes, Mégare, Ténos)», RA, 1917, 6, p. 1-67.

Gras, M., «Nécropole et histoire: quelques réflexions à propos de Mégara Hyblaea», Kokalos 21, 1975, p. 37-53.

Gras, M., «Ricerche sul pianoro meridoniale dell'abitato di Megara Hyblaea», Kokalos 30-31, 1984-1985, p. 801-804 (= Gras, Ricerche).

Gras, M., Trafics tyrrhéniens archaïques, Rome 1985.

Gras, M., «Aspects de la recherche sur la colonisation grecque. À propos du Congrès d'Athènes. Notes de lecture», RBPh 64, 1986, p. 5-21.

Gras, M., «La Méditerranée occidentale, milieu d'échanges. Un regard historiographique», in Les Grecs et l'Occident. Actes du colloque de la Villa Kérylos (1991), Collection de l'École française de Rome 208, Rome 1995, p. 109-121.

Gras, M., «Mégara Hyblaea avant Augusta. Une fontaine dans l'histoire», in «Alla Signorina >. Mélanges Noëlle de La Blanchardière, Rome 1995, p. 141-166. 
Gras, M., «Megara Hyblaea et la naissance de l'urbanisme grec en Occident», RPAA 79, 2006-2007, p. 3-11.

Gras, M., Tréziny, H., «Megara Iblea», in La città greca antica. Istituzioni, società e forme urbane, E. Greco (éd.), Roma 1999, p. 251-267 (= Gras, Tréziny, Megara Iblea).

Gras, M., Tréziny, H., «Mégara Hyblaea. Retours sur l'agora», in Architettura, urbanistica, società nel mondo antico. Giornata di studi in ricordo di Roland Martin, Tekmeria 2, Paestum 2001, p. 51-63.

Gras, M., Tréziny, H., «Mégara Hyblaea: le domande e le risposte», in Alle origini della Magna Grecia. Mobilità, migrazioni, fondazioni. Atti del cinquantesimo convegno di studi sulla Magna Grecia (Taranto, 1-4 ottobre 2010), Taranto 2012, p. 1133-1146.

Gras, M., Tréziny, H., Broise, H., Mégara Hyblaea. 5, La ville archaïque: l'espace urbain d'une cité grecque de Sicile orientale, Rome 2005 (= Mégara 5).

Greco, E., Compte rendu de T. Hölscher, Öffentliche Räume in frühen griechischen Städten, Heidelberg 1998, Gnomon 73, 2001, p. 333-336.

Greco, E., «On the Origin of the Western Greek Poleis», Ancient West \& East 10, 2011, p. 233-242.

Grimal, A.P. et al., «Neutron Activation and X-Ray Analysis of «Thapsos Class» Vases. An Attempt to Identify their Origin », Journal of Archaeological Science 7, 1980, p. 228-229.

Groag, E., Die römischen Reichsbeamten von Achaia bis auf Diokletian, Wien-Leipzig 1939.

Groningen, B. A. van, Aristote: Le second livre de l'Économique, Leyde 1933.

Groningen, B.A. van, Theognis: le premier livre, Amsterdam 1966 (= Van Groningen, Theognis).

Grotta, C., Zeus Meilichios a Selinunte, Roma 2010.

Gruben, G., «Das Quellhaus von Megara», AD 19, 1964, p. 37-41.

Gschnitzer, F., «Zwischen Denkmal und Urkunde. Kaiserzeitliche Neuerungen im Formular der Psephismata», in E fontibus haurire. Beiträge zur römischen Geschichte und zu ihren Hilfswissenschaften, R. Günther et S. Rebenich (éds.), Paderborn 1994, p. 281-294.

Guarducci, M., «Gli alfabeti della Sicilia arcaica», Kokalos 10-11, 1964-1965, p. 465488.

Guarducci, M., «Note di epigrafia selinuntina arcaica », Kokalos 12, 1966, p. 179-199.

Guarducci, M., Epigrafia greca, I-IV, Roma 1967-1978 (= Guarducci, Epigrafia gr.).

Guarducci, M., «Note di epigrafia sepolcrale», RAL 25, 1970, p. 389-402.

Guarducci, M., «Epigrafi arcaiche di Siracusa e di Megara Iblea », ArchClass 38-40, 1986 1988, p. 1-26.

Gudeman, A., s.v. «Hellanikos» 7, RE VIII, 1913, col. 104-155.

Guglielmino, L. M., «La necropoli di Entella», in Nécropoles et sociétés antiques (Grèce, Italie, Languedoc), J. de la Genière (éd.), Naples 1994, p. 203-219.

Gullini, G., «Documenti della cultura greca in Occidente durante il primo arcaismo (a proposito di Megara Hyblaea)», PP 183, 1978, p. 427-469.

Gullini, G., «L'architettura templare greca in Sicilia del primo arcaismo alla fine del V secolo", in Il tempio greco in Sicilia. Architettura e culti. Atti della $1^{a}$ riunione scientifica della Scuola di perfezionamento in archeologia classica dell'Università 
di Catania (Siracusa, 24-27 novembre 1976), Cronache di Archeologia 16/1977, Catania 1980, p. 21-42.

Gullini, G., «Il tempio E1 e l'architettura protoarcaica di Selinunte», in Rizza (éd.), Insediamenti colon. gr., p. 52-61, 72-74.

Gullini, G., «L'architettura», in SIKANIE. Storia e civiltà della Sicilia antica, G. Pugliese Carratelli (éd.), Milano 1986, p. 415-491.

Güngerich, R., Die Küstenbeschreibung in der griechischen Literatur ${ }^{2}$, Orbis antiquus, Heft 4, Münster 1975.

Guzzo, P.G., Fondazioni greche. L'Italia meridionale e la Sicilia (VIII e VII sec. a. C.), Roma 2011.

Gyuzelev, M., The West Pontic Coast between Emine Cape and Byzantion during the First Millennium BC, Burgas 2008.

Haas, C.J., «Athenian Naval Power before Themistocles», Historia 34, 1985, p. 2946.

Habicht, C., s.v. «Prusias» 1, RE XXIII, 1, 1957, col. 1086-1107.

Habicht, C., Gottmenschentum und griechische Städte ${ }^{2}$, München 1970 (= Habicht, Gottmenschentum ${ }^{2}$ ).

Habicht, C., s.v. «Zipoites» 1, RE XIX A, 1972, col. 448-455.

Habicht, C., Pausanias unde seine Beschreibung Griechenlands, München 1985.

Habicht, C., «Personenkundliches», in Festschrift für Nikolaus Himmelmann, H.-U. Cain et al. (éds.), Mainz am Rhein 1989, p. 321-325.

Habicht, C., Athènes hellénistique. Histoire de la cité d'Alexandre le Grand à Marc Antoine $^{2}$, traduction M. et D. Knoepfler, Paris 2006 (= Habicht, Athènes ${ }^{2}$ ).

Halliday, W.R., The Greek Questions of Plutarch, Oxford 1928 (= Halliday, Gr. Questions).

Hallof, K., Herrmann, K., Prignitz, S., «Alte und neue Inschriften aus Olympia I», Chiron 42, 2012, p. 213-238.

Hammond, N. G.L., «The Lycurgean Reform at Sparta», JHS 70, 1950, p. $42-64$ (= Studies in Greek History, Oxford 1973, p. 47-90).

Hammond, N. G. L., «The Heraeum at Perachora and Corinthian Encroachment », ABSA 49, 1954, p. 93-102 (= Hammond, Heraeum).

Hammond, N.G.L., «The Main Road from Boeotia to the Peloponnese through the Northern Megarid », ABSA 49, 1954, p. 103-122 (= Studies in Greek History, Oxford 1973, p. 417-446; = Hammond, Main Road).

Hammond, N. G.L., «The Peloponnese», in Cambridge Ancient History ${ }^{2}$, III, 3, J. Boardman et N. G. L. Hammond (éds.), Cambridge 1982, p. 321-359 (= Hammond, Peloponnese).

Hanell, K., Das Menologium des Liber glossarum, K. Humanistika Vetenskapssamfundets i Lund Årsberättelse (Bulletin de la société royale des lettres de Lund) 1931-1932, II, Lund 1932.

Hanell, K., Megarische Studien, Lund 1934 (= Hanell, Megarische Studien).

Hans, L.-M., Karthago und Sizilien. Die Entstehung und Gestaltung der Epikratie auf dem Hintergrund der Beziehungen der Karthager zu den Griechen und den nichtgriechischen Völkern Siziliens (VI.-III. Jahrhundert v. Chr.), Hildesheim et al. 1983. 
Hansen, P.A. (éd.), Carmina epigraphica Graeca saecolorum VIII-V a.Chr.n., BerlinNew York 1983.

Hansen, M.H., «Kome. A Study in How the Greek Designated and Classified Settlements which were not Poleis», in Studies in the Ancient Greek Polis, M.H. Hansen et K. Raaflaub (éds.), Historia Einzelschriften 95, Stuttgart 1995, p. 45-81.

Hansen, M.H., «The Use of Sub-Ethnics as Part of the Name of a Greek Citizens of the Classical Period: the Full Name of a Greek Citizen», in Once Again: Studies in the Ancient Greek Poleis, T.H. Nielsen (éd.), Stuttgart 2004, p. 117-129.

Hansen, M.H., Polis. An Introduction to the Ancient Greek City-State, Oxford 2006.

Hansen, M.H., Nielsen, T.H. (éds.), An Inventory of Archaic and Classical Poleis, Oxford 2004 [= Hansen-Nielsen (éds.), Inventory].

Harding, P., The Story of Athens. The Fragments of the Local Chronicles of Attika, London-New York 2008.

Harrison, E., Studies in Theognis: together with a Text of the Poems, Cambridge 1902.

Harter-Uibopuu, K., Das zwischenstaatliche Schiedsverfahren im achäischen Koinon, Köln et al. 1998.

Head, B. V., Historia Numorum. A Manual of Greek Numismatics ${ }^{2}$, Oxford 1911 (réimpr. London 1963; = Head, $\boldsymbol{H} \boldsymbol{N}^{2}$ ).

Heath, R. M., «Proxeny Decrees from Megara», ABSA 19, 1912-1913, p. $82-88$ (= Heath, Proxeny Decrees).

Heckenbach, J., s.v. «Kalchas», RE X, 1919, col. 1552-1555.

Hegyi, D., «Der Ursprung der Aisymneteia», ACD 13, 1977, p. 7-10.

Heiden, J., Die Tondächer von Olympia, Berlin-New York 1995.

Heitsch, E., «Ilias B 557/8», Hermes 96, 1968, p. 641-660.

Helas, S., Selinus II. Die punische Stadt auf der Akropolis, Wiesbaden 2011.

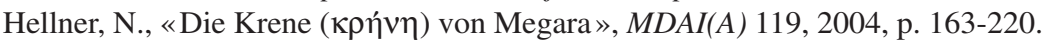

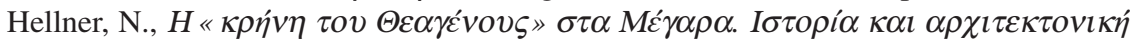

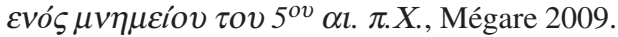

Helly, B., «Arithmétique et histoire. L'organisation militaire et politique des Ioniens en Achaïe à l'époque archaïque», Topoi(Lyon) 7, 1, 1997, p. 207-262.

Hepding, H., s.v. «Hieromnemones », RE VIII, 1913, col. 1490-1496.

Herrmann, P. (éd.), Milet VI. Inschriften von Milet, vol. I-II, Berlin-New York 19971998.

Higbie, C., «The Bones of a Hero, the Ashes of a Politician: Athens, Salamis, and the Usable Past», ClAnt 16, 1997, p. 278-307.

Highbarger, E.L., The History and Civilization of Ancient Megara, Baltimore 1927 (= Highbarger, Megara).

Highbarger, E. L., Compte rendu de Hanell, Megarische Studien, AJPh 58, 1937, p. 118 121.

Highbarger, E.L., «Suidas' Account of Theognis », in Studies presented to D. M. Robinson, vol. II, G. E. Mylonas et D. Raymond (éds.), Saint Louis 1953, p. 635-646.

Hiller von Gaertringen, F., Compte rendu de Hanell, Megarische Studien, DLZ 7, 1935 , col. 282-285.

Hind, J., «Greek and Barbarian Peoples on the Shores of the Black Sea», AR 30, 1983 1984, p. 71-97. 
Hind, J., «Archaeology of the Greeks and Barbarian Peoples around the Black Sea », AR 39, 1992-1993, p. 82-112 (= Hind, Greeks and Barbarian Peoples).

Hind, J., «Megarian Colonization in the Western Half of the Black Sea (Sister- and Daughter-Cities of Herakleia)», in The Greek Colonisation of the Black Sea Area, Historia Einzelschriften 121, G. Tsetskhladze (éd.), Stuttgart 1998, p. 131-152 (= Hind, Megarian Colonization).

Hind, J., «Pomponius Mela on colonies in West and East», in Ancient Greeks West and East, G. R. Tsetskhladze (éd.), Leiden et al. 1999, p. 77-84.

Hinz, V., Der Kult von Demeter und Kore auf Sizilien und in der Magna Grecia, Wiesbaden 1998.

Hirschberger, M., Gynaikōn Katalogos und Megalai Ēhoiai. Ein Kommentar zu den Fragmenten zweier hesiodeischer Epen, Leipzig 2004.

Höfer, O., s.v. «Hippodameia» 1, in Roscher, Lexikon, I, 2, col. 2667-2671.

Holle, J., Megara im mythischen Zeitalter, in Programm des Gymnasiums zu Recklinghausen LI. Schuljahr 1880-1881, Recklinghausen 1881.

Holloway, R. R., «Le monetazioni di Agyrion, Aluntion, Entella, Hipana, Nakone, Stiela», in Le emissioni dei centri siculi fino all'epoca di Timoleonte e i loro rapporti con la monetazione della colonie greche in Sicilia, AIIN, Suppl. 20, Roma 1975, p. 133145.

Holloway, R. R., Compte rendu de Mégara 1, AJA 82, 1978, p. 560-562.

Holloway, R. R., The Archaeology of Ancient Sicily, London-New York 1991 (= Holloway, Anc. Sicily).

Holm, A., Geschichte Siziliens im Altertum, I, Leipzig 1870.

Hope Simpson, R., Lazenby, J.F., The Catalogue of the Ships in Homer's Iliad, Oxford 1970.

Hornblower, S., A Commentary on Thucydides, volume III, Books 5.25-8.109, Oxford 2008.

How, W. W., Wells, J., A Commentary on Herodotus, vol. I-II, Oxford 1912 (réimpr. Oxford 1961).

Huber, S., «Une aire sacrificielle proche du sanctuaire d'Apollon Daphnéphoros à Érétrie. Approches d'un rituel archaïque», in Ancient Greek Cult Practice from the Archaeological Evidence. Proceedings of the Fourth International Seminar on Ancient Greek Cult, organized by the Swedish Institute at Athens, 22-24 October 1993, R. Hägg (éd.), Stockholm 1998, p. 141-155.

Huber, S., L'Aire sacrificielle au nord du sanctuaire d'Apollon Daphnéphoros, vol. I-II, Eretria. Fouilles et recherches XIV, Montreux 2003.

Hudson-Williams, T., «Theognis and his Pomes», JHS 23, 1903, p. 1-23.

Hughes, D. D., «Hero Cult, Heroic Honnors, Heroic Dead: Some Developments in the Hellenistic and Roman Periods », in Ancient Greek Hero Cult. Proceedings of the Fifth International Seminar on Ancient Greek Cult (Göteborg University, 21-23 April 1995), R. Hägg (éd.), Stockholm 1999, p. 167-175.

Humphreys, S. C., «Phrateres in Alopeke, and the Salaminioi », ZPE 83, 1990, p. 243-248. Huxley, G., Compte rendu de Legon, Megara Pol. Hist., CR 32, 2, 1982, p. 227-230.

Hyde, W.W., s.v. «Orsippos», RE XVIII, 2, 1942, col. 1420-1422.

Iacovella, A., «Les premières fouilles à Mégara Hyblaea (1860-1897)», MEFRA 113, 2001, p. 401-469. 
Imhoof-Blumer, F., «Nymphen und Chariten auf griechischen Münzen», JIArchNum 11, 1908, p. 1-213.

Imhoof-Blumer, F., «Fluss- und Meergötter auf griechischen und römischen Münzen », SNR 23, 1923, p. 173-421.

Immerwahr, H. R., Attic Script. A Survey, Oxford 1990.

Isaac, B.H., The Greek Settlements in Thrace until the Macedonian Conquest, Leiden 1986 (= Isaac, Gr. Settlem. in Thrace).

Isler, H.P., «Les nécropoles de Sélinonte», in Nécropoles et sociétés antiques (Grèce, Italie, Languedoc), J. de la Genière (éd.), Naples 1994, p. 165-168.

Isler, H.P., «Indigeni e Greci nella Sicilia Occidentale : le più antiche importazioni greche a Monte Iato», in KOINA: miscellanea di studi archeologici in onore di Piero Orlandini, Milano 1999, p. 143-156.

Isler, H.P., Monte Iato. Guida archeologica, Palermo 2000.

Ivantchik, A.I., Les Cimmériens au Proche-Orient, Fribourg-Goettingue 1993.

Ivantchik, A., «Les Thraces et les Mariandynes dans la tradition locale d'Héraclée du Pont», in The Thracian World at the Crossroads of Civilizations. Proceedings of the Seventh International Congress of Thracology (Constanta-Mangalia-Tulcea, 20 26 May 1996), vol. I, P. Roman et al. (éds.), Bucarest 1997, p. 329-337.

Ivantchik, A. I., Am Vorabend der Kolonisation. Das nördliche Schwarzmeergebiet und die Steppennomaden des 8.-7. Jhs. v. Chr. in der klassischen Literaturtradition. Mündliche Überlieferung, Literatur und Geschichte, Moskau-Berlin 2005 (= Ivantchik, Am Vorabend der Kolonisation).

Jaccottet, A.-F., Choisir Dionysos. Les associations dionysiaques ou la face cachée du dionysisme, vol. I-II, Zurich 2003.

Jackson, A. H., «Argos' Victory over Corinth», ZPE 132, 2000, p. 295-311.

Jacob, C., «L'œil et la mémoire: sur la Périégèse de la Terre habitée de Denys », in Arts et légendes d'espace. Figures du voyage et rhétoriques du monde, C. Jacob et F. Lestringant (éds.), Paris 1981, p. 23-97.

Jacoby, F., Compte rendu de R. Güngerich (éd.), Dionysii Byzantii, Anaplus Bospori una cum scholiis X saeculi, Berlin 1927, Gnomon 4, 1928, p. 262-268.

Jacoby, F., Atthis. The Local Chronicles of Ancient Athens, Oxford 1949.

Jacquemin, A., Offrandes monumentales à Delphes, Athènes-Paris 1999.

Jacquemin, A., Mulliez, D., Rougemont, D., Choix d'inscriptions de Delphes traduites et commentées, Paris 2012.

Jameson, M. H., Jordan, D. R., Kotansky, R. D., A lex sacra from Selinous, Greek, Roman, and Byzantine Monographs 11, Durham 1993 (= Jameson, Jordan, Kotansky, Lex sacra).

Janin, R., Constantinople byzantine. Développement urbain et répertoire topographique ${ }^{2}$, Paris 1964 (= Janin, Constantinople ${ }^{\mathbf{2}}$ ).

Janke, M., Untersuchungen zu Memnon von Herakleia, Diss. Würzburg 1963.

Jeffery, L. H., «Further Comments on Archaic Greek Inscriptions », ABSA 50, 1955, p. $67-$ 84.

Jeffery, L. H., «Demiourgoi in the Archaic Period», ArchClass 25-26, 1973-1974, p. 319330.

Jeffery, L.H., The Local Scripts of Archaic Greece ${ }^{2}$, Oxford 1990 (= Jeffery, LSAG $^{\mathbf{2}}$ ). 
Jefremow, N., «Der rhodisch-byzantinische Krieg von 220 v. Chr. : ein Handelskrieg im Hellenismus?», MBAH 24, 1, 2005, p. 51-98.

Johansen, H.F., «A Poem by Theognis (Thgn. 19-38), Part II», $C \& M 44,1993$, p. 5-29.

Johnston, S. I., Restless Dead. Encounters between the Living and the Dead in Ancient Greece, Berkeley et al. 1999.

Jones, A.H.M., The Cities of the Eastern Roman Provinces ${ }^{2}$, Oxford 1971.

Jones, N.P., «The Order of the Dorian Phylai », CPh 75, 3, 1980, p. 197-215.

Jones, N. F., Public Organization in Ancient Greece. A Documentary Study, Philadelphia 1987 (= Jones, Public Organization).

Jones, N. F., «Enrollement Clauses in Greek Citizenship Decrees », ZPE 87, 1991, p. $97-$ 110 (= Jones, Enrollement Clauses).

Jones, N.F., «The Athenian Phylai as Association, Disposition, Function and Purpose», Hesperia 64, 1995, p. 503-542.

Jourdain-Annequin, C., Héraclès aux portes du soir. Mythe et histoire, Paris 1989.

Jourdain-Annequin, C., «Être un Grec en Sicile : le mythe d'Héraclès », Kokalos 34-35, 1, 1993, p. 143-166.

Jourdain-Annequin, C., «I Greci - Les Grecs», in Ethne e religioni nella Sicilia antica. Atti del convegno (Palermo, 6-7 dicembre 2000), Kokalos, Suppl. 18, P. Anello et al. (éds.), Roma 2006, p. 181-203.

Kaldellis, A., «Christodoros on the Statues of Zeuxippos Baths: A New Reading of the Ekphrasis », GRBS 47, 2007, p. 361-383.

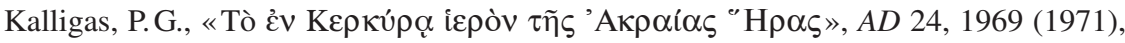
$\mathrm{A}^{\prime}$, p. 51-58.

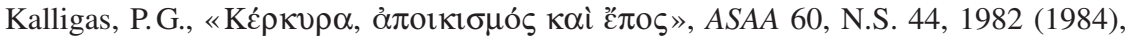
p. $57-68$.

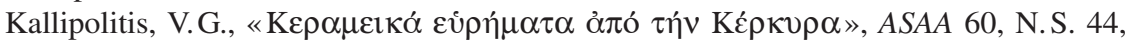
1982 (1984), p. 69-76.

Kaloyéropoulou, A. G., «Un nouveau décret de proxénie de Mégare», AAA 7, 1, 1974, p. 138-148 (= Kaloyéropoulou, Décret de Mégare).

Karagöz, Ş., « Khrysopolis'in koloni kenti olarak tarihte yeri », in Gün Işı̆̌̆ında İstanbul'un 8000 Yıll-Marmaray, Metro, Sultanahmet Kazıları, Istanbul 2007, p. 32-53 (= Karagöz, Khrysopolis).

Karagöz, Ş., «Byzance. Les périodes archaïque, hellénistique et romaine», in De Byzance à Istanbul: un port pour deux continents, Paris 2009, p. 29-47.

Karayotov, I., «La $\chi \omega ́ \rho \alpha$ de Mesambria Pontika d'après les données archéologiques et numismatiques », in Studies on Settlement Life in Ancient Thrace. Proceedings of the IIIrd International Symposium «Cabyle», 17-21 Mai 1993, D. Draganov (éd.), Jambol 1994, p. 283-292.

Karayotov, I., The Coinage of Mesambria, vol. I, Silver and Gold Coins of Mesambria, Thracia Pontica Series IV, Centre of Underwater Archaeology Sozopol, Veliko Tărnovo 1994 (= Karayotov, Coinage of Mesambria I).

Karayotov, I., The Coinage of Mesambria, vol. II, Bronze Coins of Mesambria, Sozopol 2009 (= Karayotov, Coinage of Mesambria II).

Kazdan, A., «<Constantin imaginaire〉. Byzantin Legends of the Ninth Century about Constantine the Great», Byzantion 57, 1987, p. 196-250. 
Kearns, E., The Heroes of Attica, London 1989 (= Kearns, Heroes).

Kearns, E., «Saving the City», in The Greek City from Homer to Alexander, O. Murray et

S. Price (éds.), Oxford, 1990, p. 323-344.

Kent, J.H., Corinth, vol. VIII, part III. The Inscriptions (1926-1950), Princeton 1966.

Kerény, K., «Le divinità e i templi a Selinunte», Kokalos 19, 1966, p. 3-7.

Kiepert, H., Neuer Atlas von Hellas und den hellenischen Colonien, Berlin 1879.

Kirk, G. S., The Iliad: A Commentary, I, Cambridge 1985.

Kirsten, E., s.v. «Polichne», RE XXI, 2, 1952, col. 1371-1372.

Knoepfler, D., «Autour d'une stèle mégarienne», in Mélanges d'histoire ancienne et d'archéologie offerts à Paul Collart, Lausanne 1976, p. 269-276.

Knoepfler, D., «La royauté grecque», REG 99, 1986, p. 332-341.

Knoepfler, D., «Le calendrier des Chalcidiens de Thrace. Essai de mise au point sur la liste et l'ordre des mois eubéens », JS, 1989, p. 23-59.

Knoepfler, D., «Contribution à l'épigraphie de Chalcis », BCH 114, 1990, p. 473-498.

Knoepfler, D., «Le territoire d'Érétrie et l'organisation politique de la cité (dêmoi, chôroi, phylai)», in The Polis as an Urban Centre and as a Political Community (Symposium, August 29-31 1996), Acts of the Copenhagen Polis Centre 3, M. H. Hansen (éd.), Copenhagen 1997, p. 352-449.

Knoepfler, D., «L'épigraphie de la Grèce centro-méridionale (Eubée, Béotie, Phocide et pays voisins, Delphes): publications récentes, documents inédits, travaux en cours », in XI Congresso Internazionale di Epigrafia Greca e Latina (Roma 18-24 settembre 1997). Atti I, Roma 1999, p. 229-255.

Knoepfler, D. (éd.), Décrets érétriens de proxénie et de citoyenneté, Eretria. Fouilles et recherches XI, Lausanne 2001.

Knoepfler, D., «Trois historiens hellénistiques: Douris de Samos, Hiéronymos de Cardia, Philochore d'Athènes", in Histoire et historiographie dans l'Antiquité. Actes du XI ${ }^{e}$ colloque de la Villa Kérylos (Beaulieux-sur-Mer, 13-14 octobre 2000), Cahiers de la Villa Kérylos 11, J. Leclant et F. Chamoux (éds.), Paris 2001, p. 25-44.

Knoepfler, D., «L'exercice de la magistrature fédérale béotienne par des «étrangers » à l'époque impériale: conséquence de l'extension du Koinon en dehors des frontières de la Béotie ou simple effet d'une multi-citoyenneté individuelle?», in Patrie d'origine et patries électives: les citoyennetés multiples dans le monde grec d'époque romaine. Actes du colloque international de Tours, 6-7 novembre 2009, A. Heller et A.-V. Pont (éds.), Paris 2012, p. 223-247.

Kolf, M.C. van der, s.v. «Skiron», RE III A, 1927, col. 537-545.

Kontoleon, N.M., «Zur Gründung von Naxos und Megara», in Europa. Studien zur Geschichte und Epigraphik der frühen Aegaeis. Festschrift für Ernst Grumach, W.C. Brice (éd.), Berlin 1967, p. 180-190.

Kotansky, R., Curbera, J., «Unpublished Lead Tablets in the Getty Museum», MediterrAnt 7, 2, 2004, p. 681-691.

Kovalenko, S., Die spätklassische Münzprägung von Chersonesos Taurica, Berlin 2008.

Kowalski, J.-M., Navigation et géographie dans l'Antiquité gréco-romaine. La terre vue de la mer, Paris 2012.

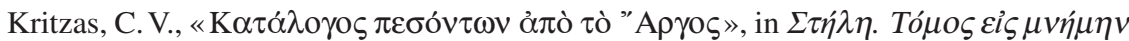

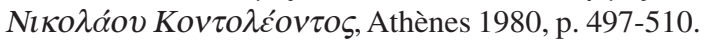




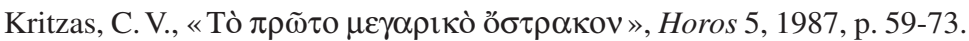

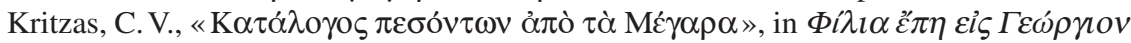

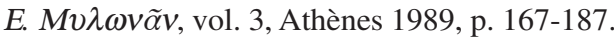

Kritzas, C., «Nouvelles inscriptions d'Argos: les archives des comptes du Trésor sacré (IV s. av. J.-C.)», CRAI, 2006 (2008), 1, p. 397-434.

Kron, U., Die zehn attischen Phylenheroen. Geschichte, Mythos, Kult und Darstellungen, Berlin 1976.

Krumbacher, K., Geschichte der byzantinischen Literatur von Justinian bis zum Ende des oströmischen Reiches (527-1453)², vol. I-II, München 1897 (réimpr. New York 1958).

Kubitschek, W., s.v. «Byzantion», RE III, 1899, col. 1150-1158.

Kunnert, U., Bürger unter sich. Phylen in den Städten des kaiserzeitlichen Ostens, Basel 2012 .

Kustermann Graff, A., «DANIMS 16. Necropoli di Selinunte (necropoli Manicalunga, gruppo di tombe Gaggera)», ASNP serie iii, 21, 1, 1991, p. 101-123.

L'Homme-Wéry, L.-M., «Solon, libérateur d'Éleusis dans les 〈Histoires > d'Hérodote», REG 107, 1994, p. 362-380.

L'Homme-Wéry, L.-M., La perspective éleusienne dans la politique de Solon, Genève 1996 (= L'Homme-Wéry, Solon).

L'Homme-Wéry, L.-M., «Les héros de Salamine à Athènes. Cultes, mythes et intégration politique», in Héros et hérö̈nes dans les mythes et les cultes grecs. Actes du Colloque organisé à l'Université de Valladolid du 26 au 29 mai 1999, V. Pirenne-Delforge et E. Suárez de la Torre (éds.), Liège 2000, p. 333-349 (= L'Homme-Wéry, Les héros de Salamine).

La Genière, (de) J., «Saggi sull' Acropoli di Selinunte. Relazione preliminare», Kokalos 21, 1975, p. 68-107 (= La Genière, Saggi sull'Acropoli).

La Genière, (de) J., «Una divinità femminile sull' acropoli di Segesta ? », Kokalos 32-33, 1976-1977, p. 680-688.

La Genière, (de) J., «Réflexions sur Sélinonte et l'Ouest sicilien », CRAI, 1977, 2, p. 251264 (= La Genière, Sélinonte).

La Genière, (de) J., «Ségeste et l’hellénisme», MEFRA 90, 1978, p. 33-49.

La Genière, (de) J., «Nuove ricerche sulla topografia di Selinunte», RAL 36, 1981, p. 211-217.

La Genière, (de) J., «Sélinonte. Recherches sur la topographie urbaine (1975-1981)», ASNP serie iii, 12, 1, 1982, p. 469-479.

La Genière, (de) J., Rougetet, J., « Recherches sur la topographie de Selinonte. Campagne 1985 », RAL 40, 1985, p. 289-297.

La Rosa, V., «Le popolazioni della Sicilia: Sicani, Siculi, Elimi», in Italia omnium terrarum parens $^{2}$, G. Pugliese Carratelli (éd.), Milano 1991, p. 3-110.

La Rosa, V., «L'ospitalità del re di Sicilia: il Sicano Kokalos ed il Siculo Hyblon », SicGymn N.S. 45, 1992, p. 103-106.

Lacroix, L., Les reproductions de statues sur les monnaies grecques: la statuaire archaïque et classique, Liège 1949.

Lacroix, L., Monnaies et colonisation dans l'Occident grec, Bruxelles 1965 (= Lacroix, Monnaies et colon.).

Lafond, Y., La mémoire des cités dans le Péloponnèse d'époque romaine (II siècle avant J.-C.-III siècle après J.-C.), Rennes 2006. 
Lahr, S. von der, Dichter und Tyrannen im archaischen Griechenland. Das Corpus Theognideum als zeitgenössische Quelle politischer Wertvorstellungen archaischgriechischer Aristokraten, München 1992.

Lambert, S. D., «The Attic Genos Salaminioi and the Island of Salamis », ZPE 119, 1997, p. 85-106.

Lambertz, M., Die griechischen Sklavennamen, in 57. Jahres-Bericht über das k. k. Staatsgymnasium im VIII. Bezirke Wiens für das Schuljahr 1906/1907, Wien 1907.

Lamboley, J.-L., Les Grecs d'Occident. La période archaïque, Paris 1996.

Lambrinudakis, W., Wörrle, M., «Ein hellenistisches Reformgesetz über das öffentliche Urkundenwesen von Paros (mit. Taf. 5-13)», Chiron 13, 1983, p. 283-368.

Lane Fox, R., «Theognis: an Alternative to Democracy», in Alternatives to Athens. Varieties of Political Organization and Community in Ancient Greece, R. Brock et S. Hodkinson (éds.), Oxford 2000, p. 35-51.

Lang, M., «The Kylonian Conspiracy », CPh 62, 1967, p. 243-249.

Langdon, M. K., A Sanctuary of Zeus on Mount Hymettos, Hesperia, Suppl. 16, Princeton 1976.

Laqueur, R., s.v. «Nymphis von Herakleia», RE XVII, 1937, col. 1608-1623.

Laqueur, R., s.v. «Philochoros», RE XIX, 1938, col. 2434-2442.

Laronde, A., Cyrène et la Libye hellénistique, Paris 1987.

Larsen, J.A.O., «The Aetolians and the Cleomenic War», in The Classical Tradition. Literary and Historical Studies in Honor of Harry Caplan, L. Wallach (éd.), IthacaNew York 1966, p. 43-57.

Larsen, J. A. O., Greek Federal States. Their Institutions and History, Oxford 1968.

Latacz, J., Homers Ilias. Gesamtkommentar, München-Leipzig 2003.

Latyshev, V., «La constitution de Chersonèse en Tauride d'après des documents épigraphiques », $B C H$ 9, 1885, p. 265-300 (= Latyshev, Const. de Chersonèse).

Latyshev, V., ПONTIKA, Saint-Pétersbourg 1909.

Lazarenko, I. et al., «The Temple of the Pontic Mother of Gods in Dionysopolis », in Ancient Sacral Monuments in the Black Sea, E. K. Petropoulos et A. A. Maslennikov (éds.), Thessaloniki 2010, p. 13-62.

Lazarov, M., «Notizen zur griechischen Kolonisation am westlichen Schwarzen Meer. Schriftquellen und archäologische Denkmäler», in The Greek Colonisation of the Black Sea Area, Historia Einzelschriften 121, G. Tsetskhladze (éd.), Stuttgart 1998, p. 131-152.

Lazzarini, L., «Monete arcaiche inedite di Selinunte e nuove considerazioni sul tipo della foglia», NAC 32, 2003, p. 11-22.

Lazzarini, M.L., Le formule delle dediche votive nella Grecia arcaica, Roma 1976.

Le Rider, G., «Sur le monnayage de Byzance au IV ${ }^{\mathrm{e}}$ siècle», $R N$ 13, 1971, p. 143-153.

Leake, W. M., Travels in Northern Greece, vol. II, London 1835.

Lebègue, J.A., De oppidis et portibus Megaridis ac Boeotiae in Corinthiaci sinus littore sitis, Paris 1875.

Lefèvre, F., L'Amphictionie pyléo-delphique: histoire et institutions, Athènes-Paris 1998.

Legon, R.P., Megara. The Political History of a Greek City-State to 336 B. C., IthacaLondon 1981 (= Legon, Megara Pol. Hist.). 
Legon, R.P., s.v. «Megara», in Hansen-Nielsen (éds.), Inventory, p. 463-465 (= Legon, Megara).

Lehmann-Haupt, C.F., «Pausanias, Heros Ktistes von Byzanz», Klio 17, 1921, p. 59-66.

Leibundgut Wieland, D., «DANIMS 25. Necropoli di Manicalunga. Tombe della contrada

Timpone Nero (Selinunte)», ASNP serie iii, 25, 1, 1995, p. 189-218.

Leighton, R., «Sicily during the Centuries of Darkness», CArchJ 3, 2, 1993, p. 271-276.

Leighton, R., Sicily before History: An Archaeological Survey from the Palaeolithic to the Iron Age, London 1999 (= Leighton, Sicily before History).

Lejeune, M., «Notes d'épigraphie sicilienne», Kokalos 16, 1970, p. 16-29.

Lenk, B., s.v. «Mesambria» 1, RE XV, 1931, col. 1072-1074.

Lenschau, T., «Forschungen zur griechischen Geschichte im VII. und VI. Jahrhundert v. Chr.», Philologus 91, 1936, p. 278-307, 385-411.

Lepore, E., «Rapporti ed analogie di colonizzazione tra Sicilia e Magna Grecia », Kokalos 14-15, 1968-1969, p. 60-94.

Lepore, E., «La fioritura delle aristocrazie e la nascita della polis », in Storia e civiltà dei Greci. I. Origini e sviluppo della città, Milano 1978, p. 181-253.

Lepore, E., «I Greci in Italia», in Storia della società italiana I. Dalla preistoria all'espansione di Roma, Milano 1981, p. 213-268.

Lepore, E., La Grande Grèce: aspects et problèmes d'une «colonisation» ancienne, Naples 2000 (= Lepore, Grande Grèce).

Leschhorn, W., Gründer der Stadt. Studien zu einem politisch-religiösen Phänomen der griechischen Geschichte, Stuttgart 1984 (= Leschhorn, Gründer).

Leschhorn, W., Antike Ären. Zeitrechnung, Politik und Geschichte im Schwarzmeerraum und in Kleinasien nördlich des Tauros, Historia Einzelschriften 81, Stuttgart 1993.

Lévêque, P., «Le dynamisme d'Érétrie la Rameuse. La genèse précoce d'une cité», MEFRA 101,1989 , p. 739-750.

Lévêque, P., «Les Grecs en Occident», in Les Grecs et l'Occident. Actes du colloque de la Villa Kérylos (1991), Collection de l'École française de Rome 208, Rome 1995, p. 11-17 (= Lévêque, Grecs en Occident).

Lévy, E., «Notes sur la chronologie athénienne au IVe siècle», Historia 27, 1978, p. 513521.

Lewis, D. B., «Symposium and the Polis», in Theognis of Megara. Poetry and the Polis, T. J. Figueira et G. Nagy (éds.), Baltimore-London 1985, p. 176-196.

Lewis, D. M., «Cleisthenes and Attica», Historia 12, 1963, p. 22-40 (= Selected Papers in Greek and Near Eastern History, Oxford 1997, p. 77-98).

Lewis, D. M., «The Origins of the First Peloponnesian War», in Classical Contributions. Studies in honor of M. F. McGregor, G. S. Shrimpton et D. J. McCarger (éds.), Locust Valley N.Y. 1981, p. 71-78 [= Selected Papers in Greek and Near Eastern History, P. J. Rhodes (éd.), Cambridge 1997, p. 9-21].

Lewy, H., s.v. «Periboia» 10, in Roscher, Lexikon, III, 2, col. 1961-1962.

Liddel, P., «The Decree Culture of the Ancient Megarid», CQ 59, 2, 2009, p. 411-436 (= Liddel, Megarid).

Linforth, I. M., Solon the Athenian, Berkeley 1919.

Lohmann, H., «Antike Hirten in Westkleinasien und der Megaris : zur Archäologie der Mediterranen Weidewirtschaft», in Volk und Verfassung im vorhellenistischen 
Griechenland. Beiträge auf dem Symposium zu Ehren von Karl-Wilhelm Welwei in Bochum, 1-2 März 1996, W. Eder et K.-J. Hölkeskamp (éds.), Stuttgart 1997, p. 6388.

Lohmann, H., «Antike Straßen und Saumpfade in Attika und der Megaris », in Stuttgarter Kolloquium zur historischen Geographie des Altertums 7, 1999. Zu Wasser und zu Land. Verkehrswege in der antiken Welt, E. Olshausen et H. Sonnabend (éds.), Stuttgart 2002, p. 109-147.

Lolling, H. G., «Nisäa und Minoa», $\operatorname{MDAI}(A)$ 5, 1880, p. 1-19.

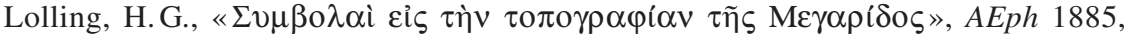
col. 201-216.

Long, C. R., The Twelve Gods of Greece and Rome, Leiden et al. 1987.

Loomis, W.T., «Pausanias, Byzantion and the Formation of the Delian League. A Chronological Note», Historia 39, 1990, p. 487-492.

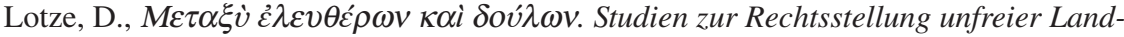
bevölkerungen in Griechenland bis zum 4. Jahrhundert v. Chr., Berlin 1959.

Loukopoulou, L. D., Contribution à l'histoire de la Thrace propontique durant la période archaïque, MELETHMATA 9, Athènes 1989 (=Loukopoulou, Thrace propontique).

Loukopoulou, L., Lajtar, A., s.v. «Byzantion », in Hansen-Nielsen (éds.), Inventory, p. 915-918 (= Loukopoulou-Lajtar, Byzantion).

Loukopoulou, L., Lajtar, A., s.v. « Perinthos », in Hansen-Nielsen (éds.), Inventory, p. 919-921.

Loukopoulou, L., Lajtar, A., s.v. «Selymbria », in Hansen-Nielsen (éds.), Inventory, p. 921-922.

Low, P., «Remembering War in the Fifth-Century Greece: Ideologies, Societies, and Commemoration beyond Democratic Athens », World Archaeology 35, 1, 2003, p. 98 111.

Lubos, M., «Zu einem hellenistischen Grabrelief», in Pontos Euxeinos. Beiträge zur Archäologie und Geschichte des antiken Schwarzmeer- und Balkanraumes. Manfred Oppermann zum 65. Geburtstag, S. Conrad et al. (éds.), Langenweißbach 2006, p. 181-188.

Lungu, V., «La tombe d'un “ $\mathrm{HPO} \Sigma$ et l'organisation de la nécropole d'une cité milésienne du Pont-Euxin: le tumulus T-A95 d'Orgamé», Talanta 32-33, 2000-2001 (2002), p. 171-188 (= in Actes du III Colloque international d'archéologie funéraire, Tulcea, 1997, Tulcea 2000, p. 67-86).

Lupu, E., Greek Sacred Law. A Collection of New Documents (NGSL), Leiden-Boston 2005. Luraghi, N., «Fonti e tradizioni nell' archaiologia siciliana (per una rilettura di Thuc. 6, 25)», in Hesperìa, 2 : studi sulla grecità di Occidente, L. Braccesi (éd.), Roma 1991, p. 41-62.

Luraghi, N., Tirannidi arcaiche in Sicilia e Magna Grecia da Panezio di Leontini alla caduta dei Dinomenidi, Firenze 1994.

Maass, E., «Mythische Kurznamen», Hermes 23, 1888, p. 613-621.

Mack, G. R., Carter, J.C. (éds.), Crimean Chersonesos: City, Chora, Museum, and Environs, Austin 2003.

Maele, S. van de, «Le site d'Ereneia et la frontière attico-mégariennne», Phoenix 34, 1980, p. 153-159 (= Van de Maele, Ereneia). 
Maele, S. van de, Compte rendu de Legon, Megara Pol. Hist., EMC 29, 1985, p. 169-171. Maele, S. van de, «La route antique du port mégarien de Pagai à la forteresse d'Aigosthènes », EMC 33, 1989, p. 183-188.

Maele, S. van de, «Le réseau mégarien de défense territoriale contre l'Attique à l'époque classique ( $\mathrm{V}^{\mathrm{e}}$ et $\mathrm{IV}^{\mathrm{e}}$ s. av. J.-C.)», in Fortificationes Antiquae, S. van de Maele et J. M. Fossey (éds.), Amsterdam 1992, p. 93-107.

Maele, S. van de, «Pausanias et la route de Mégare vers Pagai et Éréneia», CEA 38, 2001, p. 113-118.

Magie, D., Roman Rule in Asia Minor to the End of the Third Century after Christ, I-II, Princeton 1950 (= Magie, Roman Rule).

Mainardi, M., «Mesambria Pontica e i Traci», Acme 64, 3, 2011, p. 3-26.

Makarov, I., «La <Première Eleutheria〉 de Chersonèse Taurique dans les sources épigraphiques», VDI 2005, 2, p. 82-93 (en russe).

Makarov, I., «Nouvelles inscriptions de Chersonèse Taurique », VDI 2006, 4, p. 83-97 (en russe).

Makarov, I., «La ville libre grecque et l'administration romaine: le cas de Chersonèse Taurique», in Une koinè pontique. Cités grecques, sociétés indigènes et empires mondiaux sur le littoral nord de la mer Noire (VII ${ }^{e}$ s. a.C.-III ${ }^{e}$ s. p. C.), A. Bresson et al. (éds.), Bordeaux 2007, p. 327-342.

Malkin, I., «What's in a Name? The Eponymous Founder of Greek Colonies », Athenaeum 63, 1985, p. 114-130.

Malkin, I., Religion and Colonisation in Ancient Greece, Leiden et al. 1987 (= Malkin, Religion and Colon.).

Malkin, I., «Categories of Early Greek Colonization : the Case of the Dorian Aegean », in Antonetti (éd.), Il dinam. della colon. gr., p. 25-38.

Malkin, I., «Exploring the Validity of the Concept of <Foundation〉: a Visit to Megara Hyblaia», in Oikistes. Studies in Constitutions, Colonies, and Military Power in Ancient World. Oferred in Honor of A. J. Graham, V. B. Gorman et E. W. Robinson (éds.), Leiden-Boston-Köln 2002, p. 195-225 (= Malkin, Megara Hyblaia).

Malkin, I., «Networks and the Emergence of Greek Identity », in Mediterranean Paradigms and Classical Antiquity, I. Malkin (éd.), London-New York 2005, p. 56-74 (= Malkin, Networks).

Malkin, I., «Foundations », in A Companion to Archaic Greece, K. A. Raaflaub et H. van Wees (éds.), Malden-Oxford 2009, p. 373-394 (= Malkin, Foundations).

Malkin, I., A Small Greek World. Networks in the Ancient Mediterranean, Oxford 2011 (= Malkin, A Small Greek World)

Malkin, I., Shmueli, N., «The <City of the Blind > and the Founding of Byzantium », MHR 3, 1988, p. 21-36 (= Malkin-Shmueli, City of the Blind).

Mallwitz, A., Olympia und seine Bauten, München 1972.

Manganaro, G., «Ricerche di antichità e di epigrafia siceliota», ArchClass 17, 2, 1965 , p. $183-220$.

Manganaro, G., «Epigrafia e istituzioni di Creta», in Antichità cretesi. Studi in onore di Doro Levi, vol. II, Cronache di Archeologia 13/1974, Catania 1978, p. 39-58.

Manganaro, G., «Studi di epigrafia siceliota», $R A L$ serie ix, 8, 1, 1996, p. 27-63 (= Manganaro, Studi di epigrafia). 
Manganaro, G., «Mondo religioso greco e mondo <indigeno» in Sicilia», in Antonetti (éd.), Il dinam. della colon. gr., p. 71-82.

Manganaro, G., «Epigrafia greca dell'Occidente», in XI Congresso Internazionale di Epigrafia Greca e Latina (Roma 18-24 settembre 1997). Atti I, Roma 1999, p. 147-156.

Manganaro, G., in «L'epigrafia greca di Sicilia», in Sicilia Epigraphica. Atti del convegno (Erice, 15-18 Ottobre 1998), ASNP serie iv, Quaderni 2, M. I. Gulletta (éd.), Pisa 1999, p. 417-424.

Manganaro, G., «Hybla Megala (Heraia) e Hybla Geleatis (Etnea)», in Un ponte fra l'Italia e la Grecia. Atti del simposio in onore di Antonino di Vita (Ragusa, 13-15 febbraio 1998), A. di Vita (éd.), Padova 2000, p. 149-154 (= Manganaro, Hybla).

Manganaro, G., «Iscrizioni greche del V sec. a.C. della Sicilia», ZPE 144, 2003, p. $147-$ 156.

Manganaro, G., «Una defixio giudiziaria in alfabeto selinuntino», REG 116, 2003, p. 685-689.

Manni Piraino, M. T., «Koiné alfabetica fra Siracusa, Megara Iblea e Selinunte ?», Kokalos 21, 1975, p. 121-153 (= Manni Piraino, Koiné alfabetica).

Manni Piraino, M. T., «L'apporto dell'epigrafia», Kokalos 30-31, 1984-1985, p. 79-97.

Manni, E., «Greci in Sicilia fra l'VIII e il VI secolo», in Epis. Epet. t. Philos. Sch. Athenôn,

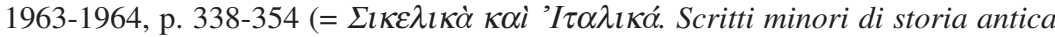
della Sicilia e dell'Italia meridionale, Roma 1990, p. 79-94).

Manni, E., «Fidone d'Argo, i Bacchiadi di Corinto e le fondazioni di Siracusa e di Megara Iblea », Kokalos 20, 1974, p. 77-91.

Manni, E., «Sémites et Grecs en Sicile jusqu' au Ve siècle av. J.-C.», BAGB 1, 1974, p. 63 -

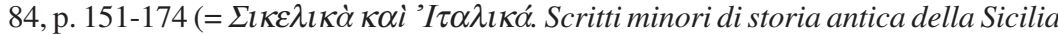
e dell'Italia meridionale, Roma 1990, p. 151-174).

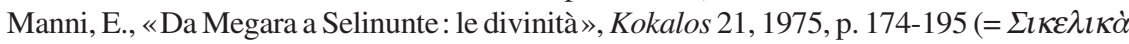
$\kappa \alpha i$ 'I $\tau \alpha \lambda \iota \kappa \alpha ́$. Scritti minori di storia antica della Sicilia e dell'Italia meridionale, Roma 1990, p. 423-442).

Manni, E., «〈Indigeni > e colonizzatori nella Sicilia preromana», in Assimilation et résistance à la culture gréco-romaine dans le monde ancien. Travaux du VI ${ }^{e}$ Congrès International d'Études Classiques (Madrid, Septembre 1974), D. M. Pippidi (éd.), Paris-Bucarest 1976, p. 181-211 (= Manni, Sicilia preromana).

Manni, E., Compte rendu de Mégara 1, Kokalos 24-25, 1978-1979, p. 220-223.

Manni, E., Geografia fisica e politica della Sicilia antica, Kokalos, Suppl. 4, Roma 1981 (= Manni, Geog. della Sicilia).

Mănucu-Adameşteanu, M., «Orgame», in Ancient Greek Colonies in the Black Sea, D. V. Grammenos et E. K. Petropoulos (éds.), Thessaloniki 2003, p. 341-388.

Marasco, G., «Note ellenistiche», Prometheus 9, 3, 1983, p. 221-231.

Marasco, G., Economia e storia, Viterbo 1992.

Marchesini, S., «Il segno $И$ in Elimo: una nuova proposta», ASNP serie iv, 3, 1-2, 1998, p. 289-299.

Marconi, C., Selinunte. Le metope dell'Heraion, Modena 1994.

Marconi, C., «Mito e autorappresentazione nella decorazione figurate dei thesauroi di età arcaica», in Stranieri e non citadini nei santuari greci, A. Naso (éd.), Firenze 2006, p. 158-186. 
Marconi, C., Temple Decoration and Cultural Identity in the Archaic Greece. The Metopes of Selinus, Cambridge 2007.

Marek, C., Stadt, Ära und Territorium in Pontus-Bithynia und Nord-Galatia, Tübingen 1993.

Marek, C., «Die Phylen von Klaudiupolis, die Geschichte der Stadt und die Topographie Ostbithyniens », $M H$ 59, 2002, p. 31-50.

Marek, C., Geschichte Kleinasiens in der Antike, München 2010.

Martin, R., «Problèmes d'urbanisme dans les cités grecques de Sicile», Kokalos 18-19, 1972-1973, p. 348-365.

Martin, R., «Rapport sur l'urbanisme de Sélinonte», Kokalos 21, 1975, p. 54-67.

Martin, R., «L'histoire de Sélinonte d'après les fouilles récentes », CRAI, 1977, 1, p. 4663 (= Martin, Histoire de Sélinonte).

Martin, R. et al., «Le città greche», in La Sicilia antica, I, 3, E. Gabba et G. Vallet (éds.), Napoli 1980, p. 483-705 (= Martin et al., Città greche).

Martin, R., «Recherches sur l'acropole de Sélinonte», Kokalos 26-27, 1980-1981, p. 10091016.

Martin, R., «Sélinonte. Résultats et problèmes de la première phase de recherches (19731979)», ASAA 60, N.S. 44, 1982 (1984), p. 183-188 (= Martin, Sélinonte).

Martina, A., Solone. Testimonianze sulla vita e l'opera, Roma 1968.

Masaracchia, A., Solone, Firenze 1958.

Masson, O, «La Sicile et le monde grec archaïque : l'apport de la linguistique », Kokalos 30-31, 1984-1985, p. 71-75.

Masson, O., «L'onomastique de l'ancienne Byzance (épithaphes et monnaies)», EA 23, 1994 (1995), p. 137-144 (= Onomastica Graeca selecta, vol. III, Genève 2000, p. 206-213).

Masson, O., «La grande imprécation de Sélinonte (SEG XVI, 573)», BCH 96, 1972, p. 375-388 (= Onomastica Graeca selecta, vol. I, Nanterre 1990, p. 135-146; = Masson, L'imprécation de Sélinonte).

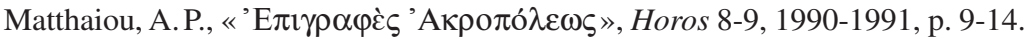

Mayer, M., «Mythistorica. I. Megarische Sagen», Hermes 27, 1892, p. 481-515.

Mazarakis Ainian, A., From Rulers' Dwellings to Temples. Architecture, Religion and Society in Early Iron Age Greece (1100-700 B.C.), Jonsered 1997 (= Mazarakis Ainian, From Rulers' Dwellings to Temples).

Mazzarino, S., «Metropoli e colonie», in Metropoli e colonie di Magna Grecia. Atti del terzo convegno di studi sulla Magna Grecia (Taranto 1963), Napoli 1964, p. 51-85.

McCredie, J. R., Fortified Military Camps in Attica, Hesperia, Suppl. 11, Princeton 1966.

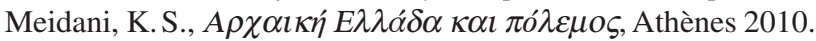

Meiggs, R., The Athenian Empire, Oxford 1972.

Meister, K., Die griechische Geschichtsschreibung. Von den Anfängen bis zum Ende des Hellenismus, Stuttgart et al. 1990.

Mele, A., «Cuma in Opicia tra Greci e Romani», in Cuma. Atti del quarantottesimo Convegno di studi sulla Magna Grecia (Taranto, 27 settembre-1 ottobre 2008), Taranto 2009, p. 75-168.

Mele, A., Il commercio Greco arcaico. Prexis ed emporie, Cahiers du Centre Jean Bérard 4, Napoli 1979. 
Mellink, M. J., «Archaeology in Asia Minor», AJA 60, 4, 1956, p. 369-384.

Menadier, B., The Sixth Century BC Temple and the Sanctuary and Cult of Hera Akraia, Perachora, UMI Dissertation, Cincinnati 1995 (= Menadier, Perachora).

Menadier, B., «The Sanctuary of Hera Akraia and its Religious Connections with Corinth», in Peloponnesian Sanctuaries and Cults. Proceedings of the Ninth International Symposium at the Swedish Institute at Athens, 11-13 June 1994, Stockholm 2002, p. $85-90$.

Meola, E., Necropoli di Selinunte, I: Buffa, vol. I-III, Palermo 1996-1998.

Merante, V., «Sui rapporti greco-punici nel Mediterraneo occidentale nel VI secolo a.C.», Kokalos 16, 1970, p. 98-138.

Mercuri, L., «Tête sans corps, corps sans tête. De certaines pratiques funéraires en Italie méridionale et en Sicile (VIII ${ }^{\mathrm{e}}-\mathrm{V}^{\mathrm{e}}$ siècles avant J.-C.)», MEFRA 113, 2001, p. 7-31.

Meritt, B. D., «Greek Inscriptions », Hesperia 7, 1938, p. 77-160.

Merkelbach, R., «Die pisistratische Redaktion der homerischen Gedichte , RhM 95, 1952, p. 23-47.

Merkelbach, R., «Der Kult der Hestia im Prytaneion der griechischen Städte», ZPE 37, 1980, p. 77-92.

Merkelbach, R., Stauber, J. (éds.), Steinepigramme aus dem griechischen Osten, Band I, Stuttgart-Leipzig 1998.

Merle, H., Die Geschichte der Städte Byzantion und Kalchedon von ihrer Gründung bis zum Eingreifen der Römer in die Verhältnisse des Ostens, Kiel 1916 (= Merle, Byzantion und Kalchedon).

Mertens, D., Der Tempel von Segesta und die dorische Tempelbaukunst des griechischen Westen in klassischer Zeit, Mainz am Rhein 1984.

Mertens, D., «Verso l'agora di Selinunte», in La colonisation grecque en Méditerranée Occidentale. Actes de la rencontre scientifique en hommage à Georges Vallet organisée par le Centre Jean-Bérard, l'École française de Rome, l'Istituto universitario orientale et l'Università degli studi di Napoli «Federico II» (Rome-Naples, 15 18 novembre 1995), Rome 1999, p. 185-193.

Mertens, D., «Die Planstadt Selinunt. Entwurf und Realisierung», in Die Stadt als Gro $\beta$ baustelle. Von der Antike bis zur Neuzeit. Internationaler Kongress vom 7. bis 11. November 2001 im Auswärtigen Amt, Berlin, Berlin 2003, p. 24-31.

Mertens, D., Selinus I. Die Stadt und ihre Mauern, Mainz am Rhein 2003 (= Mertens, Selinus 1).

Mertens, D., Städte und Bauten der Westgriechen. Von der Kolonisationszeit bis zur Krise um 400 vor Christus, München 2006 (= Mertens, Städte und Bauten).

Mertens, D., «L'< heroon 〉 sull'agora di Selinunte. Note preliminare», in Atti del Convegno Internazionale. Sepolti tra $i$ vivi. Buried among the Living (Roma, 26-29 Aprilie 2006), G. Bartoloni et M. G. Benedettini (éds.), Scienze dell'Antichità 14/1, Roma 2008, p. 489-496.

Mertens, D., «Raumgestaltung in westgriechischen Kolonialstädten», GeogrAnt 18, 2009, p. 75-95.

Mertens, D., «Von Megara nach Selinunt. Raumordnung und Baukunst als Mittel zur Identitätsbildung griechischer Poleis während der Großen Kolonisation », $\operatorname{MDAI}(R)$ 116, 2010, p. 55-103 (= Mertens, Von Megara nach Selinunt). 
Mertens, D., «Selinunte: l'eredità di Megara Hyblaea e tante domande aperte», in Alle origini della Magna Grecia. Mobilità, migrazioni, fondazioni. Atti del cinquantesimo convegno di studi sulla Magna Grecia (Taranto, 1-4 ottobre 2010), Taranto 2012, p. 1151-1170.

Mertens, D. et al., «Die Agora von Selinunt. Neue Grabungsergebnisse zur Frühzeit der griechischen Kolonialstadt», $\operatorname{MDAI}(R)$ 110, 2003, p. 389-446 (= Mertens et al., Agora).

Mertens, D. et al., «Die Agora von Selinunt. Der Platz und die Hallen », MDAI $(R)$ 118, 2012, p. 51-178.

Meyer, E., s.v. «Bithynia», RE III, 1899, col. 507-524.

Meyer, E., Die Grenzen der hellenistischen Staaten in Kleinasien, Zürich-Leipzig 1925.

Meyer, E., s.v. «Megara» 2, RE XV, 1931, col. 152-205 (= Meyer, Megara).

Meyer, E., s.v. «Peraia» 1, RE XIX, 1938, col. 565.

Meyer, E., s.v. «Tripodiskos», RE VII A, 1948, col. 201-202.

Meyer, E., s.v. «Panormos», RE XVIII, 2, 1949, col. 658.

Meyer, E., s.v. «Megara», RE Suppl. XII, 1970, col. 842-851.

Migeotte, L., L'emprunt public dans les cités grecques, Québec-Paris 1984.

Migeotte, L., "Téménè dèmosia», in $\Phi ı \lambda o \lambda o \gamma i \alpha$. Mélanges offerts à Michel Casevitz, P. Brillet-Dubois et É. Parmentier (éds.), Lyon 2006, p. 187-195.

Mihailov, G., «Epigraphica», Bulletin de l'Institut bulgare d'archéologie 25, 1956, p. 205-217.

Miller, E., Compte rendu de C. Wescher (éd.), Dionysii Byzantii, De Bospori navigatione, Paris 1874, in $J S, 1874$, p. 200-218.

Miller, J., «Ist Byzanz eine megarische Colonie?», Philologus 56, 1897, p. 326-333 (= Miller, Ist Byzanz eine megar. Colonie ?).

Miller, J., s.v. «Byzantion», RE III, 1899, col. 1127-1150 (= Miller, Byzantion).

Miller, J., s.v. «Byzas», RE III, 1899, p. 1158-1159.

Miller, M., The Sicilian Colony Dates. Studies in Chronography, New York 1970 (= Miller, Colony Dates).

Miller, S.G., The Prytaneion. Its Function and Architectural Form, Berkeley et al. 1978.

Miller, T., Die griechische Kolonisation im Spiegel literarischer Zeugnisse, Tübingen 1997.

Millett, P., Lending and Borrowing in Ancient Athens, Cambridge 1991.

Minns, E.H., Scythians and Greeks, Cambridge 1913.

Mirone, S., «Stiela, topografia e numismatica», Zeitschrift für Numismatik 38, 1928, p. 29-55.

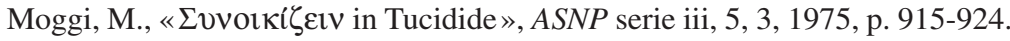

Moggi, M., Sinecismi Interstatali Greci, Pisa 1976 (= Moggi, Sinecismi).

Moggi, M., «L'insediamento a Salamina di Antidoro Lemnio e degli uccisori di Mirrina », ASNP serie iii, 8, 4, 1978, p. 1301-1312.

Moggi, M., «Alcuni episodi della colonizzazione ateniese (Salamina - Potidea - Samo)», in Studi sui rapporti interstatali nel mondo antico, Pisa 1981, p. 1-55 (= Moggi, Salamina). 
Moggi, M., «Sinecismi arcaici del Peloponneso », in La transizione dal miceneo all'alto arcaismo. Dal palazzo alla città. Atti del Convegno Internazionale (Roma, 14-19 marzo 1988), D. Musti et al. (éds.), Roma 1991, p. 155-165.

Moggi, M., «Emigrazioni forzate e divieti di ritorno nella colonizzazione greca die secoli VIII-VII a.C. », in Coercizione e mobilità umana nel mondo antico, M. Sordi (éd.), Milano 1995, p. 27-49.

Molyneux, J.H., Simonides. A Historical Study, Wauconda IL 1992.

Morakis, A., «Thucydides and the Character of Greek Colonisation in Sicily », CQ 61, 2, 2011, p. 460-492.

Mordtmann, J.H., «Zur Epigraphik von Thracien», AEM 8, 1884, p. 199-227.

Mordtmann, J.H., «Inschriften aus dem Tschinili Kiösk», MDAI(A) 10, 1885, p. 15-20.

Morel, J.-P., «La colonisation grecque jusqu'à la fin de l'archaïsme», L'information historique 57, 1995, p. 190-201.

Morel, J.-P., «Problématiques de la colonisation grecque en Méditerranée occidentale: l'exemple des réseaux », in Antonetti (éd.), Il dinam. della colon. gr., p. 59-70.

Moretti, L., «Olympionikai, i vincitori negli antichi agoni olimpici», in Atti dell'Academia dei Lincei, Memorie, serie VIII, vol. VIII, 2, Roma 1957.

Moretti, L., Iscrizioni storiche ellenistiche, vol. I-II, Firenze 1967-1976.

Morgan, C. A., «Corinth, the Corinthian Gulf and Western Greece during the Eighth Century $\mathrm{BC} », A B S A 83,1988$, p. 313-338.

Morgan, C.A., «The Evolution of a Sacral 〈Landscape〉: Isthmia, Perachora, and the Early Corinthian State», in Placing the God. Sanctuaries and Sacred Spaces in Ancient Greece, S.E. Alcock et R. Osborne (éds.), Oxford 1994, p. 105-142.

Morgan, C., Isthmia VIII. The Late Bronze Age Settlement and Early Iron Age Sanctuary, Princeton 1999 (= Morgan, Isthmia VIII).

Morris, I., «Village Society and the Rise of the Greek State», in Structures rurales et sociétés antiques. Actes du colloque de Corfu (14-16 mai 1992), P. N. Doukellis et L. Mendoni (éds.), Paris 1994, p. 49-53.

Morris, I., «The Absolute Chronology of the Greek Colonies in Sicily », AArch 67, 1996, p. 51-59.

Morris, I., «Archaeology and Archaic Greek History », in Archaic Greece : New Approaches and New Evidence, N. Fisher et H. van Wees (éds.), London 1998, p. 1-91.

Morris, I., "The Eighth-century Revolution», in A Companion to Archaic Greece, K. A. Raaflaub et H. van Wees (éds.), Malden-Oxford 2009, p. 64-80 (= Morris, The Eighth-century Revolution).

Moscati, S., «Fenici e Greci in Sicilia: alle origini di un confronto», Kokalos 30-31, 1984-1985, p. 1-19.

Mosshammer, A.A., The Chronicle of Eusebius and Greek Chronographic Tradition, London 1979.

Muller, A., «Megarika», BCH 104, 1980, p. 83-92.

Muller, A., «Megarika», $B C H$ 105, 1981, p. 203-225.

Muller, A., «Megarika», BCH 106, 1982, p. 379-407.

Muller, A., «De Nisée à Mégare. Les siècles de formation de la métropole mégarienne », MEFRA 95, 2, 1983, p. 619-628 (= Muller, De Nisée à Mégare).

Muller, A., «Megarika», BCH 107, 1983, p. 157-179. 
Muller, A., «Megarika», BCH 108, 1984, p. 249-266.

Müller, C., «La procédure d'adoption des décrets en Béotie de la fin du $\mathrm{III}^{\mathrm{e}}$ s. av. J.-C. au $\mathrm{I}^{\mathrm{er}} \mathrm{s}$. apr. J.-C.», in Citoyenneté et participation à la basse époque hellénistique, P. Fröhlich et C. Müller (éds.), Genève 2005, p. 95-119.

Müller, C., «La dissolution du koinon béotien en 171 av. J.-C. et ses conséquences territoriales », in Pouvoir et territoire. Actes du colloque de Saint-Étienne (novembre 2005), P. Rodriguez (éd.), Saint-Étienne 2007, p. 31-46.

Müller, C., D'Olbia à Tanaïs. Territoires et réseaux d'échanges dans la mer Noire septentrionale aux époques classiques et hellénistiques, Bordeaux 2010 (= Müller, D'Olbia à Tanaïs).

Münsterberg, R., Die Beamtennamen auf den griechischen Münzen: geographisch und alphabetisch geordnet, Hildesheim-New York 1973 (Wien 1911-1927).

Murzin, V. Y., Skory, S. A., «An Essay of Scythian History», Il Mar Nero 1, 1994, p. 55-98.

Musti, D., "Le tradizioni ecistiche di Agrigento», in Agrigento e la Sicilia greca. Atti della settimana di studio (Agrigento, 2-8 maggio 1988), L. Bracessi et E. de Miro (éds.), Roma 1992, p. 27-45.

Nagy, G., «Theognis of Megara: the Poet as Seer, Pilot and Revenant», Arethusa 15, 1982, p. 109-128.

Nagy, G., «Poet and Tyrant: Theognidea 39-52, 1081-1082 b», ClAnt 2, 1983, p. 82-91.

Nagy, G., «Theognis and Megara: a Poet's Vision of his City », in Theognis of Megara. Poetry and the Polis, T. J. Figueira et G. Nagy (éds.), Baltimore-London 1985, p. $22-$ 81 (= Nagy, Theognis and Megara).

Napoleone, A., «La $\delta \eta \mu о \kappa \rho \alpha \tau i \alpha$ a Cirene: probleme e prospettive», AION(archeol) N. S. 5, 1998, p. 91-107.

Nawotka, K., «Melsas, the Founder of Mesambria», Hermes 122, 1994, p. 320-326.

Nawotka, K., The Western Pontic Cities. History and Political Organization, Amsterdam 1997 (= Nawotka, West. Pont. Cities).

Neeft, C. W., «Observations on the Thapsos Class», MEFRA 93, 1981, p. 7-88.

Neeft, C. W., «Absolute Chronology and Corinthian Pottery », in La Sicilia in età arcaica, R. A. Panvini et L. Sole (éds.), à paraître.

Nenci, G., «Les rapports internationaux dans la Grèce archaïque (650-550 av. J.-C.)», in Studi sui rapporti interstatali nel mondo antico, Pisa 1981, p. 57-72.

Nenci, G., «Una nuova iscrizione greca arcaica dall' area selinuntina », ASNP serie iii, 25, 1, 1995, p. 1329-1331.

Nenci, G., «Novità epigrafiche dall' area elima», in Seconde giornate internazionali di studi sull'area elima (Gibelina, 22-26 ottobre 1994). Atti, vol. III, Pisa-Gebellina 1997, p. 1187-1188.

Nesselhauf, H., Untersuchungen zur Geschichte der delisch-attischen Symmachie, Klio Beiheft 30, Leipzig 1933.

Newskaja, W.P., Byzanz in der klassischen und hellenistischen Epoche, Leipzig 1955 (= Newskaja, Byzanz).

Nicolai, R., «Solone e la conquista di Salamina: da guerre tradizionale a mito politico», in Costruzione e uso del passato storico nella cultura antica. Atti del convegno internazionale di studi (Firenze, 18-20 settembre 2003), P. Desideri et al. (éds.), Alessandria 2007, p. 3-19. 


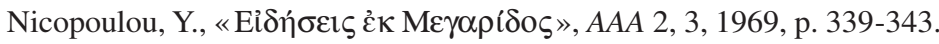

Nicosia, F., «Fonte relative alla data della fondazione di Megara Hyblaea», SicGymn N.S. 16, 2, 1963, p. 154-182 (= Nicosia, Megara).

Niese, B., Geschichte der griechischen und makedonischen Staaten seit der Schlacht bei Chaeronea, Gotha 1893 (réimpr. Darmstadt 1963).

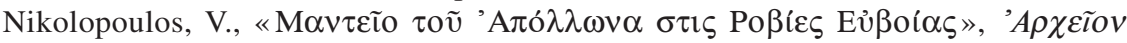

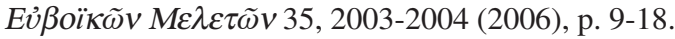

Nillson, M.P., Griechische Feste von religiöser Bedeutung ${ }^{2}$, Leipzig 1906.

Nilsson, M.P., «The New Inscription of the Salaminioi », AJPh 59, 1938, p. 385-393.

Nilsson, M.P., «Political Propaganda in Sixth Century Athens », in Studies presented to D. M. Robinson, vol. II, G.E. Mylonas et D. Raymond (éds.), Saint Louis 1953, p. 743-748.

Nilsson, M.P., Cults, Myths, Oracles, and Politics in Ancient Greece, New York 1972.

Novaro-Lefèvre, D., «Le culte d'Héra à Pérachora (VIII ${ }^{\mathrm{e}}-\mathrm{VI}^{\mathrm{e}} \mathrm{s}$.) : essai de bilan», REG 113, 2000, p. 42-69.

Novikova, R.A., «Les symnamons et les nomophylaques de la Chersonèse Taurique», $V D I, 1961,2$, p. 102-108 (en russe).

Ober, J., «Solon and the Horoi : Facts on the Ground in the Archaic Athens », in Solon of Athens. New Historical and Philological Approaches, J.H. Blok et A.P.M.H. Lardinois (éds.), Leiden-Boston 2006, p. 441-456.

Oberhummer, E., s.v. «Asopos» 2, RE II 2, 1896, col. 1705-1706.

Oberhummer, E., s.v. «Astai», RE II, 1896, col. 1772-1773.

Oberhummer, E., s.v. «Bosporos » 1, RE III, 1899, col. 742-757 (= Oberhummer, Bosporos).

Oberhummer, E., s.v. «Byzantion», RE III, 1899, col. 1116-1127.

Oberhummer, E., s.v. «Kalchedon» 2, RE X, 1919, col. 1559.

Oberhummer, E., s.v. «Sely[m]bria», RE II A, 1923, col. 1324-1327 (= Oberhummer, Selymbria).

Ogan, A., «Les fouilles de Topkapu Saray», Belleten 4, 1940, p. 329-335.

Ognenova, L., «Les fouilles de Messambria», BCH 84, 1960, p. 221-232.

Ognenova, L., «L'architecture domestique à Messambria IV ${ }^{\mathrm{e}}-\mathrm{II}^{\mathrm{e}}$ s. av. J.-C.», in Nessèbre III, Burgas 2005, p. 10-29.

Ognenova, L., «Terres cuites de Messambria», in Nessèbre III, Burgas 2005, p. 51-90.

Ognenova-Marinova, L., «Mesambria Pontica», Wiadomości Archeologiczne 44, 1, 1979, p. 34-40 (= Ognenova-Marinova, Mesambria).

Ognenova-Marinova, L., «Le système de défense hellénique de Mesambria du côté nord à la lumière des recherches sous-marines », in Nessèbre II, Sofia 1980, p. 96109.

Ognenova-Marinova, L., «Thracia Pontica», in Thracia Pontica I. La mer Noire et le monde méditerranéen (Sozopol, 9-12 octobre 1979), Sofia 1982, p. 69-81.

Ognenova-Marinova, L., «Mesambria et le monde thrace entre le VII ${ }^{\mathrm{e}}$ et le V $\mathrm{V}^{\mathrm{e}}$ s. av. n. è», in Thracia Pontica III. Les Thraces et les colonies grecques, VII-Vs. av. n. è. (Sozopol, 6-12 octobre 1985), Sofia 1986, p. 238-244.

Ognenova-Marinova, L., «Au sujet de Dioskouridas de Mesambria», in Actes du IX $X^{e}$ Congrès international d'épigraphie grecque et latine (31.08-7.09.1987). Acta 
Centri Historiae. Terra Antiqua Balcanica II, A. Fol (éd.), Veliko Tărnovo-Sofia 1987, p. 262-263.

Ognenova-Marinova, L., «Mesambria Pontica», in Mesambria-Mesemvria-Nessebur, Sofia 1987, p. 32-71.

Ognenova Marinova, L., «Nesebăr: trent'anni di ricerche di terra e subacque», $B A 75$, 59, 1990, p. 125-129.

Ognenova-Marinova, L., «La 〈bria〉 thrace d'après les recherches archéologiques à Nessèbre », in Thracia Pontica IV, Sofia 1991, p. 133-136.

Ognenova-Marinova, L., «Mesembriacus portus», in Thracia Pontica V, 1994, p. 139142.

Okin, L. A., «Theognis of Megara and the Sources of Archaic Megara», in Theognis of Megara. Poetry and the Polis, T.J. Figueira et G. Nagy (éds.), Baltimore-London 1985, p. 9-21 (= Okin, Theognis).

Oliver, J.H., Marcus Aurelius. Aspects of Civic and Cultural Policy in the East, Hesperia, Suppl. 13, Princeton 1970.

Olshausen, E., s.v. «Bosporos» 1, in Der neue Pauly. Enzyklopädie der Antike, vol. II, Stuttgart-Weimar 1997, col. 750-754.

Oost, S.I., «The Megara of Theagenes and Theognis», CPh 68, 1973, p. 188-196 (= Oost, Megara).

Oppermann, M., Die westpontischen Poleis und ihr indigenes Umfeld in vorrömischer Zeit, Langenweißbach 2004.

Orsi, P., «Megara Hyblaea. Storia, topografia, necropoli e anathemata», MAL 1, 1890, col. 693-950.

Orsi, P., «Thapsos», MAL 6, 1895, col. 88-150.

Osborne, M. J., Naturalization in Athens, vol. I-III, Brussel 1981-1983.

Osborne, R., Classical Landscape with Figures. The Ancient Greek City and its Countryside, London 1987 (= Osborne, Classical Landscape).

Osborne, R., «Archaeology, the Salaminioi, and the Politics of Sacred Spaces in Archaic Athens », in Placing the God. Sanctuaries and Sacred Spaces in Ancient Greece, S.E. Alcock et R. Osborne (éds.), Oxford 1994, p. 152-153.

Osborne, R., «Early Greek Colonization? The Nature of Greek Settlement in the West», in Archaic Greece: New Approaches and New Evidence, N. Fisher et H. van Wees (éds.), London 1998, p. 251-269.

Østby, E., «Chronological Problems of Archaic Selinus », ActaHyp 6, 1995, p. 83-101.

Otto, W., «Zu den syrischen Kriegen der Ptolemäer», Philologus 86, 1931, p. 400418.

Öztürk, B., Sönmez, İ.F., «New Inscriptions from the Karadeniz Ereğli Museum II», Arkeoloji Sanat 137, 2011, p. 155-169.

Padgug, R. A., «Eleusis and the Union of Attika», GRBS 13, 1972, p. 135-150.

Page, D. L., Further Greek Epigrams, Cambridge 1981.

Pais, E., Storia della Sicilia e della Magna Grecia, Torino-Palermo 1894.

Paladino, I., «Il gallo e i riti di passaggio in Grecia», in Transition Rites. Cosmic, Social and Individual Order, Proceedings of the Finnish-Swedish-Italian seminar held at the University of Rome «La Sapienza» $\left(24^{\text {th }}-28^{\text {th }}\right.$ March 1984), U. Bianchi (éd.), Rome 1986, p. 237-245. 
Paltseva, L. A., «Sur les notables du Conseil de Chersonèse durant les premiers siècles de notre ère», VDI, 1977, 3, p. 175-182 (en russe).

Paltseva, L. A., Sur l'histoire de la Grèce archaïque: Mégare et les colonies mégariennes, Saint-Pétersbourg 1999 (en russe ; = Paltseva, Mégare).

Panvini, R., s.v. «Caltabellotta», in BTCGI IV, 1985, p. 269-270.

Panvini, R., «Scavi e ricerche a Caltabellotta», Kokalos 34-35, 1988-89, p. 559-572.

Panvini, R., Ѓ́̇ $\alpha \varsigma$. Storia e archeologia dell'antica Gela, Torino 1996.

Panvini di Stefano, R., «Contributo alla conoscenza di un centro indigeno ellenizzato presso Caltabellotta (Agrigento)», QuadMess 2, 1986-87, p. 105-109.

Papadopoulos, J., «Una terracotta dedalica da Caltabellotta», Xenia 2, 1981, p. 9-12.

Papakonstantinou, Z., «Theognis and the Late Archaic Greek Aristocracy », Dike 7, 2004, p. 7-17.

Papazarkadas, N., Sacred and Public Land in Ancient Athens, Oxford 2011.

Papazoglou, F., Laoi et paroikoi. Recherches sur la structure de la société hellénistique, Belgrade 1997 (= Papazoglou, Laoi et paroikoi).

Pape, W., Wörterbuch der griechischen Eigennamen, 3. Auflage neu bearbeitet von G. E. Benseler, Braunschweig 1884.

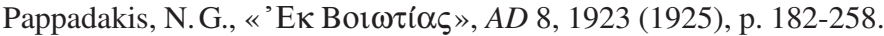

Parisi Presicce, C., «La funzione delle aree sacre nell'organizzazione urbanistica primitiva delle colonie greche alla luce della scoperta di un nuovo santuario periferico di Selinunte», ArchClass 36, 1984, p. 19-132 (= Parisi Presicce, Selinunte).

Parisi Presicce, C., «L'importanza di Hera nelle spedizioni coloniali e nell'insediamento primitivo delle colonie greche », ArchClass 37, 1985 (1988), p. 44-83 (= Parisi Presicce, L’importanza di Hera).

Parisi Presicce, C., «Selinunte dalla scelta del sito alle prime fasi di vita », $\operatorname{MDAI}(R) 110$, 2003, p. 263-283.

Parissaki, M.-G., Prosopography and Onomasticon of Aegean Thrace, MEAETHMATA 49, Athens 2007.

Parke, W., Wormell, D.E. W., The Delphic Oracle, Oxford 1956.

Parker, R., Athenian Religion. A History, Oxford 1996 (= Parker, Athenian Religion).

Parker, R., Polytheism and Society at Athens, Oxford 2005 (= Parker, Polytheism and Society).

Parker, R., « $\pi \alpha \tau \rho \tilde{\omega}$ or $\theta \varepsilon o$ i: The Cults of Sub-Groups and Identity in the Greek World», in Religion and Society. Rituals, Resources and Identity in the Ancient GraecoRoman World. The BOMOS-Conferences 2002-2005, A. Holm Rasmussen et S. W. Rasmussen (éds.), Rome 2008, p. 201-214.

Parker, V., Untersuchungen zum Lelantischen Krieg und verwandten Problemen der frühgriechischen Geschichte, Historia Einzelschriften 109, Stuttgart 1997.

Parlama, L., «Palaiologou Shaft: Marble Memorial Stele», in The City Beneath the City. Antiquities from the Metropolitan Railway Excavations, L. Parlama et N. Stampolidis (éds.), Athens 2000, p. 396-399.

Parmeggiani, G., Eforo di Cuma. Studi di storiografia greca, Studi di storia 14, Bologna 2011.

Partida, E. C., The Treasuries at Delphi: an Architectural Study, Jonsered 2000. 
Paschidis, P., Between City and King. Prosopographical Studies on the Intermediaries between the Cities of the Greek Mainland and the Aegean and the Royal Courts in the Hellenistic Period (322-190 BC), MEAETHMATA 59, Athens 2008.

Patera, I., Offrir en Grèce ancienne. Gestes et contextes, Stuttgart 2012.

Pavlopoulou, A., «Légende et culte des héros fondateurs dans les colonies grecques de Thrace», in Thrace, Athènes 1994, p. 115-134.

Payen, P., «Rhétorique et géographie dans les Questions romaines et Questions grecques de Plutarque », in Plutarque : Grecs et Romains en Questions, Entretiens d'archéologie et d'histoire 4, P. Payen (éd.), Saint-Bertand-de-Comminges 1998, p. 39-73.

Payne, H., Necrocorinthia: a Study of Corinthian Art in the Archaic Period, Oxford 1931.

Payne, H., Protokorinthische Vasenmalerei, Berlin 1933.

Payne, H., Perachora: the Sanctuaries of Hera Akraia and Limenia. Excavations of the British School of Archaeology at Athens, 1930-1933. 1, Architecture, Bronzes, Terracottas, Oxford 1944 (= Payne, Perachora I).

Peek, W., «Griechische Inschriften», MDAI(A) 59, 1934, p. 35-80.

Peek, W., Griechische Vers-Inschriften, I, Berlin 1955 (= Peek, Gr. Vers-Inschriften).

Peek, W., «Ein milesisches Polyandrion», WS 79, 1966, p. 218-230.

Pelagatti, P., «Siracusa. Elementi dell'abitato di Ortigia nell'VIII e nel VII secolo a. C.», in Rizza (éd.), Insediamenti colon. gr., p. 119-133.

Pelaggati, P., «I più antichi materiali d'importazione a Siracusa, a Naxos e in altri siti della Sicilia orientale», in La céramique grecque ou de tradition grecque au VIII ${ }^{e}$ siècle en Italie centrale et méridionale, Cahiers du Centre Jean Bérard 3, G. Vallet (éd.), Naples, 1982, p. 113-180.

Pélékidis, C., Histoire de l'éphébie attique des origines à 31 avant Jésus-Christ, Paris 1962.

Perrin-Saminadayar, E., Éducation, culture et société à Athènes. Les acteurs de la vie culturelle athénienne (229-88): un tout petit monde, Paris 2007.

Persolja, F., «L'espansionismo selinuntino di VI secolo alle luce delle testimonianze epigrafiche e letterarie», ZPE 167, 2008, p. 113-118.

Petropoulos, E. K., Hellenic Colonization in Euxeinos Pontos. Penetration, Early Establishment, and the Problem of the <Emporion > revisited, Oxford 2005 (= Petropoulos, Emporion).

Pfister, F., Die mythische Königsliste von Megara und ihr Verhältnis zum Kult und zur topographischen Bezeichnung, Diss. Ruprecht-Karls-Universität zu Heidelberg 1907 (= Pfister, Mythische Königsliste).

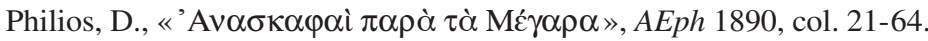

Philippson, A., Die griechischen Landschaften, Band I, Teil III: Attika und Megaris, Frankfurt am Main 1952.

Picard, C., «Les luttes primitives d'Athènes et d'Éleusis », $R H$ 166, 1931, p. 1-76.

Piccirilli, L., Gli arbitrati interstatali greci, vol. I, Pisa 1973 (= Piccirilli, Arbitrati).

Piccirilli, L., «Tre ricerche sulla storiografia megarese », ASNP serie iii, 4, 2, 1974, p. 387 422 (= Piccirilli, Tre ricerche).

Piccirilli, L., MEGARIKA. Testimonianze e frammenti, Pisa 1975 (= Piccirilli, MEGARIKA). 
Piccirilli, L., «Solone e la guerra per Salamina», ASNP serie iii, 8, 1, 1978, p. 1-13 (= Piccirilli, Solone) .

Pick, B., «Die Personen- und Götternamen auf Kaisermünzen von Byzantion », NZ 27, 1895, p. 27-56.

Pick, B., Die antiken Münzen von Dacien und Moesien, I, Berlin 1898 (= Pick, Münzen von Dacien und Moesien).

Piérart, M., «Phratries et <kômai〉 d'Argos», BCH 107, 1983, p. 269-275.

Piérart, M., «Un oracle d'Apollon à Argos », Kernos 3, 1990, p. 319-333.

Piérart, M., «Argos. Une autre démocratie», in Polis and Politics. Studies in Ancient Greek History. Presented to M. H. Hansen on his Sixtieth Birthday, August 20, 2000, Copenhagen 2000, p. 297-314.

Piérart, M., s.v. «Argos », in Hansen-Nielsen (éds.), Inventory, p. 602-606.

Piérart, M., Touchais, G., Argos. Une ville grecque de 6000 ans, Paris 1996.

Pippidi, D. M., «Luttes politiques et sociales à Héraclée pontique», StudClas 11, 1969, p. 235-238 (en roumain ; = Pippidi, Héraclée).

Pippidi, D.M., «Le problème de la main-d'œuvre agricole dans les colonies grecques de la mer Noire », in Problèmes de la terre en Grèce ancienne, M. I. Finley (éd.), Paris 1973, p. 63-82.

Pippidi, D. M., Scythica Minora. Recherches sur les colonies grecques du littoral roumain de la mer Noire, Bucarest-Amsterdam 1975.

Pippidi, D. M., «Gètes, Grecs et Romains en Scythie Mineure: coexistence politique et interférences culturelles », in Assimilation et résistance à la culture gréco-romaine dans le monde ancien. Travaux du VI Congrès International d'Études Classiques (Madrid, Septembre 1974), D. M. Pippidi (éd.), Paris-Bucarest 1976, p. 445-453 (= Parerga. Écrits de philologie, d'épigraphie et d'histoire ancienne, BucarestParis 1984, p. 177-188; = Pippidi, Gètes, Grecs et Romains en Scythie).

Piraino, M. T., «Sulla cronologia della fondazioni siceliote», Kokalos 3, 1957, p. 123-128.

Pitéros, C., Oliver, J.-P., Melena, J.L., «Les inscriptions en linéaire B des nodules de Thèbes (1982): la fouille, les documents, les possibilités d'interprétation », $B C H$ 114, 1990, p. 103-184.

Pizzo, M., «Sulla ceramica più antica di Gela e la topografia della città », in KOINA: miscellanea di studi archeologici in onore di Piero Orlandini, Milano 1999, p. 157-168.

Podlecki, A., «Solon or Peisistratus? ACase of Mistaken Identity », AncW16, 1987, p. 3-10.

Polignac (de), F., La naissance de la cité grecque. Cultes, espace et société, VIII ${ }^{e}-V_{I I}{ }^{e}$ siècles ${ }^{2}$, Paris 1995 (= Polignac, Naissance de la cité gr.).

Polignac (de), F., «Repenser la <cité> ? Rituels et société en Grèce archaïque », in Studies in the Ancient Greek Polis, M.H. Hansen et K. Raaflaub (éds.), Historia Einzelschriften 95, Stuttgart 1995, p. 7-19.

Polignac (de), F., «Héra, le navire et la demeure: offrandes, divinité et société en Grèce archaïque», in Héra. Images, espaces, cultes. Actes du colloque international (Lille, 29-30 novembre 1993), J. de la Genière (éd.), Naples 1997, p. 113-122.

Polignac (de), F., «Divinités régionales et divinités communautaires dans les cités archaïques », in Les Panthéons des cités des origines à la Périegèse de Pausanias. Actes du Colloque organisé à l'Université de Liège du 15 au 17 mai 1997 (2e partie), Kernos, Suppl. 8, V. Pirenne-Delforge (éd.), Liège 1998, p. 23-34 (=Polignac, Divinités). 
Polignac (de), F., «L'installation des dieux et la genèse des cités en Grèce d'Occident, une question résolue? Retour à Mégara Hyblaea», in La colonisation grecque en Méditerranée Occidentale. Actes de la rencontre scientifique en hommage à Georges Vallet organisée par le Centre Jean-Bérard, l'École française de Rome, l'Istituto universitario orientale et l'Università degli studi di Napoli «Federico II» (RomeNaples, 15-18 novembre 1995), Rome 1999, p. 209-230 (= Polignac, Mégara Hyblaea).

Polignac (de), F., «Héritage, rupture et projection: aspects du rapport au temps dans les fondations grecques », in La fundación de la ciudad. Mitos y ritos en el mundo antiguo, P. Azare et al. (éds.), Barcelona 2000, p. 111-117.

Polignac (de), F., «Ajax l'Athénien. Communautés cultuelles, représentations de l'espace et logique institutionnelle dans une tribu clisthénienne», in Athènes et le politique. Dans le sillage de Claude Mossé, P. Schmitt Pantel et F. de Polignac (éds.), Paris 2007, p. 111-132 (= Polignac, Ajax l'Athénien).

Pompeo, L., Il complesso architettonico del Tempio M di Selinunte: analisi tecnica e storia del monumento, Studi e materiali di archeologia 12, Torino 1999.

Pont, A.-V., «L'empereur <fondateur 〉: enquête sur les motifs de la reconnaissance civique», $R E G 120,2007$, p. 526-552.

Popova, E. A., Kovalenko, S. A., «On the Cult of Herakles in the North-Western Crimea: Recent Finds from the Chaika Settlement», in New Studies on the Black Sea Littoral, Colloquia Pontica 1, G. R. Tsetskhladze (éd.), Oxford 1996, p. 63-71.

Popova, E.A., Kovalenko, S.A., «A New Relief with Heracles in the North-Western Crimea», Talanta 32-33, 2000-2001 (2002), p. 103-108.

Porozhanov, K., «La ville thrace de Mesembria sur la côte de la mer Noire», in Thracia 13. Studia in memoriam Velizari Velkov, Sofia 2000, p. 345-350.

Porozhanov, K., «Thracian Kings-Gods-Heroes as Founders of Hellenic Apoikiai in the Sea of Marmora and the Black Sea Regions », in Praktika, IA'Diethnous Synedriou Klassikôn Spoudôn, Kavalla 24-30 Augoustou 1999, vol. III, Athena 2004, p. 514521 (= Porozhanov, Founders).

Posamentir, R., The Polychrome Grave Stelai from the Early Hellenistic Necropolis, Chersonesan Studies 1, Austin 2011 (= Posamentir, Grave Stelai).

Prakken, D. W., «A Note on the Megarian Historian Dieuchidas », AJPh 69, 1941, p. 348351.

Prakken, D. W., «On the Date of Hereas, the Megarian Historian», CW 37, 1943-1944, p. 122-123.

Preller, L., Griechische Mythologie. Vierte Auflage bearbeitet von Carl Robert, vol. I-III, Berlin 1894-1921.

Preshlenov, H., «Die mesambrische Politeia», in Thracia 15. In honour of A. Fol's $70^{\text {th }}$ Anniversary, K. Jordanov et al. (éds.), Sofia 2003, p. 523-529.

Preshlenov, H., «Mesambria», in Ancient Greek Colonies in the Black Sea, D. V. Grammenos et E. K. Petropoulos (éds.), Thessaloniki 2003, p. 159-208.

Procelli, E., «Aspetti e problemi dell'ellenizzazione calcidese nella Sicilia orientale», MEFRA 101, 1989, p. 679-689.

Puech, B., Orateurs et sophistes grecs dans les inscriptions d'époque impériale, Paris 2002. 
Pugliese Carratelli, G., «Note di storia greca arcaica, I: Aisymnetai», RAAN 21, 1941, p. 295-308.

Pugliese Carratelli, G., «Minos e Cocalos », Kokalos 2, 1956, p. 89-103 (= Tra Cadmo e Orfeo. Contributi alla storia civile e religiosa dei Greci d'Occidente, Bologna 1990, p. 43-57).

Pugliese Carratelli, G., «L'oggeto storico di Selinunte», in V. Tusa, La scultura in pietra di Selinunte, Palermo 1983, p. 17-25 (= «Per la storia di Selinunte», in G. Pugliese Carratelli, Tra Cadmo e Orfeo. Contributi alla storia civile e religiosa dei Greci d'Occidente, Bologna 1990, p. 157-176; = Pugliese Carratelli, Selinunte $)$.

Pugliese Carratelli, G., «Storia civile», in SIKANIE. Storia e civiltà della Sicilia antica, G. Pugliese Carratelli (éd.), Milano 1986, p. 1-78.

Rallo, A., «Scavi e ricerche nella città antica di Selinunte. Relazione preliminare», Kokalos 22-23, 1976-1977, p. $720-733$ (= Rallo, Selinunte).

Rallo, A., «Selinunte: Le ceramiche di VII secolo a.C. della necropoli meridionale di Manuzza dopo gli scavi 1978 », ASAA 60, N.S. 44, 1982 (1984), p. 203-218 (= Rallo, Ceramiche di Manuzza).

Rallo, A., «Nuovi aspetti dell'urbanistica di Selinunte», ASAA 62, N.S. 46, 1984 (1988), p. 81-91.

Rallo, A., «Considerazioni su una rotta tra Etruria, Sicilia e Cartagine», in Etrusca et Italica. Scritti in ricordo di Massimo Pallottino, vol. 2, Pisa-Roma 1997, p. 537-549 (= Rallo, Considerazioni).

Rallo, A., «Contributions sur les fouilles récentes de Sélinonte», $R A, 2002$, 1, p. 194-198 (= Rallo, Contributions).

Rallo, A., «Considerazioni su un gruppo di tombe protoarcaiche di Selinunte», in Atti del Convegno Internazionale. Sepolti tra i vivi. Buried among the Living (Roma, 26-29 Aprilie 2006), G. Bartoloni et M. G. Benedettini (éds.), Scienze dell'Anntichità 14/1, Roma 2008, p. 489-496.

Rangabé, A.-R., Antiquités helléniques ou répertoire d'inscriptions et d'autres antiquités découvertes depuis l'affranchissement de la Grèce, Athènes, vol. I-II, 18421855.

Raubitschek, A. E., «Theseus at the Isthmus», in Corinthiaca. Studies in Honor of Darrell A. Amyx, M. A. Del Chiaro (éd.), Columbia 1986, p. 1-2.

Reber, K., Hansen, M.H., Ducrey, P., s.v. «Chalkis », in Hansen-Nielsen (éds.), Inventory, p. 647-649.

Reber, K., Hansen, M.H., Ducrey, P., s.v. «Karystos », in Hansen-Nielsen (éds.), Inventory, p. 658-659.

Reger, G., s.v. «Lemnos», in Hansen-Nielsen (éds.), Inventory, p. 756-757.

Rehm, A. (éd.), Das Delphinion in Milet, Berlin 1914.

Reichert-Südbeck, P., Kulte von Korinth und Syrakus. Vergleich zwischen einer Metropolis und ihrer Apoikia, Dettelbach 2000.

Reinganum, H., Das alte Megaris, Berlin 1825.

Reinmuth, O. W., «The Ephebic Inscription, Athenian Agora I 286 », Hesperia 24, 1955, p. 220-239.

Rhodes, P.J., Lewis, D. M., The Decrees of the Greek States, Oxford 1997 (= RhodesLewis, Decrees). 
Rhodes, P.J., Osborne, R. (éds.), Greek Historical Inscriptions (404-323 BC), Oxford 2003.

Richards, G. C., «Archaeology in Greece, 1897-8», JHS 18, 1898, p. 328-339.

Rigsby, K. J., «Megara and Tripodiscus », GRBS 28, 1987, p. 93-102 (= Rigsby, Megara).

Rigsby, K. J., Asylia. Territorial Inviolability in the Hellenistic World, Berkeley-Los Angeles-London 1996 (= Rigsby, Asylia).

Riotto, M., «Il santuario della Malophoros a Selinunte: spunti per una discussione storicoreligiosa », SicArch XVIII, 59, 1985, p. 25-51.

Rizza, G., «Siculi e Greci sui colli di Leontini », Cronache di Archeologia 1, 1962, p. 3-27.

Rizza, G. (éd.), Insediamenti coloniali greci in Sicilia nell'VIII e VII secolo a. C.. Atti della $2^{a}$ riunione scientifica della Scuola di perfezionamento in archeologia classica dell'Università di Catania (Siracusa, 24-27 novembre 1977), Cronache di Archeologia 17/1978, Catania 1980 [= Rizza (éd.), Insediamenti colon. gr.].

Rizza, G., «Leontini nell’VIII e nel VII secolo a. C. », in Rizza (éd.), Insediamenti colon. gr., p. 26-37.

Rizzo, F. P., «Akragas e la fondazione di Minoa», Kokalos 13, 1967, p. 117-142.

Rizzo, G.E., Monete greche della Sicilia, Roma 1946.

Robert, C., Pausanias als Schriftsteller. Studien und Beobachtungen, Berlin 1909.

Robert, L., Collection Froehner I. Inscriptions grecques, Paris 1936.

Robert, L., «Études d'épigraphie grecque. XL. Inscriptions d'Hérakleia», $R P h$ 10, 1936, p. 113-122.

Robert, L., Études épigraphiques et philologiques, Paris 1938.

Robert, L., «Hellenica. I. Inscriptions de Pagai en Mégaride relatives à un arbitrage», RPh 13, 1939, p. 97-122 (=OpMinSel, II, p. 1250-1275; = Robert, Inscr. de Pagai).

Robert, L., Hellenica. Recueil d'épigraphie, de numismatique et d'antiquités grecques, IXIII, Paris 1940-1965 (= Robert, Hellenica).

Robert, L., «Griechische Vers-Inschriften hrsg. von Peek. 1. Grabepigramme », Gnomon 31,1959 , p. 1-30.

Robert, L., «Les inscriptions grecques de Bulgarie », RPh85, 1959, p. 165-236 (=OpMinSel, V, p. 195-266; = Robert, Inscr. de Bulgarie).

Robert, L., Opera Minora Selecta, I-VII, Amsterdam 1969-1990 (= Robert, OpMin$\mathrm{Sel}$ ).

Robert, L., À travers l'Asie Mineure. Poètes et prosateurs, monnaies grecques, voyageurs et géographie, Paris 1980 (= Robert, À travers l'Asie Mineure).

Robert, L., Documents d'Asie Mineure, Athènes-Paris 1987 (= Robert, Documents).

Robert, L., Robert, J., La Carie. Histoire et géographie historique, II, Paris 1954.

Robertson, N., Festivals and Legends: the Formation of Greek Cities in the Light of Public Ritual, Toronto et al. 1992.

Robertson, N., Religion and Reconciliation in Greek Cities. The Sacred Laws of Selinus and Cyrene, Oxford 2010.

Robinson, E. W., The First Democracies. Early Popular Government outside Athens, Historia Einzelschriften 107, Stuttgart 1997.

Robinson, E. W., Democracy beyond Athens. Popular Governement in the Greek Classical Age, Cambridge 2011.

Robu, A., «L'affaire de Salamine», Dacia N. S. 48-49, 2004-2005, p. 161-172. 
Robu, A., «Chronique mégarienne. À propos d'un livre récent portant sur les cités mégariennes de Sicile», AC 75, 2006, p. 205-212.

Robu, A., «Notes sur les dédicaces mégariennes pour Hadrien et Sabine », Dacia N. S. 51, 2007, p. 171-176.

Robu, A., «Réflexions sur le culte d'Apollon à Chalcédoine », LEC 75, 1-2, 2007, p. 137 155 (= Robu, Chalcédoine).

Robu, A., «Le culte de Zeus Meilichios à Sélinonte et la place des groupements familiaux et pseudo-familiaux dans la colonisation mégarienne», in La norme en matière religieuse en Grèce ancienne. Actes du XII colloque international du CIERGA (Rennes, septembre 2007), P. Brulé (éd.), Kernos, Suppl. 21, 2009, p. 277-291 (= Robu, Zeus Meilichios).

Robu, A., «Les fondations mégariennes de Sicile: origine des colons et appropriation du territoire», Cahiers «Mondes anciens » 2, 2011 (<http ://mondesanciens.revues.org/ index347.html >).

Robu, A., «Recherches sur l'épigraphie de la Mégaride: le décret d'Aigosthènes pour Apollodôros de Mégare (IG VII, 223)», in Philologos Dionysios. Mélanges offerts au professeur Denis Knoepfler, N. Badoud (éd.), Genève 2011, p. 79-101 (= Robu, Décret d'Aigosthènes).

Robu, A., «La cité de Mégare et les Antigonides: à propos d'une magistrature mégarienne extraordinaire (le collège des six stratèges)», in Communautés locales et pouvoir central dans l'Orient hellénistique et romain, C. Feyel et al. (éds.), Nancy 2012, p. 85-115 (= Robu, Mégare et les Antigonides).

Robu, A., «Les établissements mégariens de la Propontide et du Pont-Euxin: réseaux, solidarités et liens institutionnels », Pallas 89, 2012, p. 181-195 (= Robu, Réseaux).

Robu, A., «Traditions et innovations institutionnelles : l'organisation civique de Byzance et de Chalcédoine », Il Mar Nero 7, 2007-2009 (2013), p. 149-166 (= Robu, Organisation civique).

Robu, A., «Traditions et rapprochements onomastiques dans les cités grecques de la mer Noire: quelques exemples tirés du 〈monde mégarien〉», Il Mar Nero 8, 2010-2011 (2013), p. 281-293 (= Robu, Trad. onomastiques).

Robu, A., «Le culte de Poséidon à Mégare et dans ses colonies», Dacia N. S. 57, 2013, p. $65-80$.

Robu, A., «Les relations de Byzance avec les cités du Pont Gauche à l'époque hellénistique : la guerre pourl'emporion de Tomis », in Actes du colloque Die Außenbeziehungen pontischer und kleinasiatischer Städte in hellenistischer und römischer Zeit (Constantza, 20-24 septembre 2010), V. Cojocaru et C. Schuler (éds.), à paraître.

Robu, A., «The Epigraphy of Hellenistic Megara Revisited», in Actes du colloque The Epigraphy and History of Boeotia: New Finds, New Developments (University of California, Berkeley, September 2-3, 2011), N. Papazarkadas (éd.), à paraître (= Robu, Hellenistic Megara).

Rocca, G., Nuove iscrizioni da Selinunte, Alessandria 2009.

Roebuck, C., Ionian Trade and Colonization, New York 1959 (= Roebuck, Ionian Trade).

Roesch, P., Thespies et la confédération béotienne, Paris 1965.

Röhl, H. (éd.), Inscriptiones Graecae antiquissimae praeter Atticas in Attica repertas, Berlin 1882. 
Roscher, W.H. (éd.), Ausführliches Lexikon der griechischen und römischen Mythologie, Leipzig 1884-1937 (réimpr. Hildesheim-New York 1965-1978; = Roscher, Lexikon).

Rostovtseff, M.I., Histoire économique et sociale du monde hellénistique, traduction O. Demange, Paris 1989.

Rougemont, G., «Delphes et les cités grecques d'Italie du Sud et de Sicile», in La Magna Grecia e i grandi santuari della madrepatria. Atti del trentunesimo convegno di studi sulla Magna Grecia (Taranto, 4-8 ottobre 1991), Taranto 1992, p. 157-192.

Rousset, D., «Les frontières des cités grecques. Premières réflexions à partir du recueil des documents épigraphiques », $C C G 5$, 1994, p. 97-126.

Rubel, A., «Hellespontophylakes - Zöllner am Bosporos ? Überlegungen zur Fiskalpolitik des attischen Seebundes (IG I ${ }^{3}$ 61)», Klio 83, 1, 2001, p. 39-51.

Ruge, W., s.v. «Astakos» 2, RE II, 1896, col. 1774-1775 (= Ruge, Astakos).

Ruge, W., s.v. «Kalchedon» 1, RE X, 1919, col. 1555-1559.

Ruge, W., s.v. «Mariandynoi », RE XIV, 1930, col. 1747-1749.

Ruge, W., s.v. «Olbia» 1, RE XVII, 1937, col. 2403-2404.

Rusjaeva, A. S., «Le culte de la Parthénos à Chersonèse Taurique à l'époque de sa fondation», in Religions du Pont-Euxin. Actes du VIII Symposium de Vani (Colchide)1997, O. Lordkipanidzé et P. Lévêque (éds.), Besançon-Paris 1999, p. 99-104.

Russell, T., «<The Land of Inachus >, Byzantium's Early Coinage and Two Bosporus Toponyms», ZPE 180, 2012, p. 133-138.

Russu, I., La langue des Thraco-Daces ${ }^{2}$, Bucarest 1967 (en roumain).

Ruzé, F., «La fonction des probouloi dans le monde grec antique», in Mélanges d'histoire ancienne offerts à William Seston, Paris 1974, p. 443-462 (= Eunomia. À la recherche de l'équité, Boulogne-sur-Mer-Paris 2003, p. 11-29).

Ruzé, F., «Les tribus et la décision politique dans les cités grecques archaïques et classiques », Ktèma 8, 1983, p. 299-306 (= Eunomia. À la recherche de l'équité, Boulogne-sur-Mer-Paris 2003, p. 55-65).

Ruzé, F., Délibération et pouvoir dans la cité grecque de Nestor à Socrate, Paris 1997.

Şahin, S., Neufunde von antiken Inschriften in Nikomedia (Izmit) und in der Umgebung der Stadt, Diss. Münster 1973 (= Şahin, Nikomedia).

Sakellariou, M. B., Le peuplement de la Grèce et du bassin égéen aux hautes époques. 3. Les proto-Grecs, Athènes 1980.

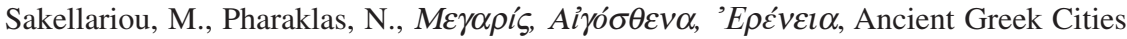

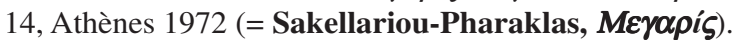

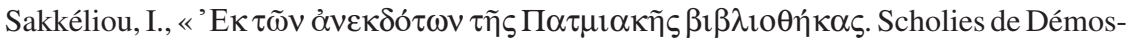
thène et d'Eschine d'après un manuscrit inédit de Patmos », $B C H$ 1, 1877, p. 1-16, 137-155.

Salkin, A., «Evidence for the Earlier Foundation of Bizone Colony », in Thracia Pontica III. Les Thraces et les colonies grecques, VII-V s. av. n. è. (Sozopol, 6-12 octobre 1985), Sofia 1986, p. 251-255.

Sallet, A. von, «Ein Goldstater der taurischen Chersonesus mit dem Beinamen BA $\Sigma$ I$\Lambda E Y O Y \Sigma A$ und einer Jahreszahl der Chersonesischen Aera», Zeitschrift für Numismatik 4, 1877, p. 273-277.

Sallet, A. von, «Beiträge zur antiken Münz- und Altertumskunde», Zeitschrift für Numismatik 9, 1882, p. 138-189. 
Salmon, J., «The Heraeum at Perachora and the Early History of Corinth and Megara», ABSA 67, 1972, p. 159-204 (= Salmon, Heraeum).

Salmon, J., Compte rendu de Legon, Megara Pol. Hist., JHS 103, 1983, p. 202-203.

Salmon, J., Wealthy Corinth. A History of the City to 338 B. C., Oxford 1986 (= Salmon, Wealthy Corinth).

Sammartano, R., «Dedalo, Minosse e Cocalo in Sicilia», Mythos 1, 1989, p. 201-229.

Sammartano, R., «Tradizioni ecistiche e rapporti greco-siculi : le fondazioni di Leontini e di Megara Hyblaea», Seia 11, 1994, p. 47-93 (=Sammartano, Tradizioni ecistiche).

Sammartano, R., Origines gentium Siciliae. Ellanico, Antioco, Tucidide, Roma 1998.

Samuel, A.E., Greek and Roman Chronology. Calendars and Years in Classical Antiquity, Munich 1972 (= Samuel, Chronology).

Sánchez, P., L'Amphictionie des Pyles et de Delphes: recherches sur son rôle historique, des origines au II ${ }^{e}$ siècle de notre ère, Historia Einzelschriften 148, Stuttgart 2001.

Saprykin, S. J., «Le culte d'Héraclès à Chersonèse et à Héraclée à l'époque de l'hellénisme», SovArch 1, 1978, p. 38-52 (en russe).

Saprykin, S.J., «Les poleis et la population locale du littoral sud de la mer Noire à l'époque archaïque et classique: Héraclée et les Mariandyniens », in La situation démographique dans la région de la mer Noire durant la période de la grande colonisation grecque, Tbilisi 1981, p. 9-22 (en russe).

Saprykin, S. J., «The Northern League: International Relations in the Southern Euxine Seaboard in the Early Hellenistic Period », in The Black Sea Littoral in the Hellenistic Times. Materials of the $3^{\text {rd }}$ All-Union Symposium on the Ancient History of the Black Sea Littoral, Tsqaltubo-1982, Tbilisi 1985, p. 49-61 (en russe).

Saprykin, S. J., «Héraclée du Pont et Chersonèse Taurique : institutions publiques et rapports fonciers », DHA 17, 1, 1991, p. 103-117 (= Saprykin, Institutions et rapports fonciers).

Saprykin, S.J., Ancient Farms and Land-Plots on the Khora of Khersonesos Taurike (Research in the Herakleian Peninsula 1974-1990), Amsterdam 1994.

Saprykin, S. J., «Megarice-Heracleia-Chersonesus: Three Names of a Greek City-State in South-Western Taurica», OTerr 1, 1995, p. 25-38.

Saprykin, S. J., «La Boulè de Chersonèse», Archeologija (Kiev), 1995, 1, p. 75-82 (en russe).

Saprykin, S. J., «Inscriptions grecques de Chersonèse», VDI, 1996, 4, p. 43-53 (en russe).

Saprykin, S.J., Heracleia Pontica and Tauric Chersonesus before Roman Domination (VI-I centuries B. C.), Amsterdam 1997 (= Saprykin, Heracleia and Chersonesus).

Saprykin, S. J., «Proxénie de Chersonèse pour un Sinopéen», VDI, 1998, 4, p. 41-65 (en russe ; = Saprykin, Proxénie de Chersonèse).

Saprykin, S. J., «The Foundation of Tauric Chersonesus », in The Greek Colonisation of the Black Sea Area, Historia Einzelschriften 121, G. Tsetskhladze (éd.), Stuttgart 1998, p. 227-248.

Savalli-Lestrade, I., Les «philoi » royaux dans l'Asie hellénistique, Genève 1998.

Sayar, M.H., Perinthos-Herakleia (Marmara Ereğlisi) und Umgebung, Wien 1998 (= Sayar, Perinthos-Herakleia).

Schachter, A., Cults of Boiotia, BICS, Suppl. 38.1-4, London 1981-1994. 
Schachter, A., «Boiotia in the Sixth Century B.C.», in Boiotika. Vorträge vom 5. internationalen Böotien-Kolloquim (Institut für alte Geschichte Ludwig-MaximiliansUniversität München, 13.-17. Juni 1986), H. Beister et J. Buckler (éds.), München 1989, p. 73-86.

Scheer, T. S., Mythische Vorväter. Zur Bedeutung griechischer Heroenmythen im Selbstverständnis kleinasiatischer Städte, München 1993.

Scheid-Tissinier, E., «Les prétendants de l'Odyssée, une génération perdue », in L'initiation. Actes du colloque de Montpellier (11-14 avril 1991), A. Moreau (éd.), Montpellier 1992, p. 105-118.

Scheid-Tissinier, E., «Télémaque et les prétendants. Les véor d'Ithaque », AC 62, 1993, p. 1-22.

Scheid-Tissinier, E., «Laos et dèmos, le peuple de l'épopée», $A C$ 71, 2002, p. 1-26.

Schenal Pileggi, R., I pinakes di Locri Epizefiri, Reggio Calabria 2011.

Scherling, K., s.v. «Kodros», RE XV, 1922, col. 984-994.

Schettino, M. T., Introduzione a Polieno, Pisa 1998.

Schmidt, F., s.v. «Teukros», RE V A, 1934, col. 1123-1131.

Schnapp-Gourbeillon, A., Aux origines de la Grèce (XIII ${ }^{e}$-VIII ${ }^{e}$ siècles avant notre ère). La genèse de la politique, Paris 2002.

Schneiderwirth, H., Das pontische Heraklea, Heiligenstadt 1882.

Schönert, E., «Zur Geschichte der Stadt Perinthos», Altertum 8, 2, 1962, p. 73-80.

Schönert-Geiss, E., «Der Io-Mythos auf den Silbermünzen von Byzanz», Helikon 6, 1966, p. 174-182.

Schönert-Geiss, E., Die Münzprägung von Byzantion, vol. I-II, Berlin-Amsterdam 19701972 (= Schönert-Geiss, Byzantion).

Schönert-Geiss, E., Die Münzprägung von Bisanthe, Dikaia, Selymbria, Berlin 1977.

Schönfelder, W., Die städtischen und Bundesbeamten des griechischen Festlandes vom 4. Jahrhundert vor Chr. Geb. bis in die römische Kaiserzeit, Diss. Leipzig 1917.

Schörner, H., Sepulturae Graecae intra urbem. Untersuchungen zum Phänomen der intraurbanen Bestattungen bei den Griechen, Boreas Beiheft 9, Möhnesee 2007.

Schuler, C., Ländliche Siedlungen und Gemeinden im hellenistischen und römischen Kleinasien, Vestigia 50, München 1998.

Schuller, W., Die Herrschaft der Athener im Ersten Attischen Seebund, Berlin-New York 1974.

Schultz, H., s.v. «Hesychios» 10, RE VIII, 1913, col. 1322-1327.

Schwabacher, W., «Die Tetradrachmenprägung von Selinunt», MBNG 43, 1925, p. 1-90.

Schwartz, E., s.v. «Apollodorus» 61, RE I, 1894, col. 2855-2886.

Schwartz, E., s.v. «Demetrios» 77, RE IV, 1901, col. 2806-2807.

Schwyzer, E., Dialectorum Graecorum exempla epigraphica potiora, Leipzig 1923.

Scott, L., «Were there Polis Navies in Archaic Greece?», in The Sea in Antiquity, G. J. Oliver et al. (éds.), Oxford 2000, p. 93-115.

Sealey, R., A History of the Greek City States ca. 700-338 B. C., Berkeley et al. 1976.

Seeliger, K., «Alkathöos und die megarische Königliste. Eine Pausaniasstudie», in Festschrift für Johannes Overbeck, Leipzig 1893, p. 27-44.

Selle, H., Theognis und die Theognidea, Berlin-New York 2008.

Sergent, B., «Les premiers Celtes d'Anatolie», REA 90, 3-4, 1988, p. 329-358. 
Seure, G., «Archéologie thrace. Documents inédits ou peu connus », RA, 1911, 2, p. 423 449.

Seure, G., «Antiquités thraces de la Propontide», $B C H$ 36, 1912, p. 534-641.

Seyrig, H., «Monnaies hellénistiques de Byzance et de Calcédoine», in Essays in Greek Coinage presented to Stanley Robinson, C. M. Kraay et G. K. Jenkins (éds.), Oxford 1968, p. 183-200 (= Scripta Numismatica, Paris 1986, p. 215-235 ; = Seyrig, Monnaies).

Shapiro, H. A., «Exekias, Ajax, and Salamis: A Further Note», AJA 85, 2, 1981, p. 173-175.

Shcheglov, A. N., Polis et chora. Cité et territoire dans le Pont-Euxin, Paris 1992.

Shepherd, G., «The Pride of Most Colonials : Burial and Religion in the Sicilian Colonies », ActaHyp 6, 1995, p. 51-82.

Shepherd, G., «Greeks bearing Gifts : Religious Relationships between Sicily and Greece in the Archaic Period», in Sicily from Aeneas to Augustus. New Approaches in Archaeology and History, C. Smith et J. Serreti (éds.), Edinburg 2000, p. 55-70.

Sherk, R. K., «The Eponymous officials of Greek Cities. III», ZPE 88, 1991, p. 225-260.

Sherk, R. K., «The Eponymous Officials of Greek Cities. IV», ZPE 93, 1992, p. 223-272.

Shipley, G., A History of Samos, Oxford 1987.

Simon, E., «Héra en Béotie et en Thessalie», in Héra. Images, espaces, cultes. Actes du colloque international (Lille, 29-30 novembre 1993), J. de la Genière (éd.), Naples 1997, p. 83-86.

Sinn, U., «Das Heraion von Perachoara. Eine sakrale Schutzzone in der korinthischen Peraia», MDAI(A) 105, 1990, p. 53-116 (= Sinn, Heraion)

Sinn, U., «La funzione dell'Heraion di Perachora nella peraía corinzia», in Geografia storica della Grecia Antica. Tradizioni e problemi, F. Prontera (éd.), Roma-Bari 1991, p. 209-232.

Sjöqvist, E., Sicily and the Greeks. Studies in the Interrelationship between the Indigenous Populations and the Greek Colonists, Ann Arbor 1973.

Smith, P. J., «Megara and her Colonies: what could the Metropolis have exported to her Colonies?», AncW 37, 1, 2006, p. 76-80 (= Smith, Megara and her Colonies).

Smith, P. J., The Archaeology and Epigraphy of Hellenistic and Roman Megaris, Greece, BAR International Series 1762, Oxford 2008 (= Smith, Megaris).

Snodgrass, A. M., «Two Demographic Notes», in The Greek Rennaissance of the Eight Century B.C. Tradition and Innovation. Proceedings of the Second International Symposium at the Swedish Institute in Athens, 1-5 June 1981, R. Hägg (éd.), Stockholm 1983, p. 167-171.

Sokolowski, F., Lois sacrées des cités grecques. Supplément, Paris 1962.

Sölch, J., «Bithynische Städte im Altertum», Klio 19, 1925, p. 140-188.

Solmsen, F., Beiträge zur griechischen Wortforschung, Strasbourg 1909.

Solomonik, E. I., Nouveaux monuments épigraphiques de Chersonèse, vol. I-II, Kiev 1964-1973 (en russe ; = Solomonik, Épigraph. Chersonèse).

Solomonik, E. I., «Graffiti de l' antique Chersonèse», VDI, 1976, 3, p. 121-141 (en russe).

Solomonik, E. I., «Une inscription fragmentaire de Chersonèse concernant des exilés politiques », VDI, 1984, 3, p. 72-81 (en russe).

Solomonik, E.I., Nikolaenko, G. M., «Les lots agraires de Chersonèse au début du III $^{\mathrm{e}}$ siècle av. J. C. (ad IOSPE $\mathrm{I}^{2}$ 403)», VDI, 1990, 2, p. 79-99 (en russe). 
Solovyov, S. L., Ancient Berezan. The Architecture, History and Culture of the First Greek Colony in the Northern Black Sea, Leiden et al. 1999.

Sourov, E. G., «Nouvelle inscription de Chersonèse », VDI, 1960, 3, p. 154-158 (en russe ; $=$ Sourov, Inscr. de Chersonèse).

Sourvinou-Inwood, C., <Reading > Greek Death to the End of the Classical Period, Oxford 1995.

Sourvinou-Inwood, C., Athenian Myths and Festivals. Aglauros, Erechthus, Plynteria, Panathenia, Dionysia, Oxford 2011.

Spatafora, F., «L'alta e media Valle del Belice tra la Media Età del Bronzo e l'età arcaica », Kokalos 42, 1996, p. 189-191.

Spratt, T., «Remarks on the Supposed Situation of Minoa and Nisaea », The Journal of the Royal Geographical Society 8, 1838, p. 205-209 (= in Thucydides, The History of the Peloponnesian War, T. Arnold (éd.), Oxford 1847, p. 540-543).

Srebrny, S., «Kult der thrakischen Göttin Kotyto in Korinth und Sicilien », in Mélanges Franz Cumont, vol. I, Bruxelles 1936, p. 423-447.

Staab, G., «Das Grabepigramm des Euelpistos aus Tomi», ZPE 179, 2011, p. 97-102.

Stahl, M., Aristokraten und Tyrannen im archaischen Athen. Untersuchungen zur Überlieferung, zur Sozialstruktur und zur Entstehung des Staates, Stuttgart 1987.

Stavrianopoulou, E., «Normes of Public Behaviour towards Greek Priests : Some Insights from the Leges Sacrae», in La norme en matière religieuse en Grèce ancienne. Actes du XII colloque international du CIERGA (Rennes, septembre 2007), P. Brulé (éd.), Kernos, Suppl. 21, 2009, p. 213-229.

Steffen, W., «Zur Geschichte Megaras im sechsten Jahrhundert v.u.Z.», in Neue Beiträge zur Geschichte der alten Welt. 1. Alter Orient und Griechenland, Berlin 1964, p. 293-299.

Stein-Hölkeskamp, E., «Adel und Volk bei Theognis», in Volk und Verfassung im vorhellenistischen Griechenland. Beiträge auf dem Symposium zu Ehren von KarlWilhelm Welwei in Bochum, 1-2 März 1996, W. Eder et K.-J. Hölkeskamp (éds.), Stuttgart 1997, p. 21-35.

Steinrück, M., Iambos. Studien zum Publikum einer Gattung in der frühgriechischen Literatur, Zürich et al. 2000.

Steinrück, M., The Suitors in the Odyssey. The Clash between Homer and Archilochus, New York et al. 2008.

Steinrück, M., Der neue Iambos. Studien zu den Formwegen eines griechischen Diskurses im Hellenismus und der Kaiserzeit, Zürich-New York 2009.

Stickler, T., Korinth und seine Kolonien. Die Stadt im Mächtegefüge des klassischen Griechenland, Berlin 2010.

Stolba, V.F., «Une nouvelle dédicace de la Crimée du Nord-Ouest et les aspects du culte d'Héraclès à Chersonèse », VDI, 1989, 4, p. 55-70 (en russe).

Stolba, V.F., «Quelques noms dans les inscriptions sur des céramiques de Chersonèse », Archeologičeski Vesti 2, 1993, p. 107-112 (en russe).

Stoll, H. W., s.v. «Astakos» 2, in Roscher, Lexikon, I, 1, col. 645.

Stoll, H. W., s.v. «Byzas» 1, in Roscher, Lexikon, I, 1, col. 841 (= Stoll, Byzas).

Stoll, H. W., s.v. «Kynosoura», in Roscher, Lexikon, II, 1, col. 1706.

Stoll, H. W., s.v. «Kynosouros» 2, in Roscher, Lexikon, II, 1, col. 1706. 
Stoll, H. W., Immisch, O., s.v. «Kalchas», in Roscher, Lexikon, II, 1, col. 921-924.

Stoyanov, R. V., «Quelques notes sur l'époque et les causes de la fondation de Chersonèse Taurique», VDI, 2007, 2, p. 125-144 (en russe).

Stronk, J., «Wreckage at Salmydessos », in Thracia Pontica III. Les Thraces et les colonies grecques, VII-V s. av. n. è. (Sozopol, 6-12 octobre 1985), Sofia 1986, p. 203-215.

Surikov, I.E., «Ostracisme et ostraka à Athènes et en dehors de ses frontières », Hyperboreus 6, 1, 2000, p. 103-123 (en russe).

Surikov, I. E., Compte rendu de Paltseva, Mégare, VDI 2002, 3, p. 212-217.

Svenbro, J., «A Mégara Hyblaea: le corps géomètre », Annales (HSS) 37, 1982, p. 953 964.

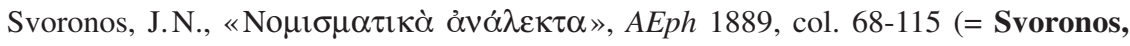
Nomism. Analekta).

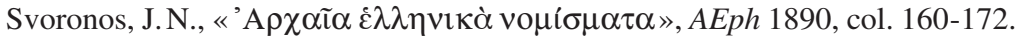

Sweet, W. E., «Protection of the Genitals in Greek Athletics», AncW 11, 1985, p. 43-52.

Swoboda, H., Die griechischen Volksbeschlüsse, Leipzig 1890 (= Swoboda, Gr. Volksbeschlüsse).

Swoboda, H., «Studien zu den griechischen Bünden», Klio 12, 1912, p. 17-50.

Szanto, E., Die griechischen Phylen, Wien 1901.

Tacheva-Hitova, M., Eastern Cults in Moesia inferior and Thracia (5th Century BC4th Century AD), Leiden 1983.

Talmaţchi, G., The Coinage of the West-Pontic Cities of Histria, Callatis and Tomis during the Autonomous Era. Iconography, Legend, Metrology, Chronology and Countermarking, Cluj-Napoca 2011 (en roumain).

Tamburello, I., «La Montagnola di Marineo», SicArch III, 10, 1970, p. 31-38.

Tarn, W. W., «The Greeks Leagues and Macedonia», in The Cambridge Ancient History, vol. VII, The Hellenistic Monarchies and the Rise of Rome, S. A. Cook et al. (éds.), Cambridge 1928, p. 732-768.

Tausend, K., Amphiktyonie und Symmachie. Formen zwischenstaatlicher Beziehungen im archaischen Griechenland, Stuttgart 1992.

Taylor, M. C., Salamis and the Salaminioi. The History of an unofficial Athenian Demos, Amsterdam 1997.

Tedeschi, G., «La guerra lelantina e la cronologia esiodea», in Studi triestini di antichità in onore di L.A. Stella, Trieste 1975, p. 149-167.

Thamm, M., De re publica ac magistratibus Megarensium, Dissertation Halle 1885.

Thomas, R., Literacy and Orality in Ancient Greece, Cambridge 1992.

Thomasson, B.E., Laterculi Praesidium, vol. 1, Göteborg 1984.

Thompson, M., Mørkholm, O., Kraay, C. M., An Inventory of Greek Coin Hoards, New York 1973.

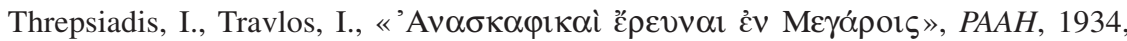
p. 39-57.

Tinnefeld, F., s.v. «Nomophylakes», in Der neue Pauly. Enzyklopädie der Antike, vol. 8, Stuttgart-Weimar 2000, col. 981-982.

Tod, M. N., Compte rendu de Hanell, Megarische Studien, CR 49, 1935, p. 76-77.

Toepffer, J., Quaestiones Pisistrateae, Dorpat 1886.

Toepffer, J., Attische Genealogie, Berlin 1889. 
Toepffer, J., s.v. «Aisymnetes» 1, RE I, 1, 1893, col. 1089-1091.

Toepffer, J., «Astakos», Hermes 31, 1896, p. 124-136.

Tokhtasyev, S.R., «Sur l'onomasticon et la datation des ostraka de Chersonèse », VDI, 2007, 2, p. 110-125 (en russe).

Tomlinson, R.A., «Perachora: the Remains outside two Sanctuaries », ABSA 64, 1969, p. 155-258.

Tomlinson, R. A., Argos and the Argolid. From the End of the Bronze Age to the Roman Occupation, Ithaca-New York 1972.

Tomlinson, R. A., Greek Sanctuaries, London 1976.

Tomlinson, R. A., «The Upper Terraces at Perachora», ABSA 72, 1977, p. 197-202.

Tomlinson, R.A., «Perachora», in Le sanctuaire grec, Entretiens sur l'Antiquité classique 37, A. Schachter et J. Bingen (éds.), Genève 1990, p. 321-346 (= Tomlinson, Perachora).

Tomlinson, R.A., «The Chronology of the Perachora Hestiatorion and its Significance», in Sympotica. A Symposium on the Symposion, O. Murray (éd.), Oxford 1990, p. 95101.

Touloumakos, J., Der Einfluß Roms auf die Staatsform der griechischen Stadtstaaten des Festlandes und der Inseln im ersten und zweiten Jhdt. v. Chr., Diss. Göttingen 1967.

Travlos, J., Bildlexikon zur Topographie des antiken Attika, Tübingen 1988.

Tréheux, J., «Sur les probouloi en Grèce», BCH 113, 1989, p. 241-247.

Trever, A.A., «The Intimate Relation between Economic and Political Conditions in History, as illustrated in Ancient Megara», CPh 20, 1925, p. 115-132 (= Trever, Megara).

Treves, P., «Les documents apocryphes du Pro Corona», LEC 9, 1940, p. 138-174.

Tréziny, H., «Navires attiques et navires corinthiens à la fin du VIII ${ }^{\mathrm{e}}$ siècle. À propos d'un cratère géométrique de Mégara Hyblaea», MEFRA 92, 1980, p. 17-34.

Tréziny, H., Les enceintes de Mégara Hyblaea, thèse de doctorat d'État, Université de Provence, Aix-en-Provence 1997 (= Tréziny, Enceintes de Mégara).

Tréziny, H., «Lots et îlots à Mégara Hyblaea. Questions de métrodologie», in La colonisation grecque en Méditerranée Occidentale. Actes de la rencontre scientifique en hommage à Georges Vallet organisée par le Centre Jean-Bérard, l'École française de Rome, l'Istituto universitario orientale et l'Università degli studi di Napoli «Federico II»(Rome-Naples, 15-18 novembre 1995), Rome 1999, p. 141-183 (= Tréziny, Lots et îlots à Mégara).

Tréziny, H., «Urbanisme et voirie dans les colonies grecques archaïques de Sicile orientale», Pallas 58, 2002, p. 267-282 (= Tréziny, Urbanisme et voirie).

Tréziny, H., «Les colonies grecques de Méditerranée occidentale», Revue d'histoire urbaine 13, 2005, p. 51-66 (= Tréziny, Colonies gr. de Méditerranée).

Tréziny, H., «Les fortifications archaïques dans le monde grec colonial d'Occident», in Guerra e pace in Sicilia e nel Mediterraneo antico (VIII-III sec. a. C.). Arte, prassi e teoria della pace e della guerra, vol. I, Pisa 2006, p. 255-266.

Tréziny, H., Compte rendu de De Angelis, Megara Hyblaia and Selinous, Gnomon 78, 2006, p. 712-716.

Tréziny, H., «Nouvelles recherches à Mégara Hyblaea», RA, 2007, 1, p. 183-188. 
Tréziny, H., «Chronique, Mégara Hyblaea», MEFRA 120, 1, 2008, p. 256-260.

Tréziny, H., «De Mégara Hyblaea à Sélinonte, de Syracuse à Camarine: le paysage urbain des colonies et de leurs sous-colonies », in Colonie di colonie. Le fondazioni sub-coloniali greche tra colonizzazione e colonialismo. Atti del Convegno Internazionale (Lecce, 22-24 giugno 2006), M. Lombardo et F. Frisone (éds.), Galatina 2009, p. 161-181 (= Tréziny, De Mégara à Sélinonte).

Tréziny, H., «Aux origines de Mégara Hyblaea», in The 〈DarkAges > revisited. Acts of an International Symposium in Memory of William D. E. Coulson (University of Thessaly, Volos, 14-17 June 2007), A. Mazarakis Ainian (éd.), Volos 2011, p. 541-548.

Tréziny, H., «Grecs et indigènes aux origines de Mégara Hyblaea », MDAI(R) 117, 2011, p. 15-34 (= Tréziny, Grecs et indigènes).

Tréziny, H., «L'agora de Mégara Hyblaea», in Agora greca e agorai di Sicilia, C. Ampolo (éd.), p. 119-123.

Tréziny, H., «Mégara Hyblaea vers 600 av. J.-C.», in Une Odyssée gauloise. Parures de femmes à l'origine des premiers échanges entre la Grèce et la Gaule, S. Verger et L. Pernet (éds.), Arles 2013, p. 288-292.

Trümpy, C., Untersuchungen zu den altgriechischen Monatsnamen und Monatsfolgen, Heidelberg 1997 (= Trümpy, Monatsnamen).

Tscherikower, V., Die hellenistischen Städtegründungen von Alexander dem Großen bis auf die Römerzeit, Philologus, Suppl. 19, 1, Leipzig 1927.

Tsetskhladze, G. R., «Greek Colonisation of the Black Sea Area. Historical Interpretation of Archaeology », in The Greek Colonisation of the Black Sea Area, Historia Einzelschriften 121, G. Tsetskhladze (éd.), Stuttgart 1998, p. 9-68.

Tsetskhladze, G. R., Hargrave, J. F., «Colonization from Antiquity to Modern Times : Comparisons and Contrasts », Ancient West \& East 10, 2011, p. 161-182.

Türk, G., s.v. «Thestor» 1, RE VI A, 1, 1936, col. 185.

Türk, G., s.v. «Pamphylos» 2, RE XVIII, 3, 1949, col. 408.

Tusa, S., «Presenze indigene nel territorio selinuntino », SicArch XV, 49-50, 1982, p. 111118.

Tusa, S., «Prima di Selinunte», in Selinunte, S. Tusa (éd.), Roma 2010, p. 33-64 (= Tusa, Prima di Selinunte).

Tusa, S. et al., «Selinunte-Malophoros : rapporto preliminare sulla II campagna di scavi », SicArch XIX, 60-61, 1986, p. 13-88.

Tusa, V., «Il santuario arcaico di Segesta», in Atti del settimo congresso internazionale di archeologia classica, vol. 2, Roma 1961, p. 31-40.

Tusa, V., «Le divinità ed i templi di Selinunte», Kokalos 13, 1967, p. 186-193.

Tusa, V., «Le necropoli di Selinunte», in Odeon ed altri «monumenti » archeologici, A. Adriani et al. (éds.), Palermo 1971, p. 175-230.

Tusa, V., «La necropoli arcaica e adiacenze. I. Relazione preliminare degli scavi eseguiti a Mozzi negli anni 1972, 1973, 1974», in Mozia IX, Roma 1972, p. 7-98.

Tusa, V., «La zona archeologica di Poggioreale», SicArch V, 18-20, 1972, p. 57-60.

Tusa, V., «Materiali greci dell'VIII e del VII secolo a.C. nella Sicilia Occidentale», in Rizza (éd.), Insediamenti colon. gr., p. 47-51.

Tusa, V., «Ricerche e scavi nelle necropoli selinuntine», ASAA 60, N.S. 44, 1982 (1984), p. 189-202. 
Tusa, V., «Greci e punici», in Les Grecs et l'Occident. Actes du colloque de la Villa Kérylos (1991), Collection de l'École française de Rome 208, Rome 1995, p. 19-28 (= Tusa, Greci e punici).

Tusa Cutroni, A., «La presenza del bucchero a Selinunte: suo significato », Kokalos 12, 1966, p. 240-248.

Tusa Cutroni, A., «Aspetti e problemi della monetazione arcaica di Selinunte (inizi480 a. C.). Natura, metrologia, organizzazione, circolazione», Kokalos 21, 1975, p. 154-173.

Tusa Cutroni, A., «Riflessioni sulla monetazione di Segesta ed Erice», in AПАPXAI. Nuove ricerche e studi sulla Magna Grecia e la Sicilia antica in onore di Paolo Enrico Arias, vol. I, M. L. Gualandi et al. (éds.), Pisa 1982, p. 239-244.

Tusa Cutroni, A., «Recenti studi e ricerche sulla monetazione della Sicilia antica», Kokalos 34, 1988-1989, p. 367-403.

Tusa Cutroni, A., «La monetazione di Selinunte», in Selinunte, S. Tusa (éd.), Roma 2010, p. 157-165.

Urban, R., Wachstum und Krise des achäischen Bundes. Quellenstudien zur Entwicklung des Bundes von 280 bis 222 v. Chr., Historia Einzelschriften 35, Wiesbaden 1979.

Ure, P.N., The Origin of Tyranny, Cambridge 1922.

Vagalinski, L. F., Blood and Entertainments. Sports and Gladiatorial Games in Hellenistic and Roman Thrace, Sofia 2009 (en bulgare).

Vaglio, M., «L'ecista ateniese. Una nota su Teocle, il fondatore di Nasso », Hesperìa, 17 : studi sulla grecità di Occidente, L. Braccesi (éd.), Roma 2003, p. 159-164.

Valk, M. van der, «Ajax and Diomede in the Iliad», Menmosyne 5, 1952, p. 269-286.

Valk, M. van der, Researches on the Text and Scholia of the Iliad, vol. I-II, Leiden 19631964.

Vallet, G., «La colonisation chalcidienne et l'hellénisation de la Sicile orientale », Kokalos 8, 1962, p. 30-51 (= Vallet, Le monde gr. colonial, p. 87-105).

Vallet, G., «Métropoles et colonies. Leurs rapports jusque vers la fin du $\mathrm{VI}^{\mathrm{e}}$ siècle», in Metropoli e colonie di Magna Grecia. Atti del terzo convegno di studi sulla Magna Grecia (Taranto, 13-17 otobre 1963), Napoli 1964, p. 209-229 (= Vallet, Le monde gr. colonial, p. 19-32).

Vallet, G., «Céramique d'importation en Sicile avant 730», in Incontro di studi sugli inizi della colonizzazione greca in Occidente (Napoli-Ischia 1968), Dialoghi di archeologia 3, 1969, p. 126-171 (= Vallet, Le monde gr. colonial, p. 323-361).

Vallet, G., «Espace privé et espace public dans une cité coloniale d'Occident (Mégara Hyblaea)», in Problèmes de la terre en Grèce ancienne, M. I. Finley (éd.), Paris 1973, p. 83-94 (= Vallet, Le monde gr. colonial, p. 463-475).

Vallet, G., «La colonisation grecque en Occident», in Vallet, Le monde gr. colonial, p. 317 [communication au XIII ${ }^{e}$ Congrès international des Sciences Historiques, Moscou (1970), 1973, p. 53-72].

Vallet, G., «Travaux et recherches à Mégara Hyblaea», Kokalos 26-27, 1980-1981, p. $789-804$.

Vallet, G., «Rhégion et Zancle, vingt ans après », in Il commercio greco nel Tirreno in età arcaica. Atti del seminario in memoria di Mario Napoli (Salerno, 1977), Salerno 1981, p. 111-125 (= Vallet, Le monde gr. colonial, p. 389-403). 
Vallet, G., «La céramique grecque ou de tradition grecque au VIII ${ }^{\mathrm{e}}$ siècle en Italie centrale et méridionale. Position des problèmes", in La céramique grecque ou de tradition grecque au VIII siècle en Italie centrale et méridionale, Cahiers du Centre Jean Bérard 3, G. Vallet (éd.), Naples, 1982, p. 11-19 (= Vallet, Le monde gr. colonial, p. 363-372).

Vallet, G., «Urbanisation et organisation de la chora coloniale grecque en Grande Grèce et en Sicile», in Modes de contacts et processus de transformation dans les sociétés anciennes (Actes du colloque de Cortone, mai 1981), Pise-Rome 1983, p. 937-956 (= Vallet, Le monde gr. colonial, p. 477-495; = Vallet, Urbanisation).

Vallet, G., «Bilan des recherches à Mégara Hyblaea», in Atti del Convegno internazionale «Grecia, Italia e Sicilia nell'VIII e VII secolo a. C. (Athènes 1979), ASAA 60, N.S. 44, 1982 (1984), p. 173-182 (= Vallet, Le monde gr. colonial, p. 453-462; = Vallet, Bilan].

Vallet, G., «Les cités chalcidiennes du Détroit et de Sicile», in Gli Eubei in Occidente. Atti del diciottesimo convegno di studi sulla Magna Grecia (Taranto 1978), Taranto 1984, p. 83-114 (= Vallet, Le monde gr. colonial, p. 115-162).

Vallet, G., s.v. «Brucoli», in BTCGI IV, 1985, p. 200-204.

Vallet, G., s . v. «Megara Iblea», in BTCGI IX, 1991, p. 511-534.

Vallet, G., «Chronique, Mégara Hyblaea», MEFRA 105, 1993, p. 462-470.

Vallet, G., Le monde grec colonial d'Italie du Sud et de Sicile, Paris-Rome 1996 (= Vallet, Le monde gr. colonial).

Vallet, G., Villard, F. «Les dates de fondation de Mégara Hyblaea et de Syracuse», $B C H$ 76, 1952, p. 289-346 (= Vallet-Villard, Dates de fondation).

Vallet, G., Villard, F., «À propos des dates de fondation de Mégara Hyblaea, de Syracuse et de Sélinonte», BIBR 24, 1955, p. 199-214.

Vallet, G., Villard, F., «La date de fondation de Sélinonte: les données archéologiques », BCH 82, 1958, p. 16-26 (= Vallet-Villard, La fond. de Sélinonte).

Vallet, G., Villard, F., «Le repeuplement du site de Mégara Hyblaea à l'époque de Timoléon », Kokalos 4, 1958, p. 100-106.

Vallet, G., Villard, F., «Céramique et histoire grecque», $R H$ 458, 1961, p. 295-318 (= Vallet, Le monde gr. colonial, p. 231-252).

Vallet, G., Villard, F., Mégara Hyblaea 2. La céramique archaïque, Paris 1964 (=Mégara 2).

Vallet, G., Villard, F., Mégara Hyblaea 4. Le temple du IVe siècle, Paris 1966.

Vallet, G., Villard, F., «Mégara Hyblaea IX. Les problèmes de l'agora et de la cité archaïque», MEFR 81, 1969, p. 7-35.

Vallet, G., Villard, F., Auberson, P., «Expériences coloniales et urbanisme: les fouilles de Mégara Hyblaea», Annales (HSS) 25, 1970, p. 1102-1113 (= Vallet, Le monde gr. colonial, p. 437-452).

Vallet, G., Villard, F., Auberson, P., Mégara Hyblaea 1. Le quartier de l'agora archaïque, avec la collaboration de M. Gras et H. Tréziny, Rome 1976 (=Mégara 1).

Vallet, G., Villard, F., Auberson, P., Mégara Hyblaea 3. Guide des fouilles. Introduction à l'histoire d'une cité coloniale d'Occident, Rome 1983 (= Mégara 3).

Vallet, G., Voza, G., Dal neolitico all'era industriale nel territorio da Augusta a Siracusa, Siracusa 1984 (= Vallet-Voza, Augusta).

Vanicelli, P., Compte rendu de Mégara 3, RFIC 115, 2, 1987, p. 335-339. 
Vanotti, G., «L'archaiologhia siciliana di Filisto», in Hesperìa, 3 : studi sulla grecità di Occidente, L. Braccesi (éd.), Roma 1993, p. 115-135.

Vanotti, G., «L'idea di colonizzazione in Elanico e in Tucidide», in Antonetti (éd.), Il dinam. della colon. gr., p. 97-107.

Vatin, C., «Quelques inscriptions d'époque impériale», $B C H$ 90, 1966, p. 240-247.

Vatin, C., «La stèle funéraire de Byzance n. $41 », B C H$ 92, 1968, p. 220-225.

Vatin, C., «Citoyenneté et ethnique des colonies grecques. À propos de Diodore XV, 18 », Anatolia Antiqua 2, 1993, p. 71-80 (= Vatin, Citoyenneté et ethnique).

Veligianni-Terzi, C., Damiurgen. Zur Entwicklung einer Magistratur, Diss. Heidelberg 1977.

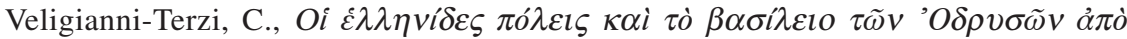

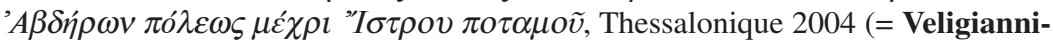
Terzi, Hellenides poleis).

Velissaropoulos-Karakostas, J., Droit grec d'Alexandre à Auguste (323 av. J.-C.-14 ap. J.-C.). Personnes-Biens-Justices, vol. I-II, MEAETHMATA 66, Athènes 2010.

Velkov, V., «Mesambria-Mesembria-Nessèbre (Situation, recherches, notes historiques) », in Nessèbre I, Sofia 1969, p. 9-28 (= Velkov, Mesambria).

Velkov, V., «Zur Geschichte der Mesambria Pontica im III. Jh. v.u.Z.», in Acta of the Fifth International Congress of Greek and Latin Epigraphy, Cambridge 1967, Oxford 1971, p. 109-112.

Velkov, V., «Mesambria Pontica», in Die bulgarische Schwarzmeerküste im Altertum, Xenia 16, W. Schuller (éd.), Konstanz 1985, p. 29-50 (= Geschichte und Kultur Thrakiens und Mösiens, Amsterdam 1988, p. 81-101).

Velkov, V., «Inscriptions antiques de Messambria (1964-1984)», in Nessèbre III, Burgas 2005, p. 159-193 (= Velkov, Inscr. de Messambria).

Venedikov, I., «La Mésambria thrace», in Nessèbre II, Sofia 1980, p. 7-22.

Venedikov, I., «Les fortifications dans la partie nord-ouest de Nessèbre», in Nessèbre II, Sofia 1980 , p. 23-80.

Venedikov, I., «Trois reliefs surprenants de Mésambria», in Nessèbre II, Sofia 1980, p. 83-95.

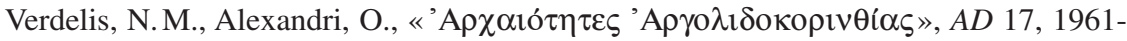
1962, p. 52-54.

Verger, S., «Des objets gaulois dans les sanctuaires archaïques de Grèce, de Sicile et d'Italie», CRAI, 2003, 1, p. 525-571.

Verger, S., «Les objets gaulois dans la Sicile méridionale grecque», in Une Odyssée gauloise. Parures de femmes à l'origine des premiers échanges entre la Grèce et la Gaule, S. Verger et L. Pernet (éds.), Arles 2013, p. 234-236.

Vernant, J.-P., Mythe et pensée chez les Grecs. Études de psychologie historique ${ }^{3}$, Paris 1985.

Veronese, F., Lo spazio e la dimensione del sacro. Santuari greci e territorio nella Sicilia arcaica, Padova 2006 (= Veronese, Santuari greci).

Vian, F., «Génies des passes et des défilés », $R A$ 39, 1952, p. 129-155.

Vidal-Naquet, P., «Réflexions sur l'historiographie grecque de l'esclavage», in Actes du Colloque 1971 sur l'esclavage, Paris 1972, p. 25-39 (= Le chasseur noir. Formes de pensée et formes de société dans le monde grec ${ }^{2}$, Paris 1991, p. 223-248; = VidalNaquet, L'historiographie gr. de l'esclavage). 
Villard, F., «Mégara Hyblaea», MEFR 63, 1951, p. 7-52.

Villard, F., «Le cas de Mégara Hyblaea: est-il exemplaire?», in La colonisation grecque en Méditerranée Occidentale. Actes de la rencontre scientifique en hommage à Georges Vallet organisée par le Centre Jean-Bérard, l'École française de Rome, l'Istituto universitario orientale et l'Università degli studi di Napoli «Federico II» (Rome-Naples, 15-18 novembre 1995), Rome 1999, p. 133-140.

Villard, F., Vallet, G., «Mégara Hyblaea II : les fouilles de $1950 », M E F R$ 64, 1952, p. 7-38.

Villard, F., Vallet, G., «Mégara Hyblaea III: les fouilles de 1951 », MEFR 65, 1953, p. 9 38.

Villard, P., «Sociétés et armées civiques en Grèce: de l'union à la subversion », $R H$ 266, 1981, p. 297-310.

Vinogradov, J.G., Compte rendu de Solomonik, Épigraph. Chersonèse II, VDI, 1975, 1, p. 169-176.

Vinogradov, J. G., «Les tribus doriennes à Chersonèse Taurique », VDI, 1993, 4, p. 61-66 (en russe ; = Vinogradov, Les tribus doriennes).

Vinogradov, J.G., «Greek Epigraphy of the North Black Sea Coast, the Caucasus and Central Asia (1985-1990)», ACSS 1, 1, 1994, p. 63-74.

Vinogradov, J.G., «Un nouveau dossier documentaire de l'époque impériale de Chersonèse », $V D I, 1996,1$, p. 48-60 (en russe).

Vinogradov, J.G., «Ostrakismos als strenges Kampfmittel für Demokratie im Lichte der neuen Funde aus Chersonesos Taurike», in Gab es das Griechische Wunder? Griechenland zwischen dem Ende des 6. und der Mitte des 5. Jahrunderts v. Chr., D. Papenfuß et M. Strocka (éds.), Mainz 2001, p. 379-386.

Vinogradov, J. G., «Milet und Megara erschliessen den Pontos Euxeinos », in Frühes Ionien - eine Bestandsaufnahme: Panionion-Symposion Güzelçamı, 26. September-1. Oktober 1999, Mainz am Rhein 2007, p. 465-473 (= Vinogradov, Milet und Megara).

Vinogradov, J.G., Zolotarev, M.I., «La Chersonèse de la fin de l'archaïsme», in J. G. Vinogradov, Pontische Studien. Kleine Schriften zur Geschichte und Epigraphik des Schwarzmeerraumes, Mainz 1997, p. 397-419 [= in Le Pont-Euxin vu par les Grecs. Sources écrites et archéologie. Symposium de Vani (Colchide, septembreoctobre 1987), T. Khartchilava et E. Gény (éds.), Paris 1990, p. 85-119; = Vinogradov-Zolotarev, Chersonèse].

Vinogradov, J. G., Zolotarev, M. I., «L'ostracismo e la storia della fondazione di Chersonesos Taurica. Analisi comparata con gli ostraka dal Kerameikós di Atene », MEP 2, 1999, p. 111-131 (= Vinogradov-Zolotarev, Ostracismo).

Visser, E., Homers Katalog der Schiffe, Stuttgart-Leipzig 1997.

Vitucci, G., Il regno di Bitinia, Roma 1953 (= Vitucci, Regno di Bitinia).

Vlahov, K. A., «Die thrakische Herkunft der Ortsnamen an der Schwarzmeerküste während und nach der griechischen Kolonisation», in Thracia Pontica III. Les Thraces et les colonies grecques, VII-V s. av. n. è. (Sozopol, 6-12 octobre 1985), Sofia 1986, p. 174-181.

Vogt, G., De rebus Megarensium usque ad bella Persica, Cassel 1857.

Voza, G., «Ricerche in Ortigia. Esplorazioni nell'area delle necropoli e dell'abitato », in Archeologia nella Sicilia Sud-Orientale, P. Pelagatti et G. Voza (éds.), Napoli 1973, p. 81-107. 
Voza, G., «Villasmundo-Necropoli in contrada Fossa», in Archeologia nella Sicilia SudOrientale, P. Pelagatti et G. Voza (éds.), Napoli 1973, p. 57-63.

Voza, G., «La necropoli della valle del Marcellino presso Villasmundo», in Rizza (éd.), Insediamenti colon. gr., p. 104-110.

Voza, G., «Evidenze archeologiche di VIII e VII secolo a. C. nel territorio di Siracusa: la necropoli di Villasmundo, nella valle del Marcellino», ASAA 60, N.S. 44, 1982 (1984), p. 169-171.

Vulpe, A., «En marge de Ps.-Scymnos 766-770», in La première époque du fer à l'embouchure du Danube et dans les régions pontiques. Actes du colloque international, Tulcea, septembre 1993, Tulcea 1997, p. 181-185.

Wachter, R., «Eine Weihung an Athena von Assesos», EA 30, 1998, p. 1-8.

Wachter, R., Non-Attic Greek Vase Inscriptions, Oxford 2001.

Waddington, W.H., Babelon, E., Reinach, T., Recueil général des monnaies grecques d'Asie Mineure, I, 1-4, Paris 1908-1925 (réimpr. Hildesheim-New York 1976; = Waddington-Babelon-Reinach, Recueil).

Wagner, R., s.v. «Asopos » 8, RE II 2, 1896, col. 1706-1708.

Walbank, F.W., A Historical Commentary on Polybius, vol. I-III, Oxford 1957-1979 (= Walbank, Commentary).

Walbank, F. W., «The Historians of Greek Sicily», Kokalos 14-15, 1968-1969, p. 476-498. Wallensten, J., «Resources for Manpower: Magistrates' Dedications to Aphrodite», in Religion and Society. Rituals, Resources and Identity in the Ancient Graeco-Roman World. The BOMOS-Conferences 2002-2005, A. Holm Rasmussen et S. W. Rasmussen (éds.), Rome 2008, p. 139-150.

Warren, J. W. A., The Bronze Coinage of the Achaian Koinon. The Currency of a Federal Ideal, London 2007.

Wartelle, A. Lexique de la «Poétique» d'Aristote, Paris 1985.

Wasowicz, A., «Traces de lotissements anciens en Crimée», MEFRA 84, 1972, p. 199-229.

Wasowicz, A., «Les lieux de culte des cités pontiques», in Religione e città nel mondo antico. Atti, Centro di ricerche e documentazione sull'antichità classica 11, 19801981, Roma 1984, p. 189-210.

Water, K.H., «The Rise and Decline of some Greek Colonies in Sicily », AncSoc 5, 1974, p. 1-19.

Weber, W., Untersuchungen zur Geschichte des Kaisers Hadrianus, Leipzig 1907.

Wees, H. van, Status Warriors. War, Violence and Society in Homer and History, Amsterdam 1992.

Wees, H. van, «Greeks bearing Arms. The State, the Leisure Class, and the Display of Weapons in Archaic Greece», in Archaic Greece: New Approaches and New Evidence, N. Fisher et H. van Wees (éds.), London 1998, p. 333-378.

Wees, H. van, «The Mafia of Early Greece. Violent Exploitation in the Seventh and Sixth Centuries BC», in Organized Crime in Antiquity, K. Hopwood (éd.), London 1999, p. 1-51 (= Van Wees, Mafia of Early Greece).

Wees, H. van, «Megara's Mafiosi : Timocracy and Violence in Theognis », in Alternatives to Athens. Varieties of Political Organization and Community in Ancient Greece, R. Brock et S. Hodkinson (éds.), Oxford 2000, p. 52-67 (= Van Wees, Megara's Mafiosi). 
Wees, H. van, «<Stasis, Destroyer of Men >. Mass, Elite, Political Violence and Security in Archaic Greece», in Sécurité collective et ordre public dans les sociétés anciennes, Entretiens sur l'Antiquité classique 54, C. Brélaz et P. Ducrey (éds.), VandœuvresGenève 2007, p. 1-39.

Weiss, C., Griechische Flussgottheiten in vorhellenistischer Zeit. Ikonographie und Bedeutung, Würzburg 1984.

Welwei, K.-W., «Heroenkult und Gefallenenehrung im antiken Griechenland», in Tod und Jenseits im Altertum, G. Binder et B. Effe (éds.), Trier 1991, p. 50-70 (= Polis und Arché, Historia Einzelschriften 146, Stuttgart 2000, p. 134-154).

Wentker, H., «Die Ktisis von Gela bei Thukydides », MDAI(R) 63, 1956, p. 129-139.

West, M.L., Studies in Greek Elegy and Iambus, Berlin-New York 1974 (= West, Gr. Elegy and Iambus).

West, M.L., The Hesiodic Catalogue of Women. Its Nature, Structure and Origin, Oxford 1985.

West, M. L. (éd.), Iambi et elegi Graeci ante Alexandrum cantati ${ }^{2}$, vol. II, Oxford 1992 (= West, Iambi et elegi Graeci ${ }^{2}$ ).

West, M.L., Studies in the Text and Transmission of the Iliad, Munich-Leipzig 2001.

Wilhelm, A., «Inschrift aus Pagai», JÖAI 10, 1907, p. 17-32 (= Kleine Schriften, vol. II, 1, Leipzig 1984, p. 261-276).

Wilisch, E., s.v. «Asopos », in Roscher, Lexikon, I, 1, col. 642-644.

Will, E., Korinthiaka. Recherches sur l'histoire et la civilisation de Corinthe des origines aux guerres médiques, Paris 1955 (= Will, Korinthiaka).

Will, E., Compte rendu d'Aristote, Économique, Paris 1968, REA 71, 1969, p. 437-446 (= Historica Graeco-Hellenistica. Choix d'écrits, 1953-1993, Paris 1998, p. 492501).

Will, E., Compte rendu de Mégara 1, RH 261, 1976, p. 463-466.

Will, E., Histoire politique du monde hellénistique (323-30 av. J.-C.) $)^{2}$, vol. I-II, Nancy 1979-1982 (= Will, Histoire ${ }^{2}$ ).

Willamowitz-Moellendorff, U. von, «Oropos und die Graer», Hermes 21, 1886, p. 91-115.

Willi, A., Sikelismos: Sprache, Literatur und Gesellschaft im griechischen Sizilien (8.5. Jh. v. Chr.), Basel 2008.

Williams, C.K., «Archaic and Classical Corinth», in Corinto e l'Occidente. Atti del trentaquattresimo Convegno di studi sulla Magna Grecia (Taranto, 7-11 ottobre 1994), Taranto 1995, p. 31-45.

Wilson, J.-P., «<Ideologies > of Greek Colonization», in Greek and Roman Colonization : Origins, Ideologies and Interactions, G. Bradley et J.-P. Wilson (éds.), Swansea 2006, p. 25-57.

Wilson, R. J. A., «Archeaology in Sicily», AR for 1981-1982, p. 84-105.

Wilson, R. J. A., Leonard, A. Jr., «Field Survey at Heraclea Minoa (Agrigento), Sicily», JFA 7, 1980, p. 219-239.

Wiseman, J., The Land of the Ancient Corinthians, Göteborg 1978 (= Wiseman, Land).

Woodhead, A. G., The Athenian Agora. Vol. XVI: Inscriptions. The Decrees, PrincetonNew Jersey 1997.

Wörrle, M., Untersuchungen zur Verfassungsgeschichte von Argos im 5 Jhdt. v. Chr., Diss. Friedrich-Alexander-Universität, Erlangen-Nürnberg 1964. 
Wycherly, R.E., The Athenian Agora. Vol. III: Literary and Epigraphical Testimonia, Princeton-New Jersey 1957.

Zedgenidze, A.A., «La date de fondation de Chersonèse taurique», KSIA 159, 1979, p. 26-34 (en russe).

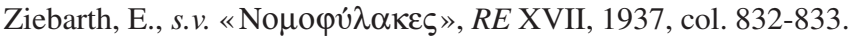

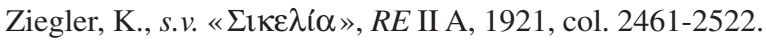

Zirone, D., s.v. «Sciacca», in BTCGI XVIII, 2010, p. 457-463.

Zirone, D., s.v. «Terme Selinuntine», in BTCGI XX, 2011, p. 440-442.

Zolotarev, M.I., "Sur la chronologie de Chersonèse à l'époque archaïque», in Sur les traces des Argonautes. Actes du $6^{e}$ symposium de Vani (Colchide), 22-29 septembre 1990, O. Lordkipanidzé et P. Lévêque (éds.), Paris 1996, p. 311-317.

Zolotarev, M.I., «Chersonesus Tauricus (sic). The Foundation and the Development of the Polis», in Ancient Greek Colonies in the Black Sea, D. V. Grammenos et E. K. Petropoulos (éds.), Thessaloniki 2003, p. 603-644.

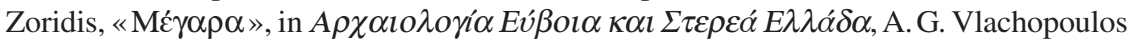
(éd.), Athènes 2008, p. 200-205 (= Zoridis, Mégara).

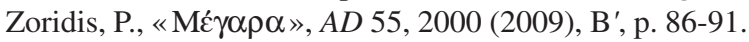

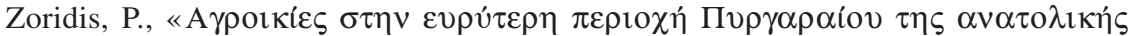

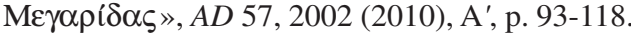

Zurbach, J., «Question foncière et départs coloniaux. À propos des apoikiai archaïques », ASAA 86, serie III, 8, 2008 (2010), p. 87-103.

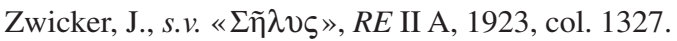




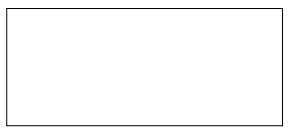




\section{Cartes et planches}

Carte 1 Mégare, les colonies mégariennes et héracléotes.

Carte 2 La Mégaride antique.

Carte 3 L'Attique et l'île de Salamine.

Carte 4 Plan de Mégara Hyblaea.

Carte 5 Plan de Sélinonte.

Pl. I Vue de la ville de Mégare.

Pl. II Vue de la plaine de Mégare, située entre la ville et son port, Nisaia.

Pl. III Vue du golfe d'Aigosthènes.

$P l$. IV Vue de l'arrière-pays d'Aigosthènes.

$P l$. V-VI Vues du sanctuaire de Zeus Aphésios.

$P l$. VII Chersonèse Taurique. Stèle funéraire pourvue d'une tablette. Éd.: Posamentir, Grave Stelai, p. 89, $\mathrm{n}^{\circ}$ C 8. Réserve archéologique de Chersonèse. Inv. 4609.

Pl. VIII, Fig. 1 Mégare. Tablette funéraire. Éd.: P. Graindor, RA, 1917, 6, p. 37, nº 6. Musée épigraphique d'Athènes. Inv. EM 3546.

Pl. VIII, Fig. 2 Pagai. Tablette funéraire.Éd.: IG VII 205. Musée épigraphique d'Athènes. Inv. EM 6002.

Pl. VIII, Fig. 3 Callatis. Tablette funéraire. Éd.: ISM III, 152. Musée d'histoire nationale et d'archéologie de Constanţa. Inv. 92. 


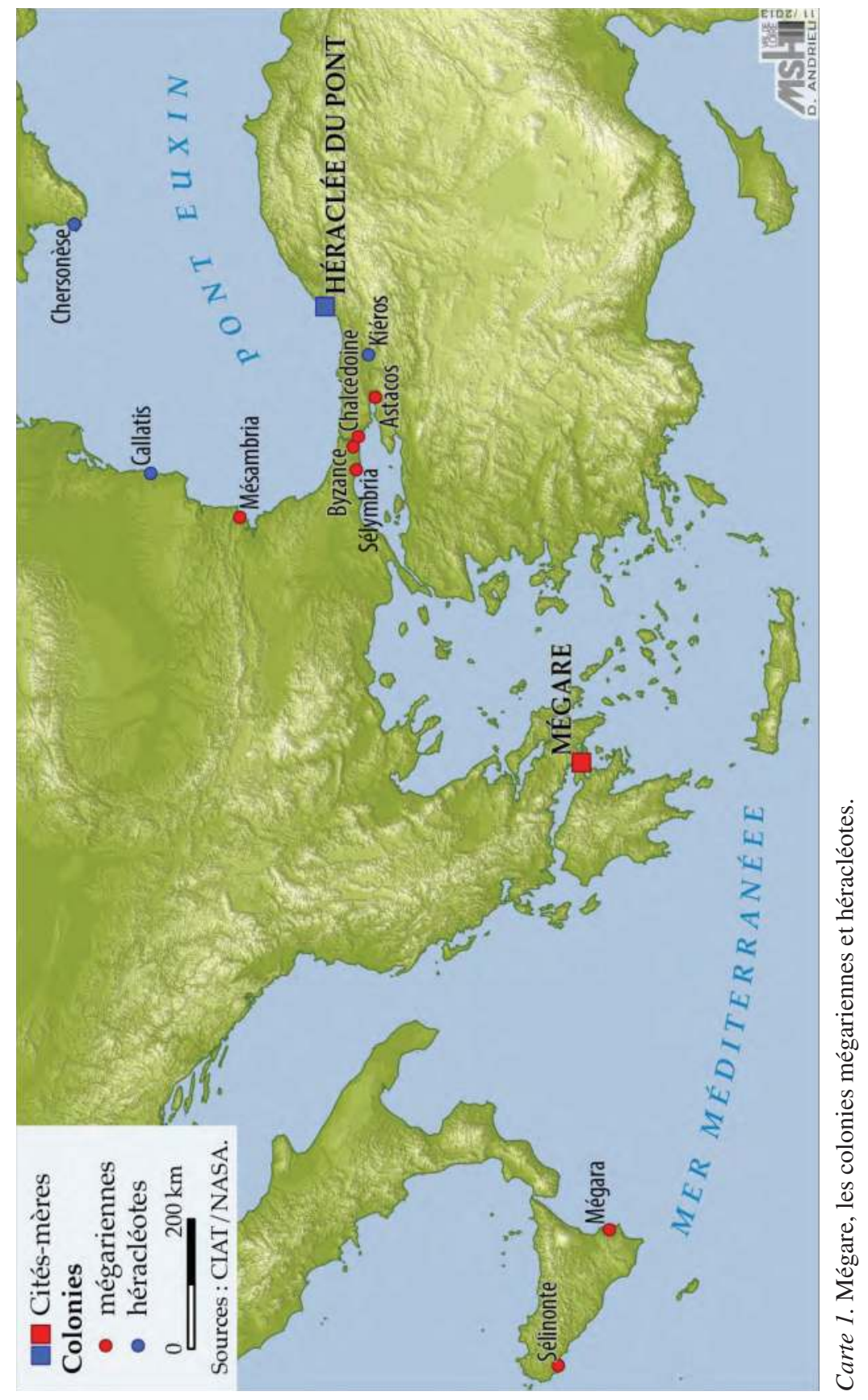




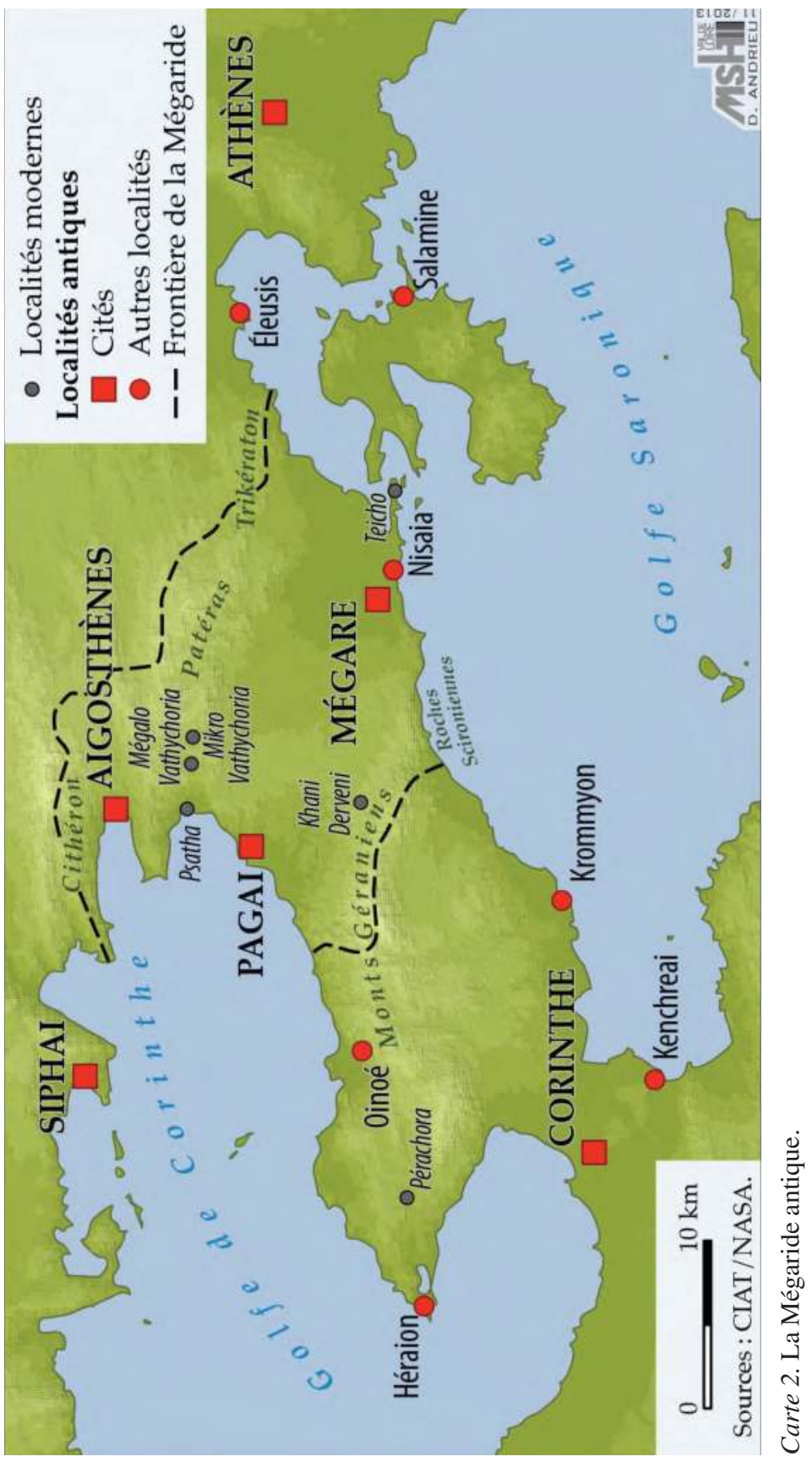




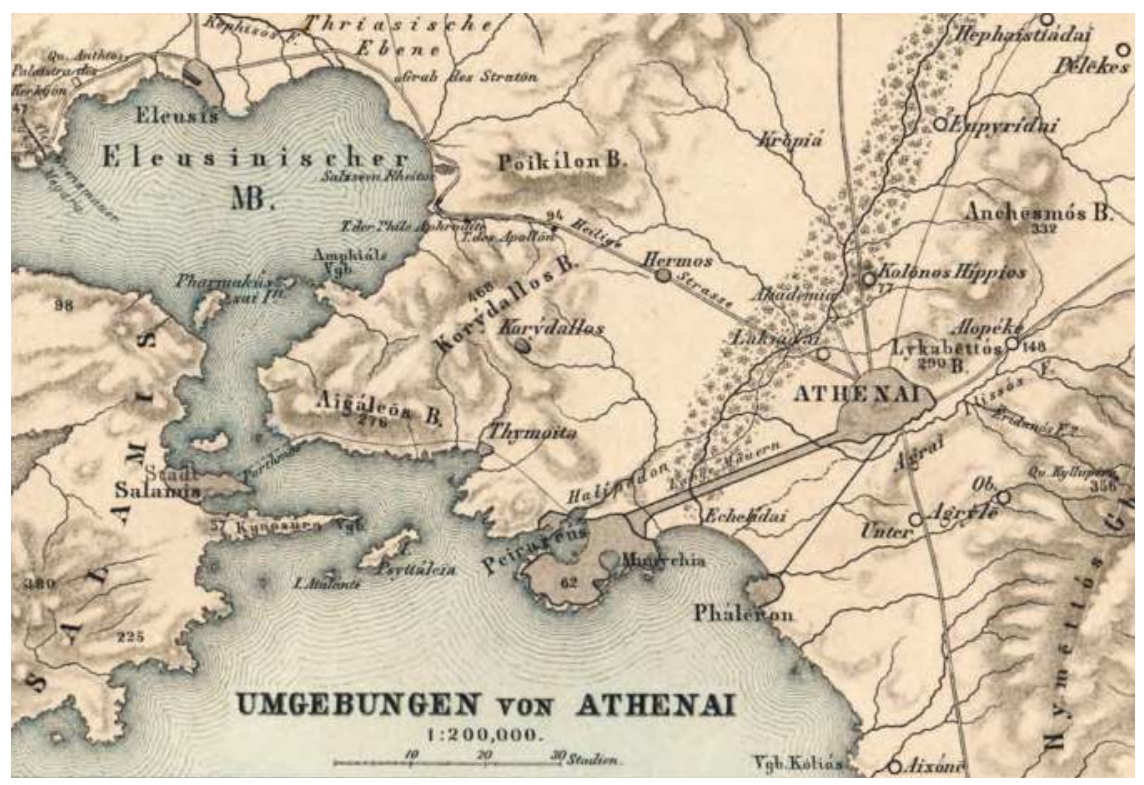

Carte 3. L'Attique et l'île de Salamine. 


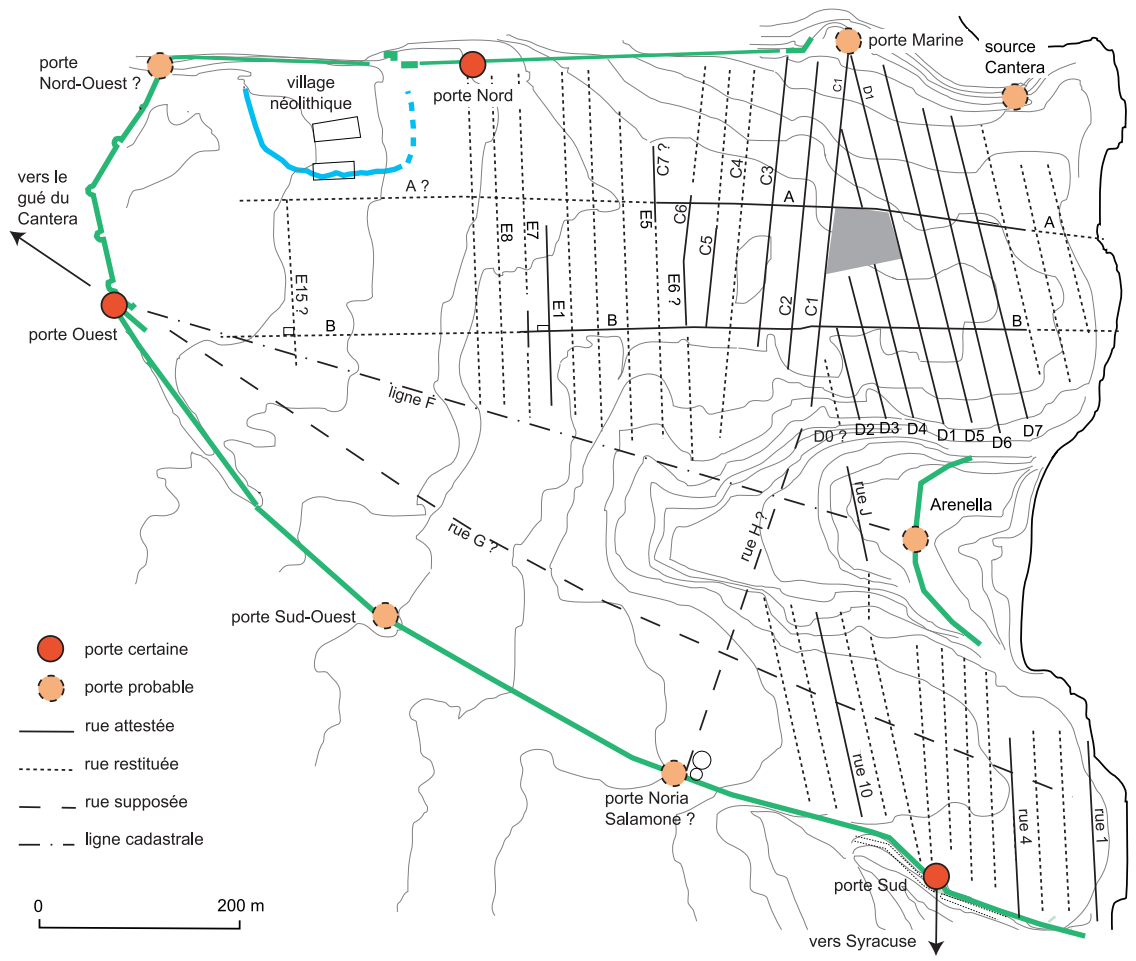

Carte 4. Plan de Mégara Hyblaea. 


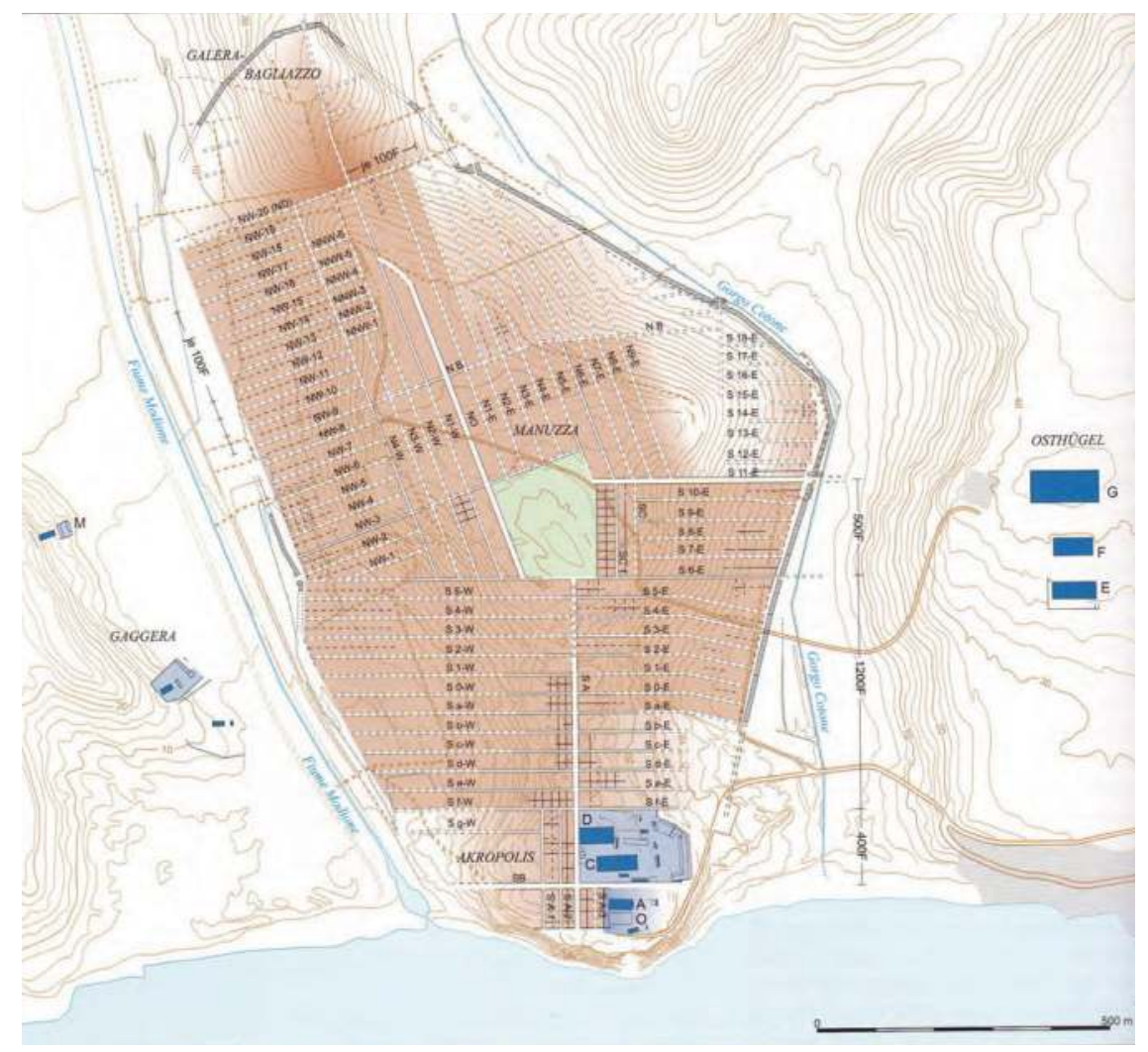

Carte 5. Plan de Sélinonte. 


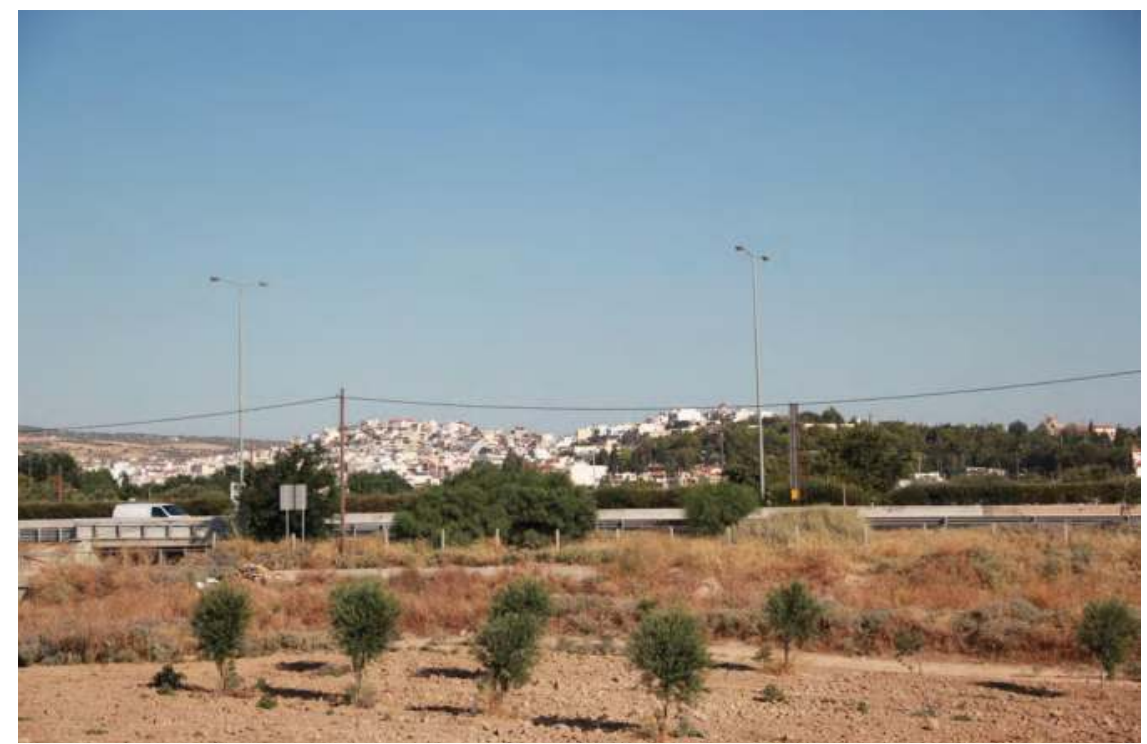

$P l . I$. Vue de la ville de Mégare.

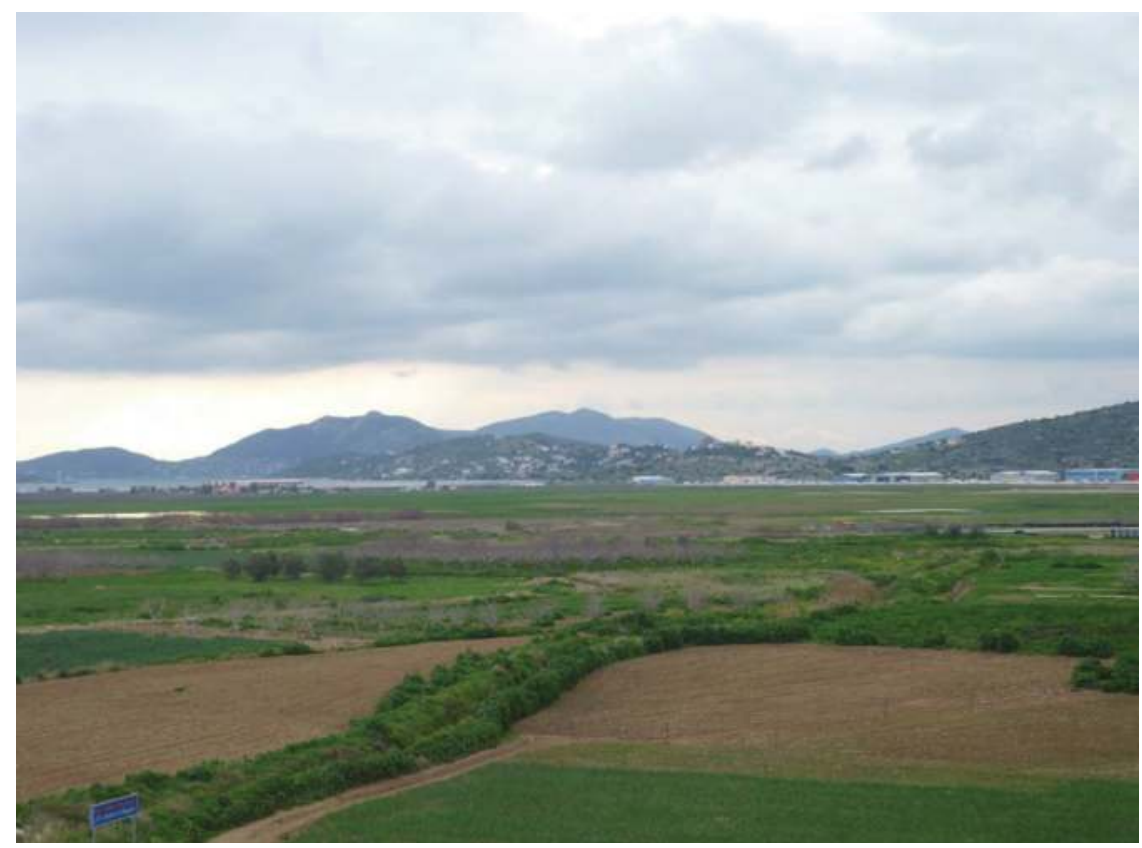

Pl. II. Vue de la plaine de Mégare, située entre la ville et son port, Nisaia. 


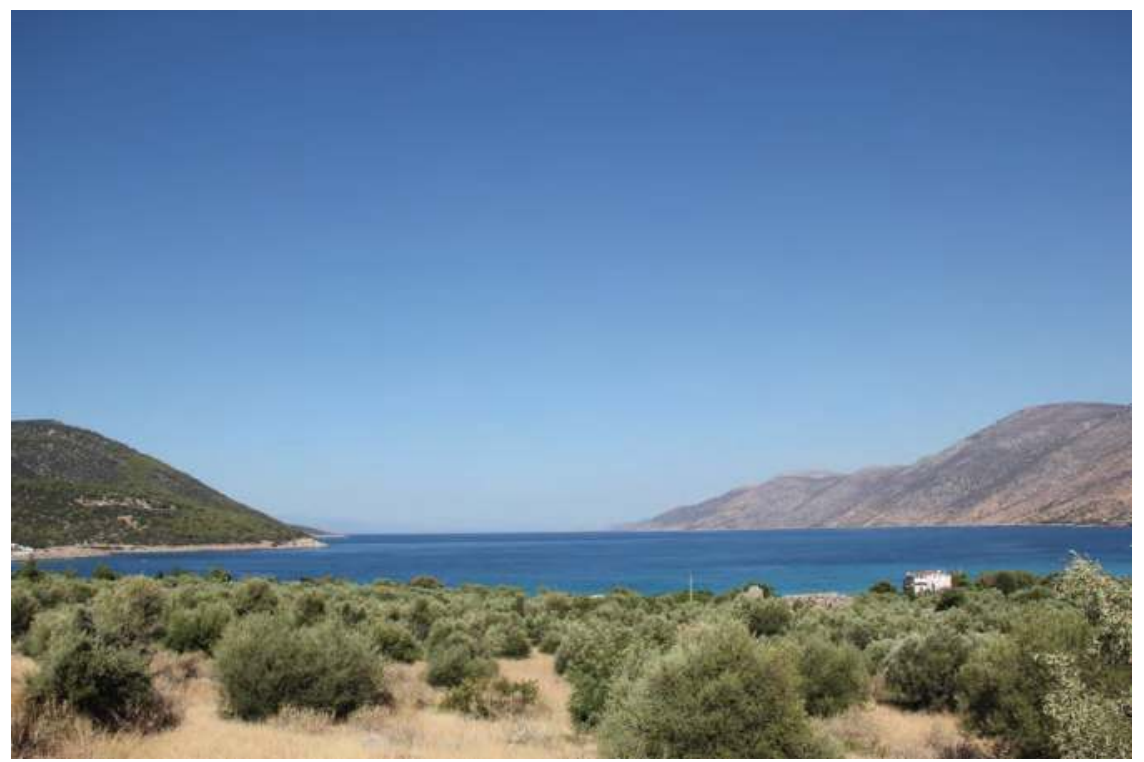

Pl. III. Vue du golfe d'Aigosthènes.

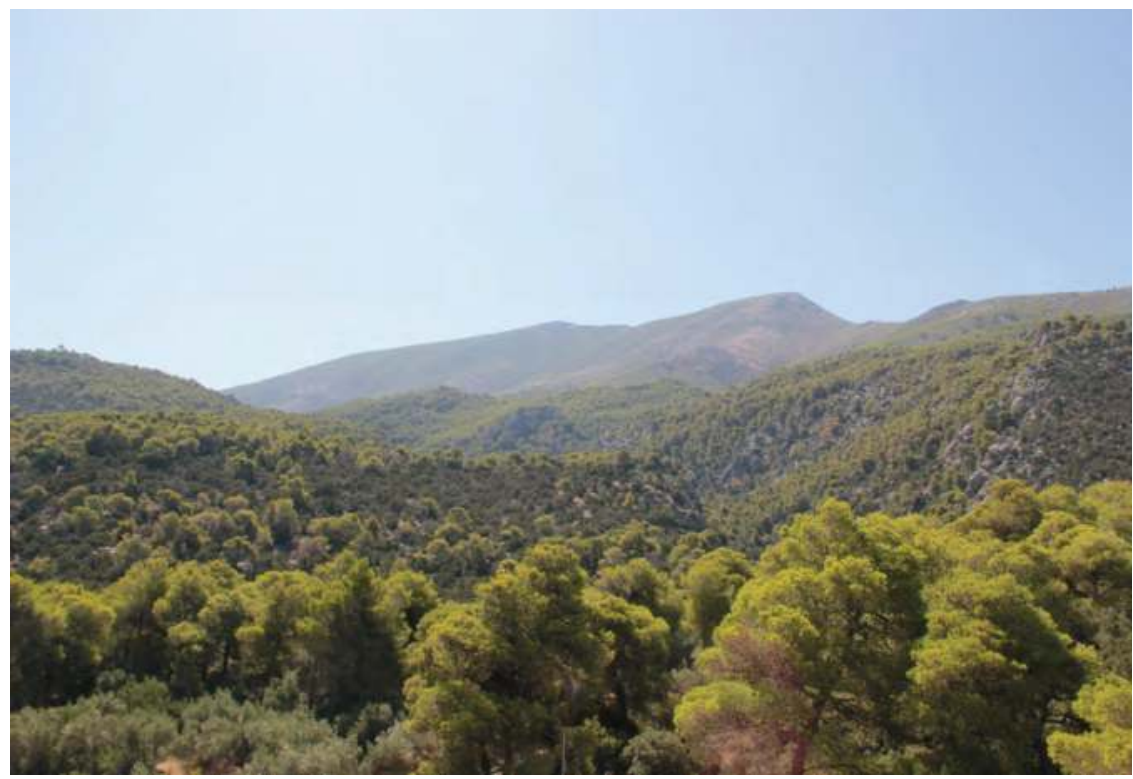

$P l . I V$. Vue de l'arrière-pays d'Aigosthènes. 

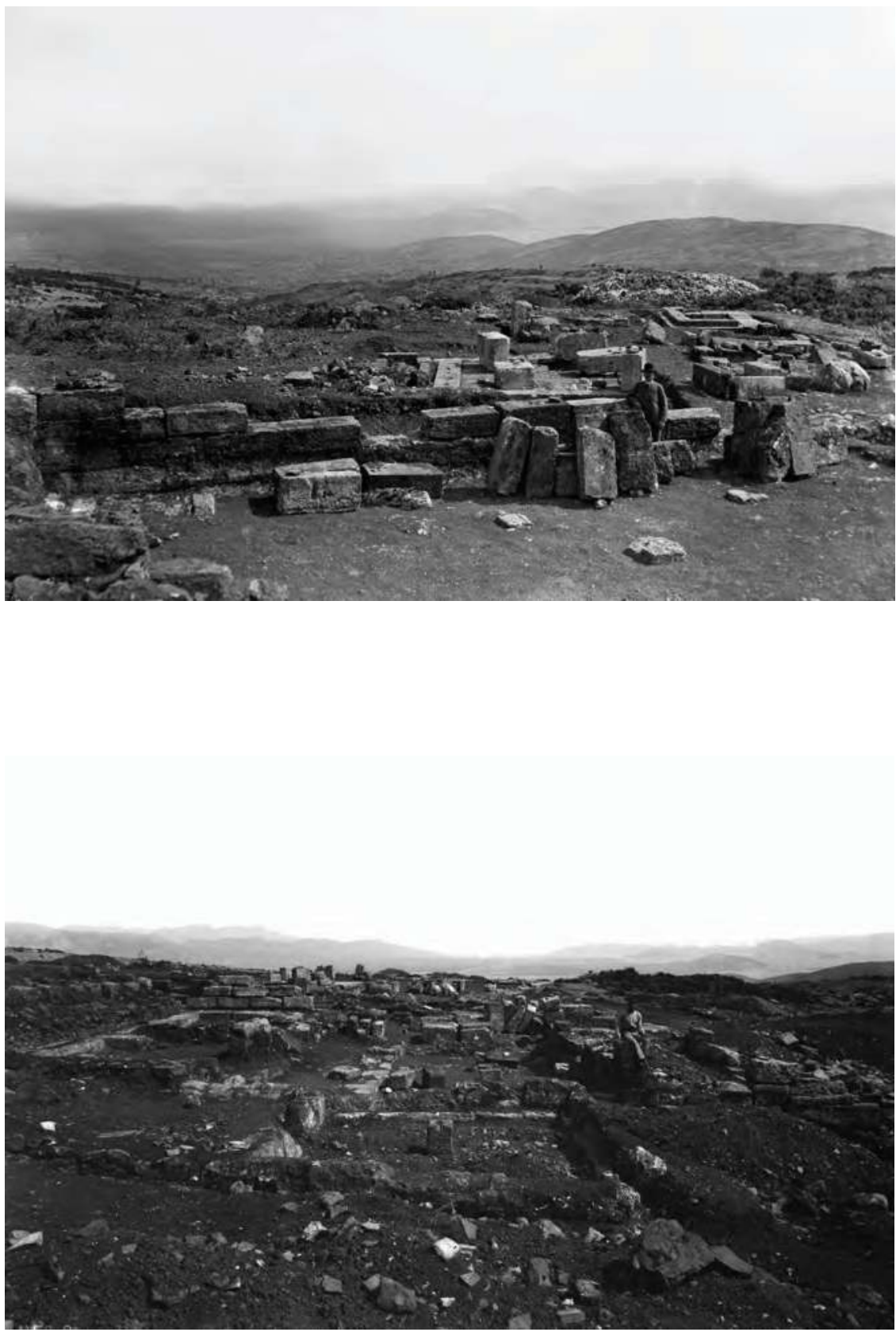

Pl. V-VI. Vues du sanctuaire de Zeus Aphésios. 


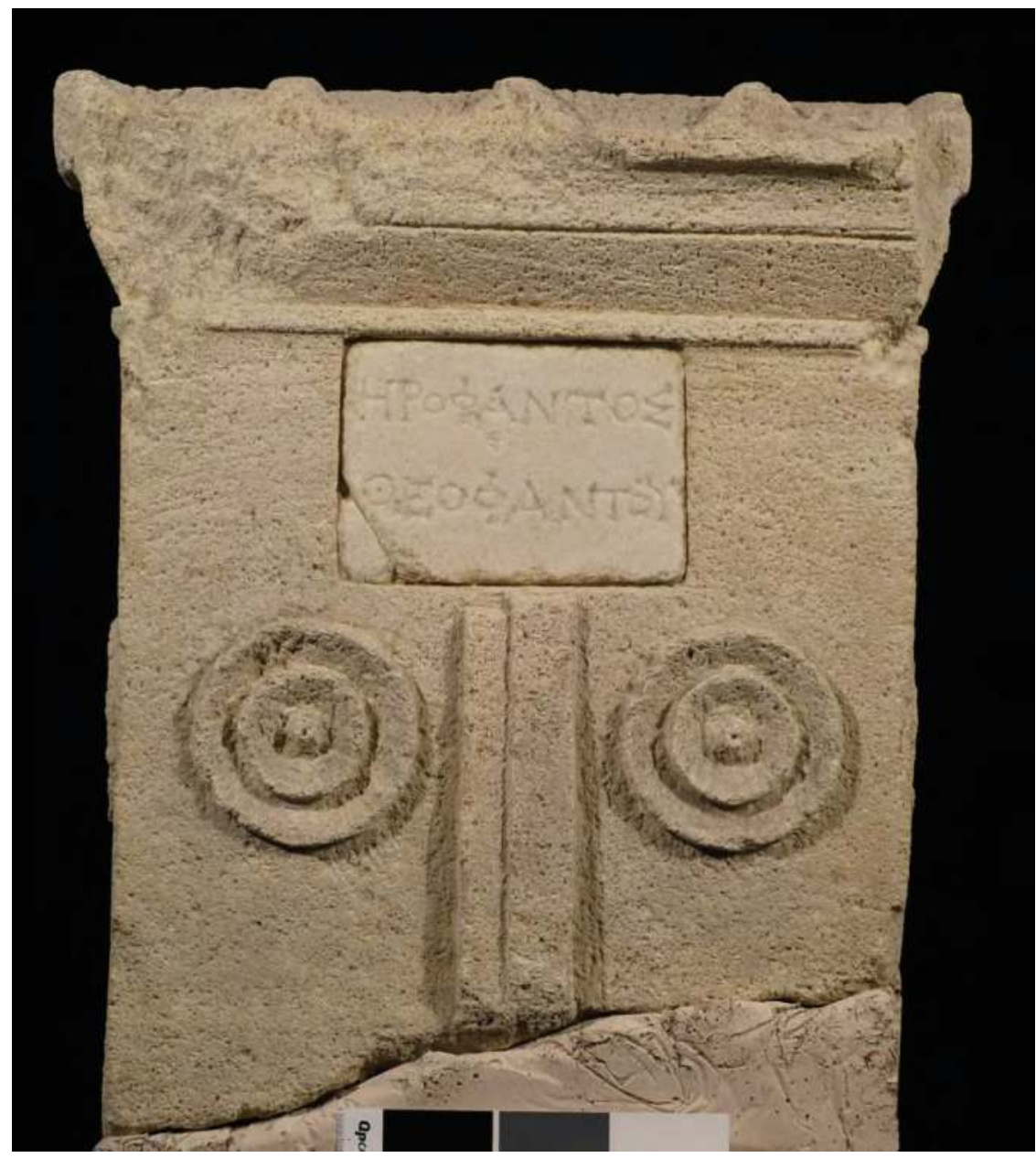

Pl. VII. Chersonèse Taurique. Stèle funéraire pourvue d'une tablette. Éd. : Posamentir, Grave Stelai, p. 89, n ${ }^{\circ}$ C 8. Réserve archéologique de Chersonèse. Inv. 4609. 


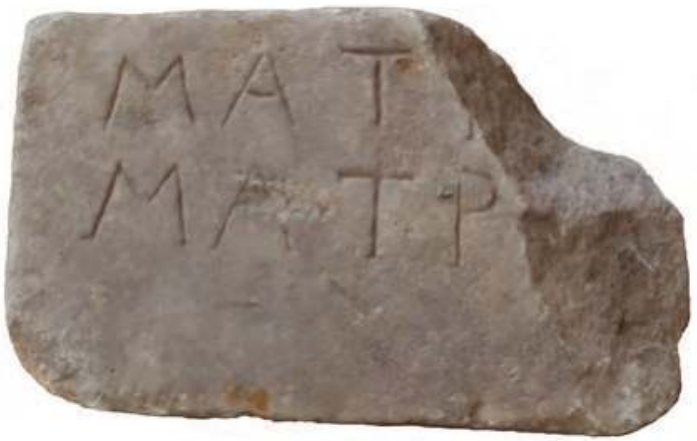

Fig. 1 .

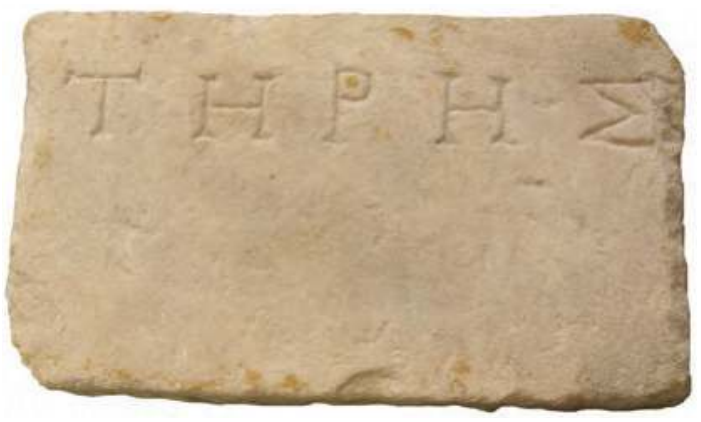

Fig. 2.

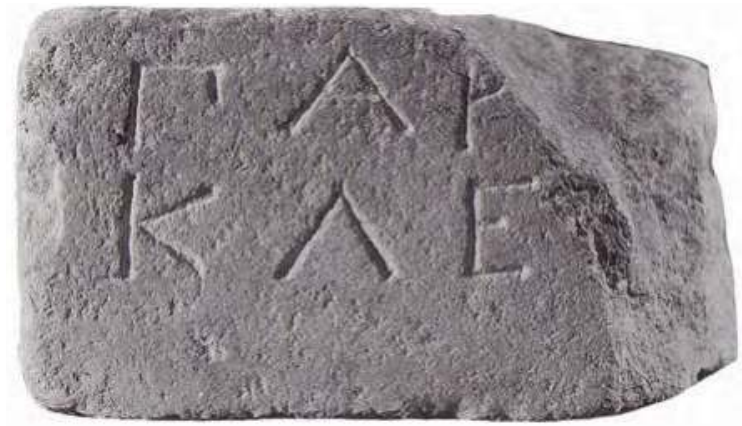

Fig. 3.

Pl. VIII, Fig. 1. Mégare. Tablette funéraire. Éd.: P. Graindor, RA, 1917, 6, p. 37, no 6. Musée épigraphique d'Athènes. Inv. EM 3546.

Pl. VIII, Fig. 2. Pagai. Tablette funéraire. Éd.: IG VII 205. Musée épigraphique d'Athènes. Inv. EM 6002.

Pl. VIII, Fig. 3. Callatis. Tablette funéraire. Éd. : ISM III, 152. Musée d'histoire nationale et d'archéologie de Constanţa. Inv. 92. 


\section{Crédits des illustrations}

Page de titre Musée épigraphique d'Athènes (cliché A. Robu).

Cartes 1-2 D. Andrieu. MSH de Tours.

Carte 3 D'après H. Kiepert, Neuer Atlas von Hellas und den hellenischen Colonien, Berlin 1879, carte 6.

Carte 4 École française de Rome. D’après Mégara 5, p. 529, fig. 470, avec l'aimable autorisation de M. Gras et H. Tréziny.

Carte 5 D'après Mertens, Städte und Bauten, p. 174, fig. 303, avec l'aimable autorisation de D. Mertens.

Pl. I-IV Clichés A. Robu

Pl. V-VI Deutsches Archäologisches Institut, Athenische Abteilung.

Pl. VII I. Engelmann, C. Williams/Institut of Classical Archaeology, Austin, avec l'aimable autorisation de R. Posamentir.

Pl. VIII, Fig. 1-2 Musée épigraphique d'Athènes (clichés A. Robu).

Pl. VIII, Fig. 3 Musée d'histoire nationale et d'archéologie de Constanţa. D'après ISM III, 152, avec l' aimable autorisation d'A. Avram. 


\section{Index}

\section{Index locorum}

\section{I.1 Documents épigraphiques}

$A D$ 8, 1923 (1925), p. 205-206

(= SEG III, 344): 370 n. 212

L. Agostiniani, Iscrizioni anelleniche di

Sicilia. Le iscrizioni elime, Firenze

$1977, \mathrm{n}^{\text {os }} 222,277,281,289,317$ :

186 n. 298

R. Arena (éd.), Iscrizioni greche arcaiche di Sicilia e Magna Grecia. Vol. V: Iscrizioni di Taranto, Locri Epizefiri, Velia e Siracusa, Alessandria 1998, 98 : 144 n. 98

Arkeoloji Sanat 137, 2011, p. 156-157, $\mathrm{n}^{\circ} 1: 404$ n. 364

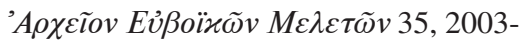
2004 (2006), p. 11-13, no 1 (= SEG LVI, 1030): 167 n. 208

ASNP serie iii, 20, 1, 1990, p. 548, n 2 (= SEG XL, 786): 187 n. 301

ASNP serie iii, 25, 3, 1995, p. 1329 (= SEG XLV, 1415): 173 n. 232

$B C H 13,1889$, p. $316-317, \mathrm{n}^{\circ} 26: 337$ n. 66

$B C H$ 88, 1964, p. 380-382: 144 n. 96

$B C H$ 90, 1966, p. 242-244 (= SEG XXIII, 266, 267): 370 n. 211

$B C H 109,1985$, p. 501-505 (= SEG XXXV, 665): 331 n. 28

Bettarini, Defixiones, ${ }^{\circ} 15$ (=IGDS, 29; IGASM $\left.\mathrm{I}^{2}, 59\right): 170$ ก. 219

- 20 (=IGDS, 37; IGASM $\left.\mathrm{I}^{2}, 61\right)$ : 183 n. 280

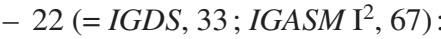

189 n. 312

$$
\begin{aligned}
- & 23\left(=I G D S, 38 ; I G A S M \mathrm{I}^{2}, 63\right): \\
& 170 \text { n. } 218,183 \text { n. } 282,185 \text { n. } 290, \\
& 189 \text { n. } 312 \\
- & 24\left(=I G D S, 36 ; I^{\prime} A S M \mathrm{I}^{2}, 69\right): \\
& 170 \text { n. } 218,353 \text { n. } 139
\end{aligned}
$$

W. Blümel (éd.), Die Inschriften von Iasos, vol. I, Bonn 1985, 1: 390 n. 308

Chiron 42, 2012, p. 217-218: 254 n. 611

K. Clinton, Eleusis. The Inscription on Stone. Documents of the Sanctuary of the Two Goddesses and Public Documents of the Deme, vol. I, Athens $2005, \mathrm{n}^{\text {os }} 159$ (=IG $\left.\mathrm{II}^{2} 1673\right)$ et 177 (= IG $\mathrm{II}^{2}$ 1672): 105 n. 402

N. M. Dimitrova, Theoroi and Initiates in Samothrace. The Epigraphical Evidence, Hesperia, Suppl. 37, Athens 2008, p. 216-217, no 134 : 379 n. 255

L. Dubois (éd.), Inscriptions grecques dialectales d'Olbia du Pont, Genève 1996, $\mathrm{n}^{\circ} 88$ (=IOSPE $\left.\mathrm{I}^{2}, 76\right): 360$ n. 180

Dunbabin, Perachora II, p. 395, $\mathrm{n}^{\circ} 17$; p. $398, n^{\circ} 101: 25$ n. 34

EA 17, 1991, p. 81, no 1 (= SEG XLI, 1102): 344 nn. $100-101,377$ n. 247

H. Engelmann, R. Merkelbach (éds.), Die Inschriften von Erythrai und Klazomenai, Bonn 1972, 24, 29, 32 , 33, 103, 104, 112, 114, 119: 401 n. 353 
FD III, 1, 158: 302

- $177: 341$ nn. $82+85$

$F D$ III $4,372\left(=S I G^{3} 550\right): 268$ n. 680 , $269 \mathrm{nn} .681+683$

P. Frisch (éd.), Die Inschriften von Lampsakos, Bonn 1978, 6 et 9: 335 n. 52

Gephyra 3, 2006, p. 136-137, $\mathrm{n}^{\circ} 2$ (= SEG LVI, 1406): 336 n. 57

Heath, Proxeny Decrees, p. 84-85, ${ }^{\text {os }} \mathrm{I}-$ II: 367 n. 200, 391 n. 313,392

- p. $85, n^{\circ}$ III : 330 n. 23,367 n. 200 , 391 n. 312

P. Herrmann (éd.), Milet VI. Inschriften von Milet, vol. II, Berlin-New York 1998, 732 (= Peek, Griech. VersInschriften, 33): 261 n. 646

Hesperia 7, 1938, p. 3-5, $\mathrm{n}^{\circ} 1$ (= SEG XXI, 527): 66 n. 230

Hesperia 7, 1938, p. 95, $\mathrm{n}^{\circ} 15$ (= A. G. Woodhead, The Athenian Agora. Vol. XVI: Inscriptions. The Decrees, Princeton-New Jersey 1997, no 86): 68 n. 231

Hesperia 24,1955 , p. 228-232 (= SEG XV, 104): 67 n. 227,68 n. 233

Horos 5, 1987, p. 63 (= SEG XXXVII, 371): 97 n. 371

Horos 8-9, 1990-1991, p. 10-12, $\mathrm{n}^{\circ} 1: 66$ n. 220

Horos 13, 1999, p. 173-174 (= SEG XLIX, 500): 369 n. 211

I. Apameia und Pylai, 114: 376 n. 246

I. Byzantion, 1: 342 n. 91, 389 n. 306,

$390 \mathrm{nn} .307+309$

- 2: 264 n. 654,342 n. 92,375 n. 240 , 380 n. 266,381 n. 271,390 n. 307 , 399 n. 343,400 nn. $346,348,351$

- 3: 342 n. 93,399 nn. 343-344

$-4: 399$ n. 343

- $11: 266$ n. 666

- 16:345 nn. 106+109

- 19: 376 n. 241,377 n. 249

$-22: 376$ n. 242

- $30: 344$ n. 104,377 n. 248,378 n. 251
- $31: 377$ n. 248

- 32: 373 n. 228,377 n. 249

- 33: 271 n. 692,377 n. 249

- $34: 373$ n. 228,377 n. 249

$-35: 357$ n. 157,377 n. 249

- 36: 373 n. 228,377 n. 251

- 37-40: $377-378$ n. 251

$-42: 229$ n. 500

- 43: 344 nn. 100-101

- 103: 292 n. 780

- 138-139: 346 n. 112

- 189: 292 n. 781

- 190: 345 n. 106

- 214: 292 n. 781

- 219: 266 n. 665

- 248: 344 n. 103,357 n. 156

- 315 c: 343 n. 95,378 n. 254

- 315 d: 378 n. 254

- 318: 344 nn. $96+99$

- 319 a: 344 n. 105

- 319 b: 344 n. 101

- 320 a: 344 n. 98,359 n. 168

- $323: 374$ n. 231

- 324: 346 n. 113

$-325: 292$ n. 780

- 340: 280 n. 729,292 n. 779

- 368: 292 n. 780

$-369: 292$ n. 780

- 378: 344 n. 97

- S 1:383 n. 279

- S 3:401 n. 352

- S 18: 246 n. 568

- S 23 (=Sayar, Perinthos-Herakleia, 304): 343 n. 94,376 n. 244

- S 24: 246 n. 570, 343 n. 94

- S 44, S 54, S 55: 246 n. 568

$I G \mathrm{I}^{3} 1: 66$ n. 220,79 et n. 293

- 259,260, 263, 267, 268:214 n. 420

- 501: 79 n. 288

- 522 bis: 79 n. 289

- 1149: 328 n. 11

- 1162, 1164, 1165, 1168, 1184 : $328 \mathrm{n} .10$

- 1248, 1267: 144 n. 96

- 1466: 79 n. 289 


$$
\begin{aligned}
& I G \mathrm{II}^{2} 1008: 67 \text { n. } 227,68 \text { n. } 233 \\
& \text { - 1035: } 59 \text { n. } 183 \\
& \text { - 1232: } 68 \text { n. } 232,69 \text { n. } 234 \\
& \text { - 1672, 1673: } 105 \text { n. } 402 \\
& \text { - 8395: } 222 \text { n. } 467 \\
& \text { IG } \text { II }^{3} 1166: 70 \text { n. } 243 \\
& \text { - 1313: } 67 \text { n. } 227 \\
& \text { IG IV 329: } 24 \text { n. } 29 \\
& \text { - 493, 506: } 403 \text { n. } 362 \\
& \text { - 517: } 277 \text { n. } 714 \\
& \text { - 614: } 403 \text { n. } 362
\end{aligned}
$$

IG VII $1: 330$ n. 23, 364 nn. 195-196, 367

n. 200,391 n. 312,392 n. 315,393

n. 321,402 n. 356

- 2-7: 330 n. 23,367 n. 200,391 n. 312

- 8-10: 367 n. 200,391 n. 313

$-11: 367$ n. 200,391 n. 313,392 n. 315

- $12,13: 367$ n. 200,391 n. 313

- 14: 367 nn. $200+203,391$ n. 313

$-15\left(=S I G^{3} 642\right): 382$ n. 275,384 n. 280

- $18: 380$ n. 267

$-25\left(=I G \mathrm{IV}^{2} 2,1128\right): 369 \mathrm{n}$. 208, 394 n. 323

- 27, 28: 367 n. 202, 393 n. 321

$-29,31: 368$ n. 205

$-35: 329$ n. 15

- 37: 115 n. 445

- 39, 40:330 n. 24

- 41: 401 n. 354,402 n. 356

$-42: 331$ n. 27

- 52: 44 n. 112

- 53: 297 n. 804
- $70\left(=I G I^{2} 2,1124\right): 331$ n. 30 , 332 n. 40,394 n. 323

- $71: 332$ nn. $32+40,394$ n. 323

- $72\left(=I G I^{2} 2,1125\right): 331$ n. 31 , 332 n. 40, 394 n. 323

- $73\left(=I G I^{2} 2,1126\right): 332$ n. 33, 394 n. 323

- 74, $75: 394$ n. 323

$-76: 332$ n. 34

- 90: 369 n. 208,394 n. 323

- $101: 333$ n. 41

- $102\left(=I G I^{2} 2,1120\right): 369$ n. 208

- $106\left(=I G I^{2} 2,1122\right): 394$ n. 324

- $107\left(=I G \mathrm{IV}^{2} 2,1121\right): 369$ n. 208

- 188+189 (= Robert, Inscr. de Pagai, p. 107-108): 367 et n. 203, 391 n. 313

- 190 (=JÖAI 10, 1907, p. 19-20): 370 n. 214

- 192: 267 n. 670

- 193-196: 370 n. 215

$-205: 41$ n. 98

- 207: 295 n. 795

- 209, 212:369 n. 210

- 213: 267 n. 670

- 214-218, 220-222: 369 n. 210

- 223: 105 n. 405,369 n. 209, 402 n. 359

- 226-227: 370 n. 211

- 303: 390 n. 308

- 3473: 367 n. 200,391 n. 313

$-3475: 394$ n. 323

- 3491: 332 n. 40,394 n. 323

- 3494: 113 n. 437

$-4236: 394$ n. 323

$I G$ IX 1, 698 : 28 n. 48

$I G$ XII 2, 526 b: 390 n. 308

IG XII 4, 215 (= SEG LIII, 850) : 391

n. 311

- 226: 371 n. 216,375 n. 235,380 n. 261

$I G$ XII 6, $577: 210$ n. 408

$I G$ XII 9, 1188: 133 n. 52

IG XIV, $291: 382$ n. 274 
IGASM I ${ }^{2}, 3$ (=IGDS, 22): 229 n. 501

- 11 (=IGDS, 21): 143 n. 93

- 18 (= IGLMP, 80; IGDS, 73): 173 n. 233

- 25 bis: 354 n. 141-142

- 26-34, 33 bis : 144 n. 97

- 35 (= IGLMP, 35; IGDS, 84) : 172 n. 225

- $41(=I G D S, 45): 157$ n. 157

- 50: 190 n. 319

- $51(=I G D S, 47): 157$ n. 157

- $52(=I v O, 22 ; I G D S, 28): 189$ n. 317

- 53: 173 n. 228,188 n. 310

- 59 (=IGDS, 29; Bettarini,

Defixiones, $\left.\mathrm{n}^{\circ} 15\right): 170$ n. 219

- 61 (=IGDS, 37; Bettarini, Defixiones, $\left.\mathrm{n}^{\circ} 22\right): 183$ n. 280

- 63 (=IGDS, 38; Bettarini,

Defixiones, $\left.\mathrm{n}^{\circ} 23\right): 170$ n. 218 , 183 n. 282,185 n. 290

- 67 (=IGDS, 33 ; Bettarini, Defixiones, $\left.\mathrm{n}^{\circ} 22\right): 189$ n. 312

- 69 (=IGDS, 36; Bettarini,

Defixiones, $\left.\mathrm{n}^{\circ} 24\right)$ : 170 n. 218 , 353 n. 140

- $72: 185$ n. 291

- 79 (=IGDS, 72): 191 n. 329

- $80(=I G D S, 79): 192$ n. 330

- 81: 189 n. 315

IGBulg $\mathrm{I}^{2}, 172: 292$ n. 782

- 307: 323 n. 931

- 308 sexies: 319 n. 912

- 308 septies : $360 \mathrm{nn} .174+177$

- 308 octies : 360 n. 174

- 312: 322 n. 929

- 314 b: 369 nn. 177-178, 404 n. 366

$-318: 32$ n. 65

- 322 bis: 371 n. 219

- 322 ter: 324 n. 936

- 323 : 323 n. 933,334 n. 49, 397

n. 331

- 324: 334 n. 49,396 n. 327

- $325: 334$ n. 50

- 326: 334 n. 49,397 n. 332
- 335 bis: 277 n. 716

- 335 septies: 321,397 n. 330

- $344: 324$ n. 934

- $345: 245$ n. 563,318 nn. $910-911$

- $352: 315$ n. 897

- 354, 354 quater, 355, $363: 324$ n. 936

IGBulg V, 5086: 323 n. 931

- 5091: 360 n. 174

- 5102: 283-284, 395 n. 325,396 n. 328

- 5103: 319 n. 912,395 nn. 325-326, 397

- 5104: 395 n. 325,396 n. 329

- 5111:322 n. 927

IGDS, $21: 143$ n. 93

- $22\left(=I G A S M \mathrm{I}^{2}, 3\right): 229$ n. 501

- 23 (=IGASM I, 25 bis $): 354$ n. 141

- $28\left(=I v O, 22 ;\right.$ IGASM $\left.\mathrm{I}^{2}, 52\right)$ : 189 n. 317,190 nn. $320+322,383$ n. 278

- 29 (= IGASM $\mathrm{I}^{2}, 59$; Bettarini, Defixiones, $\left.\mathrm{n}^{\circ} 15\right)$ : 170 n. 219

- 33 (= IGASM I, 67; Bettarini, Defixiones, $\left.\mathrm{n}^{\circ} 22\right): 189$ n. 212

- 36 (= IGASM I², 69; Bettarini, Defixiones, $\left.\mathrm{n}^{\mathrm{0}} 24\right)$ : 170 n. 218, 353 n. 139

- 37 (= IGASM I², 61; Bettarini, Defixiones, $\left.\mathrm{n}^{\circ} 20\right): 183$ n. 280

- 38 (=IGASM I², 63; Bettarini, Defixiones, $\mathrm{n}^{\mathrm{0}} 23$ ): 170 n. 218 , 183 n. 282,185 n. 290

- 45 (=IGASM $\left.\mathrm{I}^{2}, 41\right), 47$ $\left(=\right.$ IGASM I$\left.^{2}, 51\right): 157$ n. 157

- 56: 193 n. 337

- 63-69: 144 n. 97

- $72\left(=\right.$ IGASM $\left.\mathrm{I}^{2}, 79\right): 191$ n. 329

- 73 (= IGLMP, 80; IGASM I $\left.{ }^{2}, 18\right)$ : 173 n. 233

- 79 (= IGASM I $\mathrm{I}^{2}$ 80): 192 n. 330

- 84 (=IGLMP, 35; IGASM I², 35): 172 n. 225

- 204, $205: 187$ n. 302,382 n. 274

- 206: 382 n. 274 
- 207: 187 n. 302

- 216: 382 n. 274

IGDS II, 18 : 193 n. 336,329 n. 18

- $20: 172$ n. 224,183 n. 283

- 21 : 144 n. 97,186 n. 300,189 n. 315

- 23: 354 n. 141

- $24: 183 \mathrm{nn} .281+284$

IGLMP, 35 (=IGDS, 84; IGASM I $\left.{ }^{2}, 35\right)$ :

172 n. 225

- 80 (=IGDS, 73; IGASM $\left.\mathrm{I}^{2}, 18\right)$ : 173 n. 233

I. Heraclea, $1: 371$ n. 218

- 2 b, 4: 371 n. 217

I. Kalchedon, 1, 2: 401 n. 353

$-4: 380$ n. 263

- 6: 346 n. 116, 347, 384 n. 281, 385 n. 287,386 et n. 288

- $7: 267$ n. 674,334 n. 46, 346 n. $117,347,371$ n. 216,379 n. 260,385 n. 287,386 et n. 288 , 405 n. 367

- 8: 334 n. 47,371 n. 216

- 10: 266 n. 669,371 n. 216,374 n. 234,386 n. 290

- $11: 266$ n. 669,374 n. 234,386 n. 290,405 n. 367

- 12: 374 n. 234,386 n. 290

$-13: 133$ n. 51

$-19: 371$ n. 216

- 30: 228 n. 496

- 35 (= Anthologie Palatine VII, 169) : 258 n. 629,276 n. 709

$-42,61: 380$ n. 264

IOSPE $\mathrm{I}^{2}, 26,31: 390$ n. 308

- 32: 360 nn. 179-180

- 76 [= L. Dubois (éd.), Inscriptions grecques dialectales d'Olbia du Pont, Genève 1996,

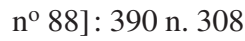

- 342, $343: 405$ n. 369

- 344: 381 n. 268

- 347: 405 n. 369

- 349: 381 n. 268

- 351: 405 n. 368,405 n. 369
- 352: 371 n. 221,381 n. 268,387 n. 294

- 353, 354: 371 n. 221

- 357-361:371 n. 222

- 357: 299 n. 816,389 n. 304

- 359: 298 n. 816,339 n. 72,350 n. 127,389 n. 304,405 n. 368

-362 : 299 n. 816,389 n. 304

- $364: 389$ n. 304,405 n. 368

- $365: 371$ n. 222

- 366, $367: 389$ n. 304

- 376: 371 n. 222

- 384: 371 nn. 221-222

- $401: 403$ n. 360

$-403: 352$ n. 135,307 n. 221

- 410, 414, 415: 371 n. 221

- 420: 403 n. 360

- 423: 403 n. 360,405 n. 368,405 n. 369

- 424, $429: 403$ n. 360

$-436: 298$ n. 815

- 577: 298 n. 814

- 690: 387 n. 294

- $691: 405$ n. 369

- 699: 371 n. 222

I. Prusias ad Hyp., 1-12, 14 : 336 n. 57

- 18:372 n. 223

- 19: 372 nn. 223-224

$-149: 336$ n. 57

ISM I, $28: 360$ n. 181

$-64: 317$ n. 905

ISM III, 2 : 388 n. 297

- 3: 371 n. 220,375 n. 236,388 n. 299

$-4: 388$ nn. $297+300$

$-6: 371$ n. 220

- $7: 371$ n. 220,375 n. 236,388 nn. $297+300,390,398$ n. 335,399 n. 340

- 10: 371 n. 220,387 n. 294

$-11: 371$ n. 220

- 12: 371 n. 220,387 n. 294

- 19: 388 nn. $297+300$

- 28:398 n. 335

- 30: 371 n. 220,398 n. 335, 399 n. 341 
- $35: 371$ n. 220,387 n. 294

$-38,44,46: 371$ n. 220

$-48-50: 298$ n. 812

$-51-55: 352$

$-70: 339$ n. 74

$-72: 300$

$-75: 371$ n. 220

- 106: 398 n. 339

- 112, $122: 371$ n. 220

- 152: 408 n. 4

- $161: 398$ n. 336

IvO, 22 (=IGDS, 28; IGASM $\left.\mathrm{I}^{2}, 52\right): 189$

n. 317

Jameson, Jordan, Kotansky, Lex sacra, p. $14-17: 157$ n. 155,187 n. 303 , 188 n. 310,192 n. 332,329 n. 18

JHS 18, 1898, p. 332 (= SEG XXXVII, $370): 329$ n. 13

JÖAI 10, 1907, p. 19-20 (= IG VII 90): 370 n. 214

Kaloyéropoulou, Décret de Mégare, p. 140: 367 n. 200,391 n. 313,392

J.H. Kent, Corinth, vol. VIII, part III. The Inscriptions (1926-1950), Princeton $1966, n^{\text {os }} 1$ et $5: 49$ n. 137

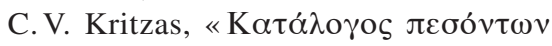

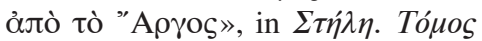

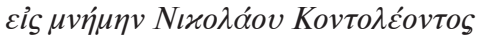
Athènes 1980, p. 498: 328 n. 11

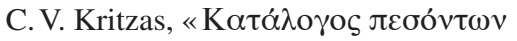

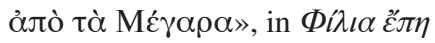

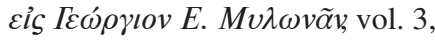
Athènes 1989, p. 169 (= SEG XXXIX, 411): 326 n. 7

Manganaro, Studi di epigrafia, p. 30: 354 nn. 141-142

$\operatorname{MDAI}(A) 10,1885$, p. $19, \mathrm{n}^{\circ} 6$ (= I. Byzantion, 320 a) : 344 n. 98

$\operatorname{MDAI}(A) 59,1934$, p. 52-54, $\mathrm{n}^{\circ} 10$ (= SEG XIII, 300): 72 n. 253

- p. 54-56, n ${ }^{\text {os }} 12$ a-h (= SEG XIII, 317): 407 n. 3

MediterrAnt 7, 2, 2004, p. 686-687, no 3 (= SEG LIV, 941): 170 n. 218

MEFRA 120, 2008, p. 22 : 188 n. 311
MH 59, 2002, p. 32-33 (= SEG LII, 1231): 337 n. 65

L. Moretti, Iscrizioni storiche

ellenistiche, Firenze 1967-1976, vol.

I, no 41 : 335 n. 53

- vol. II, $\mathrm{n}^{\mathrm{o}} 123$ (=IGBulg I $\left.\mathrm{I}^{2}, 307\right)$ : 323 n. 931

Payne, Perachora I, pl. 27, 2; pl. 29, 1-2:

25 n. 34

- pl. $36: 26$ n. 37

- pl. 43, 5-7; pl. 131, 1-2: 25 n. 34

- pl. 131, 7:273 n. 699

- pl. 132, 3-4: 26 n. 37

Peek, Griech. Vers-Inschriften, 33

[= P. Herrmann (éd.), Milet VI.

Inschriften von Milet, vol. II, Berlin-

New York 1998, 732] : 261 n. 646

- 788: 298 n. 815

Posamentir, Grave Stelai, p. $31, \mathrm{n}^{\mathrm{o}} 20$; p. $87, n^{\circ}$ C 6 ; p. $89, n^{\circ}$ C 8 ; p. 93 , $\mathrm{n}^{\circ} \mathrm{C} 12$; p. $99, \mathrm{n}^{\circ} \mathrm{C} 23$; p. 101 , $n^{\circ}$ C 25 ; p. 103-111, n ${ }^{\text {os }}$ C $28-36$;

p. $114, n^{\circ} \mathrm{C} 40: 407$ n. 2

$R A 1917,6$, p. 33-48, nos 1-29: 407 n. 3

- p. $49-51$, n $^{\circ} 30$ (corr. 31): 391 n. 313

RAL 25, 1970, p. $389: 189$ n. 316,407 n. 3 REG 116, 2003, p. 685 (= SEG LIII, 1038): 170 n. 220

A. Rehm (éd.), Das Delphinion in Milet, Berlin 1914, 37 d: 356 n. 150

- 136, $137: 111$ n. 424

- 150: 356 n. 150

P. J. Rhodes, R. Osborne (éds.), Greek Historical Inscriptions (404-323 BC), Oxford 2003, no 37 : 68 nn. 230+232, 69 n. 234

L. Robert, Collection Froehner I. Inscriptions grecques, Paris 1936, p. 23, no 19 (= SEG XIII, 330): 407 n. 3

- p. 23-24, no 20 (= SEG XIII, 316): 407 n. 3

Robert, Inscr. de Pagai, p. 107-108 (= IG VII 188+189) : 368 n. 204, 391 n. 313 
H. Röhl (éd.), Inscriptiones graecae antiquissimae praeter atticas in Attica repertas, Berlin 1882, $\mathrm{n}^{\circ} 381$ a: 390 n. 309

Sayar, Perinthos-Herakleia, 56: 379 nn. 256-257

- 304 (= I. Byzantion, S 23): 342 n. 94

SEG III, 344 : 370 n. 212

- IV, 105: 222 n. 467

- IX, 2: 104 n. 399

- IX, 3: 54 n. 161, 116 n. 446

- XI, 229: 273 n. 699

- XI, 314, 336: 403 n. 362

- XIII, 275 : 277 n. 714

- XIII, 300: 72 n. 253

- XIII, 316, $317: 407$ n. 3

- XIII, $327: 368$ n. 204

- XIII, 330: 407 n. 3

- XV, 104: 67 n. 227, 68 n. 233

- XXI, $527: 68$ n. 230

- XXIII, 266, 267: 370 n. 211

- XXV, $362: 335$ n. 53

- XXX, 702:395 n. 325, 396 n. 328

- XXX, 703: 395 nn. 325-326

- XXX, 704: 395 n. 325

- XXXIII, 275 : 277 n. 714

- XXXIII, 438: 115 n. 444

- XXXV, 400: 44 n. 115

- XXXV, 665: 331 n. 28

- XXXVI, 853: 193 n. 338

- XXXVII, 369: 332 n. 35

- XXXVII, 370: 329 nn. 13+17

- XXXVII, $371: 97$ n. 371

- XXXVII, 614: 322 n. 926

- XXXVIII, 959: 193 n. 338

- XXXIX, $411: 326$ n. 7, 328 n. 12

- XL, 615: 371 n. 221

- XL, 786: 187 n. 301

- XLI, 1102: 344 n. 100, 377 nn. $247+250$

- XLII, 689: 350 n. 127

- XLIII, 497 : 338 n. 69

- XLV, 984: 339 n. 73, 350 n. 127
- XLV, 985 : 339 n. 72, 350 n. 127, 371 n. 222,389 n. 305,405 n. 368

- XLV, 1415: 173 n. 232

- XLV, 2262: 381 n. 267

- XLVIII, 999: 339 n. 72

- XLIX, 500: 370 n. 211

- XLIX, 1031: 98 n. 372, 353 n. 138

- XLIX, 1326: 354 n. 143

- L, 464: 46 n. 121

- LII, 1231: 337 n. 65

- LIII, 850: 391 n. 311

- LIII, 1038: 170 n. 220

- LIV, $941: 170$ n. 218

- LV, 838: 339 n. 72

- LVI, 873: 405 n. 368

- LVI, 1030: 167 n. 208

- LVI, 1406: 336 n. 57

- LVII, 415: 332 n. 36

- LVII, $702: 98$ n. 375

- LVII, 889: 188 n. 311

- LVIII, 423: 391 n. 313

- LVIII, 426: 326 n. 7

- LVIII, 705 : 318 n. 910

SicArch XIX, 60-61, 1986, p. 52-53

(= SEG XXXVI, 853): 193 n. 338

$S I G^{2}, 438: 390$ n. 309

$S I G^{3}, 11: 144$ n. 96

$-331: 402$ n. 356

- 550 (=FD III 4, 372): 268 n. 680 , 269 n. 681

- 642 (= IG VII 15): 384 n. 280

- 644: 389 n. 306

- 709: 386 n. 290,387 n. 295

- 1009: 386 n. 290

Saprykin, Proxénie de Chersonèse, p. 43 (= SEG XLVIII, 999): 339 n. 72, 350 n. 127,371 n. 222,389 n. 304 , 405 n. 368

Solomonik, Épigraph. Chersonèse II, 111 : 339 n. 72,350 n. 127,371 n. 222, 405 n. 368

- II, 112: 339 n. 72,371 n. 222, 405 n. 368 
Sourov, Inscr. de Chersonèse, p. 154-155:

339 n. 72,350 n. 127,371 n. 222,

389 n. 304,405 n. 368

Şahin, Nikomedia, $\mathrm{n}^{\text {os }} 67,68: 290$ n. 768

TAM IV 1, 72: 290 n. 768

VDI, 1996, 1, p. 54-55 (= SEG XLV, 985): 339 n. 72,389 n. 305

VDI, 1996, 4, p. 49-50, no 9: 372 n. 222

VDI 2006, 4, p. 92-94, no 4 (= SEG LVI, 873) : 405 n. 368

Velkov, Inscr. de Messambria, p. 164, $\mathrm{n}^{\mathrm{0}} 5$ : 380 n. 265

- p. $165, \mathrm{n}^{\circ} 6$ (=IGBulg $\mathrm{I}^{2} 308$ sexies): 319 n. 912
- p. $168, n^{\circ} 11: 322$ n. 926

- p. $171, \mathrm{n}^{\circ} 17$ (= IGBulg $\mathrm{I}^{2} 322$

bis) : 371 n. 219

Vinogradov, Les tribus doriennes, p. 64

(= SEG XLIII, 497): 338 n. 69

Vinogradov-Zolotarev, Ostracismo, p. 111-131 (= SEG XLIX, 1031): 98 n. 372, 306 n. 851, 353 n. 138

A. G. Woodhead, The Athenian Agora. Vol. XVI: Inscriptions. The Decrees, Princeton-New Jersey 1997, $n^{\circ} 86$ : 68 n. 231

ZPE 178, 2011, p. $128: 276$ n. 711

\section{I.2 Textes littéraires}

Achille Tatius, II, 14, 2; II, 14, 6; VI, 16, $5: 400$ n. 347

Alciphron, Lettres, III, 8, 1: 102 n. 390

Ammien Marcellin, Histoires, XXII, 8, 5 : 221 n. 460

- XXII, 8, 8: 257 n. 622

Anaximène de Lampsaque, FGrHist 72 F 26: 264 nn. 655-656

Andron d'Halicarnasse, FGrHist $10 \mathrm{~F} 14$ (apud Strabon, IX, 1, 6, C 392): 73 n. 255

Androtion, FGrHist 324 F 34 (apud Plutarque, Solon, 15, 3): 86 n. 321

Anonyme de Mégare, FGrHist 487 F 1 (apud Plutarque, Thésée, 10, 1-4): 38 n. 89,40 n. 96,71 n. 248,73 n. 256

- F 13 (apud Plutarque, Périclès, 30, 4): 38 n. 89

Anonymus, Periplus Ponti Euxini, 10-11

(éd. A. Diller): 293 n. 784

- 84-85: 311 n. 876

Anthologie Palatine, V, 6: 102 n. 389

- VII, 154: 21 n. 19,47 n. 127

- VII, 169 (=I. Kalchedon, 35) : 258 n. 629
- VII, 627, 701 (éds. F. Conzia et al.): 222 n. 467

- XIV, 115: 249 n. 591

Antiphane, Anteia, fr. 36 (éds. R. Kassel

et C. Austin; apud Athénée, III, 126

F et 127 B) : 104 n. 397

Antiochos de Syracuse, FGrHist 555

F 1 (apud Pausanias, X, 11, 3): 172

n. 226

Apollodore, I, 5, 1: 359 n. 169

- III, 12, 7: 65 n. 216,72 n. 249

- III, 15,5 et $8: 73$ n. 259

Apollonios de Rhodes, II, 141 : 304 n. 845

- II, 353-356: 299 n. 822

- II, 531-533: 133 n. 51

- II, 728-736: 299 n. 822

- II, 743-749: 294 n. 789

- II, 746-750: 246 n. 566, 308

- II, 752-810: 308

- II, 842-844 : 297

- II, 846-850: 296 n. 800

- II, 854: 295 n. 794

- II, 911 : 297 n. 809

Archéstratos, fr. 38 (éd. S. Douglas Olson et A. Sens) : 234 n. 519

Archiloque, fr. 216 (éd. F. Lasserre, CUF) : 109 n. 418 
Arrien, FGrHist 156 F 16: 112 n. 434

- F 18: 204 n. 383, 272 n. 696

- F 26 (apud Stéphane de Byzance,

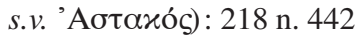

- F 78 (apud Eustathe, GGM II, 803, p. 356): 224 n. 477

Arrien, Périple du Pont-Euxin, XIII, 3 :

294 n. 787

Aristophane, fr. 72 (éds. R. Kassel et

C. Austin) : 357 n. 153

Acharniens, 519-522: 106 n. 407

- 519: 105 n. 401

- 524-529: 38 n. 89

$-729-835: 103$ n. 392

$-754-756: 388$

$-761: 106$ n. 407

- $774: 73$ n. 257

Guêpes, 57 : 363 n. 194

Paix, 246 et 1000-1002: 106 n. 407

- 1002: 105 n. 401

Aristote, fr. 392 (éd. V. Rose, apud

Plutarque, Solon, 32, 4) : 57 n. 174

- fr. 550 (apud Strabon, VII, 7, 2, C 322): 38 n. 87

Éthique à Nicomaque, IV, 2, 1123a

23-24: 363 n. 194

Poétique, III, 1448a 28-40: 19 n. 11, 93 n. 349, 363 n. 194

Politique, I, 2, 5, 1252b 14: 157

n. 156

- I, 2, 6-8, 1252b 15-35: 19 n. 9

- I, 2, 6, 1252b 20-22: 48 n. 133, 293 n. 783

- II, 12, 6, 1274a 23: 157 n. 156

- III, 1, 1, 1274b 38: 325 n. 1

- III, 9, 9, 1280b 13-17: 42 n. 101

- III, 9, 14, 1280b 40-1281a 4: 19 n. 9

- IV, 4, 21, 1291b 22-23: 234 n. 519

- IV, 15, 15, 1300a 17-19: 89 n. 334, 96 n. 363

- V, 3, 5, 1302b 31: 88 n. 328

- V, 3, 11-12, 1303a 25-34: 97 n. 369, 110 n. 421,146 n. 103,281 n. 731
- V, 5, 3-4, 1304b 31-39: 86 n. 322, 96 nn. $363+366,303$ n. 840

- V, 5, 9, 1305a 24-26: 83 n. 310

- V, 6, 2-3, 1305b 1-12: 338 n. 67, 349 n. 126

- V, 8, 6, 1308a 13-16: 401 n. 353

- VI, 4, 19, 1319b 23-27: 351 n. 129

- VII, 6, 8, 1327a 10-15: 307 n. 857, 310 n. 872

Rhétorique, I, 2, 1357b 30-36: 83

n. 308

- I, 15, 1375b 29-30: 63 n. 203

Ps.-Aristote, Constitution d'Athènes,

VI, $1: 85-86$ n. 321

- XIV, 1: 61 n. 194

- XVII, 2: 58 n. 176

- XXI, 5: 358 n. 167

- XXI, 6: 67 n. 225

De mirabilibus auscultationibus,

LVIII, 834b 18-31: 238 n. 533

Économique, II, 2, 3a, 1346b 13-20:

158 n. 158,234 n. 519

- II, 2, 3c, 1346b 29-33: 235 n. 522,260 n. 641

- II, 2, 8, 1347b 3-15: 399 n. 342

- II, 3, 10, 1347b 20-30: 235 n. 522,260 n. 641

Athénée, III, 116 B : 234 n. 519

- III, 126 F et 127 B : 104 n. 397

- VI, 263 C-E: 307 nn. 885-856, 308 n. 860

- X, 440 E: 106 n. 408

- X, 442 C: 400 n. 349

- XII, 526 D-E: 235 n. 524

Avienus, GGM II, 972-974: 230 n. 507

Bacchylide, Dithyrambes, III, 1, 14-15:

75 n. 269

- IV, 2, 24-25: 71 n. 246

Callimaque, fr. 31 (éd. R. Pfeiffer) : 21 n. 19

- fr. 600 (apud scholie à Apollonios de Rhodes, II, 904-10a) : 359 n. 171

Épigrammes, XXV (= Anthologie

Palatine, V, 6): 102 n. 389

Hymnes, VI, 15: 359 n. 169 
Carminum medicorum reliquiae, in Poetae bucolici et didactici, Paris 1851, p. 97 (éd. U. C. Bussemaker) : 266 n. 665

Charon de Lampsaque, FGrHist 262 F 6 (apud Photius, Lexicon, s.v. ỏotaxóc, éd. S. A. Naber): 204 et n. 381

Chrestomathie de Strabon, VII, C 319, 14-17 (éd. S. Radt) : 318 n. 909

Chronicon Paschale, I, p. 328

(éd. L. Dindorf): $221 \mathrm{n} .461$

- p. 493-495: 272 n. 695, 286 n. 746, 400 n. 350

Chronique de Lindos, FGrHist 532 C 30 : 176 n. 247

Cicéron, De officiis, I, 30, 108: 57 n. 171

Clément d'Alexandrie, Protreptique, II, 17, $1: 20$ n. 13

Stromates, VII 18, 110: 103 n. 390

Conon, FGrHist 26 F 1, XX: 135 n. 59 - F 19: 21 n. 19

Constantin Porphyrogénète, $\mathrm{De}$ Thematibus, I, p. 25 (éd. I. Bekker): 201 n. 370,221 n. 463

- p. $27: 221$ n. 463

- p. 46: 257 n. 623,264 n. 657

Daïmachos de Platées, FGrHist 65 F 7 (apud Plutarque, Comparatio Solonis et Publicolae, 4, 1): 58 n. 175

Damon, FGrHist 389 F 1 (apud Athénée, X, 442 C; Élien, Histoire variée, III, 14) : 400 n. 349

Deinias, FGrHist $306 \mathrm{~F} 6$ (apud scholie à Théocrite, XIV, 48/49a): 102 n. 388

Démon, FGrHist 327 F 19 (apud scholie à Pindare, Néméennes, VII, 155b) : 42 n. 103

Démosthène, V, Sur la Paix, 25 : 260 n. 641

- XV, Pour la liberté des Rhodiens, 26: 387 n. 293

- XVIII, Sur la couronne, 90: 375

- XIX, Sur les forfaitures de l'ambassade, 252: 57 nn. 171-172, 330 n. 22
- L, Contre Polyclès, 4-6 et 17-19: 260 n. 641

Démosthène de Bithynie, FGrHist 699

F 5 (apud Stéphane de Byzance,

s.v. $\left.{ }^{\mathrm{e}} \mathrm{H} \rho \alpha i \alpha\right)$ : 272 n. 696

Denys de Byzance, 7, p. 4

(éd. R. Güngerich) : 276 n. 709

- 8, p. 4-5: 288 n. 758

- 14, p. 6-7: 226 n. 488, 248 n. 582, 271 n. 692

- 15 , p. $7: 270$ n. 685

- 16, p. 7: 288 n. 758

- 19, p. $8: 255$ n. 617

- 23, p. $11: 249$ n. 591

- 24, p. $12: 276$ n. 709,286 n. 746

- 32, p. $15: 248$ n. 582

- 34, p. $15: 248$ n. 582,265 n. 569

- 39, p. 17: 248 n. 582, 366 n. 198

- 41, p. 17: 289 n. 764

- 48, p. 19-20: 223 n. 473

- 49, p. $20: 226$ n. 489,248 n. 582

- 53, p. 22-23: 116 n. 449,155 n. 144 , 248 n. $582,251-252$ n. 597,288 n. 758

- 63, p. 25 : 248 n. 582,265 n. 659

- 71, p. $26: 248$ n. 582

- 75, p. $27: 133$ n. 51

- 95, p. $30: 266$ n. 668

- 104, p. $32: 248$ n. 582

- 111, p. $34: 223$ n. 475

Denys d'Halicarnasse, VII, 72, 2-3 : 44

n. 115

Denys le Périégète, GGM II, 140-142:

276 n. 709

$-304,362: 230$

$-764: 227$

- 803-804: 227 n. 493

- 1069:230

Didymos, apud scholie à Platon, Lois I, 630 a: 91 n. 341

Dieuchidas, FGrHist 485 F 5 (apud

Plutarque, Lycurque, 1, 8): 38 n. 89

- F 6 (apud Diogène Laërce, I, 57): 37 n. 85 
- F 10 (apud scholie à Apollonios de Rhodes, I, 516-18c): 374 n. 232

Diodore, IV, 49, 1 : 286 n. 746

- IV, 59: 71 n. 246

- IV, $72: 72$ n. 249

- IV, 78, $3: 176$ n. 249

- IV, 79: 175 n. 244

- V, 9: 161 n. 175,172 n. 226

- IX, 1, 1:57 n. 173

- XI, 21, 4-5: 191 n. 326

- XI, 53, 5 : 190 n. 324

- XII, 34, 5: 214 n. 422

- XII, 82, 2: 211 n. 413

- XIII, 43, 5: 185 n. 293

- XIII, 54: 160 n. 171

- XIII, 54, 6: 174 n. 237

- XIII, 55, 1: 191 n. 326

- XIII, 59, 4: 160 n. 170

- XIII, $62: 161$ n. 175,179 n. 260

- XIII, 64, 2-3: 235 n. 525

- XIV, 12, 2: 281 n. 732, 288 n. 760

- XIV, 12, 3: 235, 333 n. 43

- XIV, 31, 3: 294 n. 787, 299 n. 822

- XIX, 60, 3: 212 n. 414, 216 n. 431

- XX, 32, 4: 172

Diogène Laërce, I, 45, 1 : 57 n. 173

- I, 46-48: 57 n. 171

- I, $48: 63$ n. 203,65 n. 214

- I, $57: 37$ n. 85,63 n. 203

- I, 62: 57 n. 174

- VI, 41 : 105 n. 403

Diogénien, VI, 34 ; VII, 65 (éd. E. Lelli) : 43 n. 106

Dion Cassius, LXXV, 10, 1: 234 n. 519

Dion Chrysostome, XXXIII, 24 : 234 n. 519

Dionysios, fils de Calliphon, GGM I, 101102: 35 n. 76

Douris de Samos, FGrHist 75 F 59: 166 n. 198

Élien, Histoire variée, III, 14: 400 n. 349

- VII, 19: 57 n. 171, 60 n. 188, 65 n. 211,80 n. 300

- VIII, 16: 57 n. 174

Énée le Tacticien, Poliorcétique, IV, 811 : 61 n. 194,80 n. 301,81 n. 302
- XI, 10 bis- 11 : 335 n. 55, 348 n. 120 , 356 n. 152

Éphore, FGrHist 70 F 44 a (apud scholie à Apollonios de Rhodes, II, 845) :

294 n. 788

- F 137 a (apud Strabon, VI, 2, 2, C 267) : 122, 141

- F 137 b (apud Ps.-Scymnos, 270282): 126 n. 27,141 n. 84

Eschine, I, Contre Timarque, 25 : 57 n. 172 - 115 : 121 n. 11

Eschyle, Edônoi, fr. 57 (éd. S. Radt) : 192 n. 335

Perses, 570: 65 n. 217

Prométhée, 635-686: 276 n. 709

Etymologicon Magnum, s.v. Гع $\rho \alpha ́ v \varepsilon ı \alpha$

(éd. T. Gaisford) : 20 n.15

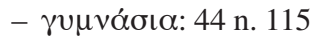

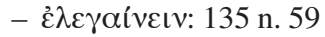

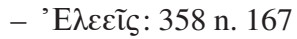

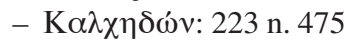

- ỏ $\beta \gamma \alpha ́ \delta \alpha ~ \gamma \tilde{\eta} v: 62$ n. 199

Euphorion, fr. 78 (éd. J. U. Powel, apud Athénée, VI, 263 D-E) : 307 n. 856

- fr. 177 (apud scholie à Apollo-

nios de Rhodes, II, 351-352a) : 294

n. 790

Eupolis, Baptai, fr. 93 (éds. R. Kassel et

C. Austin, apud Hésychios, Lexicon,

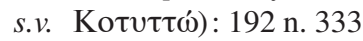

Euripide, Héraclès, 687-690: 359

- 954: 74 n. 262

Ion, 1075 : 359 n. 169

Phéniciennes, 24 : 30 n. 52

Suppliantes, 392, 619:359 n. 169

Eusèbe, Chron. (éd. R. Helm), p. 88b:

$241 \mathrm{n} .547$

- p. 91 b: 29 n. 48,203 n. 378,221 n. 459

- p. 93 b: 240 n. 539,241 n. 547

- p. $94 b: 240$ n. $539,271,283$

- p. 95b: 161 n. 173, 242

- p. 98 b: 209 n. 403

- p. 102a: 293 n. 785

- p. $131: 216$ n. 435,221 n. 459 
Eusèbe, Chron. (éd. J. Karst), p. 181: 161

n. 173

- p. $183: 203$ n. 378,221 n. 459

- p. 185: 240 n. 539

Eusèbe, Chron. (éd. A. Schöne), p. 85: 29

n. 49

- p. $91: 209$ n. 403

- p. $95: 293$ n. 785

Eustathe, Commentaire à Denys le

Périégète, GGM II, 453, p. 302: 166

n. 199

- 764, p. 348-349: 223 n. 471,230

n. 509,233 n. 515

- 803, p. 356-357: 224 n. 477,230

n. 509,249 n. 591,312 n. 883

Commentaire à l'Iliade, II, 557 (éd.

M. van der Valk) : 63 n. 203

Favorin d'Arles, Sur l'exil, 24, 7-9

(éd. A. Barigazzi ; = XXII, 33-35,

éd. A. Tepedino Guerra): 108 n. 414

Frontin, Strat., II, 9, 9: 61 n. 194, 80 n. 301

Georgius Cedrenus, Historiarum compen-

dium, I, p. 197 (éd. I. Bekker): 248

n. 586,286 n. 746

- p. $496: 234$ n. 518

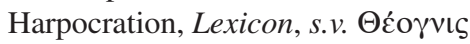

(éd. W. Dindorf) : 91 nn. 342-343

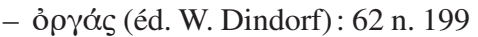

Hécatée, FGrHist 1 F 198: 309 n. 865

Hellanicos de Lesbos, FGrHist 4 F 6 a-b :

134 n. 54

- F 82 (apud Stéphane de Byzance,

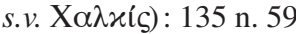

Hérakleidès Lembos, fr. 59

(éd. M. R. Dilts) : 175 n. 240

Héréas de Mégare, FGrHist 486 F 1

(apud Plutarque, Thésée, 20, 2) : 37

n. 85,38 n. 89,64 n. 205

- F 2 (apud Plutarque, Thésée 32, 7 : 38 n. 89,73 n. 258

- F 4 (apud Plutarque, Solon, 10, 5): 38 n. 89,65 n. 212

Hérodoros, FGrHist 31 F 51 (apud scholie à Apollonios de Rhodes, II, 848) : 297 n. 802
Hérodote, I, 1-2: 276 n. 709

- I, 28: 309 n. 864

- I, 30: 62 n. 198

- I, $34: 321$ n. 924

- I, 59: 61 n. 194, 80 n. 298

- I, 145 : 362 n. 191

- II, 178-179: 263

- III, $78: 321$ n. 924

- III, $90: 309$ n. 864

- IV, $93: 314$ n. 889

- IV, 144: 231 n. 510, 240 n. 540, 249

- IV, 145: 54 n. 160

- IV, 153: 116 n. 446

- V, 46, 2: 175 n. 239

- V, 66: 33 n. 69,67 n. 225

- V, $76: 18$ n. 6

- V, $77: 79$ n. 288

- VI, 33: 312 n. 881, 313 n. 885

- VI, 58, 2-3: 43 n. 108

- VI, 108: 134 n. 55

- VI, 136, 140: 79 n. 289

- VII, 72: 309 n. 864

- VII, 75: 292 n. 778

- VII, 156: 92 n. 344, 109 n. 419, $122 \mathrm{nn} .13+16$

- VII, 157: 92 n. 344,122 n. 16

- VII, 158: 194 n. 343

- VIII, $1: 112$ n. 430

- VIII, $94: 69$ n. 237

Hésiode, Travaux et jours, 376-377 : 109 n. 417

Ps.-Hésiode, fr. 372 (éds. R. Merkelbach et M. L. West; apud Athénée, III, 116 B) : 234 n. 519

Catalogue des femmes, fr. 204, 48 (éds. R. Merkelbach et M. L. West; = fr. 155, 48 éd. G. W. Most) : 64 n. 209

Hésychios d'Alexandrie, Lexicon, s.v. ßoíav (éd. K. Latte) : 245 n. 563

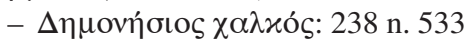

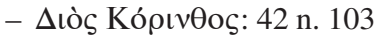

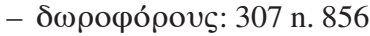

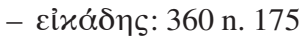

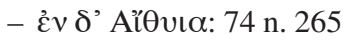




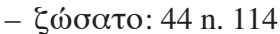

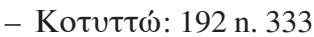

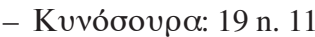

- $\sum x[\varepsilon] \iota \rho \alpha ̀ \varsigma^{\prime} \mathrm{A} \theta \eta v \tilde{\alpha}$ (éd. M. Schmidt) : 70 n. 242

Hésychios de Milet, FGrHist 390 F 2: 274

n. 701

- F 3: 48 n. 130, 249 n. 592, 253 n. 605,274

- F 4: 48 n. 130, 274 n. 703, 287 n. 754

- F 5 : 248 n. 585, 274 n. 703, 286 n. 746

- F 6: 48 n. 130, 276 n. 709

- F 10: 288 n. 759

- F 12-34: 400

- F $12: 286$ n. 746,287 n. 756

- F $16: 265$ n. 659,400 n. 350

- F 17-23: 288 n. 759

- F $20: 240$ n. 541, 275 n. 704, 279 n. 723

- F 21 : 223 n. 474,232 n. 512, 279 n. 723

- F 22: 252 n. 598,279 n. 723

- F 23: 279 n. 723

- F 27: 275 n. 706

- F 28: 258 n. 629

- F 33: 133 n. 51

- F 37: 266 n. 667

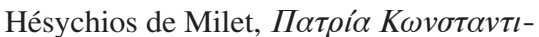
vovлó $\varepsilon \varepsilon \omega \mathcal{\text { in }}$ T. Preger (éd.), Scriptores originum Constantinopolitanarum, vol. I, Leipzig 1901, 39, p. $17: 400-401$ n. 351

Hippys de Rhégion, FGrHist 554 F 4 : 124 n. 20

Histoire auguste. Les deux Galliens, IV, 8: 221 n. 460

Homère, Iliade, II, 508: 35 n. 76

- II, 558: 63, 64 n. 206

- VII, 452-453; XXI, 441-449: 287 n. 755

Odyssée, XI, 631: 37 n. 85

Hymnes homériques à Déméter, 272: 359 n. 169
Ion de Chios, fr. 88 [éd. A. Leurini, apud

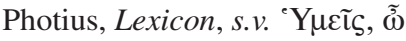

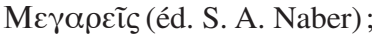

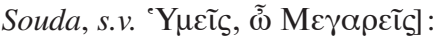
102 n. 390

Isocrate, Sur la Paix, VIII, 116-119: 101 n. 385,102 n. 387

Istros, FGrHist $334 \mathrm{~F} 10: 72$ n. 250

Jean le Lydien, Des Magistratures de l'État romain, III, 70, 4: 240 n. 543, 248 n. 584,264 n. 655,283 n. 738

Josephus Genesius, in J.-P. Migne (éd.), Patrologia Graeca, vol. 109, Paris 1887, col. 1024 : 249 n. 588, 256 n. 618,270 n. 686

Julius Africanus, F 65, 62 (éd. M. Wallraff et al., p. 196): 44 n. 114

- F 65, 99: 56 n. 168

Justin, II, 7, 7-12: 57 n. 171

- II, 8, 1-5: 55 n. 162, 61 n. 194, 80 n. 301

- IX, 1, 3: 257 n. 620

- XVI, 3, 4-8:296 n. 797, 303 n. 840, 304, 309 n. 868

- XVI, 4, 17: 349 n. 127

- XVI, 5, 1-4: 310 n. 873

- XLIII, 3, 4-13: 170 n. 217

Kallistratos, FGrHist 348 F 14 (apud Athénée, VI, 263 E) : 307 nn. 855-856

Léôn de Byzance, FGrHist 132 F 2: 265 n. 662

Malalas, Chronographia, VII, 7, 86-94, p. 246 (éd. J. Thurn) : 286 n. 746 - XII, 20, 62-67, p. $221: 272$ n. 695

Marmor Parium, FGrHist 239 A 31: 53 n. 157,93 n. 352,124 n. 20

Memnon d'Héraclée, FGrHist 434 F 9, 5 : 297 n. 805

- F 11: 239 n. 537, 289 n. 764

- F 12 (apud Photius, Bibliothèque, 228 a): 203 n. $377,214,215$ n. 425 , 216 n. 433,217 n. 436,218 n. 439 , 220

- F 15 : 239 n. 538 
Ménandre, Sur l'éloge des pays, I, 3, 353,

5-19 (éds. D. A. Russell et

N. G. Wilson): 225 n. 483

Mennipi Pergameni Periplus, 5812

(éd. A. Diller): 201 n. 370

Mnaséas de Patras, fr. 59

(éd. P. Cappelletto) : 102 n. 389

Narratio historica in depositione vestis

S. Mariae in Blachernis, in

F. Combefis (éd.), Historia haeresis

Monothelitarum, Paris 1648,

col. 755 D-E: 249 n. 590, 280

n. 726

Nicolas de Damas, FGrHist 90 F 35 : 47

n. 124

- F 43 (apud Stéphane de Byzance,

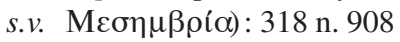

- F 57, 7: 54 n. 159

Oracles Sibyllins, III, 436-437 (éd. V. Nikiprowetzky): 289 n. 765

Orose, Histoires contre les païens, III, 13, 2: 257 n. 621

Paraphrase anonyme, GGM II, 762-771 et 799-808: 230 n. 508

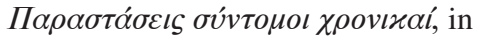

T. Preger (éd.), Scriptores originum

Constantinopolitanarum, vol. I,

Leipzig 1901, 38, p. 42; 41, p. 48 :

286 n. 746

Pausanias, I, 3, $1: 71$ n. 246

- I, 5, $3: 73$ n. 259,74 n. 265

- I, 5, 4: 41 n. 97

- I, 17, 3: 75 n. 269

- I, 19, 4: 74 n. 261

- I, 19, $5: 18$ n. 6

- I, 28, $1: 57$ n. 170,83 n. 309

- I, 29, 4; 32, $3: 328$ n. 10

- I, 35, 2: 66 n. 219

- I, 35, $3: 67$ n. 228

- I, 36, 1: 65 n. 217

- I, 36, 3: 103 n. 393

- I, 36, 4: 70 n. 241

- I, 38, 6: 359 n. 169

- I, 39, 4: 18 n. 6,73 n. 259,74

n. 262,296 n. 801
- I, 39, 5: 18 n. 6, 20 nn. 13-14, 50 n. 141,277

- I, 39, 6: 20 nn. 14-15, 47, 50 n. 142, 74 n. 267

- I, 40, 1: 20 n. 15,57 n. 170,83 n. 309,84 n. 315

- I, 40, 3: 133 n. 51

- I, 40, 4: 112 n. 429

- I, 40, 5: 59 n. 179,78 n. 286, 112 n. 429

- I, 40, 6: 20 n. 13

- I, 41, 2: 84 n. 315,329 n. 20

- I, 41, 3: 50 n. 142,329 n. 20

- I, 41, 4-5: 50 n. 142

- I, 41, 6: 50 n. 142,74 n. 265

- I, 41, 8-9: 41 n. 97

- I, 42-43: 198 n. 360

- I, 42, 1: 20 n. 14, 32 n. 63, 253 n. 606,254 n. 607

- I, 42, $2: 32$ n. 63,75 n. 269,253 n. 606

- I, 42, 4: 50 n. 142,51 n. 146,72 n. 249

- I, 42, 5: 114 n. 440, 115 n. 442, 332 n. 37

- I, 42, 6:32 n. 64

- I, 43, 1: 47 n. 129, 226 n. 487

- I, 43, 2: 32 n. 64,51 n. 147,385

- I, 43, $3: 50$ n. 142, 51 nn. 143+146, 82 n. 306,297 n. $804,384,385$ n. 283

- I, 43, 4: 32 n. 64,51 n. 148

- I, 43, $5: 226$ n. 488

- I, 43, 7: 21 n. 19,22 n. 20,47 n. 127

- I, 43, 8: 20 n. 16,21 n. 19

- I, 44, $1: 43$ n. 111

- I, 44, $3: 74$ n. 262

- I, 44, 5: 40 n. 94

- I, 44, 6: 50 n. 141,74 n. 267,332 n. 38

- I, 44, 8: 71 n. 246

- I, 44, 9: 112 n. 433

- II, 4, 6: 272 n. 695

- II, $15,5: 47$ n. 125

- II, 29, 7-8: 112 n. 433 
- II, 34, 7: 73 n. 259

- III, 16, 9: 19 n. 11

- IV, 14, 4: 43 n. 108

- V, 10, 5: 321 n. 923

- V, 12, 7: 215 n. 428,221 n. 458

- V, 23, 6: 143 n. 94

- V, 26, 7: 294 n. 791, 299 n. 821, 309 n. 867

- VI, 19, 13-14: 45 n. 116, 124 n. 22, 278 n. 721

- VIII, 32, $1: 385$ n. 283

- X, 11, 3: 172 n. 226

- X, 15, 1: 115 n. 443

Pherekydes, FGrHist 3 F 107: 295 n. 794

Philistos de Syracuse, FGrHist 556 F 20

(apud Stéphane de Byzance,

s.v. $\left.{ }^{\text {"}} \mathrm{Y} \beta \lambda \alpha \mathrm{l}\right)$ : 143 n. 94

Philochore, FGrHist 328 , p. 121, n ${ }^{\text {os }} 7-9$ :

39 n. 92

- F $14: 70$ n. 241

- F 94 (apud Strabon, IX, 1, 20, C 397): 73 n. 255

- F 107: 73 n. 259

- F 111 (apud Plutarque, Thésée, 17, 6-7): 69 n. 236

Philostrate, Vies des sophistes, I, 24, 528 :

284 n. 741

- I, 24, 529: 76 n. 274, 248 n. 583, 284 n. 741

Photius, Bibliothèque, 228 a: 203 n. 377

Lexicon, s.v. ỏotaxós

(éd. S. A. Naber) : 204 n. 381

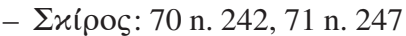

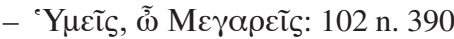

Phylarque, FGrHist 81 F 8: 291 n. 773

Pindare, Néméennes, V, 85 : 74 n. 262

Olympiques, VI, 8-9: 125 n. 24

- X, 43-50: 134 n. 54

Pythiques, IX, $161: 74$ n. 262

Platon, Critias, 110 d-e: 75 n. 270

Lois, I, 630 a: 91 n. 342,122 n. 13

- V, 736 a: 108 n. 413

- VI, 776 c-d: 307 n. 855

Protagoras, 316 d: 247 n. 576

République, VIII, 14, 562 d: 85 n. 318
Pline, $N H$, III, $90: 176$ n. 248

- IV, 7, 23: 370 n. 215

- IV, 9, 46: 273 n. 697

- IV, $11,45: 318$ n. 909,322 n. 930

- IV, 12, $85: 298$ n. 814

- IV, 18, 44: 301 n. 830

- V, 31, 112: 264 n. 655

- V, 40, 142: 227 n. 491

- V, 43, 148: 204 n. 383

- V, 43, 149: 201 n. 370, 224 n. 481,232 n. 511

- V, 43, 150: 252 n. 598

- VII, 196: 105 n. 401

- IX, 20, 50-51: 234 n. 519

- XVI, 76, 199: 297 n. 806

- XVIII, 12, 64: 180 n. 264

- XXXVII, 72: 238 n. 533

Plutarque, Alcibiade, 29, 6: 211 n. 413

Cimon, 17, 2: 42 n. 101

Comparatio Solonis et Publicolae,

4, $1: 58$ n. 175

Lycurgue, 1, 8: 38 n. 89

Marc-Antoine, 23, 3: 76 n. 273, 385

n. 285

Moralia 293 B (Questions grecques,

$\mathrm{XI}): 28$ n. 48

- 295 A-B (Questions grecques, XVI): 20 n. 15,38 n. 86

- 295 B-C (Questions grecques, XVII) : 17-18, 38-39, 41, 340, 361 et n. $183,362,363$ n. 193, 365

- 295 D (Questions grecques, XVIII) : 80 n. 295, 84-85, 87

- $302 \mathrm{E}-\mathrm{F}$ (Questions grecques, XLIX) : 212 n. 415

- 303 E-304 C (Questions grecques, LVII) : 60 n. 186, 181, 209-210

- 304 E-F (Questions grecques, LIX) : 36 et n. 80, 80 n. 295, 87-88

- 399 F (Sur les oracles de la Pythie, 12): 167 n. 207

- 402 A (Sur les oracles de la Pythie, 16): 115 n. 443

- 675 E (Propos de table, V, 3, 1): 38 n. 89 
- 682 F (Propos de table, V, 7, 6): 102 n. 389

- 730 D-E (Propos de table, VIII, 8, 4) : 102 n. 389,381 n. 271

- 772 D-773 B (Histoires d'amour, II) : 47 n. 124

- 826 C-D (Sur la monarchie, la démocratie et l'oligarchie, 2): 267 n. 670

- 868 C (De la malignité d'Hérodote, XXXV): 42 n. 101

Périclès, 30, 4 : 38 n. 89

Solon, 8-9: 57 n. 171

$-8,1: 78$ n. 283

$-8,3: 58$ n. 176

- 8, 4-6: 80 n. 300

$-9,1: 65$ n. 215,78 n. 285

$-9,2: 78$ n. 285

$-9,4-5: 81$ n. 302

$-9,6: 70$ n. 240,81 n. 302

$-9,7: 81$ n. 302

- 10:60 n. 188

- 10, 1-2: 34 n. 70,63 n. 202

$-10,3: 65$ n. 211,66 n. 219

$-10,4: 65$ n. 211

- 10, 5 : 38 n. 89,65 nn. 212-213

- 10, 6: 65 n. 218

- 12, 5: 56 n. 167,61 n. 193

- 25, 2-3: 86 n. 321

- 32, $4: 57$ n. 174

Thésée, 10, $1: 71$ nn. 246+248, 73

n. 256

- 10, 2: 38 n. 89,71 n. 248,73 n. 256

$-10,3: 65$ n. 217,71 n. 248,73 n. 256

- 10, 4: 40 n. 96,71 n. 248,73 n. 256

- 17, 6-7: 69 n. 236

- 20, $2: 37$ n. 85,38 n. 89,64 n. 205

- 24, $3: 252$ n. 601

- 25, 4-5: 75 n. 270

- 25, 6: 71 n. 246,75 n. 270

- 29, $1: 72$ n. 250

$-32,6: 73$ n. 258

- $32,7: 38$ n. 89,73 n. 258

Pollux, III, 83 : 307 n. 856
Polybe, IV, $38: 234$ n. 519, 250

- IV, 39, 6: 133 n. 51

- IV, 39, 7-44, 10: 235 n. 521

- IV, 43-52: 250

- IV, 43-44: 234 n. 519

- IV, 43, $5: 252$ n. 598

- IV, 43, 6-7: 276 n. 710

- IV, 44, $3: 235$ n. 525,276 n. 710

- IV, 44, 4: 235 n. 525

- IV, 44, 5-8: 234 n. 520

- IV, $45: 245$ n. 560,288 n. 761

- IV, 46: 288 n. 761

- IV, 47, 5 : 400 n. 346

- IV, 50, 4: 288 n. 762

- IV, 51, 8: 290 n. 772

- IV, $52: 288$ n. 763

- IV, 52, 4: 375 n. 237

- IV, 52, 7: 290 n. 769

- IV, 52, 9: 290 n. 770

- VI, 11a, 5 (apud Athénée, X, 440 E) : 106 n. 408

- XIII, 10, 10: 322 n. 930

- XV, 23, 7-9: 269 n. 681

- XVIII, 2, 4: 379 n. 258

Polyen, I, 20, 2: 57 n. 171,80 n. 300

- I, 27, 3: 122 n. 16

- I, 28, 2: 173 n. 234

- II, 2, $7: 288$ n. 760,334 n. 43, 399 n. 345

- II, 30, 2: 338 n. 68

- II, 30, 3 : 206 n. 391, 212 n. 417, 215 n. 427,220 n. 455

- V, 5, 1-2: 130 n. 40, 131 n. 46, 137 n. 68,139 n. 73,146

- V, $47: 179$ n. 259

Pomponius Mela, I, 19, 100: 201 n. 371, 204 n. 380,220 n. 453

- I, 19, 101: 223 n. 472

- II, 2, 22: 259 n. 634

- II, 7, $118: 176$ n. 248

Porphyre, De l'Abstinence, IV, 16: 246 n. 572

Posidonius, FGrHist 87 F 8 (apud Athénée, VI, 263 C-D) : 302 n. 838, 308 n. 860 
Praxiôn de Mégare, FGrHist 484 F 1: 70

n. 241

Priscien, GGM II, 737, 770-771 : 230

n. 507

Procope, De aedificiis, I, 5 : 234 n. 519

Promathidas d'Héraclée, FGrHist $430 \mathrm{~F} 1$ (apud scholie à Apollonios de Rhodes, I, 1126/31a): 307 n. 854

- F 3 (apud scholie à Apollonios de Rhodes, II, 844-47a) : 297 n. 807

Ptolémée, Géographie, III, 11, 10: 322

n. 930

- V, 1, 3: 221 et $n .462$

- V, 1, 4: 220 n. 453

Quintilien, V, 11, 40:60 n. 188

Scholie à Apollonios de Rhodes, I, 516-

$18 \mathrm{c}: 374$ n. 232

- I, 1126/31a; II, 140a: 307 n. 854

- II, 351-352a: 294 n. 790

- II, 353-356: 299 n. 822

- II, 531-533: 133 n. 51

- II, 723; II, 780-783a: 307 n. 854

- II, 844-47a: 297 n. 807

- II, 845 : 294 n. 788

- II, 848 : 297 n. 802

- II, 904-10a: 359 n. 171

- IV, 1212: 47 n. 124

Scholie à Aristophane, Cavaliers, 855b: 97 n. 370

Scholie à Aristophane, Grenouilles, 439: 42 n. 103

Scholie à Clément d'Alexandrie, Protreptique, II, 17, p. 302 (éd. O. Stählin) : 70 n. 241

Scholie à Démosthène, V, 25 : 249 n. 589 , 286 n. 746

- XIX, 251: 57 n. 171, 63 n. 203

- XXIII, 71: 66 et $n .223$

Scholie à Denys de Byzance, $19(\mathrm{ad} 7,1)$, p. 37 (éd. R. Güngerich) : 226 n. 488, 248 n. 582

- 20 (ad 7, 4), p. $37: 270$ n. 685

- 28 (ad 11,9), p. $37: 249$ n. 591

Scholie b à Homère, Iliade, II, 558: 63

n. 203
Scholie a à Homère, Iliade, III, 230: 63

n. 204

Scholie à Lucien, Dialogue des courtisanes, II, $1: 20$ n. 13

Scholie b à Pindare, Néméennes, V, 84 :

32 n. 63

- VII, 155b: 42 n. 103

Scholies a et b à Pindare, Olympiques, VI, 8: 125 n. 24

- X, 43-50: 134 n. 54

- XIII, 156: 73 n. 257

Scholie à Platon, Lois I, 630 a: 91 n. 341

Scholie à Platon, Euthydème, 292 e: 42 n. 103

Scholie à Théocrite, XII, 27b : 111 n. 428 - XIV, 48/49a: 102 n. 388,

Ps.-Scylax, 39: 35 n. 79

- 55: 49 n. 139

- 90: 359 n. 171

- 92: 201 n. 371,202 n. 372

- 93: 202 n. 372, 219 n. 444

Ps.-Scymnos, 270-282: 126 nn. 26-27

- 272: 123 n. 17

- 275: 136 n. 65

- 276-277: 141 n. 84

- 292: 160 n. 168

- 502-503: 42 n. 104

$-715-716: 243$ n. 551

$-717: 248$ n. 581

- 728-729: 322 n. 930

- 738-742: 311 n. 876

- 741-742: 243 n. 554

- F 3: 317 n. 904

- F 4: 298 n. 811

- F 12: 298 n. 813, 305 n. 848, 306 n. 852

- F $31: 293$ n. 784

- F 34: 305 n. 850

Servius, ad Aen., VI, 21 : 75 n. 269

ad Buc., I, $54: 141$ n. 85

Simonide, fr. 11, 37, in West, Iambi et elegi Graeci ${ }^{2}$, p. $119: 74$ n. 262

- fr. 124 (éd. D. L. Page): 111 n. 428

Sophocle, Antigone, 1165-1166: 121 n. 11

Egée, fr. 24 (éd. S. Radt): 73 n. 260 


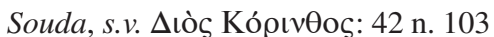

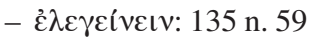

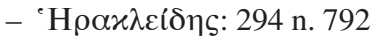

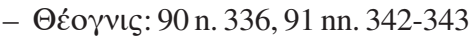

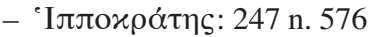

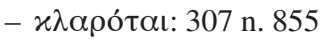

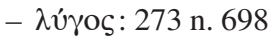

- ỏ

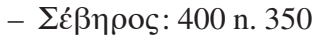

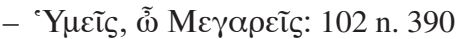

Sousariôn, in West, Iambi et elegi Graeci $^{2}$, p. $167: 21$ n. 18

Stéphane de Byzance, s.v. Aîcı $\rho o u ́ \sigma \sigma \alpha:$ 35 n. 79

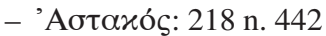

- Bıөuvía: 226 n. 490

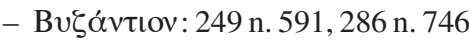

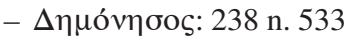

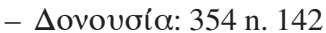

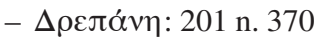

- Zıлoítıov: 216 n. 433

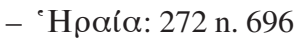

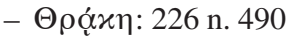

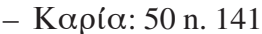

- Kúßos: 143 n. 93

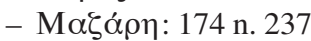

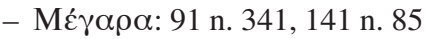

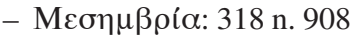

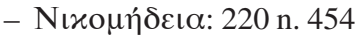

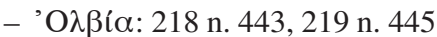

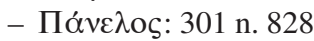

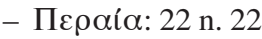

- Пú日ıov: 201 n. 370, 207 n. 397

- $\Sigma \eta \lambda v \mu \beta \rho i ́ \alpha: 245$ n. 562

- $\Sigma \tau u ́ \varepsilon \lambda \lambda \alpha: 143$ n. 94

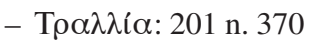

- "Y $\beta \lambda \alpha \iota: 143$ n. 94

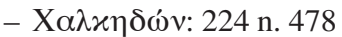

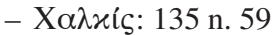

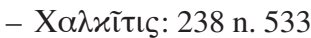

- Хрขбо́лодıs: 235 n. 525

Strabon, IV, 1, 5, C 180: 390 n. 309

- VI, 1, 6, C 257: 114 n. 441

- VI, 1, 11, C 262: 53 n. 157

- VI, 2, 2, C $267: 123$ n. 18, 127, 141
- VI, 2, 4, C 269-270: 28-29 n. 48, 53 n. 157,123 n. 19,130 n. 39

- VI, 2, 6, C 272: 160 n. 169

- VII, 3, 2, C 295 : 292 n. 778, 307 n. 854

- VII, 4, 2, C 308 : 352 n. 134

- VII, 6, 1, C 319: 245 n. 562, 312 n. $879,317 \mathrm{nn} .903+906,318$ n. 910,322 n. 930,323 n. 931

- VII, 6, 2, C 320: 223 n. 471, 232 n. $513,250,322$ n. 930

- VII, 7, 2, C 322: 38 n. 87

- VII, fr. 47: 322 n. 930

- VIII, 1, 2, C 333: 18 n. 6

- VIII, 3, 2, C 336-337: 19 n. 9 , 363 n. 192

- VIII, 6, 22, C 380: 25 n. 34, 34 n. 75,48 n. 134,53 n. 157

- VIII, 7, 5, C 386-387: 122 n. 14, 166 n. 200, 362 n. 191

- IX, 1, 4, C $391: 71$ n. 246

- IX, 1, 6, C $392: 73$ nn. 255+259, 75 n. 270

- IX, 1, 7, C 393: 18 n. 6

- IX, 1, 8, C 393: 104 n. 396

- IX, 1, 9, C 393: 69 n. 239

- IX, 1, 10, C 394: 20 n. 16, 34 n. 71, 60 n. 188,63 n. 203,64 n. 207

- IX, 1, 11, C 394: 67 n. 224

- IX, 1, 20, C 397: 73 n. 255

- IX, 2, 14, C 405: 35 n. 76

- X, 1, 3, C 445: 167 n. 208

- X, 2, 21, C 459: 201 n. 370, 220 n. 457

- X, 3, 16, C 470: 192 n. 335

- XII, 3, 3, C 541-542: 292 n. 778

- XII, 3, 4, C 542: 259 n. 633, 302 nn. 834+836, 307 n. 854,308 n. 860

- XII, 3, 10, C 544: 298 n. 815

- XII, 4, 2, C 563: 201 n. 370, 204 n. 379,211 n. 410,215 et n. 424 , 217 n. 438, 220 n. 456,223 n. 471

- XII, 4, 8, C 566: 292 n. 778

- XII, 8, 11, C 576: 289 n. 767 
- XIII, 1, 48, C 605: 134 n. 54

- XIV, 2, 6, C 653: 278 n. 720

Syméon Magister, Chronographia, p. 729

(éd. I. Bekker) : 224 n. 479, 266 n. 666

Ps.-Syméon, Chronique, in Parisinius $G r$.

1712 , fol. $72^{\mathrm{v}}$ : 224 n. 480,249 n. 587

Tacite, Annales, XII, 63, 1-2: 233 n. 514

Théocrite, XII, 27-34: 73 n. 257

- XII, 27: 111 n. 428

- XIV, 48-49: 100 n. 380, 102 n. 389

Théognis, 39-58: 92 n. 345

- 39-42: 82 n. 305

- 41-50: 94 n. 356

- 53-60: 93 n. 351

- 93-100: 80 n. 296

- 183-196: 94 n. 354

- 183-192: 92 n. 345

- 209-210: 80 n. 295

- 213-217: 80 n. 296

- 305-308: 94 n. 354

- 309-312: 80 n. 296

- 333-350: 80 n. 295

- 345-385: 91 n. 340

- 667-680:90

- 675-679: 92 n. 347

- 773-774: 32 n. 63

- 783-786: 91 n. 340,147 n. 112

- 825-830: 80 n. 295

- 833-836: 91 n. 340,92 n. 345

- 855-856: 92 n. 345

- 893: 15 n. 1

- 894: 15 n. 1,42 n. 101

- 963-970: 80 n. 296

- 1123-1128: 95 n. 359

- 1164 a-h: 80 n. 296

- 1197-1202: 80 n. 295

Théophraste, Des pierres, IV, 25 : 238

n. 533

Recherches sur les plantes, II, 8, 11 : 78 n. 287, 104 n. 397

- V, 2, 4: 297 n. 806

- IX, 16, 4: 309 n. 866

Théopompe, FGrHist $115 \mathrm{~F} 7$

(apud Stéphane de Byzance,

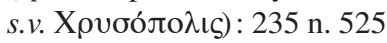

- F 62 (apud Athénée, XII, 526 DE) : 235 n. 524,387 n. 293

- F 70: 122 n. 13

- F 241 (apud Stéphane de Byzance,

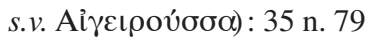

- F 388 (apud Strabon, XII, 3, 4, C 542): 307 n. 854

Thucydide, I, 10, $2: 19$ n. 9

- I, 24, 2: 160 n. 167

- I, 27, 2; 46, 1: 112 n. 431

- I, 97, 2: 135 n. 58

- I, 103, 4: 42 n. 101

- I, 126, 3-5: 57 n. 170

- I, 126, $3: 83$ n. 309

- II, 15, 1: 19 n. 9

- II, 15, 2: 19 n. 9,252 n. 601

- III, 51, 2-3: 77 n. 277

- IV, 70, $1: 20$ n. 16

- IV, 75, 2: 222 n. 470

- IV, 93, 4: 357 n. 153

- IV, 118, 4: 74 n. 263,77 n. 277

- VI, 2, 2-6: 138 n. 72

- VI, 3-5: 120 n. 6, 125 n. 23

- VI, 3, 2: 53 n. 157, 139 n. 74

- VI, 3, 3: 138, 139 n. 73

- VI, 4, 1: 120 n. 7, 131 n. 47, 132 n. 48

- VI, 4, 2: 120 n. 7, 146, 159 n. 163, 164

- VI, 4, $3: 179$ n. 261

- VI, 5, 1:59 n. 182,179 n. 260

- VI, 6, 2: 187 n. 306

- VI, 20, 4: 180 n. 264

- VI, 54, 6-7: 133 n. 53

- VI, 62, 5 : 143 n. 94

- VI, 94, $1: 120$ n. 13

- VII, 57, 8: 191 n. 328

- VII, 79, 1: 357 n. 153

- VIII, 80, 3: 268 n. 678

Timée, FGrHist 566 F 80: 28 n. 48, 53

n. 158

Tite-Live, XXXII, 22, 2: 393 n. 318, 402

n. 355

- XXXII, 33, 7: 379 n. 258

- XXXVIII, 40, $7: 322$ n. 930 
Velleius Paterculus, II, 7, 7: 258 n. 631

Vie de Théodore de Sykéôn, XXVIII, 157,

p. 130 (éd. A. J. Festugière) : 221

n. 465

Ps.-Virgile, Ciris, 133-150 (éd. D. Knecht) : $30 \mathrm{n} .53$

Xénophon, Anabase, VI, 2, 1: 294 n. 787

- VI, 2, 2: 299 n. 822

- VI, 4, 2: 211 n. 412

- VII, 1, 24: 291 n. 774

- VII, 5, 12-14: 323 n. 931

Art de la chasse, I, 9: 72 n. 249

Helléniques, I, 1, $22: 235$ n. 525
- I, 1, $35: 268$ n. 679

- I, 3, 20: 291 n. 774

- III, 15-21: 268 n. 679

- IV, 4, 13: 49 n. 139

- IV, 5, 5: 22 n. 22,34 n. 75

- IV, 8, 27-28: 358 n. 161

Mémorables, II, 7, 6: 105 n. 401

Zénobios, V, 8: 42 n. 103

Zonaras, Annales, IX, 28, p. 288

(éd. M. Pinder) : 286 n. 747

- XIII, 3, 1-4, p. 13-14 (éd.

T. Büttner-Wobst): 234 n. 518

Zosime, II, $30: 234$ n. 519

\section{Index géographique et prosopographique}

Abdère: 184

Acanthos (athlète spartiate) : 44 n. 115

Acarnanie: 218 n. 442, 368

Achaïe/Achéens : 99, 102, 331 n. 30, 392394, 402, voir aussi Ligue achéenne

Achéloos (dieu): 84 et n. 315 (- à Mégare)

Acones (bourg des Mariandyniens) : 309 et n. 866

Acrai : 194

Adramyttion: 305 n. 848

Agamemnon: 47, 50-51, 134 et n. 54, 384

Agamestor (héros) : 296-297, 303

(- à Héraclée du Pont), voir aussi

Idmôn

Agésilas (roi de Sparte): 22

Agioi Theodoroi : voir Krommyon

Aglaïdas (médecin byzantin) : 266 et n. 665 , 284

Agrigente: 160,176 et n. 247, 190-191, 409

Aigeiroussa/Aigeiroi (lieu en Mégaride): 34-36, 64, 87

Aigion (ville d'Achaïe) : 102-103

Aigos Potamos: 112

Aigosthènes (bourg mégarien qui acquit le statut de cité à l'époque hellénis- tique) : 30, 39, 40 n. 95,101 et n. $386,104-106,109,267$ n. 670 , 280 n. $728,295,364$ et n. 196,367 370, 393, 402 et n. 359

Aisymnos (héros mégarien) : 50-52, 384 385

Aithiops (apoikos corinthien): 109

Ajax, fils de Télamon (héros) : 33, 67-68, 70-71 (- à Athènes), 33, 248 n. 582

(- à Byzance), 34, 50, 64, 71

(- à Mégare), 34, 38 n. 89, 63-64, 66 et n. $219,69,72$

Alcathoos (héros mégarien) : 32 et nn. 63 $64,47,50-51,71-72,75,253$ et n. $606,267,287,374$ n. 232,385

Alcibiade : 235

Alcméonides (famille athénienne) : 56, 61

Alectryon (héros) : 246

Alepouchori : voir Pagai

Alexandre le Grand (roi de Macédoine): 96 n. 367

Althaiménès (chef argien) : 278

Amastris : 298 n. 815

Ambracie: 331 n. 28

Amompharétos (arbitre spartiate) : 60 
Amphiaraos (héros) : 265 n. 659 (- en

Béotie), 265 et n. 659 (- à Byzance)

Amphitrite: 23 (- à Corinthe)

Amyntas I (roi de Macédoine) : 305 n. 847

Amyntas III (roi de Macédoine) : 305 n. 847

Anaplous : voir Hestiai

Anaxilas (arbitre spartiate): 60

Anchialos (héros mégarien): 72, 317

Anchialos (site dans le Pont-Euxin) : 317318

Anthémocritos (messager athénien) : 38 n. 89,103

Antigénès (commerçant mégarien) : 105

Antigone Monophthalmos (roi hellénistique) : $211-212,399$ n. 343

Antiochos de Syracuse (historien) : 13, 124125, 127, 172 n. 226,

Antiochos I (roi séleucide) : 289 n. 764

Antiochos II (roi séleucide) : 239

Antiochos IV (roi séleucide) : 342

Antiphémos de Rhodes (œciste de Géla): 179

Antonin le Pieux (empereur romain) : 371 et n. 218

Aphidnai (localité de l'Attique): 73 et n. 258

Aphrodite: 401 et n. 354 (- à Mégare), 315 n. 895 (- à Mésambria)

Apollodore d'Athènes (grammairien) : 37 n. 84

Apollon: 287, 389-390 (- à Byzance), 225 n. 486 (- à Chalcédoine), 253,

287, 331 n. 27 (- à Mégare), 323

(- à Mésambria), 167-168

(- à Sélinonte), 21 (- à Tripo-

diskos), 225 n. 485,359

Apollon Archégète: 114 et n. 440, 253 -

254 (- à Mégare), 127 (- à Naxos)

Apollon Chrestèrios : 225 et n. 484, 380 n. 264 (- à Chalcédoine)

Apollon Daphnèphoros : 156 (- à Érétrie)

Apollon Dékatèphoros: 114-115 (- à Mégare)

Apollon Lykeios: 47 (- à Argos), 329

(- à Athènes), 47, 329 et n. 15

(- à Mégare)
Apollon Prostatèrios : 330 et n. 24

(- à Mégare)

Apollon Pythaeus : 47 (- à Argos)

Apollon Pythien : 47, 225-226, 268-269, 380 n. 264 (- à Chalcédoine), 96, 102,108 et n. 414, 114-115, 167, 232-233, 294 n. 789, 296, 298 (- de Delphes), 7 n. 13, 47, 114 n. 440, 207 et n. 397, 226 n. 487, 332 (- à Mégare)

Apollon Sélinaios/Sélinountios : 167 et n. 208 (- à Orobiai, dans le territoire d'Histiée)

Apollonia (établissement d'Héraclée du Pont): voir Thynias

Apollonia du Pont: 229 et n. 503, 313-314, 317, 322, 399

Apollônidas, fils de Memnôn (juge milésien) : 264 n. $654,342,375$

Arcadie/Arcadiens : 32,125 et n. 24, 255256

Arcadius (empereur de l'Orient): 243 n. 550

Archeion (site sur la rive européenne du Bosphore thrace) : 223 et n. 473

Archias de Corinthe (œciste de Syracuse) : 53 et n. 157, 120, 123-124, 126, 137, 223 n. 472, 278

Archias de Mégare (œciste de Chalcédoine): 223 et $n .472$

Archias, fils d'Aristonymos, de Thasos (fondateur d'Archeion) : 223

Arès : 246-247

Argos/Argiens : 3, 18, 21, 25, 29-30, 4548, 60 n. 190, 97-98, 112, 116, 123 $125,137,233,236,249,255-256$, 273-278, 281-282, 284, 328, 335 et n. 53,353 n. 138,362 n. 189,381 382, 400-401, 403-404, 409

Argolide: 280 n. 728,404 n. 363

Aristarque de Samothrace (grammairien): 37 n. 84

Artémis : 47 (- à Mégare)

Artémis Eukleia: 265 n. 661 (- en Béotie)

Artémis Lygodesma: 273 n. 698 
Artémis Sôteira: 133 (- à Mégare)

Asclépios: 375, 380, 391 (- à Cos), 113

$$
\text { n. } 437 \text { (-à Mégare ?) }
$$

Asôpos (dieu-fleuve) : 267, 358 et n. 164 (- en Béotie), 267, 358 (- à Chalcédoine)

Astacos (cité en Acarnanie) : 218 n. 442, 220

Astacos (cité en Propontide) : 1, 9 n. 17, 13 n. 27, 107, 201-208, 210-222, 243-244, 283, 409

Astacos (golfe) : 201, 204, 207-208, 211 n. 410, 217-220, 237, voir aussi Olbia (golfe)

Astacos (œciste de la cité d'Astacos): 217-220, 222

Astes (tribu thrace) : 218 n. 442, 322 et n. 930

Athéna: 59 et n. 184 (- à Athènes), 320 321 (- à Byzance), 115 (- à Mégare), 320-321 (- à Mésambria)

Athéna Aiantis: 33, 71 (- à Mégare)

Athéna Aithyia: 74 (- à Mégare)

Athéna Itônia: 301 (- à Coronée)

Athéna Polias : 67 (- à Athènes)

Athéna Skiras: 69-70 (- à Athènes)

Athéna Sôteira: 397 (- à Mésambria)

Athènes/Athéniens : 5, 12, 15, 18-19, 3134, 36-40, 42 n. 101, 44-45, 55-81, $83,85,88-89,91$ et n. $343,95-99,101$, 103,106 n. 407,108 et n. 415, 111$112,114-115,122-126,130,133-136$, 191, 203-204, 207, 213-215, 219, 235$236,252,255-258,260,268,275$ n. $705,278,284,304-305,328-330$, 334-335, 343, 347, 350, 358, 363-365, 384-390, 392, 400 et n. 348, 412-413

Athènes Diades : 135 n. 59

Attique: 16, 18, 31 n. 58, 59, 66-69, 73, 75 et n. $270,77-79,104,106,111,114-$ 115,136 n. $62,224,252,357$ n. 160 , 359

Augusta (golfe) : 148

Bacchiades (famille corinthienne) : 43 et n. $105,47,54,271$
Barbysès (roi thrace) : 286 et $n .746$

Baş Iskele : 202

Bathynias (fleuve) : 343

Bébryces (peuple) : 304 n. 845, 308 et n. 860

Belice (fleuve) : 167, 169, 171, 174, 180 et n. 263,184

Bendis : 291 (- à Byzance)

Béotie/Béotiens : 3, 20, 29-30, 35 n. 76, 44, 81, 96, 99, 104, 108, 116, 218 , 236, 248 n. 582, 255-257, 264-269, 278, 280-282, 284, 293-297, 299301, 303-304, 306 et nn. 851-852, 310, 334-337, 358, 364, 368 n. 205, 402, 409, voir aussi Ligue béotienne

Bérézan: voir Olbia/Borysthène

Besses (tribu thrace) : 324

Bithynie/Bithyniens: 177, 201-204, 206, 208, 211-219, 221 et nn. 458, 459+461, 227, 288-292, 297, 301, 305 n. $849,337,375$ et n. 238,399 , 410

Bithynion-Claudiopolis : 337 et n. 65

Bizonè : 317 et n. 904

Boidion (épouse du stratège athénien Charès) : 258 n. 629

Bourgas (golfe) : 311

Brucoli : 130 et n. 43

Bruttia Crispina (impératrice romaine) : 376, 378 n. 251

Byrébistas (roi des Gètes) : 323, 397

Byzance/Byzantins : 1, 3, 5 n. 11, 9 et n. 16,29 n. $49,33,48,76,97,107$, 110,124 et n. 22,133 n. 51,155 , 158,189 et $n .314,201,205-212$, 215, 218 n. 442, 223-224, 226-227, 229-240, 243-245, 248-293, 303, 308, 312-316, 319-322, 324, 328, 333-334, 336 n. 61, 340-347, 354, 356-360, 371-379, 381-382, 387, 389-390, 395, 399-401, 409-413

Byzas (œciste de Byzance) : 248-249, 274-276, 278-280, 284-288, 290, 320,400

Calchas (devin) : 33, 110 n. 422, 223, 225-227, 238 n. 534, 320 
Calchas (exilé athénien) : 224 et n. 480

Calchédon, fils de Calchas (œciste de Chalcédoine) : 110 n. 422, 223, 225227

Calchédon, fils de Cronos (œciste de Chalcédoine) : 224-227, 287, 320

Callatis/Callatiens: 7 n. 12, 9 et nn. 1617, 108 et n. $415,158,192$ et n. 334, 259-261, 298, 300-302, 305 et n. $847,310,317,326,339,351-353$, 371 et n. 220, 375, 387-390, 395, 398-399, 407-408, 412

Callipolis (héros mégarien) : 32 n. 64

Callistratos (homme politique athénien): 134 n. 55

Caltabellotta: 174 et n. 235

Çamdağ (montagne) : 304 n. 845

Campobello di Mazaro: 173

Canéthos: 75

Cantera (fleuve) : 148

Cap Zéphyrion : 123 et n. 19, 125-126

Capo Bruzzano: voir Cap Zéphyrion

Car, fils de Phoroneus (roi de Mégare) : 19, $47,50,277$

Caracalla (empereur romain) : 346, 373 n. 229,378 n. 251

Cariens (peuple): 111 n. 426

Carthage/Carthaginois: 160 et n. 171, 166, $173,182,185,187,191,195,258$ n. 631,409

Carystos/Carystiens : 3, 236, 255-256, 270 , 281-282, 409

Cavalier thrace : 291 (- à Byzance)

Catane: 120, 129, 138, 157

Cécrops I (roi d'Athènes) : 73

Cécrops II (roi d'Athènes): 73 n. 259

Celtes (peuple) : 307

Céroessa (héroïne byzantine) : 278-279, 286 et n. 749

Chalcédoine/Chalcédoniens : 1,9 et n. 17, 29 n. 49, 33, 47-48, 81, 107, 109110, 133 n. 51, 201, 203-206, 208213, 216, 222-240, 243-244, 250, 255-258, 260 et n. 641,263 n. 651 , 266-269, 272, 275 n. 705, 277 et n. $715,278-284,287,292-293,298$

n. 810, 311-316, 320-321, 333-334, 336 n. 61, 340-347, 349, 356-360, 366,371 et n. 216,374 et n. 234, 378-387, 390, 395, 401, 404-405, 409, 411-412

Chalcédoine (fleuve) : 223-225

Chalcis/Chalcidiens : 42 n. 101, 59, 79, 112, $114,116,119-120,123,125-126,129$ 141,146 et n. $106,158,178-179,200$, $208,223,227-231,262,409$

Chalcis (fille ou sœur de Nicomède $\mathrm{I}^{\mathrm{er}}$ ): 224-225

Chalcis (fleuve) : 224-225

Chalcitis (île dans la Propontide) : 229, 237 238

Chamailéon d'Héraclée du Pont (historien) : 38 n. 86

Charadros: 331 n. 28

Charès (stratège d'Athènes) : 258 et $\mathrm{n}$. 629,275 n. $705,358,400$

Chariclo: 71

Charites : 306 n. 853 (- à Héraclée du Pont?)

Charondas (législateur de Catane): 157 et n. 156

Chersicratès/Charicrate (œciste de Corcyre) : 28 n. 48,53

Chersonèse Taurique/Chersonésitains: 9 , 72 n. 251, 97-99, 192 et n. 334, 259261, 298-300, 305-306, 309-310, 326, 338-339, 342, 349-353, 371-372, 381, 386-387, 389 et nn. 304-305, 403-405, 407-408, 412

Chios : 262, 315 n. 894, 390 n. 309

Chrysopolis : 235-236, 240, 260, 276, 371 n. 216

Çiftlik Köy : 376

Cimmériens (peuple) : 213 n. 419, 236, 306

Cios : 202 n. 372, 269 n. 681

Cithéron (montagne) : 29, 104, 267, 374

n. 232

Claude (empereur romain) : 204

Cléarque (général spartiate) : 268, 288 n. $760,333-334,338,399$ et n. 345 
Cléarque (tyran d'Héraclée du Pont) : 206,

212-213, 215 et n. $427,310,348-349$

Cléoménè (roi spartiate) : 60

Cléson (roi de Mégare) : 50

Clisthène: 66-67, 350, 358 n. 167, 364

Cnide/Cnidiens : 166

Codros (roi d'Athènes) : 18 et n. 6

Commode (empereur romain) : 376

Constantin le Grand (empereur romain): 233-234, 249 n. 591, 273, 370 n. 211, 401 n. 351

Constantin II (empereur romain) : 370 n. 211

Constantinople: 202, 233, 249 n. 589, 257 n. 622,274 n. 700

Corcyre/Corcyréens : 28 et n. 48,53 et n. $158,112,160,191$ n. $329,205,270$

Corinthe/Corinthiens: 1, 3, 5, 12, 15-17, 22$30,33,36,39-50,53-54,71,77,100$ n. $382,106-107,109,112,116,120$, 123-124, 126, 137, 141, 145-146, 160, 181-182, 184, 191-194, 200, 205, 223 n. $472,236,242,255-256,258$ n. 631 , 262, 265 n. 661, 270-273, 277-278, 281-282, 284, 330-331, 364-365, 409, 411-412

Corinthe (golfe) : 29, 101, 111

Corinthie : 16, 48-49, 104, 270

Coroibos (héros argien) : 21-22, 41, 47 (- à Mégare)

Coronée: 301

Cos: $375,380,391$

Crète: 30 n. 53, 32, 75, 179 et n. 261, 278, 307

Critolaïdos (arbitre spartiate) : 60

Cronos : 224-227, 287, 320

Crotôpos (roi d'Argos) : 21

Cybèle: 371 n. 216

Cychreus, fils de Poséidon (roi de Salamine): 65 et $\mathrm{n} .217,71$

Cylon: 56-57, 61, 83

Cypsèlos (tyran de Corinthe): 15, 53, 271 et n. 691

Cyrène: 53-54, 98, 104-105, 110, 116 n. 446
Cyrus (roi des Perses): 293 et n. 784

Cyzique/Cyzicéniens : 111 n. 424, 229 et 503,241 et 547,258 et n. 631,260 n. 641,264 n. 655

Damis (fondateur d'un génos d'Héraclée du Pont) : 294 et 792, 303

Darius (roi des Perses) : 271, 311, 313-314

Daskylion (lac) : 289

Daulis : 40

Dédale : 175-176

Déinomènes, fils d'Hérotimos (stratège de Mésambria) : 395

Délion: 306 et n. 852

Delkanoi (bourg des - à Byzance): voir Derkos/Derkoz

Délos/Déliens : 298, 305-306, 359

Delphes/Delphiens : 21, 36, 44, 50-52, 65, $78,87-88,96$ et n. $365,102,108$ et n. $414,112,114-115,144,167,232-$ 233, 249 et n. 591, 266, 268-269, 295296, 298, 301-304, 341, 384-385, 390 n. 309

Déméter: 377 et n. 249 (- à Byzance), 62, 103, 359 (-à Éleusis), 247 (-à Locres Épizéphyrienne), 19-20, 50, 247

n. 575, 277 (- à Mégare), 246-247 (-à Sélymbria), 244 n. 559, voir aussi Thesmophories

Déméter Malophoros: 162-163, 168-169, 174, 182 n. 277, 193, 199 (- à Sélinonte)

Démétrias : 301

Démétrios de Callatis (historien et géographe): 312 et n. 877

Démétrios Poliorcète (roi de Macédoine): 392, 399 n. 343

Démétrios II (roi de Macédoine) : 364, 367 n. $201,369,392-393$

Démocratie (personnifiée) : 70 et n. 243 (- à Athènes)

Démonèsos : voir Chalcitis (île dans la Propontide)

Démos (personnifié) : 306 n. 853 (- à Héraclée du Pont ?)

Derkos/Derkoz: 285 n. 744, 376 et n. 243 
Deucalion (héros) : 20, 112, 134 et n. 54

Dieuchidas (historien mégarien) : 12, 37 -

39,374 et n. 232

Dieux de Samothrace: 388 (- à Callatis), 397-398 (- à Dionysopolis)

Dinéos/Deinias (stratège de Byzance) : 209, 275 n. 705, 278-282, 285, 400

Dioclès (héros mégarien) : 40 et n. 96, 73 et n. 257, voir aussi Diokleia

Diogène le Cynique (philosophe) : 105

Dionysoboleitai (thiase de Byzance) : 377

Dionysopolis : 317, 397

Dionysos : 337 (- en Bithynie), 357, 377

n. 249 (- à Byzance), 388

(- à Callatis), 379 (- à Périnthe),

voir aussi Dionysies

Dionysos Éleuthéreus : 396 et n. 327

(- à Mésambria)

Dionysos Kallôn: 377 (- à Byzance)

Dionysos Parabolos: 377 (- à Byzance)

Dionysos Patrôos: 158 (- à Callatis), 226 n. 488 (- à Mégare)

Diophante (stratège de Mithridate VI Eupatôr): 387 n. 294

Dioscures : 360 et n. 174 (- à Mésambria), 73 et n. 258

Dodone : 70

Doedalsès (souverain bithynien) : 203-204, 214-215

Domitien (empereur romain) : 377-378

Donousia (île) : 354 et n. 142

Doriens (peuple) : 18, 35 n. 77, 42 n. 104, 48, 119, 123-126, 136-138, 158, 277-278, 298, 363, 403, 409

Dorieus (chef spartiate) : 175

Dôros (héros): 298 et n. 815

Douris de Samos (historien): 166 n. 198, 210 n. 407

Douze Dieux : 133-134 (- à Athènes), 133-134 (- à Hiéron), 133 (- à Histiée), 131-134 (- à Léontinoi), 133 (- à Mégare), 134 et n. 54 (- à Olympie), 134 et n. 54 (- sur le promontoire Lekton en Troade), 134 et n. 54 ( - en Thessalie)
Dorykleioi (groupement de Mégare) : 59

et nn. $180+184,80-81,88,96,158$

Éaque (roi d'Égine) : 71, 74, 112

Égée (roi d'Athènes) : 73 n. 259

Égine/Éginètes : 42 n. 101, 74, 110 et n. $423,112,184,262,383-384$

Égypte: 50, 289

Éleusis : $31,40,55,61-62,69-73,79,88$ n. $329,103,105,359$

Éleusis (golfe) : 77

Élis/Éléens : 45

Élymes (peuple): 138, 163, 169, 172-173, 185-188, 382 n. 274

Endéis : 71

Entella: 187 et n. 301,382 n. 274

Entimos de Crète (œciste de Géla): 179

Éphèse : 98, 229, 383-384

Éphore (historien) : 119, 122-123, 126-127, 130-131, 135-136, 141 et n. 84, 294 et n. 788

Épidamne: 160, 205

Épidaure: 49, 330-331, 339, 404 n. 363

Épire: 331 n. 28,368

Éréchtée (roi d'Athènes) : 70

Ereğli : voir Héraclée du Pont

Éréneia (bourg mégarien) : 40 et nn. 94-95, 104

Érétrie/Érétriens : 28 n. 48, 42 n. 101, 52 n. 152,110 et n. 423,135 n. 59, 156, 262, 393 n. 318

Ériboia: voir Périboia

Érichthonios (roi d'Athènes) : 73 n. 259

Érythrée: 229, 262, 401 n. 353

Éryx : 186

Étoliens : 269 n. 681 , voir aussi Ligue étolienne

Étrurie/Étrusques (peuple) : 182-184

Eubée/Eubéens: 3, 120, 123, 125, 131-133, 135 et n. 59, 138, 167 et n. 208, 223, 227-228, 231, 256, 368 n. 205, voir aussi Carystiens, Chalcidiens, Érétriens

Euclide (philosophe) : 102 n. 387

Euclide (l'un des fondateurs de Zancle): 137 
Eudémos, fils de Nikôn (ami du roi

Antioche IV) : 342 et n. 91, 401

Eudoxie (impératrice d'Orient) : 243 n. 550

Eudoxiopolis (nom porté par Sélymbria): 243 n. 550

Euelpistos, fils de Sôsos (acteur byzantin): 276

Euhippos, fils de Mégareus (héros mégarien) : 51,385

Eumélos (poète corinthien) : 43

Eumène II (roi de Pergame) : 383-384

Euménides: 187 (-à Entella), 187 et n. 303 (- à Sélinonte)

Euryalos (héros mégarien) : 72

Euryléon (chef spartiate) : 175-176

Eurysacès, fils d'Ajax (héros salaminien) : 64,66 et n. 219, 68-69

Eurytè (nymphe): 72

Euthydamos (héros sélinontin): 329 et n. 18

Évarchos (œciste de Catane): 138

Faustine l'Ancienne (impératrice romaine): 378 n. 251

Faustine la Jeune (impératrice romaine): 378 n. 251

Fenerbahçe: voir Hiéria

Galates (peuple): 203, 239 et n. 537, 260, 289 n. 764

Gaule/Gaulois : 181-182, 275

Géla: 163,179 et n. 261

Gélon (tyran de Syracuse) : 91-92, 120, 122 et n. 16, 130, 159, 191, 194 et n. 343

Géraneia (montagne de la Mégaride) : 2022, 28 et n. 44, 34, 104, 301

Gérania (site aux abords de Callatis) : 301

Géta (empereur romain) : 369 n. 211

Gètes (peuple) : 311, 313-314, 323 et n. 933

Giscon : 185

Gnésiochos (œciste d'Héraclée du Pont): 294 et n. 790, 303

Gorgo Cottone (fleuve) : 163, 168-169, 199 et n. 362

Habroté: 20 n. 15

Hadès : 270 n. 685 (- à Byzance), 299 (grotte d'- à Héraclée du Pont)
Hadrien (empereur romain) : 76, 103, 227, 284, 290 n. 768, 331-332, 377-378

Haimos (montagne) : 311

Halcyonique (golfe) : 23 n. 25, 295, 369

Halicarnasse : 229

Halirothios (héros mégarien) : 72

Halirrothios, fils de Poséidon (héros athénien) : 72

Halykos, fils de Sciron (héros mégarien): 73 et n. 258,175

Halykos (fleuve): 175 et n. 242

Hannibal, fils de Giscon : 185

Hékatôdoros (stratège ? de Byzance) : 399

Hélios: 272 n. 695 (- à Byzance), 272 n. 695 (- à Corinthe)

Hélixos (amiral mégarien): 112, 268

Hellanicos de Lesbos (historien) : 13, 134135

Hénioché : 75

Héra: 194 (- à Acrai), 30 n. 53, 275, 381 (- à Argos), 29-30, 300 et n. 827 (- en Béotie), 29 et n. 49, 270-272, 277 et n. 718, 315-316, 377 et $n$. 249 (- à Byzance), 300 et n. 827 (- à Callatis), 29 et n. 49, 272 et n. 696, 315-316 (- à Chalcédoine), 24, 29 (- à Corinthe), 29 et n. 49, 300 et n. 827 (- à Héraclée du Pont), 29 et n. 49, 193 (- à Mégara ?), 2930, 193 (- à Mégare ?), 29 et n. 49, 315 et n. 897 (- à Mésambria), 210 n. 408 (- à Samos), 29 et n. 49, 193 et n. 338, 271-272 (- à Sélinonte), 194 (- à Syracuse)

Héra Akraia: 271 (- à Byzance ?), 28 et n. 48 (- à Corcyre), 22, 24-25, 272 et n. 695 (- à Pérachora)

Héra Leukolenos: 26 n. 37 (- à Pérachora)

Héra Liménéia : 25-27 (- à Pérachora)

Héraclée Minôa: voir Minôa (colonie de Sélinonte)

Héraclée (site dans le territoire de Callatis): 301 n. 831

Héraclée du Pont/Héracléotes: 1, 5 n. 11, 9 et n. 17, 29 et n. 49, 81-82, 86-87, 
89, 96-98, 108, 110 n. 422, 115, 198 et n. $360,202,205-206,210,212-$ 213, 215, 239 et n. 537, 245-246, $259,261,263$ n. $651,266-267,293-$ $310,326,335-338,340-342$, 347353, 355-357, 359, 371-372, 387, 395, 399, 404-405, 407-410, 412 Héraclès : 267 n. 670 (- à Aigosthènes), 299 et n. 818 (- en Béotie), 266-267, 285 (- à Byzance), 300 et n. 823 (- à Callatis), 266-267 (- à Chalcédoine), 300 (- à Chersonèse Taurique), 5 n. 11, 29, 295, 297, 299-300, 303, 308 (- à Héraclée du Pont), 266267, 299 et n. 818 (- à Mégare), 267 n. 670 (- à Pagai), 300 (- à Prusias de l'Hypios), 172-173, 267 n. 673 (- à Selinonte), 266-267 (- à Sélymbria), 173 n. 228,267 n. 673 (- en Sicile), 134 et n. 54, 246, 329

Héraclès Pharangeitès : 299-300 (- à Callatis)

Héraclide le Pontique (philosophe) : 294 et n. 792

Héraclides : 124 (- à Argos), 53 (- à Corinthe), 173 n. 230, 353 (clan ou hékatostys à Sélinonte), 193 n. 336

Héraeis (habitants de l'un des cinq districts primitifs de la Mégaride) : 16-17, 22$25,30,33,362,364$

Héréas (historien mégarien) : 12, 37-39, 64 65,73 et n. 258

Hermès : 266 n. 666 (- à Byzance), 32, 247, 290 n. 768

Hermioné : 280 n. 728, 404 n. 363

Héros Sôsipolis : 395 et n. 326 (- à Mésambria)

Hérodicos de Mégare/Sélymbria (sophiste): 247 et n. 576

Hestia (déesse) : 252 et n. 600

Hestiai (site sur la rive européenne du Bosphore thrace) : 155, 248 n. 582, 250-254, 279

Heybeliada: voir Chalcitis (île dans la Propontide)
Hiéria (promontoire) : 272 n. 696

Hiéron : 133-134

Hikésios d'Éphèse (gouverneur d'Égine) : 383-384

Himère: 59, 122 n. 16, 137, 161 et n. 175, 179 et n. 260, 184-185, 187, 191

Hippias (tyran d'Athènes) : 60 et n. 190, 133

Hippodamie (héroïne) : 32

Hipposthénès (héros mégarien) : 248 n. 582 (- à Byzance)

Histiée: 133 et n. 52, 167

Histria: voir Istros (cité)

Hybla: 123, 126, 140-141, 143 et n. 94, voir aussi Styella

Hybla Géléatis/Géréatis : 143 n. 94

Hybla Héraia: 143-144

Hybléens (monts -): 122 et n. 15

Hyblôn (roi des Sicules): 116, 120-121, 131, 138, 140-141, 145, 148, 245, 409

Hygie: 376-377 (- à Byzance)

Hyllos, fils d'Héraclès (héros) : 329 (- à Mégare)

Hypérion, fils d'Agamemnon (roi de Mégare) : 50-51, 384

Hypsas (fleuve): 167 et n. 205, 169

Hypsichidas (arbitre spartiate) : 60

Iamides (famille sacerdotale originaire d'Arcadie et d'Olympie): 125 n. 24

Iasos : 390 n. 308

Idmôn (héros argonaute) : 198 n. 360, 294 n. 789, 296-297, 303

Inachos (roi d'Argos) : 274-276

Inô (héroïne) : 30 n. 53, 38 n. 89

Iô (héroïne) : 274-276, 286

Ionie/Ioniens : $75,123,125-126,136$ et n. $65,229,259-261,264$ n. 655,306 et n. $851,310,382-383$

Iphigénie (héroïne) : 47 (- à Mégare)

Iphinoé (héroïne mégarienne) : 20 n. 15, 32 n. 64

Ischépolis, fils d'Alcathoos (héros mégarien) : $32 \mathrm{n} .64,51,385$

Isis : $345-346$ (- à Byzance)

Isos : 35 n. 76

Istranca (montagne) : 322 
Istros (cité): 142, 227-228, 238, 242 et

n. $548,313-314,360$

Istros (fleuve) : 142

Ithaque: 95

Itys, fils de Térée : 41

Iulius Candidus (proconsul d'Achaïe): 331 n. 30

İzmit (golfe) : 201, 217-218, 376, voir aussi Astacos (golfe), Olbia (golfe)

Jason (héros argonaute) : 133-134

Justinien (empereur byzantin) : 272 n. 696

Kalliadès (stratège de Byzance): 275 n. 705,400

Kallias (commerçant mégarien) : 105

Kallichoros (fleuve) : 301 n. 829, 359

Kallichoros (héros ?): 268 n. 677, 359

(- à Byzance), 268 n. 677, 359

(- à Chalcédoine), 301 n. 829, 359

(- à Héraclée du Pont)

Kassopée: 368

Kavarna: voir Bizonè

Kefken (île du Pont-Euxin): voir Thynias

Kenchreai : 22

Képhalos (héros) : 357 et n. 160 (- à Athènes), 357 (- à Byzance)

Kéramos (héros) : 357 et n. 160 (- à Athènes), 357 (- à Byzance)

Khani Derveni : 20

Kiérion: 301

Kiéros: 9 n. 17, 294, 300-301, 305 et n. 849, 326, 335-337, 372, voir aussi Prusias de l'Hypios

Kleulidai (groupement de Sélinonte) : 157 n. 157

Koiratadas (général béotien) : 268

Komôn (amiral mégarien) : 112

Kôralios (fleuve) : 301

Korinthos, fils de Zeus (héros corinthien): $42-43$

Kôthôn, fils de Kalligeitôn (hiéromnamôn de Byzance) : 375

Kotys (dynaste thrace) : 323

Kotyt(t)ô (déessse): 192-193 (-à Corinthe), voir aussi Kotyteia et Kotyttia

Krénides : 301
Krommyon (bourg mégarien, puis corinthien) : 40, 48-49, 107

Küçük Çekmece : 285 n. 744, 377

Kybos (cite punique en Afrique) : 143 n. 93

Kynosoura (montagne d'Arcadie) : 32

Kynosoura (nymphe/localité en Crète) : 32

Kynosoura (presqu'île de l'Attique) : 31

n. 58

Kynosoura (presqu'île de Salamine): 3132,72

Kynosoura (village spartiate) : 19 n. 11, 31

Kynosoureis (habitants de l'un des cinq districts primitifs de la Mégaride):

16-17, 30-33, 36, 340, 351, 362, 364

Kynosouros, fils d'Hermès (héros) : 32 (- en Arcadie)

Kynosouros, fils de Pélops (héros) : 32-33, 72, 340, 358 (- à Mégare), 32-33

(- à Mésambria)

Kytoros : 298 n. 815

Laconie/Lacédémoniens : 19 n. 11, 54, 60, $63,256-257,288,333$, voir aussi Sparte/Spartiates

Lakiadès (devin mégarien) : 33, 226, 248 n. 582 (- à Byzance)

Lamis (chef mégarien) : 48, 54, 119-120, 129-132, 136-138, 179, 409

Lampos/Lampôn (exilé mégarien) : 108 n. 414

Lampôn (œciste de Thourioi) : 108 n. 415

Lampsaque : 334-335

Lamptrai (dème attique): 59

Laomédon (roi de Troie) : 287

Lasthénès (golfe) : 248 n. 582

Lekton (promontoire) : 134 et n. 54

Lélex, fils de Poséidon (roi de Mégare) : 47, 50

Lemnos : 54, 79

Léôn (philosophe de Byzance) : 265 et n. 662,400 n. 348

Léôn (stratège de Byzance) : 275 n. 705, 400 et nn. 348-349

Léônidas (stratège de Byzance): 400 et n. 349

Léontinoi: 116, 120-121, 129-134, 137$139,141,145-146,179,409$ 
Licinius (empereur romain) : 370 n. 211

Lilybée : 195

Limenouchos (héros mégarien): 72

Lipara: 161 et n. 175

Locres Épizéphyrienne: 247

Lygos (œciste de Byzance): 273 et nn. 697698, 285

Lykadion (golfe) : 248 n. 582

Lypéros (montagne) : 216

Lysimacheia: 269 n. 681

Lysimaque (roi de Thrace et de Macédoine) : 204, 215-217

Macédoine : 258, 268, 286 n. 748, 305 n. 847,358

Majačnij (péninsule) : 352 et n. 134

Makara: 175 et n. 240

Marathon (golfe) : 31 n. 58

Marc-Antoine (général romain) : 76

Marcellino (fleuve) : 139

Mariandyniens (peuple): 246, 293-294, 297,302 et n. 834,304 et n. 845, 306310,355 n. 147,410

Markos de Byzance (sophiste) : 76, 284 et n. 742

Marmara (lieu en Mégaride) : 113 et n. 437

Marsala: voir Lilybée

Massalia: 170 n. 217, 181, 258 n. 631, 390 et n. 309

Mazara del Vallo: voir Mazare

Mazare: 174-175, 180

Mazaro (fleuve) : 173-174

Médée: 24

Médie: 293 et n. 784

Medistas (dynaste thrace) : 323

Mégabaze (général perse) : 231, 233, 240

n. $540,249,298$ n. 810

Megálo Vathychoria: 36, 40, 104 et n. 398

Mégalopolis : 385 n. 283

Mégara/Mégariens de Sicile: 1, 9 et n. 16, 13-14, 29 n. 49, 54, 91-92, 107, 109, 116-124, 126-134, 136-156, 158-160, 163-166, 170, 177-184, 188-190, 193$197,200,229,238,241,247,326$, 363, 409-410, 412

Mégare/Mégariens de Grèce: passim
Mégareus, fils de Poséidon (héros béotien/ mégarien) : 20 et $n .15,50-51,385$

Mégaride: 7, 9-10, 12, 16-19, 22, 27-31, $33-41,49,52-54,64,71,73-75,78$, 82-83, 87-89, 100, 104-106, 114 n. 438,136 et n. $62,146,175,267$ et nn. $670+676,270,278,280$ et n. 728 , 299, 301, 355, 361-362, 364-365, 367 n. 201,369 et n. 210,386 n. $289,392-$ 394, 402-403, 407-408, 412

Mégaros, fils de Zeus (héros mégarien) : 20

Mélampous (devin) : 226 n. 488, 402

Méliboia: voir Périboia

Mélitè (dème attique) : 68

Melsas/Melsos/Ména (œciste de Mésambria) : 317-320, 322

Men (dieu) : 290 n. 768 (- en Bithynie)

Mermnades (dynastie lydienne) : 236

Mésambria/Mésambriens: 1, 3, 5, 9 et n. 16,29 n. $49,32-33,48,81,109$ 110, 115, 206, 218 n. 442, 228-229, 243, 257, 277, 293, 310-324, 333334, 346 n. 113, 360, 371, 379-380, 382 et n. 274, 395-398, 404 et n. 366, 409, 411-412

Messène/Messéniens : 42 n. 104, 81

Messine (détroit) : 208

Métaponte: 184

Métèr Pontia: 397-398 (- à Dionysopolis)

Midas (commerçant mégarien) : 105

Mikro Vathychoria: 40, 104 et n. 398

Milet/Milésiens : 1, 97-98, 110 et n. 424, 116, 209 n. 405, 229 et n. 504, 238, 255-256, 258-264, 282 n. 737, 302303, 306 n. 851, 308 n. 860, 342, 356 n. 150,375 et n. 240,382

Minôa (établissement sélinontin en Sicile): 175-176, 180, 190-191, 194 n. 343, 409

Minôa (île dans le golfe Saronique) : 77 et n. 277,175 et $n .243$

Minos (roi de Crète) : 20 et n. 15, 30 n. 53, $73-75,175$ et $n .244$

Minotaure : 69

Minyens (peuple) : 54 
Mithridate VI Eupatôr (roi du Pont) : 289

$$
\text { n. } 766,387 \text { n. } 294
$$

Modione (fleuve) : 166, 168, 200

Montagnoli : 169-171

Monte Adranone: 174 et n. 236

Monte Iato: 171 et n. 223

Mopseustis (dynaste thrace) : 323

Motyè : 173, 182 n. 278, 184-185

Mycènes/Mycéniens : 238 n. 534, 255-256, 270, 403-404

Mylai : 208

Mylétidai (groupement de Syracuse) : 59 et n. $182,137,179$

Myrrhine : 66

Mysie/Mysiens : 201-202, 208, 211, 213 219, 288 et n. 762, 290, 292 et n. 778, 308,410

Myskos (héros sélinontin) : 329 et n. 18

Naucratis: 261-263

Naulochos : 317 et n. 903

Nauseiros/Nausithoos (héros salaminien): 69 et nn. 234+236, 72

Naustolos (héros mégarien): 72

Naxos (cité de Sicile): 120, 123, 126-127, $129-130,135$ et $n .59,138,141$ n. 84

Némésis : 377 et n. 249

Neôridès/Neôris (héros mégarien) : 72

Néron (empereur romain) : 266 n. 665

Nessèbre: voir Mésambria

Nicomède I ${ }^{\text {er }}$ (roi bithynien) : 202-203, 215 217, 220-221, 224-225, 289 n. 764

Nicomédie : 202-204, 213, 216-217, 220222,289

Nikè : 321 n. 921,357 et n. 158, 377 et n. 249 ( - à Byzance)

Nil (fleuve) : 261-262

Nipséens (tribu thrace) : 314

Nisa (localité en Béotie) : 35 n. 76

Nisaia (port de Mégare) : 30, 34-37, 56, 61-62, 64, 74-75, 77 et n. 277, 80, 83 n. $310,101,115$ et n. 444,145 , 175, 296 n. 801, 329

Nisos, fils de Pandion (roi de Mégare): 20 et n. $15,30,50,72-75,274,296$ n. 801
Nymphaion (site dans le territoire de Callatis): 301 n. 831

Nymphaion (site dans le territoire d'Héraclée du Pont) : 301 n. 831

Nymphis d'Héraclée du Pont (historien): 202 et n. 376, 204-205, 214, 296, 308

Obzor: voir Naulochos

Odessos : 229, 292

Odryses (tribu thrace): $346 \mathrm{n} .113$

Oinoé (fort corinthien) : 34 et n. 75

Olbia/Borysthène (cité du Pont-Euxin) : 111 n. 424, 227-228, 238, 360, 382

Olbia (golfe) : 204 n. 380, 217-220, voir aussi Astacos (golfe)

Olbia (nymphe) : 218-220

Olbia (site en Propontide): 201-202, 207, 217-222

Olympie: 43, 45-46, 107, 125 n. 24, 134 et n. 54, 189-190, 271 n. 689, 299, 309, 321, 383, 399 n. 343

Olympiodôros (stratège ? de Byzance) : 399

Onchestos (cité) : 20, 218

Onchestos (héros béotien) : 20 n. 15

Orchomène (cité béotienne) : 301

Orchomène (site dans le Pont-Euxin) : 301

Orgamé: 238, 242 et n. 548

Orminion (bourg de Démétrias) : 301

Orminion (montagne en Bithynie) : 301

Orobiai (bourg d'Histiée): 167 et n. 208

Oropos : 265 n. 659, 390 n. 308

Orsippos/Orrhippos (héros mégarien) : 43 44, 107

Ortaköy: voir Archeion

Pachi : voir Nisaia

Pagai (bourg mégarien qui acquit le statut de cité à l'époque hellénistique): 34 , 39-41, 83 n. 310,101 et n. 386, 104 et n. $398,109,267$ n. 670, 367-370, 391 n. 313

Pammilos (œciste de Sélinonte) : 159-160, 188

Pamphylos (héros): 329 et n. 19

Panaitios (tyran de Léontinoi) : 179

Pandion I, fils d'Érichthonios (roi d'Athènes): 73 n. 259 
Pandion II, fils de Cécrops II (roi

d'Athènes) : 40, 73-75

Panélos (cité du Pont-Euxin) : 300-301, 305

Panélos (héros) : 300-301, 303

Panormos (cité phénicienne en Sicile) : 184

Panormos (port sur le golfe de Corinthe): 101 et n. 386, 104, 368

Pantakyas (fleuve): 120

Pantalica: 140 et n. 76

Paphlagoniens (peuple) : 308 n. 860

Parthénopolis (site dans le territoire de Callatis): 301 n. 831

Parthénopolis (site dans le territoire d'Héraclée du Pont): 301 n. 831

Parthénos (déesse) : 371-372

(- à Chersonèse Taurique)

Patéras (montagne) : 104

Pausanias (général spartiate) : 215, 256-257, 265,313

Pedagaggi : 144

Peiraion (bourg de Corinthe) : 22-23

Pélasges (peuple) : 54

Pélée (roi de Phthie) : 71

Pélops (roi de Pisa): 32, 374 n. 232

Pénélope (épouse d'Ulysse) : 95 et n. 359

Pentathlos (chef cnidien) : 165, 172 et n. 226

Pérachora (péninsule): 17, 22-30, 33-34, 36-37, 39, 106-107, 145, 181-182, 193, 242, 272-273, 328 n. $12,365,411$

Pergame : 383

Périandre (tyran de Corinthe) : 48

Périboia (heroïne) : 71-72, 75

Périnthe/Périnthiens : 60, 181, 209-210, 238, 243-244, 259, 263 n. 651, 282, 322,337 n. 66,346 n. 113,379 et n. 258

Périphémos (héros salaminien) : 65

Perséphone/Koré: 62, 103 (- à Éleusis), 247 n. 575 (- à Mégare et dans ses colonies), 315 n. 895 (-à Mésambria), 246-247 (- à Sélymbria)

Perses (peuple) : 65, 112, 194 n. 343, 256, $271,309,312$ et n. $880,382,412$

Pescennius Niger: 379
Phaiax (héros salaminien): 69 et n. 234

Phalaris (tyran d'Agrigente) : 176 et n. 247

Phalère (dème attique) : 69 et n. 237

Phalion: 212 et n. 415, 216

Pheidon (tyran d'Argos) : 46-47

Phéniciens (peuple) : 138, 172 et n. 226, $175,184-185,312$, voir aussi Puniques

Phidaleia (héroïne) : 286 et n. 746

Philaios, fils d'Ajax (héros salaminien) : 64, 66

Philippe II (roi de Macédoine) : 258, 275 et n. 705, 305 n. 847, 358

Philippe V (roi de Macédoine) : 269 n. 681, 379 n. 258

Philistos de Syracuse (historien) : 13, 143 et n. 94, 161 et n. 172

Philochore d'Athènes (historien) : 39 et n. 92,69 n. 236,70 et n. 241,73 et nn. $255+259$

Philomèle : 40

Phocéens : 40, 125, 258 n. 631

Phocidiens/Phocide : 295-296, 304

Phocion (stratège d'Athènes) : 400 n. 348

Phorbas (archonte athénien) : 45-46

Phormion (archonte athénien) : 46 et n. 120

Phoroneus (roi d'Argos): 47, 50, 277

Piraeis (habitants de l'un des cinq districts primitifs de la Mégaride) : 16-17, 22$24,30,33,362,364$

Pirée (port d'Athènes) : 31

Pisistrate (tyran d'Athènes): 37 et n. 85, 58 et n. 176, 60-61, 64, 66, 75 n. 272 , 80

Pisitrate le Jeune, fils d'Hippias: 133

Pithée: 75

Platani (fleuve): voir Halykos

Platée/Platéens: 35 n. 76, 60, 134 n. 55

Poggioreale : 171-172

Poiné: 21

Polémaios (stratège d'Antigone Monophthalmos): 211

Polichnè : 34-37, 64

Polichnion Mégarikon (site en Propontide): 204 et n. 383, 207, 219 
Pollis (roi de Syracuse) : 124

Polyeidos (devin mégarien): 33, 226 et n. 488,248 n. 582

Polyxénos, fils de Melséôn (stratège de Mésambria) : 397

Porto Germeno: voir Aigosthènes

Poséidon: 287 (- à Byzance), 371 n. 216 (- à Chalcédoine), 23, 75 (- à Corinthe), 7 n. 13 (- à Mégare), 220 et n. 453 (sanctuaire de - sur un promontoire du golfe d'Astacos), $20,50,65,70,72,218-219,286$, 381 n. 271

Poseidonie/Poseidoniates : 125, 184

Potniai : 295 n. 794

Pratomyseitai (bourg des - à Byzance) : 344 n. 100,376

Praxitèle (sculpteur athénien) : 133

Procné: 40

Prodomeis (divinités) : 253-254, 413 (- à Mégare)

Prôtomachos (stratège de Byzance) : 275 n. 705,400

Prusias de l'Hypios: 9 n. 17, 294 et n. 793, 300, 305 n. 849, 326, 335-337, 372, voir aussi Kiéros

Prusias $\mathrm{I}^{\mathrm{er}}$ (roi bithynien) : 288 et n. 763 , 290,305 n. 849,337 et n. 65,375 et n. 238,399

Psamathé: 21 et n. 19

Psatha: voir Panormos

Ptolémée II (roi d'Égypte) : 289 et n. 764

Puniques (peuple) : 184-185, 188, 195, voir aussi Phéniciens

Punta Castelluzo: 130 et n. 43

Pylas (roi de Mégare) : 50, 73-74

Pyrgari: 31 n. 61

Pyrgo (héroïne mégarienne) : 32 n. 64

Pythie: 21, 65, 67, 102, 108, 274, 295, 298 n. 810, voir aussi oracle d'Apollon de Delphes

Pythion (site en Propontide) : 207 et n. 397, 219

Raguse : voir Hybla Héraia

Rémus (fondateur de Rome) : 275
Rhégion (cité de l'Italie): 114, 124, 183 , 208

Rhégion (localité en Propontide) : voir Küçük Çekmece

Rhodes/Rhodiens : 166, 179 et n. 261, 260, 278-279, 288 et n. 763, 354 et n. 142,375 et n. 238,379 n. 258 , 399

Rhoimétalkès I (roi des Odryses) : 346 n. 113

Rhoimétalkès III (roi des Odryses) : 346 n. 113

Rhous (lieu à Mégare): 84 et n. 315

Rome: 275, 284, 289 n. 766, 400-401

Romulus (fondateur de Rome) : 275

Rovies : 167 n. 208

Sabine (impératrice romaine) : 332

Sacon (l'un des fondateurs de Zancle): 137

Sadalas (dynaste thrace) : 323

Salamine (île) : 31-34, 36-37, 39, 55-72, 75-81, 88, 95-96, 108-109, 112, 115, 316,328 n. 12, 365, 411

Salamis (nymphe) : 65, 70

Salmydessos : 313-314, 323 n. 931

Samos/Samiens : 60, 110-111, 116, 209210, 238, 259, 262

Samothrace : 378

Sandion: 50-51

Sangarios (fleuve) : 304 n. 845

Sarapis : 345-346, 376-377 (- à Byzance)

Saron (héros mégarien) : 248 n. 582 (- à Byzance)

Saronique (golfe) : 22-23, 48, 71, 76 n. 275, $101,109,111,182$ n. $275,256,316$

Sébastopol : 305

Schoiniklos (héros béotien) : 248 n. 582, 265 et n. 659 (- à Byzance)

Sciacca: 176

Sciradion (promontoire) : 69-70

Sciron (brigand/héros mégarien) : 33, 38

n. $89,70-75,88$ n. $329,175,332$

Sciron (lieu en Attique) : 69 n. 237

Sciros (devin de Dodone) : 70

Sciros, fils de Poséidon (héros salaminien): 69-71 
Scylla, fille du roi megarien Nisos : 30 et n. 53

Scythes (peuple) : 271, 278-280, 311, 313314

Ségeste/Ségestains: $166,172,175,185$ 187, 382 n. 274

Séleucie du Kalykadnos : 342

Séleucos I (roi séleucide) : 217 n. 437

Sélinonte/Sélinontins : 1, 5, 7 et n. 12, 9 et nn. 16-17, 13-14, 29 n. 49, 49, 109$110,117-119,127-129,144,146,148$ n. $114,156-200,220$ n. $452,238,241$, 267 n. 673, 271-272, 326, 328-329, 353-354, 382-383, 396 n. 326, 409411,413

Sélinous (fleuve) : 166-167

Sélymbria/Sélymbriens : 1,9 et n. 16, 107, 201, 205-206, 208-210, 218 n. 442, 243-247, 266-267, 283, 285 n. 744, $320,324,343$ et n. 94, 376, 383, 395, 401,411

Sélys (œciste de Sélymbria) : 245 et nn. $562+565$

Sémestrè (nymphe) : 274, 286

Sénat: 376-377 (culte du - romain à Byzance)

Sepeia: 60 n. 190

Septime Sévère (empereur romain) : 267 n. 671,283 et n. 739,369 n. 211 , 373 n. 229,379

Sicanes (peuple) : 138, 168-171, 174-176

Sicules (peuple) : 120-121, 131-134, 138$145,148,158,245,409$

Silivri: voir Sélymbria

Simonide (poète) : 43, 74 n. 262, 111 et n. 428,297 n. 804

Simos (l'un des fondateurs de Zancle): 137

Sinope: 261, 280 n. 728, 306 n. 851, 339 n. 72,382

Siphai : 295 et nn. 794-795, 303

Skutari: voir Chrysopolis

Skyrmiades (tribu thrace) : 314

Solon (législateur athénien) : 37 et n. 85 , 57-65, 70, 78, 80, 85-86

Solonte (cité phénicienne en Sicile) : 184
Sousariôn, fils de Philinos (poète mégarien) : 21 et n. 18,95 n. 359

Sparte/Spartiates : 22, 31, 34, 37, 43-44, 46 n. 120, 54-55, 60-63, 79, 81, 89, $102,109,115,175,215,255-257$, 264-265, 268, 281 n. 732, 288 n. 760, 291 et n. 773, 307, 313, 316, 333-334, 362 n. 189, 399, voir aussi Laconie/ Lacédémoniens

Stephanis (cité des Mariandyniens) : 309 et n. 865

Sthénélos (héros argonaute): 297 et n. 809 Strobilos : 376

Strombos : 275, 278-279

Styella: $143-144$

Sybaris : 184

Syracuse/Syracusains : 29 n. 48, 53, 59, 91 92, 98, 109, 118, 120-130, 137, 139$140,142-143,146$ et n. 106, 148, 159 n. 162,179 et n. $261,182,191,194$ et n. 343,223 n. 472,258 n. 631,278 , 307, 409

Tanagra/Tanagréens : 265 n. 661, 294 et nn. 791-792, 303, 306 n. 852

Tanit (déesse) : 198

Tarente: 53 n. 158,180

Taroutinas (dynaste thrace) : 323

Taures (peuple) : 309

Teicho (presqu'île): 30-31, 77 n. 277

Télamon (roi de Salamine) : 71-72

Télémaque, fils d'Ulysse: 95

Tellos: 62

Téménos: 124

Ténéa (bourg de Corinthe) : 53 et n. 157

Téos : 229

Térée (roi de Pagai) : 40-41

Teucros (héros salaminien): 69 et n. 234

Thapsos: 120, 130-131, 134, 138, 146 et n. 106,148

Théagène (tyran de Mégare) : 56-57, 59 n. $180,82-85,90 \mathrm{nn}$. 335-336, 94-95, 383

Thèbes/Thébains: 134 n. 55, 203, 217-218, 256 n. 618, 294 et n. 792, 301, 303, 336- 337,359 
Thibais (site dans le Pont-Euxin) : 301

Thémistocle: 77

Théoclès/Thouclès : 120, 122-123, 125126, 131-138

Théodora (impératrice byzantine) : 272 n. 696

Théodore (thaumaturge de l'époque byzantine) : 221 n. 465

Théognis (poète athénien): 91 et n. 343

Théognis (poète mégarien) : 12, 15 n. 1, 32 n. 63,42 n. $101,79-80,82$ et n. 305 , 84, 89-96, 103 nn. 390-391, 147-148, 247

Théra/Théréens : 54, 116 n. 446

Thermae Himeraeae: 176 n. 249

Thermae Selinuntiae: 176 et n. 249

Théron (tyran d'Agrigente) : 190-191, 409

Théron, fils de Miltiade (tyran de Sélinonte): 173

Thésée (héros athénien) : 40, 66, 69-73, 75 et n. 270,88 n. 329,252

Thespies: 294 n. 792

Thessalie/Thessaliens : 102, 134 et n. 54, 262, 301, 307

Thestor, fils d'Apollon (héros) : 225 n. 485

Thisbé: 370 et n. 212

Thourioi : 108 n. 415, 135

Thrace/Thraces: 9 n. 18, 40, 177, 192-193, $201,208,212,215$ et n. 427,218 n. 442, 223, 226 et n. 490, 236, 239, 245-246, 248 n. 586, 259, 273 n. $698,275,278,280$ et nn. $728-729$, 282, 285-288, 290-293, 306, 311, 313-314, 316-317, 319 et n. 913, 322-324, 328 n. 12, 333, 399-400, 410

Thrakion (lieu à Byzance) : 291

Thrasydée, fils de Théron (tyran d'Agrigente) : 190-191, 409

Thriasia (plaine d'Éleusis) : 73

Thynias (île du Pont-Euxin) : 305

Thyrreion: 368

Tiéion: 301

Timalcos, fils de Mégareus (héros mégarien) : 51
Timée de Tauromenium (historien) : 28 n. 48,53 et n. 158,134 n. 56,161

Timèsios d'Argos (stratège de Byzance): 275 n. 705,400

Timoléon: 176, 194

Tiphys (héros béotien): 295 et n. 794, 297

Titus Quinctius Flamininus (général romain) : 379 n. 258

Tomis : 276,280 n. 728

Trajan (empereur romain) : 352, 378 n. 251

Trézène: 404 n. 363

Triokola: 174 n. 235

Tripodiskioi (habitants de l'un des cinq districts primitifs de la Mégaride): 16-17, 19-20, 22, 33, 362, 364

Tripodiskos/Tripodiskoi (et aussi Tripodes/Tripodiskion) : 20-22, 28 n. $44,33-34,36-37,41,47$

Troie/Ilion : 126-127, 249 n. 591, 287, voir aussi guerre de Troie

Trôtilon: 120,130 et nn. 40+43, 132 et n. $48,134,136$ n. 64,146 n. 106

Tychè: 377 n. 249 (- à Byzance), 300 n. 827 (- à Héraclée du Pont ?)

Tyr: 258 n. 631

Ulysse: 95 et n. 359

Üsküdar: voir Chrysopolis

Utique: 143 n. 93

Vélia: 125

Villasmundo: 139-140, 142

Vouliasmeni (lac) : 36

Xerxès (roi des Perses) : 309

Yağcilar: 289

Yalova: 289 n. 764, 376

Yuvadjyk/Yuvacik: 202

Zancle: 59, 137, 179, 208

Zeus : 306 n. 853 (- à Héraclée du Pont?), 315 n. 897 (- à Mésambria), 190 (- à Olympie), 15, 20, 42-43, 275, 286, 290 n. 768

Zeus Aithrios: 376 (- à Byzance)

Zeus Aphésios: 112-114 (- à Mégare)

Zeus Brontaios: 344 n. 102 (- à Byzance)

Zeus Euménès: 187 et n. 303 (-à Sélinonte) 
Zeus Hapsasios: 255 et n. 617 (-à Byzance)

Zeus Hyperdexios: 371 et n. 219

(- à Mésambria)

Zeus Kômatikos: 376 (- à Byzance)

Zeus Machaneus: 265 n. 661 (-à Tanagra)

Zeus Meilichios: 7 n. 13, 329 (- à Mégare),

157-158, 329 et n. 18 (- à Sélinonte)

Zeus Olympios: 58, 112 (- à Mégare)

Zeus Panellénios: 112

\section{Index thématique}

accords : 170 n. 217,245 n. 561,308

n. 860 ( - entre les Grecs et les indigènes), 302 (- entre les Mariandyniens et les Milésiens à Héraclée du Pont), 308 (- entre les Mariandyniens et les Héracléotes), 81 (- entre les Mégariens et les Athéniens), 130-132 (- entre les Mégariens et les Chalcidiens à Léontinoi), 245 (- entre les Mégariens et les indigènes à Sélymbria?), 258-264 (- entre les Mégariens et les Milésiens dans la colonisation), 323 (- entre Mésambria et Sadalas), 189-190, 383 (- entre Sélinonte et des exilés sélinontins), 187 (-d'intermarige entre Sélinonte et Ségeste)

acropole: 112 (- d'Argos), 114 n. 438

(- d'Athènes), 131-132 ( - de

Léontinoi), 32 et n. 63, 71, 74

(- occidentale de Mégare), 50, 84, 97, 112 (- orientale de Mégare), 311 (- de Mésambria), 164, 169 et n. 912, 195-197 (- de Sélinonte), 102 (- des Thessaliens)

agathoi: $89,92-94$

agonothète (magistrat) : 394 n. 324

(- à Mégare)
Zeus Pratomysios: 376 (- à Byzance)

Zeuxippos (chef mégarien) : 283 et n. 739, 285

Zipoition: 216 et n. 433

Zoilos, fils de Kélainos (chef de la garnison macédonienne d'Aigosthènes) : 364

Zypoitès (roi bithynien) : 211-212, 215217, 297 agora: 114 n. 438, 133 (- d'Athènes), 235, 283 et n. 739 (- de Byzance), 198 n. 360, 297 (- d'Héraclée du Pont), 131-133 (- de Léontinoi), 147 et n. $108,149-151,153-155$, 196, 200 (-de Mégara), 22, 44 n. 112, 297, 326 (- de Mégare), 20 (- des Mégariens à Tripodiskos), 57 (- de Salamine), 156-157, 163-164, 169, 195-196, 198, 200 (- de Sélinonte)

agoranome (magistrat): 394 n. 324 (- à Mégare)

agriculture: 100 (- en Mégaride), 147 et n. 110 (- en Sicile)

Aiantéia (fête) : 67 et n. 227, 70 et n. 243 (- à Athènes)

aisimnatai (magistrats): 387, 389 (- à Byzance ?), 387-389 (- à Callatis ?), 346-347, 357, 383-387, 390, 412 (- à Chalcédoine), 387-389, 403 n. 360 (- à Chersonèse Taurique ?), 52 et n. 151,190 n. 323, 382-386, 388, 411 (- à Mégare), 382 et n. 276 (- à Milet et dans ses colonies), 190, 383 (- à Sélinonte), 383 (- à Sélymbria), 6, 366

Aisymnion (bâtiment public/hérôon) : 51 n. 146, 384-385 (- à Mégare) 
alphabet: 49 et n. 137, 173, 192 (- corinthien), 228-229 (- ionien), 49 et n. $137,173,186,188-189,254,271$ (- mégarien), 185-189 (- sélinontin) ambassade/ambassadeurs : 43, 194 n. 343, 284,322 n. 928,379 n. 258

Amphictionie pyléo-delphique : 87-89, 96, 107-108, 269, 394 n. 324

ancêtres : 295 et n. 795 (- à Aigosthènes), 256, 284 (- à Byzance), 303

(- à Héraclée du Pont), 323

(- à Mésambria), 263 (-à Milet), 157 et n. 157 (- à Sélinonte), 295 et n. 795 (- à Siphai), 76 n. 274, 412-413

ankritères (magistrats) : 334 (- à Chalcédoine)

arbitre/arbitrage : $34,37,55,60$ et nn. 189190, 62-63, 74, 79, 81, 108-109, 115, $316,368,383,393$, voir aussi juge archiereia: 372-373 (- à Byzance), 371 et n. 218 (- à Héraclée du Pont), voir aussi prêtresse

archiereus : 372-373 (- à Byzance), 369 et n. 208 (- à Mégare), voir aussi prêtre archives : 51, 61, 256 n. 618, 397

archonte (magistrat) : 369 et n. 210, 393

(- à Aigosthènes), 45-46, 133

(- à Athènes), 339 n. 72, 405

(- à Chersonèse Taurique), 367 et

n. 202, 369 et n. 210 ( - de la Ligue béotienne), 367 et n. 202, 369, 393 (- à Mégare), 376 (- du village byzantin des Pratomyseitai), 366

Argonautes: 54, 286 n. 746, 294 n. 789, 297-298, 303

association: 158 (- cultuelle à Byzance), 300 (- des Héracléotes à Callatis), voir aussi Dionysoboleitai, génos, patria, thiase

asylia («inviolabilité»): 269, 375, 380, 391,397

Assemblée: 356, 390, 399 et n. 344 (- de Byzance), 388 (- de Callatis), 386 et nn. 288+290 ( - de Chalcédoine), 338, 388-389 (- de Chersonèse
Taurique), 397 (- de Dionysopolis), 338 n. 67 (-d'Héraclée du Pont), 402 n. 358 (- de la Ligue achéenne), 83, 383-384, 391 (- de Mégare), 397 (- de Mésambria), 356 n. 150 (- de Milet), 366

basileus («roi », magistrat): 369

(- à Aigosthènes), 372-375

(- à Byzance), 371 et n. 220, 375

et n. 236 (- à Callatis), 346, 371

et n. 216, 374-375, 379-380

(- à Chalcédoine), 371-372

( - à Chersonèse Taurique), 371 et

n. 217 (- à Héraclée du Pont), 367

et n. 203, 369, 374, 411 (-à Mégare),

371 et n. 219 (- à Mésambria), 370

(- à Pagai ?), 372 (- à Prusias de l'Hypios), 378 (- à Samothrace), 6, 366

basilissa («reine», magistrat): 372

(- à Byzance), 371 et n. 218

(- à Héraclée du Pont)

Bendideia (fête) : 192 et n. 335

(- en Thrace)

béotarque: 394 n. 324

bois : 106 (- en Mégaride), 266 (- sacré d'Héraclès à Byzance)

Boulè : voir Conseil

Bouleutèrion («salle du Conseil ») : 390 et n. 307 (- à Byzance), 385 n. 283 (- à Mégalopolis), 51-52, 76, 82, 384-385 (- à Mégare), voir aussi Thersilion

bouleutes: voir conseillers bourg/village: 362 n. 191 (- achéen), 404 n. 363 (- argien), 19, 114 n. 438, 252, 413 (- athénien), 211, 289-290 (- bithynien), 244, 344 n. 100, 376 (- byzantin), 22, 48 et n. 134, 53 et n. 157 (- corinthien), 19 n. 11 ( - lacédémonien), 309 et n. 866 (- mariandynien), 6, 16-22, 32 n. 65, 40,48 et n. 134, 93, 153, 325, 361364, 369-370, 412 (- mégarien), 148 (- néolithique à Mégara), 222 
(- nicomédien), 379 (- périnthien), 200 (- sélinontin), 169 (- sican à Sélinonte), 19, 245 et n. 563, voir aussi dème, kômè

calendrier/mois : 337 (-bithynien), 255, 265

n. 661, 270-271 (- de Byzance), 388

n. 297 ( - de Callatis), 380 n. 261, 385

n. 287 (- de Chalcédoine), 270 (- de Corcyre), 270-271 (-deCorinthe), 187 (-d'Entella), 407 et n. 1 (-d'Héraclée du Pont et de ses colonies), 133 et n. 52 (-d'Histiée), 5-7, 270-271 (-de Mégare et de ses colonies)

céréales : 104 et n. 397 (culture des en Mégaride), 180 (culture des à Sélinonte), 244 (culture des à Sélymbria), 146-147 (exportation de - depuis Mégara vers sa métropole), 104 n. 399 (importation de - de Cyrène), 289 (Ptolémée II envoie des - à Byzance)

chiliastys («millier», subdivision civique): 335 n. 146

chôra/territoire: 204, 208, 211 n. 410, 213, 219 (-d'Astacos), 36, 66-67, 75

(- d'Athènes), 155, 239 n. 537, 244245, 285 et n. 744, 288 et n. 762, 290, 343-344, 376-377 (-de Byzance), 301 n. 831, 352-353, 398 (- de Callatis), 211 n. 410, 235, 240 (- de Chalcédoine), 352-353 (- de Chersonèse Taurique), 25, 27, 36 (- de Corinthe), 301 (- de Démétrias), 393 n. 318 (-d'Érétrie), 301 n. 831, 306-307, 410 (- d'Héraclée du Pont), 167

( - d'Histiée), 142 (- d'Istros), 132 et n. 49 (- de Léontinoi), 120-121, 141144, 177-178 (- de Mégara), 22, 104, 106, 111, 394 (- de Mégare), 317 et n. 902, 322 (- de Mésambria), 220, 222 (- de Nicomédie), 265 n. 659 (- d'Oropos), 379 (- de Périnthe), 166, 169, 171 n. 222, 174, 176, 179 (- de Sélinonte), 244 (- de Sélymbria), 139 n. 74, 194 (- de Syracuse),
306 n. 852 (- de Tanagra), 102 (- des Thessaliens), 117, 208, 237, 307, 310, voir aussi pérée

citoyenneté/droit de cité : 54,66 et n. 219 , 91, 148, 247, 264 n. 654, 267, 298 n. $816,310,322-323,325,335,342$, 349, 364, 388, 397, 399 n. 343

clérouques: 59, 78 (- de Mégare à Salamine)

comédie: 21, 93 et n. 349, 363 et n. 194

commerçants : 304 (-d'Héraclée du Pont), 94, 105 (- de Mégare), 111, 228, 260 commerce : 234-236, 250, 260 (- des Byzantins), 110 n. 423 (- des Éginètes), 182 n. 275, 235, 241, 260 (-des Grecs en mer Noire), 123 ( - des Grecs en Sicile), 316 (- des Grecs avec les Thraces), 305 n. 846 (- des Héracléotes), 8 n. 15, 15, 76, 94, 100, 110111, 145-146, 208, 237 (- des Mégariens), 177, 179-180, 182-185, 188, 194, 196, 409 (-des Sélinontins), 244 n. 559,254 n. 609

concours : 32 n. 63 (- en l'honneur d'Alcathoos à Mégare), 375-376 (- des Dionysies à Byzance), 75 (- isthmiques), 96 n. 367 (- olympiques), 23-24 (- de Péraion, en Corinthie), voir aussi Pythia

Confédération: voir Ligue conflits (ou luttes) internes/stasis : 97 , 281-282, 288, 333 (- à Byzance), 53 n. 158 ( - cause de la colonisation grecque), $86,96,303$ et n. 840 (- à Héraclée du Pont), 146 (- à Léontinoi), 6, 15-17, 41, 49, 52$53,79,81-82,84,86,88-89,92,96-$ 97, 107, 110 n. 422, 112, 114-115, 145, 242, 304, 383, 411 (- à Mégare), 210 (- à Samos), 189-190 (- à Sélinonte), 101-102

Conseil : 269, 394 n. 324 (- de l'Amphictionie phyléo-delphique), 356, 389390, 399 n. 343 (- de Byzance), 388 (- de Callatis), 347, 380, 386 et 
n. 290, 401 et n. 353 (- de Chalcédoine), 338, 350 n. 127, 389, 403 n. 360 ( - de Chersonèse Taurique), 397 (- de Dionysopolis), 338 et n. 67, 349 (-d'Héraclée du Pont), 402 n. 358 (- de la Ligue achéenne), 330 n. 22, 369 n. 208, 383-384 (- de Mégare), 366, voir aussi synédrion conseillers (magistrats): 394 n. 324 (-de l'Amphictionie phyléo-delphique), 349 (- à Byzance), 350 n. 127, 389 et n. 305, 403 n. 360 (- à Chersonèse Taurique), 397 (- à Dionysopolis), 390 n. 309 (- à Massalia), 82, 385 (- à Mégare), voir aussi synèdres, timouques contremarque : 320 n. 919 (- à Mésambria), 167 et n. 206 (- à Sélinonte) culte impérial : 373, 377 (-à Byzance), 371 (- à Héraclée du Pont)

damiorgoi (magistrats): 402 et n. 359 (- à Aigosthènes), 403-404 (- à Argos), 402-403 (- à Chersonèse Taurique), 404 n. 363 (- à Épidaure), 404 et n. 364 (- à Héraclée du Pont), 404 n. 363 (- à Hermioné), 393 n. 318, 401-402 (- de la Ligue achéenne), 341, 361, 393, 398, 401-404, 411 (- à Mégare), 403-404 (- à Mycènes), 404 n. 363 (- à Trézène), 6, 366

dékateutèrion («bureau de perception de la dîme»): 235 n. 525 (- établi par les Athéniens à Chrysopolis)

dème : 19, 59, 65-66, 68, 335, 357, 363-364, voir aussi bourg/village

démocratie/démocrates: 358 (-à Byzance), 387 (- à Chalcédoine), 349 (- à Chersonèse Taurique), 86-87, 89, 96, 303 et n. 840, 310, 347, 349-351, 355, 357 (- à Héraclée du Pont), 38, 59 n. 180, 79, 82, 84-90, 92-97, 99 n. 378, 107$108,115,148,303$ n. 840, 363, 389 (- à Mégare), 396 n. 326, 401 n. 353 dikè («justice»): 91

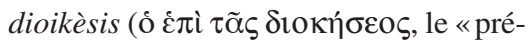
posé à l'administration », magistrat) : 405 et n. 369 (- à Chersonèse Taurique)

Diokleia (fête): 40, 73 (- à Mégare)

Dionysies (fête) : 375-376 (- à Byzance), 388 et n. 299 (- à Callatis)

Dioskouria (fête) : 360 et n. 174 (- à Mésambria)

district/méros: 362 n. 191, 393 et n. 318 (- achéen), 393 n. 318 (- érétrien), 16-19, 22-26, 30-33, 36, 40-41, 52, $340,351,361-365,386$ n. 289, 393394, 412 (- mégarien)

les «Dix» (magistrats) : 360 (- à Istros)

Dorykleion (téménos d'Athéna) : 59 et n. 184 (- dans le dème attique de Lamptrai)

éklogistai (magistrats) : 404 et n. 366 (- à Mésambria)

emporion: 174, 194 n. 343, 204 n. 380 , 235, 286 n. 746

éphèbes: 67, 70 (- à Athènes), 397 (- à Dionysopolis), 368 (- à Mégare)

épigamia («droit d'intermariage»): 54 (- entre les Minyens et les Spartiates), 187-188 (-entre les Sélinontins et les Ségestins)

épimènioi (magistrats): 335 (- à Lampsaque)

épinomia («droit de pâturage») : 105

épistate (magistrat): 386-387 (- des prytanes à Athènes)

époikoi («colons additionnels ») : 213-214 (- à Astacos), 97, 110, 211-213, 236, 256, 269, 278, 281-282 (-à Byzance), 54 et n. 161 (- à Cyrène), 179 n. 261 (- à Géla), 87, 303 (- à Héraclée du Pont), 131-132 (- à Léontinoi), 153 n. 134 (- à Mégara), 327-328 (- à Mégare), 313-315, 360, 382, 412 (-à Mésambria), 194 (- à Sélinonte), 2-3, 8, 118, 146, 366, 410

ère : 216-217 (- bithynienne), 217 n. 437 (- séleucide) 
esclave: 22, 106 n. 407, 302, 310, 328 n. 12 eugeneia («noble origine»): 222, 336 exil/exilés (et aussi bannissement/bannis): 73, 134 n. 55, 224 (- d'Attique), 54, 271 (- de Corinthe), 185 (- de Giscon à Sélinonte), 86, 303 n. 840 (- d'Héraclée du Pont), 122 n. 16 (- de Mégara), 59, 80 n. 295, 86, 8890, 95-98, 107-108, 112, 147, 191 (- de Mégare), 132 (- mégariens de Léontinoi), 189-190, 383 (- de Sélinonte), 190 (- de Thrasydée à Mégare), 2

foyer: 199, 251-254, 413

frontière: 61 et n. 196 (borne de -), 179 (conflits de - entre Mégara et Léontinoi), 107 (conquête des terres de par le Mégarien Orsippos), 302 (- d'Héraclée du Pont), 75 et n. 270 (l'isthme en tant que - entre les Péloponnésiens et les Ioniens), 31, 62 et n. 199, 65 n. 212, 106 (- de Mégare avec Athènes), 29-30 (- de Mégare avec la Béotie), 34, 49, 104, 107 (- de Mégare avec Corinthe), 176 n. 247 (- de Sélinonte avec Agrigente), 331 (tracé de la - entre Épidaure et Corinthe), 29 n. 51, 109, 365.

génos: 294 et n. 792, 303 (- de Damis à Héraclée du Pont), 59 et n. 182 (- des Mylétidai ? à Syracuse), 36, 87-89, 158 ( - «des renverseurs de chariots » à Mégare), 67-69, 72 (-des Salaminiens à Athènes), 156, 303, 413, voir aussi Dorykleioi, homosépyoi/homosipyoi, Kleulidai, Mylétidai

geôrgoi («cultivateurs »): 290, 308, 410 (-à Byzance, population dépendante), 307, 310 n. 872 (- à Héraclée du Pont, population dépendante), 16-17, 52 (- de Mégare)

gnôrimoi («notables»): 86 (- à Héraclée du Pont) guerre: 268 («-des Alliés »), 45-46, 48,

124 et n. 22 ( - d'Argos contre Corinthe), 46 n. 120 (-d'Argos contre Sparte), 211-213 (- d'Astacos contre les Bithyniens), 203, 211 (- d'Astacos contre ses voisins), 295-296, 304 (- des Béotiens contre les Phocidiens, 239 (- de Byzance contre Antiochos II), 275 n. 705, 358 (-de Byzance contre Philippe II), 260, 288-289, 375 n. 238, 399 (- de Byzance contre Rhodes et Prusias $\left.\mathrm{I}^{\mathrm{er}}\right)$, 223, 250-251, 259, 278-279, 282, 288 et n. 758, 399-400 (- de Byzance contre les Thraces), 211-212 (- de Chalcédoine contre les Bithyniens), 22 («- de Corinthe »), 112 ( - de Corinthe contre Corcyre), 311, 313-314 (- de Darius contre les Scythes), 172 n. 226 ( - des Grecs de Pentathlous contre les Élymes et les Phéniciens), 212-213 (- d'Héraclée du Pont contre Astacos), 297, 305 n. 849 (- d'Héraclée du Pont contre les Bithyniens), 304, 309 (- d'Héraclée du Pont contre les Mariandyniens), 399 (- d'Héraclée du Pont contre le royaume du Bosphore cimmérien), 145-146, 262263 (- lélantine), 42 n. 101, 65, 90 n. 335, 112, 256, 297 et n. 804 (- médiques), 179 (- de Mégara contre Léontinoi), 15, 34, 55-63, 75-81, 95, 108, 111-112, 115, 304, 411 (- de Mégare contre Athènes), 15-16, 4246, 48-49, 106-107, 124 et n. 22, 145146, 242 (- de Mégare contre Corinthe), 261-263 (- des Mégariens contre les Milésiens), 131-132 (- des Mégariens contre les Sicules à Léontinoi), 317 (- de Mésambria contre Apollonia du Pont), 324 (- de Mésambria contre les Besses), 323, 397 (- de Mésambria contre les Gètes), 81 (-de Messénie), 20, 73 (- contre Minos), 38 n. 89, 76-77, 91, 100-103, 
112,236 n. 525, 260, 268, 327 (-du Péloponnèse), 60, 116, 209-210, 259260, 263 n. 651 (- de Périnthe), 268 (première - de Macédoine), $289 \mathrm{n}$. 766 (- de Rome contre Mithridate), 173 (- de Sélinonte contre les Carthaginois), 166, 172 (- de Sélinonte contre Ségeste), 123 et n. 17, 125-127, 223, 301 et n. 828 ( - de Troie), 15, 107, 111, 115, 145, 291, 303 n. 840 , $326,328,396$

gymnase: 266 n. 666 (- de Byzance), 397 (- de Dionysopolis)

gymnasiarque (magistrat) : 371 et n. 219 (- à Mésambria)

hagémôn boulas (magistrat) : 346, 386-387 (- à Chalcédoine)

hékatostys ( «centaine», subdivision civique): $258,334,340-347,354$, 356-359, 376 n. 244, 382, 387 (- de Byzance), 351-353 (- de Callatis?), 258, 267, 340-347, 349, 356-359, 382, 387, 412 (- de Chalcédoine), 342, 349-353 (- de Chersonèse Taurique), 310 et n. 872, 340-342, 347-352, 355-357, 412 (- d'Héraclée du Pont), 335 (- de Lampsaque), 6, 31, 33, 40, 72, 155, 325, 339-342, 347-348, 351, 355 et n. 145, 358, 394, 411 (-de Mégare), 173 n. 230, 353-354 (- de Sélinonte ?)

Héraia (fête): 24 (- à Corinthe), 30 (- à Mégare ?)

héroïne : 286, 358

hérôon: 156, 198 (- de l'agora de Sélinonte), 51 (-d'Alcathoos à Mégare), 47 (- d'Iphigénie à Mégare), 69 (- de Nauseiros à Athènes), 74 et n. 265 ( - de Pandion à Mégare), 69 (- de Phaiax à Athènes), voir aussi Aisymnion, Thersilion, tombe/tombeau

héros: 14, 20-21, 32-33, 38 n. 89, 44 et n. $112,47,51-52,65$ et n. $215,67-75$, $78,81,88$ n. $329,133,175,198$ et n. $360,217-218,222,225$ et n. 483 ,
246, 248 n. 582, 253, 265-268, 280, 284-285, 287, 290, 295-298, 300-301, 303, 317, 321-322, 329-330, 340-341, $357-359,274$ n. 232 , 384-385, 395$397,402,413$

hestiatorion (salle de banquets) : 196 et n. 351 (- à Mégara), 27 (- dans l'Héraion de Pérachora), 196 et n. 351 (- à Sélinonte)

hiéromnamôn/hiéromnémôn (magistrat): 276-277, 381 (- à Argos), 5-6, 48, 255, 271 n. 692, 276-277, 281-282, 284-285, 289 n. 764, 315, 357, 360 n. $173,366,373,375-379,381-382$, 411-412 (- à Byzance), 48, 277 et n. $715,281-282,315,346,360$ n. 173, 378-382, 411-412 (- à Chalcédoine), 394 n. 324 (- à Delphes), 382 n. 274 (- à Entella), 48, 315, 379-380, 382 et n. 274, 412 (- à Mésambria), 282, 379 et n. 258 (- à Périnthe), 382 n. 274 (- à Ségeste), 382 n. 274 (- à Sélinonte ?)

hiérope (magistrat) : 377 et n. 249 (- à Byzance)

hilotes : 43, 291 et n. 773, 302, 307, 310 n. 872

homosépyoi/homosipyoi (groupement familial ou pseudo-familial) : 157 (- à Catane), 157 et n. 155, 413 (- à Sélinonte)

huile: 397 (fourniture en - pour le gymnase à Dionysopolis)

hybris («violence»): 91 et n. 339, 95

ikadeis : voir les «Vingt»

isopolitie: 111 n. 424

isotéleia : 397

juge: 49, 330-331 (-mégarien), 264 n. 654, 342, 375-376 (- milésien), 63 (- spartiates), voir aussi arbitre

kakoi: 89, 92-95

kômarchès (magistrat) : 343 et n. 94 (- à Byzance)

kômè («bourg»): 289-290 (- bithynienne), 244 et n. 557, 343 (-de Byzance), 301 
(- de Démétrias), 153-155, 412 (- de Mégara), 6, 16-19, 20, 153-155, 325, $340,350-351,355,361-364,369,386$ n. 289, 412 (- de Mégare), 222 (- de Nicomédie), 200 (-de Sélinonte), 40, voir aussi bourg/village

Kotyteia (fête): 192 et n. 335 (- en Thrace) Kotyttia (fête): 192 (- à Callatis ?), 192

(- à Chersonèse Taurique ?), 192 (- à Selinonte)

ktistès («fondateur», «bâtisseur») : 216, 222 et n. 468, 299-300, 332 et n. 39

Kybernèsia (fête): 69 (- à Athènes)

laoi: 290 et n. 769, 308, 410 (-à Byzance, population dépendante)

Ligue/Confédération : 49, 330, 367-370,

392-394, 402 et nn. 355+358

(- achéenne, voir aussi Achaïe/

Achéens), 367-369, 384 n. 280, 393,

402 (- béotienne, voir aussi Béotie/

Béotiens), 135, 211 et n. 411, 213-214,

236 n. 525, 258, 338 (-de Délos), 268

(- étolienne, voir aussi Étoliens), 239

et n. 538 (- du Nord), 42 n. 101, 268

(- du Péloponnèse)

mégaron (lieu de culte) : 19-20, 50 (- de

Déméter à Mégare), 199 (- de

Déméter Malophoros à Sélinonte)

mercenaires : 260 n. 641, 290, 333

métèque: $328 \mathrm{n} .12$

mnamôn (magistrat): 277 et n. 715, 380-

381, 411 (- à Mégare), voir aussi

symnamones

monnaies : 184 (- d'Abdère), 369 et n. 211

(-d'Aigosthènes), 218-220 (-d'Asta-

cos), 9 et n. 17, 189, 234 n. 519, 266 et

n. $669,271,276$ n. 709,284 et

n. $742,286,320-321,328,346,357$ et

n. $158,372-373,378$ et nn. $251-253$

(-de Byzance), 9, 300 et n. 827 ( - de

Callatis), 9 et n. 17, 225-226, 228 et n. 499, 266 et n. 669, 320-321 (- de Chalcédoine), 9 n. 17, 371-372, 405 (-de Chersonèse Taurique), 184 (-de Corinthe), 184 (- d'Égine), 9 n. 17,
299-300, 306 et n. 853 (- d'Héraclée du Pont), 184 (-d'Himère), 9 et n. 17, 112 n. 429, 267 n. 671,368 et n. 207 (- de Mégare), 9 et n. 17, 228, 315316, 320-321, 324, 398 (-de Mésambria), 184 (- de Métaponte), 370 et n. 215 (- de Pagai), 184 (- de Poseidonie), 9 n. 17, 300 (- de Prusias de l'Hypios), 187 (-de Ségeste), 9 n. 17, 166-167, 173, 180 et n. $268,182,184$, 395-396 n. 326 (- de Sélinonte), 9 et n. 17, 244 et n. 559, 246, 266 et n. 669 (-de Sélymbria), 143-144 (-de Styella), 184 (- de Sybaris)

mystes: 377-379 (- de Byzance)

navigation: $29,72,100,111,234$ et n. 520 , 272 et n. 694, 295-296

navire: $29,72,77,92,112$ et n. 429,123 , 207, 234-236, 250, 254, 260 et n. 641, 268, 279, 323 et n. 931, voir aussi trière

nécropole: 343 (- de Byzance), 142, 149 et n. 121 (- de Mégara), 324 n. 935 (- de Mésambria), 175 (- de Minôa), 184 (- de Motyè), 139 (- de Villasmundo), 162-163, 169 n. 212, 172, 196-197, 200 et n. 367 (- de Sélinonte), 124 n. 21 (- de Syracuse), voir aussi tombe/tombeau

les «Neuf» (magistrats) : 360 (- à Mésambria), 360 (- à Olbia)

nomima («coutumes»): 8, 41, 116, 255 n. $614,326,366,371,407$ (- mégariens), 8 n. 14 (- milésiens), 3-4, 6 nomophylakes (magistrats) : 334, 346, 404-405 (- à Chalcédoine), 338, 404-405 (- à Chersonèse Taurique), 404 (- à Mésambria), 6, 366, 411

nymphe: 20, 32, 65, 70, 72, 218-220, 274, 286

œciste: 78, 116, 121, 124-125, 135-136, 138, 159-160, 164, 188, 216, 218-219, 223 et n. 472, 225-226, 245, 278, 280, $285,287,294,303,318-321,396$ et n. 328 
oikos («famille»): 53, 107, 155 et n. 145 , $157,253,284-285,411,413$

oligarchie/oligarques : 349 (-à Chersonèse Taurique), 86, 96, 303, 338, 347-351, 356 (-à Héraclée du Pont), 59 n. 180, 82, 84, 86, 89, 92, 94-97, 107-108, 115, 330 n. 22, 384-385 (-à Mégare), 210 (- à Samos)

oracle: $44,52,65$ et n. $215,78,96$ et n. $365,102-103,108,112,202-203,232-$ 233, 249 et nn. 591+593, 274, 294298, 384 (- d'Apollon de Delphes), 167 n. 208 (- d'Apollon Sélinaios/ Sélinountios à Orobiai), 25 n. 34 (- d'Héra Akraia à Pérachora)

orgas («pleine»): 62, 103 (-sacrée d'Éleusis)

ostracisme: $97-98$ (- à Argos), 97-98 (- à Athènes), 97-99 (- à Chersonèse Taurique ?), 98 (- à Cyrène), 98 (-à Éphèse), 97-99 (- à Mégare), 9798 (- à Milet), 98 (- à Syracuse) ostrakon: $97-98,259,306$ n. 851, 353 (- de Chersonèse Taurique), 97 (- de Mégare)

palintokia («le retour des intérêts »): 82 , 84-85, 87, 95 (- à Mégare)

Panhellénion: 394 n. 324

patria (groupe pseudo-familial) : 158, 303 (- à Byzance), 157-158, 413 (- à Sélinonte), 147

patria (récits d'origine) : 274 et n. 700, 287 (- à Constantinople)

pâturage: 83, 95, 105 (- en Mégaride)

pénestes : 307 (- en Thessalie)

pentékaidéka (les «Quinze», magistrats): 6, 334, 360, 366, 389-390 (- à Byzance), 390 n. 309 (- à Chios), 390 n. 309 (- à Delphes), 390 n. 309 (- à Massalia)

pentékostys («cinquantaine», subdivision civique): 335 et n. 53 (-d'Argos), 356 pérée: 285 n. 744, 289 n. 764, 376 (-de Byzance), voir aussi chôra/territoire périèques: 307,310 n. 872 periodoi («soldats de ronde»): 396 et n. 327 phratrie: 335 et n. 53 (-d'Argos), 335 (- d'Athènes), 390 n. 309 (- des Labyades à Delphes)

phrourion: 143 et n. 94, 174

phylakes («gardes»): 395-396 (- de jour et de nuit à Mésambria)

phylarque (magistrat): 339 (- à Callatis ?)

phylè («tribu», subdivision civique): 276-277, 328 (- d'Argos), 33, 6668, 70, 73 n. 259, 328, 330, 335 ( - d'Athènes), 337 (- de BithynionClaudiopolis), 333-334, 390 (- de Byzance), 339, 398 ( - de Callatis ?), 334, 341, 347, 349, 356, 405, 412 (- de Chalcédoine), 338-339, 349350, 405 ( - de Chersonèse Taurique), 335-337, 341, 347-351, 357 (-d'Héraclée du Pont), 337 n. 66 (- d'Héraclée-Périnthe), 335 et n. 53 (- de Lampsaque), 6, 40, 325-333, 341, 361, 392-394, 398, 411 (- de Mégare), 334, 398 (-de Mésambria), 356 n. 150 (-de Milet), 294 et n. 793, 335-337 (- de Prusias de l'Hypios), 54 (- de Sparte), 65 n. 215, 155, 360 et $\mathrm{n} .175$

pirates : 56,123

plomb: 14, 326 (usage du - pour les inscriptions), 170

polémarque (magistrat) : 179 (- à Léontinoi), 341, 361, 393 et n. 321, 402 (- à Mégare)

polichnion: 306 et n. 852, 317 et n. 904, voir aussi polichnion Mégarikon

Potamia (fête ?): 83 n. 310 (- à Mégare?) prêtre: 266 et n. 669 (- d'Héraclès à Chalcédoine), voir aussi archiereus prêtresse : 67 (-d'Athéna Polias à Athènes), 374 et n. 234 (- à Chalcédoine), 371 (- de l'empereur Antonin le Pieux à Héraclée du Pont), 30 n. 53, 275 (- d'Héra à Argos), 381 n. 271, voir aussi archiereia prisonniers : 16-17, 81, 210-211, 290 
pr(o)aisymnôn (magistrat) : 387-389 (- à Callatis), 386-389 (- à Chersonèse Taurique)

probouloi (magistrats) : 387-390 (- à Callatis), 388-389, 411 (- à Mégare), 6, 366

proèdres (magistrats) : 389 et nn. 304-305 (- à Chersonèse Taurique)

proedria : 295

prophètas (magistrat) : 346, 366, 379-380

(- à Chalcédoine)

prophètis (magistrat): 380 n. 264

(- à Chalcédoine)

proxène: 380

proxénie: 302, 341, 367, 370, 397, 401-402

Prytanée: 252, 413 (- à Athènes), 375 et n. 236 (- à Callatis), 51, 385 et n. 284

(- à Mégare), 253 n. 604

prytanes (magistrats): 338 et n. 70, 347, 384-390, 412 (- à Athènes)

Pythia (fête): 22, 47, 76 (- à Mégare)

remparts/enceinte: 57 n. 174 (-d'Athènes), 141, 149, 151, 198 (-de Mégara), 32, 47, 253, 297, 332 (-de Mégare), 311 , 319 n. 912 (- de Mésambria), 197 (- de Sélinonte), 165, 261-262

sacrifices : 67, 70 et n 243 (- à Ajax faits par les éphèbes athéniens arrivés à Salamine), 69 (- à Athéna Skiras, Athènes), 20 n. 13 (- à Déméter), 253-254, 287 et n. 754 (- aux divinités grecques et locales faits par les Grecs au moment de la fondation de Byzance), 131-132 (- aux Douze Dieux, Léontinoi), 395 (- au Héros Sôsipolis, Mésambria), 69, 72 (- à Nauseiros, Athènes), 69 (- à Phaiax, Athènes), 69 (- à Sciros, Athènes), 41 (- à Térée, Mégare), 69 (-à Teucros, Athènes), 83 n. 310, 157, 295, 322, 374 et n. 232, 396

sanctuaire: 68 et n. 233 (-d'Ajax à

Athènes), 265 n. 659 (-d'Amphiaraos à Oropos), 389-390 (- d'Apollon à Byzance), 225, 268-269
(- d'Apollon à Chalcédoine), 114

(-d'Apollon à Mégare), 323

(- d'Apollon à Mésambria), 21

(-d'Apollon à Tripodiskos), 127

(- d'Apollon Archégète à Naxos),

156 (- d'Apollon Daphnèphoros à

Érétrie), 47 (- d'Apollon Pythaeus à

Argos), 167 (-d'Apollon Sélinaios/

Sélinountios à Orobiai), 47

(- d'Artémis à Mégare), 133

(- d'Artémis Sôteira à Mégare),

375, 380, 391 (- d'Asclépios à Cos), 113 n. 437 (- d'Asclépios en

Mégaride, à Marmara?), 71

(-d'Athéna Aiantis à Mégare), 301

(- d'Athéna Itônia à Coronée), 69 et nn. 234, 237, 238 (- d'Athéna

Skiras au Phalère), 69-70 (-

d'Athéna Skiras à Salamine), 69 nn.

237-238 (-d'Athéna Skiras à

Sciron), 329 (célébration de Zeus

Meilichios dans les - des héros

Myskos et Euthydamos à Sélinonte), 79 (- de Déméter à Éleusis), 162-

163, 168, 173-174, 182 n. 277 (- de

Déméter Malophoros à Sélinonte),

388 (- des Dieux de Samothrace à

Callatis), 397-398 (- des Dieux de

Samothrace à Dionysopolis), 68 et nn. 232-233 (- d'Eurysacès à

Athènes), 276 (- d'Héra à Argos),

271 (- d'Héra à Byzance), 272 et

n. 696 (- d'Héra à Chalcédoine),

193-194 (- d'Héra à Mégara ou à

Syracuse ?), 193-194, 199 et n. 364

(- d'Héra à Sélinonte), 22, 24-26,

28-29, 36, 39, 181, 272-273, 411

(- d'Héra Akraia à Pérachora), 24

(- d'Héra Akraia dans la ville de

Corinthe), 402 (- de Mélampous à

Aigosthènes), 397-398 (- de la

Métèr Pontia à Dionysopolis), 220

( - de Poséidon sur un promontoire

du golfe d'Astacos), 23 (- de Poséi-

don et d'Amphitrite à Corinthe), 69 
(- de Sciros à Athènes), 190 (- de

Zeus à Olympie), 113 et n. 437 (- de

Zeus Aphésios à Mégare), 112 (- de

Zeus Olympios à Mégare), 13, 29,

181, 184 n. 286, 196, 200, 284, 290

n. $768,321,329,380$, voir aussi

mégaron, temple, téménos

secrétaire (magistrat) : 368 (- de l'Assem-

blée à Mégare), 335 (- de la cité de

Lampsaque), 390 et n. 307 ( - du

Conseil à Byzance), 386 et n. 288

( - du Conseil et de l'Assemblée à

Chalcédoine), 368 (- du Conseil à

Mégare), 391 ( - du Conseil et de

l'Assemblée à Mégare), 398, 401,

404 n. 364 (- des damiorgoi à

Mégare), 375 (- d'un juge envoyé

par Milet à Byzance), 368 et n. 206

(- de la Ligue achéenne), 398 (- des

stratèges à Callatis ?), 395-397

(- des stratèges à Mésambria), 366

seisachtheia: 85 et n. 321 (- à Athènes)

les «Sept» (magistrats) : 360 (- à Olbia)

serment: 403 (- des citoyens de Cherso-

nèse Taurique), 323 (échange des -

entre les Mésambriens et Sadalas),

131-132 (- faits par les Chalcidiens

de Léontinoi aux Sicules), 54, 110,

116 n. 446 ( - des fondateurs de

Cyrène)

silos: 146-147, 156 (- de Mégara)

Skira/Skirophoria (fête) : 69-70

(- à Athènes)

sôphrosynè («modération») : 102

sténochôria («exiguité des terres »): 18

(cause de la colonisation grecque), 8

n. 15, 100, 145, 411 (cause de la

colonisation mégarienne), voir aussi surpopulation

stéphanophore (magistrat) : 397

(- à Mésambria)

stratège (magistrat/commandant de

l'armée): 401 n. 353 (- à Argos),

258, 358 (- à Athènes), 211

(-d'Antigone Monophthalmos), 258,
275 et n. 705, 279, 288 n. 760, 358, 395, 399-401 (-à Byzance), 395, 398399 (- à Callatis), 380, 395, 401 et n. 353 (- à Chalcédoine), 281 n. 732, 288 et n. 760, 333 (- envoyé par Sparte à Byzance), 401 n. 353 (- à Érythrée), 395, 399 (- à Héraclée du Pont), 330, 402 n. 358 (- de la Ligue achéenne), 43, 330, 341, 361, 369 et n. 208, 391-394, 411 (- à Mégare), 319 n. 912, 321-322, 324, 334 et n. 49, 395-398 (- à Mésambria), 387 n. 294 (- de Mithridate VI Eupatôr), 395, 401 (- à Sélymbria), 6, 366

Stratègion (bâtiment public) : 400-401 (- à Byzance)

surpopulation: 100-101 (cause de la colonisation grecque), 15, 100, 107, 109-110, 238, 242 (cause de la colonisation mégarienne), 178 (- à Mégara, cause de la fondation de Sélinonte), voir aussi sténochôria symnamones (magistrats): 381 (-à Chersonèse Taurique), voir aussi mnamôn sympolitie («union politique»): 359 (- entre Byzance et Chalcédoine), 244 n. 557, 379 et n. 258 (- entre Byzance et Périnthe) synagoroi/synégoroi (magistrats) : 390 n. 308 (- à Athènes), 390 et nn. 307308 (- à Byzance), 390 n. 308 (- à Oropos)

synarchiai (magistrats): 393 (- à Aigosthènes), 383-384, 393 (- à Mégare)

synèdres (magistrats) : 399 et n. 341 (- à Callatis), voir aussi conseillers synédrion: 368 et n. 205 (- de Mégare), voir aussi Conseil

syngéneia («parenté»): 3,48 et n. 133 , 67, 74, 117, 191, 213, 226, 253 , 268-269, 287, 298, 302

syngénès («parent»): 191 et n. 327, 277 synœcisme: 298 n. 815 (- d'Amastris), 66 (-d'Athènes), 41 et $n .100$ ( - des cités grecques), 15, 17, 22, 25, 27, 30, 
33, 41, 43, 50, 52, 54, 82, 107, 115, 145, 242, 361-362, 365, 412 (- de Mégare), 217 n. 438 (- de Nicomédie), 70 (-de Salamine), 252-253, 413

Synoikia (fête) : 252 (- à Athènes)

synoikistèr («cofondateur»): 125 n. 24, voir aussi synoikoi

synoikoi («cofondateurs»): 2, 29, 146, 236, 239, 281, 306, 315, 409, 412, voir aussi synoikistèr

taxe: 235-236, 260 et n. 641 (- de passage imposée aux navires traversant le Bosphore thrace), 79 (- payée par les Athéniens résidant à Salamine)

taxiarques (magistrats) : 334 (- à Mésambria)

téménos: 59 (- d'Athéna dans le dème attique de Lamptrai), 193, 199 (- de la Malophoros à Sélinonte), 197 (- des temples C et D à Sélinonte), voir aussi mégaron, sanctuaire, temple

temple: 196 (-A à Sélinonte), 67 (-d'Ajax à Salamine), 114 n. 440, 331-332 (-d'Apollon à Mégare), 21 (-d'Apollon à Tripodiskos), 71 (- d'Athéna Aiantis à Mégare), 173, 197 (- C à Sélinonte), 377 ( - du culte impérial à Byzance), 197 (-D à Sélinonte), 193, 199, 271 (- E à Sélinonte), 173, 188 n. 310 (- G à Sélinonte), 199, 271 (-d'Héra à Sélinonte, dans le secteur de la Gaggera), 24-26 (- d'Héra Akraia à Pérachora), 25-27 (- d'Héra Liménéia à Pérachora), 266 (- d'Héraclès à Byzance), 173 (- M à Sélinonte), 196 (- O à Sélinonte), 87-88 (pillage des - à Mégare), 289 (- de Ptolomée II à Byzance), 186 et n. 296 (- de Ségeste), 377 (- du Sénat à Byzance), 40 n. 93 (- trouvé à Bouri Alepochoriou, en Mégaride), 173 (- Y à Sélinonte), 321 (- de Zeus à Olympie), 113 (-de Zeus Aphésios à
Mégare), 255 et n. 617 (- de Zeus Hapsasios à Byzance), 58-59 (- de Zeus Olympios à Mégare), 315 n. 897 (- de Zeus et d'Héra à Mésambria), 7 n. 12, voir aussi mégaron, sanctuaire, téménos

termastai/termastères: 331 et n. 28

thalassocratie: 111

théaroi (magistrats) : 330 et n. 24 (- à Mégare)

théâtre: 388 et n. 299 (- à Callatis)

théores/théorie : 36, 87-89, 96, 375 et n. 235

thermes: 283 et n. 739 (- de Zeuxippos à Byzance)

Thersilion (salle du Conseil/hérôon) : 385 n. 283 (- à Mégalopolis)

Thesmophories (fête) : 104 n. 397 (- à Mégare)

thiase: 158, 377 et n. 251 (- de Byzance), voir aussi Dionysoboleitai

timè («honneur») : 53-54

timouques (magistrats) : 390 n. 309

(- à Massalia)

tombe/tombeau: 65 (- à Athènes), 198 n. 360,295 n. 794,297 et n. 809 (-à Héraclée du Pont), 143, 148, 156, 184 n. 286, 198 (- à Mégara), 20-22, 28 n. 44,32 n. $64,40-41,44$ et n. 112 , 50-52, 65, 74, 82, 198 n. 360, 297 et n. 804, 384-385 (- en Mégaride), 324 n. 935 (- à Mésambria), 65 (- à Salamine), 198 (- à Sélinonte), 131 n. 44 (- à Thapsos), voir aussi nécropole traité: 288, 375 (- de Byzance avec

Rhodes et Prusias I ${ }^{\mathrm{er}}$ ), 323 (- entre

Mésambria et Sadalas), 111 n. 424

(- entre Milet et ses colonies), 289

n. 764 (- entre Nicomède $\mathrm{I}^{\mathrm{er}}$ et les

Galates)

Trente Tyrans : 91, 334 n. 44 (- à Athènes) trésor (bâtiment) : 301 et n. 832 (- béotien

à Delphes), 266, 301-302 (-mégarien

à Delphes), 45-46, 107 (- mégarien à

Olympie)

trésor (monétaire) : 180, 184 
trésorier (magistrat) : 323 (- à Mésambria) tribunal: 339 n. 72 (- à Chersonèse Taurique), 330 et n. 22 (- à Mégare) tribut: 75 (- envoyé par Athènes à Minos), 260 (- payé par Byzance aux Galates), 288 (- payé par Byzance aux Thraces), 309 (- payé par les Mariandyniens aux Perses)

trière: 58-59, 77, 112, 239, 307, voir aussi navire

troupeaux : 22, 83, 95

tyran/tyrannie: 176 et n. 247, 190-191,
409 (- d'Agrigente), 46 et n. 123

(-d'Argos), 57, 60, 80, 91, 133

(-d'Athènes), 333, 338, 348 n. 121

(-de Byzance), 48, 53, 271 (- de Corinthe), 206, 212-213, 215, 310

(-d'Héraclée du Pont), 179 (- de Léontinoi), 56 et n. 169, 83-85, 90 nn. 335-336, 94, 383 (- de Mégare), 173 (- de Sélinonte), 92, 120 (- de Syracuse), 401

les «Vingt» (magistrats) : 360 et n. 174 (- à Mésambria) 